\title{
Article
}

\section{Refined families of Sordariomycetes}

Hyde $\mathrm{KD}^{1,2,3,4,5,6,7}$, Norphanphoun $\mathrm{C}^{2,3,6,15,19}$, Maharachchikumbura $\mathrm{SSN}^{26}$, Bhat $\mathrm{DJ}^{21}$, Jones EBG ${ }^{12,32}$, Bundhun $\mathrm{D}^{2,13}$, Chen $\mathrm{YJ}^{2,6}$, Bao $\mathrm{DF}^{2,11,13}$, Boonmee $\mathrm{S}^{2}$, Calabon $\mathrm{MS}^{2,6}$, Chaiwan $\mathrm{N}^{2,6}$, Chethana $\mathrm{KWT}^{2,}{ }^{23}$, Dai $\mathrm{DQ}^{9}$, Dayarathne $\mathrm{MC}^{2,}, 3,5,6$, Devadatha $\mathrm{B}^{2,18}$, Dissanayake $\mathrm{AJ}^{26}$, Dissanayake $\mathbf{L S}^{29}$, Doilom $\mathbf{M}^{5}$, Dong $\mathrm{W}^{2,3}, 13,31$, Fan $\mathrm{XL}^{30}$, Goonasekara $\mathrm{ID}^{2,3,5,7}$, Hongsanan $\mathrm{S}^{27,28}$, Huang $\mathrm{SK}^{2,}$ 3, 6, 29, Jayawardena $\mathrm{RS}^{2}$, Jeewon $\mathrm{R}^{14}$, Karunarathna $\mathrm{A}^{2,5,13,15}$, Konta $\mathrm{S}^{2,3,5,6}$, Kumar $\mathrm{V}^{2,13}$, Lin $\mathrm{CG}^{2,3,6}$, Liu $\mathrm{JK}^{26}$, Liu NG ${ }^{2,17}$, Luangsa-ard $\mathrm{J}^{25}$, Lumyong $\mathrm{S}^{4,8}$, ${ }^{10}$, Luo ZL ${ }^{11}$, Marasinghe $\mathrm{DS}^{2,}$ 6, 15, McKenzie $\mathrm{EHC}^{24}$, Niego $\mathrm{AGT}^{2,22}$, Niranjan $\mathrm{M}^{18}$, Perera $\mathrm{RH}^{2,3,6,19}$, Phukhamsakda $\mathrm{C}^{2}$, Rathnayaka $\mathrm{AR}^{2,6}$, 16, Samarakoon $\mathrm{MC}^{2,4,26}$, Samarakoon SMBC ${ }^{2,6}$, Sarma VV ${ }^{18}$, Senanayake $\mathrm{IC}^{2,28}$, Shang $\mathbf{Q J}^{2,6}$, 19, Stadler $\mathrm{M}^{20}$, Tibpromma $\mathrm{S}^{5,}$, Wanasinghe $\mathrm{DN}^{5}$, Wei $\mathrm{DP}^{2,}, 3,5,13$, Wijayawardene $\mathrm{NN}^{9}$, Xiao $\mathrm{YP}^{2,3,6,19}$, Yang $\mathrm{J}^{2,3,6,19}$, Zeng $X \mathrm{Y}^{2,6,19}$, Zhang $\mathrm{SN}^{2,13}$, Xiang $\mathbf{M M}^{1}$

${ }^{1}$ Institute of Plant Health, Zhongkai University of Agriculture and Engineering, Haizhu District, Guangzhou 510225, P.R. China

${ }^{2}$ Center of Excellence in Fungal Research, Mae Fah Luang University, Chiang Rai 57100, Thailand

${ }^{3}$ Mushroom Research Foundation, 128 M.3 Ban Pa Deng T. Pa Pae, A. Mae Taeng, Chiang Mai 50150, Thailand

${ }^{4}$ Department of Biology, Faculty of Science, Chiang Mai University, Chiang Mai 50200, Thailand

${ }^{5}$ Key Laboratory for Plant Diversity and Biogeography of East Asia, Kunming Institute of Botany, Chinese Academy of Science, Kunming 650201, Yunnan, P.R. China

${ }^{6}$ School of Science, Mae Fah Luang University, Chiang Rai 57100, Thailand

${ }^{7}$ World Agroforestry Centre, East and Central Asia, Kunming 650201, Yunnan, P.R. China

${ }^{8}$ Academy of Science, The Royal Society of Thailand, Bangkok 10300, Thailand

${ }^{9}$ Center for Yunnan Plateau Biological Resources Protection and Utilization, College of Biological Resource and Food Engineering, Qujing Normal University, Qujing, Yunnan 655011, P.R. China

${ }^{10}$ Center of Excellence in Microbial Diversity and Sustainable Utilization, Faculty of Science, Chiang Mai University, Chiang Mai 50200, Thailand

${ }^{11}$ College of Agriculture and Biological Sciences, Dali University, Dali 671003, Yunnan Province, P.R. China

${ }^{12}$ Department of Botany and Microbiology, College of Science, King Saud University, P.O Box 2455, Riyadh 11451, Kingdom of Saudi Arabia

${ }^{13}$ Department of Entomology and Plant Pathology, Faculty of Agriculture, Chiang Mai University, Chiang Mai 50200, Thailand

${ }^{14}$ Department of Health Sciences, Faculty of Science, University of Mauritius, Reduit, Mauritius

${ }^{15}$ Department of Plant Medicine, National Chiayi University, 300 Syuefu Road, Chiayi City 60004, Taiwan

${ }^{16}$ Engineering Research Center of Southwest Bio-Pharmaceutical Resources, Ministry of Education, Guizhou University, Guiyang, Guizhou 550025, P.R. China

${ }^{17}$ Faculty of Agriculture, Natural Resources and Environment, Naresuan University, Phitsanulok 65000, Thailand

${ }^{18}$ Fungal Biotechnology Lab, Department of Biotechnology, School of Life Sciences, Pondicherry University, Kalapet, Pondicherry-605014, India

${ }^{19}$ Guizhou Key Laboratory of Agricultural Biotechnology, Guizhou Academy of Agricultural Sciences, Guiyang, Guizhou 550006, P.R. China

${ }^{20}$ Helmholtz Centre for Infection Research, Department Microbial Drugs, Inhoffenstrasse 7, 38124 Braunschweig, Germany

${ }^{21}$ House No. 128/1-J, Azad Housing Society, Curca, Goa Velha 403108, India 
${ }^{22}$ Iloilo Science and Technology University, La Paz, Iloilo, Philippines

${ }^{23}$ Institute of Plant and Environment Protection, Beijing Academy of Agriculture and Forestry Sciences, Beijing 100097, P.R. China

${ }^{24}$ Landcare Research Manaaki Whenua, Private Bag 92170, Auckland, New Zealand

${ }^{25}$ National Center for Genetic Engineering and Biotechnology (BIOTEC), 113 Thailand Science Park, Phahonyothin Road, Khlong Nueng, Khlong Luang, Pathum Thani 12120, Thailand

${ }^{26}$ School of Life Science and Technology, University of Electronic Science and Technology of China, Chengdu 611731, P.R. China

${ }^{27}$ Shenzhen Key Laboratory of Laser Engineering, College of Optoelectronic Engineering, Shenzhen University, Shenzhen, P.R. China

${ }^{28}$ Shenzhen Key Laboratory of Microbial Genetic Engineering, College of Life Sciences and Oceanography, Shenzhen University, Shenzhen, P.R. China

${ }^{29}$ The Engineering Research Center of Southwest Bio-Pharmaceutical Resource Ministry of Education, Guizhou University, Guiyang 550025, Guizhou Province, P.R. China

${ }^{30}$ The Key Laboratory for Silviculture and Conservation of Ministry of Education, Beijing Forestry University, Beijing 100083, P.R. China

${ }^{31}$ Yunnan Institute of Food Safety, Kunming University of Science and Technology, Kunming 650500, P.R. China

${ }^{32} 33 B$ St Edwards Road, Southsea, Hants., PO53DH, UK

Faculty of Agriculture, Natural Resources and Environment, Naresuan University, Phitsanulok 65000, Thailand

Hyde KD, Norphanphoun C, Maharachchikumbura SSN, Bhat DJ, Jones EBG, Bundhun D, Chen YJ, Bao DF, Boonmee S, Calabon MS, Chaiwan N, Chethana KWT, Dai DQ, Dayarathne MC, Devadatha B, Dissanayake AJ, Dissanayake LS, Doilom M, Dong W, Fan XL, Goonasekara ID, Hongsanan S, Huang SK, Jayawardena RS, Jeewon R, Karunarathna A, Konta S, Kumar V, Lin CG, Liu JK, Liu NG, Luangsa-ard J, Lumyong S, Luo ZL, Marasinghe DS, McKenzie EHC, Niego AGT, Niranjan M, Perera RH, Phukhamsakda C, Rathnayaka AR, Samarakoon MC, Samarakoon SMBC, Sarma VV, Senanayake IC, Shang QJ, Stadler M, Tibpromma S, Wanasinghe DN, Wei DP, Wijayawardene NN, Xiao YP, Yang J, Zeng XY, Zhang SN, Xiang MM 2020 - Refined families of Sordariomycetes. Mycosphere 11(1), 305-1059, Doi 10.5943/mycosphere/11/1/7

\section{Abstract}

This is a continuation of the papers "Towards a classification of Sordariomycetes" (2015) and "Families of Sordariomycetes" (2016) in which we compile a treatment of the class Sordariomycetes. The present treatment is needed as our knowledge has rapidly increased, from 32 orders, 105 families and 1331 genera in 2016, to 45 orders, 167 families and 1499 genera (with 308 genera incertae sedis) at the time of publication. In this treatment we provide notes on each order, families and short notes on each genus. We provide up-to-date DNA based phylogenies for 45 orders and 163 families. Three new genera and 16 new species are introduced with illustrations and descriptions, while 23 new records and three new species combinations are provided. We also list 308 taxa in Sordariomycetes genera incertae sedis. For each family we provide general descriptions and illustrate the type genus or another genus, the latter where the placement has generally been confirmed with molecular data. Both the sexual and asexual morphs representative of a family are illustrated where available. Notes on ecological and economic considerations are also given.

Key words - 19 new taxa - Amphisphaeriales - Amplistromatales - Annulatascales Atractosporales - Boliniales - Calosphaeriales - Catabotryales - Cephalothecales Chaetosphaeriales - Coniochaetales - Conioscyphales - Coronophorales - Delonicicolales Diaporthales - Distoseptisporales - Falcocladiales - Fuscosporellales - Glomerellales Hypocreales - Jobellisiales - Koralionastetales - Lulworthiales - Magnaporthales - Meliolales Microascales, Myrmecridiales, new records, Ophiostomatales, Pararamichloridiales, Parasympodiellales - Phomatosporales - Phyllachorales - Pisorisporiales - Pleurotheciales Pseudodactylariales - Savoryellales - Sordariales - Spathulosporales - Sporidesmiales Tirisporellales - Togniniales - Torpedosporales - Tracyllalales - Vermiculariopsiellales Xenospadicoidales - Xylariales 


\section{Contents}

\section{Class Sordariomycetes}

\section{Subclasses}

1. Diaporthomycetidae Senan., Maharachch. \& K.D. Hyde, Fungal Divers. 72: 208 (2015) contributed by Senanayake IC, Maharachchikumbura SSN

2. Hypocreomycetidae O.E. Erikss. \& Winka, Myconet 1: 6 (1997) - contributed by Perera RH, Maharachchikumbura SSN

3. Lulworthiomycetidae Dayar., E.B.G. Jones \& K.D. Hyde, Fungal Divers. 72: 208 (2015) - contributed by Dayarathne MC, Jones EBG

4. Pisorisporiomycetidae Bundhun, Maharachch. \& K.D. Hyde, subclass nov.- contributed by Bundhun D, Maharachchikumbura SSN, Hyde KD

5. Savoryellomycetidae Hongsanan, K.D. Hyde \& Maharachch., Fungal Divers. 84: 35 (2017) - contributed by Dayarathne MC, Jones EBG

6. Sordariomycetidae O.E. Erikss. \& Winka, Myconet 1: 10 (1997) - contributed by Huang SK, Jeewon R

7. Xylariomycetidae O.E. Erikss. \& Winka, Myconet 1: 12 (1997) - contributed by Samarakoon MC, Stadler M

\section{Orders}

1. Amphisphaeriales Hawksw. \& O.E. Erikss., Syst. Ascom. 5: 177 (1986) - contributed by Samarakoon MC, Maharachchikumbura SSN

2. Amplistromatales M.J. D'souza, Maharachch. \& K.D. Hyde, Fungal Divers. 72: 212 (2015) - contributed by Samarakoon MC, Liu JK

3. Annulatascales M.J. D'souza, Maharachch. \& K.D. Hyde, Fungal Divers. 72: 212 (2015) - contributed by Dong W, Doilom M

4. Atractosporales H. Zhang, K.D. Hyde \& Maharachch., Fungal Divers. 85: 88 (2017) contributed by Dong W, Doilom M

5. Boliniales P.F. Cannon, Ainsworth \& Bisby's Dictionary of the Fungi, Edn 9 (Wallingford): x (2001) - contributed by Huang SK, Jeewon R, Maharachchikumbura SSN

6. Calosphaeriales M.E. Barr, Mycologia 75: 11 (1983) - contributed by Huang SK, Jeewon $\mathrm{R}$

7. Catabotryales K.D. Hyde \& Senan., ord. nov. - contributed by Hyde KD, Senanayake IC

8. Cephalothecales Maharach. \& K.D. Hyde, ord. nov. - contributed by Maharachchikumbura SSN, Hyde KD

9. Chaetosphaeriales Huhndorf, A.N. Mill. \& F.A. Fernández, Mycologia 96: 378 (2004) contributed by Perera RH, Lin CG, Liu JK

10. Coniochaetales Huhndorf, A.N. Mill. \& F.A. Fernández, Mycologia 96: 378 (2004) contributed by Goonasekara ID, Samarakoon MC, Jayawardena RS

11. Conioscyphales Réblová \& Seifert, Persoonia 37: 63 (2015) - contributed by Bundhun D, Liu NG, Dayarathne MC, Jones EBG

12. Coronophorales Nannf., Nova Acta R. Soc. Scient. upsal., Ser. 4 8(no. 2): 54 (1932) contributed by Huang SK, Hyde KD

13. Delonicicolales R.H. Perera, Maharachch. \& K.D. Hyde, Cryptog. Mycol. 38: 329 (2017) - contributed by Samarakoon MC, Perera RH

14. Diaporthales Nannf., Nova Acta R. Soc. Scient. upsal., Ser. 4 8(no. 2): 53 (1932) contributed by Senanayake IC, Maharachchikumbura SSN

15. Distoseptisporales Z.L. Luo, H.Y. Su \& K.D. Hyde, Fungal Divers. 99: 482 (2019) contributed by Luo ZL 
16. Falcocladiales R.H. Perera, Maharachch. \& K.D. Hyde, Fungal Divers. 72: 218 (2015) contributed by Perera RH

17. Fuscosporellales J. Yang, J. Bhat \& K.D. Hyde, Cryptog. Mycol. 37: 457 (2016) contributed by Bundhun D, Dayarathne MC, Jones EBG

18. Glomerellales Chadef. ex Réblová, W. Gams \& Seifert, Stud. Mycol. 68: 170 (2011) contributed by Jayawardena RS, Maharachchikumbura SSN

19. Hypocreales Lindau, Nat. Pflanzenfam., Teil. I (Leipzig) 1: 343 (1897) - contributed by Perera RH, Xiao YP, Liu JK

20. Jobellisiales M.J. D'souza \& K.D. Hyde, Fungal Divers. 72: 219 (2015) - contributed by Huang SK, Hyde KD, Jeewon R, Maharachchikumbura SSN

21. Koralionastetales Kohlm., Volkm.-Kohlm., J. Campb. \& Inderb., Mycol. Res. 113: 377 (2009) - contributed by Bundhun D, Dayarathne MC, Jones EBG

22. Lulworthiales Kohlm., Spatafora \& Volkm.-Kohlm., Mycologia 92: 456 (2000) contributed by Bundhun D, Dayarathne MC, Jones EBG

23. Magnaporthales Thongk., Vijaykr. \& K.D. Hyde, Fungal Divers. 34: 168 (2009) contributed by Norphanphoun C, Maharachchikumbura SSN

24. Meliolales Gäum. ex D. Hawksw. \& O.E. Erikss., Syst. Ascom. 5: 180 (1986) contributed by Hongsanan $S$

25. Microascales Luttr. ex Benny \& R.K. Benj., Mycotaxon 12: 40 (1980) - contributed by Kumar V, Dayarathne MC, Jones EBG

26. Myrmecridiales Crous, Persoonia 34: 219 (2015) - contributed by Wei DP, Doilom M

27. Ophiostomatales Benny \& Kimbr., Mycotaxon 12: 48 (1980) - contributed by Norphanphoun C, Maharachchikumbura SSN, Doilom M

28. Pararamichloridiales Crous, Persoonia 39: 357 (2017) - contributed by Lin CG, Maharachchikumbura SSN

29. Parasympodiellales Hern.-Restr., Gené, R.F. Castañeda \& Crous, Stud. Mycol. 86: 87 (2017) - contributed by Bundhun D, Dayarathne MC, Jones EBG

30. Phomatosporales Senan., Maharachch. \& K.D. Hyde, Mycosphere 7: 631 (2016) contributed by Bundhun D, Dayarathne MC, Jones EBG

31. Phyllachorales M.E. Barr, Mycologia 75: 11 (1983) - contributed by Dayarathne MC, Maharachchikumbura SSN

32. Pisorisporiales Réblová \& J. Fourn., Persoonia 34: 43 (2014) - contributed by Bundhun D, Dayarathne MC, Jones EBG

33. Pleurotheciales Réblová \& Seifert, Persoonia 37: 63 (2015) - contributed by Bundhun D, Dayarathne MC, Jones EBG, Yang J

34. Pseudodactylariales Crous, Persoonia 39: 421 (2017) - contributed by Lin CG, Liu JK

35. Savoryellales Boonyuen, Suetrong, Sivichai, K.L. Pang \& E.B.G. Jones, Mycologia 103: 1368 (2011) - contributed by Bundhun D, Dayarathne MC, Jones EBG

36. Sordariales Chadef. ex D. Hawksw. \& O.E. Erikss., Syst. Ascom. 5: 182 (1986) contributed by Huang SK, Jeewon R, Maharachchikumbura SSN

37. Spathulosporales Kohlm., Mycologia 65: 615 (1973) - contributed by Dayarathne MC, Jones EBG

38. Sporidesmiales Crous, Persoonia 40: 377 (2018) - contributed by Luo ZL

39. Tirisporellales Suetrong, E.B.G. Jones \& K.L. Pang, Fungal Divers. 73: 42 (2015) contributed by Dayarathne MC, Jones EBG

40. Togniniales Senan., Maharachch. \& K.D. Hyde, Fungal Divers. 72: 220 (2015) contributed by Huang SK, Wei DP, Jeewon R

41. Torpedosporales E.B.G. Jones, Abdel-Wahab \& K.L. Pang, Fungal Divers. 73: 42 (2015) - contributed by Dayarathne MC, Jones EBG

42. Tracyllalales Crous, Persoonia 40: 365 (2018) - contributed by Calabon MS

43. Vermiculariopsiellales Hern.-Restr., J. Mena, Gené \& Crous, Stud. Mycol. 86: 91 (2017) - contributed by Lin CG, Liu JK 
44. Xenospadicoidales Hern.-Restr., J. Mena \& Gené, Stud. Mycol. 86: 91 (2017) contributed by Dong W, Doilom M

45. Xylariales Nannf., Nova Acta R. Soc. Scient. upsal., Ser. 4 8(no. 2): 66 (1932) contributed by Samarakoon MC, Stadler M

\section{Families}

1. Acrodictyaceae J.W. Xia \& X.G. Zhang, Scientific Reports 7 (no. 7888): 2 (2017) contributed by Liu NG

2. Amphisphaeriaceae G. Winter, Rabenh. Krypt.-Fl., Edn 2 (Leipzig) 1.2: 259 (1885) contributed by Samarakoon MC, Senanayake IC, Liu JK

3. Amplistromataceae Huhndorf, A.N. Mill., Greif \& Samuels, Mycologia 101: 905 (2009) - contributed by Samarakoon MC, Liu JK

4. Annulatascaceae S.W. Wong, K.D. Hyde \& E.B.G. Jones, Syst. Ascom. 16: 18 (1998) contributed by Dong W, Doilom M

5. Apiosporaceae K.D. Hyde, J. Fröhl., Joanne E. Taylor \& M.E. Barr, Sydowia 50: 23 (1998) - contributed by Dai DQ, Hyde KD

6. Apiosporopsidaceae Senan., Maharachch. \& K.D. Hyde, Stud. Mycol. 86: 234 (2017) contributed by Senanayake IC

7. Apoharknessiaceae Senan., Maharachch. \& K.D. Hyde, Stud. Mycol. 86: 234 (2017) contributed by Senanayake IC

8. Armatellaceae Hosag., Sydowia 55: 165 (2003) - contributed by Zeng XY, Hongsanan S

9. Asterosporiaceae Senan., Maharachch. \& K.D. Hyde, Stud. Mycol. 86: 236 (2017) contributed by Senanayake IC

10. Atractosporaceae H. Zhang, K.D. Hyde \& Maharachch., Fungal Divers. 85: 88 (2017) contributed by Dong W, Doilom M

11. Auratiopycnidiellaceae Senan., Maharachch. \& K.D. Hyde, Stud. Mycol. 86: 237 (2017) - contributed by Senanayake IC

12. Australiascaceae Réblová \& W. Gams, Stud. Mycol. 68: 171 (2011) - contributed by Shang QJ, Jayawardena RS, Liu JK

13. Barbatosphaeriaceae H. Zhang, K.D. Hyde \& Maharachch., Fungal Divers. 85: 94 (2017) - contributed by Dong W, Doilom M

14. Barrmaeliaceae Voglmayr \& Jaklitsch, Mycol. Progr. 17: 162 (2018) - contributed by Samarakoon MC, Liu JK

15. Batistiaceae Samuels \& K.F. Rodrigues, Mycologia 81: 54 (1989) - contributed by Shang QJ, Liu JK

16. Beltraniaceae Nann., Repert. mic. uomo: 498 (1934) - contributed by Lin CG, Liu JK

17. Bertiaceae Smyk, Ukr. bot. Zh. 38: 47 (1981) - contributed by Huang SK, Jeewon R

18. Bionectriaceae Samuels \& Rossman, Stud. Mycol. 42: 15 (1999) - contributed by Perera RH, Niranjan M, Sarma VV, Jeewon R

19. Boliniaceae Rick, Brotéria, sér. bot. 25: 65 (1931) - contributed by Huang SK, Jeewon R

20. Cainiaceae J.C. Krug, Sydowia 30:123 (1978) - contributed by Samarakoon MC, Liu JK, Senanayake IC

21. Calcarisporiaceae Jing Z. Sun, X.Z. Liu \& K.D. Hyde, Mycol. Prog. 16: 435 (2017) contributed by Calabon MS

22. Calosphaeriaceae Munk, Dansk bot. Ark. 17: 278 (1957) - contributed by Huang SK, Jeewon R

23. Castanediellaceae Hern.-Restr., Guarro \& Crous, Stud. Mycol. 86: 93 (2017) contributed by Samarakoon MC, Liu JK, Lin CG

24. Catabotryaceae Petr. ex M.E. Barr, Mycotaxon 39: 83 (1990) - contributed by Zhang SN, Liu JK

25. Cephalothecaceae Höhn., Annls mycol. 15: 362 (1917) - contributed by Shang QJ, Maharachchikumbura SSN, Jeewon R 
26. Ceratocystidaceae Locq. ex Réblová, W. Gams \& Seifert, Stud. Mycol. 68: 188 (2011) contributed by Doilom M

27. Ceratosphaeriaceae Z.L. Luo, H.Y. Su \& K.D. Hyde, Fungal Divers. 99: 490 (2019) contributed by Luo ZL

28. Ceratostomataceae G. Winter, Rabenh. Krypt.-Fl., Edn 2 (Leipzig) 1.2: 247 (1885) contributed by Norphanphoun C, Hongsanan S

29. Chadefaudiellaceae Faurel \& Schotter ex Benny \& Kimbr., Mycotaxon 12: 46 (1980) contributed by Kumar V, Dayarathne MC

30. Chaetomiaceae G. Winter, Rabenh. Krypt.-Fl., Edn 2 (Leipzig) 1.2: 153 (1885) contributed by Shang QJ, Niranjan M, Sarma VV, Liu JK

31. Chaetosphaerellaceae Huhndorf, A.N. Mill. \& F.A. Fernández, Mycol. Res. 108: 1387 (2004) - contributed by Huang SK, Jeewon R

32. Chaetosphaeriaceae Réblová, M.E. Barr \& Samuels, Sydowia 51: 56 (1999) contributed by Perera RH, Luo ZL

33. Clavicipitaceae O.E. Erikss., Mycotaxon 15: 224 (1982) - contributed by Xiao YP, Hongsanan S, Luang-sard J

34. Clypeophysalosporaceae A. Giraldo \& Crous, Mycol. Progr. 16: 340 (2017) contributed by Chaiwan $\mathrm{N}$

35. Clypeosphaeriaceae G. Winter, Rabenh. Krypt.-Fl., Edn 2 (Leipzig) 1.2: 554 (1886) contributed by Konta S, Boonmee S

36. Cocoonihabitaceae W.Y. Zhuang \& Z.Q. Zeng - contributed by Bundhun D

37. Coniocessiaceae Asgari \& Zare, Mycol. Progr. 10: 195 (2011) - contributed by Norphanphoun $\mathrm{C}$, Hongsanan $\mathrm{S}$

38. Coniochaetaceae Malloch \& Cain, Can. J. Bot. 49: 878 (1971) - contributed by Samarakoon MC, Liu JK

39. Conioscyphaceae Réblová \& Seifert, Persoonia 37: 63 (2015) - contributed by Bundhun D

40. Conlariaceae H. Zhang, K.D. Hyde \& Maharachch., Fungal Divers. 85: 90 (2017) contributed by Dong W, Doilom M

41. Cordanaceae (Sacc.) Nann., Repert. mic. uomo: 498 (1934) - contributed by Goonasekara ID, Jayawardena RS

42. Cordycipitaceae Kreisel ex G.H. Sung, J.M. Sung, Hywel-Jones \& Spatafora, Stud. Mycol. 57: 48 (2007) - contributed by Xiao YP, Hongsanan S, Luang-sard J

43. Coronophoraceae Höhn., Sber. Akad. Wiss. Wien, Math.-naturw. Kl., Abt. 1 116: 624 (1907) - contributed by Huang SK, Maharachchikumbura SSN

44. Coryneaceae Corda, Icon. fung. (Prague) 3: 36 (1839) - contributed by Senanayake IC, Bundhun D

45. Cryphonectriaceae Gryzenh. \& M.J. Wingf., Mycologia 98: 246 (2006) - contributed by Senanayake IC

46. Cylindriaceae Crous \& L. Lombard, Fungal Systematics and Evolution 1: 183 (2018) contributed by Perera RH, Norphanphoun C

47. Cytosporaceae Fr., Syst. orb. veg. (Lundae) 1: 118 (1825) - contributed by Norphanphoun C, Hongsanan S

48. Delonicicolaceae R.H. Perera, Maharachch. \& K.D. Hyde, Cryptog. Mycol. 38: 334 (2017) - contributed by Perera RH, Jones EBG

49. Diaporthaceae Höhn. ex Wehm., Am. J. Bot. 13: 638 (1926) - contributed by Dissanayake AJ, Niranjan M

50. Diaporthosporellaceae C.M. Tian \& Q. Yang, Mycoscience 59: 230 (2018) - contributed by Rathnayaka AR, Dissanayake A

51. Diaporthostomataceae X.L. Fan \& C.M. Tian, Persoonia 40: 124 (2018) - contributed by Rathnayaka AR, Dissanayake A 
52. Diatrypaceae Verh. naturh. Ver. preuss. Rheinl. 26: 73 (1869) - contributed by Shang QJ S, Niranjan M, Sarma VV, Tibpromma S

53. Distoseptisporaceae K.D. Hyde \& McKenzie, Fungal Divers. 80: 402 (2016) contributed by Yang J, Liu JK, Luo ZL

54. Dwiroopaceae K.V. Xavier, A.N. KC, J.Z. Groenew., Vallad \& Crous, Fungal Systematics and Evolution 4: 38 (2019) - contributed by Devadatha B, Norphanphoun C

55. Erythrogloeaceae Senan., Maharachch. \& K.D. Hyde, Stud. Mycol. 86: 258 (2017) contributed by Senanayake IC, Bundhun D

56. Etheirophoraceae Rungjind., Somrith. \& Suetrong, Cryptog. Mycol. 35: 134 (2014) contributed by Dayarathne MC, Jones EBG

57. Falcocladiaceae Somrith., E.B.G. Jones \& K.L. Pang, Cryptog. Mycol. 35: 134 (2014) contributed by Kumar V

58. Flammocladiellaceae Crous, L. Lombard \& R.K. Schumach., Sydowia 67: 103 (2015) contributed by Perera RH, Wei DP, Jones EBG

59. Fuscosporellaceae J. Yang, J. Bhat \& K.D. Hyde, Cryptog. Mycol. 37: 457 (2016) contributed by Yang J, Liu JK, Luo ZL

60. Glomerellaceae Locq. ex Seifert \& W. Gams, Mycologia 98: 1083 (2007) - contributed by Jayawardena RS, Hyde KD

61. Gnomoniaceae G. Winter, Rabenh. Krypt.-Fl., Edn 2 (Leipzig) 1.2: 570 (1886) contributed by Senanayake IC

62. Gondwanamycetaceae Réblová, W. Gams \& Seifert, Stud. Mycol. 68: 188 (2011) contributed by Dayarathne MC, Jones EBG

63. Graphiaceae Z.W. de Beer, Seifert \& M.J. Wingf., CBS Diversity Ser. (Utrecht) 12: 8 (2013) - contributed by Kumar V

64. Graphostromataceae M.E. Barr, J.D. Rogers \& Y.M. Ju, Mycotaxon 48: 533 (1993) contributed by Samarakoon MC, Liu JK, Stadler M

65. Halosphaeriaceae E. Müll. \& Arx ex Kohlm., Can. J. Bot. 50: 1951 (1972) - contributed by Dayarathne MC, Jones EBG

66. Hansfordiaceae Crous, Fungal Systematics and Evolution 3: 84 (2019) - contributed by Dissanayake LS

67. Harknessiaceae Crous, Persoonia 28: 55 (2012) - Marasinghe DS, Boonmee S

68. Helminthosphaeriaceae Samuels, Cand. \& Magni, Mycologia 89: 144 (1997) contributed by Huang SK, Hyde KD

69. Hispidicarpomycetaceae Nakagiri, Mycologia 85: 649 (1993) - contributed by Dayarathne MC, Jones EBG

70. Hypocreaceae De Not., G. bot. ital. 2: 48 (1844) - contributed by Perera RH, Niranjan M, Sarma VV, Tibpromma S

71. Hyponectriaceae Petr., Annls mycol. 21: 305 (1923) - contributed by Konta S, Boonmee $\mathrm{S}$

72. Hypoxylaceae DC., Fl. franç., Edn 3 (Paris) 2: 280 (1805) - contributed by Samarakoon MC, Niranjan M, Stadler M

73. Induratiaceae Samarak., Thongbai, K.D. Hyde \& M. Stadler (in press) - contributed by Samarakoon MC

74. Iodosphaeriaceae O. Hilber, The Genus Lasiosphaeria and Allied Taxa (Kelheim): 7 (2002) - contributed by Konta S, Boonmee S

75. Jobellisiaceae Réblová, Mycologia 100: 899 (2008) - contributed by Dong W, Doilom M

76. Juglanconidaceae Voglmayr \& Jaklitsch, Persoonia 38: 142 (2017) - contributed by Wei DP, Fan XL

77. Juncigenaceae E.B.G. Jones, Abdel-Wahab \& K.L. Pang, Cryptog. Mycol. 35: 133 (2014) - contributed by Karunarathna A, Dayarathne MC

78. Junewangiaceae J.W. Xia \& X.G. Zhang, Scientific Reports 7 (no. 7888): 12 (2017) contributed by Liu NG 
79. Kathistaceae Malloch \& M. Blackw., Can. J. Bot. 68: 1719 (1990) - contributed by Norphanphoun C, Hongsanan S

80. Koralionastetaceae Kohlm. \& Volkm.-Kohlm., Mycologia 79: 764 (1987) - contributed by Dayarathne MC, Jones EBG

81. Lamproconiaceae Norph., T.C. Wen \& K.D. Hyde, Phytotaxa 270: 94 (2016) contributed by Norphanphoun C, Hongsanan S

82. Lasiosphaeriaceae Nannf., Nova Acta R. Soc. Scient. upsal., Ser. 4 8(no. 2): 50 (1932) contributed by Huang SK, Jeewon R

83. Lautosporaceae Kohlm., Volkm.-Kohlm. \& O.E. Erikss., Bot. Mar. 38: 169 (1995) contributed by Dayarathne MC, Jones EBG

84. Leptosilliaceae Voglmayr \& Jaklitsch, Persoonia 42: 240 (2019) - contributed by Dissanayake LS

85. Leptosporellaceae S. Konta \& K.D. Hyde, Mycosphere 8: 1956 (2017) - contributed by Konta S, Boonmee S

86. Linocarpaceae S. Konta \& K.D. Hyde, Mycosphere 8: 1962 (2017) - contributed by Konta S, Boonmee S

87. Lopadostomataceae Daranag. \& K.D. Hyde, Fungal Divers. 73: 129 (2015) - contributed by Samarakoon MC, Liu JK, Stadler M

88. Lulworthiaceae Kohlm., Spatafora \& Volkm.-Kohlm., Mycologia 92: 456 (2000) contributed by Dayarathne MC, Jones EBG

89. Macrohilaceae Crous, IMA Fungus 6: 180 (2015) - contributed by Wijayawardene N, Chethana KWT

90. Magnaporthaceae P.F. Cannon, Syst. Ascom. 13: 26 (1994) - contributed by Norphanphoun C, Hongsanan S

91. Malaysiascaceae Tibpromma \& K.D. Hyde, Fungal Divers. 93: 88 (2018) - contributed by Tibpromma $\mathrm{S}$

92. Melanconidaceae G. Winter, Rabenh. Krypt.-Fl., Edn 2 (Leipzig) 1.2: 764 (1886) contributed by Samarakoon SMBC, Senanayake IC

93. Melanconiellaceae Senan., Maharachch. \& K.D. Hyde, Stud. Mycol. 86: 275 (2017) contributed by Samarakoon SMBC, Senanayake IC

94. Meliolaceae W. Martin ex Hansf., Mycol. Pap. 15: 23(1946) - contributed by Zeng XY, Hongsanan S

95. Melogrammataceae G. Winter, Rabenh. Krypt.-Fl., Edn 2 (Leipzig) 1.2: 797 (1886) contributed by Shang QJ, Liu JK

96. Microascaceae Luttr. ex Malloch, Mycologia 62: 734 (1970) - contributed by Kumar V

97. Microdochiaceae Hern.-Restr., Crous \& J.Z. Groenew., Persoonia 36: 64 (2015) contributed by Samarakoon MC, Liu JK

98. Myelospermataceae K.D. Hyde \& S.W. Wong, Mycol. Res. 44: 349 (1999) - contributed by Konta S, Boonmee S

99. Myrmecridiaceae Crous, Persoonia 34: 219 (2015) - contributed by Wei DP, Wanasinghe DN

100. Myrotheciomycetaceae Crous, Persoonia 40: 351 (2018) - contributed by Norphanphoun $\mathrm{C}$

101. Nectriaceae Tul. \& C. Tul., Select. fung. carpol. (Paris) 3: 3 (1865) - contributed by Perera RH, Niranjan M, Sarma VV, Liu JK

102. Neomelanconiellaceae Crous, Persoonia 41: 267 (2018) - contributed by Senanayake IC

103. Niessliaceae Kirschst., Annls mycol. 37: 89 (1939) - contributed by Huang SK, Jeewon R, Hyde KD

104. Nitschkiaceae Nannf., Nova Acta R. Soc. Scient. upsal., Ser. 4 8(no. 2): 56 (1932) contributed by Huang SK, Jeewon R, Hyde KD

105. Obryzaceae Körb., Syst. lich. germ. (Breslau): 427 (1855) - contributed by Bundhun D 
106. Ophioceraceae Klaubauf, E.G. LeBrun \& Crous, Studies in Mycology 79: 85-120 (2014) - contributed by Luo ZL

107. Ophiocordycipitaceae G.H. Sung, J.M. Sung, Hywel-Jones \& Spatafora, Stud. Mycol. 57: 35 (2007) - contributed by Xiao YP, Luangsa-ard J, Hongsanan S

108. Ophiostomataceae Nannf., Nova Acta R. Soc. Scient. upsal., Ser. 4 8(no. 2): 30 (1932) contributed by Norphanphoun C, Hongsanan $\mathrm{S}$

109. Oxydothidaceae S. Konta \& K.D. Hyde, Mycosphere 7: 1431 (2016) - contributed by Zhang S, Liu JK

110. Papulosaceae Winka \& O.E. Erikss., Mycoscience 41: 102 (2000) - contributed by Dayarathne MC, Jones EBG

111. Pararamichloridiaceae Crous, Persoonia 39: 357 (2017) - contributed by Lin CG, Liu JK

112. Parasympodiellaceae Hern.-Restr., Gené, Guarro \& Crous, Stud. Mycol. 86: 87 (2017) contributed by Bundhun D, Maharachchikumbura SSN

113. Phaeoappendicosporaceae Crous \& M.J. Wingf., Fungal Systematics and Evolution 3: 96 (2019) - contributed by Senanayake IC

114. Phaeochoraceae K.D. Hyde, P.F. Cannon \& M.E. Barr, Syst. Ascom. 15:118 (1997) contributed by Zhang SN, Liu JK

115. Phaeochorellaceae Guterres, Galvão-Elias \& Dianese, Mycologia - contributed by Bundhun D

116. Phlogicylindriaceae Senan. \& K.D. Hyde, Fungal Divers. 73: 35 (2015) - contributed by Goonasekara ID, Jayawardena RS

117. Phomatosporaceae Senan., Maharachch \& K.D. Hyde, Mycosphere 7: 633 (2016) contributed by Bundhun D, Senanayake IC

118. Phyllachoraceae Theiss. \& P. Syd., Annls mycol. 13: 168 (1915) - contributed by Dayarathne MC, Maharachchikumbura SSN

119. Pisorisporiaceae Réblová \& J. Fourn., Persoonia 34: 43 (2014) - contributed by Kumar V

120. Plectosphaerellaceae W. Gams, Summerb. \& Zare, Nova Hedwigia 85: 476 (2007) contributed by Shang QJ, Liu JK

121. Pleurostomataceae Réblová, L. Mostert, W. Gams \& Crous, Stud. Mycol. 50: 540 (2004) - contributed by Huang SK, Jeewon R

122. Pleurotheciaceae Réblová \& Seifert, Persoonia 37: 63 (2015) - contributed by Lin CG, Liu JK

123. Podosporaceae X. Wei Wang \& Houbraken, Stud. Mycol. (2019) - contributed by Chen YJ

124. Polystigmataceae Höhn. ex Nannf., Nova Acta R. Soc. Scient. upsal., Ser. 4 8(no. 2): 51 (1932) - contributed by Bundhun D, Maharachchikumbura SSN

125. Prosopidicolaceae Senan. \& K.D. Hyde, Stud. Mycol. 86: 281 (2017) - contributed by Senanayake IC

126. Pseudodactylariaceae Crous, Persoonia 39: 421 (2017) - contributed by Lin CG, Liu JK

127. Pseudohalonectriaceae Hongsanan \& K.D. Hyde, Fungal Divers. 84: 25-41(2017) contributed by Bao DF, Luo ZL

128. Pseudomassariaceae Senan., Maharachch. \& K.D. Hyde, Fungal Divers. 73: 132 (2015) contributed by Samarakoon MC, Liu JK

129. Pseudomelanconidaceae C.M. Tian \& X.L. Fan, Persoonia 40: 128 (2018) - contributed by Niego AGT, Fan, Senanayake IC, Jeewon R

130. Pseudoplagiostomataceae Cheew., M.J. Wingf. \& Crous, Fungal Divers. 44: 95 (2010) contributed by Niego AGT, Fan XL, Senanayake IC, Jeewon R

131. Pseudoproboscisporaceae H. Zhang, K.D. Hyde \& Maharachch., Fungal Divers. 85: 93 (2017) - contributed by Dong W, Doilom M

132. Pseudosporidesmiaceae Crous, Persoonia 39: 365 (2017) - contributed by Luo ZL

133. Pseudotruncatellaceae Crous, Persoonia 42: 309 (2019) - contributed by Perera RH 
134. Pyriculariaceae Klaubauf, M.H. Lebrun \& Crous, Stud. Mycol. 79: 104 (2014) contributed by Norphanphoun $\mathrm{C}$, Hongsanan $\mathrm{S}$

135. Requienellaceae Boise, Mycologia 78: 37 (1986) - contributed by Wei DP

136. Reticulascaceae Réblová \& W. Gams, Stud. Mycol. 68: 180 (2011) - contributed by Shang QJ, Liu JK

137. Rhamphoriaceae Réblová, Mycologia 110: 750-770 (2018) - contributed by Chen YJ

138. Sarocladiaceae L. Lombard, Persoonia 41: 343 (2018) - contributed by Phukhamsakda C

139. Savoryellaceae Jaklitsch \& Réblová, Index Fungorum 209: 1 (2015) - contributed by Dayarathne MC, Jones EBG

140. Schizoparmaceae Rossman, D.F. Farr \& Castl., Mycoscience 48: 137 (2007) contributed by Chethana KWT

141. Scortechiniaceae Huhndorf, A.N. Mill. \& F.A. Fernández, Mycol. Res. 108: 1387 (2004) - contributed by Huang SK, Jeewon R

142. Sordariaceae G. Winter, Rabenh. Krypt.-Fl., Edn 2 (Leipzig) 1.2: 162 (1885) contributed by Huang SK, Jeewon R, Hyde KD

143. Spathulosporaceae Kohlm., Mycologia 65: 615 (1973) - contributed by Dayarathne MC, Jones EBG

144. Sporidesmiaceae Fr., Summa veg. Scand., Sectio Post. (Stockholm): 504 (1849) contributed by Luo ZL

145. Sporocadaceae Corda, Icon. Fungorum (Prague) 5: 34 (1842) - contributed by Goonasekara ID, Jayawardena RS

146. Stachybotryaceae L. Lombard \& Crous, Persoonia 32: 283 (2014) - contributed by Lin CG, Liu JK

147. Stilbosporaceae Link, Abh. dt. Akad. Wiss. Berlin: 180 (1826) - contributed by Samarakoon SMBC, Fan XL

148. Sydowiellaceae Lar.N. Vassiljeva, Pirenomits. Lokuloaskomits. Severa Dal'nego Vostoka (Leningrad): 210 (1987) - contributed by Senanayake IC

149. Synnemasporellaceae X.L. Fan \& J.D.P. Bezerra, Persoonia 40: 130 (2018) - contributed by Bundhun D, Fan XL, McKenzie E, Maharachchikumbura SSN

150. Telimenaceae Mardones, T. Trampe \& M. Piepenbr., Persoonia 39: 83 (2017) contributed by Dayarathne MC, Maharachchikumbura SSN

151. Thyridiaceae J.Z. Yue \& O.E. Erikss., Syst. Ascom. 6: 233 (1987) - contributed by Perera RH, Jones EBG

152. Tilachlidiaceae L. Lombard \& Crous, Stud. Mycol. 80: 237 (2015) - contributed by Perera RH, McKenzie EHC

153. Tirisporellaceae Suetrong, E.B.G. Jones \& K.L. Pang, Cryptog. Mycol. 36: 323 (2015) contributed by Dayarathne MC, Zhang SN, Liu JK, Jones EBG

154. Togniniaceae Réblová, L. Mostert, W. Gams \& Crous, Stud. Mycol. 50: 540 (2004) contributed by Wei DP

155. Torpedosporaceae E.B.G. Jones \& K.L. Pang, Cryptog. Mycol. 35: 135 (2014) contributed by Dayarathne MC, Jones EBG

156. Tracyllaceae Crous, Persoonia 40: 365 (2018) - contributed by Calabon MS

157. Triadelphiaceae Y.Z. Lu, J.K. Liu, Z.L. Luo \& K.D. Hyde, Fungal Divers. 99: 555 (2019) - contributed by Luo ZL

158. Trichosphaeriaceae G. Winter, Rabenh. Krypt.-Fl., Edn 2 (Leipzig) 1.2: 191 (1885) contributed by Liu NG, Norphanphoun C, Luo ZL

159. Tubakiaceae U. Braun, J.Z. Groenew. \& Crous, Fungal Systematics and Evolution 1:62 (2018) - contributed by Marasinghe DS, Hongsanan S

160. Vermiculariopsiellaceae Hern.-Restr., J. Mena, Gené \& Crous, Stud. Mycol. 86: 91 (2017) - contributed by Liu NG, Liu JK

161. Vialaeaceae P.F. Cannon, Mycol. Res. 99: 368 (1995) - contributed by Senanayake IC, Samarakoon MC 
162. Woswasiaceae H. Zhang, K.D. Hyde \& Maharachch., Fungal Divers. 85: 104 (2017) contributed by Dong W, Luo ZL, Doilom M

163. Xenodactylariaceae Crous, Persoonia 41: 289 (2018) - contributed by Karunarathna A

164. Xenospadicoidaceae Hern.-Restr., J. Mena \& Gené, Stud. Mycol. 86: 91 (2017) contributed by Liu NG, Luo ZL

165. Xyladictyochaetaceae Crous \& Hern.-Restr., Fungal Systematics and Evolution 1: 212 (2018) - contributed by Samarakoon MC

166. Xylariaceae Tul. \& C. Tul., Select. fung. carpol. (Paris) 2: 3 (1863) - contributed by Samarakoon MC, Niranjan M, Stadler M

167. Zygosporiaceae Locq., Mycol. gén. struct. (Paris): 202 (1984) - contributed by Tibpromma S, Chaiwan N

\section{Introduction}

Molecular data based on DNA sequence data is rapidly advancing taxonomic knowledge of the fungi and recent efforts to provide classification schemes have been published for the basal fungi (Wijayawardene et al. 2018a), and Basidiomycota (He et al. 2019). The eventual outcome will be a classification scheme of all fungi, which can be updated periodically (Wijayawardene et al., in prep). The last 15 years in mycology have seen turbulent times, especially for the Ascomycota. This began with the AFTOL project which provided molecular data for the main orders and families of Ascomycota (James et al. 2006). This was followed by the "one fungus one name" concept to resolve the dual nomenclature problem for pleomorphic genera, a period of great changes where many genera were combined under an arguably preferred name (Taylor 2011) and notes on all genera of ascomycetes were provided (Wijayawardene et al. 2017b). Numerous new higher taxa have been introduced, initially with phylogenetic evidence, followed by support from molecular dating (Mapook et al. 2016, Hyde et al. 2017a, Hongsanan et al. 2017, Liu et al. 2017, Zeng et al. 2019).

The first main attempts at classifying all genera of Sordariomycetes were those of Barr (1983, 1987, 1990b) and Eriksson \& Hawksworth (1986a, 1993). These were magnificent attempts to classify often poorly known taxa and were based solely on morphology. We should not forget the incredible knowledge these authors had and incorporated into these documents. Classification of the sexual morphs of Sordariomycetes were continued by Lumbsch \& Huhndorf $(2007,2010)$, which incorporated morphology and available phylogenies. The first classification of Sordariomycetes in which the asexual and sexual states were included, and was partially based on molecular data were published by Maharachchimbura et al. (2015b, 2016b). Hongsanan et al. (2017) used divergence time estimates to provide support for the various orders and families in the class. These ground-breaking papers provided the background for the present paper, where we update the classification of Sordariomycetes, with notes on the orders, families and genera.

Sordariomycetes is an important class of ascomycetes, characterized by non-lichenized, flaskshaped fruiting bodies or less frequently cleistothecial ascomata and unitunicate asci (Zhang et al. 2006, Maharachchikumbura et al. 2016b), and can have a varied growth form and colonise diverse habitats (Hongsanan et al. 2017). It is the second largest class of Ascomycota (Hyde et al. 2013, Maharachchikumbura et al. 2015, 2016b). Sordariomycetes have a cosmopolitan distribution and can be found in almost all ecosystems (Pratibha et al. 2014, Jones et al. 2015). Some Sordariomycetes are phytopathogens causing leaf, stem, root and fruit diseases (e.g. Colletotrichum, Coniella, Diaporthe), while some are pathogenic to arthropod and mammals (eg. Sporothrix, Fusarium). Some members are endophytes (e.g. Pestalotiopsis) (Maharachchikumbura et al. 2014b, Norphanphoun et al. 2019) and some are saprobes involved in decomposition and nutrient cycling (Chaetomium, Neurospora) (Zhang \& Wang 2015). Some taxa are fungicolous (Sun et al. 2019) and several are opportunistic pathogens of humans (Gostinčar et al. 2018). Some taxa of Sordariomycetes are economically important as biocontrol agents (Harman et al. 2004, Hyde et al. 2019a) and some species produce a wide range of important secondary metabolites (Maharachchikumbura et al. 2016b). 
The classification of the class Sordariomycetes has changed drastically over the past decade (Wijayawardene et al. 2018). Characters alone are insufficient to resolve the identification of many species and even some genera (Tang et al. 2007, 2009). Molecular studies on this class began in the early 1990s using SSU and LSU sequence data (Berbee \& Taylor 1992, Zhang et al. 2006). However, SSU and LSU sequence data are insufficient to provide a good resolution in most of the groups in this class. It has been established that the use of protein genes can yield a higher phylogenetic resolution (Tang et al. 2007, 2009, Schoch et al. 2009, Maharachchikumbura et al. 2016b).

The subclasses of Sordariomycetes have expanded from three to six. Eriksson \& Winka (1997) introduced Hypocreomycetidae, Sordariomycetidae and Xylariomycetidae based on morphology and nrDNA sequence data. In a revision of Sordariomycetes, Maharachchikumbura et al. (2016b) used morphology and a combined analysis of LSU, SSU, tefl and rpb2 sequence data and introduced another three new subclasses; Diaporthomycetidae, Lulworthiomycetidae, and Meliolomycetidae. The subclass Meliolomycetidae was found to be a synonym of Sordariomycetidae, while Savoryellomycetidae was raised to subclass level (Hongsanan et al. 2017, Wijayawardene et al. 2018a, Dayarathne et al. 2019a).

Kirk et al. (2008) listed 1,119 genera and over 10,000 species in this class. In the outline of the Sordariomycetes, Maharachchikumbura et al. (2015) included 28 orders, 90 families and 1344 genera. According to the outline by Maharachchikumbura et al. (2016b), Sordariomycetes had six subclasses, 32 orders, 105 families and 1331 genera. Hongsanan et al. (2017) provided an updated backbone tree for Sordariomycetes based on divergence times and proposed changes to this class. In this paper, we deal with the family level classification of Sordariomycetes by updating the outline given by Maharachchikumbura et al. (2016b).

\section{Layout of the paper}

Family descriptions, notes on history and a brief account of the genera including phylogenetic data if available are provided for each family. The type genus/new species/new host record are illustrated with a representative plate of features followed by a description and a note for each family. This is followed by ecological and economic significance of the family and the accepted genera and their type species. For consistency, authorities and abbreviations follow Index Fungorum (2020).

\section{Arrangement of Sordariomycetes}

The arrangement of this paper follows Maharachchikumbura et al. (2016b), which has been updated based on recent publications and interpretation of genera from the literature (Wijayawardene et al. 2018a).

\section{Examination of specimens}

\section{Herbarium material}

Specimens or slides were obtained from CF, CUP, DAOM, F, FH, G, GZUH, HKAS, IFO, IFO-H, ILLS, ILLS, IMI, IMS, K(M), KCM, KUN, M, MFLU, MICH, MUCL, NY, O-F, PDD, PREM, PRM, S-F, TRTC, WU, and ZT MYZ. Fruiting bodies were rehydrated in water and/or 5\% $\mathrm{KOH}$ prior to examination and sectioning. Hand sections of the fruiting bodies were mounted in water for microscopic studies and photomicrography.

\section{Fresh collection}

Samples were collected from China, India, Italy, Russia and Thailand. Fungi were isolated by a modified single spore isolation method (Chomnunti et al. 2014). Cultures were transferred to different media i.e. $2 \%$ potato dextrose agar (PDA) and malt dextrose agar (MEA) or water agar (WA; $15 \mathrm{~g} / \mathrm{l}$ sterile distilled water), and incubated under different conditions depending on the taxon to induce sporulation. Extype or representative isolates were deposited in Mae Fah Luang 
University culture collection (MFLUCC) with duplicates in FU, GZCC, JZB, KUMCC, and NFCC. The collected specimens were deposited in the Herbarium of Mae Fah Luang University (MFLU), Thailand, AMH, FU, and HKAS. Vegetative and reproductive structures were mounted in clear lactic acid or water, either directly from specimens or from colonies sporulating on media. Sections of fruiting bodies were made by hand and examined. Isolates were grown and incubated on different culture media and temperatures as required for each genus. Colour notations followed the colour charts of Rayner (1970). Taxonomic descriptions were deposited in the Facesoffungi (FOF) database as described in Jayasiri et al. (2015) and Index Fungorum numbers were obtained as detailed in Index Fungorum database. New species were established based on the guidelines provided by Jeewon \& Hyde (2016).

Both herbarium and fresh collections were examined using a Nikon ECLIPSE 8oi compound microscope and photographed with a Cannon 450D digital camera fitted to the microscope. Measurements were made with the Tarosoft (R) Image Frame Work program (v.0.9.0.7) and images used for figures processed with Adobe Photoshop CS6 software (Adobe Systems, USA). For the specimens that were in poor condition, hand drawings based on the original publications were prepared using drawing pens and parchment papers. DNA extraction, PCR amplification, sequencing and phylogenetic analyses follow previous papers (Hyde et al. 2016a, Tibpromma et al. 2017).

\section{Phylogenetic analysis and divergence estimates}

The phylogenetic analysis follows Maharachchimbura et al. (2015b, 2016b). The MCC analysis was performed in BEAST v1.10.2. The crown age of Sordariomycetes was set with Normal distribution, mean $=250, \mathrm{SD}=30$, with $97.5 \%$ of $\mathrm{CI}=308.8 \mathrm{MYA}$, and crown age of Dothideomycetes with Normal distribution mean $=360, \mathrm{SD}=20$, with $97.5 \%$ of $\mathrm{CI}=399$ MYA. The substitution models were selected based on jModeltest2.1.1; GTR+I+G for LSU, RPB2 and SSU, and TrN+I+G for TEF (the model TrN is not available in BEAUti 1.10.2, thus we used TN93). Lognormal distribution of rates was used during the analyses with uncorrelated relaxed clock model. The Yule process tree prior was used to model the speciation of nodes in the topology with a randomly generated starting tree. The analyses were performed for 100 million generations, with sampling parameters every 10000 generations. The effective sample sizes were checked in Tracer v.1.6 and the acceptable values are higher than 200. The first $20 \%$ representing the burn-in phase were discarded and the remaining trees were combined in LogCombiner 1.10.2., summarized data and estimated in TreeAnnotator 1.10.2. Bars correspond to the 95\% highest posterior density (HPD) intervals. The scale axis (Fig. 2) shows divergence times as millions of years ago (MYA).

Arrangement of Sordariomycetes with classes, subclasses, orders, families and genera with numbers of species in brackets

Class Sordariomycetes O.E. Erikss. \& Winka

Subclass Diaporthomycetidae Senan. et al.

Annulatascales D'souza et al.

Annulatascaceae S.W. Wong et al.

Annulatascus K.D. Hyde

Annulusmagnus J. Campb. \& Shearer

Aqualignicola Ranghoo et al.

Ascitendus J. Campb. \& Shearer

Ayria Fryar \& K.D. Hyde

Cataractispora K.D. Hyde

Chaetorostrum Zelski et al.

Longicollum Zelski et al.

Submersisphaeria K.D. Hyde

Vertexicola K.D. Hyde et al. 
Annulatascales genera incertae sedis

Clohiesia K.D. Hyde

Atractosporales H. Zhang et al.

Atractosporaceae H. Zhang et al.

Atractospora Réblová \& J. Fourn.

Rubellisphaeria Réblová \& J. Fourn.

Conlariaceae H. Zhang et al.

Conlarium F. Liu \& L. Cai

Riomyces A. Ferrer et al.

Pseudoproboscisporaceae $\mathrm{H}$. Zhang et al.

Diluviicola K.D. Hyde et al.

Pseudoproboscispora Punith.

Calosphaeriales M.E. Barr

Calosphaeriaceae Munk

Calosphaeria Tul. \& C Tul.

Flabellascus Réblová

Jattaea Berl

Togniniella Réblová et al.

Pleurostomataceae Réblová et al.

Pleurostoma Tul. \& C. Tul.

Calosphaeriales genus incertae sedis

Calosphaeriopsis Petr.

Enchnoa Fr.

Kacosphaeria Speg.

Sulcatistroma A.W. Ramaley

Diaporthales Nannf.

Apiosporopsidaceae Senan. et al.

Apiosporopsis (Traverso) Mariani.

Apoharknessiaceae Senan. et al.

Apoharknessia Crous \& S.J. Lee

Lasmenia Speg.

Asterosporiaceae Senan. et al.

Asterosporium Kunze

Auratiopycnidiellaceae Senan. et al.

Auratiopycnidiella Crous \& Summerell

Coryneaceae Corda

Coryneum Nees

Cryphonectriaceae Gryzenh. \& M.J. Wingf.

Amphilogia Gryzenh. et al. 
Aurantioporthe G. Beier \& R.A. Blanchette

Aurantiosacculus Dyko \& B. Sutton

Aurapex Gryzenh. \& M.J. Wingf.

Aurifilum Begoude et al.

Capillaureum M.E.S. Oliveira

Celoporthe Nakab. et al.

Chromendothia Lar.N. Vassiljeva

Chrysofolia Crous \& M.J. Wingf.

Chrysomorbus S.F. Chen

Chrysoporthe Gryzenh. \& M.J. Wingf.

Corticimorbus S.F. Chen \& M.J. Wingf.

Cryphonectria (Sacc.) Sacc. \& D. Sacc.

Cryptometrion Gryzenh. \& M.J. Wingf.

Diversimorbus S.F. Chen \& J. Roux

Endothia Fr.

Foliocryphia Cheew. \& Crous

Holocryphia Gryzenh. \& M.J. Wingf.

Immersiporthe S.F. Chen et al.

Latruncellus M. Verm. et al.

Luteocirrhus C.F. Crane \& T.I. Burgess

Mastigosporella Höhn.

Microthia Gryzenh. \& M.J. Wingf.

Myrtonectria Marinc. et al.

Rostraureum Gryzenh. \& M.J. Wingf.

Ursicollum Gryzenh. \& M.J. Wingf.

Wuestneia Auersw. ex Fuckel

Cytosporaceae Fr.

Cryptascoma Ananthap.

Cytospora Ehrenb.

Pachytrype Berl. ex M.E. Barr et al.

Paravalsa Ananthap.

Waydora B. Sutton

Xenotypa Petr.

Diaporthaceae Höhn. ex Wehm.

Apioporthella Petr.

Apiosphaeria Höhn.

Chaetoconis Clem.

Chiangraiomyces Senan. \& K.D. Hyde

Diaporthe Nitschke

Hyaliappendispora Senan. et al.

Leucodiaporthe M.E. Barr \& Lar.N. Vassiljeva

Massariothea Syd.

Mazzantia Mont.

Ophiodiaporthe Y.M. Ju et al.

Paradiaporthe Senan. et al.

Phaeocytostroma Petr.

Phaeodiaporthe Petr.

Pustulomyces D.Q. Dai et al.

Stenocarpella Syd. \& P. Syd. 
Diaporthosporellaceae C.M. Tian \& Q. Yang Diaporthosporella C.M. Tian \& Q. Yang

Diaporthostomataceae X.L. Fan \& C.M. Tian

Diaporthostoma X.L. Fan \& C.M. Tian

Dwiroopaceae K.V. Xavier et al.

Dwiroopa Subram. \& Muthumary

Erythrogloeaceae Senan. et al.

Chrysocrypta Crous \& Summerell

Dendrostoma X.L. Fan \& C.M. Tian

Disculoides Crous et al.

Erythrogloeum Petr.

Gnomoniaceae G. Winter

Alnecium Voglmayr \& Jaklitsch

Ambarignomonia Sogonov

Amphiporthe Petr.

Anisomyces Theiss. \& Syd.

Apiognomonia Höhn.

Apioplagiostoma M.E. Barr

Asteroma DC.

Bagcheea E. Müll. \& R. Menon

Chadefaudiomyces Kamat

Clypeoporthe Höhn.

Cryptosporella Sacc.

Dictyoporthe Petr.

Diplacella Syd.

Ditopella De Not.

Ditopellopsis J. Reid \& C. Booth

Gloeosporidina Petr.

Gnomonia Ces. \& De Not.

Gnomoniella Sacc.

Gnomoniopsis Berl.

Maculatipalma J. Fröhlich \& K.D. Hyde

Mamianiella Höhn.

Marsupiomyces Senan. \& K.D. Hyde

Millerburtonia Cif .

Occultocarpon L.C. Mejía \& Zhu L. Yang

Ophiognomonia (Sacc.) Sacc.

Phragmoporthe Petr.

Phylloporthe Syd.

Plagiostoma Fuckel

Pleuroceras Riess.

Sirococcus Preuss

Spataporthe Bronson et al.

Tenuignomonia Minosh. et al.

Uleoporthe Petr.

Uniseta Ciccar

Valsalnicola D.M. Walker \& Rossman

Vismaya V.V. Sarma \& K.D. Hyde 
Harknessiaceae Crous

Harknessia Cooke

Mebarria J. Reid \& C. Booth

Juglanconidaceae Voglmayr \& Jaklitsch

Juglanconis Voglmayr \& Jaklitsch

Lamproconiaceae C. Norphanphoun et al.

Hercospora Fr.

Lamproconium (Grove) Grove

Macrohilaceae Crous

Macrohilum H.J. Swart

Melanconidaceae G. Winter

Melanconis Tul. \& C. Tul.

Melanconiellaceae Senan. et al.

Dicarpella Syd. \& P. Syd.

Greeneria Scribn. \& Viala

Massariovalsa Sacc.

Melanconiella Sacc.

Microascospora Senan. \& K.D. Hyde

Septomelanconiella Samarak. \& K.D. Hyde

Sheathospora X.L. Fan

Neomelanconiellaceae Crous

Neomelanconiella Crous

Phaeoappendicosporaceae Crous \& M.J. Wingf. Neophaeoappendicospora Crous \& M.J. Wingf.

Phaeoappendicospora Senan. et al.

Phaeochorellaceae Guterres et al.

Phaeochorella (Henn.) Theiss. \& Syd.

Prosopidicolaceae Senan. \& K.D. Hyde

Prosopidicola Crous \& C.L. Lennox

Pseudomelanconidaceae C.M. Tian \& X.L. Fan

Pseudomelanconis C.M. Tian \& X.L. Fan

Neopseudomelanconis C.M. Tian \& N. Jiang

Pseudoplagiostomataceae Cheew. et al.

Pseudoplagiostoma Cheew. et al.

Schizoparmaceae Rossman

Coniella Höhn.

Stilbosporaceae Link

Crinitospora B. Sutton \& Alcorn 
Natarajania Pratibha \& Bhat

Stegonsporium Corda

Stilbospora Pers.

Sydowiellaceae Lar.N. Vassiljeva

Alborbis Senan. \& K.D. Hyde

Breviappendix Senan. \& K.D. Hyde

Cainiella E. Müll.

Calosporella J. Schröt

Caudospora Starbäck

Chapeckia M.E. Barr

Hapalocystis Auersw. ex Fuckel

Italiomyces Senan. et al.

Lambro Racib.

Paragnomonia Senan. \& K.D. Hyde

Ranulospora Senan. et al.

Rossmania Lar.N. Vassiljeva

Sillia P. Karst.

Sydowiella Petr.

Tenuiappendicula Senan. et al.

Tortilispora Senan. \& K.D. Hyde

Synnemasporellaceae X.L. Fan \& J.D.P. Bezerra

Synnemasporella X.L. Fan \& J.D.P. Bezerra

Tubakiaceae U. Braun et al.

Apiognomonioides U. Braun et al.

Involutscutellula U. Braun \& C. Nakash.

Oblongisporothyrium U. Braun \& C. Nakash.

Paratubakia U. Braun \& C. Nakash.

Racheliella Crous \& U. Braun

Saprothyrium U. Braun et al.

Sphaerosporithyrium U. Braun et al.

Tubakia B. Sutton

Diaporthales genera incertae sedis

Ceratoporthe Petr.

Cryptoleptosphaeria Petr.

Cytomelanconis Naumov

Diaporthella Petr.

Diatrypoidiella Manohar et al.

Ditopellina J. Reid \& C. Booth

Durispora K.D. Hyde

Exormatostoma Gray

Fremineavia Nieuwl.

Gibellia Sacc.

Gyrostroma Naumov

Hyalorostratum Raja \& Shearer

Hypophloeda K.D. Hyde \& E.B.G. Jones

Hypospilina (Sacc) Traverso

Kapooria J. Reid \& C. Booth

Keinstirschia J. Reid \& C. Booth 
Lollipopaia Inderb.

Macrodiaporthe Petr.

Melanamphora Lafl.

Phragmodiaporthe Wehm.

Phruensis Pinruan

Plagiophiale Petr.

Plagiostigme Syd.

Prostratus Sivan. et al.

Pseudocryptosporella J. Reid \& C. Booth

Pseudothis Theiss. \& Syd.

Pseudovalsella Höhn.

Savulescua Petr.

Sphaerognomoniella Naumov \& Kusnezowa

Stioclettia Dennis

Trematovalsa Jacobesco

Wehmeyera J. Reid \& C. Booth

Distoseptisporales Z.L. Luo et al.

Distoseptisporaceae K.D. Hyde \& McKenzie

Distoseptispora K.D. Hyde et al.

Jobellisiales M.J. D'souza \& K.D. Hyde

Jobellisiaceae Réblová

Jobellisia M.E. Barr

Magnaporthales Thongk. et al.

Ceratosphaeriaceae Z.L. Luo et al.

Ceratosphaeria Niessl

Magnaporthaceae P.F. Cannon

Bifusisporella R.M.F. Silva

Budhanggurabania P. Wong et al.

Buergenerula Syd.

Bussabanomyces Klaubauf et al.

Ceratosphaerella Huhndorf et al.

Clasterosporium Schwein

Clavatisporella K.D. Hyde

Falciphora J. Luo \& N. Zhang

Falciphoriella M. Hern.-Restr. \& Crous

Gaeumannomycella M. Hern.-Restr. \& Crous

Gaeumannomyces Arx \& D.L. Olivier

Herbampulla Scheuer \& Nograsek

Kohlmeyeriopsis Klaubauf et al.

Magnaporthiopsis J. Luo \& N. Zhang

Muraeriata Huhndorf et al.

Mycoleptodiscus Ostaz.

Nakataea Hara

Neogaeumannomyces D.Q. Dai \& K.D. Hyde

Omnidemptus P.F. Cannon \& Alcorn

Pseudophialophora J. Luo \& N. Zhang

Pyriculariopsis M.B. Ellis

Slopeiomyces Klaubauf et al. 
Ophioceraceae Klaubauf et al.

Ophioceras Sacc.

Pseudohalonectriaceae Hongsanan \& K.D. Hyde

Pseudohalonectria Minoura \& T. Muroi

Pyriculariaceae Klaubauf et al.

Bambusicularia Klaubauf et al.

Barretomyces Klaubauf et al.

Deightoniella S. Hughes

Macgarvieomyces Klaubauf et al.

Neocordana Hern.-Rest. \& Crous

Neopyricularia Klaubauf et al.

Proxipyricularia Klaubauf et al.

Pseudopyricularia Klaubauf et al.

Pyricularia Sacc.

Pyriculariomyces Y. Marín et al.

Xenopyricularia Klaubauf et al.

Myrmecridiales Crous

Myrmecridiaceae Crous

Myrmecridium Arzanlou et al.

Neomyrmecridium Crous

Xenodactylariaceae Crous

Xenodactylaria Crous

Ophiostomatales Benny \& Kimbr.

Kathistaceae Malloch \& M. Blackw.

Kathistes Malloch \& M. Blackw.

Mattirolella S. Colla

Termitariopsis M. Blackw. et al.

Ophiostomataceae Nannf.

Afroraffaelea C.C. Bateman et al.

Aureovirgo J.A. van der Linde et al.

Ceratocystiopsis H.P. Upadhyay \& W.B. Kendr.

Fragosphaeria Shear

Graphilbum H.P. Upadhyay \& W.B. Kendr.

Hawksworthiomyces Z.W. de Beer et al.

Klasterskya Petr.

Leptographium Lagerb. \& Melin

Ophiostoma Syd. \& P. Syd.

Raffaelea Arx \& Hennebert

Sporothrix Hektoen \& C.F. Perkins

Spumatoria Massee \& E.S. Salmon

Subbaromyces Hesselt.

Pararamichloridiales Crous

Pararamichloridiaceae Crous

Pararamichloridium Crous 
Phomatosporales Senan. et al.

Phomatosporaceae Senan. \& K.D. Hyde

Lanspora K.D. Hyde \& E.B.G. Jones

Phomatospora Sacc.

Tenuimurus Senan. et al.

Sporidesmiales Crous

Sporidesmiaceae Fr.

Sporidesmium Link

Tirisporellales Suetrong et al.

Tirisporellaceae Suetrong et al.

Bacusphaeria Norlailatul et al.

Thailandiomyces Pinruan et al.

Tirisporella E.B.G. Jones et al.

Togniniales Senan. et al.

Togniniaceae Réblová et al.

Conidiotheca Réblová \& L Mostert

Phaeoacremonium W. Gams et al.

Xenospadicoidales Hern.-Restr., J. Mena \& Gené

Xenospadicoidaceae Hern.-Restr., J. Mena \& Gené

Calyptosphaeria Réblová \& A.N. Mill.

Lentomitella Höhn.

Neospadicoides Z.L. Luo

Spadicoides S. Hughes

Torrentispora K.D. Hyde et al.

Diaporthomycetidae families incertae sedis

Barbatosphaeriaceae $\mathrm{H}$. Zhang et al.

Barbatosphaeria Réblová

Ceratostomella Sacc.

Xylomelasma Réblová

Papulosaceae Winka \& O.E. Erikss.

Brunneosporella V.M. Ranghoo \& K.D. Hyde

Fluminicola S.W. Wong et al.

Papulosa Kohlm \& Volkm-Kohlm.

Wongia Khemmuk et al.

Rhamphoriaceae Réblová

Rhamphoria Niessl

Rhamphoriopsis Réblová \& Gardiennet

Rhodoveronaea Arzanlou, W. Gams \& Crous

Xylolentia Réblová

Thyridiaceae J.Z. Yue \& O.E. Erikss.

Pleurocytospora Petr.

Thyridium Nitschke

Trichosphaeriaceae G. Winter 
Brachysporium Sacc.

Collematospora Jeng \& Cain

Coniobrevicolla Réblová

Eriosphaeria Sacc.

Koorchaloma Subram.

Rizalia Syd. \& P. Syd.

Schweinitziella Speg.

Setocampanula Sivan. \& W.H. Hsieh

Trichosphaeria Fuckel

Unisetosphaeria Pinnoi et al.

Woswasiaceae H. Zhang et al.

Cyanoannulus Raja et al.

Woswasia Jaklitsch et al.

Xylochrysis Réblová et al.

Diaporthomycetidae genera incertae sedis

Aquapteridospora Jiao Yang et al.

Aquaticola W.H. Ho et al.

Fusoidispora D. Vijaykrishna et al.

Platytrachelon Réblová

Proliferophorum G.N. Wang et al.

Pseudostanjehughesia J. Yang \& K.D. Hyde

Subclass Hypocreomycetidae O.E. Erikss. \& Winka

Coronophorales Nannf.

Bertiaceae Smyk

Bertia De Not.

Gaillardiella Pat.

Ceratostomataceae G. Winter

Arxiomyces P.F. Cannon \& D. Hawksw.

Dactylidispora Y. Marín et al.

Echinusitheca Y. Marín et al.

Erythrocarpon Zukal

Harzia Costantin

Melanospora Corda

Microthecium Corda

Pseudomicrothecium Y. Marín et al.

Pustulipora P.F. Cannon

Rhytidospora Jeng \& Cain

Scopinella Lév.

Setiferotheca Matsush.

Syspastospora P.F. Cannon \& D. Hawksw.

Vittatispora P. Chaudhary et al.

Chaetosphaerellaceae Huhndorf et al.

Chaetosphaerella E. Müll. \& C. Booth

Crassochaeta Réblová

Spinulosphaeria Sivan.

Coronophoraceae Höhn. 
Nitschkiaceae (Fitzp.) Nannf.

Acanthonitschkea Speg.

Biciliosporina Subram. \& Sekar

Botryola Bat. \& J.L. Bezerra

Fracchiaea Sacc.

Groenhiella Jørg. Koch et al.

Janannfeldtia Subram. \& Sekar

Lasiosphaeriopsis D. Hawksw. \& Sivan.

Loranitschkia Lar.N. Vassiljeva

Neochaetosphaerella Lar.N. Vassiljeva et al.

Neotrotteria Sacc.

Nitschkia G.H. Otth ex P. Karst.

Rhagadostoma Körb.

Rhagadostomella Etayo

Tortulomyces Lar.N. Vassiljeva et al.

Scortechiniaceae Huhndorf et al.

Biciliospora Petr.

Coronophorella Höhn.

Cryptosphaerella Sacc.

Euacanthe Theiss.

Neofracchiaea Teng

Pseudocatenomycopsis Crous \& L.A. Shuttlew.

Scortechinia Sacc.

Scortechiniella Arx \& E. Müll.

Scortechiniellopsis Sivan.

Tympanopsis Starbäck

Coronophorales genus incertae sedis

Papulaspora Preuss

Sphaerodes Clem.

Falcocladiales R.H. Perera et al.

Falcocladiaceae Somrithipol et al.

Falcocladium S.F. Silveira et al.

Glomerellales Chadef. ex Réblová et al.

Australiascaceae Réblová \& W. Gams

Monilochaetes Halst. ex Harter

Glomerellaceae Locq. ex Seifert \& W. Gams

Colletotrichum Corda

Malaysiascaceae Tibpromma \& K.D. Hyde

Malaysiasca Crous \& M.J. Wingf.

Plectosphaerellaceae W. Gams et al.

Acremoniisimulans Tibpromma \& K.D. Hyde

Acrostalagmus Corda

Brunneochlamydosporium Giraldo López \& Crous

Brunneomyces A. Giraldo, Gené \& Guarro 
Chlamydosporiella Giraldo López \& Crous

Chordomyces Bilanenko et al.

Furcasterigmium Giraldo López \& Crous

Fuscohypha Giraldo López \& Crous

Gibellulopsis Bat. \& H. Maia

Lectera P.F. Cannon

Longitudinalis Tibpromma \& K.D. Hyde

Musicillium Zare \& W Gams

Musidium Giraldo López \& Crous

Nigrocephalum Giraldo López \& Crous

Paragibellulopsis Giraldo López \& Crous

Paramusicillium Giraldo López \& Crous

Phialoparvum Giraldo López \& Crous

Plectosphaerella Kleb.

Sayamraella Giraldo López \& Crous

Sodiomyces A.A. Grum-Grzhim. et al.

Stachylidium Link

Summerbellia Giraldo López \& Crous

Theobromium Giraldo López \& Crous

Verticillium Nees

Reticulascaceae Réblová \& W. Gams

Blastophorum Matsush.

Cylindrotrichum Bonord.

Kylindria DiCosmo et al.

Sporoschismopsis Hol-Jech. \& Hennebert

Glomerellales genera incertae sedis

Ascocodinaea Samuels et al.

Hypocreales Lindau

Bionectriaceae Samuels \& Rossman

Acremonium Link

Anthonectria Döbbeler

Aphanotria Döbbeler

Battarrina (Sacc.) Clem. \& Shear

Bryocentria Döbbeler

Bryotria Döbbeler \& P.G. Davison

Bullanockia Crous

Clibanites (P. Karst.) P. Karst.

Clonostachys Corda

Dimerosporiella Speg.

Fusariella Sacc.

Geonectria Lechat \& J. Fourn.

Geosmithia Pitt

Gliomastix Guég.

Globonectria Etayo

Gracilistilbella Seifert

Halonectria E.B.G. Jones

Heleococcum P.M. Jørg.

Hydropisphaera Dumort

Ijuhya Starbäck 
Kallichroma Kohlm. \& Volkm.-Kohlm.

Laniatria Döbbeler \& P.G. Davison

Lasionectria (Sacc.) Cooke

Lasionectriella Lechat \& J. Fourn.

Mycoarachis Malloch \& Cain

Mycocitrus Möller

Nectriella Nitschke ex Fuckel

Nectriopsis Maire

Nigrosabulum Malloch \& Cain

Ochronectria Rossman \& Samuels

Ovicuculispora Etayo

Paracylindrocarpon Crous et al.

Paranectria Sacc.

Periantria Döbbeler \& P.G. Davison

Peristomialis (W. Phillips) Boud.

Pronectria Clem.

Protocreopsis Yoshim Doi

Rhopalocladium Schroers et al.

Roumegueriella Speg.

Selinia P. Karst.

Stephanonectria Schroers \& Samuels

Stilbocrea Pat.

Stromatonectria Jaklitsch \& H. Voglmayr

Synnemellisia N.K. Rao et al.

Trichonectria Kirschst.

Verrucostoma Hirooka et al.

Xanthonectria Lechat et al.

Calcarisporiaceae Jing Z. Sun et al.

Calcarisporium Preuss

Clavicipitaceae (Lindau) Earle ex Rogerson

Aciculosporium I. Miyake

Aschersonia Mont.

Atkinsonella Diehl

Balansia Speg.

Cavimalum Yoshim. Doi et al.

Claviceps Tul.

Collarina Giraldo et al.

Conoideocrella D. Johnson et al.

Corallocytostroma Y.N. Yu \& Z.Y. Zhang

Dussiella Pat.

Ephelis Fr.

Epichlö̈ (Fr.) Tul. \& C. Tul.

Epicrea Petr.

Helicocollum Luangsa-ard

Helminthascus Tranzschel

Heteroepichloë E. Tanaka et al.

Konradia Racib.

Loculistroma F. Patt \& Charles

Metapochonia Kepler et al.

Metarhiziopsis D.W. Li et al. 
Metarhizium Sorokīn

Moelleriella Bres.

Mycomalus A. Möller

Mycophilomyces Crous \& M.J. Wingf.

Myriogenospora G.F. Atk.

Neobarya Lowen

Neocordyceps Kobayasi

Nigelia Luangsa-ard

Nigrocornus Ryley \& Langdon

Orbiocrella D. Johnson et al.

Parepichlö̈ J.F. White \& P.V. Reddy

Periglandula U. Steiner et al.

Pochonia Bat. \& O.M. Fonseca

Pseudomeria G.L. Barron

Regiocrella Chaverri \& K.T. Hodge

Romanoa Thirum.

Rotiferophthora G.L. Barron

Samuelsia Chaverri \& K.T. Hodge

Shimizuomyces Kobayasi

Sphaerocordyceps Kobayasi

Tyrannicordyceps Kepler \& Spatafora

Ustilaginoidea Bref.

Cocoonihabitaceae W.Y. Zhuang \& Z.Q. Zeng

Cocoonihabitus W.Y. Zhuang \& Z.Q. Zeng

Cordycipitaceae Kreisel ex G.M. Sung et al.

Akanthomyces Lebert

Amphichorda Fr.

Ascopolyporus Möller

Beauveria Vuill.

Beejasamuha Subram. \& Chandrash.

Blackwellomyces Spatafora \& Luangsa-ard

Cordyceps (Fr.) Link

Coremiopsis Sizova \& Suprun

Engyodontium de Hoog

Gibellula Cavara

Hevansia Luangsa-ard et al.

Hyperdermium J. White et al.

Leptobacillium Zare \& W. Gams

Parengyodontium C.C. Tsang

Pseudogibellula Samson \& H.C. Evans

Samsoniella Mongkols. et al.

Simplicillium W. Gams \& Zare

Flammocladiellaceae Crous et al.

Flammocladiella Crous et al.

Hypocreaceae De Not.

Arachnocrea Z. Moravec.

Dialhypocrea Speg.

Escovopsioides H.C. Evans \& J.O. Augustin

Escovopsis J.J. Muchovej \& Della Lucia 
Hypocreopsis P. Karst.

Hypomyces (Fr.) Tul. \& C. Tul.

Kiflimonium Summerb. et al.

Lichenobarya Etayo et al.

Mycogone Link

Protocrea Petch

Rogersonia Samuels \& Lodge

Sepedonium Link

Sphaerostilbella (Henn.) Sacc. \& D. Sacc

Sporophagomyces K. Põldmaa \& Samuels

Stephanoma Wallr.

Trichoderma Pers.

Verticimonosporium Matsush.

Myrotheciomycetaceae Crous

Emericellopsis J.F.H. Beym

Leucosphaerina Arx

Myrotheciomyces Crous

Trichothecium Link

Nectriaceae Tul. \& C. Tul.

Albonectria Rossman \& Samuels

Allantonectria Earle

Allonectella Petr.

Aphanocladium W. Gams

Aquanectria L. Lombard \& Crous

Atractium Link

Baipadisphaeria Pinruan

Bisifusarium L. Lombard et al.

Calonectria De Not.

Calostilbe Sacc. \& Syd.

Campylocarpon Halleen et al.

Chaetonectrioides Matsush.

Chaetopsina Rambelli

Coccinonectria Lombard \& Crous

Corallomycetella Henn.

Corallonectria C. Herrera \& P. Chaverri

Corinectria C. González \& P. Chaverri

Cosmospora Rabenh.

Cosmosporella S.K. Huang et al.

Curvicladiella Decock \& Crous

Cyanochyta Höhn.

Cyanonectria Samuels \& Chaverri

Cyanophomella Höhn.

Cylindrocladiella Boesew.

Cylindrodendrum Bonord.

Dacryoma Samuels

Dactylonectria L. Lombard \& Crous

Dematiocladium Allegr. et al.

Fusarium Link

Fusicolla Bonord

Geejayessia Schroers et al. 
Gliocephalotrichum J.J. Ellis \& Hesselt.

Gliocladiopsis S.B. Saksena

Ilyonectria P. Chaverri \& C. Salgado

Macroconia (Wollenw.) Gräfenhan et al.

Mariannaea G. Arnaud ex Samson

Microcera Desm.

Murinectria M. Niranjan \& V.V. Sarma

Nalanthamala Subram.

Nectria (Fr.) Fr.

Neocosmospora E.F. Sm.

Neonectria Wollenw.

Neothyronectria Crous \& Thangavel

Ophionectria Sacc.

Pandanaceomyces Tibpromma \& K.D. Hyde

Paracremonium L. Lombard \& Crous

Payosphaeria W.F. Leong

Penicillifer Emden

Persiciospora P.F. Cannon \& D. Hawksw.

Pleiocarpon L. Lombard \& D. Aiello

Pleogibberella Sacc.

Pleurocolla Petr.

Pseudoachroiostachys Tibpromma \& K.D. Hyde

Pseudocosmospora C. Herrera \& P. Chaverri

Pseudonectria Seaver

Rectifusarium Lombard et al.

Rugonectria P. Chaverri \& Samuels

Sarcopodium Ehrenb.

Stylonectria Höhn.

Thelonectria P. Chaverri \& C.G. Salgado

Thyronectria Sacc.

Varicosporella Lechat \& J. Fourn.

Varicosporellopsis Lechat \& J. Fourn.

Volutella Fr.

Xenoacremonium Lombard \& Crous

Xenocylindrocladium Decock et al.

Xenogliocladiopsis Crous \& W.B. Kendr.

Xenoleptographium Marinc. et al.

Xenonectriella Weese

Niessliaceae Kirschst.

Atronectria Etayo

Circinoniesslia Samuels \& M.E. Barr

Cryptoniesslia Scheuer

Eucasphaeria Crous

Hyaloseta A.W. Ramaley

Malmeomyces Starb.

Melchioria Penz. \& Sacc.

Miyakeomyces Hara

Myrmaeciella Lindau

Myrtacremonium Crous

Neoeucasphaeria Crous

Niesslia Auersw. 
Paraniesslia K.M. Tsui et al.

Pseudohyaloseta Tibpromma \& K.D. Hyde

Pseudonectriella Petr.

Pseudorhynchia Höhn.

Rosasphaeria Jaklitsch \& Voglmayr

Taiwanascus Sivan \& H.S. Chang

Trichosphaerella E. Bommer et al.

Valetoniella Höhn.

Valetoniellopsis Samuels \& M.E. Barr

Ophiocordycipitaceae G.H. Sung et al.

Drechmeria W. Gams \& H.B. Jansson

Harposporium Lohde

Hirsutella Pat.

Hymenostilbe Petch

Ophiocordyceps Petch

Paraisaria Samson \& B.L. Brady

Perennicordyceps Matočec \& I. Kušan

Polycephalomyces Kobayasi

Purpureocillium Luangsa-ard et al.

Tolypocladium W. Gams

Sarocladiaceae L. Lombard

Parasarocladium Summerb. et al.

Sarocladium W. Gams \& D. Hawksw.

Stachybotryaceae L. Lombard \& Crous

Achroiostachys L. Lombard \& Crous

Albifimbria L. Lombard \& Crous

Albosynnema E.F. Morris

Alfaria Crous et al.

Alfariacladiella Crous \& R.K. Schumach.

Brevistachys L. Lombard \& Crous

Capitofimbria L. Lombard \& Crous

Cymostachys L. Lombard \& Crous

Didymostilbe Henn.

Digitiseta Gordillo \& Decock

Dimorphiseta L. Lombard \& Crous

Globobotrys L. Lombard \& Crous

Grandibotrys L. Lombard \& Crous

Gregatothecium L. Lombard \& Crous

Hyalinostachys C.G. Lin \& K.D. Hyde

Inaequalispora L. Lombard \& Crous

Kastanostachys L. Lombard \& Crous

Koorchalomella Chona et al.

Melanopsamma Niessl

Memnoniella Höhn.

Myrothecium Tode

Myxospora L. Lombard \& Crous

Neomyrothecium L. Lombard \& Crous

Paramyrothecium L. Lombard \& Crous

Parasarcopodium Mel'nik et al. 
Parvothecium L. Lombard \& Crous

Peethambara Subram. \& Bhat

Pseudoornatispora Tibpromma \& K.D. Hyde

Septomyrothecium Matsush.

Sirastachys L. Lombard \& Crous

Smaragdiniseta L. Lombard \& Crous

Stachybotrys Corda

Striatibotrys L. Lombard \& Crous

Striaticonidium L. Lombard \& Crous

Tangerinosporium L. Lombard \& Crous

Virgatospora Finley

Xenomyrothecium L. Lombard \& Crous

Xepicula Nag Raj

Xepiculopsis Nag Raj

Tilachlidiaceae Lombard \& Crous

Psychronectria J. Pawłowska et al.

Septofusidium W. Gams

Tilachlidium Preuss

Hypocreales genera incertae sedis Acremoniopsis Giraldo et al.

Berkelella (Sacc.) Sacc.

Bulbithecium Udagawa \& T Muroi

Cephalosporiopsis Peyronel

Chondronectria Etayo et al.

Cylindronectria Etayo

Diploöspora Grove

Gynonectria Döbbeler

Hapsidospora Malloch \& Cain

Haptospora G.L. Barron

Illosporiopsis D. Hawksw.

Illosporium Mart.

Leptobarya Etayo

Lichenopenicillus Etayo

Metadothella Henn.

Munkia Speg.

Neomunkia Petr.

Peloronectria Möller

Pseudoacremonium Crous

Pseudoidriella Crous \& R.G. Shivas

Pseudomeliola Speg.

Rodentomyces Doveri et al.

Roselliniella Vain

Saksenamyces A.N. Rai \& P.N. Singh

Sedecimiella K.L. Pang et al.

Stanjemonium W. Gams et al.

Stilbella Lindau

Ticonectria Döbbeler

Tilakidium Vaidya et al.

Microascales Luttr. ex Benny \& Kimbr. 
Ceratocystidaceae Locq. ex Réblová et al.

Ambrosiella Brader ex Arx \& Hennebert

Berkeleyomyces W.J. Nel et al.

Bretziella Z.W. de Beer et al.

Ceratocystis Ellis \& Halst.

Chalaropsis Peyronel

Davidsoniella Z.W. de Beer et al.

Endoconidiophora Münch

Huntiella Z.W. de Beer et al.

Meredithiella McNew et al.

Phialophoropsis L.R. Batra emend. T.C. Harr.

Thielaviopsis Went.

Chadefaudiellaceae Faurel \& Schotter ex Benny \& Kimbr.

Chadefaudiella Faurel \& Schotter

Faurelina Locq-Lin.

Gondwanamycetaceae Réblová et al.

Custingophora Stolk

Knoxdaviesia M.J. Wingf et al.

Graphiaceae De Beer

Graphium Corda

Halosphaeriaceae E. Müll \& Arx ex Kohlm.

Alisea J. Dupont \& E.B.G. Jones

Amphitrite S. Tibell

Aniptodera Shearer \& M. Miller

Aniptosporopsis (K.D. Hyde) K.L. Pang

Anisostagma K.R.L. Petersen \& Jørg. Koch

Antennospora Meyers

Appendichordella R.G. Johnson et al.

Arenariomyces Höhnk

Bathyascus Kohlm.

Carbosphaerella I. Schmidt

Ceriosporopsis Linder

Chadefaudia Feldm.-Maz.

Corallicola Volkm.-Kohlm. \& Kohlm.

Corollospora Werderm

Cucullosporella K.D. Hyde \& E.B.G. Jones

Ebullia K.L. Pang

Gesasha Abdel-Wahab \& Nagah.

Haiyanga K.L. Pang \& E.B.G. Jones

Haligena Kohlm.

Halosarpheia Kohlm. \& E. Kohlm.

Halosphaeria Linder

Halosphaeriopsis T.W. Johnson

Havispora K.L. Pang \& Vrijmoed

Iwilsoniella E.B.G. Jones

Kitesporella Jheng \& K.L. Pang

Kochiella Sakay. et al.

Lautisporopsis E.B.G. Jones et al. 
Lignincola Höhnk

Limacospora Jørg. Koch \& E.B.G. Jones

Luttrellia Shearer

Magnisphaera J. Campb. et al.

Marinospora A.R. Caval.

Moana Kohlm. \& Volkm.-Kohlm.

Morakotiella Sakay.

Naïs Kohlm.

Natantispora J. Campb. et al.

Nautosphaeria E.B.G. Jones

Neptunella K.L. Pang \& E.B.G. Jones

Nereiospora E.B.G. Jones et al.

Nimbospora Jørg. Koch

Nohea Kohlm. \& Volkm.-Kohlm.

Oceanitis Kohlm.

Ocostaspora E.B.G. Jones et al.

Okeanomyces K.L. Pang \& E.B.G. Jones

Ondiniella E.B.G. Jones et al.

Ophiodeira Kohlm. \& Volkm.-Kohlm.

Paraaniptodera K.L. Pang et al.

Phaeonectriella R.A. Eaton \& E.B.G. Jones

Praelongicaulis Jones et al.

Panorbis J. Campb. et al.

Pileomyces K.L. Pang \& Jheng

Pseudolignincola Chatmala \& E.B.G. Jones

Remispora Linder

Saagaromyces K.L. Pang \& E.B.G. Jones

Sablicola E B.G. Jones et al.

Thalassogena Kohlm. \& Volkm.-Kohlm.

Thalespora Chatmala \& E.B.G. Jones

Tinhaudeus K.L. Pang et al.

Tirispora E.B.G. Jones \& Vrijmoed

Toriella Sakay. et al.

Trailia G.K. Sutherl.

Trichomaris Hibbits et al.

Tubakiella Sakay. et al.

Tunicatispora K.D. Hyde

Microascaceae Luttr. ex Malloch

Acaulium Sopp

Brachyconidiellopsis Decock et al.

Canariomyces Arx

Cephalotrichum Link

Doratomyces Corda

Echinobotryum Corda

Enterocarpus Locq.-Lin.

Fairmania Sacc.

Gamsia M. Morelet

Kernia Nieuwl.

Lomentospora Hennebert \& B.G. Desai

Lophotrichus R.K. Benj.

Microascus Zukal 
Parascedosporium Gilgado et al.

Petriella Curzi

Pseudallescheria Negroni \& I. Fisch.

Pseudoscopulariopsis M. Sandoval-Denis et al.

Rhinocladium Sacc. \& Marchal

Scedosporium Sacc. ex Castell. \& Chalm.

Scopulariopsis Bainier

Wardomyces F.T. Brooks \& Hansf.

Wardomycopsis Udagawa \& Furuya

Yunnania H.Z. Kong

Triadelphiaceae Y.Z. Lu et al.

Synnematotriadelphia Chuaseehar et al.

Triadelphia Shearer \& J.L. Crane

Microascales genera incertae sedis

Bisporostilbella Brandsb. \& E.F. Morris

Cephalotrichiella Crous

Cornuvesica C.D. Viljoen et al.

Gabarnaudia Samson \& W. Gams

Sporendocladia G. Arnaud ex Nag Raj \& W.B. Kendr.

Parasympodiellales Hern.-Restr. et al.

Parasympodiellaceae Hern.-Restr. et al.

Parasympodiella Ponnappa

Torpedosporales E.B.G. Jones et al.

Etheirophoraceae Rungjindamai et al.

Etheirophora Kohlm. \& Volkm.-Kohlm.

Swampomyces Kohlm. \& Volkm.

Juncigenaceae E.B.G. Jones et al.

Elbamycella A. Poli

Fulvocentrum E.B.G. Jones \& Abdel-Wahab

Juncigena Kohlm Kohlm. et al.

Khaleijomyces Abdel-Wahab

Marinokulati E.B.G. Jones \& K.L. Pang

Torpedosporaceae E.B.G. Jones \& K.L. Pang

Torpedospora Meyer

Hypocreomycetidae genera incertae sedis

Campylospora Ranzoni

Dendroclathra Voglmayr \& G. Delgado

Subclass Lulworthiomycetidae Dayar. et al.

Koralionastetales Kohlm. et al.

Koralionastetaceae Kohlm. \& Volkm.-Kohlm.

Koralionastes Kohlm. \& Volkm.-Kohlm.

Pontogeneia Kohlm.

Lulworthiales Kohlm. et al. 
Lulworthiaceae Kohlm. et al.

Cumulospora I. Schmidt

Halazoon Abdel-Aziz et al.

Haloguignardia A. Cribb \& J. Cribb

Hydea K.L. Pang \& E.B.G Jones

Kohlmeyeriella E.B.G. Jones et al.

Lindra I. Wilson

Lulwoana Kohlm. et al.

Lulwoidea Kohlm. et al.

Lulworthia G.K. Sutherl

Matsusporium E.B.G. Jones \& K.L. Pang

Moleospora Abdel-Wahab et al.

Moromyces Abdel-Wahab et al.

Orbimyces Linder

Rostrupiella Jørg Koch et al.

Sammeyersia S.Y. Guo et al.

Subclass Pisorisporiomycetidae Bundhun et al.

Pisorisporiales Réblová \& J. Fourn.

Pisorisporiaceae Réblová \& J. Fourn.

Achroceratosphaeria Réblová et al.

Pisorisporium Réblová \& J. Fourn.

Subclass Savoryellomycetidae Hongsanan et al.

Conioscyphales Réblová \& Seifert

Conioscyphaceae Réblová \& Seifert

Conioscypha Höhn.

Fuscosporellales J. Yang et al.

Fuscosporellaceae J. Yang et al.

Bactrodesmiastrum Hol.-Jech.

Fuscosporella J. Yang et al.

Mucispora J. Yang et al.

Parafuscosporella J. Yang et al.

Plagiascoma Réblová \& J. Fourn.

Pseudoascotaiwania J. Yang et al.

Pleurotheciales Réblová \& Seifert

Pleurotheciaceae Réblová \& Seifert

Adelosphaeria Réblová

Anapleurothecium Hern.-Restr. et al.

Helicoascotaiwania Dayar. et al.

Melanotrigonum Réblová

Monotosporella S. Hughes

Phaeoisaria Höhn.

Phragmocephala E.W. Mason \& S. Hughes

Pleurotheciella Réblová

Pleurothecium Höhn.

Sterigmatobotrys Oudem.

Savoryellales Boonyuen et al.

Savoryellaceae Jaklitsch \& Réblová 
Ascotaiwania Sivan. \& H.S. Chang

Canalisporium Nawawi \& Kuthub.

Dermatiosporium Z.L. Luo et al.

Savoryella E.B.G. Jones \& R.A. Eaton

Subclass Sordariomycetidae O.E. Erikss \& Winka

Boliniales P.F. Cannon

Boliniaceae Rick

Apiocamarops Samuels \& J.D. Rogers

Apiorhynchostoma Petr.

Camaropella Lar.N. Vassiljeva

Camarops P. Karst.

Cornipulvina Huhndorf et al.

Endoxyla Fuckel

Mollicamarops Lar.N. Vassiljeva

Neohypodiscus J.D. Rogers et al.

Pseudovalsaria Spooner

Cephalothecales Maharachch. \& K.D. Hyde

Cephalothecaceae Höhn.

Albertiniella Kirschst.

Cephalotheca Fuckel

Cryptendoxyla Malloch \& Cain

Phialemonium W. Gams \& McGinnis

Victoriomyces D Davolos et al.

Chaetosphaeriales Huhndorf et al.

Chaetosphaeriaceae Réblová et al.

Adautomilanezia Gusmão et al.

Anacacumisporium Y.R. Ma \& X.G. Zhang

Ascochalara Réblová

Brunneodinemasporium Crous \& R.F. Castañeda

Catenularia Grove

Chaetosphaeria Tul. \& C. Tul.

Chloridium Link

Codinaea Maire

Conicomyces R.C. Sinclair et al.

Craspedodidymum Hol.-Jech.

Cryptophiale Piroz.

Cryptophialoidea Kuthub. \& Nawawi

Dendrophoma Sacc.

Dictyochaeta Speg.

Dictyochaetopsis Aramb. \& Cabello

Dinemasporium Lév.

Eucalyptostroma Crous \& M.J. Wingf.

Exserticlava S. Hughes

Hemicorynespora M.B. Ellis

Infundibulomyces Plaingam et al.

Kionochaeta P.M. Kirk \& B. Sutton

Lecythothecium Réblová \& Winka

Menispora Pers.

Menisporopsis S. Hughes 
Miyoshiella Kawam.

Morrisiella Saikia \& A.K. Sarbhoy

Nawawia Marvanová

Neopseudolachnella A. Hashim. \& Kaz. Tanaka

Paliphora Sivan. \& B. Sutton

Phialosporostilbe Mercado \& J. Mena

Polynema Lév.

Pseudodinemasporium A. Hashim. \& Kaz. Tanaka

Pseudolachnea Ranoj.

Pseudolachnella Teng

Pyrigemmula D. Magyar \& R. Shoemaker

Rattania Prabhug. \& Bhat

Sporoschisma Berk. \& Broome

Striatosphaeria Samuels \& E. Müll.

Tainosphaeria F.A. Fernández \& Huhndorf

Thozetella Kuntze

Umbrinosphaeria Réblová

Verhulstia Hern.-Rest.

Zanclospora S. Hughes \& W.B. Kendr.

Helminthosphaeriaceae Samuels et al. Echinosphaeria A.N. Mill. \& Huhndorf Endophragmiella B. Sutton

Helminthosphaeria Fuckel

Hilberina Huhndorf \& A.N. Mill.

Ruzenia O. Hilber

Synaptospora Cain

Tengiomyces Réblová

Leptosporellaceae Konta \& K.D. Hyde

Leptosporella Penz. \& Sacc.

Linocarpaceae Konta \& K.D. Hyde

Linocarpon Syd. \& P. Syd.

Neolinocarpon K.D. Hyde

Chaetosphaeriales genera incertae sedis

Calvolachnella Marinc. et al.

Caudatispora J. Fröhl. \& K.D. Hyde

Erythromada Huhndorf et al.

Lasiosphaeriella Sivan.

Neoleptosporella Phukhums. et al.

Rimaconus Huhndorf et al.

Coniochaetales Huhndorf et al.

Coniochaetaceae Malloch \& Cain

Barrina A.W. Ramaley

Coniochaeta (Sacc.) Cooke

Cordanaceae Nann.

Cordana Preuss 
Coniochaetales genera incertae sedis

Cannonia J.E. Taylor \& K.D. Hyde

Pseudogliomastix W. Gams

Meliolales Gäum. ex D. Hawksw. \& O.E. Erikss.

Armatellaceae Hosag.

Armatella Theiss. \& Syd.

Meliolaceae G.W. Martin ex Hansf.

Amazonia Theiss.

Appendiculella Höhn.

Asteridiella McAlpine

Cryptomeliola S. Hughes \& Piroz.

Endomeliola S. Hughes \& Piroz.

Irenopsis F. Stevens

Meliola Fr.

Setameliola D.R. Reynolds

Phyllachorales M.E. Barr

Phaeochoraceae K.D. Hyde et al.

Cocoicola K.D. Hyde

Phaeochora Höhn.

Phaeochoropsis K.D. Hyde \& P.F. Cannon

Serenomyces Petr.

Phyllachoraceae Theiss. \& H. Syd.

Ascovaginospora Fallah et al.

Brobdingnagia K.D. Hyde \& P.F. Cannon

Camarotella Theiss. \& Syd.

Coccodiella Hara

Cyclodomus Höhn.

Deshpandiella Kamat \& Ullasa

Diachora Müll. Arg.

Diatractium Syd. \& P. Syd.

Erikssonia Penz. \& Sacc.

Fremitomyces P.F. Cannon \& H.C. Evans

Geminispora Pat.

Gibellina Pass. Ex Roum.

Imazekia Tak. Kobay. \& Y. Kawabe

Isothea Fr.

Lichenochora Hafellner

Lindauella Rehm

Linochora Höhn.

Lohwagia Petr.

Maculatifrondes K.D. Hyde

Malthomyces K.D. Hyde \& P.F. Cannon

Muelleromyces Kamat \& Anahosur

Neoflageoletia J. Reid \& C. Booth

Neophyllachora Dayar. \& K.D. Hyde

Ophiodothis Sacc.

Ophiodothella (Henn.). Höhn.

Orphnodactylis Malloch \& Mallik 
Oxodeora K.D. Hyde \& P.F. Cannon

Parberya C.A. Pearce \& K.D. Hyde

Petrakiella Syd.

Phycomelaina Kohlm.

Phyllachora Nitschke ex Fuckel

Phylleutypa Petr.

Phyllocrea Höhn.

Pseudothiella Petr.

Pseudothiopsella Petr.

Pterosporidium W.H. Ho \& K.D. Hyde

Rehmiodothis Theiss. \& Syd.

Retroa P.F. Cannon

Rhodosticta Woron.

Rikatlia P.F. Cannon

Schizochora Syd. \& P. Syd.

Sphaerodothella C.A. Pearce \& K.D. Hyde

Sphaerodothis (Sacc. \& P. Syd.) Shear

Stigmatula (Sacc.) Syd. \& P. Syd.

Stigmochora Theiss. \& Syd.

Stromaster Höhn.

Tamsiniella S.W. Wong et al.

Telimenella Petr.

Telimenochora Sivan.

Trabutia Sacc. \& Roum.

Tribulatia J.E. Taylor et al.

Uropolystigma Maubl.

Vitreostroma P.F. Cannon

Zimmermanniella Henn.

Telimenaceae Mardones et al.

Telimena Racib.

Phyllachorales genus incertae sedis

Marinosphaera K.D. Hyde

Pseudodactylariales Crous

Pseudodactylariaceae Crous

Pseudodactylaria Crous

Sordariales Chad. ex D. Hawksw. \& O.E. Erikss.

Chaetomiaceae G. Winter

Achaetomium J.N. Rai et al.

Acrophialophora Edward

Allobotryotrichum M. Raza \& L. Cai

Amesia X. Wei Wang et al.

Arcopilus X. Wei Wang et al.

Arxotrichum A. Nováková \& M. Kolařik

Botryotrichum Sacc. \& Marchal

Chaetomium Kunze

Collariella X. Wei Wang et al.

Corynascella Arx \& Hodges

Crassicarpon Y. Marín et al. 
Dichotomopilus X. Wei Wang et al.

Guanomyces M.C. Gonzáles et al.

Humicola Traaen

Madurella Brumpt

Melanocarpus Arx

Myceliophthora Costantin

Mycothermus D.O. Natvig et al.

Ovatospora X. Wei Wang et al.

Remersonia Samson \& Seifert

Staphylotrichum J.A. Mey. \& Nicot

Subramaniula Arx

Thermothelomyces Y. Marín et al.

Thielavia Zopf

Trichocladium Harz

Lasiosphaeriaceae Nannf.

Anopodium Lundq.

Apiosordaria Arx \& W. Gams

Apodospora Cain \& J.H. Mirza

Apodus Malloch \& Cain

Arnium Nitschke ex G. Winter

Bellojisia Réblová

Biconiosporella Schaumann

Bombardia (Fr.) P. Karst.

Bombardioidea C. Moreau ex N. Lundqv.

Camptosphaeria Fuckel

Cercophora Fuckel

Corylomyces Stchigel et al.

Diffractella Guarro et al.

Diplogelasinospora Cain

Emblemospora Jeng \& J.C. Krug

Eosphaeria Höhn.

Episternus Górz \& Boroń

Fimetariella N. Lundq.

Immersiella A.N. Mill. \& Huhndorf

Jugulospora N. Lundq.

Lasiosphaeria Ces. \& De Not.

Mammaria Ces. ex Rabenh.

Periamphispora J.C. Krug

Ramophialophora M. Calduch et al.

Rinaldiella Deanna A. Sutton et al.

Schizothecium Corda

Strattonia Cif.

Thaxteria Sacc.

Tripterosporella Subram. \& Lodha

Zopfiella G. Winter

Zygopleurage Boedijn

Zygospermella Cain

Podosporaceae X. Wei Wang \& Houbraken

Cladorrhinum Sacc. \& Marchal

Podospora Ces. 
Triangularia Boedijn

Sordariaceae G. Winter

Copromyces N. Lundq.

Effetia Bartoli et al.

Guilliermondia Boud.

Neurospora Shear \& B.O. Dodge

Pseudoneurospora Dania García et al.

Sordaria Ces. \& De Not.

Stellatospora T. Ito \& A. Nakagiri

Sordariales genera incertae sedis

Abyssomyces Kohlm

Acanthotheciella Höhn.

Ascolacicola Ranghoo \& K.D. Hyde

Bombardiella Höhn.

Coronatomyces Dania García et al.

Cuspidatispora Shearer \& Bartolata

Globosphaeria D. Hawksw.

Isia D. Hawksw \& Manohar

Lasiosphaeris Clem.

Lunulospora Ingold

Lockerbia K.D. Hyde

Nitschkiopsis Nannf. \& R. Sant.

Onygenopsis Henn.

Phaeosporis Clem.

Reconditella Matzer \& Hafellner

Rhexodenticula W.A. Baker \& Morgan-Jones

Rhexosporium Udagawa \& Furuya

Roselliniomyces Matzer \& Hafellner

Roselliniopsis Matzer \& Hafellner

Stromatographium Höhn.

Utriascus Réblová

Ypsilonia Lév.

Sordariomycetidae families incertae sedis

Batistiaceae Samuels \& K.F. Rodrigues

Batistia Cif.

Sordariomycetidae genera incertae sedis

Arecacicola Joanne E. Taylor et al.

Bullimyces A. Ferrer et al.

Cancellidium Tubaki

Ceratolenta Réblová

Chaetosphaerides Matsush.

Cryptophyllachora L. Kiss et al.

Hanliniomyces Raja \& Shearer

Hydromelitis A. Ferrer et al.

Merugia Rogerson \& Samuels

Mycomedusiospora G.C. Carroll \& Munk

Myxocephala G. Weber et al.

Nigromammilla K.D. Hyde \& J. Fröhl. 
Phaeotrichosphaeria Sivan.

Phragmodiscus Hansf.

Plagiosphaera Petr.

Pseudobotrytis Krzemien. \& Badura

Subclass Xylariomycetidae O.E. Erikss \& Winka

Amphisphaeriales D. Hawksw. \& O.E. Erikss.

Amphisphaeriaceae G. Winter

Amphisphaeria Ces. \& De Not.

Griphosphaerioma Höhn.

Lepteutypa Petr.

Apiosporaceae K.D. Hyde et al.

Appendicospora K.D. Hyde

Arthrinium Kunze

Dictyoarthrinium S. Hughes

Endocalyx Berk. \& Broome

Nigrospora Zimm.

Beltraniaceae Nann.

Beltrania Penz.

Beltraniella Subram.

Beltraniopsis Bat. \& J.L. Bezerra

Hemibeltrania Piroz.

Parapleurotheciopsis P.M. Kirk

Porobeltraniella Gusmão

Pseudobeltrania Henn.

Pseudosubramaniomyces Crous

Subsessila C.G. Lin \& K.D. Hyde

Castanediellaceae Hern.-Restr. et al.

Castanediella Hern.-Restr. et al.

Clypeophysalosporaceae Giraldo \& Crous

Bagadiella Cheew. \& Crous

Clypeophysalospora H.J. Swart

Neophysalospora Crous \& M.J. Wingf.

Plectosphaera Theiss.

Cylindriaceae Crous \& L. Lombard

Cylindrium Bonord

Hyponectriaceae Petr.

Apiothyrium Petr.

Arecomyces K.D. Hyde

Arwidssonia B. Erikss.

Cesatiella Sacc.

Chamaeascus L. Holm et al.

Discosphaerina Höhn.

Exarmidium P. Karst.

Frondicola K.D. Hyde

Hyponectria Sacc. 
Lichenoverruculina Etayo

Micronectria Speg.

Papilionovela Aptroot

Pellucida Dulym. et al.

Phragmitensis M.K.M. Wong et al.

Physalospora Niessl

Rachidicola K.D. Hyde \& J. Fröhl.

Xenothecium Höhn.

Iodosphaeriaceae O. Hilber

Iodosphaeria Samuels

Melogrammataceae G. Winter

Melogramma Fr.

Oxydothidaceae Konta \& K.D. Hyde

Oxydothis Penz. \& Sacc.

Phlogicylindriaceae Senan. \& K.D. Hyde

Ciferriascosea Senan. et al.

Idriellomyces Crous

Phlogicylindrium Crous et al.

Pseudomassariaceae Senan. \& K.D. Hyde

Leiosphaerella Höhn.

Pseudapiospora Petr.

Pseudomassaria Jacz.

Pseudomassariella Petr.

Pseudosporidesmiaceae Crous

Pseudosporidesmium K.D. Hyde \& McKenzie

Pseudotruncatellaceae Crous

Pseudotruncatella R.H. Perera et al.

Sporocadaceae Corda

Allelochaeta Petr.

Annellolacinia B. Sutton

Bartalinia Tassi

Broomella Sacc.

Ciliochorella Syd.

Diploceras (Sacc.) Died.

Disaeta Bonar

Discosia Lib.

Distononappendiculata F. Liu et al.

Diversimediispora $\mathrm{F}$. Liu et al.

Doliomyces Steyaert

Heterotruncatella $\mathrm{F}$. Liu et al.

Hyalotiella Papendorf

Hymenopleella Munk

Immersidiscosia Kaz. Tanaka et al.

Monochaetia (Sacc.) Allesch. 
Morinia Berl. \& Bres.

Neopestalotiopsis Maharachch. et al.

Nonappendiculata F. Liu et al.

Parabartalinia F. Liu et al.

Pestalotiopsis Steyaert

Pseudopestalotiopsis Maharachch. et al.

Pseudosarcostroma F. Liu et al.

Robillarda Sacc.

Sarcostroma Cooke

Seimatosporium Corda

Seiridium Nees

Sporocadus Corda

Strickeria Körb.

Synnemapestaloides T. Handa \& Y. Harada

Truncatella Steyaert

Xenoseimatosporium F. Liu et al.

Vialaeaceae P.F. Cannon

Vialaea Sacc.

Xyladictyochaetaceae Crous \& Hern.-Restr

Xyladictyochaeta Hern.-Restr. et al.

Amphisphaeriales genera incertae sedis

Chitonospora E. Bommer et al.

Fasciatispora K.D. Hyde

Delonicicolales R.H. Perera et al.

Delonicicolaceae R.H. Perera et al.

Delonicicola R.H. Perera et al.

Furfurella Voglmayr \& Jaklitsch

Leptosilliaceae Voglmayr \& Jaklitsch

Leptosillia Höhn.

Xylariales Nannf.

Barrmaeliaceae Voglmayr \& Jaklitsch

Barrmaelia Rappaz

Entosordaria (Sacc.) Höhn.

Cainiaceae J.C. Krug

Alishanica Karun. et al.

Amphibambusa D.Q. Dai \& K.D. Hyde

Arecophila K.D. Hyde

Atrotorquata Kohlm. \& Volkm.-Kohlm.

Cainia Arx \& E. Müll.

Seynesia Sacc.

Clypeosphaeriaceae G. Winter

Aquasphaeria K.D. Hyde

Apioclypea K.D. Hyde

Brunneiapiospora K.D. Hyde et al.

Clypeosphaeria Fuckel 
Crassoascus Checa et al.

Palmaria K.D. Hyde et al.

Coniocessiaceae Asgari \& Zare

Coniocessia Dania García et al.

Paraxylaria Wanas. et al.

Diatrypaceae Nitschke

Allocryptovalsa Senwanna et al.

Anthostoma Nitschke

Cryptosphaeria Ces \& De Not.

Cryptovalsa Ces. \& De Not. ex Fuckel

Diatrypasimilis J.J. Zhou \& Kohlm.

Diatrype Fr.

Diatrypella (Ces. \& De Not.) De Not.

Echinomyces Rappaz

Endoxylina Romell

Eutypa Tul. \& C. Tul.

Eutypella (Nitschke) Sacc.

Halocryptovalsa Dayar. \& K.D. Hyde

Halodiatrype Dayar. \& K.D. Hyde

Leptoperidia Rappaz

Libertella Desm.

Monosporascus Pollack \& Uecker

Neoeutypella M. Raza et al.

Pedumispora K.D. Hyde \& E.B.G. Jones

Peroneutypa Berl.

Quaternaria Tul. \& C. Tul.

Graphostromataceae M.E. Barr et al.

Biscogniauxia Kuntze

Camillea Fr.

Graphostroma Piroz.

Obolarina Pouzar

Vivantia J.D. Rogers et al.

Hansfordiaceae Crous

Hansfordia S. Hughes

Hypoxylaceae DC.

Annulohypoxylon Y.M. Ju et al.

Anthocanalis Daranag. et al.

Chlorostroma A.N. Mill. et al.

Daldinia Ces. \& De Not.

Durotheca Læssøe et al.

Entonaema Möller

Hypomontagnella Sir et al.

Hypoxylon Bull.

Jackrogersella L. Wendt et al.

Natonodosa Heredia et al.

Phylacia Lév.

Pyrenomyxa Morgan 
Pyrenopolyporus Lloyd

Rhopalostroma D. Hawksw.

Rostrohypoxylon J. Fourn. \& M. Stadler

Ruwenzoria J. Fourn. et al.

Thamnomyces Ehrenb.

Theissenia Maubl.

Thuemenella Penz. \& Sacc.

Induratiaceae Samarak et al.

Induratia Samuels et al.

Emarcea Duong et al.

Lopadostomataceae Daranag. \& K.D. Hyde Creosphaeria Theiss.

Jumillera J.D. Rogers et al.

Lopadostoma (Nitschke) Traverso

Whalleya J.D. Rogers et al.

Microdochiaceae Hern.-Restr. et al.

Idriella P.E. Nelson \& S. Wilh.

Microdochium Syd.

Selenodriella R.F. Castañeda \& W.B. Kendr.

Polystigmataceae Höhn. ex Nannf.

Polystigma DC.

Requienellaceae Boise

Acrocordiella O.E. Erikss.

Lacrymospora Aptroot

Parapyrenis Aptroot

Requienella Fabre

Xylariaceae Tul. \& C. Tul.

Abieticola Hyang B. Lee

Amphirosellinia Y.M. Ju et al.

Anthostomella Sacc.

Anthostomelloides Tibpromma \& K.D. Hyde

Ascotricha Berk.

Astrocystis Berk. \& Broome

Brunneiperidium Daranag. et al.

Collodiscula I. Hino \& Katum.

Coniolariella Dania García et al.

Engleromyces Henn.

Entalbostroma J.D. Rogers \& P.R. Johnst.

Entoleuca Syd.

Euepixylon Füisting

Halorosellinia Whalley et al.

Helicogermslita Lodha \& D. Hawksw.

Hypocopra (Fr) J. Kickx f .

Hypocreodendron Henn.

Kretzschmaria Fr.

Kretzschmariella Viégas 
Leprieuria Laessøe et al.

Lunatiannulus Daranag. et al.

Nemania Gray

Podosordaria Ellis \& Holw.

Poronia Willd.

Rosellinia De Not.

Sarcoxylon Cooke

Squamotubera Henn.

Stilbohypoxylon Henn.

Vamsapriya Gawas \& Bhat

Virgaria Nees

Wawelia Namysl.

Xylaria Hill ex Schrank

Zygosporiaceae Li et al.

Zygosporium Mont.

Xylariales genera incertae sedis

Adomia S. Schatz

Alloanthostomella Daranag. et al.

Anungitea B. Sutton

Ascotrichella Valldos. \& Guarro

Basifimbria Subram. \& Lodha

Biporispora J.D. Rogers et al.

Castellaniomyces Senan. et al.

Chaenocarpus Rebent.

Circinotrichum Nees

Cryptostroma P.H. Greg. \& S. Waller

Cyanopulvis J. Fröhl. \& K.D. Hyde

Diamantinia A.N. Mill. et al.

Gigantospora B.S. Lu \& K.D. Hyde

Guestia G.J.D. Sm. \& K.D. Hyde

Gyrothrix (Corda) Corda

Hadrotrichum Fuckel

Idriellopsis Hern.-Restr. \& Crous

Kirstenboschia Quaedvl. et al.

Lanceispora Nakagiri et al.

Lasiobertia Sivan.

Leptomassaria Petr.

Neoanthostomella D.Q. Dai \& K.D. Hyde

Neoidriella Hern.-Restr. \& Crous

Nipicola K.D. Hyde

Occultitheca J.D. Rogers \& Y.M. Ju

Ophiorosellinia J.D. Rogers et al.

Palmicola K.D. Hyde

Pandanicola K.D. Hyde

Paraidriella Hern.-Restr. \& Crous

Paramphisphaeria F.A. Fernández et al.

Paraphysalospora Crous

Paucithecium Lloyd

Pidoplitchkoviella Kiril.

Polyancora Voglmayr \& Yule 
Polyscytalum Riess

Poroleprieuria M.C. González et al.

Pseudoanthostomella Daranag. et al.

Pseudophloeospora Crous \& R.G. Shivas

Pulmosphaeria Joanne E. Taylor et al.

Pyriformiascoma Daranag. et al.

Roselymyces Fiuza et al.

Sabalicola K.D. Hyde

Spirodecospora B.S. Lu et al.

Sporidesmina Subram. \& Bhat

Striatodecospora D.Q. Zhou et al.

Stromatoneurospora S.C. Jong \& E.E. Davis

Surculiseries Okane

Synnemadiella Crous \& M.J. Wingf.

Tristratiperidium Daranag. et al.

Xylocrea Möller

Xylotumulus J.D. Rogers et al.

Yuea O.E. Erikss.

Xylariomycetidae families incertae sedis

Myelospermataceae K.D. Hyde \& S.W. Wong

Myelosperma Syd. \& P. Syd.

Xylariomycetidae genera incertae sedis

Calceomyces Udagawa \& S. Ueda

Sordariomycetes orders incertae sedis

Amplistromatales D'souza et al.

Amplistromataceae Huhndorf et al.

Acidothrix Hujslová \& M. Kolařík

Amplistroma Huhndorf et al.

Wallrothiella Sacc.

Catabotryales K.D. Hyde \& Senan.

Catabotryaceae Petr. ex M.E. Barr

Catabotrys Theiss. \& Syd.

Spathulosporales Kohlm.

Hispidicarpomycetaceae Nakagiri

Hispidicarpomyces Nakagiri

Spathulosporaceae Kohlm.

Retrostium Nakagiri \& Tad Ito

Spathulospora A.R. Caval. \& T.W. Johnson

Tracyllalales Crous

Tracyllaceae Crous

Tracylla (Sacc.) Tassi

Vermiculariopsiellales Hern.-Restr. et al.

Vermiculariopsiellaceae Hern.-Restr. et al.

Vermiculariopsiella Bender 
Sordariomycetes families incertae sedis Acrodictyaceae J.W. Xia \& X.G. Zhang Acrodictys M.B. Ellis

Junewangiaceae J.W. Xia \& X.G. Zhang Dictyosporella Abdel-Aziz

Junewangia W.A. Baker \& Morgan-Jones

Lautosporaceae Kohlm. et al.

Lautospora K.D. Hyde \& E.B.G. Jones

Obryzaceae Körb.

Obryzum Wallr.

Sordariomycetes genera incertae sedis Acerbiella Sacc.

Acrospermoides Miller \& G.E. Thomps. Ameromassaria Hara

Amphisphaerellula Gucevič

Amphisphaerina Höhn.

Amphorulopsis Petr.

Amylis Speg.

Anisomycopsis I. Hino \& Katum.

Anthostomaria (Sacc.) Theiss. \& Syd.

Anthostomellina L.A. Kantsch.

Apodothina Petr.

Apogaeumannomyces Matsush.

Aquadulciospora Fallah \& Shearer

Areolospora S.C. Jong \& E.E. Davis

Aropsiclus Kohlm. \& Volkm.-Kohlm.

Ascorhiza Lecht.-Trinka

Ascoyunnania L. Cai \& K.D. Hyde

Atrogeniculata J.S. Monteiro et al.

Aulospora Speg.

Azbukinia Lar.N. Vassiljeva

Bactrosphaeria Penz. \& Sacc.

Basidiobotrys Höhn.

Biciliopsis Diederich

Bombardiastrum Pat.

Botryosporium Corda

Brenesiella Syd.

Byrsomyces Cavalc.

Byssotheciella Petr.

Caleutypa Petr.

Caproniella Berl.

Chaetoamphisphaeria Hara

Ciliofusospora Bat. \& J.L. Bezerra

Clypeoceriospora Sousa da Câmara

Clypeosphaerulina Sousa da Câmara

Cryptoascus Petri

Cryptomycella Höhn. 
Cryptomycina Höhn.

Cucurbitopsis Bat. \& Cif.

Curvatispora V.V. Sarma \& K.D. Hyde

Dasysphaeria Speg.

Delpinoëlla Sacc.

Diacrochordon Petr.

Didymobotryum Sacc.

Duradens Samuels \& Rogerson

Ellisembia Subram.

Esfandiariomyces Ershad

Fantasmomyces D.Hyeon Lee et al.

Fassia Dennis

Flammispora Pinruan et al.

Frondisphaeria K.D. Hyde

Hapsidascus Kohlm. \& Volkm.-Kohlm.

Heliastrum Petr.

Hyaloderma Speg.

Hyalotiopsis Punith.

Hydronectria Kirschst.

Immersisphaeria Jaklitsch

Iraniella Petr.

Konenia Hara

Kravtzevia Schwartzman

Kurssanovia Kravtzev

Lecythiomyces Doweld

Leptosacca Syd.

Leptosphaerella Speg.

Mangrovispora K.D. Hyde \& Nakagiri

Marisolaris Jørg. Koch \& E.B.G. Jones

Melanographium Sacc.

Microcyclephaeria Bat.

Mirannulata Huhndorf et al.

Neonawawia J. Yang et al.

Natantiella Réblová

Naumovela Kravtzev

Neocryptospora Petr.

Neoeriomycopsis Crous \& M.J. Wingf.

Neolamya Theiss. \& Syd.

Neothyridaria Petr.

Ophiomassaria Jacz.

Ophiomeliola Starbäck

Paoayensis Cabanela et al.

Paradiplococcium Hern.-Restr. et al.

Paramicrodochium Hern.-Restr. \& Crous

Pareutypella Y.M. Ju \& J.D. Rogers

Phialemoniopsis Perdomo et al.

Phragmeriella Hansf.

Phyllocelis Syd.

Pleocryptospora J. Reid \& C. Booth

Pleosphaeria Speg.

Pleurophragmium Costantin

Protocucurbitaria Naumov 
Pulvinaria Bon.

Pumilus Viala \& Marsais

Rehmiomycella E. Müll.

Rhamphosphaeria Kirschst.

Rhizophila K.D. Hyde \& E.B.G. Jones

Rhopographella (Henn.) Sacc. \& Trotter

Rhynchosphaeria (Sacc.) Berl.

Rivulicola K.D. Hyde

Romellina Petr.

Saccardoëlla Speg.

Sartorya Vuill.

Scharifia Petr.

Scoliocarpon Nyl.

Scotiosphaeria Sivan.

Selenosporella G. Arnaud ex MacGarvie

Servazziella J. Reid \& C. Booth

Sporoctomorpha J.V. Almeida \& Sousa da Câmara

Stanjehughesia Subram.

Stearophora L. Mangin \& Viala

Steganopycnis Syd. \& P. Syd.

Stegophorella Petr.

Stellosetifera Matsush.

Stereosphaeria Kirschst.

Stomatogenella Petr.

Sungaiicola Fryar \& K.D. Hyde

Synsphaeria Bon.

Teracosphaeria Réblová \& Seifert

Thelidiella Fink

Thyridella (Sacc.) Sacc.

Thyrotheca Kirschst.

Trichospermella Speg.

Trichosphaeropsis Bat. \& Nasc.

Tunstallia Agnihothr.

Tulipispora Révay \& Gönczöl

Urosporella G.F. Atk.

Urupe Viégas

Vleugelia J. Reid \& C. Booth

Xenodium Syd.

Zalerion R.T. Moore \& Meyers

\section{Results}

The combined LSU, SSU, tef1 and rpb2 gene data set comprised 298 taxa, with Botryotinia fuckeliana (AFTOL ID-59), Dothidea sambuci (DAOM 231303), and Pyxidiophora arvernensis (AFTOL-ID 2197) as outgroup taxa. The combined dataset comprised 4303 characters including gaps. The best scoring RAxML tree is shown in Fig 1. In the phylogenetic tree, the Sordariomycetes strains included in the analysis clustered into seven subclasses including Sordariomycetidae, Hypocreomycetidae and Xylariomycetidae as in the previous treatment of Lumbsch \& Huhndorf (2010); Diaporthomycetidae and Lulworthiomycetidae as suggested by Maharachchikumbura et al. (2015), as well as Savoryellomycetidae suggested by Hongsanan et al. (2017) and the addition of a new subclass, the Pisorisporiomycetidae in this paper. The seven subclasses separate into 45 orders including the newly introduced Cephalothecales. Furthermore, sequence data of 153 families are included in the phylogenetic analysis. 


\section{The subclasses}

There are seven subclasses accepted in Sordariomycetes with the addition of Pisorisporiomycetidae in this paper.

Diaporthomycetidae Senan., Maharachch. \& K.D. Hyde, Fungal Divers. 72: 208 (2015)

The subclass Diaporthomycetidae was introduced by Maharachchikumbura et al. (2015) for some taxa already placed in Sordariomycetidae, but that were phylogenetically and morphologically distinct from Sordariomycetidae. Members of Diaporthomycetidae occur in both aquatic and terrestrial habitats as saprobes, pathogens, or endophytes. Previously there were ten orders in this subclass (Hongsanan et al. 2017). Crous et al. (2017a) introduced Pararamichloridiales and Crous et al. (2019a) introduced Sporidesmiales. Hyde et al. (2017a) proposed Catabotryales based on evolutionary data and here we formally introduce it. Currently there are 15 orders and 65 families in this subclass (Hyde et al. 2017a, this paper). The divergence time for Diaporthomycetidae is estimated as 247 MYA (Fig. 2). The orders and families in this subclass are mostly well-supported in our phylogenetic analysis (Figs 6, 8, 13, 14, 18).

Hypocreomycetidae O.E. Erikss. \& Winka, Myconet 1(1): 6 (1997)

Maharachchikumbura et al. (2016b) accepted Conioscyphales, Coronophorales, Falcocladiales, Glomerellales, Hypocreales, Melanosporales, Microascales, Pleurotheciales and Savoryellales in Hypocreomycetidae. Yang et al. (2016b) introduced Fuscosporellales to the subclass based on LSU, SSU and rpb2 sequence data. Hongsanan et al. (2017) placed Fuscosporellales and Pleurotheciales in the newly introduced subclass Savoryellomycetidae. The families Etheirophoraceae, Juncigenaceae and Torpedosporaceae have previously been treated in Torpedosporales by Jones et al. (2015), but Torpedosporales was maintained in Hypocreomycetidae, incertae sedis by Maharachchikumbura et al. (2015). Maharachchikumbura et al. (2016b) accepted Torpedosporales in Hypocreomycetidae and this was confirmed by Hongsanan et al. (2017) based on the divergent time estimates. Later, Parasympodiellales was added to the subclass by Hernández-Restrepo et al. (2017). Our phylogenetic analysis of a combined LSU, SSU, tef1, rpb2 sequence data (Figs. 1, 24) also supports the placement of Torpedosporales in Hypocreomycetidae. Currently there are seven orders (Coronophorales, Falcocladiales, Glomerellales, Hypocreales, Microascales, Parasympodiellales and Torpedosporales) and 37 families in this subclass (Hyde et al. 2017a, this paper). The divergence time for Hypocreomycetidae has been estimated as 256.5 MYA (Fig. 2). The orders in this subclass are mostly well-supported in our analysis, except Torpedosporales (Fig. 1).

Lulworthiomycetidae Dayar., E.B.G. Jones \& K.D. Hyde, Fungal Divers. 72: 208 (2015)

Maharachchkumbura et al. (2016b) established the subclass Lulworthiomycetidae to accommodate Koralionastetales, Lulworthiales and Pisorisporiales as proposed by Maharachchikumbura et al. (2015). Taxa related to Lulworthiomycetidae are saprobic on wood, sea grasses and marsh plants or parasites on algae. The divergence time for Lulworthiomycetidae has been estimated as 257 MYA (Fig. 2). Currently there are two orders and two families in this subclass and Pisorisporiales is transferred to the introduced subclass Pisorisporiomycetidae in this study.

Pisorisporiomycetidae Bundhun, Maharachch. \& K.D. Hyde, subclass nov.

Index Fungorum number: IF556880; Facesoffungi number: FoF06688

Saprobic on submerged wood or driftwood. Sexual morph: Ascomata astromatic, perithecial, solitary or aggregated in small groups, immersed, semi-immersed to superficial, ostiolate. Ostiole periphysate. Peridium 2-layered, leathery to fragile, partly carbonaceous. Paraphyses abundant,- 


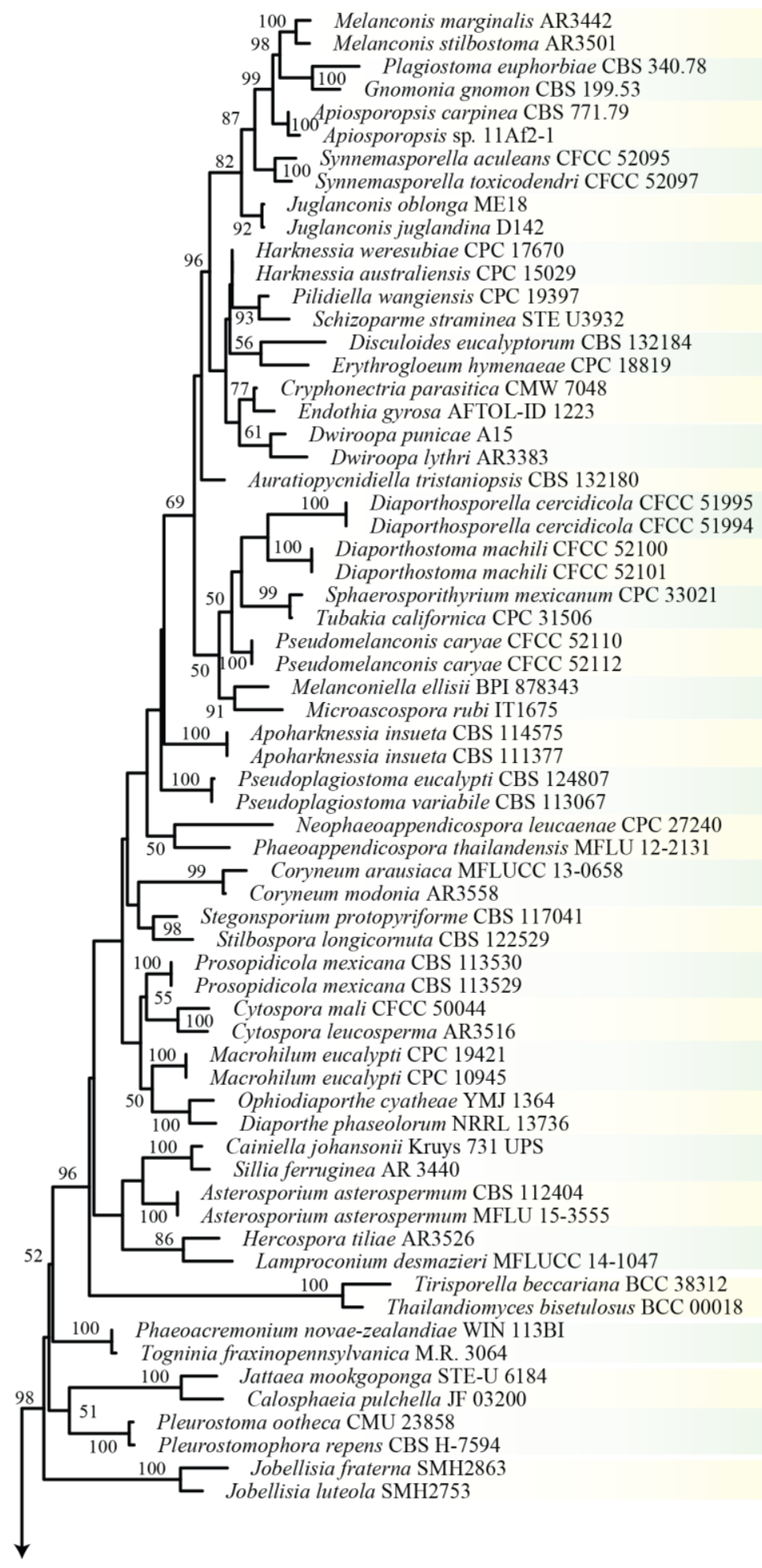

\begin{tabular}{|c|c|}
\hline Melanconidaceae & \multirow{28}{*}{ Diaporthales } \\
\hline Gnomoniaceae & \\
\hline Apiosporopsidaceae & \\
\hline Synnemasporellaceae & \\
\hline Juglanconidaceae & \\
\hline Harknessiaceae & \\
\hline Schizoparmeaceae & \\
\hline Erythrogloeaceae & \\
\hline Cryphonectriaceae & \\
\hline Dwiroopaceae & \\
\hline Auratiopycnidiellaceae & \\
\hline Diaporthosporellaceae & \\
\hline Diaporthostomataceae & \\
\hline Tubakiaceae & \\
\hline Pseudomelanconidaceae & \\
\hline Melanconiellaceae & \\
\hline Apoharknessiaceae & \\
\hline Pseudoplagiostomataceae & \\
\hline Phaeoappendicosporaceae & \\
\hline Coryneaceae & \\
\hline Stilbosporaceae & \\
\hline Prosopidicolaceae & \\
\hline Cytosporaceae & \\
\hline Macrohilaceae & \\
\hline Diaporthaceae & \\
\hline Sydowiellaceae & \\
\hline Asterosporiaceae & \\
\hline Lamproconiaceae & \\
\hline Tirisporellaceae & Tirisporellales \\
\hline Togniniaceae & Togniniales \\
\hline Calosphaeriaceae & Calosphaeriales \\
\hline Pleurostomataceae & \\
\hline Jobellisiaceae & Jobellisiales \\
\hline
\end{tabular}

Figure 1 - Maximum likelihood (ML) majority rule combined LSU, SSU, tef1 and $r p b 2$ consensus tree for the analyzed Sordariomycetes isolates. Families are indicated in yellow and green coloured blocks and orders are indicated in dark and light grey coloured blocks. RAxML bootstrap support values (MLB above $50 \%$ ) are given at the nodes. The scale bar represents the expected number of changes per site. The tree is rooted with Botryotinia fuckeliana (AFTOL ID-59), Dothidea sambuci (DAOM 231303), and Pyxidiophora arvernensis (AFTOL-ID 2197). 


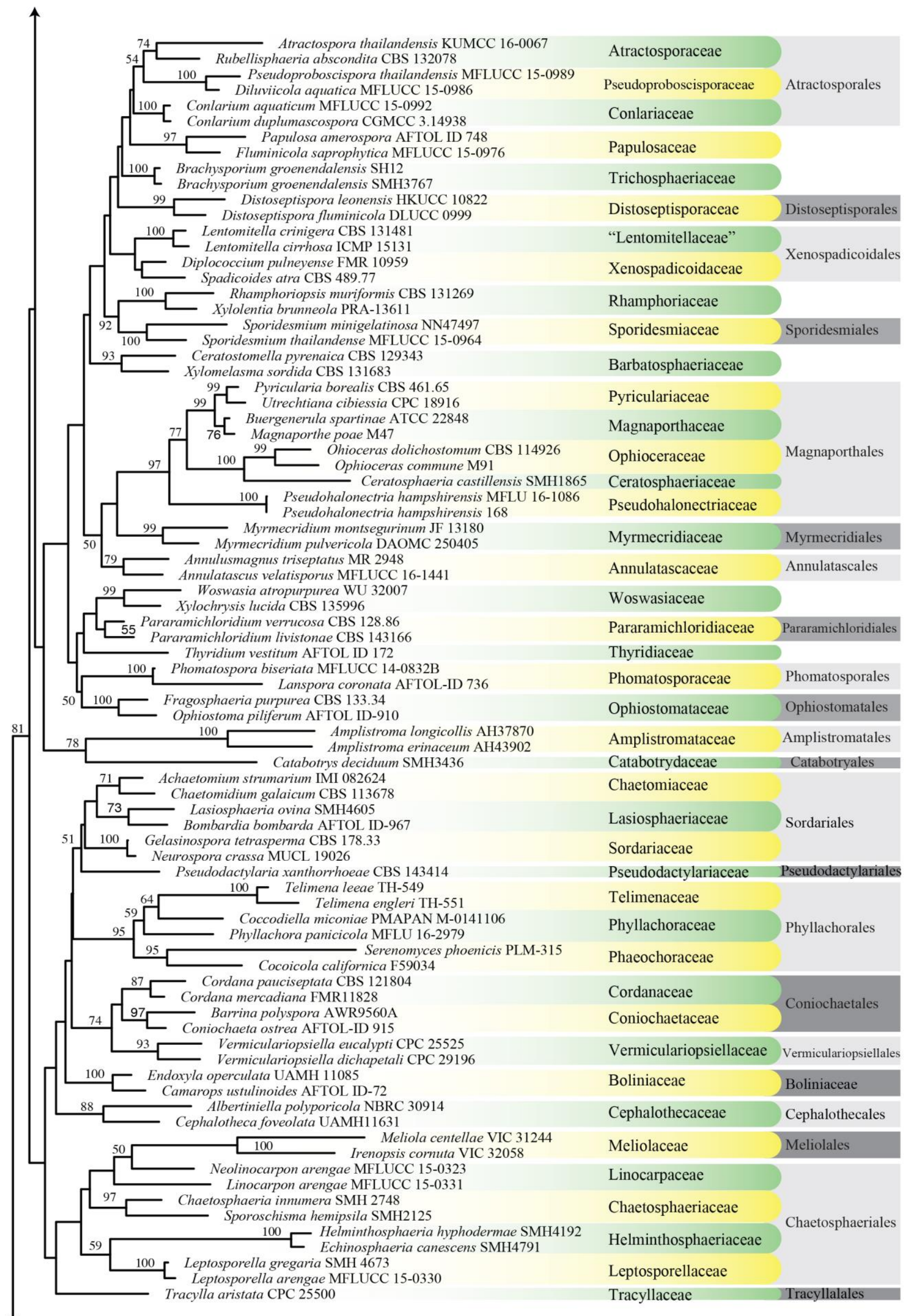

Figure 1 - Continued. 


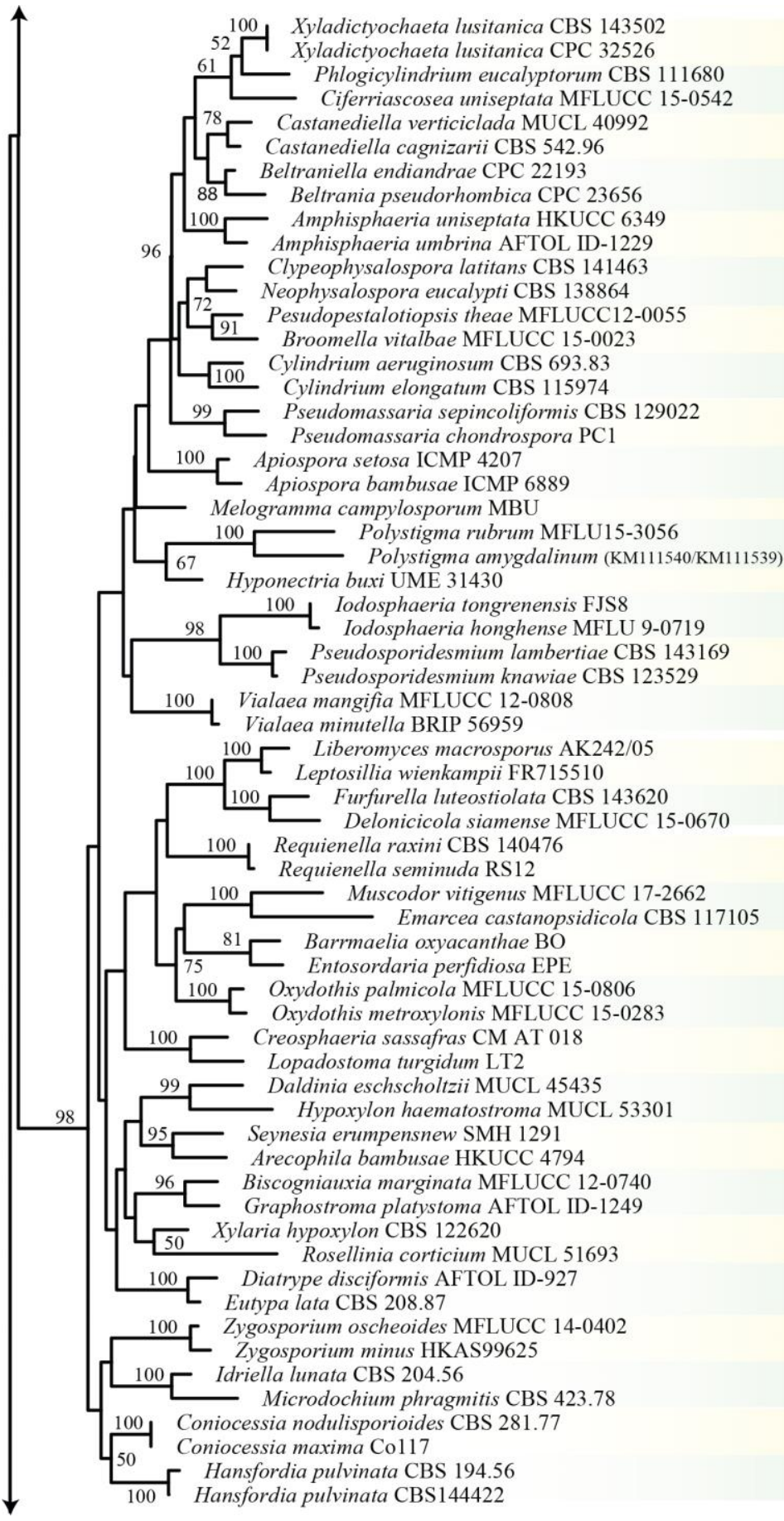

\begin{tabular}{|c|c|}
\hline Xyladictyochaetaceae & \multirow{16}{*}{ Amphisphaeriales } \\
\hline Phlogicylindriaceae & \\
\hline Castanediellaceae & \\
\hline Beltraniaceae & \\
\hline Amphisphaeriaceae & \\
\hline Clypeophysalosporaceae & \\
\hline Sporocadaceae & \\
\hline Cylindriaceae & \\
\hline Pseudomassariaceae & \\
\hline Apiosporaceae & \\
\hline Melogrammataceae & \\
\hline Polystigmataceae & \\
\hline Hyponectriaceae & \\
\hline Iodosphaeriaceae & \\
\hline Pseudosporidesmiaceae & \\
\hline Vialaeaceae & \\
\hline Leptosilliaceae & \multirow{2}{*}{ Delonicicolales } \\
\hline Delonicicolaceae & \\
\hline Requienellaceae & \multirow{14}{*}{ Xylariales } \\
\hline Induratiaceae & \\
\hline Barrmaeliaceae & \\
\hline Oxydothidaceae & \\
\hline Lopadostomaceae & \\
\hline Hypoxylaceae & \\
\hline Cainiaceae & \\
\hline Graphostromataceae & \\
\hline Xylariaceae & \\
\hline Diatrypaceae & \\
\hline Zygosporiaceae & \\
\hline Microdochiaceae & \\
\hline Coniocessiaceae & \\
\hline Hansfordiaceae & \\
\hline
\end{tabular}

Figure 1 - Continued.

-hyaline, persistent. Asci 8-spored, unitunicate, pedicellate, persistent, with a $\mathrm{J}+$ or $\mathrm{J}$-, apical ring. Ascospores hyaline, multi-septate, often guttulate, lacking any mucilaginous sheath or appendages. Asexual morph: Undetermined.

Type order - Pisorisporiales Réblová \& J. Fourn.

Notes - Pisorisporiales was reported to form a sister clade with Lulworthiales and Koralionastetales in Lulworthiomycetidae with a stem age of 266 MYA (Hongsanan et al. 2017, Hyde et al. 2017a). This is congruent to the results obtained in the present study (257 MYA). Since this stem age falls within the subclass status range (250-300 MYA), Pisorisporiomycetidae is proposed here as a new subclass. This subclass contains Pisorisporiales, family Pisorisporiaceae and the two genera Achroceratosphaeria and Pisorisporium (Réblová et al. 2015a). 

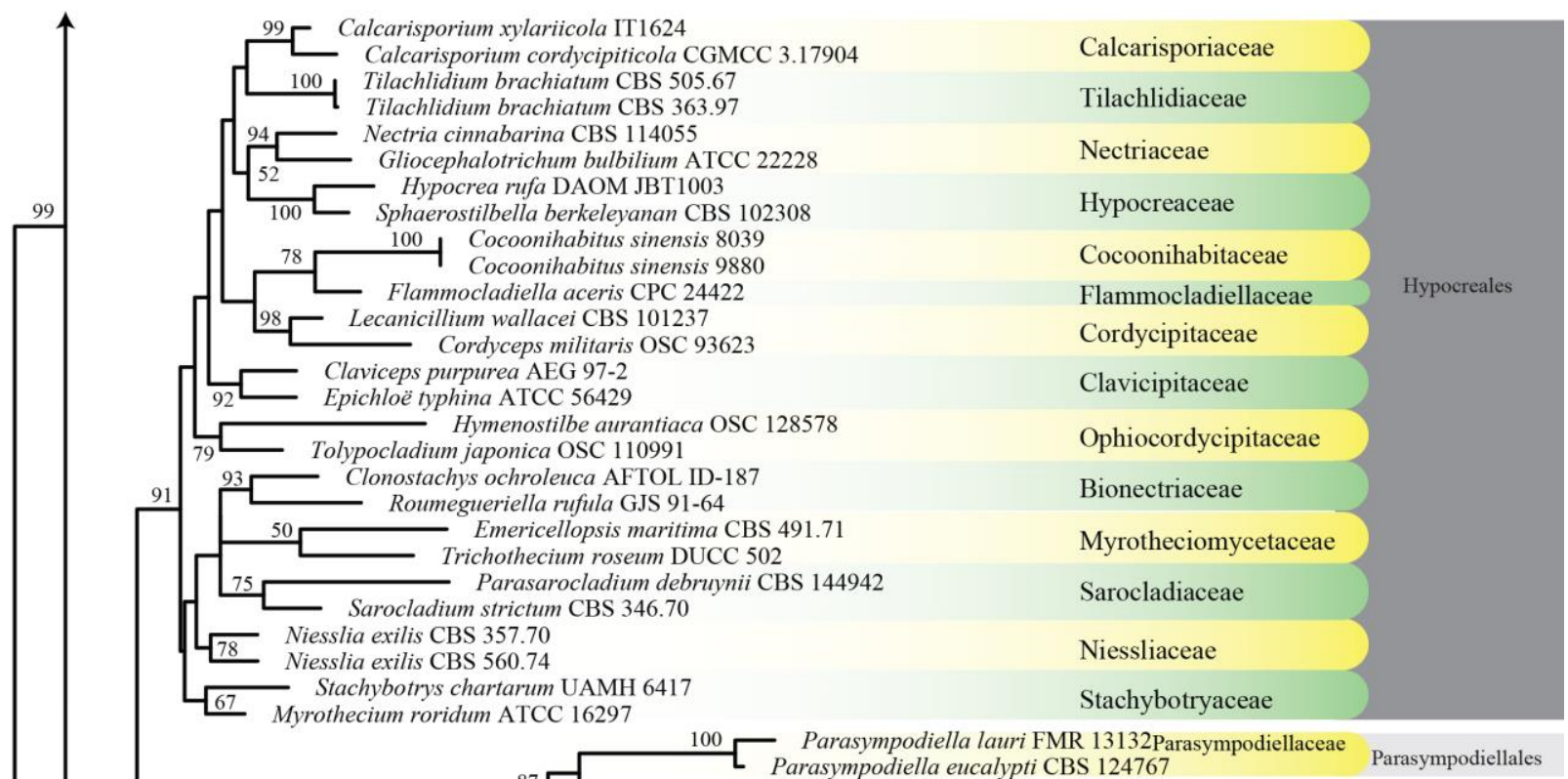

Parasympodiella eucalypti CBS 124767 Parasympodiellales

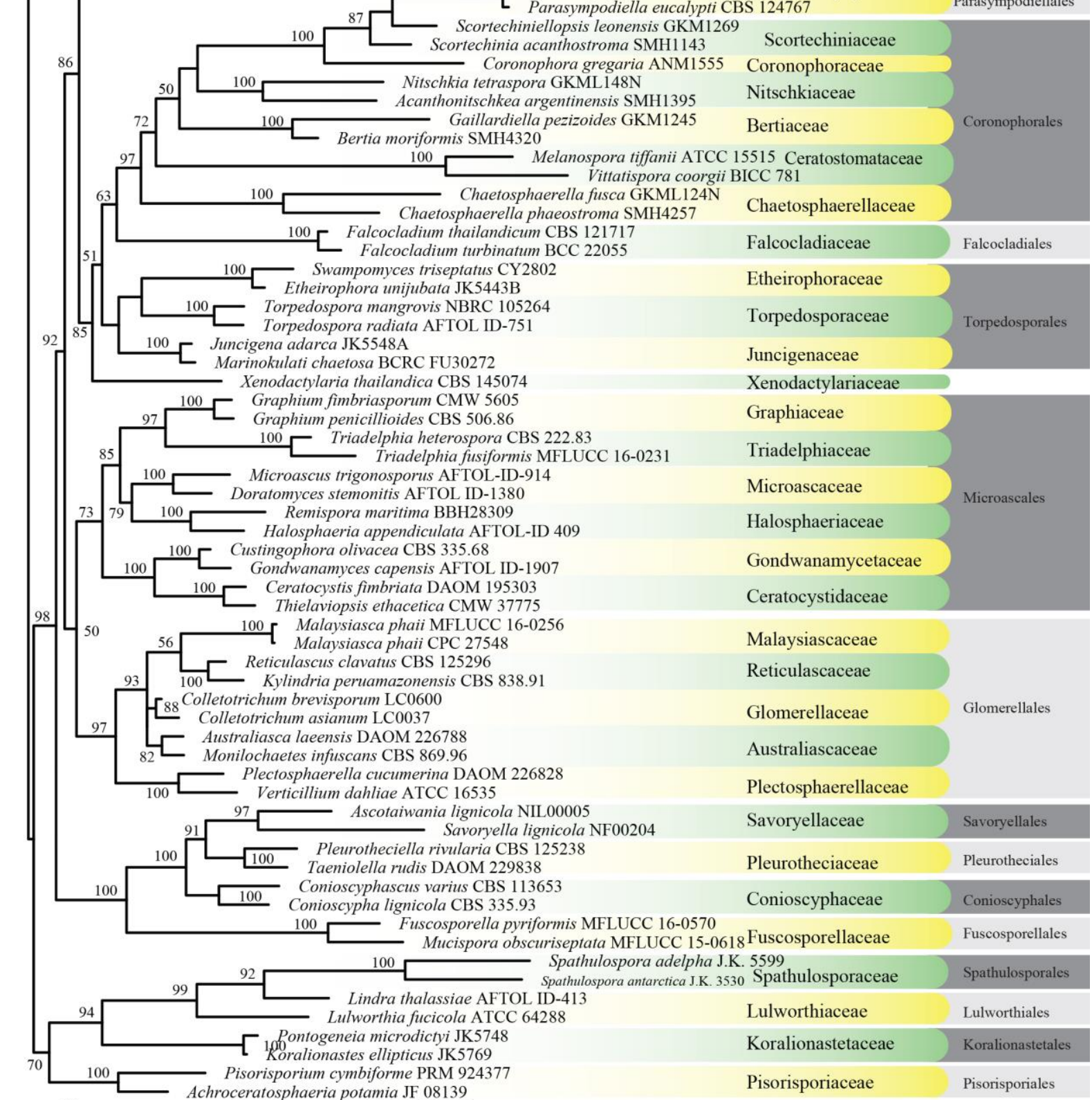

$99 \quad 100 \square \begin{gathered}\text { Dothidea sambuci DAOM } 231303 \\ \text { Botryotinia fuckeliana AFTOL ID-59 }\end{gathered}$

Figure 1 - Continued. 
Divergence times of lineages were used to analyze the status of higher ranks of fungi (Hongsanan et al. 2017, 2018, Hyde et al. 2017, Liu et al. 2017). Hyde et al. (2017) provided a maximum clade credibility (MCC) tree of families in Sordariomycetes and also proposed a series of evolutionary periods that could be used as a guide to define ranking of fungi in Sordariomycetes. In our paper, we provide the MCC tree base on updated classification of Sordariomycetes (Fig. 2). The same dataset as in Fig. 1 was used in our molecular clock analysis to compare the phylogenetic placement generated from both approaches. We use divergence time to confirm familial status of families in Sordariomycetes according to the guidance of Hyde et al. (2017). Some families and orders are not supported by divergence times, but their status is retained due to their unique characters or lack of species (notes are provided in each family).

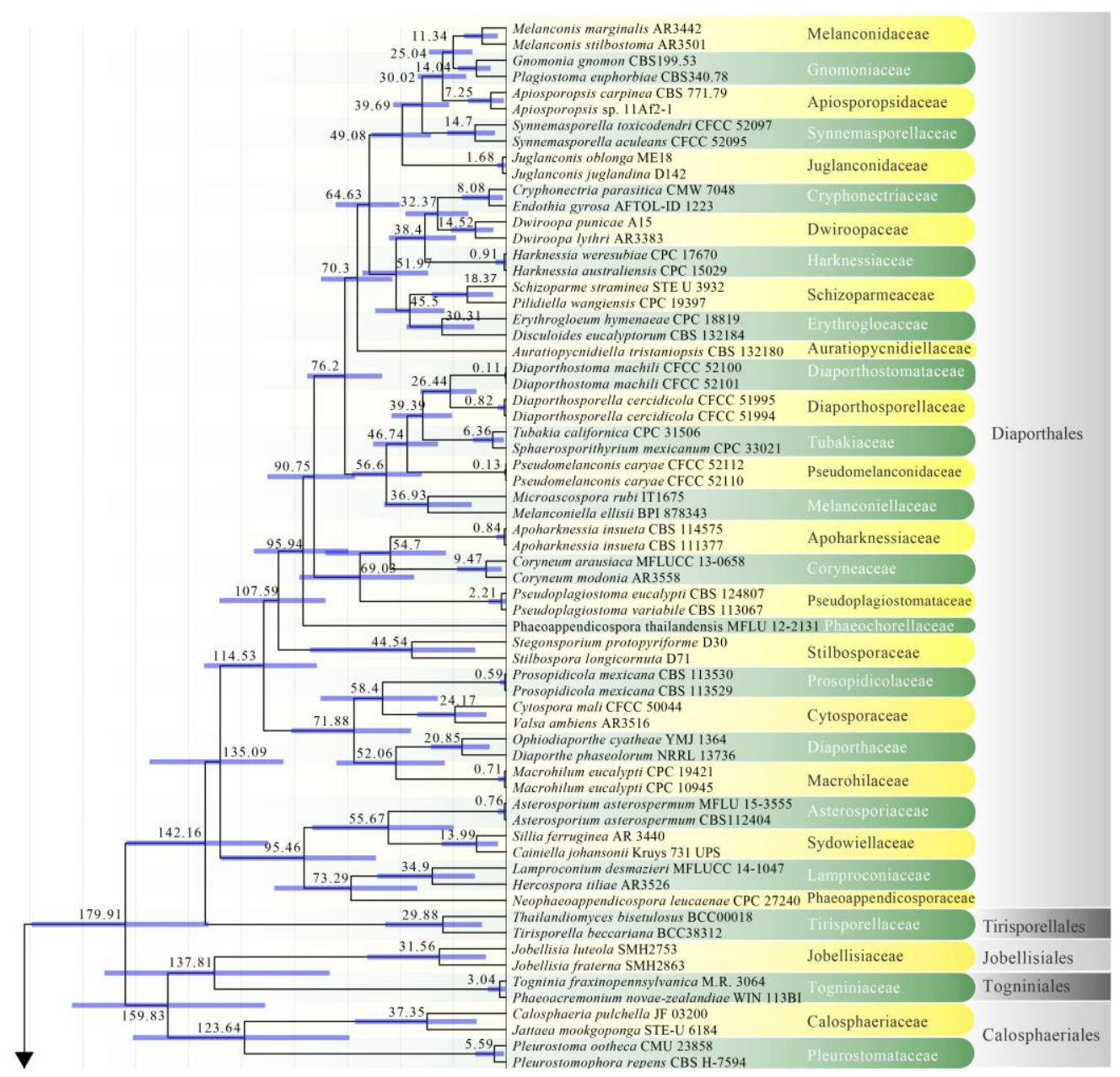

Figure 2 - The maximum clade credibility (MCC) tree, using the same dataset from Fig. 1. This analysis was performed in BEAST v1.10.2. The crown age of Sordariomycetes was set with Normal distribution, mean $=250, \mathrm{SD}=30$, with $97.5 \%$ of $\mathrm{CI}=308.8 \mathrm{MYA}$, and crown age of Dothideomycetes with Normal distribution mean $=360, \mathrm{SD}=20$, with $97.5 \%$ of $\mathrm{CI}=399 \mathrm{MYA}$. The substitution models were selected based on jModeltest2.1.1; GTR+I+G for LSU, $r p b 2$ and SSU, and TrN+I+G for tefl (the model TrN is not available in BEAUti 1.10.2, thus we used TN93). Lognormal distribution of rates was used during the analyses with uncorrelated relaxed clock model. The Yule process tree prior was used to model the speciation of nodes in the topology with a randomly generated starting tree. The analyses were performed for 100 million generations, with sampling parameters every 10000 generations. The effective sample sizes were checked in Tracer v.1.6 and the acceptable values are higher than 200 . The first $20 \%$ representing the burn-in phase were discarded and the remaining trees were combined in LogCombiner 1.10.2., summarized data and estimated in TreeAnnotator 1.10.2. Bars correspond to the 95\% highest posterior density (HPD) intervals. The scale axis shows divergence times as millions of years ago (MYA). 


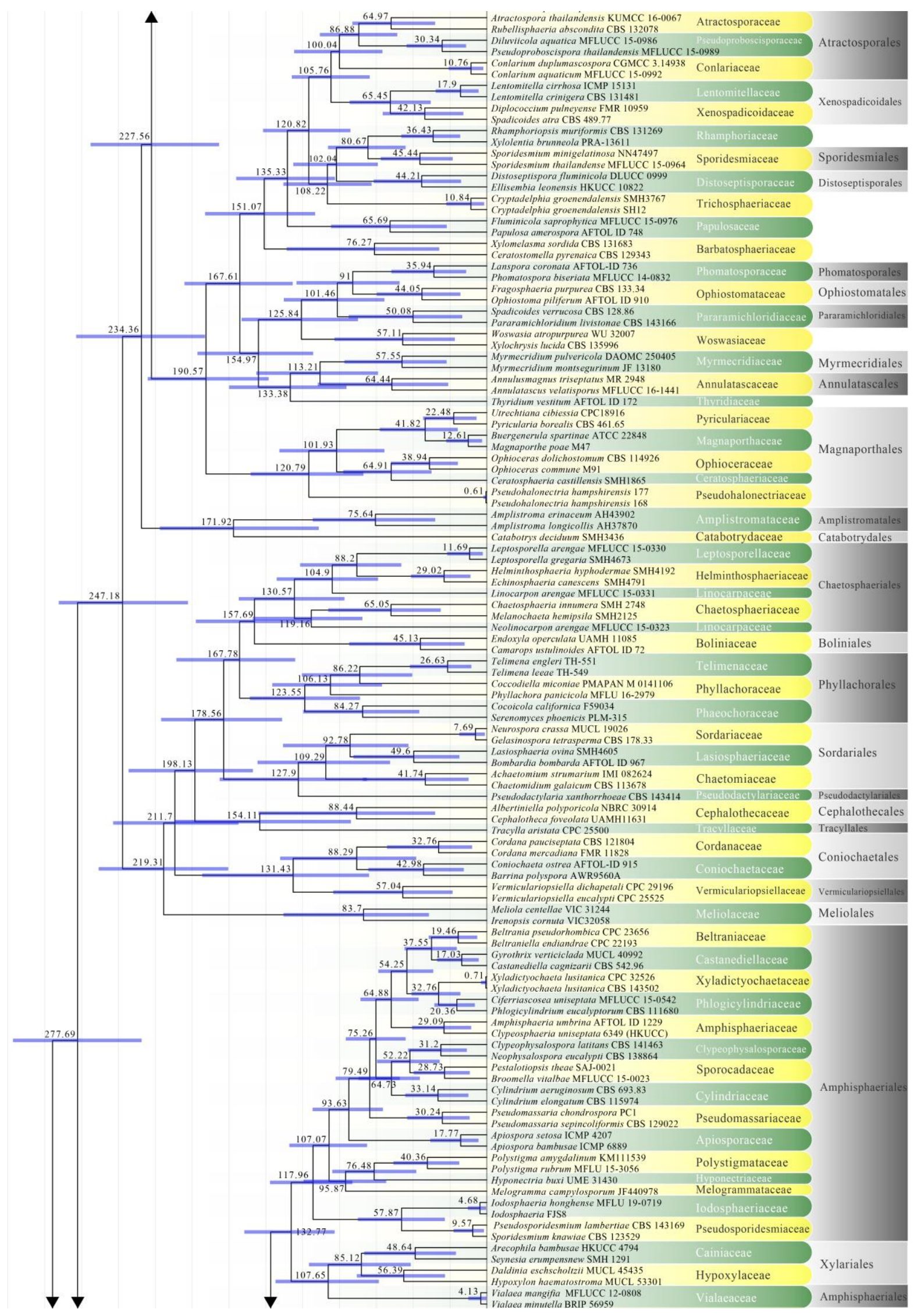

Figure 2-Continued. 


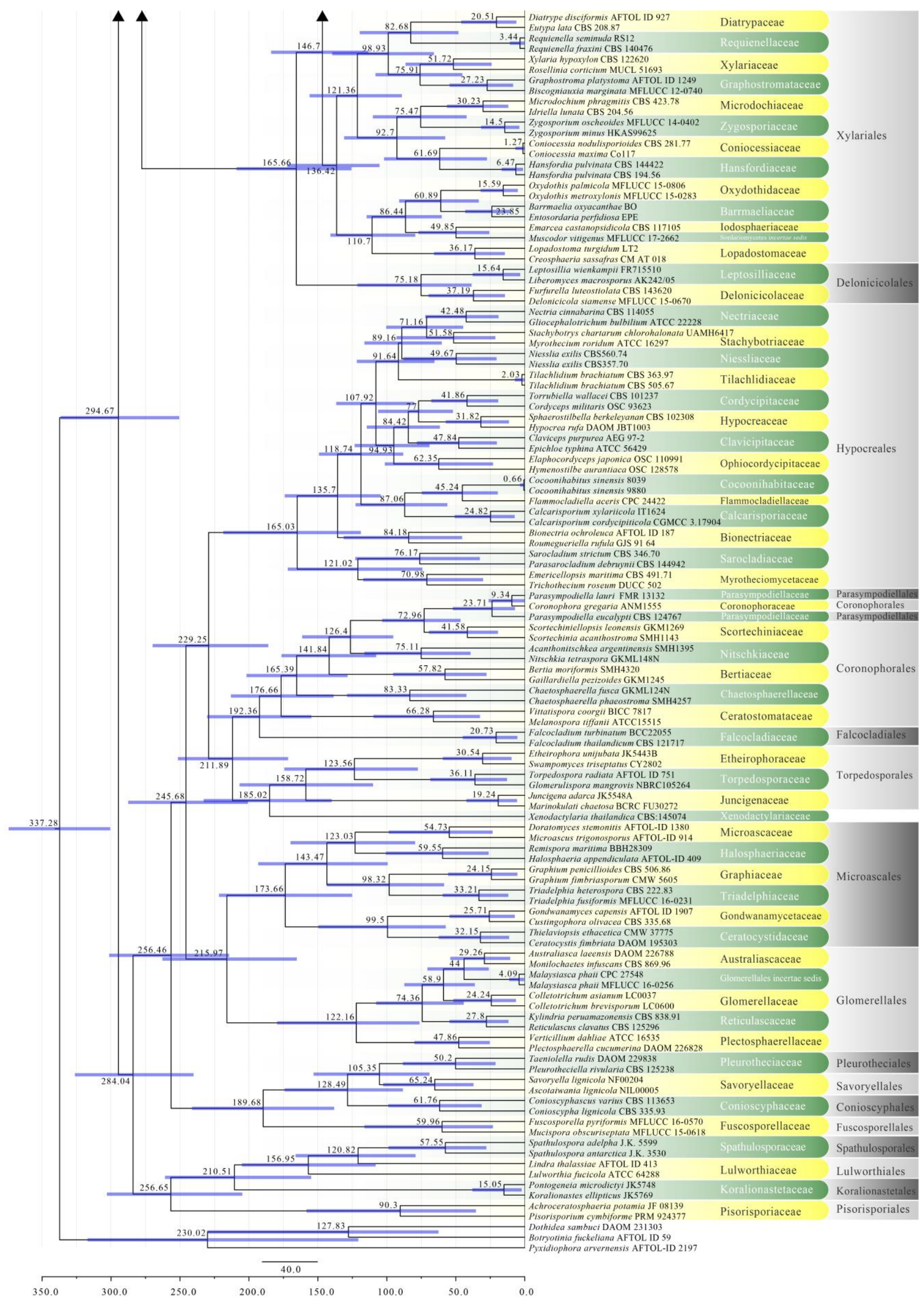

Figure 2 - Continued. 
Savoryellomycetidae Hongsanan, K.D. Hyde \& Maharachch., Fungal Divers. 84: 35 (2017) According to Maharachchikumbura et al. (2016b) and Yang et al. (2016b) Conioscyphales was assigned to Diaporthomycetidae, genera incertae sedis, while Fuscosporellales, Pleurotheciales, and Savoryellales were included in the subclass Hypocreomycetidae. In the phylogenetic and molecular clock analyses of (Hongsanan et al. 2017, Hyde et al. 2017a), Conioscyphales, Fuscosporellales, Pleurotheciales, and Savoryellales clustered together as a distinct clade, with a stem age of 268 MYA. Hence, they were referred to a new subclass Savoryellomycetidae by Hongsanan et al. (2017) and this was reinforced in the paper by Dayarathne et al. (2019a). Our phylogenetic analyses with combined LSU, SSU, ITS and rpb2 sequence data also showed Conioscyphales, Fuscosporellales, Pleurotheciales, and Savoryellales formed well-supported distinct clades (100\% ML, 1.00 PP, 100\% ML, 1.00 PP, 98\% ML, 1.00 PP and 100\% ML, 1.00 PP, respectively) within the subclass Savoryellomycetidae (Fig. 10). Currently there are four orders and four families in this subclass (this paper).

\section{Sordariomycetidae O.E. Erikss. \& Winka, Myconet 1(1): 10 (1997)}

The subclass Sordariomycetidae was established by Eriksson \& Winka (1997) and comprised six orders, 12 families and two families incertae sedis. Members of this subclass are mainly characterized by dark ascomata with inoperculate, unitunicate asci and occur in terrestrial, aquatic and marine habitats and are widely distributed as plant and animal pathogens, endophytes, saprobes as well as coprophilous and lichenicolous taxa (Maharachchikumbura et al. 2015, 2016b, Huang et al. 2019). They are mycophilic, rich in coprophilous taxa and associated with invertebrates and their ecological aspects and biotechnological potential have been researched (Zhang et al. 2006, Raghukumar 2008, Bovio et al. 2018). An MCC tree based on a combined SSU, LSU, tef1 and rpb2 sequence data revealed that this subclass evolved around 145-216 MYA (Hongsanan et al. 2017, Hyde et al. 2017a). The divergence time for Sordariomycetidae is estimated as 247 MYA (Fig. 2). Currently there are eight orders and 19 families in this subclass (this paper).

\section{Xylariomycetidae O.E. Erikss \& Winka, Myconet 1: 12 (1997)}

Different outlines of Xylariomycetidae have been published by Maharachchikumbura et al. (2016b), Samarakoon et al. (2016b) and Hongsanan et al. (2017). However, in the present study, we have revised the subclass. Concatenated LSU, ITS, rpb2 and tub2 based maximum likelihood phylogeny resulted in a well-supported backbone tree for 34 families in Xylariomycetidae (Fig. 4). The divergence time for Xylariomycetidae is estimated as 278 MYA (Fig. 2). There are three distinct clades in the tree representing the orders discussed in previous studies: Xylariales, Amphisphaeriales and Delonicicolales. The sister orders Xylariales (15 families) and Amphisphaeriales (17 families) have moderate statistical support (55\% ML) and basal to these is the highly supported clade Delonicicolales (100\% ML). Samarakoon et al. (2016b) and Hongsanan et al. (2017) provided divergence time estimations as additional information for Amphisphaeriales, which is estimated to have diverged from Xylariales around 152-187 Mya and provides evidence for these as distinct orders. Families accepted in Amphisphaeriales in this paper are similar to Hongsanan et al. (2017). In this study, we accept Cainiaceae as placed in Xylariales (Figs 1, 4), while Iodosphaeriaceae (Figs 1,4) which was previously referred to the Xylariomycetidae incertae sedis, (Hongsanan et al. 2017) is placed in Amphisphaeriales. Xyladictyochaetaceae (Crous et al. 2018b) is accepted in Amphisphaeriales and clusters with Phlogicylindriaceae with high statistical support (95\% ML; Fig. 4). Hansfordiaceae (Crous et al. 2019b) is sister to Coniocessiaceae in Xylariales with strong statistical support (82\% ML; Fig. 4). Cylindriaceae (Crous et al. 2018b) and Pseudotruncatellaceae (Crous et al. 2019b) are placed in Amphisphaeriales with poor statistical support (Fig. 4). Induratiaceae will be introduced by Samarakoon et al. (2020) and is placed in Xylariales (Fig. 4). Voglmayr et al. (2019a) introduced Leptosilliaceae as a new family which is sister to Delonicicolaceae, while rejecting Delonicicolales. However, with high statistical support (Fig. 4), we accept Delonicicolales in this study. Currently there are three orders and 35 families in this subclass (this paper). 


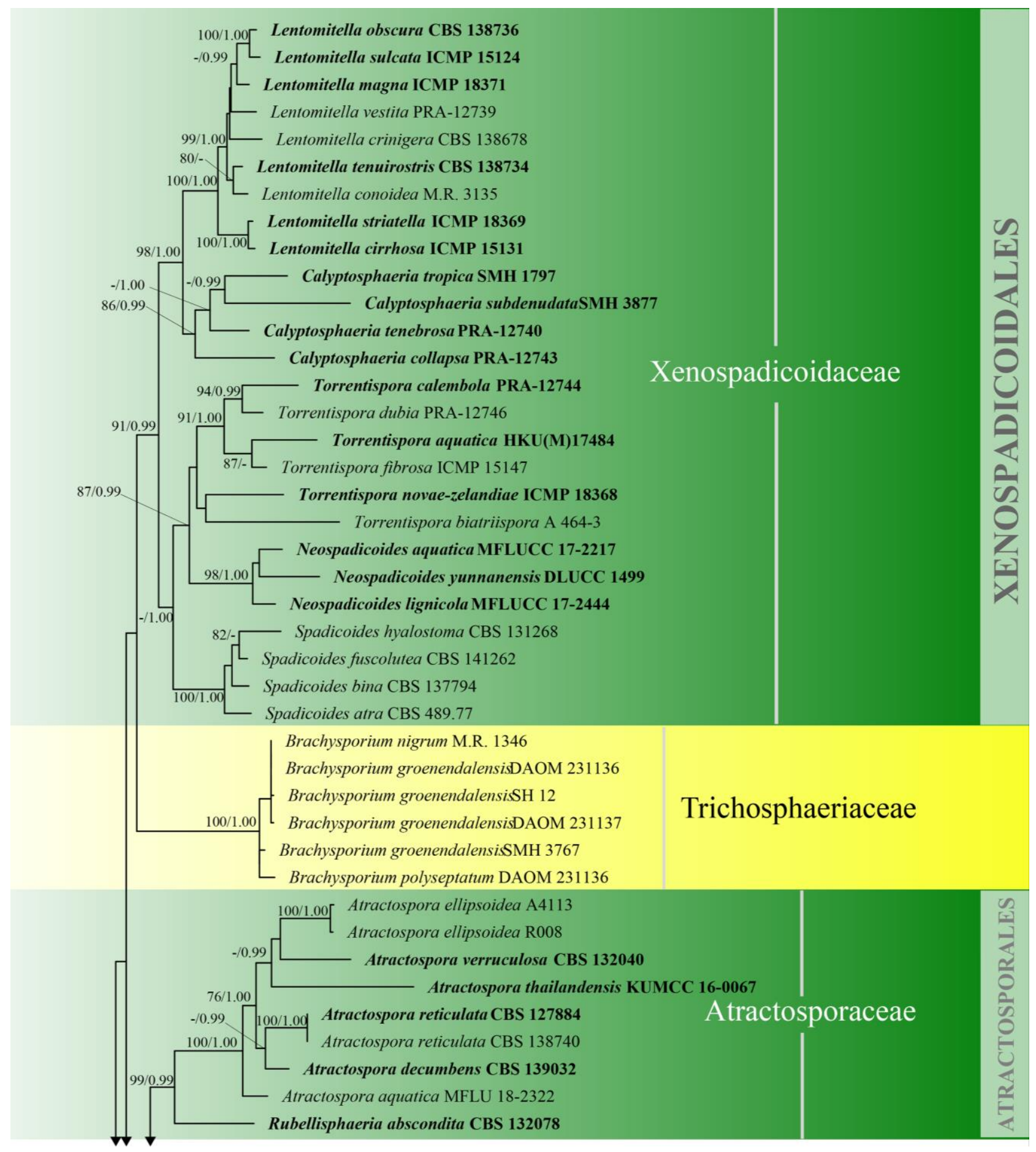

Figure 3 - Phylogram generated from maximum likelihood analysis based on combined LSU, SSU, ITS and $r p b 2$ sequence data of Diaporthomycetidae. One hundred and ninety-three strains are included in the combined analyses which comprised 3545 characters (859 characters for LSU, 972 characters for SSU, 659 characters for ITS) after alignment. Single gene analyses were carried out and the topology of each tree had clade stability. Tree topology of the maximum likelihood analysis is similar to the Bayesian analysis. The best RaxML tree with a final likelihood value of 68207.368884 is presented. Estimated base frequencies were as follows: $\mathrm{A}=0.248206, \mathrm{C}=$ $0.241993, \mathrm{G}=0.285500, \mathrm{~T}=0.224301$; substitution rates $\mathrm{AC}=1.369088, \mathrm{AG}=2.887040, \mathrm{AT}=$ 1.413053, $\mathrm{CG}=1.152137, \mathrm{CT}=6.303994, \mathrm{GT}=1.000000$; gamma distribution shape parameter a $=0.315782$. Bootstrap support values for ML greater than $75 \%$ and Bayesian posterior probabilities greater than 0.95 are given near the nodes. The tree is rooted with Diatrype disciformis (AFTOL-ID 927). Ex-type strains are in bold. The newly generated sequences are indicated in blue. 


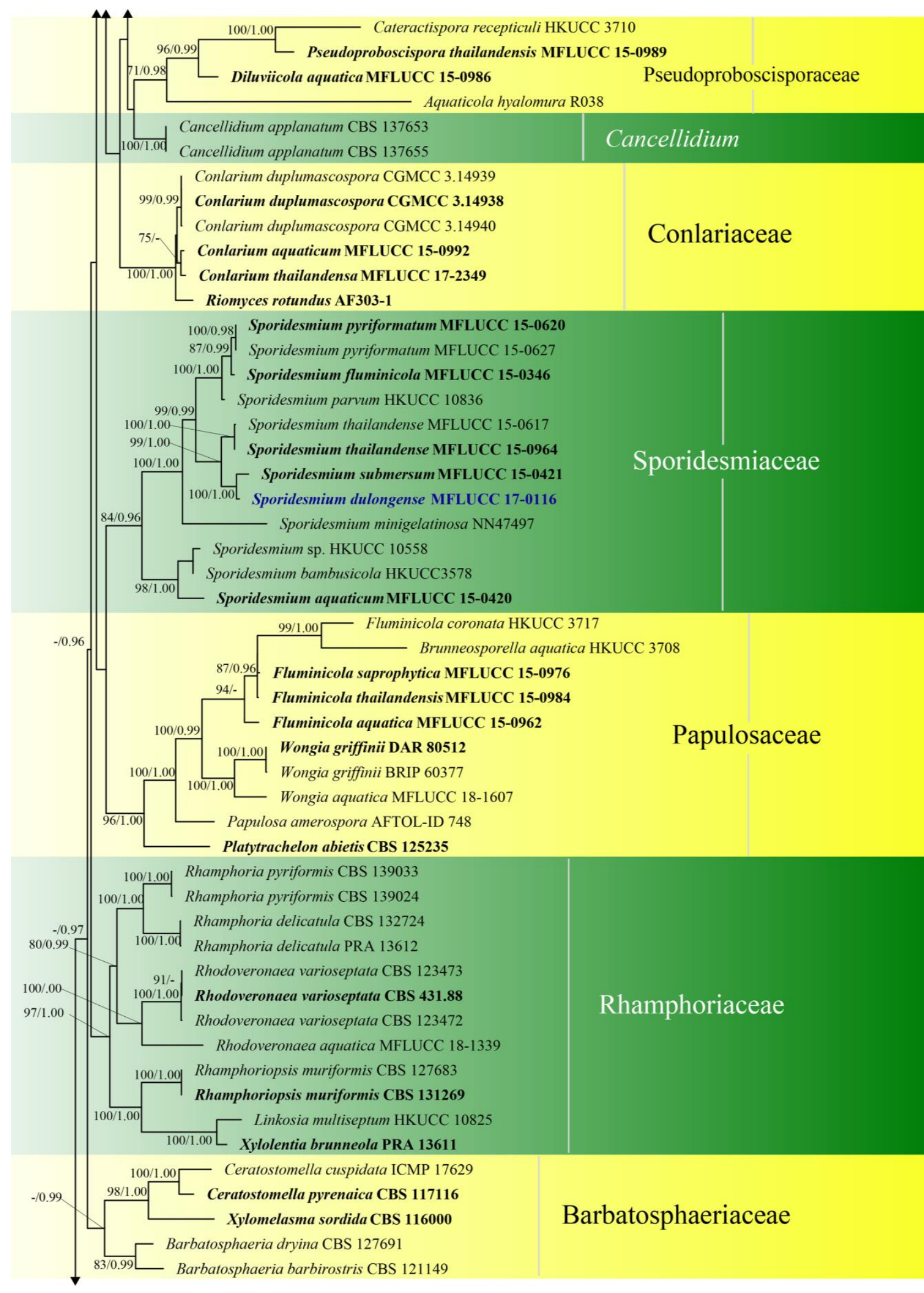

Figure 3 - Continued. 


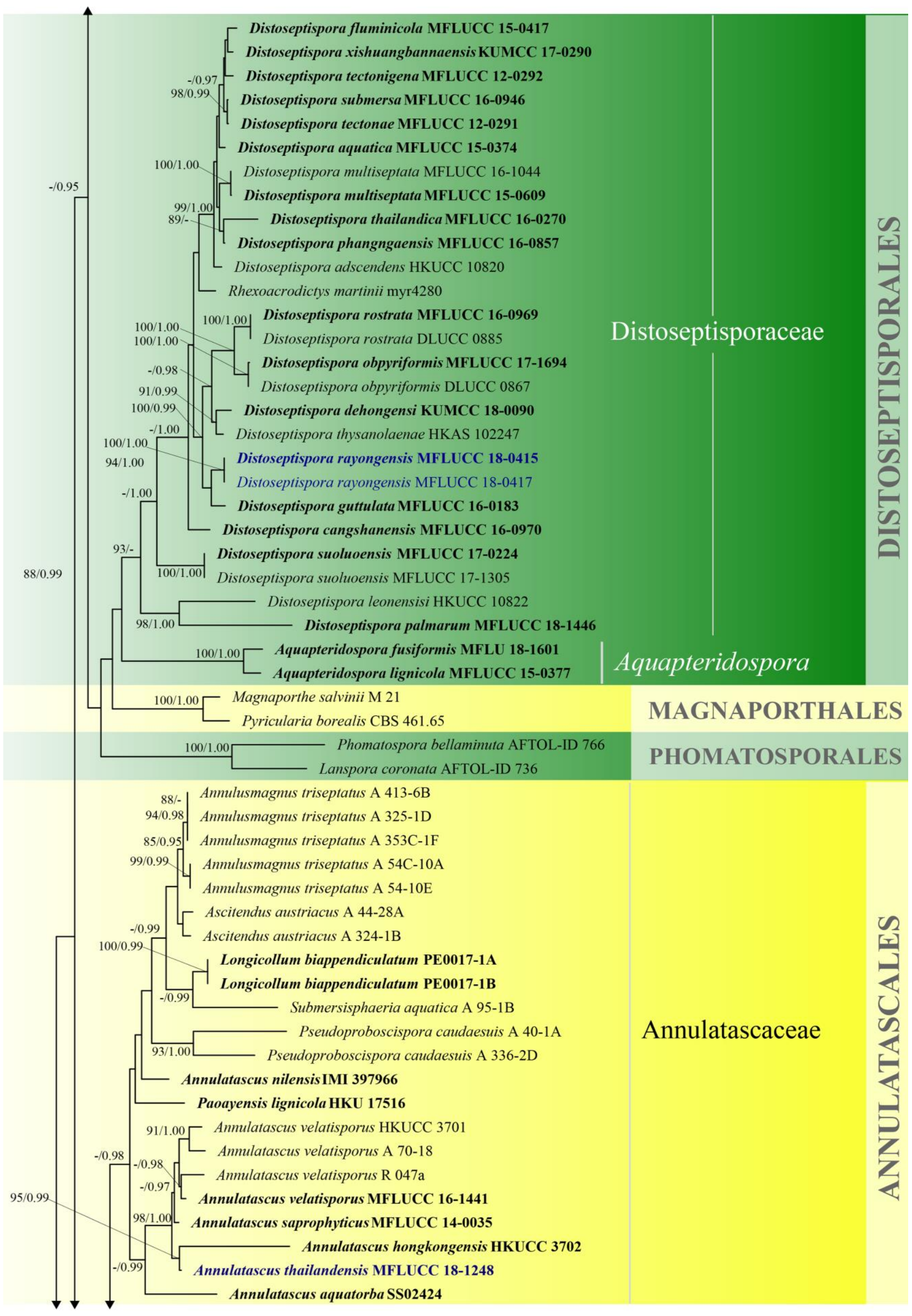

Figure 3 - Continued. 


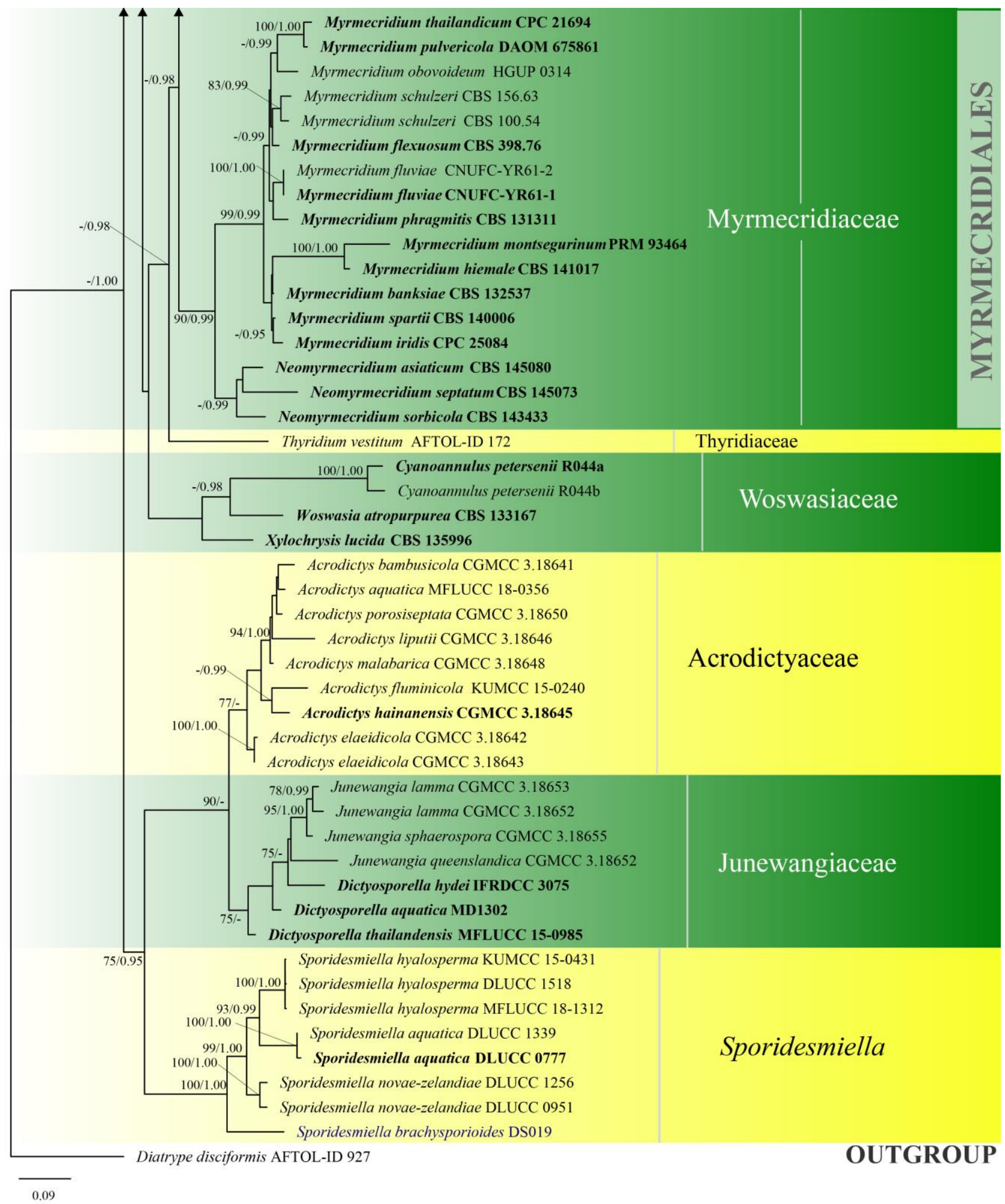

Figure 3 - Continued.

\section{The orders}

The orders are listed alphabetically with notes on new data since Maharachchimbura et al. (2016b). The divergence time for each order has been estimated, and stem ages are used to consider their ordinal status.

Amphisphaeriales Hawksw. \& O.E. Erikss., Syst. Ascom. 5(1): 177 (1986)

Amphisphaeriales has been accepted in consecutive studies using multigene phylogenies in the subclass Xylariomycetidae (Senanayake et al. 2015, Samarakoon et al. 2016b, Hongsanan et al. 
2017, Crous et al. 2018b). However, based on previous studies, Wijayawardene et al. (2018a) accepted 11 families in Amphisphaeriales, i.e. Amphisphaeriaceae, Apiosporaceae, Beltraniaceae, Clypeophysalosporaceae, Hyponectriaceae, Melogrammataceae, Oxydothidaceae, Phlogicylindriaceae, Pseudomassariaceae, Sporocadaceae and Vialaeaceae, while Cainiaceae, Coniocessiaceae, and Iodosphaeriaceae were accepted in Xylariomycetidae families incertae sedis. In this study, Amphisphaeriales is a moderately supported clade sister to Xylariales and comprises 17 families viz. Amphisphaeriaceae, Apiosporaceae, Beltraniaceae, Castanediellaceae, Clypeophysalosporaceae, Cylindriaceae, Hyponectriaceae, Iodosphaeriaceae, Melogrammataceae, Oxydothidaceae, Phlogicylindriaceae, Pseudomassariaceae, Pseudosporidesmiaceae, Pseudotruncatellaceae, Sporocadaceae, Vialaeaceae, and Xyladictyochaetaceae. The divergence time for Amphisphaeriales has been estimated as 133 MYA. This number did not include Vialaeaceae because this family goes to Xylariales in MCC tree (Fig. 2). Currently there are 17 families and 88 genera in this order (this paper).

Amplistromatales D'souza, Maharachch. \& K.D. Hyde, Fungal Divers. 72: 212 (2015)

Maharachchikumbura et al. (2015) introduced Amplistromatales (in Sordariomycetes order incertae sedis) comprising two families, Amplistromataceae and Catabotryaceae. Subsequent studies by Daranagama et al. (2017) and Hongsanan et al. (2017) accepted Amplistromatales in Sordariomycetes incertae sedis with a stem age of 165 MYA. Hyde et al. (2017a) proposed Catabotryaceae as a separate order based on stem age at 165 MYA. In this study, Catabotryaceae is placed in Catabotryales, and Amplistromataceae is placed in Amplistromatales with high statistical support (100\% MP/100\% ML/1.00 PP; Fig. 5). Catabotryales is introduced as a new order based on its stem age (172 MYA). Currently there is one family and three genera in Amplistromatales (this paper).

Annulatascales M.J. D’souza, Maharachch. \& K.D. Hyde, Fungal Divers. 72(1): 212 (2015)

Annulatascales comprises a single family Annulatascaceae and currently five genera are confirmed with molecular data (Zhang et al. 2017a; Fig. 3). The phylogenetic relationship of this family is inferred mainly using LSU gene data as ITS and SSU genes are available for only a few taxa. More genes generated from fresh collections are needed to clarify the phylogenetic relationships of Annulatascales species. Paoayensis clustered in Annulatascaceae in our phylogenetic analyses, but we consider that it should not belong to this family because of its 2-6spored asci and absence of large ring, which is different from familial concept of Annulatascaceae, and its weak bootstrap support in Annulatascaceae. The placement of Annulatascus nilensis (phylogenetically distant from other Annulatascus species) also warrant further investigations (Fig. $3)$. Fresh collections of this taxon are also needed. The divergence time for Annulatascales has been estimated as 112 MYA (Fig. 2). Currently there is one family and 11 genera in this order (this paper).

Atractosporales H. Zhang, K.D. Hyde \& Maharachch., Fungal Divers. 85: 88 (2017)

Atractosporales was introduced to resolve the taxonomic problems of annulatascaceae-like taxa previously placed in Annulatascaceae and Sordariomycetes genera incertae sedis. Three families (viz. Atractosporaceae, Conlariaceae, and Pseudoproboscisporaceae) were included in the order by Zhang et al. (2017a). The monophyly of this order is not well-supported in previous studies (Luo et al. 2019) and in this study. Luo et al. (2019) showed that Junewangiaceae and Cancellidium also clustered in Atractosporales and this agrees with our phylogenetic analyses, but with low bootstrap support (Fig. 3). We therefore retain Cancellidium (Tubaki 1975) as Sordariomycetes genera incertae sedis. This ambiguous group may be included in this order with larger taxon sampling in future phylogenetic analyses. The divergence time for Atractosporales has been estimated as 106 MYA (Fig. 2), which falls in the range for family status. The status of Atractosporales members may therefore need revision following further study. Currently there are three families and six genera in this order (this paper). 


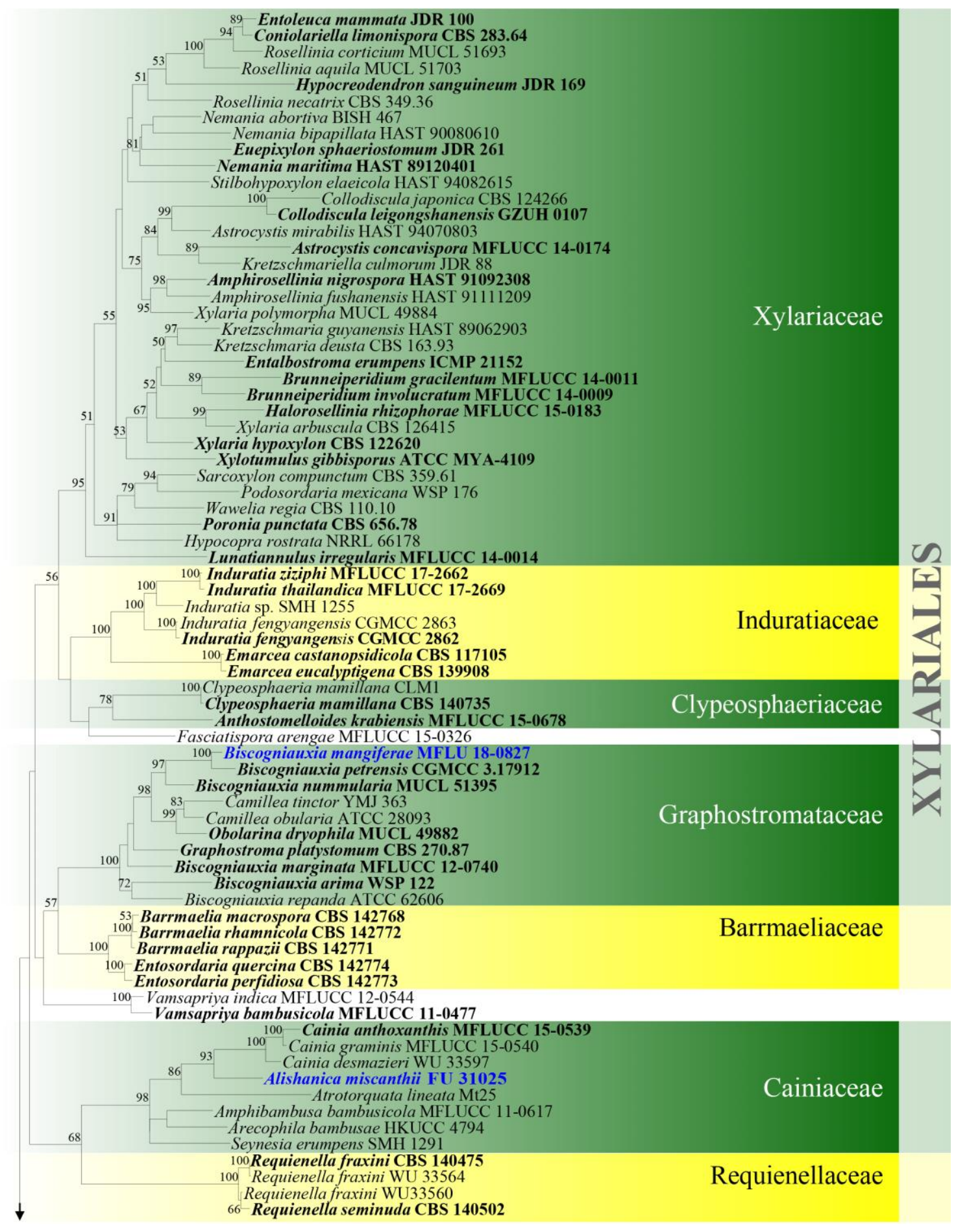

Figure 4 - Phylogram generated from maximum likelihood analysis based on combined ITS, LSU, $r p b 2$ and $t u b 2$ sequence data for Xylariomycetidae. Two hundred and seventy-two strains are included in the combined analyses which comprised 4211 characters (1168 characters for ITS, 937 characters for LSU, 1128 characters for $r p b 2$, 978 characters for tub2) after alignment. Achaetomium macrosporum (CBS 532.94), Chaetomium elatum (CBS 374.66) and Sordaria fimicola (CBS 723.96) are outgroup taxa. Single gene analyses were carried out and the topology of each tree had clade stability. The best RaxML tree with a final likelihood value of -132297.706952 is presented. Estimated base frequencies were as follows: $\mathrm{A}=0.241914, \mathrm{C}=0.251908, \mathrm{G}=$ $0.265558, \mathrm{~T}=0.240620$; substitution rates $\mathrm{AC}=1.281946, \mathrm{AG}=3.512297, \mathrm{AT}=1.499895, \mathrm{CG}=$ $1.121065, \mathrm{CT}=6.472834, \mathrm{GT}=1.000000$; gamma distribution shape parameter $\mathrm{a}=0.678614$. Bootstrap support values for ML greater than $75 \%$ are given near the nodes. Ex-type strains are in bold. The newly generated sequences are indicated in blue. 


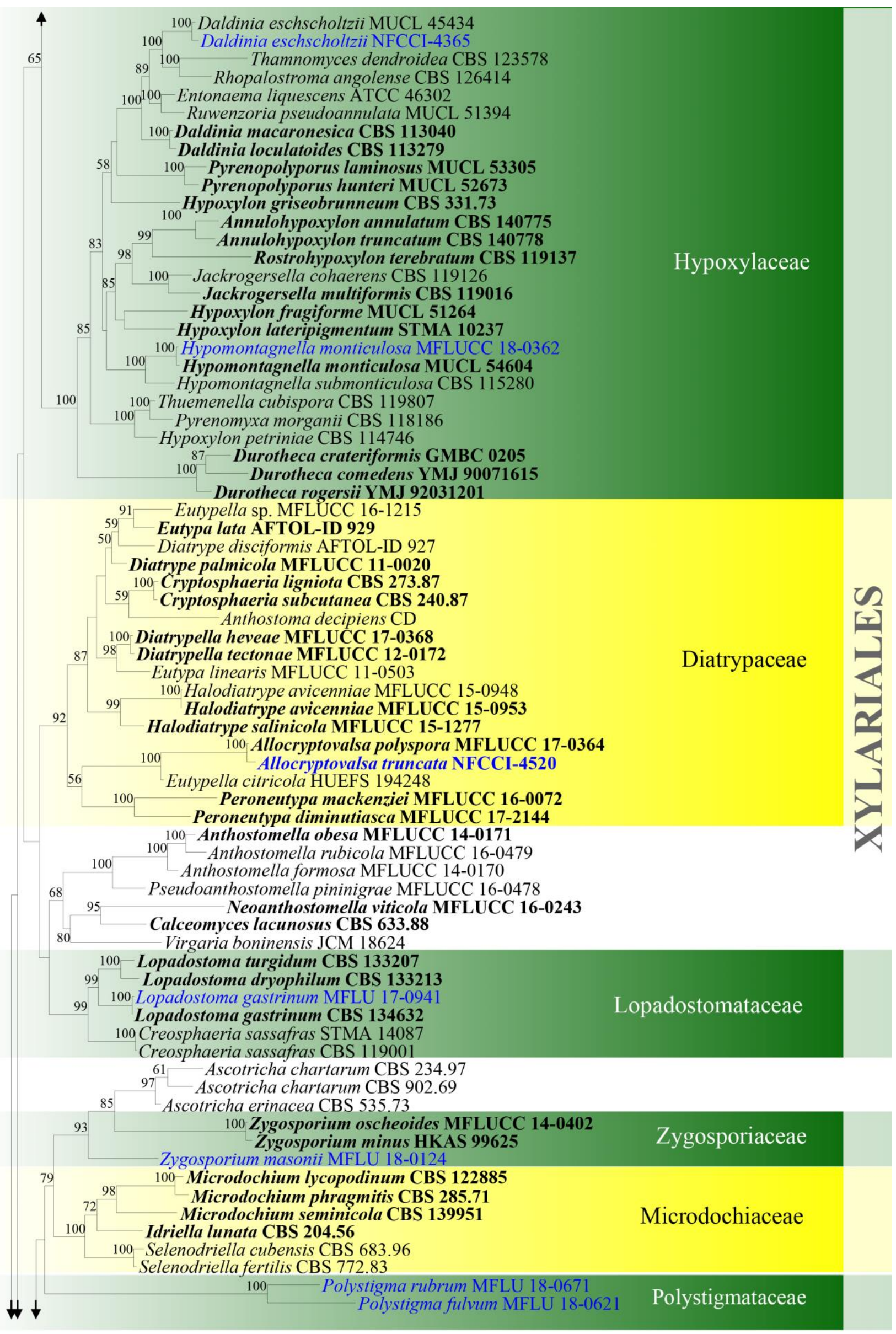

Figure - 4 Continued. 


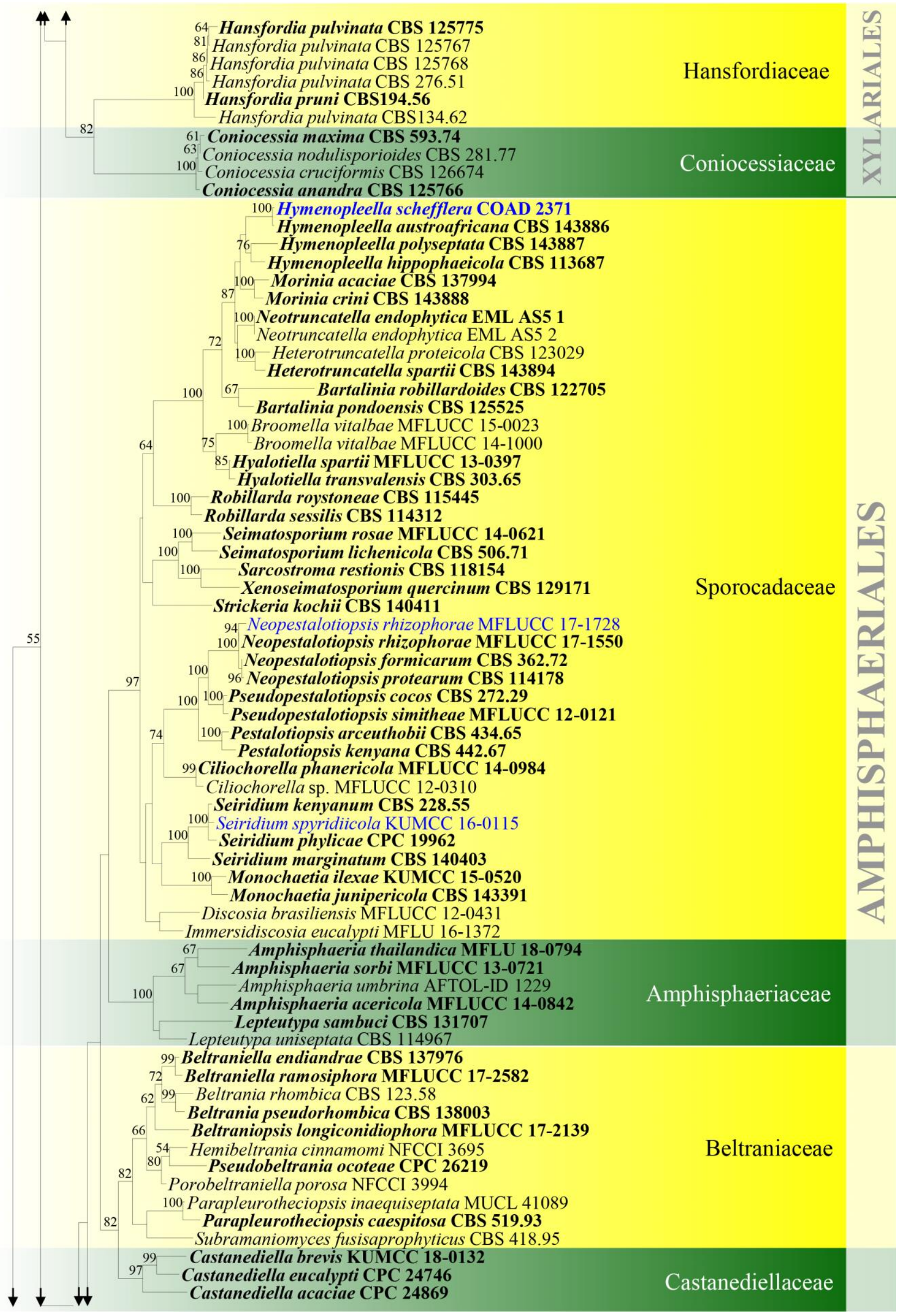

Figure - 4 Continued. 


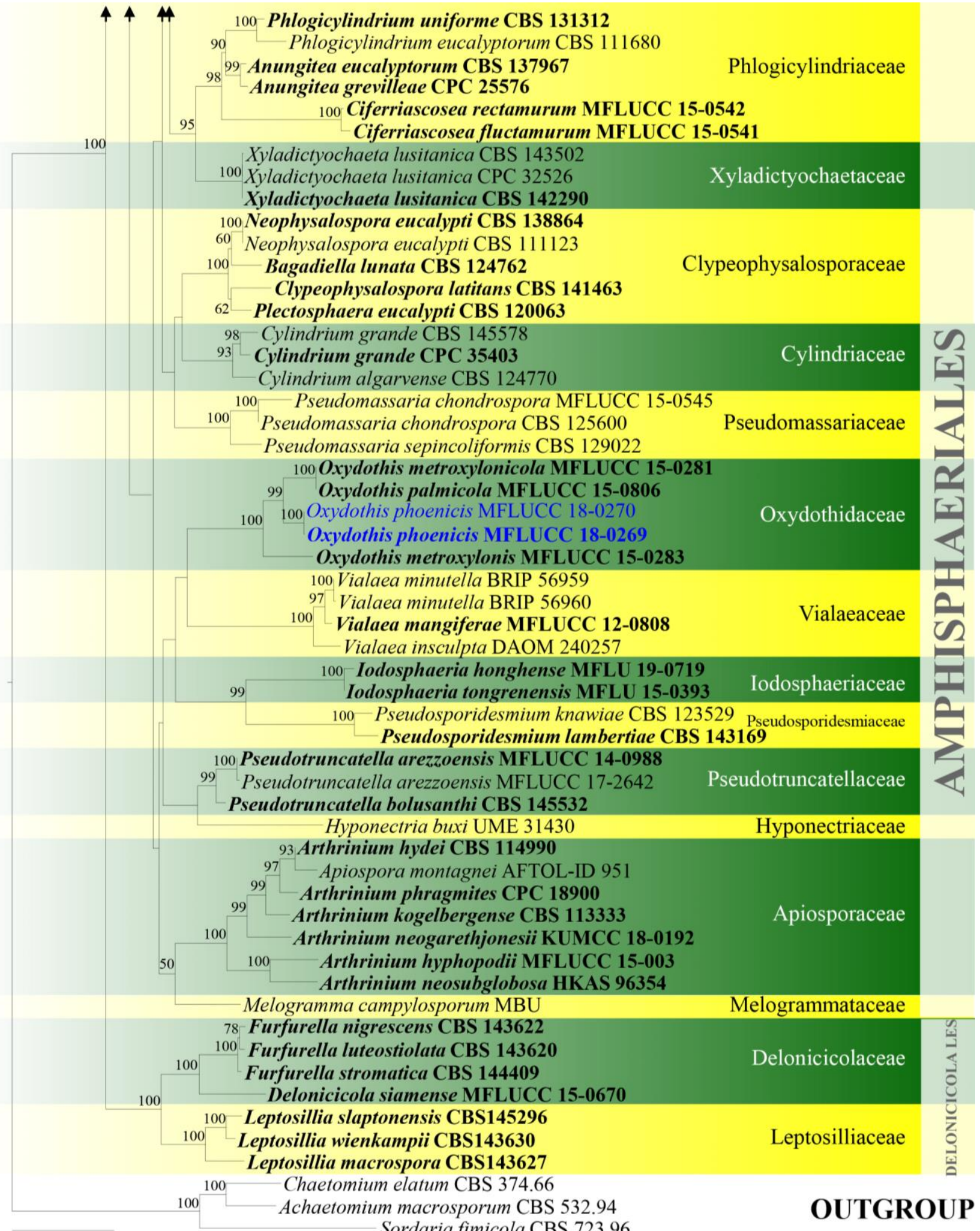

0.2

Figure 4 - Continued.

Boliniales P.F. Cannon, Ainsworth \& Bisby's Dictionary of the Fungi, Edn 9 (Wallingford): x (2001)

Boliniales was established by Kirk et al. (2001) and comprises a single family Boliniaceae based on perithecial, brown to black ascomata and cylindrical asci with smooth, ellipsoid ascospores with apical germ pores (Rick 1931, Huang et al. 2019). Most members in Boliniales have been found in America and Europe and primarily occur on wood and no asexual morph is 
known (Zhang et al. 2006, Huang et al. 2019). Multi-gene analyses have shown that the order is closely related to Meliolales, Phyllachorales and Chaetosphaeriales within Sordariomycetidae (Lumbsch \& Huhndorf 2010, Hongsanan et al. 2017, Hyde et al. 2017a, Huang et al. 2019). The divergence time for Boliniales has been estimated as 158 MYA (Fig. 2). Currently there is one family and nine genera in this order (this paper).

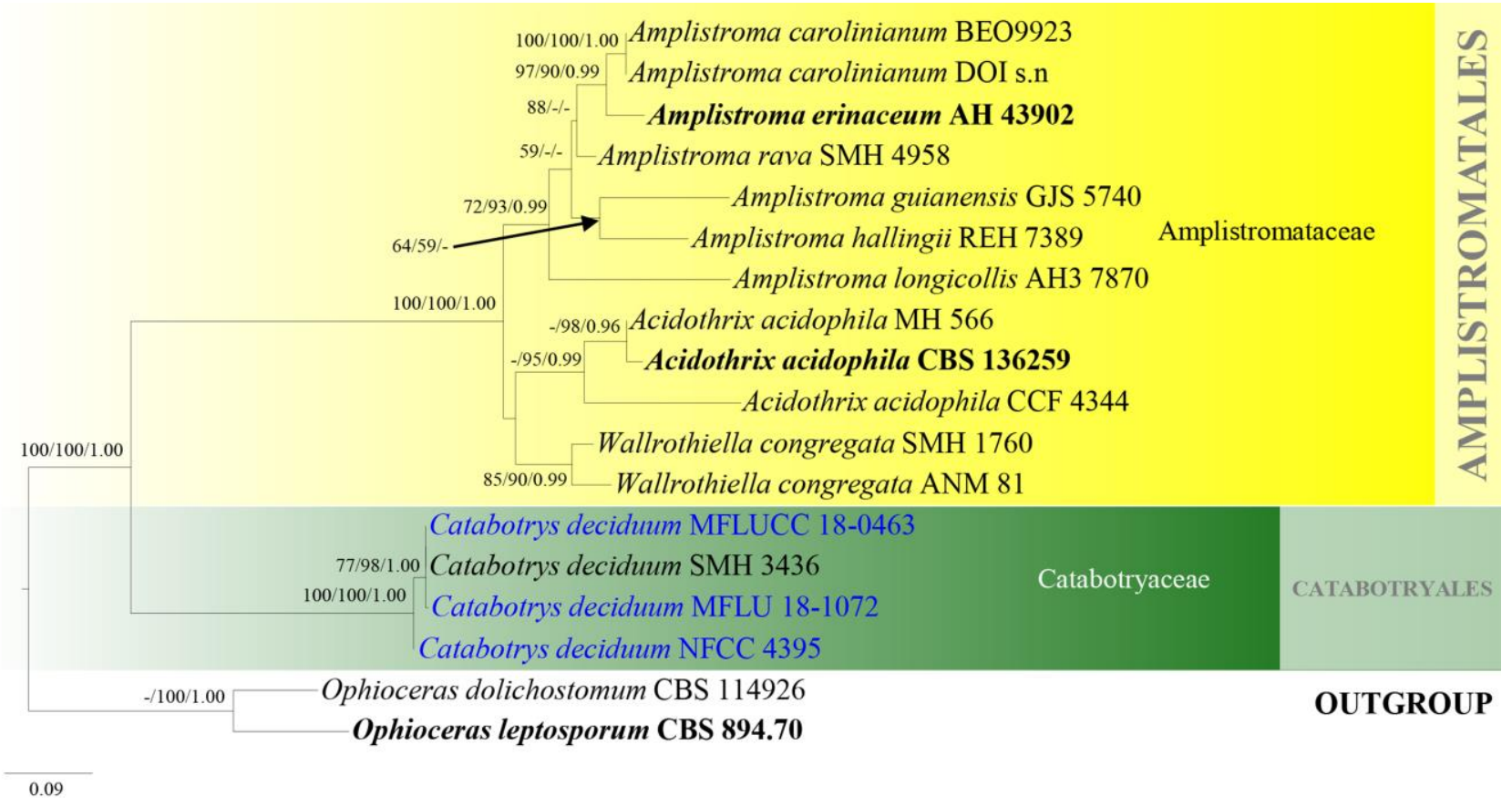

Figure 5 - Phylogram generated from maximum likelihood analysis based on combined LSU and ITS sequence data of Amplistromatales. Eighteen strains are included in the combined analyses which comprised 1661 characters (908 characters for LSU, 753 characters for ITS) after alignment. Ophioceras dolichostomum (CBS 114926) and O. leptosporum (CBS 894.70) are used as outgroup taxa. Single gene analyses were also carried out and the phylogenies were similar in topology and clade stability. Tree topology of the maximum likelihood analysis is similar to the Bayesian analysis. The best RaxML tree with a final likelihood value of - 6986.920872 is presented. Estimated base frequencies were as follows: $\mathrm{A}=0.226, \mathrm{C}=0.264, \mathrm{G}=0.321, \mathrm{~T}=0.190$; substitution rates $\mathrm{AC}=0.643764, \mathrm{AG}=1.471407, \mathrm{AT}=1.612417, \mathrm{CG}=0.654293, \mathrm{CT}=$ $5.330856, \mathrm{GT}=1.000000$; gamma distribution shape parameter $\mathrm{a}=0.653797$. Bootstrap support values for MP and ML greater than 55\% and Bayesian posterior probabilities greater than 0.95 are given near the nodes. Ex-type strains are in bold. The newly generated sequences are indicated in blue.

Calosphaeriales M.E. Barr, Mycologia 75(1): 11 (1983)

Members of Calosphaeriaceae and Pleurostomataceae are accommodated in Calosphaeriales and are characterized by brown to black ascomata with reniform to clavate asci, phialidic conidiophores and ellipsoid to allantoid conidia (Maharachchikumbura et al. 2016b, Huang et al. 2019). Some species are plant pathogens (Barr 1983, Damm et al. 2008, Trouillas et al. 2012). In previous phylogenetic analyses, species of Calosphaeriales were closely related to Jobellisiales and Togniniales (Maharachchikumbura et al. 2015, 2016b, Hongsanan et al. 2017). Calosphaeriales comprises seven genera within the two families Calosphaeriaceae and Pleurostomataceae (Huang et al. 2019). The monotypic genera, Kacosphaeria and Sulcatistroma are accepted in Calosphaeriales based on the small, clavate asci with allantoid to ellipsoid, hyaline ascospores similar to Calosphaeria (Huang et al. 2019). The divergence time for Calosphaeriales has been estimated as 160 MYA (Fig. 2). Currently there are two families and nine genera in this order (this paper). 


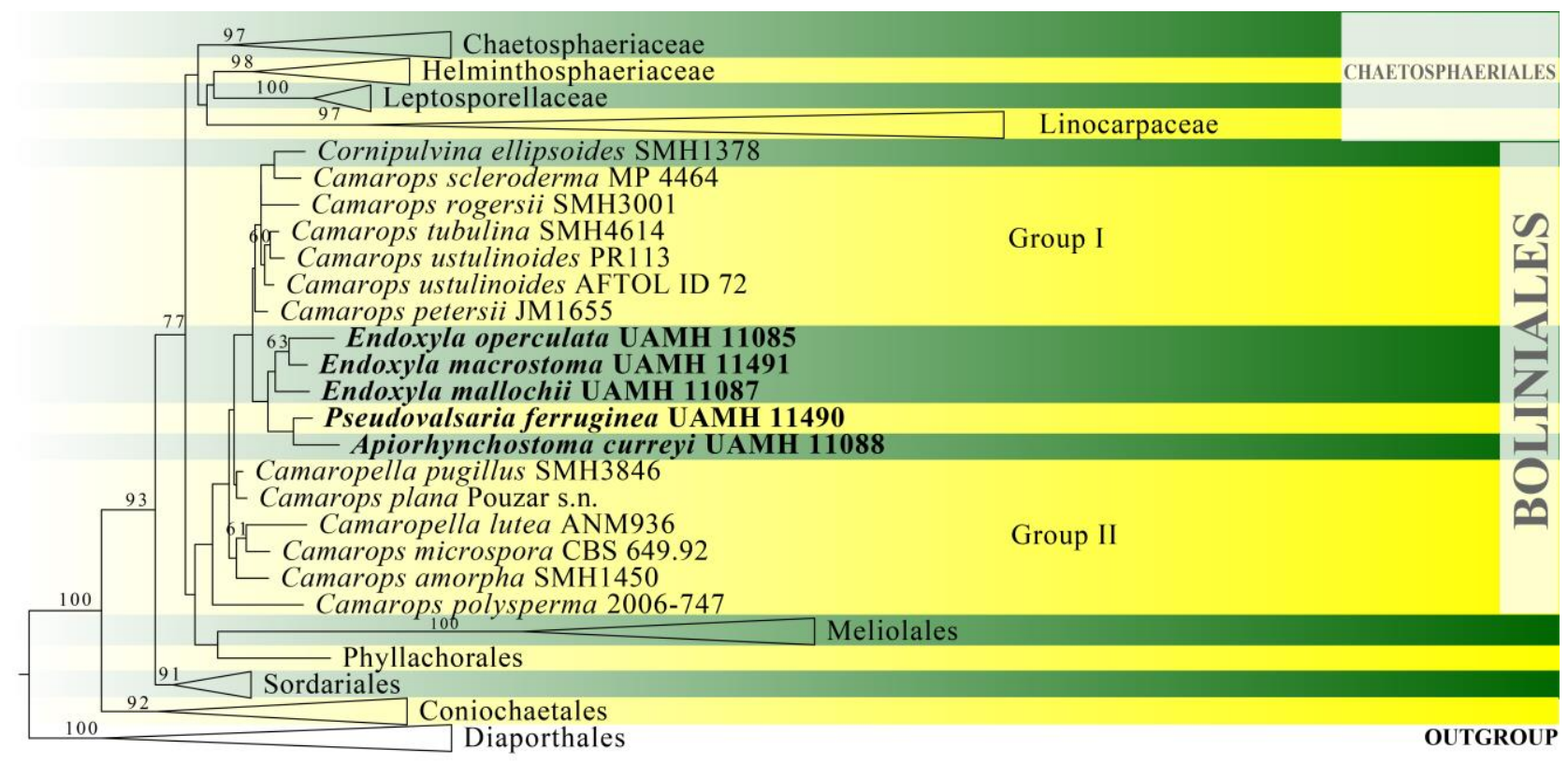

Figure 6 - Phylogram generated from maximum likelihood analysis based on combined LSU, ITS and $t u b 2$ sequence data of Boliniales. Related sequences are taken from Læssøe et al. (2013). Seventy-three strains are included in the combined analyses which comprised 2081 characters (867 characters for LSU, 561 characters for ITS, 653 characters for $t u b 2)$ after alignment. Members of Diaporthales are used as outgroup taxa. Single gene analyses were also carried out and the phylogenies were similar in topology and clade stability. The best RAxML tree with a final likelihood value of -34809.341208 is presented. Estimated base frequencies were as follows: $\mathrm{A}=$ $0.209463, \mathrm{C}=0.298053, \mathrm{G}=0.289389, \mathrm{~T}=0.203095$; substitution rates $\mathrm{AC}=1.086242, \mathrm{AG}=$ 2.378803, $\mathrm{AT}=1.369068, \mathrm{CG}=1.213916, \mathrm{CT}=6.024342, \mathrm{GT}=1.000000$; gamma distribution shape parameter $\mathrm{a}=0.567627$. Bootstrap support values for ML greater than $60 \%$ are given near the nodes. Ex-type strains are in bold. The newly generated sequences are indicated in blue.

Catabotryales K.D. Hyde \& Senan., ord. nov.

Index Fungorum number: IF556718; Facesoffungi number: FoF06864

Saprobic on dead plant parts. Sexual morph: Stromata irregularly scattered, conspicuous, multi-loculate, superficial, with base slightly penetrating the epidermis, discoid to pulvinate, reddish brown to black, scurfy surface, flat or slightly convex, composed of rather thin-walled, reddish yellow cells of textura angularis, textura globosa or textura epidermoidea. Ascomata perithecial, deeply imbedded in stromatic tissues, globose, with a long, periphysate, ostiolar neck. Peridium thick, composed of several layers of reddish brown cells of textura angularis. Paraphyses hypha-like, numerous, tapering towards the apex, not embedded in a gelatinous matrix. Asci 8spored, unitunicate, broad cylindrical, short pedicellate, apically rounded or truncate, with a J-, discoid, refractive, apical ring. Ascospores bi-seriate, hyaline, 1-celled, ellipsoidal to cylindrical, smooth-walled, lacking a mucilaginous sheath. Asexual morph: Undetermined.

Type family - Catabotryaceae Petr. ex M.E. Barr

Notes - Catabotryaceae was placed in Amplistromatales based on DNA sequence analyses (Maharachchikumbura et al. 2015, 2016b). However, this family was later placed in Sordariomycetes families incertae sedis based on phylogeny and molecular clock evidence (Hongsanan et al. 2017). Catabotryaceae has only one strain representing its taxonomic placement and more samples are needed to provide evidence for its ordinal status. Hyde et al. (2017a) however suggested that a new order Catabotryales was needed to accommodate the monotypic family Catabotryaceae based on divergent time estimations. Catabotryales is formally introduced 
here for the single family Catabotryaceae. Catabotryales comprises saprobic species on dead leaves and stems of tropical monocotyledons. This order is distinct from its sister orders in having astromatic ascomata, broad cylindrical asci and ellipsoidal to cylindrical ascospores without a mucilaginous sheath. The divergence time for Catabotryales has been estimated as 172 MYA (Fig. 2).

Cephalothecales Maharachch. \& K.D. Hyde, ord. nov.

Index Fungorum number: IF557027; Facesoffungi number: FoF06900

An order within the class Sordariomycetes, subclass Sordariomycetidae occurring as saprobes or epiphytes on rotting or dead plants or fungi, and causing systemic mycotic infection in humans with burns. Sexual morph: Ascomata perithecial, solitary to gregarious, carbonaceous, covered by sulphureous hyphae, without periphyses. Peridium cephalothecoid. Ascogenous hyphae septate. Asci 8-spored, unitunicate, evanescent, apedicellate, without an apical ring. Ascospores irregularly arranged, brown, variously shaped, without germ pores. Asexual morph: Hyphomycetous. Mycelium branched septate. Conidiophores long, stiffly upright, cylindrical, septate. Conidiogenous cells phialidic, cylindrical. Conidia in chains, cylindrical, ovate or obovate, with or without an apiculate or truncate base, 1-celled.

Type family - Cephalothecaceae Höhn.

Notes - Cephalothecaceae was introduced by Höhnel (1917c) and is characterized by ascomata with a cephalothecoid peridium. The peridial cells form plate-like complexes made up of radiating groups of cells, where each plate is separated by well-defined lines of dehiscence (Malloch \& Cain 1970). Albertiniella, Cephalotheca, Cryptendoxyla, Phialemonium and the newly introduced Victoriomyces (Davolos et al. 2019) are presently placed in the family. Although the placement of Cephalothecaceae is not stable within subclass Sordariomycetidae, it has high support in the MCC tree (Hyde et al. 2017a, Hongsanan et al. 2017). Cephalothecaceae has a divergence time at 154 MYA (present study), thus, here we raise Cephalothecaceae to ordinal status.

Chaetosphaeriales Huhndorf, A.N. Mill. \& F.A. Fernández, Mycologia 96(2): 378 (2004)

Huhndorf et al. (2004) introduced this order for Chaetosphaeriaceae. Linocarpaceae was added to Chaetosphaeriales by Konta et al. (2017) to accommodate Neolinocarpon and Linocarpon, which are previously accepted in Xylariales, genera incertae sedis (Maharachchikumbura et al. 2015, 2016b). Konta et al. (2017) also established Leptosporellaceae to accommodate Leptosporella, which was maintained in Chaetosphaeriales genera incertae sedis by Maharachchikumbura et al. (2016b). Wijayawardene et al. (2018a) accepted Leptosporellaceae and Linocarpaceae in Chaetosphaeriales and this is confirmed in our phylogenetic analysis (Figs. 1, 8). The polyphyletic genus Diplococcium was previously excluded from Sordariomycetes and accepted in Helotiales by Maharachchikumbura et al. (2015). Wijayawardene et al. (2018a) listed Diplococcium in Helminthosphaeriaceae. However, a phylogenetic analysis by Hernández-Restrepo et al. (2017) confirmed that Diplococcium is not related to Helminthosphaeriaceae and was placed in Helotiales. Lin et al. (2019) introduced Multiguttulispora and placed it within Chaetosphaeriaceae. Neoleptosporella (incertae sedis) will be added to the order by Phukhamsakda et al. (2020). Chaetosphaeriales grouped sister to Tracyllalales with a low statistical support in our phylogenetic analysis (Figs 1,8). The divergence time for Chaetosphaeriales has been estimated as 158 MYA (Fig. 2). Here we accept four families and 59 genera in the order.

Coniochaetales Huhndorf, A.N. Mill. \& F.A. Fernández, Mycologia 96(2): 378 (2004)

This order consists of two families Coniochaetaceae representing the genera Barrina and Coniochaeta and Cordanaceae which accommodates Cordana. Cordanaceae was previously classified in Cordanales, however based on molecular clock evidence Hongsanan et al. (2017) treated Cordanales as a synonym of Coniochaetales. The phylogenetic tree presented here supports this synonymy (Fig. 9). The divergence time for Coniochaetales has been estimated as 131 MYA (Fig. 2). Currently there are two families and five genera in this order (this paper). 


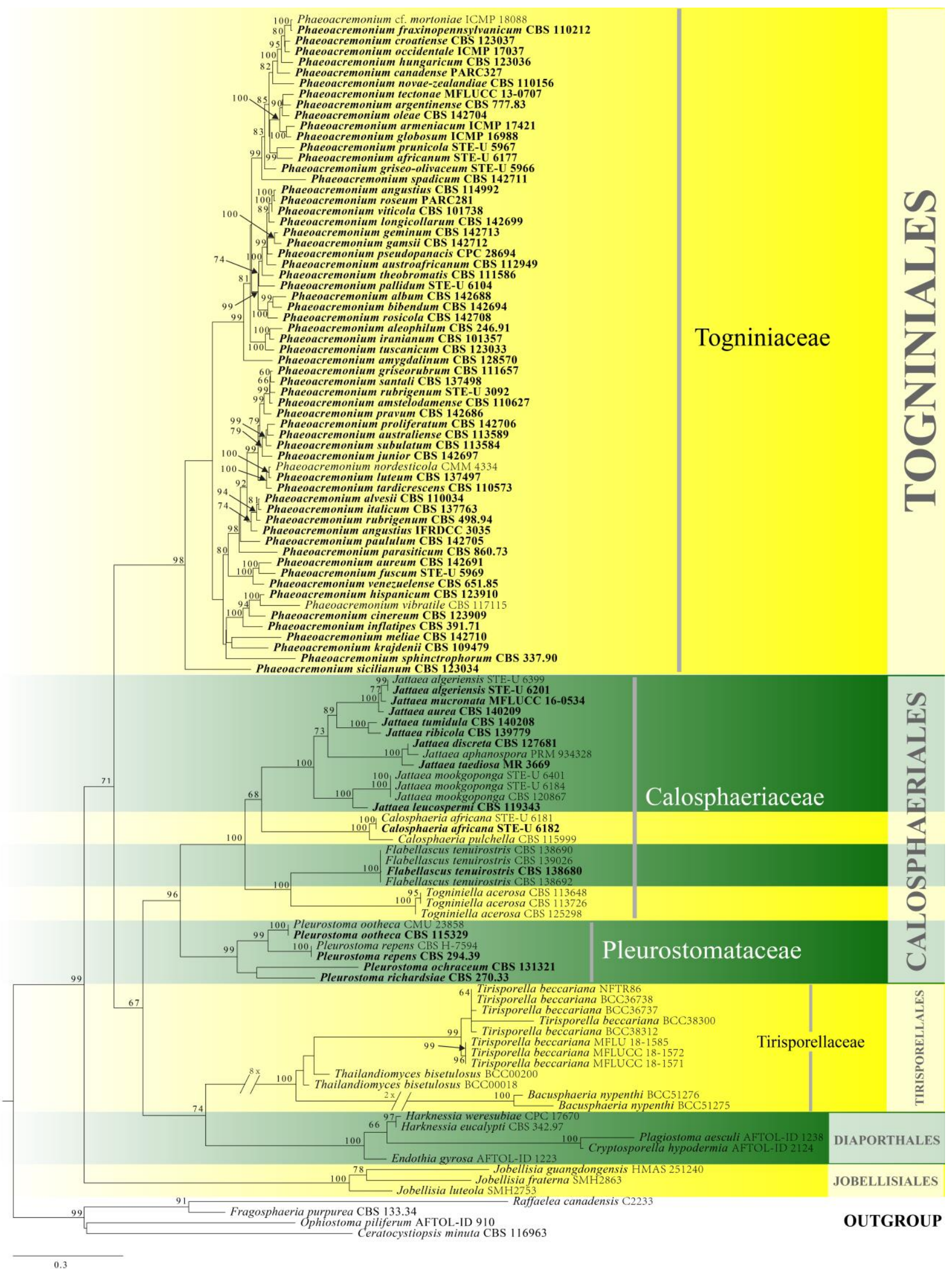

Figure 7 - Phylogram generated from maximum likelihood analysis based on combined tub2, act, ITS and LSU sequence data of Calosphaeriales, Togniniales, Jobellisiales and Tirisporallales. One hundred and fifteen strains are included in the combined analyses which comprised 2296 characters (572 characters for $t u b 2,269$ characters for $a c t, 586$ characters for ITS, 869 characters for LSU) after alignment. Three species of Ophiostomataceae are used as outgroup taxa. Single gene analyses were also carried out and the phylogenies were similar in topology and clade stability. The 
best RAxML tree with a final likelihood value of -29642.219830 is presented. Estimated base frequencies were as follows: $\mathrm{A}=0.222849, \mathrm{C}=0.289953, \mathrm{G}=0.265413, \mathrm{~T}=0.221786$; substitution rates $\mathrm{AC}=1.361161, \mathrm{AG}=3.471108, \mathrm{AT}=1.335451, \mathrm{CG}=1.139165, \mathrm{CT}=$ 4.985065, GT $=1.000000$; gamma distribution shape parameter $\mathrm{a}=1.412987$. Bootstrap support values for ML greater than $60 \%$ are given near the nodes. Ex-type strains are in bold. The newly generated sequences are indicated in blue.

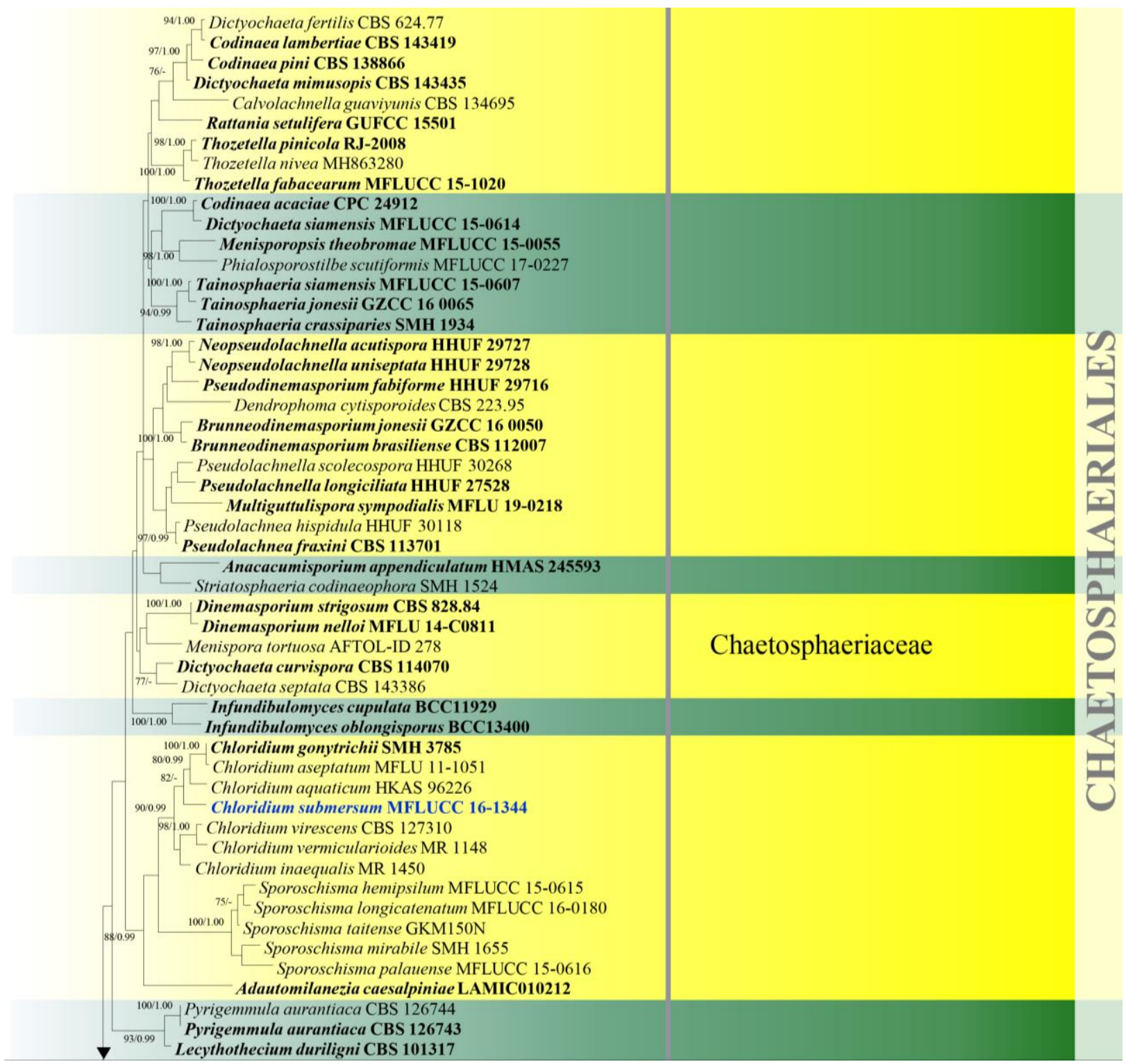

Figure 8 - Phylogram generated from maximum likelihood analysis based on combined LSU and ITS sequence data of Chaetosphaeriales and Tracyllalales taxa. Ninety-six strains are included in the combined analyses which comprised 1695 characters (1081 characters for LSU, 614 characters for ITS) after alignment. Neurospora crassa MUCL 19026 and Gelasinospora tetrasperma CBS 178.33 (Sordariaceae, Sordariales) are used as outgroup taxa. Single gene analyses were carried out and the phylogenies were similar in topology and clade stability. Tree topology of the maximum likelihood analysis is similar to the Bayesian analysis. The best RaxML tree with a final likelihood value of - 23777.689886 is presented. Estimated base frequencies were as follows: $\mathrm{A}=0.231060, \mathrm{C}$ $=0.264793, \mathrm{G}=0.308265, \mathrm{~T}=0.195882 ;$ substitution rates $\mathrm{AC}=1.388486, \mathrm{AG}=1.836207, \mathrm{AT}=$ $1.649563, \mathrm{CG}=0.971659, \mathrm{CT}=6.316962, \mathrm{GT}=1.000000$; gamma distribution shape parameter a $=0.460297$. Bootstrap support values for ML greater than $75 \%$ and Bayesian posterior probabilities greater than 0.95 are given near the nodes. Ex-type strains are in bold. The newly generated sequences are indicated in blue. 


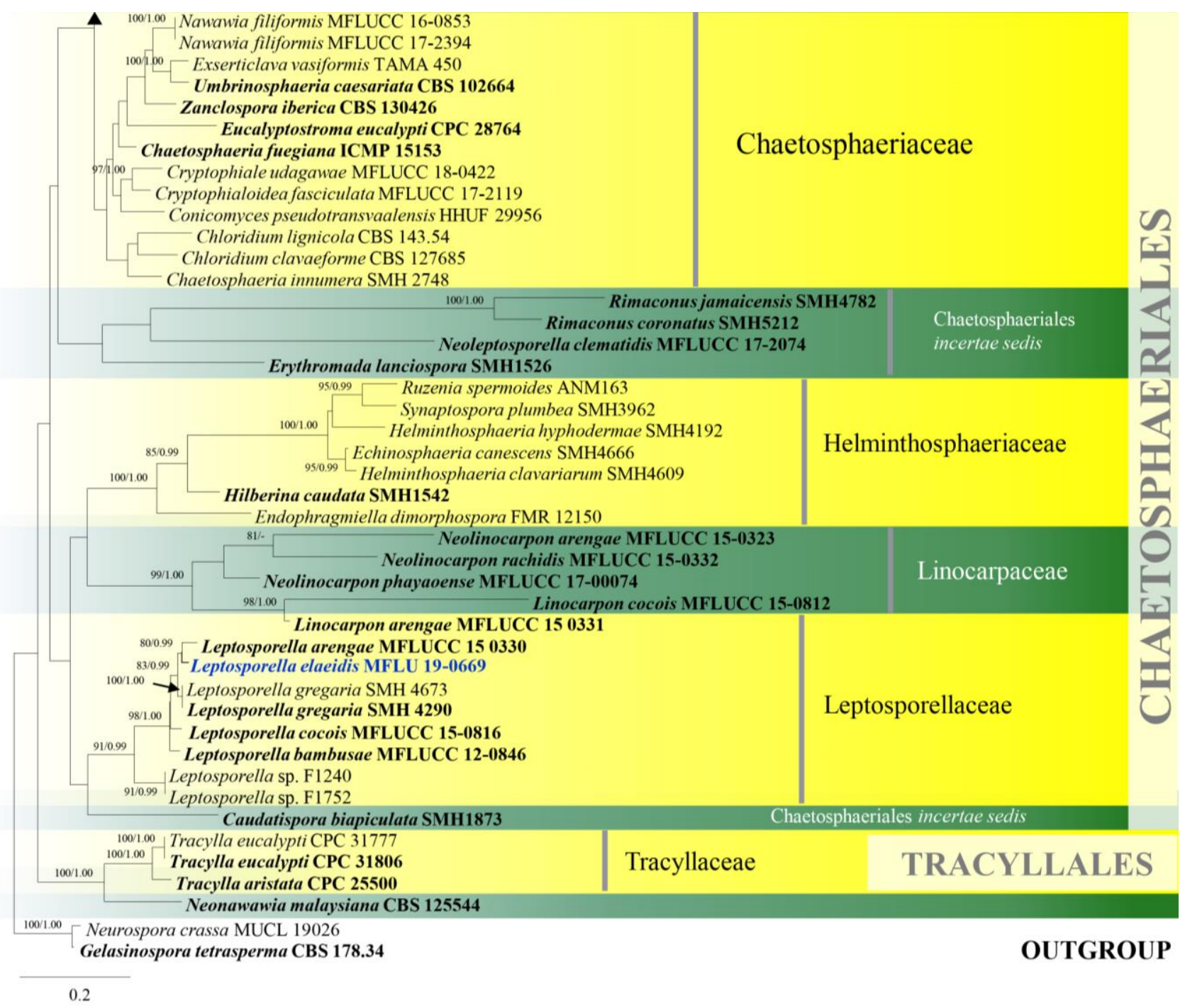

Figure 8 - Continued.

Conioscyphales Réblová \& Seifert, Persoonia 37: 63 (2015)

Conioscyphales comprises the monotypic family Conioscyphaceae with species originating from both terrestrial and freshwater habitats (Réblová et al. 2016c). Conioscyphales is phylogenetically related to Pleurotheciales, Savoryellales and Fuscosporellales. The order was initially introduced based on a multi-gene phylogeny using sequence data from five Conioscypha species (Réblová et al. 2016c). Conioscyphales represents a distinct taxonomic entity which accommodates species with astromatic ascomata, paraphyses, asci bearing J- apical ring and transversely multiseptate ascospores. The conidia undergo schizolytic seccession (Réblová et al. 2016c). The divergence time for Conioscyphales has been estimated as 128.5 MYA (Fig. 2). Currently there is one family and one genus in this order (this paper).

Coronophorales Nannf., Nova Acta R. Soc. Scient. upsal., Ser. 4 8(no. 2): 54 (1932)

$=$ Melanosporales N. Zhang \& M. Blackw., Mycol. Res. 111(5): 531 (2007)

Members of Coronophorales have a worldwide distribution as saprobes on wood (Mugambi \& Huhndorf 2010, Maharachchikumbura et al. 2016b, Nannfeldt 1932). Most species in this order have superficial ascomata, sometimes with a subiculum (Mugambi \& Huhndorf 2010). The quellkörper is a conical structure sometimes present in the centrum of the cupulate or collapsed ascomata and Munk pores are unique structures. These are rings of thickening between cells and are important characters in peridium cells (Huang et al. 2019, Mugambi \& Huhndorf 2010). Coronophorales is a poorly studied group and was considered as synonym of Sordariales or 
Nitschkiaceae (Barr 1990b, Müller \& von Arx 1973, Nannfeldt 1932, 1975, Nannfeldt \& Santesson 1975, Subramanian \& Sekar 1990). Huhndorf et al. (2004a) used LSU sequence data to show that Coronophorales is an independent member and lineage within Hypocreales, Hypocreomycetidae. Multi-gene analyses were used to demonstrate the position of Coronophorales which accommodates Bertiaceae, Ceratostomataceae, Chaetosphaerellaceae, Coronophoraceae, Nitschkiaceae and Scortechiniaceae (Hongsanan et al. 2017, Huang et al. 2019, Hyde et al. 2017a, Maharachchikumbura et al. 2015, Mugambi \& Huhndorf 2010). However, Parasympodiellales clusters as a sister group for Scortechiniaceae in our phylogenetic analysis (Fig. 11). The divergence time for Coronophorales has been estimated as 192 MYA (Fig. 2). Currently there are six families and 46 genera in this order (this paper).

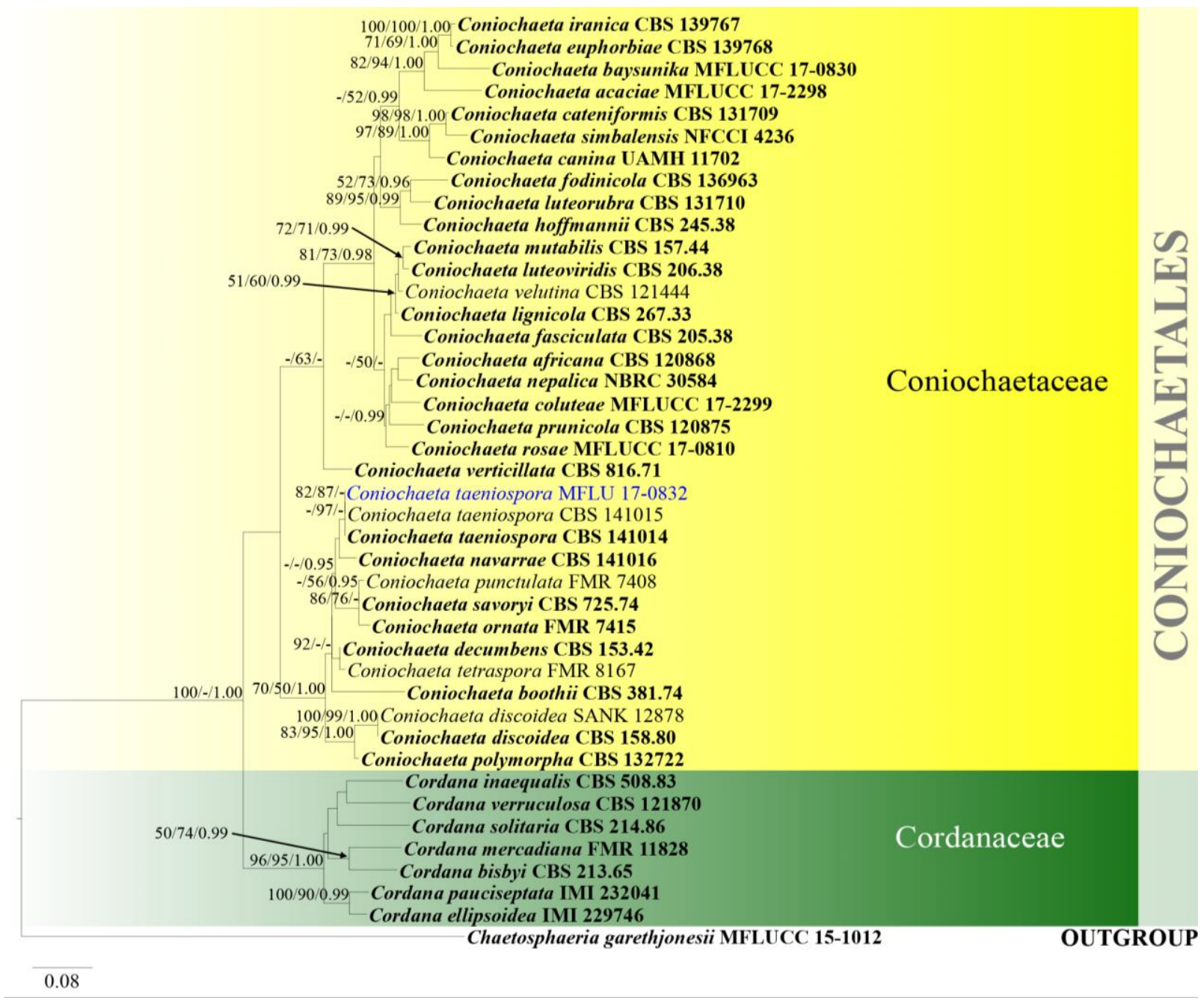

Figure 9 - Phylogram generated from maximum likelihood analysis based on combined LSU and ITS sequence data of Coniochaetales. Forty-two strains are included in the combined analyses which comprised 2640 characters (521 characters for LSU, 567 characters for ITS) after alignment. Chaetosphaeria garethjonesii (MFLUCC 15-1012) (Chaetosphaeriaceae, Chaetosphaeriales) is used as outgroup taxon. Single gene analyses were carried out and the phylogenies were similar in topology and clade stability. Tree topology of the maximum likelihood analysis is similar to the Bayesian analysis. The best RaxML tree with a final likelihood value of - 6488.978861 is presented. Estimated base frequencies were as follows: $\mathrm{A}=0.249647, \mathrm{C}=0.238753, \mathrm{G}=$ $0.279808, \mathrm{~T}=0.231793$; substitution rates $\mathrm{AC}=1.587009, \mathrm{AG}=2.017143, \mathrm{AT}=1.817611, \mathrm{CG}=$ $1.386630, \mathrm{CT}=7.265255, \mathrm{GT}=1.0000$; gamma distribution shape parameter $\mathrm{a}=0.484696$. Bootstrap support values for MP and ML greater than $50 \%$ and Bayesian posterior probabilities greater than 0.9 are given near the nodes. Ex-type strains are in bold. The newly generated sequences are indicated in blue. 


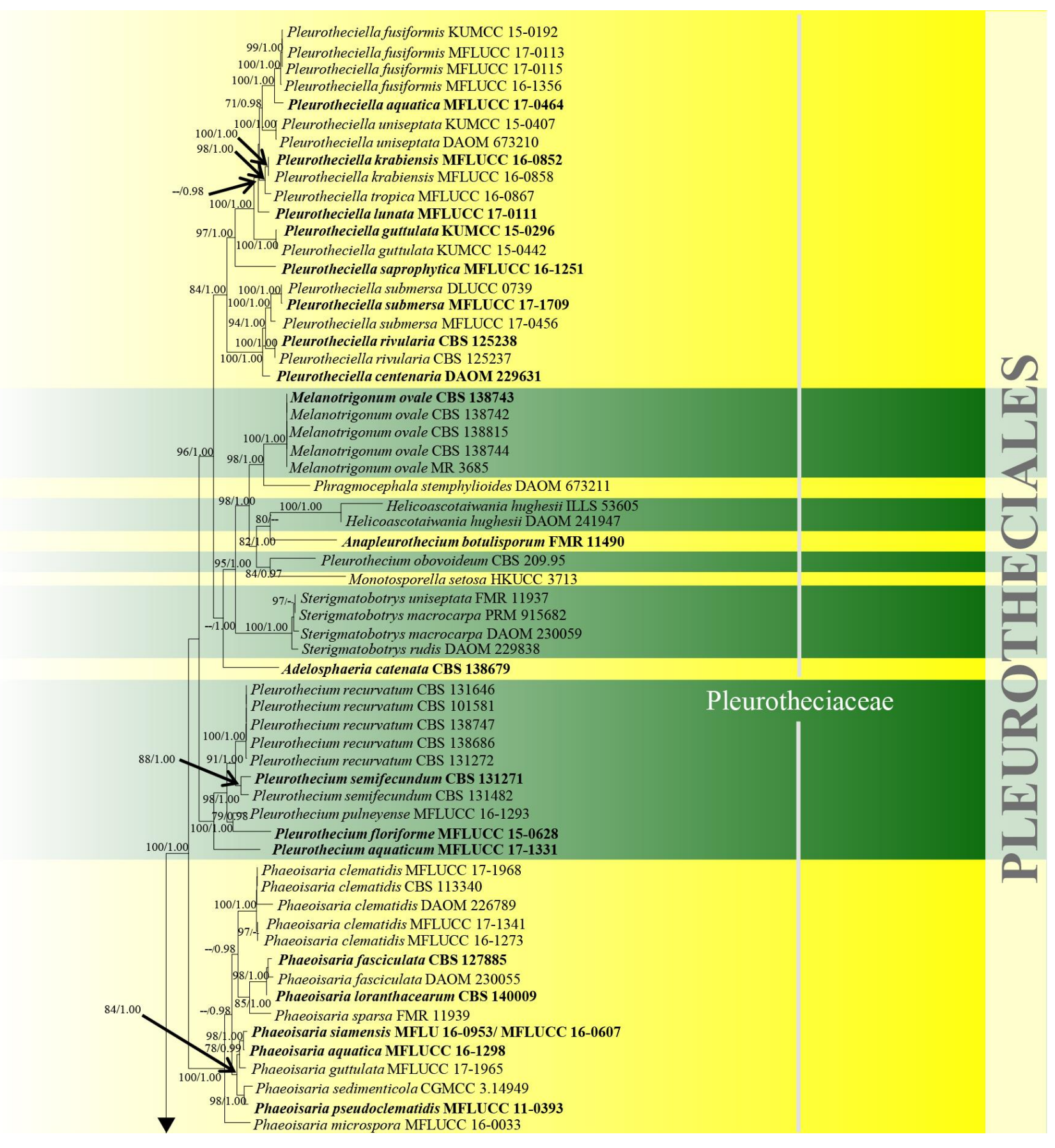

Figure 10 - Phylogram generated from maximum likelihood analysis based on combined LSU, SSU, ITS and rpb2 sequence data of Conioscyphales, Fuscosporellales, Parasympodiellales, Pleurotheciales and Savoryellales. One hundred and twenty-nine strains are included in the combined analyses which comprised 4253 characters (910 characters for LSU, 1499 characters for SSU, 759 characters for ITS and 1085 characters for rpb2) after alignment. Lindra thalassiae (AFTOL-ID 413) and Lulworthia uniseptata (AFTOL-ID 5014) are used as outgroup taxa. Single gene analyses and the phylogenies were similar in topology and clade stability. Tree topology of the maximum likelihood analysis is similar to the Bayesian analysis. The best RaxML tree with a final likelihood value of -50774.805453 is presented. Estimated base frequencies were as follows: $\mathrm{A}=0.233897, \mathrm{C}=0.263834, \mathrm{G}=0.294235, \mathrm{~T}=0.208033$; substitution rates $\mathrm{AC}=1.342378, \mathrm{AG}$ $=2.736022, \mathrm{AT}=1.339928, \mathrm{CG}=0.989078, \mathrm{CT}=6.301203, \mathrm{GT}=1.000000 ;$ gamma distribution shape parameter $\mathrm{a}=0.440908$. Bootstrap support values for ML greater than $70 \%$ and Bayesian posterior probabilities greater than 0.95 are given near the nodes. The tree is rooted with Lindra thalassiae (AFTOL-ID 413) and Lulworthia uniseptata (AFTOL-ID 5014). Type strains are in bold and black. The newly generated sequence is indicated in blue. 


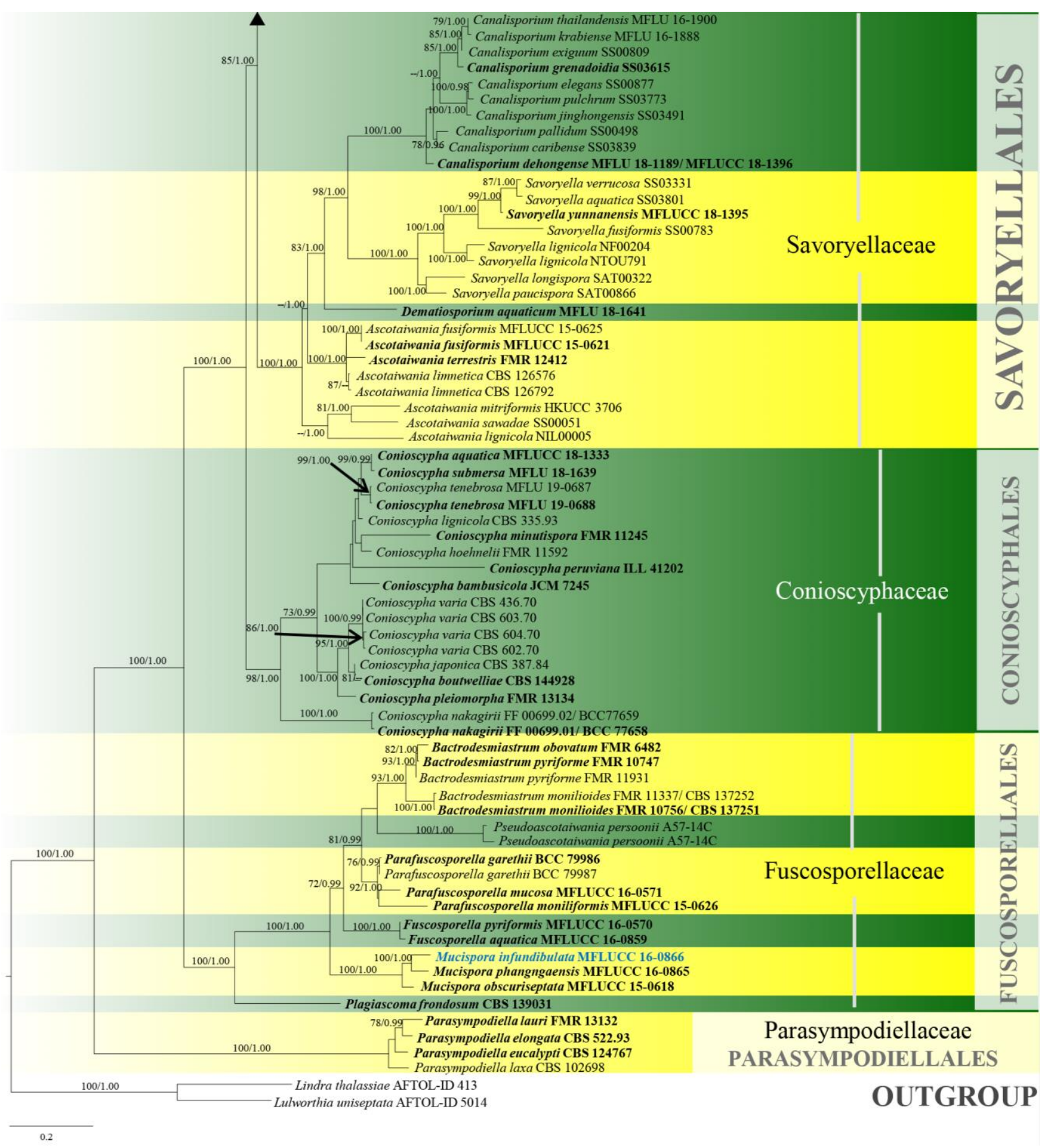

Figure 10 - Continued.

Delonicicolales R.H. Perera, Maharachch. \& K.D. Hyde, Cryptog. Mycol. 38(3): 329 (2017)

Delonicicolales was introduced by Perera et al. (2017) to accommodate Delonicicolaceae which comprises Delonicicola and Liberomyces. The divergence time estimates for the order are 181 (133-234) MYA and 95 (51-157) MYA (Perera et al. 2017). Voglmayr et al. (2019a) introduced a new genus Furfurella to Delonicicolaceae and in the same study, Liberomyces was synonymized under Leptosillia. Voglmayr et al. (2019a) also introduced Leptosilliaceae, which is typified by Leptosillia, while rejecting Delonicicolales based on phylogenetic analyses with several gene combinations (ITS-LSU and SSU-ITS-LSU-rpb1-rpb2-tef1-tub2). In our study, based on a LSU-ITS-rpb2-tub2 matrix Delonicicolales forms a highly supported clade (100\% ML) comprising Delonicicolaceae and Leptosilliaceae, basal to Amphisphaeriales and Xylariales (Fig. 4). However, 
in another combined gene analysis of LSU-SSU-tef1-rpb2, Delonicicolales forms an internal clade in Xylariales (Fig. 1). The divergence time estimates in this study are a stem age of 165 Mya which supports the order establishment by Perera et al. (2017). Currently there are two families and three genera in this order (this paper).

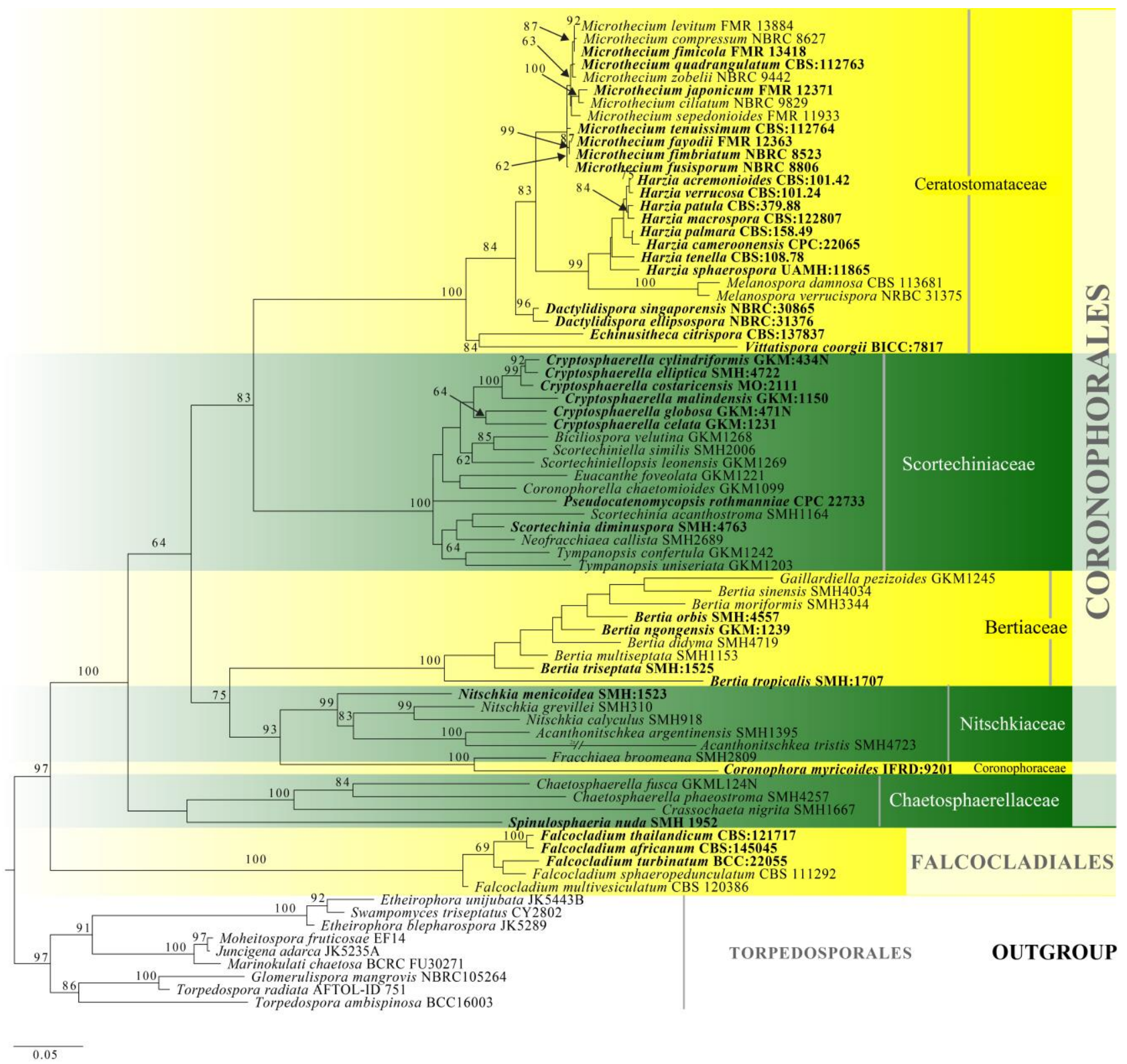

Figure 11 - Phylogram generated from maximum likelihood analysis based on combined LSU, tef1 and ITS sequence data for Coronophorales. Related sequences are referred to Hongsanan et al. (2017). Seventy-nine strains are included in the combined analyses which comprised 2211 characters (1044 characters for LSU, 627 characters for tefl, 540 characters for ITS) after alignment. Members of Torpedosporales are used as outgroup taxa. Single gene analyses were carried out and the phylogenies were similar in topology and clade stability. The best RaxML tree with a final likelihood value of -23354.525618 is presented. Estimated base frequencies were as follows: $\mathrm{A}=0.228019, \mathrm{C}=0.288494, \mathrm{G}=0.281955, \mathrm{~T}=0.201533$; substitution rates $\mathrm{AC}=$ $1.194725, \mathrm{AG}=2.787601, \mathrm{AT}=1.703067, \mathrm{CG}=0.955075, \mathrm{CT}=3.781057, \mathrm{GT}=1.000000$; gamma distribution shape parameter $\mathrm{a}=0.736138$. Bootstrap support values for ML greater than $50 \%$ are given near the nodes. Ex-type strains are in bold. The newly generated sequences are indicated in blue. 


\begin{tabular}{|c|c|}
\hline 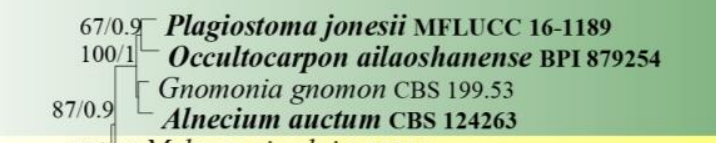 & Gnomoniaceae \\
\hline $\begin{array}{l}\text { 85/0.92 Melanconis alni AR3748 } \\
1004 \text { Melanconis italica MFLUCC 16-1199 } \\
99 / 1 \mathrm{Melanconis} \text { stilbostoma AR3501 }\end{array}$ & Melanconidaceae \\
\hline $\begin{array}{l}\text { 100/L Apiosporopsis carpinea } \text { CBS } 771.79 \\
96 / 0.9 \quad \text { Apiosporopsis sp 11Af2 } 1\end{array}$ & Apiosporopsidaceae \\
\hline 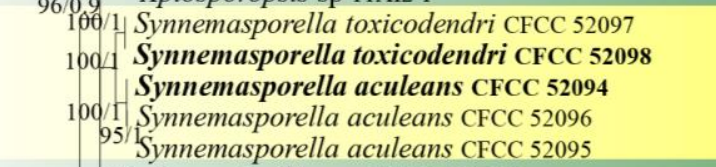 & Synnemasporellaceae \\
\hline $\begin{array}{l}\text { 93/0.99 Juglanconis oblonga MAFF } 410216 \\
64 \text { Juglanconis pterocaryae MAFF } 410079 \\
\text { Juglanconis juglandina AR } 3876\end{array}$ & Juglanconidaceae \\
\hline $\begin{array}{l}\text { 53/-- Immersiporthe knoxdaviesiana CMW37314 } \\
\text { 66/9.9 Cryphonectria parasitica ATCC } 38755 \\
78 / 4 \text { Cryptometrion aestuescens CMW18790 } \\
62 \text { C. Aurapex penicillata CMW10032 }\end{array}$ & Cryphonectriaceae \\
\hline $\begin{array}{l}\text { Coniella koreana CBS 143.97 } \\
\text { Coniella vitis MFLUCC 18-0094 } \\
84009 \text { Coniella vitis MFLUCC 16-1399 } \\
\text { Coniella africana CBS 114133 } \\
\text { Coniella pseudokoreana MFLUCC 12-0427 } \\
\text { Coniella tibouchinae CPC 18511 }\end{array}$ & Schizoparmaceae \\
\hline 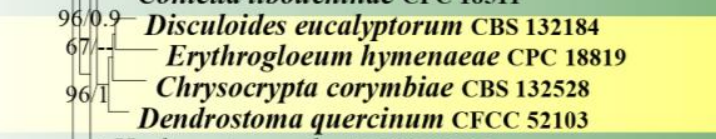 & Erythrogloeaceae \\
\hline $\begin{array}{l}\text { 77- Harknessia encalypti CBS } 342.97 \\
100 / 1-\text { Harknesia molokaiensis CBS } 114877\end{array}$ & Harknessiaceae \\
\hline $\begin{array}{l}\text { Dwiroopa lythri AR3383 } \\
\text { 92/-- Pseudomelanconis caryae CFCC } 52111 \\
\text { 100/1 Pseudomelanconis caryae CFCC } 52112 \\
\text { Pseudomelanconis caryae CFCC } 52113 \\
\text { 100/1 Pseudomelanconis caryae CFCC } 52110\end{array}$ & Pseudomelanconidaceae \\
\hline $\begin{array}{c}\text { 100/1 Diaporthostoma machili CFCC } 52101 \\
\text { \$3/1 } \\
\text { Diaporthostoma machili CFCC } 52100\end{array}$ & Diaporthostomataceae \\
\hline $\begin{array}{c}\text { 100/1 Diaporthosporella cercidicola } \text { CFCC } 51994 \\
\text { 73/--- Diaporthosporella cercidicola } \text { CFCC } 51996 \\
\text { Diaporthosporella cercidicola } \text { CFCC } 51995\end{array}$ & Diaporthosporellaceae \\
\hline 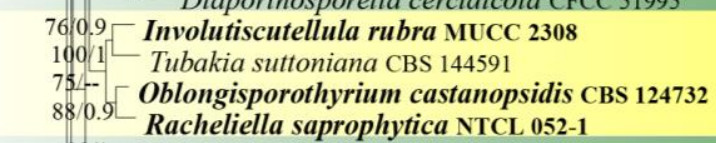 & Tubakiaceae \\
\hline 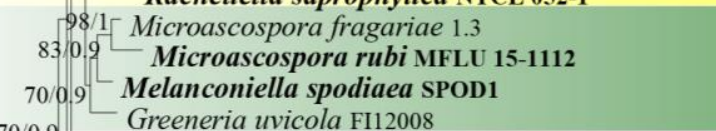 & Melanconiellaceae \\
\hline Diaporthella corylina CBS 121124 & \\
\hline $\begin{array}{c}100 / 1 \text { Auratiopycnidiella tristaniopsis CBS } 132180 \\
\text { Auratiopycnidiella tristaniopsis CPC } 16371\end{array}$ & Auratiopycnidiellaceae \\
\hline$\sqrt{10}\left[\begin{array}{l}\text { Pseudoplagiostoma corymbiae CPC } 19287 \\
\text { Pseudoplagiostoma eucalypti CPC } 14161\end{array}\right.$ & Pseudoplagiostomataceae \\
\hline
\end{tabular}

Figure 12 - Phylogram generated from maximum likelihood analysis based on combined LSU, ITS, rpb2 and tef1 sequence data of Diaporthales. One hundred and fifteen strains are included in the combined analyses which comprised 2890 characters (892 characters for LSU, 526 characters for ITS, 1062 characters for $r p b 2,407$ characters for tefl) after alignment. Leotia lubrica (AFTOL ID 1) is used as outgroup taxon. Single gene analyses were carried out and the phylogenies were similar in topology and clade stability. Tree topology of the maximum likelihood analysis is similar to the Bayesian analysis. The best RaxML tree with a final likelihood value of -41459.517722 is presented. Estimated base frequencies were as follows: $\mathrm{A}=0.250714, \mathrm{C}=0.246950, \mathrm{G}=$ $0.282507, \mathrm{~T}=0.219829$; substitution rates $\mathrm{AC}=1.688056, \mathrm{AG}=2.747632, \mathrm{AT}=1.764840, \mathrm{CG}=$ $1.180905, \mathrm{CT}=6.854636, \mathrm{GT}=1.000000$; gamma distribution shape parameter $\mathrm{a}=0.339516$. Bootstrap support values for ML greater than $50 \%$ and Bayesian posterior probabilities greater than 0.90 are given near the nodes. Ex-type strains are in bold. The newly generated sequences are indicated in blue. 


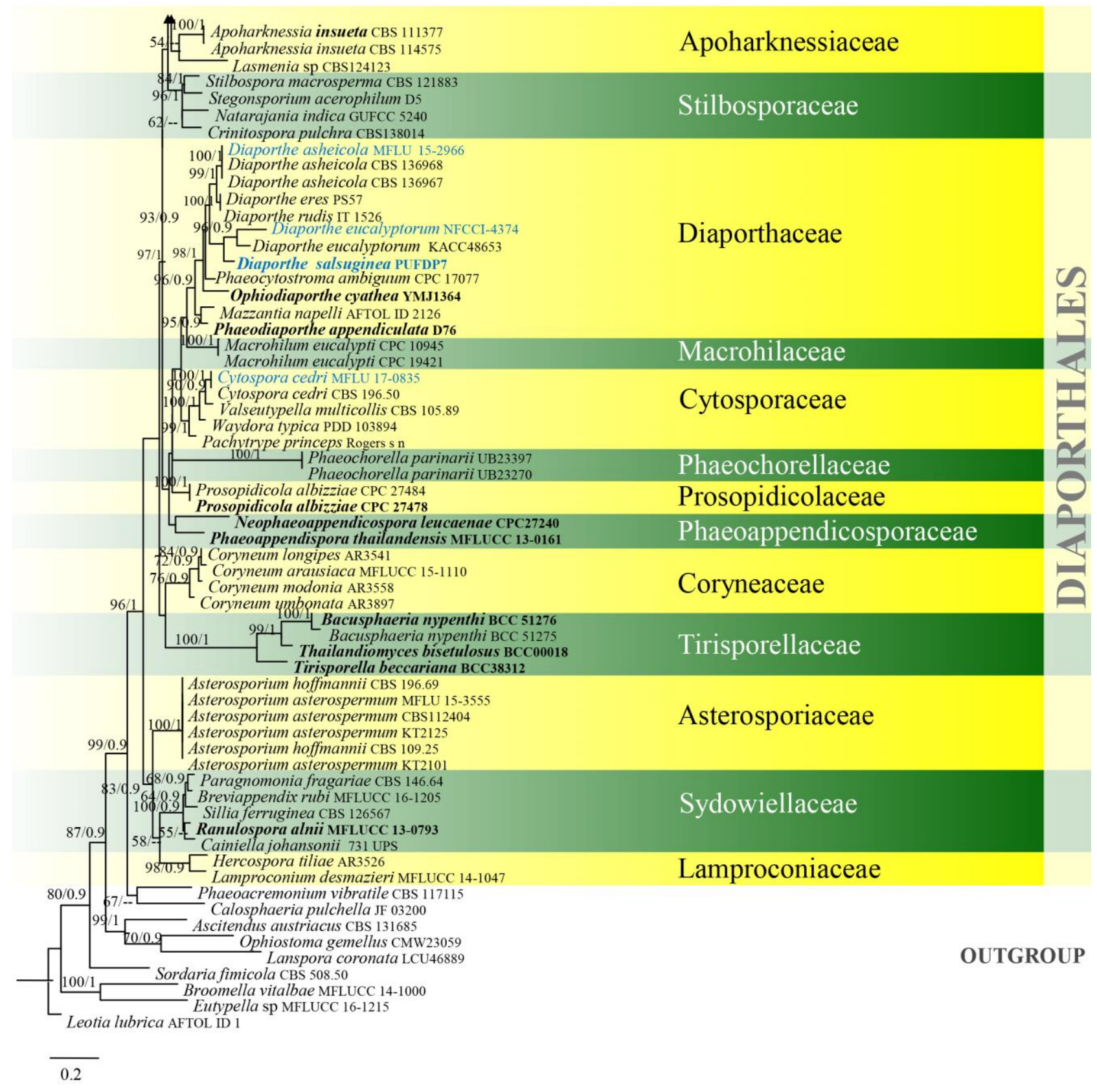

Figure 12 - Continued.

Diaporthales Nannf., Nova Acta R. Soc. Scient. upsal., Ser. 4 8(no. 2): 53 (1932)

The order comprises terrestrial or aquatic taxa on plants, animals or in soil, which are saprobes, endophytes, and pathogens (Senanayake et al. 2017a, 2018). This order has been extensively revisited and new information on its taxonomy, morphology, ecology, mode of life, and biotechnological potential have been reported (Alvarez et al. 2016, Senanayake et al. 2017a, 2018, Braun et al. 2018, Carvalho et al. 2018, Fan et al. 2018, Pádua et al. 2019). This order is characterized by sexual morph with solitary or aggregated perithecia sometimes with long papilla, 2-32-spored, unitunicate asci having a conspicuous refractive ring and the asexual morph is generally coelomycetous, although rarely hyphomycetous (Rossman et al. 2007, Senanayake et al. 2018). Several research publications suggested that combined LSU, ITS, rpb2 and tef1 sequence data provides the best resolution for the order. However, SSU, calM, tub2 and act have been used in some cases to resolve the inter-generic taxonomic complications. The divergence time for Diaporthales has been estimated as 180 MYA (Fig. 2). Currently, there are 30 families and 181 genera in this order (this paper). 


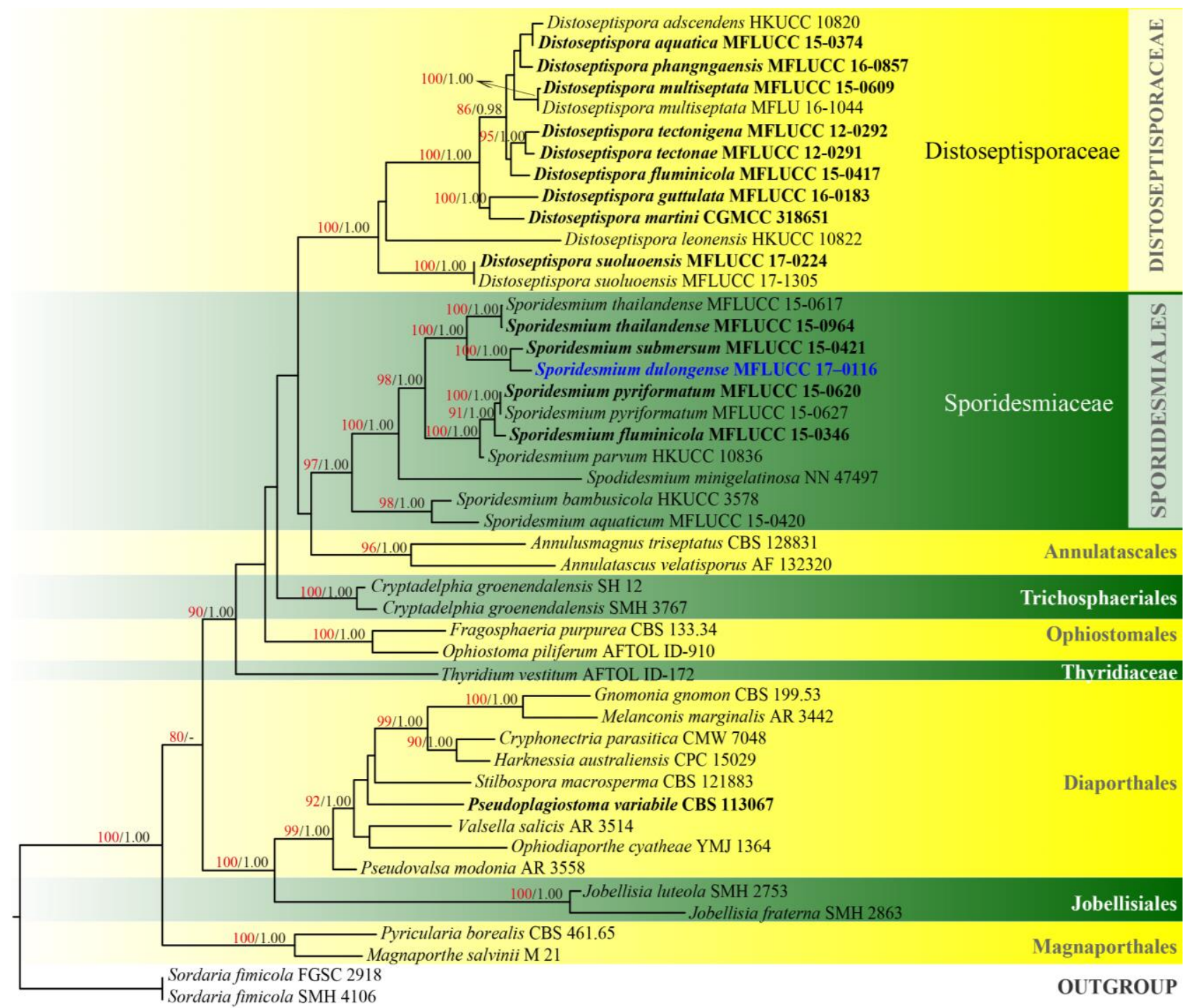

0.06

Figure 13 - Phylogram generated from maximum likelihood analysis based on combined ITS, LSU, rpb2 and tefl sequence data of Distoseptisporales and Sporidesmiales. Forty-six strains are included in the combined analyses which comprised 3153 characters (789 characters for LSU, 546 characters for ITS, 1038 characters for $r p b 2,779$ characters for tefl) after alignment. Single gene analyses were carried out and the phylogenies were similar in topology and clade stability. Tree topology of the maximum likelihood analysis is similar to the Bayesian analysis. The best RaxML tree with a final likelihood value of -22582.382236 is presented. Estimated base frequencies were as follows: $\mathrm{A}=0.236961, \mathrm{C}=0.261709, \mathrm{G}=0.291323, \mathrm{~T}=0.210007$; substitution rates $\mathrm{AC}=$ 1.206796, $\mathrm{AG}=2.260744, \mathrm{AT}=1.272906, \mathrm{CG}=1.049687, \mathrm{CT}=6.479176, \mathrm{GT}=1.000000$; gamma distribution shape parameter $\mathrm{a}=0.651156$. Bootstrap support values for ML greater than $75 \%$ and Bayesian posterior probabilities greater than 0.95 are given near the nodes. The tree is rooted with Sordaria fimicola (FGSC 2918 and SMH 4106). Ex-type strains are in bold. The newly generated sequences are indicated in blue.

Distoseptisporales Z.L. Luo, K.D. Hyde \& H.Y. Su, Fungal Divers. 99: 482 (2019)

The monotypic order Distoseptisporales is placed in the class Sordariomycetes, subclass Diaporthomycetidae and comprises a single family Distoseptisporaceae and Aquapteridospora (Distoseptisporales genera incertae sedis). Distoseptisporaceae was established by Su et al. (2016b) with a single genus Distoseptispora based on morphology and phylogeny. Yang et al. (2015) 
introduced Aquapteridospora and was placed as Diaporthomycetidae genera incertae sedis. Luo et al. (2019) raised Distoseptisporaceae to Distoseptisporales based on the morphology and phylogenetic analysis of combined LSU, SSU, rpb2 and tef1 sequence data. The divergence time for Distoseptisporales has been estimated as 102 MYA (Fig. 2), which falls in the range of family status. The status may need revision following further study. Currently there is one family and one genus in this order (this paper).

Falcocladiales R.H. Perera, Maharachch., Somrith., Suetrong \& K.D. Hyde, Fungal Divers. 72: 218 (2015)

Falcocladiales was introduced to accommodate Falcocladiaceae by Maharachchikumbura et al. (2015). Falcocladiaceae comprises a single genus Falcocladium (Jones et al. 2014). Falcocladiales grouped sister to Coronophorales and Parasympodiellales with low statistical support (63\% ML) in our phylogenetic analysis (Fig. 1). The divergence time for Falcocladiales has been estimated as 192 MYA. Currently there is one family with one genus in this order (this paper).

Fuscosporellales J. Yang, J. Bhat \& K.D. Hyde, Cryptog. Mycol. 37(4): 457 (2016)

The order has been established in Hypocreomycetidae based on combined SSU, LSU and rpb2 phylogenetic analyses and comprises one family, Fuscosporellaceae (Yang et al. 2016b). Six genera, namely, Fuscosporella, Parafuscosporella, Mucispora, Bactrodesmiastrum, Plagiascoma and Pseudoascotaiwania are accommodated within Fuscosporellaceae. Earlier, Bactrodesmiastrum and Plagiascoma were placed in Sordariomycetes genera incertae sedis (Réblová et al. 2016c). Yang et al. (2016b) showed that these two genera clustered with three newly introduced genera, Fuscosporella, Parafuscosporella and Mucispora. The species Ascotaiwania persoonii also grouped with the five genera, away from the type species of Ascotaiwania. This species was therefore synonymized under Pseudoascotaiwania persoonia (Yang et al. 2016b). The six genera form a monophyletic clade represented by Fuscosporellales, which is sister to Conioscyphales, Pleurotheciales and Savoryellales (Yang et al. 2016b). The divergence time for Fuscosporellales has been estimated as 190 MYA (Fig. 2). Currently there is one family and six genera in this order (this paper).

Glomerellales Chadef., Stud. Mycol. 68: 170 (2011)

The ordinal name Glomerellales including Colletotrichum (= Glomerella) and three other genera in a non-ranked group "Eu-Glomérellales" was introduced by Chadefaud (1960), but was not validly published. Réblová et al. (2011) proposed Glomerellales to accommodate the families Australiascaceae, Glomerellaceae and Reticulascaceae based on morphology, as well as analyses of ITS, LSU, SSU and rpb2 sequence data. Maharachchikumbura et al. (2016b) established the taxonomic position of Plectosphaerellaceae in Glomerellales. Tibpromma et al. (2018) introduced a monotypic family, Malaysiascaceae to this order based on morphology and phylogeny. The divergence time for Malaysiascaceae has been estimated as 44 MYA, which falls in the genus status (Fig. 14). Therefore, the status of Malaysiascaceae may need revision following further study. The divergence time for Glomerellales has been estimated as 216 MYA (Fig. 2). Currently there are five families and 32 genera in this order (this paper).

Hypocreales Lindau, Nat. Pflanzenfam., Teil. I (Leipzig) 1(1): 343 (1897)

According to Wijayawardene et al. (2018a) Hypocreales comprised nine families. Maharachchikumbura et al. (2016b) listed 223 genera belonging to families of Hypocreales based on the literature and phylogenetic analysis. Later, two new genera were introduced to Bionectriaceae: Bullanockia, and Paracylindrocarpon, based on DNA evidence and morphological data (Crous et al. 2016a, b). Corinectria, Pleiocarpon, Varicosporella and Xenoleptographium were also added in Nectriacae (González \& Chaverri 2017, Aiello et al. 2017, Lechat \& Fournier 2015, Crous et al. 2015d). Cryptoniesslia was introduced from previous research to Niessliaceae by Scheuer (1993) and Crous et al. (2016b) added Mycophilomyces to Clavicipitaceae. 
Blackwellomyces was added to Cordycipitaceae by Kepler et al. (2017). Maharachchikumbura et al. (2016b) listed seven genera in Stachybotryaceae. Lombard et al. (2016) revisited the family and 36 genera were accepted in Stachybotryaceae, including 22 new genera which based on multigene phylogeny and morphological data. Cylindriaceae, Sarocladiaceae and Xenodactylariaceae were added to the order by Crous et al. (2018a, b). However, in our phylogentic anlysis, Cylindriaceae groups within Amphisphaeriales (Xylariomycetidae), sister to Clypeophysalosporaceae and Sporocadaceae (Figs 1, 2). Xenodactylariaceae does not appear to be related to Hypocreales as it forms a separate lineage from the order, and basal to Torpedosporales (Figs 1, 2). Flammocladiellaceae was introduced to accommodate the monotypic genus Flammocladiella by Crous et al. (2015b). It grouped as sister clade to Clavicipitaceae with low statistical support (Crous et al. 2015b), and similar results were obtained by Maharachchikumbura et al. (2016b). Flammocladiellaceae grouped within Clavicipitaceae (Hongsanan et al. 2017, Sun et al. 2017), hence it was not accepted as a family. Hongsanan et al. (2017) treated Flammocladiellaceae under Clavicipitaceae based on phylogenetic data. However, Lechat \& Fournier (2018a) observed that Flammocladiellaceae is affiliated to Bionectriaceae. In our phylogenetic analysis, Flammocladiellaceae forms a separate clade distant from Clavicipitaceae with low statistical support (Figs 1, 15). Hence, we maintain Flammocladiellaceae as a separate family in Hypocreales following Crous et al. (2015b). Here we accept 14 families in Hypocreales, namely: Bionectriaceae, Calcarisporiaceae, Clavicipitaceae, Cocoonihabitaceae, Cordycipitaceae, Flammocladiellaceae, Hypocreaceae, Myrotheciomycetaceae, Nectriaceae, Niessliaceae, Ophiocordycipitaceae, Sarocladiaceae, Stachybotryaceae, and Tilachlidiaceae, based on molecular evidence. The divergence time for Hypocreales has been estimated as 229 MYA (Fig. 2). Currently there are 303 genera in this order (this paper).

Jobellisiales M.J. D'souza \& K.D. Hyde, Fungal Divers. 72: 219 (2015)

Jobellisiales was established by Maharachchikumbura et al. (2015) and comprises a single family Jobellisiaceae based on perithecial, yellow, orange or brown ascomata and cylindrical asci with brown ascospores (Ranghoo et al. 2001, Liu et al. 2012, Maharachchikumbura et al. 2016b). Most members in Jobellisiales have been found in America in terrestrial and freshwater habitats and no asexual morph is known (Ranghoo et al. 2001, Liu et al. 2012, Maharachchikumbura et al. 2016b). Jobellisiales species are similar to some members of Diaporthales in having brown, 1septate ascospores (Maharachchikumbura et al. 2015, Senanayake et al. 2017a). Phylogenetically, Jobellisiales was a sister clade of Calosphaeriaceae (Maharachchikumbura et al. 2015, 2016b, Hongsanan et al. 2017), and Hyde et al. (2017a) proposed that Jobellisiales is closely related to Togniniaceae. Hongsanan et al. (2017) and Wijayawardene et al. (2018a) considered Jobellisiales to be synonym of Calosphaeriales. However, Jobellisiales is an unstable clade, and we accept it as an independent order and related to Calosphaeriales and Diaporthales (Fig. 12). The divergence time for Jobellisiales is estimated as 138 MYA (Fig. 2). Currently there is one family with one genus in this order (this paper).

Koralionastetales Kohlm., Volkm.-Kohlm., J. Campb. \& Inderb., Mycol. Res. 113(3): 377 (2009)

Koralionastetales was introduced to accommodate the genera Pontogenia and Koralionastes (Campbell et al. 2009). Pontogenia was initially classified as Sordariomycetes, genera incertae sedis, while Koralionastes as Ascomycota, genera incertae sedis (Eriksson 2006). The order was established based on the monophyletic clade formed by three Koralionastes species and one Pontogeneia species in the LSU and SSU-based phylogeny (Campbell et al. 2009). Species of Koralionastetales are distinct from taxa belonging to other orders in Sordariomycetes by the formation of antheridia on their germinating ascospores (Zhang et al. 2006). Furthermore, all Koralionastetales species are restricted to marine habitats, in association with corals, sponges and algae (Campbell et al. 2009, Jones et al. 2019). The divergence time for Koralionastetales is estimated as 210.5 MYA (Fig. 2). Currently there is one family and two genera in this order (this paper). 


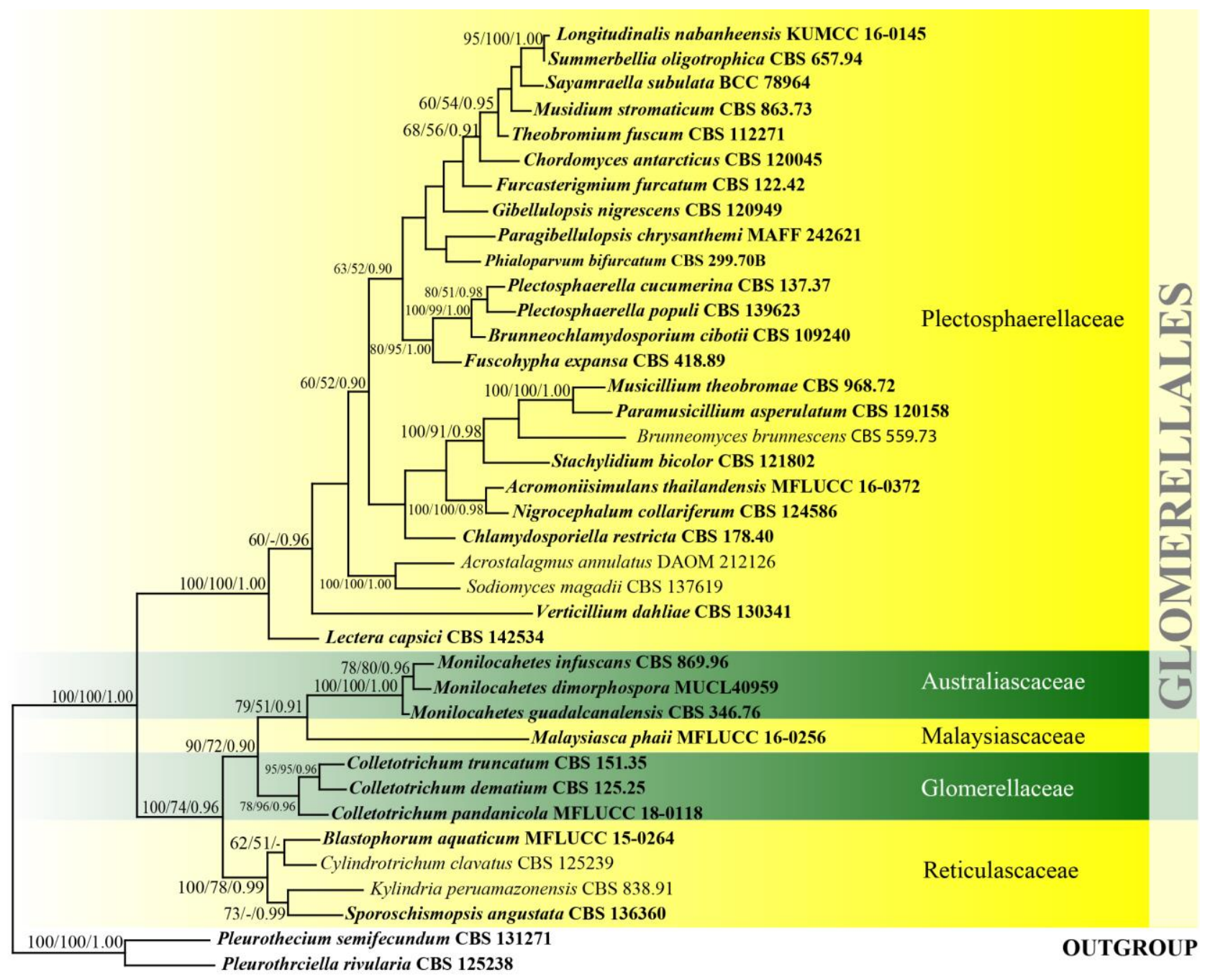

$\overline{10}$

Figure 14 - One of the 100 most phylogenetic tree generated by maximum parsimony analysis of combined LSU, ITS and tefl sequence data of species in Glomerellales. Thirty-eight strains are included in the analyses, which comprise 2162 characters including gaps (800 characters for LSU, 558 characters for ITS, 793 characters for tef1) after alignment. Pleurothecium semifecundum (CBS 131271) and Pleurotheciella rivularia (CBS 125238) (Pleurotheciaceae, Pleurotheciales) are used as outgroup taxa and the tree is rooted with. Single gene analyses were carried out and the phylogenies were similar in topology and clade stability. Tree topology of the maximum parsimony analysis is similar to the maximum likelihood and Bayesian analysis. The maximum parsimonious dataset consisted of 1189 constant, 630 parsimony-informative and 343 parsimony-uninformative characters. The parsimony analysis of the data matrix resulted in the maximum often equally most parsimonious trees with a length of 2672 steps $(\mathrm{CI}=0.522, \mathrm{RI}=0.666, \mathrm{RC}=0.348, \mathrm{HI}=0.478)$ in the first tree. Bootstrap support values for MP and ML greater than $50 \%$ and Bayesian posterior probabilities greater than 0.90 are given near the nodes. Ex-type strains are in bold. The newly generated sequences are indicated in blue.

Lulworthiales Kohlm., Spatafora \& Volkm.-Kohlm., Mycologia 92(3): 456 (2000)

Lulworthiales was introduced based on morphology and LSU and SSU phylogeny to accommodate the genera Lulworthia and Lindra, which were initially accommodated in Halosphaeriales (Kohlmeyer et al. 2000). All taxa referred to this order are marine aquatic fungi. The order is accommodated in Lulworthiomycetidae, where it forms a strongly-supported clade with Koralionastetales (Maharachchikumbura et al. 2016b) with a divergent age of 289 MYA (Hongsanan et al. 2017). Lulworthia is polyphyletic, as observed from the combined LSU, SSU and 
ITS phylogeny (Fig. 16). This is in accordance with other studies which also reported the polyphyly of Lulworthia (Jones et al. 2008, 2009, 2019, Abdel-Wahab et al. 2010, Azevedo et al. 2017). Spathulosporaceae, typified by Spathulospora is also reported to group in Lulworthiales (Jones et al. 2019). Spathulosporaceae was initially placed in Spathulosporales based on morphology (Kohlmeyer 1973), but molecular data of some Spathulosporaceae species have shown that the taxa have a higher affinity to Lulworthiales, even though the type species of Spathulosporaceae was not included, since it lacks sequence data (Inderbitzin et al. 2004, Campbell et al. 2005, Jones et al. 2009). Currently there is one family (the placement of Spathulosporaceae is not confirmed in Lulworthiales) and 15 genera in this order with both asexual and sexual morphs (this paper). Further studies are required to resolve the higher order rank of the marine algicolous parasites Spathulospora.

Magnaporthales Thongk., Vijaykr. \& K.D. Hyde, Fungal Divers. 34: 168 (2009)

Maharachchikumbura et al. (2016b) listed Magnaporthaceae, Ophioceraceae, and Pyriculariaceae in Magnaporthales based on the literature and phylogenetic analysis. Pseudohalonectriaceae was introduced as a novel family in Magnaporthales to accommodate Pseudohalonectria based on phylogenetic and molecular dating evidence (Hongsanan et al. 2017). The stem age of Pseudohalonectria falls within the range of family status (95 MYA) and has high support in the phylogenetic and MCC trees. Silva et al. (2019) introduced a new genus Bifusisporella, in Magnaporthaceae, to accommodate an endophytic fungus in Brazil. Hence, Magnaporthales comprises five families, Ceratosphaeriaceae, Magnaporthaceae, Ophioceraceae, Pseudohalonectriaceae, and Pyriculariaceae. The divergence time for Magnaporthales is estimated as 190 MYA (Fig. 2). Currently there are 36 genera in this order (this paper).

Meliolales Gäum. ex D. Hawksw. \& O.E. Erikss., Syst. Ascom. 5(1): 180 (1986)

Meliolales was introduced by Hawksworth \& Eriksson (1986) accommodating a single family Meliolaceae. Hosagoudar (2003) introduced Armatellaceae as a new family in this order based on the morphology. Lumbsch \& Huhndorf (2010) placed Meliolales in the class Sordariomycetes. This was confirmed and followed by Hongsanan et al. $(2015,2017)$ and Maharachchikumbura et al. (2016b). Hongsanan et al. (2015) provided a recent monograph that reappraised the genera of Meliolales. Zeng et al. (2017) provided a checklist for identifying Meliolales species, including current names of host plants with their corresponding Meliolales species. Currently, Meliolales comprises two families, viz. Armatellaceae and Meliolaceae, but sequence data is only available for Meliolaceae. The phylogenetic relationship of Meliolaceae in the current study is different from Hongsanan et al. (2015) and Zeng et al. (2018) with regards to the position of Irenopsis, which is sister to the main Meliola clade (Fig. 19). All recent studies indicated that Meliola is polyphyletic and the clade including some Meliola species clusters in the Appendiculella and Asteridiella lineages with low bootstrap support. The divergence time for Meliolales is estimated as 219 MYA (Fig. 2). Currently there are two families and nine genera in this order (this paper).

Microascales Luttr. ex Benny \& R.K. Benj., Mycotaxon 12(1): 40 (1980)

Microascales comprises Ceratocystidaceae, Chadefaudiellaceae, Gondwanamycetaceae, Halosphaeriaceae, Microascaceae and Graphiaceae (Réblová et al. 2011, Maharachchikumbura et al. 2016b). In an outline of Ascomycota by Wijayawardene et al. (2018a), 99 genera have been accepted under Microascales, distributed in six families, but only 89 have molecular data (www.ncbi.nlm.nih.gov/Taxonomy/). A new genus Bretziella was introduced in Ceratocystidaceae by de Beer et al. (2017) to accommodate B. fagacearum. Microascales may be paraphyletic, due to the inclusion of Halosphaeriales (Zhang et al. 2006, Hibbett et al. 2007). However, in this study, Microascales formed a monophyletic clade and this agrees with Maharachchikumbura et al. (2015, 2016b) and Hongsanan et al. (2017). The divergence time for Microascales is estimated as 216 MYA (Fig. 2). Currently there are seven families and 110 genera in this order (this paper). 


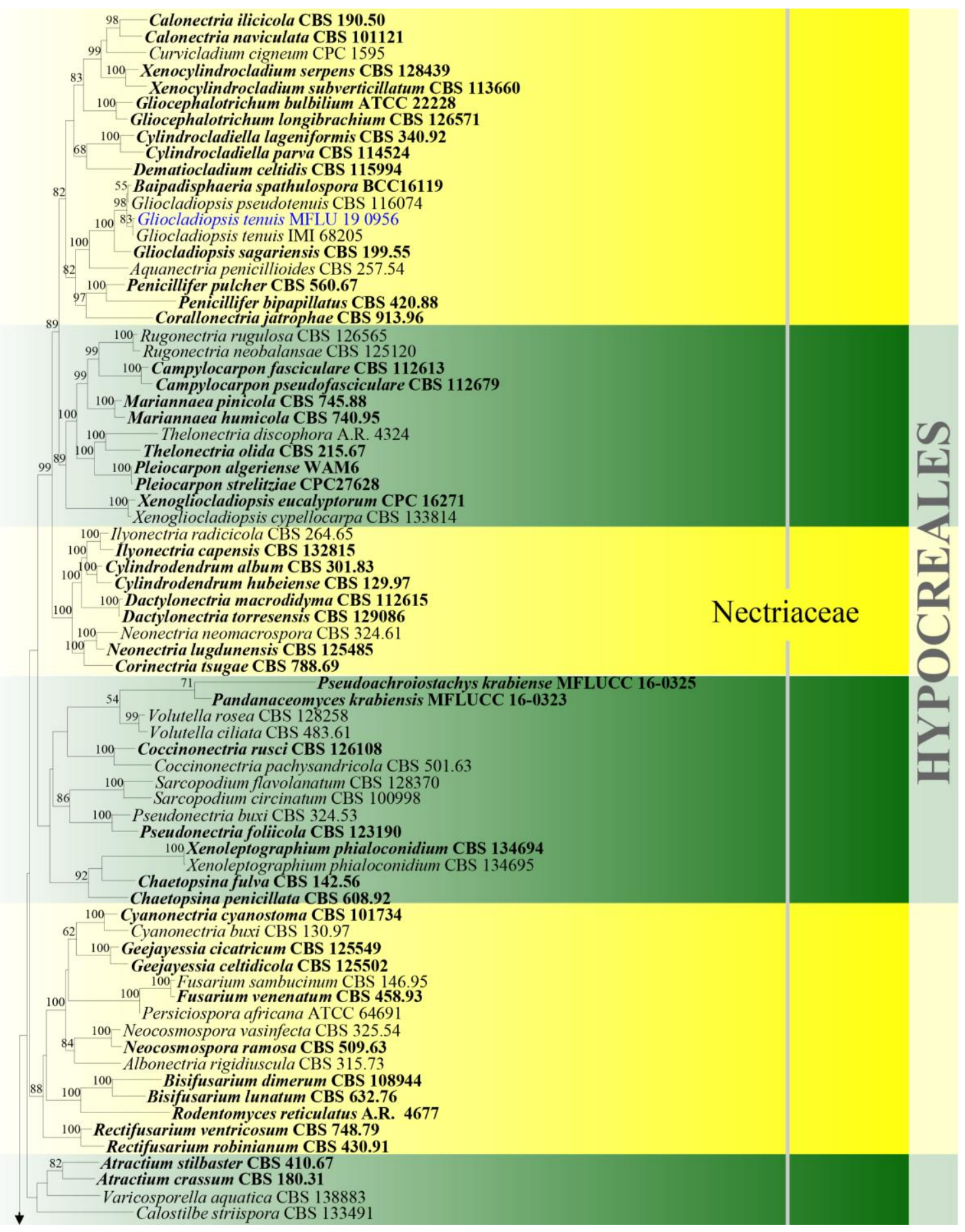

Figure 15 - Phylogram generated from maximum likelihood analysis based on combined LSU, ITS, $c m d A$, rpb2, tefl and tub2 sequence data for Hypocreales. Two hundred sixty six strains are included in the combined analysis which comprised 4731 characters (890 characters for LSU, 906 characters for ITS, 557 characters for $c m d A, 862$ characters for $r p b 2,1163$ characters for tef1, 348 characters for tub2) after alignment. Single gene analyses were carried out and the phylogenies were similar in topology and clade stability. The best RaxML tree with a final likelihood value of 143259.087299 is presented. Estimated base frequencies were as follows: $\mathrm{A}=0.238481, \mathrm{C}=$ $0.265503, \mathrm{G}=0.275795, \mathrm{~T}=0.220220$; substitution rates $\mathrm{AC}=1.361350, \mathrm{AG}=3.162200, \mathrm{AT}=$ 1.584547, $\mathrm{CG}=1.000927, \mathrm{CT}=7.415164, \mathrm{GT}=1.000000$; gamma distribution shape parameter a $=0.592521$. Bootstrap support values for ML greater than $50 \%$ are given near the nodes. The tree is rooted with Achaetomium macrosporum CBS 532.94, Chaetomium elatum CBS 374.66, Gelasinospora tetrasperma AFTOL-ID 1287, and Neurospora crassa ICMP 6360. Ex-type strains are in bold. The newly generated sequences are indicated in blue. 


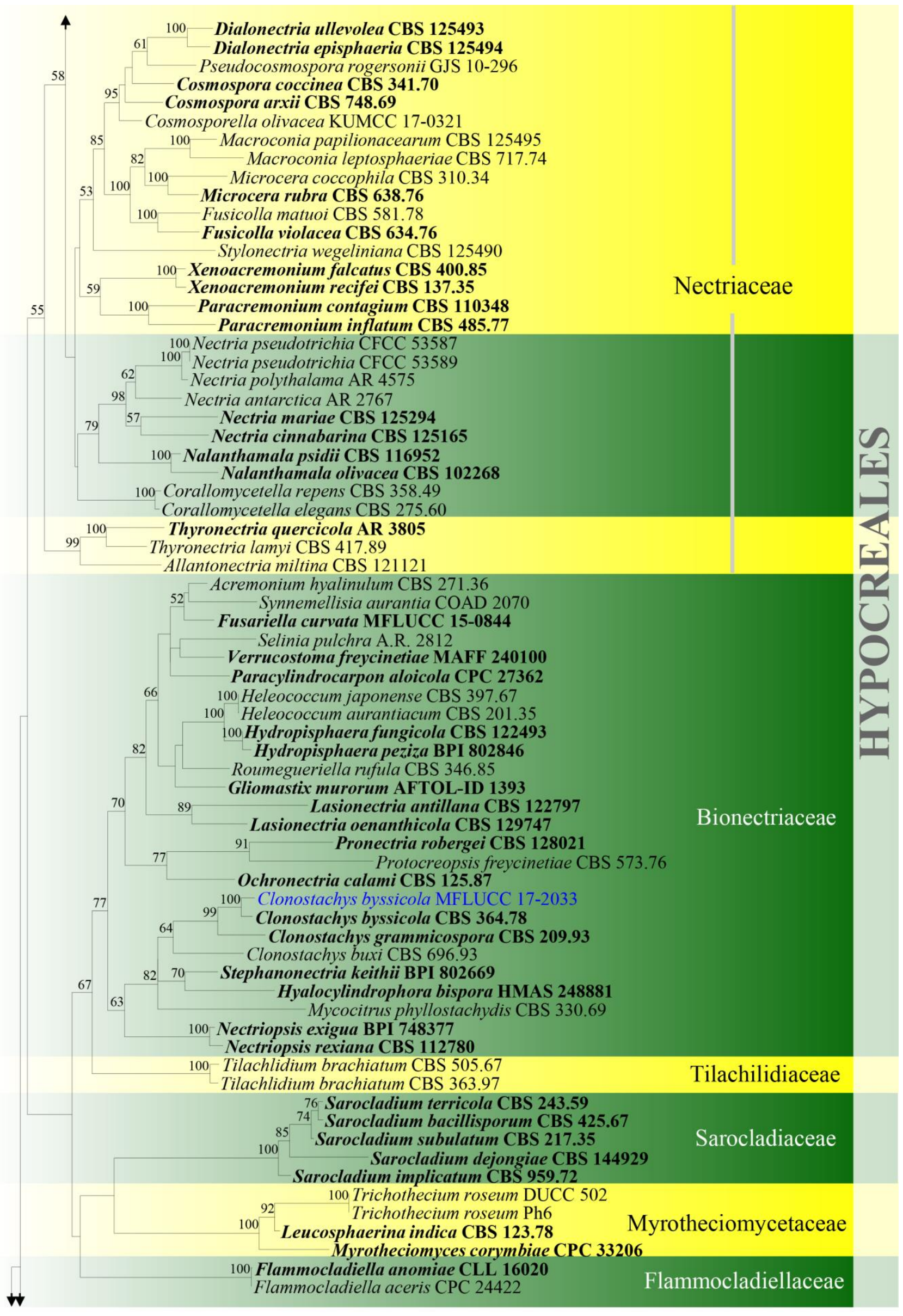

Figure 15 - Continued. 


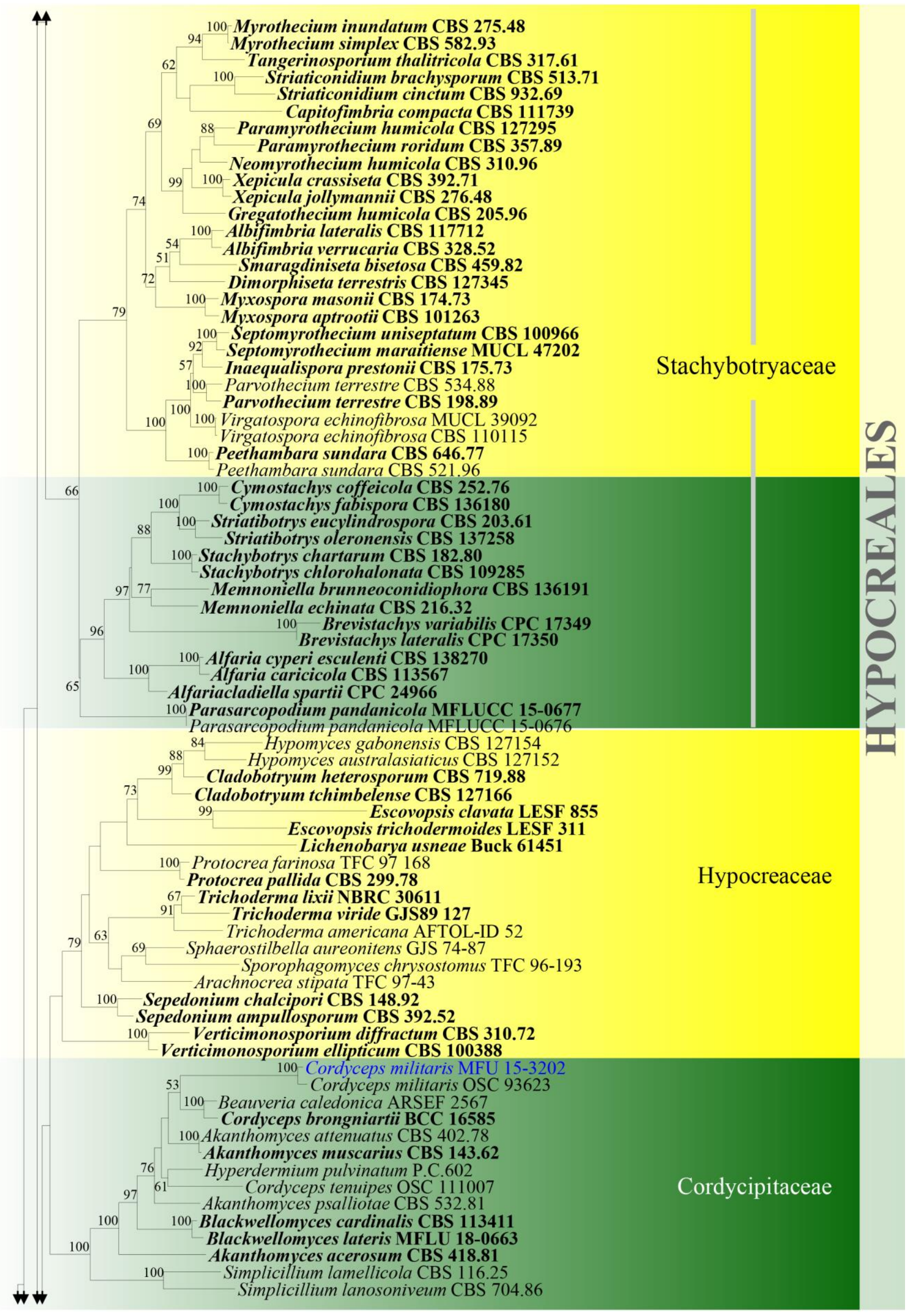

Figure 15 - Continued. 


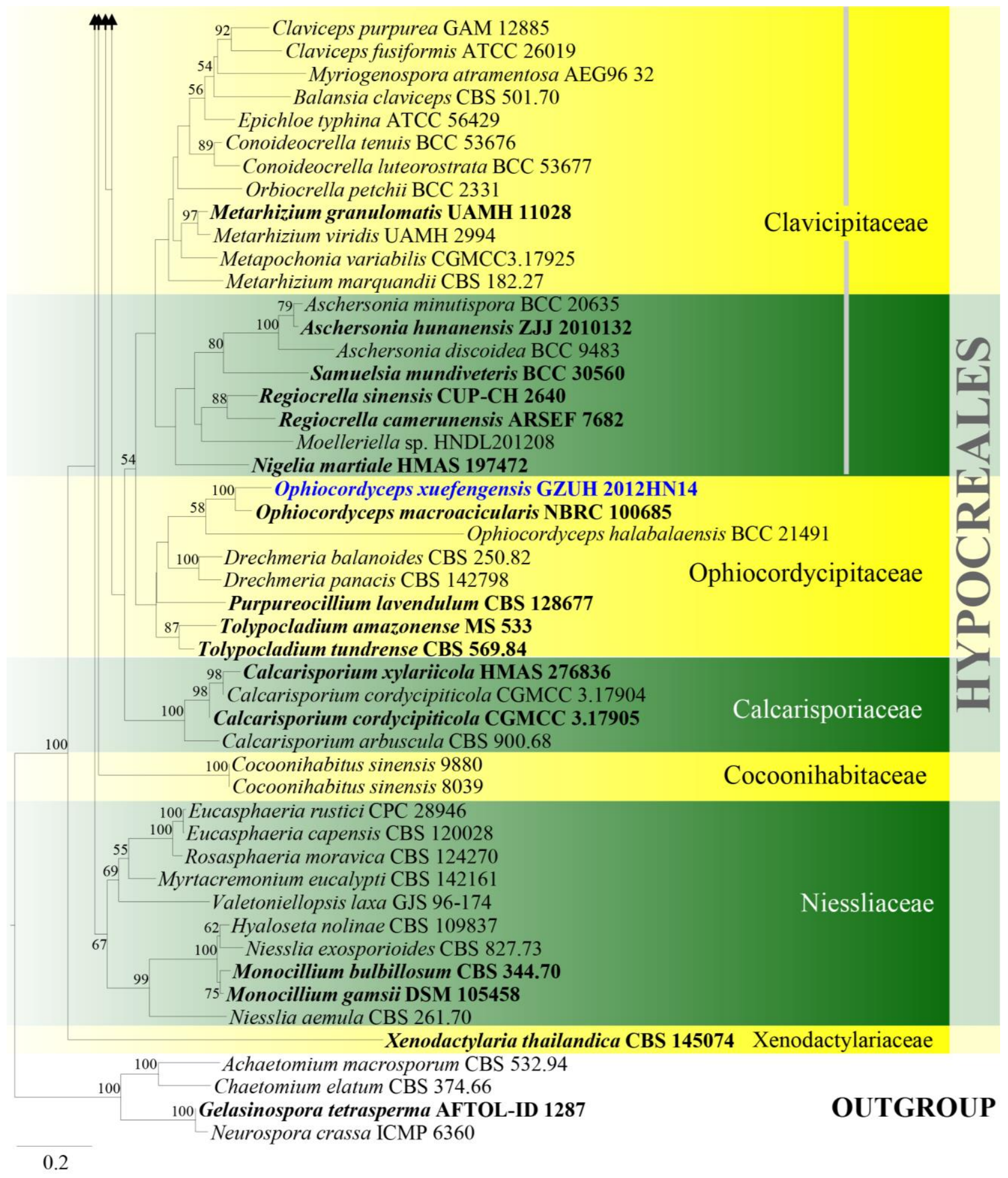

Figure 15 - Continued.

Myrmecridiales Crous, Persoonia 34: 219 (2015)

Myrmecridiales was established to accommodate Myrmecridium which was previously placed in Hypocreomycetidae, genera incertae sedis (Crous et al. 2015, Maharachchikumbura et al. 2016b). Another genus Neomyrmecridium was later included in the order in a strongly supported clade with Myrmecridium (Crous et al. 2018) and this is confirmed in this study (Fig. 3). The divergence time for Myrmecridiales is estimated as 113 MYA (Fig. 2). Currently there are two families and three genera in this order (this paper). 


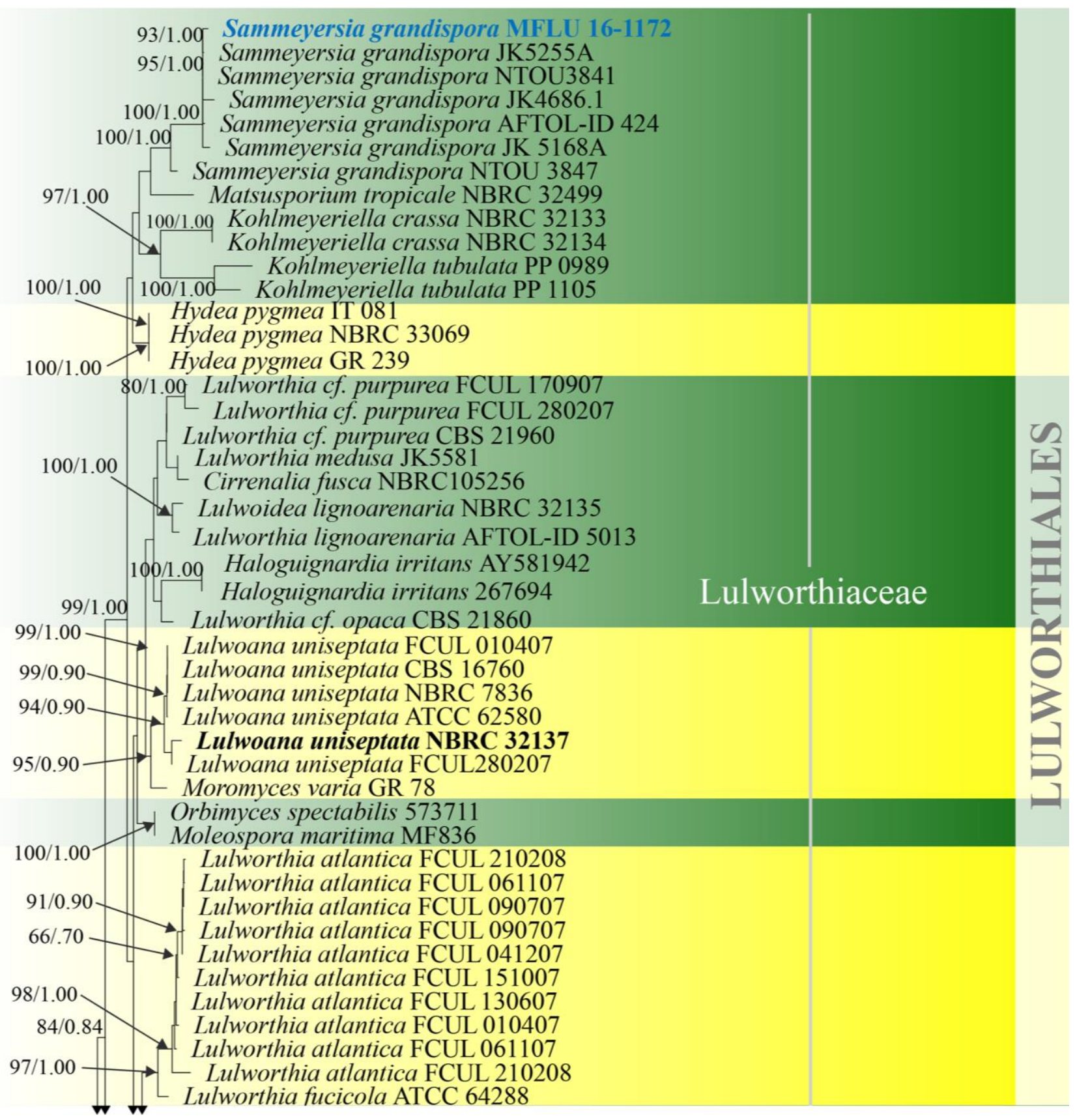

Figure 16 - Phylogram generated from maximum likelihood analysis based on combined LSU, SSU and ITS sequence data of selected taxa from Koralionastetales, Lulworthiales and Pisorisporiales. Sixty-nine strains are included in the combined gene analyses comprising 2780 characters after alignment (930 characters for LSU, 1059 characters for SSU and 784 characters for ITS). Fuscosporella pyriformis (MFLUCC 16-0570) and Parafuscosporella mucosa (MFLUCC 160571) are used as outgroup taxa. Analyses of each single gene were performed and the topology of each tree had clade stability. The tree topology of the maximum likelihood was similar to the Bayesian and maximum parsimony analyses. Maximum likelihood analysis with 1000 bootstrap replicates yielded a best tree with the likelihood value of -24852.531353 . The matrix had 1582 distinct alignment patterns, with $38.88 \%$ of undetermined characters or gaps. Estimated base frequencies were as follows; $\mathrm{A}=0.249996, \mathrm{C}=0.239207, \mathrm{G}=0.291483, \mathrm{~T}=0.219314$; substitution rates $\mathrm{AC}=1.016404, \mathrm{AG}=2.006035, \mathrm{AT}=1.090073, \mathrm{CG}=1.243791, \mathrm{CT}=$ 5.331398, GT $=1.000000$; gamma distribution shape parameter $\alpha=0.395174$. Maximum parsimony (black) and maximum likelihood (black) bootstrap values $>65 \%$ and Bayesian posterior probabilities (green) $>0.90$ (ML/BYPP) are given above the nodes. Ex-type strains are in bold and new strains are in blue. 


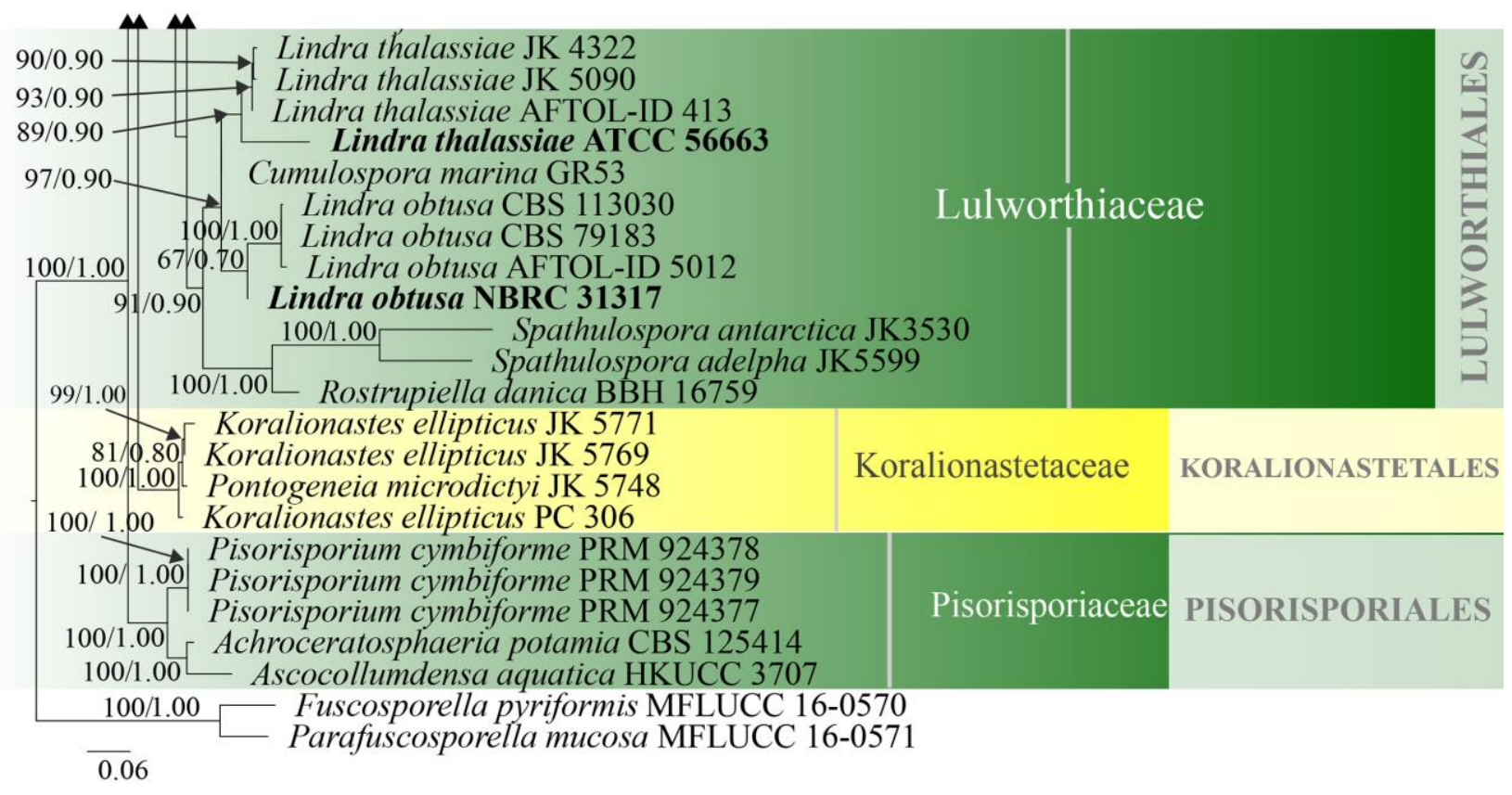

Figure 16 - Continued.

Ophiostomatales Benny \& Kimbr., Mycotaxon 12(1): 48 (1980)

This order was introduced by Benny \& Kimbrough (1980) for Ophiostomataceae, while Kathistaceae was added by Malloch \& Blackwell (1990). In our phylogenetic analyses generated from LSU, ITS, tub2 and SSU sequence data Ophiostomataceae formed a monophyletic clade with Kathistaceae with high statistical support (99\% ML, 0.99 PP) (Fig. 20). Nevertheless, based on phylogenetic analysis, Subbaromyces splendens (strain U63552), a species in Ophiostomataceae, grouped with Kathistaceae. However, the type genus Subbaromyces lacks sequence data and recollection and sequencing is needed to confirm its position. Ophiostomataceae comprises 13 genera of which sequence data is available for 11 genera (Wijayawardene et al. 2018a). Kathistaceae comprises three genera and sequence data are available for only Kathistes (Wijayawardene et al. 2018a). The divergence time for Ophiostomatales is estimated as 91 MYA (Fig. 2). Currently there are two families and 16 genera in this order (this paper).

Pararamichloridiales Crous, Persoonia 39: 357 (2017)

Pararamichloridiales comprises the monotypic family Pararamichloridiaceae and includes a single genus Pararamichloridium. In our phylogenetic analyses generated from LSU and ITS sequence data, Pararamichloridiales formed a monophyletic clade with high statistical support (100\% MLBS/1.00PP), which is the same with Crous et al. (2017a) (Fig. 17). Pararamichloridiales is characterised by branched, subhyaline to brown, septate conidiophores, with polyblastic, terminal and intercalary conidiogenous cells that produce solitary, hyaline, aseptate, clavate to ellipsoid conidia (Crous et al. 2017a). In this study, we accept only one family i.e. Pararamichloridiaceae with one genus i.e. Pararamichloridium. The divergence time for Pararamichloridiales is estimated as 101.5 MYA (Fig. 2), which falls in the range of family status. The status of this order may need revision following further study.

Parasympodiellales Hern.-Restr., Gené, R.F. Castañeda \& Crous, Stud. Mycol. 86: 87 (2017)

The monotypic order Parasympodiellales accommodates Parasympodiellaceae, typified by Parasympodiella (Hernández-Restrepo et al. 2017). The order has been introduced based on a LSU and ITS phylogeny for four Parasympodiella species, including the type species, P. laxa, all of which grouped together to form a monophyletic clade (Hernández-Restrepo et al. 2017). In addition, taxa of Parasympodiellales are characterised by stylaspergillus-like synasexual morphs, supporting this order as a distinct taxonomic entity (Cheewangkoon et al. 2009, Hernández- 
Restrepo et al. 2017). Parasympodiellales clusters as a sister group to Coronophorales in our phylogenetic analysis (Fig. 2). Their status may need revision following further study. Currently there is one family and one genus in this order (this paper).

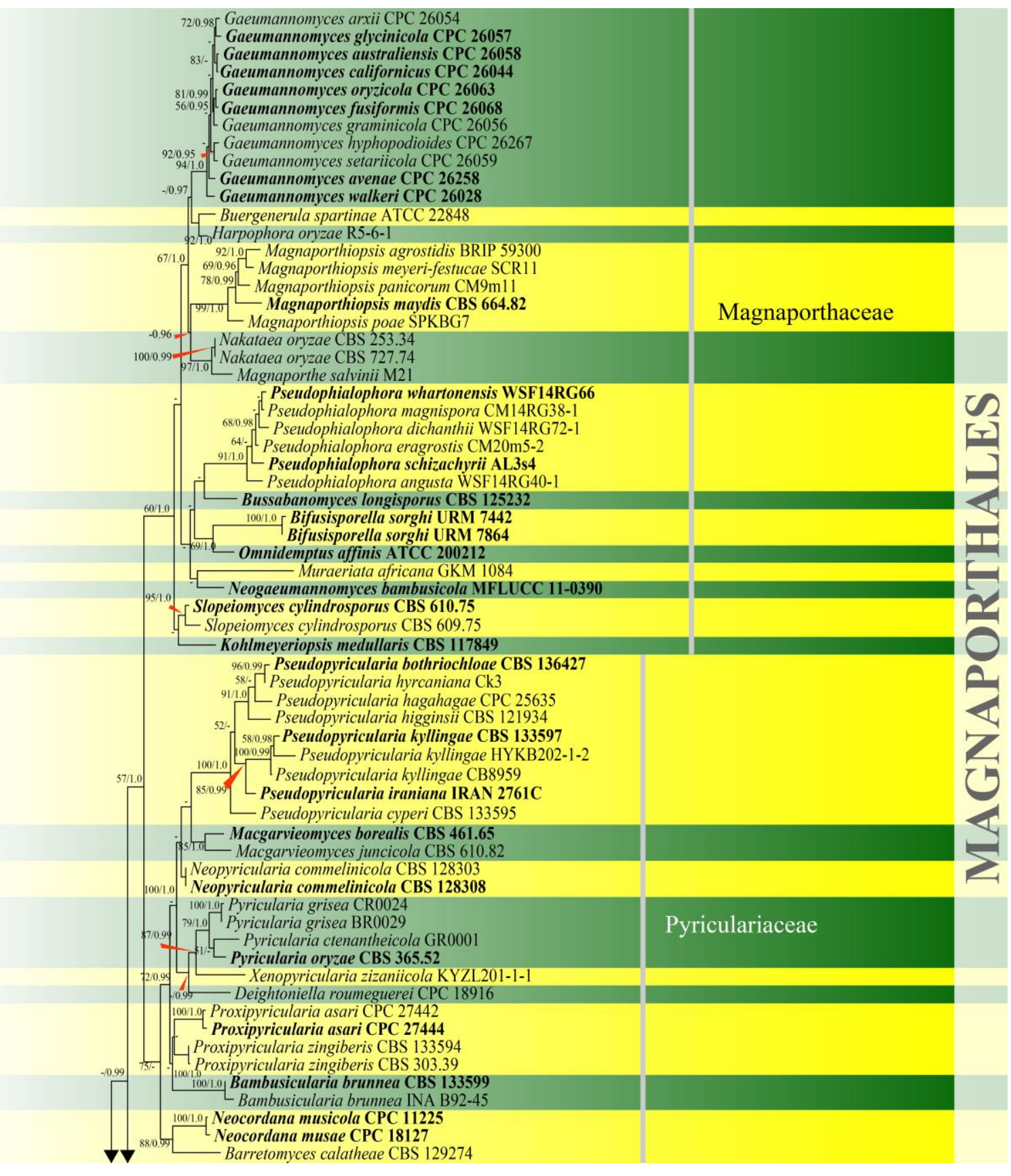

Figure 17 - Phylogram generated from maximum likelihood analysis based on combined LSU and ITS sequence data of Magnaporthales and Pararamichloridiales. Eighty-seven strains are included in the combined analyses which comprised 1559 characters (875 characters for LSU, 684 characters for ITS) after alignment. Diaporthe obtusifoliae (CPC 32336) and D. passiflorae (CBS 132527) are used as outgroup taxa. Single gene analyses were carried out and the phylogenies were similar in topology and clade stability. Tree topology of the maximum likelihood analysis is similar to the Bayesian analysis. The best RaxML tree with a final likelihood value of -12664.4150 is presented. Estimated base frequencies were as follows: $\mathrm{A}=0.2243, \mathrm{C}=0.2819, \mathrm{G}=0.2966, \mathrm{~T}=0.1971$; substitution rates $\mathrm{AC}=1.5257, \mathrm{AG}=2.2337, \mathrm{AT}=2.6637, \mathrm{CG}=1.0862, \mathrm{CT}=7.4361, \mathrm{GT}=$ 1.0000; gamma distribution shape parameter $\mathrm{a}=0.4747$. Bootstrap support values for ML greater than $50 \%$ and Bayesian posterior probabilities greater than 0.95 are given near the nodes. Ex-type strains are in bold. The newly generated sequences are indicated in blue. 


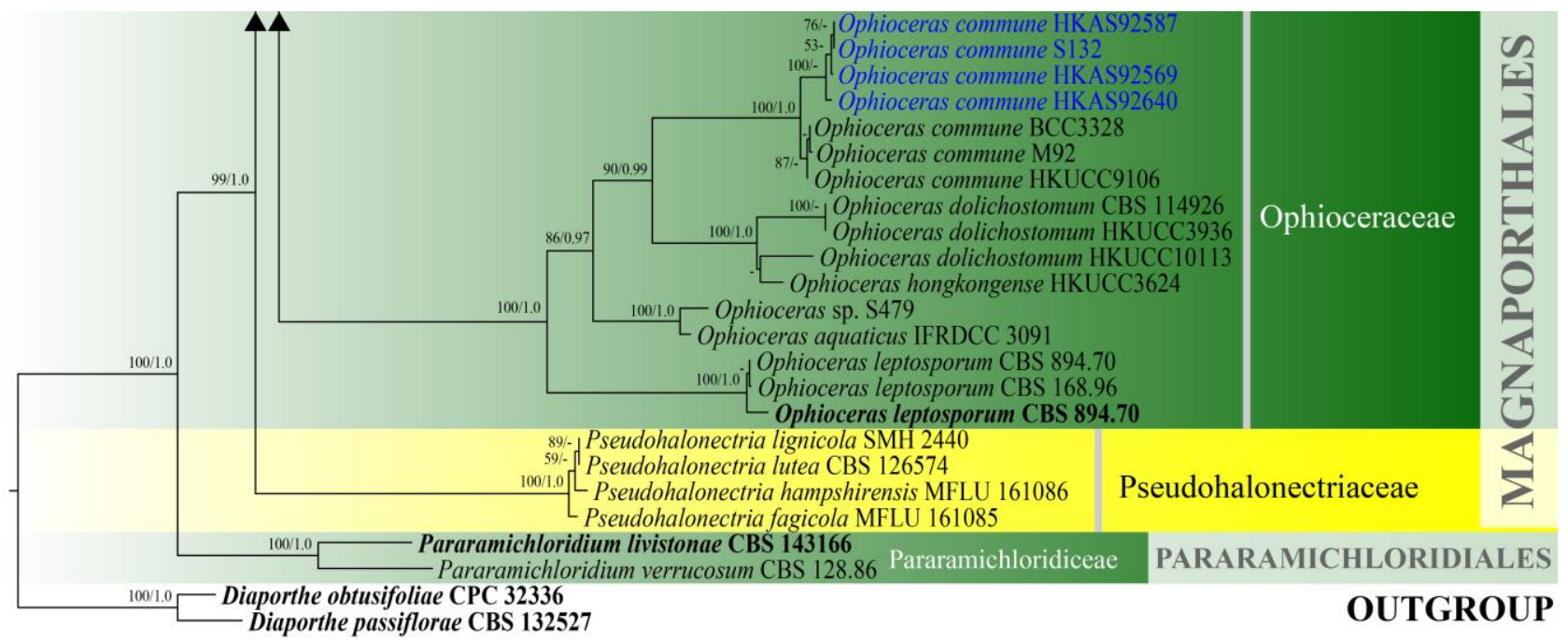

0.08

Figure 17 - Continued.

Phomatosporales Senan., Maharachch. \& K.D. Hyde, Mycosphere 7(5): 631 (2016)

Phomatosporales comprises Phomatospora, Lanspora and Tenuimurus (Senanayake et al. 2016). Phomatospora and Lanspora cluster together with statistical support of $86 \%$ ML and 0.97 PP, while Tenuimurus forms a clade with the other two genera with good support (100\% ML, 1.00 PP) (Fig. 20). Phomatosporales contains the single family Phomatosporaceae (Senanayake et al. 2016). The divergence time for Phomatosporales is estimated as 91 MYA (Fig. 2), which falls in the range of family status. Its status may need revision following further study. Currently there is one family and three genera in this order (this paper).

Phyllachorales M.E. Barr, Mycologia 75(1): 11 (1983)

Phyllachorales comprises three families viz. Phaeochoraceae, Phyllachoraceae and Telimenaceae (Dayarathne et al. 2017, Mardones et al. 2017). In our phylogenetic analyses with concatenated ITS, LSU and SSU sequence data, the Phaeochoraceae formed a monophyletic clade with high statistical support (98\% ML) (Fig. 21). Phaeochoraceae comprises Cocoicola, Phaeochora, Phaeochoropsis and Serenomyces and sequence data are available only for two Cocoicola strains and one Serenomyces species. However, the type genus Phaeochora lacks sequence data. Phyllachoraceae formed a less stable clade within Phyllachorales. Out of 54 genera in Phyllachoraceae, sequences data are available for only five genera. A few Polystigma strains grouped within Phyllachorales in two different places which is similar to the study of Dayarathne et al. (2017). However, Polystigma was excluded and placed within the reinstated Polystigmataceae by Jones et al. (2019) and Bundhun et al. (2019). Telimenaceae species also formed a monophyletic clade in our phylogram, but with low statistical support (Fig. 21). The divergence time for Phyllachorales is estimated as 168 MYA (Fig. 2). Currently there are three families and 60 genera in this order (this paper).

Pisorisporiales Réblová \& J. Fourn., Persoonia 34: 43 (2014)

Phylogenetic analyses of strains from an aquatic environment, including LSU, SSU and $r p b 2$ sequence data, grouped them in a monophyletic clade with Achroceratosphaeria species (Réblová et al. 2015a). The new taxa were placed in the novel genus, Pisorisporium and a new family, Pisorisporiaceae was erected to accommodate Pisorisporium and Achroceratosphaeria. The latter genus was, upon its introduction, initially placed in Sordariomycetes incertae sedis (Réblová et al. 2010). This new family Pisorisporiaceae was, in turn, accommodated in Pisorisporiales based on its distinct taxonomy and phylogeny at the ordinal level (Réblová et al. 2015a). Pisorisporiales forms a 
moderately-supported sister clade with Lulworthiales and Koralionastetales in Lulworthiomycetidae (Hongsanan et al. 2017). The order has been reported to have a stem age which falls between 250-300 MYA, thereby placing it at a subclass level (Hyde et al. 2017a, Hongsanan et al. 2017). In this study, therefore Pisorisporiales is raised to the subclass Pisorisporiomycetidae. Currently there is one family and two genera in this order (this paper).

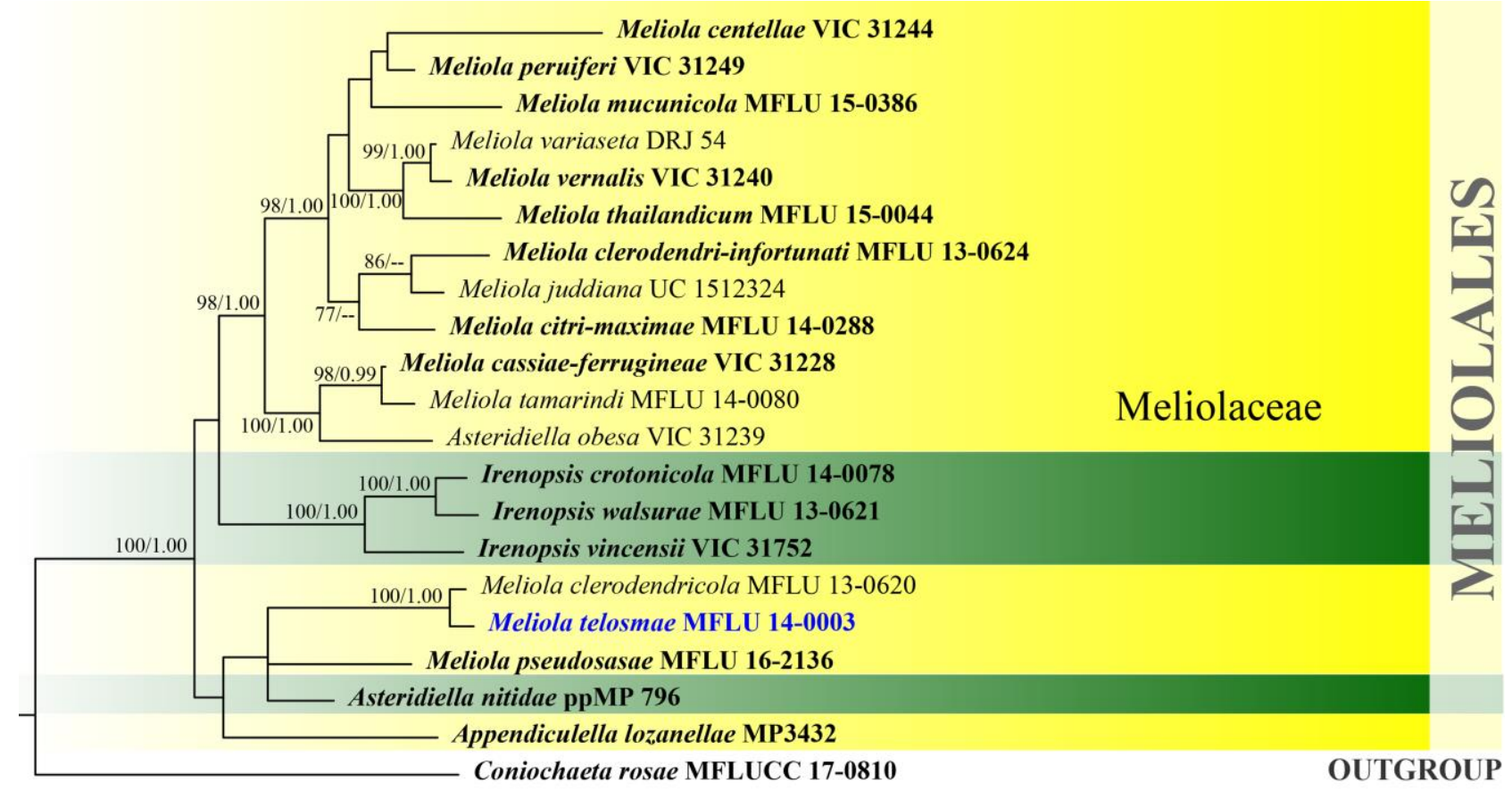

$\overline{0.05}$

Figure 18 - Phylogram generated from Bayesian inference based on combined LSU, SSU and ITS sequence data of Meliolales. Twenty-one strains are included in the combined analyses which comprised 2688 characters (869 characters for LSU, 1020 characters for SSU, 799 characters for ITS) after alignment. Coniochaeta rosae (MFLUCC 17-0810) is used as outgroup taxa. Single gene analyses were carried out and the phylogenies were similar in topology and clade stability. Tree topology of the maximum likelihood analysis is similar to the Bayesian analysis. Estimated base frequencies were as follows: $\mathrm{A}=0.25335, \mathrm{C}=0.2223, \mathrm{G}=0.281553, \mathrm{~T}=0.242798$; substitution rates $\mathrm{AC}=1.021441, \mathrm{AG}=3.556619, \mathrm{AT}=2.123549, \mathrm{CG}=0.380727, \mathrm{CT}=6.542902, \mathrm{GT}=$ 1.000000; gamma distribution shape parameter $\alpha=0.549005$. Bootstrap support values for ML greater than $75 \%$ and Bayesian posterior probabilities greater than 0.95 are given near the nodes. Ex-type strains are in bold. The newly generated sequences are indicated in blue.

\section{Pleurotheciales Réblová \& Seifert, Persoonia 37: 63 (2015)}

Pleurotheciales was introduced based on a combined ITS, SSU, LSU, tub2, $m c m 7$ and $r p b 2$ dataset (Réblová et al. 2016c) and it presently accommodates Pleurotheciaceae which in turn comprises ten genera. Taxa belonging to Pleurotheciales cannot be successfully differentiated based on their overlapping sexual morphology. The type of conidiogenesis can, to a certain extent, delineate species into groups within the order, since conidial secession is rhexolytic or schizolytic with holoblastic, monoblastic or polyblastic (sympodially extending) conidiogenesis (Réblová et al. 2016c). Molecular data and/or cultures are essential to establish the placement of Pleurotheciales taxa (Réblová et al. 2016c). In this study, Pleurothecium obovoideum does not cluster with other Pleurothecium species, including the type species, P. recurvatum (Fig. 10). This result is in agreement with Réblová et al. (2012). The divergence time for Pleurotheciales is estimated as 105 MYA (Fig. 2), which is evidence of family status. The status as an order may need revision following further study. Currently there is one family and ten genera in this order (this paper). 


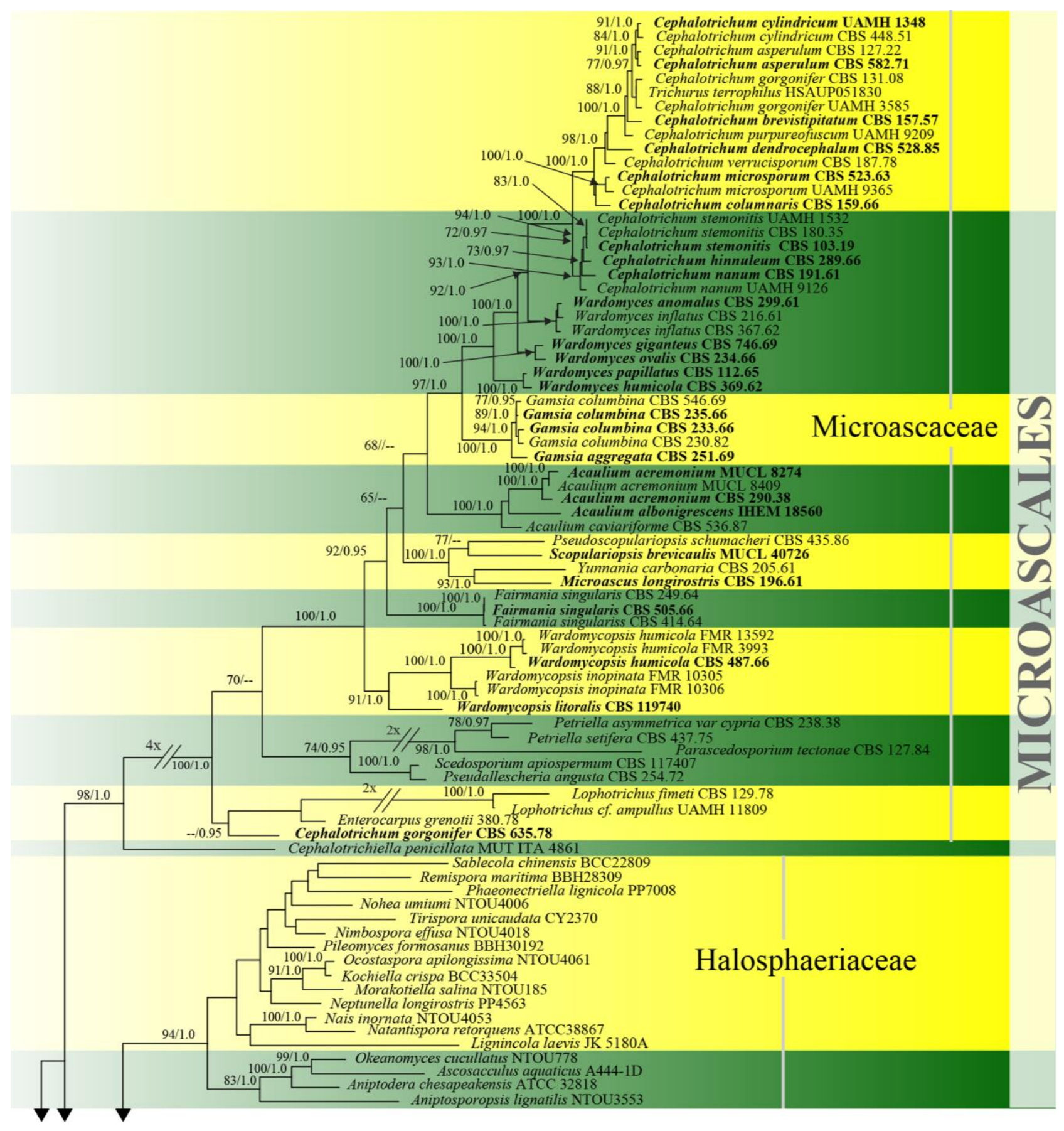

Figure 19 - Phylogram generated from maximum likelihood analysis based on combined ITS, LSU, SSU and tef1 sequence data of Microascales. One hundred and thirty-two strains are included in the combined analyses which comprised 4538 characters (653 characters for ITS, 1215 characters for LSU, 1685 characters for SSU, 985 characters for tefl) after alignment. Lecanicillium fungicola var. aleophilum (CBS 357.80) and L. fungicola var. fungicola (CBS 992.69) (Cordycipitaceae, Hypocreales) are used as outgroup taxa. Single gene analyses were carried out and the phylogenies were similar in topology and clade stability. Tree topology of the maximum likelihood analysis is similar to the Bayesian analysis. The best RaxML tree with a final likelihood value of -46610.749560 is presented. Estimated base frequencies were as follows: $\mathrm{A}=$ $0.240650, \mathrm{C}=0.256729, \mathrm{G}=0.270623, \mathrm{~T}=0.231998$; substitution rates $\mathrm{AC}=0.965367, \mathrm{AG}=$ 2.062871, $\mathrm{AT}=1.418856, \mathrm{CG}=0.960832, \mathrm{CT}=4.902766, \mathrm{GT}=1.000000$; gamma distribution shape parameter $\mathrm{a}=0.478984$. Bootstrap support values for ML greater than $65 \%$ and Bayesian posterior probabilities greater than 0.95 are given near the nodes. Ex-type strains are in bold. 


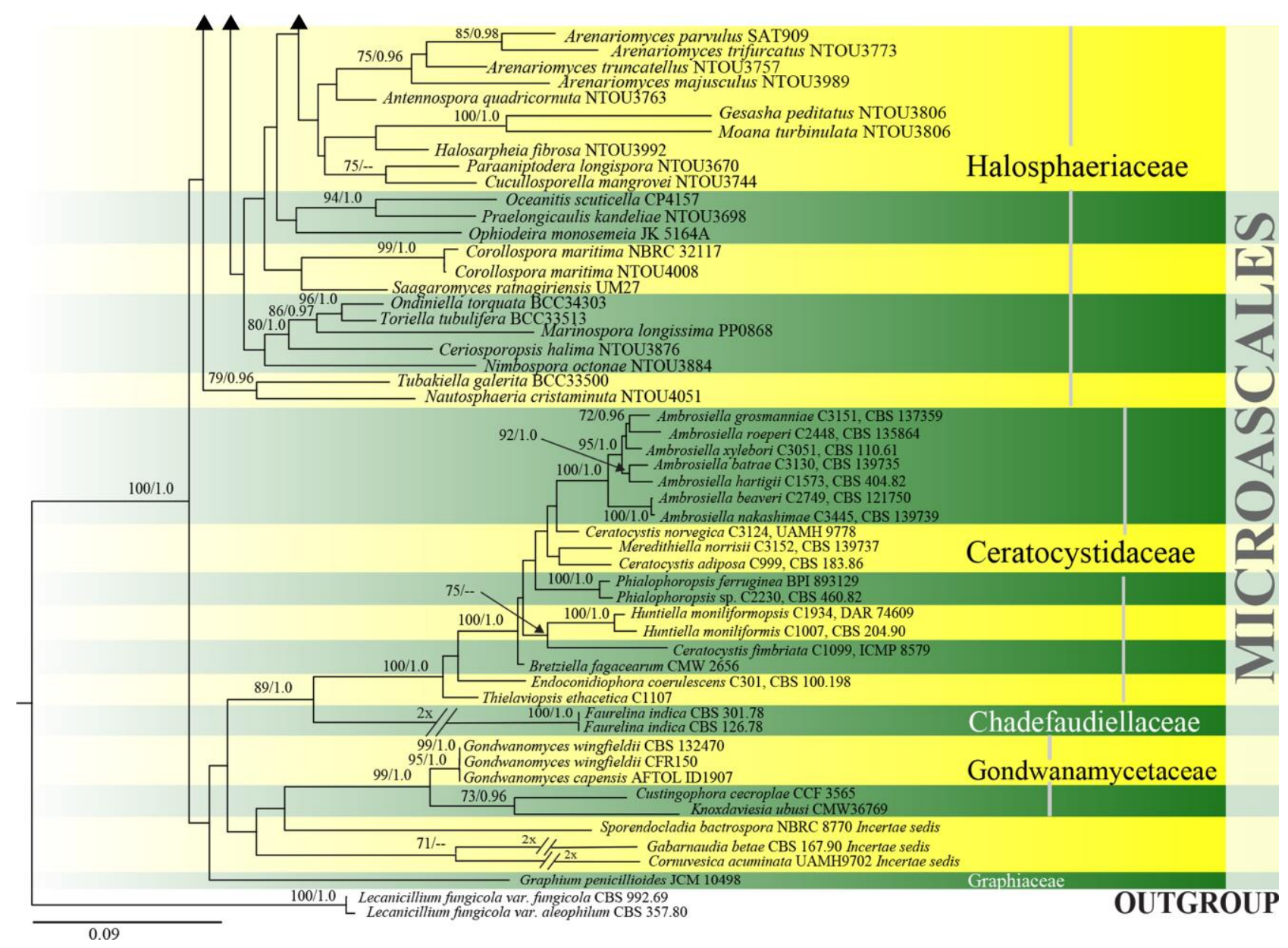

Figure 19 - Continued.

Pseudodactylariales Crous, Persoonia 39: 421 (2017)

Pseudodactylariales was introduced by Crous et al. (2017a) and Pseudodactylariaceae, one genus, Pseudodactylaria, and three species were placed in this order. In our phylogenetic analyses generated from LSU, ITS, SSU and rpb2 sequence data, Pseudodactylariales formed a monophyletic clade with high statistical support (100\% MPBS/1.00 PP) (Fig. 22). The divergence time for Pseudodactylariales is estimated as 128 MYA (Fig. 2). Currently there is one family and one genus in this order (this paper).

Savoryellales Boonyuen, Suetrong, Sivichai, K.L. Pang \& E.B.G. Jones, Mycologia 103(6): 1368 (2011)

Savoryellales consists of Savoryellaceae with the genera Ascotaiwania, Canalisporium, Dermatisporium and Savoryella (Réblová et al. 2016c, Luo et al. 2019). Species are found in terrestrial, marine, brackish and freshwater habitats, as well as water-cooling towers (Jones \& Eaton 1969, Minoura \& Muroi 1978, Hyde \& Jones 1988, Chang et al. 1998, Ranghoo \& Hyde 1998, Luo et al. 2019). The sexual morphs of Savoryellales species have perithecial ascomata with elongate necks, while the asexual morphs are dematiaceous hyphomycetes with semimacronematous conidiophores and monoblastic conidiogenous cells (Réblová et al. 2016c, Dayarathne et al. 2019a, Zhang et al. 2019). Savoryellales was initially placed in Hypocreomycetidae based on multi-gene phylogeny (Boonyuen et al. 2011). However, later it was raised to the subclass Savoryellomycetidae following molecular dating data with a stem age of 268 MYA, indicating a subclass status (Hongsanan et al. 2017). Currently there is one family and four genera in this order (this paper). 


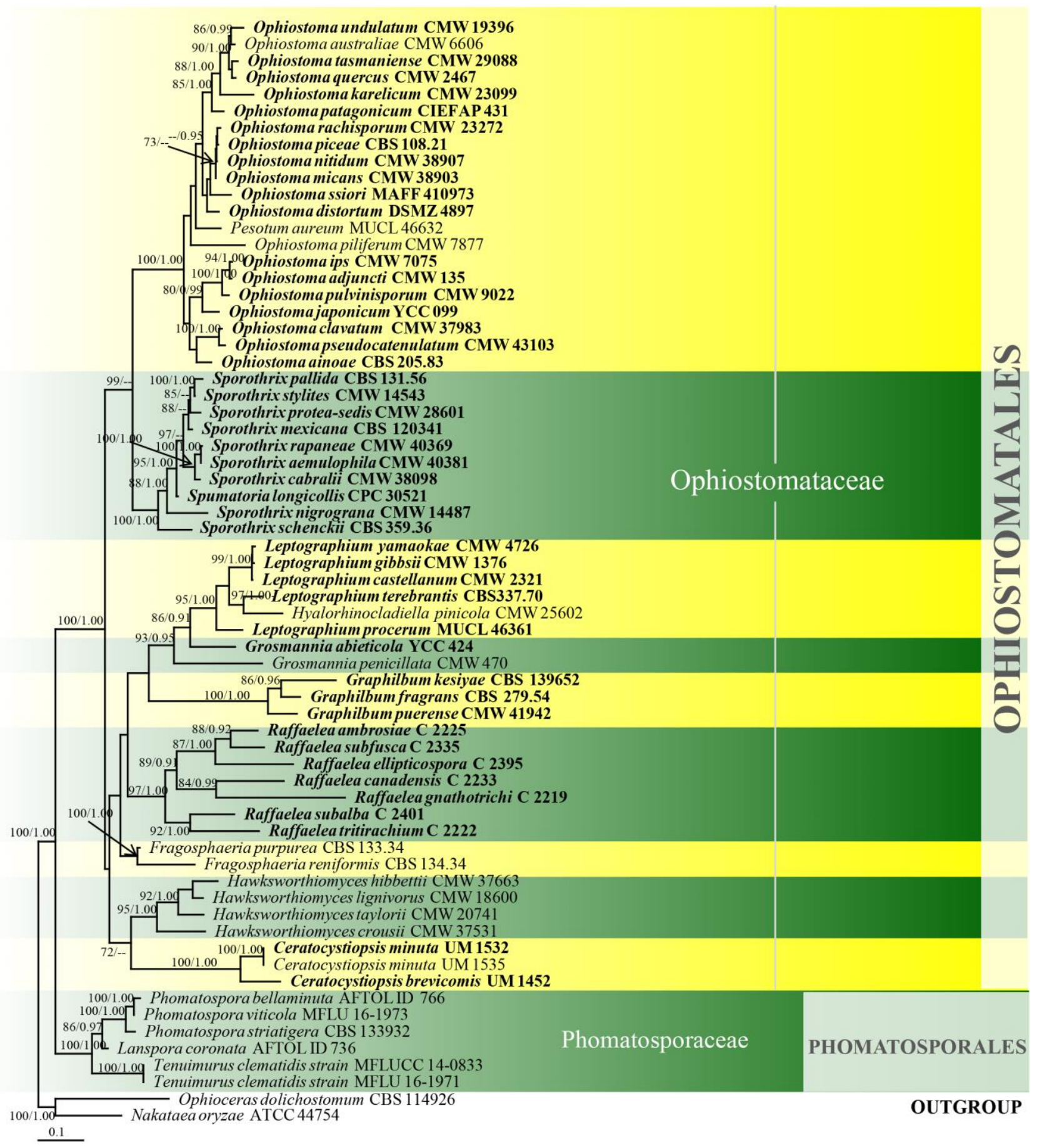

Figure 20 - Phylogram generated from maximum likelihood analysis based on combined LSU, SSU ITS and $t u b 2$ sequence data of Ophiostomatales and Phomatosporales. Sixty-six strains are included in the combined analyses which comprised 2897 characters (584 characters for LSU, 985 characters for SSU, 737 characters for ITS, 591 characters for tub2) after alignment. Ophioceras dolichostomum (CBS 114926) (Ophioceraceae, Magnaporthales) and Nakataea oryzae (ATCC 44754) (Magnaporthaceae, Magnaporthales) are used as outgroup taxa. Tree topology of the maximum likelihood analysis is similar to the Bayesian analysis. The best RaxML tree with a final likelihood value of -21546.866789 is presented. Estimated base frequencies were as follows: $\mathrm{A}=$ $0.213168, \mathrm{C}=0.292921, \mathrm{G}=0.285293, \mathrm{~T}=0.208619$; substitution rates $\mathrm{AC}=1.227359, \mathrm{AG}=$ 2.074779, $\mathrm{AT}=1.607139, \mathrm{CG}=1.020705, \mathrm{CT}=4.744232, \mathrm{GT}=1.000000$; gamma distribution shape parameter $\mathrm{a}=0.294947$. Bootstrap support values for ML greater than $70 \%$ and Bayesian posterior probabilities greater than 0.90 are given near the nodes. Ex-type strains are in bold. 


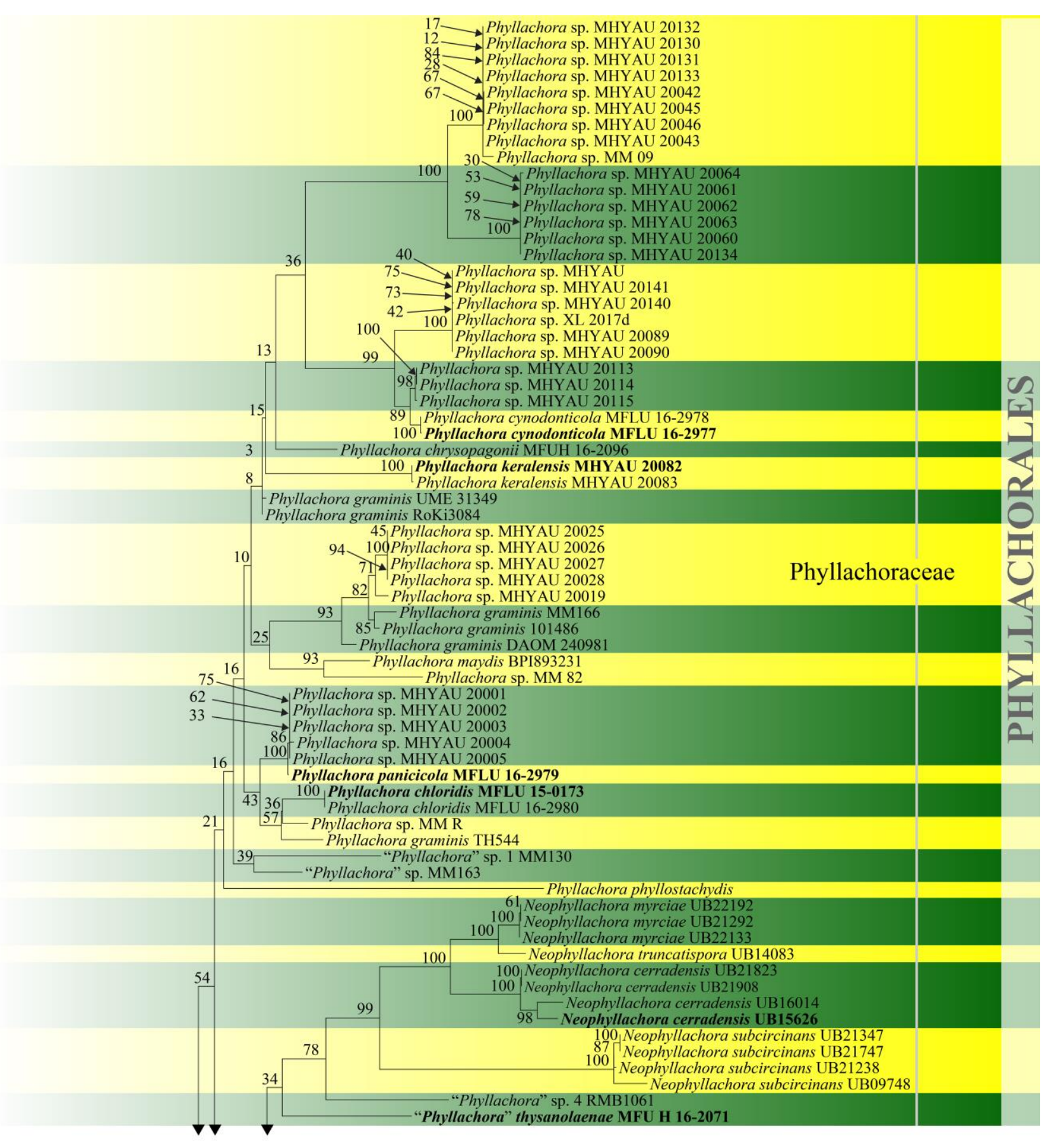

Figure 21 - Phylogram generated from maximum likelihood analysis based on combined LSU, SSU and ITS sequence data of selected taxa from Phyllachorales. Related sequences are taken from Dayarathne et al. (2017). One hundred and sixteen strains are included in the combined gene analyses comprising 1326 characters after alignment (610 characters for LSU, 972 characters for SSU and 657 characters for ITS). Gelasinospora tetrasperma (CBS 178.33), Neurospora crassa (MUCL 19026) and Sordaria fimicola (CBS 508.50) are used as outgroup taxa. Analyses of each single gene were performed and the topology of each tree had clade stability. Maximum likelihood analysis with 1000 bootstrap replicates yielded a best tree with the likelihood value of 27773.000538. The matrix had 1583 distinct alignment patterns, with $57.76 \%$ of undetermined characters or gaps. Estimated base frequencies were as follows; $\mathrm{A}=0.250314, \mathrm{C}=0.239655, \mathrm{G}=$ $0.269539, \mathrm{~T}=0.240492$; substitution rates $\mathrm{AC}=1.057397, \mathrm{AG}=2.260386, \mathrm{AT}=1.375589, \mathrm{CG}=$ $0.834187, \mathrm{CT}=4.235196, \mathrm{GT}=1.000000$; gamma distribution shape parameter $\alpha=0.534795$. Maximum likelihood bootstrap (ML, black) values > 60\%) are given above the nodes. Ex-type strains are in bold. 


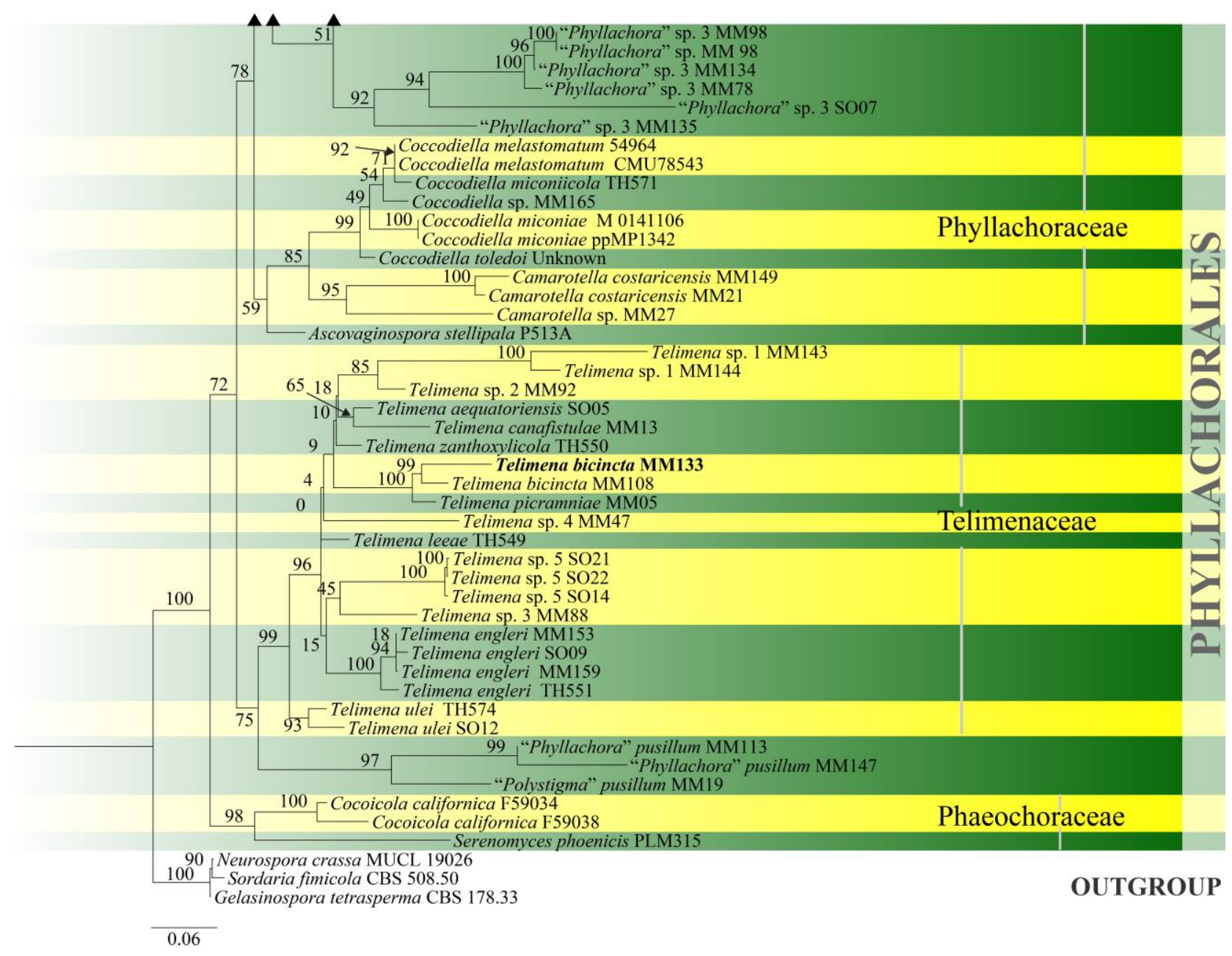

Figure 21 - Continued.

Sordariales Chadef. ex D. Hawksw. \& O.E. Erikss., Syst. Ascom. 5(1): 182 (1986)

Sordariales was established by Hawksworth \& Eriksson (1986) and clarified by Huhndorf et al. (2004b) based on LSU sequences analysis. Chaetomiaceae, Sordariaceae and Lasiosphaeriaceae are accommodated in this order and taxa are characterized by cleistothecial or perithecial ascomata and hyaline or brown ascospores often with appendages or sheaths (Huhndorf et al. 2004b, Kruys et al. 2015, Maharachchikumbura et al. 2016b, Huang et al. 2019). Sordariales members cluster in a clade with Boliniales, Chaetosphaeriales and Phyllachorales (Hongsanan et al. 2017, Hyde et al. 2017a). The traditionally defined Chaetomiaceae and Lasiosphaeriaceae were found to be polyphyletic (Huhndorf et al. 2004b, Kruys et al. 2015, Wang et al. 2016a). Some members of Lasiosphaeriaceae, Triangularia, Cladorrhinum and Podospora, were placed in a new family Podosporaceae (Wang et al. 2019a). In this study, Chaetomiaceae, Podosporaceae, Lasiosphaeriaceae (I, II, III), and Sordariaceae form a distinct lineage (Fig. 23). However, more data is needed to determine the phylogenetic affinities of this order. The divergence time for Sordariales is estimated as 128 MYA (Fig. 2). Currently there are four families and 89 genera in this order (this paper).

Spathulosporales Kohlm., Mycologia 65(3): 615 (1973)

Spathulosporales includes Hispidicarpomycetaceae and Spathulosporaceae, while, Hispidicarpomycetaceae lacks sequence data in GenBank. Sequence data are available only for two species of Spathulospora. Our phylogenetic analyses with combined LSU, SSU and ITS data showed that Spathulospora and Rostrupiella species form a well-supported single clade (99\% ML, 1.00 PP) within Lulworthiaceae (Fig. 16) and this is similar to Inderbitzin et al. (2004), Campbell et 
al. (2005) and Jones et al. (2009, 2019). However, sequence data are not available for the type species of Spathulospora hence, further collections are need from the type to resolve the phylogenetic placement of this order. The divergence time for Sordariales is estimated as $121 \mathrm{MYA}$ (Fig. 2), which falls in the range of family status. The order status may need revision following further study. Currently there are two families and three genera in this order (this paper).

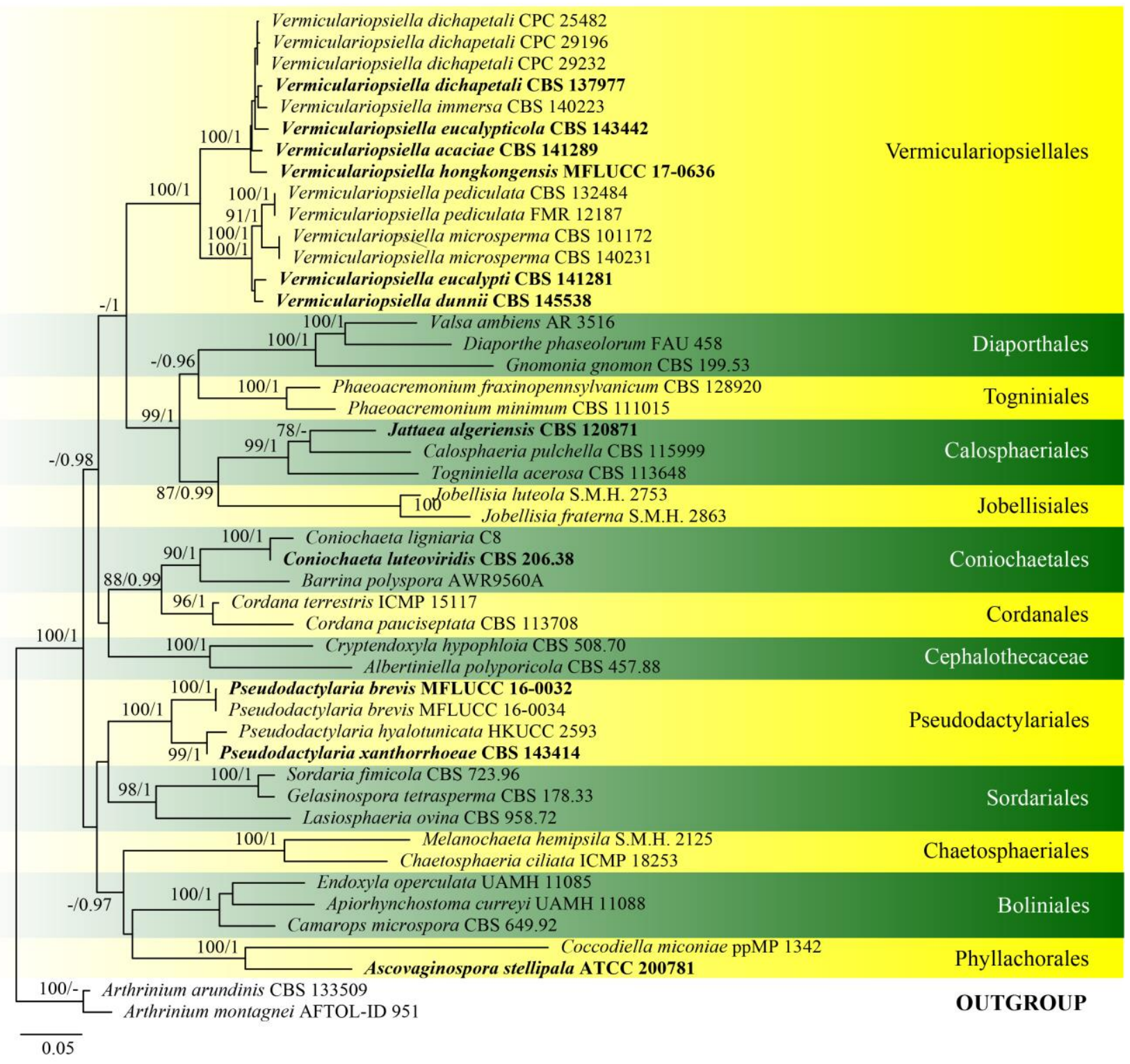

Figure 22 - Phylogram generated from maximum likelihood analysis based on combined LSU, SSU, ITS and rpb2 sequence data of Pseudodactylariales and Vermiculariopsiellales. Forty-seven strains are included in the combined analyses which comprised 4320 characters ( 865 characters for LSU, 1634 characters for SSU, 662 characters for ITS, 1159 characters for $r p b 2)$ after alignment. Arthrinium arundinis (CBS 133509) and Arthrinium montagnei (AFTOL-ID 951) (Apiosporaceae, Xylariales) are used as outgroup taxa. Single gene analyses were carried out and the phylogenies were similar in topology and clade stability. Tree topology of the maximum likelihood analysis is similar to the Bayesian analysis. The best RaxML tree with a final likelihood value of 29256.470401 is presented. Estimated base frequencies were as follows: $\mathrm{A}=0.249068, \mathrm{C}=$ $0.239305, \mathrm{G}=0.280423, \mathrm{~T}=0.231203$; substitution rates $\mathrm{AC}=1.369489, \mathrm{AG}=2.705642, \mathrm{AT}=$ 1.345736, $\mathrm{CG}=1.341396, \mathrm{CT}=6.599852, \mathrm{GT}=1.000000$; gamma distribution shape parameter a $=0.220775$. Bootstrap support values for ML greater than $75 \%$ and Bayesian posterior probabilities greater than 0.95 are given near the nodes, respectively. Ex-type strains are in bold. 


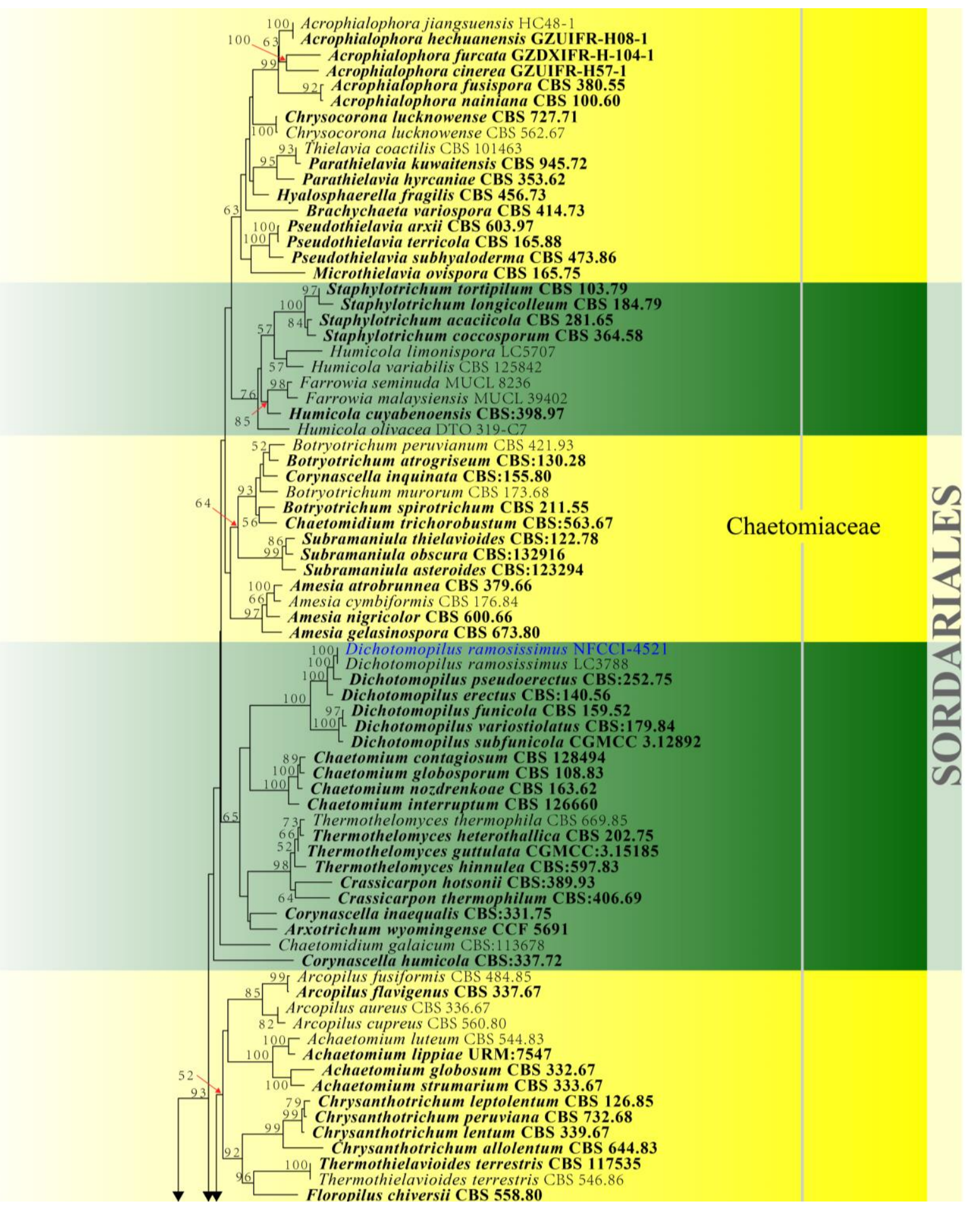

Figure 23 - Phylogram generated from maximum likelihood analysis based on combined LSU, ITS, $t u b 2$ and $r p b 2$ sequence data of Sordariales. Related sequences were taken from Wang et al. (2016b). Two hundred and fifty-seven strains are included in the combined analyses which comprised 2717 characters (855 characters for LSU, 480 characters for ITS, 860 characters for tub2, 522 characters for $r p b 2$ ) after alignment. Members of Amphisphaeriales are used as outgroup taxa. Single gene analyses were carried out and the phylogenies were similar in topology and clade stability. The best RAxML tree with a final likelihood value of $\mathbf{- 5 9 0 8 2 . 0 7 9 0 7 4}$ is presented. Estimated base frequencies were as follows: $\mathrm{A}=0.238795, \mathrm{C}=0.266829, \mathrm{G}=0.275292, \mathrm{~T}=$ 0.219085; substitution rates $\mathrm{AC}=1.483472, \mathrm{AG}=3.436969, \mathrm{AT}=1.859704, \mathrm{CG}=1.064423, \mathrm{CT}$ $=6.934931, \mathrm{GT}=1.000000$; gamma distribution shape parameter $\mathrm{a}=0.757314$. Bootstrap support values for ML greater than $50 \%$ are given near the nodes. Ex-type strains are in bold. The newly generated sequences are indicated in blue. 


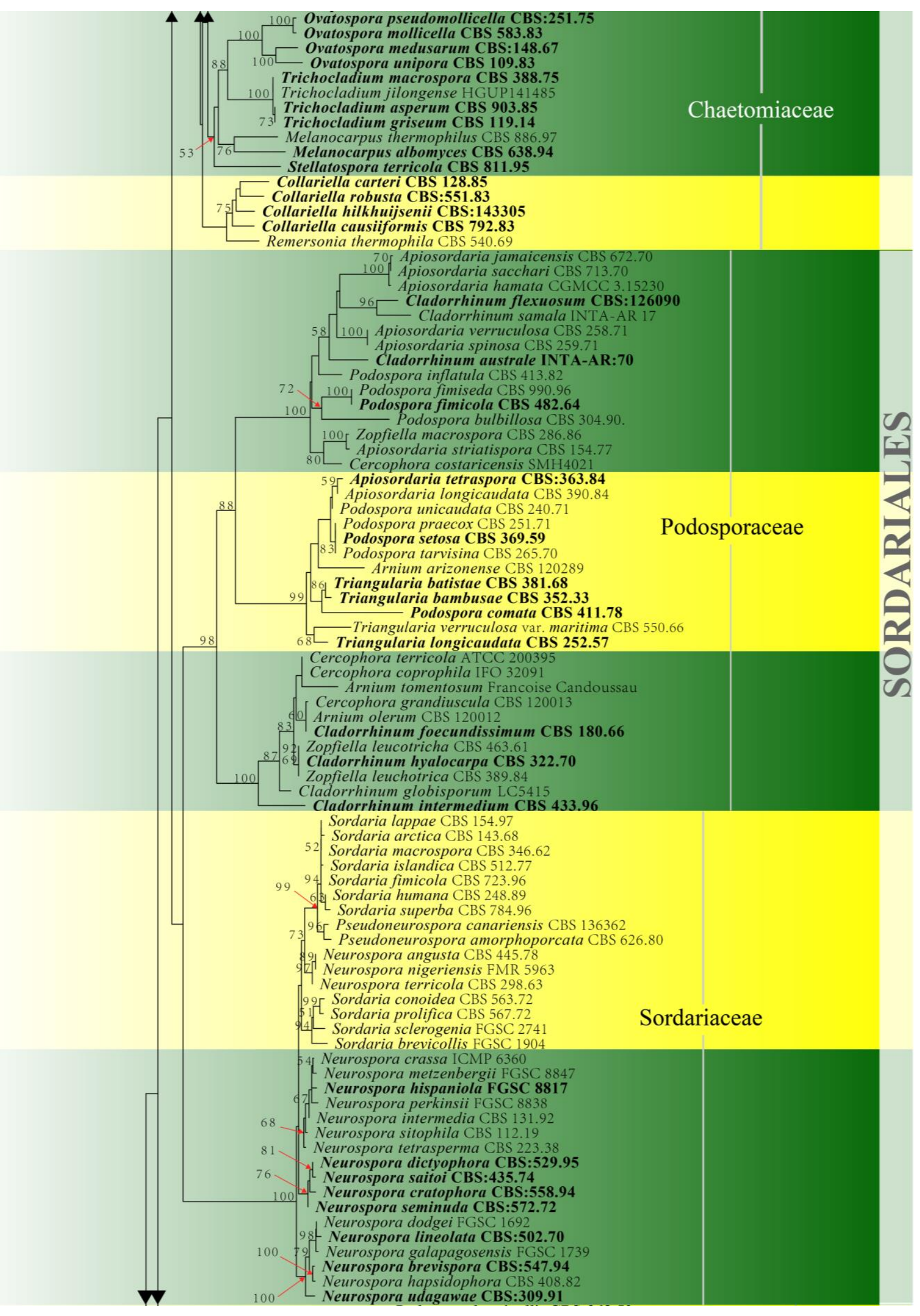

Figure 23 - Continued. 


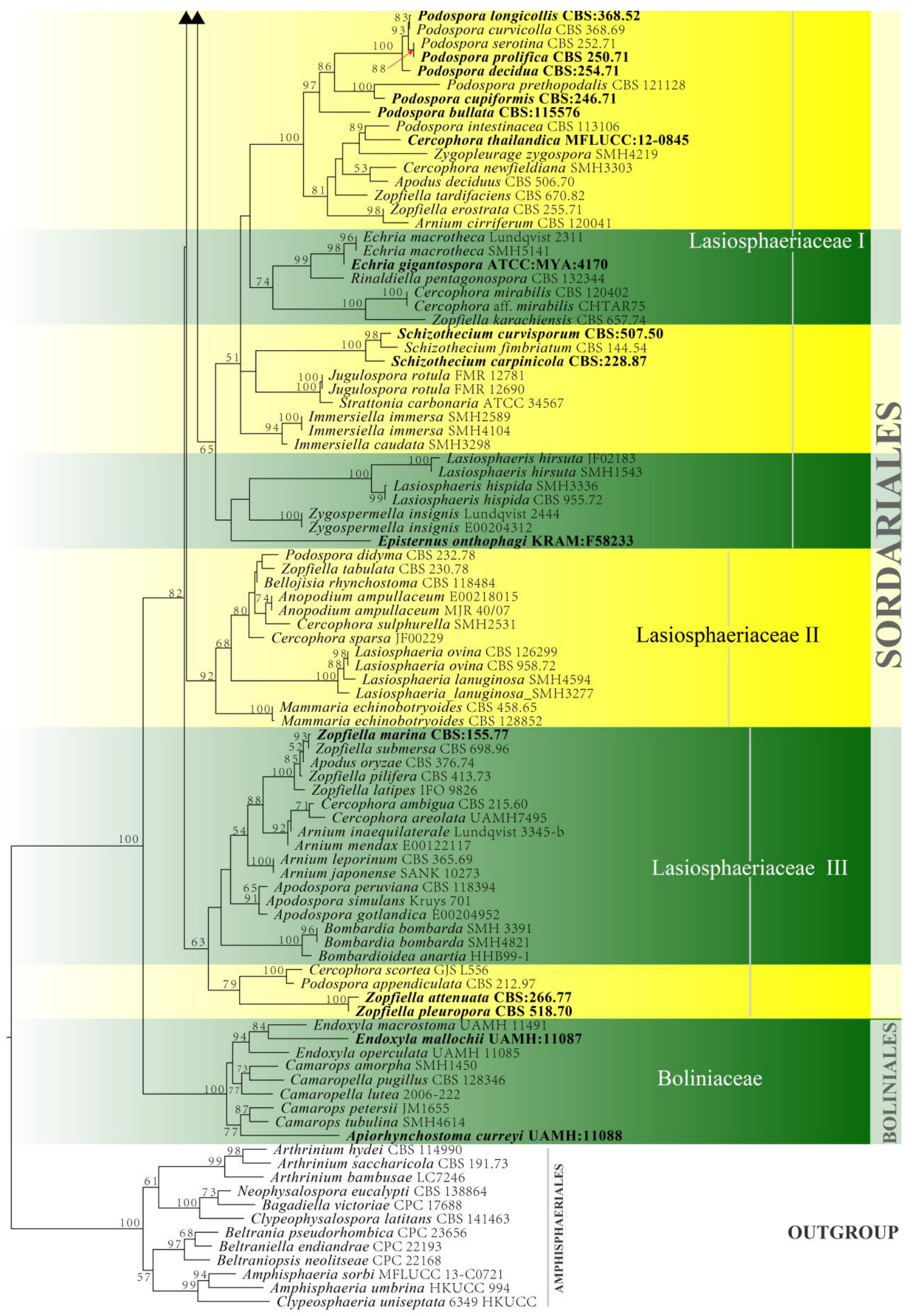

Figure 23 - Continued. 
Sporidesmiales Crous, Persoonia 40: 377 (2018)

Sporidesmiales was introduced by Crous et al. (2018d) and presently only contains Sporidesmiaceae with a single genus. Taxa are saprobic on woody debris in terrestrial and aquatic habitats or mycoparasites of fungi. The divergence time for Sporidesmiales is estimated as 81 MYA (Fig. 2), which is evidence of family status but ranking it as an order may need revision following further study. Currently there is one family and one genus in this order (this paper).

Tirisporellales Suetrong, E.B.G. Jones \& K.L. Pang, Fungal Divers. 73(1): 42 (2015)

The monotypic order Tirisporellales is placed in the class Sordariomycetes, subclass Diaporthomycetidae and comprises a single family Tirisporellaceae. Suetrong et al. (2015) introduced Tirisporellaceae with two monotypic genera Tirisporella and Thailandiomyces. Jones et al. (2015) introduced Tirisporellales to accommodate the genera Tirisporella, Thailandiomyces with an additional genus Bacusphaeria. In our phylogram generated with concatenated LSU and SSU sequence data, the genera Tirisporella (100\% ML, 100\% MP), Thailandiomyces (93\% ML, $100 \%$ MP), and Bacusphaeria (100\% ML, 100\% MP) formed strongly supported clades within Tirisporellales (Fig. 25). In Fig. 1 this order formed an internal clade of Diaporthales and this observation is supported in Hongsanan et al. (2017). However, Tirisporellales was not formally synonymized under Diaporthales by either Hyde et al. (2017a) or Hongsanan et al. (2017). Tirisporellaceae is primarily aquatic with both freshwater and marine taxa with a hyphomycetous asexual morphs which are not usually found in Diaporthales (Zhang et al. 2019). Therefore, we do not place this order in Diaporthales. The divergence time for Tirisporellales is estimated as 142 MYA (Fig. 2). Currently there is one family and three genera in this order (this paper).

Togniniales Senan., Maharachch. \& K.D. Hyde, Fungal Divers. 72: 220 (2015)

Togniniales comprises a single family Togniniaceae based on phylogenetic analyses and it is similar to some members of Calosphaeriaceae in having perithecial ascomata and clavate, tiny asci with hyaline ascogenous hyphae and cylindrical to allantoid ascospores (Maharachchikumbura et al. 2015, Réblová et al. 2015b). Togniniaceae was placed in Diaporthales based on SSU and LSU gene analyses (Mostert et al. 2006). However, multi-gene analyses showed that Togniniales as an independent clade with Diaporthales and Calosphaeriales (Maharachchikumbura et al. 2015, 2016b, Réblová et al. 2015b, Huang et al. 2019). Species of this order have a worldwide distribution and are well-known pathogens of plants and animals (Rooney-Latham et al. 2005, Hoffmann \& Voigt 2011, Kredics et al. 2011, Huang et al. 2018). The divergence time for Togniniales is estimated as 138 MYA (Fig. 2). Currently there is one family and two genera in this order (this paper).

Torpedosporales E.B.G. Jones, Abdel-Wahab \& K.L. Pang, Fungal Divers. 73(1): 42 (2015)

The families Etheirophoraceae, Juncigenaceae and Torpedosporaceae form well-separated (99\% ML, 1.00 PP, 99\% ML, 1.00 PP and 100\% ML, 1.00 PP) clades within Torpedosporales in the phylogram generated from combined LSU, SSU and rpb2 sequence data (Fig. 24). This observation is supported by previous studies of Jones et al. (2015) and Maharachchkumbura et al. (2016b). The divergence time for Torpedosporales is estimated as 185 MYA (Fig. 2). Currently there are three families and ten genera in this order (this paper).

Tracyllalales Crous, Persoonia 40: 365 (2018)

Hernandez-Restrepo et al. (2016a) placed Tracylla aristata within Sordariomycetidae incertae sedis based on LSU and ITS sequence data. With the description of a new species of Tracylla from Eucalyptus urophylla in Colombia, Crous et al. (2018d) introduced Tracyllalales to accommodate the monotypic family Tracyllaceae. Multigene phylogenetic analysis (ITS, LSU, SSU) of T. aristata and T. eucalypti group these taxa in a well-supported clade distinct from known orders within Sordariomycetidae. Tracyllalales is closely related to Chaetosphaeriales. The divergence time for Tracyllalales is estimated as 154 MYA (Fig. 2). Currently there is one family with one genus in this order (this paper). 


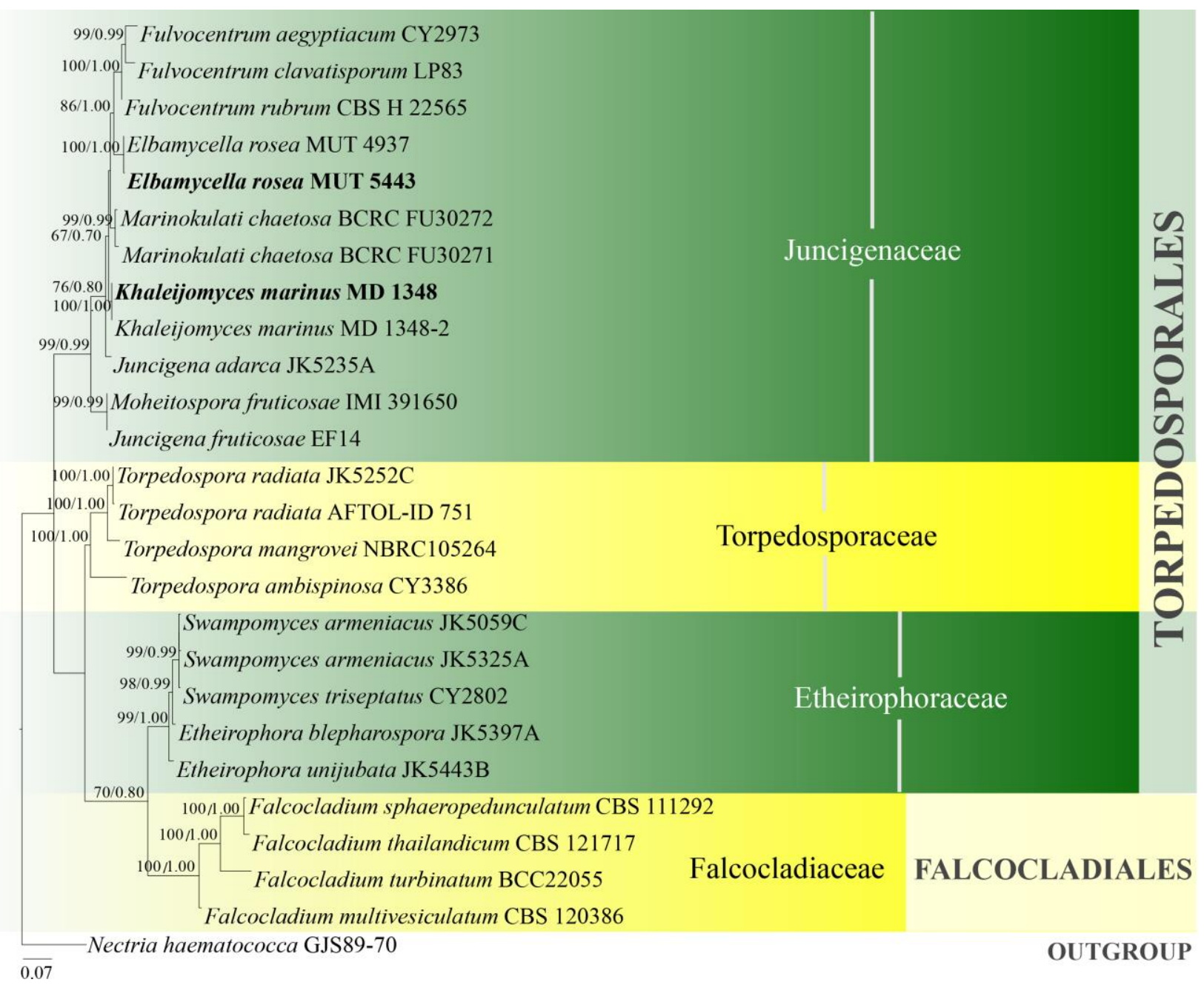

Figure 24 - Phylogram generated from maximum likelihood analysis based on combined LSU, SSU and $r p b 2$ sequence data of selected taxa from Falcocladiales and Torpedosporales. Twenty-six strains are included in the combined gene analyses comprising 3557 characters after alignment (1142 characters for LSU, 1440 characters for SSU and 967 characters for rpb2). Nectria haematococca (GJS89-70) is used as the outgroup taxon. Analyses of each single gene were performed and the topology of each tree had clade stability. The tree topology in maximum likelihood analysis was similar to the Bayesian and maximum parsimony analyses. Maximum likelihood analysis with 1000 bootstrap replicates yielded a best tree with the likelihood value of 14936.746257. The matrix had 1096 distinct alignment patterns, with $25.55 \%$ of undetermined characters or gaps. Estimated base frequencies were as follows; $\mathrm{A}=0.247642, \mathrm{C}=0.231060, \mathrm{G}=$ $0.304405, \mathrm{~T}=0.216894$; substitution rates $\mathrm{AC}=1.746605, \mathrm{AG}=3.110551, \mathrm{AT}=1.540183, \mathrm{CG}=$ $1.746965, \mathrm{CT}=7.476678, \mathrm{GT}=1.000000$; gamma distribution shape parameter $\alpha=0.291342$. Maximum parsimony (black) and maximum likelihood (black) bootstrap values $>65 \%$ and Bayesian posterior probabilities (blue) $>0.90$ (ML/BYPP) are given above the nodes. Ex-type strains are in bold.

Vermiculariopsiellales Hern.-Restr., J. Mena, Gené \& Crous, Stud. Mycol. 86: 91 (2017)

Hernández-Restrepo et al. (2017) introduced Vermiculariopsiellales and one family, Vermiculariopsiellaceae, and one genus, Vermiculariopsiella, were accepted. ITS, LSU, SSU, actA and tefl sequence data are available for species of Vermiculariopsiella. In our phylogenetic analyses generated from LSU, ITS, SSU and $r p b 2$ sequence data, Vermiculariopsiellales formed a monophyletic clade with high statistical support (100\% MPBS/1.00 PP) (Fig. 22). The divergence time for Vermiculariopsiellales is estimated as 131 MYA (Fig. 2). Currently there is one family with one genus in this order (this paper). 
Xenospadicoidales Hern.-Restr., J. Mena \& Gené, Stud. Mycol. 86: 91 (2017)

Xenospadicoidales is shown as a strongly supported monophyletic group and the single family Xenospadicoidaceae was proposed to replace Lentomitellaceae (Hernández-Restrepo et al. 2017, Réblová et al. 2018). The genera Xenospadicoides and Pseudodiplococcium were also synonymized under Spadicoides (Réblová et al. 2018). Luo et al. (2019) introduced another freshwater genus Neospadicoides. All genera formed a well-supported clade in this study (Fig. 3). The divergence time for Xenospadicoidales is estimated as 106 MYA (Fig. 2). Currently there is one family and five genera in this order (this paper).

Xylariales Nannf., Nova Acta R. Soc. Scient. upsal., Ser. 4 8(no. 2): 66 (1932)

Maharachchikumbura et al. (2016b) accepted Xylariales as the only order in the subclass Xylariomycetidae, which comprised 22 families. However, Samarakoon et al. (2016) and Hongsanan et al. (2017) provided phylogenetic and divergence time estimations for the subclass Xylariomycetidae and accepted Amphispheriales and Xylariales. Wijayawardene et al. (2018a) accepted 12 families in Xylariales, including Myelospermataceae, which lacks molecular data. However, the phylogenetic placements of the families Oxydothidaceae and Polystigmataceae are uncertain in two different analyses (Figs 1, 4). However, following the previous phylogenetic treatments (Konta et al. 2016, Dayarathne et al. 2017) we accept Oxydothidaceae and Polystigmataceae as families of Xylariales. We accept 15 families in Xylariales, including Barrmaeliaceae, Cainiaceae, Clypeosphaeriaceae, Coniocessiaceae, Diatrypaceae, Graphostromataceae, Hansfordiaceae, Hypoxylaceae, Induratiaceae, Lopadostomataceae, Microdochiaceae, Polystigmataceae, Requienellaceae, Xylariaceae and Zygosporiaceae, while Myelospermataceae is placed in the Xylariomycetidae families, incertae sedis. The divergence time for Xylariales is estimated as 147 MYA (Fig. 2). Here we accept 160 genera in Xylariales.

\section{The families and genera of Sordariomycetes}

In this section we list the families of Sordariomycetes in alphabetical order, providing descriptions, brief history and notes on the ecological and economic significance. The accepted genera are listed, starting with the type genus and rest alphabetically, with brief notes.

Acrodictyaceae J.W. Xia \& X.G. Zhang, Scientific Reports 7 (no. 7888): 2 (2017)

Index Fungorum number: IF818894; Facesoffungi number: FoF06600; 25 species.

Saprobic on terrestrial or freshwater habitats. Sexual morph: Undetermined. Asexual morph: Hyphomycetous. Colonies on natural substrate effuse, hairy or velvety, yellowish brown to black. Mycelia immersed, composed of pale brown, septate, branched hyphae. Conidiophores macronematous, mononematous, erect, cylindrical, greenish brown to brown, septate, mostly unbranched, straight or broadly curved, thick-walled. Conidiogenous cells monoblastic, integrated, terminal, cylindrical, greenish brown to brown, thick-walled. Conidia acrogenous, solitary, dry, greenish brown to dark brown, obovoid to pyriform, muriform, deeply constricted at septa; conidial secession schizolytic (adapted from Xia et al. 2017).

Type genus - Acrodictys M.B. Ellis

Notes - Xia et al. (2017) studied acrodictys-like species and established Acrodictyaceae based on molecular data. Acrodictyaceae is a monotypic family containing the type genus Acrodictys. Acrodictyaceae species are characterized by macronematous, mostly unbranched conidiophores and obovoid to pyriform, muriform conidia. Sexual morphs in this family have not been reported.

\section{Ecological and economic significance of Acrodictyaceae}

Acrodictyaceae species often occur as saprobes in both freshwater and terrestrial habitats. As decomposers, species are involved in nutrient cycling. Moreover, the ecological role of freshwater fungi has increasingly been recognized (Hyde et al. 2016a). Freshwater fungi can cause soft rot decay (Zare-Maivan \& Shearer 1988b, Yuen et al. 2000, Bucher et al. 2004), therefore, lignicolous 
freshwater species, such as A. aquatica, may play important functional roles in nutrient cycling of woody material.

\section{Genus included in Acrodictyaceae}

Acrodictys M.B. Ellis, Mycological Papers 79: 5 (1961)

Index Fungorum number: IF7034; 25 morphological species (Species Fungorum 2020), 10 species with sequence data (Luo et al. 2019).

Type species - Acrodictys bambusicola M.B. Ellis

Notes - Ellis (1961) introduced Acrodictys, typified by A. bambusicola. Baker et al. (2002) reviewed the status of Acrodictys and refined the generic concept in a stricter sense. Based on the narrower concept, some species were excluded from Acrodictys and transferred to new genera, for example, Junewangia, Rhexoacrodictys, Pseudoacrodictys and Ramoacrodictys (Baker et al. 2002, Baker \& Morgan-Jones 2003, Zhao et al. 2009). Seifert et al. (2011) provided a taxonomic key to Acrodictys and similar genera. The sexual morph of A. aquatica is illustrated in this entry (Fig. 25).

Amphisphaeriaceae G. Winter, Rabenh. Krypt.-Fl., Edn 2 (Leipzig) 1.2: 259 (1885)

Index Fungorum number: IF80452; Facesoffungi number: FoF00673; 105 species.

Saprobic on leaves, twigs, and branches of deciduous shrubs and trees, conifers or monocotyledons and occasionally hemibiotrophic or necrotrophic, appearing as slightly raised, black dots on host surface, often surrounded by a darkened area. Sexual morph: Pseudostromata when present made up of host cells and brown to black fungal hyphae, solitary, uni- to bi-loculate, hemisphaerical, initially appearing as raised, pale brown areas, with small, black dots at the center, becoming dark at maturity, glabrous. Ascomata perithecial, scattered to clustered, immersed in host cortex, becoming raised, subglobose to lenticular, glabrous, dark brown to black, vegetative hyphae surrounding the locules, ostioles individual, central. Papilla erumpent through host surface, internally lined by hyaline, filamentous periphyses. Peridium of unequal thickness, thinner at the base, thicker towards the mid-upper section of the ascomata, comprising several layers of dark brown pseudoparenchymatous cells, the outer layer of thick-walled, brown cells of textura prismatica, the inner layer of flattened, hyaline cells of textura prismatica. Paraphyses numerous, septate, filamentous. Asci 8-spored, unitunicate, cylindrical, short pedicellate, apex rounded, with $\mathrm{J}+$ or J-, apical ring. Ascospores overlapping uniseriate, light to dark brown, ellipsoidal to fusiform, 1-septate. Asexual morph: Coelomycetous. Conidiomata solitary or aggregated, globose, dark brown. Peridium comprising thick-walled, septate, brown mycelium. Conidiophores dichotomously branched, septate, thick-walled, smooth, hyaline. Conidiogenous cells elongated, wide at the base and narrow at the tip, thin-walled, hyaline. Conidia hyaline, 1-celled, smooth-walled, elongate to fusiform, narrow at both ends (adapted from Maharachchimbura et al. 2016).

Type genus - Amphisphaeria Ces. \& De Not.

Notes - Amphisphaeriaceae was introduced by Winter (1885a) as 'Amphisphaerieae' and later established as Amphisphaeriaceae to accommodate the type genus Amphisphaeria and similar genera, viz. Caryospora, Ohleria, Strickeria, Trematosphaeria and Winteria (Winter 1887). Kirk et al. (2008) confirmed the family within the Xylariales comprising 32 genera with 499 species. Senanayake et al. (2015) accepted only the type genus Amphisphaeria while excluding all other genera based on their morphology and phylogeny. Some were transferred to Bartaliniaceae, Discosiaceae, Iodosphaeriaceae, Sporocadaceae, and Phlogicylindriaceae. Jaklitsch et al. (2016b) and Maharachchikumbura et al. (2016b) accepted only Amphisphaeria and Lepteutypa as belonging to the family based on molecular phylogenetic studies.

Earlier, Amphisphaeriaceae was classified in Xylariales and thought to share a close relationship with Cainiaceae, Clypeosphaeriaceae, and Hyponectriaceae (Jeewon 2002). However, Senanayake et al. (2015) resurrected Amphisphaeriales, which was introduced by Eriksson \& Hawksworth (1986a) based on combined gene analyses. Amphisphaeriales was not followed in Maharachchikumbura et al. (2016b) and Jaklitsch et al. (2016b). Samarakoon et al. (2016) and Hongsanan et al. (2017) provided divergence estimates as additional information for 
Amphisphaeriales. Wijayawardene et al. (2018a) accepted three genera Amphisphaeria, Griphosphaerioma, and Lepteutypa in Amphisphaeriaceae (Amphisphaeriales).

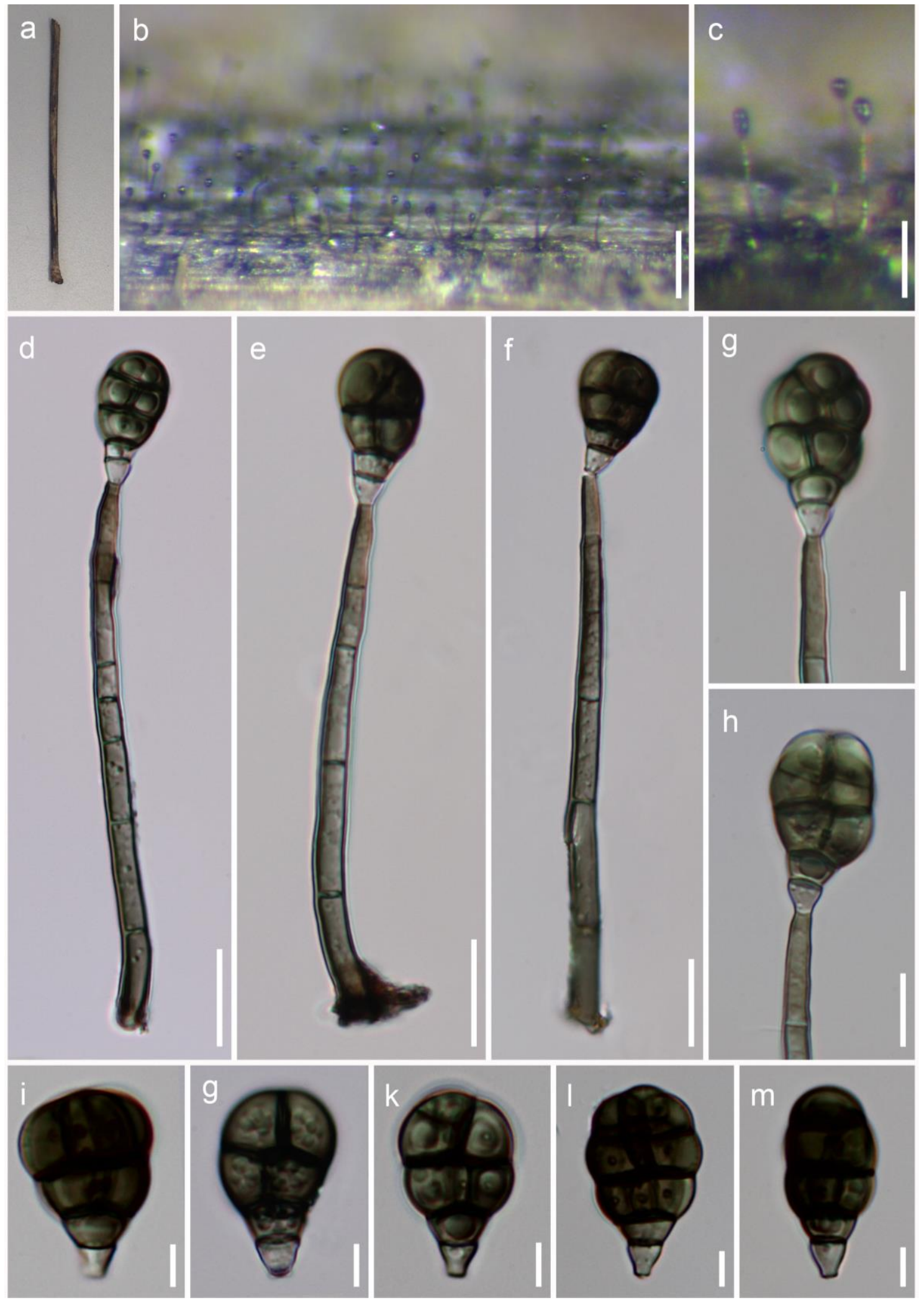

Figure 25 - Acrodictys aquatica (Material examined - THAILAND, Chiang Rai Province, Muang, Ban Nang Lae Nai, on decaying wood submerged in a freshwater stream, 31 December 2016, NG Liu, CR004, MFLU 18-0040, holotype). a Specimen. b, c Colonies on substrate. d-f Conidiophores and conidia. g, $h$ Conidiogenous cells and conidia. i-m Conidia. Scale bars: $b=100 \mu \mathrm{m}, \mathrm{c}=50 \mu \mathrm{m}$, $\mathrm{d}-\mathrm{f}=15 \mu \mathrm{m}, \mathrm{g}, \mathrm{h}=10 \mu \mathrm{m}, \mathrm{i}-\mathrm{m}=5 \mu \mathrm{m}$. 


\section{Ecological and economic significance of Amphisphaeriaceae}

Amphisphaeriaceous taxa play a major role as saprobes on dead plant material in terrestrial, aquatic (submerged wood) and marine habitats (Wang et al. 2004, Liu et al. 2015, Senanayake et al. 2015, 2019, Jaklitsch et al. 2016b, Phookamsak et al. 2018, Samarakoon et al. 2018). Some species (e.g. Lepteutypa hederae) are important decomposers of hardwood (Rappaz 1995).

\section{Genera included in Amphisphaeriaceae}

Amphisphaeria Ces. \& De Not., Comm. Soc. crittog. Ital. 1(4): 223 (1863)

Index Fungorum number: IF173; 88 morphological species (Species Fungorum 2020), 18 morphological species (Senanayake et al. 2019), 6 species with sequence data.

Type species - Amphisphaeria umbrina (Fr.) De Not.

Notes - Amphisphaeria was introduced by Cesati \& De Notaris (1863). Wang et al. (2004) re-examined more than 170 type species described as Amphisphaeria and accepted 12 species. Senanayake et al. (2015) reviewed the phylogenetic status of the genus, which is sister to Lepteutypa (Jaklitsch et al. 2016b). Based on phylogenetic investigations, other six new species have been added: A. doidgeae (Marincowitz et al. 2008), A. sorbi (Liu et al. 2015), A. mangrovei (Phookamsak et al. 2019), A. flava, A. thailandica (Samarakoon et al. 2019a) and A. acericola (Senanayake et al. 2019) respectively. The sexual morph of $A$. acericola and asexual morph of $A$. sorbi are illustrated in this entry (Figs. 26, 27).
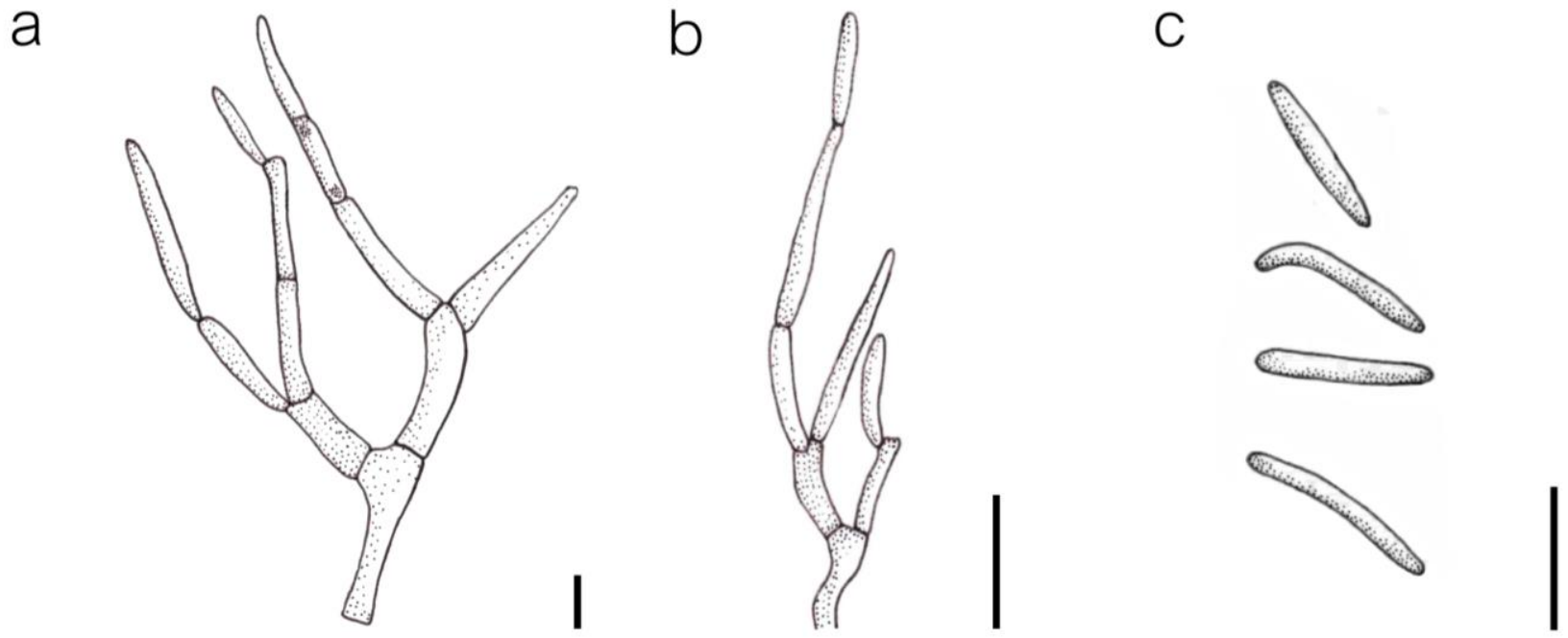

Figure 26 - Amphisphaeria sorbi (ex-type culture MFLUCC 13-0721, redrawn from Liu et al. 2015). a, b Conidiophores and conidiogenous cells with attached conidia. c Conidia. Scale bars: a-c $=10 \mu \mathrm{m}$.

Griphosphaerioma Höhn., Ber. dt. bot. Ges. 36(7): 312 (1918)

Index Fungorum number: IF2140; 2 morphological species (Species Fungorum 2020).

Type species - Griphosphaerioma symphoricarpi (Ellis \& Everh.) Höhn.

Notes - Wijayawardene et al. (2018a) accepted Griphosphaerioma in Amphisphaeriaceae based on the known asexual morphs. Griphosphaerioma is characterised by unitunicate, cylindrical asci with a $\mathrm{J}$-, apical ring, and uniseriate, ellipsoidal, hyaline, 1-septate or rarely 2- to 3-septate ascospores (Kang et al. 1999a). Ono \& Kobayashi (2003) introduced G. zelkovicola from bark of Zelkova serrata with a Sarcostroma asexual morph. However, the phylogenetic affinity of the genus is still in doubt due to the lack of cultures and DNA sequences.

Lepteutypa Petr., Ann. Mycol. 21(3/4): 276. (1923)

Index Fungorum number: IF2758; 15 morphological species (Jaklitsch et al. 2016b, Species Fungorum 2020), 5 species with sequence data. 

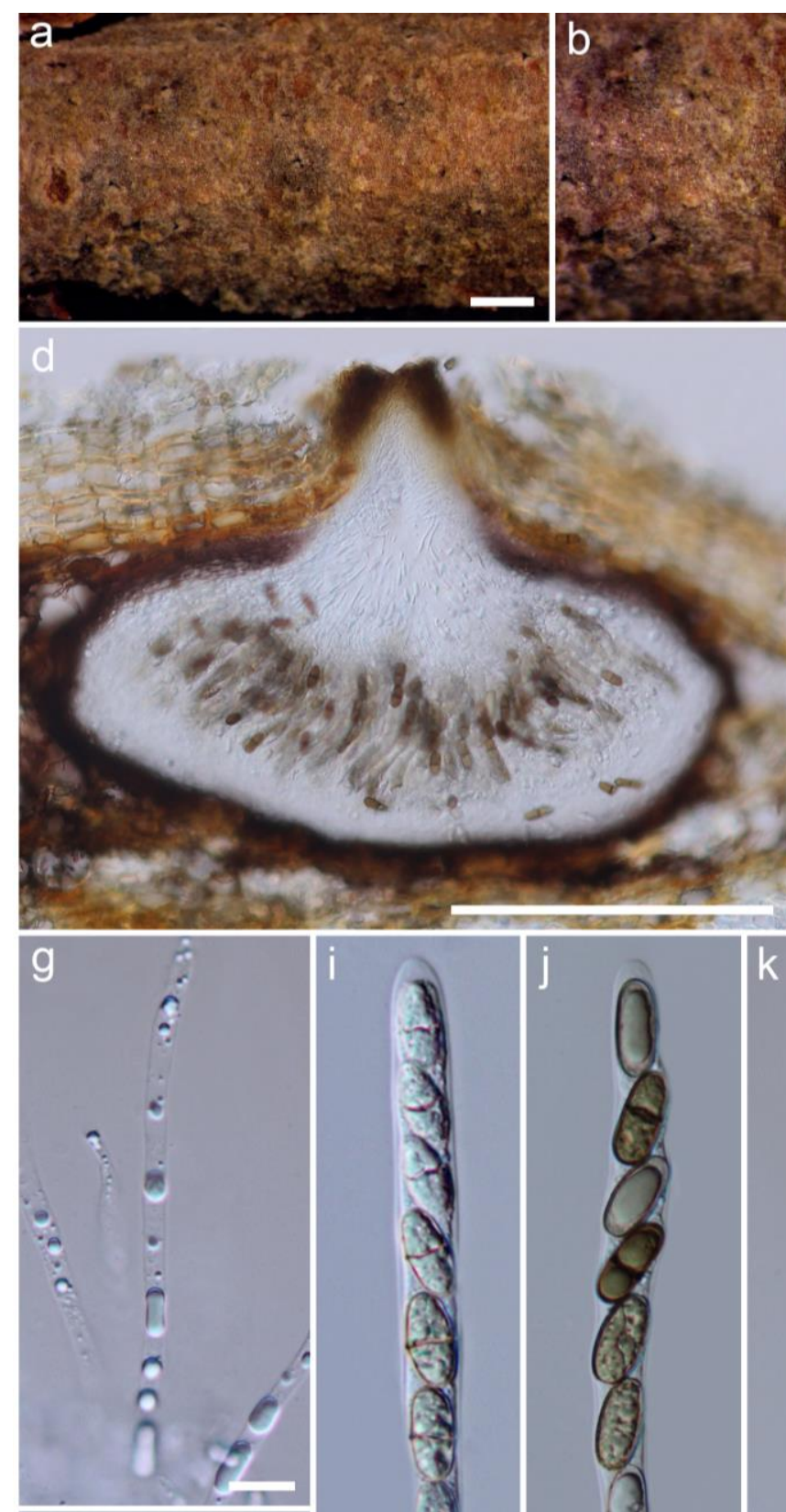

h
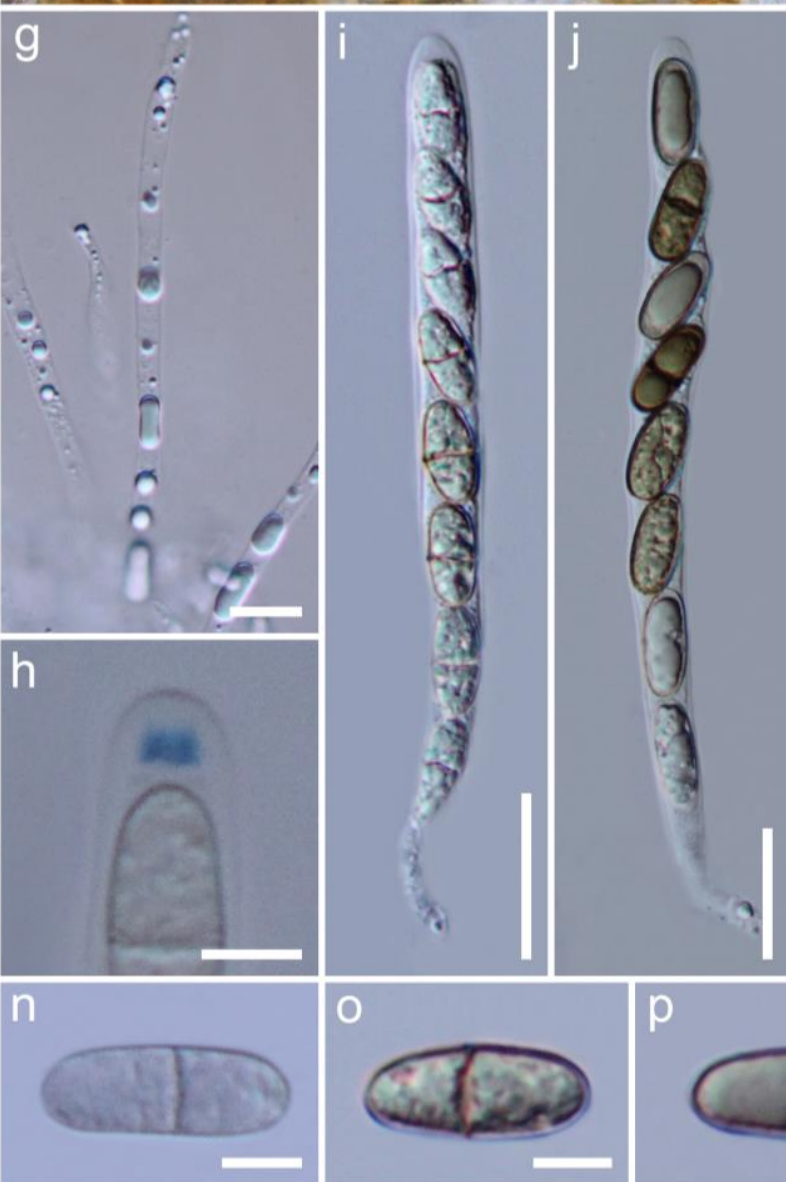
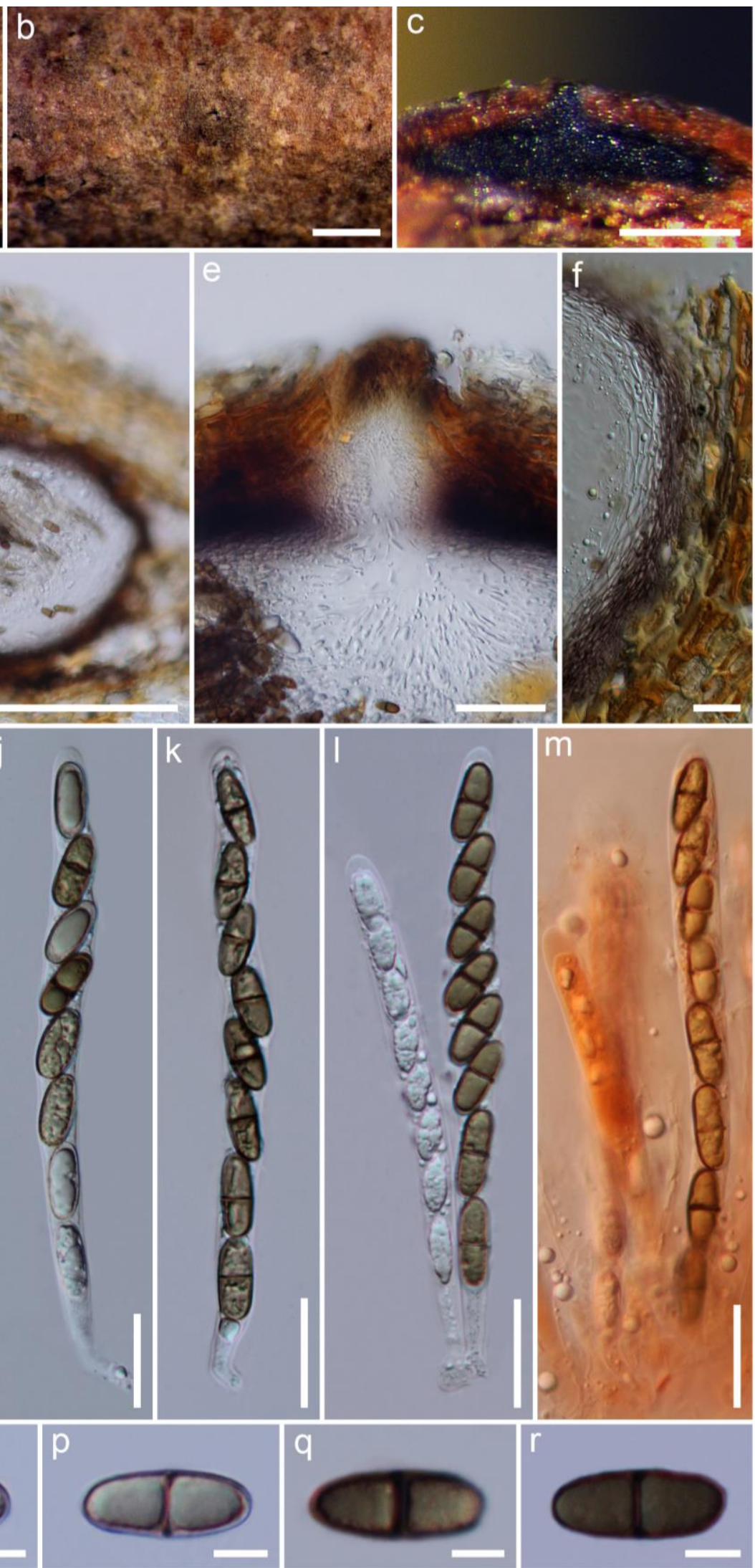

m
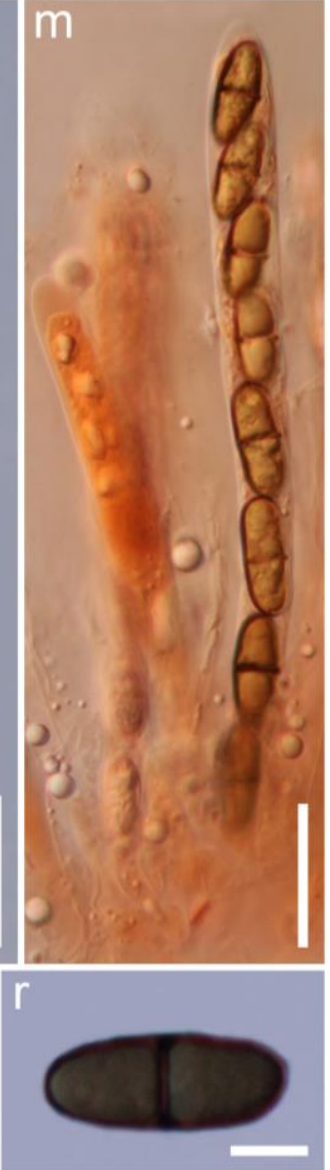

Figure 27 - Amphisphaeria acericola (Material examined - ITALY, Province of Forlì-Cesena, Galeata, Strada San Zeno, on a branch of Acer campestre, 26 March 2014, E. Camporesi, IT 1779, MFLU 16-2479, holotype). a, b Ascomata on the substrate. c, d Cross-sections of ascoma. e Ostiole. f Peridium. g Paraphyses. $\mathrm{h} \mathrm{J}+$, apical ring. i-m Asci (m stained in Congo Red). n-r Ascospores. Scale bars: a, $\mathrm{b}=500 \mu \mathrm{m}, \mathrm{c}, \mathrm{d}=200 \mu \mathrm{m}, \mathrm{e}=50 \mu \mathrm{m}, \mathrm{f}, \mathrm{i}-\mathrm{m}=20 \mu \mathrm{m}, \mathrm{g}=10 \mu \mathrm{m}, \mathrm{h}, \mathrm{n}-\mathrm{r}$ $=5 \mu \mathrm{m}$. 
Type species - Lepteutypa fuckelii (G.H. Otth) Petr.

Notes - Lepteutypa species are saprobes with a worldwide distribution (Wijayawardene et al. 2017a). Jaklitsch et al. (2016b) revisited the genus, designated the neotype for L. fuckelii, and introduced a new species, L. sambuci. Luo et al. (2019) introduced L. aquatica on decaying wood submerged in freshwater habitats. Some of the sequences in GenBank are similar to species of those members of Sporocadaceae and need further studies with molecular data.

Amplistromataceae Huhndorf, A.N. Mill., Greif \& Samuels, Mycologia 101(6): 905 (2009)

Index Fungorum number: IF513238; Facesoffungi number: FoF00618; 31 species.

Saprobic on bark or wood or in highly acidic soil. Sexual morph: Stromata superficial, turbinate, obovoid to irregularly pulvinate, texture soft or firm with polystichous or monostichous ascomata, or stromata absent and ascomata single to clustered, with or without a hyphal subiculum. Ascomata globose or subglobose, with a cylindrical or rostrate neck. Paraphyses abundant, tapering, of broad cells. Asci 8-spored, unitunicate, cylindrical to clavate, pedicellate, apical ring J-. Ascospores uniseriate, unicellular, tiny, globose, hyaline. Asexual morph: Hyphomycetous. acrodontium-like. Conidiophores semi-macronematous or macronematous. Conidiogenous cells lageniform to ampulliform, elongating sympodially forming a rachis; conidiogenesis holoblasticdenticulate. Conidia single, globose, or ellipsoidal to lacrimose, hyaline to pale brown (adapted from Maharachchimbura et al. 2016b).

Type genus - Amplistroma Huhndorf, A.N. Mill., Greif \& Samuels

Notes - Amplistromataceae was introduced by Huhndorf et al. (2009) to accommodate Amplistroma and Wallrothiella and referred to Sordariomycetidae, family incertae sedis. Wallrothiella differs from Amplistroma mainly by the lack of stromatal structures (Huhndorf et al. 2009). Maharachchikumbura et al. (2015) introduced Amplistromatales with two families Amplistromataceae and Catabotryaceae. Phylogenetic analyses based on LSU, SSU, tef1 and rpb2 markers revealed that Amplistromatales is distinct from Meliolales and other members of Sordariomycetidae and was referred to Sordariomycetes incertae sedis until further data is available. Amplistromatales was accepted in Diaporthomycetidae, Sordariomycetes (Hongsanan et al. 2017, Wijayawardene et al. 2017a). In this entry, the asexual morphs of Acidothrix acidophila and sexual morph of Amplistroma erinaceum are illustrated (Figs. 28, 29).

\section{Ecological and economic significance of Amplistromataceae}

Amplistromataceae species play a major role as saprobes thriving on decaying wood or bark (Amplistroma and Wallrothiella) and in extremely acidic soil $(\mathrm{pH}<3)$ (Acidothrix) (Huhndorf et al. 2009, Hujslová et al. 2014). However, there is potential to use the acidophilic fungi in bioremediation processes (Hujslová et al. 2019). We could not find any published chemical profiling associated with amplistromataceous taxa, and therefore the secondary metabolites associated with these species adapted to extremely variable environments might be worth investigating.

\section{Genera included in Amplistromataceae}

Acidothrix Hujslová \& M. Kolařík, Mycol. Progr. 13(3): 824 (2014)

Index Fungorum number: IF805194; 1 species with sequence data.

Type species - Acidothrix acidophila Hujslová \& M. Kolařík

Notes - Acidothrix was isolated from acidic soil from the Czech Republic (Hujslová et al. 2014). It is known only as the asexual morph (Fig. 28) and is morphologically similar to acrodontium-like asexual morphs reported for Amplistroma and Wallrothiella.

Amplistroma Huhndorf, A.N. Mill., Greif \& Samuels, Mycologia 101(6):907 (2009)

Index Fungorum number: IF513239; 9 morphological species (Species Fungorum 2020), 6 species with sequence data.

Type species - Amplistroma carolinianum Huhndorf, A.N. Mill., Greif \& Samuels 
Notes - Amplistroma was introduced by Huhndorf et al. (2009) as sister to Wallrothiella. Members are saprobes with hyphomycetous, acrodontium-like asexual morphs.
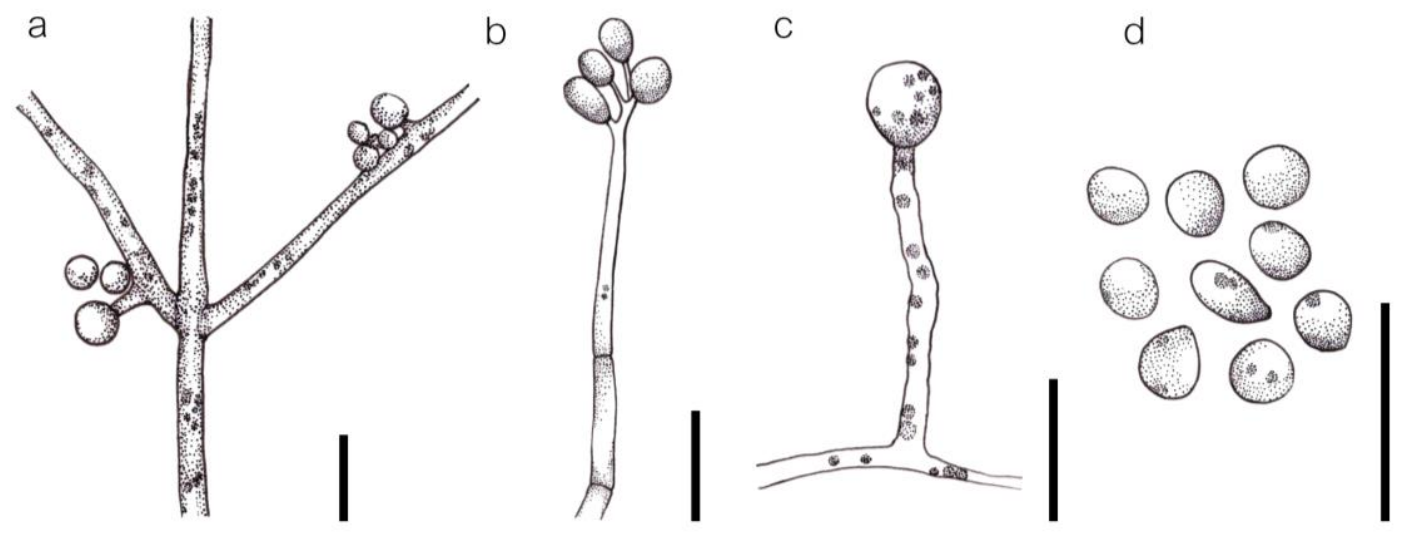

Figure 28 - Acidothrix acidophila (ex-type culture CBS 136259, redrawn from Hujslová et al. 2014). a-c Conidiophores and conidia. d Conidia. Scale bars: $10 \mu \mathrm{m}$.

Wallrothiella Sacc., Syll. fung. (Abellini) 1: 455 (1882)

Index Fungorum number: IF5760; 21 morphological species (Species Fungorum 2020), 3 species with sequence data.

Type species - Wallrothiella congregata (Wallr.) Sacc.

Notes - Wallrothiella was introduced by Saccardo (1882) and re-described by Réblová \& Seifert (2004b) based on new collections; a neotype for $W$. congregata, the type species of the genus, was proposed. Wallrothiella is characterized by the absence of stromata, globose to subglobose ascomata with a rostrate neck, sometimes surrounded by a whitish subiculum, and tiny, globose ascospores in cylindrical asci.

Annulatascaceae S.W. Wong, K.D. Hyde \& E.B.G. Jones, Syst. Ascom. 16(1-2): 18 (1998)

Index Fungorum number: IF81939; Facesoffungi number: FoF01212; 38 species.

Saprobic on submerged wood; sometimes on bamboo and on other substrates in terrestrial habitats. Sexual morph: Ascomata perithecial, scattered or densely aggregated in patches, immersed, partially superficial, brown to black, ostiolate, unilocular, rarely clypeate, globose to subglobose, ellipsoidal, smooth or rough-walled with short setose-like hyphae on the outside. Ostiolar necks cylindrical to conical, black, black at the base and pale yellow or lighter at the apex in some genera, glabrous, rarely with setae, hyphae or hairs. Peridium carbonaceous or coriaceous composed of cells of textura angularis, textura intricata, textura epidermoidea or textura prismatica with compressed cells. Paraphyses numerous, septate, branched or unbranched, tapering. Asci 8-spored, unitunicate, cylindrical, pedicellate, usually with a massive J-, refractive, cylindrical to flaring, doughnut-shaped, apical ring. Ascospores usually uniseriate, sometimes overlapping, hyaline to pale yellow or brown, ellipsoidal to oval or fusiform or lunate or citriform, unicellular or septate, septa mostly transverse, smooth or roughed, with or without appendages, mucilaginous sheath and germ pores. Asexual morph: Hyphomycetous. taeniolella-like for Chaetorostrum where Conidiophores are micronematous, mononematous. Conidia monoblastic, elongate cylindrical, trans-septate, euseptate, brown, paler near the apex. Conidial secession schizolytic (adapted from Maharachchimbura et al. 2016b).

Type genus - Annulatascus K.D. Hyde

Notes - Annulatascaceae was introduced by Wong et al. (1998d), with Annulatascus as the type genus. Maharachchikumbura et al. (2015) formally placed it in Annulatascales based on phylogenetic analyses. Many genera, having a relatively massive apical ring, were placed in Annulatascaceae as listed in Maharachchikumbura et al. (2016b). Zhang et al. (2017a) excluded some genera to other families and Diaporthomycetidae genera incertae sedis based on phylogenetic 
analyses and divergence estimates. Currently, ten genera are accepted in this study (as listed below). Annulatascaceae species clustered in a distinct clade, but with low bootstrap support as shown in Luo et al. (2019) and this study.

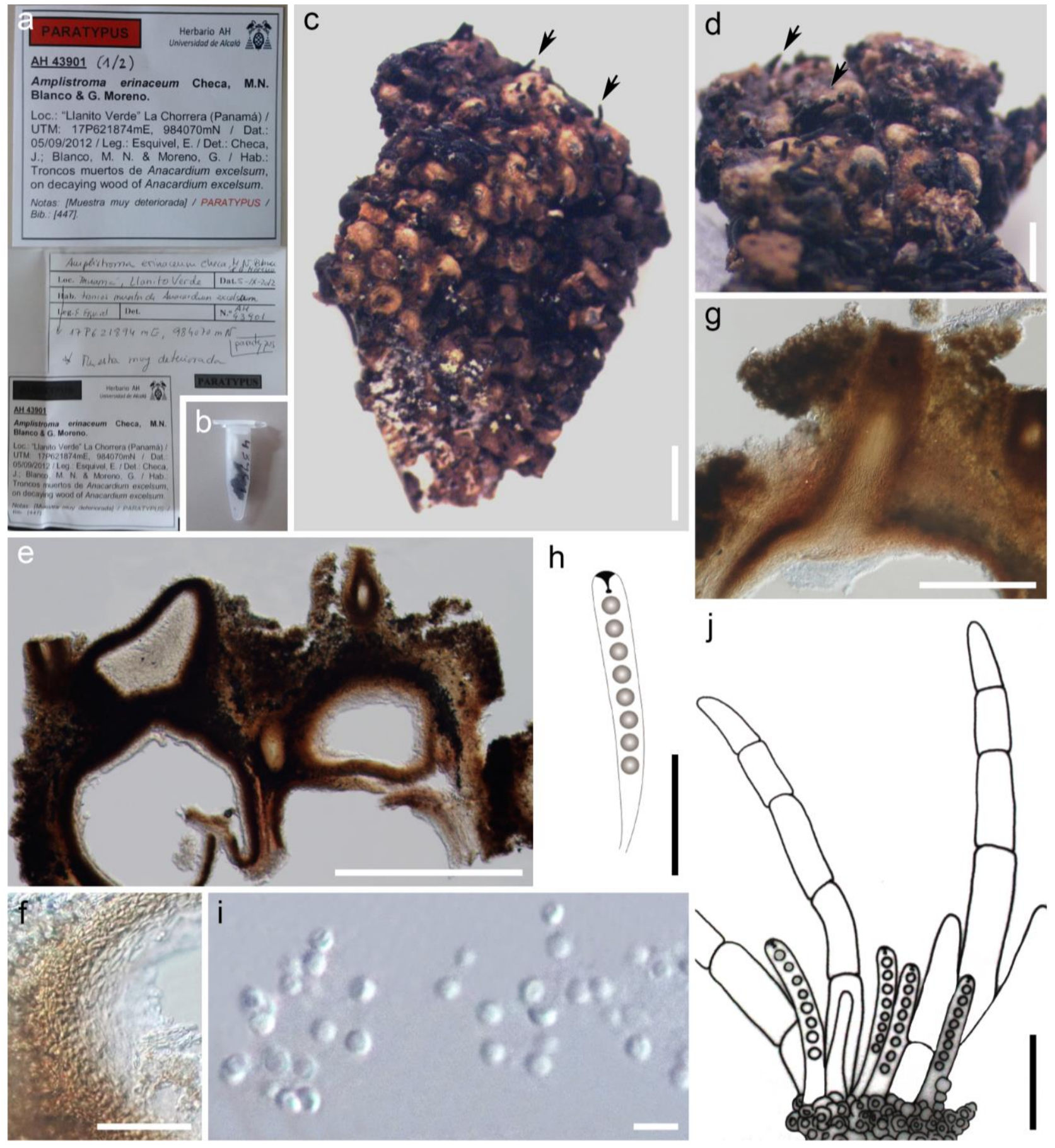

Figure 29 - Amplistroma erinaceum (Material examined - PANAMA, La Chorrera, Llanito Verde, on decaying wood of Anacardium excelsum (Anacardiaceae), E. Esquivel, 5 September 2012, AH 43901, paratype). a, b Herbarium details. c, d Stroma (long ostiolar necks are in black arrows). e Longitudinal section of stroma. f Peridium. g Longitudinal section through the neck. $\mathrm{h}$ Asci. $\mathrm{i}$ Ascospores. j Paraphyses and asci ( $h, j$ redrawn from Checa et al. 2013). Scale bars: $c=1000 \mu \mathrm{m}$, $\mathrm{d}, \mathrm{e}=500 \mu \mathrm{m}, \mathrm{g}=200 \mu \mathrm{m}, \mathrm{f}=50 \mu \mathrm{m}, \mathrm{h}, \mathrm{j}=10 \mu \mathrm{m}, \mathrm{i}=5 \mu \mathrm{m}$.

\section{Ecological and economic significance of Annulatascaceae}

Annulatascaceae species are generally saprobic on submerged wood in freshwater, sometimes on bamboo and on other substrates in terrestrial habitats (Maharachchikumbura et al. 2016b). 
Annulusmagnus triseptatus produces soft-rot cavities on balsa wood in culture (Campbell \& Shearer 2004). Species are involved in nutrient cycling (Tsui et al. 2000).

\section{Genera included in Annulatascaceae}

Annulatascus K.D. Hyde, Aust. Syst. Bot. 5(1): 118 (1992)

Index Fungorum number: IF25398; 17 morphological species (Species Fungorum 2020), 7 species with sequence data.

Type species - Annulatascus velatispora K.D. Hyde

Notes - Annulatascus is the type genus of Annulatascaceae and was introduced by Hyde (1992b) based on two tropical freshwater taxa, A. velatispora as the type species and A. bipolaris. However, the holotype of $A$. velatisporus was in poor condition as herbarium material had only a few ascomata. Thus, Dayarathne et al. (2016a) designated an epitype, which was collected from submerged wood in a river, at Millaa Millaa Falls, north Queensland, Australia, based on morphological examination and DNA sequences. The genus presently contains 19 epithets (Index Fungorum 2020) and molecular data has demonstrated that this genus is polyphyletic (AbdelWahab et al. 2011, Luo et al. 2015) and confirmed that placement of species in this genus based solely on the relatively massive apical ascal ring is not very reliable (Abdel-Wahab et al. 2011, Luo et al. 2015). In our phylogenetic analyses, Annulatascus nilensis does not cluster within Annulatascus, but is basal to Ascitendus, Longicollum and Submersisphaeria with low bootstrap support (Fig. 3). Annulatascus nilensis also formed a weakly-supported clade with members of Annulatascus (Abdel-Wahab et al. 2011, Luo et al. 2019). Fresh collections and multigene phylogenies are needed to resolve the taxonomy of this group of fungi. We introduce a new species, Annulatascus thailandensis (Fig. 30) and redescribe the type species, A. velatisporus (Fig. 31).

Annulatascus thailandensis W. Dong, H. Zhang \& K.D. Hyde, sp. nov.

Fig. 30

Index Fungorum number: IF556954; Facesoffungi number: FoF06860

Etymology - In reference to the host location in Thailand, where the holotype was collected.

Holotype - MFLU 18-1556.

Saprobic on decaying wood submerged in freshwater. Sexual morph: Ascomata 170-200 $\mu \mathrm{m}$ high, 250-300 $\mu \mathrm{m}$ diam, solitary or gregarious, superficial, ellipsoidal or subglobose, black, coriaceous, with a lateral neck, often lying horizontally or obliquely to the substrate surface. Neck long or short, black, curving upwards or lying on the host surface, up to $600 \mu \mathrm{m}$ long. Ostiole eccentric, lateral, black, periphysate. Peridium 32-37 $\mu \mathrm{m}$ thick at upper part, comprising 5-8 layers of brown to dark brown, thick-walled, compressed cells of textura angularis or round cells; 75-85 $\mu \mathrm{m}$ thick near the base where below the neck, comprising 12-15 layers of pale brown to brown, thin-walled, compressed cells of textura angularis or irregular cells; 3-5 layers of hyaline, compressed cells of textura angularis inwardly. Paraphyses ca 4-5.5 $\mu \mathrm{m}$ diam. near the base, tapering distally, hypha-like, numerous, hyaline, unbranched, septate, constricted at the septa. Asci 275-375 $\times 13-15 \mu \mathrm{m}(\bar{x}=310 \times 13.7 \mu \mathrm{m}, \mathrm{n}=10), 8$-spored, unitunicate, cylindrical, apically rounded, with a long pedicel, up to $130 \mu \mathrm{m}$ long, with a massive, wedge-shaped, refractive apical ring, 3.5-4 $\mu \mathrm{m}$ high $\times 5.5-6 \mu \mathrm{m}$ wide. Ascospores $28-33 \times 10.5-11.5 \mu \mathrm{m}(\bar{x}=30.8 \times 11.2 \mu \mathrm{m}, \mathrm{n}=$ 10), uniseriate, hyaline, ellipsoidal to fusiform, straight to curved, 1-2-septate, slightly constricted at the septa, minutely guttulate, thin-walled, with a large, nearly ellipsoidal, mucilaginous sheath, 10-15 $\mu \mathrm{m}$ thick. Asexual morph: Undetermined.

Culture characteristics - On PDA, colony circular with filamentous margin, reaching $30 \mathrm{~mm}$ in 35 days at $25^{\circ} \mathrm{C}$, brown to white from above, white to pale brown from below, surface rough, dry, raised, with dense mycelia, edge filiform.

Material examined - THAILAND, Nakhon Si Thammarat Province, on submerged wood in a stream, 10 May 2018, W. Dong hat650 (MFLU 18-1556, holotype), ex-type living culture MFLUCC 18-1248; on submerged wood in a stream, 10 May 2018, W. Dong hat650 (HKAS 105023, isotype), living culture KUMCC 19-0038.

GenBank numbers - ITS: MN733256, LSU: MN733254, SSU: MN733253 
Notes - Annulatascus thailandensis fits well within the generic concept of Annulatascus in having a typical massive, apical ring and ellipsoidal to fusiform ascospores (Hyde 1992b, Maharachchikumbura et al. 2016b). In our phylogenetic tree, A. thailandensis clustered with $A$. hongkongensis with strong bootstrap support (Fig. 3). However, A. thailandensis has smaller ascospores $(28-33 \times 10.5-11.5 \mu \mathrm{m}$ vs. $35-37.5 \times 12.5-15 \mu \mathrm{m})$ and longer and thinner asci (275$375 \times 13-15 \mu \mathrm{m} v s .250-275 \times 25-30 \mu \mathrm{m})$. The ascospores of A. thailandensis are 1-2-septate, whereas those of A. hongkongensis are 3-septate (Ho et al. 1999). Annulatascus thailandensis is also similar to A. saprophyticus in asci and ascospore morphology and they have overlapping ascospore size (Luo et al. 2015). However, they can be separated by characters of ascomata (superficial, with long or short necks, lying horizontally or obliquely to the substrate surface vs. partly immersed, with straight upright necks to the substrate surface), size of asci (275-375 $\times 13-$ $15 \mu \mathrm{m}$ vs. $230.5-261 \times 13.5-16.5 \mu \mathrm{m})$ and septa of ascospores (1-2-septate vs. 0-3-septate) (Luo et al. 2015).

Annulusmagnus J. Campb. \& Shearer, Mycologia 96(4): 826 (2004)

Index Fungorum number: IF28870; 1 species with sequence data.

Type species - Annulusmagnus triseptatus (S.W. Wong, K.D. Hyde \& E.B.G. Jones) J. Campb. \& Shearer

Notes - The genus comprises a single species which occurs on submerged corticated or decorticated wood in freshwater habitats and causes soft-rot cavities on balsa wood in culture (Campbell \& Shearer 2004)

Aqualignicola Ranghoo, C.K.M. Tsui \& K.D. Hyde, Mycol. Res. 105(5): 628 (2001)

Index Fungorum number: IF28493; 2 morphological species (Species Fungorum 2020).

Type species - Aqualignicola hyalina Ranghoo, C.K.M. Tsui \& K.D. Hyde

Notes - Aqualignicola was introduced by Ranghoo et al. (2001) to accommodate a single species A. hyalina which was isolated from submerged wood in freshwater in Hong Kong, China. Another species, A. vaginata, was introduced in the genus from submerged wood in Yunnan, China (Hu et al. 2012). There is no sequence data for either species and the family placement requires confirmation.

Ascitendus J. Campb. \& Shearer, Mycologia 96(4): 829 (2004)

Index Fungorum number: IF28871; 2 species with sequence data.

Type species - Ascitendus austriacus (Réblová, Winka \& Jaklitsch) J. Campb. \& Shearer

Notes - Ascitendus was introduced by Campbell \& Shearer (2004) to accommodate Ascolacicola austriaca based on morphology and phylogenetic analyses of 28S rDNA sequence data. Ascitendus aquaticus was introduced in the genus by Hyde et al. (2018b). Ascitendus austriacus occurs on submerged corticated or decorticated wood in freshwater habitats and causes soft-rot cavities on balsa wood in culture (Campbell \& Shearer 2004).

Ayria Fryar \& K.D. Hyde, Cryptog. Mycol. 25(3): 248 (2004)

Index Fungorum number: IF28835; 2 morphological species (Species Fungorum 2020).

Type species - Ayria appendiculata Fryar \& K.D. Hyde

Notes - Ayria was collected from decaying wood submerged in brackish and seawater. Another species, A. nubispora Raja, Ferrer \& Shearer, was isolated from decorticated woody debris submerged in a lake (Raja et al. 2009). There is no sequence data for either species and the family placement needs confirmation.

Cataractispora K.D. Hyde, S.W. Wong \& E.B.G. Jones, Mycol. Res. 103(8): 1019 (1999)

Index Fungorum number: IF28328; 5 morphological species (Species Fungorum 2020), 3 species with sequence data.

Type species - Cataractispora aquatica K.D. Hyde, S.W. Wong \& E.B.G. Jones 

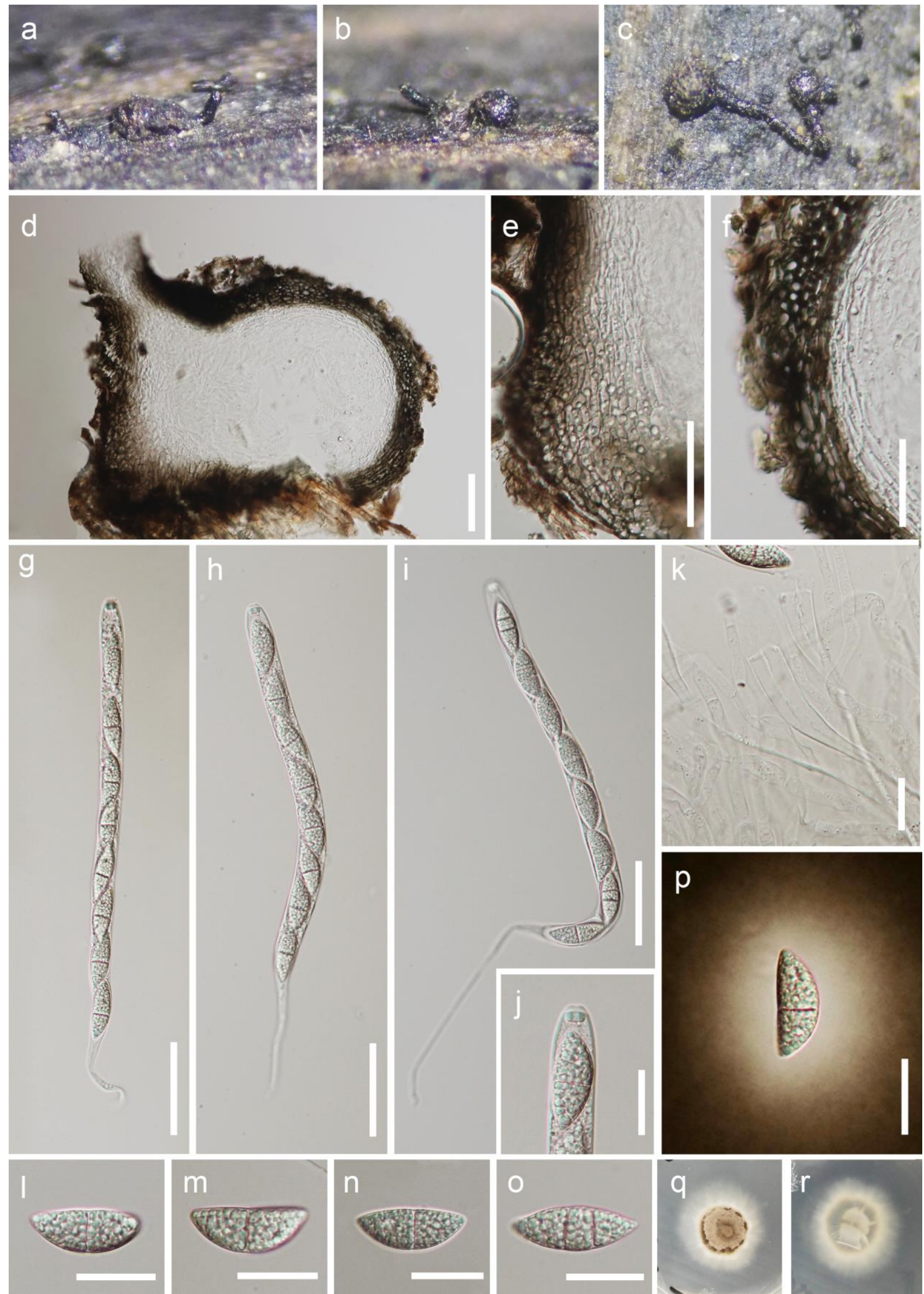

Figure 30 - Annulatascus thailandensis (MFLU 18-1556, holotype). a-c Ascomata superficial on host surface. d Vertical section of ascoma. e Structure of peridium near the base. f Structure of peridium at upper part. g-j Unitunicate asci. k Paraphyses. 1-o Ascospores. p Ascospore mounted in India ink. q Colony on PDA (from front). $r$ Colony on PDA (from reverse). Scale bars: $d$, e, g-i = $50 \mu \mathrm{m}, \mathrm{f}=30 \mu \mathrm{m}, \mathrm{j}-\mathrm{p}=20 \mu \mathrm{m}$. 

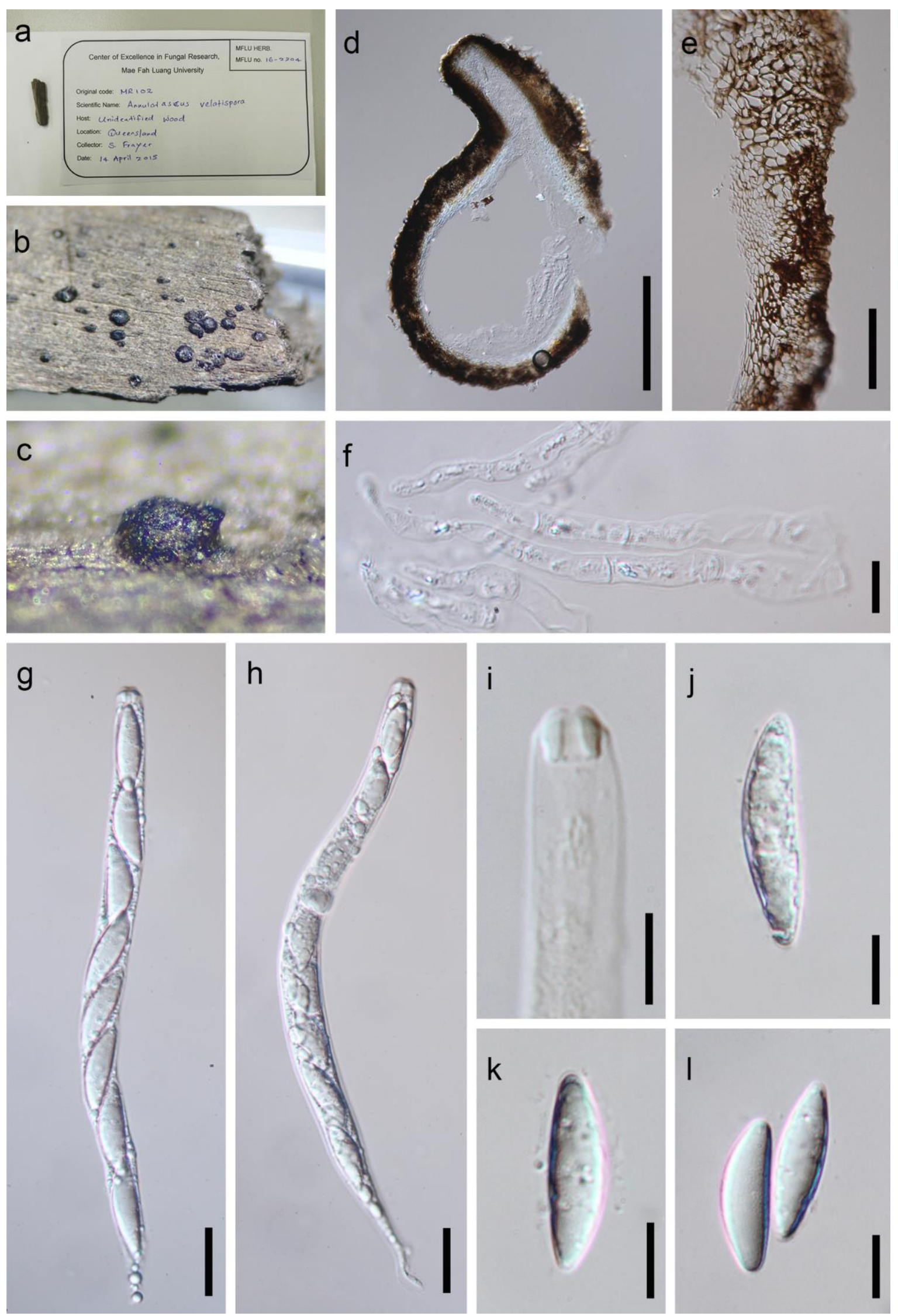

Figure 31 - Annulatascus velatisporus (Material examined - AUSTRALIA, North Queensland, on submerged wood in a small river, 14 April 2015, S. Fryar \& B. Cawson MR102A, MFLU 16-2204, epitype) a Herbarium material. b, c Appearance of black ascomata on host. d Vertical section of ascoma. e Structure of peridium. f Paraphyses. g-i Unitunicate asci. $j-1$ Ascospores. Scale bars: $d=$ $100 \mu \mathrm{m}, \mathrm{e}=50 \mu \mathrm{m}, \mathrm{f}, \mathrm{i}-\mathrm{l}=10 \mu \mathrm{m}, \mathrm{g}, \mathrm{h}=20 \mu \mathrm{m}$. 
Notes - Cataractispora was introduced by Hyde et al. (1999a) to accommodate four freshwater species, C. appendiculata (Brunei), C. aquatica (Brunei), C. bipolaris (Queensland) and C. viscosa (Hong Kong), based on their unique appendage ontogeny. Ho et al. (2004) introduced a fifth freshwater species, $C$. receptaculorum, from Hong Kong. The LSU sequence data of $C$. receptaculorum is identical to an invalid species $C$. recepticuli, which was accommodated in Pseudoproboscisporaceae by Zhang et al. (2017a) and they stated that it appears to be an invalidly published synonym of Pseudoproboscispora based on morphology. The family placement of Cataractispora needs confirmation with sequence data from the type species.

Chaetorostrum Zelski, Raja, A.N. Mill. \& Shearer, Mycosphere 2(5): 594 (2011)

Index Fungorum number: IF563571; 1 morphological species.

Type species - Chaetorostrum quincemilense Zelski, Raja, A.N. Mill. \& Shearer

Notes - The monotypic genus, Chaetorostrum was introduced by Zelski et al. (2011b) from woody debris in a semi-aquatic, intermittent stream in Peru. It is the first member of the Annulatascaceae that produces its asexual morph (taeniolella-like) in culture (Zelski et al. 2011b). There is no sequence data for this species and the family placement needs confirmation.

Longicollum Zelski, F.R. Barbosa, Raja, A.N. Mill. \& Shearer, Mycosphere 2(5): 540 (2011)

Index Fungorum number: IF563241; 1 species with sequence data. Shearer

Type species - Longicollum biappendiculatum Zelski, F.R. Barbosa, Raja, A.N. Mill. \&

Notes - The monotypic genus, Longicollum was introduced by Zelski et al. (2011a) from submerged woody debris in Peru. It appears to be widely distributed in freshwater in the Neotropics, i.e. Brazil, Costa Rica, Peru, and USA (Zelski et al. 2011a).

Submersisphaeria K.D. Hyde, Nova Hedwigia 62(1-2): 172 (1996)

Index Fungorum number: IF27640; 5 morphological species (Species Fungorum 2020), 1 species with sequence data.

Type species - Submersisphaeria aquatica K.D. Hyde

Notes - Sequences of a collection of S. aquatica (strain A95-1B) are available in GenBank and placed the genus in Annulatascaceae (Zhang et al. 2017a; Fig. 3).

Vertexicola K.D. Hyde, Ranghoo \& S.W. Wong, Mycologia 92(5): 1019 (2000)

Index Fungorum number: IF28465; 2 morphological species (Species Fungorum 2020)

Type species - Vertexicola caudata K.D. Hyde, S.W. Wong \& Ranghoo

Notes - Vertexicola was introduced by Ranghoo et al. (2000) to accommodate V. caudata which was isolated from submerged wood in China and Philippines. Vertexicola was listed in Annulatascaceae by Maharachchikumbura et al. (2015) and Wijayawardene et al. (2018a). However, it was placed in Diaporthomycetidae genera incertae sedis based on sequence data of one strain of $V$. confuse, which was invalidly published (Nom. inval. in Index Fungorum 2020). Due to absence of morphological data, the validity of sequence data used by Zhang et al. (2017a) is unknown. We therefore, retain Vertexicola in Annulatascaceae until the sequence data of the type species $V$. caudata are available.

Apiosporaceae K.D. Hyde, J. Fröhl., Joanne E. Taylor \& M.E. Barr, Sydowia 50(1): 23 (1998)

Index Fungorum number: IF81935; Facesoffungi number: FoF00629; 114 species.

Saprobic or pathogenic on leaves, stems and roots of monocotyledons, mostly grasses, or endophytic on plant tissues, lichens, and marine algae, occasionally infecting humans, or isolated from soil. Sexual morph: Pseudostromata visible as raised, linear, blackened areas on the host surface, with neck and upper surface visible through splits in the host tissue, mostly gregarious, fusiform, ellipsoid to irregular, black, cells between ascomata and darkened layer above usually thick, composed of brown cells of textura angularis. Ascomata solitary or usually gregarious in 
linear groups, immersed under pseudostromata, globose to subglobose, membranous, papillate, ostiole with periphyses. Peridium composed of several layers, comprising smallish, brown, reddish brown to hyaline cells of textura angularis. Paraphyses dense, hypha-like, long, broad, septate and branched. Asci 8-spored, unitunicate, broad cylindrical to clavate or subglobose, without an apical ring. Ascospores overlapping 1-3-seriate to irregularly arranged, hyaline, apiosporous, with a large, straight or curved, upper cell and smaller lower cell, usually surrounded by a gelatinous sheath. Asexual morph: Coelomycetous or hyphomycetous. Conidiomata sporodochial or acervuli, solitary to gregarious, immersed, erumpent from host tissue when mature, irregular, black, carbonaceous, coriaceous. Conidiomata wall composed of several layers of dark brown to hyaline cells of textura angularis, thick at sides, thin at upper and lower walls. Setae absent, or occasionally present, intermingled among conidiophores. Conidiophore mother cells ampulliform, verrucose wall, producing a single conidiophore. Conidiophores hyphoid, cylindrical, 1-2-septate, verrucose, flexuous. Conidiogenous cells basauxic, cylindrical, with or without verrucose wall. Conidia globose to subglobose, dark brown, smooth-walled or with minute wall ornamentations, with a truncate basal scar (adapted from Maharachchimbura et al. 2016b).

Type genus - Arthrinium Kunze

Notes - Apiosporaceae was introduced to accommodate taxa which produce apiospores and a basauxic, arthrinium-like conidiogenesis (Samuels et al. 1981, Hyde et al. 1998a, Bahl 2006, Senanayake et al. 2015, Dai et al. 2017, Wang et al. 2018, Pintos et al. 2019). Kirk et al. (2008), Senanayake et al. (2015), Maharachchikumbura et al. (2016b) and Wijayawardene et al. (2018a) accepted six genera viz. Appendicospora, Arthrinium (= Apiospora), Dictyoarthrinium, Endocalyx, Scyphospora and Spegazzinia in this family.

Appendicospora was placed in this family based on its apiospores, and it differs from Arthrinium in having ascospores with a bifurcate appendage at the lower cell (Hyde 1995b). This genus includes two species, A. coryphae, and A. hongkongensis, however, only A. hongkongensis and an unidentified species with sequence data. A blast search of SSU sequences in GenBank shows Appendicospora is similar to Arthrinium, however, it more similar to Oxydothis based on the LSU rDNA sequences. Phylogenetic analyses of Appendicospora are required to clarify its relationship within Apiosporaceae. Dictyoarthrinium is a hyphomycetous genus with basauxic conidiophores and conidiogenous cells producing 4-celled, cruciately septate conidia. Endocalyx was established in Apiosporaceae on the basis of its basauxic conidiophores, however, species of Endocalyx usually produce funnel-shaped to elongated cupulate sporodochia, which are not observed in other genera of this family (Seifert et al. 2011). Spegazzinia produces basauxic conidiophores and conidiogenous cells with a basal mother cell and stellate to disc-shaped conidia with radiating spine-like appendages (Seifert et al. 2011). Tanaka et al. (2015) transferred Spegazzinia to Didymosphaeriaceae based on the establishment of two species phylogenetically assigned in this family. Two more species were included in Didymosphaeriaceae based on morphology and phylogenetic analysis (Thambugala et al. 2017, Jayasiri et al. 2019), thus this genus is no longer included in Apiosporaceae. Scyphospora was introduced by Kantschaveli (1928) and typified by $S$. phyllostachydis. Index Fungorum (2020), however synonymized the type species under Arthrinium hysterinum probably based on morphology. The hand drawings of both epithets provided by Nag Raj (1974) and Kirk (1986) also show they are the same species. Therefore, we accept the combination as in Index Fungorum (2020) and regard Scyphospora as a synonym of Arthrinium. Nigrospora was introduced by Zimmermann (1902) and redrawn by Seifert et al. (2011). Wang et al. (2017) transferred Nigrospora to Apiosporaceae based on morphology and phylogeny. Thus, we conclude that Apiosporaceae accommodates five genera. We illustrate a new species, Arthrinium neogarethjonesii with sexual and asexual morphs.

\section{Ecological and economic significance of Apiosporaceae}

Arthrinium has a widespread distribution and is an important genus comprising species reported as endophytes or pathogens. Some species cause scabs or spots on leaves or culms of crops, or even cause damping-off, such as Arthrinium sacchari (Speg.) M.B. Ellis (Mavagani et al. 
2007). Some species have been reported as human pathogens; for example, cutaneous mycosis is caused by A. phaeospermum (Corda) M.B. Ellis (Rai 1989). Some species such as Arthrinium arundinis (Corda) Dyko \& B. Sutton, have been utilized in the pharmaceutical industry as antifungal agents.

\section{Genera included in Apiosporaceae}

Appendicospora K.D. Hyde, Sydowia 47(1): 31 (1995)

Index Fungorum number: IF27559; 2 morphological species (Species Fungorum 2020), 1 species with sequence data.

Type species - Appendicospora coryphae (Rehm) K.D. Hyde

Notes - Appendicospora is similar to Arthrinium in having apiospores. However, it differs in its ascospores having basal bifurcate appendages. Appendicospora coryphae was originally collected from a palm in the Philippines. A second species, A. hongkongensis described by Yanna et al. (1997) was collected from Hong Kong.

Arthrinium Kunze, Mykologische Hefte (Leipzig) 1: 9 (1817)

Index Fungorum number: IF7214; 73 morphological species (Kirk et al. 200, Index Fungorum 2020), 57 species with sequence data.

Type species - Arthrinium caricicola Kunze \& J.C. Schmidt

Notes - Crous \& Groenewald (2013) showed that Apiospora is the sexual morph of Arthrinium. Crous \& Groenewald (2013) placed the younger sexual typified name, i.e. Apiospora under the older asexual typified name. This adoption was followed in subsequent publications by Dai et al. (2016), Maharachchikumbura et al. (2016b) and Wijayawardene et al. (2016b). Molecular data has proved that Arthrinium is a speciose genus (Dai et al. 2017, Wang et al. 2018, Pintos et al. 2019). We introduce a new holomorph species, Arthrinium neogarethjonesii from bamboo.

Arthrinium neogarethjonesii D.Q. Dai \& K.D. Hyde, sp. nov.

Fig. 32

Index Fungorum number: IF555481; Facesoffungi number: FoF05112

Etymology - Based on the similarities with species Arthrinium garethjonesii.

Holotype - HKAS 102408.

Saprobic on dead bamboo culms. Sexual morph: Stromata 1-2 mm long, 0.25-0.5 mm wide, 175-250 $\mu \mathrm{m}$ high, scattered to gregarious, immersed, becoming slightly erumpent through the host tissue, black to dark brown, fusiform to elongated ellipsoid, with a central slit-like opening at the top. Ascomata perithecial, 125-230 $\mu \mathrm{m}$ high, 120-230 $\mu \mathrm{m}$ diam., arranged in rows, clustered, gregarious, with 2-7 perithecia forming groups immersed in stromata and surrounding by stromatic tissue, ellipsoidal to subglobose, or obpyriform with a slightly flattened base, brown to reddishbrown, membranous. Ostiole raised from centre of perithecia, internally lined with periphyses. Peridium 15-25 $\mu \mathrm{m}$ thick, composed of dark brown to reddish brown to hyaline cells of textura angularis. Stromatic cells between perithecia 150-350 $\mu \mathrm{m}$ wide, comprising host and fungal tissues, composed of elongated, brown cells of textura angularis. Paraphyses dense, long, 3.5-6 $\mu \mathrm{m}$ wide, septate, un-branched with the wider base and thinner apex. Asci $95-125 \times 20-25 \mu \mathrm{m}(\bar{x}=$ $97.6 \times 21.3 \mu \mathrm{m}, \mathrm{n}=20), 8$-spored, unitunicate, clavate, apedicellate, apically rounded. Ascospores 25-30 $\times 9.5-11 \mu \mathrm{m}(\bar{x}=29.1 \times 10.3 \mu \mathrm{m}, \mathrm{n}=20), 2$-seriate, overlapping, 1-septate, ellipsoidal, with a small lower cell and a large upper cell, with many guttules, hyaline, smooth-walled, with a thick gelatinous sheath, 3-10 $\mu \mathrm{m}$ wide. Asexual morph: Coelomycetous or Hyphomycetous on substrates, Conidiomata 450-600 $\mu \mathrm{m}$ wide $\times 1-1.5 \mathrm{~mm}$ long, 150-250 $\mu \mathrm{m}$ high, solitary to gregarious, immersed, then raised from host tissue when mature, ellipsoid to irregular, black, coriaceous. Conidiomata wall composed of one layer of dark brown to brown to hyaline cells of textura angularis. Conidiophores mother cells 4.5-6 $\times 3.5-4.5 \mu \mathrm{m}(\bar{x}=5.4 \times 4.3 \mu \mathrm{m}, \mathrm{n}=20)$, cylindrical, aseptate. Conidiogenous cells 10-48 $\times 4-5.5 \mu \mathrm{m}(\bar{x}=35.4 \times 4.3 \mu \mathrm{m}, \mathrm{n}=20)$, basauxic, cylindrical, discrete, smooth-walled. Conidia 20-35 $\times 15-30 \mu \mathrm{m}(\bar{x}=28.5 \times 25.6 \mu \mathrm{m}, \mathrm{n}$ $=20$ ), globose to subglobose, dark brown, smooth-walled, with a truncate basal scar. 

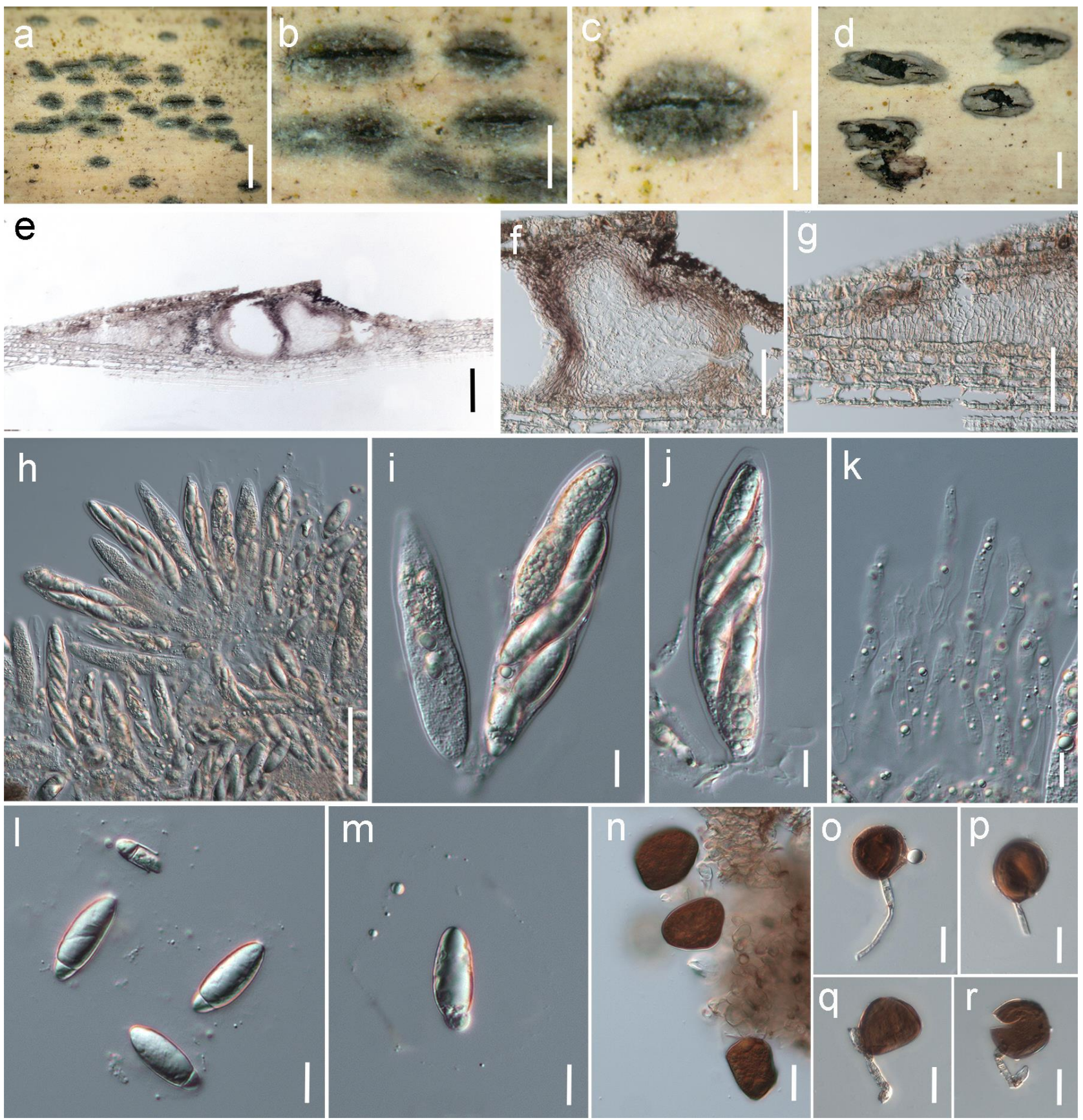

Figure 32 - Arthrinium neogarethjonesii (HKAS 102408, holotype). a-c Appearance of stromata on host. d Appearance of conidiomata on host. e Section of ascostroma. f Section of ascoma. $g$ Stromatic tissue. h-j Asci. k Paraphyses. 1, m Ascospores surrounded by a gelatinous sheath. $\mathrm{n}$ Conidia. o-r Conidia and conidiogenous cells. Scale bars: $\mathrm{a}=1 \mathrm{~mm}, \mathrm{~b}-\mathrm{d}=5 \mu \mathrm{m}, \mathrm{e}=100 \mu \mathrm{m}, \mathrm{f}-\mathrm{h}=$ $50 \mu \mathrm{m}, \mathrm{i}-\mathrm{r}=10 \mu \mathrm{m}$.

Culture characters - Ascospores germinating on WA within $24 \mathrm{~h}$ and germ tubes developing from the upper cell. Colonies on PDA reaching $50 \mathrm{~mm}$ in 1 week at $27^{\circ} \mathrm{C}$, in dark, cottony, circular, with irregular edge, white from above and below, becoming dark from centre after 2 weeks. Mycelium superficial to immersed in media, with branched, septate, smooth hyphae.

Material examined - CHINA, Yunnan Province, Xishuangbanna Topical Botanical Garden, Bamboo Collection, on bamboo culm, 2 April 2017, Dong-Qin Dai DDQ00403, HKAS 102408, holotype; ex-type living culture KUMCC 18-0192.

GenBank numbers - ITS: MK070897, LSU: MK070898, SSU: MK070899. 
Notes - This species is similar to Arthrinium garethjonesii which was introduced by Dai et al. (2016) based on morphological and phylogenetic analyses, and is only known from the southwest of China. However, A. neogarethjonesii has smaller asci (95-125 × 20-25 $\mu \mathrm{m}$ vs. $125-154 \times 35-42$ $\mu \mathrm{m})$ and ascospores $(25-30 \times 9.5-11 \mu \mathrm{m}$ vs. 30-42 $\times 11-16 \mu \mathrm{m})$, and the conidia are larger when compared with most Arthrinium species. Based on a Blast search using the ITS sequence in NCBI's GenBank, the closest hits with highest similarity is A. garethjonesii (GenBank KY356086; similarity $=575 / 595(97 \%)$, Gaps $=8 / 595(1 \%)$ ). A similar search using the LSU sequence showed highest similarity to $A$. garethjonesii (GenBank KY356091, similarity $=851 / 854$ (99\%), no gaps), and closest hits with $A$. ovatum (GenBank NG_042782; similarity $=849 / 875$ (97\%), no gaps). The phylogenetic tree generated from maximum-parsimony analysis indicated that the new species is close to A. garethjonesii and these two species cluster in two well-supported clades (MP/BYPP 100/1.00) (Fig. 4).

Dictyoarthrinium S. Hughes, Mycol. Pap. 48: 29 (1952)

Index Fungorum number: IF7993; 7 morphological species (Species Fungorum 2020), 1 species with sequence data.

Type species - Dictyoarthrinium quadratum S. Hughes

Notes - Dictyoarthrinium was erected by Hughes (1952) for two hyphomycetes, collected in Ghana. The genus is characterized by terminal and lateral, septate conidiophores, basauxic conidiogenous cells and muriform conidia.

Endocalyx Berk. \& Broome, J. Linn. Soc., Bot. 15(1): 84 (1876)

Index Fungorum number: IF8158; 7 morphological species (Species Fungorum 2020), 1 species with sequence data.

Type species - Endocalyx thwaitesii Berk. \& Broome

Notes - Petch (1908) emended the genus, and considered that E. thwaitesii and E. psilostoma were identical. Okada \& Tubaki (1984) described E. melanoxanthus var. grossus and E. melanoxanthus var. melanoxanthus. The genus is characterized by funnel-shaped synnemata or sporodochia, branched conidiophores and dark brown conidia with a germ slit (Seifert et al. 2011).

Nigrospora Zimm., Centbl. Bakt. ParasitKde, Abt. I 8: 220 (1902)

Index Fungorum number: IF9124; 25 species with morphological data (Species Fungorum 2020), 17 species with sequence data.

Type species - Nigrospora panici Zimm.

Notes - Seifert et al. (2011) revised the genus and mentioned Khuskia as its sexual morph. Maharachchikumbura et al. (2016b) placed Nigrospora in Sordariomycetes, genera incertae sedis. Two new collections of $N$. oryzae and $N$. musae were sequenced (Vu et al. 2019), while Wang et al. (2017) published 12 new Nigrospora taxa and combined N. vietnamensis under Arthrinium and placed the genus in Apiosporaceae. Raza et al. (2019) introduced five new species from sugarcane. The genus is characterized by sphaerical to subsphaerical conidiogenous cells and black and globose to subglobose conidia (Seifert et al. 2011, Wang et al. 2017).

Apiosporopsidaceae Senan., Maharachch. \& K.D. Hyde, Stud. Mycol. 86: 234 (2017)

Index Fungorum number: IF821538; Facesoffungi number: FoF03455; 3 species.

Parasitic on living leaves and twigs. Sexual morph: Ascomata scattered, black, oval to almost sphaerical, immersed in the leaf tissue beneath a thin, well-developed clypeus, without a neck or only slightly papillate, periphysate. Peridium comprising 5-6 outer layers of dark, thick-walled cells of textura angularis and inner, thin-walled, strongly flattened cells of textura angularis. Paraphyses not seen. Asci 8-spored, unitunicate, short-pedicellate, blunt at the apex with a J-, apical ring. Ascospores 1-2-seriate, elliptical to fusoid, often slightly flattened on one side, unicellular, hyaline. Asexual morph: Coelomycetous. Stroma loculate, globose to irregular, sometimes with beaks. Conidiogenous cells phialidic, short to elongate, simple or branched. 
Conidia oblong or cylindrical to allantoid, 1-celled, hyaline (adapted from Senanayake et al. 2017a).

Type genus - Apiosporopsis (Traverso) Mariani

Notes - Apiosporopsidaceae was introduced by Senanayake et al. (2017a) to accommodate Apiosporopsis species which are morphologically distinct from other families in Diaporthales. The asci initially form a hymenium-like fascicle within a papillate ascomata, asci have a bilobed apical ring and residual stromatic tissue is present within the locules. This family is supported by molecular data (Braun et al. 2018, Fan et al. 2018, Senanayake et al. 2017a, 2018, Tian et al. 2018).

\section{Ecological and economic significance of Apiosporopsidaceae}

Apiosporopsis species are generally associated with over-wintered plant parts as epifoliar fungi and rarely on living leaves (Barr 1978, Reid \& Dowsett 1990). Apiosporopsis species are considered as saprobes or mild pathogens (Senanayake et al. 2018).

\section{Genus included in Apiosporopsidaceae}

Apiosporopsis (Traverso) Mariani, Atti Soc. ital. Sci. nat. 50: 165 (1911)

Index Fungorum number: IF268; 3 morphological species (Species Fungorum 2020), 1 species with sequence data.

Type species - Apiosporopsis carpinea (Fr.) Mariani

Notes - Traverso (1906) erected Apiosporopsis and Mariani (1911) designated A. carpinea as the type species. Currently Apiosporopsis comprises three species: A. carpinea, A. coronillae and A. saccardoana (Senanayake et al. 2018, Index Fungorum 2020). Senanayake et al. (2017b) illustrated $A$. carpinea from Austria (IMI 11662), by the ascospore morphology of this collection (IMI 57187) is quite different to A. carpinea, A. coronillae and A. saccardoana. The collection we illustrated here has ascospores with a central septum and apical and basal ends with pores.

Apoharknessiaceae Senan., Maharachch. \& K.D. Hyde, Stud. Mycol. 86: 234 (2017)

Index Fungorum number: IF821881; Facesoffungi number: FoF03457; 10 species.

Endophytic, saprobic or pathogenic on plants. Sexual morph: Undetermined. Asexual morph: Coelomycetous. Conidiomata stromatic or eustromatic, subepidermal to immersed, solitary to gregarious, subglobose to irregular, unilocular, pale brown. Conidiomata wall outer layer composed of thin-walled, pale brown cells of textura angularis, with inner layer of pale yellow to hyaline cells. Conidiophores hyaline, septate, cylindrical, and sparingly branched or reduced to conidiogenous cells. Conidiogenous cells holoblastic, annellidic, cylindrical, lageniform to ampulliform, hyaline, smooth, invested in mucus. Conidia obclavate, conical, aseptate, pale brown, with a longitudinal band on the flat surface, thick- and smooth-walled, guttulate, with short hyaline apiculus, with small globule of mucus on base or obtuse apex with a scar at the base (adapted from Senanayake et al. 2017a).

Type genus - Apoharknessia Crous \& S.J. Lee

Notes - Apoharknessiaceae was introduced by Senanayake et al. (2017a) to accommodate Apoharknessia and Lasmenia. Lasmenia was previously assigned to Cryphonectriaceae (Maharachchikumbura et al. 2015, 2016b). However, available sequence data in GenBank for Lasmenia are not identified at the species level, thus, Wijayawardene et al. (2016b) placed Lasmenia in Diaporthales genera incertae sedis. However, phylogenetic analysis by Senanayake et al. (2017a) indicates that Apoharknessia and Lasmenia clearly belong in Diaporthales forming a well-supported clade.

\section{Ecological and economic significance of Apoharknessiaceae}

Lasmenia causes rachis necrosis, flower abortion and necrotic spots on leaves of Nephelium lappaceum and some Lasmenia species are associated with tropical fruits as pathogens (SerratoDiaz et al. 2011). Apoharknessia forms leaf spots on Eucalyptus species and some are reported from leaf litter as saprobes (Lee et al. 2004). 


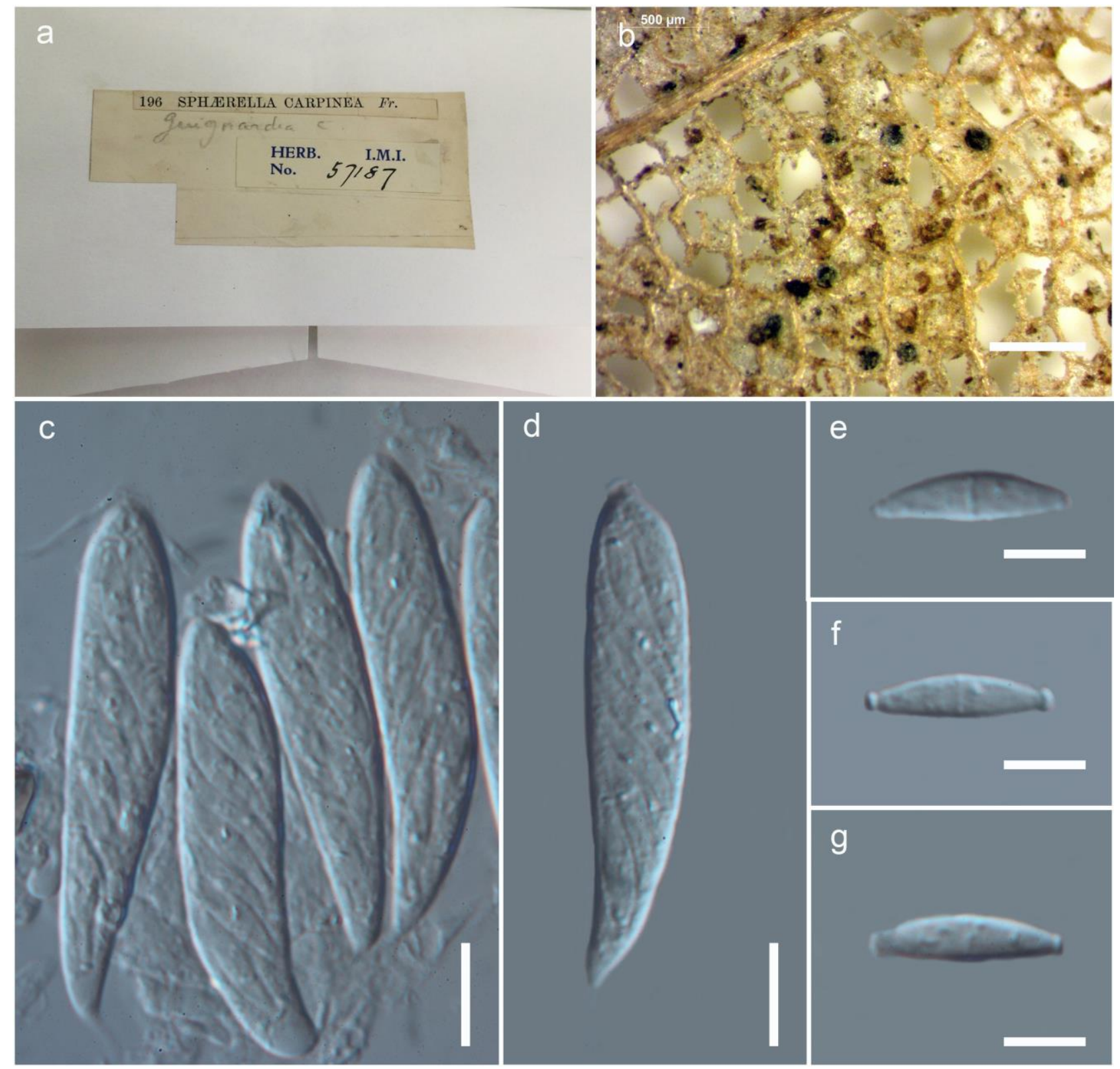

Figure 33 - Apiosporopsis carpinea (IMI 57187). a Herbarium packet. b Ascomata on substrate. c, d Asci. e-g Ascospores. Scale bars: $\mathrm{b}=500 \mu \mathrm{m}, \mathrm{c}-\mathrm{d}=10 \mu \mathrm{m}$, e-g $=5 \mu \mathrm{m}$.

\section{Genera included in Apoharknessiaceae}

Apoharknessia Crous \& S.J. Lee, Stud. Mycol. 50(1): 239 (2004)

Index Fungorum number: IF500065; 3 species with sequence data.

Type species - Apoharknessia insueta (B. Sutton) Crous \& S.J. Lee

Notes - Apoharknessia was established by Lee et al. (2004) to accommodate Harknessia insueta, and the latter constitutes a distinct phylogenetic lineage from Harknessia sensu stricto. Crous et al. (2017b) introduced A. eucalyptorum. as a second species. Marin-Felix et al. (2018) introduced a new species as A. eucalypti. This is a foliar pathogenic genus known from Brazil, Colombia, Cuba and Mauritius. Apoharknessia is similar to Harknessia, but differs in having a hyaline, apical apiculus, and lacks prominent fluffy aerial mycelium in culture medium (Lee et al. 2004). In this entry we illustrate Apoharknessia insueta.

Lasmenia Speg., Anal. Soc. cient. argent. 22(4): 199 (1886)

Index Fungorum number: IF8714; 7 morphological species (Species Fungorum 2020), molecular data available for an unnamed species. 
Type species - Lasmenia balansae Speg.

Notes - Höhnel (1910) selected Lasmenia balansae as the lectotype and there are 12 species epithets recorded under Lasmenia (Senanayake et al. 2018). Some Lasmenia species are associated with tropical fruits as pathogens. Lasmenia was treated as a member in Apoharknessiaceae by Senanayake et al. (2017a).
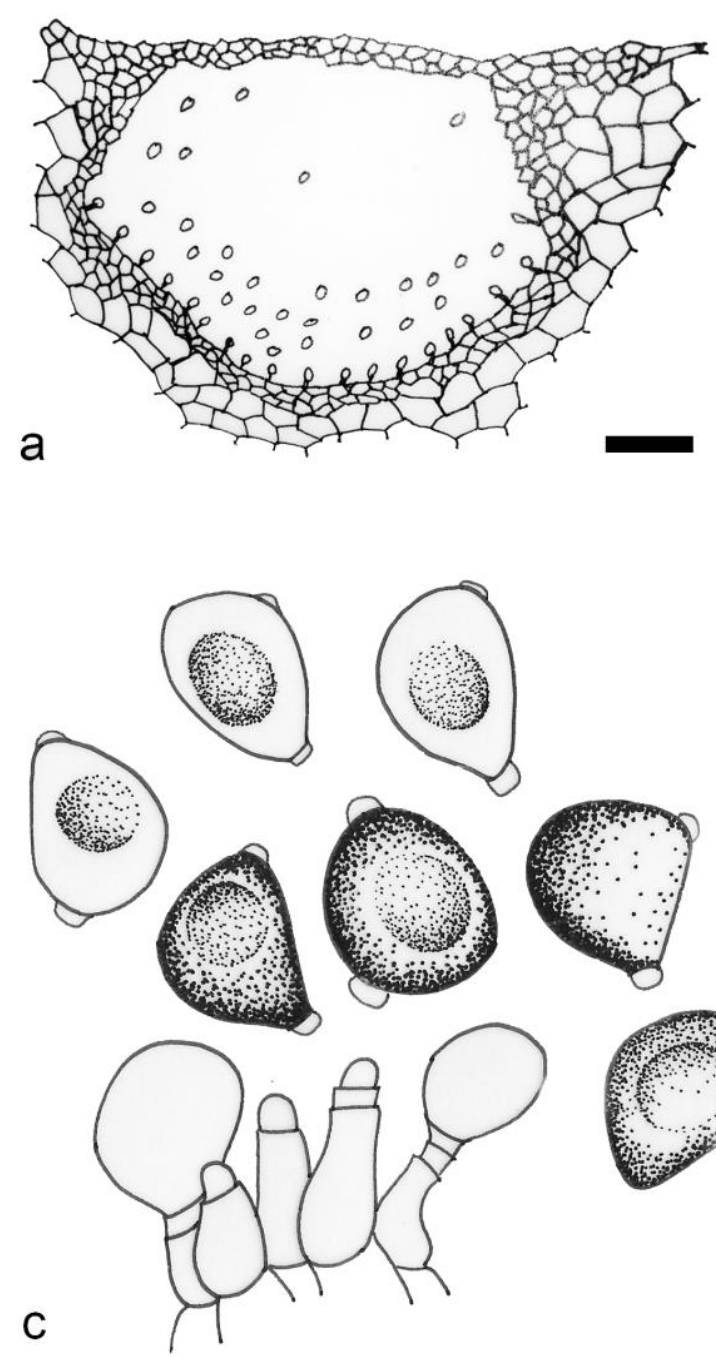
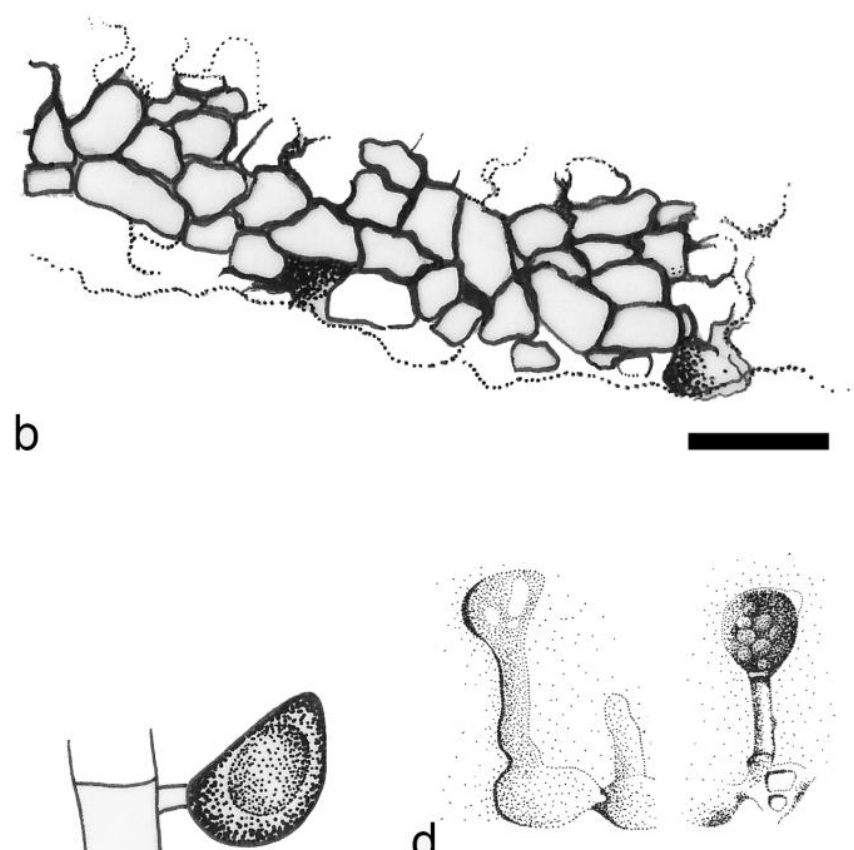

d

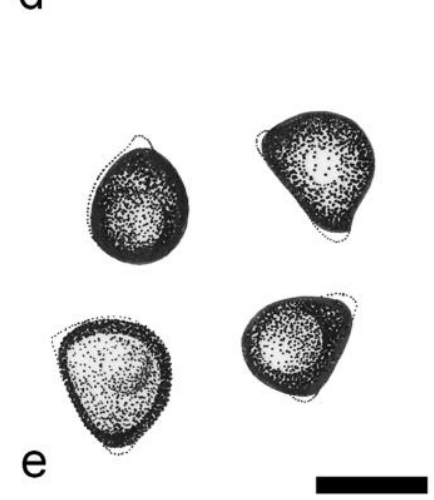

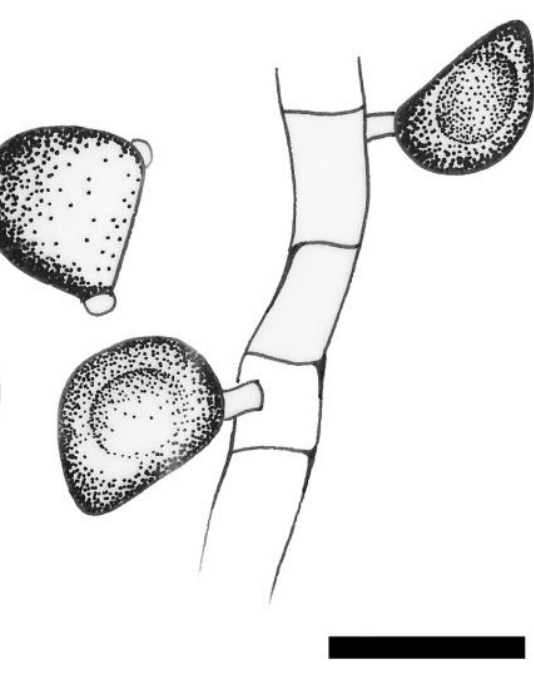

Figure 34 - Apoharknessia insueta reproduced from Lee et al. (2004). a Vertical section of conidioma. b Peridium. c, d Conidiogenous cells and conidia. e Conidia. Scale bars: a = 50 $\mu \mathrm{m}, \mathrm{b}-\mathrm{e}$ $=10 \mu \mathrm{m}$.

Armatellaceae Hosag., Sydowia 55(2): 165 (2003)

Index Fungorum number: IF82149; Facesoffungi number: FoF00723; 17 species.

Colonies epiphyllous or hypophyllous, mostly confluent. Hyphae superficial, brown, straight to flexuous, septate, branched, reticulate, with hyphopodia. Hyphopodia alternate to unilateral, mostly 2-celled, brown, with capitates head cells, with irregular lobes, stalk cells rarely septate. Sexual morph: Ascomata superficial, globose to subglobose, verrucose. Peridium thick, comprising black, verrucose outer stratum, and brown inner stratum of textura angularis. Asci 4-8-spored, unitunicate, subcylindrical to ovoid, or clavate, with ascus wall attenuated or broken when mature. Ascospores ellipsoidal to oblong, 1-septate, not constricted at the septum, hyaline when young, becoming brown at maturity. Asexual morph: Undetermined (adapted from Maharachchimbura et al. 2016b).

Type genus - Armatella Theiss. \& Syd. 
Notes - Armatellaceae was established by Hosagoudar (2003) with 16 species. It differs from Meliolaceae by its 1-septate ascospores, verrucose ascomata and lacking phialides. There is no sequence data for Armatellaceae. The taxonomic placement is supported by morphology. Armatella litseae is illustrated for this entry.

\section{Ecological and economic significance of Armatellaceae}

There is no report of Armatellaceae species causing any economic problems. However, similar to the Meliolaceae, the colonies of Armatellaceae cover the leaf surface, may reduce photosynthesis and increase the temperature and respiration in those areas, while hyphopodia can penetrate the leaf surface to gain nutrients from host plants.

\section{Genus included in Armatellaceae}

Armatella Theiss. \& Syd., Annls mycol. 13(3-4): 235(1915)

Index Fungorum number: IF309; 17 morphological species (Species Fungorum 2020).

Type species - Armatella litseae (Henn.) Theiss. \& Syd.

Notes - Armatella was placed in Polystigmellaceae (Dothideales) when introduced by Theissen \& Sydow (1915). Hansford (1946) transferred this genus to Meliolaceae. Hosagoudar (2003) included this single genus in the newly introduced family Armatellaceae. This was followed in Hongsanan et al. (2015) and Wijayawardene et al. (2017a, 2018a).

Asterosporiaceae Senan., Maharachch. \& K.D. Hyde, Stud. Mycol. 86: 236 (2017)

Index Fungorum number: IF821539; Facesoffungi number: FoF03459; 4 species.

Endophytic or saprobic on Betulaceae, Fagaceae, Juglandaceae and Sapindaceae. Sexual morph: Undetermined. Asexual morph: Coelomycetous. Conidiomata acervular, subepidermal, erumpent at maturity, solitary, or occasionally confluent, unilocular, dark brown to black. Conidiomata wall composed of thin-walled, brown cells of textura angularis. Conidiophores cylindrical, branched at the base, septate, hyaline to pale brown. Conidiogenous cells holoblastic, cylindrical, unbranched, integrated, determinate, hyaline to pale brown, smooth. Conidia terminal, transversely distoseptate, consisting of four arms, with reduced lumina, brown, smooth-walled (adapted from Senanayake et al. 2017a).

Type genus - Asterosporium Kunze

Notes - Asterosporiaceae is based on the single genus Asterosporium (Senanayake et al. 2017a) and is morphologically distinct from other families in Diaporthales having star-like arms, bearing brown conidia and acervular conidiomata. Asterosporium species occur in temperate regions. We illustrate Asterosporium asterospermum.

\section{Ecological and economic significance of Asterosporiaceae}

Cankers and branch dieback of beech may be caused by Asterosporium hoffmannii (Pirone 1978). Sieber (2007) reported that A. asterospermum may cause canker on Fagus crenata and F. sylvatica as mild pathogens. However, most species are saprobes in decaying wood.

\section{Genus included in Asterosporiaceae}

Asterosporium Kunze, Flora, Regensburg 1: 225 (1819)

Index Fungorum number: IF7270; 4 morphological species (Species Fungorum 2020), 2 species with sequence data.

Type species - Asterosporium asterospermum (Pers) S. Hughes

Notes - Asterosporium was introduced and typified by A. hoffmannii. However, Hughes (1958) regarded Stilbospora asterosperma as the older name for this taxon based on morphology. Hence, a new combination, Asterosporium asterospermum was proposed. However according to molecular analysis of this study, A. asterospermum and A. hoffmannii are phylogenetically identical. Hence, we synonymise A. hoffmannii (1819) under A. asterospermum (1801) giving priority to the older name. The sexual morph of Asterosporium has not been reported. 


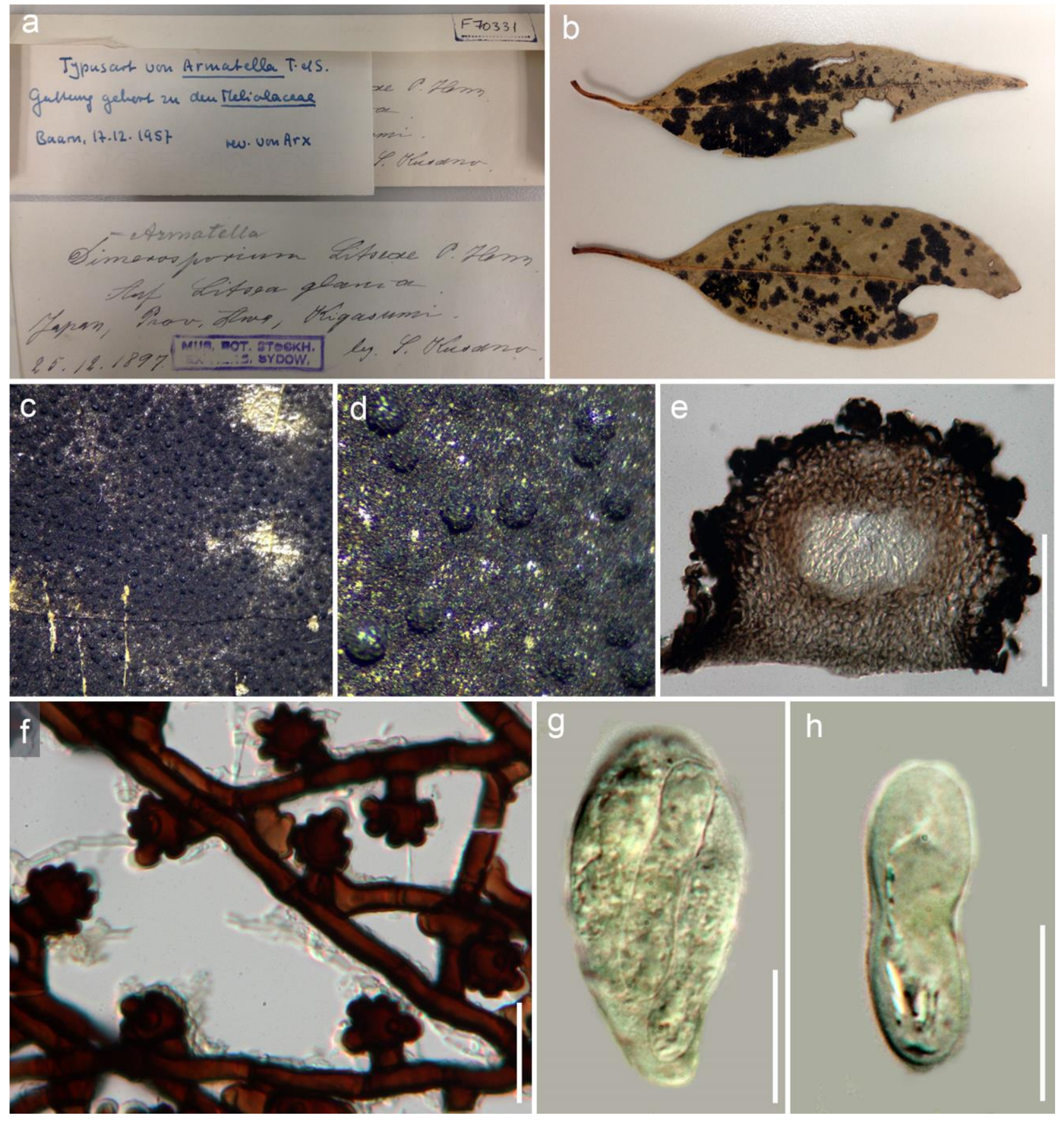

Figure 35 - Armatella litseae (Material examined - JAPAN, Tokushima, Prov. Awa, Kigasumi, on Litsea glauca (Thunb.) Siebold (Lauraceae), 25 December 1897, S. Kusano, S F70331, holotype). a Label of specimen. b Host leaves. c, d Colonies with ascomata on leaf surface. e The ascoma. $f$ Hyphae with appressoria. g Ascus. h Ascospore. Scale bars: $\mathrm{e}=100 \mu \mathrm{m}, \mathrm{f}-\mathrm{h}=20 \mu \mathrm{m}$.

Atractosporaceae H. Zhang, K.D. Hyde \& Maharachch., Fungal Divers. 85: 88 (2017) Index Fungorum number: IF553757; Facesoffungi number: FoF03334; 7 species.

Saprobic on submerged deciduous wood. Sexual morph: Ascomata solitary or aggregated in small groups, immersed or semi-immersed to superficial, astromatic, subglobose to conical, dark brown to black, with a lateral neck, often lying horizontally on the substrate surface. Ostiole periphysate. Peridium leathery to fragile, two-layered. Paraphyses abundant, persistent, cylindrical. Asci 8-spored, unitunicate, pedicellate, apically rounded or obtuse, with a J-, relatively small, apical ring. Ascospores uniseriate, hyaline, fusiform, aseptate or transversely septate, smooth or ornamented. Asexual morph: Undetermined (adapted from Zhang et al. 2017a).

Type genus - Atractospora Réblová \& J. Fourn. 
Notes - Atractosporaceae was introduced in a new order Atractosporales by Zhang et al. (2017a) with two genera i.e. Atractospora and Rubellisphaeria. Although Aquaticola hongkongensis also nested in Atractosporaceae (Zhang et al. 2017a), it has never been validly published (Ranghoo et al. 1999). This species needs to be recollected and characterized. This family represents a distinct group of freshwater Sordariomycetes, which is strongly supported by its stem age, ca 98 MYA in the MCC tree (Hyde et al. 2017a). Atractosporaceae is similar to Pseudoproboscisporaceae in the ascomata often lying parallel to the host surface. However, the ascospores of Atractosporaceae lack appendages, unlike in Conlariaceae and Pseudoproboscisporaceae which have appendages at one or both ends. We illustrate Atractospora thailandensis.
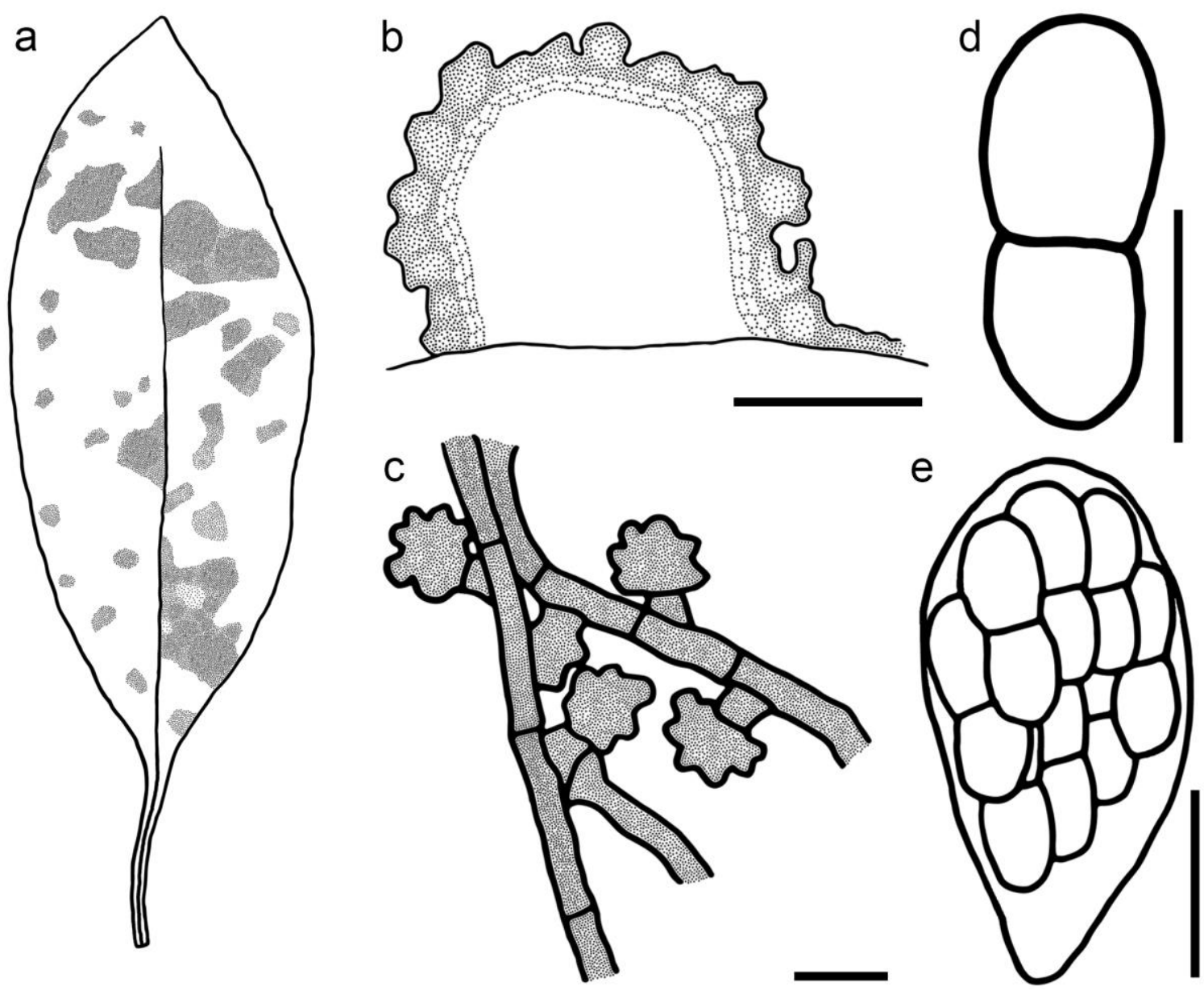

Figure 36 - Armatella litseae (redrawn from Hongsanan et al. 2015). a Colonies on the leaf. b The peridium. c Hyphae with appressoria. d Ascospores. e Asci. Scale bars: $b=100 \mu \mathrm{m}, \mathrm{d}, \mathrm{e}=20 \mu \mathrm{m}, \mathrm{c}$ $=10 \mu \mathrm{m}$.

\section{Ecological and economic significance of Atractosporaceae}

Atractospora and Rubellisphaeria have been reported as saprobic genera on submerged deciduous wood (Réblová et al. 2016a).

\section{Genera included in Atractosporaceae}

Atractospora Réblová \& J. Fourn., Mycol. Progr. 15(no. 21): 8 (2016)

Index Fungorum number: IF815026; 6 species with sequence data.

Type species - Atractospora reticulata Réblová \& J. Fourn.

Notes - Atractospora was introduced by Réblová et al. (2016a) with three new species and a new combination. Zhang et al. (2017a) extended the generic description to accommodate taxa with both thick- and thin-walled ascospores as A. thailandensis was included based on phylogeny and 
otherwise similar morphology. Asexual morphs of this genus have not been reported from the natural substrate, however, asexual structures were observed in cultures of A. decumbens and characterized by ellipsoidal to subglobose conidia, brown, aseptate, and thick-walled often forming in short chains of three to five cells (Réblová et al. 2016a).

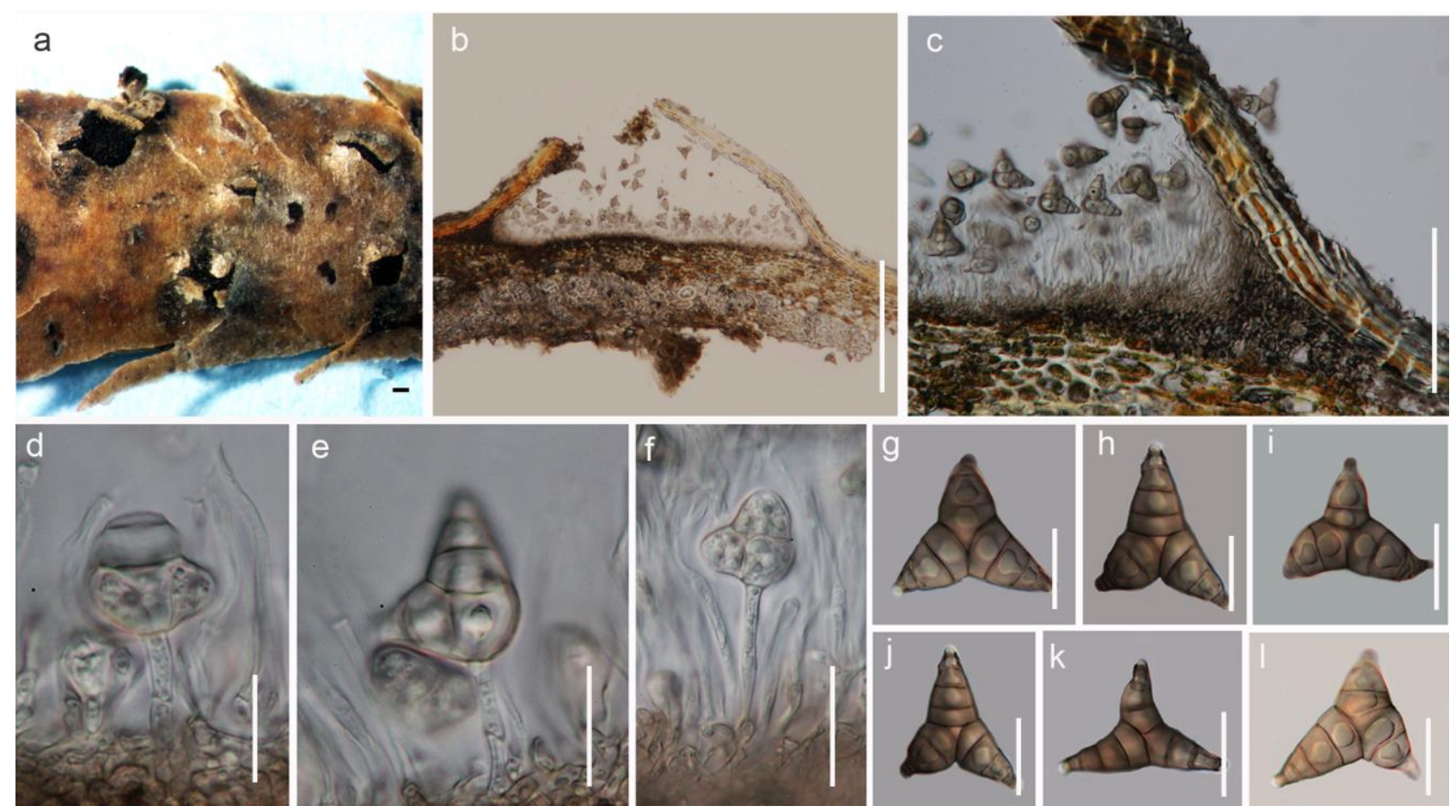

Figure 37 - Asterosporium asterospermum (Material examined - ITALY, Forl1 -Cesena Province, Santa Sofia, near Passo la Calla, on dead branch of Fagus sylvatica L. (Fagaceae), 29 September 2012, E. Camporesi, MFLU 15-3555). a Conidiomata on host substrate. b, c Vertical sections of conidiomata. d-f Different stages of conidiogenesis. g-1 Conidia. Scale bars: $a=1 \mathrm{~mm}, \mathrm{~b}=400 \mu \mathrm{m}$, $\mathrm{c}=50 \mu \mathrm{m}, \mathrm{d}-\mathrm{f}=20 \mu \mathrm{m}, \mathrm{g}-\mathrm{l}=30 \mu \mathrm{m}$.

Rubellisphaeria Réblová \& J. Fourn., Mycol. Progr. 15(no. 21): 13 (2016)

Index Fungorum number: IF815031; 1 species with sequence data.

Type species - Rubellisphaeria abscondita Réblová \& J. Fourn.

Notes - The monotypic genus Rubellisphaeria was isolated from submerged coniferous wood in a stream in France Réblová et al. (2016a). It formed a well-supported clade with Atractospora in the phylogenetic analyses of, Luo et al. (2019) and this study (Fig. 3).

Auratiopycnidiellaceae Senan., Maharachch. \& K.D. Hyde, Stud. Mycol. 86: 237 (2017)

Index Fungorum number: IF821540; Facesoffungi number: FoF03461; 1 species.

Foliicolous. Sexual morph: Undetermined. Asexual morph: Conidiomata amphigenous, pycnidial, globose, orange-coloured with dark brown border on leaves. Peridium comprises pale brown cells of textura angularis. Paraphyses hyaline, subcylindrical, septate, branched or unbranched, with obtuse apex, constricted at septa. Conidiophores reduced to conidiogenous cells. Conidiogenous cells hyaline, annellidic, smooth, ampulliform, with terminal truncate locus, thickwalled, sometimes proliferating percurrently. Conidia ellipsoidal, smooth, solitary, median 1septate, constricted at septum, obtuse at apex, truncate at base, thickened, at times with marginal frill, becoming golden brown at germination and with solitary, brown, wavy, thick, bright banded, germ-slit along the long-axis of the conidium (adapted from Senanayake et al. 2017a).

Type genus - Auratiopycnidiella Crous \& Summerell

Notes - Following molecular analysis, Crous et al. (2012b) introduced Auratiopycnidiella based on A. tristaniopsis and placed it in Diaporthales genera incertae sedis. Senanayake et al. 
(2017a) introduced Auratiopycnidiellaceae to accommodate Auratiopycnidiella. In this study we illustrate A. tristaniopsis.
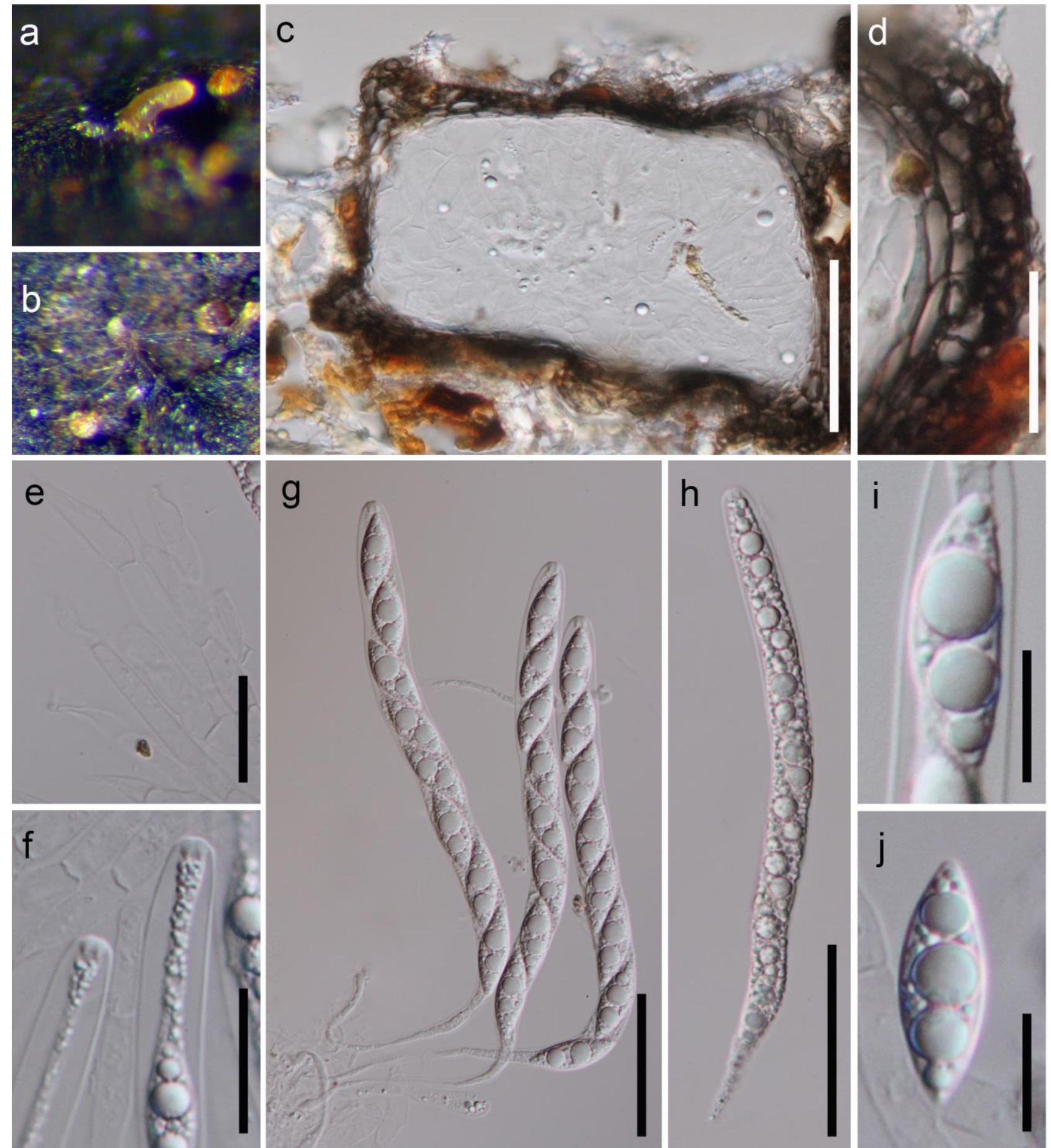

Figure 38 - Atractospora thailandensis (Material examined - THAILAND, Prachuap Khiri Khan, on submerged wood in a small river, 30 July 2015, W. Dong 56B, HKAS 96226, holotype). a, b Appearance of dark brown to black ascomata semi-immersed on host. c Vertical section of ascoma. $\mathrm{d}$ Structure of peridium. e Paraphyses. f-h Unitunicate asci. i, j Ascospores. Scale bars: $\mathrm{c}=50 \mu \mathrm{m}$, $\mathrm{d}-\mathrm{f}=20 \mu \mathrm{m}, \mathrm{g}, \mathrm{h}=40 \mu \mathrm{m}, \mathrm{i}, \mathrm{j}=10 \mu \mathrm{m}$.

\section{Ecological and economic significance of Auratiopycnidiellaceae}

Auratiopycnidiella tristaniopsis is the only species in this family and is a leaf spotting pathogen on Tristaniopsis laurina (Myrtaceae) in New South Wales, Australia (Crous et al. 2012b). 


\section{Genus included in Auratiopycnidiellaceae}

Auratiopycnidiella Crous \& Summerell, Persoonia 28: 69 (2012)

Index Fungorum number: IF564733; 1 species with sequence data.

Type species - Auratiopycnidiella tristaniopsis Crous \& Summerell

Notes - Auratiopycnidiella is monotypic and comprises only the type species A. tristaniopsis. This taxon shows some similarities to taxa of Cryphonectriaceae in having orange conidiomata. However, Auratiopycnidiella is distinct from other genera of Diaporthales in having subepidermal, pycnidial, orange conidiomata with dark brown margins, holoblastic to annellidic conidiogenous cells, ellipsoid and uni-septate conidia with a thickened hilum or minute marginal frill. Conidia becoming brown at germination forming a thin, wavy germ slit, $90^{\circ}$ to the long axis of the conidium (Crous et al. 2012b).
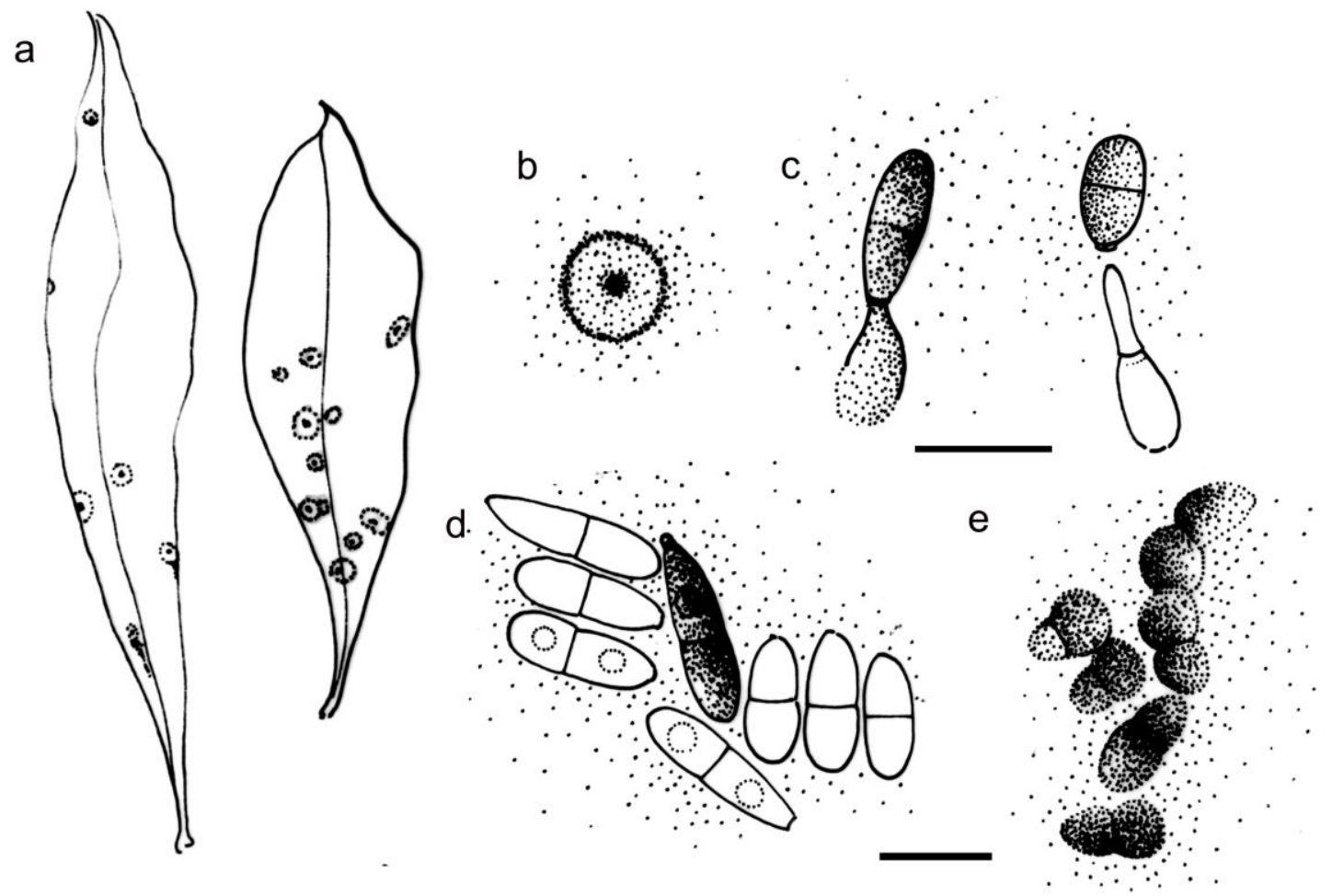

Figure 39 - Auratiopycnidiella tristaniopsis (redrawn from Crous et al. 2012b). a Host. b Close-up of orange pycnidia (top-view). c Conidiogenous cells giving rise to conidia. d Disarticulating conidial cells. e Conidia with thick, bright banded germ slit. Scale bars: c-e $=10 \mu \mathrm{m}$.

Australiascaceae Réblová \& W. Gams, Stud. Mycol. 68(1): 171 (2011)

Index Fungorum number: IF515430; Facesoffungi number: FoF01110; 8 species.

Pathogenic on tubers of sweet potato and saprobic on terrestrial plant leaves, branches, and on spathes and stipes of ferns. Sexual morph: Ascomata solitary to gregarious, brown to black, conical to obpyriform, glabrous or clothed with setae. Ostioles periphysate. Setae scant, acute, thick-walled, septate, dark brown. Peridium 2-layered, fragile, textura epidermoidea to prismatica in surface view. Paraphyses septate, persistent, branching. Asci 8-spored, unitunicate, cylindrical to clavate, short-pedicellate, apex truncate, with a distinct, shallow, J-, apical ring. Ascospores overlapping biseriate, hyaline, ellipsoidal to oblong, apiculate at both ends, septate, smooth-walled. Asexual morph: Hyphomycetous. Conidiophores macronematous, pale to dark brown, septate. Conidiogenous cells monophialidic, ampulliform to cylindrical, subhyaline, with minute collarette. Conidia ellipsoid to cylindrical-ellipsoidal, smooth-walled, hyaline, septate, aggregated in slime or in chains (adapted from Maharachchikumbura et al. 2016b).

Type genus - Monilochaetes Halst. 
Notes - The family was established in Glomerellales based on morphological and molecular DNA data, to accommodate the holomorphic genus Australiasca with its asexual morph Monilochaetes, with Dischloridium as its synonym (Réblová et al. 2011). The relationship between Monilochaetes and Dischloridium was suggested by Rong \& Gams (2000). The correct name of the taxon is Monilochaetes (Maharachchikumbura et al. 2016b) as the name is older and more commonly used, especially in the plant pathological community. Based on both phylogenetic and MCC trees, the family is well-supported and related to the families Glomerellaceae, Plectosphaerellaceae and Reticulascaceae in Glomerellales and with a stem age of 256 MYA (Réblová et al. 2011, Maharachchikumbura et al. 2016b, Hongsanan et al. 2017).

\section{Ecological and economic significance of Australiascaceae}

Members of Australiascaceae are important inhabitants of commercial crops and medicinal plants. Monilochaetes infuscans causes scurf disease or soil stain of sweet-potato (Ipomea batata) in many countries (Harter 1916, Rong \& Gams 2000). Monilochaetes nothapodytis is an endophyte isolated from Nothapodytes pittosporoides in China, a plant used in Traditional Chinese Medicine (Zhou et al. 2017).

\section{Genus included in Australiascaceae}

Monilochaetes Halst. J. Agric. Res., Washington 5: 791 (1916)

Index Fungorum number: IF8969; 8 morphological species (Species Fungorum 2020), 5 species with sequence data.

Type species - Monilochaetes infuscans Harter

Notes - Monilochaetes was experimentally linked with its sexual morph by Réblová et al. (2011). Currently, eight taxa are included in Monilochaetes. Monilochaetes camelliae (= Australiasca queenslandica) is illustrated in this entry.

Barbatosphaeriaceae H. Zhang, K.D. Hyde \& Maharachch., Fungal Divers. 85: 94 (2017)

Index Fungorum number: IF553763; Facesoffungi number: FoF03341; 26 species.

Saprobic on decaying wood or other plant materials. Sexual morph: Ascomata astromatic, leathery to fragile, dark brown to black, solitary or usually aggregated in circular to oval nests or in short rows, globose to subglobose, glabrous or roughened, with elongate necks, venter or neck are sparsely covered with a pubescence that disappears with age. Necks cylindrical, central or lateral, straight to slightly flexuous, when in circular groups decumbent to perpendicular, covering, piercing the periderm in a group. Ostiole periphysate. Peridium two-layered. Paraphyses abundant, persistent, cylindrical, unbranched, septate, constricted at the septa, tapering to the apex. Asci 8spored, unitunicate, clavate or cylindrical, tapering towards the pedicel, with a distinct or indistinct, refractive, J-, apical ring, floating freely in centrum at maturity. Ascospores 1- or 2-seriate, hyaline to pale brown, oblong to ellipsoid, subcylindrical, reniform, straight, sometimes curved, allantoid, U- to horseshoe-shaped or 3/4 circular, aseptate or septate, not- or slightly constricted at the septum, smooth-walled. Asexual morph: Hyphomycetous, ramichloridium- and sporothrix-like. Conidiophores semi-micronematous to macronematous, unbranched or branched, cylindrical to flask- or irregularly-shaped, brown or hyaline. Conidiogenous cells polyblastic, integrated, terminal, sympodially elongating with several denticles or forming rachis producing conidia holoblastically. Conidia ellipsoidal to suballantoid, straight or curved, unicellular, hyaline (adapted from Réblová 2007, Réblová et al. 2015c Zhang et al. 2017a).

Type genus - Barbatosphaeria Réblová

Notes - Barbatosphaeriaceae was introduced by Zhang et al. (2017a) with three genera, Barbatosphaeria, Ceratostomella and Xylomelasma, in Diaporthomycetidae genera incertae sedis. The family formed a strongly supported, distinct clade, with a stem age of ca 110 MYA in the MCC tree (Hyde et al. 2017a, Zhang et al. 2017a). Barbatosphaeriaceae formed a sister clade to Natantiella ligneola and Ophiostomatales in Zhang et al. (2017a), while it was a sister group to Amplistromatales, Ophiostomatales and Phomatosporales in Senanayake et al. (2016). In this entry, 
the sexual morph of Barbatosphaeria varioseptata and the ramichloridium- and sporothrix-like asexual morphs of $B$. barbirostris are illustrated.
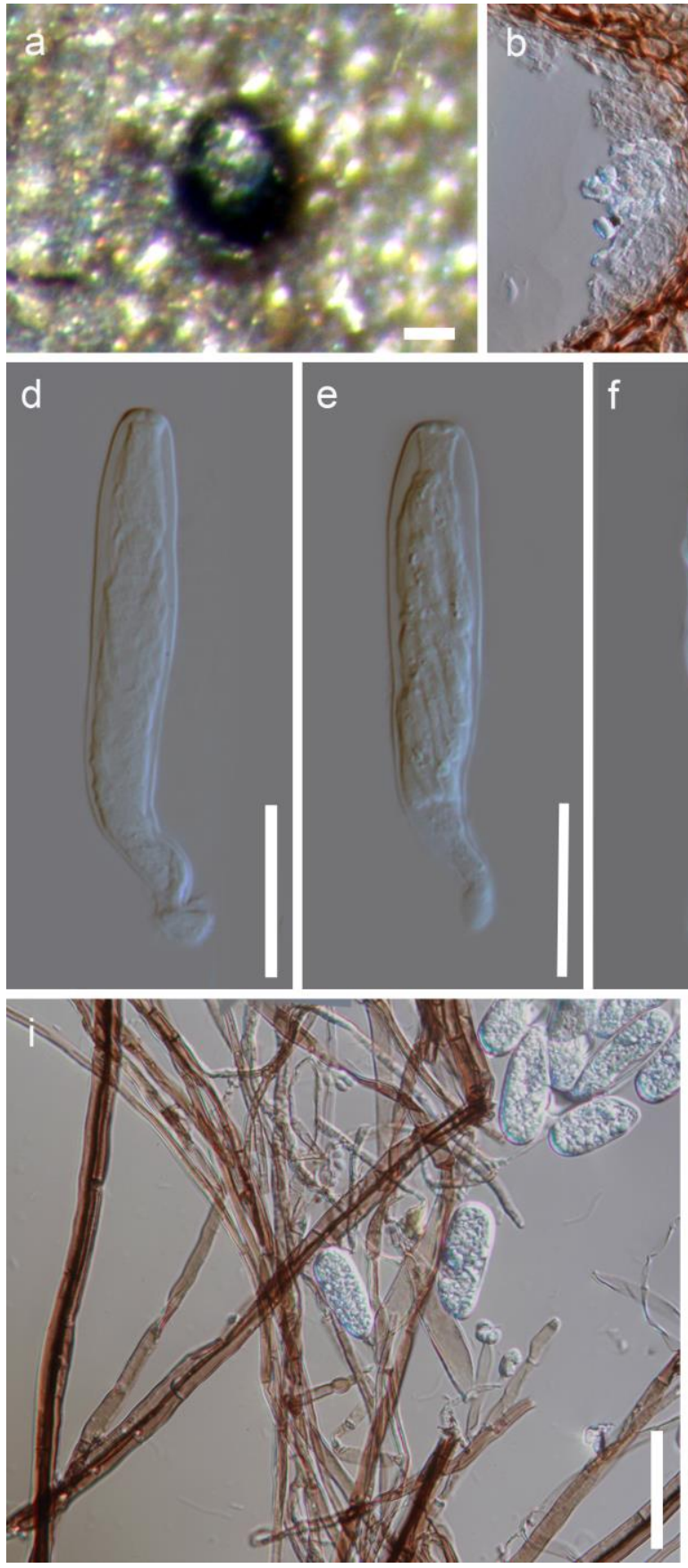
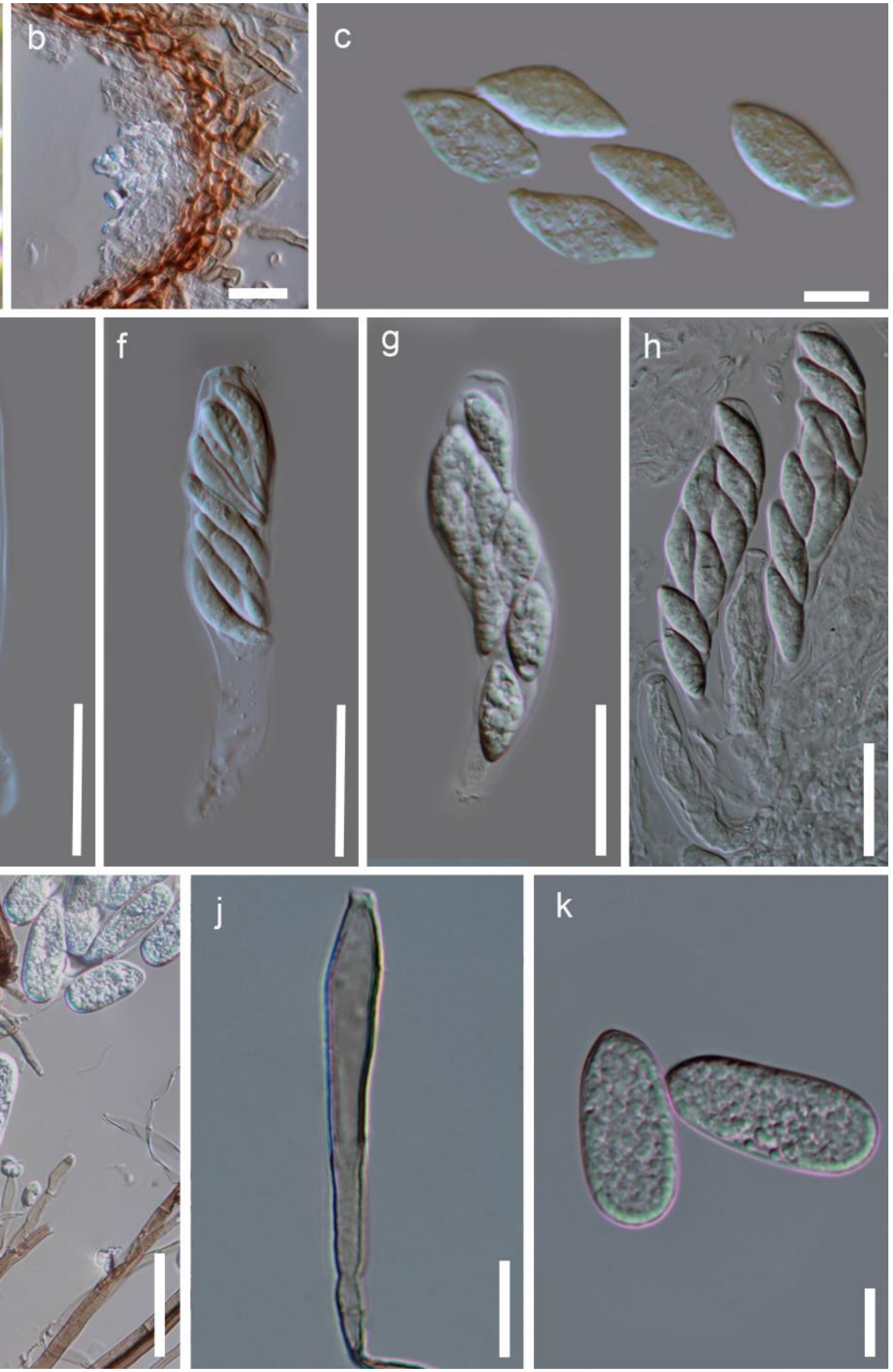

Figure 40 - Monilochaetes queenslandica (Material examined - AUSTRALIA, Queensland, Malanda, on branch of Camellia sinensis, 26 Mar 1988, J.L. Alcorn, BRIP 25190a, holotype, BRIP 24334c). a Perithecia on the host. b Peridium. c Ascospores. d-h Asci. i Conidiophores. j Conidiogenous cells. $\mathrm{k}$ Conidia. Scale bars: $\mathrm{a}=100 \mu \mathrm{m}, \mathrm{b}, \mathrm{d}-\mathrm{i}=50 \mu \mathrm{m}, \mathrm{c}=20 \mu \mathrm{m}, \mathrm{j}-\mathrm{k}=10 \mu \mathrm{m}$.

\section{Ecological and economic significance of Barbatosphaeriaceae}

Barbatosphaeriaceae comprises three genera which are saprobic on decaying wood and bark.

\section{Genera included in Barbatosphaeriaceae}

Barbatosphaeria Réblová, Mycologia 99(5): 727 (2008)

Index Fungorum number: IF505954; 9 morphological species (Species Fungorum 2020), 8 species with sequence data. 
Type species - Barbatosphaeria barbirostris (Dufour) Réblová

Notes - The genus was introduced by Réblová (2007) based on Barbatosphaeria barbirostris and defined as a well-supported monophyletic clade in Sordariomycetidae, genera incertae sedis (Réblová et al. 2015c). Zhang et al. (2017a) transferred the genus to the newly described Barbatosphaeriaceae based on a stable clade in phylogenetic and MCC trees. A key to species accepted in the genus was provided by Réblová et al. (2015c). Ramichloridium- and sporothrix-like asexual morphs have been observed regularly in cultures of various species (Samuels \& Candoussau 1996, Réblová 2007, Réblová et al. 2015c).

Ceratostomella Sacc., Michelia 1(4): 370 (1878), Mycologia 98(1): 75 (2006)

Index Fungorum number: IF901; 14 morphological species (Species Fungorum 2020), 2 species with sequence data.

Type species - Ceratostomella rostrata (Tode: Fr.) Sacc.

Notes - Ceratostomella is a well-established genus that comprises 112 epithets in Index Fungorum (2020). Ceratostomella was redescribed based on the lectotype species C. rostrata and three other species were accepted, i.e. C. cuspidate, C. pyrenaica and C. rhynchophora. Other species attributed to the genus that do not match the emended generic concept were revised. Ceratostomella species with evanescent asci were transferred to Microascales and Ophiostomatales (de Beer et al. 2013a, 2014). Ceratostomella species with persistent asci were revised by Réblová (2011) and Réblová et al. (2018). Many species were excluded from Ceratostomella, some were accommodated in other genera, and some remain as species of uncertain status and cannot presently be reassigned (de Beer et al. 2013a, 2014, Réblová et al. 2011, 2018).

Xylomelasma Réblová, Mycologia 98(1): 87 (2006)

Index Fungorum number: IF501459; 3 morphological species (Species Fungorum 2020), 2 species with sequence data.

Type species - Xylomelasma sordida Réblová

Notes - Xylomelasma was introduced and delimited from the closely related genus Ceratostomella by Réblová (2006), with two new species, X. novae-zelandiae and X. sordida, both occurring on decaying wood. The third wood-inhabiting species, X. shoalensis, was described in Hernández-Restrepo et al. (2016c). Xylomelasma moderata was transferred to Calyptosphaeria subdenudata in the Xenospadicoidaceae (Réblová et al. 2018).

Barrmaeliaceae Voglmayr \& Jaklitsch, Mycol. Progr. 17(1-2): 162 (2018)

Index Fungorum number: IF822042; Facesoffungi number: FoF06772; 12 species.

Saprobic on wood or bark. Sexual morph: Stroma if present mostly in wood and blackening the surface in wide areas or in elongate bands, sometimes darker around the ostioles; entostroma prosenchymatous, poorly developed, without $\mathrm{KOH}$ extractable pigments. Ascomata perithecial, globose, sometimes raising the substrate, singly, in small groups or gregarious. Peridium melanised, pseudoparenchymatous to prosenchymatous. Paraphyses numerous persistent, septate. Asci 8-spored, cylindrical, persistent, with $\mathrm{J}-$, or infrequently $\mathrm{J}+$, apical ring. Ascospores yellow to dark brown, unicellular with or without germ slit (Barrmaelia), or 2-celled with septum near one end, small cell hyaline, large cell dark brown and with an apical germ apparatus consisting of radial slits (Entosordaria); allantoid or ellipsoid, inequilateral, slightly inequilateral or nearly equilateral, with narrowly or broadly rounded ends. Asexual morph: libertella-like where known (Barrmaelia; Rappaz 1995, adapted from Voglmayr et al. 2018).

Type genus - Barrmaelia Rappaz

Notes - Barrmaeliaceae was introduced by Voglmayr et al. (2018) to accommodate the type genus Barrmaelia and is a sister genus to Entosordaria (Rappaz 1995). Barrmaelia macrospora, $B$. moravica, B. rhamnicola and Entosordaria perfidiosa were epitypified by Voglmayr et al. (2018). In addition, a new species B. rappazii and Entosordaria quercina were described in the family (Voglmayr et al. 2018). 

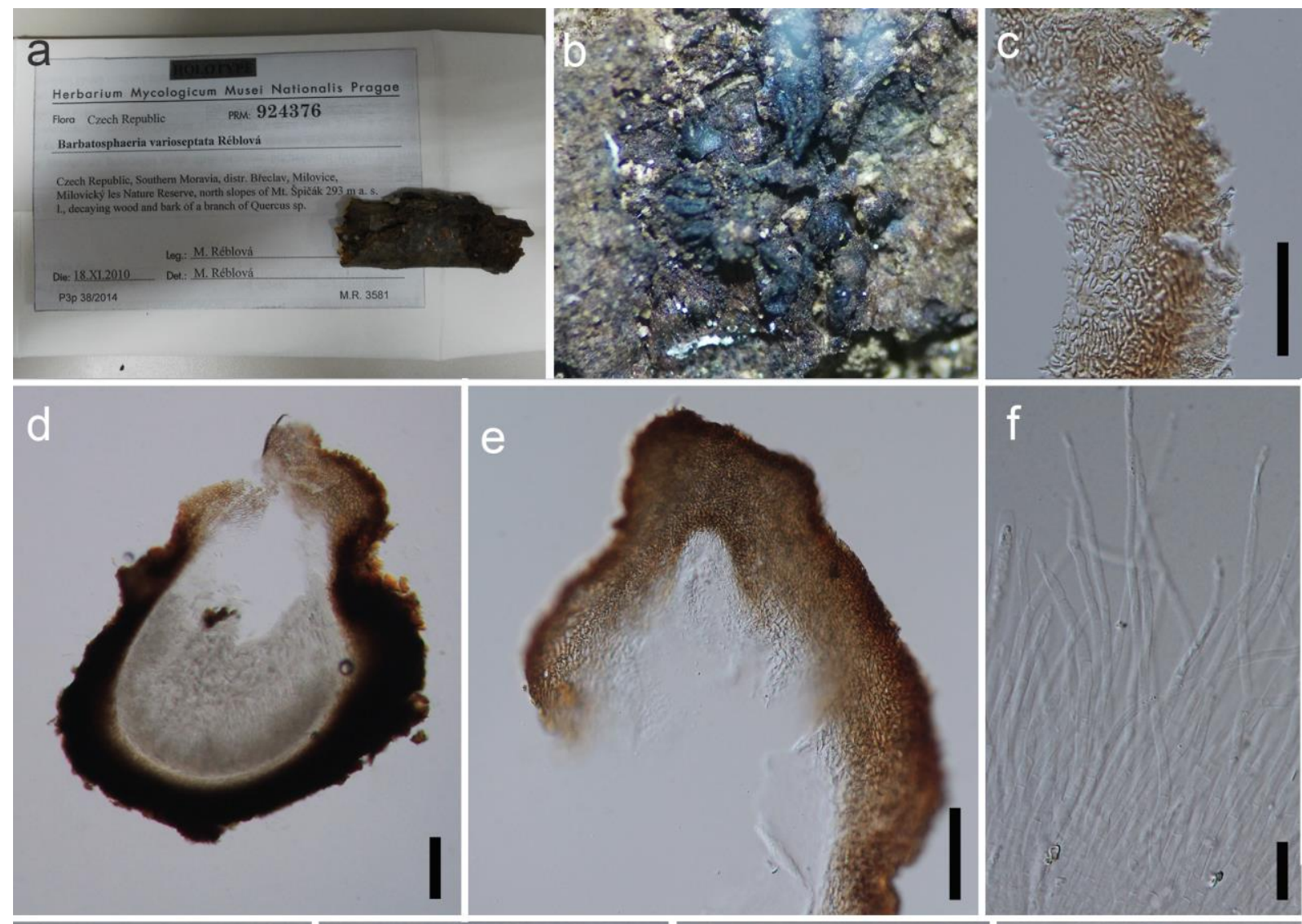

f

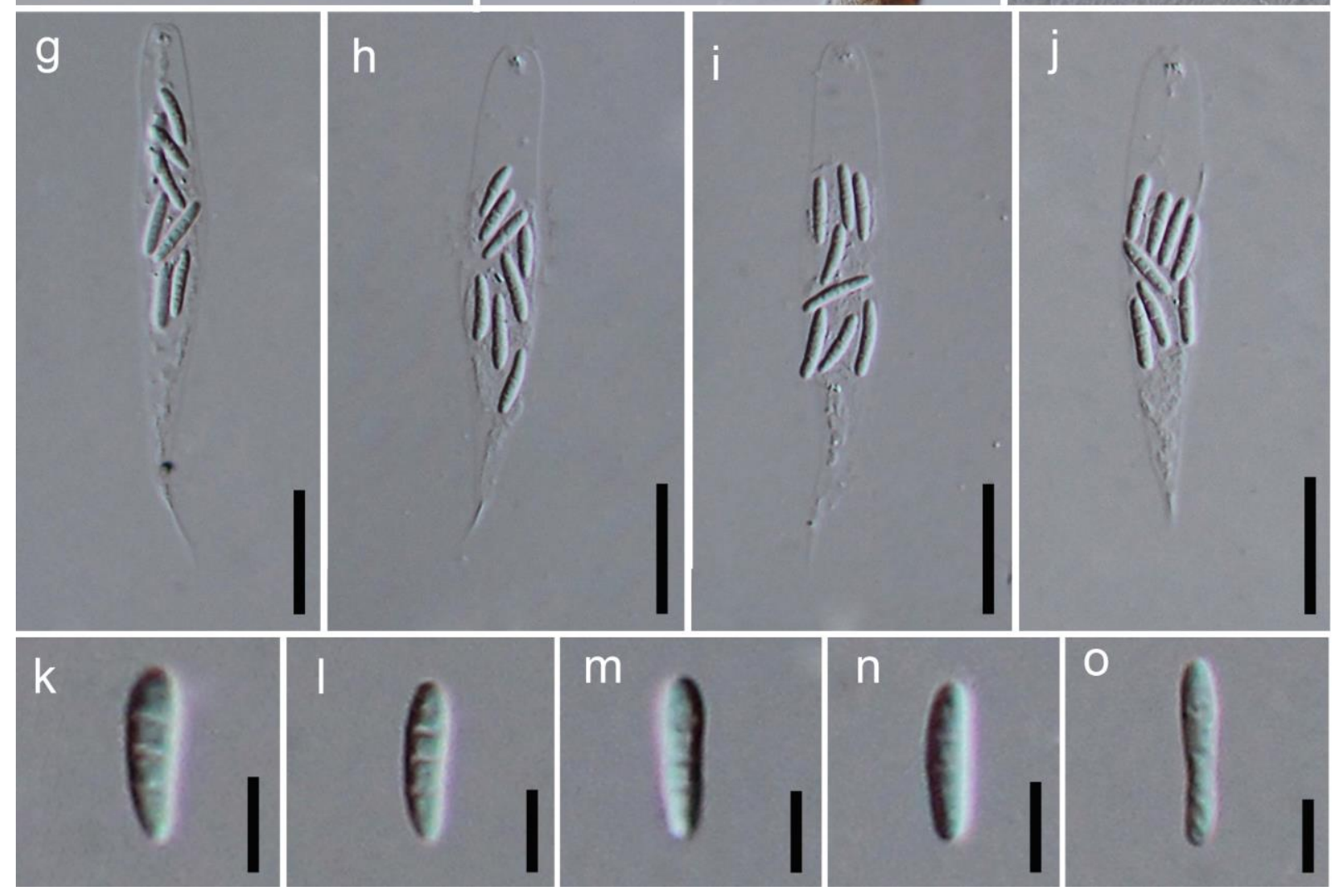

Figure 41 - Barbatosphaeria varioseptata (Material examined - CZECH REPUBLIC, Southern Moravia, distr. Břeclav, Milovice, Milovický les Nature Reserve, north slopes of Mt Špičák 293 m asl, on decaying wood and bark of a branch of Quercus sp., 18 November 2010, M. Réblová, PRM 924376, holotype). a Herbarium material with label. b Appearance of superficial black ascomata on host. c Structure of peridium. $d$ Vertical section of ascoma. e Ostiole. f Paraphyses. g-j Unitunicate asci. k-o Ascospores. Scale bars: $\mathrm{c}, \mathrm{d}=100 \mu \mathrm{m}, \mathrm{e}=50 \mu \mathrm{m}, \mathrm{f}-\mathrm{j}=20 \mu \mathrm{m}, \mathrm{k}-\mathrm{o}=5 \mu \mathrm{m}$. 
a

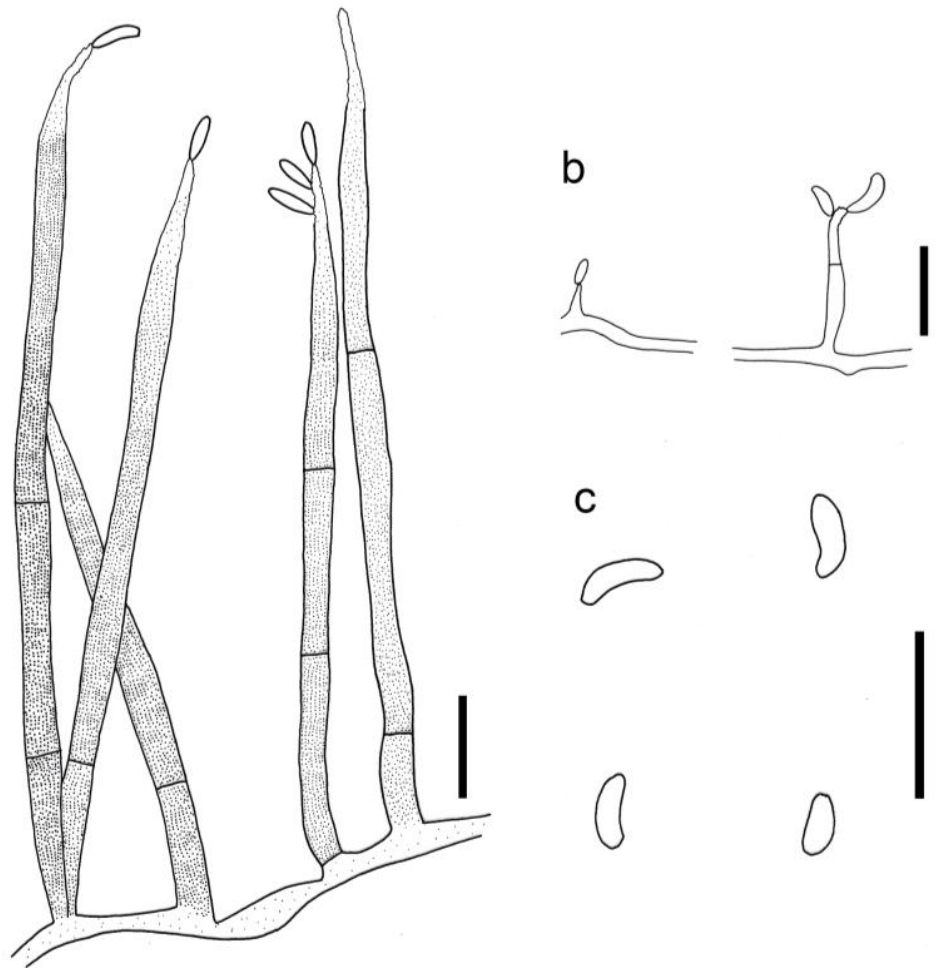

Figure 42 - Asexual morphs of Barbatosphaeria barbirostris, ramichloridium-like (a), sporothrixlike (b, c) (redrawn from Réblová 2007) a-c Conidiophores and conidia. Scale bars: a-c = $10 \mu \mathrm{m}$.

\section{Ecological and economic significance of Barrmaeliaceae}

Barrmaeliaceae comprises saprobes, especially wood and bark inhabiting species, which are important as decomposers (Rappaz 1995, Voglmayr et al. 2018). Among the Entosordaria species, E. jacobi-felicis was reported on Coffea liberica leaves from Ivory Coast (Moreau \& Moreau 1951).

\section{Genera included in Barrmaeliaceae}

Barrmaelia Rappaz, Mycol. Helv. 7(1): 130 (1995)

Index Fungorum number: IF27434; 8 morphological species (Voglmayr et al. 2018), 5 species with sequence data.

Type species - Barrmaelia rhamnicola Rappaz

Notes - Rappaz (1995) introduced Barrmaelia which resembles Diatrypaceae due to its allantoid ascospores, but in contrast, has short-pedicellate asci and J-, ascal rings. Rappaz (1995) combined six species in Barrmaelia (B. macrospora, B. moravica, B. oxyacanthae, B. picacea, B. pseudobombarda, and $B$. sustenta) and described one new species, which he also selected as the generic type, B. rhamnicola based on morphology. Maharachchikumbura et al. (2016b) regarded Barrmaelia as a xylariaceous genus with a conidial morph that did not belong to nodulisporiumlike or geniculosporium-like taxa. Wendt et al. (2018) placed Barrmaelia in Xylariales genera incertae sedis due to its unconfirmed affinities to the other families. A study on natural classification of Graphostromataceae, Hypoxylaceae, Lopadostomataceae and Xylariaceae has placed the genus in the Diatrypaceae based on their morphology and tentative phylogeny (Daranagama et al. 2018). However, the clade comprising Barrmaelia and Entosordaria within Xylariaceae sensu lato has been introduced as Barrmaeliaceae (Voglmayr et al. 2018).

Barrmaelia rhamnicola, the type species of the genus was introduced by Rappaz (1995) and epitypified by Voglmayr et al. (2018). It is characterized by often slightly curved, relatively large ascospores, which are filled with conspicuous oil drops and lack a germ slit. The known libertellalike asexual morph has been shown for B. rhamnicola. Barrmaelia rhamnicola is illustrated in this entry (Fig. 43). 

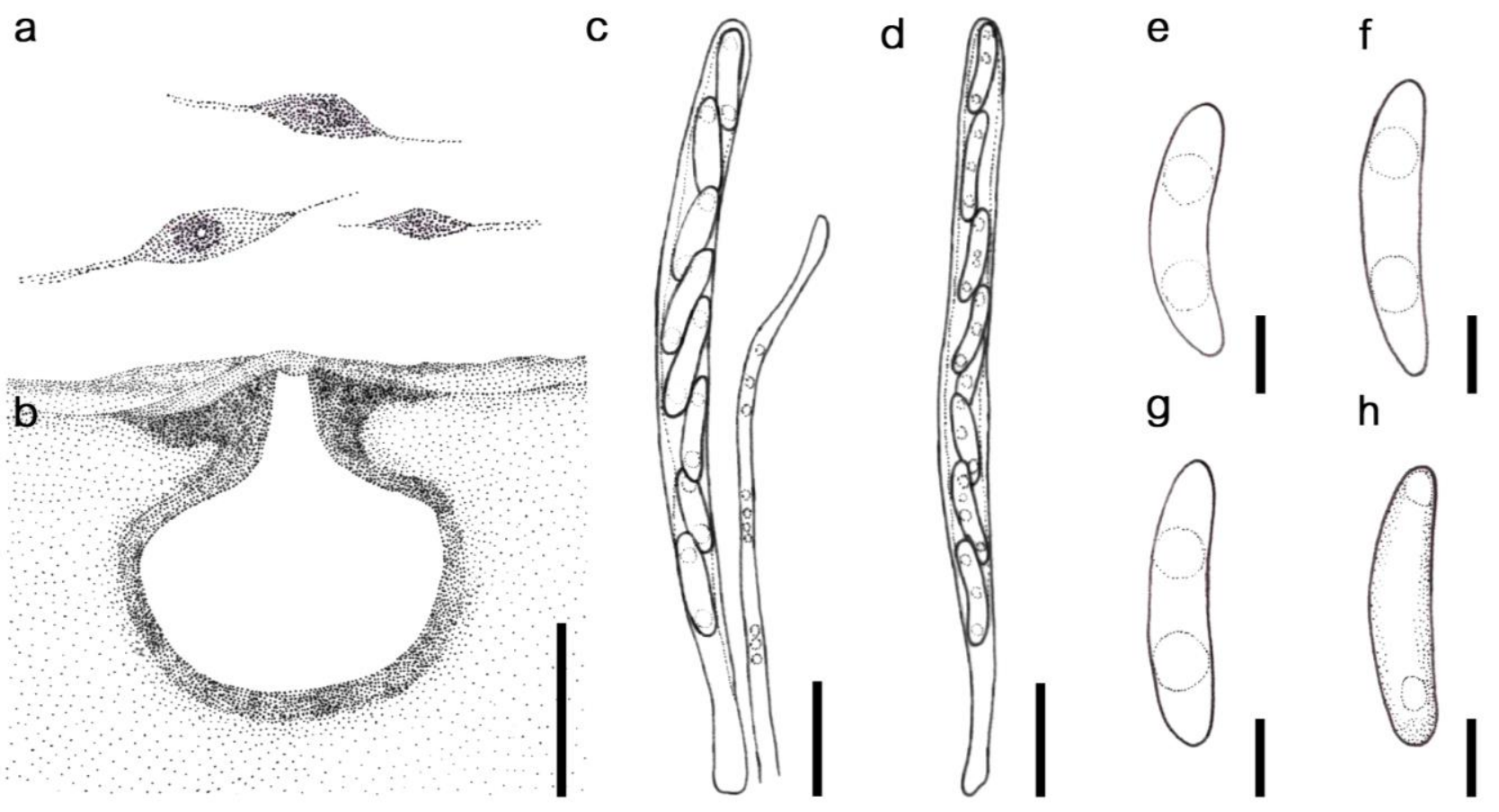

Figure 43 - Barrmaelia rhamnicola (redrawn from Voglmayr et al. 2018), a Ostioles protruding through the blackened wood surface. b Cross section of ascoma. c, d Asci e-h Ascospores. Scale bars: $\mathrm{b}=150 \mu \mathrm{m}, \mathrm{c}, \mathrm{d}=10 \mu \mathrm{m}, \mathrm{e}-\mathrm{h}=5 \mu \mathrm{m}$.

Entosordaria (Sacc.) Höhn., Sber. Akad. Wiss. Wien, Math.-naturw. Kl., Abt. 1129: 167 (1920), emend.

Index Fungorum number: IF1839; 4 morphological species (Species Fungorum 2020), 2 species with sequence data.

Type species - Entosordaria perfidiosa (De Not.) Höhn.

Notes - Voglmayr et al. (2018) re-described and validated Entosordaria in Barrmaeliaceae. Species are saprobes. The combined ITS, LSU, rpb2 and tub2 phylogenetic analyses revealed that the genus is sister to Barrmaelia.

Batistiaceae Samuels \& K.F. Rodrigues, Mycologia 81(1): 54 (1989)

Index Fungorum number: IF81989; Facesoffungi number: FoF01321; 1 species.

Saprobic on wood. Sexual morph: Ascomata cleistothecial, stipitate-capitate, solitary to gregarious, superficial, black, globose, long stipitate, carbonaceous, without an ostiole. Peridium cephalothecoid. Asci 8-spored, unitunicate, globose, lacking a visible discharge ring and deliquescent. Ascospores irregularly arranged, brown, ellipsoidal to oblong, 1-celled, without germ slits or germ pores, smooth-walled. Asexual morph: Hyphomycetous. Synnemata determinate, dark brown to black. Hyphae of stipe parallel, dark brown, septa simple. Conidiophores forming a compact, grey palisade. Capitulum terminal, globose, in vertical section composed of a darkly pigmented dome of angular cells giving rise to loose textura intricata of hyaline, more or less swollen hyphae, a compact subhymenium of similar hyphae and then a conidiogenous hymenium. Conidiogenous cells phialidic, single or in terminal pairs, light brown, cylindrical, with an abruptly terminated apex and cylindrical collarette, smooth-walled. Conidia in dry chains without connectives, pale olivaceous, light brown to grey in mass, ellipsoidal, globose, subglobose or oblong, 1-celled, with thin, smooth-walls (adapted from Maharachchimbura et al. 2016b).

Type genus - Batistia Cif.

Notes - Batistiaceae, introduced in 1989 and classified in Sordariales, is typified by Batistia (Samuels \& Rodrigues 1989, Eriksson 2001). Kirk et al. (2001) excluded the family from Sordariales and placed in Sordariomycetidae families incertae sedis. However, based on molecular 
analyses, Huhndorf et al. (2004b) placed Batistiaceae in Pezizomycotina family incertae sedis. This classification was followed by Lumbsch \& Huhndorf (2010) and Wijayawardene et al. (2012). However, Maharachchikumbura et al. (2015) determined that the sequence data published by Huhndorf et al. (2004b) was contaminated. The classification of Batistiaceae was verified in Sordariomycetidae family incertae sedis (Maharachchikumbura et al. 2015, 2016b, Hongsanan et al. 2017, Wijayawardene et al. 2018a). A lack of ex-type cultures and sequence data in GenBank makes it difficult to place Batistiaceae in a phylogenetic scheme (Kirk et al. 2008, Maharachchikumbura et al. 2015, 2016b, Hongsanan et al. 2017). We follow its classification in Sordariomycetidae family incertae sedis until other evidence emerges (Maharachchikumbura et al. 2015, 2016b). Fresh collections, especially of neotype or epitype strains, together with molecular data are needed to clarify the species and family. In this entry Batistia annulipes is illustrated.

\section{Ecological and economic significance of Batistiaceae}

Batistiaceae are likely to be saprobes involved in nutrient cycling.

\section{Genus included in Batistiaceae}

Batistia Cif., Atti Ist. bot. Univ. Lab. crittog. Pavia, Ser. 5 15: 166 (1958)

Index Fungorum number: IF522; 1 species with sequence data (likely contaminant).

Type species - Batistia annulipes (Mont.) Cif.

Notes - Batistia is typified by Batistia annulipes. Maharachchikumbura et al. (2016b) synonymized Acrostroma under Batistia based on the report by Samuels \& Rodrigues (1989) and a study of herbarium type materials of both Acrostroma and Batistia.

Beltraniaceae Nann., Repert. mic. uomo: 498 (1934)

Index Fungorum number: IF80516; Facesoffungi number: FoF05312; 80 species.

Saprobic on plant tissues. Sexual morph: Ascomata pale yellow, solitary to aggregated on OA and PDA, globose to somewhat papillate, with central ostiole; wall of 3-4 layers of subhyaline cells of textura angularis to intricata. Paraphyses septate, cellular, anastomosing, distributed among asci. Asci 8-spored, unitunicate, subcylindrical, sessile. Ascospores tri- to multi-seriate, hyaline, obovoid, granular, smooth, aseptate with dissolving mucoid sheath. Asexual morph: Hyphomycetous. Mycelium immersed to superficial, composed of subhyaline to brown, thin-walled hyphae. Stromata usually present, parenchymatous to pseudoparenchymatous, hyaline to brown, often confined to epidermal cells. Setae present or absent, straight, thick-walled, dark brown, smooth or verrucose, with radially lobed basal cell, tapering to acute apex. Conidiophores simple or sometimes branched, erect, septate, pale brown, arising from the base of setae or separate, with or without radially lobed basal cell. Conidiogenous cells holoblastic, polyblastic, pale brown, integrated, denticulate. Conidia biconic, lageniform to navicular, subhyaline to red-brown, with transverse band of pale pigment at widest part of the conidium, base rounded, 1-denticulate or rostrate, apex spicate, apiculate or truncate (adapted from Crous et al. (2015a) and Maharachchikumbura et al. (2016b)).

Type genus - Beltrania Penz.

Notes - Beltrania, Beltraniella, Beltraniopsis, Hemibeltrania, Parapleurotheciopsis, Porobeltraniella, Pseudobeltrania, Pseudosubramaniomyces and Subsessila, are accepted in the family (Maharachchikumbura et al. 2015, 2016b, Hongsanan et al. 2017, Lin et al. 2017a). We introduce and illustrate a new species, Beltraniella ramosiphora based on phylogenetic data (Figs. $4,45)$.

\section{Ecological and economic significance of Beltraniaceae}

Most Beltraniaceae species are saprobes. However, Beltrania rhombica was reported to be a pathogen which can cause a leaf spot on Tibouchina semidecandra in China (Shi et al. 2012). Milagres et al. (2018) reported Pseudobeltrania cedrelae, as the causal agent of pseudobeltrania spot on Cedrela fissilis in Brazil. 


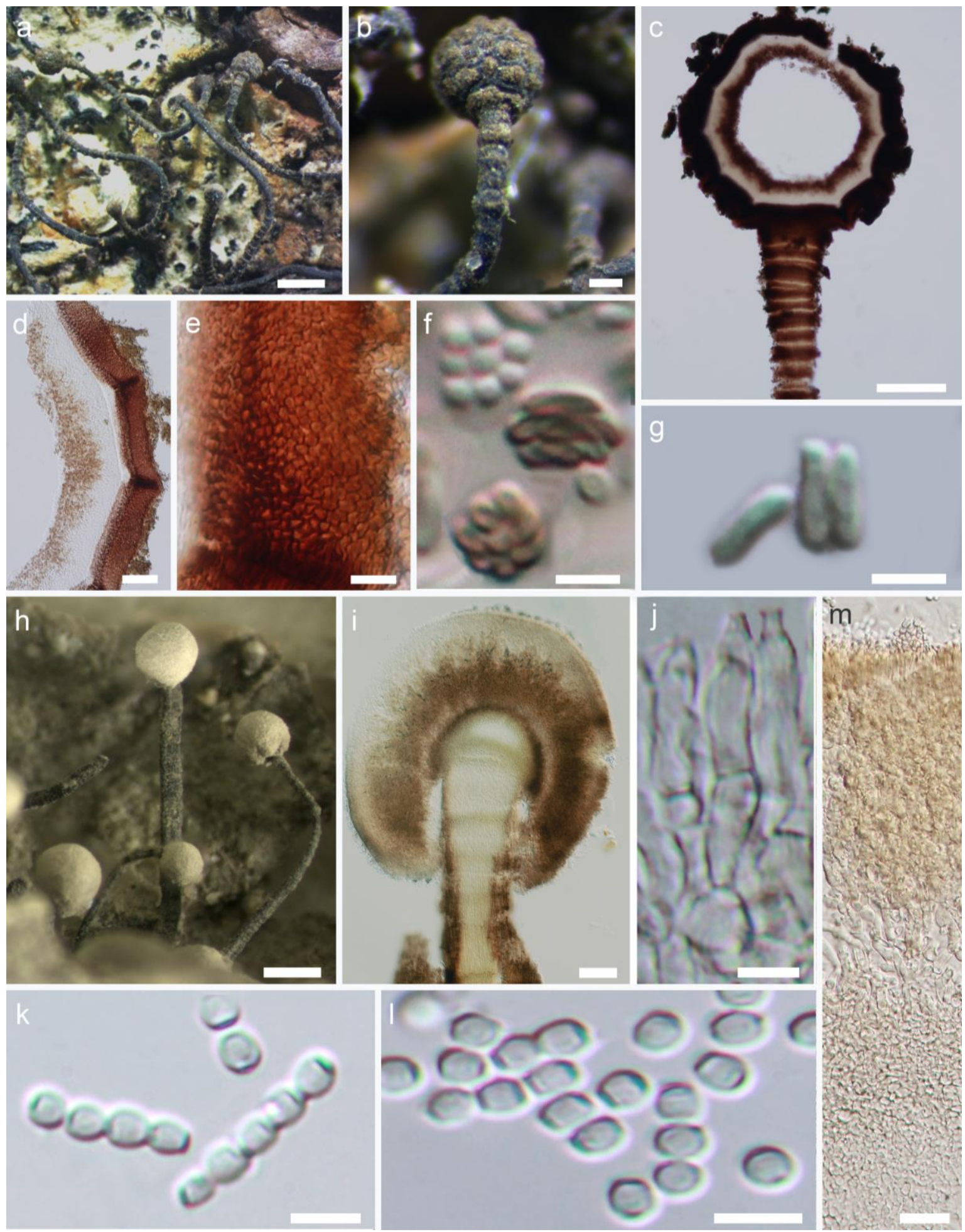

Figure 44 - Batistia annulipes a-g MNHN-PC-PC0167686 MC10053b (Material examined BRAZIL, Rio de Janeiro, Corcovado, at cortices, Montagne, 1831-1833, MNHN-PC-PC0167685 (MC10053a), MNHN-PC-PC0167686 (MC10053b) MNHN-PC-PC0167687 (MC10053c), holotype, MNHN-PC-PC0167688 (MC10054), MNHN-PC-PC0167689 (MC10055)) h-m NY 00936852 (Dumont-VE 6722) (Material examined - VENEZUELA, EDO. SURE., Trail from Los Pocitos through la Roma to town of Rio Grande Arriba, on unidentified wood, 12 July 1972, K. P. Dumont, G. J. Samuels and G. Morillo, and J. Farfan, Dumont-VE 5017, NY 00936853, paratype). a Ascomata on the host. b Ascoma. c Vertical section of ascoma. d, e Peridium. f Asci. g Ascospores. h Synnemata on the host. i Synnema longitudinal section. j Conidiogenous cells. k, 1 Conidia. $\mathrm{m}$ Detail of capitulum tissues in vertical section. Scale bars: $\mathrm{a}=1 \mathrm{~mm}, \mathrm{~b}, \mathrm{c}=200 \mu \mathrm{m}, \mathrm{d}, \mathrm{i}$ $=50 \mu \mathrm{m}, \mathrm{e}=10 \mu \mathrm{m}, \mathrm{f}, \mathrm{g}, \mathrm{j}-\mathrm{l}=3 \mu \mathrm{m}, \mathrm{h}=500 \mu \mathrm{m}, \mathrm{m}=20 \mu \mathrm{m}$. 


\section{Genera included in Beltraniaceae}

Beltrania Penz., Nuovo G. bot. ital. 14: 72 (1882)

Index Fungorum number: IF7355; 15 morphological species (Species Fungorum 2020), 5 species with sequence data.

Type species - Beltrania rhombica Penz.

Notes - Beltrania is characterised by dark and mostly unbranched setae with radially lobed basal cells, unbranched conidiophores arising from basal cells of setae or from separate radially lobed basal cells; polyblastic, sympodial and denticulate conidiogenous cells; swollen separating cells and biconic, spicate or apiculate conidia with a hyaline transverse band (Seifert et al. 2011, Lin et al. 2017b).

Beltraniella Subram., Proc. Indian Acad. Sci., Sect. B 36: 227 (1952)

Index Fungorum number: IF7356; 27 morphological species (Species Fungorum 2020), 11 species with sequence data.

Type species - Beltraniella odinae Subram.

Notes - Beltraniella species are characterised by setae that are sterile extensions of conidiophores or occur among conidiophores or are lacking, unbranched and arising from radially lobed basal cells. Conidiophores are branched, often with setiform apex, arising from radially lobed basal cells. Conidiogenous cells are polyblastic and sympodial and produce acropleurogenous, turbinate or biconic conidia with a distinct hyaline transverse band.

Crous et al. (2016a) described a new Beltraniella species, B. acaciae based on morphology and phylogenetic analysis of ITS sequence data, revealed that $B$. acaciae was intermediate between Beltraniella and Beltrania. However, Beltraniella acaciae grouped together with other Beltraniella species within the Beltraniella clade in our phylogenetic analysis of combined ITS and LSU sequence data.

Beltraniella ramosiphora C.G. Lin \& K.D. Hyde, sp. nov.

Figs 45, 46

Index Fungorum number: IF555603; Facesoffungi number: FoF03885

Etymology - Name reflects the branched conidiophores.

Holotype - MFLU 17-2649.

Saprobic on decaying leaves. Sexual morph: Undetermined. Asexual morph: Colonies on plant substrate effuse, thin, pale brown. Mycelium mostly immersed in the substratum. Setae numerous, erect, arising from radially lobed basal cells, straight or flexuous, unbranched, single, thick-walled, smooth, dark brown, 155-280 $\mu \mathrm{m}$ long, 4.5-7 $\mu \mathrm{m}$ wide at the base, tapering to a pointed apex, arising from a dark brown, swollen, radially lobed cell, 13-23 $\mu \mathrm{m}$ diam. Conidiophores macronematous, long setiform and short non-setiform; long conidiophores single, straight, septate, smooth, thick-walled, unbranched, dark brown at the base and paler at the apex, 260-365 $\mu \mathrm{m}$ long, swollen at the base and 18-22.5 $\mu \mathrm{m}$ wide, 7.5-9 $\mu \mathrm{m}$ wide just above the swollen base, slightly tapering to a pointed apex; short conidiophores, non-setiform, branched, septate, smooth-walled, subhyaline to pale brown, thin-walled, 20-55 $\mu \mathrm{m}$ long, swollen at the base and 4.5$12 \mu \mathrm{m}$ wide. Conidiogenous cells polyblastic, integrated, determinate, terminal, cylindrical, oblong, hyaline, smooth, 5-22 $\mu \mathrm{m}$ long, 3-7.5 $\mu \mathrm{m}$ wide at the base. Separating cells ovoid or obovoid, thin-walled, smooth, hyaline, 7.5-11.5 $\mu \mathrm{m}$ long, 3.5-4.6 $\mu \mathrm{m}$ wide in the broadest part. Conidia arise directly from conidiogenous cells or from separating cells, aggregated, acrogenous, simple, dry, straight, smooth, thin-walled, biconic, turbinate to pyriform, rostrate to pointed at proximal end, truncate at distal end, hyaline with a hyaline supraequatorial transverse band, $15.5-21 \mu \mathrm{m}$ long, 4.5-6.5 $\mu \mathrm{m}$ wide in the broadest part.

Culture characteristics - Conidia germinating on PDA within $12 \mathrm{~h}$. Colonies on PDA effuse, pale white from above, light yellow to dark brown from below, reaching a diam. of $4-5 \mathrm{~cm}$ in 3 days at $25^{\circ} \mathrm{C}$.

Material examined - THAILAND, Chang Wat Lampang, Amphoe Mueang Pan, Tambon Chae Son, on decaying leaf, 24 Sep 2016, CG Lin LCG10-2 (MFLU 17-2649, holotype), ex-type 
living culture, MFLUCC 17-2582.

GenBank numbers - ITS: MG717500, LSU: MG717502.

Notes - Three Beltraniella species have two types of conidiophores (long setiform and short non-setiform), viz., B. botryospora, B. clara and B. fertilis. Beltraniella ramosiphora differs from $B$. clara by smooth setae and biconic, turbinate to pyriform conidia, whereas setae are absent and conidia are lageniform in B. clara (Onofri 1983). The long setiform conidiophores of $B$. ramosiphora are unbranched, while they are branched at the apex in B. fertilis (Heredia et al. 2002). The short non-setiform conidiophores of B. ramosiphora are longer than B. botryospora, and they are branched in B. ramosiphora (Shirouzu et al. 2010).

Beltraniopsis Bat. \& J.L. Bezerra, Publicações Inst. Micol. Recife 296: 4 (1960)

Index Fungorum number: IF7357; 11 morphological species (Species Fungorum 2020), 2 species with sequence data.

Type species - Beltraniopsis esenbeckiae Bat. \& J.L. Bezerra

Notes - Beltraniopsis was introduced by Batista \& Bezerra (1960). It is characterised by unbranched, setiform conidiophores arising from radially lobed basal cells, sympodial and denticulate conidiogenous cells, swollen separating cells and biconic, rostrate conidia with a hyaline transverse band (Seifert et al. 2011). Most Beltraniopsis species were collected from terrestrial litter, however, B. tanzaniensis was reported from decaying submerged leaves in India (Patil \& Borse 2015).

Hemibeltrania Piroz., Mycol. Pap. 90: 30 (1963)

Index Fungorum number: IF8498; 8 morphological species (Species Fungorum 2020), 1 species with sequence data.

Type species - Hemibeltrania cinnamomi (Deighton) Piroz.

Notes - Hemibeltrania was established by Pirozynski (1963) to accommodate H. cinnamomi and $H$. nectandrae. The genus is characterised by unbranched or sparingly branched conidiophores arising from radially lobed basal cells, sympodial and denticulate conidiogenous cells, and broadly ellipsoidal, limoniform, ovoid, obovoid, cymbiform, navicular, biconic or fusiform, pale olivaceous, aseptate conidia without a hyaline transverse band (Seifert et al. 2011). In addition, Hemibeltrania lacks a separating cell. A synopsis of accepted Hemibeltrania species was provided by Rajeshkumar et al. (2016b). Lin et al. (2017b) provided sequence data for H. cinnamomi, which was collected from Thailand.

Parapleurotheciopsis P.M. Kirk, Trans. Br. mycol. Soc. 78(1): 63 (1982)

Index Fungorum number: IF9219; 4 morphological species (Species Fungorum 2020), 1 species with sequence data.

Type species - Parapleurotheciopsis inaequiseptata (Matsush.) P.M. Kirk

Notes - The genus was introduced by Kirk (1982) for P. ilicina and P. inaequiseptata. Crous et al. (2015d) placed this genus within Beltraniaceae. Parapleurotheciopsis is characterised by unbranched, percurrent conidiophores arising from radially lobed basal cells, sympodial and denticulate conidiogenous cells and catenate conidia without a transverse band, lacking setae and swollen separating cells (Seifert et al. 2011).

Porobeltraniella Gusmão, Mycologia 96(1): 151 (2004)

Index Fungorum number: IF28821; 2 morphological species (Species Fungorum 2020), 1 species with sequence data.

Type species - Porobeltraniella porosa (Piroz. \& S.D. Patil) Gusmão

Notes - Porobeltraniella was introduced by Fernando \& Gusmão (2004) to accommodate $P$. patilii and $P$. porosa. Rajeshkumar et al. (2016a) provided sequence data for $P$. porosa and confirmed the placement of the genus within Beltraniaceae. Porobeltraniella is characterised by unbranched or verticillate, setiform conidiophores arising from radially lobed basal cells, 
polyblastic, discrete conidiogenous cells, solitary or catenate, turbinate conidia with circular pores near the broadest part (Seifert et al. 2011).

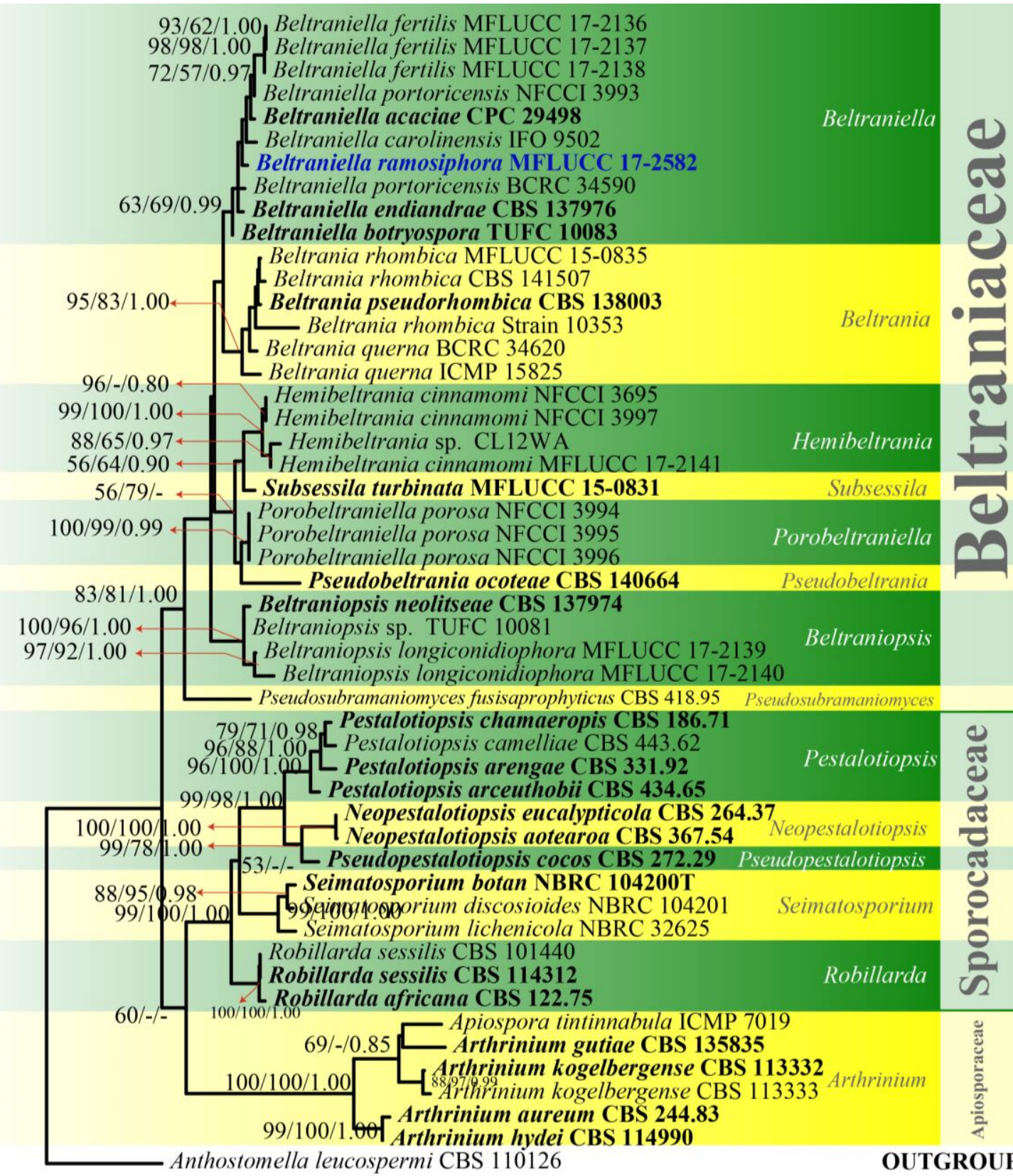

0.1

Figure 45 - Phylogram generated from maximum likelihood analysis based on combined LSU and ITS sequence data of Beltraniaceae. Fifty strains are included in the combined analyses which comprised 1546 characters (884 characters for LSU, 662 characters for ITS) after alignment. Tree topology of the maximum likelihood analysis is similar to the Bayesian and maximum parsimony analyses. The best RaxML tree with a final likelihood value of -7145.370801 is presented. Estimated base frequencies were as follows: $\mathrm{A}=0.252192, \mathrm{C}=0.214861, \mathrm{G}=0.266786, \mathrm{~T}=$ 0.266162 ; substitution rates $\mathrm{AC}=1.363640, \mathrm{AG}=2.557848, \mathrm{AT}=1.973142, \mathrm{CG}=1.035845, \mathrm{CT}=$ 5.942470, GT $=1.000000$; gamma distribution shape parameter $\alpha=0.171878$. Bootstrap support values for maximum likelihood and maximum parsimony greater than $50 \%$ and Bayesian posterior probabilities greater than 0.8 are indicated above or below the nodes as MLBS/MPBS/PP. The tree is rooted with Anthostomella leucospermi (CBS 110126). Ex-type strains are in bold and black. The newly generated sequences are indicated in blue. 


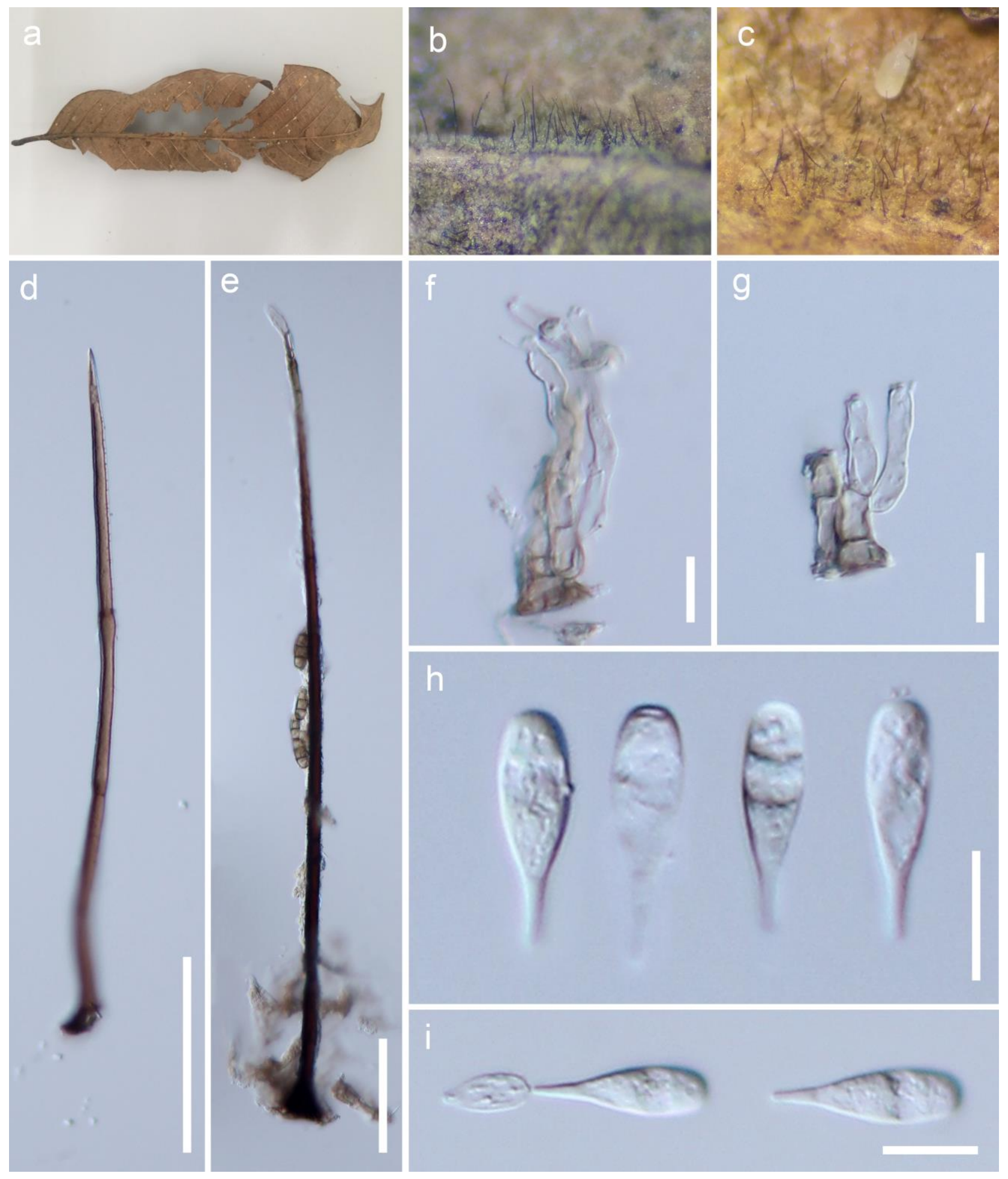

Figure 46 - Beltraniella ramosiphora (MFLU 17-2649, holotype). a Host material. b, c Conidiophores on host surface. d Setae. e Long conidiophore. f, g Short conidiophores with conidiogenous cells. $\mathrm{h}$, i Separating cell and conidia. Scale bars: $\mathrm{d}, \mathrm{e}=50 \mu \mathrm{m}, \mathrm{f}-\mathrm{i}=10 \mu \mathrm{m}$.

Pseudobeltrania Henn., Hedwigia 41: 310 (1902)

Index Fungorum number: IF9555; 9 morphological species (Species Fungorum 2020), 2 species with sequence data.

Type species - Pseudobeltrania cedrelae Henn.

Notes - Pseudobeltrania is characterised by unbranched conidiophores arising from radially lobed basal cells, polyblastic and denticulate conidiogenous cells and biconic, apiculate conidia with a transverse band, lacking of setae and swollen separating cells (Seifert et al. 2011). A key to 
species was provided by Heredia et al. (2002). Pseudobeltrania cedrelae was reported to be a pathogen which can cause leaf spot on Cedrela fissilis (Milagres et al. 2018).

Pseudosubramaniomyces Crous, Persoonia 39: 375 (2017)

Index Fungorum number: IF823465; 1 species with sequence data.

Type species - Pseudosubramaniomyces fusisaprophyticus (Matsush.) Crous

Notes - The genus was introduced by Varghese \& Rao (1979b) to accommodate S. indicus and $S$. navicularis. It is characterised by unbranched or sparingly branched, pale brown conidiophores, sympodial and denticulate conidiogenous cells and catenate conidia without a transverse band, lacking setae and swollen separating cells (Seifert et al. 2011). Rajeshkumar et al. (2016a) placed Subramaniomyces within Beltraniaceae based on phylogenetic analysis of $S$. fusisaprophyticus. However, Crous et al. (2017a) introduced a new genus Pseudosubramaniomyces to accommodate $S$. fusisaprophyticus and it differs from by lacking lateral conidiogenous cells along the length of the conidiophore stipe, and tends to have pale brown conidiophores.

Subsessila C.G. Lin \& K.D. Hyde, Mycol. Progr. 16: 396 (2017)

Index Fungorum number: IF552504; 1 species with sequence data.

Type species - Subsessila turbinata C.G. Lin \& K.D. Hyde

Notes - Subsessila is separated from Beltrania and other similar genera by the absence of distinct conidiophores and conidia without a hyaline transverse band (Lin et al. 2017a).

Bertiaceae Smyk, Ukr. bot. Zh. 38(6): 47 (1981)

Index Fungorum number: IF82053; Facesoffungi number: FoF01111; 38 species.

Saprobic on wood in freshwater and terrestrial habitats. Sexual morph: Ascomata perithecial, dark brown to black, solitary or gregarious, superficial to erumpent, cupuliform, globose to subglobose, carbonaceous to membranaceous, turbinate or tuberculate or smooth, collabent or collapsing laterally or not collapsing, ostiolate. Peridium thick, Munk pores present or absent, outer layer (pseudoparenchymatous cells) hard, composed of dark tissues, basal part mixed with host cells; inner layer composed of brown to dark brown to hyaline cells of textura angularis. Paraphyses few, inflated, branched. Asci 8-spored, unitunicate, clavate, long pedicellate, apical ring indistinct or absent. Ascospores 2-3-seriate or irregularly arranged, hyaline to brown, cylindrical to fusiform, aseptate to multi-septate, smooth-walled, mostly with guttules. Asexual morph: Undetermined (adapted from Maharachchimbura et al. 2016b).

Type genus - Bertia De Not.

Notes - Bertiaceae was introduced by Smyk (1981) and is typified by Bertia (De Notaris 1844). It is characterized by superficial, black, turbinate ascomata and clavate asci with hyaline, fusiform ascospores, irregularly arranged in the upper region of the ascus (Maharachchikumbura et al. 2016b). Nannfeldt \& Santesson (1975) reported that Nitschkiaceae consists of Acanthonitschkea, Bertia, Coronophora, Gaillardiella and Nitschkia based on similarity of ascomata. Nannfeldt \& Santesson (1975) also postulated that Bertia should be given generic status in the family based on different morphs of the ascoma without Quellkörper and 8-spored asci. Smyk (1981) was of the same view and introduced Bertiaceae. Mugambi \& Huhndorf (2010) reevaluated Coronophorales based on multi-gene analysis and proposed Bertia and Gaillardiella in Bertiaceae. Gaillardiella has superficial, brown ascomata with a roughened papulose peridium (Miller \& Huhndorf 2009). Maharachchikumbura et al. (2015) analysed a combined DNA sequence dataset to confirm the placement of Bertia and Gaillardiella in Bertiaceae, in a highly supported clade in the Coronophorales. In this study, Bertiaceae is closely related to Nitschkiaceae based on combined LSU-tefl-ITS sequence data analysis (Fig. 11). Bertia moriformis is illustrated in this entry.

\section{Ecological and economic significance of Bertiaceae}

Most Bertiaceae species are saprobic on wood, widespread with most known from America 
and Europe (De Notaris 1844, Patouillard \& Lagerheim 1895, Viégas 1947, Nannfeldt \& Santesson 1975, Mugambi \& Huhndorf 2010, Vasilyeva et al. 2015).

\section{Genera included in Bertiaceae}

Bertia De Not., Gior. Bot. Ital. 1(1): 334 (1844)

Index Fungorum number: IF551; 32 morphological species (Species Fungorum 2020), 9 species with sequence data.

Type species - Bertia moriformis (Tode) De Not.

Notes - The type species, Bertia moriformis, is characterized by tuberculate ascomata and clavate asci and brown ascospores (Mugambi \& Huhndorf 2010, Maharachchikumbura et al. 2016b). We provide a multi-gene phylogenetic tree (Fig. 11), which reveals that Bertia is closely related to members of Nitschkiaceae (Nitschkia, Acanthonitschkea and Fracchiaea) with good support (Fig. 11).
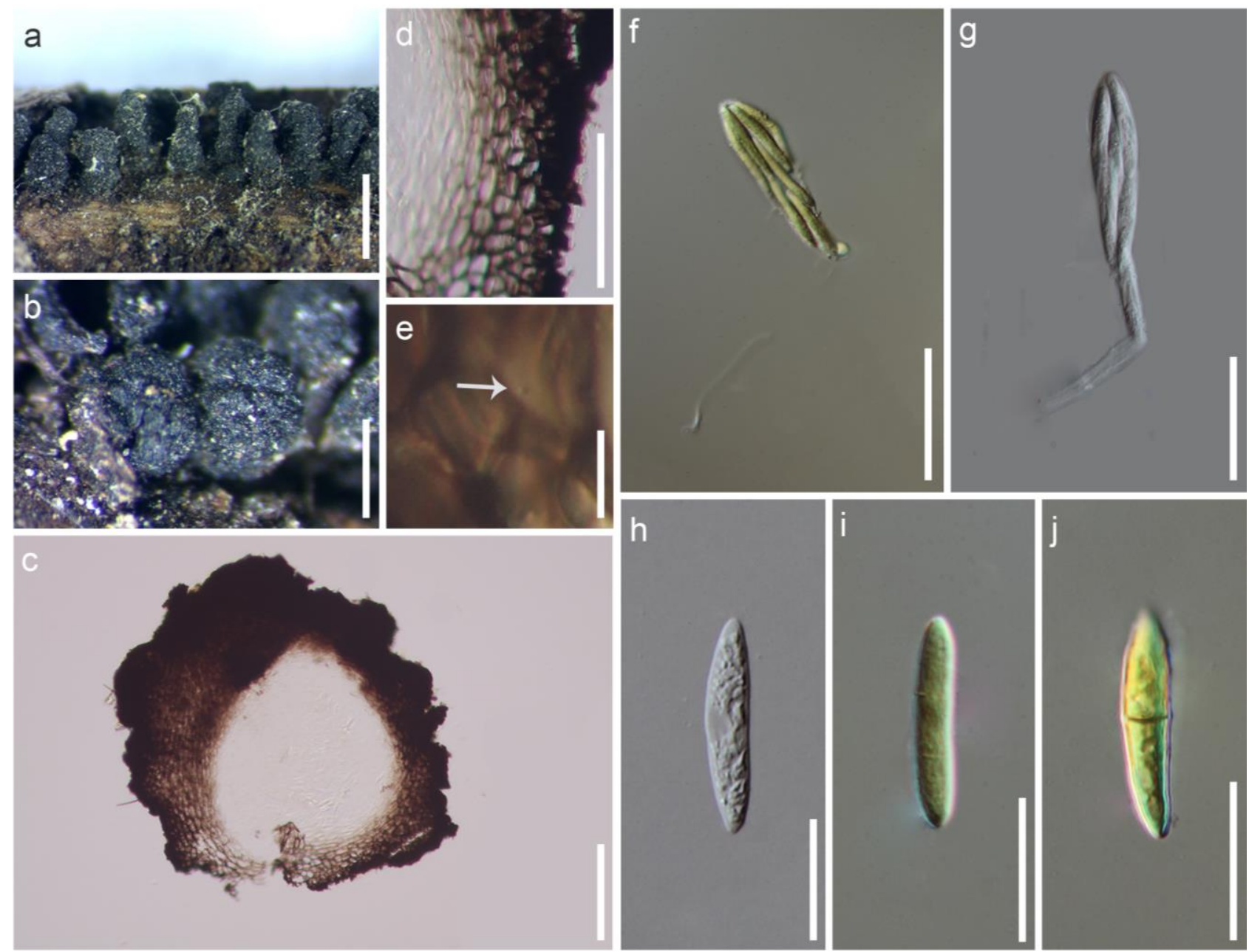

Figure 47 - Bertia moriformis (Material examined - ITALY, Riva, Valdobbia; on Rhododendron sp., Carestia, 30 April 1859, S-F298). a Ascomata on host. b Tuberculate ascomata. c Ascoma cross section. d Peridium. e Munk pores (arrows). f, g Asci. h-j Ascospores (f, i-j are stained in Melzer's reagent). Scale bars: $\mathrm{a}=1 \mathrm{~mm}, \mathrm{~b}=500 \mu \mathrm{m}, \mathrm{c}=200 \mu \mathrm{m}, \mathrm{d}=100 \mu \mathrm{m}, \mathrm{f}, \mathrm{g}=20 \mu \mathrm{m}, \mathrm{h}-\mathrm{j}=10 \mu \mathrm{m}, \mathrm{e}$ $=5 \mu \mathrm{m}$.

Gaillardiella Pat., Bull. Soc. mycol. Fr. 11(4): 226 (1895)

Index Fungorum number: IF2027; 6 morphological species (Species Fungorum 2020), 1 species with sequence data.

Type species - Gaillardiella pezizoides Pat. 
Notes - Gaillardiella is characterized by turbinate ascomata, clavate to cylindrical asci with short stalks and ring at the apex and hyaline ascospores.

Bionectriaceae Samuels \& Rossman, Stud. Mycol. 42: 15 (1999)

Index Fungorum number: IF82088; Facesoffungi number: FoF01367; 579 species.

Herbicolous, corticolous, lichenicolous or fungicolous, some are coprophilous, most occur in terrestrial or freshwater habitats, less common in marine habitats. Sexual morph: Ascomata superficial on the substratum or embedded in a weakly or well-developed erumpent stroma, solitary or densely aggregated, crowded, perithecial, rarely cleistothecial, if perithecial, globose, subglobose to pyriform, if cleistothecial, globose, white, yellow, orange, reddish-brown, greenish or purple to violet, without changing colour in $\mathrm{KOH}$ or lactic acid, smooth to rough, or warted, ostiolate or lacking ostioles. Periphyses present or absent. Peridium composed of 1-3 layers. Asci (2-)8spored, unitunicate, clavate, saccate, cylindrical, sessile or short pedicellate, rarely evanescent, apex simple or with an inconspicuous or distinct, J-, apical ring. Ascospores uniseriate, biseriate, multiseriate or irregular, hyaline, aseptate to multi-septate, sometimes muriform, globose, fusiform, ellipsoid or broadly ellipsoid, smooth-walled, spinulose to tuberculate or striate. Asexual morph: Hyphomycetous or less commonly ceolomycetous, acremonium-, gliocladium-like, gyrostroma-like or penicillium-like, sometimes conidia produced on hyphae. Conidiophores dimorphic or monomorphic, mostly sporodochial or synnematous, hyaline, subhyaline to brown or blackish brown, smooth to finely echinulate-walled. Conidiogenous cells phialidic. Phialides cylindrical to flask-shaped. Conidia unicellular to multi-septate, ellipsoidal, fusiform to subfusiform, sometimes with papillate or truncate ends, hyaline to greenish hyaline or olivaceous grey, smooth or striatewalled. Chlamydospores present or absent (adapted from Rossman et al. 1999).

Type genus - Clonostachys Corda

Notes - Rossman et al. (1999) introduced Bionectriaceae to accommodate 26 genera including five cleistothecial genera. Four cleistothecial genera were accepted in the family based on phylogenetic analysis of the LSU gene by Rossman et al. (2001). Rossman et al. (2001) reported that Bionectriaceae is monophyletic within Hypocreales, by including those genera and related asexual morphs. Maharachchikumbura et al. (2015, 2016b) listed 39 genera in the family. Wijayawardene et al. (2018a) accepted Didymostilbe and Virgatospora in Stachybotryaceae. Stromatocrea and Vesicladiella, previously included in Bionectriaceae by Maharachchikumbura et al. (2015, 2016b), were not considered by Wijayawardene et al. (2018a). Wijayawardene et al. (2018) accepted 39 genera in the family including Bullanockia, Fusariella, Paracylindrocarpon and Synnemellisia. Spicellum was listed under Bionectriaceae in Wijayawardene et al. (2018). However, Spicellum was synonymized under Trichothecium (Myrotheciomycetaceae, Hypocreales) based on morphology and DNA sequence data by Summerbell et al. (2011). LSU is commonly used and the available gene for phylogenetic analysis of Bionectriaceae. However, few additional sequence data are available for the family except for well-studied genera such as Geosmithia and Clonostachys (Voglmayr \& Jaklitsch 2019). Many genera need to be recollected and sequenced and their placement in, or exclusion from Bionectriaceae or synonymies confirmed.

\section{Ecological and economic significance of Bionectriaceae}

Only few plant-pathogenic species are recognized in Bionectriaceae e.g. Nectriella pironi causing galls on stems and leaves of woody plants (Alfieri et al. 1980). Acremonium species are causal agents of rose dieback in Iran (e.g. A. sclerotigenum) (Domsch et al. 2007, Mirtalebi et al. 2017). Some species of Acremonium and Clonostachys are effective biological control agents (Auer \& Ludwig-Müller 2014, Sutton \& Mason 2017, Bobeck \& Pearce 2017). Clonostachys rosea (strain BVT Cr-7) is a beneficial biological control agent for fungal plant pathogens such as Botrytis cinerea, Sclerotinia sclerotiorum, Pythium, Alternaria, Monilinia, Colletotrichum, Cladosporium, Rhizoctonia., Streptomyces, Didymella and Fusarium (Sutton \& Mason 2017). Furthermore, strain 88-710 helps to protect plants against environmental stresses, hence promoting plant growth and productivity (Sutton \& Mason 2017, Bobeck \& Pearce 2017). Acremonium 
alternatum strains are used as biological control agents in several countries, to control clubroot pathogen, Plasmodiophora brassicae, on Chinese cabbage (Brassica rapa) and oilseed rape (Brassica napus) (Auer \& Ludwig-Müller 2014).

\section{Genera included in Bionectriaceae}

We only list the genera in Bionectriaceae. Notes will be provided with species illustrations.

Acremonium Link, Mag. Gesell. naturf. Freunde, Berlin 3(1-2): 15 (1809)

Index Fungorum number: IF7028; 113 morphological species (Species Fungorum 2020), 72 species with sequence data.

Type species - Acremonium alternatum Link

Anthonectria Döbbeler, Mycologia 102(2): 405 (2010)

Index Fungorum number: IF514117; 1 morphological species.

Type species - Anthonectria mammispora Döbbeler

Aphanotria Döbbeler, Mycol. Res. 111(12): 1408 (2007)

Index Fungorum number: IF510591; 1 morphological species.

Type species - Aphanotria paradoxa Döbbeler

Battarrina (Sacc.) Clem. \& Shear, Gen. fung., Edn 2 (Minneapolis): 279 (1931)

Index Fungorum number: IF526; 1 morphological species.

Type species - Battarrina inclusa (Berk. \& Broome) Clem. \& Shear

Bryocentria Döbbeler, Mycol. Progr. 3(3): 247 (2004)

Index Fungorum number: IF28841; 15 morphological species (Species Fungorum 2020), 2 species with sequence data.

Type species - Bryocentria brongniartii (P. Crouan \& H. Crouan) Döbbeler

Bryotria Döbbeler \& P.G. Davison, Nova Hedwigia 106(1-2): 232 (2017)

Index Fungorum number: IF821323; 5 morphological species (Species Fungorum 2020).

Type species - Bryotria urophora Döbbeler \& P.G. Davison

Bullanockia Crous, Persoonia 37: 327 (2016)

Index Fungorum number: IF819077; 1 species with sequence data.

Type species - Bullanockia australis Crous

Clibanites (P. Karst.) P. Karst., Bidr. Känn. Finl. Nat. Folk 19: 14, 167 (1871)

Index Fungorum number: IF1107; 1 morphological species.

Type species - Clibanites paradoxa (P. Karst.) P. Karst.

Clonostachys Corda, Pracht-Fl. Eur. Schimmelbild.: 31 (1839)

Index Fungorum number: IF7701; 41 morphological species (Species Fungorum 2020), 20 species based on molecular data.

Type species - Clonostachys araucaria Corda

Notes - Bionectria was linked to Clonostachys by Rossman et al. (2013) and priority given to the older and commonly used name Clonostachys. We illustrate the sexual morph of Clonostachys rosea and asexual morph of $C$. byssicola (Figs. 48, 49).

Dimerosporiella Speg., Revta Mus. La Plata 15: 10 (1908)

Index Fungorum number: IF1585; 7 morphological species (Species Fungorum 2020).

Type species - Dimerosporiella paulistana Speg. 


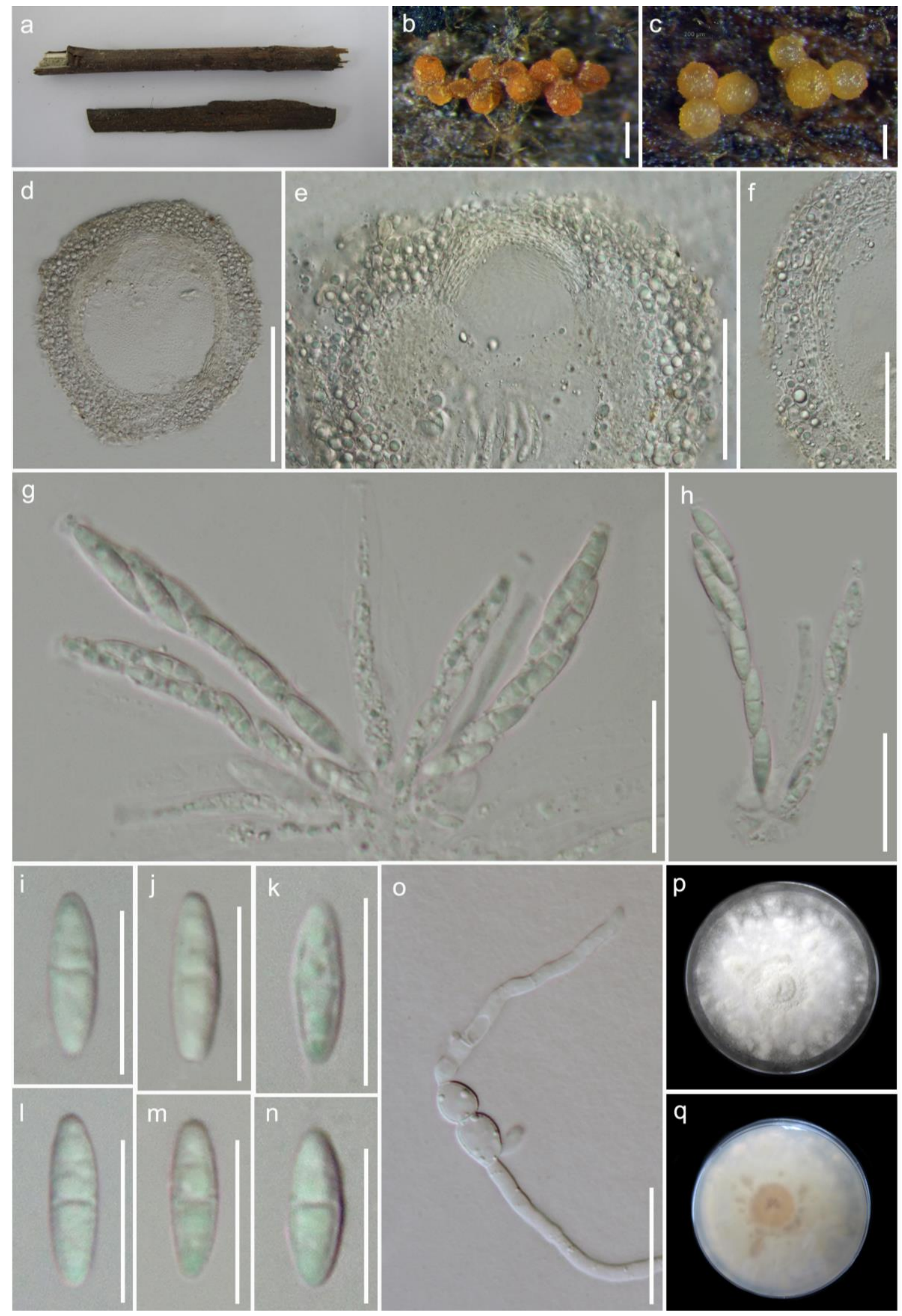

Figure 48 - Clonostachys rosea (Material examined - THAILAND, Phayao Province, Chiang Kham District, on twigs of a dicotyledonous plant, R.H. Perera, 11 September 2017, Bion 17 (MFLU 19-0960), living culture MFLUCC 17-2632). a Herbarium material. b, c Ascomata on host (a dry, b after wet with water). d Section of ascoma. e Section of ostiole. f Section of peridium. $g, h$ Asci. i-n Ascospores. o Germinating ascospore. p, q Colony on PDA. Scale bars: b, c $=200 \mu \mathrm{m}, \mathrm{d}$ $=100 \mu \mathrm{m}, \mathrm{e}, \mathrm{f}=50 \mu \mathrm{m}, \mathrm{g}, \mathrm{h}=20 \mu \mathrm{m}, \mathrm{i}-\mathrm{n}=10 \mu \mathrm{m}, \mathrm{o}=20 \mu \mathrm{m}$. 


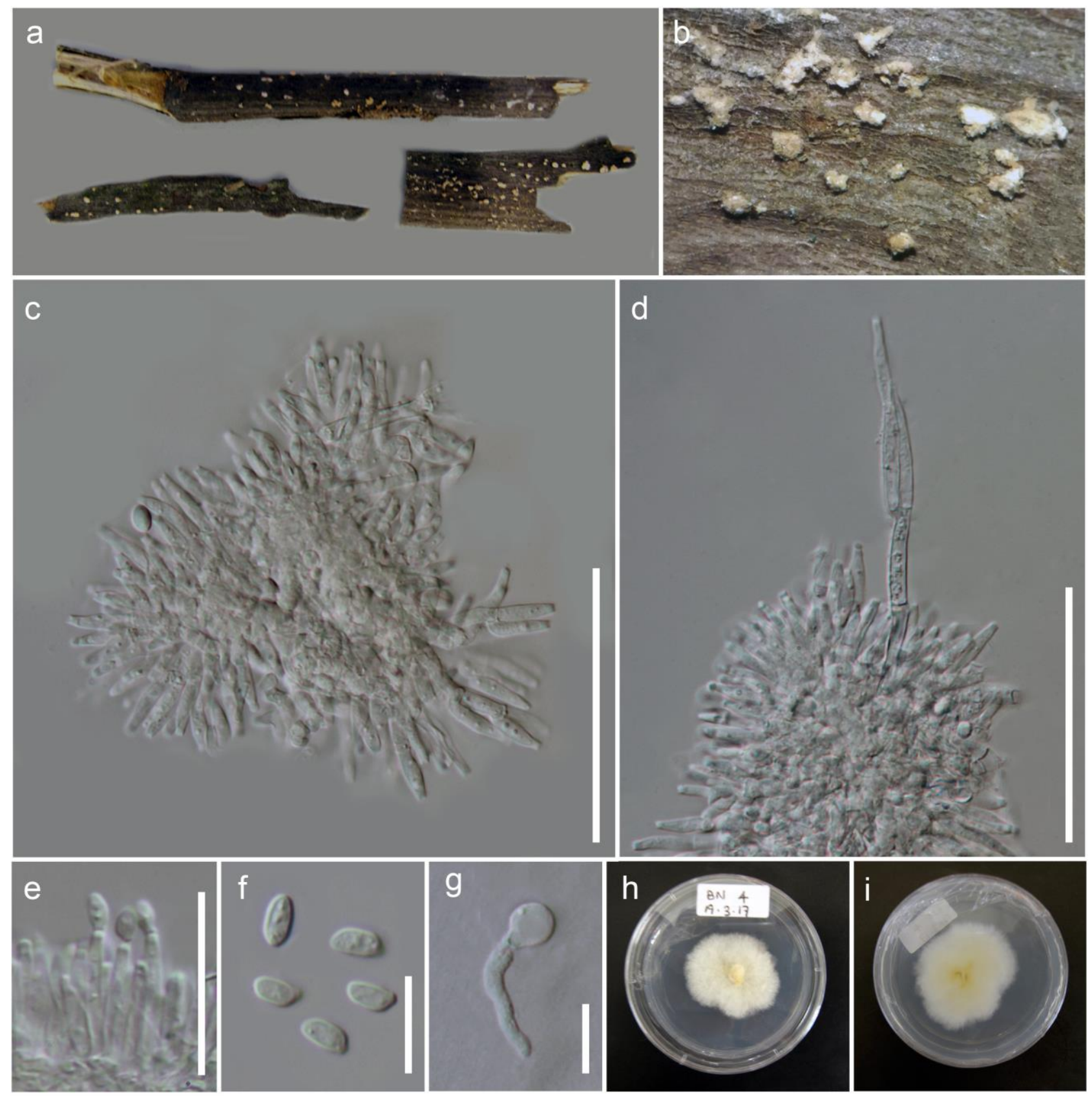

Figure 49 - Clonostachys byssicola (Material examined - THAILAND, Chiang Mai Province, on a dead stem of Chromolaena odorata, 2 February 2017, R.H. Perera BN4, MFLU 18-2729; living culture MFLUCC 17-2033). a Herbarium material. b Sporodochia on the host. c Secondary conidiophores, penicillate. $\mathrm{d}$ Secondary conidiophores and verticillium-like primary conidiophores. e Phialides with conidia. f Conidia. g Germinating conidium. h, i Colony on PDA. Scale bars: $c, d=$ $50 \mu \mathrm{m}, \mathrm{e}=20 \mu \mathrm{m}, \mathrm{f}, \mathrm{g}=10 \mu \mathrm{m}$.

Fusariella Sacc., Atti Inst. Veneto Sci. lett., ed Arti, Sér. 6 2: 463 (1884)

Index Fungorum number: IF8282; 17 morphological species (Species Fungorum 2020), 8 species with sequence data.

Type species - Fusariella atrovirens (Berk.) Sacc.

Geonectria Lechat \& J. Fourn., Ascomycete.org 10(2): 81 (2018)

Index Fungorum number: IF824881; 1 morphological species.

Type species - Geonectria subalpina Lechat, J. Fourn., M. Vega \& Priou 
Geosmithia Pitt, Can. J. Bot. 57(19): 2021 (1979)

Index Fungorum number: IF8324; 23 morphological species (Species Fungorum 2020), 16 species with sequence data.

Type species - Geosmithia lavendula (Raper \& Fennell) Pitt

Gliomastix Guég., Bull. Soc. mycol. Fr. 21: 240 (1905)

Index Fungorum number: IF8345; 20 morphological species (Species Fungorum 2020), 5 species with sequence data.

Type species - Gliomastix chartarum (Cooke) Guég.

Globonectria Etayo, Biblthca Lichenol. 84: 47 (2002)

Index Fungorum number: IF28686; 1 morphological species.

Type species - Globonectria cochensis Etayo

Gracilistilbella Seifert, Stud. Mycol. 45: 18 (2000)

Index Fungorum number: IF28455; 3 morphological species (Species Fungorum 2020).

Type species - Gracilistilbella clavulata (Mont.) Seifert

Halonectria E.B.G. Jones, Trans. Br. Mycol. Soc. 48(2): 287 (1965)

Index Fungorum number: IF2206; 1 morphological species.

Type species - Halonectria milfordensis E.B.G. Jones

Heleococcum C.A. Jørg., Bot. Tidsskr. 37: 417 (1922)

Index Fungorum number: IF2253; 4 morphological species (Species Fungorum 2020), 2 species with sequence data.

Type species - Heleococcum aurantiacum C.A. Jørg.

Hydropisphaera Dumort., Comment. bot. (Tournay): 89 (1822)

Index Fungorum number: IF2407; 27 morphological species (Species Fungorum 2020), 11 species with sequence data.

Type species - Hydropisphaera peziza (Tode) Dumort.

Ijuhya Starbäck, Bih. K. svenska VetenskAkad. Handl., Afd. 3 25(no. 1): 30 (1899)

Index Fungorum number: IF2482; 22 morphological species (Species Fungorum 2020), 14 species with sequence data.

Type species - Ijuhya vitrea Starbäck

Kallichroma Kohlm. \& Volkm.-Kohlm., Mycol. Res. 97(6): 759 (1993)

Index Fungorum number: IF22429; 4 species with sequence data.

Type species - Kallichroma tethys (Kohlm. \& E. Kohlm.) Kohlm. \& Volkm.-Kohlm.

Laniatria Döbbeler \& P.G. Davison, Nova Hedwigia 106(1-2): 239 (2017)

Index Fungorum number: IF821328; 1 morphological species

Type species - Laniatria myxostoma Döbbeler \& P.G. Davison

Lasionectria (Sacc.) Cooke, Grevillea 12(no. 64): 111 (1884)

Index Fungorum number: IF2652; 13 morphological species (Species Fungorum 2020), 10 species with sequence data.

Type species - Lasionectria mantuana (Sacc.) Cooke

Lasionectriella Lechat \& J. Fourn., Ascomycete.org 8(2): 59 (2016)

Index Fungorum number: IF815673; 2 species with sequence data 
Type species - Lasionectriella rubioi Lechat \& J. Fourn.

Mycoarachis Malloch \& Cain, Can. J. Bot. 48(10): 1820 (1970)

Index Fungorum number: IF3304; 2 morphological species (Species Fungorum 2020), 1 species with sequence data.

Type species - Mycoarachis inversa Malloch \& Cain

Mycocitrus Möller, Bot. Mitt. Trop. 9: 297 (1901)

Index Fungorum number: IF3313; 2 species with sequence data.

Type species - Mycocitrus aurantium Möller

Nectriella Nitschke, Jb. nassau. Ver. Naturk. 23-24: 175 (1870)

Index Fungorum number: IF3432; 52 morphological species (Species Fungorum 2020), 3 species with sequence data.

Type species - Nectriella fuckelii Nitschke

Nectriopsis Maire, Annls mycol. 9(4): 323 (1911)

Index Fungorum number: IF3434; 72 morphological species (Species Fungorum 2020), 11 species with sequence data.

Type species - Nectriopsis violacea (J.C. Schmidt) Maire

Nigrosabulum Malloch \& Cain, Can. J. Bot. 48(10): 1822 (1970)

Index Fungorum number: IF3507; 1 species with sequence data.

Type species - Nigrosabulum globosum Malloch \& Cain

Ochronectria Rossman \& Samuels, Stud. Mycol. 42: 53 (1999)

Index Fungorum number: IF28315; 2 species with sequence data.

Type species - Ochronectria calami (Henn. \& E. Nyman) Rossman \& Samuels

Ovicuculispora Etayo, Bull. Soc. linn. Provence 61: 110 (2010)

Index Fungorum number: IF565893; 2 morphological species (Species Fungorum 2020), 1 species with sequence data.

Type species - Ovicuculispora parmeliae (Berk. \& M.A. Curtis) Etayo

Paracylindrocarpon Crous, Roets \& L. Lombard, Persoonia 36: 367 (2016)

Index Fungorum number: IF817039; 4 species with sequence data.

Type species - Paracylindrocarpon aloicola Crous et al.

Paranectria Sacc., Michelia 1(no. 3): 317 (1878)

Index Fungorum number: IF3707; 8 morphological species (Species Fungorum 2020).

Type species - Paranectria affinis (Grev.) Sacc.

Periantria Döbbeler \& P.G. Davison, Nova Hedwigia 106(1-2): 242 (2017)

Index Fungorum number: IF821330; 2 morphological species (Species Fungorum 2020).

Type species - Periantria frullaniae (Racov.) Döbbeler \& P.G. Davison

Peristomialis (W. Phillips) Boud., Hist. Class. Discom. Eur. (Paris): 116 (1907)

Index Fungorum number: IF3830; 6 morphological species (Species Fungorum 2020),

molecular data available for an unnamed species.

Type species - Peristomialis berkeleyi Boud.

Pronectria Clem., Gen. fung., Edn 2 (Minneapolis): 78, 282 (1931) 
Index Fungorum number: IF4370; 45 morphological species (Species Fungorum 2020), 1 species with sequence data.

Type species - Pronectria lichenicola (Cooke) Clem.

Protocreopsis Yoshim. Doi, Kew Bull. 31(3): 551 (1977)

Index Fungorum number: IF4384; 12 morphological species (Species Fungorum 2020), 5 species with sequence data.

Type species - Protocreopsis zingibericola Yoshim.

Rhopalocladium Schroers, Samuels \& W. Gams, Mycologia 91(2): 375 (1999)

Index Fungorum number: IF28338; 1 morphological species.

Type species - Rhopalocladium myxophilum Schroers, Samuels \& W. Gams

Roumegueriella Speg., Revue mycol., Toulouse 2 (no. 1): 18 (1880)

Index Fungorum number: IF4798; 3 morphological species (Species Fungorum 2020), 1 species with sequence data.

Type species - Roumegueriella muricospora Speg.

Selinia P. Karst., Meddn Soc. Fauna Flora fenn. 1: 57 (1876)

Index Fungorum number: IF4996; 5 morphological species (Species Fungorum 2020), 1 species with sequence data.

Type species - Selinia pulchra (G. Winter) Sacc.

Stephanonectria Schroers \& Samuels, Sydowia 51(1): 116 (1999)

Index Fungorum number: IF28373; 1 species with sequence data.

Type species - Stephanonectria keithii (Berk. \& Broome) Schroers \& Samuels

Stilbocrea Pat., Bull. Soc. mycol. Fr. 16: 188, 186 (1900)

Index Fungorum number: IF5263; 7 morphological species (Species Fungorum 2020), 3 species with sequence data.

Type species - Stilbocrea dussii Pat.

Stromatonectria Jaklitsch \& Voglmayr, Mycologia 103(2): 435 (2011)

Index Fungorum number: IF518755; 1 species with sequence data.

Type species - Stromatonectria caraganae (Höhn.) Jaklitsch \& Voglmayr

Synnemellisia N.K. Rao, Manohar. \& Goos, Mycologia 80(6): 896 (1989)

Index Fungorum number: IF11201; 2 morphological species (Species Fungorum 2020), 1 species with sequence data.

Type species - Synnemellisia hyalospora N.K. Rao, Manohar. \& Goos.

Trichonectria Kirschst., Verh. bot. Ver. Prov. Brandenb. 48: 60 (1907)

Index Fungorum number: IF5563; 21 morphological species (Species Fungorum 2020), 1 species with sequence data.

Type species - Trichonectria aculeata Kirschst.

Verrucostoma Hirooka, Tak. Kobay. \& P. Chaverri, Mycologia 102(2): 422 (2010)

Index Fungorum number: IF513353; 2 species with sequence data.

Type species - Verrucostoma freycinetiae Hirooka, Tak. Kobay. \& P. Chaverri

Xanthonectria J. Fourn. \& P.-A. Moreau, Ascomycete.org 8(4): 173 (2016)

Index Fungorum number: IF816960; 1 species with sequence data 
Type species - Xanthonectria pseudopeziza (Desm.) Lechat, J. Fourn. \& P.-A. Moreau

Boliniaceae Rick, Brotéria, sér. bot. 25: 65 (1931)

Index Fungorum number: IF80526; Facesoffungi number: FoF01129; 46 species.

Saprobic on decorticated decaying wood, occasionally hypersaprobic on polypores, in terrestrial habitats. Sexual morph: Stroma absent or present, immersed to superficial, often erumpent, clypeate to irregular in shape, light brown to black, coriaceous, membranaceous or powdered or furfuraceous, with or without brown, septate interwoven hyphae, if present surrounding the apex of the ascomata. Ascomata perithecial, solitary to gregarious, immersed within the stromata, monostichous or polystichous or erumpent to superficial, brown to black, globose, cylindrical to obpyriform, coriaceous or membranaceous, smooth, with or without papilla, occasionally of stellate appearance. Ostiole periphysate. Peridium two-layered, outer layer composed of brown, thick-walled cells of textura angularis or textura intricata; inner layer composed of hyaline, thin-walled cells of textura prismatica. Paraphyses abundant, persistent, filamentous, tapering, septate, branched. Asci 8-spored, unitunicate, cylindrical to clavate, long pedicellate, some with an apical ring. Ascospores 2-3-seriate, hyaline or brown, with an inconspicuous apical germ pore at one or both ends that may be covered by an indistinct hyaline cap, ellipsoid to cylindrical, straight to slightly curved to suballantoid, sometimes laterally flattened, aseptate or septate, smooth-walled, mostly with guttules. Asexual morph: Undetermined (adapted from Maharachchimbura et al. 2016b).

Type genus - Camarops P. Karst.

Notes - Boliniaceae was introduced by Rick (1931) based on black stroma and cylindrical asci with smooth-walled ascospores, and is typified by Camarops (Karsten 1873). Earlier, this family was placed in Xylariales based on its morphological similarities (Barr 1990b, Romero \& Samuels 1991). Andersson et al. (1995) concluded that Boliniaceae was more closely related to Sordariales based on SSU sequence data. This family was subsequently placed in Boliniales by Kirk et al. (2001). Based on phylogenetic and morphological data, six genera were accepted in Boliniaceae (Lumbsch \& Huhndorf 2010). Untereiner et al. (2013) added Apiorhynchostoma and Pseudovalsaria based on LSU rDNA sequence data. A key to Boliniaceae genera was given in Untereiner et al. (2013).

\section{Ecological and economic significance of Boliniaceae}

Most Boliniaceae species are saprobic on wood and widespread in temperate regions (Maharachchikumbura et al. 2016b).

\section{Genera included in Boliniaceae}

Apiocamarops Samuels \& J.D. Rogers, Mycotaxon 28(1): 54 (1987)

Index Fungorum number: IF25015; 3 morphological species (Species Fungorum 2020).

Type species - Apiocamarops alba Samuels \& J.D. Rogers

Notes - Apiocamarops is characterized by ascomata surrounded by furfuraceous outer coating, cylindrical asci and brown ascospores (Samuels \& Rogers 1987). Four species were accommodated in Apiocamarops (A. alba, A. cryptocellula, A. luquilloensis, and A. pulvinata) and they are related to Camarops with turbinate stromata and ascospores with a germ pore at one end (Samuels \& Rogers 1987, Rogers \& Samuels 1988, Reagan \& Waide 1996, Rogers \& Ju 2003). Apiocamarops has furfuraceous, hyaline ascomata and 1-septate ascospores and differs from Camarops which has black ascomata and aseptate ascospores (Samuels \& Rogers 1987).

Apiorhynchostoma Petr., Annls mycol. 21(3/4): 185 (1923)

Index Fungorum number: IF261; 3 morphological species (Species Fungorum 2020), 1 species with sequence data.

Type species - Apiorhynchostoma apiculatum (Sacc.) Petr. 
Notes - Untereiner et al. (2013) revalidated Apiorhynchostoma based on herbarium material and Apiorhynchostoma curreyi.
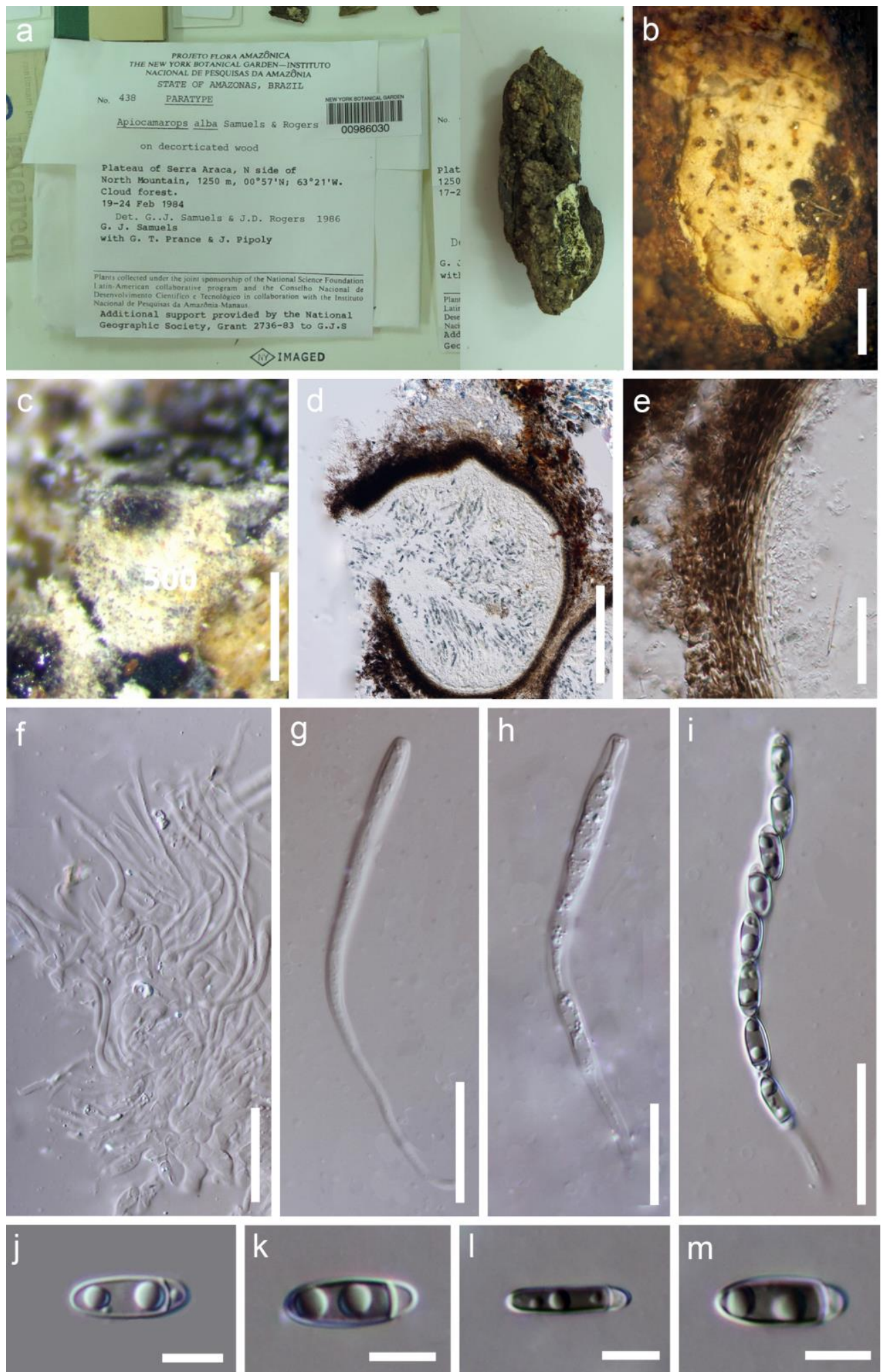

Figure 50 - Apiocamarops alba (Material examined - BRAZIL, Amazonas, Plateau of Serra Araca. Alt. 1250 m. (4101 ft.) 00 54' 06"N, 63 22' 29"W (0.902, -63.375), Cloud forest, on decorticated wood, 19 February 1984, collected by G. J. Samuels 486 with G. T. Francis, J. Pipoly, NY no. 00986029, holotype). a Material label. b Material. c Ascomata. d Ascoma cross section. e Peridium. f Paraphyses. g-i Asci. j-m Ascospores. Scale bars: $b=2000 \mu \mathrm{m}, \mathrm{c}-\mathrm{d}=200 \mu \mathrm{m}, \mathrm{e}=50$ $\mu \mathrm{m}, \mathrm{g}-\mathrm{i}=20 \mu \mathrm{m}, \mathrm{f}=10 \mu \mathrm{m}, \mathrm{j}-\mathrm{m}=5 \mu \mathrm{m}$. 
Camaropella Lar.N. Vassiljeva, Mikol. Fitopatol. 31(1): 6 (1997)

Index Fungorum number: IF27727; 2 species with sequence data.

Type species - Camaropella pugillus (Schwein.) Lar.N. Vassiljeva

Notes - Camaropella was introduced to accommodate two species, C. lutea and C. pugillus occurring on dead wood (Vassiljeva 1997). They could not be clearly distinguished from other Camarops species in the family based on LSU-ITS-tub2 sequence analysis (Fig. 6).

Camarops P. Karst., Bidr. Känn. Finl. Nat. Folk 23: 6, 53 (1873)

Index Fungorum number: IF775; 23 morphological species (Species Fungorum 2020), 9 species with sequence data.

Type species - Camarops hypoxyloides P. Karst.

Notes - Karsten (1873) introduced Camarops based on $C$. hypoxyloides. The name Bolinia was first introduced as a subgenus by Nitschke (1867) and raised to generic rank by Saccardo (1882). Shear (1938) considered Bolinia tubulina to be a homonym of Camarops tubulina. Nannfeldt (1972) reviewed the taxonomy of these taxa and concluded that Camarops and Bolinia are two different genera, but having similar characters. Lumbsch \& Huhndorf (2010) proposed Bolinia to be a synonym of Camarops.

Cornipulvina Huhndorf, A.N. Mill., F.A. Fernández \& Lodge, Fungal Divers. 20: 61 (2005)

Index Fungorum number: IF501318; 1 species with sequence data.

Type species - Cornipulvina ellipsoides Huhndorf, A.N. Mill., F.A. Fernández \& Lodge

Notes - The monotypic Cornipulvina was included as a member of Boliniaceae based on LSU sequences analysis and the unique hyaline ascospores without germ pores in this family (Huhndorf et al. 2005).

Endoxyla Fuckel, Jb. nassau. Ver. Naturk. 25-26: 321 (1871)

Index Fungorum number: IF1813; 8 morphological species (Species Fungorum 2020), 3 species with sequence data.

Type species - Endoxyla macrostoma Fuckel

Notes - Endoxyla was established by Fuckel (1872) based on Endoxyla macrostoma. Untereiner et al. (2013) provided the type strains of Endoxyla macrostoma, E. mallochii and E. operculata.

Mollicamarops Lar.N. Vassiljeva, Mycotaxon 99: 160 (2007)

Index Fungorum number: IF510602; 1 species with sequence data.

Type species - Mollicamarops stellata Lar.N. Vassiljeva

Notes - Vasilyeva (2007) introduced the monotypic genus Mollicamarops from dead wood in Russia.

Neohypodiscus J.D. Rogers, Y.M. Ju \& Læssøe, Mycologia 86(5): 684 (1994)

Index Fungorum number: IF27387; 3 morphological species (Species Fungorum 2020).

Type species - Neohypodiscus rickii (Lloyd) J.D. Rogers, Y.M. Ju \& Læssøe

Notes - Neohypodiscus was introduced by Rogers et al. (1994) in Amphisphaeriaceae and Andersson et al. (1995) transferred it to Boliniaceae based on resemblance of characters to Camarops.

Pseudovalsaria Spooner, Trans. Br. mycol. Soc. 86(3): 405 (1986)

Index Fungorum number: IF25775; 2 morphological species (Species Fungorum 2020), 1 species with sequence data.

Type species - Pseudovalsaria foedans (P. Karst.) Spooner

Notes - Spooner (1986) introduced Pseudovalsaria as a member of Trichosphaeriaceae, Barr (1994) transferred it to Clypeosphaeriaceae and Rappaz (1995) referred it to the Boliniaceae. 
Untereiner et al. (2013) provided sequence data for Pseudovalsaria ferruginea which was closely related to Apiorhynchostoma (Boliniaceae) (Fig. 6).

Cainiaceae J.C. Krug, Sydowia 30 (1-6):123 (1978)

Index Fungorum number: IF80542; Facesoffungi number: FoF00687; 50 species.

Saprobic on dead grasses, bamboo and other monocotyledons and fabaceous dicotyledons, appearing as shiny black dots, slightly effuse from the substrate, or pathogenic. Sexual morph: Pseudostromata poorly developed or lacking, or sometimes clypeate, scattered, superficial, domeshaped or slightly effuse, dark brown to black. Ascomata immersed, solitary or aggregated, globose to subglobose, coriaceous, brown, ostiolate. Ostiolar papilla short, internally lined with hyaline periphyses. Peridium one or two-layered, outer layer comprising thick-walled, brown cells of textura angularis and inner layer comprising hyaline thin-walled cells of textura angularis. Paraphyses abundant, filamentous, slightly constricted at the septa. Asci 8-spored, unitunicate, cylindrical to broadly cylindrical, short pedicellate, with a complex, $\mathrm{J}+$, cylindrical apical ring or series of rings. Ascospores uniseriate, overlapping uniseriate to biseriate, hyaline when young and dark brown at maturity, sphaerical to ellipsoidal, unicellular to 1-septate, slightly constricted at the septum, wall ornamented with longitudinal germ slits or germ pores, surrounded by a gelatinous sheath. Asexual morph: Coelomycetous. Conidiomata pycnidial, scattered, immersed, globose to subglobose, black. Conidiophores hyaline, denticulate, sympodially proliferating. Conidiogenous cells with 1-3 phialides, filiform, branched or simple, septate, hyaline. Conidia elongate fusiform, falcate to lunate, unicellular or septate, hyaline, with pointed ends (adapted from Maharachchimbura et al. 2016b).

Type genus - Cainia Arx \& E. Müll.

Notes - Cainiaceae was introduced by Krug (1978) to accommodate species of Cainia with unique apical rings in the asci, consisting of a series of rings, and ascospores with longitudinal germ slits. Kang et al. (1999b) revived Cainiaceae and included the genera Arecophila, Atrotorquata, Cainia, Ceriophora, Reticulosphaeria and Ommatomyces. The phylogenetic study conducted by Jeewon et al. (2003b) provides molecular evidence to support the generic status of Arecophila in Cainiaceae. Seynesia was included in the family based on phylogenetic analyses (Maharachchikumbura et al. 2015). Several phylogenetic and morphological studies accepted Amphibambusa, Arecophila, Atrotorquata, Cainia and Seynesia in this family (Smith et al. 2003, Maharachchikumbura et al. 2015, 2016b, Liu et al. 2015, Senanayake et al. 2015, Wijayawardene et al. 2017a). Maharachchikumbura et al. (2015, 2016b), Senanayake et al. (2015) and Jaklitsch et al. (2016b) placed the family within the Xylariales Hongsanan et al. (2017) provided divergence estimates and referred the family to Xylariomycetidae family incertae sedis. We introduce a new monotypic genus Alishanica with the type A. miscanthii collected from Taiwan.

\section{Ecological and economic significance of Cainiaceae}

Cainiaceae species are commonly recorded on dead culms of monocotyledons, and leaves and dead branches of dicotyledons as saprobes and important as decomposers in tropical and temperate regions. There are a few records of some pathogenic species in the group such as Cainia desmazieri (Krug 1978, Kang et al. 1999a).

\section{Genera included in Cainiaceae}

Alishanica Karun., C.H. Kuo \& K.D. Hyde, gen. nov.

Index Fungorum number: IF556756; Facesoffungi number: FoF06335; 1 species with sequence data.

Etymology - The specific epithet reflects the name of Ali Mountain from where the species was collected.

Saprobic on dead sheaths of Miscanthus sinansis (Poaceae). Sexual morph: Ascomata immersed beneath blackened aggregated clypeus on the surface of dead sheath, loosely aggregated or rarely solitary; dark brown to black, globose to subglobose, slightly depressed, uniloculate with 
distinct centrally erumpent ostiole with periphyses, surrounded by distinct, shiny, black flanges the tissue spreading down along the papilla. Peridium comprising 4-5 cell layers of thin-walled, brown cells of textura angularis, inwardly lighter. Paraphyses filamentous, distinctly septate, embedded in a gelatinous matrix. Asci 8-spored, unitunicate, cylindrical, short pedicellate, slightly truncate at the apex with a wedge-shaped, J+, subapical ring. Ascospores overlapping uniseriate, brown, ellipsoidal, slightly tapering at the ends, equally 2-celled and guttulate at both cells, constricted at the septum, with striations, surrounded by a thick, hyaline mucilaginous sheath, parallel to the margin of the spore. Asexual morph: Undetermined.

Type species - Alishanica miscanthii A. Karun., C.H. Kuo \& K.D. Hyde

Notes - Alishanica miscanthi resembles Cainiaceae in having clypeate, ostiolate ascomata, unitunicate, cylindrical asci, and apical ring and ascospores with a number of longitudinal germslits resembling ridges. The genus is phylogenetically well-supported with bayesian posterior probability (0.94 PP) and moderate maximum likelihood (53\%) and maximum parsimony (53\%) support (Fig. 4).

Alishanica miscanthii Karun., C.H. Kuo \& K.D. Hyde, sp. nov.

Fig. 51

Index Fungorum number: IF556757; Facesoffungi number: FoF06776

Etymology - The specific epithet reflects the host genus Miscanthus.

Holotype - MFLU 19-2333.

Saprobic on dead sheaths of Miscanthus sinansis (Poaceae). Sexual morph: Ascomata 277$272 \mu \mathrm{m}$ high $\times 288-285 \mu \mathrm{m}$ diam. $(\bar{x}=275 \times 287 \mu \mathrm{m}, \mathrm{n}=8)$, immersed beneath blackened aggregated clypeus of the surface of dead sheath, loosely aggregated or rarely solitary; dark brown to black, globose to subglobose, slightly depressed, uniloculate. Ostiole 110-108 $\mu \mathrm{m}$ long, 52-51 $\mu \mathrm{m}$ diameter $(\bar{x}=108 \times 52 \mu \mathrm{m}, \mathrm{n}=5)$, centrally erumpent, with periphyses, surrounded by distinct shiny black flanges the tissue spreads down along the papilla. Peridium 52-60 $\mu \mathrm{m}$ wide, comprising 4-5 cell layers of thin-walled, brown cells of textura angularis, inwardly lighter. Paraphyses filamentous, distinctly septate, embedded in a hyaline gelatinous matrix. Asci 173-179 $\times 23-31 \mu \mathrm{m}(\bar{x}=176 \times 28 \mu \mathrm{m}, \mathrm{n}=30), 8$-spored, unitunicate, cylindrical, short pedicellate, slightly truncate at the apex, with a wedge-shaped, J+, subapical ring. Ascospores 59-62 $\times 19-21 \mu \mathrm{m}(\bar{x}=$ $61 \times 20 \mu \mathrm{m}, \mathrm{n}=40$ ), overlapping, uniseriate, ellipsoidal, slightly tapering at the ends, equally 2 celled and guttulate at both cells, constricted at the septum, brown with striations, surrounded by a thick, hyaline mucilaginous sheath, subglobose, parallel to the margin of the spore. Asexual morph: Undetermined.

Cultural characteristics - Ascospores germinating on PDA within $12 \mathrm{~h}$ and germ tubes produced from both ends. Colonies growing on PDA, cottony, white to pale brown, mycelium superficial, irregular edge; asexual spores or sexual spores were not formed within 90 days.

Material examined - Taiwan, Chiayi Province, Ali Mountain, Kwang Hwa, on dead sheaths of Miscanthus sinansis (Poaceae), 5 May 2018, A. Karunarathna AKTW 44, MFLU 19-2333, holotype, FU31025, isotype; extype living culture FU31025.

GenBank numbers - ITS: MK503821, LSU: MK503827, SSU: MK503833.

Notes - Alishanica and Cainia ( $C$. desmazieresii and $C$. anthoxanthis) share similar ascospore characters by ellipsoid with slightly tapering ends, 2 equal cells with guttules at both ends, being constricted at the septum, brown with striations and surrounded by a thick, hyaline mucilaginous sheath. However, Alishanica miscanthii is distinct from Cainia desmazieresii and $C$. anthoxanthis in having an aggregated clypeus, distinct long ostioles with periphyses, distinct shiny black flanges around the ostioles, cylindrical asci and with uniseriate, slightly curved and distinctly closely striated ascospores (Krug 1978, Senanayake et al. 2015). Alishanica miscanthii can be distinguished from Seynesia by the absence of apical mucilaginous appendages and spore dimensions (Hyde 1995c). Atrotorquata shares more similarities with Cainia and Alishanica and has distinct in spore characters (Krug 1978, Kohlmeyer \& Volkmann-Kohlmeyer 1993, Senanayake et al. 2015). Furthermore, the separation of $A$. miscanthii is supported by sequence data. 
Amphibambusa D.Q. Dai \& K.D. Hyde, Fungal Divers. $72: 7$ (2015)

Index Fungorum number: IF550940; 1 species with sequence data.

Type species - Amphibambusa bambusicola D.Q. Dai \& K.D. Hyde

Notes - Liu et al. (2015) introduced Amphibambusa, a bambusicolous saprobic genus from Thailand. The monotypic Amphibambusa is characterized by immersed ascomata surrounded by a small blackened clypeus and ostiolar opening surrounded by a white margin, and cylindrical asci with fusiform ascospores surrounded by a wide gelatinous sheath.

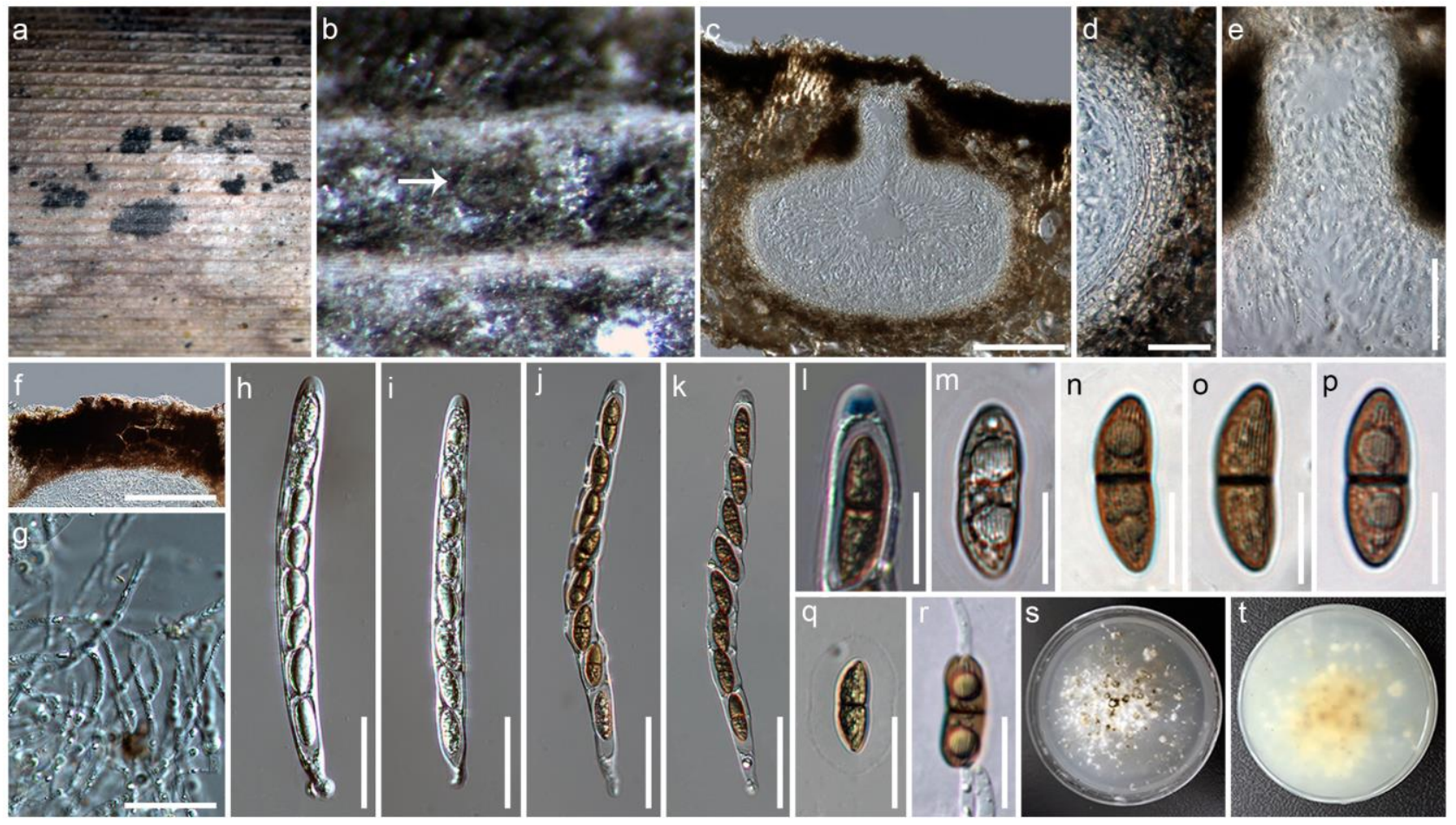

Figure 51 - Alishanica miscanthii (MFLU 19-2333 holotype). a Appearance of ascomata on the host (Miscanthus gigantius). b Clypeus with distinct flanges. c Section through ascoma. d Section through peridium. e Section through ostiole. f Section through flange. g Pseudoparaphyses. h-k Different developing stages of the asci. 1 Apical ring. m-p Ascospores. q Ascospore surrounded by mucilaginous sheath. $r$ Germinating ascospore. $s, t$ Culture characteristics on PDA ( $s=$ from below, $\mathrm{t}=$ from above). Scale bars: $\mathrm{c}-\mathrm{g}=50 \mu \mathrm{m}, \mathrm{h}-\mathrm{r}=10 \mu \mathrm{m}$.

Arecophila K.D. Hyde, Nova Hedwigia 63(1-2):82 (1996)

Index Fungorum number: IF27653; 14 morphological species (Species Fungorum 2020), 1 species with sequence data.

Type species - Arecophila gulubiicola K.D. Hyde

Notes - Arecophila was introduced to accommodate species from monocotyledons that have striate or verrucose ascospores (Hyde 1996b). Lee et al. (2013) investigated the potential antiinflammatory effect of $A$. saccharicola.

Atrotorquata Kohlm. \& Volkm.-Kohlm., Syst. Ascom. 12(1-2):8 (1993)

Index Fungorum number: IF26457; 2 species with sequence data.

Type species - Atrotorquata lineata Kohlm. \& Volkm.-Kohlm.

Notes - Atrotorquata is characterized in unitunicate asci with a $\mathrm{J}+$, subapical ring and brown 2-celled ascospores similar to Amphisphaeria (Kohlmeyer \& Volkmann-Kohlmeyer 1993). There are two accepted species with known sexual and undetermined asexual morphs (Kohlmeyer \& Volkmann-Kohlmeyer 1993). 
Cainia Arx \& E. Müll., Acta bot. neerl. 4(1): 111 (1955)

Index Fungorum number: IF719; 5 morphological species (Species Fungorum 2020), 4 species with sequence data.

Type species - Cainia graminis (Niessl) Arx \& E. Müll.

Notes - The genus was placed in a distinct family because of its longitudinal germ slits in the ascospores and the complex ascus ring comprising a series of rings (Krug 1978). Senanayake et al. (2015) designated a reference specimen for the type Cainia graminis and provided phylogenetic placement to accommodate genera in Cainiaceae.

Seynesia Sacc., Syll. fung. (Abellini) 2:668 (1883)

Index Fungorum number: IF5017; 27 morphological species (Species Fungorum 2020), 1 species with sequence data.

Type species - Seynesia nobilis (Welw. \& Curr.) Sacc.

Notes - Seynesia species are mostly confined to palms and characterized by the welldeveloped clypeus, the ascospores having cap-like appendages and germ slits in each cell, and the asci having a complex wedge-shaped subapical ring (Hyde 1995c). There are no recent studies on this genus and cultures and sequences are unavailable for the type.

Calcarisporiaceae Jing Z. Sun, X.Z. Liu \& K.D. Hyde, Mycol Prog 16 (4): 435 (2017)

Index Fungorum number: IF817660; Facesoffungi number: FoF02511; 8 species.

Fungicolous, parasitic, endophytic or saprobic on higher ascomycetes and basidiomycetes, and leaves and branches of trees. Sexual morph: Undetermined. Asexual morph: Conidiophores macronematous, mononematous, erect, unbranched or verticillate, branched hyaline, straight or flexuous. Conidiogenous cells holoblastic, polyblastic, discrete, subulate, hyaline. Conidia ovoid to ellipsoid, or acerose to narrowly obclavate, aseptate, hyaline, straight to curved (adapted from Sun et al. 2017).

Type genus - Calcarisporium Preuss

Notes - Multi-gene analysis revealed that Calcarisporium species form a monophyletic lineage which is distinct from other families in Hypocreales. This family is distinguished from other families by its verticillate conidiophores with a narrow apical part and monoblastic to polyblastic, sympodial and denticulate conidiogenous cells at the apex (Sun et al. 2017). Calcarisporium arbuscula is illustrated in the entry.

\section{Ecological and economic significance of Calcarisporiaceae}

Calcarisporium species are fungicolous, caulicolous and foliicolous. Some Calcarisporium species are saprobes of decaying leaves (C. phaeopodium) and dead bark (C. acerosum). Calcarisporium arbuscula is a common parasite on higher ascomycetes and basidiomycetes, occasionally occurring on wood (Sutton 1973, de Hoog 1974). In addition, C. arbuscula has been reported as an endophyte in sporophores of Lactarius and Russula (Watson 1955).

\section{Genus included in Calcarisporiaceae}

Calcarisporium Preuss, Linnaea 24: 124 (1851)

Index Fungorum number: IF7465; 8 morphological species (Species Fungorum 2020), 4 species with sequence data.

Type species - Calcarisporium arbuscula Preuss

Notes - Calcarisporium occurs on Pezizaceae (Preuss 1851), Russulaceae (Anke \& Sterner 1988) and Cordyceps (Sun et al. 2016, 2019), and litter leaf (Somrithipol \& Jones 2006). Species are distinguished by hyaline, erect, verticillate conidiophores with sympodial and denticulate, polyblastic conidiation.

Calosphaeriaceae Munk, Dansk bot. Ark. 17(no. 1): 278 (1957)

Index Fungorum number: IF80548; Facesoffungi number: FoF01133; 67 species. 
Saprobic on wood or decorticated wood in terrestrial habitats, sometimes hypersaprobic on old stromata or ascomata of other fungi, and several species have been isolated from wood of fruit trees showing canker symptoms. Sexual morph: Stroma absent. Ascomata perithecial, solitary to gregarious, dark brown to black, superficial or typically erumpent or immersed, globose to subglobose, coriaceous or membranous, tuberculate or smooth or with brown, septate, hyphal coating, papillate or with a cylindrical neck. Ostioles periphysate. Peridium two-layered, outer layer coriaceous or membranous, composed of dark brown, reddish-brown to brown cells of textura angularis or prismatica or porrecta; inner layer membranous, composed of hyaline cells of textura prismatica. Paraphyses numerous, broad, septate, unbranched, tapering. Ascogenous hyphae discrete, hyaline, smooth, branched, producing a sympodial sequence of hyaline, ovoid to ellipsoidal cells, often with mucronate apex, in dense clusters, each giving rise to an ascus. Asci 8spored, unitunicate, clavate, long or short pedicellate, mostly in fascicles, with a conspicuously thickened apex lacking a visible discharge mechanism. Ascospores 2-seriate or in a fascicle, hyaline to light brown, allantoid, suballantoid, oblong to subcylindrical, aseptate or transversely septate, smooth-walled. Asexual morph: Hyphomycetous, Acremonium- and phialophora-like. Conidiophores micronematous or semi-macronematous, brown or hyaline, straight or flexuous, septate, branched or unbranched. Conidiogenous cells phialides or adelophialdes, terminal, intercalary or lateral, hyaline to subhyaline, ampulliform to subcylindrical. Conidia aseptate, allantoid, oblong or subcylindrical, hyaline, smooth (adapted from Réblová et al. 2015b).

Type genus - Calosphaeria Tul. \& C. Tul.

Notes - Calosphaeriaceae was introduced by Munk (1957) for perithecial taxa with a unique ascoma centrum in Sordariomycetes. Lumbsch \& Huhndorf (2010) included eight genera (Calosphaeria, Conidiotheca, Jattaea, Kacosphaeria, Phragmocalosphaeria, Sulcatistroma, Togniniella, Wegelina) in this family. Réblová (2011) proposed Phragmocalosphaeria and Wegelina as synonyms of Jattaea based on similar septate ascospores. Maharachchikumbura et al. (2016b) accepted Calosphaeria, Jattaea, Kacosphaeria, Sulcatistroma, Togniniella and Tulipispora. A survey of Calosphaeriaceae was undertaken by Réblová et al. (2015b) and the genera Calosphaeria, Flabellascus, Jattaea and Togniniella were accepted. Their asexual morphs are dematiaceous phialidic hyphomycetes and numerous sexual-asexual relationships have been experimentally proven (Damm et al. 2008, Réblová 2011, Réblová et al. 2004, 2015b). Calosphaeriophora and Phaeocrella were originally described as asexual morphs for Calosphaeria and Togniniella (Réblová et al. 2004), however, in accordance with the abolishment of dual nomenclature for pleomorphic fungi, the names of their sexual morphs were selected following the principle of priority (Réblová et al. 2015b). In the same publication, three other genera listed in the Outline of Ascomycota (Lumbsch \& Huhndorf 2010), i.e. Conidiotheca, Sulcatistroma and Kacosphaeria, were excluded from the broadly perceived Calosphaeriaceae, however, without DNA sequence data they could not be reassigned to other families. In addition, the asexual genus Tulipispora was considered a member of Calosphaeriaceae (Maharachchikumbura et al. 2016b, Wijayawardene et al. 2018a). Unfortunately, sequence data for Tulipispora is not available. We therefore exclude it from Calosphaeriaceae.

\section{Ecological and economic significance of Calosphaeriaceae}

Most Calosphaeriaceae species are saprobic on wood and widespread in temperate regions, especially in Europe and western Asia (Réblová et al. 2004, Damm et al. 2008, Trouillas et al. 2010a, 2012, Réblová 2011, Chakusary et al. 2015). Some species of Calosphaeria and Jattaea, such as Calosphaeria pulchella, Jattaea algeriensis and J. prunicola have been reported as plant pathogens associated with disease of woody plants (Damm et al. 2008, Chakusary et al. 2015).

\section{Genera included in Calosphaeriaceae}

Calosphaeria Tul. \& C. Tul., Select. fung. carpol. (Paris) 2: 108 (1863)

Index Fungorum number: IF753; 39 morphological species (Species Fungorum 2020), 2 species with sequence data. 
Type species - Calosphaeria princeps Tul. \& C. Tul.

Notes - Calosphaeria was introduced by Tulasne \& Tulasne (1863) and typified by $C$. princeps. The acremonium-like asexual morphs, formerly referred to Calosphaeriophora, have been experimentally linked to Calosphaeria africana (Damm et al. 2008) and C. pulchella (Réblová et al. 2004). Jattaea discreta is illustrated in this entry for the sexual morph of the family.

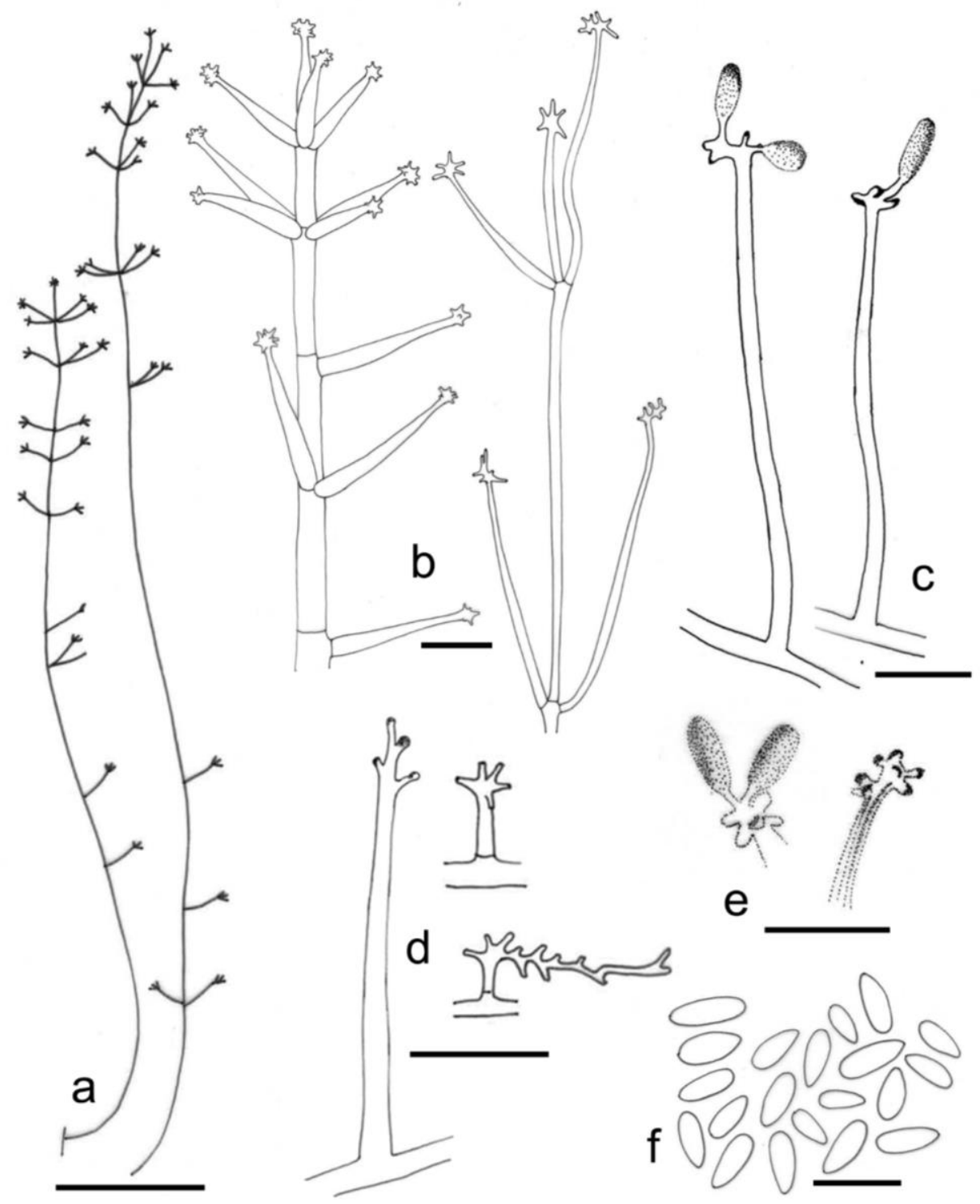

Figure 52 - Calcarisporium arbuscula (redrawn from de Hoog (1974) and Sun et al. (2017)). a Conidiophore at low magnification. b Tip of conidiophore. c Conidiophores with conidia. d Conidiophores without conidia. e Conidiogenous scars and conidia. $\mathrm{f}$ Conidia. Scale bars: $\mathrm{a}=100$ $\mu \mathrm{m}, \mathrm{b}-\mathrm{f}=10 \mu \mathrm{m}$.

Flabellascus Réblová, PLoS ONE 10(12): e0144616, 15 (2015)

Index Fungorum number: IF814416; 1 species with sequence data.

Type species - Flabellascus tenuirostris Réblová

Notes - The monotypic genus Flabellascus is characterized by tiny asci with ascogenous hyphae and ampulliform phialides with aseptate, allantoid conidia (Réblová et al. 2015b). The sexual morph of Flabellascus is similar to Jattaea and they are distinguished by the different asexual morphs. However, Flabellascus constitutes an independent clade within Calosphaeriaceae based on a multi-gene analysis (Réblová et al. 2015b; Fig. 7). 


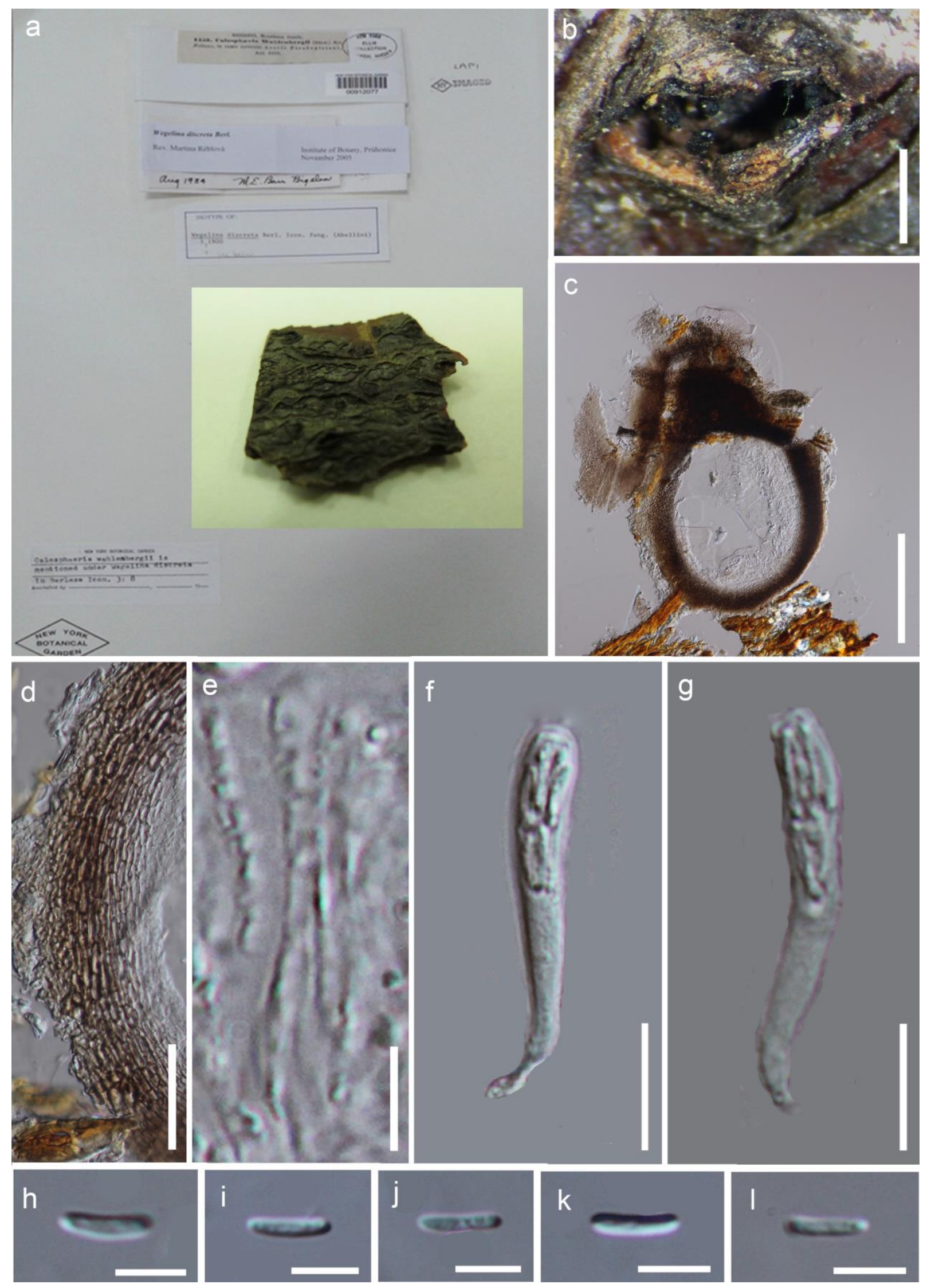

Figure 53 - Jattaea discreta (Material examined - ITALY, Belluno, Veneta, on the bark of branches, Autumn 1879, NY no.00986029, isotype). a Material label. b Ascomata. c Ascoma in cross section. d Peridium. e Asci and paraphyses attached to ascogenous hyphae with ellipsoid to obpyriform cells (arrow head indicates ascogenous hyphae). f, g Asci. h-l Ascospores. Scale bars: $b$ $=500 \mu \mathrm{m}, \mathrm{c}=200 \mu \mathrm{m}, \mathrm{d}=50 \mu \mathrm{m}, \mathrm{e}=20 \mu \mathrm{m}, \mathrm{f}, \mathrm{g}=10 \mu \mathrm{m}, \mathrm{h}-\mathrm{l}=5 \mu \mathrm{m}$. 
Jattaea Berl., Icon. fung. (Abellini) 3(1-2): 6 (1900)

Index Fungorum number: IF2528; 26 morphological species (Species Fungorum 2020), 11 species with sequence data.

Type species - Jattaea algeriensis Berl.

Notes - Jattaea has long-necked ascomata containing hyaline, cylindrical paraphyses, branched ascogenous hyphae, clavate asci and oblong to subglobose ascospores. The asexual morph has always been referred to phialophora-like (Damm et al. 2008). The monophyletic Jattaea is related to Calosphaeria and Togniniella within Calosphaeriaceae based on multi-gene analysis (Réblová et al. 2015b; Fig. 7).

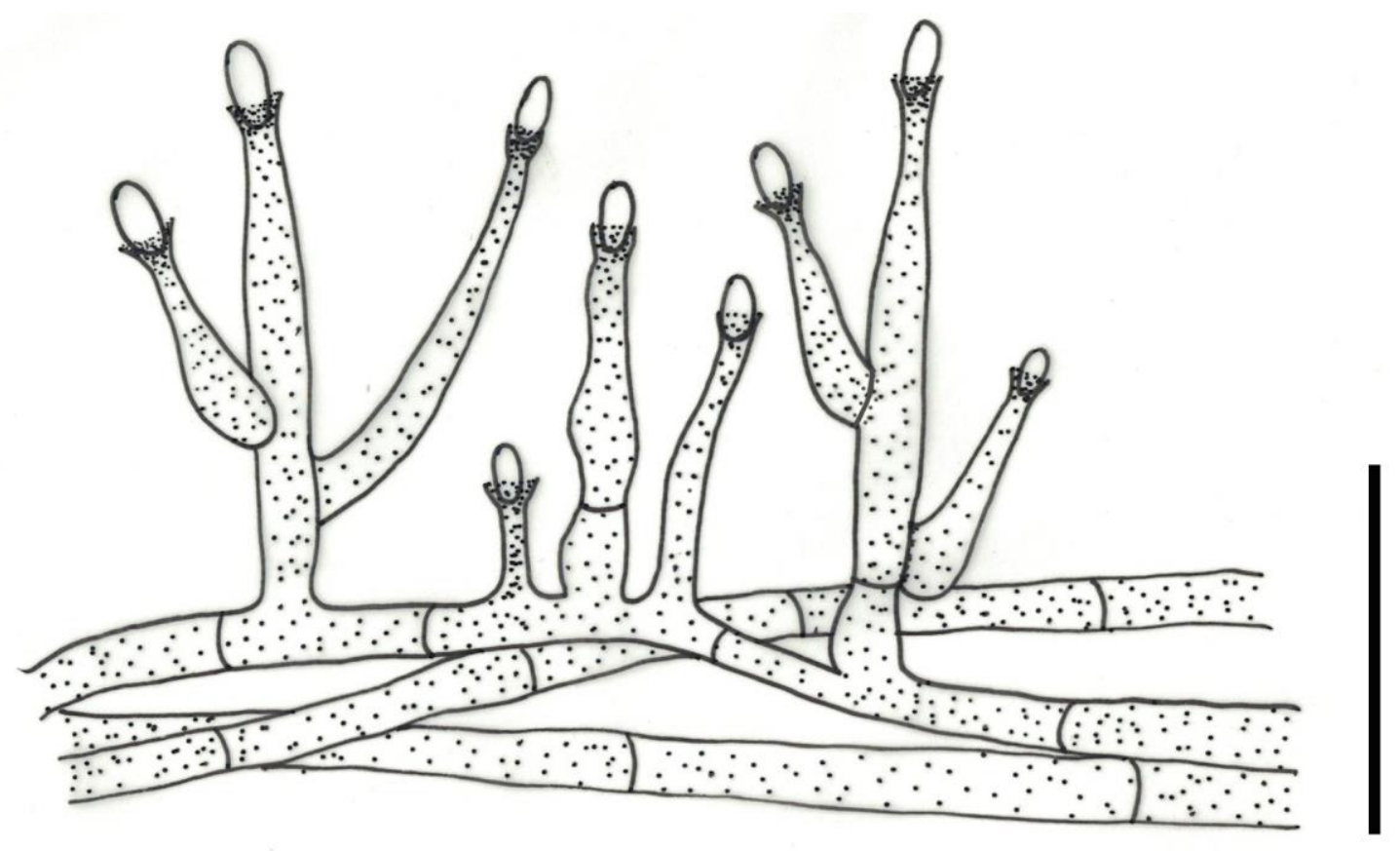

Figure 54 - Phialophora-like asexual morph of Jattaea aurea (redrawn from Réblová et al. 2015b) Conidiophores with conidia of Phialophora asexual morph. Scale bar $=10 \mu \mathrm{m}$.

Togniniella Réblová, L. Mostert, W. Gams \& Crous, Stud. Mycol. 50(2): 543 (2004)

Index Fungorum number: IF500157; 1 species with sequence data.

Type species - Togniniella microspora (Ellis \& Everh.) Réblová

Notes - Togniniella has glabrous ascomata with branched ascogenous hyphae, paraphyses longer than asci and suballantoid ascospores. After re-examining the type material of $T$. acerosa, Réblová (2011) concluded that Togniniella microspora (synonym of Ceratostomella microspora) is identical to T. acerosa and accepted T. microspora as the only species in Togniniella. Réblová et al. (2004) and Réblová (2011) found that Togniniella constitutes an independent clade and is related to Calosphaeria. In this study, Flabellascus is closely related with this genus based on tub2-ITS-actLSU analysis (Fig. 7).

Castanediellaceae Hern.-Restr., Guarro \& Crous, Stud. Mycol. 86 : 93 (2017)

Index Fungorum number: IF820354; Facesoffungi number: FoF06777; 16 species.

Foliicolous, saprobic or associated to leaf spots. Sexual morph: Undetermined. Asexual morph: Conidiophores macronematous or semi-macronematous, mononematous or aggregated in sporodochia, branched or unbranched, brown to pale brown. Conidiogenous cells mono- to polyblastic, sympodial, integrated, solitary, or in whorls, cylindrical to lageniform, hyaline to subhyaline, smooth. Conidial secession schizolytic. Conidia unicellular or transversely septate, fusiform or lunate, hyaline (adapted from Hernández-Restrepo et al. 2017).

Type genus - Castanediella Hern.-Restr. 
Notes - LSU based phylogenetic analyses revealed that Castanediellaceae is monophyletic and represents a distinct taxonomic group at the family level closely related to Beltraniaceae in Xylariales (Hernández-Restrepo et al. 2017). Lin et al. (2019a) provided a synopsis of hitherto described Castanediella species and accepted 16 species in the genus.

\section{Ecological and economic significance of Castanediellaceae}

Castanediellaceae species have been collected mainly on dead wood, leaves, leaf spots and rotten leaves, including leaf litter of Eucalyptus species, as saprobes. Since some species have been isolated from leaf spots, their parasitic nature might be hidden. However, they have a significance role as saprobes (Crous et al. 2015c, 2016a, b, Hernández-Restrepo et al. 2016b, 2017, Wanasinghe et al. 2018, Hyde et al. 2019a, Lin et al. 2019a).

\section{Genus included in Castanediellaceae}

Castanediella Hern.-Restr., Crous \& M.J. Wingf., Persoonia 34: 187 (2015)

Index Fungorum number: IF811878; 16 morphological species (Species Fungorum 2020), 11 with sequence data.

Type species - Castanediella acaciae Crous, Hern.-Restr. \& M.J. Wingf.

Notes - Castanediella was introduced by Crous et al. (2015c) and placed in Xylariales genera incertae sedis. The genus is characterized by a hyphomycetous asexual morph with branched or unbranched conidiophores, mono- to polyblastic conidiogenous cells and straight to slightly curved, 0-1-septate conidia. The species are commonly isolated from leaf litter, leaf spots and wood. Currently, the genus comprises 16 species (Crous et al. 2015c, 2016a, b, 2018c, HernándezRestrepo et al. 2016b, 2017, Wanasinghe et al. 2018, Hyde et al. 2019a, Lin et al. 2019a). In this entry we illustrate Castanediella brevis (Fig. 55).
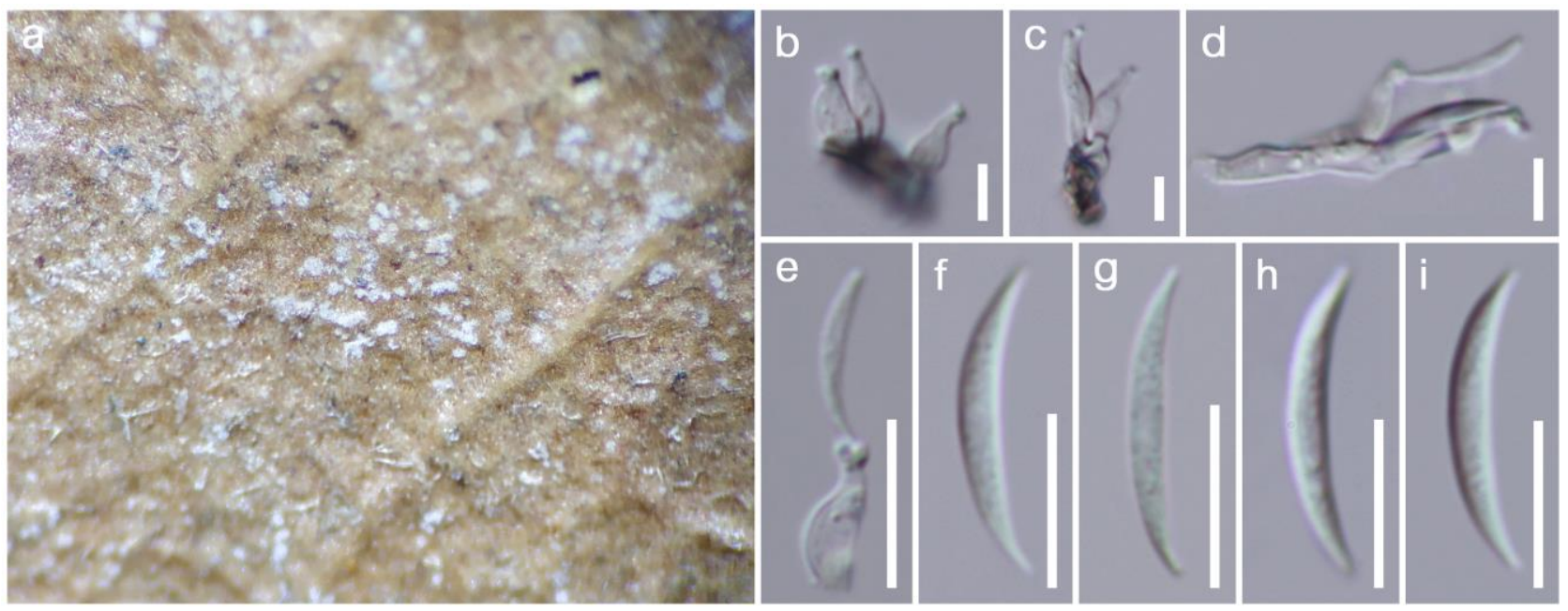

Figure 55 - Castanediella brevis (Material examined - THAILAND, Lampang, Amphoe Mueang Pan, Tambon Chae Son, on decaying leaves, 24 September 2016, Chuangen Lin, LCG 10-1, MFLU 18-1695, holotype). a Host material. b-e Conidiophores on the host surface, conidiophores, conidiogenous cells with conidia. f-i Conidia. Scale bars: $b-d=5 \mu \mathrm{m}, \mathrm{e}-\mathrm{i}=10 \mu \mathrm{m}$.

Catabotryaceae Petr., Mycotaxon 39: 83 (1990)

Index Fungorum number: IF90924; Facesoffungi number: FoF01372; 2 species.

Saprobic on tropical monocotyledons. Sexual morph: Stromata solitary or irregularly scattered, conspicuous, multi-loculate, superficial, with base slightly penetrating the epidermis at regular intervals, discoid to pulvinate, reddish brown to black, surface scurfy, flat or slightly convex. Ascomata deeply imbedded in stromatic columns, globose, with a long, periphysate, ostiolar neck. Peridium thick, composed of several reddish brown outer layer cells of textura globosa and textura epidermoidea, with pale brown to hyaline internal cells of textura angularis. 
Paraphyses hypha-like, numerous, tapering towards the apex, not embedded in a gelatinous matrix. Asci 8-spored, unitunicate, broad cylindrical, short pedicellate, apically rounded or truncate, with a $\mathrm{J}$-, discoid, refractive, apical ring. Ascospores bi-seriate, hyaline, 1-celled, ellipsoidal to cylindrical, smooth-walled. Asexual morph: Undetermined.

Type genus - Catabotrys Theiss. \& Syd.

Notes - Catabotryaceae was validated by Barr (1990b) following Petrak's (1954) invalid publication, which is monotypic and accommodates a single species Catabotrys deciduum. Barr (1990b) considered the centrum of Catabotrys as similar to that of taxa in Sordariales, and therefore proposed a monotypic family Catabotryaceae to accommodate and further placed it in Sordariales. Hyde \& Cannon (1999) suggested Catabotryaceae could be included in Xylariales, as the centrum and stromatic features are more similar to Xylariaceae and Diatrypaceae. With phylogenetic analysis of the taxa in Sordariales, Catabotryaceae has been found transitory and placed in Sordariomycetidae family incertae sedis (Huhndorf et al. 2004b, Miller \& Huhndorf 2005) and assigned in Amplistromatales (Maharachchikumbura et al. 2015). In a study of ranking fungi by using divergence estimates (Hyde et al. 2017a), Catabotryaceae has been shown to have a stem age of 165 MYA and therefore can be considered as an order. In this study the stem age was 171.92 MYA and therefore we place Catabotryaceae in a new order Catabotryales (Fig. 2).

\section{Ecological and economic significance of Catabotryaceae}

Catabotrys species have a pantropical distribution, and mainly appear on dead plant material with striking superficial stromata. Wu et al. (2014b) has reported endophytic isolates of Catabotrys from Fortunearia sinensis authorities in China. However, the frequent appearance on dead plant tissue indicates the saprobic nutrition may dominate and occupy a large part of its life cycle, while it may also at first be an endophyte within living plant tissue.

\section{Genus included in Catabotryaceae}

Catabotrys Theiss. \& Syd., Annls mycol. 13(3/4): 297 (1915)

Index Fungorum number: IF834; 2 morphological species (Species Fungorum 2020), 1 species with sequence data.

Type species - Catabotrys palmarum (Pat.) Theiss. \& Syd.

Current name - Catabotrys deciduum (Berk. \& Broome) Seaver \& Waterston

Notes - Catabotrys was erected by Theissen \& Sydow (1915) based on Bagnisiella palmarum Pat. and has been placed in Dothideaceae (Dothideae). Petrak (1934) transferred Catabotrys to Hypocreales because its thin-walled asci and bright coloured stroma are similar to the latter. Seaver \& Waterston (1946) synonymized an earlier name Hypoxylon deciduum as Catabotrys deciduum. Morphologically, Catabotrys is characterized by superficial, erumpent, multi-loculate stromata, and simple hyaline, 1-celled spores. Catabotrys deciduum is illustrated in this entry (Fig. 56).

Cephalothecaceae Höhn., Annls mycol. 15(5): 362 (1917)

Index Fungorum number: IF80571; Facesoffungi number: FoF01330; 27 species.

Saprobic on decaying wood or bark and soil or hypersaprobic on other fungi, particularly polypores, some species are opportunistic pathogens causing systemic mycotic infection in animals and humans. Sexual morph: Ascomata cleistothecial, solitary to gregarious, superficial, subglobose to globose, dark brown to black, glabrous, sometimes covered or surrounded at base by subiculum consisting of sulphureous hyphae, lacking ostioles. Peridium cephalothecoid, comprising 2-3 layers, outer layer composed of dark brown cells of textura angularis to prismatica, inner layer composed of elongated, hyaline cells of textura prismatica. Paraphyses comprising branched, and septate ascogenous hyphae. Asci forming upon the ascogenous hyphae, 8-spored, unitunicate, pyriform to subglobose to globose, evanescent, apedicellate, without an apical ring. Ascospores irregularly arranged, brown, variously-shaped, unicellular, without germ pores, smooth-walled. Asexual morph: Hyphomycetous. Mycelium pale-yellowish to brownish-yellow, branched septate. 
Conidiophores macronematous, semi-macronemous or micronematous, cylindrical, stiffly upright, septate, unbranched or verticillate. Conidiogenous cells phialidic, cylindrical, strongly tapering and thick-walled, hyaline, smooth-walled. Conidia in chains, hyaline to brown, cylindrical, ovate or obovate, with or without an apiculate or truncate base, 1-celled, smooth-walled (adapted from Maharachchikumbura et al. 2016b, Davolos et al. 2019).

Type genus - Cephalotheca Fuckel

Notes - Cephalothecaceae was previously accommodated in the Sordariales by Suh \& Blackwell (1999), but this study was based only on SSU, LSU sequence analysis. This has been revised with time and based on its uncertain phylogenetic placement and different morphology, Maharachchikumbura et al. (2015) tentatively referred the Cephalothecaceae to family incertae sedis in Sordariomycetes. Similar results were obtained by Hongsanan et al. (2017) who reported that the divergence of Cephalothecaceae was at 175 MYA. Five genera, Albertiniella, Cephalotheca, Cryptendoxyla, Phialemonium and Victoriomyces are currently included in Cephalothecaceae (Fuckel 1872, Kirschstein 1936, Malloch \& Cain 1970, Gams \& McGinnis 1983, Maharachchikumbura et al. 2016b, Davolos et al. 2019). The genus is placed in Cephalothecales in this study.

\section{Ecological and economic significance of Cephalothecaceae}

Cephalothecaceae species are emerging as fungal opportunistic pathogens of humans and other animals and they can affect both immunocompromised and immunocompetent hosts (Gavin et al. 2002, Proia et al. 2004, Suh et al. 2006, Perdomo et al. 2011, ̌̌ehulka et al. 2016, Sun et al. 2019). The infections caused by members of Cephalothecaceae were reported as peritonitis, endocarditis, osteomyelitis, and cutaneous infections of wounds following burns. In addition, $C$. sulfurea can produce Gibberellins, which are well known for plant growth promotion (Hamayun et al. 2012).

\section{Genera included in Cephalothecaceae}

Albertiniella Kirschst., Annls mycol. 34(3): 183 (1936)

Index Fungorum number: IF109; 2 morphological species (Species Fungorum 2020), 1 species with sequence data.

Type species - Albertiniella reticulata Kirschst.

Notes - Albertiniella was introduced by Kirschstein (1936) to accommodate a fungus developing ascomata on rotting Polyporus applanatus. It is characterized by globose, black, glabrous, carbonaceous cleistothecium, subglobose to globose asci and ovate to globose, aseptate, hyaline to yellowish ascospores.

Cephalotheca Fuckel, Jb. nassau. Ver. Naturk. 25-26: 297 (1871)

Index Fungorum number: IF877; 15 morphological species (Species Fungorum 2020), 3 species with sequence data.

Type species - Cephalotheca sulfurea Fuckel.

Notes - The asexual morph of Cephalotheca was reported as tritirachium-like and phialemonium-like (Limber 1940, Suh et al. 2006). In this entry we illustrate Cephalotheca sulfurea from the isotype (Figs. 57, 58).

Cryptendoxyla Malloch \& Cain, Can. J. Bot. 48(10): 1816 (1970)

Index Fungorum number: IF1309; 2 species with sequence data.

Type species - Cryptendoxyla hypophloia Malloch \& Cain

Notes - Cryptendoxyla was introduced by Malloch \& Cain (1970) in family of Pseudeurotiaceae, which was typified by Cryptendoxyla hypophloia. Based on the results of phylogenetic investigations, Cryptendoxyla was placed in Cephalothecaceae (Wijayawardene et al. 2012, Maharachchikumbura et al. 2016b). It is characterized by ascospores which are cylindrical to oblong and brown to dark brown with small guttules. 

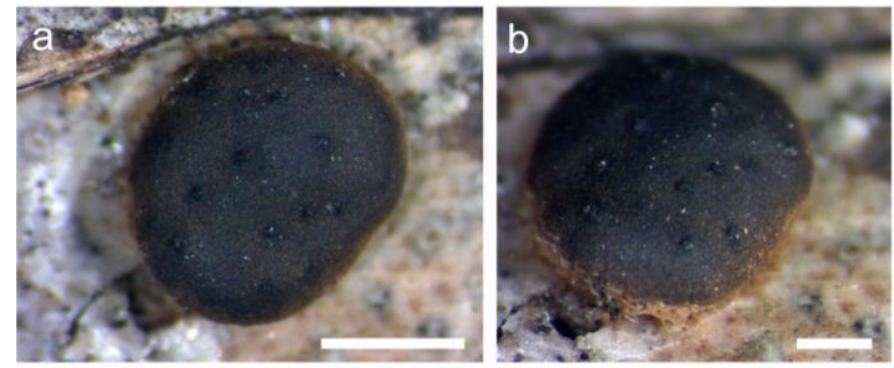

C
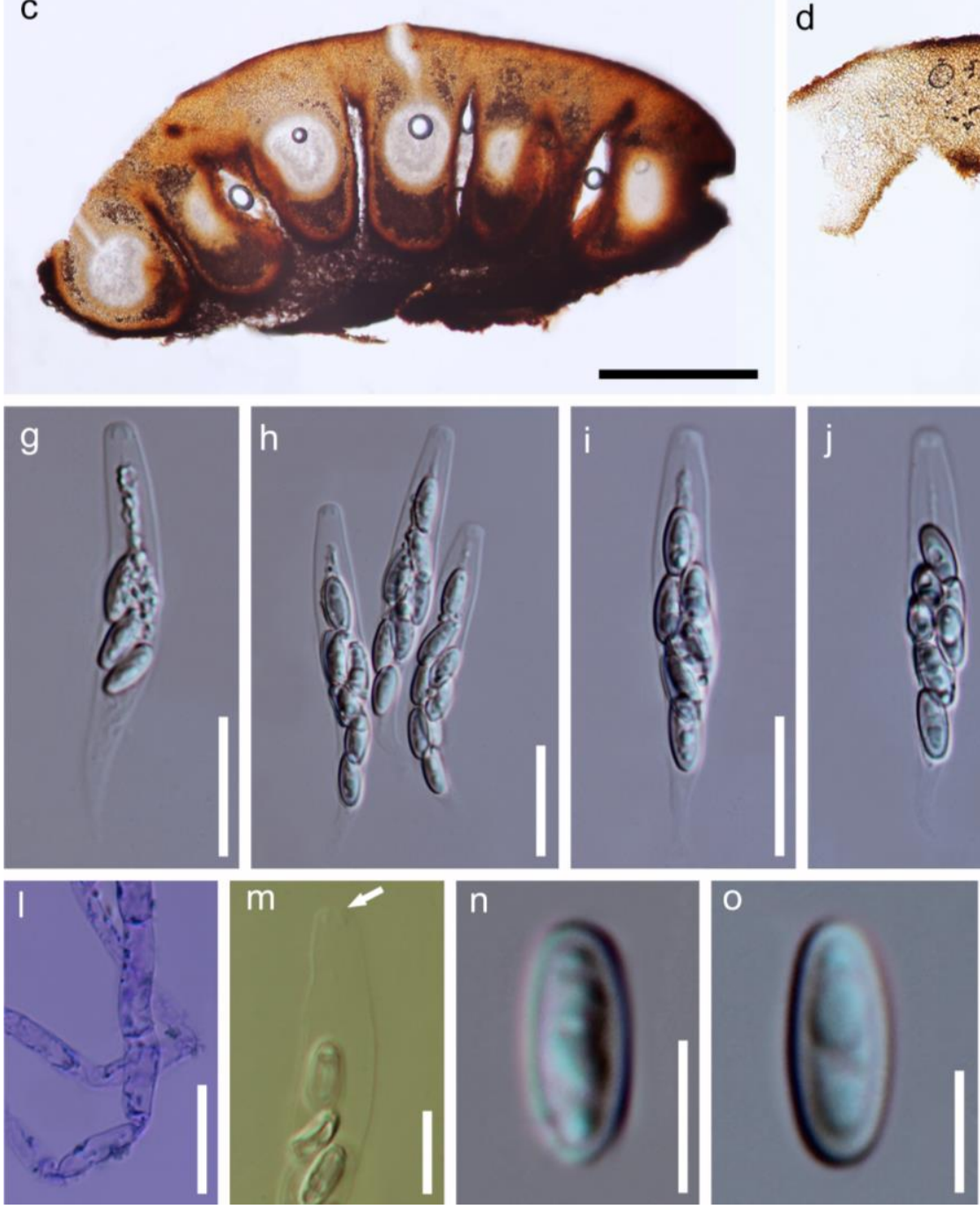

d
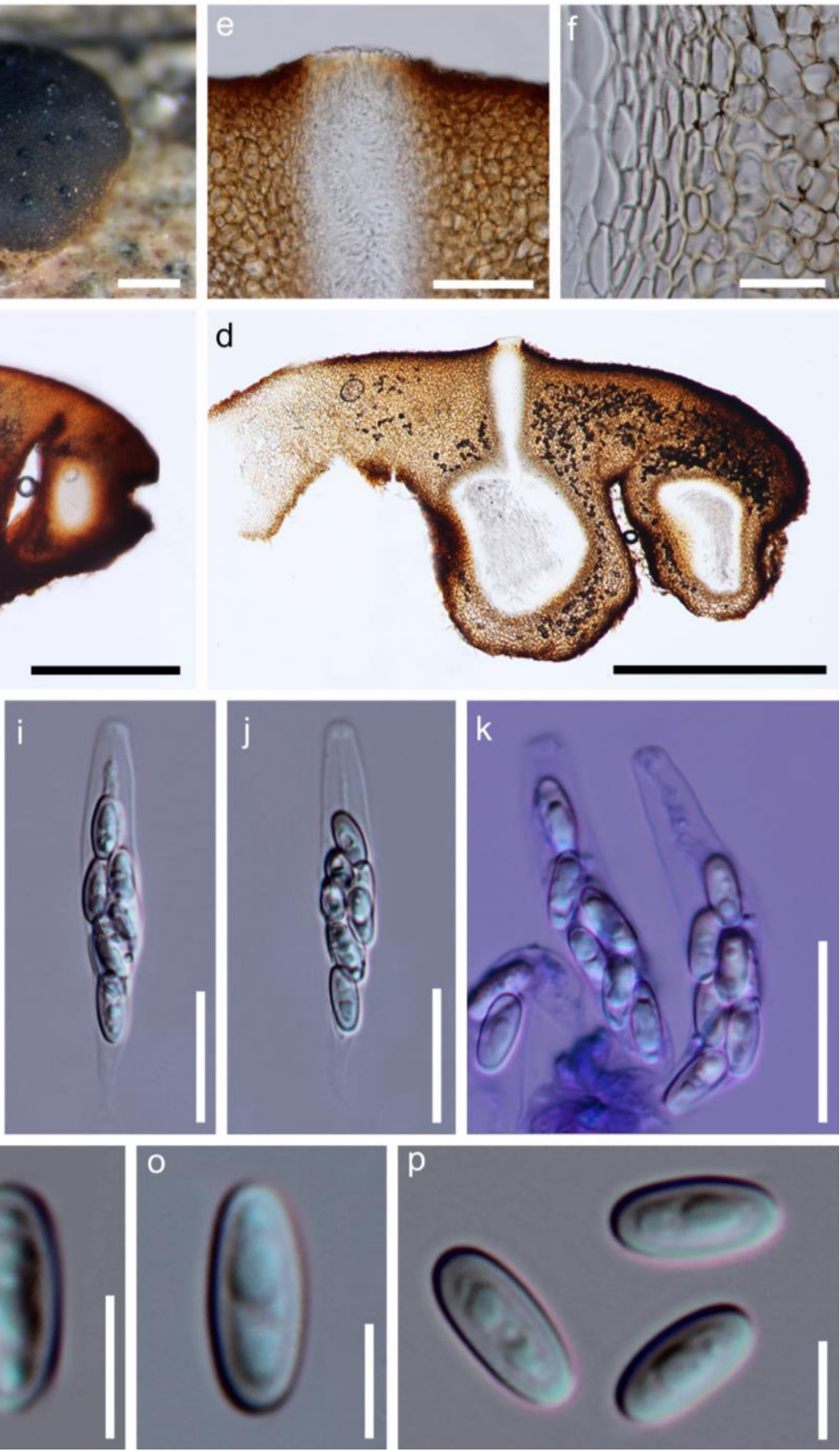

Figure 56 - Catabotrys deciduum (Material examined - THAILAND, Chumphon, Amphoe Pathio, on rachis of Salacca sp. (Arecaceae), 1 December, 2016, S.N. Zhang SNT33B (MFLU 18-1072); THAILAND, Ranong, Amphoe Mueang Ranong, on decaying petiole of oil palm (Arecaceae), 29 August 2017, S.N. Zhang SNT214, MFLU 18-1073, HKAS 97484; living culture MFLUCC 180463). a, b Appearance of stromata on host surface. c, d Vertical section through the stromata with ascomata. e Ostiole with periphyses. f Structure of peridium. g-k Asci. k Asci in Cotton blue reagent. 1 Paraphyses. $m$ Ascus apex in Melzer's reagent, with J-, subapical ring. n-p Ascospores. Scale bars: $\mathrm{a}=1000 \mu \mathrm{m}, \mathrm{b}-\mathrm{d}=500 \mu \mathrm{m}, \mathrm{e}=50 \mu \mathrm{m}, \mathrm{f}-\mathrm{l}=20 \mu \mathrm{m}, \mathrm{m}=10 \mu \mathrm{m}, \mathrm{n}-\mathrm{p}=5 \mu \mathrm{m}$.

Phialemonium W. Gams \& McGinnis, Mycologia 75(6): 978 (1983)

Index Fungorum number: IF11160; 7 species with sequence data.

Type species - Phialemonium obovatum W. Gams \& McGinnis

Notes - Phialemonium was introduced by Gams \& McGinnis (1983) to accommodate three species. The genus is characterized by phialides that are often inflated at the base, with conspicuous collarettes and conidia arranged in slimy heads or in long chains, and may have connectives at both 
ends. Phialemonium was revised by Perdomo et al. (2013b), its species are pathogens and can infect both immunocompromised and immunocompetent hosts (Perdomo et al. 2011).

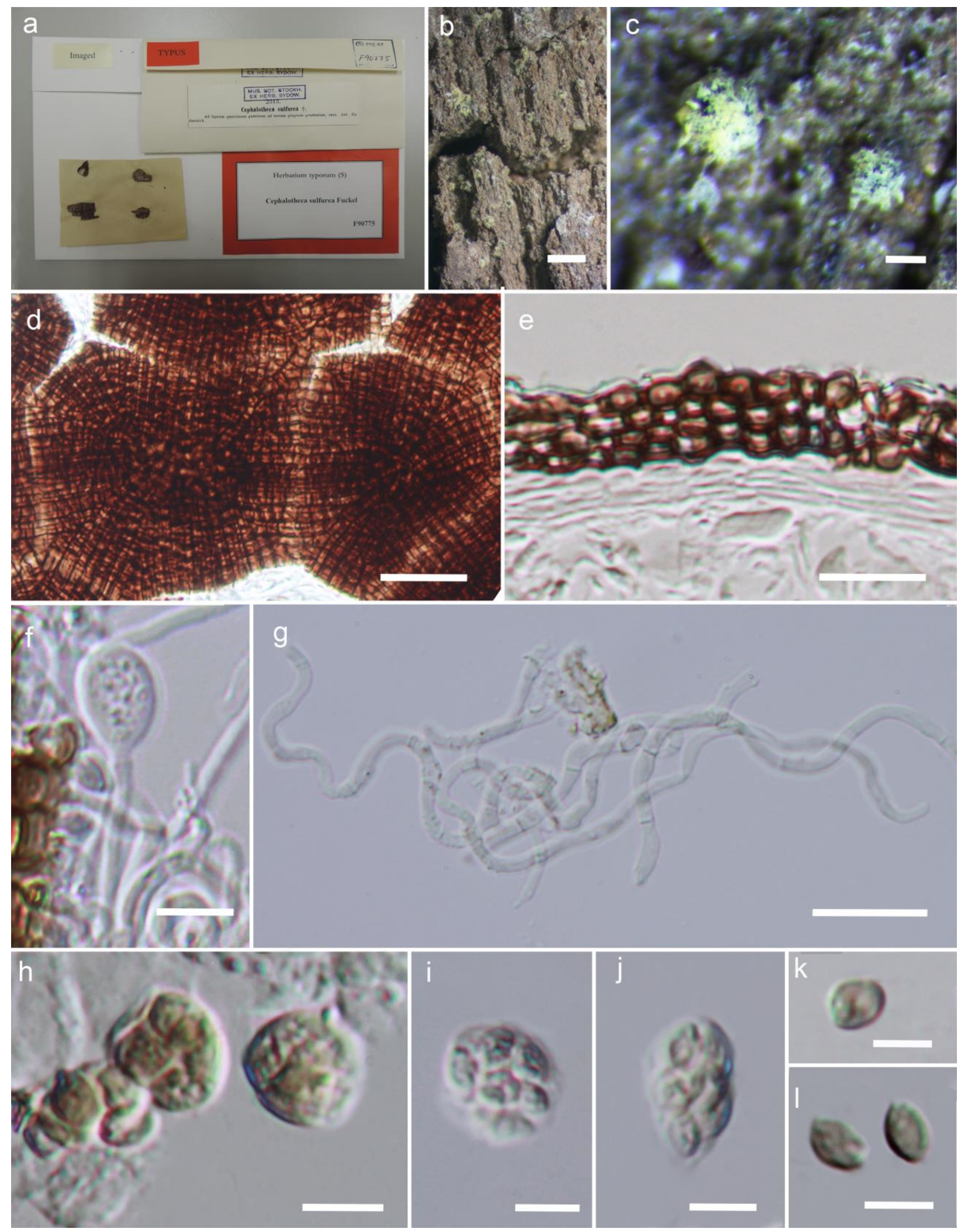

Figure 57 - Cephalotheca sulfurea (Material examined - GERMANY, on rotting planks of Oak, lying on damp ammoniacal ground, S-F90775, isotype). a Herbarium material. b, c Ascomata on the host. d Squash mount of ascoma. e Peridium. f Immature asci on the ascogenous hyphae. $g$ Ascogenous hyphae. h-j Asci. k-1 Ascospores. Scale bars: $b=1000 \mu \mathrm{m}, \mathrm{c}=100 \mu \mathrm{m}, \mathrm{d}=20 \mu \mathrm{m}$, e, $\mathrm{g}=10 \mu \mathrm{m}, \mathrm{f}, \mathrm{h}-\mathrm{l}=5 \mu \mathrm{m}$. 
Victoriomyces D Davolos, B Pietrangeli, AM Persiani \& O Maggi, Int. J. Syst. Evol. Microbiol. 69(4):1099-1110 (2019)

Index Fungorum number: IF823713; 1 species with sequence data.

Type species - Victoriomyces antarcticus Maggi, Davolos \& Persiani

Notes - The type species Victoriomyces antarcticus was isolated from soil and is characterized by metarhizium-like morphology, dark red-coloured disk-like structures, immature bodies and the production of an intense red pigment in the growth media. Its placement in Cephalothecaceae was confirmed by phylogenetic analysis of a combined LSU, SSU, rpb2 dataset.

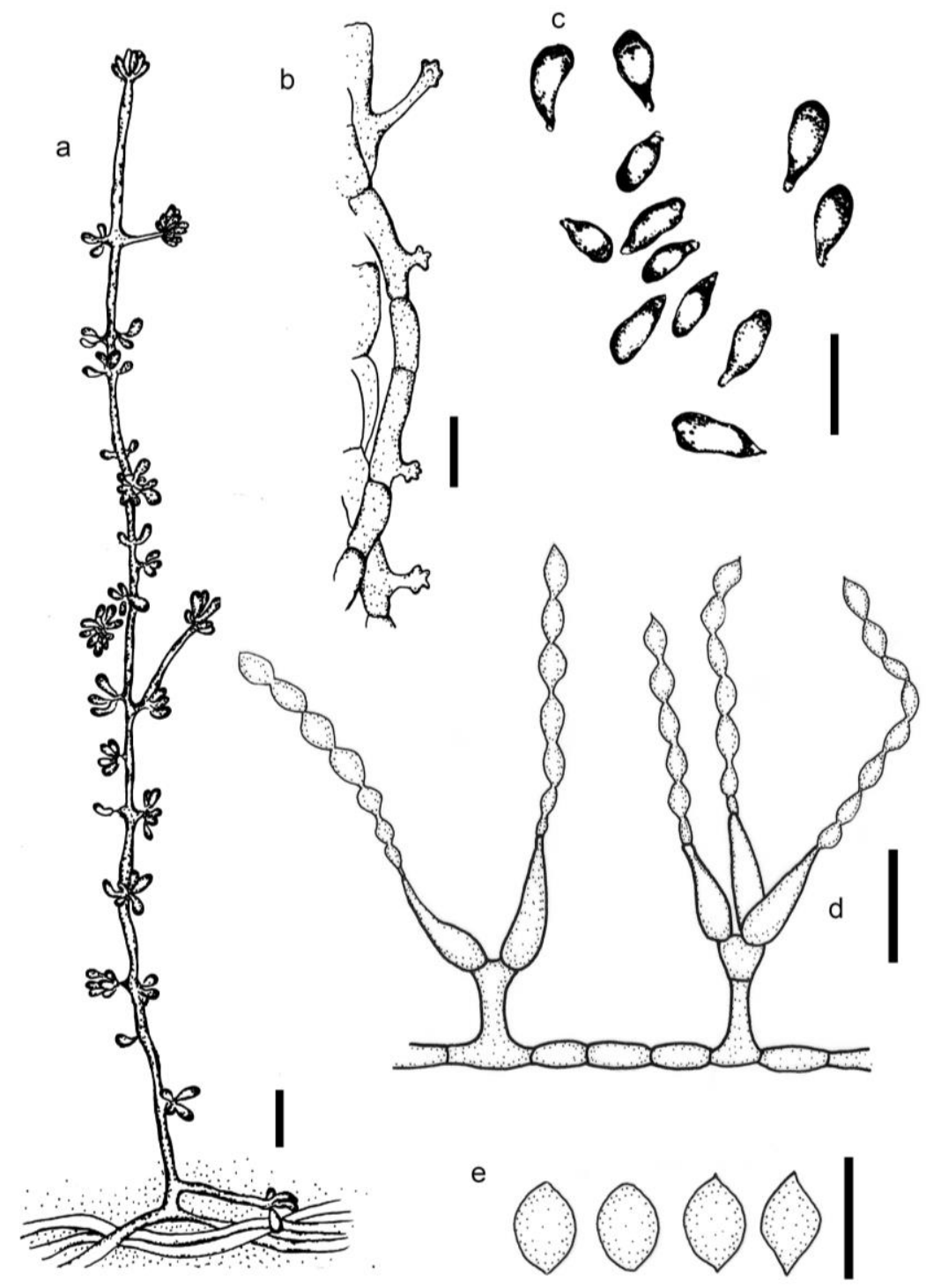

Figure 58 - Different asexual morphs of Cephalothecaceae, Cephalotheca purpurea, C. sulfurea (redrawn from Chesters 1935). a-c Fertile hyphae and radulo-conidia. d Conidiophores with conidiogenous cells and conidia. e Conidia. Scale bars: $a, d=10 \mu \mathrm{m}, \mathrm{b}, \mathrm{c}, \mathrm{e}=5 \mu \mathrm{m}$.

Ceratocystidaceae Locq., Stud. Mycol. 68(1): 188 (2011)

Index Fungorum number: IF515438; Facesoffungi number: FoF01248; 161 species.

Saprobic or pathogenic on plant materials and plants, parasitic in beetles, flies, or mites, and isolated from soil. Sexual morph: Ascomata perithecial, initially immersed to semi-immersed, becoming superficial, solitary or clustered; ascomatal bases globose, subglobose to obpyriform or ovoid, light brown or dark brown to black, clothed with spines or digitate or stellate appendages, ornamented or unornamented or with undifferentiated ornamental hyphae. Necks usually filiform, tapering and paler upwards. Ostiolar hyphae straight or divergent to convergent, aseptate, light 
brown to hyaline. Paraphyses lacking. Asci unitunicate, evanescent. Ascospores aseptate, hyaline, hat-shaped or varied in shape, ellipsoidal or elongate to slightly curved, with rounded ends, or oblong, cylindrical or narrowly fusiform to spindle-shaped, with eccentric wall thickening or surrounded by a sheath, accumulating in masses at tips of ostiole. Asexual morph: Conidiophores mononematous, single or aggregated in sporodochia or synnematous, septate, tapering towards apex, hyaline to pale brown or dark brown, unbranched or branched; in some genera such as Ceratocystis and Huntiella two types of conidiophores (primary and secondary) occur. Conidiogenous cells phialidic, borne terminally or laterally on vegetative hyphae, lageniform, tubular, rectangular, oblong cylindrical to flask-shaped, sometimes with a slightly flared collarette, subhyaline or pale brown, tapering towards the apex. Conidia unicellular, varied in shape, cylindrical to oblong, globose to subglobose, rectangular, single or formed in chains, with rounded or truncate ends, hyaline to pale brown, or becoming grey at maturity; in some genera with two types of conidia: (i) primary or bacilliform conidia hyaline, aseptate, cylindrical, and (ii) secondary or barrel-shaped conidia cylindrical to oblong, hyaline or becoming grey, aseptate, mostly in chains; aleurioconidia (some genera) globose to subglobose, ovoid to pyriform, single or in chains, hyaline or pale brown to brown (adapted from Réblová et al. 2011, Maharachchikumbura et al. 2016b).

Type genus - Ceratocystis Ellis \& Halst.

Notes - Ceratocystidaceae (as "Ceratocystaceae") was introduced by Locquin (1972), but was not validly published but validated by Réblová et al. (2011). It is currently placed in Microascales in the subclass Hypocreomycetidae (Réblová et al. 2011, de Beer et al. 2013b, Maharachchikumbura et al. 2016b). Within the order, it forms a monophyletic group, distinct from Gondwanamycetaceae based on strong bootstrap support (Réblová et al. 2011). Historically, Ceratocystidaceae and especially Ceratocystis included a highly heterogeneous group of species based on similar morphology. With the aid of multigene phylogenetic analyses, morphological characteristics and ecological preferences, several genera were delimited and placed in Ceratocystidaceae, which include Ambrosiella, Berkeleyomyces, Bretziella, Ceratocystis, Chalaropsis, Davidsoniella, Endoconidiophora, Huntiella, Meredithiella, Phialophoropsis and Thielaviopsis (Peyronel 1916, de Beer et al. 2014, 2017, Mayers et al. 2015, Nel et al. 2018).

Some asexual genera defined by similar characters are not readily identifiable which in the absence of molecular data, lead to difficulties in generic identification. DNA sequence data, the 60S ribosomal protein RPL10 (60S), nuclear ribosomal DNA large subunit (LSU) and minichromosome maintenance complex component 7 (MCM7) are suggested to delimit genera (de Beer et al. 2014, Marin-Felix et al. 2017). In addition, the internal transcribed spacer (ITS) regions and the 5.8S gene, partial $\beta$-tubulin (tub2), translation elongation factor $1 \alpha$ (tefl), second largest subunits of RNA polymerase II ( $r p b 2)$, and/or the guanine nucleotide-binding protein subunit betalike protein (MS204) gene regions are used to resolve taxa at the species level (de Beer et al. 2014, Marin-Felix et al. 2017, Liu et al. 2018). Huntiella chinaeucensis is illustrated in this study.

\section{Ecological and economic significance of Ceratocystidaceae}

Members of Ceratocystidaceae, particularly species of Ceratocystis, are destructive plant pathogens. They cause serious diseases in several economic crops, trees and ornamental plants such as coffee, cacao, eucalyptus, giant taro, and occur worldwide (Roux et al. 2004, Van Wyk et al. 2010, Li et al. 2016, Mbenoun et al. 2016). For example, Ceratocystis fimbriata causes a serious wilt and die-back disease on Eucalyptus clones in the Republic of Congo in Central Africa (Roux et al. 2000). Ceratocystis fimbriata attacks a wide variety of plants; for example, it causes a severe leaf blight disease on Alocasia macrorrhiza in Yunnan, China ( $\mathrm{Li}$ et al. 2016). The disease outbreaks result with extensive crop losses and severely affects the economy.

\section{Genera included in Ceratocystidaceae}

Ambrosiella Brader, Mycopath. Mycol. appl. 25: 314 (1965) 
Index Fungorum number: IF7119; 12 morphological species (Species Fungorum 2020), 10 species with sequence data.

Type species - Ambrosiella xylebori Brader.

Notes - Ambrosiella was invalidly described by Brader (1964) as A. xylebori from a gallery of Xylosandrus compactus in Coffea canephora from the Ivory Coast; no type was designated. The generic type was subsequently illustrated and designated based on Brader's isolate (CBS 110.61) by von Arx \& Hennebert (1965). Ambrosiella was previously a polyphyletic group. However, the genus was delimited based on DNA sequence data and new combinations and new species were proposed (Six et al. 2009, Harrington et al. 2010, 2014, Mayers et al. 2015, 2017, 2019). Ambrosiella species are obligate symbionts of the ambrosia beetle tribe Xyleborini (Mayers et al. 2015).

Berkeleyomyces W.J. Nel, Z.W. de Beer, T.A. Duong \& M.J. Wingf., Pl. Path. 67(4): 876 (2018)

Index Fungorum number: IF822838; 2 species with sequence data.

Type species - Berkeleyomyces basicola (Berk. \& Broome) W.J. Nel, Z.W. de Beer, T.A. Duong \& M.J. Wingf.

Notes - Berkeleyomyces was introduced with two species, B. basicola and B. rouxiae (Nel et al. 2018). The type species which was previously identified as Thielaviopsis basicola has a chaotic taxonomic history and was classified in several genera (Ferraris 1912, Carmichael et al. 1980, Crane \& Miller 2016, Nel et al. 2018). It was treated in Berkeleyomyces by Nel et al. (2018) based on phylogenetic analyses and morphology. The fungus is an important plant pathogen which causes serious black root rot of numerous plants such as tobacco and groundnuts (Geldenhuis et al. 2006, Coumans et al. 2011).

Bretziella Z.W. de Beer, Marinc., T.A. Duong \& M.J. Wingf., MycoKeys 27: 10 (2017)

Index Fungorum number: IF822520; 1 species with sequence data.

Type species - Bretziella fagacearum (Bretz) Z.W. de Beer, Marinc., T.A. Duong \& M.J. Wingf.

Notes - de Beer et al. (2017) reclassified the Ceratocystidaceae (Microascales) based on multi-gene phylogenetic inference and found that the oak wilt fungus Ceratocystis fagacearum (current name Bretziella fagacearum) formed a well-supported monophyletic clade distinct from all other genera in Ceratocystidaceae. They also confirmed that Chalara quercina (the first name applied to the fungus) and Endoconidiophora fagacearum (the name applied when the sexual morph was discovered) are conspecific based on their axenic cultures from the same host trees and geographical area. Thus, de Beer et al. (2017) introduced Bretziella to accommodate the oak wilt fungus with the single species B. fagacearum found on Quercus sp.

Ceratocystis Ellis \& Halst., New Jersey Agric. Coll. Exp. Sta. Bull. 76: 14 (1890)

Index Fungorum number: IF888; 101 morphological species (Species Fungorum 2020), 53 species with sequence data.

Type species - Ceratocystis fimbriata Ellis \& Halst.

Notes - Ceratocystis is characterized by black, globose ascomatal bases with filiform, elongated necks terminating in an ostiole and sticky, hat-shaped ascospores (Upadhyay 1981, Seifert et al. 1993, de Beer et al. 2014). The asexual morph of most Ceratocystis species is chalaraor thielaviopsis-like and characterized by phialidic conidiogenous cells producing chains of hyaline, single-celled, cylindrical conidia called endoconidia, and in some cases secondary dark, barrel-shaped, thick-walled aleurioconidia which are commonly produced that facilitate survival in wood or soil during dry seasons (Hedgcock 1906, Harrington 2013, de Beer et al. 2014, Maharachchikumbura et al. 2016b).

The history of Ceratocystis was discussed in Réblová et al. (2011), de Beer et al. (2014), Maharachchikumbura et al. (2016b) and Holland et al. (2019). Ceratocystis species are important plant pathogens and act as causal agents of sap stain in timber and symbiotic associates of insects. 
For example, $C$. platani is an invasive alien pathogen of Platanus trees in Europe (Ocasio-Morales et al. 2007), whereas C. albifundus is a virulent pathogen of Acacia mearnsii in Africa (Roux \& Wingfield 2013). The ITS, tub1, tef1, rpb2, ms204 gene regions are used to identify species boundaries in Ceratocystis (Marin-Felix et al. 2017, Barnes et al. 2018). The loci rpb2 and $m s 204$ provide stronger resolution among species than tefl and tubl, but also need to be used in combination with ITS (Fourie et al. 2015).

Chalaropsis Peyronel, Staz. Sper. Argar. Ital. 49: 595 (1916)

Index Fungorum number: IF7602; 3 species with sequence data.

Type species - Chalaropsis thielavioides Peyronel.

Notes - Chalaropsis has been reported as a hyphomycetous genus and the sexual morph is so far undetermined. Although $C$. ovoidea, $C$. populi and $C$. thielavioides are confirmed species with sequence data, none of the sequence data were derived from type specimens (Paulin-Mahady et al. 2002, Wingfield et al. 2013, de Beer et al. 2014).

Davidsoniella Z.W. de Beer, T.A. Duong \& M.J. Wingf., Stud. Mycol. 79: 210 (2014)

Index Fungorum number: IF810235; 4 species with sequence data.

Type species - Davidsoniella virescens (R.W. Davidson) Z.W. de Beer, T.A. Duong \& M.J. Wingf.

Notes - de Beer et al. (2014) emended four species, viz. Davidsoniella australis, D. eucalypti, $D$. neocaledoniae and D. virescens based on combined sequence data of 60S, LSU and MCM7, and introduced a new holomorphic genus with $D$. virescens as the type species. Only Davidsoniella virescens and D. eucalypti have known sexual morphs, while D. australis and D. neocaledoniae are known only as asexually fungi (Kiffer \& Delon 1983, Samuels 1993, de Beer et al. 2014).

Endoconidiophora Münch, Naturwiss. Z. Forst-Landw. 5: 564 (1907)

Index Fungorum number: IF1794; 9 species with sequence data.

Type species - Endoconidiophora coerulescens Münch

Notes - The generic description of Endoconidiophora was emended and described from both sexual and asexual morphs lacking aleurioconidia (de Beer et al. 2014). Eight species were confirmed with molecular data mostly from ex-types, and E. coerulescens was confirmed from a new collection (de Beer et al. 2014). Epitypification of E. coerulescens which is the type species of Endoconidiophora, is required.

Huntiella Z.W. de Beer et al. Stud. Mycol. 79: 211 (2014)

Index Fungorum number: IF810236; 18 morphological species (Species Fungorum 2020), 17 species with sequence data.

Type species - Huntiella moniliformis (Hedgc.) Z.W. de Beer, T.A. Duong \& M.J. Wingf.

Notes - Huntiella species occur on a wide range of hosts and are distributed worldwide on Acacia mangium in Indonesia, Eucalyptus obliqua in Australia, E. saligna in South Africa, Mangifera indica in Oman, Picea spinulosa in Bhutan (de Beer et al. 2014), Eucalyptus exserta, Acacia confusa in China (Liu et al. 2018), and Tectona grandis in Thailand (this study). The species are saprobes, weak pathogens and are also commonly found on tree wounds (Mbenoun et al. 2016, Liu et al. 2018). Huntiella chinaeucensis, is illustrated in this entry (Fig. 59).

Meredithiella McNew, C. Mayers \& T.C. Harr., Fungal Biology 119(11): 1086 (2015)

Index Fungorum number: IF812574; 3 species with sequence data.

Type species - Meredithiella norrisii McNew, C. Mayers \& T.C. Harr.

Notes - Meredithiella norrisii was collected from insect galleries and from male Corthylini punctatissimus beetles from Michigan and Iowa (Mayers et al. 2015). Meredithiella fracta and M. guianensis were subsequently introduced and their type cultures isolated from mycangium of Corthylus papulans and gallery of Corthylus crassus, respectively (Mayers et al. 2018). The genus 
is a symbiont with ambrosia beetle of the tribe Corthylini (Mayers et al. 2018). So far, members of the genus are only asexual morphs.

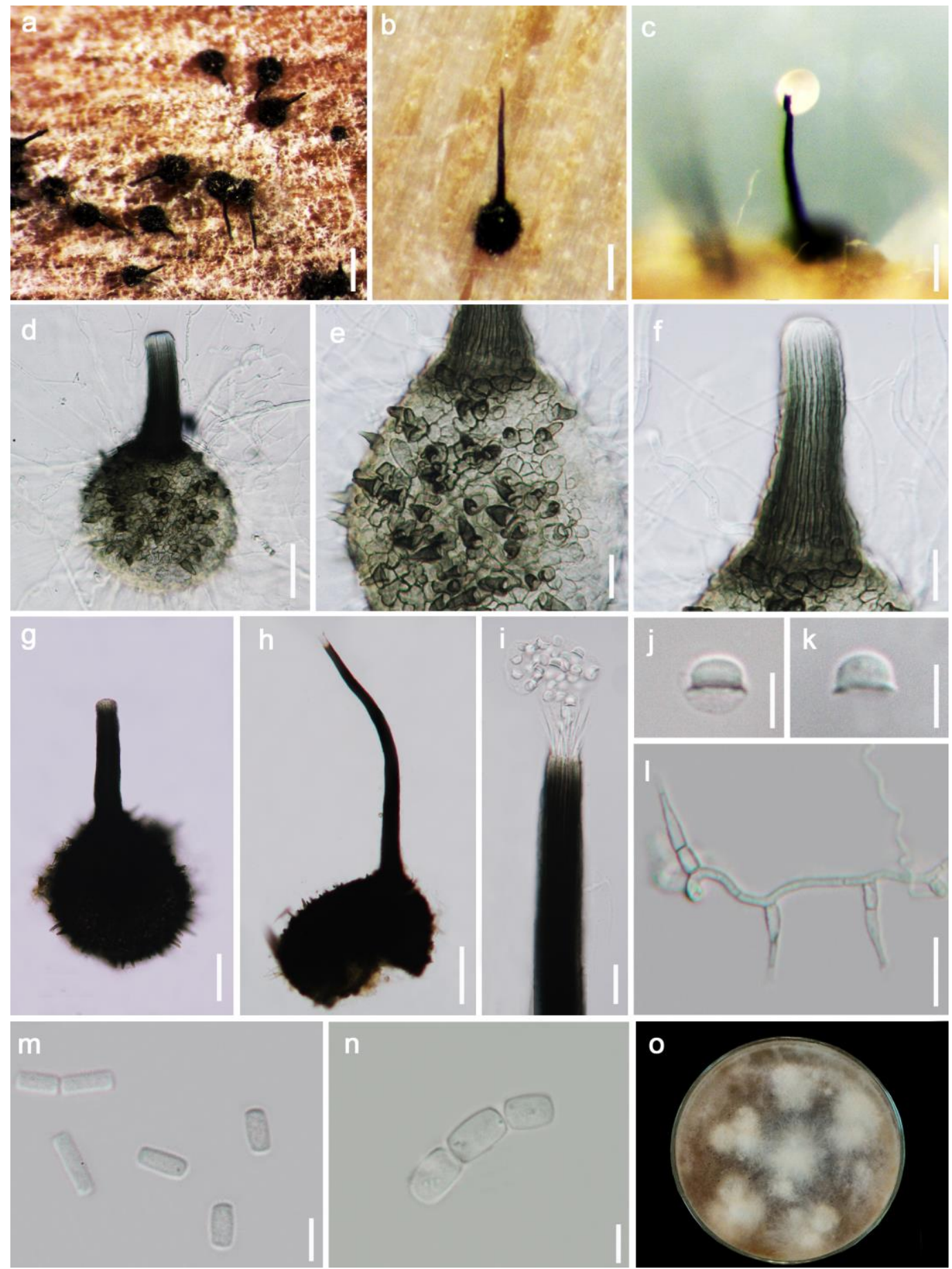

Figure 59 - Huntiella chinaeucensis (Material examined - THAILAND, Chiang Rai Province, Mae Suai District, Mae Lao garden, on stumps of Tectona grandis (Lamiaceae), 24 December 2012, M. Doilom, MFLU 15-3204). a, b Globose to subglobose ascoma bases with elongated ostiolar necks on Tectona grandis (teak) wood. c Cream-coloured ascospore mass at the tip of the ascoma neck on teak wood. d Immature globose ascoma. e Close up of ascoma base with conical spines. f Ascoma neck with longitudinal striations. g, h Mature ascoma with conical spines on the surface of bases. i Hat-shaped ascospores released through ostiolar hyphae. j, k Hat-shaped ascospores. 1 Flask-shaped conidiogenous cells. $\mathrm{m}$ Bacilliform conidia. $\mathrm{n}$ Barrel-shaped conidia in chains. o Colony on PDA. Scale bars: $\mathrm{a}=200 \mu \mathrm{m}, \mathrm{b}=300 \mu \mathrm{m}, \mathrm{c}=500 \mu \mathrm{m}, \mathrm{d}, \mathrm{g}=50 \mu \mathrm{m}, \mathrm{e}, \mathrm{f}, \mathrm{l}=$ $20 \mu \mathrm{m}, \mathrm{h}, \mathrm{i}=100 \mu \mathrm{m}, \mathrm{j}, \mathrm{k}, \mathrm{m}, \mathrm{n}=5 \mu \mathrm{m}$. 
Phialophoropsis L.R. Batra, Mycologia 59(6): 1008 (1968)

Index Fungorum number: IF9344; 1 species with sequence data.

Type species - Phialophoropsis trypodendri L.R. Batra

Notes - Phialophoropsis was resurrected by Mayers et al. (2015) to accommodate $P$. trypodendri (type species) from Trypodendron scabricollis and P. ferruginea from Trypodendron lineatum. Both species are associated with ambrosia beetles of the tribe Xyloterini (Mayers et al. 2015). Other two species, P. cambrensis and P. nipponica were treated as uncertain or excluded species which would not be consistent with the current concept of Phialophoropsis (Mayers et al. 2015). The general concept of Phialophoropsis is accommodated ambrosia beetle symbionts with deep-seated phialides and the absence of aleurioconidia (Mayers et al. 2015).

Thielaviopsis Went, Meded. Proefstn Suik Riet W. Java 5: 4 (1893)

Index Fungorum number: IF10210; 7 species with sequence data.

Type species - Thielaviopsis ethacetica Went

Notes - Went (1893) introduced Thielaviopsis and the generic description was emended to include both sexual and asexual morphs with aleurioconidia (de Beer et al. 2014). The species are plant pathogens. For example, T. paradoxa has been reported to cause trunk rot and black scorch diseases of palms (Elliott 2006, Al-Naemi et al. 2014).

Ceratosphaeriaceae Z.L. Luo, H.Y. Su \& K.D. Hyde, Fungal Divers 99: 490 (2019)

Index Fungorum number: IF555643; Facesoffungi number: FoF05415; 26 species.

Saprobic on wood. Sexual morph: Stromata absent. Ascomata globose to pyriform, deeply immersed to almost superficial, dark brown to black, carbonaceous, with a long cylindrical, black or yellow crystals neck. Periphyses well-developed. Peridium composed of a large number of layers of very thick-walled rather small cells in the neck region. Interascal tissue of paraphyses thin-walled, probably evanescent at maturity. Asci 8-spored, unitunicate, cylindrical. Ascospores biseriate, narrowly cylindric-fusiform, or filiform, ends acute, septate, smooth-walled. Asexual morph: Hyphomycetous. harpophora-like. Phialides or short conidiophores arising on aerial hyphae, with conidial heads slimy, inconspicuous, and transparent. Conidiogenous cells phialidic, ampulliform to lageniform, terminal or intercalary, cylindrical. Conidia cylindrical, hyaline, aseptate, smooth (adapted from Luo et al. 2019).

Type genus - Ceratosphaeria Niessl

Notes - Réblová (2006) accommodated Ceratosphaeria in Magnaporthaceae based on phylogenetic analyses of combined LSU and SSU sequence data. In the phylogenetic study of Luo et al. (2019), Ceratosphaeria species formed a distinct clade in Magnaporthales and they introduced Ceratosphaeriaceae to accommodate Ceratosphaeria. Presently, there is only one genus (Ceratosphaeria) accepted in this family.

\section{Ecological and economic significance of Ceratosphaeriaceae}

Ceratosphaeriaceae are saprobes which have the ability to decompose lignocellulose matter in woody litter, resulting in softening of the wood and releasing nutrients in the form of simple molecules that go back into the soil and can be reused by plants and all other organisms (Yuen et al. 1998, Bucher et al. 2004). Thus, they play an important role in nutrient and carbon cycling, biological diversity and ecosystem functioning (Palmer et al. 1997, Wong et al. 1998a).

\section{Genus included in Ceratosphaeriaceae}

Ceratosphaeria Niess1, Verh. nat. Ver. Brünn 14: 203 (1876)

Index Fungorum number: IF897; 26 morphological species (Species Fungorum 2020), 3 species with sequence data.

Type species - Ceratosphaeria lampadophora (Berk. \& Broome) Niessl

Notes - The genera was established to accommodate recombined species, Ceratosphaeria lampadophora (= Sphaeria lampadophora), species found from wood in Great Britain (Niessl 
1876). Ceratosphaeria is characterized by globose to pyriform, immersed to almost superficial, dark coloured stromatic ascomata, leathery to fragile perithecial walls, cylindric-clavate, shortstipitate asci, truncate to broadly rounded at the apex, with an apical ring and allantoid to suballantoid, pale brown, aseptate ascospores and a harpophora-like asexual morph with phialidic conidiogenesis (Hyde et al. 1997b, Niessl 1876, Réblová 2006). Five species in this genus have been recorded from freshwater habitats (Luo et al. 2019).

Ceratostomataceae G. Winter, Rabenh. Krypt.-Fl., Edn 2 (Leipzig) 1.2: 247 (1885)

Index Fungorum number: IF80575; Facesoffungi number: FoF01803; 134 species.

Saprobic or weakly parasitic, often growing on other fungi and commonly isolated from soil. Sexual morph: Ascomata perithecial or cleistothecial, yellow to pale brown, transparent, with or without ostiole: often with long-necks, smooth ostiolar setae. Interascal tissue absent. Peridium membranaceous, pale yellow to pale yellowish-brown, cells of a textura angularis or textura globulosa. Asci 8-spored, unitunicate, thin-walled, clavate, without an apical ring, deliquescing. Ascospores biseriate, brown to dark brown, ellipsoidal to citriform, occasionally discoid or fusiform, 1-celled, usually with 2 germ pores at each end, smooth to strongly ornamented, without sheath. Asexual morph: Hyphomycetous. Conidiophores simple, semi-macronematous, mononematous, some genera branched towards the apex, in some genera conidiophore with several roughened swellings along the entire length, reddish-brown to dark. Conidiogenous cells integrated, terminal, monoblastic, some genera with phialides, singly on aerial hyphae or rarely on conidiophores, lageniform, hyaline. Conidia globose, spindle-shaped, ovate to pyriform, some genera aggregated in small globose heads at the apices of phialides, 1-celled, some genera with 23-transverse septa, hyaline, brown and verrucose (adapted from Maharachchimbura et al. 2016b).

Type genus - Melanospora Corda

Notes - Ceratostomataceae (= Melanosporaceae) was introduced by Winter (1885b). Hawksworth et al. (1995) placed Ceratostomataceae in Sordariales based on characters. Jones \& Blackwell (1998) placed Ceratostomataceae in Hypocreales based on molecular phylogenetic studies. Zhang \& Blackwell (2002) considered Ceratostomataceae was derived from the Hypocreales clade and they included it in Hypocreomycetidae. Hibbett et al. (2007) introduced Melanosporales to accommodate Ceratostomataceae which clustered with Coronophorales. Hongsanan et al. (2017) treated Melanosporales as a synonym of Coronophorales based on phylogenetic analysis, which maintained monophyly with Melanosporales. Wijayawardene et al. (2018a) accepted nine genera in Ceratostomataceae (Arxiomyces, Erythrocarpon, Gonatobotrys, Melanospora, Pteridiosperma, Pustulipora, Rhytidospora, Setiferotheca, Vittatispora), when merging both asexual and sexual genera into one outline. Marin-Felix et al. (2018) re-examined the most relevant genera of Ceratostomataceae based on phylogenetic relationships, when redefining Melanospora, and re-established Microthecium and introduced three new genera to Ceratostomataceae and accepted 12 genera in this family. So far, several species and genera in Ceratostomataceae were emended and introduced, and some genera were recombined (Réblová et al. 2016a, Marin-Felix et al. 2018). Consequently, 14 genera are accepted in Ceratostomataceae based on morphological characteristic and DNA-sequence data, these include Arxiomyces, Dactylidispora, Echinusitheca, Erythrocarpon, Harzia, Melanospora (= Gonatobotrys), Microthecium (= Pteridiosperma), Pseudomicrothecium, Pustulipora, Rhytidospora, Scopinella, Setiferotheca, Syspastospora and Vittatispora (Réblová et al. 2016a, Marin-Felix et al. 2018, Wijayawardene et al. 2018a). Many of the species in this family were isolated from dung and five genera lack sequence data. Fresh collections with sequence data are therefore needed.

\section{Ecological and economic significance of Ceratostomataceae}

Most of the species in Ceratostomataceae are saprobic on plant material. Certain species have a widespread host range, and are closely associated with other fungi, on soil, rotting vegetation and some species are considered as potential biocontrol agents as they can grow on other plant pathogens (Cannon \& Kirk 2007). 

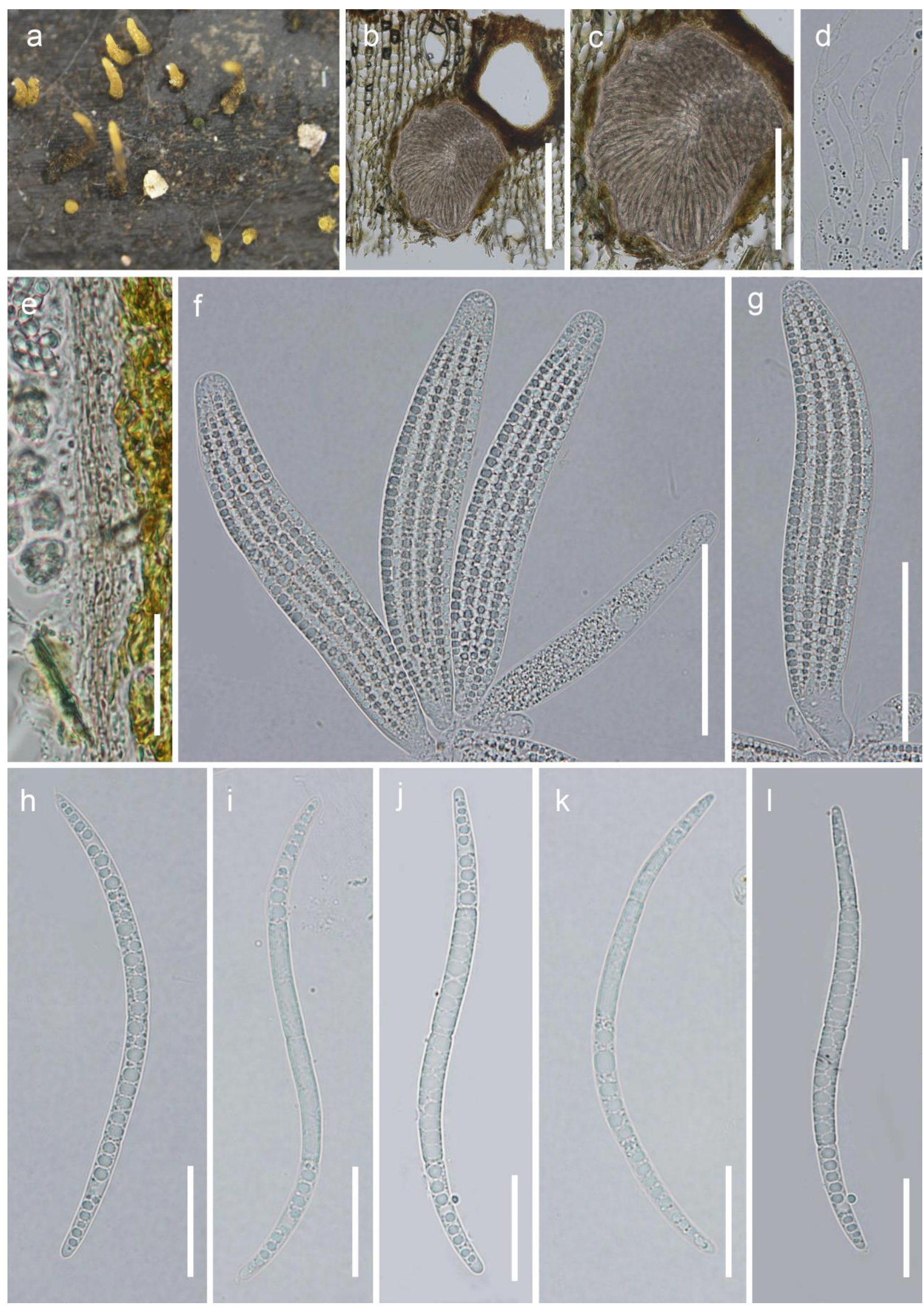

Figure 60 - Ceratosphaeria aquatica (Material examined - CHINA, Yunnan Province, saprobic on decaying wood submerged in a freshwater river, April 2015, Z.L. Luo, S-639, MFLU 18-2323). a Appearance of necks on substrate. b, c Section through ascomata. d Paraphyses. e Structure of peridium. f, g Asci. h-1 Ascospores. Scale bars: b, c $=200 \mu \mathrm{m}, \mathrm{d}, \mathrm{e}, \mathrm{h}-1=20 \mu \mathrm{m}, \mathrm{f}, \mathrm{g}=50 \mu \mathrm{m}$. 


\section{Genera included in Ceratostomataceae}

Arxiomyces P.F. Cannon \& D. Hawksw., Trans. Br. mycol. Soc. 81(3): 644 (1983)

Index Fungorum number: IF25489; 3 morphological species (Species Fungorum 2020).

Type species - Arxiomyces vitis (Fuckel) P.F. Cannon \& D. Hawksw.

Notes - Arxiomyces was introduced by Cannon \& Hawksworth (1982) to replace Phaeostoma with the type species Arxiomyces vitis, on bark in Europe (Lumbsch \& Huhndorf 2010). Arxiomyces campanulatus (on Stachybotrys chartarum, fungi from cultivated soil from Honshu and A. zuberiensis, fungi on dead stems of Phragmites australis in Iraq were also introduced (Index Fungorum 2020). The genus is characterised by ovoid to ellipsoidal ascospores rounded at the apex and with a truncate base with a broad germ pore that bears a mucilaginous and collapsing appendage (Cannon \& Hawksworth 1982, 1983). The asexual morph of the genus is undetermined.

Dactylidispora Y. Marín, Stchigel, Guarro \& Cano, MycoKeys 44: 89 (2018)

Index Fungorum number: IF812079; 3 morphological species (Species Fungorum 2020), 2 species with sequence data.

Type species - Dactylidispora ellipsospora (Takada) Y. Marín, Stchigel, Guarro \& Cano

Notes - The genus was introduced by Marin-Felix et al. (2018) to establish three new species combinations from Microthecium. They are Dactylidispora ellipsospora (= Microthecium ellipsosporum), a species isolated from forest soil in North Solomons, Dactylidispora collipora (= Microthecium collipora), a species isolated from soil in Rajasthan, and Dactylidispora singaporensis (= Microthecium singaporensis), a species isolated from soil in Singapore (MarinFelix et al. 2018). The most distinctive characteristic of the genus is short, conical ascomata, with a crown of setae surrounding the ostiole, smooth-walled and fusiform ascospores with a germ pore at each end surrounded by a raised rim, and the asexual morph with phialidic, flask-shaped conidiogenous cells and subglobose to ovoid conidia (Marin-Felix et al. 2018).

Echinusitheca Y. Marín, Stchigel, Dania García, Guarro, A.N. Mill. \& Cano, MycoKeys 44: 91 (2018)

Index Fungorum number: IF812084; 1 species with sequence data. \& Cano

Type species - Echinusitheca citrispora Y. Marín, Stchigel, Dania García, Guarro, A.N. Mill.

Notes - Echinusitheca was introduced to accommodate a single species E. citrispora, isolated from forest soil in North Carolina, USA. The genus is characterised by strongly setose, dark ascomata lacking ostioles with and unicellular, ellipsoidal ascospores with a depressed germ pore at each end. The asexual morph of the genus is undetermined (Marin-Felix et al. 2018).

Erythrocarpon Zukal, Verh. zool.-bot. Ges. Wien 35: 337 (1886)

Index Fungorum number: IF1901; 1 morphological species.

Type species - Erythrocarpon microstomum Zukal

Notes - Erythrocarpon was introduced by Zukal (1886) as monotypic genus to accommodate a species, Erythrocarpon microstomum, found on rotten branches in Hütteldorf, Austria. The genus is characterised by cylindrical, 8-spored asci and the asexual morph is characterised by spindleshaped conidia, with 3 transverse septa.

Harzia Costantin, Mucéd. Simpl. (Paris): 42 (1888)

Index Fungorum number: IF8458; 12 morphological species (Species Fungorum 2020), 10 species with sequence data.

Type species - Harzia acremonioides (Harz) Costantin

Notes - Harzia was introduced by Costantin et al. (1888) with the type species $H$. acremonioides (三 Monosporium acremonioides), a seed-borne species from soil. The genus is characterised by hyaline mycelium and conidiophores and 1-celled, brown to golden brown, ovoid to subglobose, usually smooth-walled conidia, but sometimes with a slight wrinkling/exposure, and 
each species tending to vary in conidia size (Horne \& Williamson 1923, Domsch et al. 1980). In the phylogenetic analysis, the genus formed a monophyletic clade in the family phylogenetic tree, and is sister to genus Melanospora with high bootstrap support (99\%ML; Fig. 11)

Melanospora Corda, Icon. fung. (Prague) 1: 24 (1837)

Index Fungorum number: IF3085; 69 morphological species (Species Fungorum 2020), 9 species with sequence data.

Type species - Melanospora zamiae Corda

Notes - Melanospora was established by Corda (1837) to accommodate Ceratostoma chioneum (= Melanospora chionea) and two new species, Melanospora zamiae and M. leucotricha, with the former chosen as the type species (Kowalski 1965). Melanospora is the largest genus of this family. Most Melanospora species are parasitic and associated with a wide host range, such as basidiomycetes, sexual and asexual ascomycetes, as well as with other fungi and some species obtain nutrients by fusing with the host protoplasts, an interaction called fusion biotrophism (Jeffries \& Young 1994, Sun et al. 2019). Harveson (1999) reported Melanospora species as potential biocontrol agents, which can grow on pathogenic fungi. This genus is distinguished by translucent ascomata with a neck composed of intermixed hyphae and with an apical crown of setae, and smooth or ornamented ascospores with an apiculate germ pore at each end, and a phialidic asexual morph (Marin-Felix et al. 2018). The morphologically similar genera to Melanospora and other genera in Ceratostomataceae was re-examined and discussed in MarinFelix et al. (2018).

Microthecium Corda, Icon. fung. (Prague) 5: 30, 74 (1842)

Index Fungorum number: IF3196; 23 morphological species (Species Fungorum 2020), 13 species with sequence data.

Type species - Microthecium zobelii Corda

Notes - Microthecium was introduced by Corda (1842) with M. zobelii as the type species, found on Rhizopogon albus in Germany. The genus is characterised by yellowish to reddish, globose ascomata and short necks or necks lacking, with setae around the ostiole, clavate and evanescent asci, fusiform, navicular, citriform, plataniform or spindle-shaped ascospores, which are hyaline and become brown to dark brown when mature, with a terminal apiculate or depressed germ pore at each end. The asexual morph comprises hyaline phialides with pale orange to reddishorange conidia.

Pseudomicrothecium Marin-Felix, Stchigel, Guarro \& Cano, MycoKeys 44: 114 (2018)

Index Fungorum number: IF812108; 1 species with sequence data.

Type species - Pseudomicrothecium subterraneum (L. Fan, C.L. Hou, P.F. Cannon \& Y. Li) Y. Marín, Stchigel, Guarro \& Cano

Notes - Pseudomicrothecium was introduced by Marín-Felix et al. (2018) as a monotypic genus to accommodate a single species, $P$. subterranean (= Melanospora subterranean) found on litter in Japan. The genus is characterised by globose, pale brown to dark brown ascomata, lacking ostioles when mature and shrouded with setae, 2-spored, clavate, evanescent asci with a short pedicel and lacking apical structures and ellipsoidal to citriform, 1-celled, dark brown to blackish ascospores, umbonate and truncate at both ends, with a terminal indistinct germ pore at each end (Marín-Felix et al. 2018). The asexual morph of the genus is undetermined.

Pustulipora P.F. Cannon, Mycotaxon 15: 526 (1982)

Index Fungorum number: IF4561; 1 morphological species.

Type species - Pustulipora corticola P.F. Cannon

Notes - The monotypic genus Pustulipora was introduced by Cannon (1982) with $P$. corticola occurring on bark. Pustulipora can be distinguished from Dactylidispora by its blistered, 
rarely cushion-like structures surrounding the germ pore (Cannon 1982). The asexual morph of the genus is undetermined.
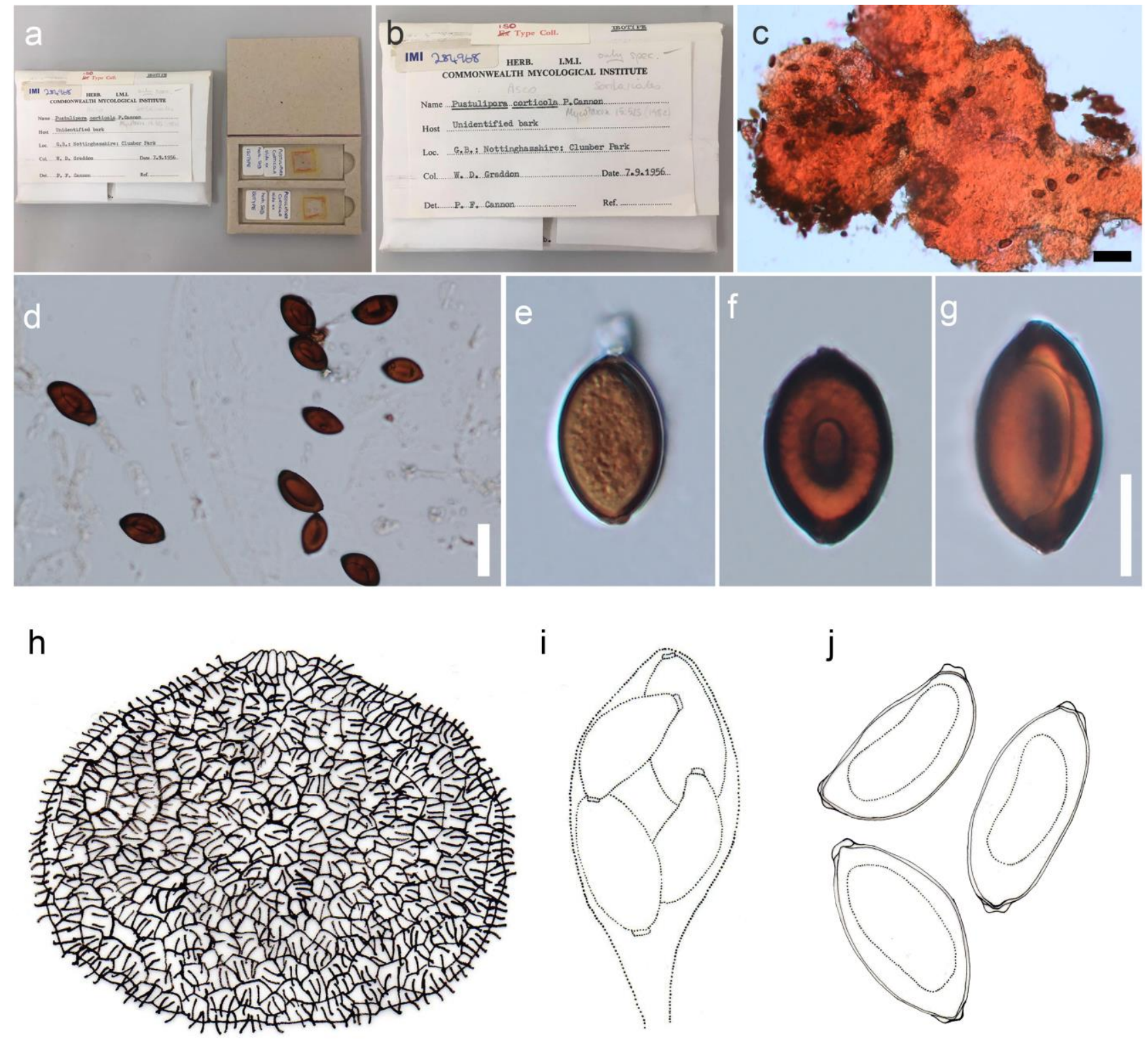

Figure 61 - Pustulipora corticola (Material examined - UK, Nottinghamshire, Clumber Park, from unidentified bark, 7 September 1956, W.D. Graddon IMI 284968, isotype). a, b Herbarium packet. c-g Ascospores. h Ascoma. i Ascus. $\mathrm{j}$ Ascospores ( $\mathrm{h}-\mathrm{j}$ : redraw from Cannon 1982). Scale bars: $\mathrm{c}=$ $100 \mu \mathrm{m}, \mathrm{d}=50 \mu \mathrm{m}, \mathrm{e}-\mathrm{g}=20 \mu \mathrm{m}$.

Rhytidospora Jeng \& Cain, Mycotaxon 5(1): 278 (1977)

Index Fungorum number: IF4744; 5 morphological species (Species Fungorum 2020).

Type species - Rhytidospora tetraspora Jeng \& Cain

Notes - Rhytidospora was introduced by Jeng \& Cain (1977) based on a single species $R$. tetraspora, isolated from burro dung in Venezuela. Rhytidospora bispora, $R$. cainii, $R$. citriformis, and $R$. inordinata, were added to this genus by (Doveri 2014). The genus is characterized by cleistothecial ascomata with a cephalothecoid peridium, globose to subglobose, irregularlyevanescent asci, and thick-walled, ellipsoidal ascospores with a wrinkled a germ pore (Krug \& Jeng 1979). The asexual morph of the genus is undetermined. 


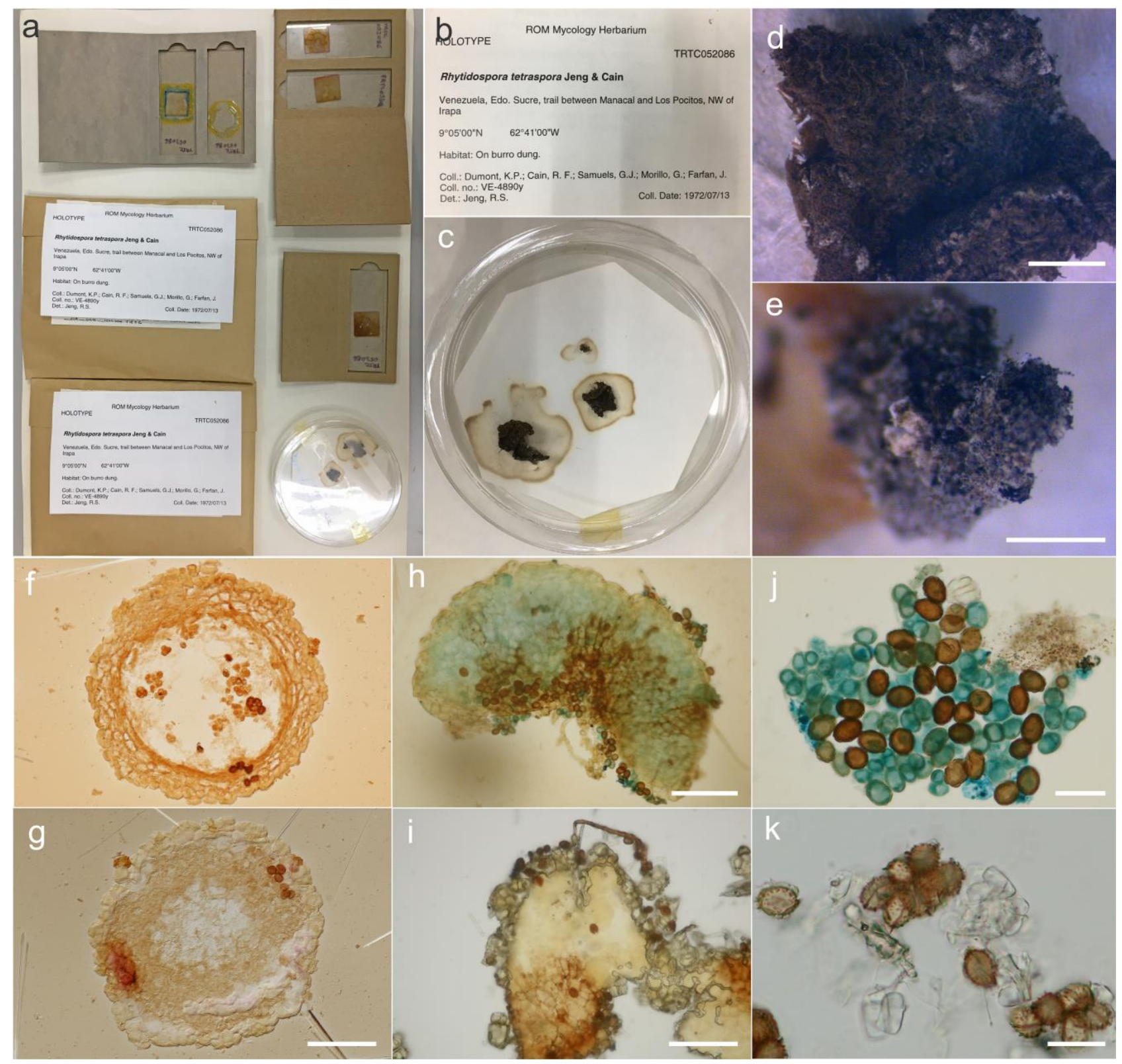

Figure 62 - Rhytidospora tetraspora (Material examined - VENEZUELA, Edo. Sucre, trail between Manacal and Los Pocitos, NW of Irapa, on burro dung, 13 July 1972, K.P. Dumont, R.F. Cain, G.J. Samuels, G. Morillo, J. Farfan, TRTC052086, holotype). a-e Herbarium package details. $\mathrm{f}-\mathrm{i}$ Ascomata. j, k Ascospores (f-k, observed from slides of herbarium package). Scale bars: $d=$ $2000 \mu \mathrm{m}, \mathrm{e}=1000 \mu \mathrm{m}, \mathrm{f}-\mathrm{i}=100 \mu \mathrm{m}, \mathrm{j}, \mathrm{k}=20 \mu \mathrm{m}$.

Scopinella Lév., Dict. Univ. Hist. Nat. 8: 493 (1846)

Index Fungorum number: IF4962; 9 morphological species (Species Fungorum 2020), 1 species with sequence data.

Type species - Scopinella pleiospora (J. Schröt.) Sacc.

Notes - The type species was described growing on rabbit dung in Norway. The genus is characterised by long necked ascomata, evanescent asci and cuboid-ellipsoidal ascospores with two prominent germ slits. Thee asexual morph of the genus is undetermined.

Setiferotheca Matsush., Matsush. Mycol. Mem. 8: 34 (1995)

Index Fungorum number: IF27340; 1 morphological species.

Type species - Setiferotheca nipponica Matsush. 
Notes - Setiferotheca nipponica is characterised by ovoid to ellipsoidal ascospores rounded at the apex and a truncate base with a broad germ pore that bears a small basal appendage and ascomata with a crown of dark brown setae surrounding the ostiole (Matsushima 1995).

Syspastospora P.F. Cannon \& D. Hawksw., J. Linn. Soc., Bot. 84(2): 152 (1982)

Index Fungorum number: IF5345; 4 morphological species (Species Fungorum 2020), 2 species with sequence data.

Type species - Syspastospora parasitica (Tul.) P.F. Cannon \& D. Hawksw.

Notes - Syspastospora was introduced by Cannon \& Hawksworth (1982) to accommodate Melanospora parasitica, with three additional species, S. boninensis, S. cladoniae, and $S$. tropicalis. The genus has ascomata with long necks composed of parallel arranged hyphae and cylindrical ascospores with a large terminal, slightly sunken germ pore at each end (Cannon \& Hawksworth 1982). The asexual morph of the genus is undetermined.

Vittatispora P. Chaudhary, J. Campb., D. Hawksw. \& K.N. Sastry, Mycologia 98(3): 461 (2006)

Index Fungorum number: IF500705; 1 species with sequence data.

Type species - Vittatispora coorgii P. Chaudhary, J. Campb., D. Hawksw. \& K.N. Sastry

Notes - Vittatispora was introduced to accommodate a single species, V. coorgii, isolated from soil in India. The taxon was observed from culture and has light brow, perithecia, with a long cylindrical neck, 8-spored, clavate asci and ellipsoidal to citriform, brown to dark brown ascospores with two apical germ pores; germ pores surrounded by a raised rim; with a thick hyaline ridge running vertical length of the ascospore between the germ pores (Chaudhary et al. 2006). The asexual morph of the genus is undetermined.

Chadefaudiellaceae Faurel \& Schotter, Mycotaxon 12(1): 46 (1980)

Index Fungorum number: IF80580; Facesoffungi number: FoF01666; 6 species.

Saprobic on mammal dung. Sexual morph: Stromata absent. Ascomata elongate or perithecial, hemisphaerical, embedded. Interascal tissue of undifferentiated hyphae, basal perithecial envelope black, globular, carbonaceous, foot cylindrical, light yellow to brown, translucent, striated, brown apex, the upper part formed from anastomosing setae, lacking ostioles. Peridium pseudoparenchymatous, composed of textura angularis embedded in the substrate and with an aerial "capillitium". Asci 8-spored, catenulate, globose or clavate, evanescent. Ascospores overlapping, pale yellow to brown, aseptate, hyaline to pale brown, ellipsoidal or fusiform, lacking germ pores, smooth-walled or with striations, dextrinoid or not dextrinoid, turning to reddish brown in Melzer's reagent (adapted from Benny \& Kimbrough 1980, Maharachchikumbura et al. 2016). Asexual morph: Hyphomycetous, forming arthrospores (Wijayawardene et al. 2017b).

Type genus - Chadefaudiella Faurel \& Schotter

Notes- Chadefaudiellaceae was validated by Benny \& Kimbrough (1980) and typified by Chadefaudiella. The family consists of species with immersed ascomata lacking ostioles, with a pseudoparenchymatous peridium and aerial thick-walled 'capillitium', enclosing catenulate, evanescent asci with non-dextrinoid ascospores devoid of germ pores (Cannon \& Kirk 2007). The species was originally found on gazelle dung at Koudou, Chad (Africa) (Benny \& Kimbrough 1980). The classification of Faurelina has been problematic and despite the similarities with Chadefaudiella noted by Locquin-Linard (1975), it has undergone many changes in terms of its higher order placement. The placement of Faurelina was debatable and has been speculated to have affinities with many different groups such as Sordariaceae, Testudinaceae, Pithoascaceae and even in Dothideomycetes (Locquin-Linard 1975, Parguey-Leduc \& Locquin-Linard 1976, von Arx 1978). Finally, the genus was placed in Chadefaudiellaceae along with Chadefaudiella (Cannon \& Kirk 2007, Tang et al. 2007, Maharachchikumbura et al. 2015).

Réblová et al. (2011) excluded Faurelina from Chadefaudiellaceae. However, they suggested that further molecular analysis was required and revision of the family. Wijayawardene et al. (2017a), in their checklist included an arthrographis-like asexual morph for Faurelina (Locquin- 
Linard 1975) and confirmed the placement of Faurelina in Chadefaudiellaceae. In Chadefaudiella ascomata have apical anastomosing setae and ascospores are not dextrinoid.

\section{Ecological and economic significance of Chadefaudiellaceae}

Ecologically the species of Chadefaudiellaceae are coprophilous, in desert environments, where they degrade dung.

\section{Genera included in Chadefaudiellaceae}

Chadefaudiella Faurel \& Schotter, Revue Mycol., Paris 30: 339 (1959)

Index Fungorum number: IF928; 2 morphological species (Species Fungorum 2020).

Type species - Chadefaudiella quezelii Faurel \& Schotter

Notes - Chadefaudiella is placed in the Chadefaudiellaceae, Microascales because it produces asci in chains and has other characteristics of Microascaceae taxa. The ascospore wall of C. quezelii is striate and non-dextrinoid (Locquin-Linard 1973, 1975). Usually Chadefaudiella species are saprobic on mammalian dung and was found on Gazelle dung from Koudou, Chad (Africa) (Benny \& Kimbrough 1980). The genus is characterized by large elongate or hemisphaerical, pale yellow to brown, carbonaceous ascomata, which are immersed at the base, and lack ostioles. The peridium is composed of cells of textura angularis embedded in the substrate and an aerial "capillitium". Asci are 8-spored, globose and evanescent. Ascospores are aseptate, fusiform, thick, striate and do not turn reddish-brown in Melzer's reagent (non dextrinoid). The asexual morph is undetermined (Benny \& Kimbrough 1980, Maharachchikumbura et al. 2016b).

Faurelina Locq.-Lin., Revue Mycologique, Paris 39(2): 127 (1975)

Index Fungorum number: IF1981; 4 morphological species (Species Fungorum 2020), 3 species with sequence data.

Type species - Faurelina fimigena Locq.-Lin.

Notes - The asexual morph is arthrographis-like, and coprophilous. The sexual morph is undetermined. Taxonomic revisions were undertaken by Kirk et al. (2013). The genus is accepted in Chadefaudiellaceae by Cannon \& Kirk (2007), Tang et al. (2007), Rossman et al. (2012), Kirk et al. (2013), Maharachchikumbura et al. (2015, 2016b), and Wijayawardene et al. (2017a, 2018a). Faurelina differs as ascomata lack apical anastomosing setae and ascospores are dextrinoid.

Chaetomiaceae G. Winter, Rabenh. Krypt.-Fl., Edn 2 (Leipzig) 1.2: 153 (1885)

Index Fungorum number: IF80582; Facesoffungi number: FoF01842; 506 species.

Saprobic or parasitic on plant debris, straw, seeds, dung, feathers of birds, soil, paper, textiles, in air, on mushrooms, rabbits, and humans. Sexual morph: Ascomata perithecial or cleistothecial, colourless to light brown or carbonaceous, egg-yellow, grey olivaceous to (greenish) grey, golden brown, or brown to black, solitary to scattered to gregarious, superficial or immersed to semi-immersed, subglobose to obpyriform, globose, ellipsoidal, ovoid to pyriform, cylindrical, covered with hairs, setae or glabrous, hairs may be simple or branched and of one or two types, ostiolate or lacking ostioles. Peridium with thick walls, comprising several layers of hyaline or brown cells of textura epidermoidea to textura intricata. Paraphyses absent or greatly reduced, if present septate, hyaline. Asci 4- or 8-spored, unitunicate, clavate, cylindrical, obovate or ellipsoidal, pedicellate, without apical structures or with an indistinct thickened ring, evanescent, with wall dissolving at maturity. Ascospores irregularly arranged, at first colourless and dextrinoid (translucent, greenish, dark), brown to black, opaque when mature, ellipsoidal, globose, subglobose, oval, fusiform or triangular, with single or sometimes two germ pores, aseptate, with thick, smooth walls. Asexual morph: Hyphomycetous. Conidiophores absent or when present simple, hyaline, branched, septate, smooth-walled or slightly rough. Conidiogenous cells phialidic or blastic, verticillate or solitary, hyaline, consisting of a lageniform or ellipsoid swollen basal portion, cylindrical. Conidia dimorphic, first type holoblastic, hyaline to brown, smooth, globose- 
a
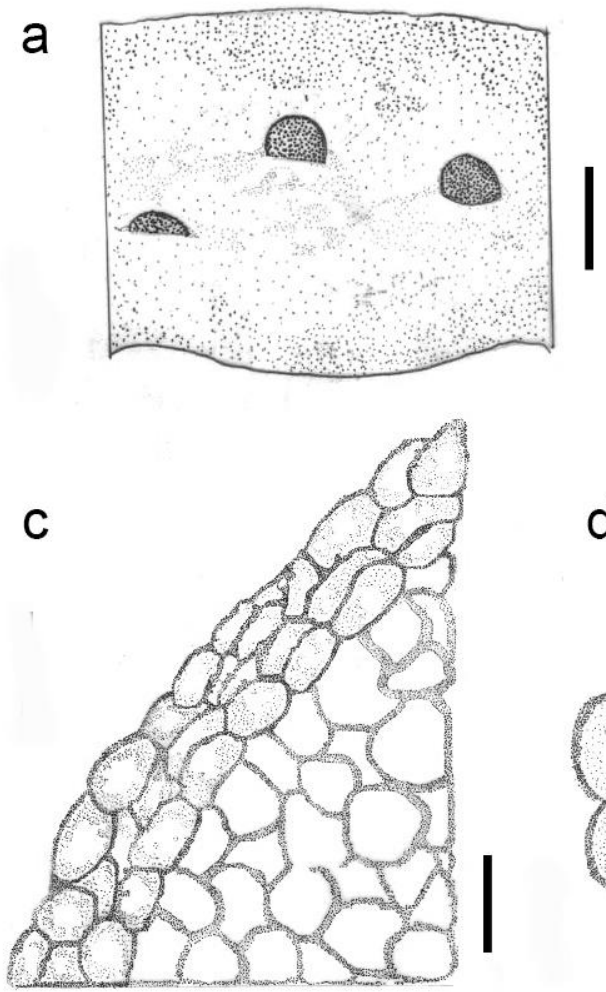

b

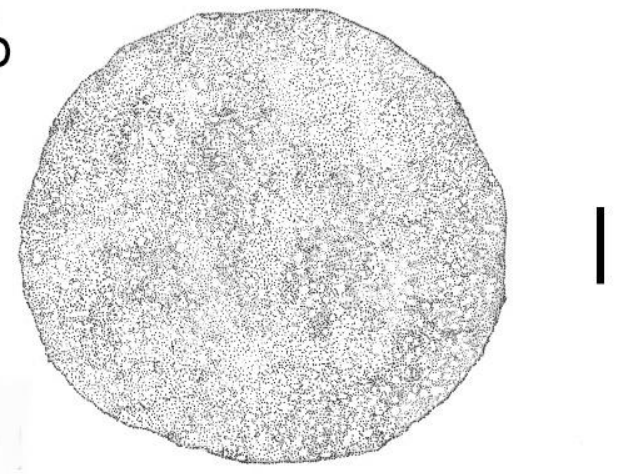

d

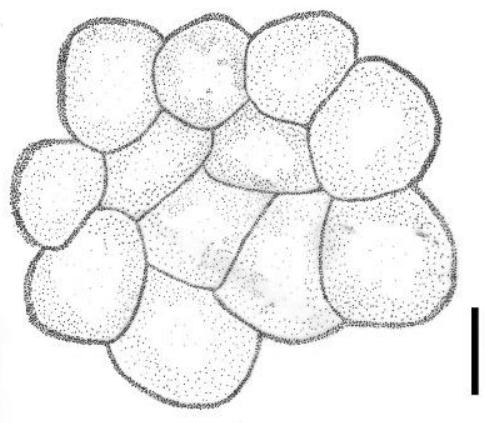

e

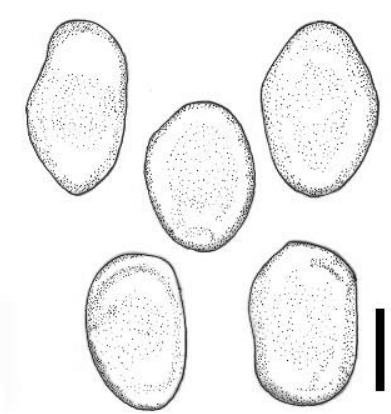

Figure 63 - Faurelina fimigena (redrawn from Melo et al. 2016). a Fruiting bodies on habit. b Closed cleistothecium. c External superficial layer of peridium. $d$ Cells of the inner layer of the peridium. e Mature ascospores. Scale bars: $\mathrm{a}=500 \mu \mathrm{m}, \mathrm{b}=30 \mu \mathrm{m}, \mathrm{c}=10 \mu \mathrm{m}, \mathrm{d}=5 \mu \mathrm{m}, \mathrm{e}=2 \mu \mathrm{m}$.

-to obclavate, 1-celled, formed on hyphae or cylindrical conidiogenous cells, single or racemose, clusters; second type produced from phialides, hyaline to brown, lutescent, or dark brown, subglobose to globose or ellipsoidal, occasionally cylindrical, pyriform or fusiform, formed singly or in chains, 1-celled, with thick, smooth wall (adapted from Maharachchimbura et al. 2016b).

Type genus - Chaetomium Kunze

Notes - Chaetomiaceae was introduced by Winter (1885a) as "Chaetomieae". It belongs to Sordariales (Hawksworth \& Wells 1973, Mehrotra \& Aneja 1990, Huhndorf et al. 2004b, Kirk et al. 2008, Lumbsch \& Huhndorf 2010, Maharachchikumbura et al. 2015, 2016b, Hongsanan et al. 2017). A key for 20 genera of Chaetomiaceae was provided by Maharachchikumbura et al. (2016b). Based on the phylogenetic analyses of $r p b 2, t u b 2$, ITS and LSU gene regions, Wang et al. (2016a) introduced five new genera: Amesia, Arcopilus, Collariella, Dichotomopilus and Ovatospora in Chaetomiaceae. In a recent paper, Wijayawardene et al. (2018a) listed 26 genera as belonging to this family. A new genus, Arxotrichum, was introduced by Crous et al. (2018d) for a strain of Chaetomium succineum and a new isolate of Arxotrichum yomingense. Based on the results of $r p b 2$ and a combined $r p b 2, t u b 2$, ITS and LSU dataset, Mycothermus was validated as a new genus and the taxonomic status of Remersonia was determined in Chaetomiaceae by Wang et al. (2019b).

\section{Ecological and economic significance of Chaetomiaceae}

Species of Chaetomiaceae are important pathogens of humans and animals (Ahmed et al. 2016, Plumlee et al. 2017, Jeragh et al. 2018, Pote et al. 2018, Wang et al. 2019b). They cause serious opportunistic infections in immunocompromised patients, and cause equine mycotic encephalitis (Ahmed et al. 2016, Plumlee et al. 2017). Species of Chaetomiaceae have been shown to have high potential for use in biological control and production of bioactive secondary 
metabolites (Soytong et al. 2001, Khumkomkhet et al. 2009, Sibounnavong et al. 2012, Wang et al. 2012, Li et al. 2014).

\section{Genera included in Chaetomiaceae}

Achaetomium J.N. Rai, J.P. Tewari \& Mukerji, Can. J. Bot. 42(6): 693 (1964)

Index Fungorum number: IF38; 14 morphological species (Species Fungorum 2020), 5 species with sequence data.

Type species - Achaetomium globosum J.N. Rai \& J.P. Tewari

Notes - Achaetomium was established by Rai et al. (1964) to accommodate A. globosum, A. luteum and A. strumarium and placed in Achaetomiaceae (Achaetomiales), however, the family was invalidly published. Achaetomiaceae was validated by Mukerji (1978). Cannon (1986) accepted only A. globosum in Achaetomium, and suggested that Achaetomium might have been derived from Sordariaceae. von Arx et al. (1988) disagreed with and accepted the species in Achaetomiaceae, while Lee et al. (1999) recommended that Achaetomium should be placed in Chaetomiaceae based on molecular data. Based on the analyses of the LSU gene, Rodríguez et al. (2004) showed Achaetomium sharing a common ancestor with Chaetomium within Chaetomiaceae. Later studies (Maharachchikumbura et al. 2015, 2016b, Wang et al. 2016a, 2019b, Wijayawardene et al. 2018a) showed that Achaetomium is an independent genus in Chaetomiaceae. Achaetomium is characterized by globose to pyriform, ostiolate ascomata covered with yellowish hypha-like hairs, with a relatively thick peridium consisting of cells of textura intricata, cylindrical asci and dark brown ascospores that are opaque with an apical germ pore and colonies usually showing a reddishbrown exudate (Rodriguez et al. 2004).

Acrophialophora Edward, Mycologia 51(6): 784 (1961)

Index Fungorum number: IF7037; 18 morphological species (Species Fungorum 2020), 7 species with sequence data.

Type species - Acrophialophora nainiana Edward

Notes - Acrophialophora was reintroduced by Samson \& Mahmood (1970) as a thermotolerant genus with A. fusispora, A. levis and A. nainiana. Based on combined analysis of ITS, SSU and tub2 sequence data, Zhang et al. (2015a) showed that Acrophialophora is a monophyletic genus in Chaetomiaceae and they synonymized Taifanglania under Acrophialophora. The genus is characterised by conidiophores that are absent or unbranched or sparingly branched conidiogenous cells that are monophialidic or polyphialidic with two necks, flask-shaped or in whorls in verticillate species. Conidia are unicellular, subglobose, elliptical to fusiform, echinulate, with spiral bands or smooth, in basipetal chains or slimy heads and with schizolytic secession (Zhang et al. 2015a). The sexual morphs are undetermined.

Allobotryotrichum Raza M., Z.F. Zhang, K.D. Hyde, Y.Z. Diao \& L. Cai, Fungal Divers. 99: 74 (2019)

Index Fungorum number: IF556672; 1 species with sequence data.

Type species - Allobotryotrichum blastospora M. Raza \& L. Cai

Notes - Allobotryotrichum was introduced by Raza et al. (2019) based on phylogenetic analysis of Botryotrichum and its sterile setae and conidia being different from that of Myceliophthora and Thielavia. This genus is characterized by hyaline to pale brown or brown, erect or flexuous, sterile setae, holoblastic, cylindrical or broadly irregular conidiogenous cells and globose to subglobose conidia produced on aerial hyphae.

Amesia X. Wei Wang, Samson \& Crous, Stud. Mycol. 84: 156 (2016)

Index Fungorum number: IF818829; 4 species with sequence data.

Type species - Amesia atrobrunnea (L.M. Ames) X. Wei Wang \& Samson

Notes - Amesia was introduced by Wang et al. (2016a) to accommodate A. atrobrunnea, A. cymbiformis, A. gelasinospora and A. nigricolor, which were transferred from Chaetomium. The 
genus is characterised by superficial, sphaerical, ellipsoid or ovate, ostiolate ascomata, with apically flexuous, spirally coiled or undulate hairs. Asci are broadly clavate and evanescent and ascospores are brown, mostly fusiform, often ovate to elongate ovate, with an apical or subapical germ pore (Wang et al. 2016a).

Arcopilus X. Wei Wang, Samson \& Crous, Stud. Mycol. 84: 159 (2016)

Index Fungorum number: IF818835; 7 species with sequence data.

Type species - Arcopilus aureus (Chivers) X. Wei Wang \& Samson

Notes - Arcopilus was established by Wang et al. (2016a) to accommodate A. aureus, A. cupreus, A. flavigenus, A. fusiformis and A. turgidopilosus, which were transferred from Chaetomium. Based on the unique phylogenetic and morphologic analyses, Raza et al. (2019) introduced A. globulus and A. tangerinicapillus, which were isolated from Saccharum officinarum. The genus is characterised by superficial, subglobose to ovate, ostiolate ascomata, with hairs at apical region which are arcuate, with apices incurved, circinate to coiled, at lateral sides flexuous or apically incurved. Asci are clavate and evanescent and ascospores brown, inequilateral, fusiform, navicular, reniform, lunate or limoniform with one or two apical germ pores.

Arxotrichum A. Nováková \& M. Kolařík, Persoonia 40: 259 (2018)

Index Fungorum number: IF824080; 2 species with sequence data.

Type species - Arxotrichum wyomingense A. Nováková \& M. Kolařík

Notes - Arxotrichum was established by Crous et al. (2018d) for A. wyomingense which was isolated from soil, based on the analysis of LSU sequence data. Ascomata if present are pale ochraceous to olivaceous grey, superficial, sphaerical to ovate and ostiolate with numerous flexuous, undulate or spirally coiled, verrucose to echinulate, septate, pale ochraceous or brown hairs. Asci are obovate-clavate and evanescent with short pedicels and ascospores are ellipsoidalfusoid to brown, with distinct apical germ pores. The asexual morph has septate conidiophores with basal yellowish brown and apically colourless, ramified, racemose branched stipes and solitary, aseptate, subglobose conidia that are rough-walled to rugose (Crous et al. 2018d).

Botryotrichum Sacc. \& Marchal, Bull. Soc. R. Bot. Belg. 24(1): 66 (1885)

Index Fungorum number: IF7431; 11 morphological species, 4 species with sequence data.

Type species - Botryotrichum piluliferum Sacc. \& Marchal

Notes - Botryotrichum has rarely been reported (Kirk et al. 2008, Wijayawardene et al. 2018a). Based on the phylogenetic analyses of ITS, LSU, rpb2 and $t u b 2$ gene regions, Wang et al. (2016a) re-organized the genus and included some species of the genera Emilmuelleria and Chaetomium. The genus is characterised by superficial, subglobose to ovate, olivaceous, ostiolate or ascomata lacking ostioles, with flexuous or undulate, often circinate, unbranched, lateral setalike hairs, fusiform, long pedicellate, evanescent asci and fasciculate, olivaceous brown, ellipsoidalfusiform ascospores, with an apical germ pore. Conidiophores are setose, terminating in setae, branched, macronematous with clusters of thick-walled conidia that have a conspicuous germ pore (Wang et al. 2016a, 2019b).

Chaetomium Kunze, Mykologische Hefte (Leipzig) 1: 15 (1817)

Index Fungorum number: IF953; 211 morphological species (Species Fungorum 2020), 106 species with sequence data.

Type species - Chaetomium globosum Kunze.

Notes - Chaetomium is the largest genus in Chaetomiaceae. The genus was reviewed by Maharachchikumbura et al. (2016b) and Wang et al. (2016a, b, 2019b). The genera Bommerella, Chaetomidium and Chaetomiopsis were proposed as synonyms of Chaetomium (Moustafa \& Abdul-Wahid 1990, Doveri 2008a, Wang et al. 2016a, b, 2019b). Chaetomium contains more than 150 species (Wijayawardene et al. 2017a); they grow on soil and decaying twigs (Wang et al. 2016a, b, Zhang et al. 2017b). Wang et al. (2016a, b, 2019b) described novel Chaetomiaceae taxa 
collected from indoor environments, which were described as new species. Many new species, collected from soil, were published by (Zhang et al. 2017b). The genus is characterised by globose, ellipsoid to ovate or obovate, ostiolate ascomata with or lacking ostioles, hypha-like, flexuous, undulate, coiled to simply or dichotomously branched ascomatal hairs, clavate or fusiform, evanescent asci, and limoniform to globose, bilaterally flattened ascospores. Asexual morphs, if produced, are acremonium-like (Wang et al. 2016a).

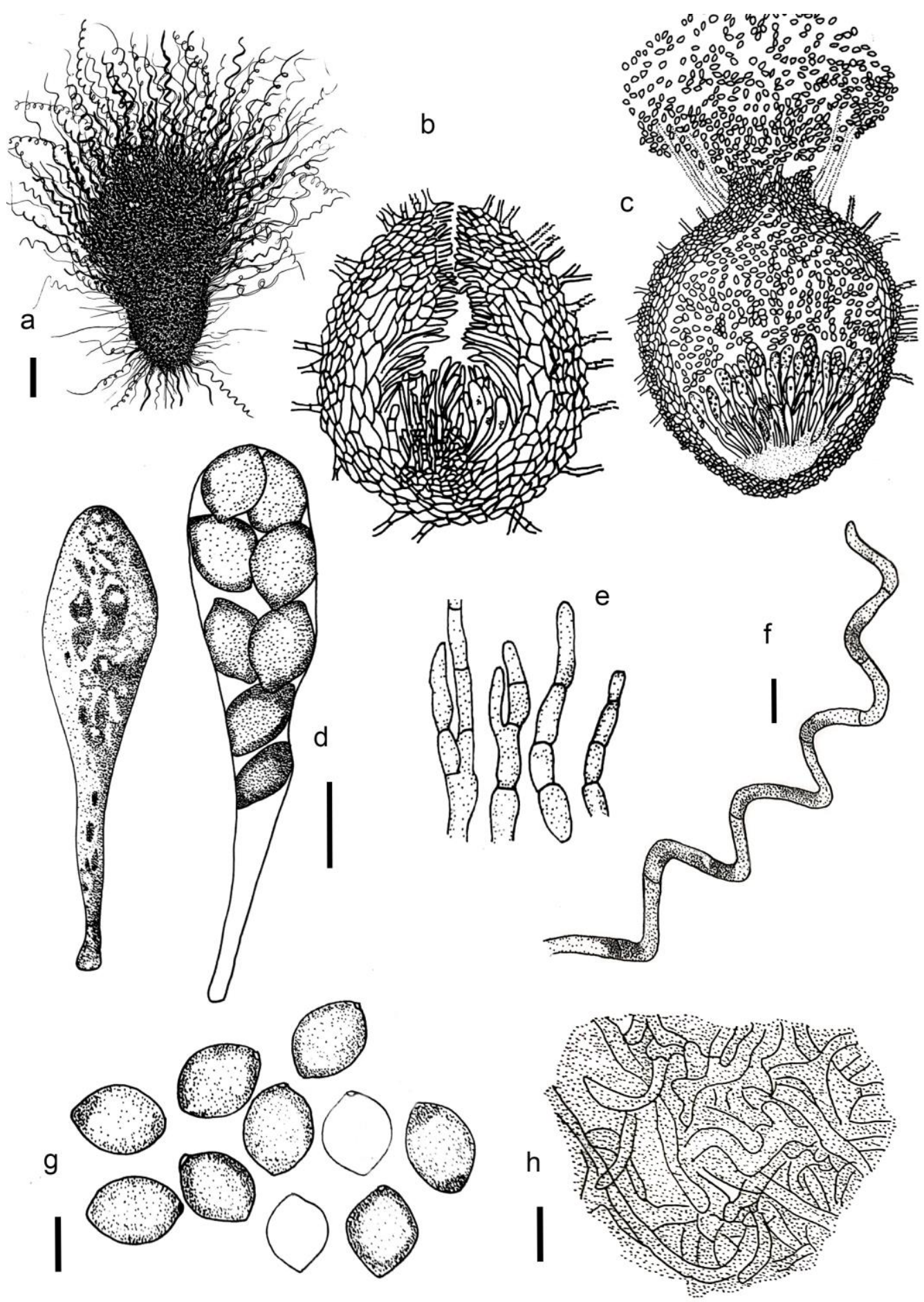

Figure 64 - Chaetomium globosum (a, d, f-h redrawn from Wang 2016b and (https://www.canada.ca/content/dam/eccc/documents/pdf/pded/chaetomium-globosum/2018-02-20C.\%20Globosum-EN.pdf), b, c, e redrawn from Whiteside 1961). a Ascoma. b, c Sections of ascomata. d Asci. e Paraphyses. f Ascomal hair. g Ascospores. h Peridium. Scale bars: $\mathrm{a}=100 \mu \mathrm{m}$, $\mathrm{d}, \mathrm{h}=10 \mu \mathrm{m}, \mathrm{f}, \mathrm{g}=5 \mu \mathrm{m}, \mathrm{b}=\times 240, \mathrm{c}=\times 300, \mathrm{e}=\times 1000$. 


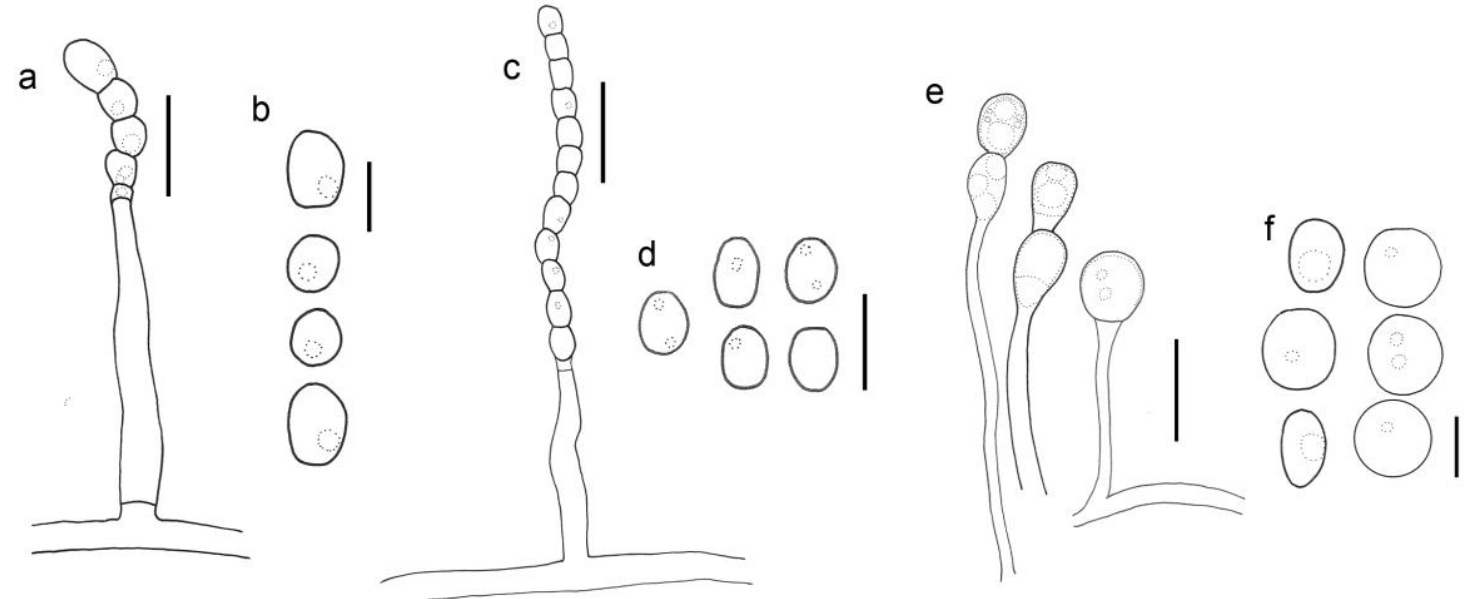

Figure 65 - Asexual morph of Chaetomium spp. (redrawn from Wang et al. 2016b). a, b Chaetomium subaffine. c, d C. rectangulare. e, f C. elatum. a, c, e Conidiophores with conidia. b, d, f Conidia. Scale bars: a, c, e $=10 \mu \mathrm{m}, \mathrm{b}, \mathrm{d}, \mathrm{f}=5 \mu \mathrm{m}$.

Collariella X. Wei Wang, Samson \& Crous, Stud. Mycol. 84: 177 (2016)

Index Fungorum number: IF818839; 9 species with sequence data.

Type species - Collariella bostrychodes (Zopf) X. Wei Wang \& Samson

Notes - Based on both phylogenetic and morphological analyses, Collariella was established by Wang et al. (2016b) to accommodate one new species and six species transferred from Chaetomium. The genus is characterised by superficial, ovate, obovate, subglobose, ampulliform or cylindrical, ostiolate ascomata, fusiform or clavate, pedicellate, evanescent asci and fasciculate olivaceous brown, broadly limoniform to quadrangular, bilaterally flattened ascospores, with one or two apical or subapical germ pores and no known asexual morphs (Wang et al. 2016a).

Corynascella Arx \& Hodges, Stud. Mycol. 8: 23 (1975)

Index Fungorum number: IF1256; 3 morphological species (Species Fungorum 2020), 2 species with sequence data.

Type species - Corynascella humicola Arx \& Hodges.

Notes - Corynascella was introduced by von Arx (1975) to accommodate the single species C. humicola, in which the ascospores have strikingly thickened walls around the germ pores. This genus was shown to cluster in a separate branch in phylogenetic analysis (van den Brink et al. 2012, Maharachchikumbura et al. 2015, Wang et al. 2016a, 2019b). The genus is characterised by superficial, sphaerical, cleistothecial ascomata, covered with dark, septate, appendage-like hairs, broadly clavate or obovate, thin-walled, evanescent asci and ellipsoidal, sphaerical or reniform, 1celled ascospores, rounded at the ends and with a large de Bary bubble, and 2(-4) apical germ pores (von Arx 1975).

Crassicarpon Y. Marín, Stchigel, Guarro \& Cano, Mycologia 107(3): 629 (2015)

Index Fungorum number: IF809487; 2 species with sequence data. Cano

Type species - Crassicarpon thermophilum (Fergus \& Sinden) Y. Marín, Stchigel, Guarro \&

Notes - Crassicarpon is characterized by a thermophilic habit, blackish ascomata with a thick wall of textura angularis, broadly clavate asci with 4-6 ascospores, broadly ellipsoidal ascospores with a germ pore at each end, and hyaline, smooth-walled conidia, yellow in mass.

Dichotomopilus X. Wei Wang, Samson \& Crous, Stud. Mycol. 84: 185 (2016)

Index Fungorum number: IF818840; 12 species with sequence data.

Type species - Dichotomopilus indicus (Corda) X. Wei Wang \& Samson. 

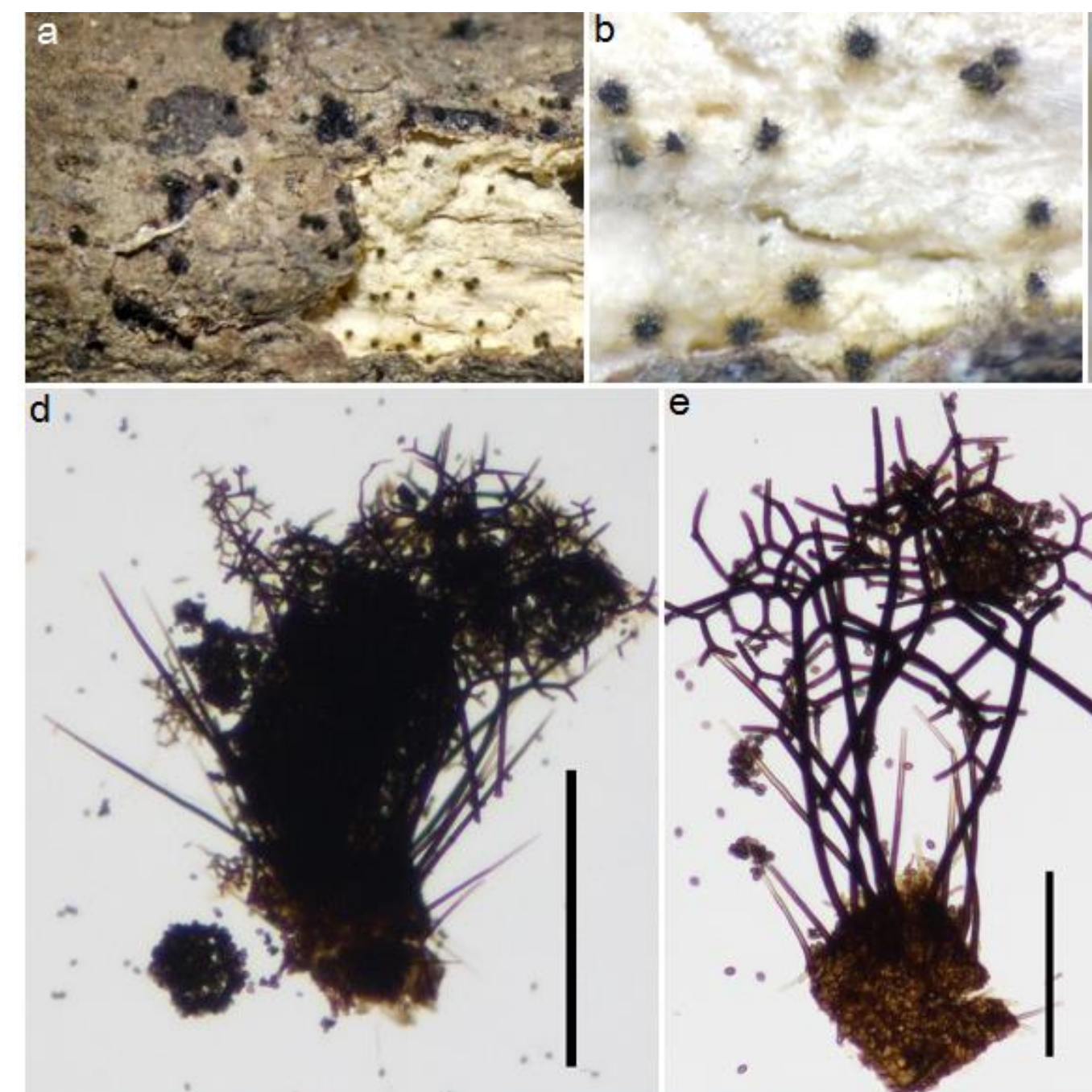

e
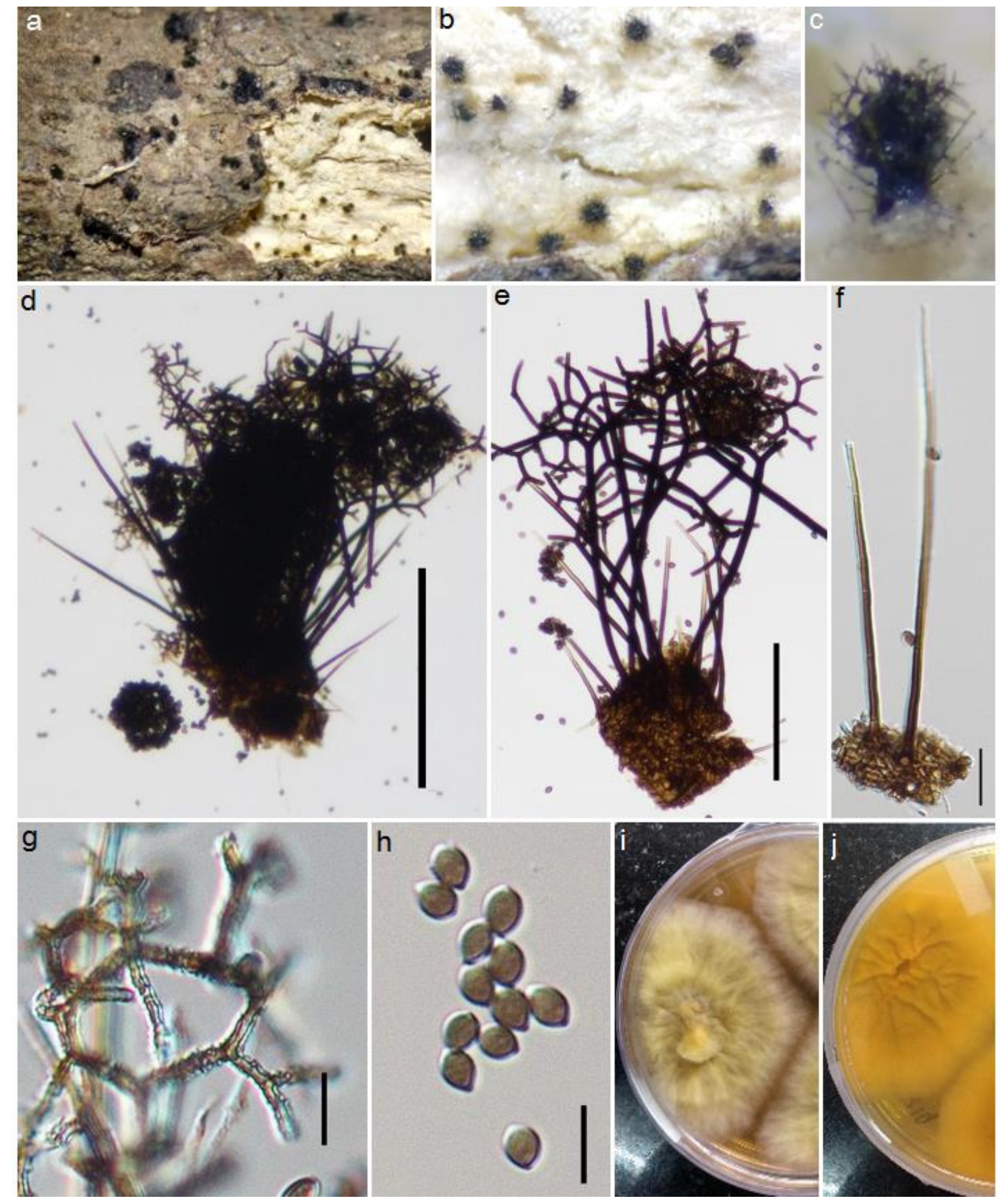

Figure 66 - Dichotomopilus ramosissimus (Material examined - INDIA, Andaman and Nicobar Islands, North Andaman, Diglipur, Near Sita Nagar (13¹1'14.2" N 92 53'11" E), isolated on decaying twig of Dolichandrone spathacea, 17 May 2018, M. Niranjan \& V.V. Sarma, PUFNI 18725, (AMH-10059). a-c Ascomata on host. d, e Mature ascomata in lactophenol mount. f, g Terminal ascomatal hair. h Ascospores. i-j Colonies on malt extract agar. Scale bars: $d=200 \mu \mathrm{m}$, e $=100 \mu \mathrm{m}, \mathrm{f}=20 \mu \mathrm{m}, \mathrm{g}, \mathrm{h}=10 \mu \mathrm{m}$.

Notes - The genus Dichotomopilus was established by Wang et al. (2016a) to include two new species, D. pseudofunicla and D. pseudoerectus, and another ten species transferred from Chaetomium. A new collection of D. ramosissimum was recorded on Clematis vitalba in the UK by 
Phukhamsakda et al. (2020). The genus is characterised by superficial, sphaerical, ellipsoid or ovate, ostiolate ascomata, with seta-like, branched, often ornamented terminal hairs, unbranched, seta-like lateral hairs tapering towards the apex, clavate to ovate, pedicellate, evanescent asci and fasciculate brown, ovate, bilaterally flattened ascospores attenuated at one or both ends and with apical or slightly subapical germ pores. Asexual morphs are undetermined. Dichotomopilus ramosissimus is illustrated in this entry (Fig. 66).

Guanomyces M.C. González, Hanlin \& Ulloa, Mycologia 92(6): 1139 (2000)

Index Fungorum number: IF28466; 1 species with sequence data.

Type species - Guanomyces polythrix M.C. González, Hanlin \& Ulloa

Notes - Based on morphology and phylogenetic analysis of LSU sequences, Guanomyces was described in Sordariales by González et al. (2000) to accommodate species which were isolated from bat dung. Stchigel et al. (2006) reported that Guanomyces was in Chaetomiaceae (Sordariales). The following studies were concerned with secondary metabolites of Guanomyces polythrix, with the taxonomic status rarely mentioned (Macías et al. 2000, 2001, Mata et al. 2003). The genus is characterised by sexual morph with ascomata that are superficial, ovoidal, ostiolate, with long neck, composed of glandular hairs, asci that are clavate, deliquescent, J- and ascospores that are ellipsoidal, unicellular, multinucleate and hyaline, not appendaged and without germ pores or slits. Asexual morphs have chlamydospores that are sphaerical or obovate and dark brown.

Humicola Traaen, Nytt Mag. Natur. 52: 31 (1914)

Index Fungorum number: IF8566; 72 morphological species (Species Fungorum 2020), 24 species with sequence data.

Type species - Humicola fuscoatra Traaen.

Notes - Humicola was introduced by Traaen (1914) to accommodate two species, $H$. fuscoatra and $H$. grisea. A comprehensive study by Wang et al. (2019b) revised the phylogenetic status of the genus. The genus is characterised sexual morphs with superficial, ostiolate ascomata covered by aerial hyphae. Terminal hairs are seta-like, flexuous, undulate, coiled or arcuate with apices incurved to coiled. Asci are clavate, early evanescent and ascospores are limoniform to quadrangular, bilaterally flattened, with an apical germ pore. Asexual morphs producing conidia arise laterally, intercalary or terminally from hyphae without differentiated conidiophores, sometimes together with acremonium-like conidiophores, occasionally only acremonium-like conidiophores are produced.

Madurella Brumpt, Compt.-Rend. Séances Mém. Soc. Biol. 58: 999 (1905)

Index Fungorum number: IF8824; 15 morphological species (Species Fungorum 2020), 3 species with sequence data.

Type species - Madurella mycetomatis (Laveran) Brumpt

Notes - Madurella was introduced by Brumpt (1905) to accommodate the species Streptothrix mycetomatis. Madurella species are the causative agents of mycetoma of human's worldwide (Findlay et al. 1979, Mukerji \& Manoharachary 2010, de Hoog et al. 2012, Bolis et al. 2018, Norina et al. 2018, Mekoguem et al. 2019). The genus is characterised by asexual morphs with slow growing, white to brown colonies, hyphae producing chlamydospores, and conidiophores and conidia have not been observed (Seifert et al. 2011).

Melanocarpus Arx, Stud. Mycol. 8: 17 (1975)

Index Fungorum number: IF3063; 5 morphological species (Species Fungorum 2020), 4 species with sequence data.

Type species - Melanocarpus albomyces (Cooney \& R. Emers.) von Arx

Notes - Based on previous studies and phylogenetic analyses of combined rpb2, tub2, ITS and LSU sequence datasets, Wang et al. (2016a, 2019b) consolidated its placement in Chaetomiaceae (Maharachchikumbura et al. 2015, 2016b, Wijayawardene et al. 2018a). The genus 
is characterised by ascomata that are superficial, or enclosed within white aerial mycelium, often aggregated, globose, black, glabrous or with a few hypha-like hyaline hairs, lacking ostioles; asci that are fasciculate, ovate to broadly ovate, pedicellate, early evanescent; ascospores that are brown at maturity, ovate to broadly ovate, bilaterally flattened, with an apical pore; and asexual morphs undetermined.

Myceliophthora Costantin, C. r. hebd. Séanc. Acad. Sci., Paris 114: 849 (1892)

Index Fungorum number: IF9013; 5 morphological species (Species Fungorum 2020), 3 species with sequence data.

Type species - Myceliophthora lutea Costantin

Notes - Based on the phylogenetic analyses of sequences from ITS, tefl and rpb2, MarinFelix et al. (2015) split Myceliophthora into four genera: Corynascus (a revalidated genus), Crassicarpon, Myceliophthora and Thermothelomyces. However, according to the molecular analyses, Corynascus was linked with Myceliophthora and all Corynascus species are proposed to be placed under Myceliophthora (van den Brink et al. 2012, Maharachchikumbura et al. 2015, 2016b, Wijayawardene et al. 2018a). Wang et al. (2016a, 2019b) hinted that all three genera be included under Myceliophthora. The genus is characterised by hyaline and smooth-walled conidia and sexual morph is undetermined.

Mycothermus D.O. Natvig, J.W. Taylor, A. Tsang, M.I. Hutch. \& A.J. Powell, Stud. Mycol. 93: 107 (2018)

Index Fungorum number: IF807381; 2 species with sequence data.

Type species - Mycothermus thermophilus (Cooney \& R. Emers.) X. Wei Wang, Houbraken \& D.O. Natvig

Notes - Mycothermus was published by Natvig et al. (2015) but as an invalid genus. The genus was validated by Wang et al. (2019b) based on multi-gene phylogenetic analyses with rpb2, tub2, ITS and LSU. The genus is characterised by its thermophilic habit, hyaline to subhyaline hyphae, holothallic chlamydospores that are thick-walled, brown, smooth to verrucose and doliiform, globose, subglobose, oblong or obovoid. The sexual morphs are undetermined.

Ovatospora X. Wei Wang, Samson \& Crous, Stud. Mycol. 84: 185 (2016)

Index Fungorum number: IF818850; 6 species with sequence data.

Type species - Ovatospora brasiliensis X. Wei Wang \& Samson

Notes - Ovatospora was introduced by Wang et al. (2016a) to accommodate $O$. brasiliensis, $O$. medusarum, O. mollicella, O. pseudomollicella, O. senegalensis, and $O$. unipora. The genus is characterised by superficial, subglobose or ovate ascomata, ostiolate, with brown walls of cells of textura angularis. Terminal hairs are usually coiled and often branched and lateral hairs are flexuous. Asci are fasciculate, cylindrical or clavate and evanescent and ascospores are brown at maturity, broadly ovate, bilaterally flattened, rounded at one end, attenuate or apiculate at other end and have an apical germ pore. No asexual morphs are known (Wang et al. 2016a).

Remersonia Samson \& Seifert, Can. J. Bot. 75(7): 1160 (1997)

Index Fungorum number: IF27809; 2 morphological species (Species Fungorum 2020), 1 species with sequence data.

Type species - Remersonia thermophila (Fergus) Seifert \& Samson

Notes - Remersonia was introduced by Seifert et al. (1997) for the thermophilic synnematous hyphomycete Stilbella thermophila. Based on previous studies and phylogenetic analyses, Wang et al. (2019b) confirmed the placement of Remersonia as a monotypic genus in Chaetomiaceae. The genus is characterised by synnemata that are cylindrical to clavate, capitate, unbranched and hyaline. Conidiophores are unbranched or simply branched, have percurrently proliferating conidiogenous cells and conidia are hyaline, oblong, clavate or ellipsoidal with truncate or rounded bases (Seifert et al. 1997). The sexual morph is undetermined. 
Staphylotrichum J. Mey. \& Nicot, Bull. trimest. Soc. mycol. Fr. 72: 322 (1957)

Index Fungorum number: IF10065; 9 morphological species (Species Fungorum 2020), 7 species with sequence data.

Type species - Staphylotrichum coccosporum J.A. Mey. \& Nicot

Notes - Staphylotrichum was introduced by Nicot \& Meyer (1956) to accommodate $S$. coccosporum. Phylogenetic analyses of ITS and LSU sequence data in Nonaka et al. (2012) reported the placement of Staphylotrichum in Chaetomiaceae. Wang et al. (2019b) confirmed this placement in this family based on analysis of combined $r p b 2$, tub2, ITS and LSU datasets for eight isolates. The genus is characterised by ascomata that are superficial with long necks comprised of a fused basal part of terminal hairs. Asci are 8-spored, clavate to fusiform and ascospores are broad limoniform to globose, with an apical germ pore. The asexual morphs have two types of conidiophores, micronematous that arise from hyphae and macronematous from apically branched, seta-like conidiophores. Conidia are thick-walled, holoblastic, hyaline to pale brown and globose to subglobose or obovoid (Wang et al. 2019b).

Subramaniula Arx, Proc. Indian Acad. Sci., Pl. Sci. 94(2-3): 344 (1985)

Index Fungorum number: IF25699; 9 morphological species (Species Fungorum 2020), 8 species with sequence data.

Type species - Subramaniula thielavioides (Arx, Mukerji \& N. Singh) Arx

Notes - Subramaniula was introduced by von Arx (1985) to accommodate Achaetomium thielavioides. The study of Ahmed et al. (2016) indicated a relationship of Subramaniula within Chaetomiaceae. Phylogenetic analyses of Wang et al. (2016a) confirmed the placement and expanded the number of species. The genus is characterised by ascomata that are globose and glabrous without necks, with translucent walls and a wide ostiole surrounded by a hyaline collar. Asci are clavate, short pedicellate, very thin-walled, evanescent and ascospores are widely fusiform, brownish, thick-walled and 1-celled, with a conspicuous subapical germ pore (von Arx et al. 1978, Wang et al. 2016a). The asexual morph in undetermined.

Thermothelomyces Y. Marín, Stchigel, Guarro \& Cano, Mycologia 107(3): 630 (2015)

Index Fungorum number: IF809489; 4 species with sequence data.

Type species - Thermothelomyces thermophilus (Apinis) Y. Marín, Stchigel, Guarro \& Cano

Notes - Thermothelomyces was introduced by Marin-Felix et al. (2015) and includes four species. Phylogenetic analyses of combined ITS, tef1 and rpb2 datasets showed that Thermothelomyces belongs in Chaetomiaceae (Marin-Felix et al. 2015). The genus is characterised by a thermophilic habit, ascomata that are immersed or semi-immersed, globose, cleistothecial, black, glabrous, with a wall of textura epidermoidea. Asci are ellipsoidal, thin-walled, pedicellate, and evanescent and ascospores are ellipsoidal, dark brown to black at maturity, thick- and smoothwalled, with a single germ pore. In the asexual morph, conidiophores are micronematous or semimacronematous and conidia are holoblastic, brown, subglobose or obovoid to ellipsoidal, ornamented or rarely smooth.

Thielavia Zopf, Verh. bot. Ver. Prov. Brandenb. 18: 101 (1876)

Index Fungorum number: IF5450; 44 morphological species (Species Fungorum 2020), 23 species with sequence data.

Type species - Thielavia basicola Zopf

Notes - Thielavia was introduced by Zopf (1876) to accommodate a species isolated from the roots of Senecio elegans and lupins. Revisions of the genus have been proposed by numerous investigators (Booth 1961, Malloch \& Cain 1973, Mouchacca 1973, von Arx 1975, Figueras \& Guarro 1988, Stchigel et al. 2002). Wang et al. (2016a, 2019b) confirmed Thielavia as a monotypic genus in Chaetomiaceae. The genus is characterised by ascomata lacking ostioles and ascospores that are unicellular, darkly pigmented with one or two germ pores. The asexual morph has conidia 
are hyaline or brightly coloured and produced as simple phialoconidia, aleurioconidia, or arthroconidia.

Trichocladium Harz, Bull. Soc. Imp. nat. Moscou 44(1): 125 (1871)

Index Fungorum number: IF10278; 38 morphological species (Species Fungorum 2020), 10 species with sequence data.

Type species - Trichocladium asperum Harz

Notes - Trichocladium was introduced by Harz (1871). A review of Trichocladium was undertaken by Goh \& Hyde (1999) who accepted 18 species. Trichocladium species are polyphyletic within Chaetomiaceae, and other families (Shearer \& Crane 1971, Kirk et al. 2008, Seifert et al. 2011, Jones et al. 2015). Based on the analyses of rpb2 and a combined rpb2, tub2, ITS and LSU datasets, 22 strains of Trichocladium formed a lineage, which includes four closely related subclades in Chaetomiaceae and they show morphologically diverse characters, and are phylogenetically distinct. The asexual morphs have conidiophores that are hyaline, developed laterally or terminally from the hyphae, and cylindrical, unbranched or branched, sometimes verticillate. Conidia are 1- to 2-celled, rarely 3-celled, obovate, pyriform, ellipsoid, constricted at the septa, conspicuously warted and olivaceous brown to dark brown, with paler basal cells. The sexual morph of Trichocladium is characterized by superficial or immersed ascomata in a thick mycelium, with or lacking ostioles. Asci are typically cylindrical, evanescent, with 8 (4) uniseriate ascospores which are typically broadly ovate, bilaterally flattened, sometimes ellipsoidal and nonflattened, with an apical germ pore (Wang et al. 2019b).

Chaetosphaerellaceae Huhndorf, A.N. Mill. \& F.A. Fernández, Mycol. Res. 108(12): 1387 (2004) Index Fungorum number: IF82145; Facesoffungi number: FoF01114; 6 species.

Saprobic on woody substrates in terrestrial habitats. Sexual morph: Ascomata perithecial, dark brown to black, scattered to densely gregarious, superficial, sitting in a subiculum or subiculum absent, pyriform, obpyriform or ovoid, turbinate, coriaceous, tuberculate or smooth, with or without, brown, branched or unbranched setae, papillate or papilla lacking, collabent or not collapsing, ostiolate. Subiculum abundant or sparse, sometimes lacking, brown to dark brown, consisting of septate, branched or unbranched with spiny hyphae. Peridium with Munk pores, outer layer composed of dark brown to brown cells of textura angularis; inner layer composed of hyaline cells of textura prismatica. Paraphyses inflated, often present only in young ascomata. Asci 8spored, unitunicate, clavate, long or short pedicellate, apical ring distinct, indistinct or absent, evanescent. Ascospores 1-3-seriate or overlapping, with brown or brown median cells and hyaline end cells, oblong cylindrical, ellipsoid or fusiform, 1-3-septate. Asexual morph Conidiophores macronematous, mononematous, erect, straight, solitary or divaricate with 2-4 metulae, brown, septate, branched, percurrent, with a terminal, ampulla. Conidiogenous cells holoblastic or enteroblastic, integrated, terminal. Conidia hyaline to dark brown, oval or elliptical, solitary or catenate (adapted from Maharachchikumbura et al. 2016b).

Type genus - Chaetosphaerella E. Müll. \& C. Booth.

Notes - Chaetosphaerellaceae, typified by Chaetosphaerella (Müller \& Booth 1972), was introduced by Huhndorf et al. (2004a) for fungi with superficial, ostiolate ascomata siting on a subiculum, clavate or cylindrical asci, with pigmented ellipsoid ascospores, and enteroblastic or holoblastic conidiogenesis. In a taxonomic re-evaluation of Chaetosphaeria species, Réblová (1999a, b, c, d) accepted Chaetosphaerella phaeostroma and C. fusca in the genus and placed them in the Helminthosphaeriaceae based on peridium anatomy, setae, ascal anatomy, absence of Quellkörper and conidiogenesis. Chaetosphaerella fusispora Sivanesan was excluded from the genus and transferred to Crassochaeta based on difference in ascus, hamathecium and ascospore anatomy by Réblová (1999b). Chaetosphaerella is associated with asexual morphs formerly referred to Oedemium and Veramycina. Réblová (1999a) discussed relationships of Chaetosphaerella with Nitschkiaceae based on the peridium. A phylogeny based on LSU rDNA sequence data showed that Chaetosphaerella and Crassochaeta clustered in the same clade, for 
which Chaetosphaerellaceae was described (Huhndorf et al. 2004a). Mugambi \& Huhndorf (2010) referred Spinulosphaeria to Sordariomycetes genera incertae sedis, based on morphology and analysis of LSU sequence data of $S$. nuda. In a combined LSU, SSU, tef1 and rpb2 dataset, S. nuda formed a sister group to Chaetosphaerella species with high support in Chaetosphaerellaceae (Mugambi \& Huhndorf 2010, Maharachchikumbura et al. 2015, 2016b). Réblová et al. (2016b) proposed Chaetosphaerella as a correct name for the genus and recommended Chaetosphaerella for protection over Oedemium and Veramycina.

\section{Ecological and economic significance of Chaetosphaerellaceae}

Most Chaetosphaerellaceae species are saprobic on wood, widespread around the world, although most have been found in Europe (Sivanesan 1974, Réblová 1999a, b, d, Huhndorf et al. 2004a, Mugambi \& Huhndorf 2010).

\section{Genera included in Chaetosphaerellaceae}

Chaetosphaerella E. Müll. \& C. Booth, Trans. Br. mycol. Soc. 58(1): 76 (1972)

Index Fungorum number: IF969; 2 species with sequence data.

Type species - Chaetosphaerella phaeostroma (Durieu \& Mont.) E. Müll. \& C. Booth

Notes - Chaetosphaerella was introduced by Müller \& Booth (1972) and included two species, $C$. phaeostroma and $C$. fusca. The type species $C$. phaeostroma, is characterized by black ascomata surrounded by a subiculum, with tuberculate or roughened perithecia, clavate asci and pigmented ascospores. Sivanesan (1976) and Varghese \& Rao (1979a) included C. fusispora and $C$. indica in Chaetosphaerella based on the characters, however, Réblová (1999a, b) excluded them based on different morphology of the peridium, setae, asci and conidiogenesis. Chaetosphaerella is closely related to Crassochaeta in Fig. 11.

\section{Crassochaeta Réblová, Mycotaxon 71: 46 (1999)}

Index Fungorum number: IF28310; 2 morphological species (Species Fungorum 2020), 1 species with sequence data.

Type species - Crassochaeta nigrita (Sacc.) Réblová

Notes - Crassochaeta nigrita is characterized by tuberculate ascomata surrounded by needleshaped setae, cylindrical asci and subglobose to ellipsoid, versicolored ascospores. The asexual morph was reported as arthrinium-like Réblová (1999d). The phylogeny based on LSU sequence data of $C$. nigrita was provided by Huhndorf et al. (2004a) and reveals a close relationship of Crassochaeta to Chaetosphaerella within Chaetosphaerellaceae (same results in Fig. 11).

Spinulosphaeria Sivan., Trans. Br. mycol. Soc. 62(1): 5 (1974)

Index Fungorum number: IF5149; 2 morphological species (Species Fungorum 2020), 1 species with sequence data.

Type species - Spinulosphaeria thaxteri (Pat.) Sivan.

Notes-Spinulosphaeria, typified by Spinulosphaeria thaxteri, was established by Sivanesan (1974) and has tuberculate ascomata, clavate asci and subglobose to ellipsoid ascospores. The second species, Spinulosphaeria nuda is characterized by tuberculate ascomata and verrucose ascospores with mucilaginous sheath (Mugambi \& Huhndorf 2010). Phylogenetic analysis of LSU sequence data of $S$. nuda reveals that Spinulosphaeria is related to Chaetosphaerellaceae and Nitschkiaceae (Mugambi \& Huhndorf 2010). In this study, Spinulosphaeria is closely related to Crassochaeta and Chaetosphaerella within Chaetosphaerellaceae (Fig. 11).

Chaetosphaeriaceae Réblová, M.E. Barr \& Samuels, Sydowia 51(1): 56 (1999)

Index Fungorum number: IF82100; Facesoffungi number: FoF01139; 658 species.

Saprobic on wood or decaying plant parts including leaves, fruits in terrestrial and aquatic habitats, sometimes isolated from soil and fresh plant parts such as leaves, less commonly - 

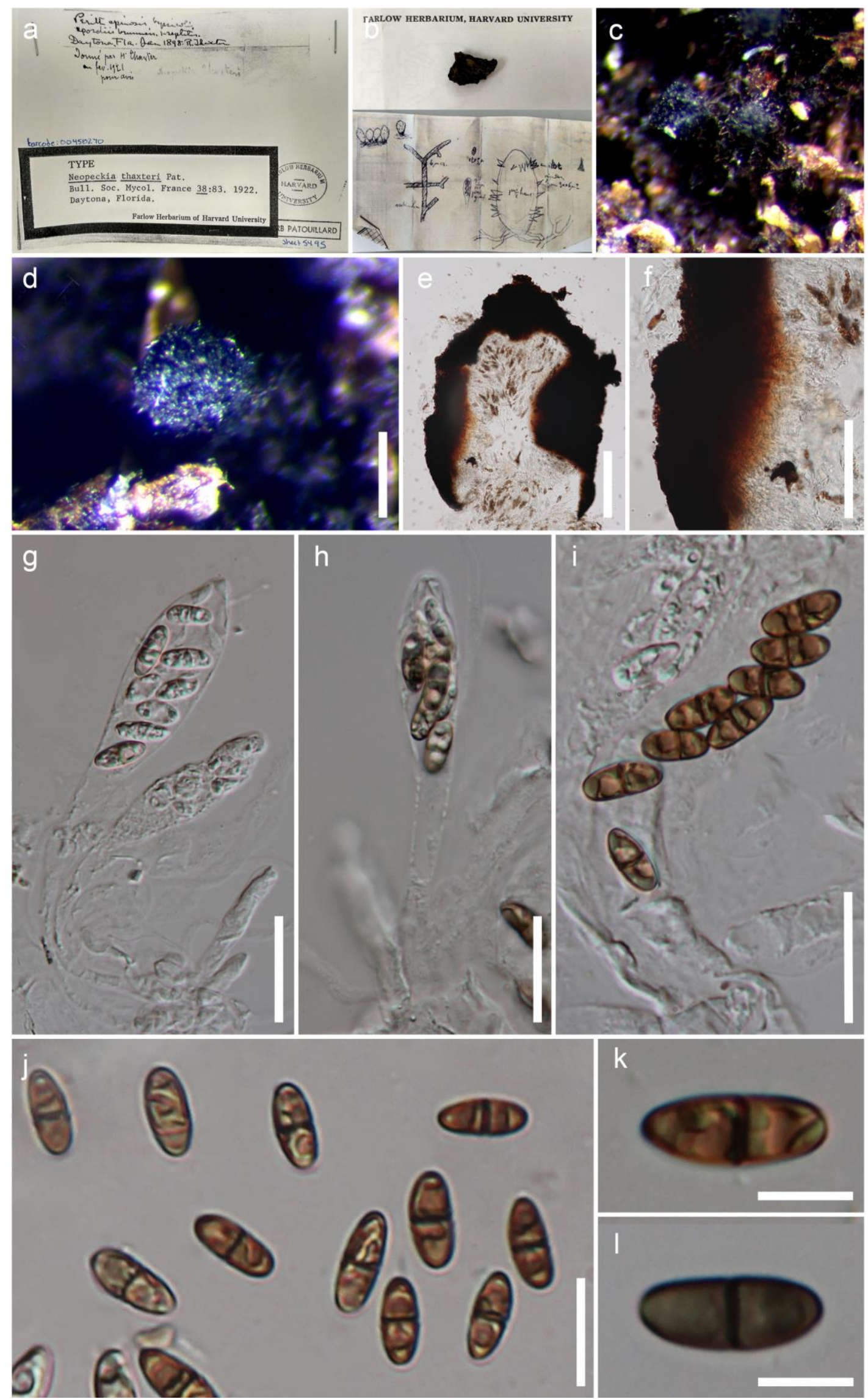

Figure 67 - Spinulosphaeria thaxteri (Material examined - USA, Florida, Dayton; on rotten wood, 1898, collected by Patouillard, FH 16-10965, holotype). a Material label. b Material and line drawing. c Ascomata on wood. d Ascoma. e Ascoma vertical section. f Peridium. g-i Asci with paraphyses. j-1 Ascospores. Scale bars: d-f $=200 \mu \mathrm{m}, \mathrm{g}-\mathrm{i}=20 \mu \mathrm{m}, \mathrm{j}=10 \mu \mathrm{m}, \mathrm{k}, \mathrm{l}=5 \mu \mathrm{m}$. 
-pathogenic. Sexual morph: Ascomata perithecial, gregarious or scattered, solitary, superficial or basally immersed on a thin stroma or on a thin subiculum, ovoid, globose to subglobose, carbonaceous, coriaceous or membranaceous, dark brown to black, rough, smooth or with short setae, papillate, the apex collapsing when dry. Ostiole lined with hyaline periphyses or periphyses absent. Subiculum thin, scanty, brown to dark brown, septate, of unbranched hyphae. Peridium composed of two layers, outer layer comprising brown cells of textura epidermoidea or angularis, carbonaceous; inner layer comprising hyaline cells of textura prismatica, thin, membranaceus. Paraphyses numerous, septate, unbranched, tapering, filiform or cylindrical. Asci 8-spored, unitunicate, thin-walled, clavate to cylindrical, long or short pedicellate, with $\mathrm{J}$-, apical ring. Ascospores 2-3-seriate, fusiform, cylindrical to ellipsoid, straight or sometimes curved, 0-3septate, with or without fragmenting, hyaline or brown or becoming dark coloured in part, smooth or striate, with guttules, sheath or appendages. Asexual morph: Hyphomycetous or coelomycetous. When hyphomycetous, Conidiophores macronematous, mononematous, scattered or gregarious, dark brown or hyaline, straight or flexuous, septate, branched or unbranched, with short encircling collar hyphae. Conidiogenous cells monophialidic or polyphialidic, holoblastic or enteroblastic, proliferating percurrently or sympodial, hyaline, with a distinct funnel-shaped collarette, smoothwalled. Conidia aggregated, continuous or mucilaginous, aseptate to multi-septate, flexuous, fusiform, allantoid, cylindrical or doliiform, curved or straight, hyaline to dark brown. When coelomycetous, Conidiomata stromatic, scattered or aggregated, superficial, cupuliform or globose, unilocular, setose, comprising black to dark brown cells of textura angularis or intricata. Setae numerous, black to brown, septate, ovoid to cylindrical or arising from the outer elements of excipulum, smooth, thick-walled, multi-septate. Conidiophores lining the basal stroma in a dense layer or arising from conidiomatal cavity, brown, 4-6-septate, unbranched, cylindrical, thin-walled, smooth. Conidiogenous cells integrated, determinate, holoblastic or enteroblastic, phialidic with conspicuous periclinal thickening at an attenuated apex, brown, smooth, subcylindrical to lageniform. Conidia aseptate, globose to subglobose or ellipsoid, fusiform to allantoid, curved or straight, obtuse to sub-obtusely rounded at apex, truncate at base, eguttulate or guttulate, hyaline to brown, thin, smooth-walled, with a single, cellular, unbranched, flexuous, with tubular appendage at each end, separated by a septum, with basal asymmetrically located appendage.

Type genus - Chaetosphaeria Tul. \& C. Tul.

Notes - Chaetosphaeriaceae was introduced without any description by Locquin (1984) to accommodate five genera including Chaetosphaeria, Loramyces, Niesslia, Rhagadostoma, and Zignöella. This was not considered as a validly published family (Hawksworth \& David $1989-$ Art. 36.1, Grueter et al. 1994). Hence, Réblová et al. (1999) re-introduced the family based on Chaetosphaeria, to accommodate another six genera: Ascocodinaea, Melanochaeta, Melanopsammella, Porosphaerella, Porosphaerellopsis, and Striatosphaeria. Réblová et al. (1999) maintained Chaetosphaeriaceae in Sordariales based on morphology. Based on LSU sequence data, Huhndorf (2004b) placed the family in Chaetosphaeriales. Subsequently more genera were added to the family and, Maharachchikumbura et al. (2016b) accepted 37 genera. Maharachchikumbura et al. (2016b) aknowledged the taxonomic confusion of genera in the family and the need for a monograph with molecular support for accepted genera. Crous et al. (2016a) introduced Adautomilanezia and Eucalyptostroma to Chaetosphaeriaceae. Ma et al. (2016b) introduced the hyphomycetes genus Anacacumisporium based on phylogenetic analyses. Five genera, Codinaeopsis, Dictyochaetopsis, Phaeostalagmus, Phialogeniculata and Zignoëlla, previously listed by Maharachchikumbura et al. (2016b) in Chaetosphaeriaceae, were not considered by Wijayawardene et al. (2018a). Wijayawardene et al. (2018a) listed 38 genera in Chaetosphaeriaceae including Adautomilanezia, Anacacumisporium, Conicomyces, Eucalyptostroma, Menisporopsis and Pseudolachnella. Yang et al. (2018a) placed Nawawia and Phialosporostilbe in Chaetosphaeriaceae based on LSU and ITS sequence data. A new genus Multiguttulispora was added to the family by Lin et al. (2019b). Crous et al. (2018d) provided first DNA sequence data for Polynema and placed it in Chaetosphaeriaceae. In this entry the sexual morph of 
Chaetosphaeria jonesii and the asexual morph of a new species, Chloridium submersum, is illustrated.

\section{Ecological and economic significance of Chaetosphaeriaceae}

Chaetosphaeriaceae members are saprobes in terrestrial and aquatic habitats (Réblová et al. 1999, Maharachchikumbura et al. 2016b). As examples Dictyochaeta, Tainosphaeria and Menisporopsis are aquatic, while Adautomilanezia, Chaetosphaeria and Thozetella are terrestrial saprobes (Crous et al. 2016a, Ho et al. 2001, Liu et al. 2016, Perera et al. 2016b, Réblová et al. 1999). Chaetosphaeriaceae species have the ability to decompose lignocellulose substrates in woody litter and release nutrients (Yuen et al. 1998, Hyde et al. 2016a, Liu et al. 2016). Hence, they play an important role in nutrient and carbon cycling and ecosystem functioning (Hyde et al. 2016a, Palmer et al. 1997, Wong et al. 1998a). Two Eucalyptostroma species (E. eucalypti and E. eucalyptorum) were isolated from leaf spots of Eucalyptus (Crous et al. 2016a, 2018d). However, there is no study confirming any pathogenicity in Chaetosphaeriaceae species. Some Dinemasporium species have been reported to produce secondary metabolites (Yamaguchi et al. 2005, Krohn et al. 2008, Hashimoto et al. 2015a).

\section{Genera included in Chaetosphaeriaceae}

Adautomilanezia Gusmão, S.S. Silva, Fiuza, L.A. Costa \& T.A.B. Santos, Persoonia 37: 229 (2016)

Index Fungorum number: IF815142; 1 species with sequence data.

Type species - Adautomilanezia caesalpiniae Gusmão, S.S. Silva, Fiuza, L.A. Costa \& T.A.B. Santos

Notes - The monotypic, hyphomycetous genus Adautomilanezia was introduced by Crous et al. (2016a) based on LSU sequence data. The type species, A. caesalpinia, was isolated from decaying twigs of Caesalpina echina in Brazil (Crous et al. 2016a). The genus is characterised by sporodochial conidiomata with setae, enteroblastic conidiogenous cells and oblong to clavate, multi-septate conidia (Crous et al. 2016a).

Anacacumisporium Y.R. Ma \& X.G. Zhang, Cryptog. Mycol. 14: 8 (2016)

Index Fungorum number: IF811418; 1 species with sequence data.

Type species - Anacacumisporium appendiculatum Y.R. Ma \& X.G. Zhang

Notes - The monotypic, hyphomycetous genus Anacacumisporium was established by Ma et al. (2016b) with the single species A. appendiculatum, which was isolated from decaying wood in China (Ma et al. 2016b). The genus is characterized by mononematous, macronematous conidiophores, inconspicuous phialidic conidiogenous cells and euseptate conidia with an appendage at the tip and base, aggregated in slimy masses (Ma et al. 2016b).

\section{Ascochalara Réblová, Sydowia 51(2): 212 (1999)}

Index Fungorum number: IF28371; 1 morphological species.

Type species - Ascochalara gabretae Réblová

Notes - Ascochalara was introduced by Réblová (1999e) to accommodate the lignicolous species, A. gabretae, characterised by black, papillate ascomata, covered with greyish to whitish powder, cylindrical-clavate asci with a J-, refractive apical ring and fusiform ascospores disarticulating into part ascospores within the asci. The asexual morph of the fungus is charala-like, with conidiophores mononematous, macronematous, phialidic conidiogenous cells and subcylindrical to wedge-shaped, aseptate conidia.

Brunneodinemasporium Crous \& R.F. Castañeda, Persoonia, Mol. Phyl. Evol. Fungi 28: 128 (2012)

Index Fungorum number: IF800158; 2 species with sequence data.

Type species - Brunneodinemasporium brasiliense Crous \& R.F. Castañeda 
Notes - The coelomycetous genus Brunneodinemasporium was introduced by Crous et al. (2012e) based on a dinemasporium-like species. Lu et al. (2016) added B. jonesii based on LSU and ITS sequence data. Brunneodinemasporium species are characterised by cupulate, setose conidiomata, with tightly aggregated brown conidiogenous cells and pale brown aseptate conidia (Crous et al. 2012e, Lu et al. 2016). Species of this genus occur on decaying wood and leaves in terrestrial and freshwater habitats (Crous et al. 2012e, Lu et al. 2016).

Catenularia Grove, Syll. fung. (Abellini) 4:303 (1886)

Index Fungorum number: IF7506; 13 morphological species (Species Fungorum 2020).

Type species - Catenularia simplex Grove

Notes - Saccardo (1886) established the hyphomycetous genus Catenularia to accommodate the species $C$. simplex and $C$. atra. Species are lignicolous and found on dead wood and decaying leaves and herbaceous substrates (Hughes \& Kendrick 1965, Subramanian \& Bhat 1987, Matsushima 1971, Li et al. 2017a). Catenularia species are characterised by macronematous, mononematous, simple or flexuous conidiophores, monophialidic, collarette conidiogenous cells and aseptate phragmoconidia formed solitary or in chains (Saccardo 1886, Subramanian \& Bhat 1987, Li et al. 2017a, Holubová-Jechová 1982).

Chaetosphaeria Tul. \& C. Tul., Select. fung. carpol. (Paris) 2: 252 (1863)

Index Fungorum number: IF970; 107 morphological species (Species Fungorum 2020), 50 species with sequence data.

Type species - Chaetosphaeria innumera Berk. \& Broome

Notes - Species of the genus are characterized by black ascomata with surface smooth or covered by setae, 8-spored asci, with a small, distinct, refractive, J-, apical ring and septate, hyaline ascospores (Maharachchikumbura et al. 2016b, Fernández et al. 2006). The asexual morph of Chaetosphaeria is hyphomycetous with macronematous or mononematous conidiophores, monophialidic or polyphialidic, conidiogenous cells, aseptate to multi-septate, guttulate or eguttulate conidia, with or without appendages (Maharachchikumbura et al. 2016b, Fernández et al. 2006). Chaetosphaeria species are saprobes on decaying plant material in terrestrial and freshwater habitats (Fernández \& Huhndorf 2005, Perera et al. 2016b, Atkinson et al. 2007). The sexual morph of Chaetosphaeria jonesii is illustrated (Fig. 68).

Chloridium Link, Mag. Gesell. naturf. Freunde, Berlin 3(1-2): 13 (1809)

Index Fungorum number: IF7624; 28 morphological species (Species Fungorum 2020), 5 species with sequence data.

Type species - Chloridium viride Link

Notes - Chloridium is characterised by mononematous or macronematous conidiophores, monophialidic or polyphialidic conidiogenous cells, with a funnel-shaped collarette and hyaline to brown, eguttulate or guttulate, appendaged or non-appendaged conidia (Link 1809, Seifert et al. 2011, Wei et al. 2018). Réblová et al. (2016b) pointed out that the generic type of Chloridium, $C$. viride is congeneric with Melanopsammella inaequalis, the type of Melanopsammella (Réblová \& Winka 2000, Fernández et al. 2006, Crous et al. 2012e). Hughes (1951c) revealed that the generic type of Gonytrichum, G. caesium, is the asexual morph of Melanopsammella inaequalis. By considering the above facts, Réblová et al. (2016b) proposed that Gonytrichum and Melanopsammella are synonyms of Chloridium. Hence, the widely used generic name Chloridium was conserved over Gonytrichum and Melanopsammella (Réblová et al. 2016b, Wei et al. 2018). Wijayawardene et al. (2018a) incorrectly treated Chloridium, Gonytrichum and Melanopsammella as three distinct genera. Here we follow Réblová et al. (2016b) which is also confirmed in our phylogenetic analysis of combined ITS and LSU sequence data (Fig. 8). Furthermore, Chloridium species seems to be polyphyletic within Chaetosphaeriaceae (Fig. 8). We introduce a new species of Chloridium in this entry. 


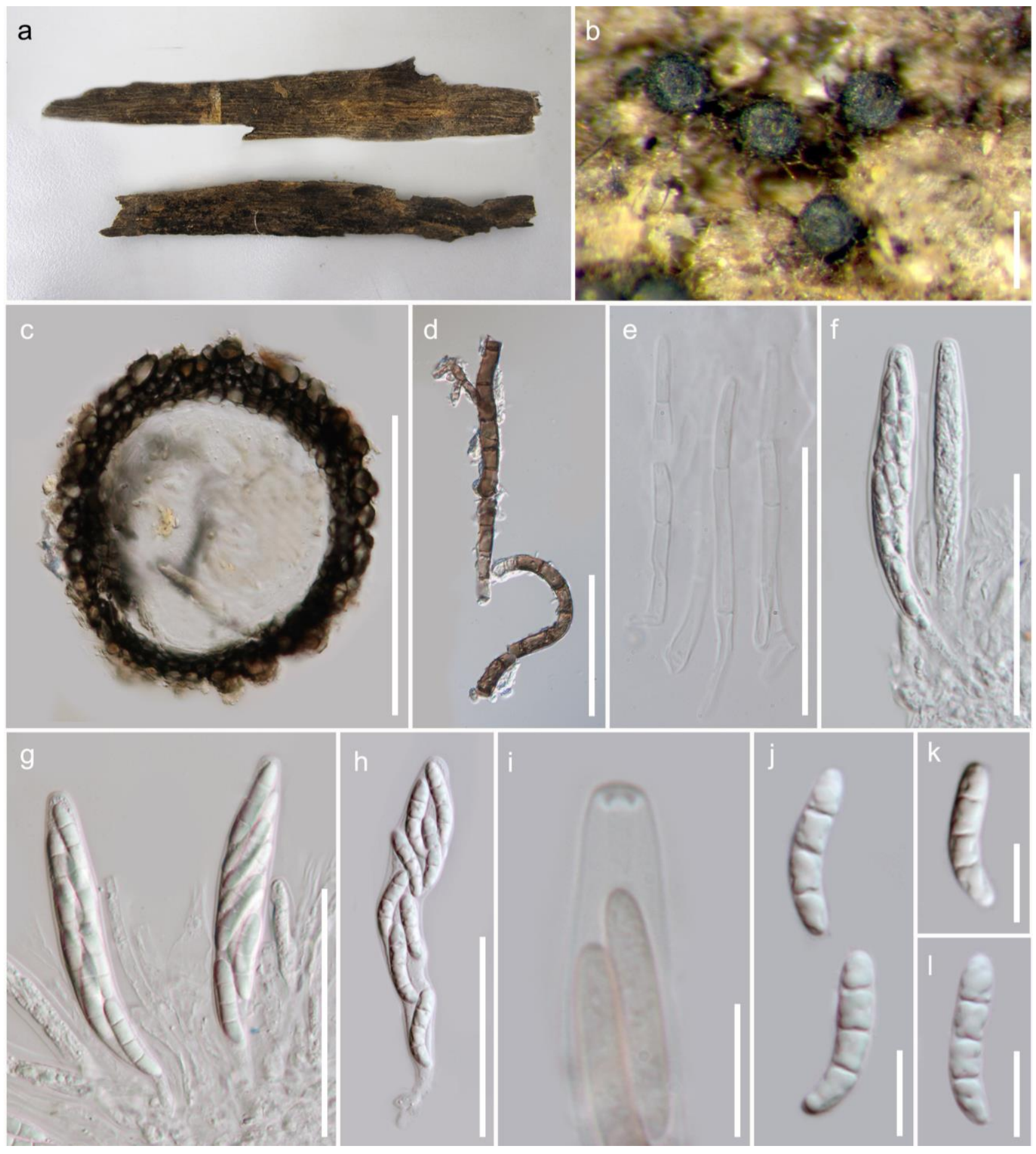

Figure 68 - Chaetosphaeria jonesii (Material examined - THAILAND, Chiang Mai Province, on decorticated wood, 5 August 2015, S. Boonmee RHP 121, MFLU 16-1020, holotype). a Herbarium material. b Appearance of ascomata on host substrate. c Section of ascoma. d Setae. e Paraphyses. $\mathrm{f}-\mathrm{h}$ Asci. i Close up of apical ascus in Melzer's reagent. j-1 Ascospores. Scale bars: $\mathrm{b}=200 \mu \mathrm{m}, \mathrm{c}=$ $100 \mu \mathrm{m}, \mathrm{d}-\mathrm{h}=50 \mu \mathrm{m}, \mathrm{i}-\mathrm{l}=10 \mu \mathrm{m}$.

Chloridium submersum Z.L. Luo, K.D. Hyde \& H.Y. Su, sp. nov.

Fig. 69

Index Fungorum number: IF556752; Facesoffungi number: FoF06866

Etymology - Referring to the submerged habitat of this fungus.

Holotype - MFLU 18-1609.

Saprobic on submerged decaying wood. Sexual morph: Undetermined. Asexual morph: Colonies effuse, brown, with long hairy mycelium, with white glistening conidial mass. Mycelium partly immersed, partly superficial, consisting of branched, septate, brown hyphae. Conidiophores 
116-264(-350) $\mu \mathrm{m}(\bar{x}=190 \mu \mathrm{m}, \mathrm{SD}=74, \mathrm{n}=10)$ long, 4-6 $\mu \mathrm{m}(\bar{x}=5 \mu \mathrm{m}, \mathrm{SD}=1, \mathrm{n}=10)$ wide, macronematous, mononematous, erect, straight or slightly flexuous, septate, brown at the base, gradually becoming paler towards apex, smooth. Conidiogenous cells integrated, terminal, polyenteroblastic, with a conspicuous outer collarette, hyaline. Conidia 3.5-4.5 $\mu \mathrm{m}(\bar{x}=4 \mu \mathrm{m}, \mathrm{SD}=$ $0.5, \mathrm{n}=30)$ long, $2-3 \mu \mathrm{m}(\bar{x}=2.5 \mu \mathrm{m}, \mathrm{SD}=0.5, \mathrm{n}=30)$ wide, acrogenous, aggregated in slimy mass at the apex of the conidiophore, ellipsoid, hyaline, aseptate, guttulate, smooth.

Material examined - CHINA, Yunnan Province, saprobic on decaying submerged wood in Dulong river, May 2015, H.Y. Su, H D5-13-1, S-510, MFLU 18-1609, holotype; ex-type living culture, MFLUCC 16-1344.

GenBank numbers - ITS MN860551, LSU MN860556.

Notes - Chloridium submersum resembles $C$. phaeosporum in having macronematous, mononematous, erect, septate conidiophores which are brown at the base, gradually becoming paler towards apex, terminal, hyaline conidiogenous cells and ellipsoid, hyaline, aseptate conidia (Wu \& Zhang 2013). However, C. submersum differs from C. phaeosporum by its longer conidiophores (116-264(-350) vs 70-120 $\mu \mathrm{m})$, polyblastic, denticulate conidiogenous cells and guttulate, hyaline conidia, while the latter species have monophialidic conidiogenous cells constricting abruptly and expanding in a flaring collarette and pale brown conidia without guttules. Chloridium submersum is phylogenetically related to C. aquaticum, C. gonythichii and C. aseptatum (Fig. 8).

Codinaea Maire, Publ. Inst. Bot. 3(4): 15 (1937)

Index Fungorum number: IF7720; 16 morphological species (Species Fungorum 2020), 4 species with sequence data.

Type species - Codinaea aristata Maire

Notes - Codinaea was introduced based on C. aristata (Maire 1937). Gamundi et al. (1977) examined several specimens of Dictyochaeta fuegiana and proposed Codinaea as a synonym of Dictyochaeta. Their treatment was accepted by most authors and many Codinaea taxa have been moved to Dictyochaeta (Kirschner \& Chen 2002, Cruz et al. 2008, Liu et al. 2016, Whitton et al. 2012). However, re-examination of the two collections, on which Gamundí et al. (1977) based their description of $D$. fuegiana (LPS 38629, LPS 38630), revealed a fungus was misidentified as the type of Dictyochaeta fuegiana (Réblová 2004). Réblová (2004) re-examined the type specimen of Dictyochaeta fuegiana and gave detailed descriptions. Molecular studies by Réblová \& Winka (2000) revealed that Dictyochaeta species with or without setulae clustered into distinct subgroups in the phylogenetic tree. Réblová (2000) proposed to retain Codinaea for species with setulae and placed species without setulae in Dictyochaeta. Seifert et al. (2011) and Li et al. (2012) accepted Réblová (2000) suggestion on segregation of Codinaea and Dictyochaeta as separate genera delineated by the presence or absence of conidial setulae and accepted both Codinaea and Dictyochaeta as valid genera.

Wijayawardene et al. (2018a) and Hernández-Restrepo (2017) also treated them as two distinct genera. Currently, 104 species of Dictyochaeta and 53 species of Codinaea have been described (Index Fungorum 2020). However, only few have DNA sequence data. There are no extype sequence data are available for the generic types of Codinaea or Dictyochaeta. Our phylogenetic analysis based on the available sequences of Dictyochaeta and Codinaea species, revealed that species of both genera are polyphyletic within Chaetosphaeriaceae (Fig. 8). Therefore, a detailed morpho-molecular analysis with more taxonomic sampling would be required to finally confirm the phylogenetic status of Codinaea and Dictyochaeta. Here we keep the Codinaea and Dictyochaeta as separate genera until the generic types of Codinaea and Dictyochaeta are recollected, sequenced and confirmed the link by molecular data.

Conicomyces R.C. Sinclair, Eicker \& Morgan-Jones, Mycologia 75(6): 1100 (1983)

Index Fungorum number: IF11019; 4 morphological species (Species Fungorum 2020), 1 species with sequence data.

Type species - Conicomyces transvaalensis R.C. Sinclair, Eicker \& Morgan-Jones 

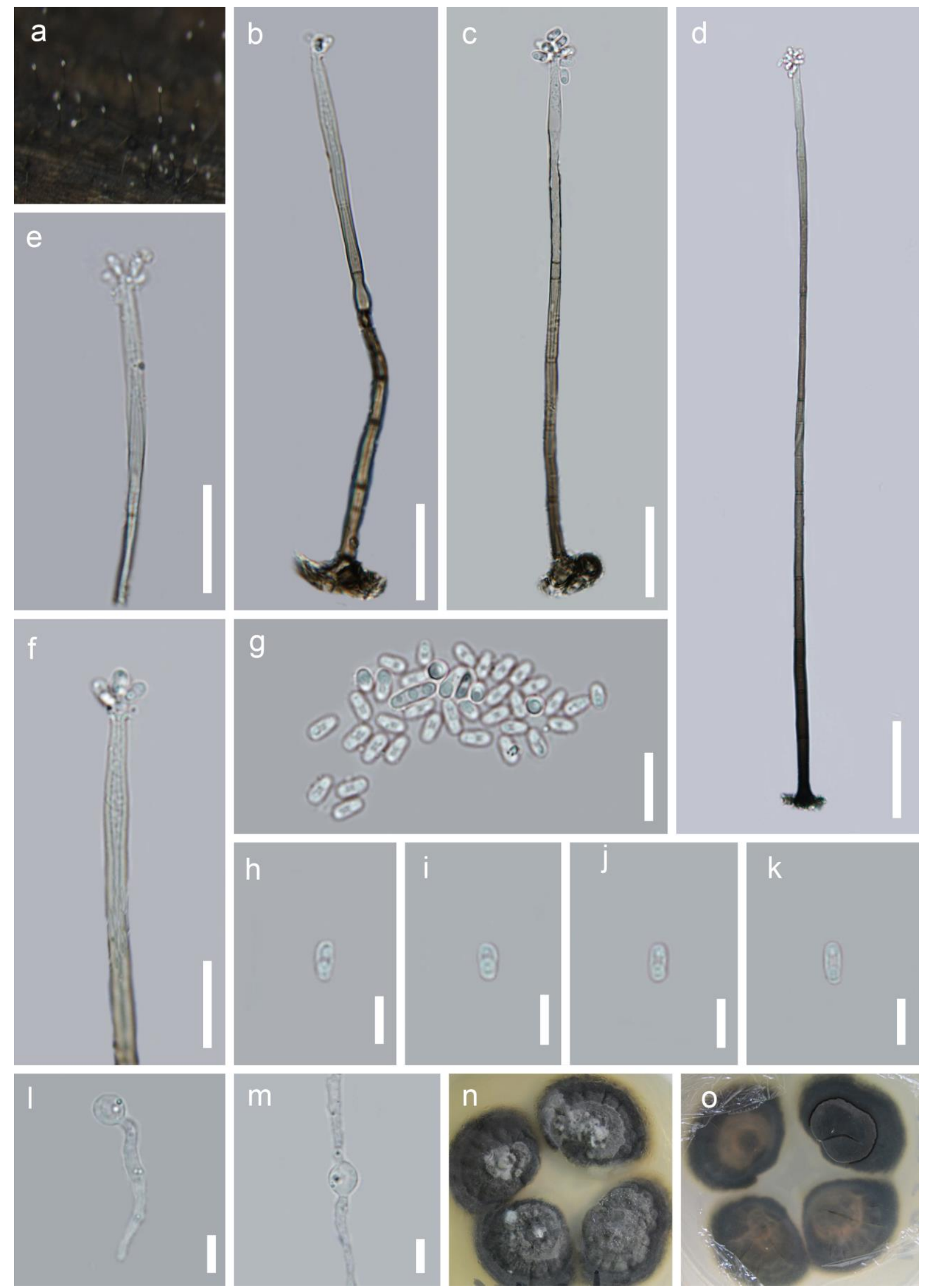

Figure 69 - Chloridium submersum (MFLU 18-1609, holotype). a Colonies on wood. b-d Conidiophores with conidia. e, f Conidiogenous cells. g-k Conidia. $1, \mathrm{~m}$ Germinating conidia. n, o Culture on PDA from surface and reverse. Scale bars: $b-d=100 \mu \mathrm{m}, \mathrm{e}, \mathrm{f}=30 \mu \mathrm{m}, \mathrm{g}=10 \mu \mathrm{m}, \mathrm{h}-\mathrm{m}$ $=5 \mu \mathrm{m}$. 
Notes - The hyphomycetous genus Conicomyces was introduced by Sinclair \& Eicker (1983). Species of Conicomyces are lignicolous being saprobic on decaying woody substrates (HolubováJechová 1973a, Sinclair \& Eicker 1983, Illman \& White 1985, Liu et al. 2015). Conicomyces species are characterised by cone-shaped, setose synnemata, macronematous, enteroblastic conidiophores and aseptate, fusiform conidia bearing an apical appendage (Sinclair \& Eicker 1983).

Craspedodidymum Hol.-Jech., Česká Mykol. 26(2): 70 (1972)

Index Fungorum number: IF7804; 14 morphological species (Species Fungorum 2020).

Type species - Craspedodidymum elatum Hol.-Jech.

Notes - The hyphomycetous genus Craspedodidymum was introduced by Holubová-Jechová (1972) based on C. elatum. Craspedodidymum species are saprobic fungi occur on decaying plant material (Pinruan et al. 2004, Ma et al. 2011, Yanna et al. 2000). Species of this genus are characterised by macronematous conidiophores and apically swollen conidiogenous cells with a large funnel-shaped terminal collarette (Pinruan et al. 2004).

Cryptophiale Piroz., Can. J. Bot. 46: 1123 (1968)

Index Fungorum number: IF7833; 21 morphological species (Species Fungorum 2020), 2 species with sequence data.

Type species - Cryptophiale kakombensis Piroz.

Notes - The hyphomycetous genus Cryptophiale was introduced by Pirozynski (1968) based on C. kakombensis. Cryptophiale species are saprobes occur on decaying leaves, wood, roots and bark (Pirozynski 1968, Goh \& Hyde 1996). Species of the genus are characterised by unbranched or apically dichotomous or verticillate, setiform, conidiophores, monophialidic, obscured conidiogenous cells in two rows and unicellular to multiseptate, hyaline conidia produced in slimy masses on one side of the conidiophore (Pirozynski 1968, Seifert et al. 2011, Yang et al. 2018a).

Cryptophialoidea Kuthub. \& Nawawi, Trans. Br. mycol. Soc. 89(4): 581 (1987)

Index Fungorum number: IF11061; 5 morphological species (Species Fungorum 2020), 1 species with sequence data.

Type species - Cryptophialoidea secunda (Kuthub. \& B. Sutton) Kuthub. \& Nawawi

Notes - Kuthubutheen \& Nawawi (1987) introduced asexual morph genus Cryptophialoidea based on $C$. secunda. The genus is characterised by setiform, brown conidiophores, monophialidic or polyphialidic phialidic, sessile conidiogenous cells, arranged on one side of the conidiophore and, hyaline, falcate conidia (Kuthubutheen \& Nawawi 1987, Yang et al. 2018a).

Dendrophoma Sacc., Michelia 2(no. 6): 4 (1880)

Index Fungorum number: IF7944; 59 morphological species (Species Fungorum 2020), 6 species with sequence data.

Type species - Dendrophoma cytisporoides Sacc.

Notes - Dendrophoma was proposed to be synonymous with Dinemasporium as Dendrophoma cytisporoides was related to Dinemasporium graminum (Sutton 1965). However, Crous et al. (2012e) epitypified Dendrophoma cytosporoides and confirmed that it is different from Dinemasporium based on morphological and DNA sequence data. Species of Dendrophoma occur on woody substrates and leaves, while some of them reported as leaf pathogens (Howard \& Albregts 1973, Moricca et al. 2016, Spegazzini 1880, Vu et al. 2019). The genus is characterised by stromatic, stipitate, setose conidiomata, discrete, or integrated, lageniform to subcylindrical conidiogenous cells and naviculate to botuliform conidia bearing an unbranched cellular appendage at each end (Crous et al. 2012e).

Dictyochaeta Speg., Physis, Rev. Soc. Arg. Cienc. Nat. 7: 18 (1923)

Index Fungorum number: IF7996; 104 morphological species (Species Fungorum 2020), 13 species with sequence data. 
Type species - Dictyochaeta fuegiana Speg.

Notes - Dictyochaeta was erected by Spegazzini (1923) based on Dictyochaeta fuegiana. Species of this genus are saprobes on decaying plant parts (Whitton et al. 2000, Réblová \& Winka 2000, Kuthubutheen \& Nawawi 1991). For more details, see note under Codinaea. Dictyochaeta is characterised by macronematous, mononematous, pale brown to dark brown conidiophores, monoor polyphialidic, sympodially proliferating conidiogenous cells with flared collarettes and hyaline, clavate conidia without setulae (Réblová \& Winka 2000).

Dictyochaetopsis Aramb. \& Cabello, Mycotaxon 38: 12 (1990)

Index Fungorum number: IF11255; 14 morphological species (Species Fungorum 2020), 1 species with sequence data.

Type species - Dictyochaetopsis apicalis (Berk. \& M.A. Curtis) Aramb. \& Cabello

Notes - Arambarri \& Cabello (1990) established Dictyochaetopsis based on D. apicalis to accommodate species producing lateral phialides. Species of the genus are characterised by macronematous, setiform conidiophores with fertile or sterile apices; discrete (rarely integrated), monophialidic or rarely polyphialidic conidiogenous cells occurring on the conidiophore or on lateral branches and, fusoid to cylindrical, 0-multiseptate, hyaline conidia (Arambarri \& Cabello 1990, Whitton et al. 2000). Whitton et al. (2000) synonymized Codinaeopsis under Dictyochaetopsis. Seifert et al. (2011) did not accept Codinaeopsis and Dictyochaetopsis as valid genera. However, Lin et al. (2019a) treated Dictyochaetopsis as a distinct genus in Chaetosphaeriaceae and is followed here.

Dinemasporium Lév., Annls Sci. Nat., Bot., sér. 3 5: 274 (1846)

Index Fungorum number: IF8040; 77 morphological species (Species Fungorum 2020), 20 species with sequence data.

Type species - Dinemasporium graminum (Lib.) Lév. (Pers.) Sacc.

Notes - Dinemasporium species are coelomycetes, mainly occurring on various plant and woody substrates, including decaying wood (Nag Raj 1993, Hashimoto et al. 2015a, Crous et al. 2012e, Duan et at. 2007). Few were isolated from soil and human sputum (Nag Raj 1993, Hashimoto et al. 2015a, Crous et al. 2012e). The genus is characterised by superficial, setose, cupulate conidiomata, discrete or integrated conidiogenous cells and fusiform, naviculate or allantoid, aseptate conidia, with one setulae at each end, with or without lateral appendages (Crous et al. 2012e).

Eucalyptostroma Crous \& M.J. Wingf., Persoonia 37: 311 (2016)

Index Fungorum number: IF819066; 2 species with sequence data.

Type species - Eucalyptostroma eucalypti Crous \& M.J. Wingf.

Notes - The hypomycetes genus Eucalyptostroma was established by Crous et al. (2016a). This genus comprises two species and both were isolated from symptomatic leaves of Eucalyptus pellita (Crous et al. 2016a, 2018d). Eucalyptostroma species are characterised by sporodochial conidiomata lacking setae, penicillate conidiogenous apparatus, and aseptate hyaline conidia, without appendages (Crous et al. 2016a, 2018d).

Exserticlava S. Hughes, N.Z. J Bot. 16(3): 332 (1978)

Index Fungorum number: IF8242; 7 morphological species (Species Fungorum 2020), 1 species with sequence data.

Type species - Exserticlava vasiformis (Matsush.) S. Hughes

Notes - The hyphomycetous genus Exserticlava has been reported from decaying woody substrates in terrestrial and freshwater habitats (Cai \& Hyde 2007a, Ren et al. 2011, Hughes 1978, Tsui et al. 2001a). The genus is characterised by simple conidiophores bearing single polyblastic, funnel-shaped, conidiogenous cells and disto-septate conidia (Tsui et al. 2001a, Hughes 1978, Kirk 1985). 
Hemicorynespora M.B. Ellis, Mycol. Pap. 131: 19 (1972)

Index Fungorum number: IF8499; 13 morphological species (Species Fungorum 2020).

Type species - Hemicorynespora deightonii M.B. Ellis

Notes - Most Hemicorynespora species are saprobes which have been collected from dead leaves, branches, rachides or petioles, from tropical localities (Ellis 1972, Mercado et al. 1997, Delgado et al. 2007, Ma et al. 2012, 2016b). The genus is characterized by macronematous, mononematous conidiophores, determinate or percurrently elongated conidiogenous cells and, acrogenous, 0-1-septate, conidia, seceding schizolytically (Ellis 1972, Seifert et al. 2011, Ma et al. 2016b).

Infundibulomyces Plaingam, Somrith. \& E.B.G. Jones, Can. J. Bot. 81(7): 732 (2003)

Index Fungorum number: IF28753; 2 morphological species (Species Fungorum 2020), 1 species with sequence data.

Type species - Infundibulomyces cupulata Plaingam, Somrith. \& E.B.G. Jones

Notes - The coelomycete genus Infundibulomyces is known only from the tropics and are considered as saprobes (Plaingam et al. 2003, Somrithipol et al. 2008). Species of this genus are characterised by stromatic, cupulate to infundibuliform conidiomata, irregularly branched conidiophores, cylindrical conidiogenous cells and holoblastic cylindrical conidia, bearing two filiform appendages at each end (Plaingam et al. 2003, Somrithipol et al. 2008).

Kionochaeta P.M. Kirk \& B. Sutton, Trans. Br. mycol. Soc. 85(4): 712 (1986)

Index Fungorum number: IF11111; 12 morphological species (Species Fungorum 2020), 5 species with sequence data.

Type species - Kionochaeta ramifera (Matsush.) P.M. Kirk \& B. Sutton

Notes - Species of Kionochaeta occur on decaying leaves and twigs in freshwater and terrestrial habitats (Crous et al. 1994b, Kuthubutheen et al. 1988, Goh \& Hyde 1997, Yanna \& Hyde 2002). Kionochaeta species are characterised by macronematous, mononematous, solitary conidiophores, densely clustered, monophialidic, ampulliform, and hyaline to pale yellow conidia aggregated into a slimy drop (Kirk \& Sutton 1985, Goh \& Hyde 1997, Okada et al. 1997).

Lecythothecium Réblová \& Winka, Mycologia 93(3): 481 (2001)

Index Fungorum number: IF28485; 1 species with sequence data.

Type species - Lecythothecium duriligni Réblová \& Winka

Notes - Lecythothecium is a monotypic genus typified by L. duriligni, which was collected from decaying wood of Quercus sp. (Réblová \& Winka 2001). Ths genus is characterised by immersed, flask-shaped ascomata, 8-spored, cylindrical asci with a refractive, J-, apical ring and ellipsoidal to fusiform transversely septate, versicolorous ascospores (Réblová \& Winka 2001). The asexual morph is hyphomycetous with macronematous, mononematous, unbranched conidiophores, proliferating percurrently and holoblastic, cylindrical to clavate or obclavate, 5-11-pseudoseptate, dark brown to reddish brown conidia (Réblová \& Winka 2001).

Menispora Pers., Mycol. eur. (Erlanga) 1: 32 (1822)

Index Fungorum number: IF8902; 19 morphological species (Species Fungorum 2020), 6 species with sequence data.

Type specie - Menispora glauca (Link) Pers.

Notes - Menispora is a hyphomycete genus established by Persoon (1822) based on $M$. glauca. Menispora species occur on decayed wood, the inner side of bark or on decayed leaves (Hughes \& Kendrick 1968, Holubová-Jechová 1973b, Réblová \& Seifert 2008). Menispora is characterised by macronematous, brown conidiophores, phialides in a lateral or terminal position with a tapering, strongly recurved apex and a incospicous collarette and hyaline conidia without or with polar setulae (Réblová \& Seifert 2008). 
Menisporopsis S. Hughes, Mycol. Pap. 48: 59 (1952)

Index Fungorum number: IF8904; 11 morphological species (Species Fungorum 2020), 3 species with sequence data.

Type species - Menisporopsis theobromae S. Hughes

Notes-Species of this hyphomycetous genus occur on decaying wood and leaf litter (Hughes $\&$ Kendrick 1968, Ruiz et al. 2001). The genus is characterised by synnematous conidiophores with a central, simple, subulate, tall seta, phialidic conidiogenous cells and appendaged conidia aggregated into a slimy mass (Ellis 1971, Tsui et al. 1999).

Miyoshiella Kawam., Jap. J. Bot. 4: 295 (1929)

Index Fungorum number: IF3228; 3 morphological species (Species Fungorum 2020).

Type species - Miyoshiella fusispora (Kawam.) Kawam.

Notes - Miyoshiella species are saprobes on decayed wood (Réblová 1999c; Kawamura et al. 1929). They are wide spread in temperate Europe and Asia (Réblová 1999c). Species of this genus are characterised by astromatic, papillate ascomata, asci with refractive, J-, apical ring and 3-septate hyaline ascospores (Réblová 1999c). The asexual morph is hyphomycetous with semimacronematous conidiophores, monoblastic, ampulliform conidiogenous cells and holoblastic, septate, cylindrical to clavate, medium to dark brown conidia (Réblová 1999c).

Morrisiella Saikia \& A.K. Sarbhoy, Mycologia 77(2): 318 (1985)

Index Fungorum number: IF11132; 1 species with sequence data.

Type species - Morrisiella indica Saikia \& A.K. Sarbhoy

Notes - Saikia \& Sarbhoy (1985) introduced the monotypic genus Morrisiella based on M. indica. Species of this genus are characterised by dark brown conidiophores, monoblastic, discrete, ampulliform conidiogenous cells, lateral or terminal on the conidiophore, and obclavate, golden brown to olivaceous brown, multipseudoseptate conidia (Saikia \& Sarbhoy 1985). Shenoy et al. (2010) confirmed phylogenetic placement of Paliphora in Chaetosphaeriaceae based on LSU sequence data and this was accepted by Seifert et al. (2011). Similar results were obtained by Lin et al. (2019) and is followed in this paper.

Nawawia Marvanová, Trans. Br. mycol. Soc. $75(2): 227$ (1980)

Index Fungorum number: IF9081; 5 morphological species (Species Fungorum 2020), 1 species with sequence data.

Type species - Nawawia filiformis (Nawawi) Marvanová

Notes - Nawawia species occur on dead plant parts including stems, wood and leaves in freshwater habitats (Hyde et al. 1996, Goh et al. 2014, Peng et al. 2016, Yang et al. 2018a). Yang et al. (2018a) has recollected and provided sequence data for the generic type species, Nawawia filiformis. Their phylogenetic analysis confirmed the placement of Nawawia within Chaetosphaeriaceae. Nawawia malaysiana was the only Nawawia species with sequence data (Crous et al. 2009). However, Yang et al. (2018a) observed that $N$. malaysiana is unrelated with Nawawia, and introduced new genus Neonawawia, to accommodate $N$. malaysiana, Chaetosphaeriales genera incertae sedis. Nawawia is characterised by brown, macronematous conidiophores, monophialidic or sometimes with annellidic conidiogenous cells and turbinatetetrahedral to obpyramidal conidia with the blunt corners at the distal end with a distinct hair-like appendage at each end (Hyde et al. 1996, Peng et al. 2016, Yang et al. 2018a).

Neopseudolachnella A. Hashim. \& Kaz. Tanaka, Mycologia 107(2): 385 (2015)

Index Fungorum number: IF808687; 3 species with sequence data.

Type species - Neopseudolachnella acutispora A. Hashim. \& Kaz. Tanaka

Notes - The coelomycetous genus Neopseudolachnella was established to accommodate species with acervuloid, setose conidiomata lacking a peridium, when compared to Pseudolachnea and Pseudolachnella species (Hashimoto et al. 2015b). Neopseudolachnella species have septate 
conidia bearing a single to multiple appendages at each end (Hashimoto et al. 2015b). Neopseudolachnella species are associated with Poaceae hosts in Japan (Hashimoto et al. 2015b).

Paliphora Sivan. \& B. Sutton, Trans. Br. mycol. Soc. 85(2): 249 (1985)

Index Fungorum number: IF11148; 7 morphological species (Species Fungorum 2020), 1 species with sequence data.

Type species - Paliphora aurea Sivan. \& B. Sutton

Notes - Sivanesan \& Sutton (1985) introduced this genus based on P. aurea. Paliphora is characterised by setiform conidiophores, integrated, determinate, polytretic, intercalary or terminal conidiogenous cells and, unicellular or euseptate, cylindrical to subfusiform or subacerose, hyaline, conidia, accumulated in slimy masses (Sivanesan \& Sutton 1985, Malosso et al. 2018).

Phialosporostilbe Mercado \& J. Mena, Revta Jardín bot. Nac., Univ. Habana 6(3): 57 (1985)

Index Fungorum number: IF11162; 5 morphological species (Species Fungorum 2020), 1 species with sequence data.

Type species - Phialosporostilbe turbinata Mercado \& J. Mena

Notes - Mercado et al. (1985) introduced the hyphomycetous genus Phialosporostilbe based on P. turbinata, which was isolated from dead stems of Arthrostylidium in Cuba. The placement of Phialosporostilbe within Chaetosphaeriaceae was confirmed by DNA molecular data by Yang et al. (2018a). The genus is characterized by synnematous conidiomata, monophialidic conidiogenous cells and subhyaline, turbinate or cordiform conidia with three apical setulae (Sierra \& Portales 1985, Yang et al. 2018a).

Polynema Lév., Annls Sci. Nat., Bot., sér. 3 5: 274 (1846)

Index Fungorum number: IF25008; 9 morphological species (Species Fungorum 2020), 1 species with sequence data.

Type species - Polynema ornata (De Not.) Lév.

Notes - The coelomycetes genus Polynema was introduced by Léveillé (1846). The genus was redescribed by Sutton (1968) and accepted Neobarclaya as a synonym of Polynema. Nag Raj (1978) identified Neobarclaya is distinct from Polynema and segregated it from Polynema. Crous et al. (2018d) confirmed the placement of Polynema in Chaetosphaeriaceae based on phylogenetic analysis of ITS sequence data. Members of Polynema are mainly saprobes associated with plant leaves, culms and dead wood (Nag Raj 1993, Crous et al. 2018d). The genus is characterized by acervuloid, cupulate, setose conidiomata, hyaline conidiophores, discrete or integrated, cylindrical to clavate, hyaline conidiogenous cells and fusoid to subcylindrical, aseptate or 3 septate, mostly hyaline conidia with attenuated or filiform appendages at each end (Nag Raj 1993, Crous et al. 2018d).

Pseudodinemasporium A. Hashim. \& Kaz. Tanaka, Mycologia 107(2): 390 (2015)

Index Fungorum number: IF808707; 1 species with sequence data.

Type species - Pseudodinemasporium fabiforme A. Hashim., G. Sato \& Kaz. Tanaka

Notes - The monotypic, coelomycetous genus Pseudodinemasporium was introduced to include P. fabiform, which occurs on dead twigs of Betula platyphylla (Hashimoto et al. 2015b). The genus is characterised by stromatic, acervular, setose conidiomata, phialidic conidiogenous cells and aseptate conidia, bearing an appendage at each end (Hashimoto et al. 2015b).

Pseudolachnea Ranoj., Annls mycol. 8(3): 393 (1910)

Index Fungorum number: IF9587; 7 morphological species (Species Fungorum 2020), 2 species with sequence data.

Type species - Pseudolachnea insignis Velen.

Notes - The coelomycetous genus Pseudolachnea occur on twigs or wood of various angiosperms (Ranojević 1910, Sutton 1980, Nag Raj 1993, Hashimoto et al. 2015b). The genus is 
characterised by stromatic, acervular, setose conidiomata, phialidic conidiogenous cells and oneseptate conidia, bearing a filiform appendage at each end.

Pseudolachnella Teng, Sinensia, Shanghai 7: 775 (1936)

Index Fungorum number: IF9588; 17 morphological species (Species Fungorum 2020), 12 species with sequence data.

Type species - Pseudolachnella scolecospora (Teng \& C.I. Chen) Teng

Notes - Pseudolachnella species mostly occur on bamboo, while some species occur on twigs or wood of various angiosperms (Zhao et al. 2004, Sato et al. 2008, Hashimoto et al. 2015b). The genus is characterized by stromatic, acervular conidiomata with marginal setae, phialidic conidogenous cells and multiseptate conidia with single to multiple appendages at each end (Hashimoto et al. 2015b).

Pyrigemmula D. Magyar \& Shoemaker, Mycol. Progr. 10(3): 310 (2011)

Index Fungorum number: IF517148; 1 species with sequence data.

Type species - Pyrigemmula aurantiaca D. Magyar \& Shoemaker

Notes - Pyrigemmula is a monotypic genus based on hyphomycete P. aurantiaca (Magyar et al. 2011) and was isolated from inner bark or bark fissures of grapevines and also from other woody hosts (Magyar et al. 2011). Even though P. aurantiaca occurs on fresh plant material, the ecological role of the species is not understood (Magyar et al. 2011). Pyrigemmula aurantiaca is characterised by pear-shaped, brown conidiogenous cells and distoseptate, reddish brown conidia without appendages (Magyar et al. 2011).

Rattania Prabhug. \& Bhat, Mycotaxon 108: 218 (2009)

Index Fungorum number: IF512876; 1 species with sequence data.

Type species - Rattania setulifera Prabhug. \& Bhat

Notes - The monotypic genus Rattania was introduced based on an endophytic hyphomycete $R$. setulifera isolated from fresh leaves of Calamus thwaitesii (Prabhugaonkar \& Bhat 2009). The genus is characterised by sporodochial, setose conidiomata, monoblastic conidiogenous cells and 0-multiseptate, setulate conidia (Prabhugaonkar \& Bhat 2009).

Sporoschisma Berk. \& Broome, Gard. Chron., London: 540 (1847)

Index Fungorum number: IF10042; 21 morphological species (Species Fungorum 2020), 8 species with sequence data.

Type species - Sporoschisma mirabile Berk. \& Broome

Notes- The hyphomycetous genus Sporoschisma has cosmopolitan distribution (Goh et al. 1997, Ho et al. 2001, 2002, Zelski et al. 2014, Luo et al. 2016, Yang et al. 2016a). Species of the genus mostly occur on submerged wood in freshwater habitats, while some species have been collected from rotting leaves (Hughes 1966, Goh et al. 1997, Ho et al. 2001, 2002, Zelski et al. 2014, Luo et al. 2016, Yang et al. 2016a). Sporoschisma species are characterized by cylindrical, stipitate conidiophores, with a swollen venter and a long, cylindrical neck, monophialidic conidiogenous cells and cylindrical conidia occurring in endogenously chains with basipetal succession (Zelski et al. 2014, Luo et al. 2016).

Striatosphaeria Samuels \& E. Müll., Sydowia 31(1-6): 131 (1979)

Index Fungorum number: IF5282; 1 species with sequence data.

Type species - Striatosphaeria codinaeaphora Samuels \& E. Müll.

Notes - The monotypic genus Striatosphaeria was based on lignicolous fungus $S$. codinaeaphora which was isolated from bark of unidentified dead tree, in Brazil (Samuels \& Müller (1978). The genus is characterised by ostiolate ascomata seated on a small, basal stroma, 48-spored, cylindrical asci and 1-septate, brown, ascospores without appendages. 
Tainosphaeria F.A. Fernández \& Huhndorf, Fungal Divers. 18: 44 (2005)

Index Fungorum number: IF28947; 5 species with sequence data.

Type species - Tainosphaeria crassiparies F.A. Fernández \& Huhndorf

Notes - This genus is typified by T. crassiparies, which was isolated from a Hymenaea seed pod (Fernández \& Huhndorf 2005). Species of this genus are saprobes and recorded from both terrestrial and freshwater habitats (Fernández \& Huhndorf 2005, Liu et al. 2016, Lu et al. 2016). Species of Tainosphaeria are characterized by subglobose to ovoid ascomata, cylindrical, pedicellate asci, with a J-, apical ring, and narrow-fusiform, septate ascospores (Fernández \& Huhndorf 2005). The asexual morph is hyphomycetous, with mononematous, unbranched conidiophores, phyalidic conidiogenous cells with a collarette and ellipsoidal to clavate, or falcate, hyaline conidia (Fernández \& Huhndorf 2005, Liu et al. 2016, Lu et al. 2016).

Thozetella Kuntze, Revis. gen. pl. (Leipzig) 2: 873 (1891)

Index Fungorum number: IF10214; 26 morphological species (Species Fungorum 2020), 17 species with sequence data.

Type species - Thozetella nivea (Berk.) Kuntze

Notes- Most Thozetella species have been reported from decaying plant material and soil in tropical habitats, while some species were reported in temperate habitats (Silva \& Grandi 2013). Species of this genus are characterised by sporodochial or synnematous conidiomata, phialidic conidiogenous cells, and aseptate conidia, with unbranched setula at each end and sterile microawns (Sutton \& Cole 1983, Paulus et al. 2004, Jeewon et al. 2009).

Umbrinosphaeria Réblová, Mycotaxon 71: 17 (1999)

Index Fungorum number: IF28309; 1 species with sequence data.

Type species - Umbrinosphaeria caesariata (Clinton \& Peck) Réblová

Notes - The monotypic, sexual morph genus Umbrinosphaeria was introduced to accommodate the saprobic taxon $U$. caesariata, which was collected on decaying wood of Fagus sylvatica (Réblová 1999c, Réblová \& Winka 2001). Species of this genus are characterised by papillate, setose ascomata, 8-spored, cylindrical asci with refractive, J-, apical ring and multiseptate, fusiform, versicoloured ascospores (Réblová 1999c, Réblová \& Winka 2001).

Verhulstia Hern.-Restr., Persoonia 39: 449 (2017)

Index Fungorum number: IF823032; 1 species with sequence data.

Type species - Verhulstia trisororum Hern.-Restr.

Notes - Crous et al. (2017a) introduced monotypic genus Verhulstia based on V. trisororum. This genus is charactrised by sporodochial, setose conidiomata, pale brown conidiophores, phialidic, integrated, terminal, lageniform to subcylindrical, conidiogenous cells and, aseptate, cylindrical to ellipsoidal, or obovoid, hyaline conidia Crous et al. (2017a).

Zanclospora S. Hughes \&W.B. Kendr., N.Z. J Bot. 3: 151 (1965)

Index Fungorum number: IF10468; 9 morphological species (Species Fungorum 2020), 3 species with sequence data.

Type species - Zanclospora novae-zelandiae S. Hughes \& W.B. Kendr.

Notes - Species of this genus are saprobes on plant parts such as dead wood and leaves (Almeida et al. 2013, Hughes \& Kendrick 1965). Zanclospora species are characterized by sterile setae, setiform conidiophores, with a verruculose, dark brown apex, setiform conidiophores and bacilliform, aseptate conidia (Almeida et al. 2013).

Clavicipitaceae Earle, Contr. U.S. natnl. Herb. 6: 170 (1901)

Index Fungorum number: IF82061; Facesoffungi number: FoF01313; 536 species.

Obligate saprotrophs, parasites and symbionts of insects, fungi, grasses, nematodes, rushes or sedges. Sexual morph: Stromata or subiculum darkly or brightly coloured, fleshy or tough. 
Ascomata perithecial, superficial to completely immersed, ordinal or oblique in arrangement. Asci cylindrical with thickened apex. Ascospores usually cylindrical and multiseptate, disarticulating into part-spores or non-disarticulating. Asexual morph: Aschersonia, Ephelis, Metarhiziopsis, Metarhizium, Neotyphodium, Nomuraea, Pochonia, paecilomyces-like, Rotiferophthora, Sphacelia, and verticillium-like.

Type genus - Claviceps Tul.

Notes - As the former Hypocreaceae subfamily, the name Clavicipitaceae was recognized by Earle (1901) without any description. Nannfeldt (1932) and Eriksson (1982) accepted the name, but no one validated it (Eriksson 1982). Rogerson (1970) affirmed the name and then Eriksson \& Hawksworth (1985) validated it. Rogers (1979) removed it and classified it as two distinct orders, Clavicipitales and Hyporeales. Clavicipitaceae was clearly placed under Hypocreales by Spatafora \& Blackwell (1993), based on SSU and LSU analyses and this was confirmed by Rehner \& Samuels (1995). Diehl (1950) proposed three subfamilies (Oomycetoideae, Clavicipitoideae, and Cordycipitoideae) under Clavicipitaceae, but Sung et al. (2007) did not accept this. Sung et al. (2007) divided Clavicipitaceae into three monophyletic groups (Clavicipitaceae, Cordycipitaceae and Ophiocordycipitaceae) based on phylogenetic analyses.

Clavicipitaceae has been treated differently by many authors. Rogerson (1970) listed 13 genera, while White et al. (2000) made a clear definition for six genera based on morphology and phylogenetic analyses. Nigrocornus was introduced to accommodate a species of Balansia which was significantly different from that of the type and all other Balansia species (Ryley 2003). Sung et al. (2007) listed 22 genera in Clavicipitaceae and also listed Berkelella, Cavimalum, Dussiella, Epicrea, Helminthascus, Konradia, Moelleriella, Mycomalus, Neobarya, Neocordyceps, Podocrella, Romanoa, Sphaerocordyceps, and Stereocrea as genera incertae sedis. Kirk et al. (2008) recorded 43 genera in this family within Hypocreales. Chaverri et al. (2008) introduced Samuelsia in Clavicipitaceae based on morphology and phylogenetic analyses. Ustilaginoidea was introduced by Brefeld (1985) and revised by Tanaka et al. (2008) as a genus in Clavicipitaceae. Conoideocrella and Orbiocrella were described by Johnson et al. (2009). Chamaeleomyces isolated from the liver of Chamaeleo calyptratus was introduced as a new monotypic genus based on morphology and phylogenetic analyses (Sigler et al. 2010). Periglandula was introduced with $P$. ipomoeae as the type species isolated from Ipomoea asarifolia in Ecuador (Steiner et al. 2011). Lumbsch \& Huhndorf (2010) listed 32 genera under Clavicipitaceae. According to phylogenetic analyses, Kepler et al. (2012) added Tyrannicordyceps to Clavicipitaceae which lives on sclerotia of Claviceps (Kepler et al. 2012). Collarina was introduced by Crous et al. (2014b) based on morphology and phylogenetic analyses. Maharachchikumbura et al. (2015) listed 46 genera in this family: Aciculosporium, Albomyces, Aschersonia, Atkinsonella, Balansia, Cavimalum, Chamaeleomyces, Claviceps, Conoideocrella, Corallocytostroma, Dussiella, Ephelis, Epichloë, Epicrea, Helminthascus, Heteroepichlö̈, Hypocrella, Konradia, Loculistroma, Metacordyceps, Metarhiziopsis, Metarhizium, Metapochonia, Moelleriella, Mycomalus, Myriogenospora, Neobarya, Neoclaviceps, Neocordyceps, Neotyphodium, Nigrocornus, Nomuraea, Orbiocrella, Parepichloë, Periglandula, Pochonia, Pseudomeria, Regiocrella, Romanoa, Samuelsia, Shimizuomyces, Sphacelia, Sphaerocordyceps, Stereocrea, Tyrannicordyceps and Ustilaginoidea. Chamaeleomyces was synonymized under Metarhizium by Kepler et al. (2014) and Neotyphodium was also synonymised under Epichloe (Leuchtmann et al. 2014). Sphacelia was combined into Claviceps (Rossman et al. 2016). Two new genera Helicocollum and Nigelia were introduced under this family (Luangsa-ard et al. 2017a, b). Neoclaviceps and Cepsiclava were combined into Aciculosporium (Píchová et al. 2018). Although no formal transfer had been made, molecular analyses by Zare \& Gams (2001) and Kepler et al. (2014) showed that Rotiferophthora belongs in Clavicipitaceae and not Cordycipitaceae. Linearistroma, Metacordyceps, Nomuraea and Stereocrea were transferred to Metarhizium (White and Glenn (1994, Kepler et al. 2014). The family is therefore in need of revision and the asexual and sexual morph names need resolving. In this entry, Aschersonia insperata (asexual morph) and Atkinsonella hypoxylon (sexual morh) are illustrated. 


\section{Ecological and economic significance of Clavicipitaceae}

The genera Aschersonia, Balansia, Claviceps, Dothichloe and Hypocrella were earlier considered economically important as most of their species infect grasses, and are harmful to cattle and other animals (e.g. insects) and cause ergot toxicity (Tulasne 1853, Atkinson 1905, Seaver 1920, Springer \& Clardy 1980). Most species of Claviceps produce ergots and often produce beneficial drugs (Molitoris 1994, Kren \& Cvak 2003). Indole-diterpenes and ergot alkaloids isolated from Claviceps cynodontis cause tremors in cattle (Uhlig et al. 2009). The secondary metabolites of Claviceps, the ergot alkaloids, have been widely researched in the chemical industry because of their toxicity (Hulvová et al. 2013). Some species are pathogenic on economic plants (Hulvová et al. 2013).

\section{Genera included in Clavicipitaceae}

Aciculosporium I. Miyake, Bot. Mag., Tokyo 22: (307) (1908)

Index Fungorum number: IF41; 4 morphological species (Species Fungorum 2020), 3 species with sequence data.

Type species - Aciculosporium take I. Miyake

Notes - This genus contains bamboo specific endophytic pathogens (Oguchi 2001, Tanaka et al. 2003). The species produce multi-septate ascospores with no obvious part spores (Oguchi 2001). Neoclaviceps and Cepsiclava were combined under Aciculosporium based on phylogenetic and evolutionary analyses (Píchová et al. 2018).

Aschersonia Mont., Annls Sci. Nat., Bot., sér. 3 10: 121 (1848)

Index Fungorum number: IF7236; 175 morphological species (Species Fungorum 2020), 12 species with sequence data.

Type species - Aschersonia tahitensis Mont.

Notes - The genus comprises insect parasitic fungi. The sexual morphs are hypocrella-like (Mongkolsamrit et al. 2009). Some species may control insect pests (Meekes et al. 2002, Wei et al. 2016). Rossman et al. (2016) recommended protecting Hypocrella over Aschersonia although Aschersonia is an earlier name. However, the name Aschersonia was wildly used and many molecular data were provided to the species of this genus. To respect the earlier name Aschersonia, we suggest preserving Aschersonia over Hypocrella. Species infect scale insect and whiteflies and produce bright, pulvinate or discoid stromata or conidiomata, superficial or embedded perithecia, cylindrical asci, non-disarticulating ascospores, and fusiform conidia with acute ends (Chaverri et al. 2008). In this entry we illustrate Aschersonia insperata.

Atkinsonella Diehl, Agriculture Monogr., US Dept Agric. 4: 48 (1950)

Index Fungorum number: IF449; 2 species with sequence data.

Type species - Atkinsonella hypoxylon (Peck) Diehl

Notes - This grass pathogen was separated from Epichloe based on morphology, producing both micro- and macroconidia (Diehl 1950) and is characterised by stromata immersed and cylindrical spores (Ambrose et al. 2014). The asexual morph is acremonium-like (Ginns 2011). In this entry, Atkinsonella hypoxylon is illustrated. Atkinsonella hypoxylon was described as Epichloe hypoxylon from infected grass (Peck 1875). Diehl (1950) transferred it to Atkinsonella hypoxylon based on morphology. Ginns (2011) accepted Balansia hypoxylon as the correct name but this was not confirmed by Ambrose et al. (2014). The specimen (DAOM 211269) was identified as Balansia hypoxylon because of its perithecia and mature ascospores (Fig. 71, Ginns 2011).

Balansia Speg., Anal. Soc. cient.argent. 19(1): 45 (1885)

Index Fungorum number: IF497; 35 morphological species (Species Fungorum 2020), 14 species with sequence data.

Type species - Balansia claviceps Speg. 


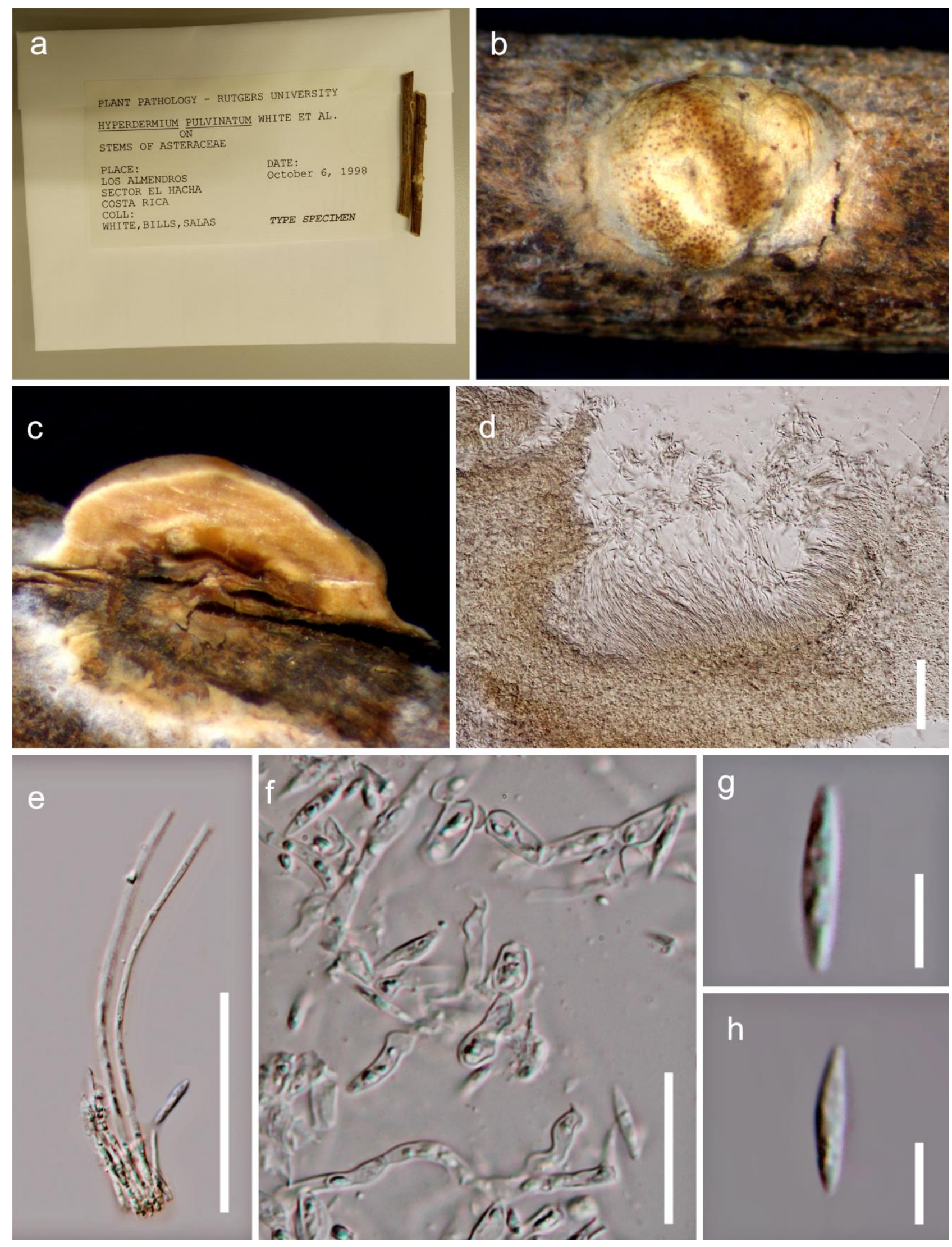

Figure 70 - Aschersonia insperata (Material examined - Philippines, on larva of unidentified homopteran on leaf of Maoutia setosa Wedd. (Urticaceae), 6 October 1998, M.C. Rombach, CUP 67438, paratype). a Herbarium material. b Overview of the stroma and host. c Vertical section of the stroma. d Stroma e Conidiogenous cells, phialides. f Hyphal bodies. g, h Conidia. Scale bars: $\mathrm{d}$ $=50 \mu \mathrm{m}, \mathrm{e}, \mathrm{f}=20 \mu \mathrm{m}, \mathrm{g}, \mathrm{h}=5 \mu \mathrm{m}$. 


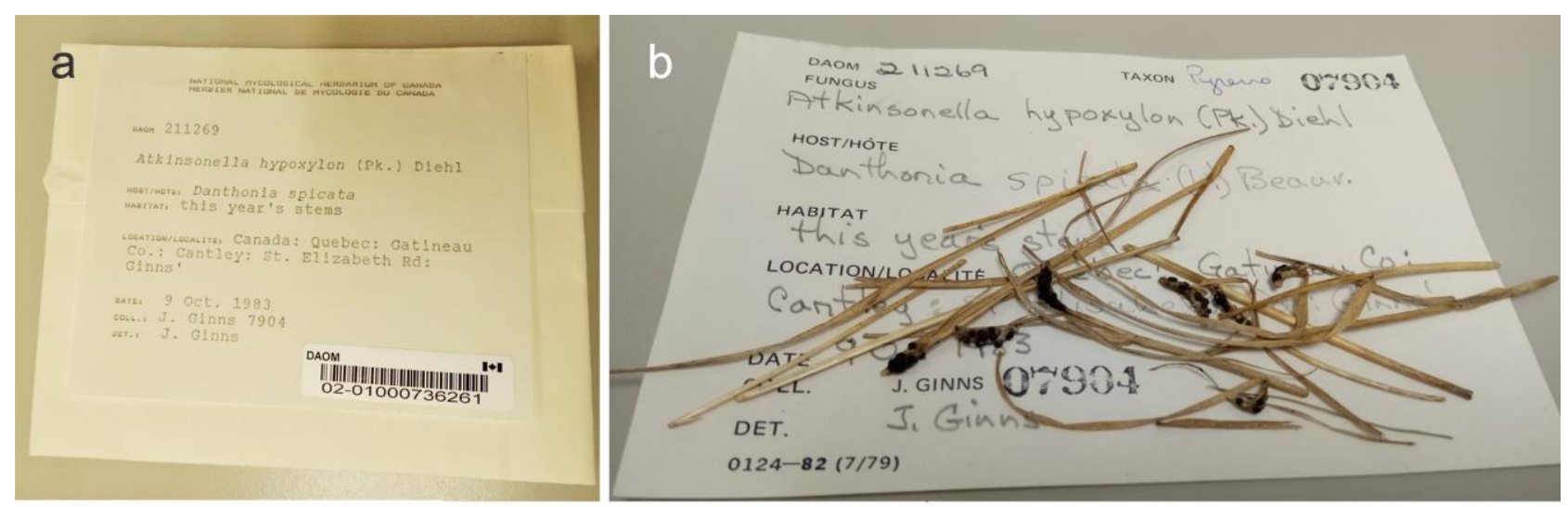

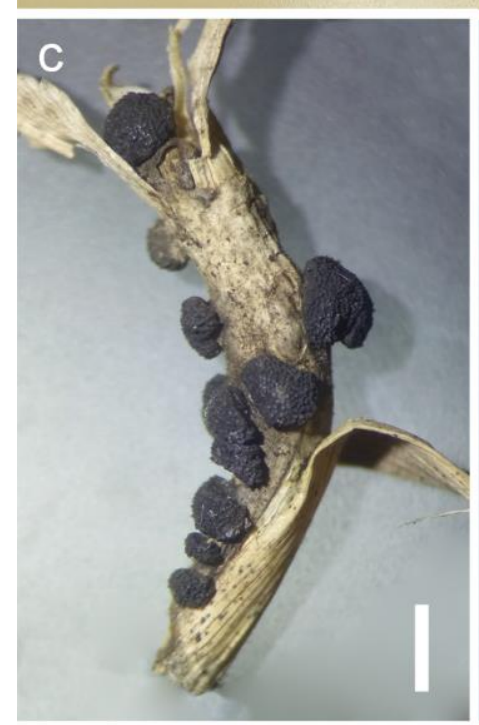
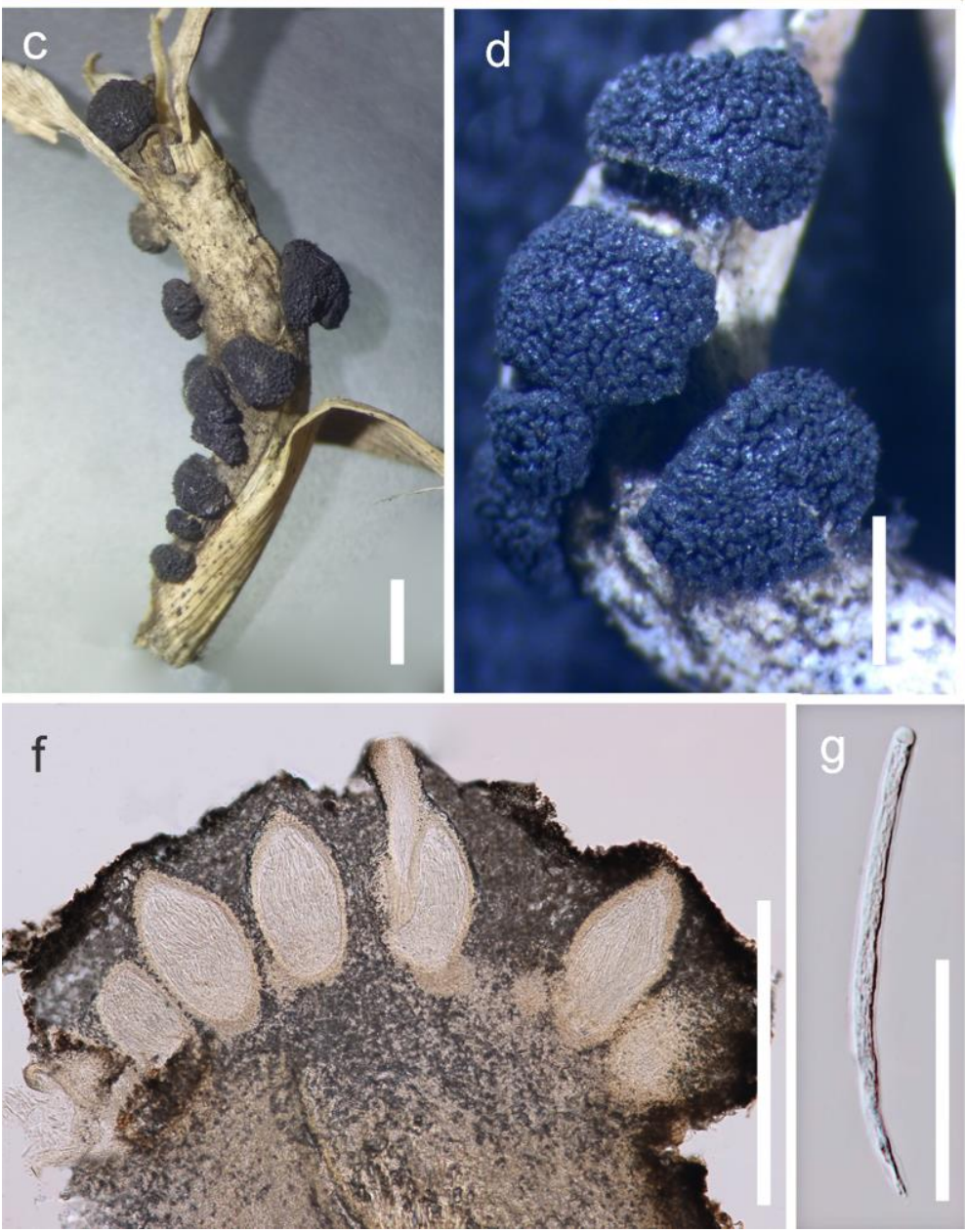

e

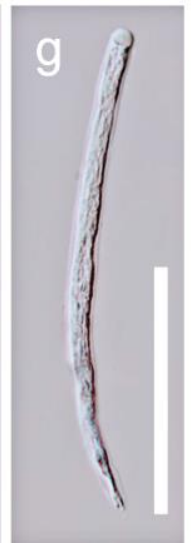

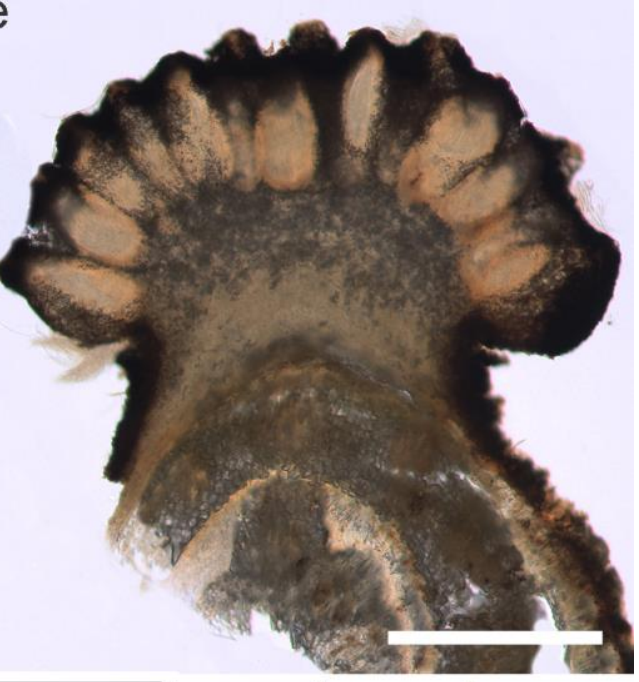
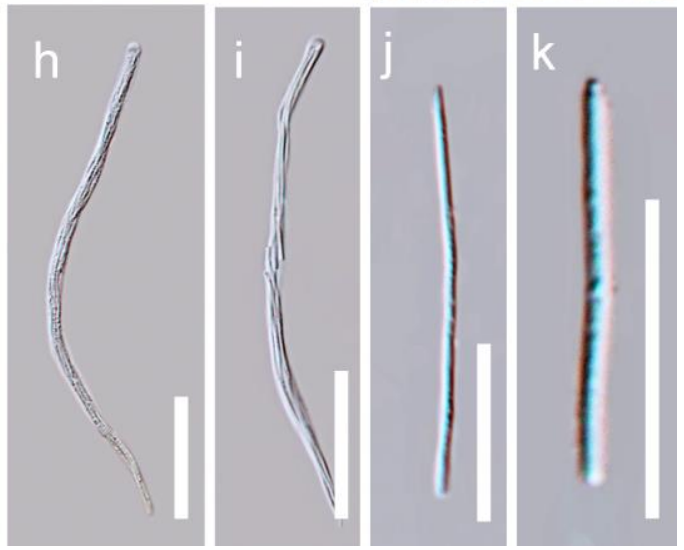

Figure 71 - Atkinsonella hypoxylon (Material examined - Canada, on living and dead stems of current year's growth of Danthonia spicata, 9 October 1983, J. Ginns, DAOM 211269). a Herbarium material. b-d Overview of the stromata and host. e Vertical section of the ascomata. $f$ Stromata. g-i Immature to mature asci. j, k Secondly ascospores. Scale bars: c, d = $1 \mathrm{~mm}, \mathrm{e}, \mathrm{f}=500$ $\mu \mathrm{m}, \mathrm{g}-\mathrm{i}=50 \mu \mathrm{m}, \mathrm{j}, \mathrm{k}=20 \mu \mathrm{m}$.

Notes - Most species are grass-associated (Sung et al. 2007). The asexual morph is linked to Ephelis (Glenn et al. 1996). Species are characterised by brown to black, superficial or immersed stromata, with or without stipes (James \& White 1994).

Cavimalum Y oshim. Doi, Dargan \& K.S. Thind, Bull. natn. Sci. Mus., Tokyo, B 3(1): 23 (1977) Index Fungorum number: IF861; 2 morphological species (Species Fungorum 2020). Type species - Cavimalum indicum Yoshim. Doi, Dargan \& K.S. Thind 
Notes - The genus comprises two poorly known species which infect bamboo and produce immersed stromata, and irregularly septate ascospores (Doi et al. 1977).

Claviceps Tul., Annls Sci. Nat., Bot., sér. 3 20: 43 (1853)

Index Fungorum number: IF1092; 63 morphological species (Species Fungorum 2020), 40 species with sequence data.

Type species - Claviceps purpurea (Fr.) Tul.

Notes - Doubts concerning the taxonomic status of this genus were resolved in recent years with molecular phylogenies and Claviceps was confirmed as the type genus of Clavicipitaceae (Píchová \& Parbery 1999, Yokoyama et al. 2006, Sung et al. 2007, Tanaka et al. 2008). Claviceps species can infect about 600 species of monocotyledonous plants (Hulvová et al. 2013) and the asexual morph, growing on honey dew, is reported in Sphacelia. The type of Sphacelia, S. segetum, has long been regarded as the asexual morph of $C$. purpurea (Tulasne 1853). The genus infects grasses and cereal crops and produces multi-colored sclerotia with 1-celled, hyaline, ephelidial conidia and stipitate and capitulum stromata with partially embedded perithecia (White et al. 2003).

Collarina Giraldo, Gené \& Guarro, Persoonia, Mol. Phyl. Evol. Fungi 33: 271 (2014)

Index Fungorum number: IF809407; 1 species with sequence data.

Type species - Collarina aurantiaca Giraldo, Gené \& Guarro

Notes - This genus was isolated from soil and is characterised by conidiophores with simple, shorter phialides and funnel-shaped collarettes, setae and large and brownish conidia (Crous et al. 2014b).

Conoideocrella D. Johnson, G.H. Sung, Hywel-Jones \& Spatafora, Mycol. Res. 113(3): 286 (2009) Index Fungorum number: IF512028; 3 morphological species (Species Fungorum 2020), 2species with sequence data.

Type species - Conoideocrella luteorostrata (Zimm.) D. Johnson, G.H. Sung, Hywel-Jones \& Spatafora

Notes - The genus was introduced for two entomophagous species from Torrubiella based on phylogenetic analyses (Johnson et al. 2009). Mongkolsamrit et al. (2016) introduced a third species, Conoideocrella krungchingensis. The genus is characterised by pulvinate to planar stromata and elongated, conical-shaped perithecia, while the hosts are whiteflies and scale insects (Johnson et al. 2009).

Corallocytostroma Y.N. Yu \& Z.Y. Zhang, Acta microbiol sin. 20(3): 232 (1980)

Index Fungorum number: IF7773; 2 morphological species (Species Fungorum 2020), 1 species with sequence data.

Type species - Corallocytostroma oryzae Y.N. Yu \& Z.Y. Zhang

Notes - The genus was introduced with one species from Yunnan Province, China. Shivas et al. (1997) described C. ornithocopreoides from Australia. Both species are plant pathogens. The genus is characterised by coralloid conidiomata with convoluted locules and holoblastic conidia (Shivas et al. 1997).

Dussiella Pat., Bull. Soc. mycol. Fr. 6: 107 (1890)

Index Fungorum number: IF1724; 3 morphological species (Species Fungorum 2020), 1 species with sequence data.

Type species - Dussiella tuberiformis (Berk. \& Ravenel) Pat.

Notes - Two species were added to this monotypic genus by Rick (1906) and Höhnel (1907a) respectively. The type species was considered as entomopathogenic, occurring on scale insects, and host jumping onto close plant fungi species (Kepler et al. 2012). The genus is characterised by superficial, subcylindrical perithecia, cylindrical asci with refractive apices, guttulate until the 
ascospores develop, multi-septate ascospores, breaking into part-spores and 1-septate, lunate conidia, swelling in water (Patouillard 1890, Höhnel 1907a, Kepler et al. 2012).

Ephelis Fr., Summa veg. Scand., Section Post. (Stockholm): 370 (1849)

Index Fungorum number: IF8185; 4 morphological species (Species Fungorum 2020), 2 species with sequence data.

Type species - Ephelis mexicana Fr.

Notes - The sexual morph has been linked to Atkinsonella, Balansia, Epichloe and Myriogenospora (White et al. 2003). The genus infects grasses, and produces holoblastic conidia in a slender, filiform palisade layer of conidiogenous cells (White et al. 2003, Hernández-Restrepo et al. 2016b).

Epichloe (Fr.) Tul. \& C. Tul., Select. fung. carpol. (Paris) 3: 24 (1865)

Index Fungorum number: IF622348; 45 morphological species (Species Fungorum 2020), 32 species with sequence data.

Type species - Epichloe typhina (Pers.) Brockm?

Notes - Epichloe species are endophytes which form symbiotic associations with cool-season grasses (Poaceae subfamily Pooideae) and produce yellow to orange ascomata (White 1994, Scott 2001, White \& Reddy 1998). The asexual morph has been linked to Ephelis (White et al. 2003). The genus produces bright stromata without stipes, with numerous perithecia and yellow to orange conidiomata and conidia on the surface of leaves (Leuchtmann et al. 2014).

Epicrea Petr., Sydowia 4(1-6): 325 (1950)

Index Fungorum number: IF1857; 1 morphological species.

Type species - Epicrea insignis Petr.

Notes - This monotypic genus is parasitic on Hypocrella chusqueae in Ecuador and is characterised by dense, ovoid to ellipsoid perithecia and cylindrical asci (Petrak 1950).

Helicocollum Luangsa-ard, Mongkols., Noisrip. \& Thanakitp., Mycol Prog 16(4): 424 (2017)

Index Fungorum number: IF817483; 3 species with sequence data.

Type species - Helicocollum surathaniense Luangsa-ard, Mongkols., Noisrip. \& Thanakitp.

Notes - This genus is closely related to Aschersonia, Moelleriella, Regiocrella, and Samuelsia, all pathogens of scale insects and whiteflies in Clavicipitaceae (Luangsa-ard et al. 2017a). Helicocollum differs from other scale insect pathogens in having phialides with helical necks and synnematous or sporodochial pycnidial conidiomata. The morphological features of its phialides resemble Hirsutella in the Ophiocordycipitaceae (Luangsa-ard et al. 2017a).

Helminthascus Tranzschel, Trudy S. Petersb. Obschch. Est. Otd. Bot. 28: 331 (1898)

Index Fungorum number: IF2258; 1 morphological species.

Type species - Helminthascus arachnophthorus Tranzschel

Notes - This genus comprises a single entomogenous species (Saccardo 1902, Popov et al. 2012) and is characterised by discoid stroma, immersed perithecia, cylindrical asci and septate ascospores (Saccardo 1902).

Heteroepichloe E. Tanaka, C. Tanaka, Gafur \& Tsuda, Mycoscience 43(2): 92 (2002)

Index Fungorum number: IF622360; 2 species with sequence data

Type species - Heteroepichloe bambusae (Pat.) E. Tanaka, C. Tanaka, Gafur \& Tsuda

Notes - Based on phylogenetic analyses, the genus was established to accommodate two species transferred from Epichloe. The asexual morph is ephelis-like and infects bamboo and produces black stromata, embedded perithecia and cylindrical asci with septate ascospores (Tanaka et al. 2002). 
Konradia Racib., Parasit. Alg. Pilze Java's (Jakarta) 2: 15 (1900)

Index Fungorum number: IF2581; 2 morphological species (Species Fungorum 2020).

Type species - Konradia bambusina Racib

Notes - The genus comprises two plant pathogenic species. No asexual morph has been reported. The genus infects bamboo and producing black stromata, immersed, globose perithecia, clavate asci and filiform and yellowish ascospores, becoming brown to dark brown after breaking into part-spores (Saccardo 1902).

Loculistroma F. Patt. \& Charles, Bull. Bureau Plant Industry U.S. Dep. Agric. 171: 11 (1910)

Index Fungorum number: IF2913; 1 morphological species.

Type species - Loculistroma bambusae F. Patt., Charles \& Veihmeyer

Notes - The genus was introduced for a single plant pathogenic species with a cladosporiumlike asexual morph (White et al. 2003). It infects bamboo and produces green to black, cylindrical, subsessile stromata, subglobose subimmersed perithecia, clavate to cylindrical asci and fusiform, olivaceous, 3-septate ascospores (Patterson et al. 1910).

Metapochonia Kepler, Rehner \& Humber, Mycologia 106(4): 820 (2014)

Index Fungorum number: IF806070; 9 morphological species (Species Fungorum 2020), 7 species with sequence data. Humber

Type species - Metapochonia suchlasporia (W. Gams \& Dackman) Kepler, Rehner \&

Notes - This genus was introduced to accommodate five species. Zhang et al. (2017c) described a new cave-inhabiting species. No sexual morph has been identified (Kepler et al. 2014). The genus infects nematodes and rotifers and has been isolated from soil and plant roots and produces conidia on slender, awl-shaped phialides (Kepler et al. 2014).

Metarhiziopsis D.W. Li, R.S. Cowles \& C.R. Vossbrinck, Mycologia 100(3): 462 (2008)

Index Fungorum number: IF511393; 1 species with sequence data.

Type species - Metarhiziopsis microspora D.W. Li, R.S. Cowles \& C.R. Vossbrinck

Notes - Metarhiziopsis was introduced as a monotypic entomopathogenic genus based on morphology and phylogenetic analyses ( $\mathrm{Li}$ et al. 2008). No sexual morph has been reported. It infects insects producing white to buff, cupulate sporodochia, surrounded by differentiated septate setae, cylindrical, unicellular phialides and unicellular, catenulate conidia ( $\mathrm{Li}$ et al. 2008).

Metarhizium Sorokīn, Veg. Parasitenk. Mensch Tieren 2: 268 (1879)

Index Fungorum number: IF8912; 47 morphological species (Species Fungorum 2020), 36 species with sequence data.

Type species - Metarhizium anisopliae (Metschn.) Sorokīn

Notes - This genus was emended by Rombach et al. (1987) and Kepler et al. (2014). It includes green-spored, Nomuraea ( $N$. rileyi), several species formerly included in Paecilomyces and Chameoleomyces. The sexual morphs were described as metacordyceps-like and most species in Metacordyceps have been transferred to Metarhizium (Kepler et al. 2014), including the type species. The genus infects arthropods and nematodes, can be found in the soil, colonizes plant roots and act as endophytes, producing variously branched conidiophores without synnemata and hyaline to brown or green conidia (Kepler et al. 2014). The sexual morph is characterised by tough, whitish greenish yellow to greenish, cylindrical to enlarging stromata, partially or completely immersed perithecia and ascospores which may or may not break into part-spores (Sung et al. 2007).

Moelleriella Bres., Boll. Soc. bot. ital. 44: 292 (1897)

Index Fungorum number: IF3231; 39 morphological species (Species Fungorum 2020), 17 species with sequence data.

Type species - Moelleriella sulphurea (Bres.) Bres. 
Notes - This genus is entomopathogenic (Chaverri et al. 2008). The asexual morphs are aschersonia-like (Chaverri et al. 2008). It infects scale insects and whiteflies and produces bright coloured, pulvinate or discoid stromata or conidiomata, superficial or embedded perithecia, cylindrical asci, filiform multiseptate ascospores that disarticulate at maturity inside the ascus and fusiform conidia (Chaverri et al. 2008).

Mycomalus Möller, Bot. Mitt. Trop. 9: 300 (1901)

Index Fungorum number: IF3324; 1 morphological species.

Type species - Mycomalus bambusinus Möller

Notes - This monotypic genus was introduced as a plant pathogen . It infects bamboo and produces white, subglobose stromata, immersed, obpyriform perithecia and ascospores which disarticulate into fusiform part-spores (Möller 1901).

Mycophilomyces Crous \& M.J. Wingf., Persoonia 37: 325 (2016)

Index Fungorum number: IF819075; 1 species with sequence data.

Type species - Mycophilomyces periconiae Crous \& M.J. Wingf.

Notes - Mycophilomyces was introduced with a single species, hyperparasite on Periconia on leaves of Albizia falcataria. It has multiseptate conidiophores and obclavate solitary conidia (Crous et al. 2016a). No sexual morph is known.

Myriogenospora G.F. Atk., Bull. Torrey bot. Club 21(5): 225 (1894)

Index Fungorum number: IF3371; 4 morphological species (Species Fungorum 2020), 1 species with sequence data.

Type species - Myriogenospora paspali G.F. Atk.

Notes - Myriogenospora atramentosa causes "tangle top disease" of mang grasses (White et al. 2003). The asexual morph is ephelis-like (White \& Glenn 1994). The genus infects grasses producing linear, hard, black stromata, immersed, subglobose perithecia and ascospores which disarticulate into cylindrical part-spores (White and Glenn 1994).

Neobarya Lowen, Syst. Ascom. 5(1): 121 (1986)

Index Fungorum number: IF25587; 11 morphological species (Species Fungorum 2020), 1 species with sequence data.

Type species - Neobarya parasitica (Fuckel) Lowen

Notes - The asexual morphs are acremonium-like, lecanicillium-like, paecilomyces-like, calcarisporium-like or torrubiella-like (Candoussau et al. 2007). This genus was reported as hostspecific parasites of lichens and non lichenized fungi (Lawrey et al. 2015). It produces soft, bright coloured stromata, sessile, superficial perithecia and filiform, aseptate or septate, entire ascospores (Candoussau et al. 2007).

Neocordyceps Kobayasi, J. Jap. Bot. 59(6): 187 (1984)

Index Fungorum number: IF25653; 1 morphological species.

Type species - Neocordyceps kohyasanensis Kobayasi

Notes - This genus was introduced as a subgenus of Cordyceps with a single plant pathogenic species. It has a hymenostilbe-like asexual morph (White et al. 2003). The genus is characterised by clavate, stipitate stromata with an elongate fertile part, pyriform to ovoid, purple to black, immersed perithecia and fusiform, septate, entire ascospores (Kobayasi 1981, White et al. 2003).

Nigelia Luangsa-ard, Tasan. \& Thanakitp., i Mycol. Progr. 16(4): 378 (2017)

Index Fungorum number: IF823565; 2 species with sequence data

Type species - Nigelia aurantiaca Luangsa-ard, Thanakitp. \& Tasan.

Notes - Nigelia was introduced as an invertebrate-pathogenic genus based on morphology and phylogenetic analyses. The genus is characterised by yellow to reddish brown, cylindrical, 
stipitate, stromata with a cylindrical, clavate to irregularly shapedfertile part, ovoid with curved, immersed perithecia and filiform, septate, whole ascospores or fragmenting into part spores (Luangsa-ard et al. 2017b). The asexual morph is characterised by verticillately or irregularly branched conidiophores and solitary conidiogenous cells or phialides with or without lateral necks (Luangsa-ard et al. 2017b).

Nigrocornus Ryley \& Langdon, Mycology Series (New York) 19: 266 (2003)

Index Fungorum number: IF28732; 1 morphological species.

Type species - Nigrocornus scleroticus (Pat.) Ryley

Notes - The genus was established to accommodate a single plant pathogenic species transferred from Balansia. The genus is characterised by black, corniform, sessile stromata, lageniform to obpyriform, immersed perithecia and filiform, 7-septate ascospores, ultimately becoming 3-septate (White et al. 2003). The asexual morph bears simple, indeterminate conidiophores and holoblastic, obclavate, multiguttulate, aseptate conidia (White et al. 2003).

Orbiocrella D. Johnson, G.H. Sung, Hywel-Jones \& Spatafora, Mycol. Res. 113(3): 286 (2009)

Index Fungorum number: IF512031; 1 species with sequence data Spatafora

Type species - Orbiocrella petchii (Hywel-Jones) D. Johnson, G.H. Sung, Hywel-Jones \&

Notes - This entomophagous genus contains a single species transferred from Torrubiella (Johnson et al. 2009). The asexual morph is simplicillium-like (Johnson et al. 2009). The genus is characterised by ring-like, sessile stroma, superficial, flask-shaped perithecia and filiform, multiseptate ascospores, not disarticulating into part-spores (Johnson et al. 2009).

Parepichloe J.F. White \& P.V. Reddy, Mycologia 90(2): 231 (1998)

Index Fungorum number: IF622359; 4 morphological species (Species Fungorum 2020), 2 species with sequence data.

Type species - Parepichloe cinerea (Berk. \& Broome) J.F. White \& P.V. Reddy

Notes - The genus was established to accommodate epibiotic species transferred from Epichloe. No asexual morph is known (White et al. 2003). The species infect grasses and produce cylindrical to fusiform, gray to black, sessile stromata, immersed, ovoid perithecia and filiform, multiseptate ascospores, not disarticulating into part-spores (White \& Reddy 1998).

Periglandula U. Steiner, E. Leistner \& Leuchtm., Mycologia 103(5): 1137 (2011)

Index Fungorum number: IF561039; 2 morphological species (Species Fungorum 2020), 1 species with sequence data.

Type species - Periglandula ipomoeae U. Steiner, E. Leistner \& Schardl

Notes - The genus forms a symbiosis with plants (Steiner et al. 2011). It produces epibiotic mycelium, chlamydospore-like and synnema-like structures, but conidia have not been observed (Steiner et al. 2011).

Pochonia Bat. \& O.M. Fonseca, Publicações Inst. Micol. Recife 462: 4 (1965)

Index Fungorum number: IF9479; 3 morphological species (Species Fungorum 2020), 2 species with sequence data.

Type species - Pochonia humicola Bat. \& O.M. Fonseca

Notes - The sexual morph of this genus is metacordyceps-like (Zare \& Gams 2007). The genus infects nematodes and produces mostly prostrate, rarely erect conidiophores, verticillate or solitary, aculeate phialides, subglobose, ellipsoidal to rod-shaped conidia and dictyochlamydospores (Batista \& Fonsêca 1965).

Pseudomeria G.L. Barron, Can. J. Bot. 58(4): 443 (1980)

Index Fungorum number: IF9589; 1 morphological species. 
Type species - Pseudomeria mucosa G.L. Barron

Notes - This monotypic genus is a parasite of rotifers (Barron 1980). The sexual morph is undetermined. The genus is characterised by unbranched, septate conidiophores and globose conidia with a conspicuous basal slime pad (Barron 1980).

Regiocrella P. Chaverri \& K.T. Hodge, Mycologia 97(6): 1232 (2006)

Index Fungorum number: IF500786; 2 species with sequence data.

Type species - Regiocrella camerunensis P. Chaverri \& H.C. Evans

Notes - This entomophagous genus has a sphacelia-like asexual morph (Chaverri et al. 2005). It infects scale insects and produces pale orange, sessile stromata, semi-immersed, obpyriform perithecia, cylindrical, not capitate asci and unicellular, fusiform ascospores (Chaverri et al. 2005).

Romanoa Thirum., R.C. Ist. Sup. Sanitä, (Rome) 17: 1326 (1954)

Index Fungorum number: IF4779; 1 species with sequence data.

Type species - Romanoa terricola Thirum.

Notes - The genus was isolated from soil.

Rotiferophthora G.L. Barron, Can. J. Bot. 69(3): 495 (1991)

Index Fungorum number: IF25566; 26 morphological species (Species Fungorum 2020), 2 species with sequence data.

Type species - Rotiferophthora globospora G.L. Barron

Notes - The genus was established by to accommodate diheterospora-like endoparasites of rotifers (Barron 1991). There is no sexual morph linked to this genus. The genus infects rotifers and produces phialides with short conidiiferous necks and dictyochlamydospores (Barron 1991).

Samuelsia P. Chaverri \& K.T. Hodge, Stud. Mycol. 60: 59 (2008)

Index Fungorum number: IF511385; 6 morphological species (Species Fungorum 2020), 3 species with sequence data.

Type species - Samuelsia rufobrunnea P. Chaverri \& K.T. Hodge

Notes - This entomophagous genus contains five species based on morphology and phylogenetic analyses. The asexual morph is aschersonia-like (Chaverri et al. 2008). Mongkolsamrit et al. (2011) described a new species, Samuelsia mundiveteris. The genus infects scale insects and whiteflies and produces bright coloured, pulvinate or discoid stromata or conidiomata, superficial or embedded perithecia, cylindrical asci, long-fusiform, non-disarticulating ascospores and small allantoid conidia (Chaverri et al. 2008).

Shimizuomyces Kobayasi, Bull. natn. Sci. Mus., Tokyo, B 7(1): 1 (1981)

Index Fungorum number: IF5024; 2 morphological species (Species Fungorum 2020), 1 species with sequence data.

Type species - Shimizuomyces paradoxus Kobayasi

Notes - This is a plant pathogenic genus. Sung et al. (2007, 2010) provided molecular data and described the culture characteristics of Shimizuomyces paradoxus. The genus has no asexual morph. It is characterised by fleshy, stipitate stromata, clavate to cylindrical stroma, immersed perithecia and fusiform, septate ascospores (Kobayasi 1981).

Sphaerocordyceps Kobayasi, Bull. natn. Sci. Mus., Tokyo, B 7(1): 2 (1981)

Index Fungorum number: IF5093; 2 morphological species (Species Fungorum 2020).

Type species - Sphaerocordyceps palustris (Berk. \& Broome) Kobayasi

Notes - This genus was segregated from Cordyceps. There is no known asexual morph. The genus infects insects and is characterised by brownish-purple or flesh-colour, stipitate stromata, and globose perithecia (Kobayashi 1981). 
Tyrannicordyceps Kepler \& Spatafora, Index Fungorum 12: 1 (2012)

Index Fungorum number: IF550079; 5 morphological species (Species Fungorum 2020), 1 species with sequence data.

Type species - Tyrannicordyceps fratricida (Tanda \& Kobayasi) Kepler \& Spatafora

Notes - This fungicolous genus was introduced for five species transferred from Cordyceps based on morphology and phylogenetic analyses. The asexual morph is verticillium-like (Kepler et al. 2012). It infects both plants and insects and produces pallid, yellow or sometimes vermilion stromata and filiform, septate ascospores which may break into part-spores (Kepler et al. 2012).

Ustilaginoidea Bref., Unters. Gesammtgeb. Mykol. (Liepzig) 12: 194 (1895)

Index Fungorum number: IF10364; 15 morphological species (Tanaka et al. 2008), 3 species with sequence data.

Type species - Ustilaginoidea oryzae (Pat.) Bref.

Notes - This is a plant pathogenic genus. Tanaka et al. (2008) reported the holomorph and provided clear illustrations of the common rice disease caused by Ustilaginoidea virens . The genus infects grasses and produces dark, hard sclerotia and dark green or brown, subglobose conidia (White et al. 2003).

Clypeophysalosporaceae A. Giraldo \& Crous, Mycol. Progr. 16(4): 340 (2017)

Index Fungorum number: IF818514; Facesoffungi number: FoF06867; 33 species.

Endophytic, saprobic or pathogenic mostly on leaves of Eucalyptus spp. Sexual morph: Ascomata perithecial, brown or black, immersed, solitary, rarely in pairs, globose, sometimes with clypeus or pseudoclypeus. Peridium of several layers of brown and flattened cells. Paraphyses septate, numerous, hyaline, hypha-like, flexuose. Asci 8-spored, unitunicate, cylindrical or obclavate, hyaline, with apical ring staining in Melzer's reagent. Ascospores uniseriate or biseriate, hyaline, fusoid-ellipsoidal, unicellular, commonly surrounded by a mucilaginous sheath. Asexual morph: Coelomycetous or hyphomycetous. Conidiomata pycnidial, globose, solitary to aggregated, brown. Conidiophores differentiated or reduced to conidiogenous cells (pycnidial form), forming fascicules or rosettes on leaves, or solitary on the hyphae (hyphomycetous form), cylindrical to subcylindrical, brown to pale grey-brown. Conidiogenous cells phialidic, ampulliform, lageniform or subcylindrical, terminal and intercalary, pale to medium brown, apex with flared collarette. Conidia solitary or in slimy heads, subcylindrical, curved, hyaline, obtuse apex and truncate to subtruncate base (adapted from Giraldo \& Crous 2017a).

Type genus - Clypeophysalospora H.J. Swart

Notes - Clypeophysalosporaceae was introduced by Giraldo \& Crous (2017a) to accommodate Bagadiella, Clypeophysalospora, Neophysalospora and Plectosphaerella. These genera share characteristics in terms of both sexual and asexual morphs, host specificity (mainly Eucalyptus spp.) and distribution (Australia, South Africa, Giraldo \& Crous 2017a). Neophysalospora eucalypti has also been isolated from Corymbia henryi (Myrtaceae) (Swart 1981, Cheewangkoon et al. 2009, Crous et al. 2011, 2014b).

\section{Ecological and economic significance of Clypeophysalosporaceae}

Members in this family usually grow on living or dead leaves of various plants, and are mostly endophytes, saprobes or pathogens (Swart et al. 1981, Cheewangkoon 2009).

\section{Genera included in Clypeophysalosporaceae}

Bagadiella Cheew. \& Crous, Persoonia 23: 59 (2009)

Index Fungorum number: IF513840; 4 species with sequence data.

Type species - Bagadiella lunata Cheewangkoon \& Crous

Notes - Cheewangkoon et al. (2009) introduced this genus with Bagadiella lunata as the type species and there are four epithets recorded under Bagadiella (Cheewangkoon et al. 2009, Crous et al. 2011). All species have been reported with asexual morphs and B. koalae is coelomycetous. 
Bagadiella koalae was reported from leaves of Eucalyptus globulus eaten by koala and B. victoriae was reported from leaves of Eucalyptus sp. in Australia (Crous et al. 2011). Bagadiella is characterised by caespituli pale, suprastomatal, pseudoparenchyma with a substomatal cavity froming a rosette of conidiophores. Conidiophores are micronematous, cylindrical and dichotomously branched. Conidiogenous cells are terminal, monophialidic, branched, subcylindrical to lageniform and conidia are hyaline, lunate, curved, with a round apices, tapering towards a subtruncate base and borne in slimy heads.

Clypeophysalospora H.J. Swart, Trans. Br. mycol. Soc. 76(1): 93 (1981)

Index Fungorum number: IF1121; 1 species with sequence data.

Type species - Clypeophysalospora latitans (Sacc.) H.J. Swart

Notes - Kang et al. (1999c) considered Clypeosphaeria to be similar with Clypeophysalospora, and $C$. latitans was accommodated in Clypeosphaeriaceae. Senanayake et al. (2015) used LSU and ITS sequence data of $C$. uniseptata to consider the affinity of this family with Amphisphaeriales. The concept of Clypeosphaeriaceae (based on C. uniseptata; Senanayake et al. 2015) was not followed in Jaklitsch et al. (2016a). Giraldo et al. (2017a) included the sequence of C. uniseptata in a LSU analysis and this species is not related at the family level with Clypeophysalospora latitans, and therefore they introduced a new family to accommodate the latter taxon.

Neophysalospora Crous \& M.J. Wingf., Persoonia 33: 247 (2014)

Index Fungorum number: IF810608; 1 species with sequence data.

Type species - Neophysalospora eucalypti Crous \& M.J. Wingf.

Notes - Crous et al. (2014b) introduced Neophysalospora eucalypti from leaves of Corymbia henryi (Myrtaceae) in Mozambique. This species has endophytic and plant pathogenic lifestyles. Neophysalospora is a holomorphic genus. Asci are unitunicate with apical $\mathrm{J}+$ rings and asexual morphs comprise conidiophores lining the inner conidiomatal wall, which are straight to curved, hyaline to pale brown.

Plectosphaera Theiss., Annls mycol. 14(6): 413 (1917)

Index Fungorum number: IF4196; 27 morphological species (Species Fungorum 2020), 1 species with sequence data.

Type species - Plectosphaera eucalypti (Cooke \& Massee) H.J. Swart

Notes - Cooke (1888) introduced Plectosphaera eucalypti from leaves of Eucalyptus in Australia. Summerell (2006) cultured this fungus for the first time and provided sequence data. Colonies on MEA, comprise flat, smooth, catenate, submerged spreading mycelium, with surface cinnamon, smoke grey due to black ascomata forming from outer region of the colony.

Clypeosphaeriaceae G. Winter, Rabenh. Krypt.-Fl., Edn 2 (Leipzig) 1.2: 554 (1886)

Index Fungorum number: IF80613; Facesoffungi number: FoF01776; 53 species.

Hemibiotrophic or saprobic on woody or herbaceous plants. Sexual morph: Pseudoclypeus comprising both host and fungal tissues, black. Ascomata immersed to erumpent, rarely superficial, solitary or aggregated, globose to subglobose, coriaceous, brown to black, ostiolate, papillate. Papilla short, narrow, internally lined with hyaline, filamentous periphyses. Peridium comprising dark brown to light brown, thick-walled cells of textura angularis, inwardly hyaline. Paraphyses numerous, hypha-like, septate, flexuose, embedded in a gelatinous matrix. Asci 8-spored, unitunicate, cylindrical to broadly cylindrical, pedicellate, with a wedge-shaped, $\mathrm{J}_{-}$, or $\mathrm{J}+$, apical ring. Ascospores uniseriate to biseriate, hyaline to brown, ellipsoidal to fusiform, sometimes oval, straight or curved, unicellular or septate, wall smooth or ornamented or striate, sometimes with sheaths, appendages, rarely with germ slits or germ pores. Asexual morph: Undetermined.

Type genus - Clypeosphaeria Fuckel 
a

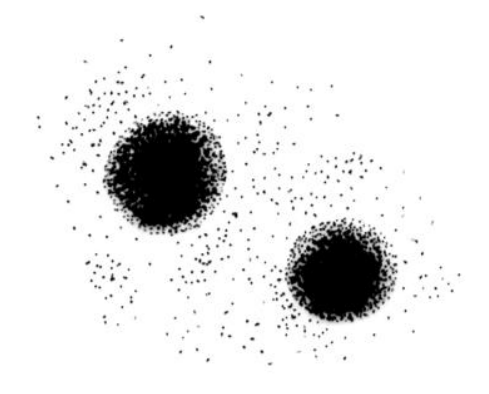

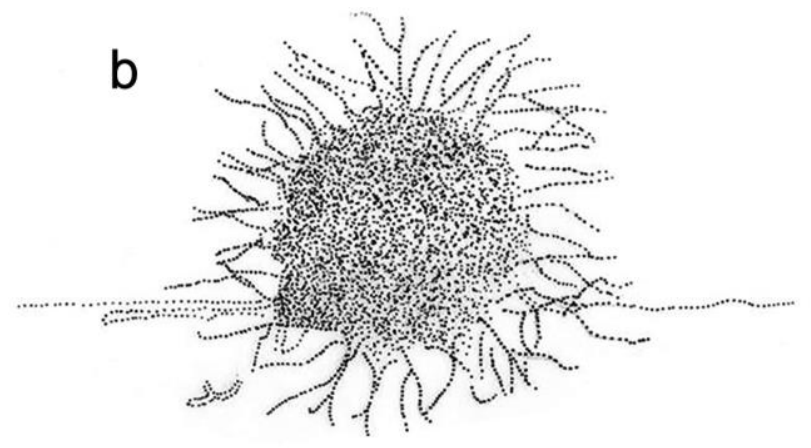

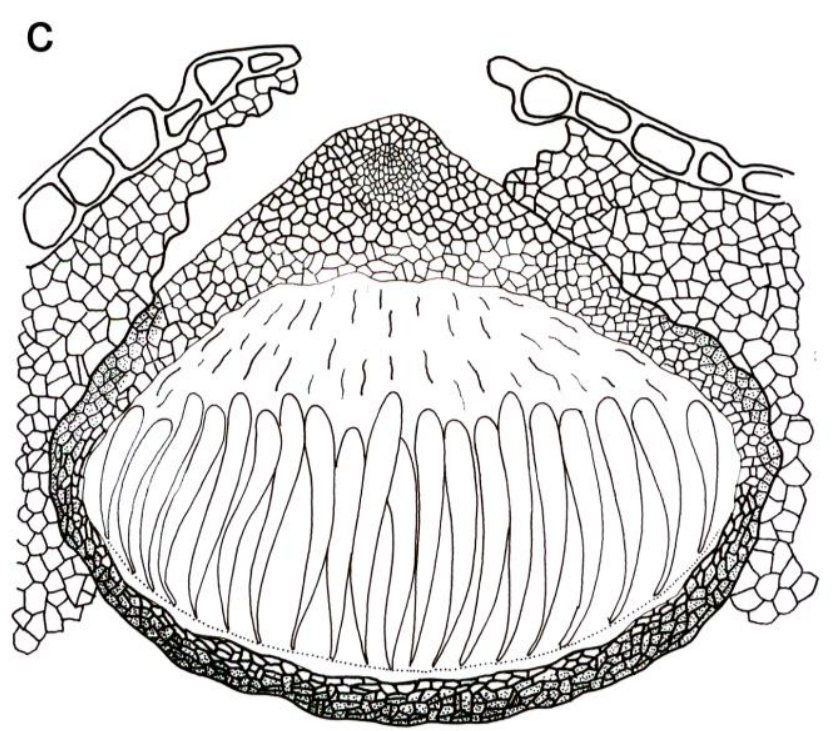

d e

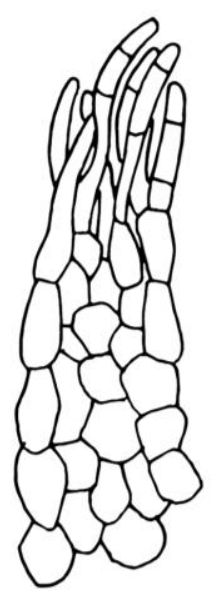

g

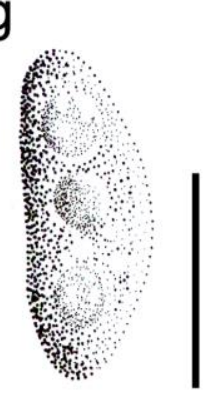

$\mathrm{h}$

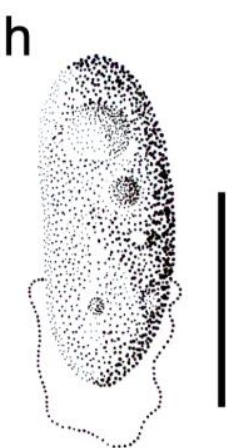

i

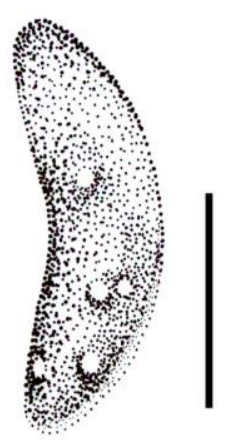

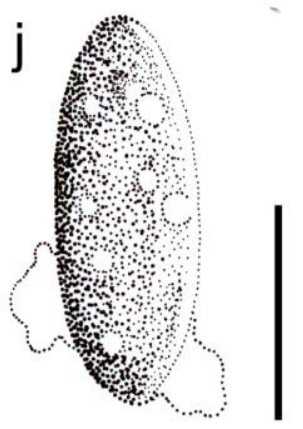

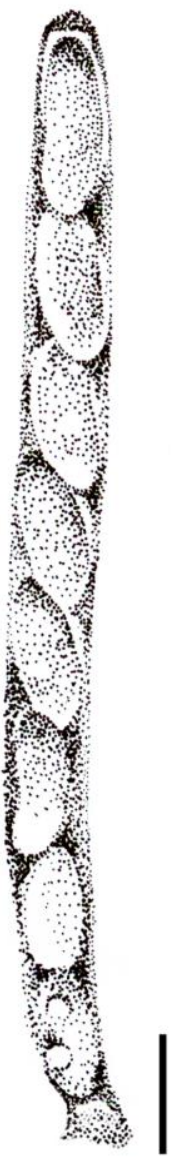

$f$

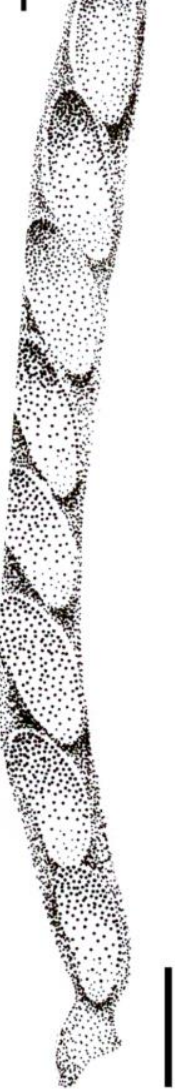

Figure 72 - Clypeophysalospora latitans (redrawn from Swart et al. 1981). a, b Ascomata on host substrate. c Vertical section of ascoma. d Peridium. e, f Asci. g-j Ascospores. Scale bars: e, j = 10 $\mu \mathrm{m}$.

Notes - Lindau (1897) resurrected Sphaeriales to accommodate Clypeosphaeriaceae which has been accommodated in Xylariales (Krug 1978, Barr 1990b, 1994, Eriksson \& Hawksworth 1993, Eriksson \& Winka 1997, Hawksworth et al. 1995, Smith et al. 2003, Douanla-Meli \& Langer 2012, Hernandez-Restrepo et al. 2015, Maharachchikumbura et al. 2015, 2016b). Senanayake et al. (2015) excluded Clypeosphaeriaceae from Xylariales and transferred it to Amphisphaeriales. Jaklitsch et al. (2016b) did not accept Amphisphaeriales because it lacked phylogenetic support in their analysis. Furthermore, in their analysis, the generic type of Clypeosphaeria; C. mamillana clusters as a basal clade within Xylariaceae. Therefore, they discontinued Clypeosphaeriaceae and synonymised under Xylariaceae. However, in present study (Fig. 4) the family type; C. mamillana form a distinct clade apart from Xylariaceae as a sister taxon to the Induratiaceae. Therefore, here we maintain Clypeosphaeriaceae as a distinct family in Xylariales. However, most genera placed in this family lack molecular data and the arrangement is reliant on ascospores being apiosporous, asci having a $\mathrm{J}_{-}$, or $\mathrm{J}+$, aprical ring and immersed ascomata. 


\section{Ecological and economic significance of Clypeosphaeriaceae}

Most taxa in Clypeosphaeriaceae have been reported as saprobes on wood worldwide (Kang et al. 1999c, Catania \& Romero 2012, Senanayake et al. 2015, Niranjan \& Sarma 2018) or as endophytic on Diospyros crassiflora (Ebenaceae fide Douanla-Meli \& Langer 2012).

\section{Genera included in Clypeosphaeriaceae}

Aquasphaeria K.D. Hyde, Nova Hedwigia 61(1-2): 122 (1995)

Index Fungorum number: IF27561; 1 morphological species.

Type species - Aquasphaeria dimorphospora K.D. Hyde

Notes - Aquasphaeria was introduced as a freshwater species on submerged wood from Queensland (Hyde 1995d). It was placed in Clypeosphaeriaceae based on morphology (Hyde 1995d). Aquasphaeria dimorphospora is illustrated in this entry. Hyde (1995d) introduced a new genus Aquasphaeria with A. dimorphospora as the type species. Munk (1957) assumed this genus to Lasiosphaeriaceae. Hyde (1995d) placed it to Clypeosphaeriaceae but Maharachchikumbura et al. (2016b) excluded Aquasphaeria from Clypeosphaeriaceae and transferred it to Sordariomycetes, genera incertae sedis. In this study, we include Aquasphaeria into Clypeosphaeriaceae base on ascomata being immersed under a clypeus. Although this genus has been reported as ubiquitous (Australia, Brunei, Seychelles, Malaysia, Thailand fide Hyde 1995d, Ho et al. 2001, Sivichai et al. 2002), there have been no recent collections.

Apioclypea K.D. Hyde, J. Linn. Soc., Bot. 116(4): 316 (1994)

Index Fungorum number: IF27441; 6 morphological species (Species Fungorum 2020), molecular data available for 3 unnamed species in the genus.

Type species - Apioclypea livistonae K.D. Hyde

Notes - The genus was introduced by Hyde et al. (1994b) with A. livistonae as the type species, as a saprobe on the dead rachis of Livistona (Arecaceae) in Papua New Guinea. Two further species were introduced by Taylor \& Hyde (2003). The genus is characterized by solitary, globose or subglobose ascomata, immersed under a clypeus, with a $\mathrm{J}_{-}$, subapical, ascal ring and hyaline apiospores with a mucilaginous sheath (Hyde et al. 1994b, Kang et al. 1999c, Taylor \& Hyde 2003).

Brunneiapiospora K.D. Hyde, J. Fröhl. \& Joanne E. Taylor, Sydowia 50(1): 40 (1998)

Index Fungorum number: IF27879; 9 morphological species (Species Fungorum 2020), molecular data available for an unnamed species.

Type species - Brunneiapiospora javensis K.D. Hyde, J. Fröhl. \& Joanne E. Taylor

Notes - Nine species have been introduced to this genus including a recent species, $B$. appendiculata from India (Hyde et al. 1998a, Crous et al. 2012a, Vitoria et al. 2012, Niranjan \& Sarma 2018). Brunneiapiospora species are characterized by solitary, subglobose ascomata, immersed beneath a darkened clypeus and with a central ostiole, a $\mathrm{J}+$, or $\mathrm{J}_{-}$, discoid, subapical, ascal ring and hyaline to light brown apiospores with a mucilaginous sheath (Hyde et al. 1998a, Kang et al. 1999c).

Clypeosphaeria Fuckel, Jb. nassau. Ver. Naturk. 23-24: 117 (1870)

Index Fungorum number: IF1125; 33 morphological species (Species Fungorum 2020), 3 species with sequence data.

Type species - Clypeosphaeria mamillana (Fr.) Lambotte

Notes - Clypeosphaeria is characterized by immersed to erumpent, dark pigmented ascomata, cylindrical to broadly cylindrical asci, with $\mathrm{J}_{-}$, or $\mathrm{J}+$, apical ring and ellipsoidal to fusiform, unicellular to septate, smooth-walled to ornamented or striate, hyaline to dark brown ascospores, sometimes with sheaths or appendages (Saccardo 1883c, Kang et al. 1999c). In this entry we illustrate Clypeosphaeria mamillana. 


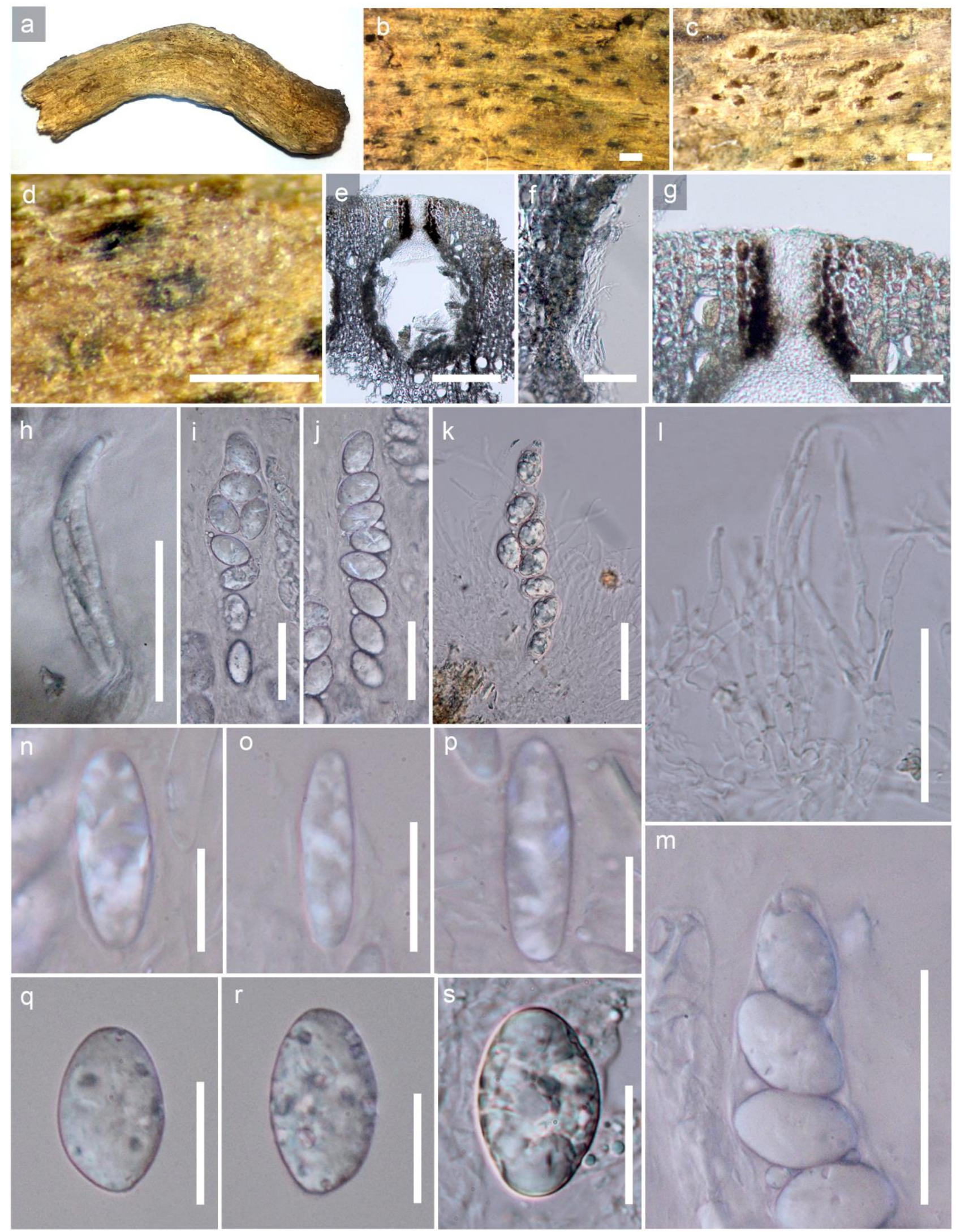

Figure 73 - Aquasphaeria dimorphospora (Material examined - AUSTRALIA, North Queensland, on submerged wood, October 1991, K.D. Hyde, BRIP21482, holotype). a Material. b, c Ascomata on host. d Close up of ascoma. e Section of ascoma. f Cell of peridium. $g$ Neck. h Cylindrical asci. $\mathrm{i}, \mathrm{j}$ Immature ovoid ascus with paraphyses. $\mathrm{k}$ Mature ovoid asci. 1 Paraphyses. $\mathrm{m} \mathrm{J}$-, apical ring in ascus. n-p Cylindrical ascospores. q, $r$ Immature ovoid ascospores s Mature ovoid ascospores. Scale bars: $\mathrm{b}-\mathrm{d}=500 \mu \mathrm{m}, \mathrm{e}=200 \mu \mathrm{m}, \mathrm{f}, \mathrm{h}-\mathrm{m}=50 \mu \mathrm{m}, \mathrm{g}=100 \mu \mathrm{m}, \mathrm{n}-\mathrm{s}=20 \mu \mathrm{m}$. 


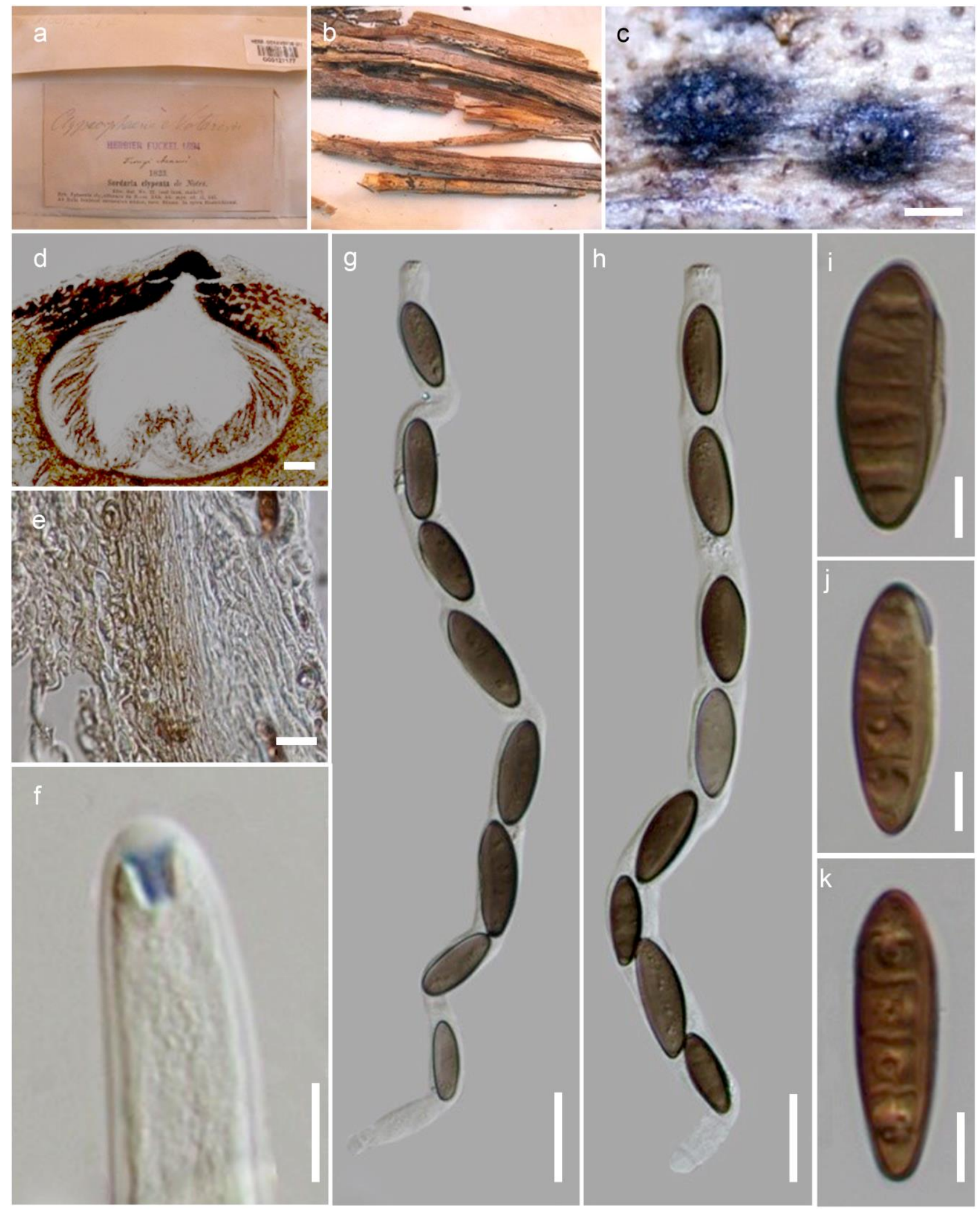

Figure 74 - Clypeosphaeria mamillana (Material examined - GERMANY, Forest of Oestriche, December 1823, Fuckel, G00127177, holotype). a Herbarium package. b Herbarium material. c Ascomata on the surface of host. d Section of ascoma. e Peridium. f Ascus apex with a J+, subapical ring. g-h Asci. i-k Ascospores. Scale bars: $\mathrm{c}=500 \mu \mathrm{m}, \mathrm{d}=50 \mu \mathrm{m}, \mathrm{e}=10 \mu \mathrm{m}, \mathrm{f}, \mathrm{i}-\mathrm{k}=5$ $\mu \mathrm{m}, \mathrm{g}-\mathrm{h}=20 \mu \mathrm{m}$.

Crassoascus Checa, Barrasa \& A.T. Martínez, Mycotaxon 46: 300 (1993) Index Fungorum number: IF26311; 3 morphological species (Species Fungorum 2020). 
Type species - Crassoascus fusisporus Checa, Barrasa \& A.T. Martínez

Notes - Crassoascus was introduced to accommodate C. fusisporus occurring on dead branches of Erica arborea in Spain (Barrasa et al. 1993). The second species, C. canadensis was found on wood of Salix in British Columbia (Barr 1994). The latest species is C. monocaudatus which was reported from a dead branch of Podocarpus parlatorei from Tucumán, in Argentina (Catania \& Romero 2012). Crassoascus species are characterised by gregarious, semi-immersed, black ascomata with ostioles, a $\mathrm{J}+$, subapical, ascal ring and bright brown to dark brown, multiseptate, fusiform ascospores, with hyaline refractive cap-like appendages at each end (Barrasa et al. 1993, Kang et al. 1999c).

Palmaria K.D. Hyde, J. Fröhl. \& Joanne E. Taylor, Fungal Divers. 86: 328 (2017) Index Fungorum number: IF553238; 1 morphological species.

Type species - Palmaria montaneus (K.D. Hyde, J. Fröhl. \& Joanne E. Taylor) K.D. Hyde, J. Fröhl. \& Joanne E. Taylor

Notes - Palmaria was introduced as Palmomyces by Hyde et al. (1998a) with P. montaneus occurring on a leaf of Oraniopsis appendiculata in Queensland. The genus was recorded associated with leaf spots on palms (Arecaceae) and only the sexual morph is known. Palmaria is characterised by solitary, immersed, subglobose ascomata, cylindric-clavate asci with a J-, subapical ring and hyaline, 1-septate, obclavate apiospores, with a mucilaginous sheath (Hyde et al. 1998a).

Cocoonihabitaceae W.Y. Zhuang \& Z.Q. Zeng, Mycosystema 36(12): 1597 (2017)

Index Fungorum number: IF570496; Facesoffungi number: FoF06759; 1 species.

Cocoon-inhabiting. Sexual morph: Ascomata superficial, solitary to aggregated, each seated on host directly or on a small basal stroma, perithecial, coriaceous, pale orange to orange, not changing colour in $100 \%$ lactic acid and $3 \% \mathrm{KOH}$. Peridium usually composed of 3 layers. Asci cylindrical, with a thick cap at the apex penetrated by a narrow pore, short pedicellate. Ascospores filiform, hyaline, multiseptate. Asexual morph: Undetermined (adapted from Zhuang \& Zeng 2017).

Type genus - Cocoonihabitus W.Y. Zhuang \& Z.Q. Zeng

Notes - Cocoonihabitaceae was introduced as a result of the separate branching of two strains of a species, sister to species of Ophiocordycipitaceae and Flammocladiellaceae in a multi-gene phylogram (Zhuang \& Zeng 2017). The species has long cylindrical asci with thick cap at the apex, penetrated by a narrow pore, characters which also exist in species belonging to Clavicipitaceae, Cordycipitaceae and Ophiocordycipitaceae. However, the characteristics of the ascomata, absence of stroma, ascospore features and habitats separated this new taxon from the other taxa. Therefore, Cocoonihabitaceae was introduced (Zhuang \& Zeng 2017).

\section{Ecological and economic significance of Cocoonihabitaceae}

Studies may likely unlock the significance of taxa accommodated in this family as has been reported for those belonging to families such as Cordycipitaceae and Ophiocordycipitaceae (Yu et al. 2004, Zhang et al. 2012b).

\section{Genus included in Cocoonihabitaceae}

Cocoonihabitus W.Y. Zhuang \& Z.Q. Zeng, Mycosystema 36(12): 1597 (2017)

Index Fungorum number: IF570495; 1 species with sequence data.

Type species - Cocoonihabitus sinensis W.Y. Zhuang \& Z.Q. Zeng

Notes - This monotypic genus was erected since the newly acquired strains of the freshly collected fungus, namely, Cocoonihabitus sinensis, clustered independently in the phylogenetic tree, apart from the other genera in other families (Zhuang \& Zeng 2017). Cocoonihabitus sinensis shares morphological resemblance to taxa belonging to some genera in Clavicipitaceae and Ophiocordycepitaceae in terms of asci and ascospores. However, the ascomata of $C$. sinensis are 
astromatic and seated directly on the substrate, contrary to the ascomata of the species in the other genera of Clavicipitaceae and Ophiocordycepitaceae, which are mostly immersed or semiimmersed (Zhuang \& Zeng 2017).
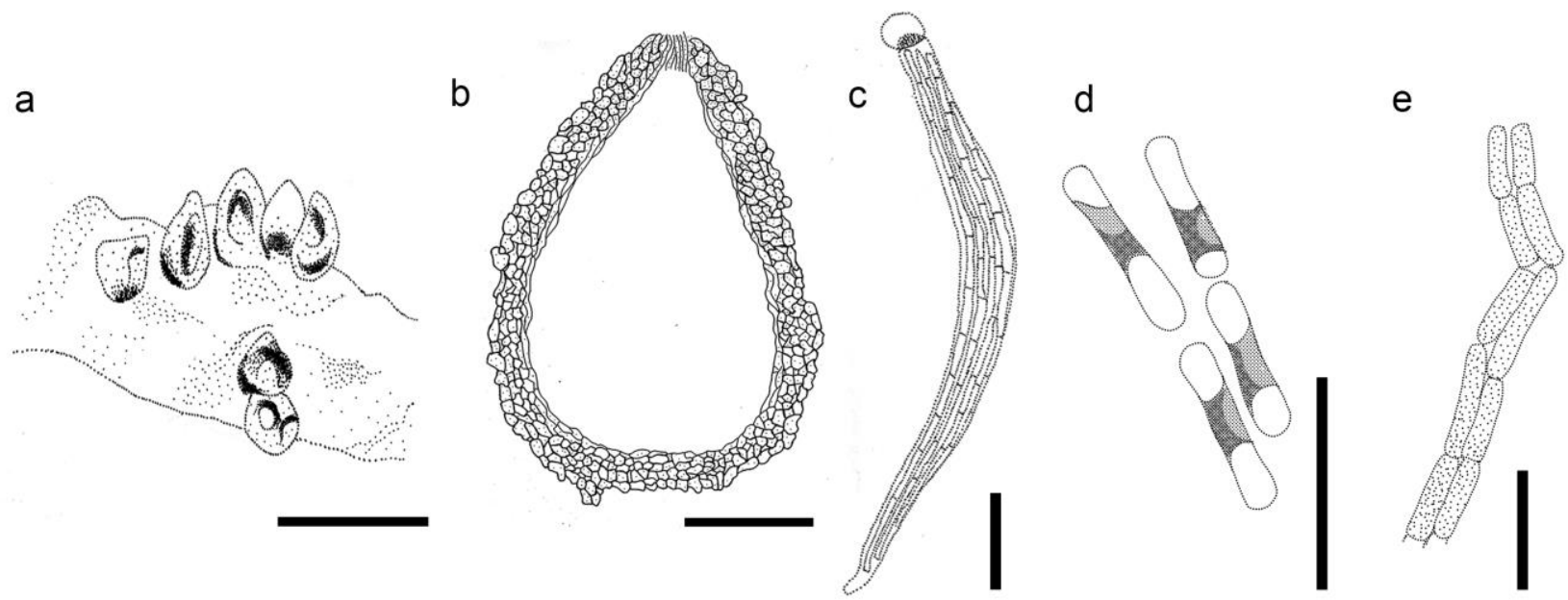

Figure 75 - Cocoonihabitus sinensis (redrawn from Zhuang \& Zeng 2017). a Perithecia on remaining leaf vein of a cocoon. b Cross-section of perithecium. c Ascus containing ascospores. d, e Disarticulated cells of ascospores. Scale bars: $a=250 \mu \mathrm{m}, \mathrm{b}, \mathrm{c}=20 \mu \mathrm{m}, \mathrm{d}, \mathrm{e}=10 \mu \mathrm{m}$.

Coniocessiaceae Asgari \& Zare, Mycol. Progr. 10(2): 195 (2011)

Index Fungorum number: IF518425; Facesoffungi number: FoF00671; 6 species.

Saprobic on grasses, soil and dung. Sexual morph: Ascomata less than $200 \mu \mathrm{m}$ diam, superficial, subglobose to pyriform, glabrous or pilose, ostiolate, with hypha-like ostiole. Peridium membranaceous, thin, translucent or sometimes opaque, outer layer comprising pale-brown to dark brown with cells of textura intricata. Paraphyses abundant or few, septate, tapering, hyphae-like, thin-walled, filamentous, branched. Asci 4-spored, unitunicate, cylindrical to subcylindrical, pedicellate, with or without an apical ring. Ascospores uniseriate, dark brown to black, ellipsoidal, with narrowly rounded ends, smooth-walled, 1-celled, with or without germ-slit, if present full length, straight. Asexual morph: Hyphomycetous, nodulisporium-like: Conidiophores micronematous to macronematous, simple or branched, smooth-walled or verrucose, hyaline. Conidiogenous cells integrated, terminal, discrete, elongating sympodially, with persistent conspicuous denticles, hyaline. Conidia globose, subglobose to pyriform, smooth-walled or verruculose, with rounded apex, hyaline, attenuated and truncated base and distinct projection at the point of attachment to the conidiogenous cells (adapted from Maharachchimbura et al. 2016b).

Type genus - Coniocessia Dania García, Stchigel, D. Hawksw. \& Guarro

Notes - Coniocessiaceae was established by Asgari \& Zare (2011) to accommodate four species of Coniocessia (C. anandra, C. cruciformis, C. maxima, C. minima) with the species $C$. nodulisporioides. The family was placed in Xylariales based on morphology and molecular analyses, and a hyaline asexual morph with polyblastic conidiogenesis (nodulisporium-like). Phylogenetic analysis of Coniocessia species showed a distinct lineage close to Diatrypaceae, which confirmed it as a family in Xylariales (Asgari \& Zare 2011, Maharachchikumbura et al. 2016b).

\section{Ecological and economic significance of Coniocessiaceae}

Species of Coniocessiaceae are saprobic on grasses, soil and dung.

\section{Genera included in Coniocessiaceae}

Coniocessia Dania García, Stchigel, D. Hawksw. \& Guarro, Mycol. Res. 110(11): 1284 (2006)

Index Fungorum number: IF29049; 5 species with sequence data. 
Type species - Coniocessia nodulisporioides (D. Hawksw.) Dania García, Stchigel, D. Hawksw. \& Guarro

Notes - García et al. (2006) introduced Coniocessia to accommodate C. nodulisporioides, by synonymising Coniochaeta nodulisporioides, isolated from soil in Jordan by Hawksworth (1978). The species was synonymised under Coniocessia, based on morphology and SSU and LSU molecular data. Asgari \& Zare (2011) introduced Coniocessiaceae and four new species in Coniocessia based on morphological and ITS and LSU molecular data, as all species clustered into a single monophyletic clade (Asgari \& Zare 2011). Maharachchikumbura et al. (2016b) provided an updated outline of the genus with five species.

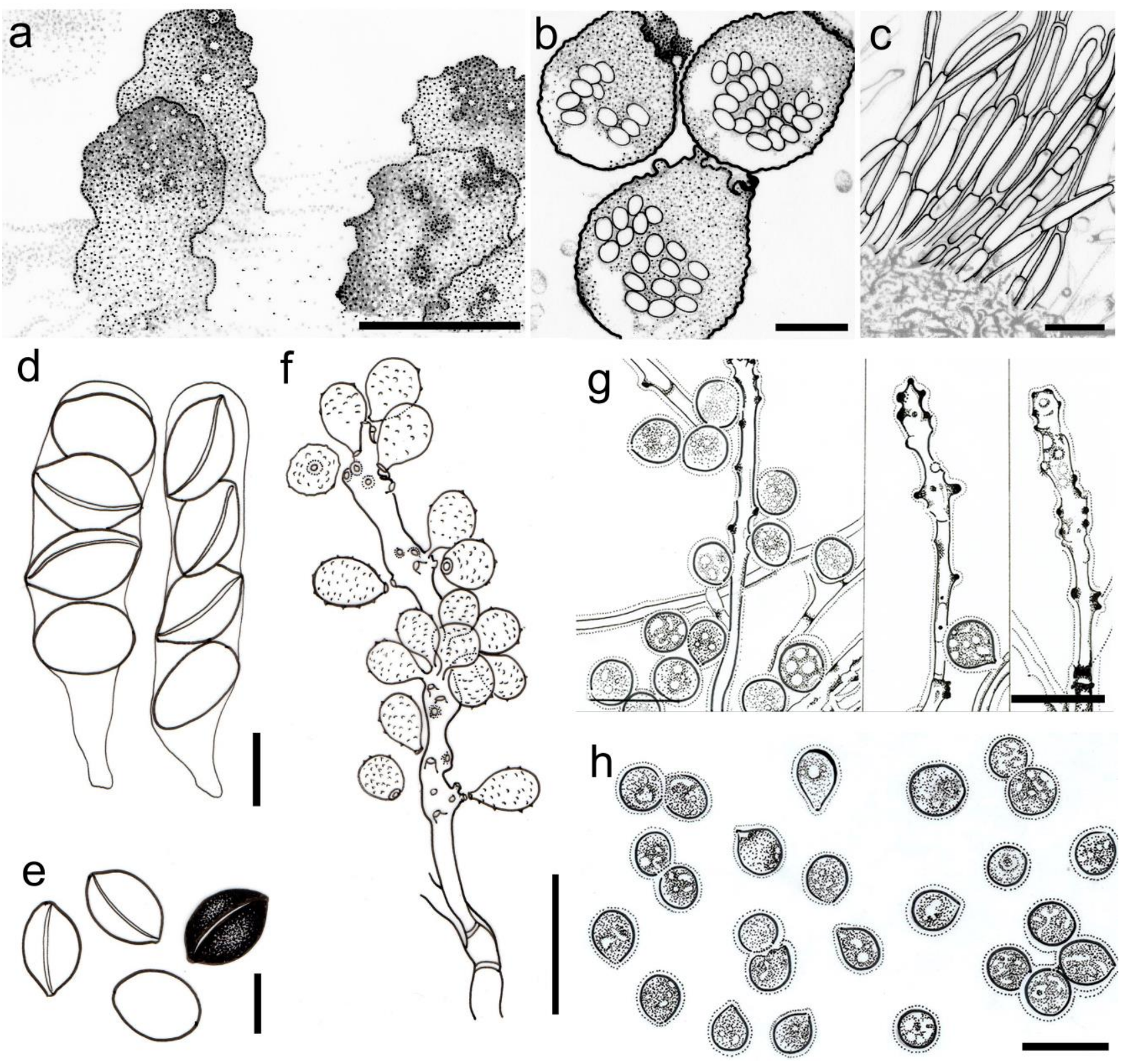

Figure 76 - Coniocessia nodulisporioides (illustration based on García et al. 2006 and Asgari \& Zare 2011). a Masses of ascospores on host surface. b Ascomata. c Paraphyses. d Asci. e Ascospores. $\mathrm{f}, \mathrm{g}$ Conidiophores and conidiogenous cells. $\mathrm{h}$ Conidia. Scale bars: $\mathrm{a}=100 \mu \mathrm{m}, \mathrm{b}=50$ $\mu \mathrm{m}, \mathrm{c}-\mathrm{h}=10 \mu \mathrm{m}$.

Paraxylaria Wanas., E.B.G. Jones, Gafforov \& K.D. Hyde, Fungal Divers. 89(1): 202 (2018) Index Fungorum number: IF554226; 1 species with sequence data.

Type species - Paraxylaria rosacearum Wanas., Gafforov, E.B.G. Jones \& K.D. Hyde 
Notes - Paraxylaria was introduced to accommodate $P$. rosacearum and is a monotypic genus saprobic on Rosaceae in Uzbekistan (Wanasinghe et al. 2018). The genus was introduced based on morphology similar to Coniocessia. However, species differ as Paraxylaria have asci with $\mathrm{J}+$, apical rings with ascospores which lack germ-slits but have a close affinity in phylogenetic analysis (Wanasinghe et al. 2018).

\section{Coniochaetaceae Malloch \& Cain, Can. J. Bot. 49: 878 (1971)}

Index Fungorum number: IF80629; Facesoffungi number: FoF01332; 99 species.

Saprobic on dung, plant litter or in soil, water, or pathogens of plants and immunocompromised humans, endophytic in leaves and lichen thalli. Sexual morph: Ascomata perithecial or cleistothecial, solitary to gregarious, superficial, semi-immersed or immersed, subglobose to globose or pyriform, dark brown to black, glabrous or hairy, ostiolate or lacking ostiole. Ostiole periphysate, sometimes surrounded by a crown of setae. Peridium membranaceous to pseudoparenchymatous, rarely coriaceous; composed of several layers of cells of textura angularis or textura intricata, or less frequently cephalothecoid. Paraphyses numerous, filiform, simple, septate, evanescent. Asci (4-), 8- to multi-spored, unitunicate, cylindrical to fusoid or clavate, globose to subglobose, short pedicellate, with a truncate to rounded apex, with a J-, apical ring, evanescent. Ascospores 1-seriate or irregularly arranged, initially hyaline, becoming brown to dark brown or olive-greenish to dark olivaceous or black at maturity, ellipsoid to fusiform, broadly ellipsoidal to globose, lenticular or cruciform, with rounded to apiculate ends, flattened on one or both sides; 1-celled, with or without a germ slit, smooth-walled or pitted. Asexual morph: Hyphomycetous or yeast-like. Colonies frequently characterized by pink or orange and a yeast-like appearance. Conidiophores macronematous or semi-macronematous. Conidiogenous cells phialidic, polyblastic, of various size and morphology, somewhat ampulliform, subulate or indistinguishable from a normal hyphal cell, collarettes present, but usually indistinct, occasionally somewhat flared. Conidia accumulating near the point of formation (in chains), hyaline, orange or pink in mass, elliptical to oblong-elliptical to reniform, 1-celled, smooth-walled.

Type genus - Coniochaeta (Sacc.) Cooke

Notes - Coniochaetaceae was introduced by Malloch \& Cain (1971) and its phylogenetic relationships were clarified by García et al. (2006). The family was accepted in the newly introduced order Coniochaetales (Huhndorf et al. 2004b). Hongsanan et al. (2017) provided evidence through phylogenetic and MCMC trees to support the ordinal status. Additional notes for Coniochaetaceae and two new species were provided by Friebes et al. (2016). For a key and type herbarium study see Maharachchikumbura et al. (2016b).

\section{Ecological and economic significance of Coniochaetaceae}

Coniochaetaceae species are mainly saprobes on dead wood. In addition, some are plant pathogens and opportunistic fungi causing serious infections in humans (Damm et al. 2010). They are also producers of potent antibiotics and some strains were evaluated to have a high potential of biological detoxification of lignocellulosic biomass (Segeth et al. 2003, López et al. 2004, Friebes et al. 2016).

\section{Genera included in Coniochaetaceae}

Barrina A.W. Ramaley, Mycologia 89(6): 962 (1997)

Index Fungorum number: IF27745; 1 species with sequence data.

Type species - Barrina polyspora A.W. Ramaley

Notes - Ramaley (1997) introduced this monotypic genus to accommodate $B$. polyspora which has ellipsoid-fusiform, aseptate, hyaline, smooth-walled, thin-walled ascospores and ascoconidia. Based on its phialophora-like asexual morph, the genus is accepted in Coniochaetaceae (Ramaley 1997, Kirk et al. 2013, Maharachchikumbura et al. 2015). However, based on available sequences, this genus clusters in this family. 
Coniochaeta (Sacc.) Cooke, Grevillea 16 (no. 77): 16 (1887)

Index Fungorum number: IF1209; 98 morphological species (Species Fungorum 2020), 55 species with sequence data.

Type species - Coniochaeta ligniaria (Grev.) Cooke
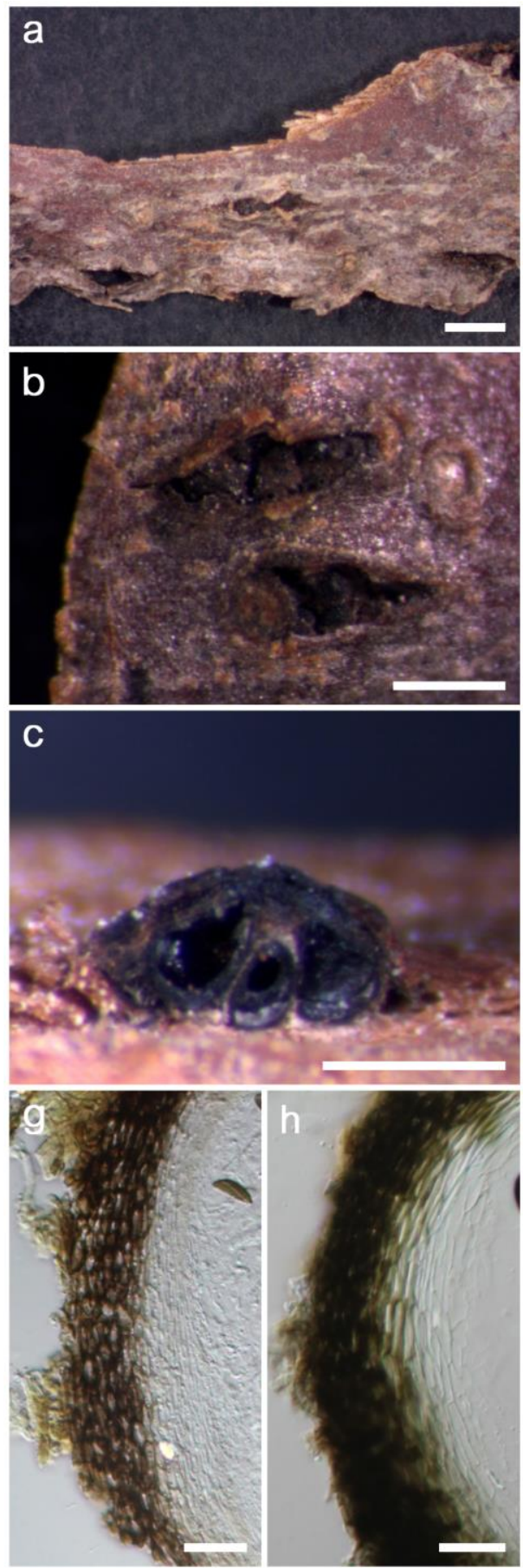
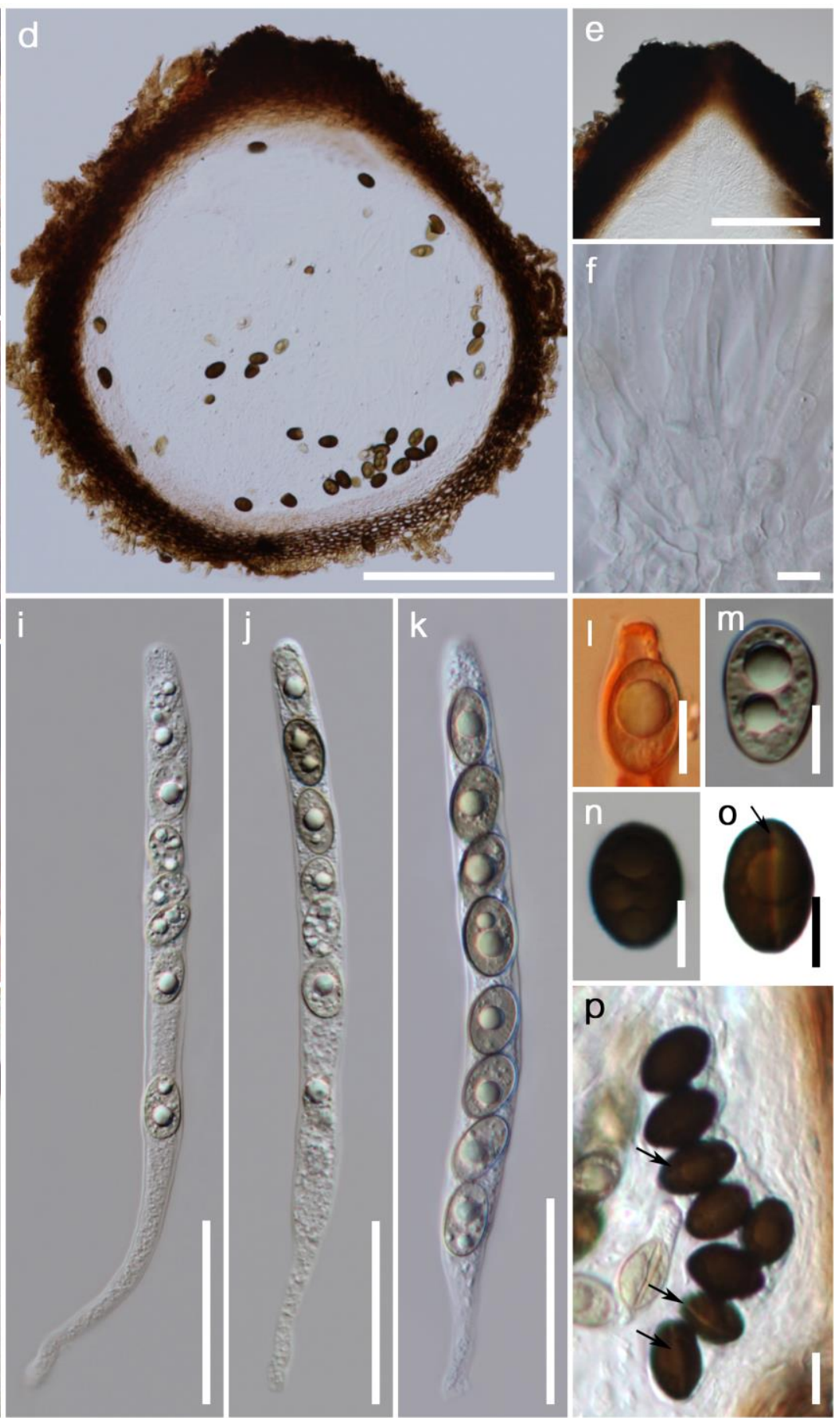

Figure 77 - Coniochaeta taeniospora (Material examined - ITALY, Province of Forlì-Cesena [FC], Camposonaldo - Santa Sofia, on dead land branch of Quercus sp. (Fagaceae), 13 March 2017, Erio Camporesi IT3275, MFLU 17-0832, HKAS 102311). a, b Stroma on the host. c Vertical section of ascoma. d Cross section of ascoma. e Ostiole in section. $f$ Paraphyses. $g$, $h$ Peridium (h in 5\% KOH). i-k Asci. 1 Ascus apex in Congo Red. m-p Ascospores (black arrow heads show germ slits). Scale bars: $\mathrm{a}=1 \mathrm{~mm}, \mathrm{~b}, \mathrm{c}=500 \mu \mathrm{m}, \mathrm{d}=200 \mu \mathrm{m}, \mathrm{e}=100 \mu \mathrm{m}, \mathrm{i}-\mathrm{k}=50 \mu \mathrm{m}, \mathrm{g}, \mathrm{h}=20 \mu \mathrm{m}, \mathrm{l}-\mathrm{p}$ $=10 \mu \mathrm{m}, \mathrm{f}=5 \mu \mathrm{m}$. 
Notes - Phialidic asexual morphs proved to be an informative character to delimit Coniochaetaceae, while the type of ascomata, which can be cleistothecial or perithecial, and the ornamentation of the ascospore walls, proved to have little taxonomic value at the generic level (García et al. 2006). Based on these conclusions, García et al. (2006) segregated several species from Coniochaeta and moved Coniocessia and Coniolariella to Xylariales. Eleven new Coniochaeta species supported by morphology and phylogeny have been introduced (Jiang et al. 2017, Coronado-Ruiz et al. 2018, Nasr et al. 2018, Samarakoon et al. 2018, Wanasinghe et al. 2018, Crous et al. 2019a, Harrington et al. 2019, Phookamsak et al. 2019). In this entry Coniochaeta taeniospora is illustrated (Fig. 77).

Conioscyphaceae Réblová \& Seifert, Persoonia 37: 63 (2015)

Index Fungorum number: IF813227; Facesoffungi number: FoF05190; 16 species.

Saprobic on wood and animal skin. Sexual morph: Ascomata perithecial, astromatic, immersed, semi-immersed or superficial, subhyaline to pale orange or pale brown when fresh, almost invisible when dry, papillate or with a cylindrical neck. Peridium coriaceous, two-layered. Ostiole periphysate. Paraphyses filiform, septate, unbranched, longer than the asci. Asci 8-spored, unitunicate, persistent, pedicellate, cylindrical to clavate, sigmoidal, with a tall and prominent J-, refractive apical ring. Ascospores 2-4-seriate, hyaline to subhyaline, ellipsoid to fusiform or fusiform-navicular, transversely septate, not constricted at the septa, lacking any gelatinous sheath or appendages. Asexual morph: Hyphomycetous. Conidiophores micronematous, mononematous, hyaline or pigmented. Conidiogenous cells holoblastic, sympodial, cyathiform or doliiform, surrounded by hyaline, multi-layered, with conspicuous cup-like collarettes. Conidia brown, unicellular, non-septate and varying in shape, thick-walled, smooth, with a pore at the point of attachment to the conidiogenous cells, formed individually and in succession, apices of conidiogenous cells proliferate percurrently, liberated after outer wall of the conidiogenous cell ruptures at the apex (adapted from Réblová \& Seifert 2004a, Zelski et al. 2015, Réblová et al. 2016c)

Type genus - Conioscypha Höhn.

Notes - Conioscyphaceae was introduced by Réblová et al. (2016c) under Conioscyphales and it includes the single genus Conioscypha. Conioscypha lignicola, the generic type, was described by Höhnel (1904) and it was reviewed by Shearer (1973) who introduced a second species $C$. varia Shearer. The number of species gradually increased and $C$. tenebrosa is the latest addition to Conioscyphales (Liu et al. 2019b). Most of the species have been isolated as saprobes from submerged substrates (Shearer 1973, Matsushima 1975, 1993, 1996, Crous et al. 2014a, 2018b, Zelski et al. 2015, Chuaseeharonnachai et al. 2017, Hernández-Restrepo et al. 2017, Liu et al. 2019b, Luo et al. 2019) or decaying wood in terrestrial biotopes (Munk 1957, Réblová \& Seifert 2004a). Hongsanan et al. (2017) transferred Conioscyphales from Hypocreomycetidae (Réblová et al. 2016c) into the newly introduced subclass Savoryellomycetidae with evidence from wellsupported phylogenetic and maximum clade credibility trees with stem age of 268 MYA.

\section{Ecological and economic significance of Conioscyphaceae}

Most species of Conioscypha are saprobic on decaying plant materials and are found in both aquatic and terrestrial habitats, with rotten wood, leaves, twigs and bamboo stems being frequent substrates. Conioscypha japonica is the sole species isolated from cuticular scrapings and hairs of a living animal (Goh \& Hyde 1998).

\section{Genus included in Conioscyphaceae}

Conioscypha Höhn., Annls mycol. 2(1): 58 (1904)

Index Fungorum number: IF7754; 16 morphological species (Liu et al. 2019b), 11 species with sequence data.

Type species - Conioscypha lignicola Höhn. 
Notes - Conioscypha comprises species reported from decaying wood, leaves and bamboo from both freshwater and terrestrial habitats, except for $C$. japonica which was isolated from $\operatorname{dog}$ skin fragments and hair (Chuaseeharonnachai et al. 2017, Liu et al. 2019b). Conioscypha is characterized by a unique mode of conidiogenesis with blastic conidia produced at inconspicuous loci along the hyphae (Shearer 1973). Traditionally, the conidia were thought to be produced from 'phialidic' conidiogenous cells (Goh \& Hyde 1998). Shearer \& Motta (1973) described Conioscypha conidiogenesis to be both 'phialidic' and 'annelidic' (Shearer \& Motta 1973), but Minter et al. (1983) did not agree with this observation. Cole \& Samson (1979) reported conidial development to be intermediate between the 'phialidic' and 'annelidic' process and after repetitive basipetal conidial secession, the remains of the outer wall of conidia collect centripetally on the conidiogenous cells to form 'collarettes'. Based on in vitro experiments and molecular DNA data, Réblová \& Seifert (2004a) introduced Conioscyphascus, typified by Ca. varius, to accommodate holomorphs with Conioscypha asexual morphs. Another sexual-asexual relationship was established for $C$. peruviana (Zelski et al. 2015). Following abolishment of dual nomenclature and adoption of one fungus, one name, Conioscyphascus was accepted as a synonym of Conioscypha (Zelski et al. 2015, Réblová et al. 2016c). Although C. gracilis is the only species of the genus known in its sexual state, the presence of typical conidia on the host near ascomata was repeatedly observed (Réblová \& Seifert 2004a, Zelski et al. 2015). Conioscypha varia Shearer is illustrated for the sexual morph and $C$. tenebrosa is illustrated for the asexual morph, in this entry.

Conlariaceae H. Zhang, K.D. Hyde \& Maharachch., Fungal Divers. 85: 90 (2017)

Index Fungorum number: IF553758; Facesoffungi number: FoF03336; 7 species.

Saprobic on submerged decaying wood in freshwater or grow on soil in terrestrial habitats. Sexual morph: Ascomata perithecioid, gregarious, coriaceous or membranous, immersed to erumpent or superficial, dark brown to black, globose to subglobose, smooth, ostiolate. Neck short or elongated, cylindrical, straight or slightly flexuous. Peridium composed of several layers of cells of textura angularis. Paraphyses cylindrical or globose, hyaline, septate. Asci 8-spored, unitunicate, cylindrical, short pedicellate, apically rounded, with a distinct, refractive, massive, barrel-shaped, apical ring or lacking apical structures. Ascospores uni- to bi-seriate, hyaline, fusiform or ellipsoidal-fusiform, straight or slightly curved, aseptate to multi-septate, guttulate, thin- or thick-walled, with or without appendages or appendages at one or both ends or surrounded by an irregular gelatinous sheath. Asexual morph: Hyphomycetous. Colonies dark brown to black. Mycelium mostly immersed, consisting of branched, septate, thin-walled, smooth, pale brown to brown hyphae. Conidiophores micronematous or semi-macronematous, mononematous, septate or aseptate, unbranched or irregularly branched, straight or flexuous, hyaline, becoming brown when old. Conidiogenous cells holoblastic, determinate, doliiform, cylindrical. Conidia brown, muriform, irregularly globose or subglobose, septate, constricted at the septa.

Type genus - Conlarium F. Liu \& L. Cai

Notes - Conlariaceae was introduced in a new order Atractosporales by Zhang et al. (2017a) for a single genus Conlarium which comprised C. aquaticum and C. dupliciascosporum. Asexual morphs of the family were found in the culture of $C$. dupliciascosporum (Liu et al. 2012), on natural decaying submerged wood (Zhang et al. 2017a) and dead wood or soil in terrestrial habitat (Phookamsak et al. 2019, Xie et al. 2019). Another genus Riomyces is included in the family based on our phylogenetic analyses (Fig. 3), and previous study (Luo et al. 2019). The phylogeny and morphology warranted a new family (Zhang et al. 2017a).

\section{Ecological and economic significance of Conlariaceae}

Conlariaceae currently comprises two genera Conlarium and Riomyces with seven species which are saprobic on submerged wood and dead wood or soil. They have so far been reported from China, Costa Rica and Thailand (Ferrer et al. 2012, Liu et al. 2012, Zhang et al. 2017a, Phookamsak et al. 2019, Xie et al. 2019). They are important plant decomposers involved in nutrient cycling. 


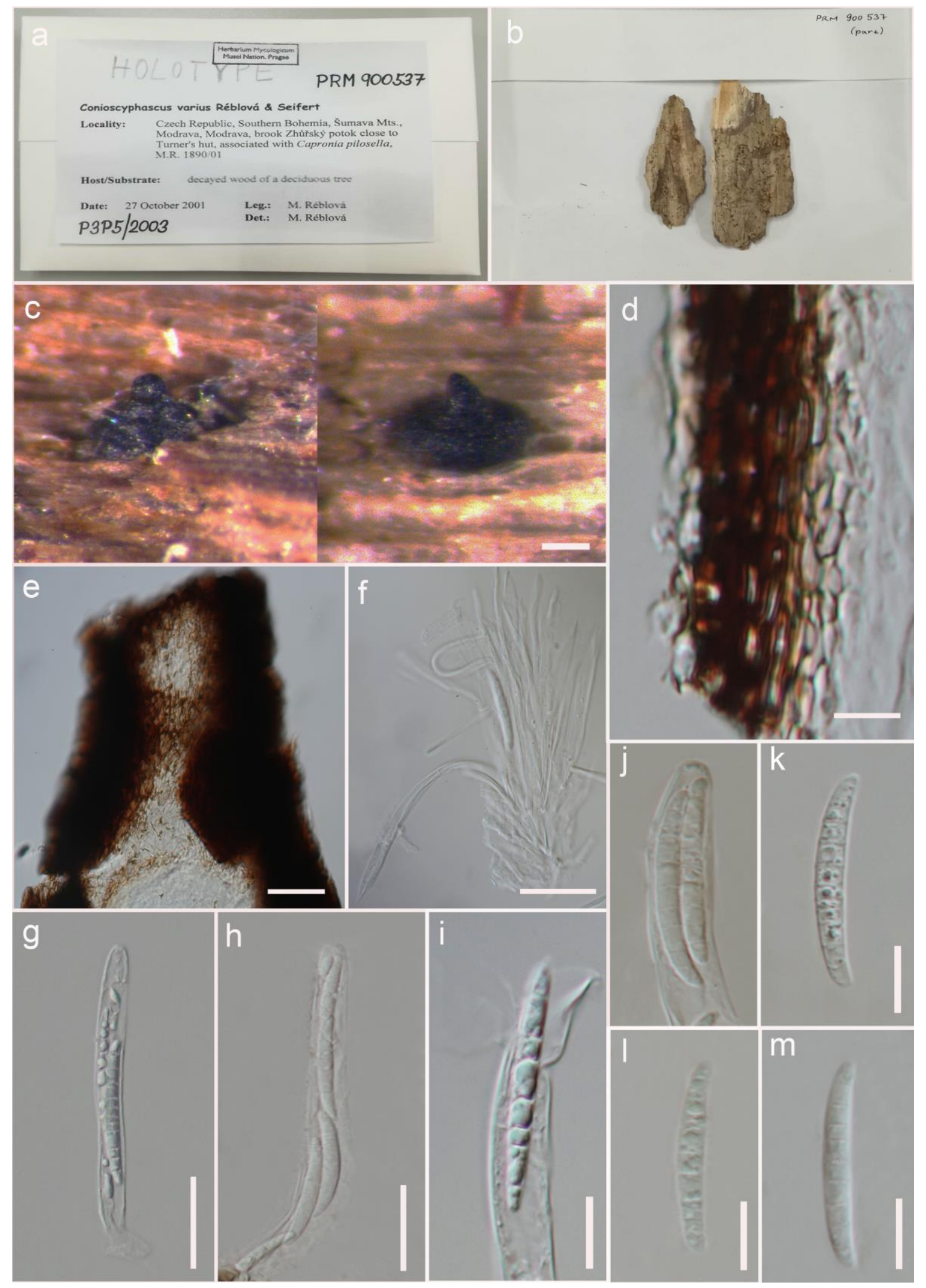

Figure 78 - Conioscypha varia (Material examined - CZECH REPUBLIC, Southern Bohemia, Šumava Mts., Modrava, Modrava, brook Zhůřský potok close to Turner's hut, associated with Capronia pilosella, M.R. 1890/01, on decayed wood of a deciduous tree, 27 October 2001, M. Réblová, PRM 900537, holotype). a, b Herbarium material. c Appearance of ascomata on host substrate. d Peridium. e Transverse section through ostiole. f Paraphyses. g, h Asci. i Evagination of ascal ring to allow discharge of spore. $\mathrm{j} \mathrm{J}$-, apical ring. $\mathrm{k}-\mathrm{m}$ Ascospores. Scale bars: $\mathrm{c}=200 \mu \mathrm{m}$, $\mathrm{d}=10 \mu \mathrm{m}, \mathrm{e}-\mathrm{m}=50 \mu \mathrm{m}$. 


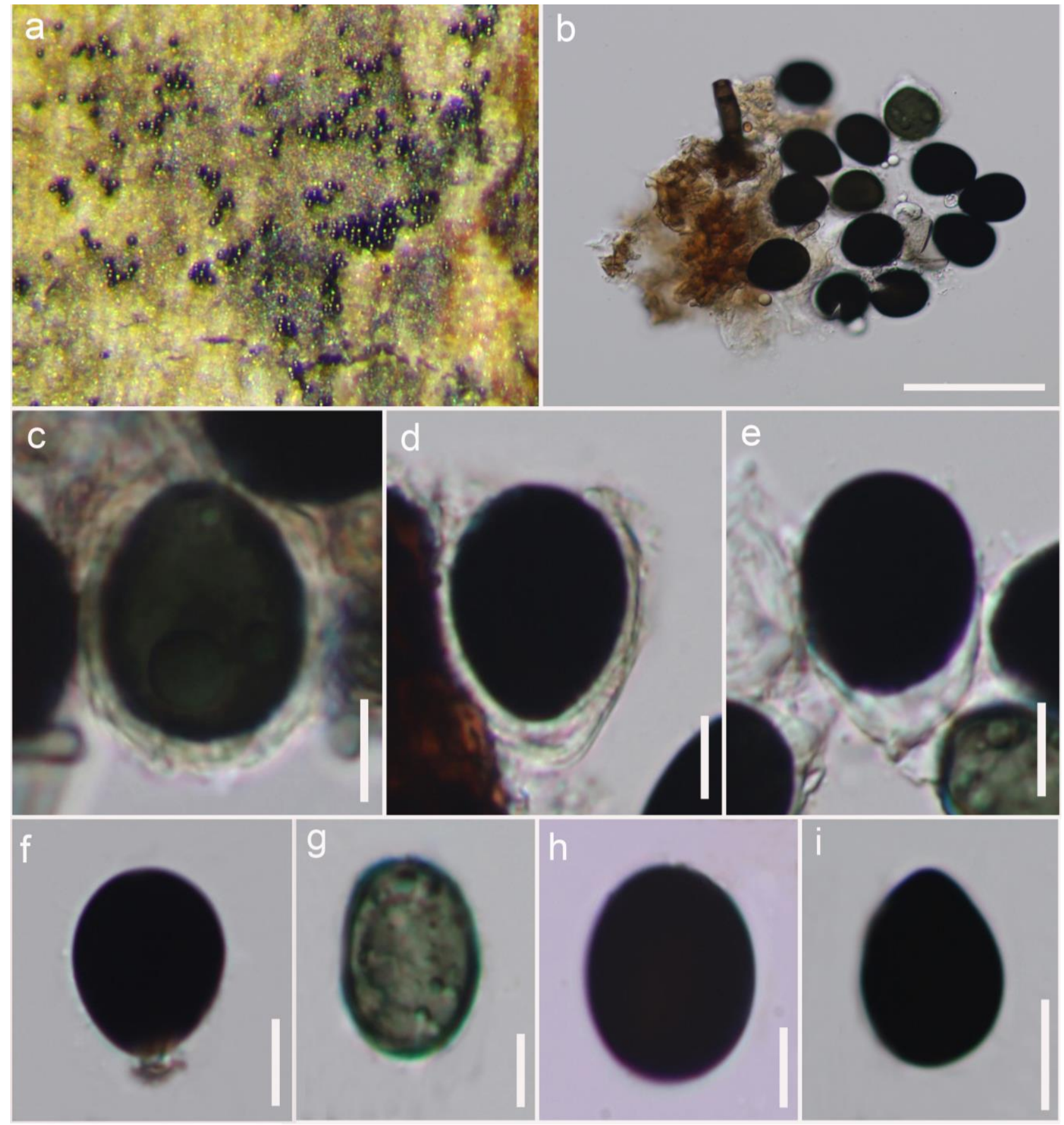

Figure 79 - Conioscypha tenebrosa (Material examined - CHINA, Guizhou Province, Dushan, on decaying wood on the bank of a small freshwater stream, 6 July 2018, N.G. Liu, MFLU 19-0688, holotype). a Colonies on natural substrate. b Mass of conidia. c-e Conidia and conidiogenous cells with cup-shaped multi-collarette. f Conidium and conidiogenous cell originating from a hypha. $\mathrm{g}-\mathrm{i}$ Conidia. Scale bars: $\mathrm{b}=50 \mu \mathrm{m}, \mathrm{c}-\mathrm{g}, \mathrm{i}=30 \mu \mathrm{m}, \mathrm{h}=10 \mu \mathrm{m}$.

\section{Genera included in Conlariaceae}

Conlarium F. Liu \& L. Cai, Mycologia 104(5): 1180 (2012)

Index Fungorum number: IF564382; 6 species with sequence data.

Type species - Conlarium dupliciascosporum F. Liu \& L. Cai

Notes - Conlarium was established by Liu et al. (2012) for the holomorph species $C$. duplumascosporum based on its distinct lineage among related taxa. Conlarium aquaticum and $C$. dupliciascosporum were found from submerged wood in freshwater, $C$. thailandense was from dead wood in a terrestrial habitat, $C$. baiseense, $C$. nanningense and $C$. sacchari were from 
sugarcane rhizosphere (Liu et al. 2012, Zhang et al. 2017a, Phookamsak et al. 2019, Xie et al. 2019). In this entry we illustrate Conlarium aquaticum and C. duplumascospora (Figs 80, 81).

a

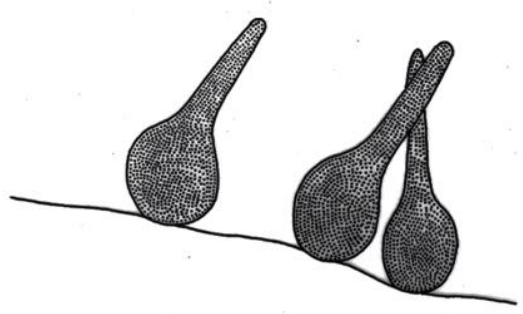

\section{b}

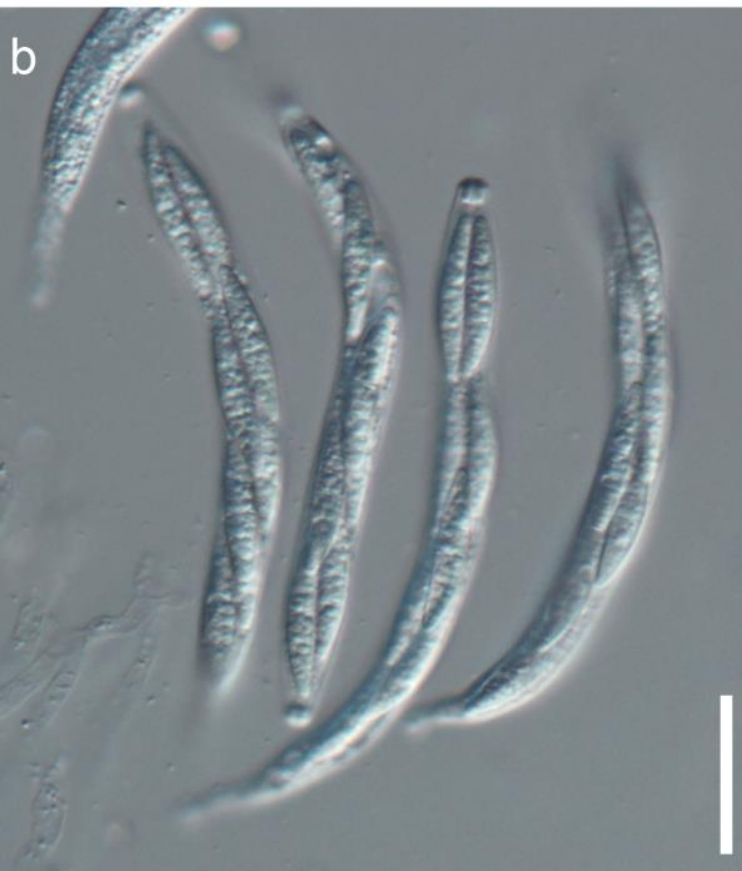

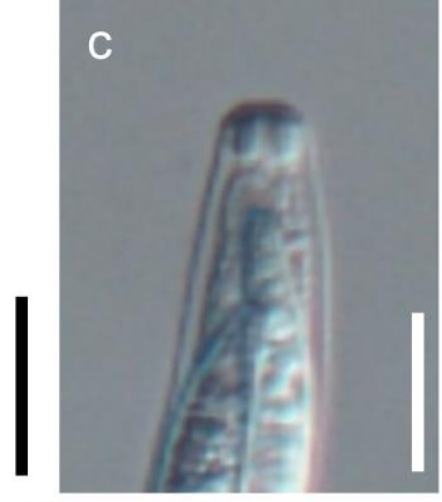
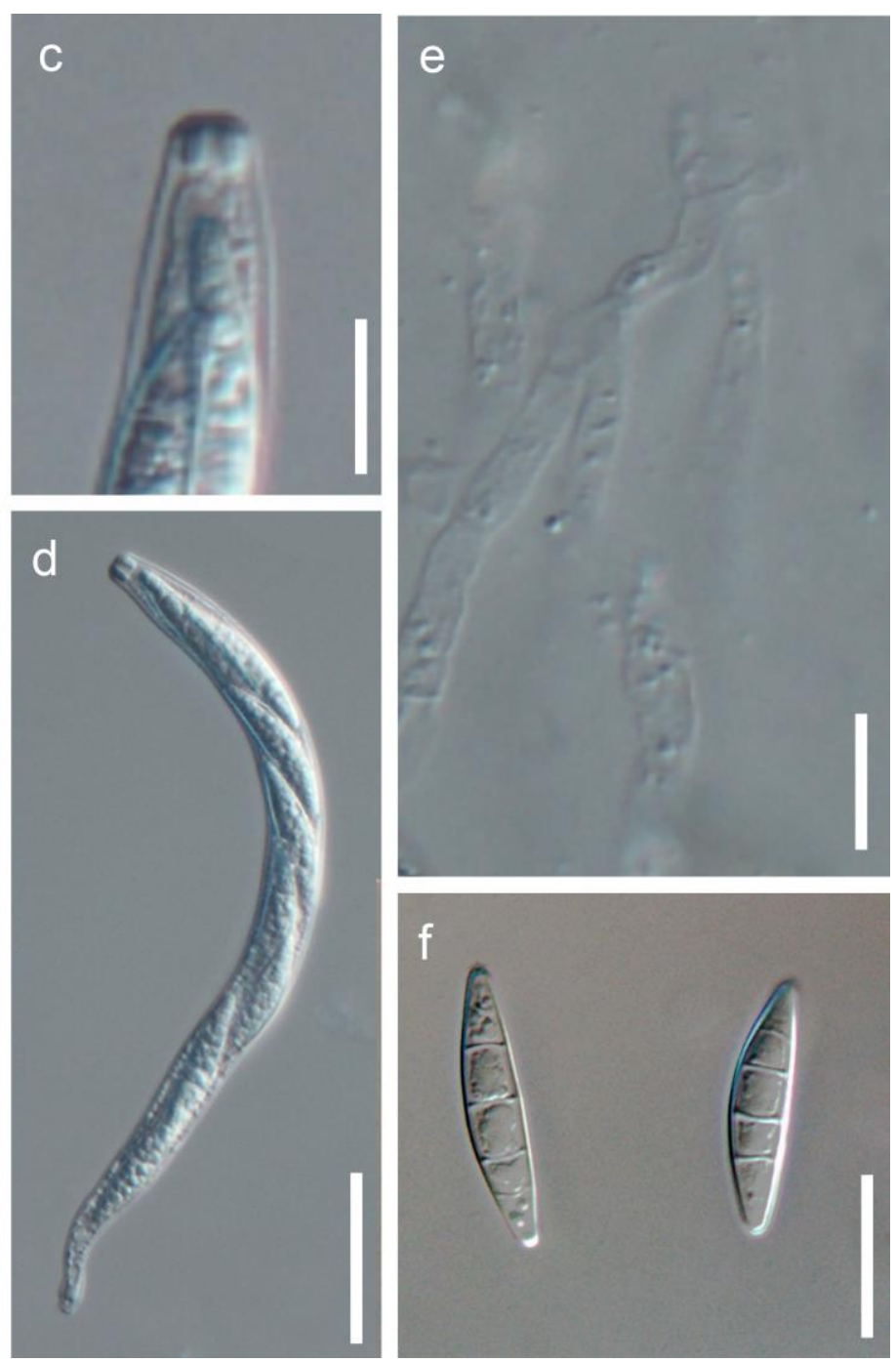

Figure 80 - Sexual morph of Conlarium duplumascospora (Material examined - CHINA, Guangdong Province, Zhaoqing Dinghu Mountain, on submerged wood in a stream, 29 December 2010, F. Liu, HMAS243129, holotype). a Gregarious ascomata on host substratum. b-d Asci. e Paraphyses. f Ascospores. Scale bars: $\mathrm{a}=500 \mu \mathrm{m}, \mathrm{b}, \mathrm{d}=20 \mu \mathrm{m}, \mathrm{c}, \mathrm{e}=10 \mu \mathrm{m}, \mathrm{f}=5 \mu \mathrm{m}$.

Riomyces A. Ferrer, A.N. Mill., Sarmiento \& Shearer, Mycologia 104(4): 876 (2012)

Index Fungorum number: IF561099; 1 species with sequence data.

Type species - Riomyces rotundus A. Ferrer, A.N. Mill., Sarmiento \& Shearer

Notes - Riomyces was introduced by Ferrer et al. (2012) to accommodate a single species $R$. rotundus, based on morphology and phylogenetic analyses of LSU sequence data. It was found on submerged decaying wood in freshwater in Costa Rica (Fig. 3).

Cordanaceae Nann., Repert. mic. uomo: 498 (1934)

Index Fungorum number: IF80640; Facesoffungi number: FoF01673; 23 species.

Saprobic or pathogenic on wood of branches, twigs and leaves of various shrubs and trees, bamboo, grasses and in soil of terrestrial habitats, occasionally in freshwater habitats. Sexual morph: Ascomata perithecial, superficial, solitary or gregarious, globose to ovoid, setose or glabrous, with basal stroma, papillate. Ostiole periphysate. Peridium comprising 3-5 layers of- 

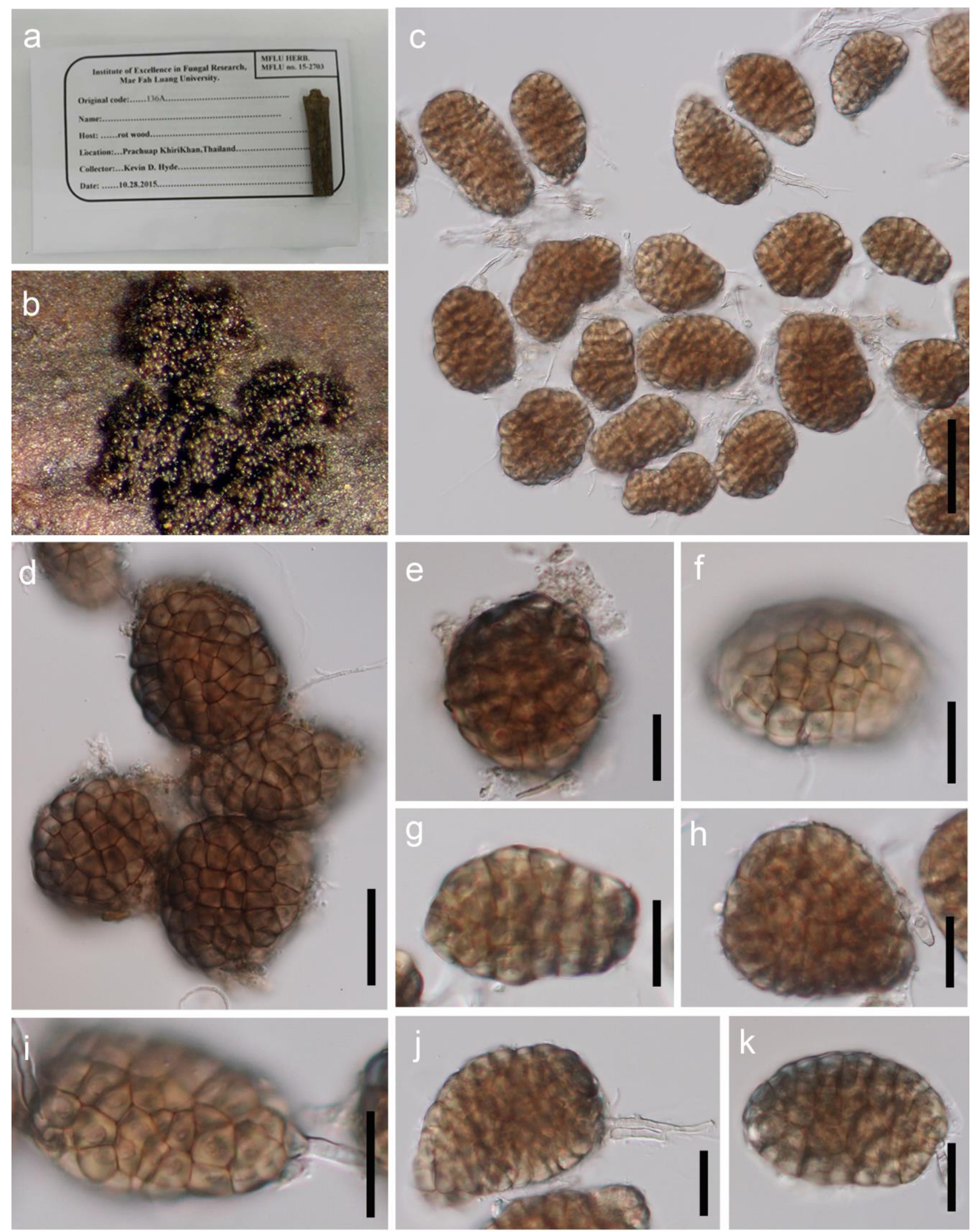

Figure 81 - Conlarium aquaticum (Material examined - THAILAND, Prachuap Khiri Khan, on submerged wood in a small river, 30 July 2015, W. Dong 136A, MFLU 15-2703, holotype). a, b Colonies on submerged wood. c-h Conidia. i-k Conidia with conidiogenous cells. Scale bars: $\mathrm{c}=50$ $\mu \mathrm{m}, \mathrm{d}, \mathrm{f}-\mathrm{k}=20 \mu \mathrm{m}, \mathrm{e}=10 \mu \mathrm{m}$.

-cells of textura prismatica. Paraphyses septate, unbranched. Asci 8-spored, unitunicate, cylindrical, with short pedicel, with or without a J-, apical ring. Ascospores uniseriate, pale brown 
to brown, ellipsoid to fusiform, sometimes with pores at both ends, 1-septate. Asexual morph: Hyphomycetous. Colonies effuse, dark brown to black. Conidiophores mononematous, macronematous, brown, septate, erect, branched or unbranched. Conidiogenous cells terminal or intercalary, polyblastic, denticulate. Conidia pale brown to brown, obovoid to ellipsoidal, smooth, sometimes with germ pores at the ends, 1-septate or aseptate (adapted from Hughes 1955, Müller \& Samuels 1982b, Hernández-Restrepo et al. 2014).

Type genus - Cordana Preuss

Notes - Cordanaceae was introduced by Nannfeldt (1934) based on the type genus Cordana. Initially, Hernández-Restrepo et al. (2015b) introduced Cordanales to accommodate Cordanaceae, which was recognized as a monotypic, monophyletic sister group to Coniochaetales (Maharachchikumbura et al. 2016b). However, in a study backed by a molecular clock evidence, Cordanaceae was found to share a common ancestor with Coniochaetaceae in Coniochaetales 77 MYA (Hongsanan et al. 2017). While the family lineage had good statistical support, Cordanales did not have enough support and was therefore combined under Coniochaetales (Hongsanan et al. 2017) of which the stem age was 176 MYA and had higher support as an order. Cordanaceae differs from the closely related Coniochaetaceae by morphology of their basally stromatic ascomata, septate ascospores and holoblastic-denticulate conidiogenesis. (Hernández-Restrepo et al. 2015b).

\section{Ecological and economic significance of Cordanaceae}

Cordana species are widespread in temperate and tropical regions of the world, including Africa, South and Central America, Spain, South East Asia and New Zealand (Fernández \& Huhndorf 2004, Hernández-Restrepo et al. 2014, Zelski et al. 2014, Ai et al. 2019). Species occur on decaying plant matter, in soil or on other fungi (Hernández-Restrepo et al. 2014). They cause leaf spots on banana and Canna species (Ellis 1976, Markovskaja 2003, Cai et al. 2004, Hernández-Restrepo et al. 2014). The type, C. pauciseptata is a common saprobe reported on dead wood.

\section{Genus included in Cordanaceae}

Cordana Preuss, Linnaea 24: 129 (1851)

Index Fungorum number: IF7777; 23 morphological species (Species Fungorum 2020), 11 species with sequence data.

Type species - Cordana pauciseptata Preuss

Notes - Cordana is a dematiaceous hyphomycetous genus introduced by Preuss (1851) together with three species, $C$. polyseptata, $C$. pauciseptata and $C$. pedunculata, without designation of a type species (Hernández-Restrepo et al. 2014). Saccardo (1877) and Hughes (1955) attempted to designate $C$. pauciseptata as the lectotype, however in both occasions the species was subjected to reclassification and the type material was reported as lost (HernándezRestrepo et al. 2014). Thus, Hernández-Restrepo et al. (2014) designated an epitype for this genus, produced a phylogram based on ITS sequences and provided a dichotomous key to the species. Based on cultural studies, Müller \& Samuels (1982b) suggested Porosphaerella cordanophora (Fig. 82) was the sexual morph of Cordana pauciseptata, and this was confirmed phylogenetically by Hernández-Restrepo et al. (2014). ITS sequence data for eight species and LSU for some are available in GenBank (Réblová \& Winka 2000, Huhndorf et al. 2004b, Réblová \& Seifert 2007, Hernández-Restrepo et al. 2014, Zelski et al. 2014, Vu et al. 2019).

\section{Cordycipitaceae Kreisel, Stud. Mycol. 57: 48 (2007)}

Index Fungorum number: IF504360; Facesoffungi number: FoF01314; 313 species.

Parasites or pathogens of scale insects or mosses, or saprobes in leaf litter and upper soil layers. Sexual morph: Stromata or subiculum, fleshy, pallid, or brightly coloured. Perithecia superficial to completely immersed, oriented at right angles to the surface of the stroma. Asci mostly 8-spored, cylindrical, with thickened ascus apex. Ascospores usually cylindrical, multi- 
septate, disarticulating into part-spores or remaining intact at maturity. Asexual morph: beauverialike, engyodontium-like, lecanicillium-like, mariannaea-like, simplicillium-like.

a

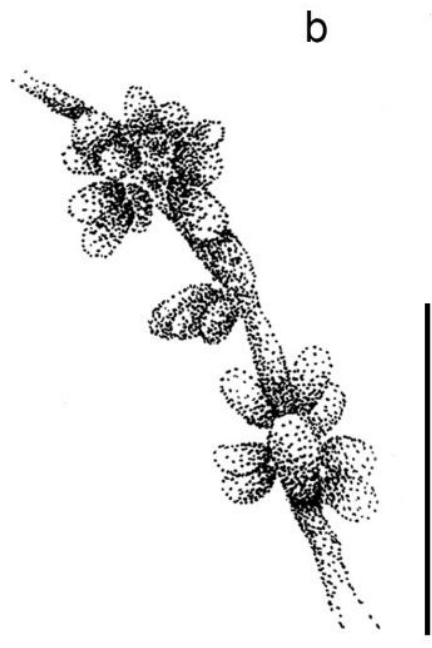

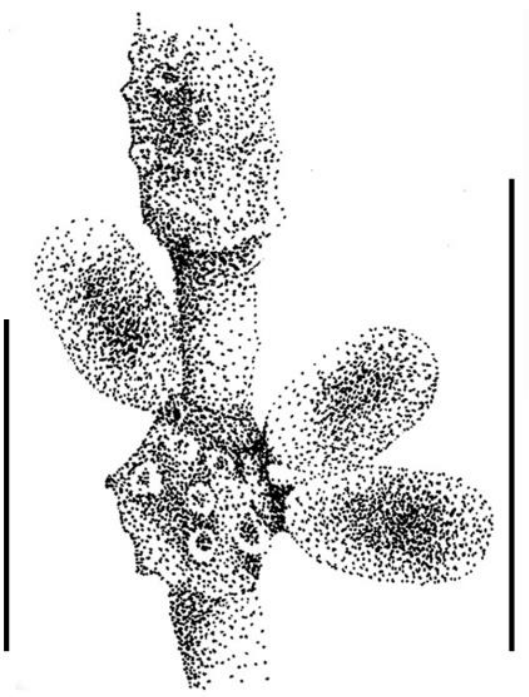

C

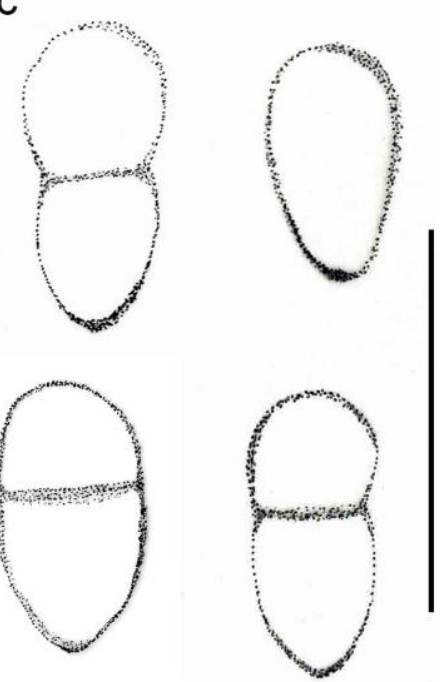

d

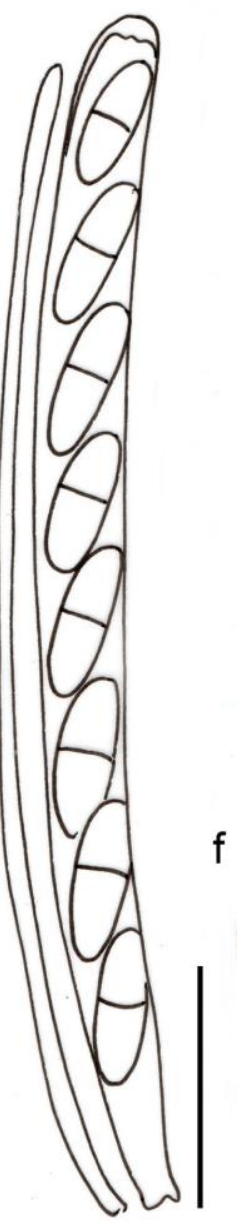

e

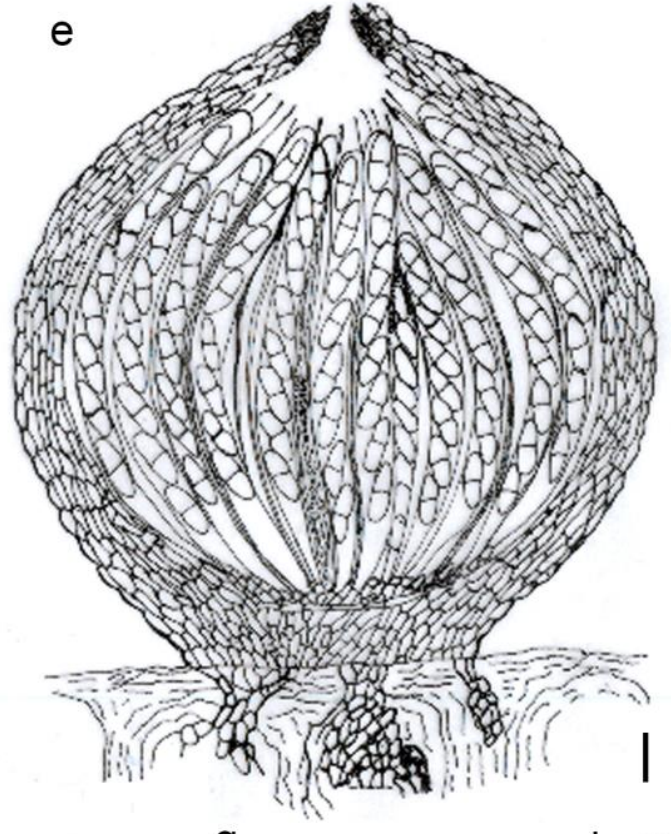

f

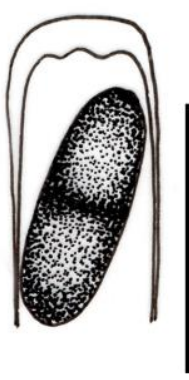

g

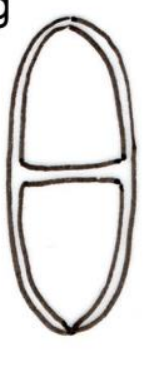

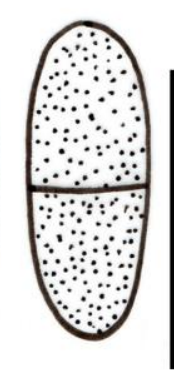
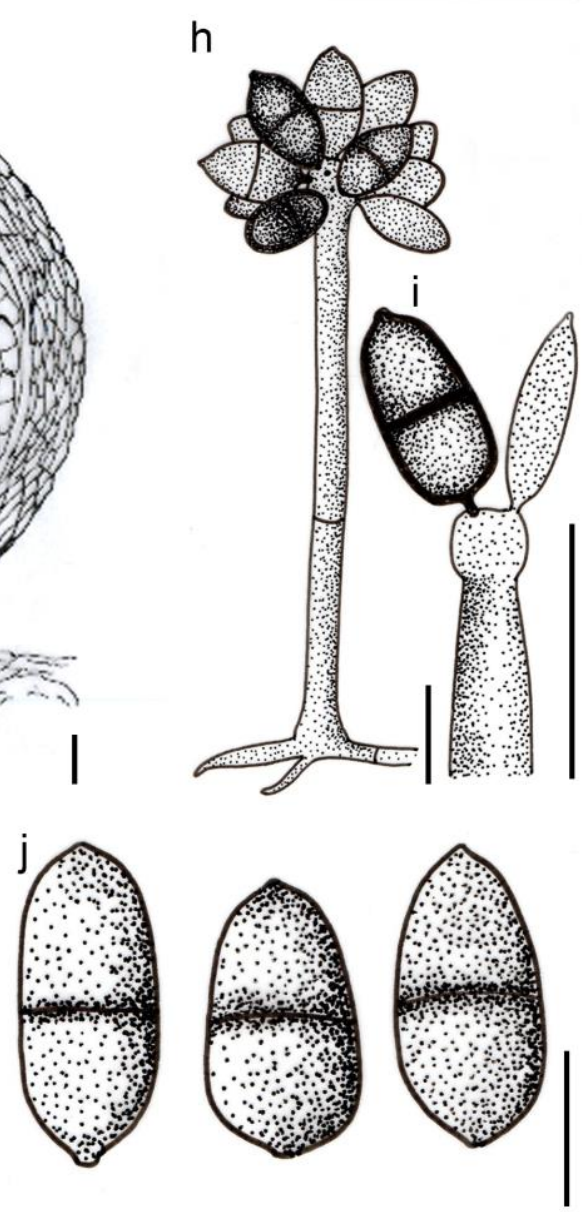

Figure 82 - Cordana mercadiana (FMR 11828, a-c), drawings based on illustrations given in Hernández-Restrepo et al. (2014). a, b Arrangement of conidia on conidiophore and denticulate conidiogenous cells giving rise to conidia (based on SEM microphotographs provided in Hernández-Restrepo et al. 2014). c Conidia. Sexual morph Porosphaerella cordanaphora, and its Cordana asexual morph (d-j, redrawn from Müller \& Samuels 1982b). d Asci with ascospores. e Vertical section of ascoma. $\mathrm{f} \mathrm{J}$-, apical ring of asci with a mature ascospore. $\mathrm{g}$ Ascospores. $\mathrm{h}$ Conidiophore with conidia clustered at apex. i Apical meristem protruding in conidiophore and developing conidia. j Conidia. Scale bars: $\mathrm{a}=50 \mu \mathrm{m}, \mathrm{b}-\mathrm{j}=10 \mu \mathrm{m}$. 
Type genus - Cordyceps Fr.

Notes - Cordycipitaceae was first used by Kreisel (1969), while Wehmeyer (1976) used Cordycipitoideae as subfamily for Clavicipitaceae based on the type genus Cordyceps. Cordycipitaceae was validly segregated from Clavicipitaceae by Sung et al. (2007), based on morphology analyses and multi-gene phylogenetic. Most of the species in the family are entomogenous and produce superficial to partially immersed to completely immersed perithecia, on a fleshy stroma or subicula, that are pallid or brightly coloured (Sung et al. 2007). Sung et al. (2007) confined 11 genera to this family, while Kepler et al. (2017) proposed maintaining nine generic names (Akanthomyces, Ascopolyporus, Beauveria, Cordyceps, Engyodontium, Gibellula, Hyperdermium, Parengyodontium, and Simplicillium) and rejected 8 generic names (Evlachovaea, Granulomanus, Isaria, Lecanicillium, Microhilum, Phytocordyceps, Synsterigmatocystis, and Torrubiella). Kepler et al. (2017) also described two new generic names (Hevansia and Blackwellomyces). The most recent addition is Samsoniella (Mongkolsamrit et al. 2018). In addition, Index Fungorum (2020) records two generic names (Beejasamuha and Rotiferophthora), which were not mentioned in papers, but are included here. Isaria and Microhilum were considered as synonyms of Cordyceps, and Granulomanus was considered as a synonym of Gibellula (Kepler et al. 2017). The asexual morphs in this family are confused.

\section{Ecological and economic significance of Cordycipitaceae}

Many species in this family are economically important, such as Cordyceps militaris, Beauveria bassiana and Cordyceps cicadae, because many significant metabolites have been extracted from these species such as nucleosides (adenine, adenosine, cordycepin) and polysaccharides (CS-F10, CSP-1) (Kiho et al. 1993, Li et al. 2001, Rukachaisirikul et al. 2004, Yu et al. 2004, Li et al. 2006). The bioactive compounds of Cordyceps militaris are well-documented as Chinese traditional medicine as they benefit immune (Kuo et al. 2001), anti-cancer (Kuo et al. 1994, Bok et al. 1999, De Silva et al. 2012, 2013), anti-inflammatory (Won \& Park 2005) and antiplasmodium (Pan et al. 2018) responses (Hyde et al. 2019b). Cordyceps militaris is cultivated in many countries (Park et al. 2001, Shih et al. 2007, Wen et al. 2014) and is industrially profitable.

\section{Genera included in Cordycipitaceae}

Akanthomyces Lebert, Z. Wiss. Zool. 9: 449 (1858)

Index Fungorum number: IF7083; 24 morphological species (Species Fungorum 2020), 10 species with sequence data.

Type species - Akanthomyces aculeatus Lebert

Notes - This genus was established by Lebert (1858) with a single species Akanthomyces aculeatus found in France (Hsieh et al. 1997a). The sexual morph was confirmed as cordyceps-like (Hodge et al. 2003, Kepler et al. 2017) and thus may be a synonym. The genus infects Lepidoptera adults and produces white, cream or flesh-colored, cylindrical, attenuated synnemata covered with a hymenium of phialides and unicellular, hyaline conidia, in short or long chains (Hodge et al. 2003). Species also occur on spiders producing synnematous or mononematous isaria-like phialides and hyaline and long chains of conidia (Mongkolsamrit et al. 2018).

Amphichorda Fr., Syst. orb. veg. (Lundae) 1: 170 (1825)

Index Fungorum number: IF7134; 2 species with molecular data.

Type species - Amphichorda felina (DC.) Fr.

Notes - Species of the genus were isolated from dung, insects and soil (Seifert et al. 2011). The genus is characterised by indeterminate synnemata, branched conidiophores, sympodial conidiogenous and amerosporous, single conidia (Seifert et al. 2011). No sexual morph has been reported.

Ascopolyporus Möller, Bot. Mitt. Trop. 9: 300 (1901) 
Index Fungorum number: IF371; 7 morphological species (Species Fungorum 2020), 3 species with sequence data.

Type species - Ascopolyporus polychrous Möller

Notes - This genus is entomopathogenic and is strongly supported as monophyletic in phylogenetic analyses (Kepler et al. 2017). The genus infects bamboo and has polypore-like, sessile stroma (Hodge et al. 2003).

Beauveria Vuill., Bull. Soc. bot. Fr. 59: 40 (1912)

Index Fungorum number: IF7346; 40 morphological species (Index Fungorum 2020), 25 species with sequence data.

Type species - Beauveria bassiana (Bals.-Criv.) Vuill

Notes - Beauveria was introduced by Vuillemin (1912) by transferring "Botrytis bassiana" and "Botrytis effusa" from Botrytis to Beauveria (Vuillemin 1912). Species of this genus are found worldwide and are parasitic on insects. The sexual morph of the species are cordyceps-like (Li et al. 2001, Rehner et al. 2011). The genus infects insects and has basally-inflated conidiogenous cells (Li et al. 2001, Rehner et al. 2011).

Beejasamuha Subram. \& Chandrash., Can. J. Bot. 55(3): 247 (1977)

Index Fungorum number: IF7350; 1 morphological species.

Type species - Beejasamuha samala Subram. \& Chandrash

Notes - Beejasamuha only has one hyphomycetous species, found on goat dung in India (Subramanian \& Chandrashekara 1977). The genus is characterised by flask-shaped conidiogenous cells and blastoconidia (Subramanian \& Chandrashekara 1977).

Blackwellomyces Spatafora \& Luangsa-ard, IMA Fungus 8: 345 (2017)

Index Fungorum number: IF820864; 3 morphological species (Species Fungorum 2020), 2 species with sequence data.

Type species - Blackwelliella cardinalis (G.H. Sung \& Spatafora) Spatafora \& Luangsa-ard

Notes - The genus was introduced to accommodate two species of Cordyceps based on morphological and phylogenetic analyses (Kepler et al. 2017). The asexual morph are Clonostachys, Hirsutella, Isaria, and Mariannaea species (Kepler et al. 2017). The genus infects insects and has irregularly septate ascospores that do not disarticulate into part-spores (Kepler et al. 2017).

Cordyceps Fr., Observ. mycol. (Havniae) 2: 316 (cancellans) (1818)

Index Fungorum number: IF1240; 180 morphological species (Species Fungorum 2020), 42 species with sequence data.

Type species - Cordyceps militaris (L.) Fr.

Notes - Cordyceps was validly published by Link (1833) and given as the group name by Fries (1818) as Cordylia (Rogers 1954). Cordyceps includes about 564 species (Index Fungorum 2015) and was formally moved to Cordycipitoideae in 2007 (Sung et al. 2007). Sung et al. (2007) moved some species from Cordyceps to several genera including Ophiocordyceps (Ophiocordycipitaceae), Elaphocordyceps current name Tolypocladium (Ophiocordycipitaceae), Metacordyceps (Clavicipitaceae), Claviceps (Clavicipitaceae), Tyrannicordyceps (Clavicipitaceae), Epichloë (Clavicipitaceae), Podostroma (Hypocreaceae) and Podocrea (Hypocreaceae). Kepler et al. (2017) suppressed the names Isaria, Microhilum, Phytocordyceps and Evlachovaea in favour of Cordyceps. The genus infects insects and produces bright, stipitate, fleshy stromata, superficial to embedded perithecia, ascospores which break or do not break into part spores (Sung et al. 2007). The asexual morph of this genus produces evlachovaea-like, isaria-like, lecanicillium-like, mariannaea-like, simplicillium-like phialides or conidia (Sung et al. 2007). A specimen of Cordyceps militaris collected from China which shows the complete sexual and asexual characteristics is illustrated here. 

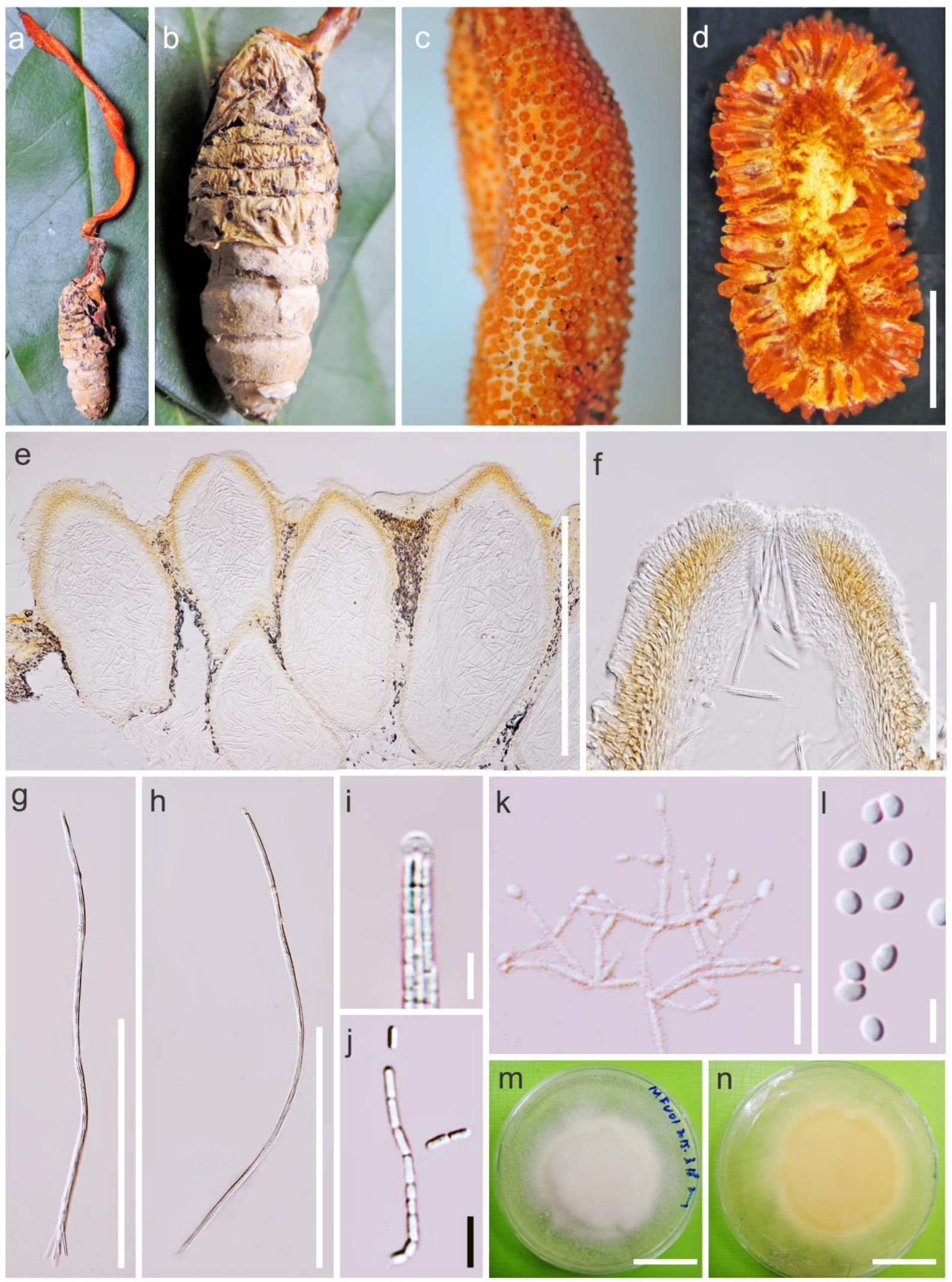

Figure 83 - Cordyceps militaris (Material examined - CHINA, Province of Liao-Ning, on dead larva. 18 June 2014, Ting-Chi Wen TL2014091004, MFLU 15-3202). a Overview of stromata and host. b Host. c Yellow, half superficial ascomata on stroma. d Cross section showing the stroma and ascomata. e Ascomata. f Ostioles. g, h Asci. i Cap of ascus. j Part spores. k Conidiophores and developing conidia. 1 Conidia. $m$ Culture from above on PDA medium after 40 days. $\mathrm{n}$ Culture from below on PDA medium after 40 days. Scale bars: $\mathrm{d}=1000 \mu \mathrm{m}, \mathrm{e}=500 \mu \mathrm{m}, \mathrm{f}=100 \mu \mathrm{m}, \mathrm{g}, \mathrm{h}$ $=200 \mu \mathrm{m}, \mathrm{i}, \mathrm{l}=5 \mu \mathrm{m}, \mathrm{j}, \mathrm{k}=10 \mu \mathrm{m}, \mathrm{m}-\mathrm{n}=2 \mathrm{~cm}$. 
Coremiopsis Sizova \& Suprun, Vestn. Moskov. Univ., Ser. biol. 12(2): 55 (1957)

Index Fungorum number: IF7781; 2 morphological species (Species Fungorum 2020).

Type species - Coremiopsis rosea Sizova \& Suprun

Notes - The genus was isolated from soil and was considered as an uncertain status by Kendrick (1974).

Engyodontium de Hoog, Persoonia 10(1): 53 (1978)

Index Fungorum number: IF8178; 4 morphological species (Species Fungorum 2020), 2 species with sequence data.

Type species - Engyodontium parvisporum (Petch) de Hoog

Notes - Engyodontium album was transfered to Parengyodontium by Tsang et al. (2016). There is no sexual morph link to this genus (Tsang et al. 2016). The genus infects insects and has stipitate synnemata, monophialidic conidiogenous cells and conidia in chains or slimey masses (de Hoog 1978, Evans \& Samson 1987).

Gibellula Cavara, Atti Ist. bot. R. Univ. Pavia, 2 Sér. 3: 347 (1894)

Index Fungorum number: IF8330; 24 morphological species (Species Fungorum 2020), 5 species with sequence data.

Type species - Gibellula pulchra (Sacc.) Cavara

Notes - The genus was recognized as spider pathogens with torrubiella-like sexual morphs (Humber \& Rombach 1987, Prathumpai et al. 2012, Kuephadungphan et al. 2014). The genus infects spiders and has stipitate synnemata, and vesiculate conidiophores (Humber \& Rombach 1987, Prathumpai et al. 2012).

Hevansia Luangsa-ard, Hywel-Jones \& Spatafora in IMA Fungus 8: 348 (2017)

Index Fungorum number: IF820885; 8 morphological species (Kepler et al. 2017), 5 species with sequence data.

Type species - Hevansia novoguineensis (Samson \& B.L. Brady) Luangsa-ard, Hywel-Jones \& Spatafora

Notes - The genus was established with eight species and diagnosed by immersed perithecia and an akanthomyces-like asexual morph (Kepler et al. 2017). The genus infects spiders and has sessile stromata, immersed perithecia and monophialidic conidiogenous cells (Kepler et al. 2017).

Hyperdermium J.F. White, R.F. Sullivan, Bills \& Hywel-Jones, Mycologia 92(5): 910 (2000)

Index Fungorum number: IF28464; 2 morphological species (Species Fungorum 2020), 1 species with sequence data.

Type species - Hyperdermium bertonii (Speg.) J.F. White, R.F. Sullivan, Bills \& HywelJones

Notes - The members of this genus are parasitic on insects and plants (Sullivan et al. 2000). The genus is characterised by bright, sessile stromata with 1-3 perithecia per stroma (Sullivan et al. 2000).

Leptobacillium Zare \& W. Gams, Mycol. Progr. 15: 1001 (2016)

Index Fungorum number: IF815489; 1 species with sequence data.

Type species - Leptobacillium leptobactrum (W. Gams) Zare \& W. Gams

Notes - This genus was separated from Verticillium as a saprotrophic or fungicolous taxon without a sexual morph reported (Zare \& Gams 2016). The genus is characterised by narrow, rodshaped conidia and chlamydospores (Zare \& Gams 2016).

Parengyodontium C.C. Tsang, J.F.W. Chan, W.M. Pong, J.H.K. Chen, A.H.Y. Ngan, M. Cheung, C.K.C. Lai, D.N.C. Tsang, S.K.P. Lau \& P.C.Y. Woo, Medical Mycology 54: 708 (2016)

Index Fungorum number: IF815049; 1 species with sequence data. 
Type species - Parengyodontium album (Limber) C.C. Tsang, J.F.W. Chan, W.M. Pong, J.H.K. Chen, A.H.Y. Ngan, M. Cheung, C.K.C. Lai, D.N.C. Tsang, S.K.P. Lau \& P.C.Y. Woo

Notes - The genus was emended to accommodate one species from Engyodontium and it infects humans and produces numerous whorls of conidiogenous cells (Tsang et al. 2016).

Pseudogibellula Samson \& H.C. Evans, Acta bot. neerl. 22(5): 524 (1973)

Index Fungorum number: IF9578; 1 morphological species.

Type species - Pseudogibellula formicarum (Mains) Samson \& H.C. Evans

Notes - Pseudogibellula was introduced with a sing species, which parasitic on ants (Samson \& Evans 1973). The genus is characterised by producing singly conidia on sympodial conidiogenous cells (Samson \& Evans 1973). The sexual morph link to Torrubiella (Samson \& Evans 1973, White et al. 2003).

Samsoniella Mongkolsamrit, Noisripoom, Thanakitpipattana, Spatafora \& Luangsa-ard, Mycologia 110(1): 230-257 (2018)

Index Fungorum number: IF823784; 3 species with sequence data.

Type species - Samsoniella inthanonensis Mongkolsamrit, Noisripoom, Thanakitpipattana, Spatafora \& Luangsa-ard

Notes - The genus was erected by Mongkolsamrit et al. (2018) and segregated from Akanthomyces to accommodate species in a monophyletic clade that are easily recognized by their oval to fusiform conidia, and bright red-orange stromata of the sexual morphs and synnemata of the isaria-like asexual morphs.

Simplicillium W. Gams \& Zare, Nova Hedwigia 73(1-2): 38 (2001)

Index Fungorum number: IF28570; 14 species with sequence data.

Type species - Simplicillium lanosoniveum (J.F.H. Beyma) Zare \& W. Gams

Notes - The asexual morphs of this genus are cordyceps-like (White et al. 2003), but molecular analyses has shown this as a separate genus from Cordyceps. The genus infects insects and produces exclusively solitary phialides, adhering in globose slimy heads or imbricate chain conidia (Zare \& Gams 2001).

Coronophoraceae Höhn., Sber. Akad. Wiss. Wien, Math.-naturw. Kl., Abt. 1 116: 624 (1907) Index Fungorum number: IF80647; Facesoffungi number: FoF01117; 17 species.

Saprobic on plant stems or wood in terrestrial habitats, or parasitic on other fungi. Sexual morph: Ascomata perithecial, gregarious or solitary, superficial, black, semi-immersed becoming erumpent through bark of host, ovoid to subglobose, carbonaceous, tuberculate, glabrous or with hairs, laterally collapsing when dry, sometimes with a short neck with or without ostioles or quellkörper. Peridium carbonaceous or membranaceous, composed of three layers, outer layer comprising dark tissue, carbonaceous; middle layer comprising dark brown to brown cells of textura angularis, membranaceous and the inner layer comprising hyaline cells of textura prismatica, membranaceous. Paraphyses numerous, filamentous, septate, unbranched. Asci polysporous, unitunicate, thin-walled, clavate to cylindrical, long pedicellate, apex blunt, without a visible discharge mechanism. Ascospores crowded, hyaline, cylindrical to allantoid, slightly curved, aseptate, smooth-walled, mostly with guttules. Asexual morph: Undetermined.

Type genus - Coronophora Fuckel

Notes - The monotypic family Coronophoraceae was introduced by Höhnel (1907b). As a synonym of Nitschkiaceae, it had been placed in Coronophorales (Nannfeldt 1932, Müller \& Arx 1973, Subramanian \& Sekar 1990) or in Sordariales (Nannfeldt 1975, Barr 1990b). Mugambi \& Huhndorf (2010) used a tefl and $r p b 2$ combined sequence dataset, which included the type species C. gregaria, to show that Coronophoraceae is distinct from Nitschkiaceae.

\section{Ecological and economic significance of Coronophoraceae}


Most Coronophora species are saprobic on wood and widespread in Europe and America and involved in nutrient cycling (Fuckel 1870, Mugambi \& Huhndorf 2010).
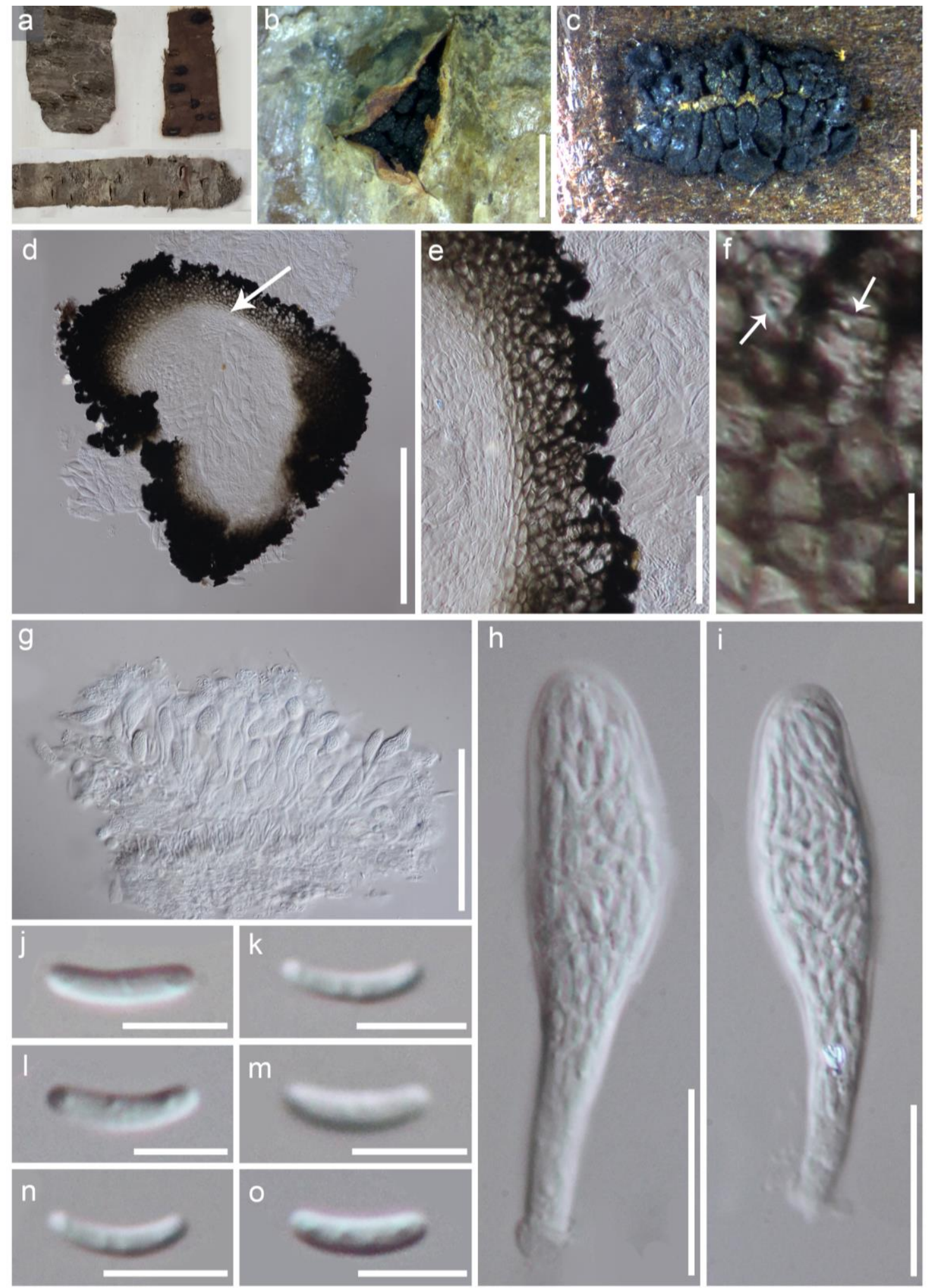

Figure 84 - Coronophora gregaria (Material examined - BELGIUM, on bark of Prunus cerasus and Sorbus aucuparia, Autumn, collected by Libert MA, BR no. 5020094489111, isotype). a Herbarium material. b Ascomata erumpent through bark of host. c Ascomata on decorticated wood. $\mathrm{d}$ Ascoma in cross section (arrow head indicates ascogenous hyphae). e Peridium. f Munk pores. $g$ Paraphyses with asci. h, i Asci. j-o Ascospores. Scale bars: b-c $=2 \mathrm{~mm}, \mathrm{~d}=200 \mu \mathrm{m}, \mathrm{g}=100 \mu \mathrm{m}$, e $=50 \mu \mathrm{m}, \mathrm{h}-\mathrm{i}=20 \mu \mathrm{m}, \mathrm{f}=10 \mu \mathrm{m}, \mathrm{j}-\mathrm{o}=5 \mu \mathrm{m}$. 


\section{Genus included in Coronophoraceae}

Coronophora Fuckel, Fungi rhenani exsic., fasc. 10: no. 961 (1864)

Index Fungorum number: IF1253; 17 morphological species (Species Fungorum 2020), 2 species with sequence data.

Type species - Coronophora gregaria Fuckel

Notes - Coronophora is characterized by tuberculate ascomata with polysporous asci and tiny, allantoid, hyaline ascospores. Coronophora gregaria is illustrated in this entry. Sphaeria gregaria is synonym as Coronophora gregaria and occurs on dead wood in Europe and America (Fuckel 1870, Mugambi \& Huhndorf 2010). The sequences of tefl and rpb2 of $C$. gregaria (ANM1555) were provided by Mugambi \& Huhndorf (2010).

\section{Coryneaceae Corda, Icon. fung. (Prague) 3: 36 (1839)}

Index Fungorum number: IF80650; Facesoffungi number: FoF06868; 79 species.

Saprobic on dead wood or pathogenic on plants. Sexual morph: Stromata solitary, erumpent, comprising pseudoparenchymatous cells. Ectostromatic disc well or poorly developed, brown to black, comprising small cells of textura prismatica. Ascomata perithecial, arranged in valsoid configuration, immersed, aggregated, globose to subglobose, coriaceous, brown to black, papillate, ostiolate. Papilla upright, central, broad, sometimes converging, comprising brown cells of textura porrecta. Peridium comprising outer, thick-walled, brown cells of textura angularis and inner, thick-walled, hyaline, compressed cells of textura angularis. Paraphyses broad, cellular, septate, attached to base, longer than asci. Asci 8-spored, unitunicate, ellipsoid to cylindrical, pedicellate, rounded at apex with a J-, apical ring. Ascospores overlapping uni- to biseriate, hyaline or initially hyaline, brown at maturity, irregularly fasciculate, ellipsoid, fusoid or elongate, 1-3-septate, often distoseptate, with end-cells pale brown or hyaline, sometimes end-cells pointed, straight or curved not constricted at the septa, guttulate, smooth-walled. Asexual morph: Coelomycetous. Conidiomata acervular, solitary, erumpent through outer periderm layers of host or immersed, scattered, surface tissues above somewhat dome-shaped. Conidiomatal wall composed of thinwalled, vertically arranged dark brown cells of textura angularis. Conidiophores branched at the base or not, cylindrical to globose, septate or aseptate, hyaline or hyaline at the apex, pale brown at the base. Conidiogenous cells terminal, hyaline, annellidic, cylindrical, sometimes with setulose apical appendages. Conidia hyaline to dark brown, curved, broadly fusiform to cylindrical or clavate, smooth-walled, 4-6-distoseptate, sometimes the apical and basal cell darker than other cells with hyaline tip in apical cell.

Type genus - Coryneum Nees

Notes - Coryneaceae was introduced by Corda (1839a) to accommodate Coryneum which was typified by $C$. umbonatum and comprises only one genus.

\section{Ecological and economic significance of Coryneaceae}

Some species of Coryneum cause coryneum-blight, a serious fungal disease that forms holes in leaves, rough areas on fruits and concentric lesions on branches (Senanayake et al. 2018). Many Coryneum species cause cankers in economically important trees and forest trees (Strouts 1972, Gadgil \& Dick 2007, Horst 2013, Senanayake et al. 2017a). Several Coryneum species occur on chestnut and oak trees (Sutton 1975). Some saprobic species are associated with decaying wood thus contributing to nutrient cycling.

\section{Genus included in Coryneaceae}

\section{Coryneum Nees, Das System der Pilze and Schwamme 34 (1817)}

Index Fungorum number: IF7798; 79 morphological species (Species Fungorum 2020), 10 species with sequence data, molecular data available for 2 unnamed species.

Type species - Coryneum umbonatum Nees

Notes - Rossman et al. (2015) synonymized Pseudovalsa under Coryneum. The asexual morph is the most common morph seen. There are more than 70 species recorded under Coryneum. 
However, molecular sequence data are lacking for most species. Wijayawardene et al. (2016b), Senanayake et al. (2017a), Jiang et al. (2018) and Senwanna et al. (2018) introduced several species providing phylogenetic analyses. Common host genera include Acer, Betula, Castanea, Eucalyptus, Populus, Quercus, Rosa, Rhododendron, Salix, Sorbus, Sambucus, Tilia, and Vitis (Farr \& Rossman 2018). Coryneum species are common in temperate regions than in tropical regions. Coryneum brachyurum, current name Coryneum lanciforme (Species Fungorum 2020) is illustrated in this entry.

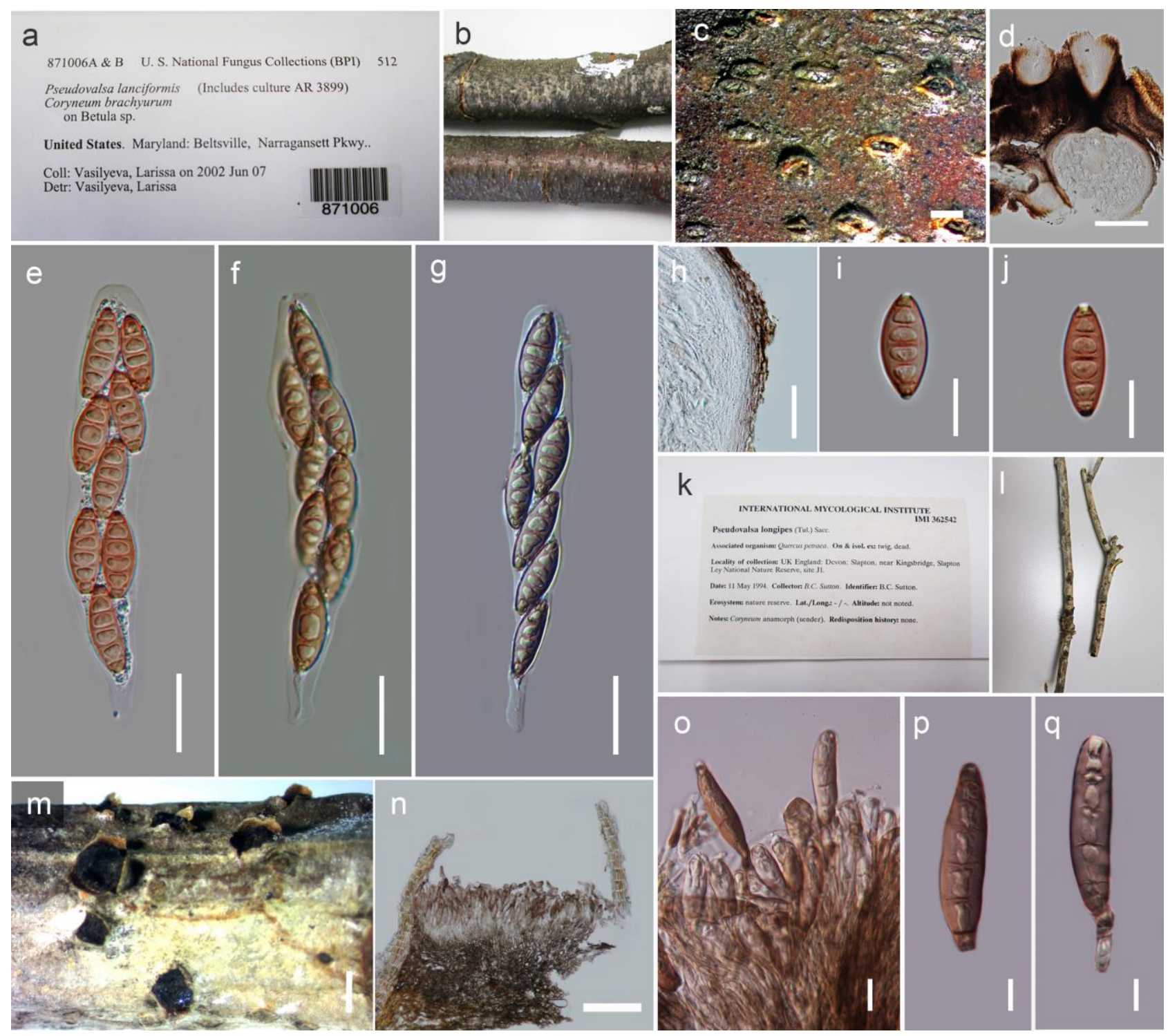

Figure 85 - Coryneum lanciforme, a-j sexual morph, k-q asexual morph (Material examined USA, Maryland, Beltsville, Narragansett Pkwy, on stem of Betula sp., 07 June 2002, Vasilyeva, Larissa BPI 871006A (sexual morph); UK, Devon, Slapton, near Kingsbridge, slapton, Ley National Nature Reserve, site J1, on twigs of Quercus petraea, 11 May 1994, B. C. Sutton, IMI 362542 (asexual morph)). a Herbarium packet. b Herbarium specimen. c Stromata on substrate. d Transverse section of stroma. e-g Asci. h Peridium. i-j Ascospores. k, 1 Herbarium packet and specimen. $m$ Conidiomata on substrate. $\mathrm{n}$ Cross section of conidioma. o Conidia attached to conidiophore. p-q Conidia. Scale bars: $\mathrm{c}=1 \mathrm{~mm}, \mathrm{~d}=100 \mu \mathrm{m}, \mathrm{e}-\mathrm{h}=20 \mu \mathrm{m}, \mathrm{i}-\mathrm{j}=10 \mu \mathrm{m}, \mathrm{m}=500$ $\mu \mathrm{m}, \mathrm{e}=100 \mu \mathrm{m}, \mathrm{o}-\mathrm{q}=10 \mu \mathrm{m}$.

Cryphonectriaceae Gryzenh. \& M.J. Wingf., Mycologia 98: 246 (2006)

Index Fungorum number: IF510585; Facesoffungi number: FoF03455; 91 species. 
Saprobic or pathogenic in forest trees and economic crops. Sexual morph: Ascostromata scattered, immersed or erumpent, aggregated, oval to circular from above, comprising two layers, with upper layer of yellowish orange to pale brown cells, purpling in $\mathrm{KOH}$ and inner layer of hyaline cells, mixed with plant cells. Ascomata immersed, aggregated, several in one stroma, globose to subglobose, fuscous black to umber, with long neck, sometimes ostiolar canal immersed in stromatic tissues or superficial, with necks covered in umber stromatic tissue of texturaporrecta, inner wall of the necks or ostiolar canal with hyaline, filamentous periphyses. Peridium comprising inner layer of small, hyaline cells of textura angularis and outer layer of small, brown cells of textura angularis. Paraphyses few, cellular, parenchymatous cells, attached at the base of asci and dissolving at maturity. Asci 8-spored, unitunicate, cylindrical-fusoid to clavate, pedicellate, with distinct, J-, refractive apical ring. Ascospores overlapping uniseriate to biseriate, hyaline, sometimes brown,ellipsoid, fusoid to cylindrical, aseptate to multi-septate, not constricted at septa, smooth-walled. Asexual morph: Coelomycetous. Conidiomata occurring as part of ascostromata, as conidial locules or solitary structures, uni- to multi-loculate, pyriform, subglobose to pulvinate, ostiolar necks absent or present; if present, with one to several attenuated necks, superficial or semi-immersed, orange to fuscous-black. Conidiophores cylindrical, aseptate, hyaline, sometimes reduced to conidiogenous cells. Conidiogenous cells lining the inner cavity of the conidiomata, phialidic, sometimes within flattened base, ampulliform,conspicuous, with attenuated or truncate apices, hyaline, smooth. Conidia minute, sometimes both micro- and macro-conidia present, sigmoid, broadly ellipsoid to fusoid, obovoid-cylindrical to allantoid, aseptate, hyaline.

Type genus - Cryphonectria (Sacc.) Sacc. \& D. Sacc.

Notes - Cryphonectriaceae comprises mostly tree and plant pathogens (Vermeulen et al. 2011) and rarely saprobes and endophytes. They cause diseases in economically important plants and forest trees. Cryphonectriaceae was established by Gryzenhout et al. (2006b) to accommodate the Cryphonectria-Endothia complex based on nrLSU sequence data.

\section{Ecological and economic significance of Cryphonectriaceae}

Cryphonectriaceae comprises highly virulent plant pathogens such as Cryphonectria parasitica which is the causal agent of chestnut blight (Anagnostakis 1987, Heiniger \& Rigling 1994). Some species are pathogenic on Myrtales tree species, especially forms causing stem canker disease (Chen et al. 2016). Species in Cryphonectriaceaeare commonly associated with serious cankers and leaf spots diseases (Crous et al. 2015a). Very few species are saprobes.

\section{Genera included in Cryphonectriaceae}

Amphilogia Gryzenhout, Glen \& M. J. Wingf., Taxon 54(4): 1017 (2005b)

Index Fungorum number: IF510065; 2 morphological species (Species Fungorum 2020), 1 species with sequence data.

Type species - Amphilogia gyrosa (Berk. \& Broome) Gryzenhout, Glen \& M.J. Wingf.

Notes - Amphilogia was introduced to accommodate Cryphonectria gyrosa (CMW 10471/CRY 1551) based on its morphological distinctness such as superficial conical conidiomata, conidia of variable size and ascospores with one to three septa (Gryzenhout et al. 2005). The second species Amphilogia major, accommodated in this genus, was reported from New Zealand (Gryzenhout et al. 2005).

Aurantioporthe G. Beier \& Blanchette, Mycologia 107(1): 71 (2015)

Index Fungorum number: IF807278; 1 species with sequence data.

Type species - Aurantioporthe corni (Wehm.) G. Beier\& R.A. Blanchette

Notes - Aurantioporthe is known from only its type species, A. corni. This species is the causative agent of golden cankers disease in USA and Canada. Aurantioporthe differs from other genera in Cryphonectriaceae in having ascogenous stromata, immersed to semi-immersed conidiomata and uni- to multi-septate ascospores. 
Aurantiosacculus Dyko \& B. Sutton, Mycologia 71(5): 922 (1979)

Index Fungorum number: IF7296; 4 morphological species (Species Fungorum 2020), 2 species with sequence data.

Type species - Aurantiosacculus eucalypti (Cooke \& Massee) Dyko \& B. Sutton

Notes - Aurantiosacculus species are associated with leaf spots on Eucalyptus (Crous et al. 2012b). Aurantiosacculus produces leaf spots, with bright orange conidiomata with brown furfuraceous tissue and aseptate conidia with swollen bases and thickened scars.

Aurapex Gryzenh. \& M.J. Wingf., Mycologia 98(1): 112 (2006b)

Index Fungorum number: IF501067; 1 species with sequence data.

Type species - Aurapexpenicillata Gryzenh. \& M.J. Wingf.

Notes - Aurapex is distinguished from other genera of Cryphonectriaceae by its orange conidiomatal necks with black bases and a unique internal stromatal structure. Species of Aurapex are serious canker pathogens of Eucalyptus species (Gryzenhout et al. 2006b).

Aurifilum Begoude, Gryzenh. \& Jol. Roux, Antonie van Leeuwenhoek 98(3): 273 (2010)

Index Fungorum number: IF546909; 1 species with sequence data.

Type species - Aurifilum marmelostoma Begoude, Gryzenh. \& Jol. Roux

Notes - The monotypic genus Aurifilum was introduced and typified by Aurifilum marmelostoma which has broad convex conidiomata, darkened ostiolar openings at the apex of the conidiomata, paraphyses or sterile cells, one septate, fusoid to ellipsoid ascospores and minute, cylindrical conidia.

Capillaureum M.E.S. Oliveira, G.A. Silva \& M.A. Ferreira, Mycol. Progr. 18(3): 392 (2019)

Index Fungorum number: IF827751; 1 species with sequence data.

Type species - Capillaureum caryovora M.E.S. Oliveira, G.A. Silva \& M.A. Ferreira

Notes - Capillaureumwas isolated from Caryocar brasiliense, a tree used in the cosmetic and food industries. This is a stem canker causing fungus. This genus is distinguished from other genera in having a fuscous-black necks with septate, branched hyphal ostioles.

Celoporthe Nakab., Gryzenh., Jol. Roux \& M.J. Wingf., Stud. Mycol. 55: 261 (2006)

Index Fungorum number: IF500886; 9 morphological species (Species Fungorum 2020), 9 species with sequence data.

Type species - Celoporthe dispersa Nakab., Gryzenh., Jol. Roux \& M.J. Wingf.

Notes - This genus is distinguished from other genera in having immersed, umber to brown to fuscous-black conidiomata with cylindrical conidia.

Chromendothia Lar.N. Vassiljeva, Mikol. Fitopatol. 27(4): 5 (1993)

Index Fungorum number: IF27570; 2 morphological species (Species Fungorum 2020), 1 species with sequence data.

Type species - Chromendothia citrina Lar.N. Vassiljeva

Notes - Chromendothia comprises three species. Chromendothia shares characters with other taxonomic groups such as hypocreaceous fungi and some diaporthalean members. The genus is characterised by characteristic brown ascospores and whitish yellow stromatic tissues. There are no records of the asexual morph of this genus.

Chrysofolia Crous \& M.J. Wingf., Persoonia, Mol. Phyl. Evol. Fungi 34: 207 (2015)

Index Fungorum number: IF812450; 2 morphological species (Species Fungorum 2020), 1 species with sequence data.

Type species - Chrysofolia colombiana Crous, Rodas \& M.J. Wingf.

Notes - Chrysofolia is distinct in having erumpent conidiomata with bright, yellow-brown furfuraceous margins (Crous et al. 2015c). 
Chrysomorbus S.F. Chen, Pl. Path. 67(1): 117 (2017)

Index Fungorum number: IF821021; 1 species with sequence data.

Type species - Chrysomorbus lagerstroemiae S.F. Chen \& Q.L. Liu

Notes - Chrysomorbus is distinct from other genera having fusoid to oval conidia, convex to globose conidiomata and lack of ostioles. Chrysomorbus lagerstroemiae is associated with cankers on Lagerstroemia speciosa (Lythraceae, Myrtales).

Chrysoporthe Gryzenh. \& M.J. Wingf., Stud. Mycol. 50(1): 129 (2004)

Index Fungorum number: IF500032; 8 species with sequence data.

Type species - Chrysoporthe cubensis (Bruner) Gryzenh. \& M.J. Wingf.

Notes - Chrysoporthe was typified by C. cubensis and the sexual morph of this genus does not commonly occur in nature. Chrysoporthe is distinguished from other genera in this family having superficial, pyriform, fuscous-black conidiomata with oblong conidia.

Corticimorbus S.F. Chen \& M.J. Wingf., Pl. Path. 65(8): 1258 (2016)

Index Fungorum number: IF815261; 1 species with sequence data.

Type species - Corticimorbus sinomyrti S.F. Chen, F.F. Liu \& M.J. Wingf.

Notes - Corticimorbus sinomyrtiis a tree pathogen on Rhodomyrtus tomentosa forming stem canker disease. The fungus is most similar to species in Chrysoporthe based on morphology. However, this genus can be distinguished from the other genera having conical pycnidia and fusoid to oval conidia.

Cryphonectria (Sacc.) Sacc. \& D. Sacc., Syll. fung. (Abellini) 17: 783. (1905)

Index Fungorum number: IF9670; 14 morphological species (Species Fungorum 2020), 8 species with sequence data.

Type species - Cryphonectria parasitica D. Sacc.

Notes - Cryphonectria is typified by $C$. parasitica the causal agent of chestnut blight (Anagnostakis 1987, Heiniger \& Rigling 1994). Cryphonectria species are sometimes serious canker pathogens but generally survive as saprobes (Roane 1986). Cryphonectria parasitica is illustrated in this entry.

Cryptometrion Gryzenh. \& M.J. Wingf., Australas. P1.Path. 39(2): 166 (2010)

Index Fungorum number: IF514188; 1 species with sequence data.

Type species - Cryptometrion aestuescens Gryzenh. \& M.J. Wingf.

Notes - Cryptometrion can be distinguished from other genera in Cryphonectriaceae based on its orange, limited stromatic tissue, uniseptate, fusoid to ellipsoid ascospores and absence of paraphyses among the conidiogenous cells in the asexual morph.

Diversimorbus S.F. Chen \& Jol. Roux, Fungal Biol. 117: 300 (2014)

Index Fungorum number: IF564805; 1 species with sequence data.

Type species - Diversimorbus metrosiderotis S.F. Chen \& Jol. Roux

Notes - Diversimorbus was isolated from South Africa associated with Myrtales' tree species. The fungus is pathogenic on its host (Chen et al. 2013). The genus is characterised by pulvinate conidiomata without necks and fusoid to allantoid conidia.

Endothia Fr., Summa veg. Scand., Section Post. (Stockholm): 385 (1849)

Index Fungorum number: IF1810; 9 morphological species (Species Fungorum 2020), 1 species with sequence data.

Type species - Endothia gyrosa (Schwein.) Berk.

Notes - Endothia was introduced based on Sphaeria gyrosa, which causes a serious canker disease (Snow et al. 1975). Endothia species cause hobnail canker on oak (Van Arsdel 1972). The 
genus is characterised by immersed, orange conidiomata without necks and with cylindrical conidia.

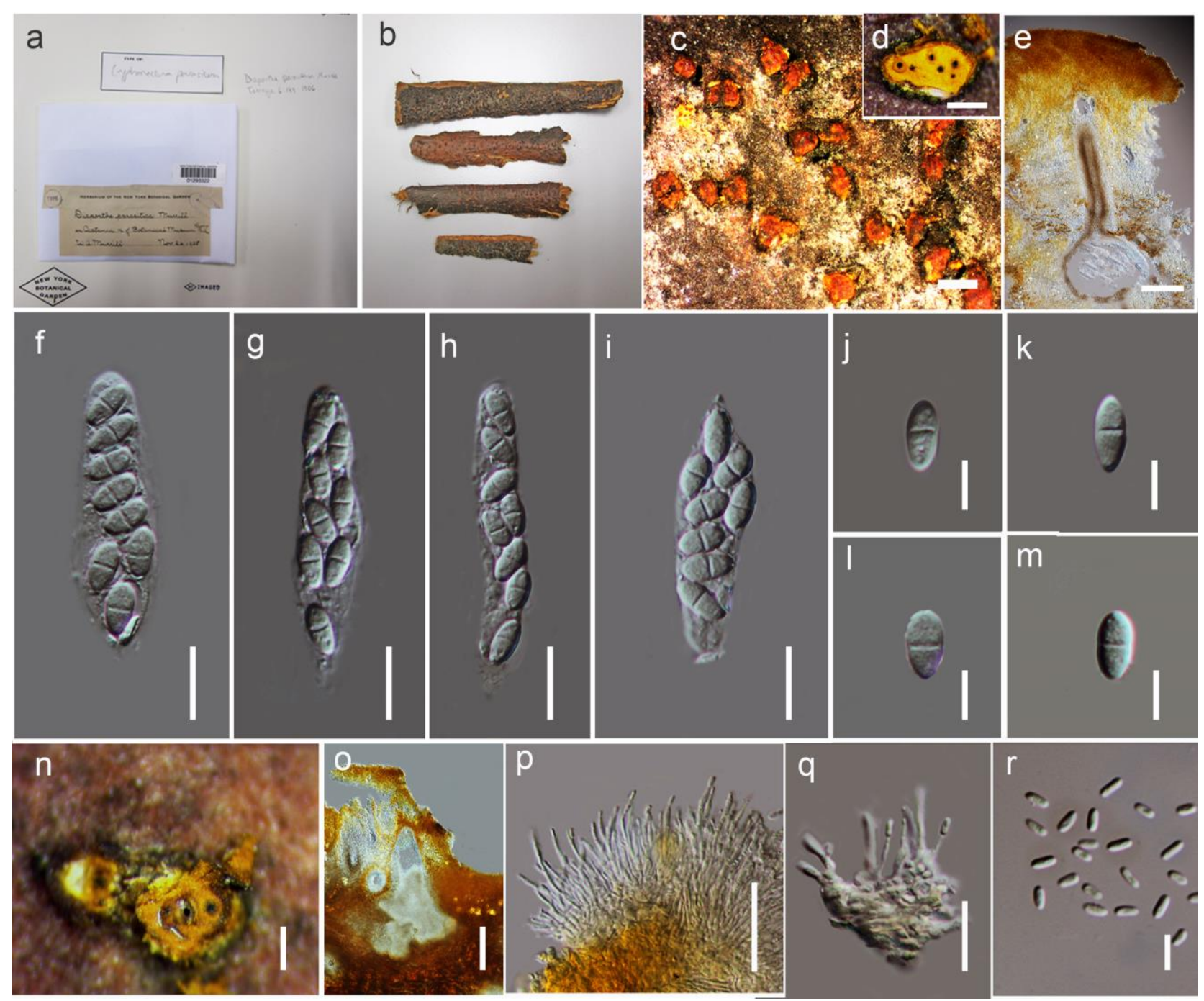

Figure 86 - Cryphonectria parasitica (Material examined - USA, New York. Bronx Co. Bronx. North of Botanical Museum, Bronx Park, on Castanea dentata (Fagaceae), 26 Nov. 1905, W.A. Murrill, NY 01293321, holotype of Diaporthe parasitica). a Herbarium packet. b Herbarium specimen. c Ascostromata on substrate. d Horizontal section of ascostroma. e Vertical cross section of ascoma. f-i Asci. j-m Ascospores. $n$ Horizontal cross section of conidiomata. o Vertical cross section of conidioma. $\mathrm{p}$, q Conidia attached to the conidiogenous cells and conidiophores. $\mathrm{r}$ Conidia. Scale bars: c, d = $1 \mathrm{~mm}, \mathrm{f}-\mathrm{i}, \mathrm{p}-\mathrm{r}=10 \mu \mathrm{m}, \mathrm{e}, \mathrm{q}, \mathrm{o}=100 \mu \mathrm{m}, \mathrm{n}=200 \mu \mathrm{m}, \mathrm{j}-\mathrm{m}=5 \mu \mathrm{m}$.

Foliocryphia Cheew. \& Crous, Persoonia 23: 65 (2009)

Index Fungorum number: IF513846; 2 species with sequence data.

Type species - Foliocryphia eucalypti Cheew. \& Crous

Notes - Foliocryphia is characterized by aseptate conidia in eustromatic conidiomata and stromata which do not turn purple in $3 \% \mathrm{KOH}$, or yellow in lactic acid.

Holocryphia Gryzenh. \& M.J. Wingf., Stud. Mycol. 55: 48 (2006b)

Index Fungorum number: IF500797; 4 species with sequence data.

Type species - Holocryphia eucalypti (M. Venter \& M.J. Wingf.) Gryzenh. \& M.J. Wingf.

Notes - Holocryphia eucalypti is an opportunistic canker pathogen of Eucalyptus and Corymbia species (Chen et al. 2013). The genus is characterised by semi-immersed conidiomata, septate conidiophores and cylindrical conidia. 
Immersiporthe S.F. Chen, M.J. Wingf. \& Jol. Roux, Pl. Path. 62: 674 (2013)

Index Fungorum number: IF564804; 1 species with sequence data.

Type species - Immersiporthe knoxdaviesiana S.F. Chen, M.J. Wingf. \& Jol. Roux

Notes - Immersiporthe knoxdaviesiana is an aggressive pathogen of Rapanea melanophloeos. Immersiporthe is morphologically distinct in having orange pulvinate conidiomata, without conidiomatal necks and with paraphyses.

Latruncellus M. Verm., Gryzenh. \& Jol. Roux, Mycologia103(3): 562 (2011)

Index Fungorum number: IF518285; 1 species with sequence data.

Type species - Latruncellus aurorae M. Verm., Gryzenh. \& Jol. Roux

Notes - This monotypic genus is associated with cankers on Galpinia transvaalica (Lythraceae, Myrtales) in Swaziland. The genus is characterised by distinct conical conidiomata with a distinct neck and subulate to flask-shaped conidiophores.

Luteocirrhus C. Crane \& T.I. Burgess, IMA Fungus 4(1): 115 (2013)

Index Fungorum number: IF563390; 1 species with sequence data.

Type species - Luteocirrhus shearii C. Crane \& T.I. Burgess

Notes - The monotypic genus Luteocirrhus was isolated from canker lesions in Banksia species and Lambertia echinata. The genus is characterised by some semi-immersed conidiomata, paraphyses within the locules and cylindrical conidia.

Mastigosporella Höhn. Sber. Akad. Wiss. Wien, Math.- naturw. Kl., Abt. 1 123: 135 (1914)

Index Fungorum number: IF8860; 5 morphological species (Species Fungorum 2020), 2 species with sequence data.

Type species - Mastigosporella hyalina (Ellis \& Everh.) Höhn.

Notes - Mastigosporella hyalina is morphologically similar to Harknessia caudata, however differs by colour of conidia. Additionally, the pattern of conidiogenesis in Harknessia and Mastigosporella differ (Sutton 1971).

Microthia Gryzenh. \& M.J. Wingf., Stud. Mycol. 55: 44 (2006)

Index Fungorum number: IF500792; 3 morphological species (Species Fungorum 2020), 1 species with sequence data.

Type species - Microthia coccolobae (Vizioli) Gryzenh. \& M.J. Wingf.

Notes - Microthia comprises two species Microthiahavanensis and M. coccolobae. Microthia is distinct in having small, pulvinate and semi-immersed stromata tending to be superficial on the substrate.

Myrtonectria Marinc., D.B. Ali \& J. Roux, Mycol. Progr. 17(8): 958 (2018)

Index Fungorum number: IF824022; 1 species with sequence data.

Type species - Myrtonectria myrtacearum Marinc., D.B. Ali \& J. Roux

Notes - Myrtonectria myrtacearum appears to be an endophyte or cryptic pathogen that was obtained from branches of Syzygium cordatum, root collars of Heteropyxisnatalensis and bark of Tibouchina grandifolia. The genus is characterised by semi-immersed to superficial, dark greyish brown, uniloculate conidiomata and aseptate, oblong conidia with a pointed base.

Rostraureum Gryzenh. \& M.J. Wingf., Mycol. Res. 109(9): 1039 (2005b)

Index Fungorum number: IF28972; 2 morphological species (Species Fungorum 2020), 1 species with sequence data.

Type species - Rostraureum tropicale Gryzenh. \& M.J. Wingf.

Notes - Rostraureum is distinguished by orange, superficial, rostrate, eustromatic conidiomata (Gryzenhout et al. 2005). 
Ursicollum Gryzenh. \& M.J. Wingf., Stud. Mycol. 55: 44 (2006a)

Index Fungorum number: IF500795; 1 species with sequence data.

Type species - Ursicollum fallax Gryzenh. \& M.J. Wingf.

Notes - Ursicollum is typified by $U$. fallax which is distinct from other genera in Cryphonectriaceae in having unique orange, pyriform to globose conidiomata with cylindrical to attenuated necks (Gryzenhout et al. 2006a).

Wuestneia Auersw., Hedwigia 3: 159 (1864)

Index Fungorum number: IF5799; 12 morphological species (Species Fungorum 2020), 1 species with sequence data.

Type species - Wuestneia aurea (Fuckel) Auersw.

Notes - The type species of Wuestneia, W. aurea was placed in Cryphonectriaceae by Rossman et al. (2007). However, most species of Wuestneia have been placed in Harknessia (Crous et al. 2012d, Senanayake et al. 2017a). The genus is characterised by cylindrical asci with aseptate ascospores and ampuliform conidiogeneous cells without conidiophores.

Cylindriaceae Crous \& L. Lombard, Fungal Systematics and Evolution 1: 183 (2018)

Index Fungorum number: IF824770; Facesoffungi number: FoF06869; 10 species.

Associated with plant substrates, especially leaves. Sexual morph: Undetermined. Asexual morph: Mycelium composed of septate, branched, hyaline, smooth-walled hyphae. Conidiophores sporodochial or solitary, erect, hyphae and basal part of conidiophores subcylindrical, septate, branched, becoming pale brown, smooth-walled. Conidiogenous cells terminal and intercalary, subcylindrical, hyaline, smooth-walled, with several sympodial flat-tipped loci, unthickened, not darkened. Ramoconidia subcylindrical, guttulate, hyaline, smooth-walled. Conidia aseptate, arranged in long, branched chains, scars not thickened, slightly refractive, hyaline, smooth-walled (adapted from Crous et al. 2018c).

Type genus - Cylindrium Bonord.

Notes - Cylindrium was considered as Hypocreales incertae sedis by Lombard et al. (2015). Crous et al. (2018c) introduced Cylindriaceae in Hypocreales to accommodate this genus based on phylogenetic analysis of ITS sequence data. We maintain Cylindriaceae in Amphisphaeriales based on our phylogenetic anlysis of combined genes and divergence estimates (Figs 2, 4).

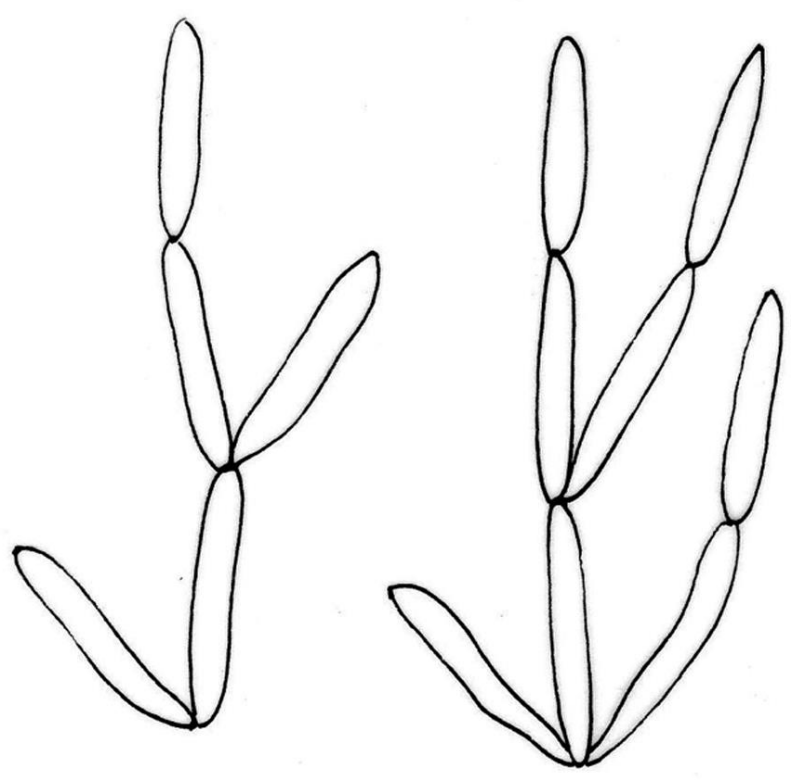

Figure 87 - Cylindrium candidum (redrawn from Bonorden 1851) Conidiophores, conidiogenous cells and conidial chains. 


\section{Ecological and economic significance of Cylindriaceae}

Cylindrium purgamentum was isolated from leaf litter (Crous et al. 2016a). Other species such as $C$. syzygii and $C$. algarvense were isolated from Syzygium and Eucalyptus leaves (Cheewangkoon et al. 2009, Crous et al. 2011). There are no report of Cylindrium species as a leaf pathogen.

\section{Genus included in Cylindriaceae}

Cylindrium Bonord., Handb. Allgem. mykol. (Stuttgart): 34 (1851)

Index Fungorum number: IF7865; 10 morphological species (Species Fungorum 2020), 3 species with sequence data.

Type species - Cylindrium elongatum Bonord.

Notes - This asexual morph genus is characterized by sporodochial conidiomata, subcylindrical conidiogenous cells and aseptate hyaline conidia arranged in long chains (Bonorden 1851, Crous et al. 2018c). The taxonomic placement of Cylindrium was doubtful for years. Cylindrium elongatum was accepted in Hypocreales incertae sedis by Lombard et al. (2015). Crous et al. (2018c) revealed that Cylindrium is a member of Hypocreales and described Cylindriaceae based on ITS sequence data. Cylindrium elongatum grouped within Amphisphaeriales in our phylogenetic analysis (Fig. 4). Cylindrium candidum and C. algarvense are illustrated in this entry (Figs. 87, 88).

Cytosporaceae Fr., Syst. orb. veg. (Lundae) 1: 118 (1825)

Index Fungorum number: IF82042; Facesoffungi number: FoF06870; 305 species.

Pathogenic or saprobic on plant tissues. Sexual morph: Ascomata perithecia or globose, immersed to erumpent, solitary or 3-10 ascomata aggregated, black to brown, with long neck swollen at the tips, ostiolate. Ostiole periphysate, with ostiolar neck. Peridium comprising outer, 46 layers of dark brown with cells of textura angularis and 5-7 layers of, inner, small, hyaline, thinwalled, cells of textura angularis. Paraphyses few, hyaline. Asci 8-spored, unitunicate,clavate, short-pedicellate, apex round, with or without apical ring. Ascospores uni- to biseriate, unicellular or rarely bicellular, allantoid or ellipsoid, hyaline, smooth-walled. Asexual morph: Conidiomata pyriform in section, brown to dark brown, divided into compartments by bending of peridium. Peridium brown to pale brown, comprised 4-6 layers with cells of textura angularis. Conidiophores reduced to conidiogenous cells. Conidiogenous cells arising from conidiomatal wall, phialidic, simple or branched, hyaline, cylindrical. Conidia unicellular, allantoid, hyaline, smooth-walled.

Type genus - Cytospora Ehrenb.

Notes - Cytosporaceae was introduced by Fries (1825) and placed into Diaporthales, which comprises phytopathogens and saprobes (Wehmeyer 1975, Barr 1978, Eriksson 2001, Castlebury et al. 2002). Maharachchikumbura et al. $(2015,2016 b)$ listed 13 genera under Cytosporaceae (viz. Amphicytostroma, Chadefaudiomyces, Cryptascoma, Cytospora, Ditopellina, Durispora, Harpostroma, Hypospilina, Kapooria, Leptosillia, Maculatipalma, Pachytrype and Paravalsa). Senanayake et al. (2017a) excluded seven genera and accepted five genera in Cytosporaceae (viz. Cytospora, Pachytrype, Paravalsa, Waydora, Xenotypa) based on morphological characteristics. Wijayawardene et al. (2018a) accepted six genera in Cytosporaceae in the outline of Ascomycota (Cytospora, Hypophloeda, Pachytrype, Paravalsa, Waydora, Xenotypa). Senanayake et al. (2018) re-examined and added two genera (viz. Cryptascoma, Hypophloeda) to Cytosporaceae based on morphology. We place Hypophloeda in Diaporthales genera incertae sedis as it is atypical of Cytosporaceae.

\section{Ecological and economic significance of Cytosporaceae}

Cytospora speies are important pathogens causing canker and dieback disease of a wide range of plants (Adams et al. 2005, 2006, Hyde et al. 2016b, Norphanphoun et al. 2017, 2018). 

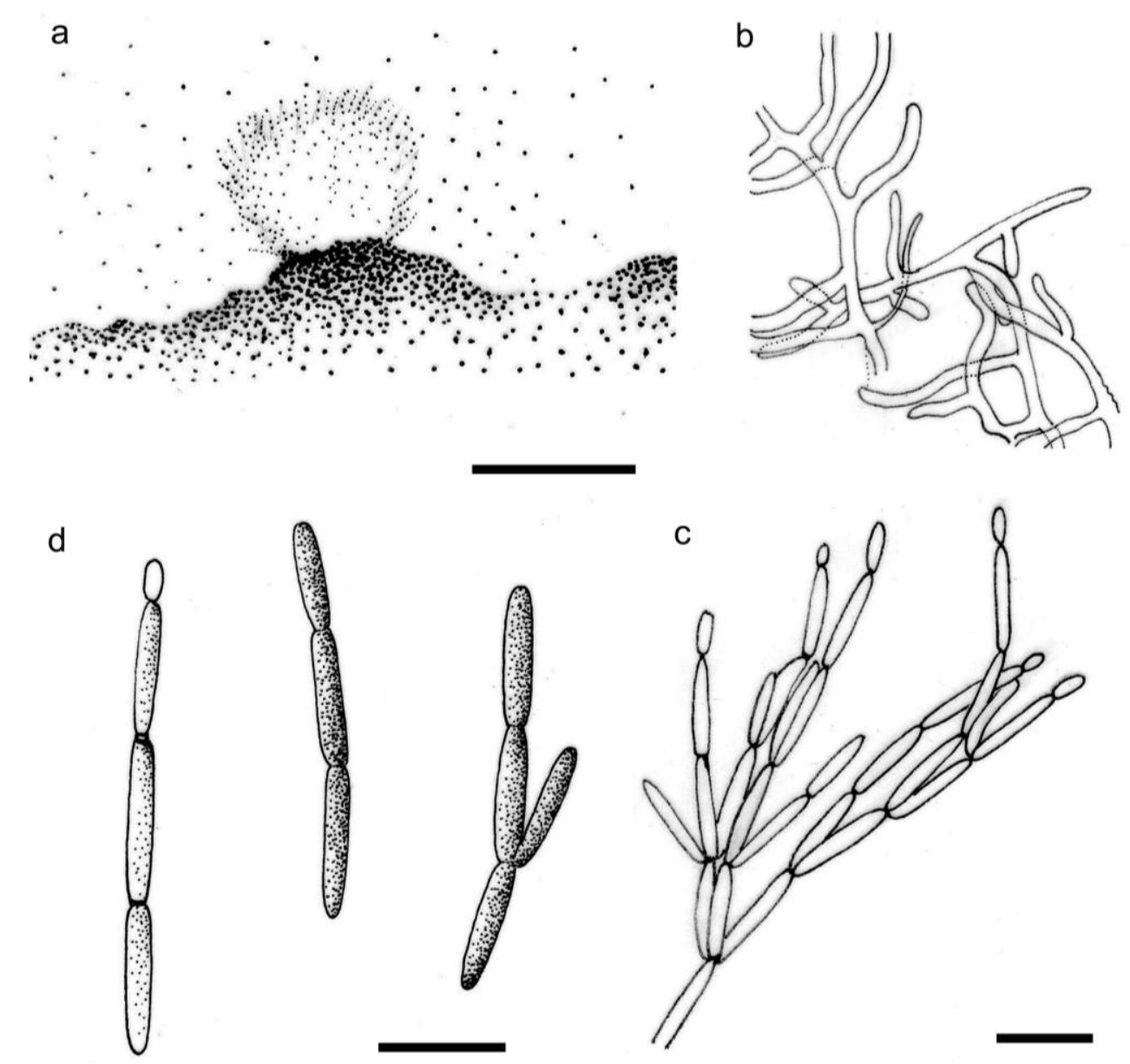

Figure 88 - Cylindrium algarvense (redrawn from Cheewangkoon et al. 2009). a Sporodochium on OA. b Creeping hyphae. c Conidiophores, conidiogenous cells and conidial chains. d Conidia. Scale bars: $\mathrm{a}=200 \mu \mathrm{m}, \mathrm{c}=10 \mu \mathrm{m}, \mathrm{d}=20 \mu \mathrm{m}$.

\section{Genera included in Cytosporaceae}

Cryptascoma Ananthap., Trans. Br. mycol. Soc. 90(3): 479 (1988)

Index Fungorum number: IF25170; 2 morphological species (Species Fungorum 2020).

Type species - Cryptascoma bisetulum Ananthap.

Notes - Cryptascoma was introduced and typified by Ananthapadmanaban (1988) with $C$. bisetula found on dead twigs in Tamil Nadu, India. This genus is distinguished by fusiform, 2celled, biseriate ascospores with protoplasmic extensions (Barr 1978, Monod 1983) and it was assigned to Cytosporaceae by Ananthapadmanaban (1988).

Cytospora Ehrenb., Sylv. mycol. berol. (Berlin): 28 (1818)

Index Fungorum number: IF7904; 297 morphological species (Species Fungorum 2020), 117 species with sequence data.

Type species - Cytospora chrysosperma (Pers.) Fr.

Notes - Cytospora was introduced by Ehrenberg (1818). The genus contains important pathogens causing canker and dieback disease of a wide range of plants (Adams et al. 2005, 2006, Hyde et al. 2016b, Norphanphoun et al. 2017). Recent accounts of the genus have been published with several new taxa (Norphanphoun et al. 2017, 2018, Tibpromma et al. 2017b, Senanayake et al. 2017a, Hyde et al. 2017b). Cytospora cedri is illustrated in this entry (Fig. 89).

Pachytrype Berl. Mycotaxon 48: 530 (1993)

Index Fungorum number: IF26475; 3 morphological species (Species Fungorum 2020), 2 species with sequence data. 
Type species - Pachytrype princeps (Penz. \& Sacc.) M.E. Barr, J.D. Rogers \& Y.M. Ju

Notes - Pachytrype was described by Barr et al. (1993) to accommodate two species, Pachytrype princeps (= Diatrype princeps), species found from undetermined tree in Java; and Pachytrype graphidioides (= Peroneutypella graphidioides), species found on Terminalia catappa in the Philippines. Pachytrype rimosa was introduced from on a log in Costa Rica (Fernández et al. 2004). The genus is characterised by stroma showing multi- locules perithecial and entostroma with perithecial beaks showing through cracks in stroma, cylindrical asci with cubical apical ring and hyaline ascospores with ellipsoid to allantoid shaped (Fernández et al. 2004).
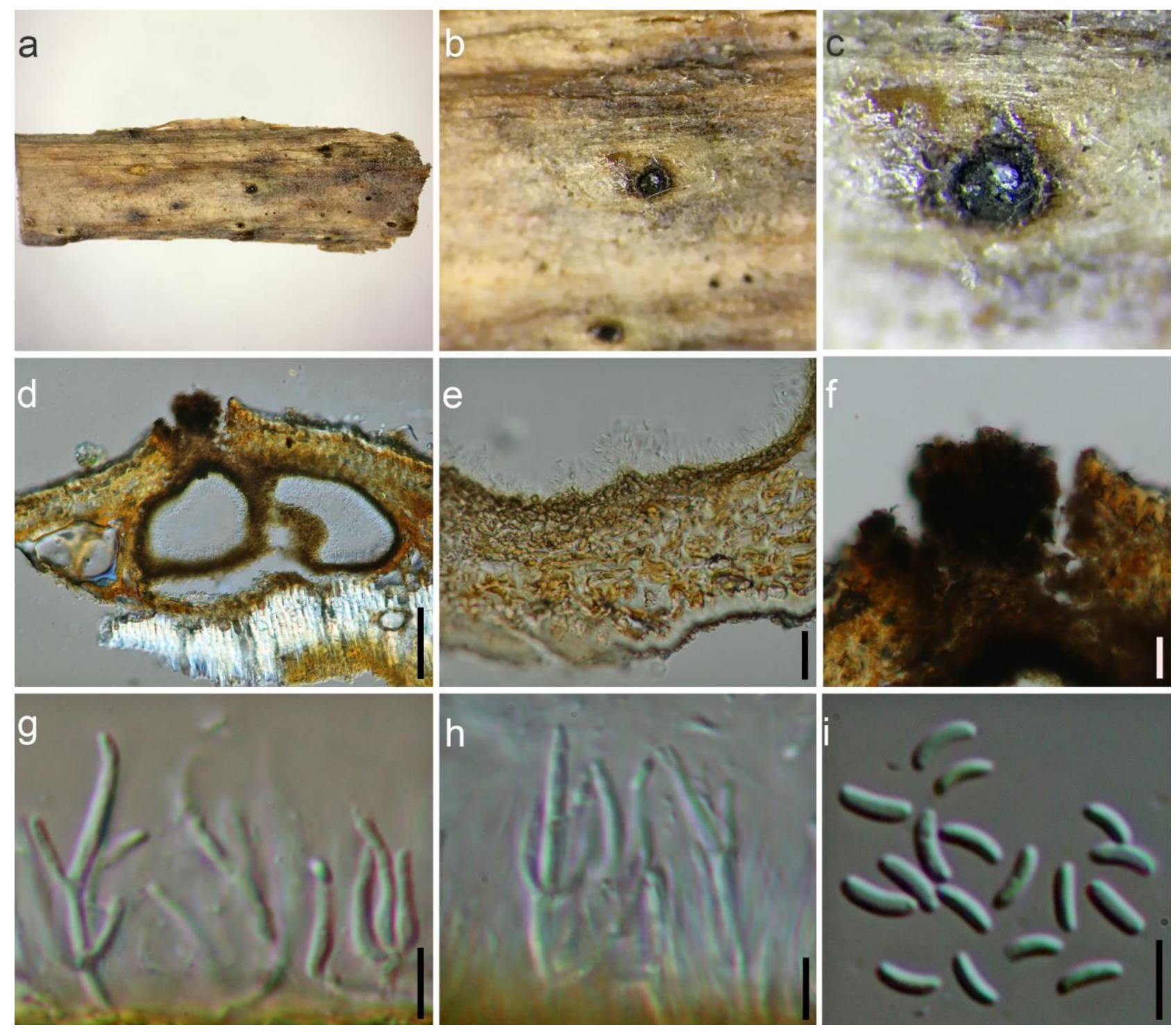

Figure 89 - Cytospora cedri (Material examined - ITALY, on branches of Rubus sp., Erio Campesori IT3288, MFLU 17-0835). a Stromatal habit in wood. b Fruiting bodies on host surface. c Surface of fruiting bodies showing the black ostioles. d Cross section of the stroma showing conidiomata. e Peridium. f Ostiolar neck. g, h Conidiogenous cell containing conidia. i Conidia. Scale bars: $\mathrm{d}=100 \mu \mathrm{m}, \mathrm{e}, \mathrm{f}=20 \mu \mathrm{m}, \mathrm{g}-\mathrm{i}=5 \mu \mathrm{m}$.

Paravalsa Ananthap., Mycol. Res. 94(2): 275 (1990)

Index Fungorum number: IF25381; 1 morphological species.

Type species - Paravalsa indica Ananthap.

Notes - Paravalsa was introduced as monotypic genus to accommodate $P$. indica, which was found on bark in Tamil Nadu (Ananthapadmanaban 1990). The genus is characterised by a lack of 
stromata, solitary perithecia immersed under host tissues with prominent necks, 8-spored, clavate, J- asci and 1-celled, allantoid ascospores (Ananthapadmanaban 1990).

Waydora B. Sutton, Trans. Br. mycol. Soc. 67(2): 248 (1976)

Index Fungorum number: IF10435; 1 species with sequence data.

Type species - Waydora typica (Rodway) B. Sutton

Notes - Waydora typica is found on capsules of Eucalyptus globulus in Tasmania (Sutton et al. 1976). The genus is characterised by multilocular conidiomata, furfuraceous ostioles, septate conidiophores which are branched at the base and above, enteroblastic phialidic conidiogenous cells and straight or allantoid, aseptate conidia.

Xenotypa Petr., Sydowia 9(1-6): 499 (1955)

Index Fungorum number: IF5828; 1 morphological species.

Type species - Xenotypa aterrima (Fr.) Petr.

Notes - Xenotypa aterrima has stromata spreading around branches and often extending between the cortical parenchyma and the periderm, splitting and pushing aside layers of bark (Petrak 1955c). The genus is characterised by perithecia with papillate, cylindric-conical necks, 8spored, clavate asci and straight, hyaline, aseptate allantoid ascospores with rounded ends, often with two rather indistinct oil droplets (Petrak 1955c).

Delonicicolaceae R.H. Perera, Maharachch. \& K.D. Hyde, Cryptog. Mycol. 38(3): 334 (2017)

Index Fungorum number: IF553776; Facesoffungi number: FoF03604; 4 species.

Saprobic on fabaceous hosts. Sexual morph: Pseudostromata conspicuously pulvinate to inconspicuous, embedded in host tissue or erumpent to rarely superficial, visible as raised, dark spots on the host surface, more or less elevated patches on the wood or erumpent through the bark, yellowish, brown to black; sometimes covered by yellow to yellow-green, bright turquoise, scurf. Ascomata perithecial, immersed in pseudostroma, multi-loculate, aggregated, globose, subglobose to conical or irregular, subhyaline to pale brown, ostiolate. Ostioles papillate. Peridium composed of subhyaline to medium brown cells of textura angularis to textura prismatica, $\mathrm{KOH}-$. Paraphyses septate, unbranched or occasionally branched, hyaline. Asci 8-spored, unitunicate, arising from the base or margins of the ascomata, clavate to cylindrical, straight, curved to sinuous, thin-walled, J-, without a distinct apical ring. Ascospores bi-seriate to uniseriate, hyaline, ellipsoid or allantoid, equilateral or inequilateral, with rounded apices, aseptate or 1-septate, not constricted at the septa, thin-walled, smooth, without appendages or gelatinous sheath. Asexual morph: Undetermined.

Type genus - Delonicicola R.H. Perera, Maharachch. \& K.D. Hyde

Notes - Perera et al. (2017) introduced Delonicicolaceae (Delonicicolales) to accommodate Delonicicola and Liberomyces. Liberomyces was synonymised under Leptosillia and added to Leptosilliaceae (Voglmayr et al. 2019a). A new genus Furfurella was added to Delonicicolaceae based on morphological and molecular evidence by Voglmayr et al. (2019a). Vitale et al. (2018) and Voglmayr et al. (2019a) accepted Delonicicolaceae within Xylariales. However, based on our phylogenetic analysis (Fig. 4) we maintain Delonicicolaceae in Delonicicolales following the classification of Perera et al. (2017).

\section{Ecological and economic significance of Delonicicolaceae}

Delonicicola siamense is a saprobic fungus occurring on decaying seed pods of Delonix regia (Perera et al. 2017). There are no reports of pathogenic species in Delonicicola or Furfurella (Perera et al. 2017, Voglmayr et al. 2019a).

\section{Genera included in Delonicicolaceae}

Delonicicola R.H. Perera, Maharachch. \& K.D. Hyde, Cryptog. Mycol. 38(3): 334 (2017)

Index Fungorum number: IF553772; 1 species with sequence data.

Type species - Delonicicola siamense R.H. Perera, Maharachch. \& K.D. Hyde 
Notes - The sexual morph, monotypic genus Delonicicola was established based on Delonicicola siamense, which was isolated from Delonix regia seed pods in Thailand (Perera et al. 2017). Delonicicola species are saprobes, characterized by pseudostromatal immersed, papillate ascomata, short pedicellate asci and 1-septate, hyaline ascospores (Perera et al. 2017). Delonicicola siamense is illustrated in this entry.

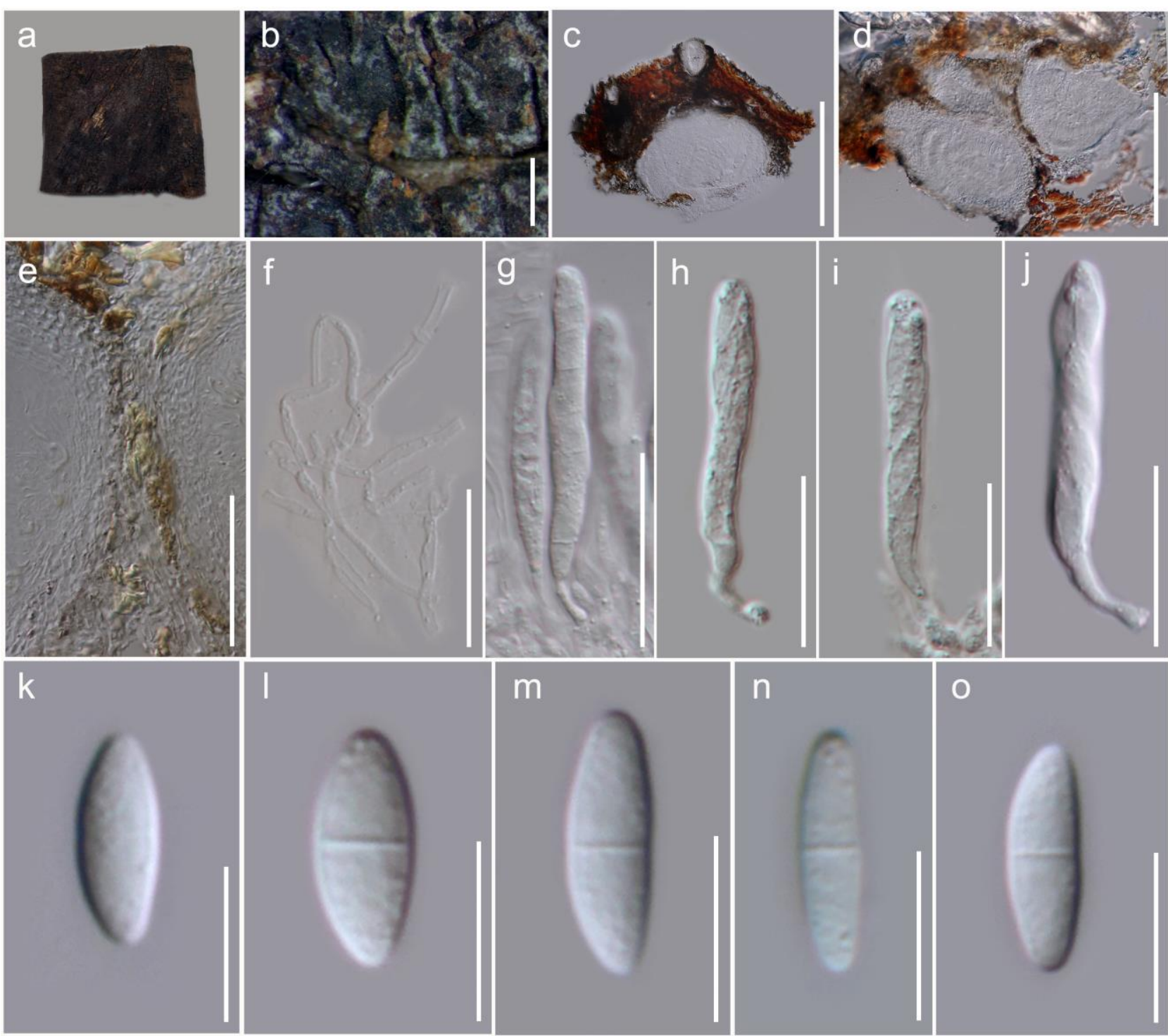

Figure 90 - Delonicicola siamense (Material examined - THAILAND, Chiang Rai Province, Mae Fah Luang University premises, on dried seed pods of Delonix regia (Boj.) Raf. (Fabaceae), 2 June 2015, R.H. Perera RHP 92, MFLU 17-0739, holotype). a Herbarium material. b Appearance of ascomata on host substrate. c, d Vertical section through pseudostroma with ascoma. e Section of the peridium. f Paraphyses. g-j Asci. k-o Ascospores. Scale bars: $b=2 \mathrm{~mm}, \mathrm{c}=200 \mu \mathrm{m}, \mathrm{d}=100$ $\mu \mathrm{m}, \mathrm{e}-\mathrm{j}=20 \mu \mathrm{m}, \mathrm{k}-\mathrm{o}=5 \mu \mathrm{m}$.

Furfurella Voglmayr \& Jaklitsch, Persoonia 42: 237 (2019)

Index Fungorum number: IF829925; 3 species with sequence data.

Type species - Furfurella stromatica Voglmayr \& Jaklitsch

Notes - Furfurella was introduced by Voglmayr et al. (2019a) to accommodate $F$. luteostiolata, $F$. nigrescens and $F$. stromatica (type species). Furfurella species are associated with dead branches of fabaceous plants in the Mediterranean basin (Voglmayr et al. 2019a). The genus is characterised by erumpent pseudostromata with bright yellow, yellow-green to turquoise scurfs, clavate to cylindrical asci and allantoid, aseptate ascospores. 
Diaporthaceae Höhn., Am. J. Bot. 13: 638 (1926)

Index Fungorum number: IF80691; Facesoffungi number: FoF01383; 497 species.

Endophytic, pathogenic or saprobic on terrestrial and rarely submerged plants. Sexual morph: Pseudostromata well or poorly developed, erumpent, pulvinate, slightly convex or flat, circular, orbicular or irregular, coriaceous, sclerotioid, whitish or brownish to black, with or lacking black zone or a crust containing of fungus tissue, solitary or having up to 10 ascomata in a stroma. Ectostromatic disk subhyaline to hyaline or brown. Ascomata immersed to erumpent, perithecial, globose or compressed, solitary or aggregated in a valsoid shape, black, coriaceous, ostiolate, papillate. Papilla short or long, black, convergent, erumpent, conical or cylindrical, internal wall concealed by hyaline periphyses, composed of vertically organized parenchymatous tissues. Peridium covering exterior layer of thick-walled, flattened, dark-brown cells of textura angularis and inner, thin-walled, hyaline cells of textura angularis. Paraphyses unbranched, septate, cylindrical. Asci 8 -spored, clavate, oblong-clavate to broadly fusoid, unitunicate, sessile, with a distinct apical ring. Ascospores biseriate to partially biseriate, hyaline, dark brown, ellipsoid, oblong to fusoid, unicellular or one septate, constricted at septum, with or without appendages at both ends, occasionally narrowly rounded at ends, multi-guttulate, smooth-walled. Asexual morph: Coelomycetous. Conidiomata globose, acervular or pycnidial, initially immersed, erumpent when mature, black, solitary, coriaceous, scattered, elongated ostiolar necks, sometime becoming multiloculate with one to numerous noticeably demarcated black necks extending over the stroma, frequently with yellowish conidial mass extruding from ostiole. Peridium comprising 3-4 layers of light brown cells of textura intricata to textura angularis. Conidiophores dimorphic. Alpha conidiophores subcylindrical, firmly aggregated, branched in middle area, comprising 2-3 associate cells, ampulliform, giving rise to septate, cylindrical to irregular conidiogenous cells or paraphyses, straight to sinuous, smooth, 1-5-septate, hyaline to pale brown, cylindrical, branched merely at the base, formed from the inner most layer cells of the conidiomata wall, sometime terminal and lateral, apex with minute periclinal thickening and collarette. Beta conidiophores hyaline, scattered between alpha conidiophores, subcylindrical, branched, 1-3-septate. Alpha Conidiogenous cells phialidic, enteroblastic, cylindrical or subcylindrical, terminal and lateral, slightly tapering towards the apex or sometimes apex with minute periclinal thickening and collarette. Beta conidiogenous cells integrated, phialidic, terminal and lateral. Alpha conidia hyaline, fusiform to ovate, subcylindrical to narrowly ellipsoid, straight or curved, occasionally irregular, smooth-walled, abundant, 0-2-septate, apex obtuse, base truncate to sub-truncate, straight to curved, occasionally slightly sigmoid, pale to medium brown, with many guttules, sometimes short, bear appendages at both ends. Beta conidia hyaline, aseptate, smooth, subcylindrical, straight to slightly curved, fusiform to hooked, base sub-truncate, occasionally widest in middle, tapering to acutely rounded apex, truncate at base.

Type genus - Diaporthe Nitschke

Notes - Diaporthaceae was introduced and placed in Diaporthales by Höhnel (1917d) and it encompasses numerous endophytic and phytopathogenic fungal species. Wehmeyer (1975) confined two genera, Diaporthe and Mazzantia to this family. However, Barr (1978) synonymized Diaporthaceae in Valsaceae. Castlebury et al. (2002) presented the distinct placement of Diaporthaceae in Diaporthales, forming an analyzed LSU sequence data of diaporthoid taxa in a well-supported clade. Previously, only Diaporthe (Phomopsis) and Mazzantia were accommodated in Diaporthaceae based on phylogenetic analysis (Castlebury et al. 2002). Nevertheless, Apioporthella and Leucodiaporthe were included in this family by Lumbsch \& Huhndorf (2010). Lamprecht et al. (2011) showed the phylogenetic placement of Stenocarpella and Phaeocytostroma in Diaporthaceae using LSU sequences analysis. Based on combined gene analysis of LSU, SSU and tefl sequence data, Dai et al. (2014b) introduced Pustulomyces. Phylogenetic placement of Phaeodiaporthe in Diaporthaceae was confirmed by Voglmayr \& Jaklitsch (2014). Maharachchikumbura et al. (2015) listed Allantoporthe, Apioporthella, Clypeoporthella, Diaporthe, Diaporthella, Diaporthopsis, Leucodiaporthe, Mazzantia, Mazzantiella, Ophiodiaporthe and Pustulomyces as genera of Diaporthaceae based on an analysis of LSU 
sequence data. Based on greater usage of the name Mazzantia, Rossman et al. (2015) synonymized Mazzantiella under Mazzantia. Clypeoporthella was established on C. brencklei Petr., and a newly collected C. brencklei (BPI 843482) specimen was developed in culture and sequenced. It has a Phomopsis asexual morph and DNA sequence data disclosed that $C$. brencklei clustered together with Diaporthe. Thus, Clypeoporthella is regarded as a synonym of Diaporthe (Sogonov et al. 2008). Diaporthopsis was introduced to accommodate species that are similar to Diaporthe, with unicellular ascospores and was typified by $D$. angelicae. Molecular analysis of LSU sequence data showed that $D$. angelicae clustered within the Diaporthe. In addition, Diaporthopsis angelicae has similar characters of Diaporthe such as stromata, perithecia, and centrum to species. Diaporthopsis was synonymized under Diaporthe based on morphology and molecular data (Castlebury et al. 2002, Gomes et al. 2013). Diaporthella is comprised of aggregated perithecia within welldeveloped stromata and median, 1-septate ascospores. Diaporthella corylina is parasitic and causes dieback of Corylus stems. Diaporthella corylina shows similar characters to Anisogramma anomala morphologically. Anisogramma belongs in the Gnomoniaceae based on A. virgultorum (Castlebury et al. 2002, Vasilyeva et al. 2007). Based on combined LSU, ITS, rpb2 and tef1 gene analysis, Senanayake et al. (2017a) confirmed the phylogenetic placement of Diaporthella outside of Diaporthaceae, and it does not show affinities with any families in Diaporthales. A recent study by Senanayake et al. (2017a) accepted a few genera within this family in addition to Maharachchikumbura et al. (2016b) by introducing three new genera: Chiangraiomyces, Hyaliappendispora and Paradiaporthe based on morphology and phylogeny. Massariothea was added to the family by Thambugala \& Hyde (2018). Therefore 15 genera: Apioporthella, Apiosphaeria, Chaetoconis, Chiangraiomyces, Diaporthe, Hyaliappendispora, Leucodiaporthe, Massariothea, Mazzantia, Ophiodiaporthe, Paradiaporthe, Phaeocytostroma, Phaeodiaporthe, Pustulomyces and Stenocarpella are accepted in Diaporthaceae (Senanayake et al. 2018).

Clypeoporthe, Cryptonectriella, Kensinjia, Lollipopaia and Skottsbergiella were listed in Diaporthaceae by Wijawawardene et al. (2017). Clypeoporthe was introduced and is typified by $C$. monocarpa. There are five species listed under this genus (Species fungorum 2020). However, some species in this genus have eutypelloid configuration of ascomata in parenchymatous stromatic tissues. Clypeoporthe was reduced to synonymy under Gnomonia by Monod (1983), while Kirk et al. (2008) mentioned Clypeoporthe is the sexual morph of Phaeocytostroma. However, the latter is not proven by culture or molecular data and it is necessary to obtain DNA sequence data to resolve this genus. Therefore, Senanayake et al. (2017a, 2018) and Wijayawardhene et al. (2018) accepted this genus in Gnomoniaceae. Cryptonectriella (Höhn.) Weese (三Cryptonectriopsis (Höhn.) Weese) was introduced and is typified by $C$. biparasitica and a second species $C$. geoglossi (Species Fungorum 2020). Weese (1919) accommodated this genus in Hypocreales. Kensinjia was introduced and is typified by K. umbrina by Reid \& Booth (1989). However this species was synonymized under Cryptosporella as $C$. umbrina (Jenkins) Jenkins \& Wehm., which is a genus in Gnomoniaceae. The monotypic genus Lollipopaia was introduced and typified by L. minuta and accommodated in Diaporthales genera incertae sedis (Inderbitzin and Berbee 2001). There are only two nrSSU sequences and blast searches in GenBank show L. minuta is closely related to economically important plant pathogens in Diaporthaceae. However our phylogenetic analysis (unpublished) shows that L. minuta clusters away from Diaporthaceae; but within Diaporthales. Lollipopaia minuta is somewhat different from taxa of Diaporthaceae in having solitary to aggregated, carbonaceous ascomata with long, slender necks and long, filiform, multiseptate ascospores. Senanayake et al. (2017a, 2018) accepted Lollipopaia within Diaporthales genera incertae sedis based on morphology and here we follow this. Skottsbergiella was introduced and typified by Skottsbergiella diaporthoides which has large perithecia immersed in massive, externally crustose, pseudoparenchymatous stromata. Petrak (1971) assigned this genus to eutypoid fungi based on its stromata. This genus is morphologically similar to Diaporthella, which is placed in Diaporthales genera incertae sedis (Barr 1978). However, Skottsbergiella diaporthoides was synonymized under Diaporthe diaporthoides (Barr 1978) and accommodated in Diaporthaceae. This was followed by Senanayake et al. (2017a, 2018). 


\section{Ecological and economic significance of Diaporthaceae}

Species of Diaporthaceae includes a number of plant pathogens of major importance causing diseases of a wide variety of plants (Dissanayake et al. 2017, Senanayake et al. 2018). Fruit production is especially affected (Dissanayake et al. 2017, Senanayake et al. 2018).

\section{Genera included in Diaporthaceae}

Apioporthella Petr., Annls mycol. 27(5/6): 401 (1929)

Index Fungorum number: IF0260; 1 morphological species.

Type species - Apioporthella vepris (Lacroix) M.E. Barr

Notes - Apioporthella was described and typified by A. bavarica. Barr (1991) proposed two new combinations as A. apiospora and A. vepris. The genus is characterised by an ectostromatic disc which appears as a cushion of brown cells containing one or a few fused ostioles.

Apiosphaeria Höhn., Sber. Akad. Wiss. Wien, Math.-naturw. Kl., Abt. 1 118: 1218 (1909)

Index Fungorum number: IF7566; 1 species with sequence data.

Type species - Apiosphaeria guaranitica (Speg.) Höhn.

Notes - Apiosphaeria has been traditionally placed in Phyllachoraceae, based exclusively on morphological studies, without supporting molecular evidence. Guterres et al. (2018) provided molecular data for the link between sexual and asexual states of the fungus and elucidate the phylogeny of A. guaranitica. Their results indicate a natural placement of Apiosphaeria within Diaporthaceae, where it represents an ancient lineage of the crown group of Diaporthaceae.

Chaetoconis Clem., Gen. fung. (Minneapolis): 125 (1909)

Index Fungorum number: IF7566; 2 morphological species (Species Fungorum 2020), 1 species with sequence data.

Type species - Chaetoconis polygoni (Ellis \& Everh.) Clem.

Notes - Chaetoconis comprises two species: C. polygoni and C. vaccinii (Index Fungorum 2020). De Gruyter et al. (2009) and Senanayake et al. (2017a) accommodated Chaetoconis in Diaporthales genera incertae sedis and Diaporthaceae respectively, based on sequence analysis. The genus is characterised by acropleurogenous conidia which form from the inner pycnidial wall cells.

Chiangraiomyces Senan. \& K.D. Hyde, Stud. Mycol. 86: 217 (2017)

Index Fungorum number: IF821544; 1 species with sequence data.

Type species - Chiangraiomyces bauhiniae Senan. \& K.D. Hyde

Notes - Based on multigene phylogeny and morphology, Chiangraiomyces was introduced by Senanayake et al. (2017a). The genus is characterised by immersed, solitary ascomata with fusiform asci and a J-, funnel-shaped, apical ring. Oval to fusiform ascospores have two large central guttules and two small marginal guttules.

Diaporthe Nitschke, Pyrenomyc. Germ. 2: 240 (1870)

Index Fungorum number: IF1497; 450 morphological species (Species Fungorum 2020), 261 species with sequence data.

Type species - Diaporthe eres Nitschke

Notes - Diaporthe is the type genus of Diaporthaceae, and it was established by Nitschke (1867) to accommodate taxa with stromata in the Sphaeriales which are often with blackened zones in the substrate, ellipsoid to fusiform ascospores and enclosed, unilocular pycnidia that contain spermatia, stylospores and conidia (Wehmeyer 1933a). Diaporthe species are saprobes, pathogens and endophytes and have a worldwide distribution (Dissanayake et al. 2017). Phomopsis was earlier the asexual morph (Udayanga et al. 2012). However, these genera were linked based on principle of significance and Diaporthe was nominated over Phomopsis to resolve nomenclatural complications (Rossman et al. 2015). The genus contains 1067 epithets listed in Index Fungorum 
(August 2019), but fewer than 200 species are accepted (Dissanayake et al. 2017). Diaporthe asheicola, D. eucalyptorum, and D. salsuginosa are illustrated in this entry (Figs. 91, 92, 93, 94 respectively).
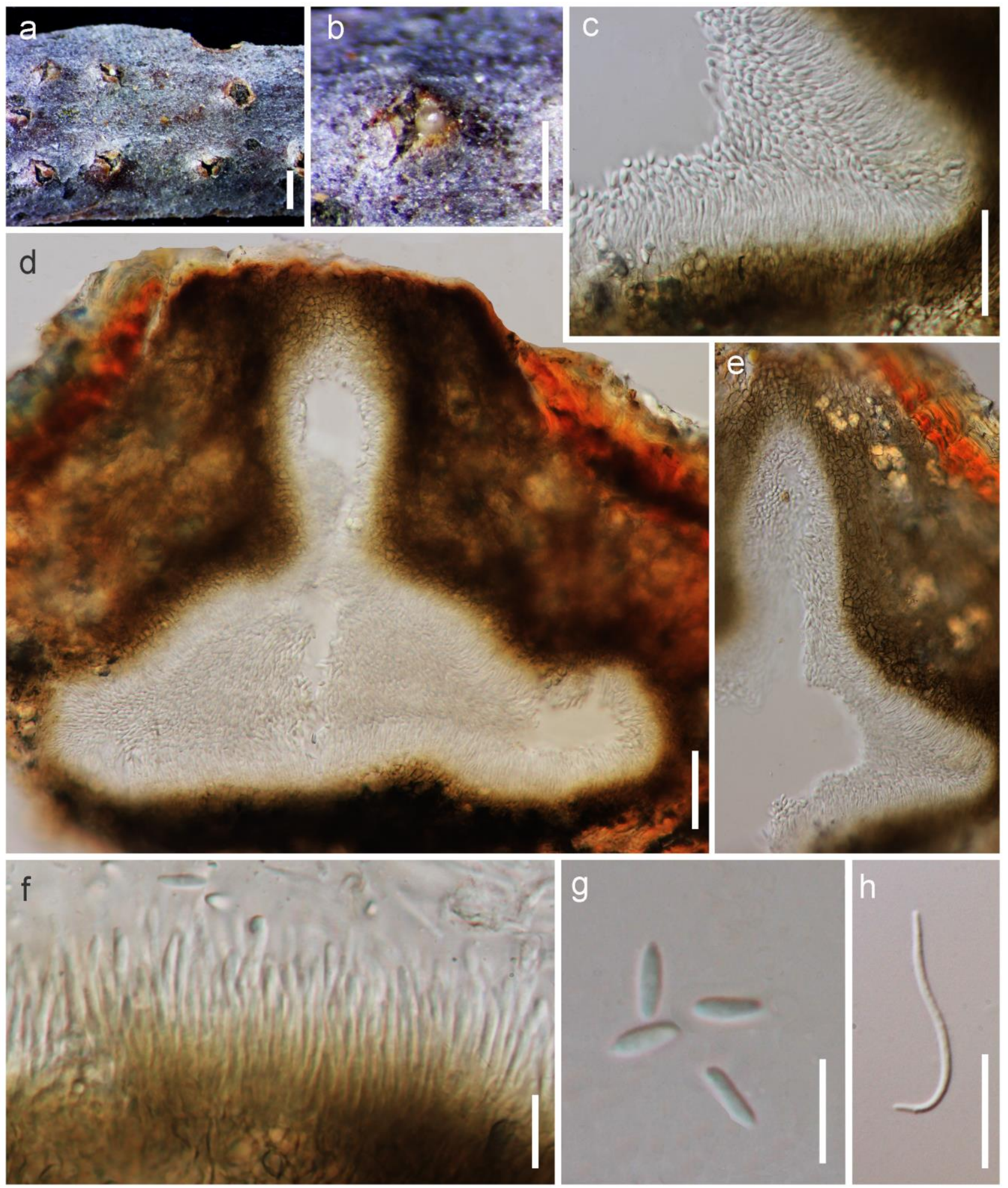

Figure 91 - Diaporthe asheicola (Material examined - RUSSIA, Rostov region, Rostov-on-Don City Botanical Garden of Southern Federal University, on stem of Fraxinus pennsylvanica (Oleaceae), 30 May 2015, T.S. Bulgakov T823, MFLU 15-2966). a, b Conidiomata on host surface. $\mathrm{b}$, c Vertical section of ascomata (semi-immersed to immersed on decaying wood). d Peridium. e Paraphyses. f-1 Immature and mature asci. m-q Ascospores with bipolar pad-like appendages. $r$ Germinating ascospore. Scale bars: $\mathrm{b}, \mathrm{d}=50 \mu \mathrm{m}, \mathrm{c}, \mathrm{e}-\mathrm{r}=10 \mu \mathrm{m}$. 


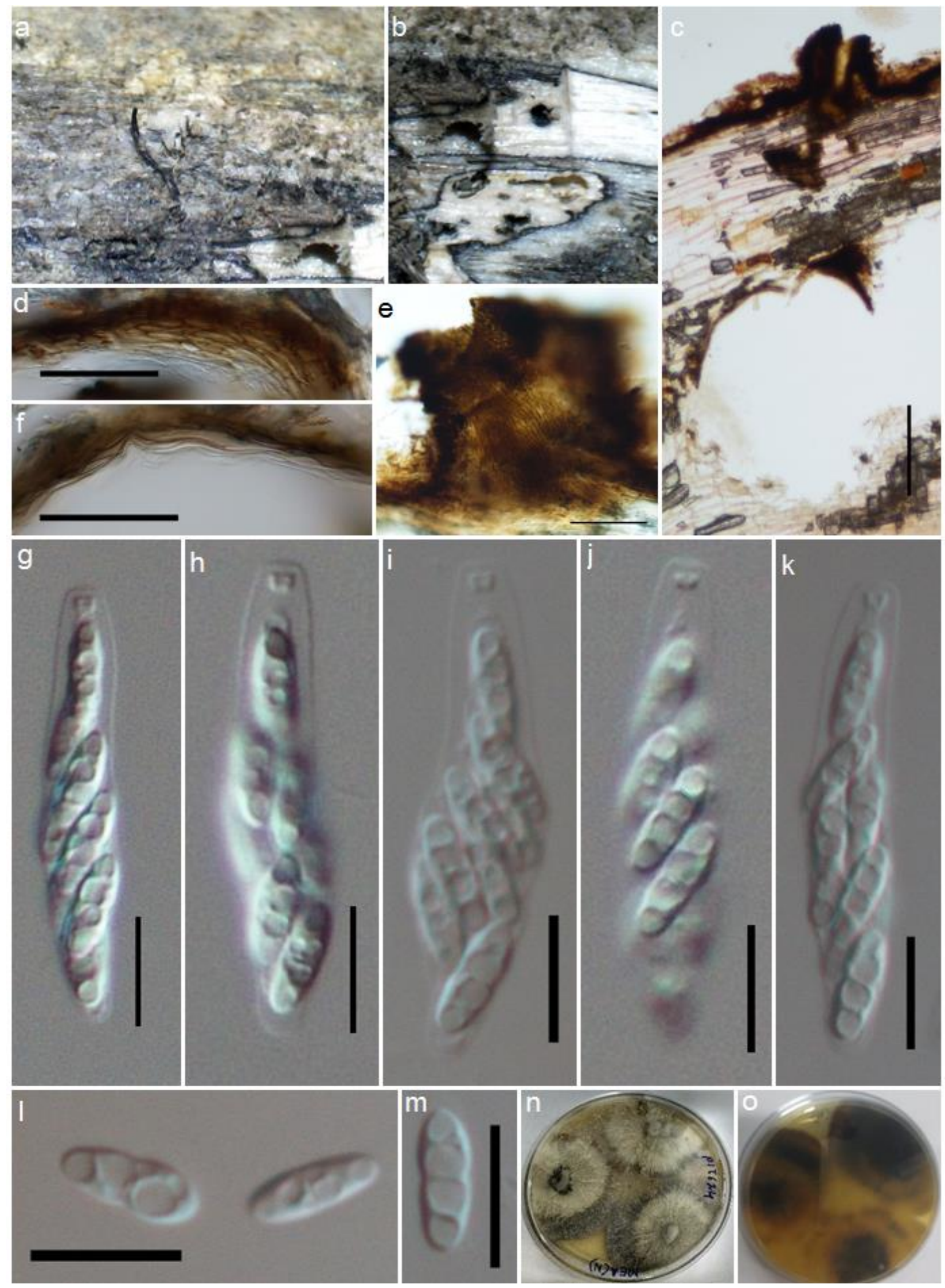

Figure 92 - Diaporthe eucalyptorum (Material examined - INDIA, Andaman and Nicobar Islands,

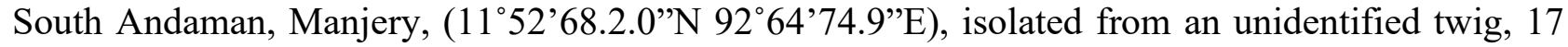
May 2018, M. Niranjan \& V.V. Sarma PUFNI 17624; living culture, NFCC-4374). a, b Ascomata on host surface. c Section of ascomata. d, f Peridium. e Neck. g-k Asci. 1, m Ascospores. n, o Colonies on MEA ( $\mathrm{n}$-from above, o-below). Scale bars: $\mathrm{c}=100 \mu \mathrm{m}, \mathrm{d}-\mathrm{f}=50 \mu \mathrm{m}, \mathrm{g}-\mathrm{m}=10 \mu \mathrm{m}$. 

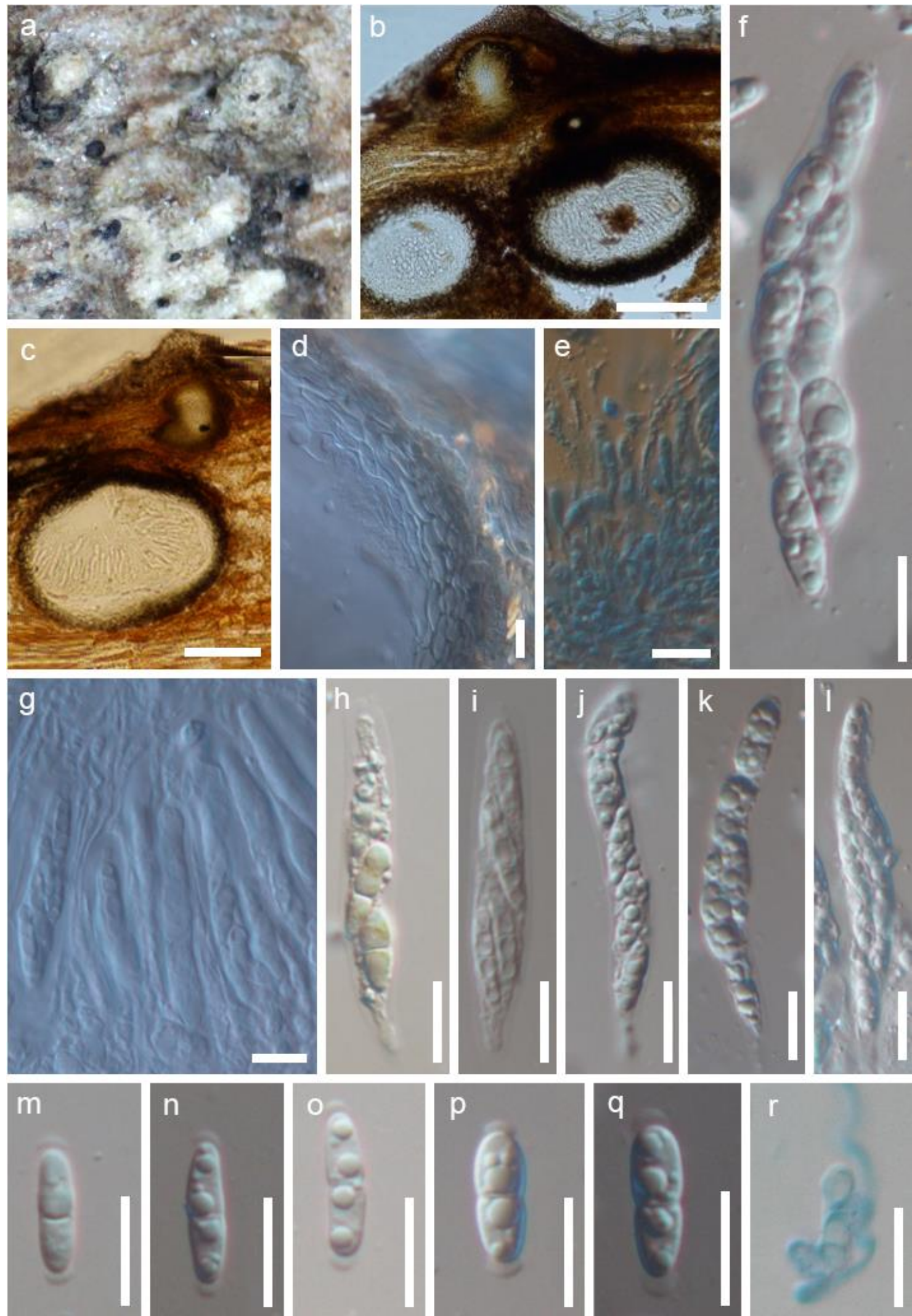

Figure 93 - Diaporthe salsuginosa (Material examined - INDIA, Tamil Nadu, Parangipettai mangroves $\left(11.59^{\circ} \mathrm{N} 79.5^{\circ} \mathrm{E}\right)$, on decaying wood of Avicennia marina (Acanthaceae), 23 April 2018, B. Devadatha AMH-10013; living culture, NFCCI-4385). a Necks in crater-like depressions on the host surface. $b$ Vertical section of ascomata (semi-immersed to immersed on decaying wood). b, d Ascomata. e Peridium. f Paraphyses. c, g-l Immature and mature asci. m-q Ascospores with bipolar pad-like appendages. $r$ Germinating ascospore. Scale bars: $b-d=50 \mu \mathrm{m}$, e-r $=10 \mu \mathrm{m}$. 


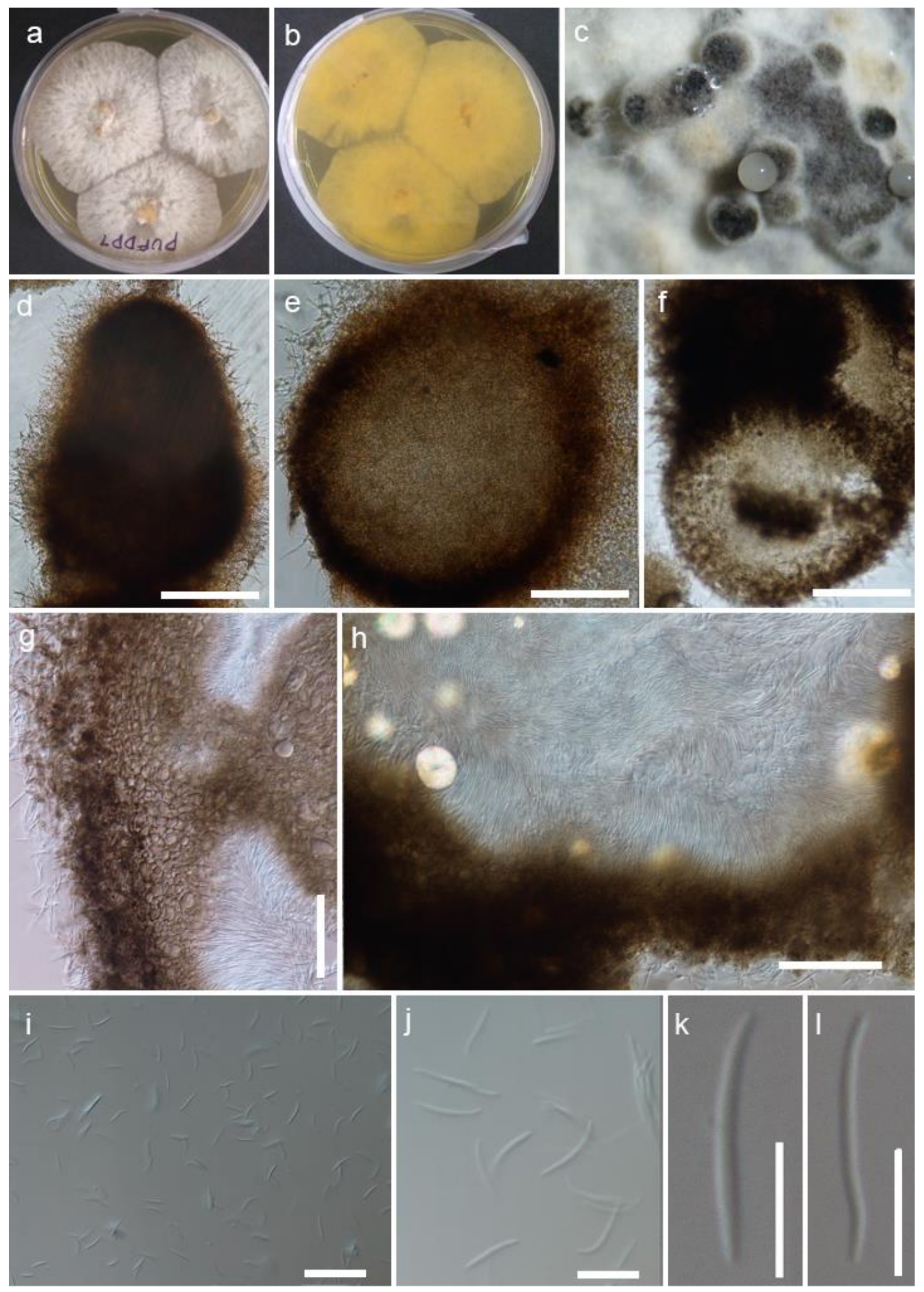

Figure 94 -Diaporthe salsuginosa, from living culture (Material examined - INDIA, Tamil Nadu, Parangipettai mangroves $\left(11.59^{\circ} \mathrm{N} 79.5^{\circ} \mathrm{E}\right)$, on decaying wood of Avicennia marina (Acanthaceae), 23 April 2018, B. Devadatha AMH-10013; living culture, NFCCI-4385). a, b Front and reverse view of culture. c Conidiomata producing hyaline conidial mass grown from the mature colonies. d-f Vertical section through conidioma. g Peridium. h Conidiophores and conidiogenous cells i-l Beta conidia. Scale bars: $\mathrm{b}-\mathrm{c}=100 \mu \mathrm{m}, \mathrm{d}=50 \mu \mathrm{m}, \mathrm{e}-1=10 \mu \mathrm{m}$. 
Hyaliappendispora Senan., Camporesi \& K.D. Hyde, Stud. Mycol. 86: 217 (2017)

Index Fungorum number: IF821548; 1 species with sequence data.

Type species - Hyaliappendispora galii Senan., Camporesi \& K.D. Hyde

Notes - The genus is characterised by biguttulate, uniseptate, hyaline ascospores with long filamentous apical and basal appendages and wall of the appendages makes a ring-like ornamentation at the proximal end.

Leucodiaporthe M.E. Barr \& Lar. N. Vassiljeva, Mycologia 99(6): 917 (2008)

Index Fungorum number: IF510561; 4 morphological species (Species Fungorum 2020).

Type species - Leucodiaporthe acerina M.E. Barr \& Lar.N. Vassiljeva

Notes - This genus is distinct in the Diaporthales in having a pale to dark stromatic disk with blackened marginal zones. Its hyaline ascospores occasionally have a gelatinous coat.

Massariothea Syd., Annls mycol. 37(3): 249 (1939)

Index Fungorum number: IF8855; 8 morphological species (Species Fungorum 2020), 2 species with sequence data.

Type species - Massariothea themedae Syd.

Notes - The genus is characterised by brown, distoseptate conidia with species commonly reported on grasses (Poaceae) with a worldwide distribution (Thambugala et al. 2018).

Mazzantia Mont., Bull. Soc. bot. Fr. 2: 525 (1855)

Index Fungorum number: IF3036; 17 morphological species (Species Fungorum 2020), 2 species with sequence data.

Type species - Mazzantia galii (Fr.) Mont.

Notes - The genus is characterised by a sharply delimited, strongly melanized, sclerotial, clypeal ectostroma, a whitish entostroma, and aseptate ascospores.

Ophiodiaporthe Y.M. Ju, H.M. Hsieh, C.H. Fu, C.Y. Chen \& T.T. Chang, Mycologia 105(4): 866 (2013)

Index Fungorum number: IF801562; 1 species with sequence data.

Type species - Ophiodiaporthe cyatheae Y.M. Ju, H.M. Hsieh, C.H. Fu, Chi Y. Chen \& T.T. Chang

Notes - Based on its unique asexual characters and host preference, Ophiodiaporthe was introduced and typified by $O$. cyatheae (Fu et al. 2013). The genus is characterised by its unique host preference on Cyathea lepifera.

Paradiaporthe Senan., Camporesi \& K.D. Hyde, Stud. Mycol. 86: 217 (2017)

Index Fungorum number: IF821546; 1 species with sequence data.

Type species - Paradiaporthe artemisiae Senan., Camporesi \& K.D. Hyde

Notes - Paradiaporthe is morphologically comparable to Diaporthe. However, phylogenetically, $P$. artemisiae is divergent from other genera in Diaporthaceae (Senanayake et al. 2017a). The genus is characterised by erumpent, solitary ascomata with prominent, wide papilla.

Phaeocytostroma Petr. Annls. mycol. 19(1/2): 45 (1921)

Index Fungorum number: IF9298; 6 morphological species (Species Fungorum 2020), 4 species with sequence data.

Type species - Phaeocytostroma ambiguum (Mont.) Petr.

Notes - Several molecular studies have established the taxonomic placement of Phaeocytostroma within Diaporthaceae (Lamprecht et al. 2011, Verkley et al. 2014). The genus is characterised by their aseptate, brown, eguttulate, cylindrical or ellipsoid, macroconidia with truncate base and fusiform, short or elongate microconidia. 
Phaeodiaporthe Petr. Annls mycol. 17(2/6): 99 (1920)

Index Fungorum number: IF3906; 1 morphological species.

Type species - Phaeodiaporthe appendiculata (G.H. Otth) Lar.N. Vassiljeva

Notes - Phaeodiaporthe was introduced based on P. keissleri and Petrak (1921) recognized it as a synonym of Diaporthe appendiculata. Voglmayr \& Jaklitsch (2014) epitypified $P$. appendiculata and synonymized $P$. keissleri under $P$. appendiculata. The genus is characterised by large brown ascospores.

Pustulomyces D.Q. Dai, Bhat \& K.D. Hyde, Cryptog. Mycol. 35(1): 68 (2014)

Index Fungorum number: IF806063; 1 species with sequence data.

Type species - Pustulomyces bambusicola D.Q. Dai et al.

Notes - The monospecific genus Pustulomyces shows similar characters to Bambusicola. However, phylogenetically of Pustulomyces bambusicola placed in Diaporthaceae (Dai et al. 2014b) and Bambusicola in Bambusicolaceae have distinct phylogenetically placements (Hyde et al. 2013). The genus is similar to Bambusicola in Bambusicolaceae with cylindrical, phialidic, conidiogenous cells and fusiform, straight to curved conidia.

Stenocarpella Syd. \& P. Syd. Annls mycol. 15(3/4): 258 (1917)

Index Fungorum number: IF10085; 2 species with sequence data.

Type species - Stenocarpella macrospora (Earle) B. Sutton

Notes - Both Stenocarpella macrospora and S. maydis are well-known pathogens of corn, the causal agents of stalk and ear rot and leaf spot (Latterell \& Rossi 1983, De Silva et al. 2014). Based on LSU sequence data, Stenocarpella was accommodated in Diaporthaceae (Crous et al. 2006a, b). Lamprecht et al. (2011) and Wijayawardene et al. (2016b) confirmed its placement in Diaporthaceae. The genus is characterised by brown, 0-3-septate conidia.

Diaporthosporellaceae C.M. Tian \& Q. Yang, Mycoscience 59: 229-235 (2017)

Index Fungorum number: IF822663; Facesoffungi number: FoF05684; 1 species.

Pathogenic on branches and twigs of Cercis chinensis. Sexual morph: Ascomata perithecial, immersed to erumpent, globose to subglobose, dark brown to black, penetrating through ectostroma, convergent to disc. Paraphyses filiform, hyaline, unbranched, deliquescent at maturity. Asci 8-spored, unitunicate, clavate to oblong-clavate, floating freely in the centrum, apical ring become unclear in dried specimens. Ascospores irregularly uniseriate, allantoid or sub-reniform, 34-guttulate, hyaline, aseptate. Asexual morph: Coelomycetous. Conidiomata pycnidial, immersed, erumpent at maturity, globose to subglobose, yellowish conidial mass release from ostiole. Ectostromatic disc black, one ostiole for each disc. Conidiophores acropleurogenous, branched or sympodially branched, cylindrical, aseptate. Conidiogenous cells enteroblastic, phialidic, cylindrical, terminal, slightly tapering towards the apex. Conidia ellipsoidal, aseptate, hyaline, slightly rounded at each end (adapted from Yang et al. 2018d, Senanayake et al. 2018).

Type genus - Diaporthosporella C.M. Tian \& Q. Yang

Notes - Diaporthosporellaceae was introduced by Yang et al. (2018d) to accommodate Diaporthosporella. Morphology and phylogeny of Diaporthosporellaceae is different from other families of Diaporthales. Diaporthosporellaceae is characterized by unicellular ascospores, branched or sympodially branched conidiophores, and hyaline, biguttulate conidia (Yang et al. 2018d, Senanayake et al. 2018). Diaporthosporellaceae comprises only one genus and one species. Diaporthosporellaceae was found on branches and twigs of Cercis chinensis (Fabaceae) in China. Sequence data are available in GenBank (Yang et al. 2018d, Fan et al. 2018).

\section{Ecological and economic significance of Diaporthosporellaceae}

Diaporthosporellaceae species play a major role as plant pathogens on branches and twigs of Cercis chinensis (Yang et al. 2018d). Cercis chinensis is widely cultivated as an ornamental plant 
(Na et al. 2009). Some parts of $C$. chinensis, such as stem, and root bark have been used to increase blood circulation and to treat bruising and injuries (Na et al. 2009).
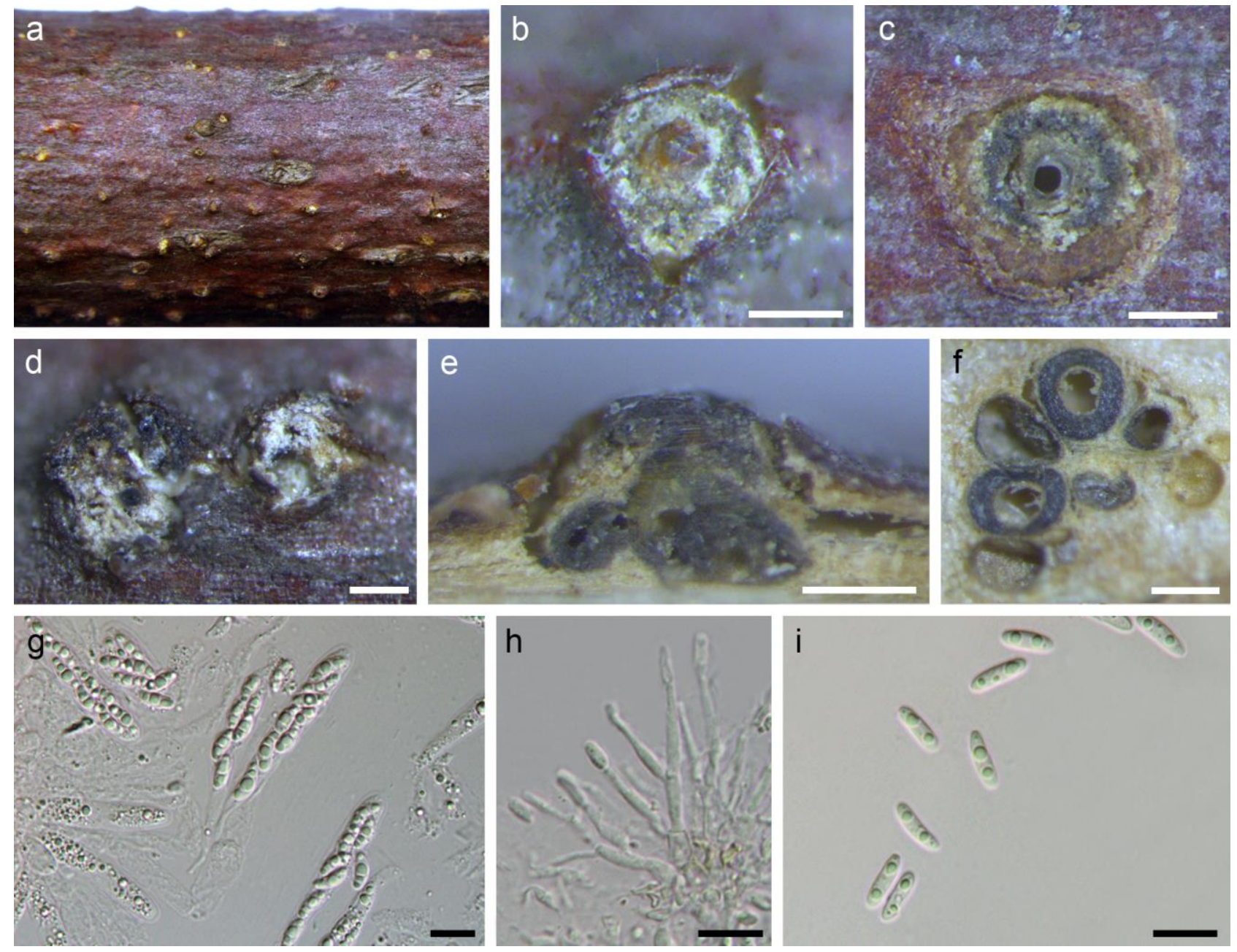

Figure 95 - Diaporthosporella cercidicola (Material examined - CHINA, Jiangsu Province, Nanjing City, Xuanwu lake scenic area, on twigs and branches of Cercis chinensis, 11 Nov. 2015, Q. Yang, BJFC-S1356, holotype). a Appearance on host. b-d Stromata on host. e Vertical section through stroma. f Horizontal section through stroma. $g$ Asci with ascospores and and paraphyses. $h$ Conidiophores with conidia. i Conidia. Scale bars: $b-f=200 \mu \mathrm{m}, \mathrm{g}-\mathrm{i}=10 \mu \mathrm{m}$.

\section{Genus included in Diaporthosporellaceae}

Diaporthosporella C.M. Tian \& Q. Yang; Mycoscience 59: 229-235 (2017)

Index Fungorum number: IF822664; 1 species with sequence data.

Type species - Diaporthosporella cercidicola C.M. Tian \& Q. Yang

Notes - Diaporthosporella was introduced by Yang et al. (2018d). Diaporthosporella cercidicola is characterized by hyaline, allantoid or sub-reniform, aseptate ascospores and acropleurogenous, branched or sympodially branched conidiophores, producing hyaline, ellipsoidal, aseptate and biguttulate conidia (Yang et al. 2018d). Diaporthosporella comprises a single species found on branches and twigs of Cercis chinensis in China (Yang et al. 2018d). Diaporthosporella cercidicola is similar to Diaporthe eres Nitschke in having unitunicate, clavate asci, hyaline, guttulate ascospores, but can be separated by phylogeny (Yang et al. 2018d). The asexual morph produces a yellowish conidial mass and aseptate, hyaline conidia, characters that are common to both Diaporthosporella cercidicola and Diaporthe eres (Udayanga et al. 2014, Yang et al. 2018d). Diaporthosporella cercidicola is closely related to Juglanconidaceae according to molecular phylogeny (Voglmayr et al. 2017). 
Diaporthostomataceae X.L. Fan \& C.M. Tian, Persoonia 40: 124 (2018)

Index Fungorum number: IF823983; Facesoffungi number: FoF05685; 1 species.

Pathogenic on twigs and branches of Machilus leptophylla. Sexual morph: Pseudostromata immersed, slightly erumpent. Ectostromatic disc ovoid to ellipsoid, yellowish to dark grey. Central column beneath the disc more or less conical. Stromatic zones lacking. Perithecia conical, surrounding the ectostromatic disc. Ostiole single, dark grey to black. Paraphyses deliquescent. Asci 8-spored, apical ring. Ascospores 2-3-seriate, hyaline, fusoid, bicellular, multiguttulate. Asexual morph: Undetermined (adapted from Fan et al. 2018, Senanayake et al. 2018).

Type genus - Diaporthostoma X.L. Fan \& C.M. Tian

Notes - Diaporthostomataceae was introduced by Fan et al. (2018) to accommodate the monophyletic genus Diaporthostoma. The species of Diaporthostomataceae are characterized by conical and separate perithecia and bicellular, fusoid, straight to curved ascospores with a median septum (Fan et al. 2018, Senanayake et al. 2018). Multi-gene phylogenetic analysis revealed that the family is monophyletic and sister to Diaporthosporellaceae (Senanayake et al. 2018). Diaporthostomataceae species are morphologically distinct from Diaporthosporellaceae, in having discrete perithecia and fusoid, straight to curved ascospores with a median septum (Fan et al. 2018, Yang et al. 2018d). Diaporthostoma machili is the only species in Diaporthostomataceae and it was collected on twigs and branches of Machilus leptophylla from China. Sequence data are available in GenBank (Fan et al. 2018).

\section{Ecological and economic significance of Diaporthostomataceae}

Diaporthostomataceae species are plant pathogens on twigs and branches of Machilus leptophylla causing cankers or dieback (Fan et al. 2018).

\section{Genus included in Diaporthostomataceae}

Diaporthostoma X.L. Fan \& C.M. Tian, Persoonia 40: 124 (2018)

Index Fungorum number: IF823984; 1 species with sequence data.

Type species - Diaporthostoma machili X.L. Fan \& C.M. Tian

Notes - Diaporthostoma was introduced by Fan et al. (2018) to accommodate Diaporthostoma machili as the type species, which was collected from twigs and branches of Machilus leptophylla in China. Diaporthostoma machili is characterized by scattered, conical perithecia and fusoid, straight to curved ascospores with a median septum (Fan et al. 2018, Senanayake et al. 2018). No asexual morph is known for this species. Diaporthostoma comprises only the type species (Index Fungorum 2020). In this entry we illustrate Diaporthostoma machili.

Diatrypaceae Nitschke, Verh. naturh. Ver. preuss. Rheinl. 26: 73 (1869)

Index Fungorum number: IF80692; Facesoffungi number: FoF00679; 599 species.

Saprobic or pathogenic on woody plants. Sexual morph: Stromata eustromatic or pseudostromatic, well-developed, immersed to erumpent, rarely superficial, mostly black or dark brown, with somewhat carbonaceous outer layer, inner layer pale, loosely packed, parenchymatous. Ascomata perithecial, immersed in stromatic tissues, mostly brown to black, globose to subglobose, with ostiolar necks. Ostioles sulcate, inner layer covered with hyaline, periphyses. Peridium consists of two layers, an inner hyaline layer and an outer layer of brown to black cells of textura angularis. Paraphyses long, wide, branched, septate. Asci 8-spored or polysporous, rarely 1-spored or 2-spored, unitunicate, cylindrical, clavate to pyriform, fusiform, with a very long pedicel, with a truncate apex, with a $\mathrm{J}_{-}$, or $\mathrm{J}_{+}$, apical ring. Ascospores crowded, most hyaline to light brown, rarely jet-black, allantoid, ellipsoidal, globose or filiform. Asexual morph: Coelomycetous, astromatic, occurring on host asacervuli. Conidiomata acervuli sub cortical, erumpent, yellow to red, with branched conidiophores and in culture as pycnidia, superficial, solitary or aggregated, yellow, dark brown to black, subconical, globose to subglobose, and thick peridium, comprising brown, thickwalled cells of textura angularis with branched conidiophores, arising from pseudoparenchymatous cells or interwoven hyphae. Conidiogenous cells in dense palisades, cylindrical, straight or curved, 
apically distorted or annulated. Conidia filiform, curved, or rarely straight with flattened base and blunt apex, hyaline (adapted from Maharachchikumbura et al. 2016b).
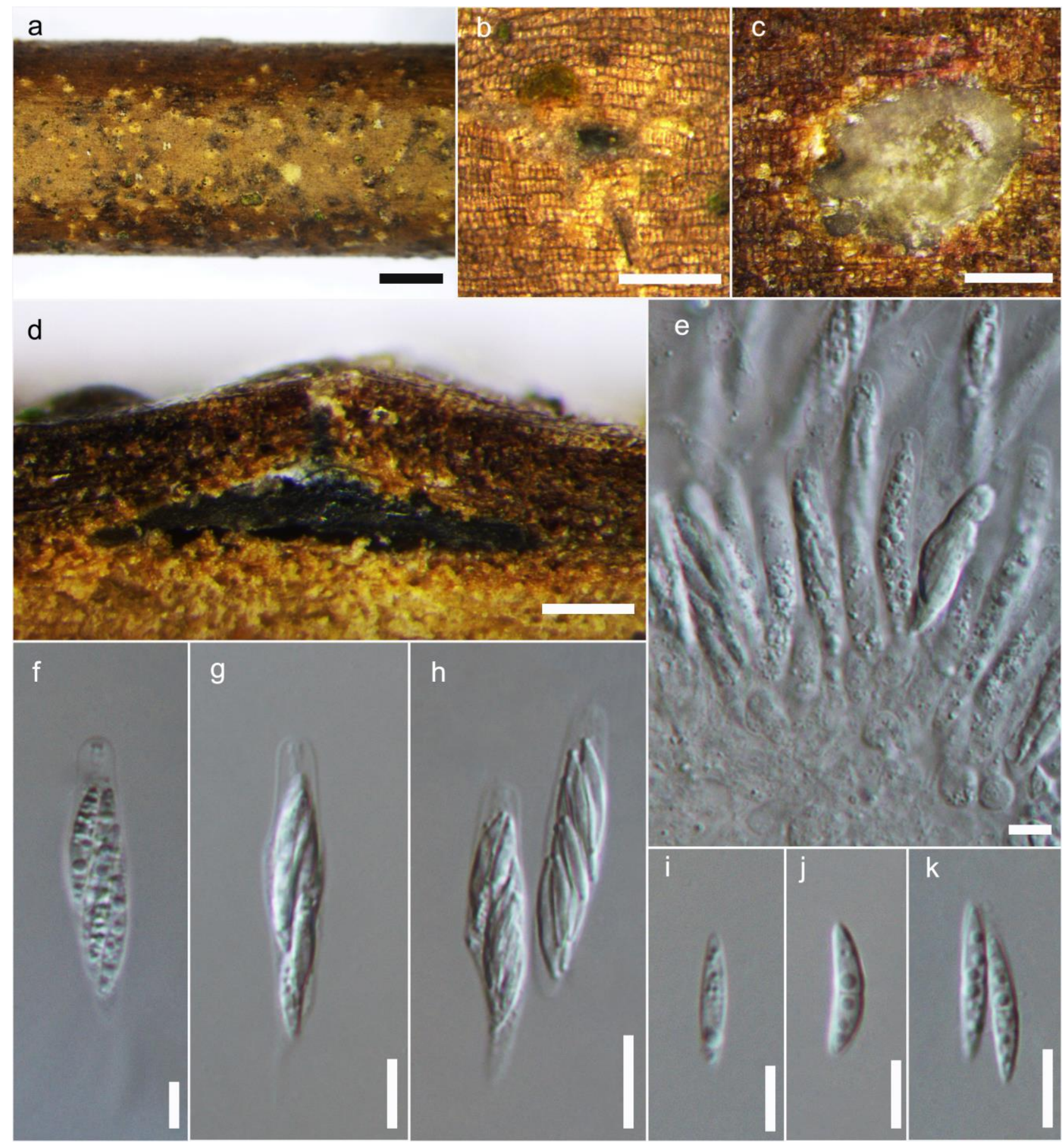

Figure 96 - Diaporthostoma machili (Material examined - CHINA, Zhejiang Province, Hangzhou City, Linan, Tianmu Mountain, N30¹9'18.21" E119²6'18.21", $354 \mathrm{~m}$ asl, on twigs and branches of Machilus leptophylla, 20 April 2017, Q. Yang \& Z. Du, CF 2017475, holotype). a, b Pseudostromata on substrate. c Transverse section of pseudostroma. d Longitudinal section of pseudostroma. e-h Asci. i-k Ascospores. Scale bars: $\mathrm{a}=1 \mathrm{~mm}, \mathrm{~b}, \mathrm{c}=200 \mu \mathrm{m}, \mathrm{d}=100 \mu \mathrm{m}, \mathrm{e}-\mathrm{h}=10$ $\mu \mathrm{m}, \mathrm{i}-\mathrm{k}=5 \mu \mathrm{m}$

Type genus - Diatrype Fr.

Notes - Diatrypaceae was introduced by Nitschke (1869) and is typified by Diatrype. Diatrypaceae is a well-studied group. Recent studies of Diatrypaceae include de Almeida et al. 
(2016), Maharachchikumbura et al. (2016b), Senwanna et al. (2017) and Shang et al. (2017, 2018). Hongsanan et al. (2017) provided a phylogenetic analysis and MCC tree with good support in Xylariomycetidae for the family, where it occurs in Xylariales (Fig. 4). Neoeutypella was introduced by Phookamsak et al. (2019) based on the phylogenetic analyses of a combined ITS and tub2 sequence dataset and its unique morphology. Halocryptovalsa was introduced by Dayarathne et al. (2019b) from marine habitats.

\section{Ecological and economic significance of Diatrypaceae}

Diatrypaceae are of great significance as pathogens of economic crops and forest trees (Trouillas \& Gubler 2010, Urbez-Torres et al. 2012, Senanayake et al. 2015). Species of Anthostoma, Cryptosphaeria, Cryptovalsa, Diatrype, Diatrypella and Eutypella have been reported as disease agents causing grapevine cankers in grape growing countries worldwide (Mostert et al. 2004, Trouillas et al. 2010b, 2011, Urbez-Torres et al. 2012, Paolinelli-Alfonso et al. 2015, Moyo et al. 2017, Agustí-Brisach et al. 2019, Barna \& Mihál 2019). Peroneutypa scoparia and Eutypella sp. can produce ligninolytic enzymes and as endophytes or saprobes of decaying wood, they play an important role in nutrient cycling ( de Errasti et al. 2014, Grassi 2014).

\section{Genera included in Diatrypaceae}

Allocryptovalsa Senwanna, Phookamsak \& K.D. Hyde, Mycosphere 8(10): 1839 (2017)

Index Fungorum number: IF553857; 2 species with sequence data.

Type species - Allocryptovalsa polyspora Senwanna, Phookamsak \& K.D. Hyde

Notes - Allocryptovalsa was introduced by Senwanna et al. (2017) to accommodate A. polyspora and two combined species: A. cryptovalsoidea, which was transferred from Eutypella and Allocryptovalsa rabenhorstii, which was transferred from Cryptovalsa. The genus is characterised by stromata immersed in host tissues, polysporous asci and allantoid ascospores. However, the combined species A. cryptovalsoidea is invalid according to the basionym of this species, Eutypella cryptovalsoidea is invalid because Trouillas et al. (2011) designated holotype with three collections when they introduced E. cryptovalsoidea. Therefore, the current status of Allocryptovalsa cryptovalsoidea is further needed to be resolved. In this study, we introduce a new species Allocryptovalsa truncata based on morphology and phylogeny support.

Allocryptovalsa truncata M. Niranjan \& V.V. Sarma, sp. nov.

Fig. 97

Index Fungorum number: IF556619; Facesoffungi number: FoF06262

Etymology - Refers to the truncate shape of the ascal apex.

Holotypus - AMH-9983.

Saprobic on decaying twigs. Sexual morph: Stromata superficial, in irregular clusters, beneath the periderm, outer black thin layer, inner white powdery coat around each ascoma. Ascomata $280-400 \times 470-620 \mu \mathrm{m}$, immersed in pseudostroma, perithecial, coriaceous, subglobose, aggregated, raised individually, ostiolate, periphysate. Ostioles 220-250 × 190-220 $\mu \mathrm{m}$. Peridium outer brown and inner hyaline layers with cells of textura angularis. Paraphyses septate, unbranched, guttulate, sparsely present. Asci (84-) 89-117(-122) $\times(10-) 12-15(-16.5) \mu \mathrm{m}(\bar{x}=103$ $\times 13.9, \mathrm{n}=25)$, polysporous, unitunicate, clavate, apically obtuse, long pedicellate, apices truncate, broader in the upper region, narrowing towards lower region, with a $\mathrm{J}$-, apical ring, persistent. Ascospores $(7) 7.2-10.7 \times 2.1-2.7 \mu \mathrm{m}(\bar{x}=8.7 \times 2.4, \mathrm{n}=25)$, hyaline to brown, allantoid, smoothwalled. Asexual morph: Undetermined.

Culture characteristics - Colonies on malt extract agar (MEA) $46 \mathrm{~mm}$ diam. in 4 days at $28^{\circ} \mathrm{C}$, white colony, radial, filamentous, raised in center, reverse center brown and white towards edges.

Material examined - INDIA, Andaman and Nicobar Islands, South Andaman, Chidiyatapu (11 ${ }^{\circ} 51^{\prime} 90.4$ " N 9265'23.8” E), decaying twig, 10 December 2017, M. Niranjan \& V.V. Sarma, AMH-9983, holotype; ex-type living cultures, NFCCI-4520.

GenBank numbers - ITS: MK990279, LSU: MK981538, SSU: MK981535. 
Notes - Allocryptovalsa truncata has narrower ascomata and smaller asci and ascospores than the type species, A. polyspora. A unique feature of the new taxon is the ascal apices that are apically, predominantly truncate in contrast to A. polyspora that has rounded apical ends. In the phylogeny (Fig. 4), taxa from Anthostoma, Cryptosphaeria, Cryptovalsa, Diatrype and Eutypella clustered with our new taxon and A. polyspora (strain MFLUC17-0364) nested with our taxon with strong boostrap support (99\% in ML).

Anthostoma Nitschke, Pyrenomyc. Germ. 1: 110 (1867)

Index Fungorum number: IF224; 36 morphological species (Species Fungorum 2020), 1 species with sequence data.

Type species - Anthostoma decipiens (DC.) Nitschke

Notes - The holomorphs of A. decipiens were studied by Rappaz $(1992,1993)$ and concluded the genus belongs in Diatrypaceae. Phylogenetic analyses of sequence data suppoted these results (Rocchi et al. 2010, Jaklitsch et al. 2014). The genus is characterised by dark brown to dark, globose to subglobose ascomata, immersed in a stroma, with cylindrical, prominent ostioles, cylindrical to clavate asci, with apically rounded to truncate apices, with a short pedicel and brown to black brown ascospores (Nitschke 1867).

Cryptosphaeria Ces. \& De Not., Comm. Soc. crittog. Ital. 1(4): 231 (1863)

Index Fungorum number: IF26092; 16 morphological species (Species Fungorum 2020), 5 species with sequence data.

Type species - Cryptosphaeria millepunctata Grev.

Notes - Cryptosphaeria has been widely accepted in Diatrypaceae (Nitschke 1867, 1870, Clement \& Shear 1931, Rappaz 1989, Trouillas et al. 2010b, 2015). The genus comprises corticolous species and is characterised by widely effuse and poorly developed stromata, often covered by a periderm, which is penetrated only by the separately emerging ostioles, generally 8spored, spindle-shaped, long pedicellate asci and sub-olivaceous to brown ascospores (Glawe 1984, Rappaz 1987).

Cryptovalsa Ces. \& De Not., Jb. nassau. Ver. Naturk. 23-24: 212 (1870)

Index Fungorum number: IF1340; 29 morphological species (Species Fungorum 2020), 4 species with sequence data.

Type species - Cryptovalsa protracta (Pers.) De Not.

Notes - Cryptovalsa was established by Cesati \& De Notaris to accommodate $C$. protracta, C. ampelina, C. nitschkei and C. effusa. The genus is characterised by eutypoid stromata that are rather variable, when erumpent separately diatrypelloid, often immersed in wood, but sometimes invading bark tissues. Asci are cylindrical or clavate, polysporous, with short or long pedicels. Ascospores are crowded, allantoid and yellowish (Spooner 1981, Vasilyeva \& Stephenson 2005).

Diatrypasimilis J.J. Zhou \& Kohlm., Index Fungorum 305: 1 (2016)

Index Fungorum number: IF552473; 1 species with sequence data.

Type species - Diatrypasimilis australiensis J.J. Zhou \& Kohlm.

Notes - Diatrypasimilis was established by Chalkley et al. (2010) based on conventional taxonomic criteria and molecular phylogeny to accommodate a species from mangroves. However, it was shown to be an invalid name and was legitimated as a nomenclatural novelty in Suh (2016). The genus is characterised by carbonaceous, black stromata, 8-spored, cylindrical asci and ellipsoidal, dark brown ascospores with a germ slit.

Diatrype Fr., Summa veg. Scand., Section Post. (Stockholm) 384 (1849)

Index Fungorum number: IF1504; 170 morphological species (Species Fungorum 2020), 17 species with sequence data.

Type species - Diatrype disciformis (Hoffm.) Fr. 


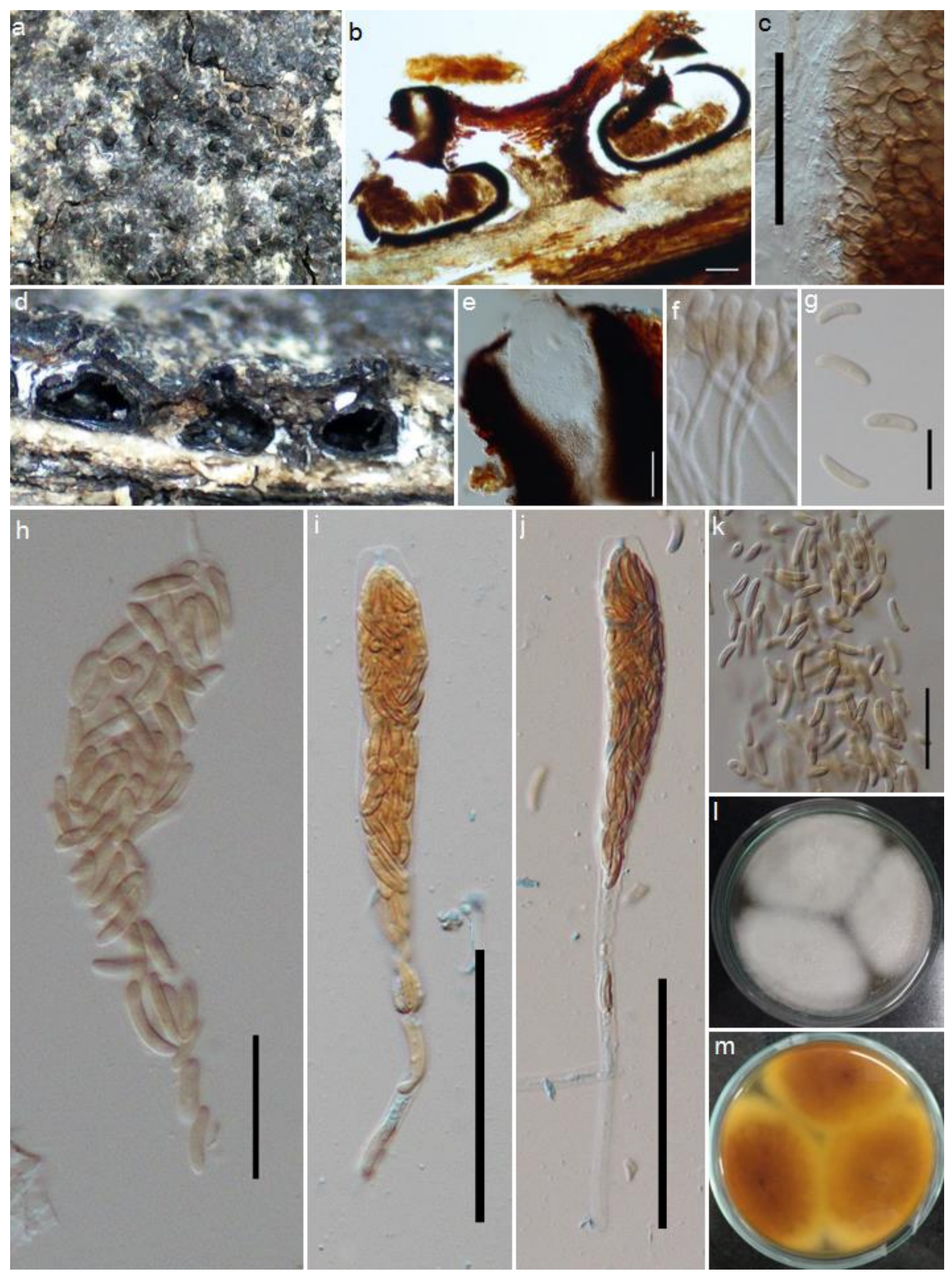

Figure 97 - Allocryptovalsa truncata (AMH-9983, holotype). a, d Ascomata on host. b Vertical section. c Peridium. e Periphysate neck. f Germinating spores. g, k Ascospores. h-j Asci. l-m Colonies on malt extract agar after 6 days (left) and 30 days (right) $(1=$ from above, $\mathrm{m}=$ from below). Scale bars: $b=100 \mu \mathrm{m}, \mathrm{c}, \mathrm{e}, \mathrm{h}-\mathrm{j}=50 \mu \mathrm{m}, \mathrm{k}=20 \mu \mathrm{m}, \mathrm{g}=10 \mu \mathrm{m}$. 


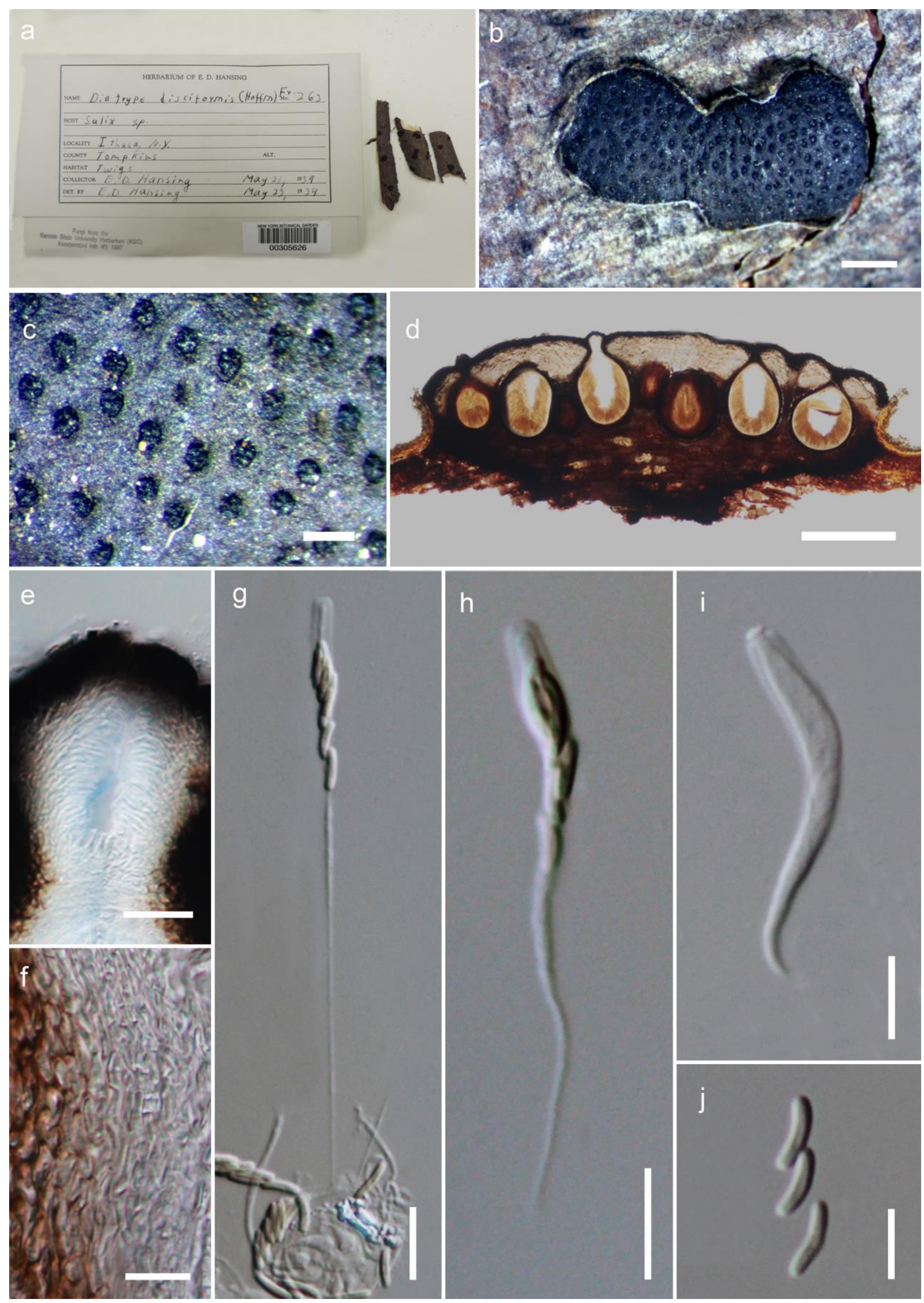

Figure 98 - Diatrype disciformis (Material examined - USA, New York, Ithaca, on twigs of Salix sp., 21 May 1939, E.D. Hansing, NY 00305626). a Herbarium material. b Stromata on host surface. c Ostiole appeared on stroma. d Vertical section of stroma. e Ostiole. f Peridium. g-i Asci. $\mathrm{j}$ Ascospores. Scale bars: $\mathrm{b}=1000 \mu \mathrm{m}, \mathrm{c}=100 \mu \mathrm{m}, \mathrm{d}=500 \mu \mathrm{m}, \mathrm{e}=50 \mu \mathrm{m}, \mathrm{f}-\mathrm{h}=10 \mu \mathrm{m}, \mathrm{i}-\mathrm{j}=5 \mu \mathrm{m}$. 
Notes - Species of Diatrype are common inhabitants on dead stems and barks of various plants throughout the world (Carmarán et al. 2006, Vasilyeva et al. 2009, de Almeida et al. 2016, Senwanna et al. 2017). In this entry we illustrate a collection of Diatrype disciformis.

Diatrypella (Ces. \& De Not.) De Not., Sfer. Ital.: 29 (1863)

Index Fungorum number: IF1505; 65 morphological species (Species Fungorum 2020), 15 species with sequence data.

Type species - Diatrypella verruciformis (Ehrh.) Nitschke

Notes - Diatrypella was established to accommodate members of stromatic Sphaeriales which were characterized by ovoid and numerous ascospores. The genus is characterised by conical to truncate, cushion-like or discoid stromata, usually delimited by a black zone in the host tissues, with umbilicate or sulcate ostioles. Asci are cylindrical, polysporous, with long stalks. Ascospores are allantoid, hyaline or yellowish.

Echinomyces Rappaz, Mycol. helv. 2(549): 547 (1987)

Index Fungorum number: IF25174; 2 morphological species (Species Fungorum 2020).

Type species - Echinomyces obesa (Syd.) Rappaz

Notes - Echinomyces was established by Rappaz (1987) to accommodate E. echidnus and E. obesus. The genus is characterised by the carbonaceous, black stromata and pale yellow ascospores, which are arc-like or full circles.

Endoxylina Romell, Bot. Notiser: 173 (1892)

Index Fungorum number: IF1814; 15 morphological species (Species Fungorum 2020), 1 species with sequence data.

Type species - Endoxylina stellulata Romell

Notes - Endoxylina was introduced and assigned to Diatrypales without assigning the familial position by Romell (1892). Based on previous morphological literature and herbarium studies, Hyde et al. (2017b) transferred Endoxylina to Diatrypaceae. The genus is characterised by flask-shaped, immersed perithecia with long pedicels and asci containing cylindrical to curved, 1septate, brown ascospores (Romell 1892).

Eutypa Tul. \& C. Tul., Select. fung. carpol. (Paris) 2: 52 (1863)

Index Fungorum number: IF1950; 66 morphological species (Species Fungorum 2020), 17 species with sequence data.

Type species - Eutypa lata (Pers.) Tul. \& C. Tul.

Notes - Species of Eutypa are the causal agents of Eutypa dieback of grapevine, apricots and cherries (Trouillas \& Gubler 2004, Baumgartner et al. 2010, Camps et al. 2010, Trouillas \& Gubler 2010, Blanco-Ulate et al. 2013, Camps et al. 2014). The genus is characterised by stromata which are irregular in shape, as confluent bumps, with conspicuous, scattered, roundish to prominent ostioles on the host surface. Asci are 8-spored, clavate, apically rounded to truncate, with indistinct apical rings, and long pedicels. Ascospores are allantoid to ellipsoidal, aseptate and pale yellowish.

Eutypella (Nitschke) Sacc., Atti Soc. Veneto-Trent. Sci. Nat., Padova, Sér. 4 4: 80 (1875)

Index Fungorum number: IF1951; 111 morphological species (Species Fungorum 2020), 17 species with sequence data.

Type species - Eutypella cerviculata (Fr.) Sacc.

Notes - Species of Eutypella have been found associated with a wide range of canker diseases (Vasilyeva \& Stephenson 2006, Trouillas et al. 2011). The genus is characterised by pustulate stromata with stout, converging ostiolar necks and asci with eight spores.

Halocryptovalsa Dayarathne \& K.D. Hyde, Cryptog. Mycol. (2019)

MycoBank: MB824308; 2 species with sequence data. 
Type species - Halocryptovalsa avicenniae (Abdel-Wahab, Bahkali \& E.B.G. Jones) Dayarathne \& K.D. Hyde

Notes - Halocryptovalsa was established by Dayarathne et al. (2019b) to accommodate species resembling Cryptovalsa from marine environments namely Cryptovalsa avicenniae and a new species Halocryptovalsa salicorniae. The genus is characterised by poorly developed stromata and poly-spored asci, with a J-, cylindrical, conspicuous apical or subapical ring. Ascospores are hyaline or yellow-brown to brown, allantoid, with small, fat globules at the end (Dayarathne et al. 2019b).

Halodiatrype M.C. Dayarathne \& K.D. Hyde, Phytotaxa 7(5): 617 (2016)

Index Fungorum number: IF552254; 3 morphological species (Species Fungorum 2020), 2 species with sequence data.

Type species - Halodiatrype salinicola M.C. Dayarathne \& K.D. Hyde

Notes - Halodiatrype was established by Dayarathne et al. (2016b) to accommodate $H$. avicenniae and $H$. salinicola isolated from mangroves. The genus is characterised by 8-spored, cylindrical to clavate, pedicellate asci, with apically rounded or flattened, lacking an apical ring and deliquescing early. Ascospores are oblong to allantoid or sub-inequilateral, aseptate or septate, not constricted at the septa, light brown, with one to few small guttules and slightly curved. The asexual morphs are libertella-like (Dayarathne et al. 2016b, 2019b).

Leptoperidia Rappaz, Mycol. helv. 2(547): 544 (1987)

Index Fungorum number: IF25186; 4 morphological species (Species Fungorum 2020).

Type species - Leptoperidia macropunctata (Rehm) Rappaz

Notes - Leptoperidia was introduced to accommodate L. applanata, L. asperrima, L. macropunctata and L. trifida. The genus is characterised by relatively small stroma, asci and ascospores, perithecia with very thin and slightly melanized walls (Rappaz 1987).

Libertella Desm., Annls Sci. Nat., sér. 1 19: 275 (1830)

Index Fungorum number: IF8769; 33 morphological species (Species Fungorum 2020), 2 species with sequence data.

Type species - Libertella betulina Desm.

Notes - Libertella was introduced by Desmazières (1830) to accommodate L. betulina, L. faginea and $L$. rosae. This genus was mostly reported as the asexual morph of Diatrypella, however, some species were reported as asexual Eutypa, Eutypella, Diaporthe, and Polystigma (Kirk et al. 2001). The genus is characterised by subcortical, erumpent, and yellow to red acervula conidiomata and branched conidiophores that produce hyaline, 1-celled, filiform conidia (Barnett \& Hunter 1972, Sutton 1980, von Arx 1981b).

Monosporascus Pollack \& Uecker, Mycologia 66(2): 348 (1974)

Index Fungorum number: IF3260; 4 morphological species (Species Fungorum 2020), 3 species with sequence data.

Type species - Monosporascus cannonballus Pollack \& Uecker

Notes - Monosporascus was introduced by Pollack \& Uecker (1974) with type species $M$. cannonballus to accommodate a fungus obtained from necrotic muskmelon roots. The genus is characterised by pyriform asci and the formation of one (rarely two) single large, sphaerical ascospores (Pollack \& Uecker 1974).

Neoeutypella M. Raza, Q.J. Shang, Phookamsak \& L. Cai, Fungal Divers. 95 (1): 1-273 (2019)

Index Fungorum number: IF555373; 1 species with sequence data.

Type species - Neoeutypella baoshanensis M. Raza, Q.J. Shang, Phookamsak \& L. Cai

Notes - Neoeutypella was introduced by Phookamsak et al. (2019) to accommodate two fungal strains under the name Eutypella caricae and a new strain isolated from Pinus armandii 
(Pinaceae). Neoeutypella is characterised by carbonaceous stromata, erumpent through host epidermis, producing yellow pigments surrounding the stroma. Asci are 8-spored, spindle-shaped, with long pedicellate, apically rounded, with refractive cytoplasmic strands, with a $\mathrm{J}+$, subapical ring.

Pedumispora K.D. Hyde \& E.B.G. Jones, Mycol. Res. 96(1): 78 (1992)

Index Fungorum number: IF25433; 1 species with sequence data.

Type species - Pedumispora rhizophorae K.D. Hyde \& E.B.G. Jones

Notes - Pedumispora was introduced by Hyde \& Jones (1992) to accommodate a fungus from mangrove habitats. A phylogenetic study based on nuclear LSU and ITS regions showed the taxonomic position of Pedumispora was in Diatrypaceae (Klaysuban et al. 2014). The genus is characterised by 8 -spored, fusiform, pedicellate, unitunicate, apically truncate asci. Ascospores are filiform, mutli-septate, curved, longitudinally striate, with tapering poles, with one or both ends crook-like (Hyde \& Jones 1992).

Peroneutypa Berl., Icon. fung. (Abellini) 3(3-4): 80 (1902)

Index Fungorum number: IF3834; 28 morphological species (Species Fungorum 2020), 11 species with sequence data.

Type species - Peroneutypa bellula (Desm.) Berl.

Notes - Peroneutypa was introduced by Berlese (1902) to accommodate P. bellula, $P$. corniculata, and $P$. heteracantha without designating the type species. Rappaz (1987) proposed $P$. bellula as the type species and synonymized Peroneutypa under Eutypella. However, based on characteristics and phylogenetic data of Acero et al. (2004), Peroneutypa was reinstated by Carmarán et al. (2006). The genus is characterised by valsoid stromata, with packed, long prominent necks, sessile to long pedicels, small asci with truncate apices and allantoid ascospores (Carmarán et al. 2006, 2014, Senwanna et al. 2017, Shang et al. 2017).

Quaternaria Tul. \& C. Tul., Select. fung. carpol. (Paris) 2: 104 (1863)

Index Fungorum number: IF4632; 10 morphological species (Species Fungorum 2020), 1 species with sequence data.

Type species - Quaternaria persoonii Tul. \& C. Tul.

Notes - Quaternaria was introduced by Tulasne \& Tulasne (1863) and was typified by $Q$. persoonii. Clements \& Shear (1931) lectotypified the illegitimate name $Q$. quaternata to $Q$. persoonii considered Quaternaria as a synonym of Eutypella (Tulasne \& Tulasne 1863). Based on analyses of LSU and ITS sequence data and the discussion of Gams (1994), Quaternaria was considered to be an independent genus by Acero et al. (2004). The genus is characterised by stromata that are cryptosphaeroid in appearance and develop within the bark parenchyma.

Distoseptisporaceae K.D. Hyde \& McKenzie, Fungal Divers. 80(1): 402 (2016)

Index Fungorum number: IF551850; Facesoffungi number: FoF01754; 26 species.

Saprobic on wood and in terrestrial and freshwater habitats. Sexual morph: Ascomata perithecial, dark brown to black, superficial, solitary, globose to ovoid, papillate. Ostiole periphysate. Peridium leathery, carbonaceous, dark brown, composing two layers of textura prismatica. Paraphyses numerous, hyaline, unbranched, septate, cylindrical. Asci 8-spored, unitunicate, cylindrical, with a $\mathrm{J}$-, apical ring. Ascospores biseriate, hyaline to light yellowishbrown, fusiform, straight, 3-septate, lacking a mucilaginous sheath or appendages. Asexual morph: Hyphomycetous. Colonies effuse, hairy or velvety, olivaceous or black. Mycelium mostly immersed, composed of branched, septate, smooth, pale brown hyphae. Conidiophores semimacronematous to macronematous, mononematous, septate, unbranched, single or in groups, erect, straight or flexuous, smooth, olivaceous to brown, cylindrical, robust at the base, sometimes elongating percurrently. Conidiogenous cells monoblastic, integrated, determinate, terminal, cylindrical. Conidia acrogenous, solitary, olivaceous, brown or yellowish-brown to reddish-brown, 
euseptate or distoseptate or muriform appearing cruciately divided by septa at right angles to one another, obclavate or cylindrical, with rounded apex, indeterminately elongating percurrently, truncate at base; basal cell with cross wall and basal scar; or transversal ellipsoid to subglobose, sometimes with pores in the septa (adapted from Su et al. 2016b).

Type genus - Distoseptispora K.D. Hyde, McKenzie \& Maharachch.

Notes - Distoseptisporaceae was introduced in Su et al. (2016b) to accommodate a single genus Distoseptispora. Asexual morphs in Distoseptisporaceae share similar morphology with species classified in Ellisembia and Sporidesmium in having holoblastic, euseptate or distoseptate conidia and monoblastic, determinate or percurrently elongating conidiogenous cells (Subramanian 1992, Shenoy et al. 2006, Yang et al. 2018b). However, many of the characters used to delimit the genera do not appear phylogenetically significant (Shenoy et al. 2006, Su et al. 2016b).

\section{Ecological and economic significance of Distoseptisporaceae}

Distoseptispora contains saprobic lignicolous taxa found in terrestrial, but mostly in freshwater habitats. They play important roles in decomposition of lignocelluloses in wood (Wong et al. 1998a, Krauss et al. 2011, Hyde et al. 2016a).

\section{Genus incuded in Distoseptisporaceae}

Distoseptispora K.D. Hyde, McKenzie \& Maharachch., Fungal Divers. 80(1): 402 (2016)

Index Fungorum number: IF551833; 26 species with sequence data.

Type species - Distoseptispora fluminicola McKenzie, H.Y. Su, Z.L. Luo \& K.D. Hyde

Notes - The generic concept of Distoseptispora was emended by Yang et al. (2018b) in respect to the characters of $D$. guttulata and D. suoluoensis, which have erect, macronematous conidiophores, percurrently elongating conidiogenous cells and euseptate conidia. The type of septum does not aid in identification of Distoseptispora species. Acrodictys martini was transferred to Diaporthe martinii (Xia et al. 2017). It differs from all other species in the genus in having muriform, transversally ellipsoid to subglobose brown conidia. Its placement in Distoseptispora was resolved with molecular DNA data. Phylogenetic placement of the genus is shown in Fig. 4. Distoseptispora clematidis was introduced by Phukhamsakda et al. (2020) from Clematis and Luo et al. (2019) introduced D. appendiculata, D. lignicola, D. neorostrata and D. obclavata from submerged wood in Thailand. In this entry we introduce a new species, Distoseptispora rayongensis.

Distoseptispora rayongensis J. Yang \& K.D. Hyde, sp. nov.

Fig. 99

Index Fungorum number: IF554770; Facesoffungi number: FoF04675

Etymology - Referring to the collecting site in Rayong Province, Thailand.

Holotype - MFLU 18-1045.

Saprobic on decaying twigs. Sexual morph: Undetermined. Asexual morph: Hyphomycetous. Colonies effuse, dark brown to black, hairy, glistening. Mycelium partly superficial, partly immersed in the substratum, composed of brown, septate, branched hyphae. Conidiophores macronematous, mononematous, solitary, cylindrical, straight or slightly flexuous, septate, brown, smooth, paler towards the apex, $75-125 \times 3.5-5.5 \mu \mathrm{m}(\bar{x}=100 \times 4.5 \mu \mathrm{m}, \mathrm{n}=10)$, rounded at apex. Conidiogenous cells integrated, terminal, monoblastic, cylindrical, brown. Conidia acrogenous, solitary, obclavate or obspathulate, rostrate, mostly 9-13-euseptate, rarely 14-15-septate, pale brown or pale olivaceous, becoming paler or hyaline towards the apex, guttulate, smooth, (36-)60$106(-120) \times 9-14.5 \mu \mathrm{m}(\bar{x}=80 \times 11.5 \mu \mathrm{m}, \mathrm{n}=20)$, with a darkened scar at the base, sometimes with percurrent proliferation and forming another conidium from the conidial apex.

Culture characteristics - Conidia germinating on PDA within $24 \mathrm{~h}$. Germ tubes produced from the conidial base. Colonies on PDA slow growing, reaching 5-10 mm diam. after one month at $25{ }^{\circ} \mathrm{C}$ in natural light, circular, aerial mycelium dense, brown; reverse dark brown, margin entire. 


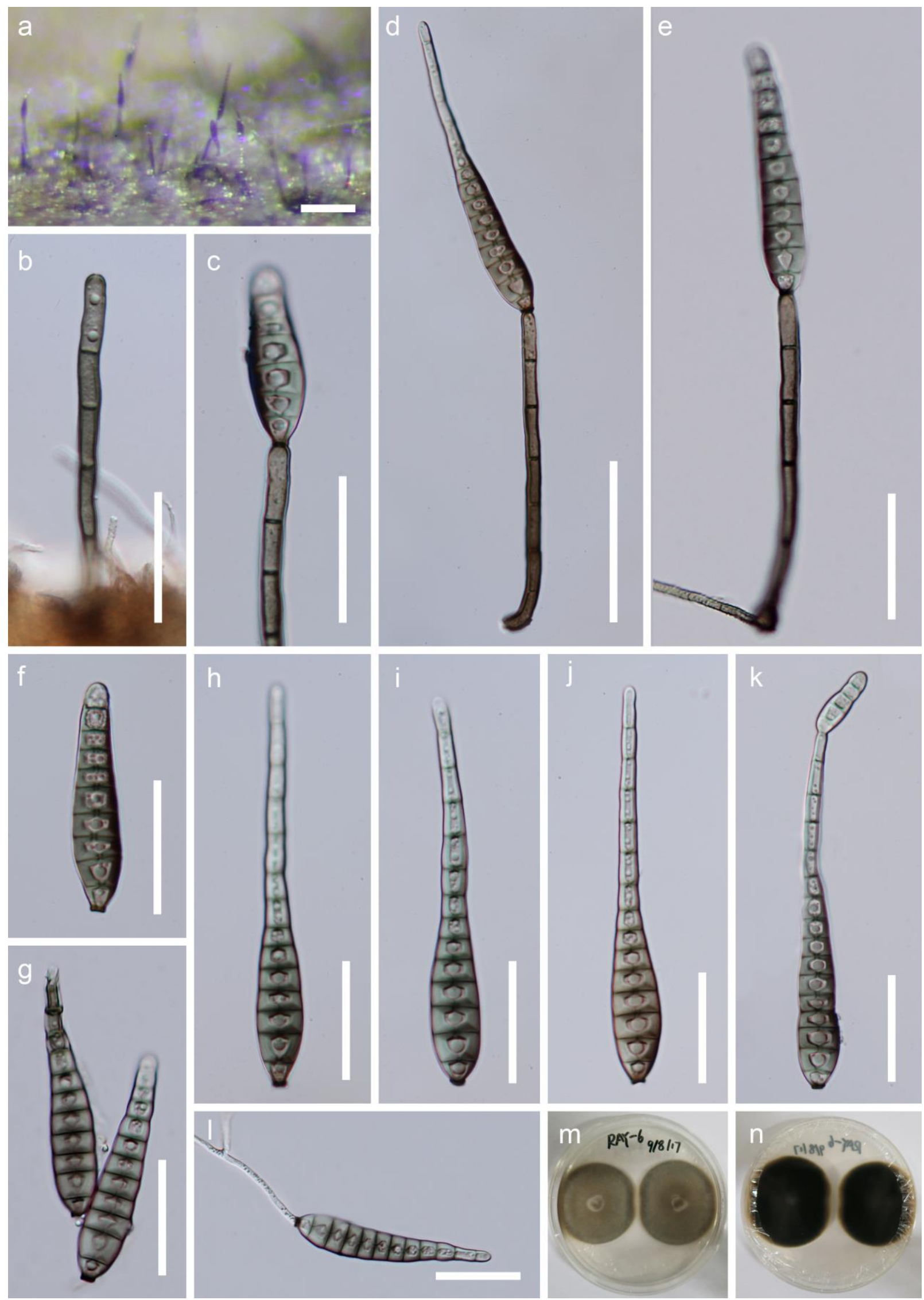

Figure 99 - Distoseptispora rayongensis (MFLU 18-1045 holotype). a Colonies on the woody substrate. $\mathrm{b}$ Conidiophore. c Conidiogenous cell with conidium. $\mathrm{d}$, e Conidia and conidiophores. $\mathrm{f}-\mathrm{k}$ Conidia. 1 Germinated conidium. $\mathrm{m}, \mathrm{n}$ Cultures, $\mathrm{m}$ from above, $\mathrm{n}$ from below. Scale bars: $\mathrm{a}=100$ $\mu \mathrm{m}, \mathrm{b}, \mathrm{c}, \mathrm{e}-\mathrm{l}=30 \mu \mathrm{m}, \mathrm{d}=50 \mu \mathrm{m}$. 
Material examined - THAILAND, Rayong Province, Klaeng, $12^{\circ} 78^{\prime} \mathrm{N}, 101^{\circ} 66^{\prime} \mathrm{E}$, on decaying wood submerged in a freshwater stream, 24 April 2017, Y.Z. Lu, RAY-6, MFLU 181045, holotype; ibid. HKAS102138, isotype; ex-type living cultures MFLUCC 18-0415; ibid. RAY-8, MFLU 18-1046, paratype; ex-paratype living culture MFLUCC 18-0417.

GenBank numbers - LSU: MH457137, SSU: MH457169, ITS: MH457172, tef1: MH463253, rpb2: MH463255 (MFLUCC 18-0415); LSU: MH457138, SSU: MH457170, ITS: MH457173, tef1: MH463254, rpb2: MH463256 (MFLUCC 18-0417).

Notes - Distoseptispora rayongensis clustered within Distoseptispora with high statistical support in a sister clade to D. guttulata (Fig. 3). Distoseptispora rayongensis resembles D. guttulata and D. suoluoensis in having conspicuous long conidiophores and euseptate conidia of similar size. However, D. rayongensis can be distinguished from D. guttulata and D. suoluoensis in conidial colour and shape. Percurrently elongating conidia are observed in D. rayongensis and D. suoluoensis.

Dwiroopaceae K.V. Xavier, A.N. KC, J.Z. Groenew., Vallad \& Crous, Fungal Systematics and Evolution 4: 38 (2019)

Index Fungorum number: IF830873; Facesoffungi number: FoF06872; 3 species.

Saprobic or pathogenic on leaves, twigs, branches and fruits. Sexual morph: Undetermined. Asexual morph: Coelomycetous. Conidiomata pycnidial, immersed to semi-immersed, erumpent, solitary, uni- to multiloculate, scattered, globose, black, ostiolate or lacking ostioles. Peridium thick-walled, comprising wall of 3-6 layers of pale brown cells of textura angularis. Conidiophores lining the innermost wall layer of peridium, mostly reduced to conidiogenous cells. Conidiogenous cells holoblastic, ampulliform to subcylindrical, hyaline to pale brown, sometimes proliferating percurrently at apex. Conidia unicellular, solitary, truncate at base, of three types: Macroconidia solitary, dark brown, aseptate, granular at surface, guttulate, thickwalled, broadly ellipsoid to obovoid, with longitudinal striations running along the length of conidia. Mesoconidia hyaline to pale brown, ellipsoid, aseptate and microconidia ellipsoid, hyaline, aseptate (adapted from Xavier et al. 2019).

Type genus - Dwiroopa Subram. \& Muthumary

Notes - Castlebury et al. (2002) placed Harknessia and Dwiroopa in Diaporthales based on LSU phylogeny. Subsequently, Crous et al. (2012d) established Harknessiaceae to include species of Harknessia with wuestneia-like sexual morphs in Diaporthales. Dwiroopaceae was established by Xavier et al. (2019) to accommodate a monotypic genus Dwiroopa including three species in Diaporthales. Dwiroopaceae species share closer characters with taxa of Harknessiaceae and have to sister relation with Harknessiaceae in a multigene phylogenetic analysis.

\section{Ecological and economic significance of Dwiroopaceae}

Species of Dwiroopaceae are saprobes and pathogens in terrestrial habitats. Dwiroopa ramya is a saprobe on dead twigs in India (Subramanian \& Muthumary 1986), while D. lythri is a pathogen on a noxious weed purple loose strife in North America (Farr \& Rossman 2001). Dwiroopa punicae represents a severe pathogen of Punica granatum across the south eastern USA causing up to $100 \%$ fruit damage (Xavier et al. 2019).

\section{Genus included in Dwiroopaceae}

Dwiroopa Subram. \& Muthumary, Proc. Indian Acad. Sci., Pl. Sci. 96(3): 196 (1986)

Index Fungorum number: IF11077; 3 morphological species (Species Fungorum 2020), 2 species with sequence data.

Type species - Dwiroopa ramya Subram. \& Muthumary

Notes - Members of Dwiroopa resemble Harknessia in having uni- to multiloculate, thickwalled, immersed to semi-immersed conidiomata, becoming erumpent, dark brown and aseptate, thick-walled macroconidia with holoblastic conidiogenesis, with conidiogenous cells bearing periclinal thickenings. Dwiroopa is distinguished from Harknessia in having distinct, holoblastic 
conidiogenesis, thick-walled conidiogenous cells and broadly spaced several longitudinal striations in the macroconidia, lacking a basal appendage and showcasing a dark scar with minute marginal frills at the conidial connection. Harknessia is distinct from Dwiroopa in having macroconidia that are smooth-walled or have closely spaced longitudinal raised bands on only one side and usually with a true basal appendage. Furthermore, Dwiroopa produces three different kinds of conidia viz. macroconidia, mesoconidia and phialoconidia (Farr \& Rossman 2003), which are not produced in Harknessia. Farr \& Rossman (2003) redescribed Dwiroopa ramya and designated it as a lectotype and also introduced Harknessia lythri as Dwiroopa lythri in Dwiroopa based on morphological similarities.

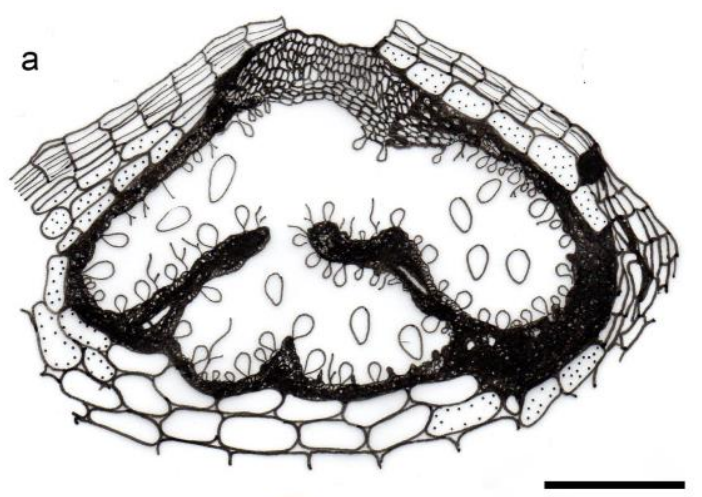

b

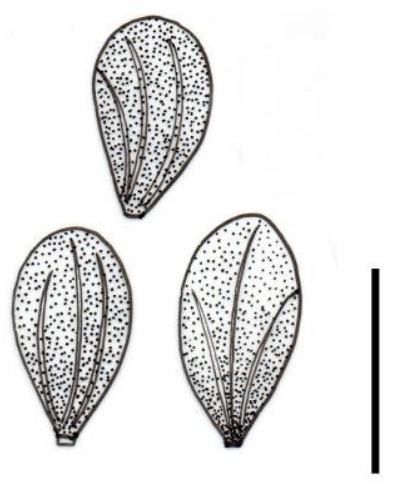

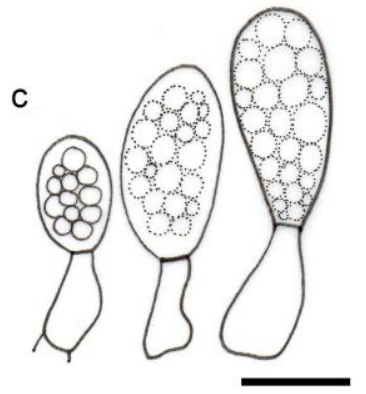

d

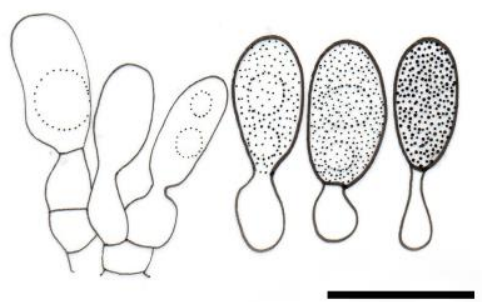

f

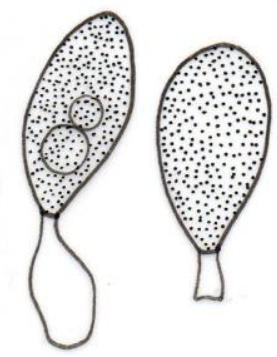

h

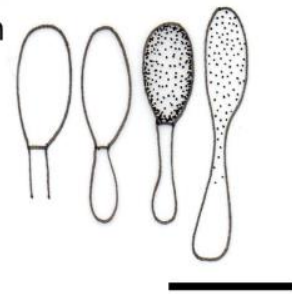

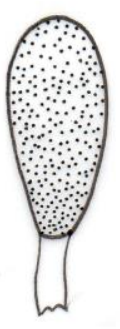
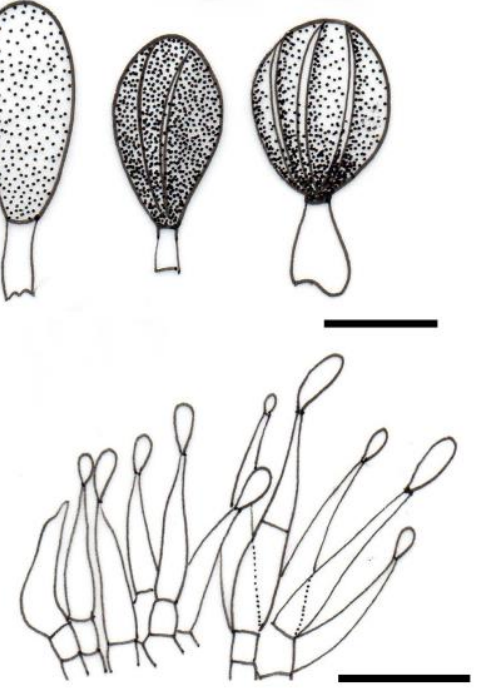

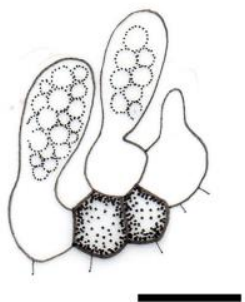

g

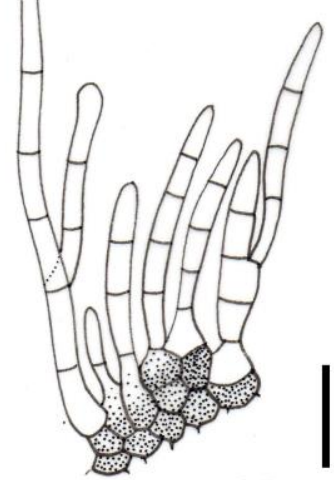

j

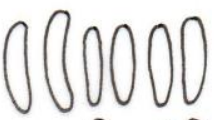
00000

Figure 100 - Dwiroopa ramya (redrawn from Subramanian \& Muthumary 1986). a Vertical section of conidioma. b Conidia. c-f Stages in the development of macroconidia. g Paraphysis-like structures. h Meso-conidia, note, developing and mature conidia. i Phialides with developing phialoconidia. j Phialoconidia. Scale bars: $a=100 \mu \mathrm{m}, \mathrm{b}=20 \mu \mathrm{m}, \mathrm{c}, \mathrm{d}, \mathrm{f}-\mathrm{i}=10 \mu \mathrm{m}, \mathrm{e}, \mathrm{j}=5 \mu \mathrm{m}$.

Erythrogloeaceae Senan., Maharachch. \& K. D. Hyde, Stud. Mycol. 86: 217-296 (2017) Index Fungorum number: IF821551; Facesoffungi number: FoF03478; 22 species. 
Foliicolous, associated with leaf spots. Sexual morph: Pseudostromata circular, erumpent, consisting of an inconspicuous, usually orange ectostromatic disc, semi-immersed to superficial. Ectostromatic disc flat or concave, orange. Perithecia conspicuous, umber to black, embedded in pseudostromatic tissue, scattered, surrounding the ectostromatic disc, ostiolate. Ostioles cylindrical, obscuring the disc, covered by orange to black crust. Paraphyses deliquescent. Asci 8-spored, fusoid, 2-3-seriate, with an apical ring. Ascospores hyaline, fusoid to cylindrical, symmetrical to asymmetrical, straight to curved, bicellular, with a median septum, constricted at the septum, smooth, multiguttulate. Asexual morph: Coelomycetous. Conidiomata epiphyllous, subepidermal, sometimes eustromatic, acervular or subglobose, brown to black or yellow-orange, amphigenous, opening by irregular rupture, orange-brown wall composed of cells of textura angularis, exuding slimy orange masses of conidia. Conidiophores reduced to conidiogenous cells. Conidiogenous cells lining the inner cavity of conidioma, hyaline to olivaceous, smooth, subcylindrical to ampulliform, tapering to a long, thin neck, at times apical part elongated into a long neck, proliferating several times percurrently near apex, with flaring collarettes, or apex truncate, with minute periclinal thickening. Conidia hyaline to olivaceous, smooth, guttulate or not, thin-walled, ellipsoid, fusoid, ovoid to somewhat obclavate, straight to curved, apex subobtuse, obtusely rounded, base truncate, with prominent marginal frill, or dimorphic, intermixed in same conidiomata. Macroconidia broadly ellipsoid to obovoid, hyaline, smooth, granular to guttulate, thick-walled, apex obtuse, base flattened. Microconidia hyaline, smooth, guttulate, fusoid-ellipsoid, acutely rounded at apex, truncate at base (adapted from Senanayake et al. 2017a).

Type genus - Erythrogloeum Petr.

Notes - Erythrogloeaceae was erected based on morphology and phylogeny and it comprised Chrysocrypta, Disculoides and Erythrogloeum (Senanayake et al. 2017a). Fan et al. (2018) accommodated Dendrostoma within this family. Erythrogloeaceae is characterized by epiphyllous acervuli, and subcylindrical to ampulliform conidiogenous cells. The sexual morph of this family is reported only from Dendrostoma (Fan et al. 2018).

\section{Ecological and economic significance of Erythrogloeaceae}

Erythrogloeum hymenaeae causes leaf spots and anthracnose of Hymenaea sp. mainly during the wet season (Ferreira et al. 1992). The second species, E. pini-acicola was described from needles of Pinus oocarpa (Evans 1984). Chrysocrypta corymbiae is associated with leaf spots on Corymbia. Disculoides forms leaf spots on Eucalyptus species.

\section{Genera included in Erythrogloeaceae}

Chrysocrypta Crous \& Summerell, Persoonia 28: 165 (2012)

Index Fungorum number: IF800379; 1 species with sequence data.

Type species - Chrysocrypta corymbiae Crous \& Summerell

Notes - Chrysocrypta, introduced by Crous et al. (2012b), is associated with leaf spots of Corymbia species. This monotypic genus is similar to Foliocryphia. However, Chrysocrypta is distinct in having dimorphic conidia.

Dendrostoma X.L. Fan \& C.M. Tian, Persoonia 40: 124 (2018)

Index Fungorum number: IF823986; 14 species with sequence data.

Type species - Dendrostoma mali X.L. Fan \& C.M. Tian

Notes - Dendrostoma is distinct in having diaporthe-type perithecia with clavate asci and fusoid to cylindrical and bi-celled ascospores (Fan et al. 2018).

Disculoides Crous, Pascoe, I.J. Porter \& Jacq. Edwards, Persoonia 28: 71 (2012)

Index Fungorum number: IF564737; 5 species with sequence data.

Type species - Disculoides eucalypti Crous, Pascoe, I.J. Porter \& Jacq. Edwards

Notes - Disculoides species are foliar pathogens of Eucalyptus and Corymbia species. The genus is characterized by acervular, amphigenous black conidiomata and conidiophores which are 
either reduced to conidiogenous cells. The conidiogenous cells are subcylindrical to ampulliform and proliferate percurrently at the apex, with flaring collarettes. Conidia are hyaline to olivaceous (Crous et al. 2012b, 2017a).

Erythrogloeum Petr., Sydowia 7(5-6): 378 (1953)

Index Fungorum number: IF8211; 2 morphological species (Species Fungorum 2020), 1 species with sequence data.

Type species - Erythrogloeum hymenaeae Gonz. Frag. \& Cif.

Notes - Erythrogloeum comprises two species, E. hymenaeae and E. pini-acicola. Both species are foliar pathogens of Hymenaeae and Pinus species. The sexual morph of this genus is not reported. The genus is characterised by acervular conidiomata with side walls comprising dark brown to black cells of textura angularis, lageniform to cylindrical conidiogenous cells and monomorphic conidia (Senanayake et al. 2017a).

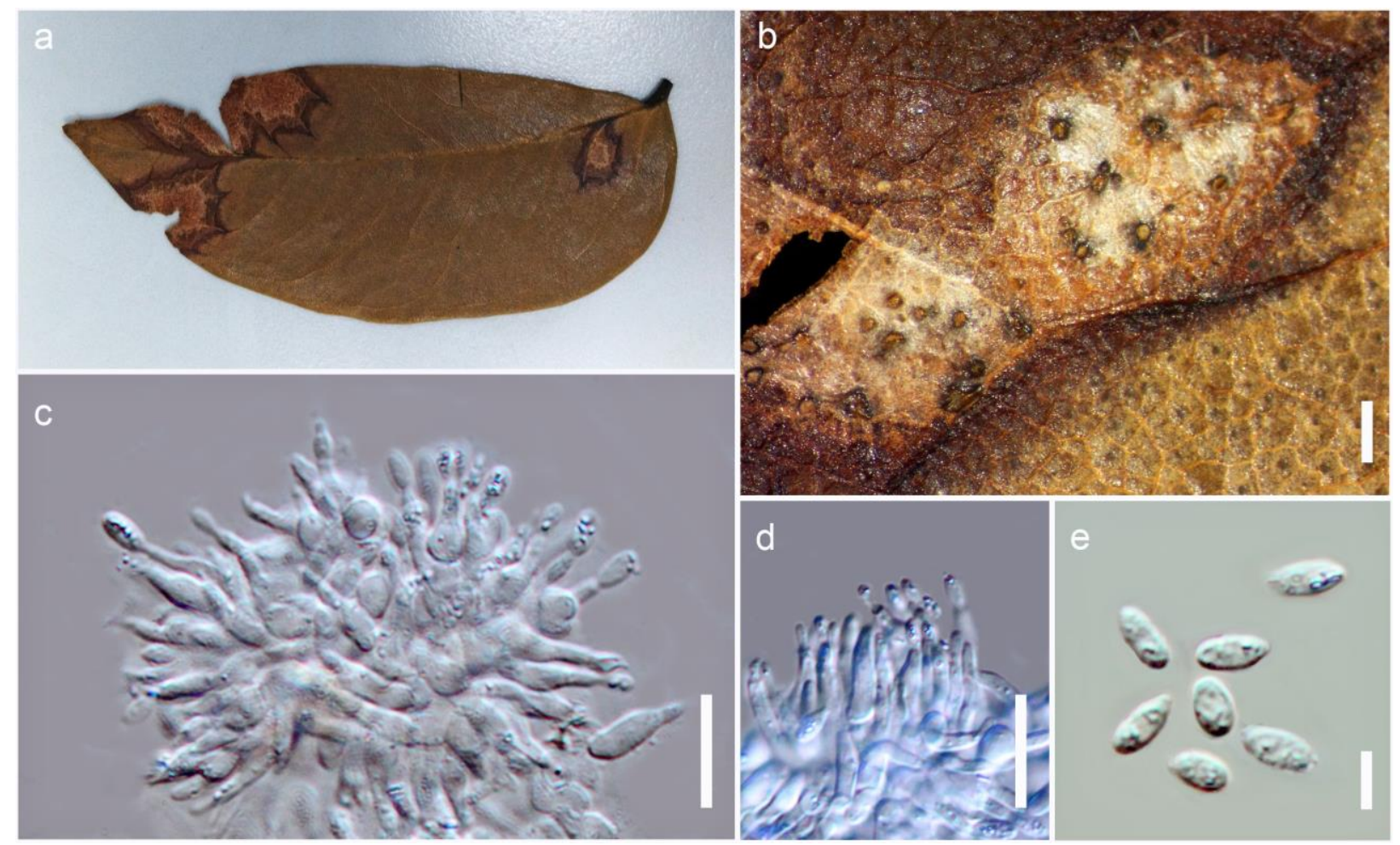

Figure 101 - Erythrogloeum hymenaeae (Material examined - COSTA RICA, San Jose, on leaves of Hymenaea courbaril, Nov. 1929, H. Schmidt, F45468, syntype). a Herbarium specimen. b Conidiomata on substrate. c, d Conidiophores, conidiogeneous cells and conidia. e Conidia. Scale bars: $\mathrm{b}=200 \mu \mathrm{m}, \mathrm{c}-\mathrm{d}=10 \mu \mathrm{m}, \mathrm{e}=5 \mu \mathrm{m}$.

Etheirophoraceae Rungjindamati, Somrothipol, \& Suetrong, Cryptog. Mycol. 35(2): 134 (2014)

Index Fungorum number: IF808178; Facesoffungi number: FoF01329; 5 species.

Saprobic on intertidal wood and bark in marine habitats. Sexual morph: Ascomata subglobose to globose or pyriform, light brown to dark brown or black, immersed, oblique or vertical to the host surface, clypeate, coriaceous, ostiolate, periphysate, papillate. Peridium composed several layers of brown to dark brown cell layers of textura angularis. Paraphyses numerous, mostly unbranched, attached to the apex of the ascomatal cavity, embedded in a gelatinous matrix. Asci 8spored, unitunicate, cylindrical to oblong, pedicellate, J-, persistent. Ascospores 1-2-seriate, hyaline, ellipsoidal, 1 to many septate, constricted at the septa, with a filamentous appendage at one or both ends. Appendages bristle-like, origin undetermined. Asexual morph: Undetermined (adapted from Jones et al. 2014).

Type genus - Etheirophora Kohlm. \& Volkm.-Kohlm. 
Notes - This family includes the genera Etheirophora (E. bijubata, E. blepharospora, E. unijubata) and Swampomyces (S. armeniacus, S. triseptatus) (Jones et al. 2014). However, the genera Etheirophora and Swampomyces are not congeneric and they form a sister clade with Falcocladium species (Falcocladiaceae) in an unsupported clade in Hypocreomycetidae, order incertae sedis (Maharachchikumbura et al. (2015). Subsequently, Jones et al. (2015) introduced Torpedosporales to accommodate the families Etheirophoraceae, Juncigenaceae and Torpedosporaceae. The order evolved with a stem age of 171-241 MYA (Hongsanan et al. 2017, Hyde et al. 2017a).

\section{Ecological and economic significance of Etheirophoraceae}

Etheirophoraceae species are commonly found as saprobes on intertidal wood and bark in marine habitats. Host-specificity of Keissleriella blephorospora (= Etheirophora blepharospora), occurring on Rhizophora species in Hawaii has been reported and the species is involved in nutrient cycling (Osorio et al. 2016).

\section{Genera included in Etheirophoraceae}

Etheirophora Kohlm. \& Volkm.-Kohlm., Mycol. Res. 92(4): 414 (1989)

Index Fungorum number: IF25298; 3 morphological species (Species Fungorum 2020), 2 species with sequence data.

Type species - Etheirophora bijubata Kohlm. \& Volkm.-Kohlm.

Notes - Kohlmeyer \& Kohlmeyer (1989) introduced Etheirophora (type species E. bijubata) to accommodate three marine species from tropical locations, including a species previously referred to as Keissleriella blepharospora. The genus was assigned to Sphaeriales by Kohlmeyer \& Kohlmeyer (1989) and to Halosphaeriales by Hawksworth et al. (1995) and Kirk et al. (2001). Schoch et al. (2006), based on molecular data and morphology, referred it to the TBM clade comprising Bertia, Melanospora and Torpedospora, within Hypocreomycetidae, with affinities to the Coronophorales. Etheirophora grouped with a range of unresolved taxa, Juncigena, Swampomyces and Torpedospora and the asexual genera Glomerulispora (= Torpedospora) and Moheitospora, in the TBM clade with high bootstrap support (Abdel-Wahab et al. 2010). Subsequently the genus was referred to Etheirophoraceae (Torpedosporales) (Jones et al. 2014, 2015).

Swampomyces Kohlm. \& Volkm.-Kohlm., Bot. Mar. 30(3): 198 (1987)

Index Fungorum number: IF6004; 2 species with sequence data.

Type species - Swampomyces armeniacus Kohlm. \& Volkm.-Kohlm.

Notes - Abdel-Wahab et al. (2001) added S. triseptatus (Hyde \& Nakagiri 1992), S. clavatispora and S. aegyptiacus. Subsequently, S. aegyptiacus and S. clavatispora were transferred to Fulvocentrum by Jones et al. (2014). Swampomyces armeniacus is illustrated in this entry.

Falcocladiaceae Somrith., E.B.G. Jones \& K.L. Pang, Cryptog. Mycol. 35(2): 134 (2014)

Index Fungorum number: IF808179; Facesoffungi number: FoF01288; 5 species.

Saprobic on leaf litter, including leaves of Eucalyptus grandis and E. camaldulensis in tropical, terrestrial habitats. Sexual morph: Undetermined. Asexual morph: Hyphomycetous. Conidiomata hyaline, sporodochial or synnematal or penicillate, intermixed with setae, arising from a stroma or microsclerotia or prostrate mycelium Setae cylindrical, thick and smoothwalled, hyaline, non-septate and terminating in variedly-shaped vesicles. Conidiophores subcylindical, hyaline, septate, branched, forming up to three series of branches per conidioma (primary, secondary and tertiary). Conidiogenous cells ampulliform, phialidic, arranged in 2-6 whorls, with elongate necks, with minute collarettes. Conidia trans- (1)-septate, hyaline, smoothwalled, falcate, guttulate, with short apical and basal appendages (adapted from Jones et al. 2014, Maharachchikumbura et al. 2016b).

Type genus - Falcocladium S.F. Silveira 


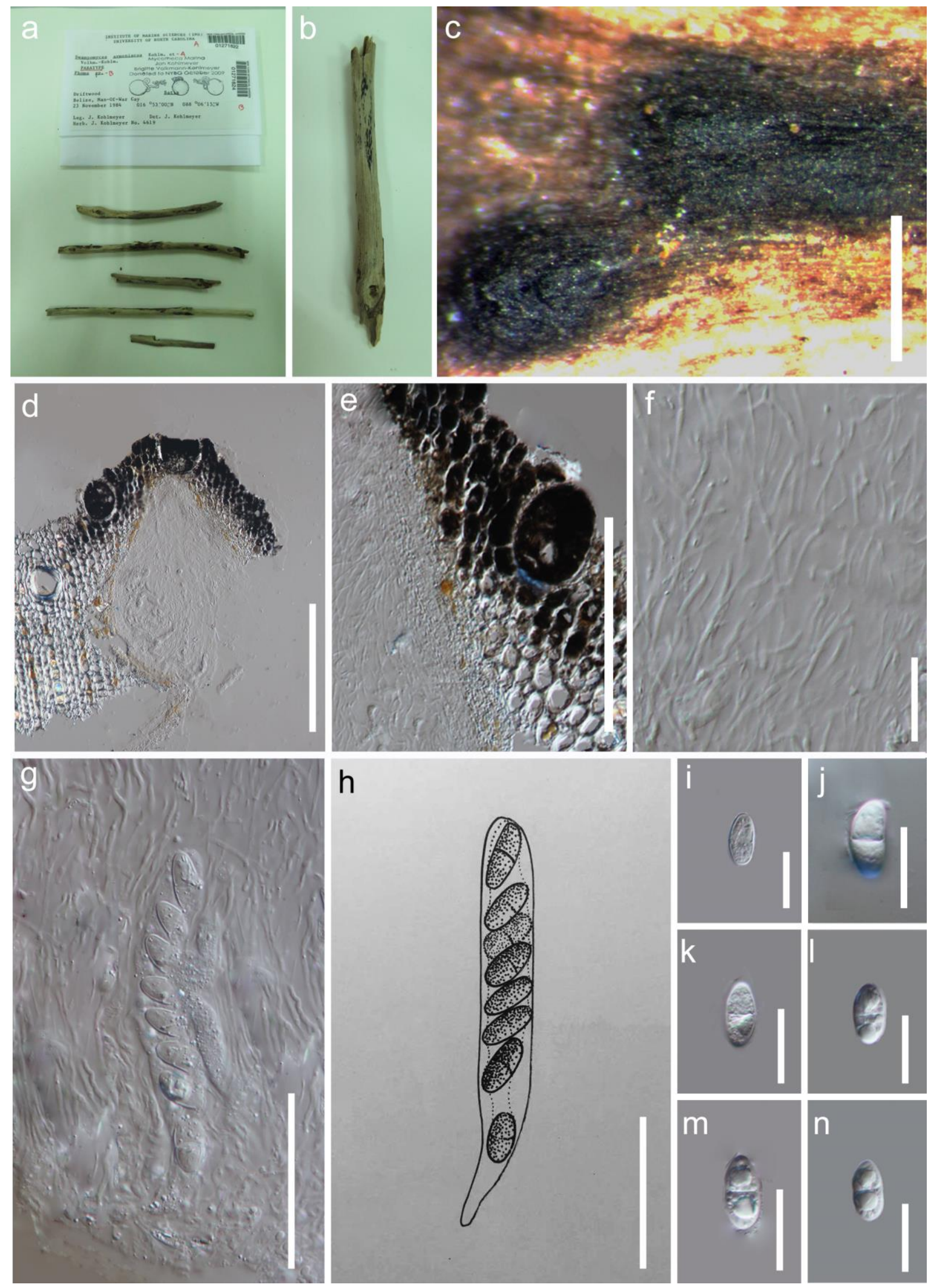

Figure 102 - Swampomyces armeniacus (Material examined - BELIZE. Man-Of-War Cay (Atlantic Ocean). $16^{\circ} 53^{\prime} 00^{\prime \prime} \mathrm{N}, 88^{\circ} 06^{\prime} 15^{\prime \prime} \mathrm{W}$ (16.883, -88.104); Driftwood; collected by J. Kohlmeyer 4619 - NY taxon A, 23 November 1984, NY no.01271822, paratype). a, b Herbarium material. c Ascomata on host substrate. d Ascoma cross section. e Peridium. f Paraphyses. g, h Asci and paraphyses. i-n Ascospores. Scale bars: c, $d=100 \mu \mathrm{m}, \mathrm{e}, \mathrm{g}, \mathrm{h}=50 \mu \mathrm{m}, \mathrm{f}, \mathrm{i}-\mathrm{n}=20 \mu \mathrm{m}$. 
Notes - Crous et al. (2007a) used the BLASTn tool to compare ITS and LSU gene regions with reference sequences, suggesting the placement of Falcocladium in Hypocreales and further considered the genus to be polyphyletic. Jones et al. (2014) introduced the monotypic family Falcocladiaceae which formed a monophyletic clade in Hypocreomycetidae, based on SSU and LSU nuclear genes to accommodate members of Falcocladium. They suggested further taxon sampling to determine its ordinal status. Based on an LSU and SSU combined gene phylogenetic study, Falcocladiaceae was placed in Falcocladiales (Maharachchikumbura et al. 2015). In a phylogenetic analysis by Réblová et al. (2016b), Falcocladiales showed close affinity to Coronophorales and Melanosporales. Several phylogenetic studies showed similar results (Maharachchikumbura et al. 2016b; Réblová et al. 2016b). Currently, the order includes one hyphomycetous genus Falcocladium introduced by Crous et al. (1994a). Falcocladium species can be distinguished based on morphology of vesicular apices of setae which ranges from ellipsoidal, sphaeropedunculate to turbinate and conidial measurements (Somrithipol et al. 2007). No sexual morph has been recorded for the family.

\section{Ecological and economic significance of Falcocladiaceae}

Species in Falcocladium are saprobes on leaves of woody plants. Falcocladium africanum occurs on leaves of Eucalyptus brassiana and E. tereticornis in Ghana and Sierra Leone (Crous et al. 2018c), F. thailandicum occurs on leaves of E. camaldulensis in Thailand (Crous et al. 2007a), $F$. turbinatum occurs on dead leaves of evergreen trees in Thailand (Somrithipol et al. 2007), $F$. spltaeropeduncuiatuln occurs on leaves of E. pellita $\times$ brassiana in Brazil (Crous et al. 1997), $F$. multivesiculatum occurs on leaf litter of E. grandis in Brazil (Crous et al. 1994a). This group plays an important role in degrading plant leaves.

\section{Genus included in Falcocladiaceae}

FalcocladiumS.F. Silveira, Alfenas, Crous \& M.J. Wingf., Mycotaxon 50: 447 (1994)

Index Fungorum number: IF25800; 5 species with sequence data.

Type species - Falcocladium multivesiculatum S.F. Silveira, Alfenas, Crous \& M.J. Wingf.

Notes - Falcocladium includes five species, all of which occur on leaves, namely $F$. africanum, F. multivesiculatum, F. sphaeropedunculatum, F. turbinatum, and $F$. thailandicum. Falcocladium species can be distinguished based on their setal vesicle shape (ellipsoidal, sphaerpedunculate or turbinate) and conidial dimensions. Phylogenetically they are distinct from other genera in the Hypocreomycetidae and form a monophyletic clade (Jones et al. 2014). In this entry we illustrate Falcocladium multivesiculatum. The species $F$. multivesiculatum has a wide host range and mainly occurs on leaves, including Eucalyptus grandis and E. camaldulensis. The fungus is distributed mainly in tropical forests (Somrithipol et al. 2007, Maharachchikumbura et al. 2016b). The taxon fits well within the species concept of Falcocladium with white sporodochia, bearing thick-walled aseptate, stipe extensions and hyaline, 0-1-septate, falcate conidia, with short apical and basal appendages (Crous et al. 1994a, Somrithipol et al. 2007).

Flammocladiellaceae Crous, L. Lombard \& R.K. Schumach., Sydowia 67: 103 (2015) Index Fungorum number: IF819623; Facesoffungi number: FoF06873; 2 species.

Fungicolous on Massaria spp. on corticated branches of Acer spp. Sexual morph: Ascomata perithecial, pale luteous to yellow-orange, aggregated in clusters, on a single stromatic base, covered in a dirty white crustose layer, turning pale luteous to dirty white, $\mathrm{KOH}-$, ostiolate. Ostiole papillate, periphysate. Peridium 3-4 layers of subhyaline, smooth-walled cells of textura angularis. Asci 8-spored, unitunicate, fusoidal-ellipsoidal to subclavate, hyaline, smooth-walled. Ascospores fasciculate, hyaline, fusoidal-ellipsoidal with obtuse ends, septate, warty, not to slightly constricted at septa. Asexual morph: Conidiomata sporodochial, determinate, hyaline, becoming orange. Conidiophores subcylindrical, septate, branched. Conidiogenous cells subcylindrical, terminal and intercalary, hyaline, smooth-walled, proliferating sympodially at apex. Conidia slimy, solitary, 
granular to guttulate, straight to gently curved, subcylindrical to narrowly obclavate, hyaline, smooth-walled (adapted from Crous et al. 2015b).

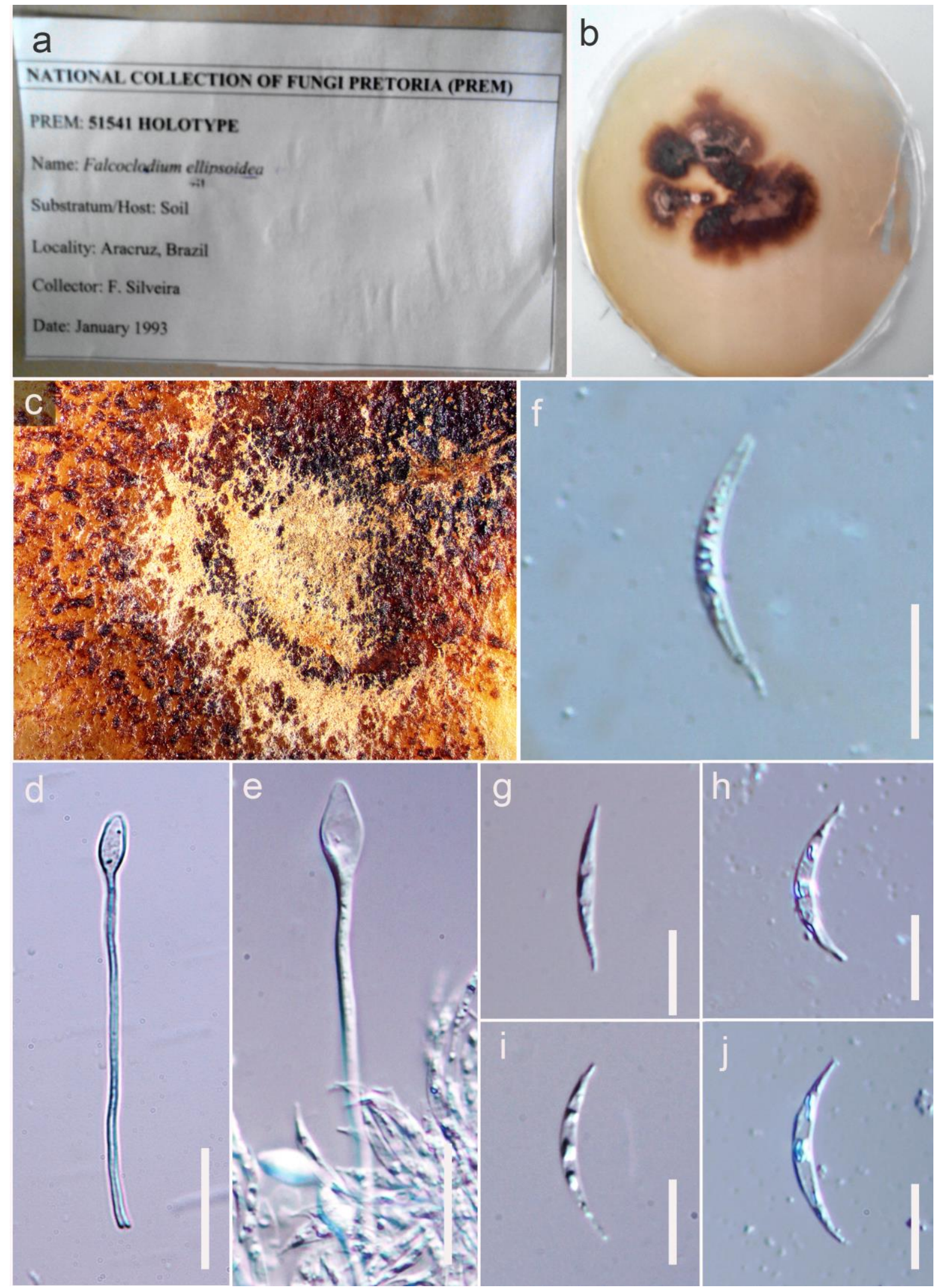

Figure 103 - Falcocladium multivesiculatum (Material examined - BRAZIL, Aracruz, Espirito Santo, from Eucalyptus grandis leaf litter, January 1993 Silvaldo F. Silveira, PREM 51541, holotype). a, c Herbarium material. b Dried culture on MEA. d, e Ellpisoidal vesicles on setae. $\mathrm{f}-\mathrm{j}$ Conidia. Scale bars: $d, e=20 \mu \mathrm{m}, \mathrm{f}-\mathrm{j}=10 \mu \mathrm{m}$. 
Type genus - Flammocladiella Crous, L. Lombard \& R.K. Schumach.

Notes - Flammocladiellaceae was introduced to accommodate the monotypic genus Flammocladiella by Crous et al. (2015b). In the molecular analysis by Hongsanan et al. (2017) and Sun et al. (2017), Flammocladiellaceae grouped within Clavicipitaceae, hence was not treated as a separate family. Further, Hongsanan et al. (2017) synonymized Flammocladiellaceae under Clavicipitaceae based on phylogenetic data and this was followed by Wijayawardene et al. (2018a). However, in the molecular clock analysis by Hyde et al. (2017a) Flammocladiellaceae forms a separate clade sister to Clavicipitaceae with low statistical support. Similar results were obtained from phylogenetic analysis by Maharachchikumbura et al. (2016b) and Lechat \& Fournier (2018). Hence, we would like to treat Flammocladiellaceae as an accepted family within Hypocreales, based on previous treatments and our phylogenetic analysis (Fig. 15).

\section{Ecological and economic significance of Flammocladiellaceae}

Flammocladiella decora is a fungicolous species occurring on immersed ascomata of Massaria species (Lechat \& Fournier 2018b). Currently, there is no data on the economic significance of Flammocladiella species.

\section{Genus included in Flammocladiellaceae}

Flammocladiella Crous, L. Lombard \& R.K. Schumach., Sydowia 67: 103 (2015)

Index Fungorum number: IF812530; 2 morphological species (Species Fungorum 2020), 1 species with sequence data.

Type species - Flammocladiella decora (Wallr.) Lechat \& J. Fourn.

Notes - Flammocladiella was introduced by Crous et al. (2015b) based on a single species $F$. aceris. Lechat \& Fournier (2018b) proposed Flammocladiella decora to accommodate Nectria decora. Flammocladiella decora produces long, subcylindrical conidia and a sexual morph, which are indistinguishable from $F$. aceris (Lechat \& Fournier 2018b). Considering morphological similarities and phylogenetic analyses Lechat \& Fournier (2018b) regarded $F$. aceris as a synonym of $F$. decora. The genus is characterised by yellowish ascomata seated on ascomata of Massaria species, aggregate in clusters, covered by a crustose layer, having a papillate, periphysate ostiolar region, and a sporodochial asexual morph forming flame-like conidial masses, conidia subcylindrical (Crous et al. 2015b, Lechat \& Fournier 2018b).

Fuscosporellaceae J. Yang, J. Bhat \& K.D. Hyde, Cryptogam. Mycol. 37(4): 457 (2016)

Index Fungorum number: IF552321; Facesoffungi number: FoF02421; 14 species.

Saprobic on dead wood mostly in freshwater habitats. Sexual morph: Ascomata immersed, brown, solitary or in small groups, papillate or with a rostrate neck. Ostiole periphysate. Peridium layered, with outer layer brown, inner layers hyaline. Paraphyses septate, hyaline. Asci 8-spored, unitunicate, cylindrical, with a J-, apical ring at the apex. Ascospores uniseriate, fusiform, hyaline or versicolorous, with brown middle cells and hyaline end cells, usually 5-septate, sometimes slightly constricted at the septa and sometimes guttulate. Asexual morph: Hyphomycetous. Colonies effuse or sporodochial, dark brown to black, scattered. Conidiophores macronematous or semi-macronematous, mononematous, branched or unbranched, hyaline, pale brown to mid brown. Conidiogenous cells monoblastic, globose to clavate, terminal, sometimes discrete. Conidia clavate, obovoid or obpyriform, septate, smooth, brown to dark brown; basal cell pale brown, trapeziform or triangular (adapted from Yang et al. 2016b).

Type genus - Fuscosporella J. Yang, J. Bhat \& K.D. Hyde

Notes - The family concept was expanded to include Bactrodesmiastrum, Mucispora, Fuscosporella, Parafuscosporella and two sexual genera Plagiascoma and Pseudoascotaiwania (Boonyuen et al. 2016, Réblová et al. 2016c, Hernández-Restrepo et al. 2017, Hongsanan et al. 2017). Mucispora is characterized by macronematous conidiophores and obovoid dark conidia. The characters shared by Bactrodesmiastrum, Fuscosporella and Parafuscosporella are sporodochial conidiomata, monoblastic conidiogenous cells and brown septate conidia (Hernández-Restrepo et 
al. 2013, 2015a, Yang et al. 2016b). Plagiascoma and Pseudoascotaiwania represent the only known sexual morphs in the order characterized by cylindrical asci, with a J-, apical ring and fusiform ascospores (Fallah et al. 1999, Réblová et al. 2016c). The understanding of Fuscosporellales (Boonyuen et al. 2016, Réblová et al. 2016c, Yang et al. 2016b) requires further collections and molecular data.
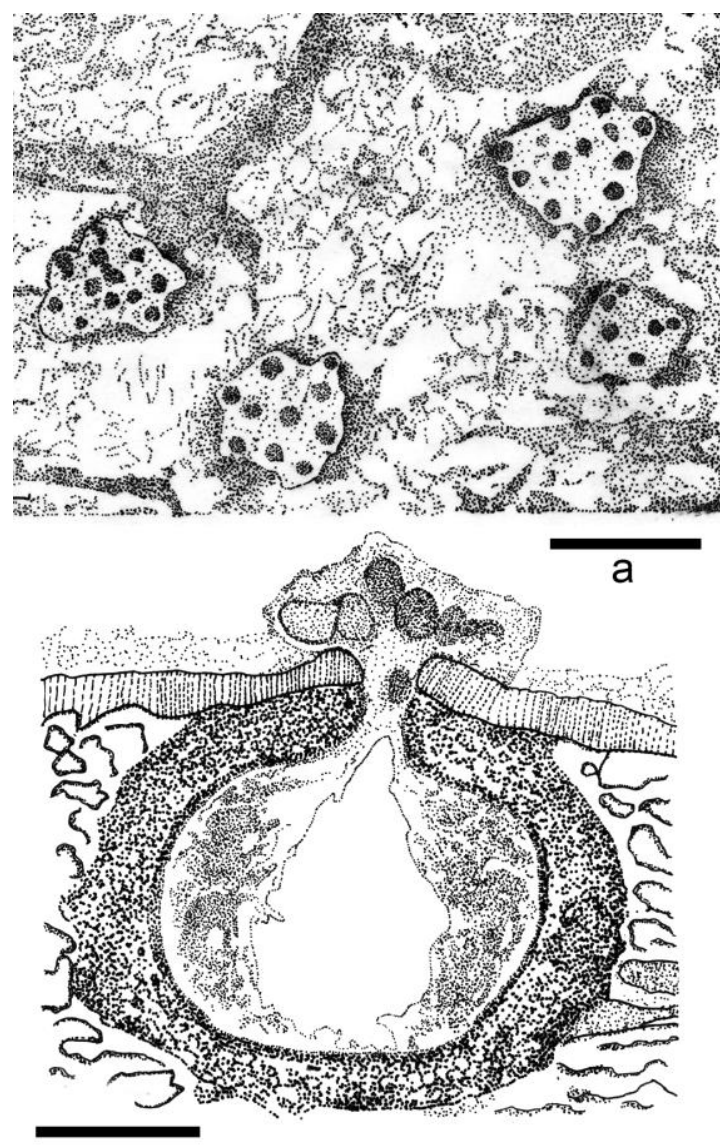

d
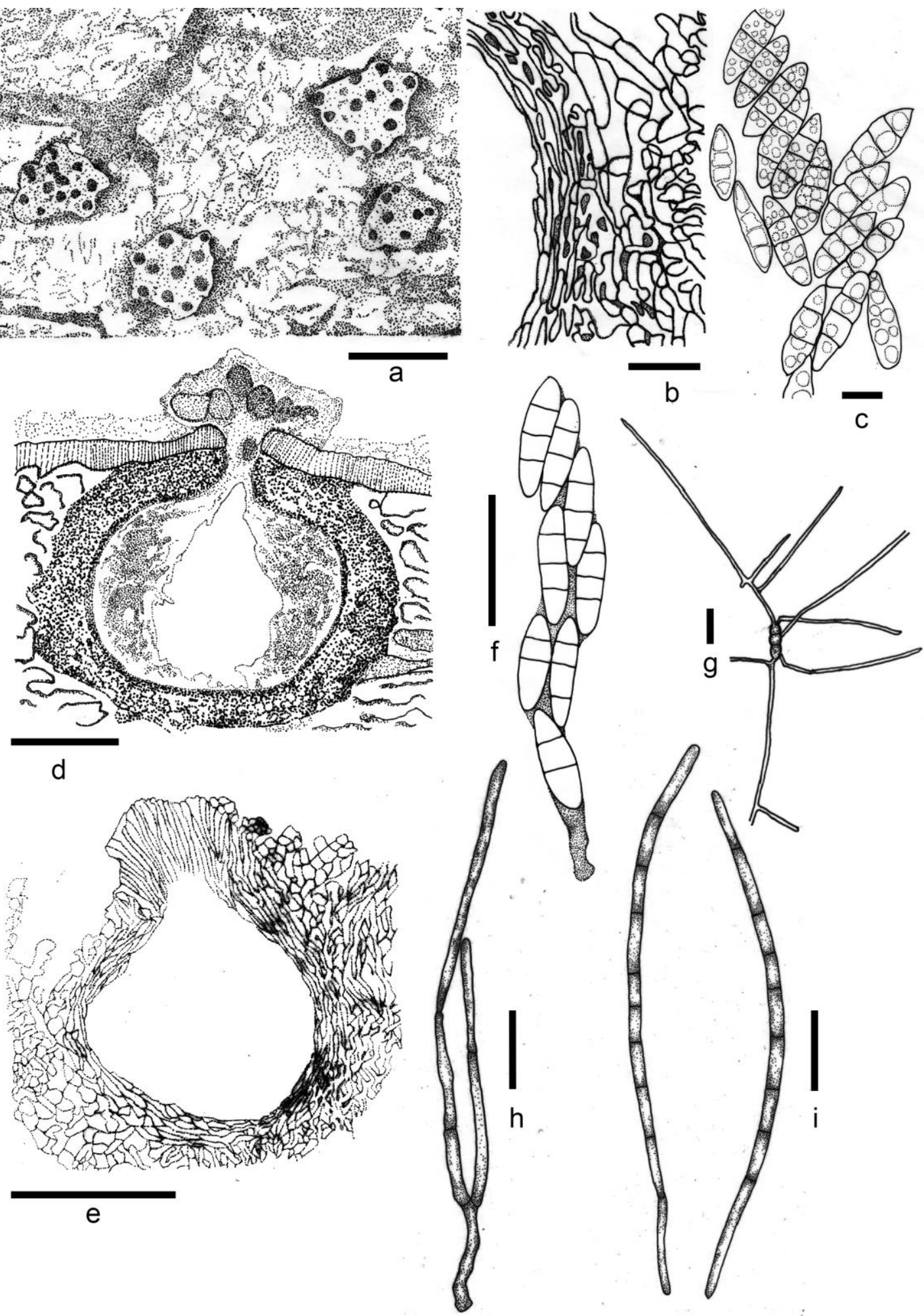

Figure 104 - Flammocladiella decora (CLL16020, holotype, redrawn from Lechat \& Fournier 2018b). a Ascomata on bark. b Vertical section of peridium. c Ascospores. d, e Vertical sections of ascomata. f Ascus. g Germinating spore. h Conidiophores. i Conidia. Scale bars: $a=1000 \mu \mathrm{m}, \mathrm{b}$ $=300 \mu \mathrm{m}, \mathrm{c}=10 \mu \mathrm{m}, \mathrm{d}=400 \mu \mathrm{m}, \mathrm{e}=150 \mu \mathrm{m}, \mathrm{f}=400 \mu \mathrm{m}, \mathrm{g}-\mathrm{i}=20 \mu \mathrm{m}$. 


\section{Ecological and economic significance of Fuscosporellaceae}

Fuscosporellaceae contains saprobic lignicolous taxa found in terrestrial, but mostly in aquatic habitats. They play important roles in decomposition of lignocelluloses in wood (Wong et al. 1998a, Krauss et al. 2011, Hyde et al. 2016a).

\section{Genera included in Fuscosporellaceae}

Bactrodesmiastrum Hol.-Jech., Folia Geobot Phytotax 19 (1): 103 (1984)

Index Fungorum number: IF25786; 5 morphological species (Species Fungorum 2020), 3 species with sequence data.

Type species - Bactrodesmiastrum obscurum Hol.-Jech.

Notes - Bactrodesmiastrum is characterized by solitary or aggregated conidiophores, mostly reduced to brown monoblastic conidiogenous cells, or arising from pulvinate to subpustulate sporodochial conidiomata with moniliform or beaded hyphoid cells and brown, clavate, obovoid or pyriform conidia often with black bands around the septa (Hernández-Restrepo et al. 2015a, Yang et al. 2016b).

Fuscosporella J. Yang, J. Bhat \& K.D. Hyde, Cryptog Mycol 37(4): 457 (2016)

Index Fungorum number: IF552289; 2 species with sequence data.

Type species - Fuscosporella pyriformis J. Yang, J. Bhat \& K.D. Hyde

Notes - Fuscosporella is morphologically similar to Parafuscosporella, but differs in the conidia which are produced in culture. Fuscosporella produced multi-celled, lamentous to helicoid conidia in culture, while Parafuscosporella produce globose to obpyriform, uniseptate conidia in culture (Yang et al. 2016b). Molecular data provided further evidence for their segregation.

Mucispora J. Yang, J. Bhat \& K.D. Hyde, Cryptog Mycol 37(4): 466 (2016)

Index Fungorum number: IF552293; 2 species with sequence data.

Type species - Mucispora obscuriseptata J. Yang, J. Bhat \& K.D. Hyde

Notes - Mucispora is similar to Monotosporella in having macronematous, mononematous conidiophores, monoblastic conidiogenous cells and brown, ellipsoidal, clavate or obovoid conidia. However, they are phylogenetically distinct. Phylogenetic studies showed Mucispora grouped in Fuscosporellales (Yang et al. 2016b, 2017), while Monotosporella clustered within Pleurotheciales (Hernández-Restrepo et al. 2017). In this entry we introduced a new species, Mucispora infundibulata.

Mucispora infundibulata J. Yang \& K.D. Hyde, sp. nov.

Fig. 105

Index Fungorum number: IF554769; Facesoffungi number: FoF04674

Etymology - Referring to the infundibular conidiogenous cells.

Holotype - MFLU 18-0142.

Saprobic on decaying, submerged twigs. Sexual morph: Undetermined. Asexual morph: Colonies on substrate sparse, scattered, glistening, black. Mycelium mostly immersed, consisting of septate, smooth, pale brown to hyaline hyphae. Conidiophores macronematous, mononematous, solitary, straight, erect, smooth, mid brown, pale brown to hyaline and inflated at the apex, guttulated, 1-2-septate, 50-65 × 4-6 $\mu \mathrm{m}(\bar{x}=60 \times 5 \mu \mathrm{m}, \mathrm{n}=10), 10-12.5 \mu \mathrm{m}$ wide at the apex, with bulbous base. Conidiogenous cells monoblastic, integrated, terminal, cupulate or infundibulate, pale brown to hyaline, guttulate. Conidia acrogenous, smooth, broadly ellipsoidal to obovoid, 3-euseptate, constricted at the septa when young, with unobservable septa when mature, truncate at the base, $(22-) 29-34 \times(15-) 19-21 \mu \mathrm{m}(\bar{x}=31 \times 20 \mu \mathrm{m}, \mathrm{n}=10)$.

Culture characteristics - Conidia germinating on PDA within $24 \mathrm{~h}$. Germ tubes produced from the conidial base. Colonies on PDA, reaching 5-10 mm diameter after one month at $25{ }^{\circ} \mathrm{C}$ in natural light, circular, with brown, greyish-green, white and dark brown mycelium from inner to outer circle; dark brown in reverse with entire margin. Hyphae subhyaline to pale brown, sometimes constricted at the septa, (4-)6-10(-14) $\mu \mathrm{m}$ wide. Conidiophores reduced to a 
monoblastic conidiogenous cell. Conidiogenous cells $8-10.5 \times 3.3-4.8 \mu \mathrm{m}$, integrated, subhyaline to pale brown. Conidia (18-)23-35.5(-40) $\times(9.5-) 12-17(-19) \mu \mathrm{m}(\bar{x}=31 \times 14 \mu \mathrm{m}, \mathrm{n}=20)$, pale brown to mid brown, 1-3-septate, mostly 2-septate, globose to obovoid, with cells becoming bigger towards the apical cell, smooth, constricted at the septa.
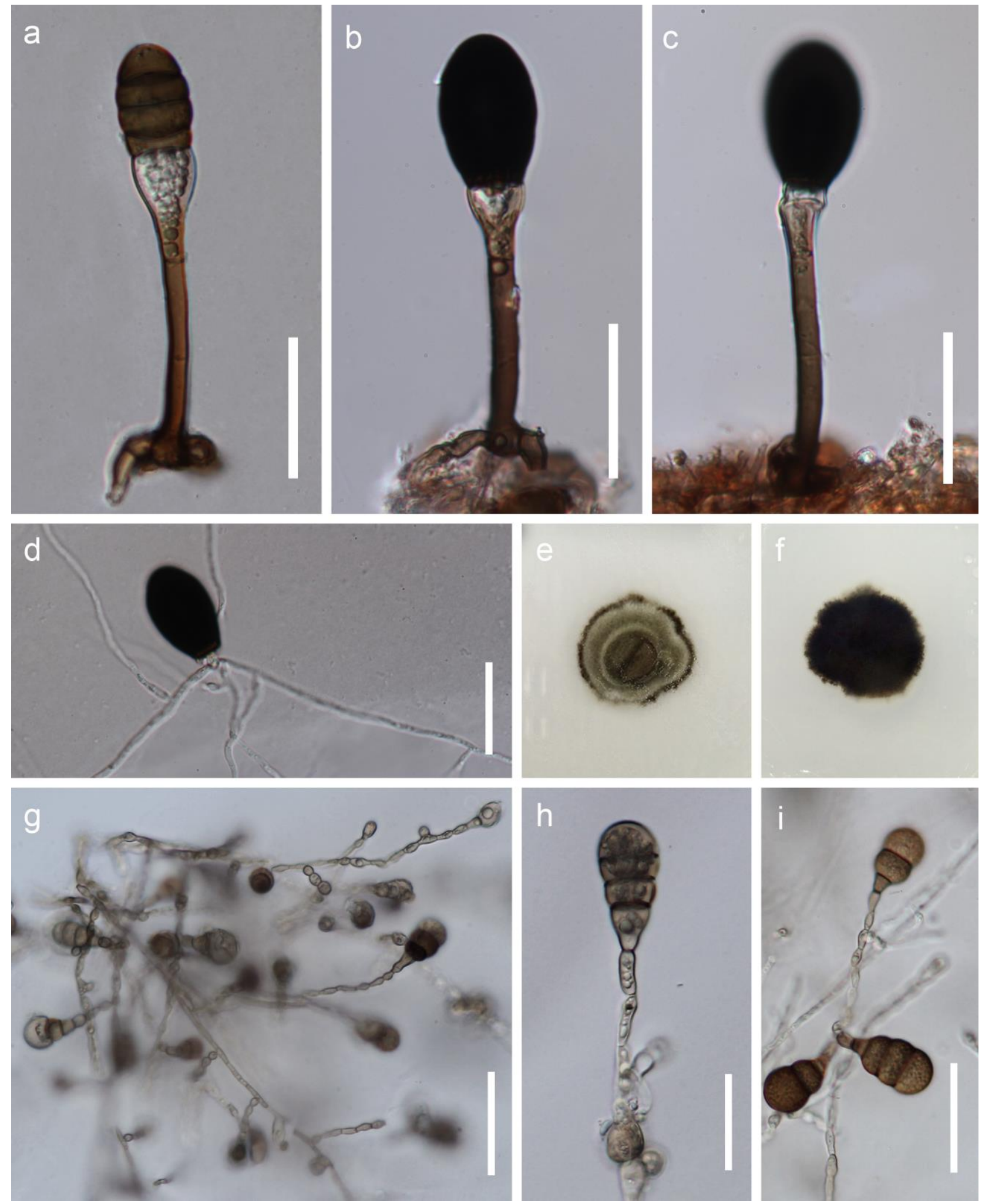

Figure 105 - Mucispora infundibulata (MFLU 18-0142, holotype). a-c Conidia and conidiophores. d Germinated conidium. e, f Cultures, e from above, f from below. g-i Asexual morph in culture. Scale bars: $\mathrm{a}-\mathrm{d}, \mathrm{h}=30 \mu \mathrm{m}, \mathrm{g}, \mathrm{i}=50 \mu \mathrm{m}$. 
Material examined - THAILAND, Phang Nga Province, Bann Tom Thong Khang, on decaying wood submerged in a freshwater stream, 17 December 2015, J. Yang, Site 7-21-3, MFLU 18-0142, holotype, HKAS 102139, isotype; ex-type living cultures MFLUCC 16-0866, GZCC 170021.

GenBank numbers - ITS: MH457174, LSU: MH457139, SSU: MH457171.

Notes - Mucispora infundibulata resembles Melanocephala australiensis in conidial shape and size (Hughes 1979). Mucispora infundibulata was placed as a sister taxon to Mucispora phangngaensis with strong support (Fig. 10).Conidiophores of Melanocephala australiensis are initially 18-30 $\mu \mathrm{m}$ long, but can reach $100 \mu \mathrm{m}$ by percurrent elongation, while conidiophores of Mucispora infundibulata are mostly around $60 \mu \mathrm{m}$ long. The obvious difference is the inflated cupulate conidiogenous cells in Mucispora infundibulata compared to flared, percurrent proliferating in Melanocephala australiensis.

Parafuscosporella J. Yang, J. Bhat \& K.D. Hyde, Cryptog Mycol 37(4): 458 (2016)

Index Fungorum number: IF552292; 3 species with sequence data.

Type species - Parafuscosporella moniliformis J. Yang, J. Bhat \& K.D. Hyde

Notes - Parafuscosporella resembles Fuscosporella based on their almost similar morphology. However, the two genera are phylogenetically distinct (Fig. 10) and can be distinguished by the morphology of conidia which are produced in culture. Among the three accepted species, conidia of $P$. garethii are obpyramidal, coronate at the apex with conical projections, while those of $P$. moniliformis and $P$. mucosa are obovoid to obpyriform (Boonyuen et al. 2016, Yang et al. 2016b).

Plagiascoma Réblová \& J. Fourn., Persoonia 37:69 (2016)

Index Fungorum number: IF813234; 1 species with sequence data.

Type species - Plagiascoma frondosum Réblová \& J. Fourn.

Notes - Plagiascoma and Pseudoascotaiwania are monotypic sexual genera in Fuscosporellaceae. The sexual morph of Plagiascoma frondosum (Fig. 106) resembles Pseudoascotaiwania persoonii in having cylindrical asci with a $\mathrm{J}$-, apical ring and uniseriate (in fresh material), euseptate, fusiform ascospores. Ascospores of Plagiascoma frondosum are hyaline and 3-5-septate, while those of Pseudoascotaiwania persoonii are 5-septate, rarely 6-septate and have light brown central cells and hyaline end cells (Fallah et al. 1999, Réblová et al. 2016c).

Pseudoascotaiwania J. Yang, J. Bhat \& K.D. Hyde, Cryptog Mycol 37(4): 471 (2016)

Index Fungorum number: IF552323; 1 species with sequence data.

Type species - Pseudoascotaiwania persoonii (Fallah, J.L. Crane \& Shearer) J. Yang, J. Bhat \& K.D. Hyde

Notes - Pseudoascotaiwania, introduced with the type species $P$. persoonii, was transferred from Ascotaiwania without known asexual morphs. The genus is characterised by 5-septate, rarely 6-septate ascospores with light brown, central cells and hyaline end cells.

Glomerellaceae Locq., Mycologia 98(6): 1083 (2007)

Index Fungorum number: IF80186; Facesoffungi number: FoF01100; 894 species.

Parasitic, endophytic and saprobic on plant leaves, stems and fruits. Sexual morph: Ascomata solitary or gregarious, globose to subglobose, dark brown to black, ostiole periphysate. Peridium composed of pale to medium brown flattened cells of textura angularis. Paraphyses composed of hyaline, septate, branched at the base, rounded at the apex. Asci 8-spored, unitunicate, cylindrical to subfusoid, short pedicellate, with a J-, refractive ring at the apex, Ascospores uni- to biseriate, hyaline, aseptate, smooth-walled, cylindrical, oval, fusiform or rhomboid, straight or curved, one end \pm acute and one end rounded or both ends rounded. Asexual morph: Coelomycetous. Conidiomata acervular, ranging from sporodochia-like aggregations to closed conidiomata that open by rupture, conidiophores and setae formed on cushions of pale to medium brown, roundish to 
angular cells. Setae may or may not be present, straight, pale to dark brown, sometimes hyaline towards the tip, smooth-walled, verruculose to verrucose, 1-8-septate, base cylindrical, conical or slightly inflated, tip \pm rounded to \pm acute. Conidiophores hyaline to pale brown, simple or septate, branched or unbranched, smooth-walled, sometimes verruculose. Conidiogenous cells enteroblastic, hyaline to pale brown, smooth-walled, discrete, ampulliform, cylindrical, doliiform or ellipsoidal, collarette usually distinct, periclinal thickening visible to conspicuous, sometimes extending to form new conidiogenous loci (percurrent) or surrounded by a gelatinous coating. Conidia hyaline, smooth-walled, aseptate, cylindrical, clavate, fusiform, sometimes ellipsoidal to ovoid, straight or curved, apex rounded to acute, sometimes with a filiform appendage, base rounded to truncate, sometimes with a prominent hilum. Appressoria single or in small groups, pale to dark brown, with a globose, elliptical, clavate, navicular or irregular outline and an entire, undulate or lobate edge (adapted from Maharachchikumbura et al. 2016b).
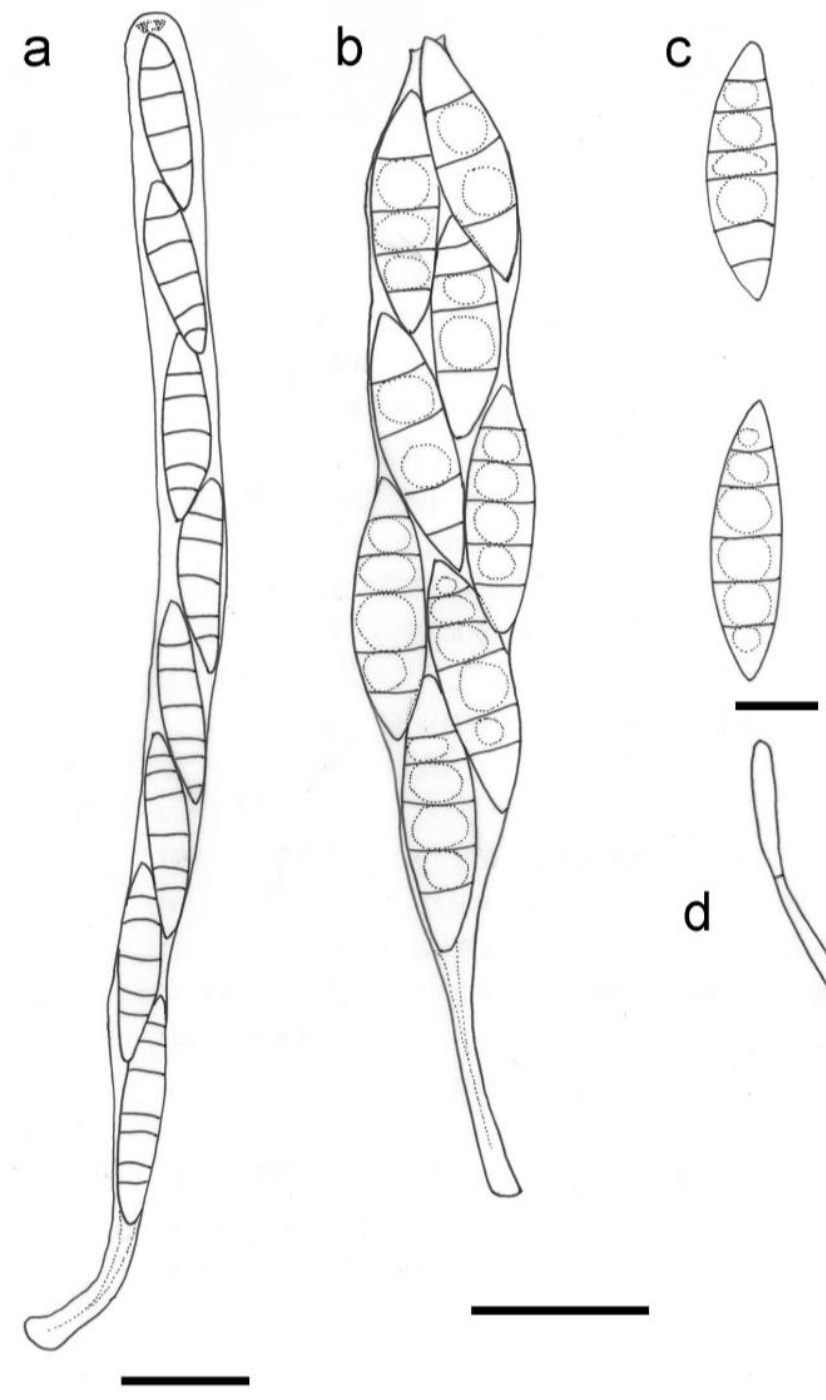

Figure 106 - Plagiascoma frondosum (Redrawn from Réblová et al. 2016c). a, b Asci. c Ascospores. $d$ Paraphyses. Scale bars: $\mathrm{a}=25 \mu \mathrm{m}, \mathrm{b}=20 \mu \mathrm{m}, \mathrm{c}, \mathrm{d}=10 \mu \mathrm{m}$.

Type genus - Colletotrichum Corda

Notes - The ordinal name Glomerellales including Colletotrichum (= Glomerella) and three other genera in a non-ranked group "Eu-Glomérellales" was introduced by Chadefaud (1960), but was not validly published. Earlier classification placed Colletotrichum in Phyllachoraceae (Ainsworth 1971, Barr 1983, Hawksworth et al. 1983). However, due to its astromatic nature, it has long been considered to be an outlier within Phyllachoraceae (Cannon 1991). The family name 
Glomerellaceae was invalidly published by Locquin (1984) and was ignored until preliminary sequence-based studies and ontogenic research confirmed that Colletotrichum and Phyllachora did not belong to the same order (Uecker 1994). In the $9^{\text {th }}$ edition of the Dictionary of Fungi the family name Glomerellaceae was adopted and placed with an uncertain position within the subclass Sordariomycetidae (Kirk et al. 2001). Zhang et al. (2006) validated Glomerellaceae with a Latin description, while placing it within Hypocreomycetidae. Kirk et al. (2008) placed this family as an uncertain position in the subclass Hypocreomycetidae. The phylogenetic position of Glomerellaceae was further clarified and validated by Réblová et al. (2011) in a study using ITS, LSU, SSU and rpb2 genes and two new families, Australiascaceae and Reticulascaceae, occupied a common clade with Glomerellaceae. Maharachchikumbura et al. (2016b) provided evidence for the phylogenetic position of Glomerellaceae within Glomerellales. This family is monotypic with the single genus Colletotrichum.

\section{Ecological and economic significance of Glomerellaceae}

Colletotrichum includes many plant pathogens of major importance causing diseases of a wide variety of plants (Cannon et al. 2012b, Jayawardena et al. 2016, Marin-Felix et al. 2017). Fruit production is especially affected.

\section{Genus included in Glomerellaceae}

Colletotrichum Corda, Deutschl. Fl., 3 Abt. (PilzeDeutschl.) 3(12): 41 (1831)

Index Fungorum number: IF7737; 894 morphological species (Species Fungorum 2020 ), $<250$ species with sequence data (Jayawardena et al. 2016).

Type species - Colletotrichum lineola Corda

Notes - Colletotrichum is the asexual morph of Glomerella, but Colletotrichum was selected for conservation by Maharachchikumbura et al. (2015). In this entry we introduced a new species, Colletotrichum orchidis.

Colletotrichum orchidis Jayaward., Camporesi \& K.D. Hyde, sp. nov.

Fig. 108

Index Fungorum number: IF556214; Facesoffungi number: FoF05784

Etymology - Refers to the host genus.

Holotype - MFLU 16-2551.

Saprobic on aerial stem of Orchis sp. Sexual morph: Undetermined. Asexual morph: Coelomycetous. Conidiomata 55-135 $\mu \mathrm{m}(\bar{x}=95 \mu \mathrm{m}, \mathrm{n}=10)$ diam., black, acervulus, oval, solitary or gregarious, comprising dark brown, roundish cells from which setae and conidiophores develop. Setae straight or \pm bent, abundant, dark brown to light brown, becoming paler towards the apex, smooth-walled, 3-5-septate, $105 \mu \mathrm{m}$ long, base cylindrical, slightly inflated, $5.6 \mu \mathrm{m}$ diam, apex acute to rounded. Chlamydospores not observed. Conidiophores simple, to $65 \mu \mathrm{m}$ long, hyaline to pale brown, smooth-walled. Conidiogenous cells $8-11 \times 3.1-4.4 \mu \mathrm{m}(\bar{x}=10.5 \pm 1.8 \times$ $3.6 \pm 0.4 \mu \mathrm{m}, \mathrm{n}=20$ ), hyaline, smooth-walled, cylindrical to slighty inflated, opening $0.5-1 \mu \mathrm{m}$ wide, collarette or periclinal thickening not observed. Conidia 15.9-20.3 $\times 1.9-3.2 \mu \mathrm{m}(\bar{x}=18.2 \pm$ $1.5 \times 2.5 \pm 0.6 \mu \mathrm{m}, \mathrm{n}=40), \mathrm{L} / \mathrm{W}$ ratio 7.3 , hyaline, smooth or verruculose, aseptate, very variable in size and shape, some strongly curved, strongly curved towards the often broadly rounded apex than towards the truncate base, some small conidia almost straight, guttulate. Appressoria 8.2-13.1 $\times 4.5-8.2 \mu \mathrm{m}(\bar{x}=11.5 \pm 3.2 \times 4.9 \pm 1.4 \mu \mathrm{m}, \mathrm{n}=10), \mathrm{L} / \mathrm{W}$ ratio 2.3 , solitary or in loose groups, single-celled, olivaceous brown to dark brown, irregularly-shaped, but often globose or clavate, smooth-walled.

Culture characteristics - Colonies on PDA flat with entire margin, aerial mycelium sparse, short, pale olivaceous-grey, iron-grey acervuli can be observed mainly on the edge of the colony after 7 days; reverse olivaceous green, reaching $60-75 \mathrm{~mm}$ in $7 \mathrm{~d}$ at $18{ }^{\circ} \mathrm{C}$.

Material examined - ITALY, Province of Forlì-Cesena, near Premilcuore, on living dead aerial stem of Orchis sp. (Orchidaceae), 5 October 2016, E. Camporesi IT3118 (MFLU 16-2551, holotype), extype-living culture MFLUCC 17-1302; ibid cultures KUMCC 17-0119, JZB330118. 
GenBank numbers - ITS: MK502144, gapdh: MK496857, CHS: MK496855, act: MK496853, tub2: MK496859 (MFLUCC 17-1302), ITS: MK502143, gapdh: MK496858, CHS: MK496856, act: MK496854, tub2: MK496860 (JZB330118).

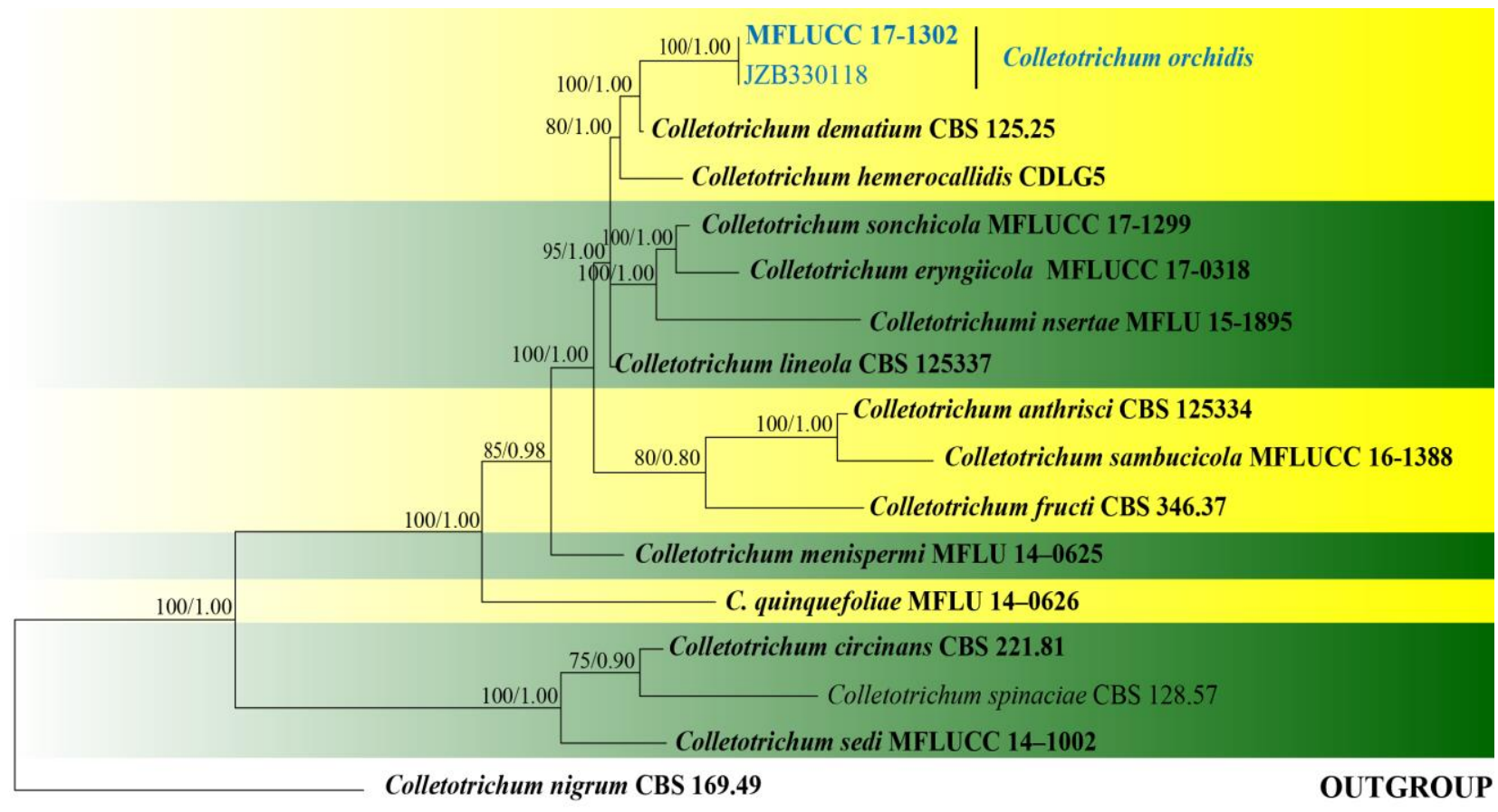

40.0

Figure 107 - One of the 100 most phylogenetic tree generated by maximum parsimony analysis of combined ITS, GAPDH, CHS, ACT and $\beta$-tubulin sequenced data of dematium species complex. Seventeen strains are included in the analyses, which comprise 1780 characters including gaps (509 characters for ITS, 267 characters for GAPDH, 250 characters for CHS, 237 characters for ACT, 501 characters for $\beta$-tubulin) after alignment. Colletotrichum nigrum (CBS 169.49, Glomerellaceae, Glomerellales) is used as the outgroup taxon and the tree is rooted with. Single gene analyses were carried out and the topology of each tree had clade stability. Tree topology of the maximum parsinmony analysis is similar to Bayesian analysis. The maximum parsimonious dataset consisted of 1182 constant, 343 parsimony-informative and 255 parsimony-uninformative characters. The parsimony analysis of the data matrix resulted in the maximum often equally most parsimonious trees with a length of 939 steps $(\mathrm{CI}=0.804, \mathrm{RI}=0.774, \mathrm{RC}=0.623, \mathrm{HI}=0.196)$ in the first tree. Bootstrap support values for MP greater than $75 \%$ and Bayesian posterior probabilities greater than 0.90 are given near nodes respectively. Ex-type strains are in bold and black. The newly generated sequences are indicated in blue.

Notes - Colletotrichum orchidis is only known from aerial stem of Orchis in Italy. The conidia of this species resemble those of several species complexes in Colletotrichum (e.g. dematium species complex, graminicola species complex, spaethianum species complex and truncatum species complex) (Jayawardena et al. 2016). Based on DNA sequences, $C$. orchidis falls within the $C$. dematium species complex clade and forms a separate branch as a sister taxon of $C$. dematium (Fig. 107). A BLASTn search of NCBI GenBank with the ITS sequence of the new species, showed $96 \%$ similarity to several Colletotrichum species with curved conidia. The closest match in a BLASTn search in GenBank with the gapdh sequence of the new species showed 99\% similarity to $C$. dematium (2bp differences) and $C$. lineola (4bp differences). $C H S$ sequence showed a $98 \%$ similarity to $C$. dematium ( 6 bp differences) and $C$. insertae ( 7 bp differences) and act sequences also showed a $98 \%$ similarity to $C$. dematium ( 4 bp differences). tub2 sequence showed $99 \%$ similarity to $C$. dematium (1bp differences) and C. lineola (1 bp difference). Colletotrichum 
orchidis differs from $C$. dematium by smaller conidia and a lower $\mathrm{L} / \mathrm{W}$ value $(C$. dematium $21.3 \times$ $3.5, \mathrm{~L} / \mathrm{W}=6.0)$.

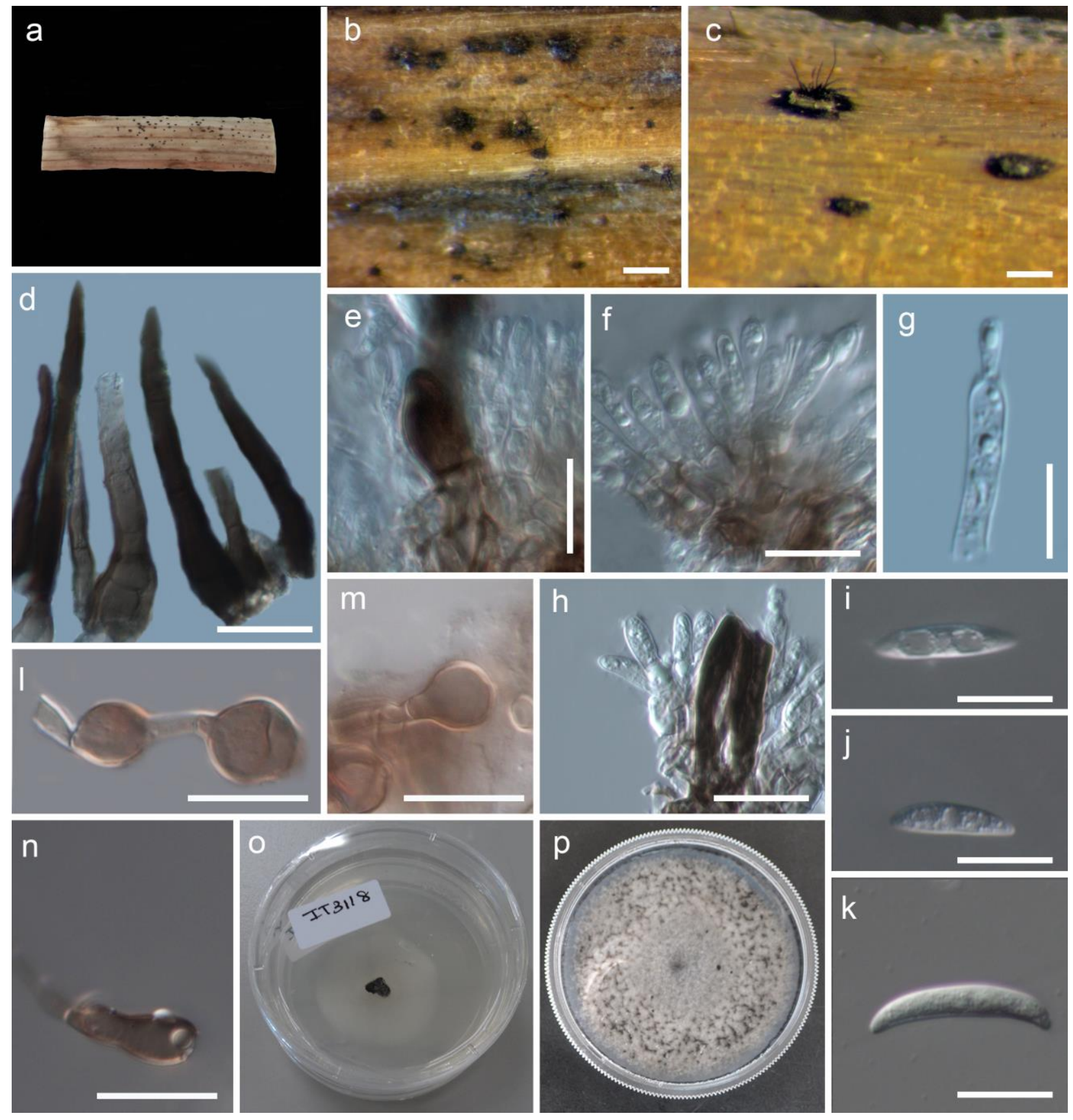

Figure 108 - Colletotrichum orchidis (MFLUCC 17-1302, holotype). a-c Appearance of conidiomata on host. d Setae. e Base of seta. $\mathrm{f}$, h Conidiophores. g Conidiogenous cell. i-k Conidia. l-n Appressoria. o 3 day old culture on PDA. p 10 day old culture on PDA. Scale bars: b, c $=200$ $\mu \mathrm{m}, \mathrm{d}, \mathrm{f}, \mathrm{h}=20 \mu \mathrm{m}, \mathrm{e}, \mathrm{g}, \mathrm{i}-\mathrm{k}, \mathrm{l}-\mathrm{n}=10 \mu \mathrm{m}$.

Gnomoniaceae G. Winter, Rabenh. Krypt.-Fl., Edn 2 (Leipzig) 1.2: 570 (1886)

Index Fungorum number: IF80810; Facesoffungi number: FoF06299; 485 species.

Saprobic on bark and leaves of overwintered plants. Sexual morph: Stromata lacking, or poorly to well-developed, scattered, erumpent, pustuliform with one or rarely two ascomata or valsoid, broadly elliptic to rounded, large. Ectostromata well-developed, brown to black, thick ectostromatic disc at perithecial necks. Ascomata immersed to erumpent, solitary or aggregated, globose to subglobose, black, coriaceous, thin-walled, with one or more long, central or eccentric necks with hyaline periphyses. Peridium comprising few layers of brown, thick-walled cells of 
textura angularis. Paraphyses few, hyaline, septate, cellular. Asci 8-32-spored, unitunicate, oval, fusiform to almost filiform, short pedicellate, with a distinct, J-, apical ring. Ascospores biseriate, overlapping uniseriate to fasciculate, hyaline, oval, fusiform, ovoid to subulate, small, unicellular to 1-septate, rarely multiseptate, ends mostly rounded, rarely pointed, appendages absent or subulate, navicular or whip-shaped, smooth-walled. Asexual morph: Coelomycetous. Conidiomata acervuli or pycnidial, subcuticular, papillate or not, oblate to globose, black, thick-walled, with one chamber containing whitish conidial mass. Conidiophores simple, filiform to fusiform, annellations visible or invisible, densely branched. Conidiogenous cells usually phialidic, rarely with a few annellidic scars, irregular in shape, lageniform to cylindrical, gradually tapering to ends for one quarter to three quarters of their length, or abruptly narrowing to long neck at about half of the phialide length, or abruptly narrowing at apex, straight or curved, sometimes asymmetric swollen nodes, proliferating into other conidiogenous cells at basal or middle part. Conidia broadly ellipsoid to oval, sometimes obovoid, allantoid, occasionally curved or sinuate to slightly angular, hyaline, often unicellular (adapted from Senanayake et al. 2018).

Type genus - Gnomonia Ces. \& De Not.

Notes - Gnomoniaceae was introduced to accommodate fungal species having upright perithecia with or without long or short neck and presence or absence of stromatic tissues (Winter 1886). Species in this family are pathogens or endophytes in leaves of herbaceous or woody trees (Rossman et al. 2007). Betulaceae, Fagaceae, and Salicaceae are the most common host families for the gnomoniaceous taxa (Mejia et al. 2011). Gnomoniaceae comprises 34 genera (Senanayake et al. 2018, Minoshima et al. 2018).

\section{Ecological and economic significance of Gnomoniaceae}

Species in Gnomoniaceae mainly occur on living, fallen or attached, overwintered leaves and petioles, leaf blades or herbaceous stems and rarely on woody substrates (Sogonov et al. 2008). Members of this family are mostly reported from temperate regions. They occur as endophytes of woody plants or pathogens causing disease to economically important hardwood trees (Danti et al. 2002, Green 2004, Moricca \& Ragazzi 2008). Sycamore anthracnose by Apiognomonia veneta, strawberry stem rot by Gnomoniopsis fructicola, foliar disease of birch and dieback of young shoots by Discula betulae, and walnut anthracnose is caused and leaf blotch disease by Ophiognomonia leptostyla are common diseases caused by members of this family (Maas 1998, Green 2004, Green \& Castlebury 2007, Pennycook 2007).

\section{Genera included in Gnomoniaceae}

Alnecium Voglmayr \& Jaklitsch, Persoonia 33: 76 (2014)

Index Fungorum number: IF805342; 1 species with sequence data.

Type species - Alnecium auctum (Berk. \& Broome) Voglmayr \& Jaklitsch

Notes - Alnecium was introduced and typified by A. auctum (Voglmayr \& Jaklitsch 2014) which was collected from corticated dead branches of overwintered plants. Alnecium auctum is considered as a saprobe (Voglmayr \& Jaklitsch 2014). The genus is characterized by immersed stroma host tissues and fusiform ascospores (Senanayake et al. 2017a).

Ambarignomonia Sogonov, Stud. Mycol. 62: 35 (2008)

Index Fungorum number: IF512170; 1 species with sequence data.

Type species - Ambarignomonia petiolorum (Schwein.) Sogonov

Notes - This is a pathogen on petioles and leaves of Liquidambar styraciflua. Ambarignomonia is distinguished from other genera in Gnomoniaceae by the whitish powdery collar surrounding the central neck (Sogonov et al. 2008).

Amphiporthe Petr., Sydowia 24(1-6): 257 (1971)

Index Fungorum number: IF169; 3 morphological species (Species Fungorum 2020), 2 species with sequence data and molecular data available for an unnamed species. 
Type species - Amphiporthe hranicensis (Petr.) Petr.

Notes - Amphiporthe is one of the well-developed stromatic genus in Gnomoniaceae which currently comprises three species (Senanayake et al. 2018). However only A. hranicensis and A. raveneliana (Thüm. \& Rehm) M.E. Barr have molecular data.

Anisomyces Theiss. \& Syd., Annls mycol. 12(3): 270 (1914)

Index Fungorum number: IF202; 2 morphological species (Species Fungorum 2020).

Type species - Anisomyces papilloideoseptatus (Henn.) Theiss. \& Syd.

Notes - Petrak (1947b) emended this genus with Anisomyces papilloideoseptatus as a synonym of A. nectrioides. This genus is morphologically distinct from other genera in having stromatic tissues surrounding the short beak and brown, apiosporous ascospores (Barr 1978). Anisomyces also comprises A. theissenii.

Apiognomonia Höhn., Ber. dt. bot. Ges. 35(8): 635 (1917)

Index Fungorum number: IF257; 23 morphological species (Species Fungorum 2020), 7 species with sequence data.

Type species - Apiognomonia veneta (Sacc. \& Speg.) Höhn.

Notes - The asexual morph of Apiognomonia has been reported as discula-like (Sogonov et al. 2007). Apiognomonia is the causative agent of several serious diseases such as sycamore cankers or plane tree anthracnose on some overwintered plant families (Sogonov et al. 2007).

Apioplagiostoma M.E. Barr, Mycol. Mem. 7: 101 (1978)

Index Fungorum number: IF258; 3 species with sequence data.

Type species - Apioplagiostoma populi (E.K. Cash \& Waterman) M.E. Barr

Notes - Apioplagiostoma was introduced by Barr (1978) for Plagiostoma populi, Sphaerella acerifera and Plagiostomella carpinicola, considering their morphological distinctness. However, Plagiostomella carpinicola was transferred to Gnomonia. Apioplagiostoma populi is the causative agent of bronze leaf disease of Populus (Senanayake et al. 2018).

Asteroma DC., Fl. franç., Edn 3 (Paris) 6: 162 (1815)

Index Fungorum number: IF7260; 62 morphological species (Species Fungorum 2020), 2 species with sequence data and molecular data available for an unnamed species.

Type species - Asteroma phyteumatis DC.

Notes - Asteroma is an asexual morph genus, characterized by filiform to fusiform conidia (Senanayake et al. 2017a) and its sexual morph is not clearly determined. This genus lacks sufficient molecular data to demarcate its species boundaries.

Bagcheea E. Müll. \& R. Menon, Phytopath. Z. 22(4): 417 (1954)

Index Fungorum number: IF490; 3 morphological species (Species Fungorum 2020).

Type species - Bagcheea castaneae E. Müll. \& R. Menon

Notes - This genus comprises three species Bagcheea taiwanensis and B. albomaculans, together with its type species. Bagcheea is distinguishable from the other genera of Gnomoniaceae by its conspicuous ascospores, which contain granular cytoplasm is divided into two parts, with the wider space forming a diplastic polarity (Senanayake et al. 2017a).

Chadefaudiomyces Kamat, V.G. Rao, A.S. Patil \& Ullasa, Revue Mycol., Paris 38(1-2): 19 (1974)

Index Fungorum number: IF929; 1 morphological species.

Type species - Chadefaudiomyces indicus Kamat, V.G. Rao, A.S. Patil \& Ullasa

Notes - Based on the distinct characters of Gnomoniaceae, Senanayake et al. (2017a) accommodated this genus within Gnomoniaceae. The fungus was from living leaves of Celastrus paniculata (Ullasa et al. 1974). 
Clypeoporthe Höhn., Sber. Akad. Wiss. Wien, Math.-naturw. Kl., Abt. 1 128(7-8): 584 (1919)

Index Fungorum number: IF431517; 8 morphological species (Species Fungorum 2020).

Type species - Clypeoporthe monocarpa Höhn.

Notes - Clypeoporthe was introduced and typified by $C$. monocarpa. There are eight species listed under this genus (Species fungorum 2020). However, some species in this genus have eutypelloid configuration of ascomata in parenchymatous stromatic tissues. Clypeoporthe was reduced to synonymy in Gnomonia by Monod (1983) while Kirk et al. (2008) mentioned Clypeoporthe is the sexual morph of Phaeocytostroma. However, this is not proved by cultural examination or molecular data and it is necessary to obtain DNA sequence data to resolve this genus. Until that Senanayake et al. (2017a, 2018), Wijayawardhene et al. (2018) accepted this genus within Gonomoniaceae.

Cryptosporella Sacc., Michelia 1(no. 1): 30 (1877)

Index Fungorum number: IF1333; 33 morphological species (Species Fungorum 2020), 20 species with sequence data and molecular data available for an unnamed species.

Type species - Cryptosporella hypodermia (Fr.) Sacc.

Notes - Cryptosporella species are from temperate regions and are saprobic, endophytic and occasionally pathogenic on hardwood trees (Mejia et al. 2011). Cryptosporella hypodermia is illustrated.

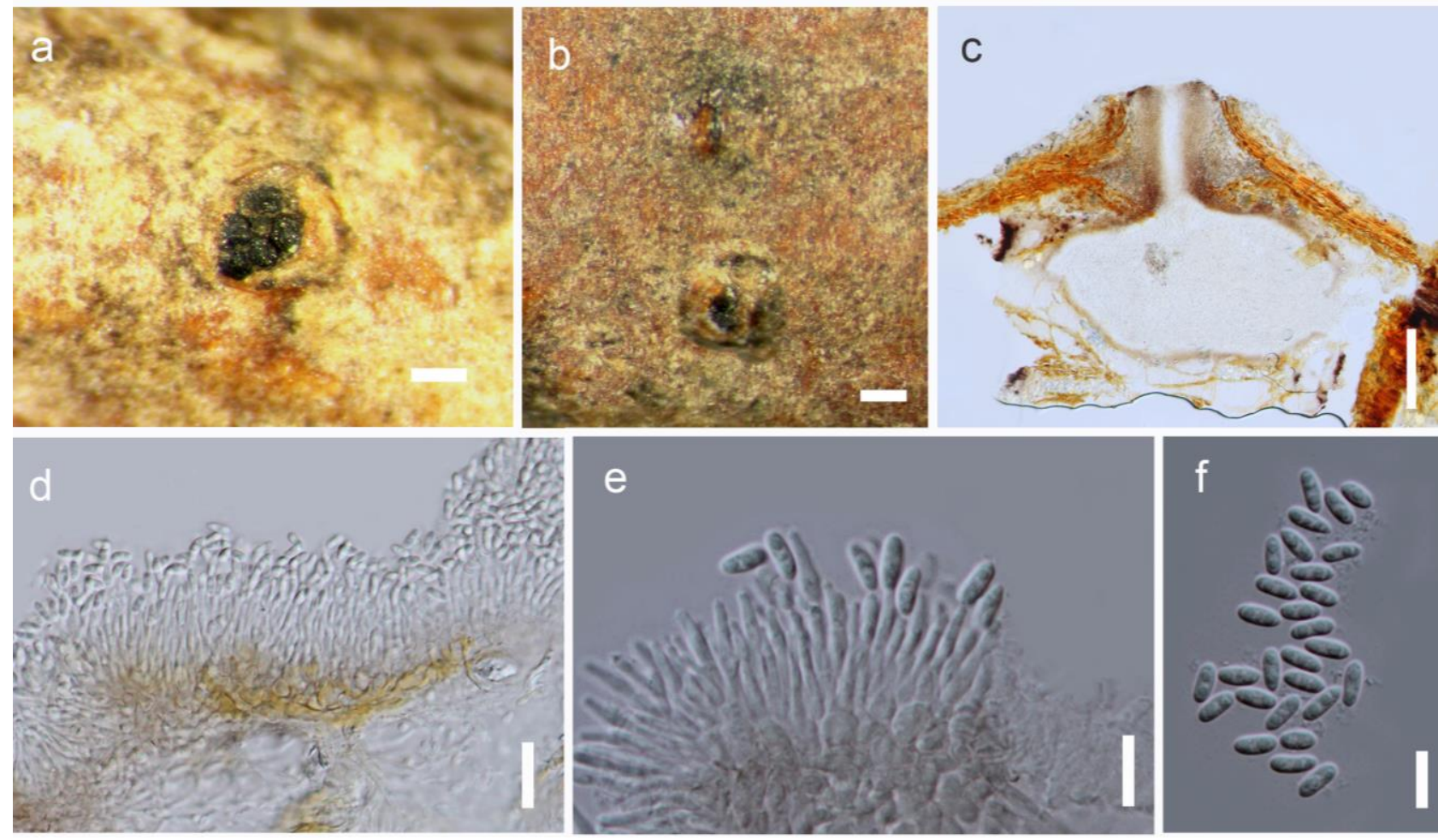

Figure 109 - Cryptosporella hypodermia (Material examined - CZECH REPUBLIC, Moravia, Hranice city, Canyon mountain, Ulmus sp., October 1925, F. Petrak, F48426, holotype). a, b Conidiomata on substrate. c Vertical cross section of conidioma. d-e Conidiogenous cells and conidia. f Conidia. Scale bars: $\mathrm{a}, \mathrm{b}=200 \mu \mathrm{m}, \mathrm{c}=100 \mu \mathrm{m}, \mathrm{d}=20 \mu \mathrm{m}, \mathrm{e}, \mathrm{f}=10 \mu \mathrm{m}$.

Dictyoporthe Petr., Sydowia 9(1-6): 556 (1955)

Index Fungorum number: IF25095; 4 morphological species (Species Fungorum 2020).

Type species - Dictyoporthe ahmadii Petr.

Notes - This genus is distinct from other genera of Diaporthaceae in having muriform ascospores (Petrak 1955a). 
Diplacella Syd., Annls mycol. 28(1/2): 101 (1930)

Index Fungorum number: IF1677; 2 morphological species (Species Fungorum 2020).

Type species - Diplacella paulliniae (Gonz. Frag. \& Cif.) Syd.

Notes - Diplacella is an endophytic fungal genus collected from leaves when form leaf spots. Currently there are two species in this genus as Diplacella mararyensis and D. paulliniae (Index Fungorum 2020). Diplacella species lack sequence data. However, most characters of Diplacella fits with gnomoniaceous species and Senanayake et al. (2018) accepted this genus within Gnomoniaceae.

Ditopella De Not., Hedwigia 2: 179 (1863)

Index Fungorum number: IF1677; 12 morphological species (Species Fungorum 2020), 3 species with sequence data and molecular data available for an unnamed species.

Type species - Ditopella fusispora De Not.

Notes - Asci in Ditopella species contain more than eight ascospores (generally 32). Senanayake et al. (2017a) and Tian et al. (2018) showed the phylogenetic placement of this genus within Gnomoniaceae.

Ditopellopsis J. Reid \& C. Booth, Can. J. Bot. 45(9): 1479 (1967)

Index Fungorum number: IF1679; 4 morphological species (Species Fungorum 2020), molecular data available for an unnamed species.

Type species - Ditopellopsis clethrae J. Reid \& C. Booth

Notes - Ditopellopsis is characterized by pseudoparenchymatous stroma surrounding the upright perithecium, short and broad necks, and ascospores with medium septum (Reid \& Booth 1967). Ditopellopsis clethrae has been reported from Alnus, Clethra, Gaultheria, and Sophora.

Gloeosporidina Petr., Annls mycol. 19(3-4): 214 (1921)

Index Fungorum number: IF8353; 6 morphological species (Species Fungorum 2020).

Type species - Gloeosporidina moravica Petr.

Notes - This genus produces subepidermal to epidermal acervuli conidiomata, enteroblastic conidiogenous cells and distinctive tiny, aseptate, hyaline conidia (Sutton 1980).

Gnomonia Ces. \& De Not., Comm. Soc. crittog. Ital. 1(fasc. 4): 231 (1863)

Index Fungorum number: IF2099; 111 morphological species (Species Fungorum 2020), 28 species with sequence data.

Type species - Gnomonia gnomon (Tode) J. Schröt.

Notes - Gnomonia is characterized by astromatic, solitary, thin-walled, immersed perithecia with long necks and ascospores with a single median septum. The sexual morph of Gnomonia gnomon is illustrated below.

Gnomoniella Sacc., Michelia 2(no. 7): 312 (1881)

Index Fungorum number: IF2100; 28 morphological species (Species Fungorum 2020), 6 species with sequence data.

Type species - Gnomoniella tubaeformis (Tode) Sacc.

Notes - Gnomoniella species are generally associated with leaves and petioles of overwintered plants (Barr 1998), although two species are known from freshwater (Luo et al. 2019).

Gnomoniopsis Berl., Icon. fung. (Abellini) 1(3): 93 (1893)

Index Fungorum number: IF2102; 17 morphological species (Species Fungorum 2020), 20 species with sequence data and molecular data available for 66 unnamed species.

Type species - Gnomoniopsis chamaemori (Fr.) Berl. 


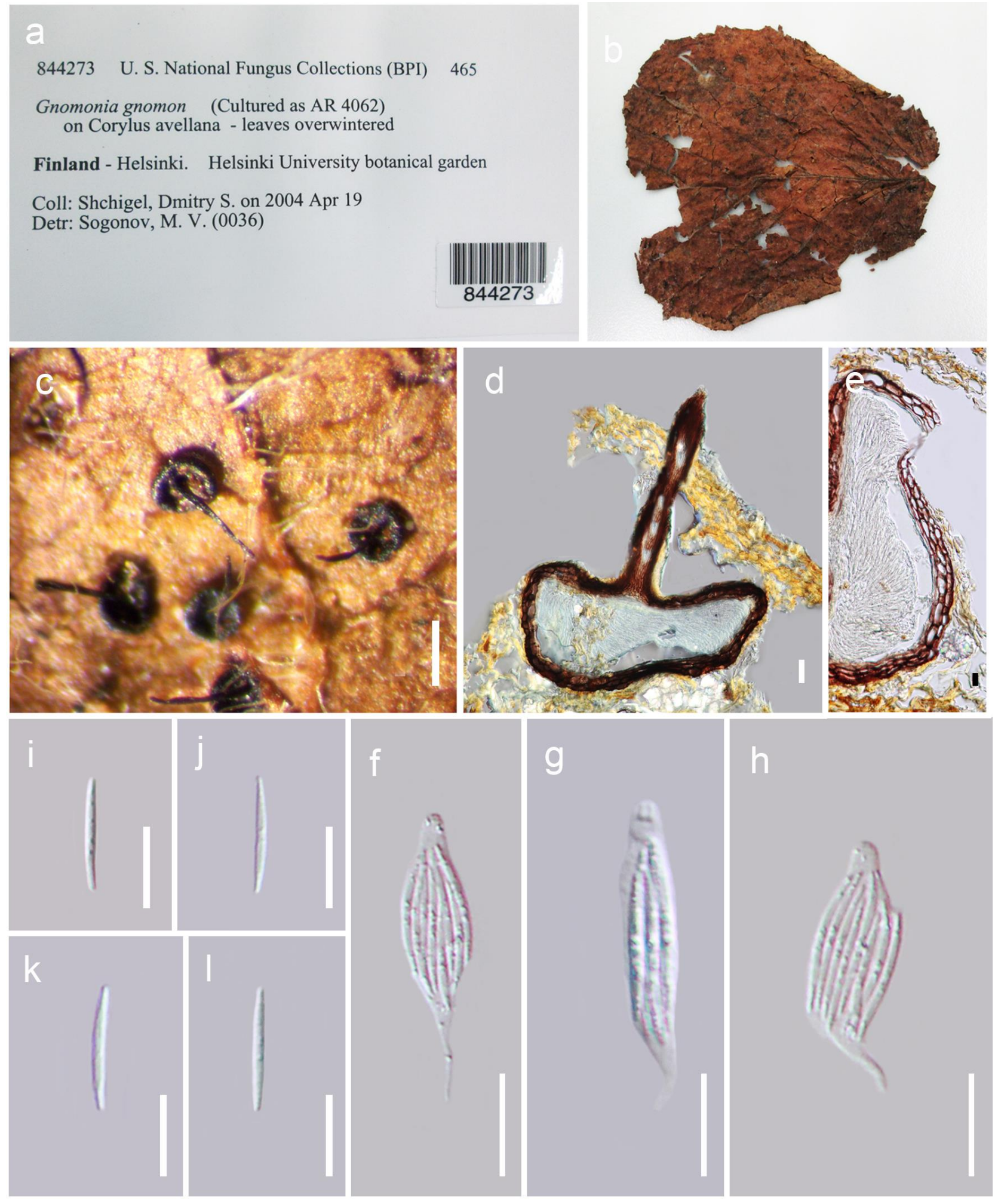

Figure 110 - Gnomonia gnomon (Material examined - FINLAND, Helsinki, Helsinki University Botanical Garden, overwintered fallen leaves of Corylus avellana L. (Betulaceae), 19 April 2004, Shchigel, Dmitry S., BPI 844273, epitype). a Packet of herbarium. b Herbarium specimen. c Ascomata on substrate. d Cross section of ascoma. e Peridium. f-h Asci. i-l Ascospores. Scale bars: $\mathrm{c}=1 \mathrm{~mm}, \mathrm{~d}=200 \mu \mathrm{m}, \mathrm{e}, \mathrm{f}-\mathrm{h}=20 \mu \mathrm{m}, \mathrm{i}-\mathrm{l}=10 \mu \mathrm{m}$.

Notes - Some species in this genus are phytopathogens, forming leaf blotch and petiole blight of strawberry (Fall 1951, Bolton 1954, Van Adriechem \& Bosher 1958, Maas 1998). Gnomoniopsis is characterized by small, black perithecia composed of single central, marginal or lateral neck and 
immersed in the host tissue or stromatic tissues, oval to fusiform asci and one-septate, oval to fusiform ascospores (Sogonov et al. 2008).

Maculatipalma J. Fröhlich\& K.D. Hyde, Mycol. Res. 99(6): 727 (1995)

Index Fungorum number: IF6033; 1 morphological species.

Type species - Maculatipalma frondicola J. Fröhl. \& K.D. Hyde

Notes - Maculatipalma frondicola fits in Gnomoniaceae in having foliicolous life mode, solitary, thin-walled ascomata, and cylindrical to fusiform asci (Fröhlich \& Hyde 1995).

Mamianiella Höhn., Ber. dt. bot. Ges. 35(8): 635 (1917)

Index Fungorum number: IF2994; 2 morphological species (Species Fungorum 2020), 1 species with sequence data.

Type species - Mamianiella coryli (Batsch) Höhn.

Notes - Senanayake et al. (2017a) synonymized Mamiania and Anisogramma under Mamianiella based on their morphological similarity. Mamianiella species mostly colonize living leaves.

Marsupiomyces Senan. \& K.D. Hyde, Stud. Mycol. 86: 265 (2017)

Index Fungorum number: IF821555; 2 species with sequence data.

Type species - Marsupiomyces epidermoideus Perera, Senan., Bulgakov \& K.D. Hyde

Notes - Marsupiomyces comprises M. quercina and the type. Species of this genus have been reported only from Fagaceae (Senanayake et al. 2017a).

Millerburtonia Cif., Mycopath. Mycol. appl. 6(1): 26 (1951)

Index Fungorum number: IF8948; 1 species with sequence data.

Type species - Millerburtonia oyedaeae Cif.

Notes - Millerburtonia was introduced to accommodate Chalcosphaeria oyedaeae (Ciferri 1950). This is a parasitic, leaf spot forming taxon on leaves of Oyedea everbesinoides.

Occultocarpon L.C. Mejía \& Zhu L. Yang, Fungal Divers. 52(1): 101 (2012)

Index Fungorum number: IF519819; 1 species with sequence data.

Type species - Occultocarpon ailaoshanense L.C. Mejía \& Zhu L. Yang

Notes - Occultocarpon is characterized by aggregated, stromatic perithecia with thin, central to eccentric necks and oblong elliptical-elongated, one-septate ascospores (Mejía et al. 2012).

Ophiognomonia (Sacc.) Speg., Revta Fac. Agron. Vet. Univ. nac. La Plata 2(19): 231 (1896)

Index Fungorum number: IF3604; 52 morphological species (Species Fungorum 2020), 48 species with sequence data and molecular data available for 27 unnamed species.

Type species - Ophiognomonia melanostyla (DC.) Sacc.

Notes - Members of this genus are leaf-inhabiting endophytes, pathogens or saprobes on several plant families such as Betulaceae, Fagaceae, Juglandaceae, Lauraceae, Malvaceae, Platanaceae, Rosaceae, Salicaceae, and Sapindaceae (Walker et al. 2012).

Phragmoporthe Petr., Annls mycol. 32(5/6): 354 (1934)

Index Fungorum number: IF4033; 3 morphological species (Species Fungorum 2020), 1 species with sequence data.

Type species - Phragmoporthe ploettneriana (Henn.) Petr.

Notes - This genus is characterized by multi-septate ascospores and 8-spored asci (Sogonov et al. 2008).

Phylloporthe Syd., Annls mycol. 23(3/6): 348 (1925)

Index Fungorum number: IF4071; 1 species with sequence data. 
Type species - Phylloporthe vernoniae Syd.

Notes - The monotypic genus Phylloporthe is a parasite on living leaves of Vernonia triflosculosa. Phylloporthe is distinct in having strongly erumpent, almost superficial stromata, an aparaphysate hamathecium and thin-walled ascospores (Senanayake et al. 2018).

Plagiostoma Fuckel, Jb. nassau. Ver. Naturk. 23-24: 118 (1870)

Index Fungorum number: IF4157; 52 morphological species (Species Fungorum 2020), 39 species with sequence data and molecular data available for 18 unnamed species.

Type species - Plagiostoma euphorbiae (Fuckel) Fuckel

Notes - Plagiostoma species occur as pathogens, endophytes or saprobes on stems, branches, twigs and leaves of woody and herbaceous plants (Mejía et al. 2011). The genus is mainly differentiated from other genera in the family by the neck characters of perithecia and ascospore morphology (Mejía et al. 2011).

Pleuroceras Riess., Hedwigia 1(6): 25 (1854)

Index Fungorum number: IF4242; 20 morphological species (Species Fungorum 2020), 4 species with sequence data and molecular data available for 6 unnamed species.

Type species - Pleuroceras ciliatum Riess.

Notes - Pleuroceras is characterized by ascomata with eccentric, lateral necks and elongated ascospores (Barr 1978). Species of this genus are found on overwintered leaves of hardwood trees in temperate regions.

Sirococcus Preuss, Linnaea 26: 716 (1855)

Index Fungorum number: IF9927; 28 morphological species (Species Fungorum 2020), 11 species with sequence data.

Type species - Sirococcus strobilinus Preuss

Notes - Sirococcus is a phytopathogenic or endophytic fungal genus (Senanayake et al. 2018).

Spataporthe Bronson, Klymiuk, Stockey \& Tomescu, Int. J. Pl. Sci. 174(3): 279 (2013)

Index Fungorum number: IF800815; 1 morphological species.

Type species - Spataporthe taylorii Bronson, Klymiuk, Stockey \& Tomescu

Notes - Spataporthe is typified by $S$. taylorii and it is the only genus fossil in Diaporthales (Bronson et al. 2013). Spataporthe is distinct from other genera in Gnomoniaceae in having perithecial necks with a bell-shaped chamber, a peridium with outer, large pseudoparenchymatous layer and inner, thin filamentous layer, and clavate asci with thinly tapered bases which are detached from the hymenium to float freely in the perithecium (Bronson et al. 2013).

Tenuignomonia Minosh., D.M. Walker \& Hirooka, Mycoscience 60: 39 (2018)

Index Fungorum number: IF824890; 1 species with sequence data.

Type species - Tenuignomonia styracis Minosh., D.M. Walker \& Hirooka

Notes - Tenuignomonia is only known from its type species, Tenuignomonia styracis which has been collected solely from Styraxo bassia. This genus is distinct from other genera in having long perithecial necks and septate ascospores. Minoshima et al. (2018) proved that Tenuignomonias tyracis has weak pathogenicity on Styraxo bassia and it may promote early defoliation.

Uleoporthe Petr., Annls mycol. 39(4/6): 279 (1941)

Index Fungorum number: IF5660; 1 morphological species.

Type species - Uleoporthe orbiculata (Syd. \& P. Syd.) Petr.

Notes - This genus is a leaf epiphyllous taxon forming circular, erumpent to superficial stromata. Morphologically this genus is closer to Phyloporthe in having a foliicolous life mode, solitary, globose, astromatic ascomata and fusiform asci (Cannon 2001). 
Uniseta Ciccar., Nuovo G. bot. ital. 54: 711 (1948)

Index Fungorum number: IF10354; 1 morphological species.

Type species - Uniseta flagellifera (Ellis \& Everh.) Ciccar.

Notes - Uniseta is morphologically distinct in having sessile, widely fusiform asci deeply immersed in a hyaline, cellular mass and fusiform, slightly curved, guttulate ascospores (Senanayake et al. 2018).

Valsalnicola D.M. Walker \& Rossman, Persoonia 29: 149 (2012)

Index Fungorum number: IF801276; 1 species with sequence data.

Type species - Valsalnicola oxystoma (Rehm) D.M. Walker \& Rossman

Notes - Valsalnicola is different from other genera in Gnomoniaceae in having allantoid, 1septate ascospores and a black line surrounding the ascomatal cavity (Crous et al. 2012c).

Vismaya V.V. Sarma \& K.D. Hyde, Nova Hedwigia 73(1-2): 247 (2001)

Index Fungorum number: IF28571; 1 morphological species.

Type species - Vismaya chaturbeeja V.V. Sarma \& K.D. Hyde

Notes - This genus has distinct characters such as immersed perithecial ascomata with long protruding necks, four-spored asci and hyaline, 1-celled, verruculose ascospores with appendages at both ends (Sarma \& Hyde 2001).

Gondwanamycetaceae Réblová, W. Gams \& Seifert, Stud. Mycol. 68(1): 188 (2011) Index Fungorum number: IF515439; Facesoffungi number: FoF01329; 14 species.

Pathogenic on terrestrial and aquatic plants or parasitic on beetles or saprobic in compost. Sexual morph: Ascomata perithecial, black, necks cylindrical to filiform, tapered towards the apex, terminating in ostiolar hyphae. Peridium fragile, thin-walled. Paraphyses lacking. Asci 8 to multispored, evanescent. Ascospores hyaline, aseptate, fusiform to lunate or falcate or allantoid with or without a gelatinous sheath. Asexual morph: Hyphomycetous. Conidiophores macronematous, mononematous, mono-verticillate or penicillate, brown. Conidiogenous cells phialidic. Conidia hyaline, 1-celled, smooth-walled, cylindrical to allantoid, aseptate, slimy (adapted from Maharachchikumbura et al. 2016b).

Type species - Knoxdaviesia M.J. Wingf., P.S. van Wyk \& Marasas

Notes - Gondwanamycetaceae was introduced for Gondwanamyces and its asexual morph Custingophora by Réblová et al. (2011). The phylogenetic relationship of the asexual genera Knoxdaviesia and Custingophora were documented in earlier studies of Viljoen et al. (1999) and subsequently in Kolařík \& Hulcr (2009) who suggested that Knoxdaviesia and Custingophora should be treated as synonyms. Van der Linde et al. (2012) and de Beer et al. (2013a) conducted a separate treatment of these genera and proposed using Knoxdaviesia, the oldest name, over Gondwanamyces (Hawksworth 2011, Moubasher et al. 2017). The apparent absence of interascal filaments in the ascomatal centrum and hyaline, allantoid ascospores, with a hyaline sheath, giving the spore a fusiform to lunate or falcate appearance, are characteristic features of the sexual morph of this family. The asexual morphs are characterized by conidiophores which are erect, darkly pigmented, and paler towards the apex, and are either monoverticillate, sometimes with a terminal vesicle or divergently penicillate, with whorls of phialides producing hyaline conidia while the conidiogenous loci are located at the base of the shallow collarette (Kolaŕík \& Hulcr 2009, Moubasher et al. 2017). Réblová et al. (2011) and Maharachchikumbura et al. (2015, 2016b) confirmed the placement of this family in Microascales based on analysis of combined SSU, LSU and $r p b 2$ data.

\section{Ecological and economic significance of Gondwanamycetaceae}

Gondwanamycetaceae comprises plant pathogens mostly occurring on infructescences of Protea species and parasites on bark beetles such as Cossonus (Wingfield et al. 1988, Marais et al. 1998, Van der Linde et al. 2012). Knoxdaviesia was first observed in an infructescence of Protea 
spp. infected by insects (Wingfield et al. 1988, Marais et al. 1998) whereas, some described species of Knoxdaviesia are associated with Scolytidae (bark beetles) (Bright \& Torres 2006, Kolařik \& Hulcr 2008). Knoxdaviesia cecropiae was isolated from the body of Scolytidae unipunctatus and Knoxdaviesia scolytodis from galleries in the sapwood of Curcuma angustifolia (Kolařík \& Hulcr 2009). Knoxdaviesia serotectus was isolated from discoloured plant material of C. angustifolia in Costa Rica (Kolař́k \& Hulcr 2009). These species are also vectors for mites that are associated with insects which infest Euphorbia species (Van der Linde et al. 2012). Gondwanamyces species produced lesions on healthy succulent branches of Euphorbia spp. hence causing decline in the populations in South Africa (Van der Linde et al. 2012). Gondwanamycetaceae species are able to grow on all monosaccharides that occur in Protea nectar (Aylward 2017). There are no reports of severe effects of Gondwanamycetaceae species on these plant species or beetles. No control methods have been reported. However, secondary metabolites are likely to be produced by Custingophora species that enable Protea spp. to tolerate bacteria, arthropod and nematode predation (Aylward 2017).

\section{Genera included in Gondwanamycetaceae}

Custingophora Stolk, Hennebert \& Klopotek, Persoonia 5(2): 195 (1968)

Index Fungorum number: IF7851; 5 morphological species (Species Fungorum 2020), 2 species with sequence data.

Type species - Custingophora olivacea Stolk, Hennebert \& Klopotek

Notes - Custingophora species have mononematous conidiophores that terminate in obovoid conidiogenous cells with distinct collarettes and conidia in slimy droplets (de Beer et al. 2013a, Moubasher et al. 2017).

Knoxdaviesia M.J. Wingf., P.S. van Wyk \& Marasas, Mycologia 80(1): 26 (1988)

Index Fungorum number: IF11113; 9 morphological species (Species Fungorum 2020), 6 species with sequence data.

Type species - Knoxdaviesia proteae M.J. Wingf., P.S. van Wyk \& Marasas

Notes - Knoxdaviesia was established for K. proteae, and the asexual morph of this species was described as Ceratocystiopsis proteae (Wingfield et al. 1988). Subsequently, Marais et al. (1998) introduced the sexual morph genus Gondwanamyces based on G. proteae to accommodate two ophiostomatoid species Ceratocystiopsis proteae (Wingfield et al. 1988) and Ophiostoma capense (Wingfield \& van Wyk 1993). Gondwanamyces was characterized by black, globose to subglobose perithecia and aseptate ascospores, with or without a sheath. The asexual morph Knoxdaviesia formed phialoconidia holoblastically from obovoid conidiogenous cells. Sequence data showed that Knoxdaviesia could be accommodated in Custingophora (Kolařík \& Hulcr 2009, Moubasher et al. 2017). Van der Linde et al. (2012) rejected the concept of synonymy of Knoxdaviesia in Custingophora and de Beer et al. (2013a) erected Knoxdaviesia over Gondwanamyces according to the one fungus one name protocol (Hawksworth 2011, Hawksworth et al. 2011, Moubasher et al. 2017). In this entry, Knoxdaviesia proteae is illustrated.

Graphiaceae Z.W. de Beer, Seifert \& M.J. Wingf., CBS Diversity Ser. 12: 8 (2013) Index Fungorum number: IF622184; Facesoffungi number: FoF01099; 59 species.

Saprobic on plant debris, woody substrates, sometimes causing wounds on tree bark or associated with beetles, occasionally isolated from soil, manure, polluted water, also reported to cause fungaemia in an immunosuppressed child post stem-cell transplant. Sexual morph: Undetermined. Asexual morph: Hyphomycetous. Conidiomata macronematous, synnematous, determinate. Conidiophores compact, pigmented, septate, penicillately branched in two to three levels, forming metulae at the apex. Conidiogenous cells in whorls of two to six, phialidic, with annellidic extensions. Conidia produced in a transparent, slimy droplet, aseptate, cylindrical to obovoid, sometimes slightly curved with age, truncate at base, often with a distinct basal frill, 
hyaline. Rarely synanamorphic forming obovoid, pigmented conidia (adapted from de Beer et al. 2013b, Maharachchikumbura et al. 2016b).
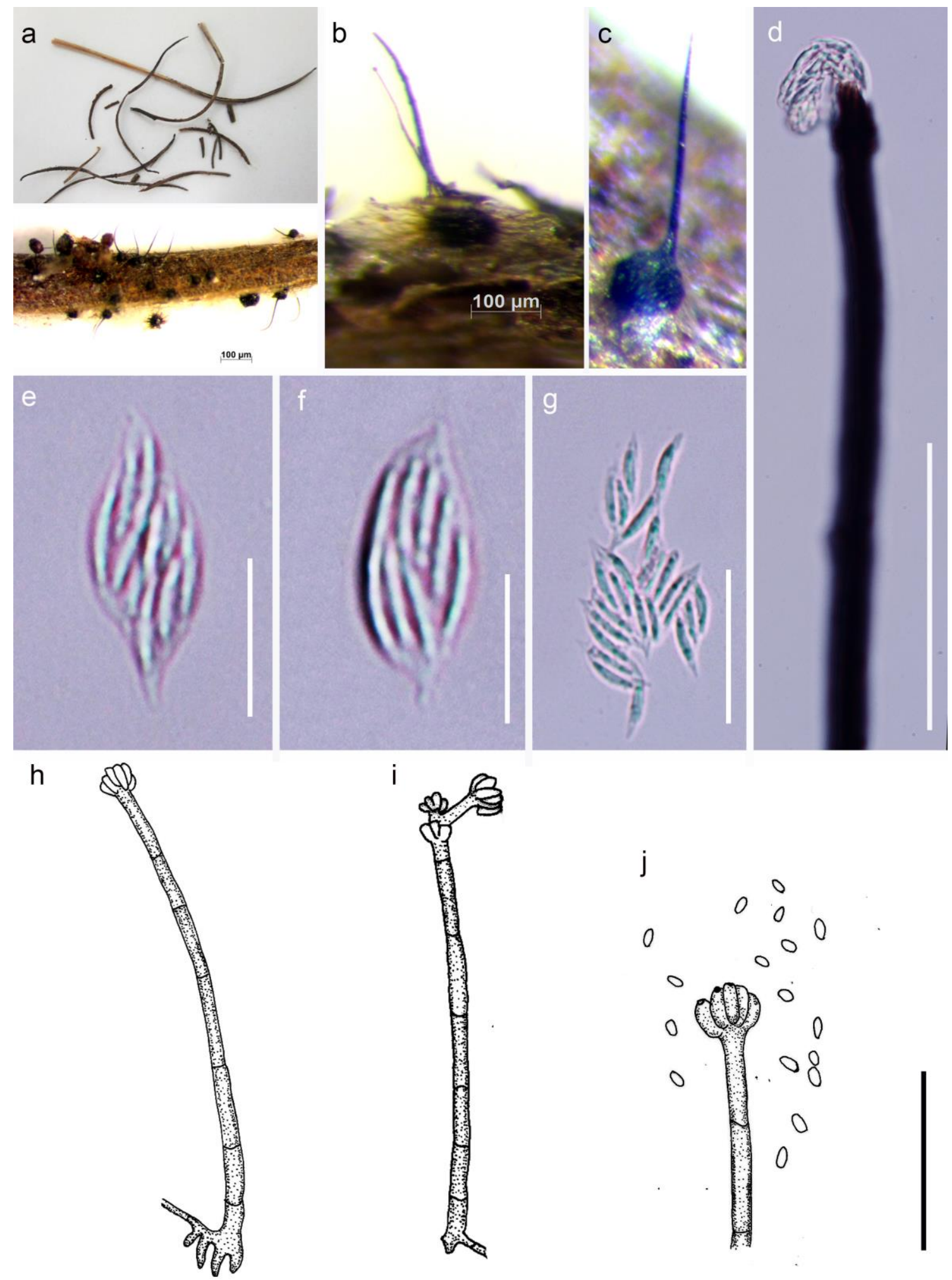

Figure 111 - Knoxdaviesia proteae (Material examined - SOUTH AFRICA, Cape Province, Stellenbosch, from flower within the inflorescence, infested by insects, L.J. Strauss, 7 October 1985, PREM 48924 holotype) and asexual morph redrawn from Wingfield et al. (1988). a Herbarium material. b, c Ascomata on host. d Long neck of ascomata. e, f Asci. g Ascospores. h-j Conidiophores, conidiogenous cells and conidia. Scale bars: $b, c=100 \mu \mathrm{m} . \mathrm{d}=50 \mu \mathrm{m}, \mathrm{g}=20 \mu \mathrm{m}$, $\mathrm{e}, \mathrm{f}=5 \mu \mathrm{m}$. 


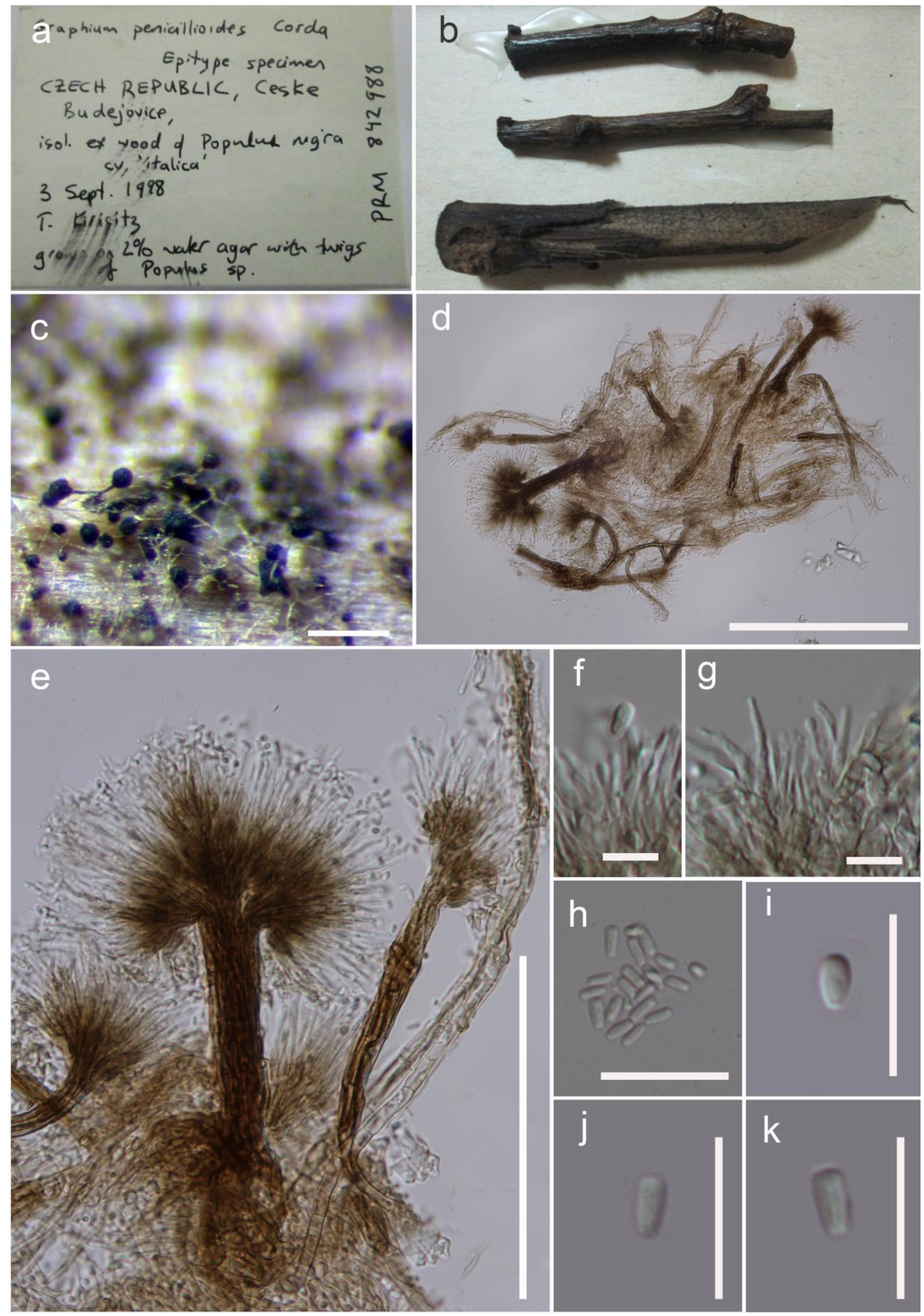

Figure 112 - Graphium penicillioides (Material examined - CZECH REPUBLIC, PRM 842988, epitype). a, b Herbarium material. c Colony on the surface of the substrate. d, e Synnemata on the host surface. f, g Conidiogenous cells. h-k Conidia. Scale bars: $c=200 \mu \mathrm{m}, \mathrm{d}=100 \mu \mathrm{m}, \mathrm{e}=50 \mu \mathrm{m}$, $\mathrm{f}-\mathrm{h}=20, \mathrm{i}-\mathrm{k}=5$. 
Type genus - Graphium Corda

Notes - Based on the phylogenetic distance between Graphium and other families of Microascales, Graphiaceae was introduced by de Beer et al. (2013b) and accommodated in Microascales (de Beer et al. 2013b, Maharachchikumbura et al. 2015, 2016b). The family is characterized by hyaline, aseptate, cylindrical to obovoid, curved conidia. In rare cases, a synanamorph with monoblastic, obovoid, pigmented chlamydospore-like conidia are formed.

Synnematous asexual morphs of Ophiostoma were treated as Graphium (Hedgcock 1906, Upadhyay 1981, Seifert \& Okada 1993). Phylogenetic studies showed that the asexual morphs of Ophiostoma clustered distantly from Graphium sensu stricto species and thus they were accommodated in Pesotum (Okada et al. 1998, 2000). However, species with annellidic conidiogenous cells and those with Microascaceae affinities were retained in Graphium (Okada et al. 1998, 2000, Jacobs et al. 2003). Graphium was referred to a separate family with nine accepted species based on the description of $G$. penicillioides and available DNA sequence data (de Beer et al. 2013b, Maharachchikumbura et al. 2015, 2016b). There are 14 species listed under Graphiaceae based on the molecular data with the addition of new species such as, G. jumulu, G. scolytodis, G. kuroshium (https://www.ncbi.nlm.nih.gov/taxonomy; $\mathrm{Na}$ et al. 2018) and many more morphological species.

Hongsanan et al. (2017) list three families in the Microascales: Microascaceae, Halosphaeriaceae and Graphiaceae with a stem age of 171-241 MYA, while Hyde et al. (2017a) indicate there is grounds for the introduction of Graphidiales with a stem age of 166 MYA. However, no formal designation was made (Hyde et al. 2017a).

\section{Ecological and economic significance of Graphiaceae}

Usually they cause wounds or colonize the outer bark of trees and are considered as pathogens. Graphium basitruncatum causes invasive disease fungaemia in an immunosuppressed child post stem-cell transplant (Kumar et al. 2007, El Feghaly et al. 2012).

\section{Genus included in Graphiaceae}

Graphium Corda, Icon. fung. (Prague) 1: 18 (1837)

Index Fungorum number: IF8398; 59 morphological species (Species Fungorum 2020), 5 species with sequence data.

Type species - Graphium penicillioides Corda

Notes - Graphium species are plant pathogens and also found in soil, plant debris, woody substrates, manure, and polluted water (de Beer et al. 2013b, Maharachchikumbura et al. 2015, 2016b, Wijayawardene et al. 2017a). The genus was believed to have ophiostomatoid affinities (Goidànich 1935, Upadhyay 1981, Seifert \& Okada 1993, de Beer et al. 2013b). Cruywagen et al. (2010), based on SSU and ITS sequence data, included eight described and seven undescribed species, including G. penicillioides, in Graphium sensu stricto. de Beer et al. (2013b) provided a description of Graphium sensu stricto and referred Graphium to the monophyletic family Graphiaceae (Microascales). Phylogenetically Graphiaceae, are distantly placed from the Microascaceae (Zhang et al. 2006, Spatafora et al. 2006, Schoch et al. 2009, Maharachchikumbura et al. 2015, 2016b). Members of Graphium are characterized by distinctive, erect, black synnemata, each bearing a single, terminal, 1-celled, hyaline conidium produced from phialidic conidiogenous cell with annellidic extensions.

Graphostromataceae M.E. Barr, J.D. Rogers \& Y.M. Ju, Mycotaxon 48: 533 (1993)

Index Fungorum number: IF81957; Facesoffungi number: FoF00624; 101 species.

Saprobic on trunks, branches, and twigs of angiosperm plants, endophytic and pathogenic. Sexual morph: Stromata erumpent, widely effuse, irregular in outline, bipartite with ectostroma and entostroma, ectostroma develops first, young ectostroma surface buff, with matted mycelium, ectostroma develops beneath, hard and brittle. Ascomata perithecial, immersed in the enostroma, bottle-shaped, more rarely pyriform or obpyriform, black, opaque, monostichous, arranged in 
diatrypoid configuration in entostroma, compressed, varying in size with carbonaceous, doliiform ascomatal embedded necks. Peridium comprising hyaline, multi-layered, thin, indistinct, flattened cells. Paraphyses sparse, elongate, tapering from wide base. Asci 8-spored, unitunicate, narrowly clavate, short-pedicellate, rounded to subtruncate at the apex, with $\mathrm{J}+$, discoid, apical ring, inconspicuously bluing in Melzer's reagent. Ascospores uni-multiseriate, unicellular, allantoid and hyaline or brown and ellipsoid, at times with appendages, with or without germ slits, without dehiscent perispores. Stromatal pigments absent. Asexual morph: in culture nodulisporium-type, most often periconiella-like or xylocladium-like (reduced form of Periconiella) (adapted from Wendt et al. 2018).

Type genus - Graphostroma Piroz.

Notes - Barr et al. (1993) introduced Graphostromataceae to accommodate Graphostroma based on species having ascospores typical of the Diatrypaceae and conidiogeneous structures typical of the Hypoxylon. Maharachchikumbura et al. (2016b) synonymized Graphostromataceae with Xylariaceae and treated Graphostroma as a genus in Xylariaceae. In recent multi-gene phylogenetic analyses reveal that Graphostromataceae is close to Barrmaeliaceae and Xylariaceae (Daranagama et al. 2018, Voglmayr et al. 2018, Wendt et al. 2018). Hongsanan et al. (2017) and Hyde et al. (2017a) provided a 63 MYA stem age for Graphostromataceae and accepted the family based on molecular clock analyses. Daranagama et al. (2015) and Senanayake et al. (2015) confirmed the monophyletic association of Biscogniauxia, Graphostroma and camillea-like genera that share common characters. Based on phylogeny and morphology, Theissenia was excluded from the family and accepted in Hypoxylaceae (Wendt et al. 2018, this study). Five accepted genera are contained in the family, Biscogniauxia, Camillea, Graphostroma, Obolarina, and Vivantia.

\section{Ecological and economic significance of Graphostromataceae}

Graphostromataceae species are mainly saprobes on terrestrial wood. Among the genera in the family, Biscogniauxia consists of known pathogens and endophytes. Biscogniauxia mediterranea, a causal organism charcoal canker is widely distributed on European oaks that probably initially invades the host via the leaves and can be detected as endophyte in apparently healthy plants, but can turn pathogenic in water-stressed host plants (Edwards et al. 2003). Raimondo et al. (2016) described Biscogniauxia rosacearum, a charcoal canker fungus on Pyrus sp., Prunus sp., and Cydonia sp. In addition, Biscogniauxia nummularia, B. nothofagi and $B$. uniapiculata are canker causing species (Granata \& Sidoti 2004, Nugent et al. 2005). Interestingly, ambrosia beetles (Platypus cylindrus; Coleoptera, Platypodidae) act as vectors for $B$. mediterranea (Inácio et al. 2011). Amand et al. (2012) described bioactive compounds viz. xylaranone and xylaranol B isolated from endophytic B. nummularia from Cephalotaxus harringtonia which have antigerminative activity on Raphanus sativus seeds might act as latent pathogens. Obolarina dryophila was described as an inner bark endophyte from Salix alba that is propagated by insects because these authors found viable ascospores from the gut of Gasterocercus depressirostris (Coleoptera, Curculionidae) beetles (Pažoutová et al. 2010). Even though little is still known about the lifestype of most Graphostromataceae species, the above cited examples indicate that these taxa may play a very important role in the ecology of their hosts, and they should be studied and monitored further, in particular with regard to the challenges that agriculture and forestry are now facing during the imminent global climate change.

\section{Genera included in Graphostromataceae}

Biscogniauxia Kuntze, Revis. gen. pl. (Leipzig) 2: 398 (1891)

Index Fungorum number: IF582; 53 morphological species (Species Fungorum 2020), 23 species with sequence data.

Type species - Biscogniauxia nummularia (Bull.) Kuntze

Notes - Biscogniauxia species develop within the bark and emerge via the overlying bark. A periconiella-like asexual morph is associated with several Biscogniauxia species and sometimes 
vary from nodulisporium-like to periconiella-like (Stadler et al. 2013). The genus appears paraphyletic together with morphologically dissimilar genera, such as Camillea, Obolarina and Graphostoma (Pažoutová et al. 2010, Raimondo et al. 2016, Daranagama et al. 2018). A case could be made to merge all these genera, were it not for the fact that over $90 \%$ of the species remain to be studied by multi-gene genealogies and of over $80 \%$ only the less relevant rDNA sequences are extant. A new species, Biscogniauxia mangiferae, is illustrated in this entry.

Biscogniauxia mangiferae Samarak. \& K.D. Hyde, sp. nov.

Fig. 113

Index Fungorum number: IF556894; Facesoffungi number: FoF06780

Etymology - Named after the host genus on which the fungus occurs.

Holotype - MFLU 18-0827.

Saprobic on dead branch of Mangifera indica L. (Anacardiaceae). Sexual morph: Stromata 0.5-3.5 cm long, 0.25-1.5 cm width, applanate, dull brown to black, carbonaceous. Perithecia 185$225 \mu \mathrm{m}(\bar{x}=205 \mu \mathrm{m})$ diam., $310-430 \mu \mathrm{m}(\bar{x}=360 \mu \mathrm{m})$ high, ovoid to obpyriform, laterally compressed. Ostiole pointed, raised. Paraphyses 3.9-6.5 $\mu \mathrm{m}(\bar{x}=5.4 \mu \mathrm{m}, \mathrm{n}=20)$ wide, hyaline, septate, round apex, guttulate. Asci $80.7-94.4 \times 6.7-8.6 \mu \mathrm{m}(\bar{x}=88.6 \times 7.8 \mu \mathrm{m}, \mathrm{n}=25)$, 8-spored, unitunicate, cylindrical, pedicellate, with $\mathrm{J}+$, apical ring bluing in Melzer's reagent, wedge-shaped with 2.6-5 $\mu \mathrm{m}(\bar{x}=4.1 \mu \mathrm{m}, \mathrm{n}=25)$ high, 2.5-3.7 $\mu \mathrm{m}(\bar{x}=3.1 \mu \mathrm{m}, \mathrm{n}=25)$ broad. Ascospores 8.8$11.7 \times 5.3-6.5 \mu \mathrm{m}(\bar{x}=10.3 \times 6 \mu \mathrm{m}, \mathrm{n}=35)$, uniseriate, unicellular, ellipsoid, rounded ends, dark brown to black at mature, smooth, with straight germ slit spore-length. Asexual morph: Undetermined.

Material examined - THAILAND, Doi Phu Kha, Naan 55000, dead branch of Mangifera indica (Anacardiaceae), 4 August 2017, M.C. Samarakoon, SAMC049 (MFLU 18-0827, holotype); ibid. (HKAS 102330, isotype).

GenBank numbers - ITS: MN337232, LSU: MN336236, rpb2: MN366247, tub2: MN509782.

Notes - Biscogniauxia nummularia (type species), B. capnodes, B. petrensis and the strain isolated in this study clustered with high statistical support (98\% ML). Our strain is sister to $B$. petrensis (100\% ML). Biscogniauxia petrensis was described by Zhang et al. (2017c) from a karst cave ecosystem with its asexual morph. Morphological comparisons are not possible and ITS comparison shows $5.7 \%$ bp differences among these two strains. Biscogniauxia capnodes differs from our strain by its obovoid to tubular perithecia, discoid apical ring and large ascospores. Biscogniauxia reticulospora described from undetermined corticated wood (Thailand) differs from our strain by its comparatively larger ascospores $(27-34 \times 14-15.5 \mu \mathrm{m})$ with ornamentations and reticulations (Ju \& Rogers 2001), as compared to ascospores in our strain $(8.8-11.7 \times 5.3-6.5 \mu \mathrm{m})$.

Camillea Fr., Summa veg. Scand., Section Post. (Stockholm): 382 (1849)

Index Fungorum number: IF777; 44 morphological species (Species Fungorum 2020), 4 species with sequence data.

Type species - Camillea leprieurii (Mont.) Mont.

Notes - Camillea species are characterized by long, erect, hard, carbonaceous, cylindrical, black stromata with light coloured ascospores (Læssøe et al. 1989). Many of the species of Camellea remain to be cultured and sequenced.

Graphostroma Piroz., Can. J. Bot. 52(10): 2131 (1974)

Index Fungorum number: IF2132; 1 species with sequence data.

Type species - Graphostroma platystomum (Schwein.) Piroz.

Notes - Pirozynski (1974) erected Graphostroma for Sphaeria platystoma with nodulisporium-like asexual morph. The combination of nodulisporium-like asexual morph and a diatrypaceae-like sexual morph having allantoid ascospores are considered as characteristic of Graphostromataceae with the type species Graphostroma platystomum (Barr et al. 1993). 
Phylogenetic analyses by Daranagama et al. (2018), and Wendt et al. (2018) confirmed that Graphostroma clustered with Biscogniauxia and Camillea in Graphostromataceae.
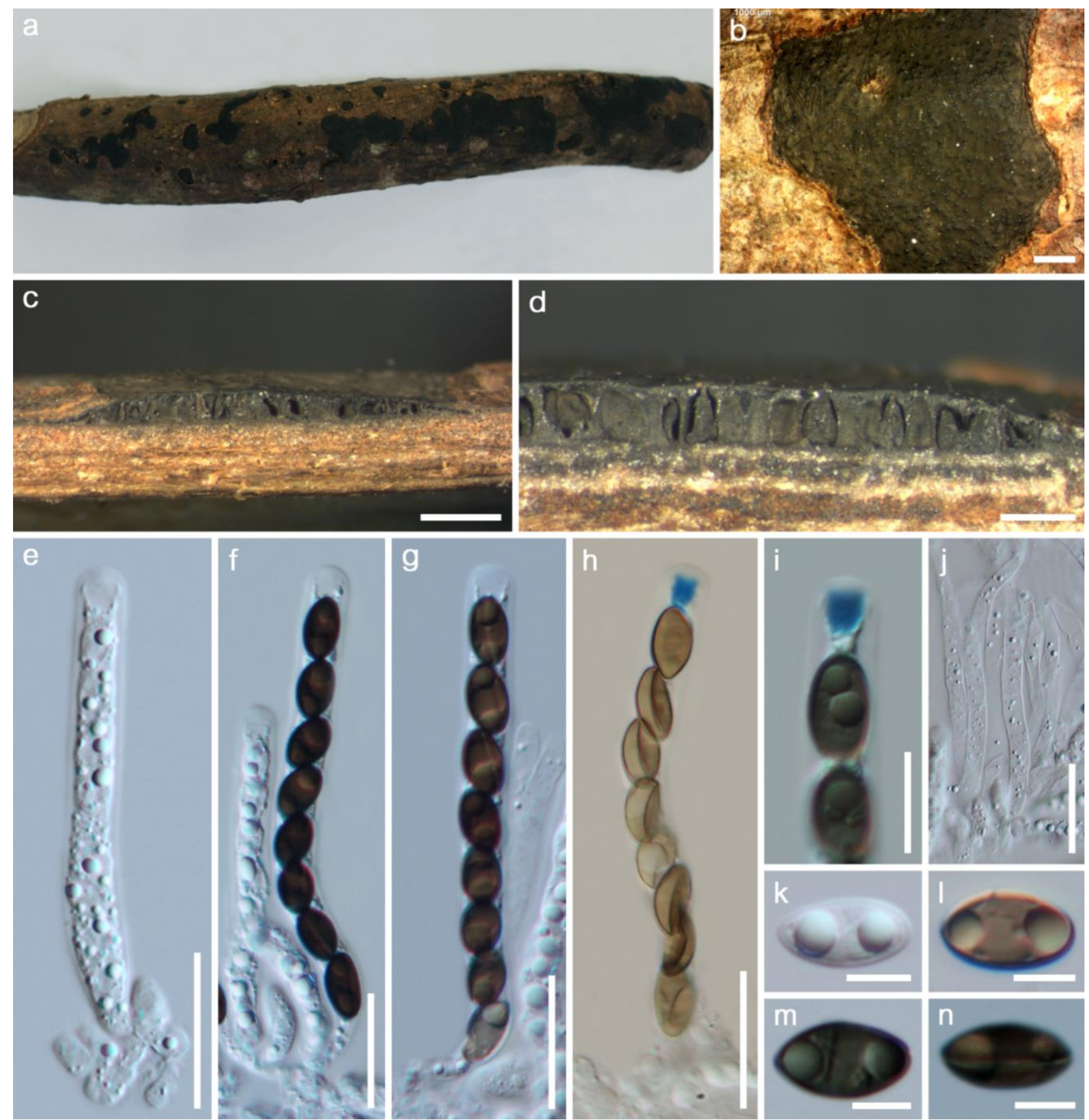

Figure 113 - Biscogniauxia mangiferae (MFLU 18-0827, holotype). a, b Stroma on the host. c, d Cross section of stromata showing the ascoma and ostiole. e-g Asci. h, i J+, apical ring in Melzer's reagent. j Paraphyses. k-n Ascospores. Scale bars: b, $c=1000 \mu \mathrm{m}, \mathrm{d}=500 \mu \mathrm{m}, \mathrm{e}-\mathrm{h}=20 \mu \mathrm{m}, \mathrm{i}, \mathrm{j}=$ $10 \mu \mathrm{m}, \mathrm{k}-\mathrm{n}=10 \mu \mathrm{m}$.

Obolarina Pouzar, Česká Mykol. 40(1): 7 (1986)

Index Fungorum number: IF25727; 2 morphological spcies with sequence data.

Type species - Obolarina dryophila (Tul. \& C. Tul.) Pouzar

Notes - Obolarina species are endophytic, saprotrophic, or rarely parasitic on wood of Quercus sp. (Daranagama et al. 2018). Mirabolfathy et al. (2013) introduced Obolarina persica from Iran, where it is widely associated with dying Quercus brantii. The phylogenetic position of Obolarina was determined in Graphostromataceae (Mirabolfathy et al. 2013, Daranagama et al. 2018, Wendt et al. 2018). 
Vivantia J.D. Rogers, Y.M. Ju \& Cand., Mycol. Res. 100(6): 672 (1996)

Index Fungorum number: IF27648; 1 morphological spcies.

Type species - Vivantia guadalupensis J.D. Rogers, Y.M. Ju \& Cand.

Notes - Daranagama et al. (2018) and Wendt et al. (2018) tentatively placed Vivantia in Graphostromataceae based on nodulisporium-like asexual morph and bipartite stromata. However, this species is only known from a single collection made in the Caribbean many decades ago and fresh collection and sequence data are needed.

Halosphaeriaceae E. Müll. \& Arx, Can. J. Bot. 50: 1951 (1972)

Index Fungorum number: IF80832; Facesoffungi number: FoF01294; 171 species.

Saprobic on algae, immersed or submersed on phanerogams, wood, bark, leaves, and other cellulosic plant remains, grains of sand, or on calcareous shell fragments, rarely parasitic or symbiotic, found in marine (oceans, mangroves and estuaries) and freshwater habitats. Sexual morph: Ascomata subglobose, cylindrical or pyriform, hyaline or dark; sometimes subiculate, rarely stromatic; superficial or immersed. Ostioles papillate to long cylindrical; ostiolar canal with periphyses or pseudoparenchyma; rarely without ostioles. Peridium soft or subcarbonaceous, composed of flattened, thick- or thin-walled cells. Centre of immature ascomata consisting of polygonal, thin-walled, pseudoparenchymatic cells, sometimes with pits, at maturation separating to form catenophyses or compressed by the asci and dissolving. Paraphyses absent. Asci fusiform, clavate or rarely subglobose, with or without apical structures, thin-walled, 1-layered, persistent or swelling and deliquescing at or before ascospore maturity. Hymenial layer at base of venter, flat or convex. Mature ascospores filling the venter of the ascoma, released singly through the ostiole or rarely within the ascus, which swells after dispersal. Ascospores overlapping 2-3 seriate, hyaline or light brown, 1- multi-celled, mostly with characteristic ornamentations, appendages or gelatinous sheaths, or both. Asexual morph: Hyphomycetous. Hyphae hyaline or brown, superficially or immersed, septate, branched. Conidiophores simple or micronematous, hyaline or mid to dark brown, paler towards the apex, unbranched, walls smooth, thin or thick-walled, terminal, integrated, monoblastic, determinate or arise as erect lateral branches from the cells of the vegetative hyphae, wide at the base, tapering only slightly above or arising singly or in groups of 24 from a small stroma or flexuous, initially short and simple becoming longer and many times septate (up to 10), old conidiophore apices become displaced laterally as the conidiophore elongates and persists as short conoid denticles. Conidiogenous cells erect, some are with a distinct collarette, produce conidia terminally in a sympodial fashion or monoblastic, integrated, terminal, determinate. Conidia solitary, hyaline to bright reddish brown, holoblastic arising singly from the apices of the conidiogenous cells or develop as a small swelling at the end of the collarette, thinwalled, smooth, fusoid, (2) 7-11 septate, sigmoid with a flat detachment scar or initially oval gradually the upper half widens and becomes turbinate and finally triangular-shaped, each corner of the triangle with a long, hair-like divergent process or helicoids, semi-contorted, mostly coiled 0.75-1 times, 3-4 (5) septate, constricted at the septa; cells increase in size and pigments from base to apex: apical cell conspicuously swollen, subglobose, darker than the others, basal cell cylindrical and tapering (adapted from Maharachchikumbura et al. 2016b).

Type genus - Halosphaeria Linder

Notes - Halosphaeriaceae which was discussed by Müller \& von Arx (1962) and Eriksson (1984) currently comprises 163 species in 64 genera (Pang 2002, Jones et al. 2009, 2015, 2017, 2019, Maharachchikumbura et al. 2015, Wijayawardene et al. 2017a, 2018a). The Halosphaeriaceae was validated by Kohlmeyer (1972) and assigned as a single family to Halosphaeriales (Hawksworth \& Eriksson 1986). Halosphaeriaceae was previously polyphyletic and the genera Lulworthia and Lindra were referred to a new family Lulworthiaceae (Campbell et al. 2003, Pang et al. 2003, Koch et al. 2007). Even though Hibbett et al. (2007) and Schoch et al. (2007) referred Halosphaeriaceae to Microascales, some other researchers included it in Halosphaeriales (Zhang et al. 2006, Tang et al. 2007, Jones et al. 2009). Recent studies by Jones et al. (2015) and Maharachchikumbura et al. $(2015,2016 \mathrm{~b})$ established the placement of the Halosphaeriaceae as 
one of the families in the Microascales. Perithecial ascomata, necks (usually with periphyses), the presence of catenophyses that easily deliquesce, unitunicate, thin-walled asci that deliquesce early, with or lacking an apical ring and appendaged ascospores are the most common characters of this family (Jones 1995, Campbell et al. 2003, Pang et al. 2003, Koch et al. 2007), while some genera have been introduced based on ascospore appendage morphology and ontogeny, such as Bovicornuta, Kohlmeyeriella, Ondiniella, and Marinospora (Jones et al. 1983, 1984, Jones 1995) but subsequently confirmed by molecular data. Halosphaeriaceous species are primarily marine, found on wood (especially mangrove wood) or seagrasses and are cosmopolitan in distribution (Jones 2011, Jones \& Pang 2012, Jones et al. 2013). Some species are found in freshwater habitats, which was belong to the genera Aniptodera, Lignincola, Luttrellia, Magnisphaera, Naïs, Natantispora, Oceanitis, Panorbis and Phaeonectriella and the majority are lignicolous (Pang \& Jheng 2012, Cai et al. 2014). Around 75\% of halosphaeriaceous species have been sequenced (Jones et al. 2017).

\section{Ecological and economic significance of Halosphaeriaceae}

Halosphaeriaceous taxa play a significant role in the decomposition of complex organic matter in the marine ecosystem by secreting wood-modifying enzymes (cellulases, laccases and lignases) that degrade lignocelluloses (Jones \& Hyde 1988). Many species are able to cause soft rot decay of wood e.g. Halosphaeria appendiculata (Mouzouras 1986). Hence, contribute to the generation of particulate and dissolved organic matter available in the food web of the oceanic environment (Jones \& Pang 2012). Several studies have shown that mangrove associated halosphaeriaceous fungi are capable of producing hydrolytic and oxidative enzymes, thus indicating their probable role in recycling of lignocellulose in mangroves (Bucher et al. 2004). A number of halosphaeriaceous species have been shown to produce bioactive secondary metabolites, e.g. Corollospora maritima the source of corollosporine (Liberra et al. 1998).

\section{Genera included in Halosphaeriaceae}

We do not provide notes on each genus as these can be found at marinefungi.org (Jones et al. 2019). A monograph on genera of Halosphaeriaceae is also planned by Dayarathne et al. (2020).

Alisea J. Dupont \& E.B.G. Jones, Mycol. Res. 113(12): 1358 (2009)

Index Fungorum number: IF513289; 1 species with sequence data.

Type species - Alisea longicolla J. Dupont \& E.B.G. Jones

Amphitrite S. Tibell, Svensk Mykologisk Tidskrift 37(2): 45 (2016)

Index Fungorum number: IF817480; 1 morphological species.

Type species - Amphitrite annulata $\mathrm{S}$. Tibell

Aniptodera Shearer \& M.A. Mill., Mycologia 69(5): 893 (1977)

Index Fungorum number: IF198; 19 morphological species (Species Fungorum 2020), 3 species with sequence data.

Type species - Aniptodera chesapeakensis Shearer \& M.A. Mill.

Aniptosporopsis K.L. Pang, C.L. Lu, W.T. Ju \& E.B.G. Jones, Bot. Mar.: 459 (2016)

Index Fungorum number: IF818199; 1 species with sequence data.

Type species - Aniptosporopsis lignatilis (K.D. Hyde) K.L. Pang, C.L. Lu, W.T. Ju \& E.B.G. Jones

Anisostagma K.R.L. Petersen \& Jørg. Koch, Mycol. Res. 100: 209 (1996)

Index Fungorum number: IF27558; 1 morphological species.

Type species - Anisostagma rotundatum K.R.L. Petersen \& Jørg. Koch 
Antennospora Meyers, Mycologia 49: 501 (1957)

Index Fungorum number: IF219; 2 morphological species (Species Fungorum 2020), 1 species with sequence data.

Type species - Antennospora quadricornuta (Cribb \& J.W. Cribb) T.W. Johnson

Appendichordella R.G. Johnson, E.B.G. Jones \& S.T. Moss, Can. J. Bot. 65(5): 941 (1987)

Index Fungorum number: IF25087; 1 morphological species.

Type species - Appendichordella amicta (Kohlm.) R.G. Johnson, E.B.G. Jones \& S.T. Moss

Arenariomyces Höhnk, Veröff. Inst. Meeresf. Bremerhaven 3: 28 (1954)

Index Fungorum number: IF303; 5 morphological species (Species Fungorum 2020), 4 species with sequence data.

Type species - Arenariomyces trifurcatus Höhnk

Bathyascus Kohlm., Revue Mycol. 41(2): 190 (1977)

Index Fungorum number: IF519; 5 morphological species (Species Fungorum 2020).

Type species - Bathyascus vermisporus Kohlm.

Carbosphaerella I. Schmidt, Feddes Repert. 80(2-3): 108 (1969)

Index Fungorum number: IF820; 2 morphological species (Species Fungorum 2020), 1 species with sequence data.

Type species - Carbosphaerella pleosporoides I. Schmidt

Ceriosporopsis Linder, Farlowia 1: 408 (1944)

Index Fungorum number: IF915; 9 morphological species (Species Fungorum 2020), 2 species with sequence data.

Type species - Ceriosporopsis halima Linder

Chadefaudia Feldm.-Maz., Revue Générale de Botanique 64: 150 (1957)

Index Fungorum number: IF927; 6 morphological species (Species Fungorum 2020).

Type species - Chadefaudia marina Feldm.-Maz.

Corallicola Volkm.-Kohlm. \& Kohlm., Mycotaxon 44(2): 418 (1992)

Index Fungorum number: IF25426; 1 morphological species.

Type species - Corallicola nana Volkm.-Kohlm. \& Kohlm.

Corollospora Werderm., Notizbl. Bot. Gart. Berlin-Dahlem: 248 (1922)

Index Fungorum number: IF1251; 27 morphological species (Species Fungorum 2020), 16 species with sequence data.

Type species - Corollospora maritima Werderm.

Notes - Corollospora cinnamomea was introduced by Koch (1986) and differs from other species of the genus by brown rugose 1-septate ascospores and specialized pseudoparenchyma in the ostiolar canal. The peridium is thin and consists only of two (rarely three) cell layers in contrast to the other Corollospora spp. that have three or more layers (Nakagiri \& Tubaki 1986). Sequence data available for this species and its phylogenetic placement within Halosphaeriaceae is confirmed (Jones et al. 2017).

Cucullosporella K.D. Hyde \& E.B.G. Jones, Mycotaxon 37: 200 (1990)

Index Fungorum number: IF25506; 1 species with sequence data.

Type species - Cucullosporella mangrovei (K.D. Hyde \& E.B.G. Jones) K.D. Hyde \& E.B.G. Jones 


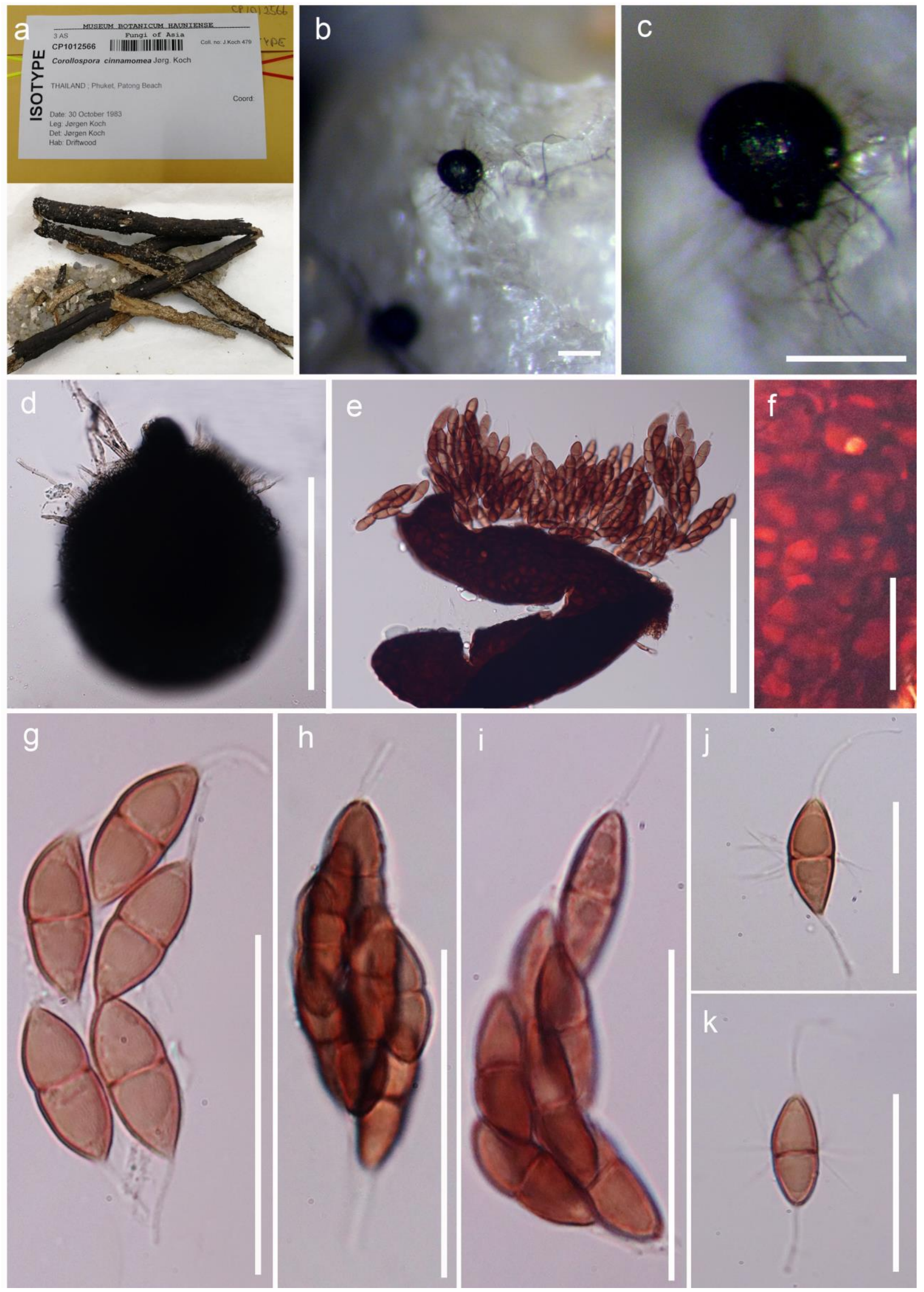

Figure 114 - Corollospora cinnamomea (Material examined - THAILAND, Phuket, Patong beach, on driftwood, 30 Oct. 1983, J. Koch., CP1012566, isotype). a Herbarium material. b, c Ascomata on sand grain. d Outer apperence of ascomata. e Squash mount of ascomta (microslide). $\mathrm{f}$ Peridium. g-i Asci. j, k Ascospores. Scale bars: b, c $=200 \mu \mathrm{m}, \mathrm{d}=100 \mu \mathrm{m}, \mathrm{e}, \mathrm{g}-\mathrm{i}=50 \mu \mathrm{m}, \mathrm{f}, \mathrm{j}, \mathrm{k}=20 \mu \mathrm{m}$. 


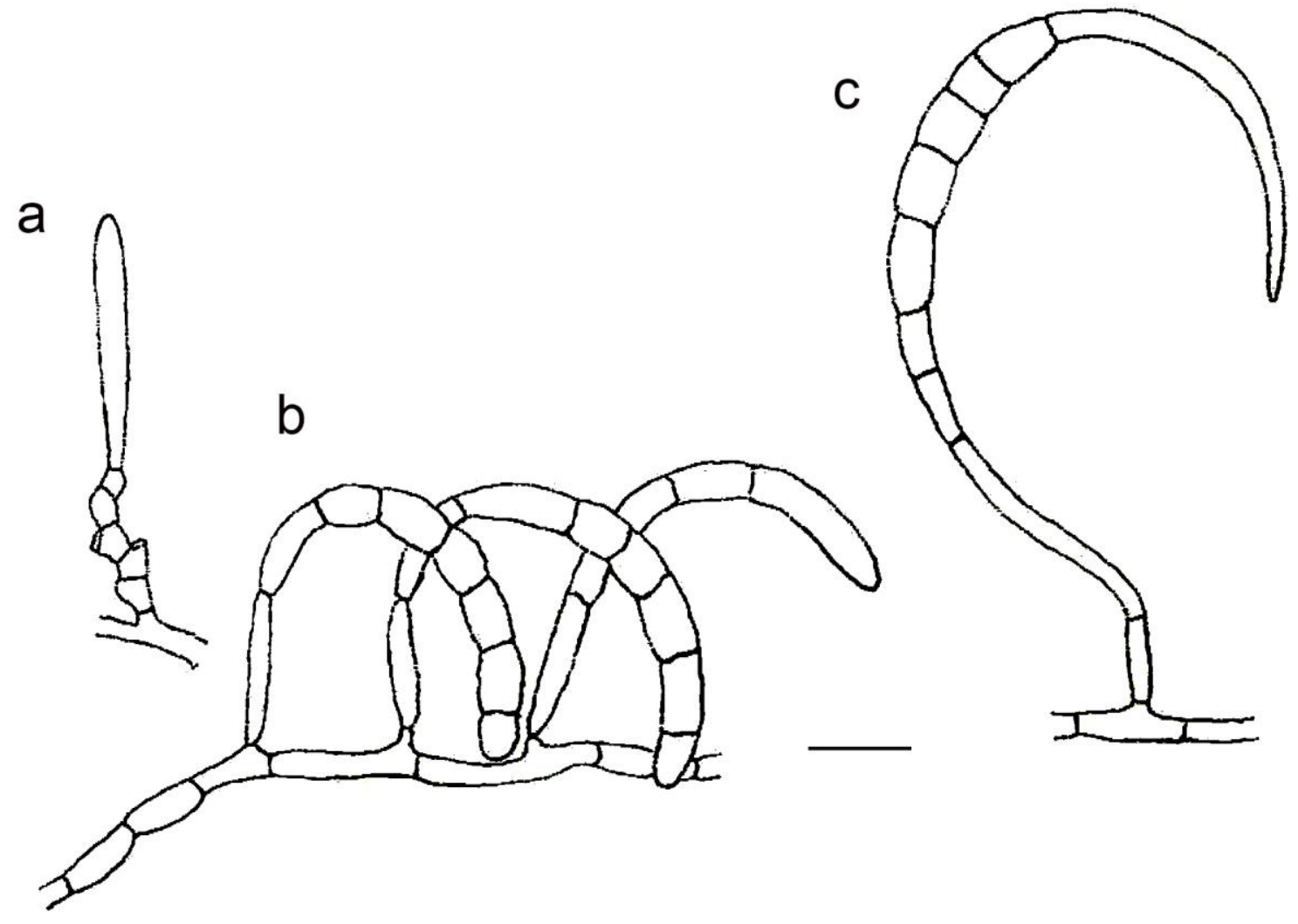

Figure 115 - Corollospora marina (redrawn from Haythorn et al. 1980). a Conidiophore with a developing conidium and scars left by the detached conidia. b, c Single conidia produced from a simple conidiophore. Scale bar: $50 \mu \mathrm{m}$.

Ebullia K.L. Pang, Mycoscience 56: 40 (2015)

Index Fungorum number: IF803444; 1 species with sequence data.

Type species - Ebullia octonae (Kohlm.) K.L. Pang

Gesasha Abdel-Wahab \& Nagahama, Nova Hedwigia 92(3-4): 501 (2011)

Index Fungorum number: IF518670; 3 species with sequence data.

Type species - Gesasha mangrovei Abdel-Wahab \& Nagah.

Haiyanga K.L. Pang \& E.B.G. Jones, Raffles Bull. Zool., Suppl. 19: 8 (2008)

Index Fungorum number: IF535842; 1 species with sequence data.

Type species - Haiyanga salina (Meyers) K.L. Pang \& E.B.G. Jones

Haligena Kohlm., Nova Hedwigia 3: 87 (1961)

Index Fungorum number: IF2204; 1 species with sequence data.

Type species - Haligena elaterophora Kohlm.

Halosarpheia sensu stricto Kohlm. \& E. Kohlm., Trans. Br. Mycol. Soc. 68(2): 208 (1977)

Index Fungorum number: IF2208; 8 morphological species (Species Fungorum 2020), 4 species with sequence data.

Type species - Halosarpheia fibrosa Kohlm. \& E. Kohlm.

Halosphaeria Linder, Farlowia 1: 412 (1944)

Index Fungorum number: IF2209; 4 morphological species (Species Fungorum 2020), 1 species with sequence data.

Type species - Halosphaeria appendiculata Linder 
Halosphaeriopsis T.W. Johnson, J. Elisha Mitchell Scient. Soc. 74: 44 (1958)

Index Fungorum number: IF2210; 1 species with sequence data.

Type species - Halosphaeriopsis mediosetigera (Cribb \& J.W. Cribb) T.W. Johnson

Havispora K.L. Pang \& Vrijmoed, Mycologia 100(2): 293 (2008)

Index Fungorum number: IF506744; 1 species with sequence data.

Type species - Havispora longyearbyenensis K.L. Pang \& Vrijmoed

Iwilsoniella E.B.G. Jones, Syst. Ascomyc. 10(1): 8 (1991)

Index Fungorum number: IF25574; 1 morphological species.

Type species - Iwilsoniella rotunda E.B.G. Jones

Kitesporella Jheng \& K.L. Pang, Bot. Mar. 55: 462 (2012)

Index Fungorum number: IF563899; 1 morphological species.

Type species - Kitesporella keelungensis J.S. Jheng \& K.L. Pang

Kochiella Sakay., K.L. Pang \& E.B.G. Jones, Fungal Divers. 46: 96 (2011)

Index Fungorum number: IF518769; 1 species with sequence data.

Type species - Kochiella crispa (Kohlm.) Sakay., K.L. Pang \& E.B.G. Jones

Lautisporopsis E.B.G. Jones, Yusoff \& S.T. Moss, Mycotaxon 67: 1 (1998)

Index Fungorum number: IF27443; 1 morphological species.

Type species - Lautosporopsis circumvestita (Kohlm.) E.B.G. Jones, Yusoff \& S.T. Moss

Lignincola Höhnk, Veröff. Inst. Meeresf. Bremerhaven 3: 216 (1955)

Index Fungorum number: IF2864; 4 morphological species (Species Fungorum 2020), 2 species with sequence data.

Type species - Lignincola laevis Höhnk

Limacospora Jørg. Koch \& E.B.G. Jones, Can. J. Bot. 73(7): 1011 (1995)

Index Fungorum number: IF27610; 1 morphological species.

Jones

Type species - Limacospora sundica (Jørg. Koch \& E.B.G. Jones) Jørg. Koch \& E.B.G.

Luttrellia Shearer, Mycologia 70(3): 692 (1978)

Index Fungorum number: IF2954; 4 morphological species (Species Fungorum 2020).

Type species - Luttrellia estuarina Shearer

Magnisphaera J. Campbell, J.L. Anderson \& Shearer, Mycologia 95(3): 546 (2003)

Index Fungorum number: IF28707; 2 species with sequence data.

Type species - Magnisphaera spartinae (E.B.G. Jones) J. Campb., J.L. Anderson \& Shearer

Marinospora A.R. Caval., Nova Hedwigia 11: 548 (1966)

Index Fungorum number: IF3002; 2 species with sequence data.

Type species - Marinospora calyptrata (Kohlm.) A.R. Caval.

Moana Kohlm. \& Volkm.-Kohlm., Mycol. Res. 92 (4): 418 (1989)

Index Fungorum number: IF25325; 1 morphological species.

Type species - Moana turbinulata Kohlm. \& Volkm.-Kohlm.

Morakotiella Sakay., Mycologia 97(4): 806 (2005)

Index Fungorum number: IF28969; 1 species with sequence data. 
Type species - Morakotiella salina (C.A. Farrant \& E.B.G. Jones) Sakay.

Naïs Kohlm., Nova Hedwigia 4: 409 (1962)

Index Fungorum number: IF92064; 2 morphological species (Species Fungorum 2020), 1 species with sequence data.

Type species - Naïs inornata Kohlm.

Natantispora J. Campbell, J.L. Anderson \& Shearer, Mycologia 95(3): 543 (2003)

Index Fungorum number: IF28703; 3 species with sequence data.

Type species - Natantispora lotica (Shearer) J. Campb., J.L. Anderson \& Shearer

Nautosphaeria E.B.G. Jones, Trans. Br. Mycol. Soc. 47(1): 97 (1964)

Index Fungorum number: IF3428; 1 species with sequence data.

Type species - Nautosphaeria cristaminuta E.B.G. Jones

Neptunella K.L. Pang \& E.B.G. Jones, Mycol. Progr. 2(1): 35 (2003)

Index Fungorum number: IF28749; 1 species with sequence data.

Type species - Neptunella longirostris (Cribb \& J.W. Cribb) K.L. Pang \& E.B.G. Jones

Nereiospora E.B.G. Jones, R.G. Johnson \& S.T. Moss, J. Linn. Soc. Bot. 87(2): 204 (1983)

Index Fungorum number: IF25825; 2 species with sequence data.

Type species - Nereiospora comata (Kohlm.) E.B.G. Jones, R.G. Johnson \& S.T. Moss

Nimbospora J. Koch, Nordic J. Bot. 2(2): 166 (1982)

Index Fungorum number: IF3509; 2 species with sequence data.

Type species - Nimbospora bipolaris K.D. Hyde \& E.B.G. Jones

Nohea Kohlm. \& Volkm.-Kohlm., Syst. Ascomyc. 10: 121 (1991)

Index Fungorum number: IF25883; 3 morphological species (Species Fungorum 2020), 2

species with sequence data.

Type species - Nohea umiumi Kohlm. \& Volkm.-Kohlm.

Oceanitis Kohlm., Revue Mycol. 41(2): 193 (1977)

Index Fungorum number: IF532552; 4 species with sequence data.

Type species - Oceanitis scuticella Kohlm.

Ocostaspora E.B.G. Jones, R.G. Johnson \& S.T Moss, Bot. Mar. 26: 353 (1983)

Index Fungorum number: IF25829; 1 species with sequence data.

Type species - Ocostaspora apilongissima E.B.G. Jones, R.G. Johnson \& S.T. Moss

Okeanomyces K.L. Pang \& E.B.G. Jones, J. Linn. Soc. Bot. 146(2): 228 (2004)

Index Fungorum number: IF28838; 1 species with sequence data.

Type species - Okeanomyces cucullatus (Kohlm.) K.L. Pang \& E.B.G. Jones

Ondiniella E.B.G. Jones, R.G. Johnson \& S.T. Moss, Bot. Mar. 27: 136 (1984)

Index Fungorum number: IF25830; 1 species with sequence data.

Type species - Ondiniella torquata (Kohlm.) E.B.G. Jones, R.G. Johnson \& S.T. Moss

Ophiodeira Kohlm. \& Volkm.-Kohlm., Can. J. Bot. 66 (10): 2062 (1988)

Index Fungorum number: IF25267; 1 species with sequence data.

Type species - Ophiodeira monosemeia Kohlm. \& Volkm.-Kohlm. 
Panorbis J. Campbell, J.L. Anderson \& Shearer, Mycologia 95(3): 544 (2003)

Index Fungorum number: IF28704; 1 species with sequence data.

Type species - Panorbis viscosus (I. Schmidt) J. Campb., J.L. Anderson \& Shearer

Paraaniptodera K.L. Pang, C.L. Lu, W.T. Ju \& E.B.G. Jones, Bot. Mar. 60(4): 460 (2017)

Index Fungorum number: IF818212; 1 species with sequence data.

Type species - Paraaniptodera longispora (K.D. Hyde) K.L. Pang, C.L. Lu, W.T. Ju \& E.B.G. Jones

Phaeonectriella R.A. Eaton \& E.B.G. Jones, Nova Hedwigia 19(3-4): 779 (1971)

Index Fungorum number: IF3928; 3 morphological species (Species Fungorum 2020), 1 species with sequence data.

Type species - Phaeonectriella lignicola R.A. Eaton \& E.B.G. Jones

Pileomyces K.L. Pang \& Jheng, Bot. Stud. 53: 536 (2012)

Index Fungorum number: IF519625; 1 species with sequence data.

Type species - Pileomyces formosanus K.L. Pang \& J.S. Jheng

Praelongicaulis E.B.G. Jones, Abdel-Wahab, \& K.L. Pang, Fungal Divers. 73(1): 54 (2015)

Index Fungorum number: IF812594; 1 species with sequence data.

Type species - Praelongicaulis kandeliae (Abdel-Wahab \& E.B.G. Jones) E.B.G. Jones,

Abdel-Wahab, \& K.L. Pang

Pseudolignincola Chatmala \& E.B.G. Jones, Nova Hedwigia 83(1-2): 225 (2006)

Index Fungorum number: IF29053; 1 species with sequence data.

Type species - Pseudolignincola siamensis Chatmala \& E.B.G. Jones

Remispora Linder, Farlowia 1(3): 409 (1944)

Index Fungorum number: IF4674; 6 morphological species (Species Fungorum 2020), 5 species with sequence data.

Type species - Remispora maritima Linder

Saagaromyces K.L. Pang \& E.B.G. Jones, Mycol. Progr. 2(1): 35 (2003)

Index Fungorum number: IF28748; 4 species with sequence data.

Type species - Saagaromyces abonnis (Kohlm.) K.L. Pang \& E.B.G. Jones

Sablicola E.B.G. Jones, K.L. Pang \& Vrijmoed, Can. J. Bot. 82(4): 486 (2004)

Index Fungorum number: IF28801; 1 species with sequence data.

Type species - Sablicola chinensis E.B.G. Jones, K.L. Pang \& Vrijmoed

Thalassogena Kohlm. \& Volkm.-Kohlm., Syst. Ascomyc. 6: 223 (1987)

Index Fungorum number: IF25208; 1 morphological species.

Type species - Thalassogena sphaerica Kohlm. \& Volkm.-Kohlm.

Thalespora Chatmala \& E.B.G. Jones, Nova Hedwigia 83(1-2): 228 (2006)

Index Fungorum number: IF29054; 1 species with sequence data.

Type species - Thalespora appendiculata Chatmala \& E.B.G. Jones

Tinhaudeus K.L. Pang, S.Y. Guo \& E.B.G. Jones, Fungal Divers. 75: 160 (2015)

Index Fungorum number: IF812936; 1 species with sequence data.

Type species - Tinhaudeus formosanus K.L. Pang, S.Y. Guo \& E.B.G. Jones 
Tirispora E.B.G. Jones \& Vrijmoed, Can. J. Bot. 72(9): 1373 (1994)

Index Fungorum number: IF27405; 2 morphological species (Species Fungorum 2020), 1 species with sequence data.

Type species - Tirispora unicaudata E.B.G. Jones \& Vrijmoed

Toriella Sakay., K.L. Pang \& E.B.G. Jones, Fungal Divers. 46(1): 99 (2011)

Index Fungorum number: IF518774; 1 species with sequence data.

Type species - Toriella tubulifera (Kohlm.) Sakay., K.L. Pang \& E.B.G. Jones

Trailia G.K. Sutherl., Trans. Br. Mycol. Soc. 5: 149 (1915)

Index Fungorum number: IF5516; 1 morphological species.

Type species - Trailia ascophylli G.K. Sutherl.

Trichomaris Hibbits, G.C. Hughes \& Sparks, Can. J. Bot. 59(11): 2123 (1981)

Index Fungorum number: IF5559; 1 morphological species.

Type species - Trichomaris invadens Hibbits, G.C. Hughes \& Sparks

Tubakiella Sakay., K.L. Pang \& E.B.G. Jones, Fungal Divers. 46: 97 (2011)

Index Fungorum number: IF518772; 1 species with sequence data.

Type species - Tubakiella galerita (Tubaki) Sakay., K.L. Pang \& E.B.G. Jones

Tunicatispora K.D. Hyde, Aust. Syst. Bot. 3: 712 (1990)

Index Fungorum number: IF25558; 1 morphological species.

Type species - Tunicatispora australiensis K.D. Hyde

Hansfordiaceae Crous, Fungal Systematics and Evolution 3: 84 (2019)

Index Fungorum number: IF829455; Facesoffungi number: FoF06206; 13 species.

Saprobic on leaf and stem tissues bearing ascomata. Sexual morph: Undetermined. Asexual morph: Mycelium superficial to immersed on stems or twigs. Conidiophores superficial or setiform, solitary, erect, multi-septate with lateral branches, surface smooth, straight to flexuous, light brown. Conidiogenous cells hyaline, cylindrical or clavate, with subdenticulate apical loci. Conidia solitary, dry, aseptate, hyaline to pale brown, globose, ellipsoid to fusoid, smooth-walled or finely roughened (adapted from Crous et al. 2019b).

Type genus - Hansfordia S. Hughes.

Notes - Hansfordiaceae was introduced by Crous et al. (2019b) and belongs in Xylariales. The family comprises a single genus, Hansfordia. Hansfordiaceae is closely related to the families Sporocadaceae, Phlogicylindriaceae and Beltraniaceae.

\section{Ecological and economic significance of Hansfordiaceae}

Mitchell \& Taber (1986) and Alderman (2010) suggested that Hansfordia pulvinata as a possible biological control agent against plant pathogenic fungi. Alderman (2010) accepted Dicyma pulvinata (= Hansfordia pulvinata), as a potential biocontrol agent of Cereosporidim personatum in peanut.

\section{Genus included in Hansfordiaceae}

Hansfordia S. Hughes, Mycol. Pap. 43: 15 (1951)

Index Fungorum number: IF8423; 13 morphological species (Species Fungorum 2020), 2 species with sequence data.

Type species - Hansfordia ovalispora S. Hughes

Notes - Hansfordia was introduced by Hughes (1951a) with 12 species based on morphology. Crous et al. (2019b) introduced H. pruni and $H$. pulvinata to this genus based on morphology and LSU and ITS sequence data. The main characters to differentiate species of 
Hansfordia is the denticulate nature of cylindrical conidiogenous cells with regular verticils inserted directly on the stipe (Hughes 1951a).

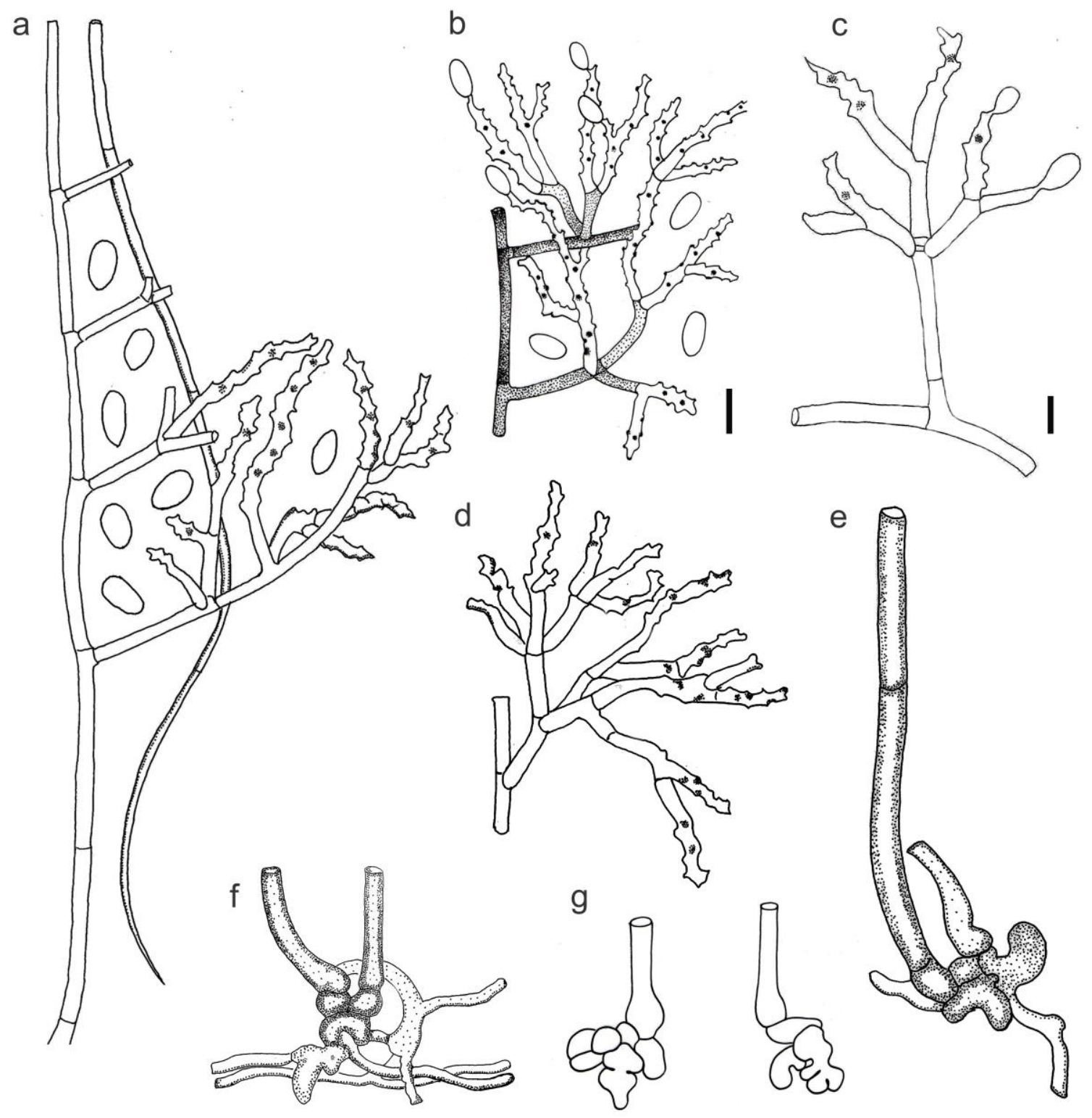

Figure 116 - Hansfordia ovalispora (redrawn asexual morph of $H$. ovalispora from Hughes 1951a). a, b, d Conidiophores with conidia. c Single conidiophore immature conidia. e-g Lateral branches. Scale bars: $b, c=10 \mu \mathrm{m}$.

Harknessiaceae Crous, Persoonia, Mol.Phyl. Evol. Fungi 28: 55 (2012)

Index Fungorum number: IF564740; Facesoffungi number: FoF01387; 69 species.

Saprobic or pathogenic on leaves or twig litter. Sexual morph: Ascomata perithecial, solitary or aggregated, immersed, globose, coriaceous, brown, ostiolate, papillate. Papilla emergent to depressed, comprising 3-5 layers of brown-walled cells of textura angularis. Paraphyses septate, branched. Asci 8-spored, unitunicate, cylindrical to clavate, short pedicellate, with J-, apical ring. Ascospores uniseriate to biseriate, hyaline, ellipsoid to fusoid, aseptate, thick-walled, guttulate, smooth-walled. Asexual morph: Coelomycetous. Conidiomata eustromatic, pycnidial, scattered or aggregated, immersed, globose, coriaceous, with single or several locules, dark brown to black, ostiolate. Peridium comprising thin-walled, almost hyaline to brown cells of textura angularis. Ostiole wide, centrally located, surrounded by brown cells. Conidiophores lining the inner cavity, 
or reduced to basal layer; sometimes septate, branched; sometimes reduced to conidiogenous cells. Conidiogenous cells holoblastic, integrated, lageniform, subcylindrical to cylindrical, hyaline to pale yellow, smooth, producing macroconidia and sometimes microconidia from same conidiogenous cell; sometimes proliferating sympodially one or several times. Macroconidia with a basal appendage, hyaline when young, brown at maturity, unicellular, although basal appendage separated by a thick, smooth-walled septum, with or without light and dark longitudinal bands, sometimes longitudinally striate, guttulate; basal appendage cellular, cylindrical to subcylindrical, hyaline, thin-walled, devoid of contents; apical appendage present or absent, if present elongate. Microconidia hyaline, oval to ellipsoid, aseptate, smooth-walled (adapted from Senanayake et al. 2018).

Type genus - Harknessia Cooke

Notes - Harknessiaceae was initially proposed by Castlebury et al. (2002), subsequently formally introduced by Crous et al. (2012d) to accommodate Harknessia with their wuestneia-like sexual morphs. Species of Harknessiaceae have pycnidial conidiomata with brown, furfuraceous margins, brown conidia with hyaline, tube-like basal appendages, longitudinal striations, and rhexolytic secession (Crous et al. 2012d, Senanayake et al. 2018). Harknessiaceae species seem to have a cosmopolitan distribution, since they have been recorded worldwide, and are commonly associated with leaf spots and branches of various hosts (Sankaran et al. 1995, Farr \& Rossman 2019). They have also been recoded as endophytes and saprobes in leaves and twigs of various angiosperm plants and noxious weeds (Crous et al. 2012d).

LSU analysis support this family which was earlier placed in Diaporthales (Crous et al. 2012d). Crous et al. (2012d) introduced six novel species of Harknessia on Eucalyptus and supported by a multi-gene analysis (ITS, calM and tub2) for these species.

\section{Ecological and economic significance of Harknessiaceae}

Most members in the family are associated with leaf spots, leaf tip-dieback or leaf scorch and stem cankers and they are suspected to be pathogens mainly in Eucalyptus (Crous et al. 1989, Marincowitz et al. 2008). However, many species have been isolated from asymptomatic plant tissues and are assumed to be saprobes. Therefore, their pathogenicity is still ambiguous. Normally they are species with less economical significance (Park et al. 2000).

\section{Genera included in Harknessiaceae}

Harknessia Cooke, Grevillea 9 (no.51): 85 (1881)

Index Fungorum number: IF8449; 68 morphological species (Species Fungorum 2020), 38 species with sequence data.

Type species - Harknessia eucalypti Cooke

Notes - Harknessia species have been recorded in wide variety of habitats and normally they appear as leaf spots, wherein leaves with tip-dieback or leaf scorch and stem cankers occur (Crous et al. 1989, Wijayawardene et al. 2016b). Some species have been recorded from leaf and twig litter (Marincowitz et al. 2008). However, the pathogenicity of Harknessia species on host plants is not proven yet, since nobody has resolved it experimentally. Harknessia species with hyaline conidia and apical appendages were transferred to Mastigosporella by Höhnel (1917c), and species with brown conidia with apical and basal appendages were placed to Apoharknessia (Lee et al. 2004), whereas species with very thick conidial walls and longitudinal slits were included in Dwiroopa (Farr \& Rossman 2003). Harknessia has enough molecular support to accommodate in a distinct lineage in Harknessiaceae. Currently, there are 74 Harknessia epithets in Index Fungorum (2020).

Yuan \& Mohammed (1997) introduced Wuestneia epispora which was identical to the asexual morph of Harkenessia eucalypti. According to the cultural characters conidia of $W$. epispora are shorter (11-22 $\times 11-15 \mu \mathrm{m})$ than those of $\mathrm{H}$. eucalypti (Crous et al. 1993). However, the average of conidial size $(25.4 \times 13.9 \mu \mathrm{m})$ by Yuan \& Mohammed (1997) is closely similar with the averages of H. eucalypti $(23 \times 14 \mu \mathrm{m})(\mathrm{Nag}$ Raj 1993). Therefore, Lee et al. (2004) treated this culture as authentic to H.eucalypti. 


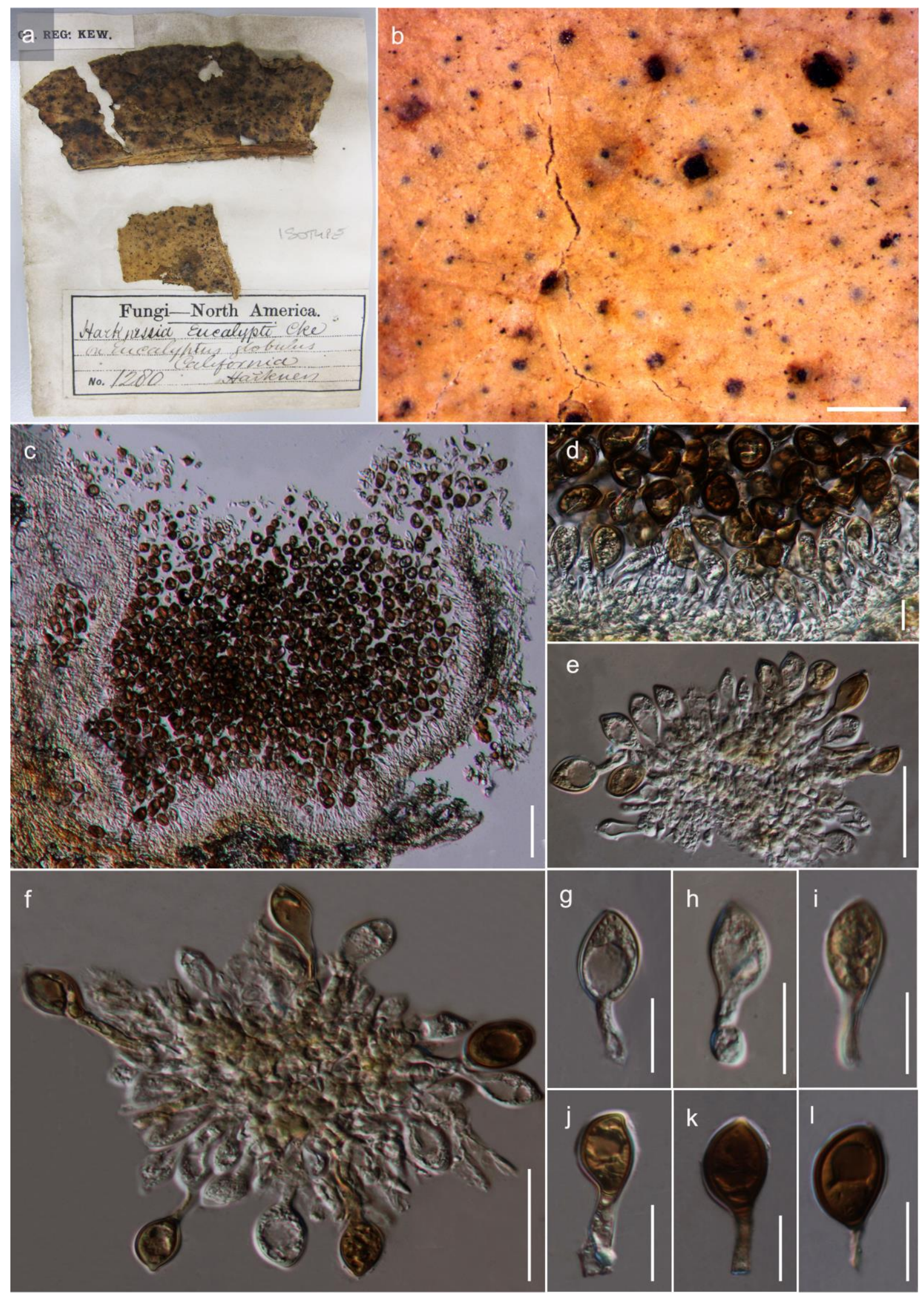

Figure 117 - Harknessia eucalypti (Material examined - USA, California, on leaves of Eucalyptus globulus. (Myrtaceae), Harknessia 1280, isotype K (M) 195744). a Herbarium specimen. b Conidiomata on host substrate. c Cross section of conidioma. d Peridium. e, f Conidia attached to conidiophores. g-k conidia are attached to conidiogenous cells. 1 Conidium with basal appendage. Scale bars: $\mathrm{c}=100 \mu \mathrm{m}, \mathrm{d}-\mathrm{f}=20 \mu \mathrm{m}, \mathrm{g}-\mathrm{l}=10 \mu \mathrm{m}$. 
Mebarria J. Reid \& C. Booth, Can. J. Bot. 67(3): 898 (1989)

Index Fungorum number: IF25321; 1 morphological species.

Type species - Mebarria thujina (Nag Raj \& DiCosmo) J. Reid \& C. Booth

Notes - Nag Raj \& DiCosmo (1981) introduced Cryptosporella thujina and Reid \& Booth (1989) synonymized as Mebarria thujina accommodating it in a new genus Mebarria. The asexual morph of this species was recorded as Harknessia thujina (Index Fungorum 2020). However, molecular data needs to confirm sexual and asexual connection of these two species.

Helminthosphaeriaceae Samuels, Cand. \& Magni, Mycologia 89(1): 144 (1997)

Index Fungorum number: IF81913; Facesoffungi number: FoF01142; 140 species.

Saprobic on wood or decorticated branch in terrestrial and aquatic habitats, some fungicolous. Sexual morph: Ascomata perithecial, gregarious or scattered, dark brown to black, solitary, superficial or immersed, ovoid, globose to subglobose, rough, tuberculate, smooth or with setae, papillate or ostiole indistinct, the apex collapsing when dry. Ostioles periphysate. Peridium composed of two layers, outer layer comprising brown cells of textura angularis or prismatica, carbonaceous or membranaceous; inner layer comprising hyaline cells of textura prismatica, thin, membranaceous. Paraphyses numerous, septate, persistent or deliquescing, swollen, filiform or cylindrical. Asci 8-spored, unitunicate, thin or thick-walled, cylindrical to clavate, pedicellate, apex truncate, J-, apical ring refractive or indistinct. Ascospores 2-seriate, hyaline or brown or becoming dark colored in part, allantoid, clavate, cylindrical to ellipsoid, 0-3-septate, smooth-walled, with or without guttules or pores. Asexual morph: Hyphomycetous. Conidiophores macronematous, mononematous, scattered or gregarious, brown, straight, septate, unbranched, smooth-walled. Conidiogenous cells mono- or polyblastic, terminal, intercalary, integrated, percurrently elongating; conidiogenesis tretic. Conidia solitary, acrogenous, brown, aseptate or septate, obclavate, globose to fusiform to cylindrical, straight, subtruncate to obtuse at the apex, truncate or swollen at the base, sometimes with guttules.

Type genus - Helminthosphaeria Fuckel

Notes - Helminthosphaeriaceae was introduced by Samuels et al. (1997) for taxa with black, setose ascomata and cylindrical asci containing brown ascospores and included the only genus Helminthosphaeria (Fuckel 1870). Tengiomyces was added to the family by Réblová (1999a) based on similar characters to Helminthosphaeria, viz. setose ascomata. Echinosphaeria, Hilberina, Ruzenia and Synaptospora, many of which are Lasiosphaeria segregates, were included based on analysis of LSU sequence data and characters (Miller \& Huhndorf 2004, Miller et al. 2014). Endophragmiella was accepted as the asexual morph of Echinosphaeria (Hughes 1979). Helminthosphaeriaceae forms a well-supported clade in Chaetosphaeriales, with Chaetosphaeriaceae as a sister clade (Maharachchikumbura et al. 2015). Currently seven genera are accepted in the family based on morphological and phylogenic analyses of LSU, SSU, tefl and rpb2 sequence data (Fig. 8). Although we include Tengiomyces here, it lacks molecular data, which is needed to confirm its placement.

\section{Ecological and economic significance of Helminthosphaeriaceae}

Members of Helminthosphaeriaceae are usually saprobic on wood or/and other fungi in terrestrial, marine or freshwater habitats and are distributed worldwide, but more taxa are reported from Europe, such as Echinosphaeria canescens (on driftwood of half buried in sand), Helminthosphaeria clavariarum (on Clavulina sp.) (Hughes 1979, Réblová 1999a, Miller \& Huhndorf 2004, Miller et al. 2014, Hernández-Restrepo et al. 2017).

\section{Genera included in Helminthosphaeriaceae}

Echinosphaeria A.N. Mill. \& Huhndorf, Mycol. Res. 108(1): 29 (2004)

Index Fungorum number: IF28829; 14 morphological species (Species Fungorum 2020), 1 species with sequence data.

Type species - Echinosphaeria canescens (Pers.) A.N. Mill. \& Huhndorf 
Notes - Echinosphaeria, typified by Echinosphaeria canescens, has setose ascomata and cylindrical asci with reniform ascospores. This genus is closely related to Helminthosphaeria and Synaptospora within Helminthosphaeriaceae (Miller \& Huhndorf 2004) (Fig. 8).

Endophragmiella B. Sutton, Mycol. Pap. 132: 58 (1973)

Index Fungorum number: IF8167; 84 morphological species (Species Fungorum 2020), 2 species with sequence data.

Type species - Endophragmiella pallescens B. Sutton

Notes - Endophragmiella pallescens has branched, septate, flexuous conidiophores and ellipsoid, septate conidia (Sutton 1973). This genus was accepted in Helminthosphaeriaceae and is closely related to Helminthosphaeria (Hernández-Restrepo et al. 2017).

Helminthosphaeria Fuckel, Jb. nassau. Ver. Naturk. 23-24: 166 (1870)

Index Fungorum number: IF2263; 18 morphological species (Species Fungorum 2020), 9 species with sequence data.

Type species - Helminthosphaeria clavariarum (Desm.) Fuckel

Notes - Helminthosphaeria was included in Melanosporaceae, in Sordariales based on its 1septate ascospores with apical pores (Parguey-Leduc 1960). Lundqvist (1972) excluded Helminthosphaeria from Melanosporaceae due to its distinct filamentous pseudoparaphyses and asci lacking sheaths. Barr (1990b) reevaluated Sordariaceae and included Helminthosphaeria. Eriksson \& Hawksworth (1993) placed Helminthosphaeria in Sordariales. Samuels et al. (1997) monographed the genus, including the asexual morph Diplococcium, and introduced Helminthosphaeriaceae (Goh \& Hyde 1998, Réblová 1999a, Hernández-Restrepo et al. 2017).

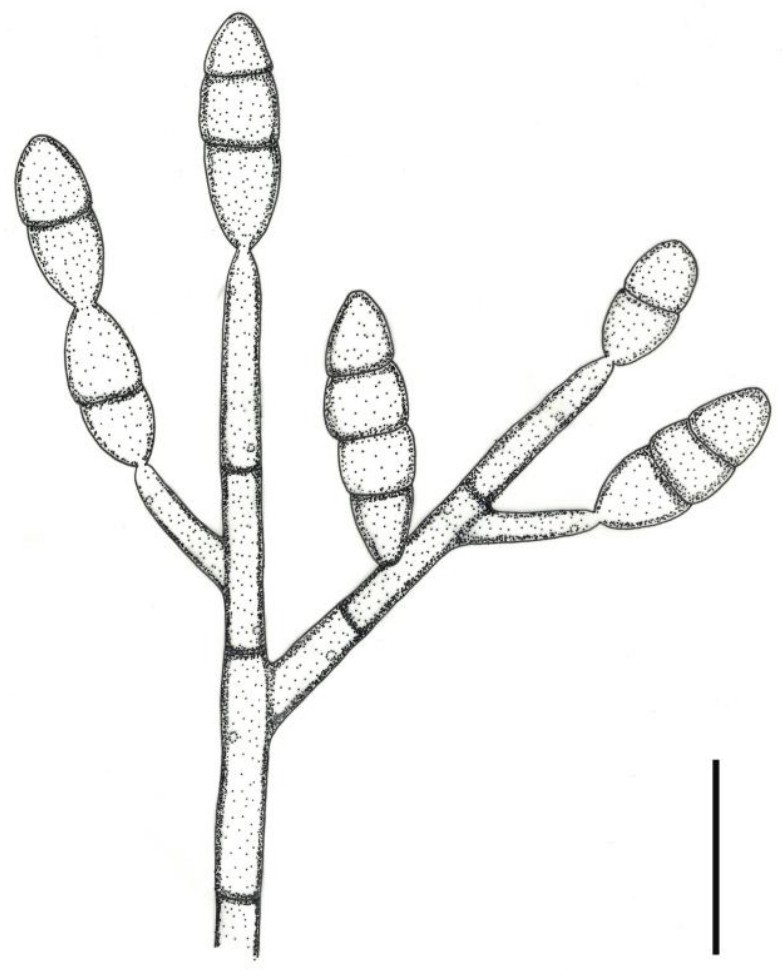

Figure 118 - Helminthosphaeria pilifera (diplococcium-like, redrawn from Réblová 1999a). Conidiophore with conidia of Diplococcium asexual morph. Scale bar $=20 \mu \mathrm{m}$.

Hilberina Huhndorf \& A.N. Mill., Mycol. Res. 108(1): 31 (2004)

Index Fungorum number: IF28830; 17 morphological species (Species Fungorum 2020), 5 species with sequence data.

Type species - Hilberina caudata (Fuckel) Huhndorf \& A.N. Mill. 
Notes - Hilberina caudata has setose ascomata, cylindrical asci with rings and geniculate ascospores with one end tapering to a distinct point (Miller \& Huhndorf 2004). Sequence data of five members in Hilberina were provided by Miller et al. (2014) and reveals that Hilberina was closely related to Synaptospora, Ruzenia and Helminthosphaeria within Helminthosphaeriaceae (Fig. 8).
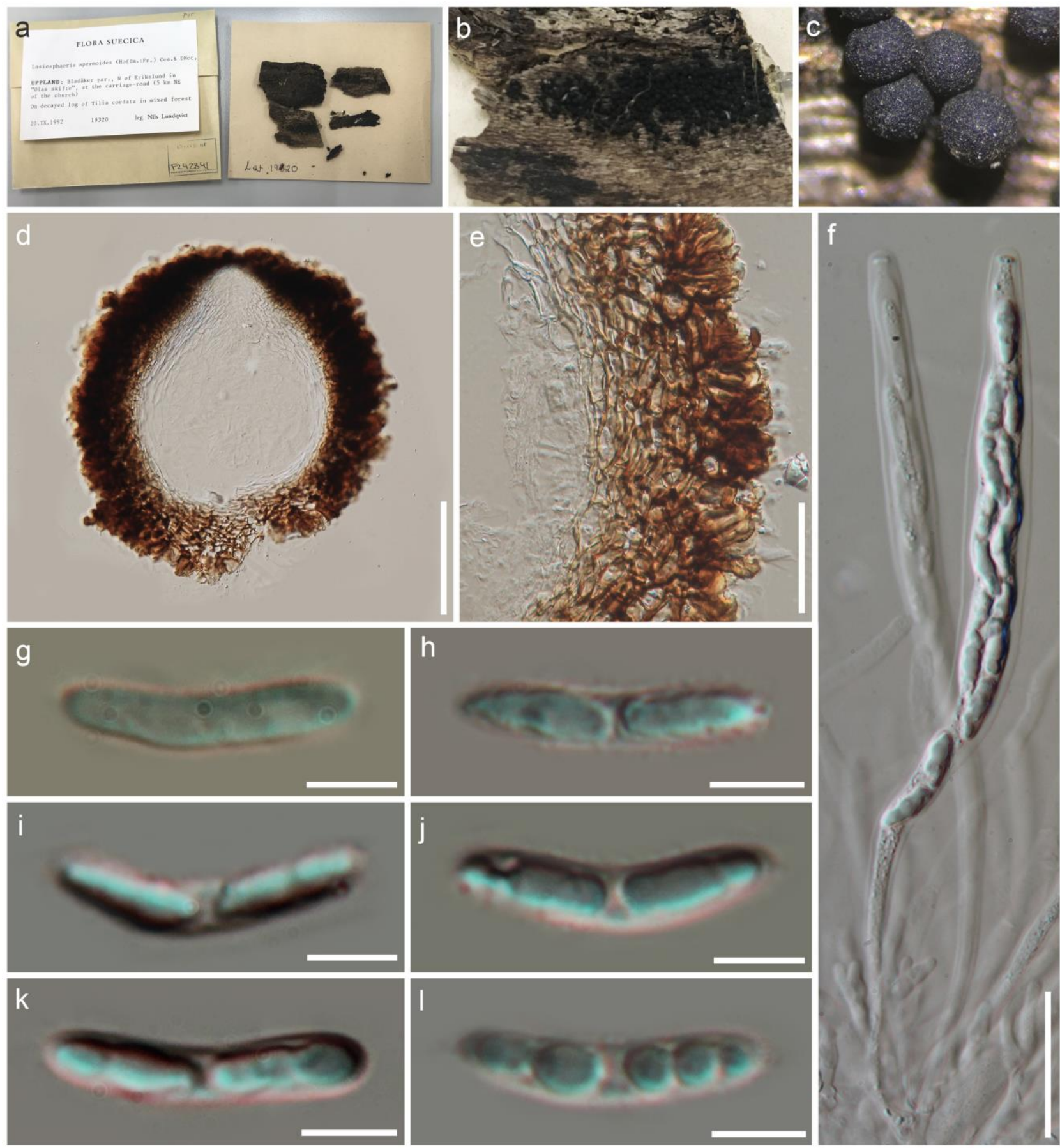

Figure 119 - Ruzenia spermoides (Material examined - SWEDEN, Uppland, Bladaker; on dead wood of Tilia cordata; 20 September 1992, S-F 242341). a Material label. b Material. c Ascoma on host. d Ascoma cross section. e Peridium. f Asci. g-l Ascospores. Notes: figs f-l stained in $\mathrm{KOH}$ reagent. Scale bars: $\mathrm{d}=200 \mu \mathrm{m}$, e-f $=50 \mu \mathrm{m}, \mathrm{g}-\mathrm{l}=10 \mu \mathrm{m}$.

Ruzenia O. Hilber, The Genus Lasiosphaeria and Allied Taxa (Kelheim): 7 (2002) Index Fungorum number: IF530833; 1 species with sequence data. Type species - Ruzenia spermoides (Hoffm.) O. Hilber 
Notes - Ruzenia spermoides has glabrous ascomata, cylindrical asci and allantoid ascospores with guttules (Miller \& Huhndorf 2004). It is closely related to Synaptospora based on multi-gene analysis (Miller et al. 2014) (Fig. 8).

Synaptospora Cain, Beih. Sydowia 1: 4 (1957)

Index Fungorum number: IF5328; 5 morphological species (Species Fungorum 2020), 1 species with sequence data.

Type species - Synaptospora petrakii Cain

Notes - Synaptospora petrakii has setose ascomata, cylindrical asci and cylindrical ascospores breaking ascoconidia (Cain 1957, Huhndorf et al. 1999). It is closely related to Ruzenia within Helminthosphaeriaceae (Miller et al. 2014, Fig. 8).

Tengiomyces Réblová, Mycotaxon 70: 408 (1999)

Index Fungorum number: IF28271; 1 morphological species.

Type species - Tengiomyces indicus (Varghese \& V.G. Rao) Réblová

Notes - Tengiomyces has setose ascomata, cylindrical asci and versicolored ascospores with 2-3 septa. This genus is similar to Helminthosphaeria based on setose ascomata and versicoloured ascospores and it is associated with spadicoides-like asexual morphs (Réblová 1999a).

Hispidicarpomycetaceae Nakagiri, Mycologia 85(4): 649 (1993)

Index Fungorum number: IF81958; Facesoffungi number: FoF01098; 1 species.

Parasitic on a marine alga. Sexual morph: Ascomata superficial, solitary to gregarious, ostiolate, apapillate. Peridium composed of three-layers: outer layer with thick-walled, short hyphal projections, brown to dark brown, middle layer of light brown to dark brown, thick-walled hyphal, flattened cells of textura epidermoidea, and an inner layer of pale brown, thin-walled, flattened cells of textura epidermoidea, lining the whole ascomatal venter. Paraphyses septate branched. Asci 8-spored, unitunicate, thin-walled, clavate to pyriform, deliquescing early and lacking an apical ring. Ascospores hyaline, ellipsoid to elliptic-fusiform, unicellular, lacking appendages or a sheath, overlapping. Reproductive state of brown hyphae, Spermodochia composed of a mass spermatiosphores. Spermatiosphores, verticilliate, asymmetrical penicilliate-like, brown at the base, paler and hyaline towards the apex. Stipes septate, branched, brown at the base. Spermatia cylindrical, unicellular, hyaline. Trichogynes septate, cylindrical, brown.

Type genus - Hispidicarpomyces Nakagiri

Notes - Hispidicarpomycetaceae is a monotypic family, which was introduced to include a marine ascomycete, Hispidicarpomyces galaxauricola (Nakagiri 1993). Previously, Hispidicarpomycetaceae was referred to Spathulosporales by Nakagiri (1993). However, phylogenetic studies by Inderbitzin et al. (2004) placed Spathulospora (S. adelpha, S. antartica) in Lulworthiales. Consequently, the affinity of Spathulospora within the Lulworthiales raises the question as to the phylogenetic position of Hispidicarpomycetaceae. Maharachchikumbura et al. (2015) accepted the taxonomic placement of Hispidicarpomycetaceae within Spathulosporales. Cultures and sequences are unavailable for this family and consequently a generic revision is needed for the family.

\section{Ecological and economic significance of Hispidicarpomycetaceae}

Biotrophic on the marine alga Galaxaura falcata (Rhodophyta), which was found along the Japanese coast (Nakagiri 1993). Infection of the host alga by H. galaxauricola probably occurs in June to July when its ascospores are abundantly released (Nakagiri 1993). Spermodochia and ascocarps are produced from the base up to around the first to third branches of the algal frond. It is believed that the absorption of photosynthetic nutrients from the epithelial cells can be occurring due to dense distribution of hyphae beneath the epithelial layer. However, there was no evidence of hyphal invasion into a host cell, though close contact of the hyphae with algal cells was often observed (Nakagiri 1993). 


\section{Genus included in Hispidicarpomycetaceae}

Hispidicarpomyces Nakagiri, Mycologia 85(4): 639 (1993)

Index Fungorum number: IF26466; 1 morphological species.

Type species - Hispidicarpomyces galaxauricola Nakagiri

Notes - Hispidicarpomyces was introduced by Nakagiri (1993) is a monotypic genus which shares similar morphological features with Spathulospora. There is no sequence data available for this genus, therefore, further taxon sampling is essential to determine its phylogenetic position within the Ascomycota (Jones et al. 2015, 2019).

Hispidicarpomyces galaxauricola is similar to members of Spathulospora in morphology and parasitism on marine red algae (Kohlmeyer 1973, Kohlmeyer \& Kohlmeyer 1979). However, they are different in that $H$. galaxauricola has true hyphae growing throughout the algal frond and, in contrast, those of Spathulospora spp. are reduced-hyphoid (Kohlmeyer 1973). Further, intracellular invasion into the algal cell by an infection peg and formation of intracellular crusts can be seen in Spathulospora species, but $H$. galaxauricola showed only intercellular infection (Nakagiri 1993).

Hypocreaceae De Not., G. bot. ital. 2(1): 48 (1844)

Index Fungorum number: IF80892; Facesoffungi number: FoF01904; 606 species.

Biotrophic, hemibiotrophic, saprobic or hypersaprobic on plants, other fungi, myxomycetes and lichens, some are mycoparasites, rarely coprophillus, occuring in terrestrial and aquatic habitats worldwide. Sexual morph: Stromatic tissue well-developed, or weakly developed and existing only as subiculum of interwoven pallid or brightly pigmented hyphae, when present soft and fleshy, pallid or brightly pigmented to light brownish, immersed erumpent, effuse, tuberculate or pulvinate, occasionally stipitate, then fertile region clavate. Ascomata solitary or often arranged in groups, perithecial or rarely cleistothecial, immersed in or erumpent to superficial on substrate, pallid, brightly pigmented, or shades of light brown or blue to violet (appearing black), rarely brown, globose, ovoid, obpyriform or spheroid, collabent at times, apex papillate, with periphysate ostiole, surface glabrous or warted or bearing hyaline or pallid hyphal appendages or rarely thick-walled setae. Peridium externally composed of pseudoparenchymatous cells, sometimes with thick, sclerotial walls, internally composed of compressed rows of cells, pallid to brightly pigmented or brown, blue or violet. Paraphyses apical (periphysoids), usually deliquescent, occasionally visible at maturity, as cellular remnants among asci or as remnants of apical fringe. Asci basal to peripheral, mostly 8-spored, occasionally polysporous or less than eight, cylindric, oblong or inflated, apical ring often lacking, when present shallow, refractive, J-. Ascospores uniseriate, biseriate or in fascicle, hyaline, yellowish, pinkish to greenish or occasionally brown, 1-celled or one to several septate, occasionally with longitudinal septa, disarticulating into part-spores at times or budding to form conidia within ascus, ellipsoid, fusoid, allantoid, elongate or globose, with smooth, verruculose or longitudinally striate cell wall. Asexual morph: Hyphomycetous or coelomycetes. Primirily phialidic. Conidiomata non-exsistent to sporodochial or synnematal, conidiogenous cells enteroblastic phialidic, thick-walled structures present at times. Conidia hyaline to bright colored, less commonly produce aleurioconidia and ampulloconidia.

Type genus - Trichoderma Pers.

Notes - Hypocreaceae is characterized by often disarticulating ascospores and perithecia that are mostly immersed in a stroma or seated on a subiculum. Hypocreaceae was recognized within Hypocreales and divided into six subfamilies by Lindau (1897). Rogerson (1970) recognized Hypocreales as the only family in Hypocreales. However, Kreisel (1969) accepted Hypocreaceae and Nectriaceae as two families in Hypocreales. Rossman et al. (1999) defined Hypocreaceae in a more restricted sense and recognized Nectriaceae, Hypocreaceae and Bionecriaceae as three separate families within the Hypocreales. Molecular analyses of Rossman et al. (2001) based on LSU data supported this family. Members of Hypocreaceae are characterized by their brightly coloured and fleshy perithecial stromata (Rogerson 1970).

\section{Ecological and economic significance of Hypoceaeceae}


Trichoderma species play an important ecological role as producers of bioactive compounds, biocontrol agents of plant diseases and as pathogens of animals and mushrooms (Schuster \& Schmoll 2010). For example, Trichoderma harzianum, and $T$. viride are widely used as biofungicides for the biocontrol of plant pathogens (Wraight et al. 1998, Harman et al. 2004, Kaewchai et al. 2009, Thiruvudainambi et al. 2010, Stocco et al. 2016, Hyde et al. 2019b). They have been also utilized for production of antibiotics (Harman et al. 2006). Trichoderma polysporum produces antifungal Cyclosporine A (CsA), a calcineurin inhibitor, used as an immunosuppressant (Dreyfuss et al. 1976). Root colonization by Trichoderma species enhances root growth and development, crop productivity, resistance to abiotic stresses and the uptake and use of nutrients, hence it is becoming widely used in horticulture (Harman 2000, Harman et al. 2004). Fungicolous specis of Hypoceaeceae, such as species of Mycogone and Hypomyces are mushroom pathogens (Rossman et al. 1999). Mycogone perniciosa, Hypomyces rosellus and $H$. aurantius are the causal agents of dry bubble, wet bubble and cobweb disease of the button mushroom, Agaricus bisporus (Baars et al. 2013, Tanovic et al. 2006).

\section{Genera included in Hypoceaeceae}

Arachnocrea Z. Moravec, Bull. trimest. Soc. mycol. Fr.72 : 161 (1956)

Index Fungorum number: IF292; 3 morphological species (Species Fungorum 2020), 2 species with sequence data.

Type species - Arachnocrea stipata (Lib.) Z. Moravec

Notes - Arachnocrea species occur on decaying wood, herbaceous substrates or polypores (fungicolous) (Moravec 1956, Rossman et al. 1999). The genus is characterized by white to yellow orange, papillate, perithecial ascomata, cylindrical asci with hylaine, fusiform, 1-septate ascospores disarticulating into monomorphic part ascospores and verticillium-like asexual morphs (Põldmaa 1999, Rossman et al. 1999, Rossman 2000).

Dialhypocrea Speg., Boln Acad. nac. Cienc. Córdoba 23(3-4): 475 (1919)

Index Fungorum number: IF1490; 1 species with sequence data.

Type species - Dialhypocrea puiggariana Speg.

Notes - Dialhypocrea puiggariana is associated with decaying branches (Rossman et al. 1999). The genus is characterized by stromatic, perithecial ascomata, cylindrical asci and hyaline, 1-septate ascospores disarticulating into part ascospores (Rossman et al. 1999). No asexual morph is linked to this genus.

Escovopsioides H.C. Evans \& J.O. Augustin, PLoS ONE 7(12): e51392, 6 (2012)

Index Fungorum number: IF800474; 1 species with sequence data.

Type species - Escovopsioides nivea H.C. Evans \& J.O. Augustin

Notes - Augustin et al. (2013) introduced the monotypic genus Escovopsioides based on mycoparasitic species E. nivea isolated from of leaf-cutting ant Acromyrmex subterraneus subterraneus. The genus is characterized by conidiophores with terminal and intercalary, globose vesicles and phialides produced on vesicles and, hyaline conidia occuring in long chains (Augustin et al. 2013). No sexual morph is linked to this genus.

Escovopsis J.J. Muchovej \& Della Lucia, Mycotaxon 37: 192 (1990)

Index Fungorum number: IF11249; 14 species with sequence data.

Type species - Escovopsis weberi J.J. Muchovej \& Della Lucia

Notes - Escovopsis, typified by E. weberi was introduced by Muchovej \& Della Lucia (1990) to replace Phialocladus (1972). Taxa are mycoparasites found only from the fungus gardens of attine ants (Reynolds \& Currie 2004, Augustin et al. 2013, Montoya et al. 2019). The genus is characterized by conidiophores with or without terminal variously-shaped vesicles and synchronous or sympodial conidiogenesis with pigmented conidia occuring in chains (Muchovej \& Della Lucia 1990, Montoya et al. 2019). No sexual morph is linked to this genus. 

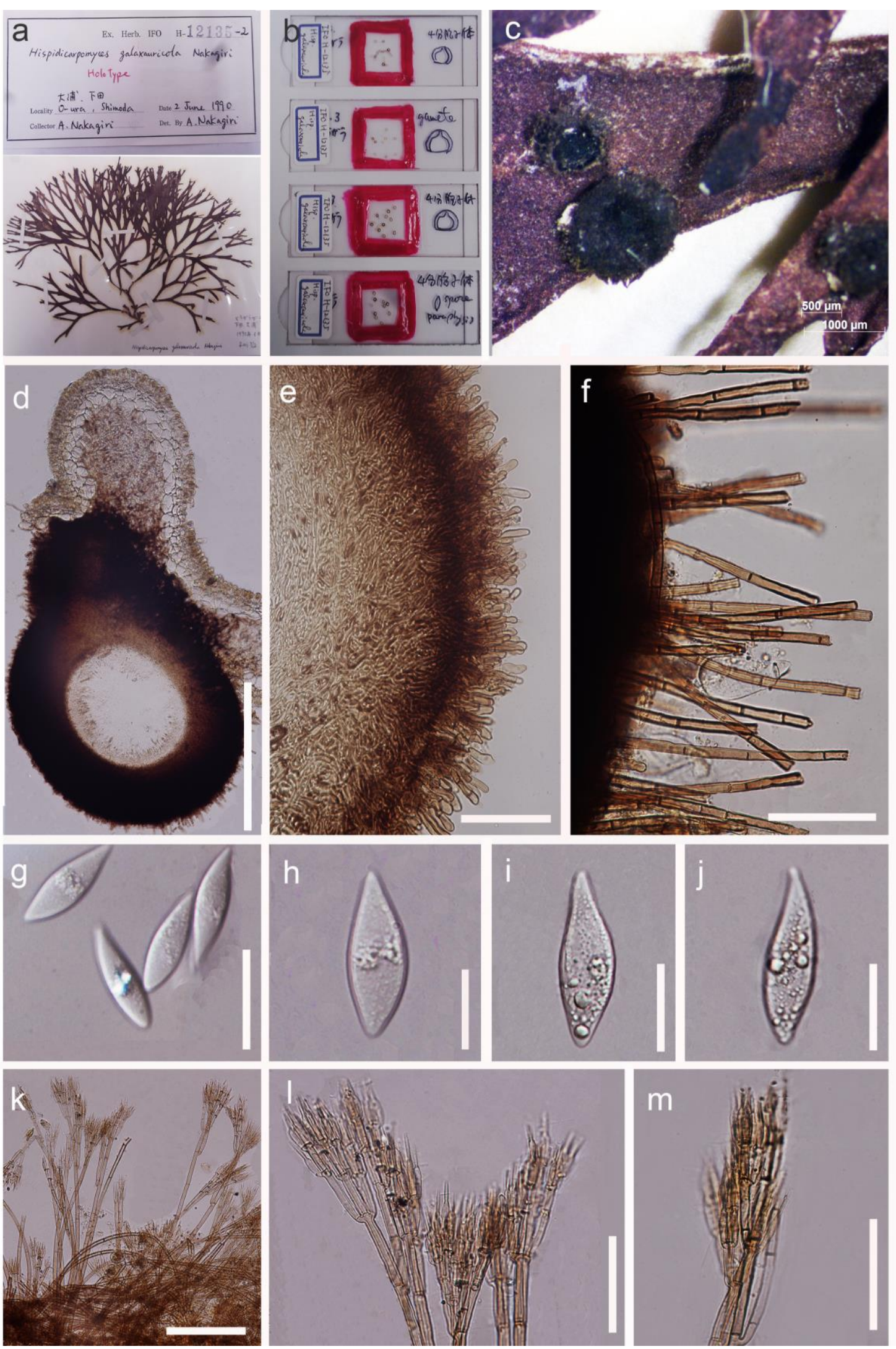

Figure 120 - Hispidicarpomyces galaxauricola (Material examined - JAPAN, O-ura, Shimoda, 2 June 1990, IFO H-12135, holotype). a Herbarium material of Hispidicarpomyces galaxauricola. b Microslides. c Ascomata on host surface. d Section through ascoma. e Peridium. f Short hyphal projections arising from outer layer of peridium. g-j Ascospores. k, 1 Branching spermatiophores. $\mathrm{m}$ Penicilliate phialides of spermatiophores. Scale bars: $c=500 \mu \mathrm{m}, \mathrm{d}=50 \mu \mathrm{m}, \mathrm{e}, \mathrm{f}, \mathrm{k}=20 \mu \mathrm{m}, 1-\mathrm{m}=$ $10 \mu \mathrm{m}, \mathrm{g}-\mathrm{j}=5 \mu \mathrm{m}$. 
Hypocreopsis P. Karst., Bidr. Känn. Finl. Nat. Folk 23: 251 (1873)

Index Fungorum number: IF2436; 10 morphological species (Species Fungorum 2020), 3 species with sequence data.

Type species - Hypocreopsis riccioidea (Bolton) P. Karst.

Notes - Hypocreopsis species occur on decaying woody substrates and resupinate basidiomycetes (Rossman et al. 1999, Stasinska 2004, Johnston et al. 2007). The genus is characterized by globose, white to pale yellow, perithecial ascomata, immersed in a welldeveloped, radially shreaded, often lobate, reddish brown to grey stromata, cylindrical asci and ellipsoid to fusiform, 1-3 septate, hyaline, minutly to coarsely warted ascospores (Rossman et al. 1999, Stasinska 2004, Johnston et al. 2007). No asexual morph is linked to this genus.

Hypomyces (Fr.) Tul.\&C. Tul.,Annls Sci. Nat., Bot., sér. 4 13: 11 (1860)

Index Fungorum number: IF2446; 115 morphological species (Species Fungorum 2020), 54 species with sequence data.

Type species - Hypomyces lactifluorum (Schwein.) Tul. \& C. Tul.

Notes - Hypomyces species are fungicolous, mostly on mushrooms (Agaricales, Boletales), bracket fungi (Poriales) and discomycetes (Helotiales, Pezizales) (Rossman et al. 1999, Põldmaa 2011, Zeng \& Zhuang 2016, Wei \& Kirschner 2017). Arnold (1970) introduced the fungicolous genus Sibirina based on S. fungicola. Sibirina was synonymyzed under Cladobotryum by Rogerson \& Samuels (1993), and was followd by Põldmaa (2003). However the name Hypomyces was protected against Cladobotryum by Rossman et al. (2013). Hence here we consider Sibrina as a synonym of Hypomyces by following Gams (2017) and Vu et al. (2019). The genus is characterized by brightly or lightly coloured, perithecial ascomata in a concolorous subiculum, cylindrical asci with a thickened apex and, fusiform, aseptate or 1-septate, usually warted ascospores with welldeveloped apiculus at both ends (Põldmaa et al. 2000, Rossman \& Seifert 2011). Asexual morphs are mainly cladobotryum-like, while several other asexual morphs are reported for the genus (i.e. acremonium-, dactylaria-, mycogone-, papulaspora-, sepedonium-, stephanoma-, trichotheciumand verticillium-like) (Rogerson \& Samuels 1993, 1994, Rossman et al. 1999, 2013, Rossman 2000, Wijayawardene et al. 2017b).

Kiflimonium Summerb., J.A. Scott, Guarro \& Crous, Microorganisms 6(3, 88): 17 (2018)

Index Fungorum number: IF826819; 1 species with sequence data.

Type species - Kiflimonium curvulum (W. Gams) Summerb., J.A. Scott, Guarro \& Crous

Notes - The monotypic genus Kiflimonium was introduced by Summerbell et al. (2018) based on K. curvulum. Kiflimonium species are mostly isolated from the soil (Summerbell et al. 2018). The genus is characterized by simple conidiophores arising laterally from somatic hyphae, bearing 1-4 phialidic conidiogenous cells, and 0-1 septate, lunate to falcate, hyaline conidia (Summerbell et al. 2018).

Lichenobarya Etayo, Diederich \& Lawrey, Bryologist 118: 88 (2015)

Index Fungorum number: IF811832; 1 species with sequence data.

Type species - Lichenobarya usneae (Etayo) Etayo, Diederich \& Lawrey

Notes - Lawrey et al. (2015) established Lichenobarya for the lichenicolous species $N$. usneae based on DNA sequence data. The genus is characterized by superficial, obpyriform, perithecial, brown ascomata, immersed in a poorly-developed and inconspicuous subiculum, elongate asci with or without slightly-thickened apex and long, filiform, multi-septate ascospores (Lawrey et al. 2015). There is no report of a asexual morph for this genus (Lawrey et al. 2015).

Mycogone Link, Mag. Gesell. naturf. Freunde, Berlin 3(1-2): 18 (1809)

Index Fungorum number: IF9026; 28 morphological species (Species Fungorum 2020), 2 species with sequence data.

Type species - Mycogone rosea Link 
Notes - Mycogone species are fungicolous parasites of mushrooms (Agaricales) (Veihmeyer 1914). The genus is characterized by monoblastic, branched or verticillate conidiophores; hyaline, aseptate or rarely 2-3 septate phialoconidia and 1-septate aleurioconidia (Gray \& Morgan-Jones 1980, Gams 1983). No sexual morph is linked to this genus.

Protocrea Petch, J. Bot., Lond. 75: 219 (1937)

Index Fungorum number: IF4383; 6 morphological species (Species Fungorum 2020), 3 species with sequence data.

Type species - Protocrea farinosa (Berk. \& Broome) Petch

Notes - Petch (1937) established Protocrea to accomodate Hypocrea farinosa, H. delicatula and H. stipata. Protocrea species occur on bark, decaying woody substrates or fungicolous on effused basidiomycetes (Rossman et al. 1999, Jaklitsch et al. 2008). The genus is characterized by perithecial ascomata, partly or completely immersed in the subiculum, cylindrical asci, fusiform to ellipsoid, 1-septate ascospores, disarticulating at the septum inside the asci and gliocladium-like asexual morphs (Rossman et al. 1999, Jaklitsch et al. 2008).

Rogersonia Samuels \& Lodge, Sydowia 48(2): 250 (1996)

Index Fungorum number: IF27816; 1 morphological species.

Type species - Rogersonia striolata Samuels \& Lodge

Notes - The monotypic genus Rogersonia was introduced by Samuels \& Lodge (1996) to accommodate a single species $R$. striolata, isolated from decaying wood. The genus is characterized by perithecial ascomata, partly to completely immersed in the subiculum, cylindrical asci and aseptate, broadly ellipsoidal, striate ascospores (Samuels \& Lodge 1996). No sexual morph is described for this genus.

Sepedonium Link, Mag. Gesell. naturf. Freunde, Berlin 3(1-2): 18 (1809)

Index Fungorum number: IF9876; 23 morphological species (Species Fungorum 2020), 4 species with sequence data.

Type species - Sepedonium mycophilum (Pers.) Nees

Notes - Link (1809) introduced the asexual morph genus Sepedonium based on $S$. mycophilum (Uredo mycophila) as the type of the genus. Sepedonium species are parasitic on basidiomycetes, mostly on Boletales species (Sahr et al. 1999). The genus is characterized by hyaline, septate conidiophores and occurrence of two or more synanamorphs producing aleurioconidia, phialoconidia and ampulloconidia (Sahr et al. 1999). No sexual morph has been linked to this genus.

Sphaerostilbella (Henn.) Sacc. \& D. Sacc., Syll. fung. (Abellini) 17: 778 (1905)

Index Fungorum number: IF5122; 12 morphological species (Species Fungorum 2020), 5 species with sequence data.

Type species - Sphaerostilbella lutea (Henn.) Sacc. \& D. Sacc.

Notes - Sphaerostilbella species are mainly fungicolous, occurring on aphyllophorales basidiomycetes and rarely on wood (Rossman et al. 1999, Põldmaa et al. 2000, Põldmaa \& Samuels 2004, Lombard et al. 2015). The genus is characterized by obipyriform ascomata with dark red to purple, or in shades of yellow, naviculate to ellipsoid, hyaline, 1-septate ascospores and a gliocladium-like asexual morph (Rossman et al. 1999, Põldmaa et al. 2019).

Sporophagomyces K. Põldmaa \& Samuels, Can. J. Bot. 77(12): 1765 (1999)

Index Fungorum number: IF28375; 3 morphological species (Species Fungorum 2020), 1 species with sequence data.

Type species - Sporophagomyces chrysostomus (Berk. \& Broome) K. Põldmaa \& Samuels

Notes - Sporophagomyces species are fungicolous, associated with aphyllophorous basidiomycetes (Põldmaa et al. 2000). The genus is characterised by buff to yellow, obypyriform 
ascomata, cylindrical asci with or without thickened apices and (0-) or 1-septate fusiform to naviculate or lanceolate ascospores (Põldmaa et al. 2000). Asexual morphs are acremonium-like, comprising simple conidiogenous cells immersed directly on mycelial hyphae, bearing 3-septate conidia (Põldmaa et al. 2000).

Stephanoma Wallr., Fl. crypt. Germ. (Norimbergae) 2: 269 (1833)

Index Fungorum number: IF10087; 6 morphological species (Species Fungorum 2020).

Type species - Stephanoma strigosum Wallr.

Notes - Stephanoma species are mycoparasites on ascomycetes or sometimes associated with orchid roots (Wallroth 1833, van Zinderen-Bakker 1934, Butler \& McCain 1968, Rakvidhyasastra $\&$ Butler 1973). The genus is characterised by hyphomycetous asexual morphs producing globose to cuboid, hyaline or golden brown to brown conidia and ovoid, hyaline conidia on verticillate branches (Wallroth 1833, Butler \& McCain 1968). No sexual morph has been linked to this genus.

Trichoderma Pers., Neues Mag. Bot. 1: 92 (1794)

Index Fungorum number: IF10282; 378 morphological species (Species Fungorum 2020), 318 species with sequence data.

Type species - Trichoderma viride Pers.

Notes - Trichoderma is typified by T. viride (Persoon 1794). Trichoderma species are associated with decaying woody substrates and other fungi (Rossman et al. 1999, Jaklitsch \& Voglmayr 2015). Barrasa et al. (1985) introduced the monotypic genus Aphysiostroma based on coprophilous taxon, A. stercorarium. However this genus was synonymized under Trichoderma by Jaklitsch \& Voglmayr (2015) based on DNA sequence data. Doi (1972) introduced Pseudohypocrea to accommodate Hypocrea citrinella. Pseudohypocrea species occur mainly on decaying wood, bark and dead leaves (Zhu \& Zhuang 2014). However, based on morphological and molecular data Pseudohypocrea was synonymised under Trichoderma by Zeng \& Zhuang (2017). Trichoderma erinaceum is illustrated in this entry (Fig. 121).

Verticimonosporium Matsush., Microfungi of the Solomon Islands and Papua-New Guinea (Osaka): 68 (1971)

Index Fungorum number: IF10401; 3 morphological species (Species Fungorum 2020), 2 species with sequence data.

Type species - Verticimonosporium diffractum Matsush.

Notes - Matsushima (1971) introduced the asexual morph genus Verticimonosporium based on $V$. diffractum. The genus is characterised by swollen, phialidic, conidiogenous cells which are discrete or in clusters and aseptate, hyaline conidia (Matsushima 1971, 1975, Wang et al. 2005).

Hyponectriaceae Petr., Annls mycol. 21(3/4): 305 (1923)

Index Fungorum number: IF80898; Facesoffungi number: FoF01775; 229 species.

Saprobic or pathogenic on dead plant matter, in terrestrial and aquatic habitats. Sexual morph: appearing as black, shiny spots on host surface or small black lines arising from cracks in bark. Pseudostromata present or lacking, if present, superficial, forming clypeus over the ascomata. Ascomata solitary or aggregated, immersed, erumpent or rarely somewhat superficial, globose to ovoid, upright or horizontal, brown to black. Papilla short, ostiolate, with or without periphyses. Peridium comprising two layers, outer layer of brown cells of textura angularis, inner layer of hyaline cells of textura angularis, in some genera cells are of textura globosa. Paraphyses sparse, septate, tapering towards the apex, often deliquescing at maturity. Asci 8-spored, unitunicate, oblong, cylindrical or ellipsoidal, short pedicellate, with a $\mathrm{J}+$, or $\mathrm{J}-$, apical ring. Ascospores overlapping biseriate, or fasciculate, hyaline, yellow to light brown, fusoid, isthmoid, elongate filiform, obovoid, or oblong, asymmetric or symmetric, unicellular or septate, smooth-walled or verruculose, with or without a mucilaginous sheath. Asexual morph: Undetermined.

Type genus - Hyponectria Sacc. 
Notes - The most recent treatments and updated accounts of Hyponectriaceae were by Maharachchikumbura et al. (2016b) which we follow here. Most of the genera included in this family lack molecular data, but have characteristics typical of Hyponectria. This includes ascomata visible as tiny black spots on the leaf surface and $\mathrm{J}_{+}$, or $\mathrm{J}_{-}$, apical rings and unicellular ascospores. The family is therefore, likely to be a dustbin for numerous unrelated genera and is in need of fresh collections and sequence data.

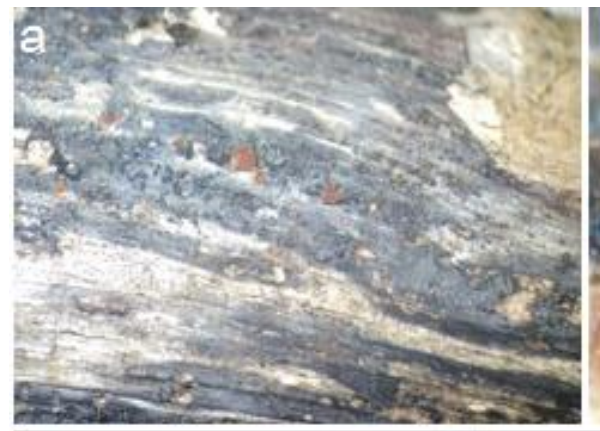

d

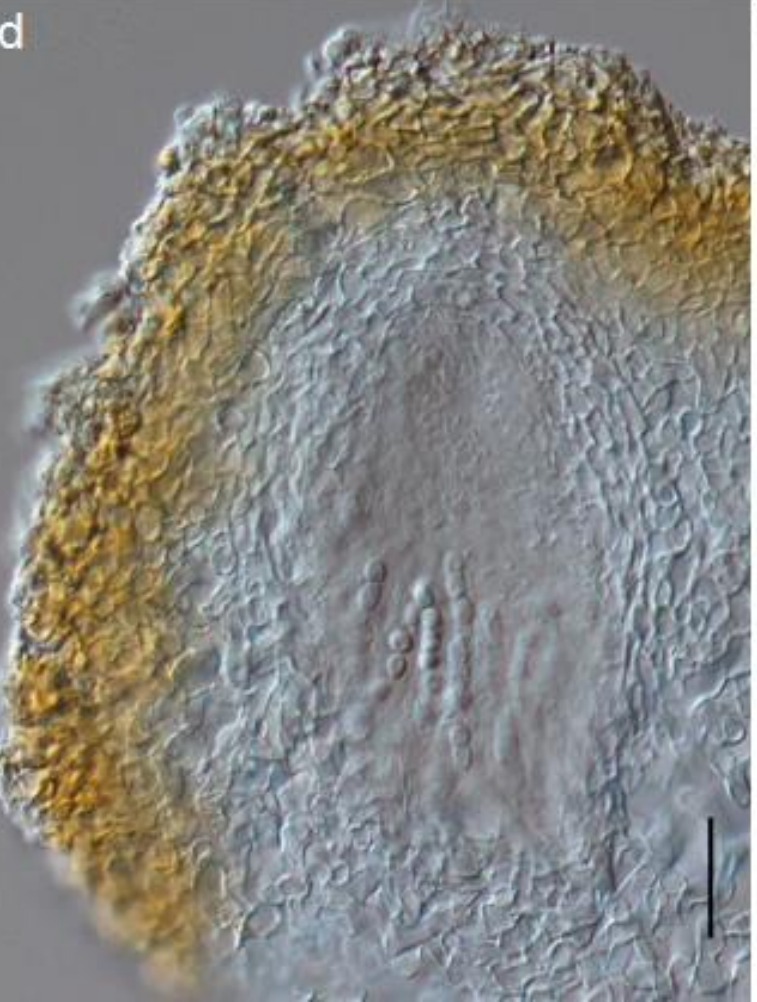

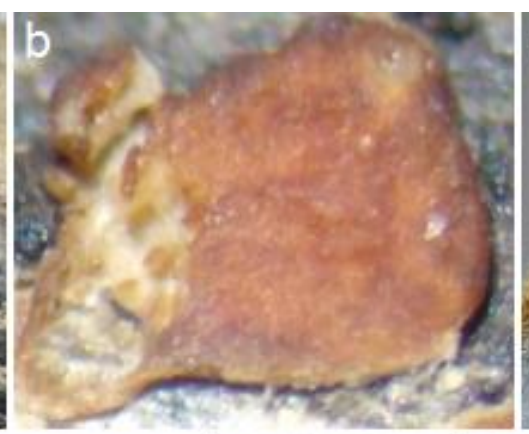
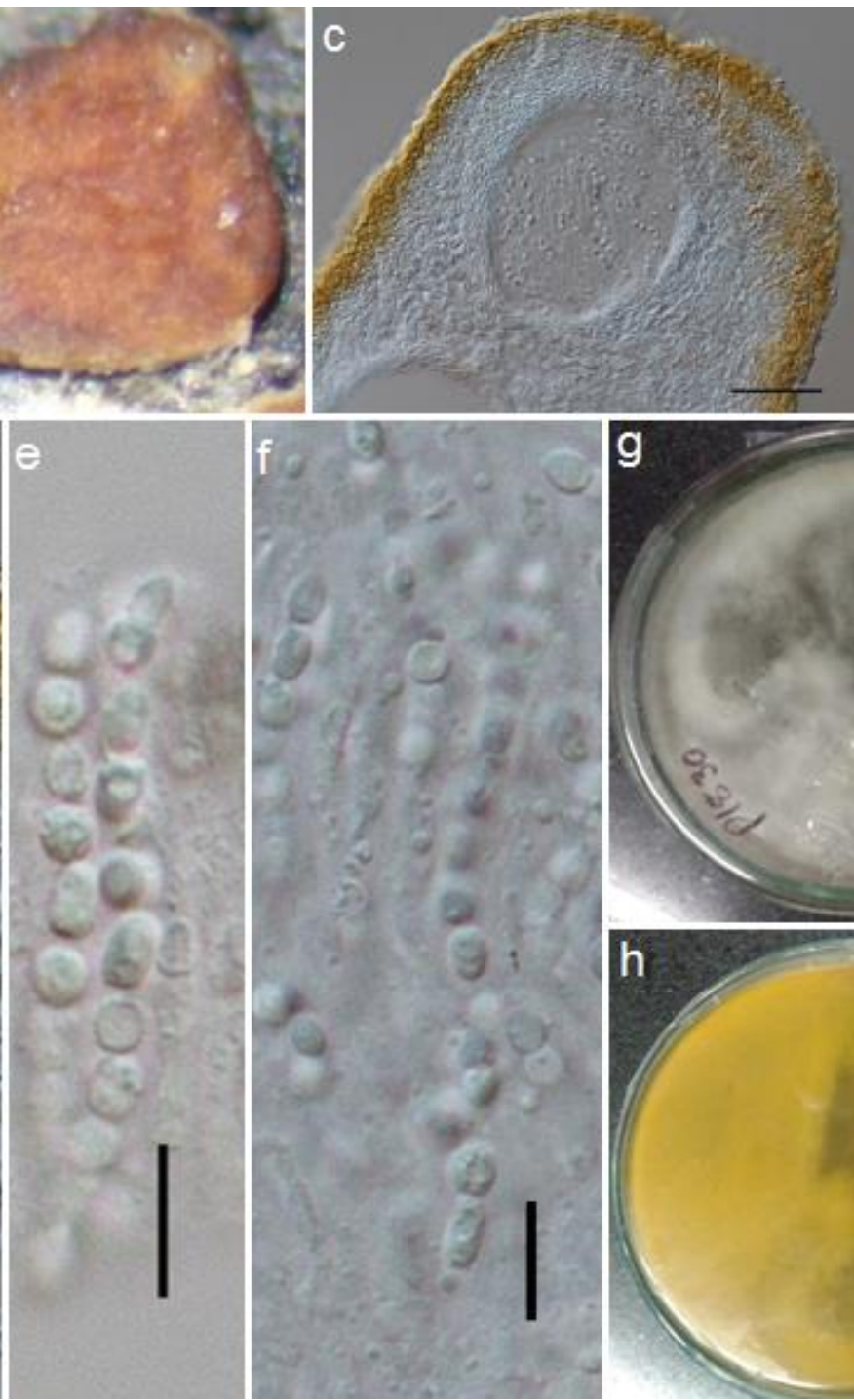

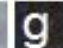

g

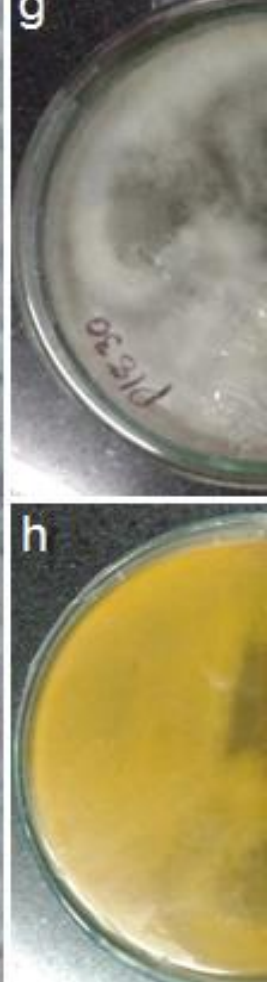

Figure 121 - Trichoderma erinaceum (Material examined - INDIA, Andaman and Nicobar

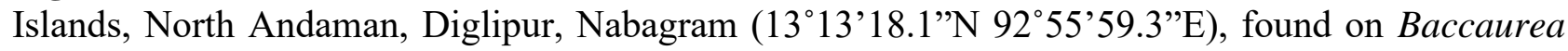
ramiflora decaying twig, 17 May 2018, M. Niranjan \& V.V. Sarma, AMH-10060; living culture,

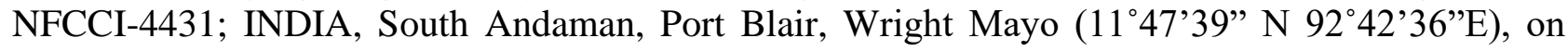
Pterocarpus dalbergioides, 22 October 2015, T38F5, T39F2, T52F2, isotypes; INDIA, Mannarghat (11 43'14" N 92 39'33'E), on Pterocarpus dalbergioides, 04 January 2017, Niranjan. M \& Sarma. V.V., T184F1, T193Fl). a, b Stromata on host. c, d Vertical section of ascoma. e, f Asci. g, h Culture (NFCCI-4431) on malt extract agar plates (g-from above, h-reverse). Scale bars: $\mathrm{c}=50 \mu \mathrm{m}$, $\mathrm{d}=20 \mu \mathrm{m}, \mathrm{e}, \mathrm{f}=10 \mu \mathrm{m}$.

\section{Ecological and economic significance of Hyponectriaceae}

Species are saprobes, endophytes, and plant pathogens (Boddy \& Griffith 1989, Hyde \& Pearce 1993, Olatinwo et al. 2003, Tubajika 2006, Schaechter 2011, Hussain et al. 2014, Promputtha et al. 2007, Uppala 2019). Physalospora has also been reported as lichenicolous 
(Hoffmann \& Hafellner 2000). Physalospora vaccinia causes a common and widely distributed fruit disease (blotch rot, fruit rot), and other species are plant pathogens, such as $P$. piricola (apple ring rot) (Olatinwo et al. 2003, Tubajika 2006, Kang et al. 2019, Uppala 2019). Extracts of an endophytic Physalospora sp. exhibited biological activity and showed significant antibacterial, antifungal, and herbicidal activities (Hussain et al. 2014).

\section{Genera included in Hyponectriaceae}

Apiothyrium Petr., Sydowia 1(1-3): 1 (1947)

Index Fungorum number: IF269; 2 morphological species (Species Fungorum 2020).

Type species - Apiothyrium arcticum Petr.

Notes - Apiothyrium was introduced to accommodate A. arcticum occurring on dead leaves of Diapensia lapponica (Diapensiaceae) in Finland and later A. tasmanicum on dead needles of Athrotaxis cupressoides (Cupressaceae) in Tasmania, Australia (Petrak 1947a, Swart 1988b). Apiothyrium species have solitary, immersed ascomata, visible as dots on the host surface, with a central ostiole, irregular stromata, cylindric-clavate asci with a $\mathrm{J}+$, apical ring, and hyaline, oblong to clavate, apiospores with a mucilaginous sheath (Petrak 1947a, Swart 1988b).

Arecomyces K.D. Hyde, Sydowia 48(2): 227 (1996)

Index Fungorum number: IF27749; 10 morphological species (Species Fungorum 2020).

Type species - Arecomyces frondicola K.D. Hyde

Notes - Most species of Arecomyces are found on palms (Arecaceae, Hyde 1996a, Hyde \& Fröhlich 2003, Vitoria et al. 2011). The genus has been reported from Australia, Brazil, Brunei, and Ecuador (Hyde 1996a, Hyde \& Fröhlich 2003, Vitoria et al. 2011). Arecomyces is characterised by solitary or gregarious, immersed, raised darkened discs or minute black dots on the host surface, a pseudostroma, central ostioles, (2--)4-8 spored, broadly cylindrical asci with J-, apical rings, and hyaline, ellipsoidal-fusiform or ovoid, unicellular ascospores surrounded by a mucilaginous sheath (Hyde 1996a, Vitoria et al. 2011).

Arwidssonia B. Erikss., Svensk bot. Tidskr. 68: 199 (1974)

Index Fungorum number: IF340; 2 morphological species (Species Fungorum 2020).

Type species - Arwidssonia empetri (Rehm) B. Erikss.

Notes - Arwidssonia has immersed ascomata opening by 3-5 lobes, cylindrical to slightly saccate asci, with $\mathrm{J}+$, apical rings and hyaline, (1-)3(-5)-septate ascospores (Wang \& Hyde 1999). In this study, we examined the holotype of Arwidssonia empetri and accept it in Hyponectriaceae based on its morphology (Barr 1990b, Wang \& Hyde 1999, Maharachchikumbura et al. 2016b, Wijayawardene et al. 2018a).

Cesatiella Sacc., Michelia 1(no. 2): 250 (1878)

Index Fungorum number: IF917; 3 morphological species (Species Fungorum 2020).

Type species - Cesatiella australis Sacc. \& Speg.

Notes - The type species was found on what was probably a dead branch of Olea europaea (Oleaceae) in Italy (Rossman et al. 1999). Cesatiella has solitary, immersed, cylindric asci with a $\mathrm{J}+$, apical ring and hyaline, fusoid, oblong to ellipsoid, 3-septate ascospores, without a mucilaginous sheath (Saccardo 1878).

Chamaeascus L. Holm, K. Holm \& M.E. Barr, Blyttia 51(3-4): 121 (1993)

Index Fungorum number: IF26460; 1 morphological species.

Type species - Chamaeascus arcticus L. Holm, K. Holm \& M.E. Barr

Notes - The species is a saprobe on dried leaves of Carex (Cyperaceae) found in Norway. Chamaeascus has solitary, immersed ascomata without papilla, which are darker around the pore, ellipsoidal asci without an apical ring and bacilliform to lunate, 1-celled ascospores, with obtuse or slightly pointed ends (Wang \& Hyde 1999). 

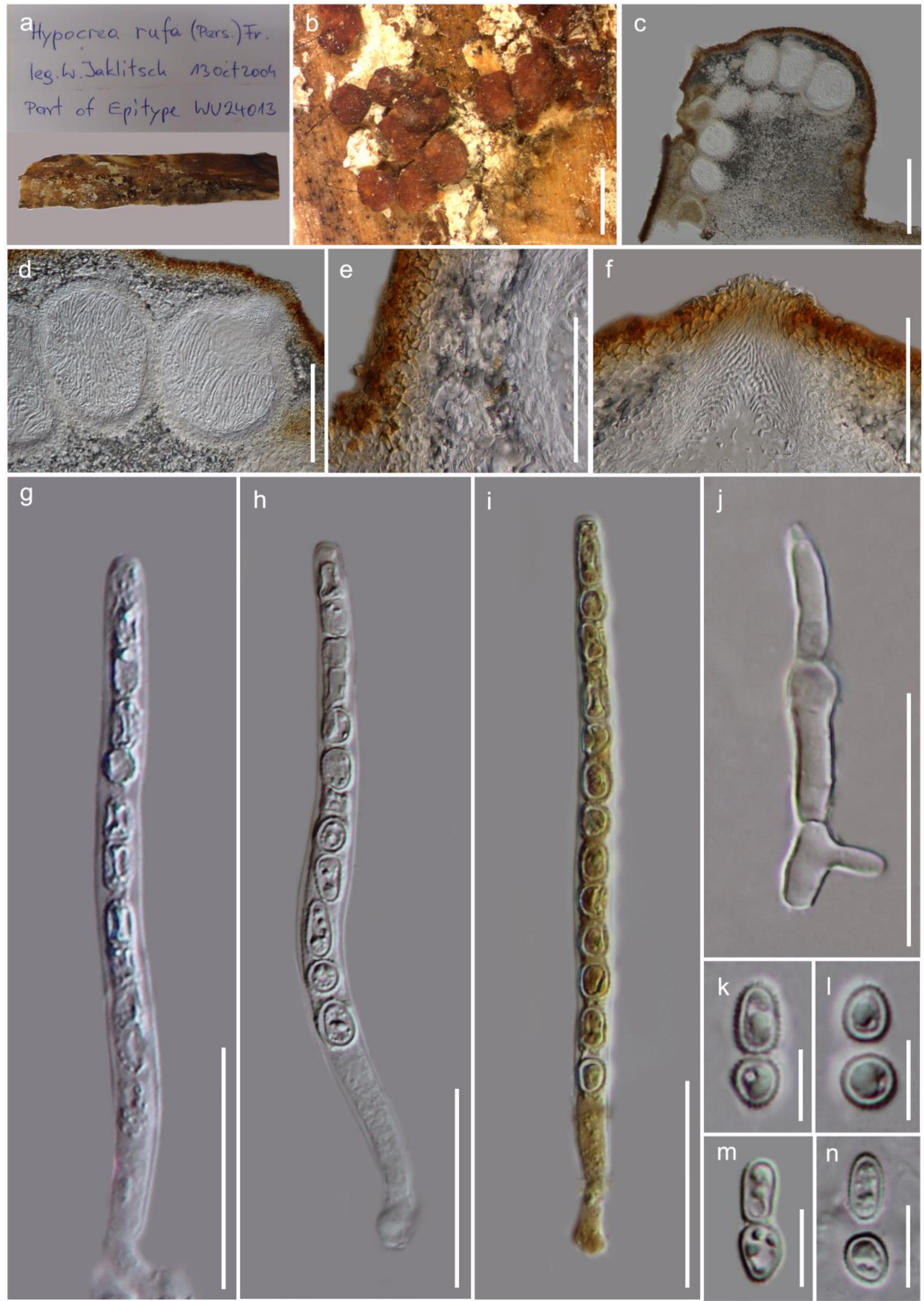

Figure 122 - Trichoderma viride (Material examined - CZECH REPUBLIC, South Bohemia, Frymburk, on partly decorticated logs of Pinus sylvestris L., leg. W. Jaklitsch, W.J. 2753, 3 October 2004, WU 24013, epitype). a Herbarium material. b Stromata on host substrate. c, d Transverse sections through stromata with perithecia. e Peridium in section. f Ostiole in transvers section. g-i Asci (i in Melzer's reagent). j Hair on surface of stroma. k-n Ascospores. Scale bars: b $=2 \mathrm{~mm}, \mathrm{c}=200 \mu \mathrm{m}, \mathrm{d}=100 \mu \mathrm{m}, \mathrm{e}, \mathrm{f}=50 \mu \mathrm{m}, \mathrm{g}-\mathrm{j}=20 \mu \mathrm{m}, \mathrm{k}-\mathrm{n}=5 \mu \mathrm{m}$. 


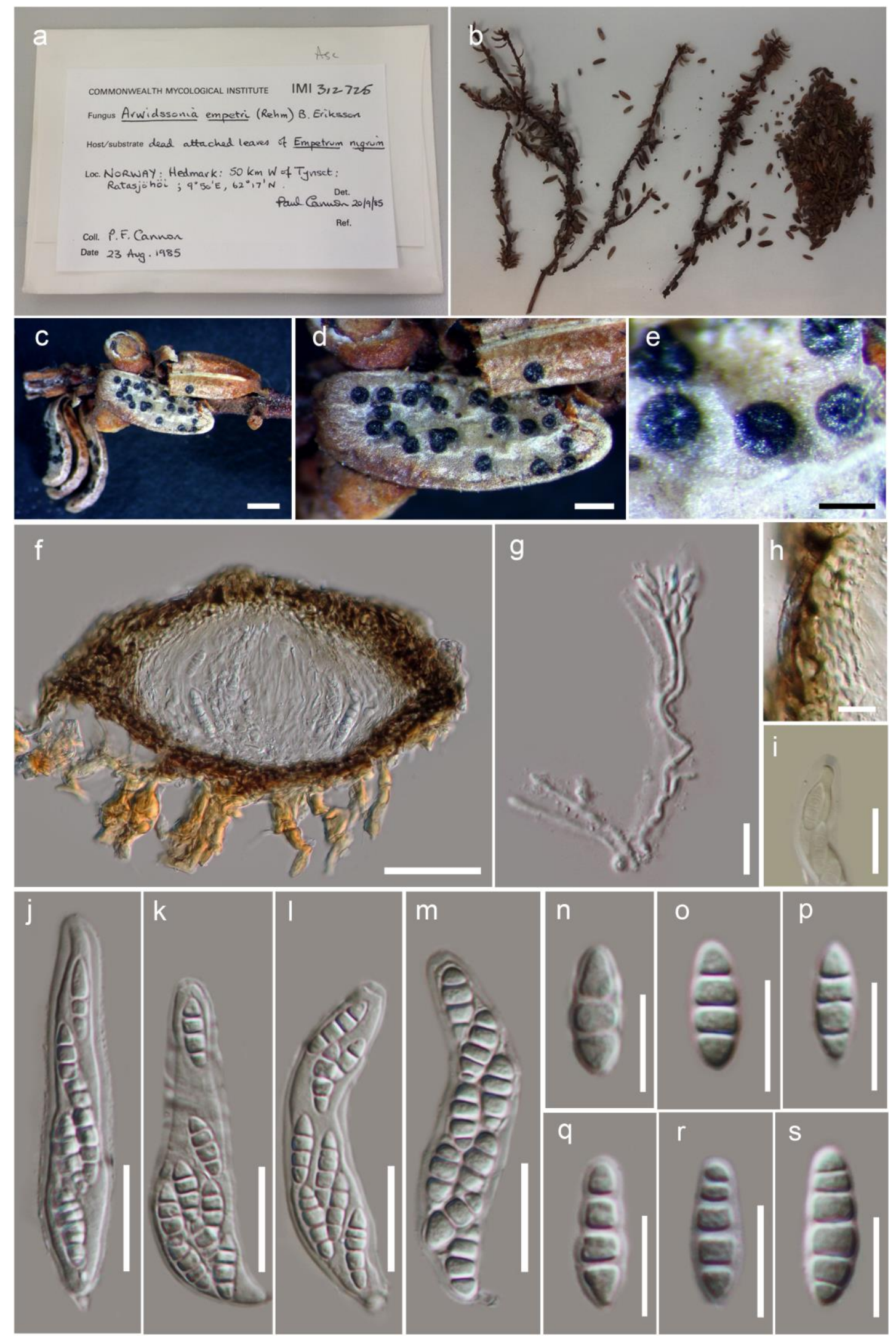

Figure 123 - Arwidssonia empetri (Material examined - NORWAY: Hedmark: $50 \mathrm{~km}$ W of Tynset: Tatasjöhöi; on dead attached leaves of Empetrum nigrum, 23 August 1985, P.F. Cannon, IMI 312725, holotype). a Material label. b Specimen. c, d Ascomata on the upper leaf surface. e Close up of ascomata. f Section of ascoma. g Paraphyses. h Peridium. i J+, reaction of apical ascal ring stained with Melzer's reagent. j-m Asci. n-s Ascospores. Scale bars: e $=1000 \mu \mathrm{m}, \mathrm{d}=500 \mu \mathrm{m}, \mathrm{e}=$ $200 \mu \mathrm{m}, \mathrm{f}=50 \mu \mathrm{m}, \mathrm{g}-\mathrm{h}, \mathrm{j}-\mathrm{s}=10 \mu \mathrm{m}, \mathrm{i}-\mathrm{m}=20 \mu \mathrm{m}$. 
Discosphaerina Höhn., Sber. Akad. Wiss. Wien, Math.-naturw. Kl., Abt. 1 126(4-5): 353 (1917)

Index Fungorum number: IF1667; 21 morphological species (Species Fungorum 2020), 1 species with sequence data.

Type species - Discosphaerina discophora Höhn.

Notes - Discosphaerina cytisi is the only species in this genus with sequence data (Vu et al. 2019). Species occur on leaves and stems of various plants worldwide, as saprobes, endophytes, and plant pathogens (Höhnel 1917b, Petrak 1924, 1927, 1934, 1941, Gonzales-Menendez et al. 2014, Godeas et al. 1985, Holm et al. 1999). Discosphaerina has gregarious, often two or three confluent, semi-immersed ascomata formed under a clypeus, cylindric-clavate asci with a J+, apical ring and hyaline, ellipsoid, aseptate ascospores (Höhnel 1917b, 1919).

Exarmidium P. Karst., Bidr. Känn. Finl. Nat. Folk 23: 29, 222 (1873)

Index Fungorum number: IF1959; 14 morphological species (Species Fungorum 2020).

Type species - Exarmidium hysteriiforme P. Karst.

Notes - The type species occurs on branches of Juniperus (Cupressaceae) in Finland. Exarmidium has solitary, aggregated, dark-brown or black ascomata, immersed under a clypeus, elongate to clavate asci, with a poorly defined apical ring, $\mathrm{J}+$ in some species and hyaline or faintly yellowish, ascospores with 3 or more transverse septa (Barr \& Boise 1985, Aptroot 1998).

Frondicola K.D. Hyde, Bot. J. Linn. Soc. 110(2): 100 (1992)

Index Fungorum number: IF26302; 1 morphological species.

Type species - Frondicola tunitricuspis K.D. Hyde

Notes - Frondicola tunitricuspis, illustrated in this entry, was found on decaying fronds of Nypa fruticans (Arecaceae). Frondicola has solitary ascomata, visible as dark, raised, circular spots with central ostiolar dots, immersed under a clypeus, cylindrical asci with $\mathrm{J}$-, apical ring and hyaline, unicellular, ellipsoidal ascospores with a mucilaginous sheath (Hyde 1992a).

Hyponectria Sacc., Michelia 1(no. 2): 250 (1878)

Index Fungorum number: IF2448; 30 morphological species (Species Fungorum 2020); 1 species and 3 unnamed species with sequence data.

Type species - Hyponectria buxi (Alb. \& Schwein.) Sacc.

Notes - Hyponectria was revised and described in Maharachchikumbura et al. (2016b). Hyponectria has solitary or mostly gregarious, immersed ascomata with a central ostiole, visible as orange to brown dots on the host surface, cylindric-clavate to clavate, short pedicellate asci with a $\mathrm{J}$-, apical ring and hyaline, ellipsoidal or oblong, aseptate ascospores, without a mucilaginous sheath (Maharachchikumbura et al. 2016b). Hyponectria buxi is illustrated in this entry.

Lichenoverruculina Etayo, Herzogia 24(2): [379] (2011)

Index Fungorum number: IF563512; 1 morphological species.

Type species - Lichenoverruculina sigmatospora (Speg.) Etayo \& Sharuddin

Notes - Lichenoverruculina is lichenicolous with immersed perithecia under the thallus of Heterodermia sp. The genus has abundant paraphyses, 32-spored, cylindrical asci and fusoidsigmoid, 2-celled, hyaline ascospores (Spegazzini 1889, Etayo \& Rosato 2008).

Micronectria Speg., Anal. Soc. cient. argent. 19(1): 45 (1885)

Index Fungorum number: IF3175; 4 morphological species (Species Fungorum 2020).

Type species - Micronectria guaranitica Speg.

Notes - Micronectria guaranitica forms a sexual morph on leaves of Luehea divaricata while no asexual morph is known (Spegazzini 1885). This species has been reported from India, Sri Lanka, and Ethiopia, (Petch 1920, Ciccarone 1951, Ananthanarayanan 1964). Micronectria appears as scattered, often aggregated, brownish-black, raised spots, immersed, flask-shaped ascomata, 
oblong-clavate asci without an apical ring and hyaline, 4-5-septate, filiform ascospores, pointed at both ends (Spegazzini 1885, Ananthanarayanan 1964).

Papilionovela Aptroot, Mycol. Res. 101(3): 266 (1997)

Index Fungorum number: IF27748; 1 morphological species.

Type species - Papilionovela albothallina Aptroot

Notes - Papilionovela albothallina is a saprobe found on branches of an unidentified large tree in lowland rain forest in Papua New Guinea (Aptroot 1997). Papilionovela has solitary, dark brown discoid ascomata, cylindrical asci without apical rings, and hyaline, 1(-3)-septate, ellipsoid ascospores, ornamented with gelatinous wings (Aptroot 1997).

Pellucida Dulym., Sivan., P.F. Cannon \& Peerally, Mycol. Res. 105(2): 250 (2001)

Index Fungorum number: IF28461; 1 morphological species.

Type species - Pellucida pendulina Dulym., Sivan., P.F. Cannon \& Peerally

Notes - Pellucida pendulina occurs on native plants in Mauritius (Dulymamode et al. 2001). The genus was placed in Hyponectriaceae and no close relatives have been identified (Dulymamode et al. 2001). Pellucida has immersed, white to buff, globose, ascomata on the abaxial and adaxial leaf surfaces, externally only visible as minute depressed areas representing the ostioles, cylindrical asci with a $\mathrm{J}_{+}$, apical ring, and hyaline, filiform, multiseptate, ascospores, parallel or helically arranged in the ascus (Dulymamode et al. 2001).

Phragmitensis M.K.M. Wong, Poon \& K.D. Hyde, Bot. Mar. 41(4): 379 (1998)

Index Fungorum number: IF27890; 2 morphological species (Species Fungorum 2020).

Type species - Phragmitensis marina M.K.M. Wong, Poon \& K.D. Hyde

Notes - Phragmitensis marina occurs on dead culms of Phragmites australis in a saline estuarine habitat in Hong Kong (Wong et al. 1998b), while P. ellipsoidea was found in freshwater (Wong et al. 1999). Phragmitensis has aggregated, immersed, pseudostromata, containing several obpyriform ascomata, clavate asci, lacking an apical ring and hyaline unicellular, cymbiform, ellipsoidal to reniform ascospores, with distal end tapered more than the proximal end and surrounded by a mucilaginous sheath (Wong et al. 1998b, 1999).

Physalospora Niessl, Verh. nat. Ver. Brünn 14: 170 (1876)

Index Fungorum number: IF4079; 132 morphological species (Species Fungorum 2020), 3 species and 5 unnamed species with sequence data.

Type species - Physalospora alpestris Niessl

Notes - Physalospora species have solitary, immersed, clypeate, black ascomata, cylindrical asci, and hyaline, fusiform ascospores, sometimes becoming pale brown at maturity and with or without a mucilaginous sheath (Wang \& Hyde 1999, Sivanesan \& Shivas 2002).

Rachidicola K.D. Hyde \& J. Fröhl., Sydowia 47(2): 217 (1995)

Index Fungorum number: IF27632; 1 morphological species.

Type species - Rachidicola palmae K.D. Hyde \& J. Fröhl.

Notes - Rachidicola palmae occurs on living and dead fronds of palms (Arecaceae) in Brunei (on rachis of Oncosperma horridum), Hong Kong (on rachis of Calamus sp.) and Malaysia (on Daemonorops sp.). Rachidicola has solitary, dark-brown, raised ascomata, immersed under a clypeus, with a central ostiole, cylindric-clavate asci with a non-refractive apical ring and 2-3seriate, hyaline, straight or slightly curved, 3-celled ascospores surrounded by a mucilaginous sheath. (Hyde \& Fröhlich 1995).

Xenothecium Höhn., Sber. Akad. Wiss. Wien, Math.-naturw. Kl., Abt. 1 128: 589 (1919)

Index Fungorum number: IF5827; 1 morphological species.

Type species - Xenothecium jodophilum Höhn. 


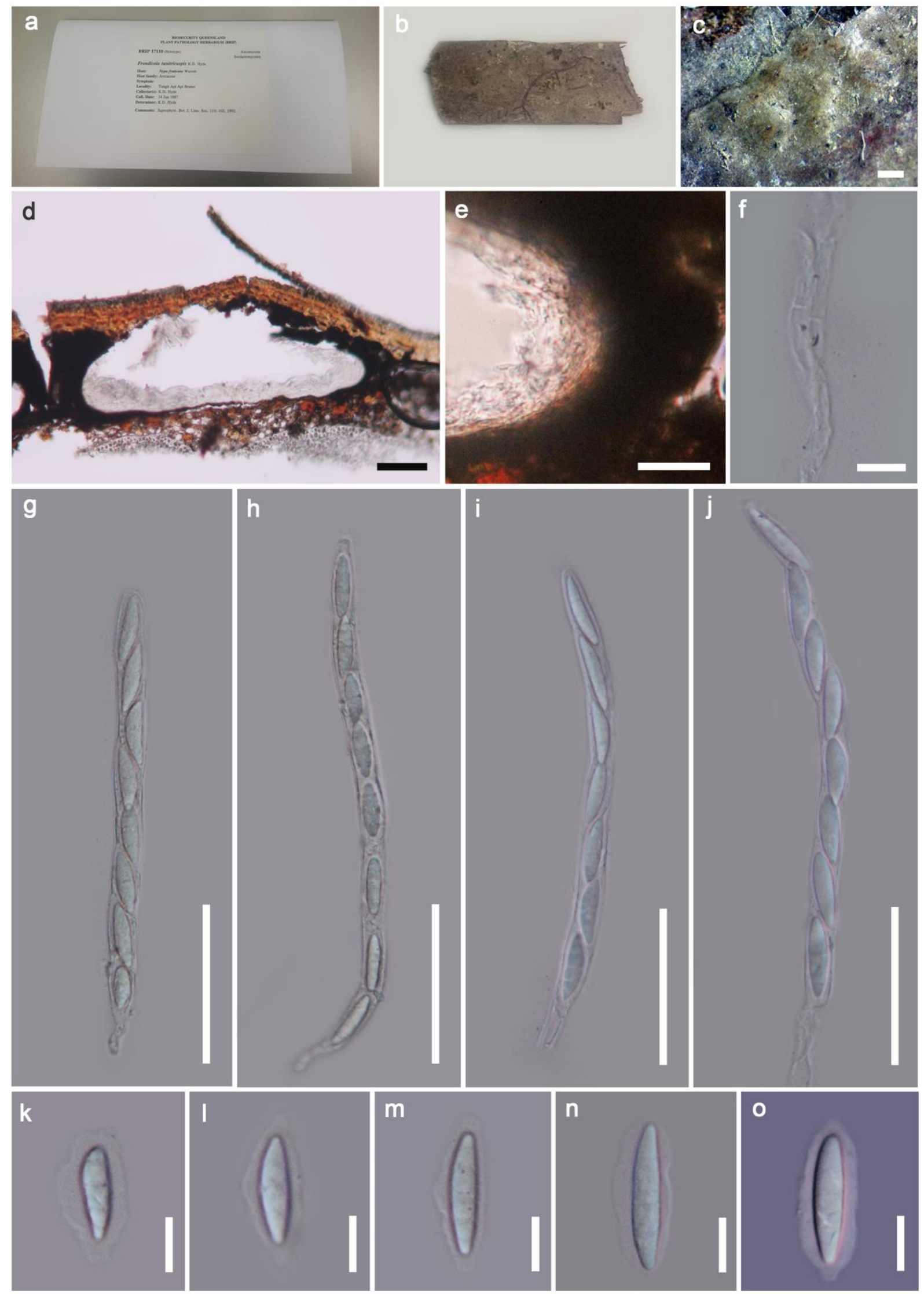

Figure 124 - Frondicola tunitricuspis (Material examined - BRUNEI, on bark of Nypa fruticans Wurmb (Arecaceae), 14 June 1987, K.D. Hyde, BRIP17110, holotype). a Material label. b Ascomata on host substrate. c Close up of ascoma. d Section of ascoma. e Peridium. f Paraphyses. g-j Asci. k-o Ascospores. Scale bars: $\mathrm{c}=500 \mu \mathrm{m}, \mathrm{d}=100 \mu \mathrm{m}, \mathrm{e}=20 \mu \mathrm{m}, \mathrm{f}, \mathrm{k}-\mathrm{o}=10 \mu \mathrm{m}, \mathrm{g}-\mathrm{j}=50$ $\mu \mathrm{m}$. 

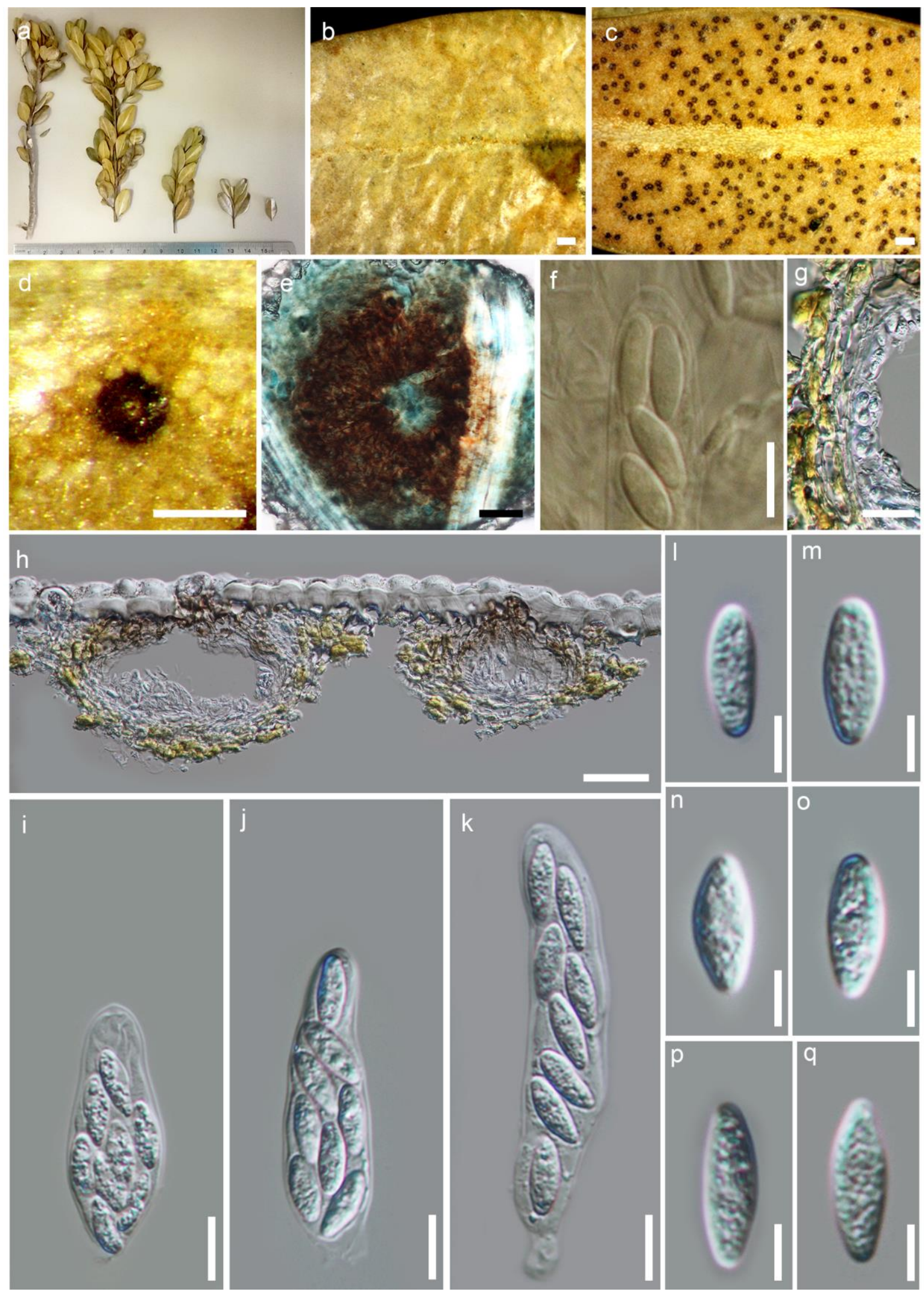

Figure 125 - Hyponectria buxi (Material examined - UK, Surrey, Mickleham, on leaves of Buxus sp., 1927, E.W. Mason no. 365, IMI 16895, IMI52229, IMI49466). a Herbarium specimen. b Ascomata on the upper leaf surface. c Ascomata on the lower leaf surface. d Close up of ascoma. e Close up of ascomata under microscope. $\mathrm{f} \mathrm{J-}$, reaction of apical ring in Melzer's reagent. $\mathrm{g}$ Cells of peridium. h Section of ascomata. i-k Asci. 1-q Ascospores. Scale bars: b-c $=500 \mu \mathrm{m}, d=200 \mu \mathrm{m}$, e, $\mathrm{h}=50 \mu \mathrm{m}, \mathrm{f}, \mathrm{i}-\mathrm{k}=10 \mu \mathrm{m}, \mathrm{g}=20 \mu \mathrm{m}, \mathrm{l}-\mathrm{q}=5 \mu \mathrm{m}$. 
Notes - Xenothecium jodophilum has short-pedicellate, cylindrical asci, with a $\mathrm{J}+$, apical ring and uniseriate, 1-celled, hyaline ascospores, lacking a mucilaginous sheath (Höhnel 1919).

Hypoxylaceae DC. Fl. franc,., Edn 3 (Paris) 2: 280 (1805)

Index Fungorum number: IF81885; Facesoffungi number: FoF02979; 422 species.

Saprobic or endophytic in wood, leaves and fruits, sometimes symbiotically associated with insect vectors in terrestrial and aquatic habitats (Pažoutová et al. 2010, 2013). Sexual morph: Stromata (if present) erect, glomerate, pulvinate, discoid, effused-pulvinate, hemispherical, spherical or peltate, or sometimes rudimentary or lacking, arising singly or aggregated into groups, with one to several ascomata, surface colour variable, mostly black-brown, ostiolate, mostly with extractable stromal pigments, unipartite, attached to the surface by broad bases, conical-dome shaped, raised areas. Ascomata variable in size and shape, globose-subglobose or elongate cylindrical-pyriform, embedded in the stroma, monostichous, interior sometimes zonate or filled with liquid. Ostiole papillate or umbilicate or at the same level as the stromal surface, with or without discs. Paraphyses hyaline, filamentous, septate, embedded in a gelatinous matrix, usually longer than the asci. Asci 4-8-spored, unitunicate, cylindrical to clavate, rarely globose, pedicellate or apedicellate, apically rounded, with or without a J+, or J-, apical ring, or with apical thickenings. Ascospores uniseriate-biseriate (crowded in Phylacia and Pyrenomyxa), uni-bicellular, ellipsoidalsubglobose, brown to black, rarely hyaline, mostly with a germ slit, straight, spiral or sigmoid, sometimes with rostrate, hyaline dwarf cell. Perispore dehiscent or sometimes lacking, smooth or with patterns. Asexual morph: Conidiophores mostly nodulisporium-like, hyaline to light brown, smooth, branched, mononematous or infrequently synnematous, usually macronematous. Conidiogenous cells cylindrical, usually hyaline, one to several on each branch of the conidiophore, swollen apex. Conidia hyaline, roughened or smooth, ellipsoidal (adapted from Wendt et al. 2018).

Type genus - Hypoxylon Bull.

Notes - The term Hypoxylaceae was not used in modern classifications until 2017, and treated under Xylariaceae (as 'Hypoxyloideae'). Wendt et al. (2018) validated the family in the Xylariales based on multi-locus phylogeny, morphology and chemotaxonomy studies. Molecular clock evidence confirmed the familial position of Hypoxylaceae within Xylariales (Hongsanan et al. 2017). Daranagama et al. (2018) accepted 18 genera including Alloanthostomella, Neoanthostomella and Pseudoanthostomella in the Hypoxylaceae. However, according to the phylogenetic studies by Voglmayr et al. (2018) and Wendt et al. (2018), these three genera cluster as a separate clade in Xylariaceae sensu stricto; thus they are placed in Xylariales genera incertae sedis. Herein, we accept 19 genera in Hypoxylaceae.

\section{Ecological and economic significance of Hypoxylaceae}

Species of Hypoxylaceae are mainly saprobes and endophytes, however, none are serious pathogens although there have been several reports on Hypoxylaceae species causing disease symptoms in water-stressed trees (Stadler 2011). The endophytic stages of Hypoxylaceae species have a rather interesting ecology and may even be beneficial to their host plants, because they protect them from pathogens, including other fungi, as well as invertebrates. Daldinia and Hypoxylon have been intensively studied for chemical profiling (Helaly et al. 2018).

\section{Genera included in Hypoxylaceae}

Annulohypoxylon Y.M. Ju, J.D. Rogers \& H.M. Hsieh, Mycologia 97(4): 855 (2005)

Index Fungorum number: IF500298; 62 morphological species (Wendt et al. 2018), 35 species with sequence data.

Type species - Annulohypoxylon truncatum (Starbäck) Y.M. Ju, J.D. Rogers \& H.M. Hsieh

Notes - Annulohypoxylon was introduced to accommodate Hypoxylon sect. Annulata sensu $\mathrm{Ju} \&$ Rogers (1996). Kuhnert et al. (2017) provided a concise revision of the genus and described several additional species based on molecular phylogenetic and chemotaxonomic evidence. Based on a multigene genealogy, Jackrogersella was segregated from Annulohypoxylon (Kuhnert et al. 
2017). Jackrogersella is characterised by papillate ostioles and its species produce azaphilones of the cohaerin type as predominant stromatal metabolites, while stromata of Annulohypoxylon sensu stricto mostly have ostioles encircled by an annulated disc and lack azaphilones but contain binaphthalenes as major stromatal metabolites (Wendt et al. 2018).

Anthocanalis Daranag., Camporesi \& K.D. Hyde, Fungal Divers. 73: 211 (2015)

Index Fungorum number: IF809515; 1 species with sequence data.

Type species - Anthocanalis sparti Daranag., Camporesi \& K.D. Hyde

Notes - The monotypic genus Anthocanalis was introduced to accommodate an anthostomella-like species characterized by ascomata with a reduced clypeus, shiny papilla, a peridium with hyaline cells of textura angularis, light brown cells of textura irregularis and limoniform ascospores with a prominent sheath only at the ventral side. Combined ITS, LSU, tub2 and rpb2 phylogenetic analyses suggested that the genus is closely related to Rhopalostroma, Ruwenzoria and Thamnomyces in Hypoxylaceae (Daranagama et al. 2018, Wendt et al. 2018). However, the available LSU, ITS, rpb2 and tub2 DNA sequences of $A$. sparti as well as the reported conidiogeneous structures are similar to Daldinia eschscholtzii, which needs further clarification.

Chlorostroma A.N. Mill., Lar.N. Vassiljeva \& J.D. Rogers, Sydowia 59(1): 142 (2007)

Index Fungorum number: IF29126; 3 morphological species (Daranagama et al. 2018).

Type species - Chlorostroma subcubisporum A.N. Mill., Lar.N. Vassiljeva \& J.D. Rogers

Notes - Chlorostroma has character of green stromata, J-, ascal apical ring and more or less cubical ascospores. All the species have been described based on stromata of Hypoxylon (Miller et al. 2007, Nordén et al. 2014). Læssøe et al. (2010) and Wendt et al. (2018) placed Chlorostroma in Hypoxylaceae based on highly similar secondary metabolite profiles to Hypoxylon aeruginosum.

Daldinia Ces. \& De Not., Comm. Soc. crittog. Ital. 1(fasc. 4): 197 (1863)

Index Fungorum number: IF1408; 53 morphological species (Species Fungorum 2020), 43 species with sequence data.

Type species - Daldinia concentrica Ces. \& De Not.

Notes - The genus was revisited and redefined by Stadler et al. (2014) and later included in Hypoxylaceae because of its affinities with Hypoxylon. Most species are characterized by welldefined concentric zones in the stromatal interior (Stadler et al. 2014). Multigene phylogeny studies showed that the genus comprises two well-supported clades within the family (Daranagama et al. 2018, Wendt et al. 2018). Daldinia eschscholtzii is illustrated in this entry (Figs. 126, 127).

Durotheca Læssøe, Srikitik., Luangsa-ard \& M. Stadler, IMA Fungus 4(1): 62 (2013)

Index Fungorum number: IF803610; 6 morphological species (De Long et al. 2019), 6 species with sequence data.

Type species - Durotheca depressa Læssøe \& Srikitik.

Notes - Durotheca species have narrow, undulating stromata with ostioles in deep depressions and ascospores with a germ slit or inconspicuous germ slit. Daranagama et al. (2018) and Wendt et al. (2018) treated the genus in Xylariales, incertae sedis due to chemotaxonomic affinities with Chlorostroma and Hypoxylon aeruginosum. Based on multigene phylogeny, De Long et al. (2019) described two species D. crateriformis and D. guizhouensis confirming their taxonomic placement in Hypoxylaceae.

Entonaema A. Möller, Botanische Mittheilungen aus den Tropen 9: 306 (Möller 1901)

Index Fungorum number: IF1837; 6 morphological species (Daranagama et al. 2018), 2 species with sequence data.

Type species - Entonaema liquescens A. Möller 


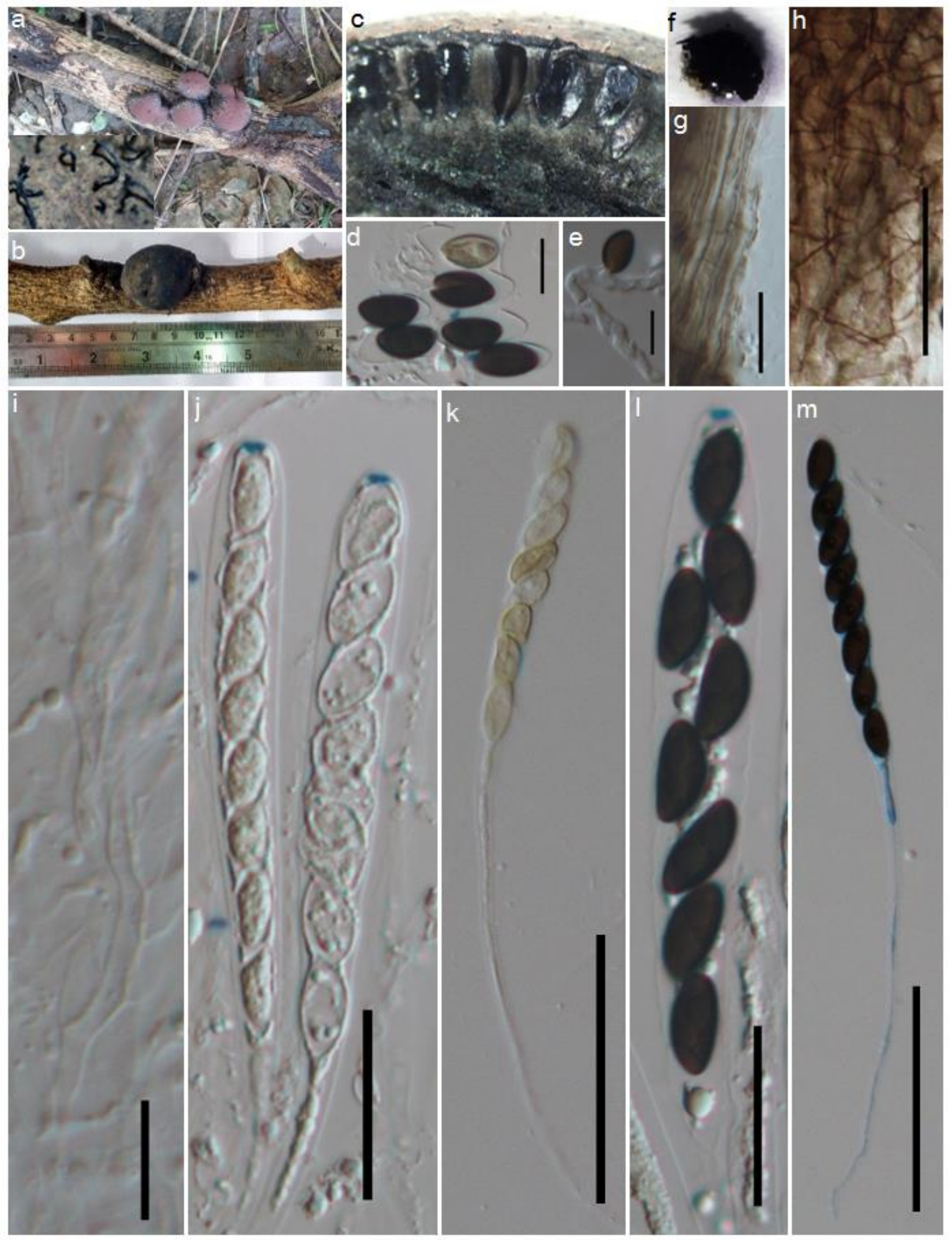

Figure 126 - Daldinia eschscholtzii (Material examined - INDIA, Andaman and Nicobar Islands, South Andaman, Manjery, Near Amber Sunset Point (11 51'68.6'N 92 65'38.8'E), on Tamarindus indica 10 December 2017, M. Niranjan, PUFNI 1761 (AMH-10066); living culture, NFCC 4365.

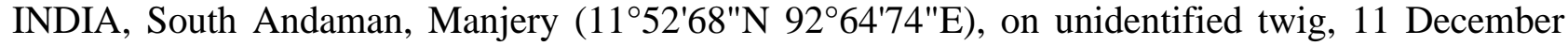
2017, M. Niranjan (T101F1); INDIA, Middle Andaman, Mayabunder (1249'15” N 9251'02”E), on unidentified twig, 7 January 2017 (T95F2). a, b Stromata on decaying host. c Vertical section of stromata. d Ascospores. e Germinating spore. f Stromata giving the purple colour in $10 \% \mathrm{KOH}$. $\mathrm{g}$ Peridium of textura oblita. h Textura angularis. i Paraphyses. j-m Immature and mature asci. Scale bars: $\mathrm{d}=200 \mu \mathrm{m}, \mathrm{g}, \mathrm{h}, 1, \mathrm{n}=50 \mu \mathrm{m}, \mathrm{j}, \mathrm{k} \mathrm{m}=20 \mu \mathrm{m}, \mathrm{d}, \mathrm{e}, \mathrm{g}=10 \mu \mathrm{m}$. 


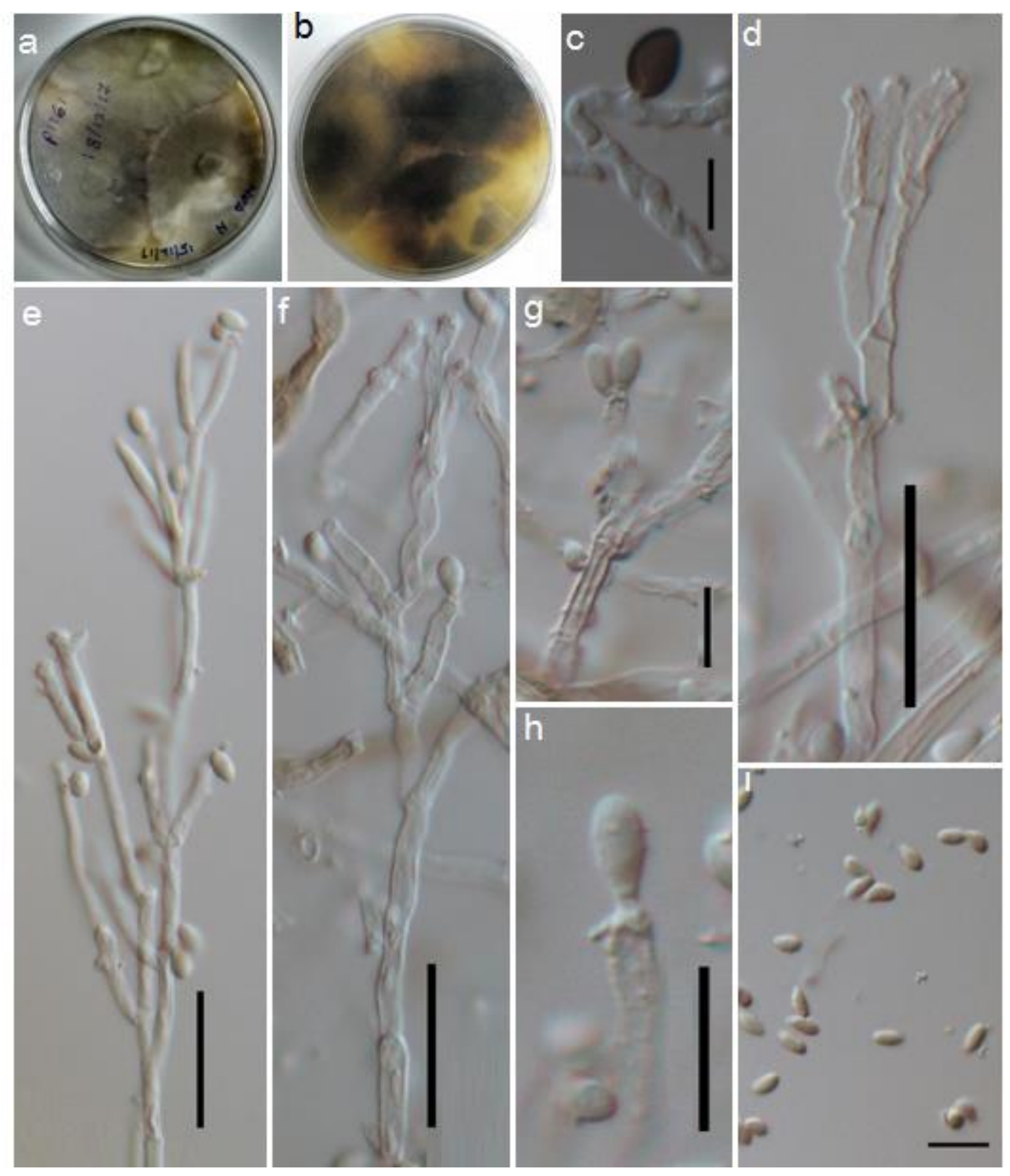

Figure 127 - Daldinia eschscholtzii (NFCC 4365), a, b Colonies on MEA (a-from above, bbelow). c Germinating spore. $\mathrm{d}$-h Conidiophores with attached conidia. $\mathrm{i}$ Conidia. Scale bars: $\mathrm{d}-\mathrm{f}=$ $20 \mu \mathrm{m}, \mathrm{g}-\mathrm{i}=10 \mu \mathrm{m}$.

Notes -Entonaema is characterized by hollow, gelatinous stromata similar to Daldinia (Stadler et al. 2008). Based on the stromatic sexual morph, nodulisporium-like asexual morph, chemotaxonomy and multigene phylogeny, Entonaema has been placed in Hypoxylaceae (Wendt et al. 2018).

Hypomontagnella Sir, L. Wendt \& C. Lamb. Mycological Progress: 1-15 (2018)

Index Fungorum number: IF827251; 5 morphological species (Lambert et al. 2019), 2 species with sequence data. 
Type species - Hypomontagnella monticulosa (Mont.) Sir, L. Wendt \& C. Lamb.

Notes - Lambert et al. (2019) erected Hypomontagnella to accommodate several species previously described as Hypoxylon species. Hypomontagnella differs from Annulohypoxylon and Jackrogersella by smooth perispores or with transversally striate ornamentations. It differs from species of Hypoxylon in having woody to carbonaceous stromata lacking coloured granules, papillate ostioles usually with a black annulate disc, and without apparent $\mathrm{KOH}$-extractable pigments in mature stromata (Lambert et al. 2019). Cultures of all Hypomontagnella species studied so far produce the strongly antifungal polyketides of the sporothrolide type, which have never been found in any other species of Xylariales and are otherwise only known from spurious endophytes. Hypomontagnella monticulosa is illustrated in this entry (Fig. 128).

Hypoxylon Bull., Histoire des champignons de la France. I: 168 (1791)

Index Fungorum number: IF2456; 232 morphological species (Species Fungorum 2020), 95 species with sequence data.

Type species - Hypoxylon fragiforme (Pers.) J. Kickx f.

Notes - Hypoxylon is an extensively studied, species rich genus with more than 200 taxa, but with more than 1000 epithets (Kuhnert et al. 2014, Wijayawardene et al. 2017a). Miller (1961) followed stromatal and ascospore morphology for species delimitation and Ju \& Rogers (1996) widely used morphology of asexual morph and stromatal pigments. Currently, the genus has further been restricted with a modern phylogenetic concept based on molecular data. Hypoxylon species are widely distributed and mainly inhabit dead wood as saprobes (Ju \& Rogers 1996, Wendt et al. 2018). Some Hypoxylon species occur as endophytes and facultative parasites on diseased hosts (Ju \& Rogers 1996, Kuhnert et al. 2014). Many secondary metabolites have been investigated from Hypoxylon species (Helaly et al. 2018).

Jackrogersella L. Wendt, Kuhnert \& M. Stadler, Mycol. Prog. (2018)

Index Fungorum number: IF819742; 6 morphological species (Wendt et al. 2018), 3 species with sequence data.

Type species - Jackrogersella multiformis L. Wendt, Kuhnert \& M. Stadler

Notes - Jackrogersella was introduced to accommodate species previously described as Annulohypoxylon, and characterized by papillate ostioles and lacking prominent ostiolar disks. Species in Jackrogersella also differ from Annulohypoxylon by containing cohaerin/multiformin type azaphilones rather than binaphthalele derivatives as predominant secondary metabolites. Based on the phylogeny of ITS, LSU, $t u b 2$ and $r p b 2$, the genus is well supported in Hypoxylaceae (Wendt et al. 2018). One species, which is for the time being retained as A. michelianum, occupies a separate clade.

Natonodosa Heredia, R.F. Castañeda \& D.W. Li, Mycological Progress 19: 23 (2020)

Index Fungorum number: IF819412; 1 species with sequence data (Heredia et al. 2020).

Type species - Natonodosa speciosa Heredia, R.F. Castañeda \& D.W. Li

Notes -Natonodosa is characterized by effuse, hairy, pigmented colonies. Conidiophores are septate, greyish brown to yellowish brown, paler towards the apex, with integrated, terminal and intercalary, doliiform, cylindrical or subcylindrical conidiogenous cells, with several subhyaline minute denticles and acropleurogenous, simple, fusiform to navicular, unicellular, dry, smooth and hyaline conidia. The sexual morph is undetermined (Heredia et al. 2020).

Phylacia Lév., Annls Sci. Nat., Bot., sér. 3 3: 61 (1845)

Index Fungorum number: IF4047; 10 morphological species (Species Fungorum 2020), 2 species with sequence data.

Type species - Phylacia globosa Lév.

Notes - Phylacia is characterized by cleistocarpous pyrenomycetes, lacking an ostiolar canal and opening by regular rupture of the ascomatal apex (Rodrigues \& Samuels 1989, Medel et al. 
2006). Earlier the genus was accepted in Phylaciaceae (Speer 1980b). Based on morphology (particularly the asexual morph), the strikingly similar metabolite profiles of the cultures to Daldinia (Bitzer et al. 2008) as well as inferred from molecular phylogenetic data, Phylacia was accommodated in Hypoxylaceae by Wendt et al. (2018). The asexual morph and stromatal pigments produced by Phylacia species also have close affinities to Thamnomyces and Rhopalostroma (Stadler et al. 2004, 2010).

Pyrenomyxa Morgan, J. Cincinnati Soc. Nat. Hist. 18: 42 (1895)

Index Fungorum number: IF22327; 3 morphological species (Species Fungorum 2020), 2 species with sequence data.

Type species - Pyrenomyxa invocans Morgan

Notes - Stromata of Pyrenomyxa are similar too species of the H. rubiginosum complex when collected in the field, but their ascal morphology is different, since they feature subglobose asci in which phaseoliform, laterally compressed ascospores are arranged in a similar manner to the slices of an orange fruit. The ascospores are not forcibly discharged as in most other Hypoxylaceae genera aside from Phylacia, Rhopalostroma and Thamnomyces, but they are released from the mature stromata in powdery masses.

A comparison of morphological features and secondary metabolite profiles of Pyrenomyxa invocans, Hypoxylon piceum and Pulveria porrecta were evaluated by Stadler et al. (2005) and it was concluded that they are congeneric with Pyrenomyxa which is the older name and takes preference. The molecular data and the secondary metabolite profiles (rubginosins and hypomiltins as prevailing stromatal metabolites) clearly suggest that this genus has affinities with Hypoxylon.

Pyrenopolyporus Lloyd, Mycological Writings 5 (50): 706 (1917)

Index Fungorum number: IF4599; 5 morphological species (Species Fungorum 2020), 4 species with sequence data.

Type species - Pyrenopolyporus hunteri Lloyd

Notes - Pyrenopolyporus is characterized by massive stromata with vinaceous shades on the surface, long tubular perithecia and umbilicate ostioles. Superficially, these stromata actually resemble a polyporaceous basidiomycete. Based on morphology, phylogeny and chemotaxonomy, Wendt et al. (2018) resurrected Pyrenopolyporus and transferred it to Hypoxylaceae. The genus has a close affinity to Daldinia, and the stromata resemble those of $D$. placentiformis and D. korfii, which lack conspicuous internal stromatal concentric zones. However, Pyrenopolyporus species deviate from those of the latter genus by producing a characteristic virgariella-like asexual morph in culture, by having characteristic, irregular ascospores and by producing drastically different secondary metabolite profiles in their stromata as well as their cultures (Wendt et al. 2018). For example, the cultures of Pyrenopolyporus produce cochliodinol, whereas those of Daldinia produce chromones and other small polyketides.

Rhopalostroma D. Hawksw., Kew Bull. 31(3): 422 (1977)

Index Fungorum number: IF4722; 11 morphological species (Species Fungorum 2020), 4 species with sequence data.

Type species - Rhopalostroma indicum D. Hawksw. \& Muthappa

Notes - Rhopalostroma species are characterized by pedicellate, melanized stromata with often abruptly expanded convex heads. The globose to subglobose stromatal morphology of Rhopalostroma is close to Phylacia. Rhopalostroma possesses a single layer of ascomata in the stroma, asci with apical ring and ascospores with a germ slit, which differs from Phylacia with multilayers and compact ascomata in the stroma, lack of ascal apical ring and lack of germ slit in the ascospores. Rhopalostroma species are restricted to subtropical Africa and South Asia. Based on morphological affinities with Thamnomyces and Phylacia, phylogenetic analyses and secondary metabolite profiles, the genus is accepted in Hypoxylaceae (Hawksworth 1977, Stadler et al. 2010, Daranagama et al. 2014, 2018, Wendt et al. 2018). 


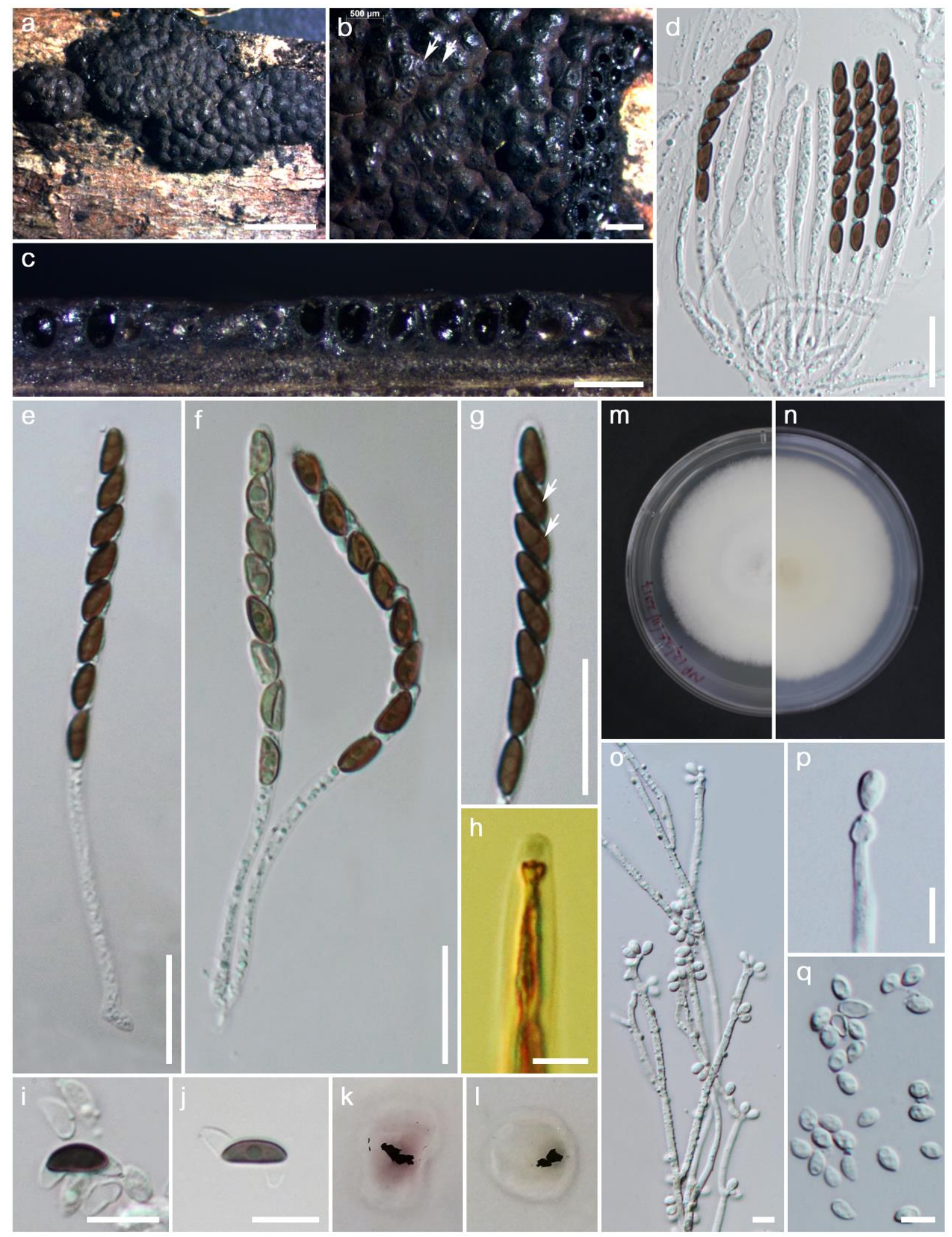

Figure 128 - Hypomontagnella monticulosa (Material examined - THAILAND, Naan, Doi Phu Kha, dead branch of Leucaena leucocephala (Fabaceae), 04 August 2017, MC. Samarakoon SAMC007, MFLU 18-0822, HKAS 102355, living culture MFLUCC 18-0362). a Mature stroma on bark. b Stromatal surface showing papillate and ostiolar discs (indicated by white arrows). c Stromata in vertical section. d-f Asci. g Ascospores (sigmoid germ slits indicated by white arrows). $\mathrm{h}$ Ascus tip in Lugol's reagent. i, j Perispores. k, $1 \mathrm{KOH}$-extractable pigments. m Surface of colony. $\mathrm{n}$ Reverse of colony. o-q Conidiophores and conidia. Scale bars: $\mathrm{a}=2 \mathrm{~mm}, \mathrm{~b}, \mathrm{c}=500 \mu \mathrm{m}, \mathrm{d}-\mathrm{g}=20$ $\mu \mathrm{m}, \mathrm{i}, \mathrm{j}=10 \mu \mathrm{m}, \mathrm{o}-\mathrm{q}=5 \mu \mathrm{m}$. 
Rostrohypoxylon J. Fourn. \& M. Stadler, Fungal Divers. 40: 24 (2010)

Index Fungorum number: IF512543; 1 species with sequence data.

Type species - Rostrohypoxylon terebratum J. Fourn. \& M. Stadler

Notes - Rostrohypoxylon is a monotypic genus characterized by its erumpent effuse stromata featuring stout, strongly protruding ostiolar necks and $\mathrm{KOH}$ extractable pigments. Multigene phylogenies confirmed that Rostrohypoxylon has a close affinity to Annulohypoxylon, but it appeared in a sister clade to the species of the latter genus and has different stromal HPLC profiles. Therefore, the genus is accepted as a separate genus in Hypoxylaceae (Fournier et al. 2010, Daranagama et al. 2018, Wendt et al. 2018).

Ruwenzoria J. Fourn., M. Stadler, Læssøe \& Decock, Mycol. Progr. 9(2): 171 (2010)

Index Fungorum number: IF515155; 1 species with sequence data.

Type species - Ruwenzoria pseudoannulata J. Fourn., M. Stadler, Læssøe \& Decock

Notes - Ruwenzoria is characterized by a blackish, slightly nodulose and cracked stromatal surface, ostioles with an umbilicate opening at the centre of a raised disc and J-, ascal apical ring. Based on phylogenetic and chemotaxonomic analysis, Ruwenzoria is accepted in Hypoxylaceae and has close affinity to Daldinia and Thamnomyces (Stadler et al. 2010, 2014, Daranagama et al. 2018, Wendt et al. 2018).

Thamnomyces Ehrenb., Horae Phys. Berol.: 79 (1820)

Index Fungorum number: IF5402; 11 morphological species (Stadler et al. 2010), 1 species with sequence data.

Type species - Thamnomyces chamissonis Ehrenb.

Notes - Thamnomyces is characterized by erect, black, unbranched to dendroid stromata with ascomata embedded on the tips of branches or laterally on the unbranched, wiry stromata. Its species are mostly known from the neotropics, except for Thamnomyces camerunensis, which was only found from Western Africa. Morphology, multigene phylogenies and chemical profiling have revealed that the genus is close to Daldinia, Phylacia and Rhopalostroma (Stadler et al. 2010), and accordingly is included in Hypoxylaceae (Daranagama et al. 2018, Wendt et al. 2018).

Theissenia Maubl., Bull. Soc. mycol. Fr. 30(1): 52 (1914)

Index Fungorum number: IF5418; 1 species with sequence data.

Type species - Theissenia pyrenocrata (Theiss.) Maubl.

Notes - Theissenia has a conspicuous central bulge or umbo in the perithecium and early dissolving asci. Ju et al. (2007) accepted the genus in Xylariaceae based on its nodulisporium-like asexual morph and $a c t$ and tub2 phylogeny. Læssøe et al. (2013) accepted it in Graphostromataceae because of its nodulisporium-like asexual morph and close relationship to Biscogniauxia. Daranagama et al. (2018) and Wendt et al. (2018) accepted the genus in Xylariales genera incertae sedis. A recent study by De Long et al. (2019) placed the genus in Hypoxylaceae.

Thuemenella Penz. \& Sacc., Malpighia 11(11-12): 518 (1898)

Index Fungorum number: IF5459; 4 morphological species (Species Fungorum 2020), 1 species with sequence data.

Type species - Thuemenella cubispora (Ellis \& Holw.) Boedijn

Notes - Thuemenella is characterized by having bright yellow stromata, green ascospores and a nodulisporium-like asexual morph. Several recent studies have transferred this genus to Hypoxylaceae based on its nodulisporium-like asexual morph and ITS and tub2 similarity of a sequence derived from Thuemenella cubispora with those of Hypoxylon rubiginosum (Miller et al. 2007, Wendt et al. 2018).

Induratiaceae Samarak., Thongbai, K.D. Hyde \& M. Stadler, Fungal Divers. (in press) MycoBank number: MB833443; Facesoffungi number: FoF06905; 29 species. 
Saprobic on dead wood, leaves, endophytic on leaves, stems and barks. Sexual morph: Stromata scattered, solitary or rarely pair-wise, globose to subglobose, barely raised above the host surface, visible as light brown-black, carbonaceous spots, immersed to semi-immersed in host tissue, attached to substrate with a broad base, with a single ascomata per stroma. Clypeus black, thick-walled, short, comprising dark fungal hyphae and host epidermal cells. Ostiole papillate, centric. Peridium wide at base, composed of two layers; inner layer hyline, thin walled cells of textura angularis; outer layer yellowish brown, thick walled cells of textura angularis. Paraphyses hyaline, smooth, thin-walled, two types; type 1 branched, with short, lateral bridges, aseptate, type 2 infrequently branched, septate. Asci 8-spored, unitunicate, cylindrical, short pedicellate, apically rounded with a $\mathrm{J}+$, apical ring. Ascospores uniseriate, naviculate to ellipsoidal or long fusiform, mostly hyaline, smooth-walled, constricted apiosporous; apical cell conical shape, guttulate with remnant at the top; base cell rarely brown, guttulate with remnant at the base, produce germ tube during the spore germination. Culture charcateristics: White to pale orange, straight, right angle hyphae, wavy or cottony hyphal growth, rope-like with cauliflowerlike hyphal bodies, strong odour. Asexual morph: Conidiophores nodulisporium-like (Induratia), abundant, and irregularly branched in the upper part. Conidiogenous cells terminal, solitary or sometimes two celled at the ends of branches, cylindrical, pale brown, bearing inconspicuous denticles. Conidia narrowly ellipsoidal to subglobose, hyaline, smooth, with a flat, wide, basal scar. idriella-like (Emarcea) (Samarakoon et al. 2019b).

Type genus - Induratia Samuels, E. Müll. \& Petrini

Notes - Samarakoon et al. (2020) introduced Induratiaceae to accommodate genera Emarcea and Induratia (= Muscodor) with apiosporous ascospores. Two novel species collected from northern Thailand revealed their phylogenetic affinity to earlier described Muscodor, Emarcea species and one Induratia sp. SMH 2155. Based on morphology, ITS-LSU-rpb2-tub2 phylogeny and gas chromatography coupled with mass spectrometry (GC-MS), Induratiaceae was established in Xylariales (Samarakoon et al. 2020).

\section{Ecological and economic significance of Induratiaceae}

Induratiaceae consists of mainly endophytic species (which were previously referred to as Muscodor spp.) and a few known saprobic species. Strobel et al. (2001) described at least 28 VOCs associated with Induratia species (as "Muscodor") that can induce lethal effects against a broad range of fungal and bacterial plant and human pathogens, as well as acari, insects and nematodes (Daisy et al. 2002, Atmosukarto et al. 2005, Mercier \& Manker 2005, Strobel 2006, Kudalkar et al. 2012, Hutchings et al. 2017).

\section{Genera included in Induratiaceae}

Emarcea Duong, Jeewon \& K.D. Hyde, Stud. Mycol. 50(1): 255 (2004)

Index Fungorum number: IF500070; 3 morphological species (Species Fungorum 2020), 2 species with sequence data.

Type species - Emarcea castanopsidicola Duong, Jeewon \& K.D. Hyde

Notes - Emarcea castanopsidicola was introduced from dead leaves of Castanopsis diversifolia in northern Thailand (Duong et al. 2004). The genus is characterized by immersed, globose to subglobose, coriaceous, solitary ascomata, immersed under a blackened clypeus and hyaline apiospore with mucilage at the ends and idriella-like asexual morphs. Emarcea differs from Induratia by its long fusiform ascospores, obclavate apical cells and similar by its apiospores without germ slits (Li et al. 2009, Daranagama et al. 2018). The ITS, LSU, rpb2 and tub2 multigene phylogeny revealed that Emarcea is basal to Induratia with high statistical support.

Induratia Samuels, E. Müll. \& Petrini, Mycotaxon 28(2): 484 (1987)

Index Fungorum number: IF25403; 26 morphological species (Samarakoon et al. 2020; mostly previously classified as Muscodor spp.), 25 species with sequence data.

Type species - Induratia apiospora Samuels, E. Müll. \& Petrini 


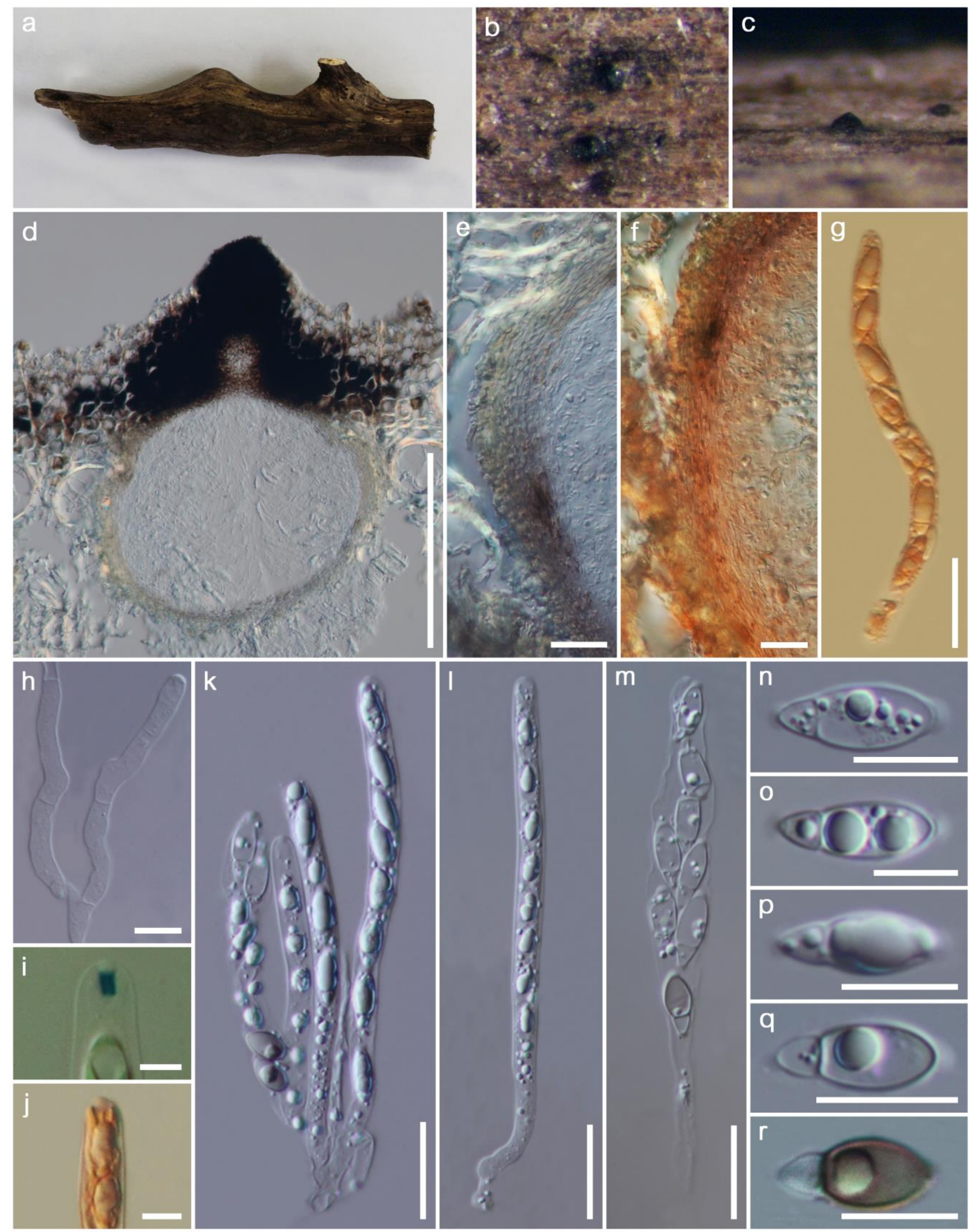

Figure 129 - Induratia thailandica (Material examined - THAILAND, Chang Wat Chiang Mai, Amphoe Mae Taeng, Tambon Pa Pae, on dead wood, 1 September 2017, M.C. Samarakoon, SAMC015, MFLU 18-0784, holotype). a-c Ascomata on the host surface. d Vertical section of ascoma. e, $\mathrm{f}$ Section of peridium ( $\mathrm{f}$ in Congo Red). $\mathrm{g}, \mathrm{k}-\mathrm{m}$ Asci ( $\mathrm{g}$ in Congo Red). $\mathrm{h}$ Paraphyses. $\mathrm{i}$ Apical ring $\mathrm{J}+$ in Melzer's reagent. $\mathrm{j}$ Ascus apex in Congo Red. n-r Ascospores. Scale bars: $\mathrm{d}=200$ $\mu \mathrm{m}, \mathrm{e}-\mathrm{g}, \mathrm{k}-\mathrm{m}=20 \mu \mathrm{m}, \mathrm{h}, \mathrm{n}-\mathrm{r}=10 \mu \mathrm{m}, \mathrm{i}, \mathrm{j}=5 \mu \mathrm{m}$. 
Notes - Muscodor was introduced by Worapong et al. (2001) and the species identification is mainly based on their characteristic volatile organic compounds (VOCs), inconclusive hyphal characters such as coiling, ropyness and by right angle branching patterns and inadequate phylogenetic analyses (Worapong et al. 2001, González et al. 2009). Due to the lack of taxon sampling, incomplete phylogenetic comparisons and undetermined morphology the taxonomic placement of Muscodor was considered doubtful (Stadler et al. 2013, Wendt et al. 2018). Therefore, Lumbsch \& Huhndorf (2010) did not accept the genus, while Seifert \& Gams (2011), Maharachchikumbura et al. (2016b) and Daranagama et al. (2018) accepted the genus and placed it in Xylariales genera incertae sedis. Wendt et al. (2018) proposed to reject the genus from the family because of poor taxonomic standards. Samarakoon et al. (2020) found evidence that the Muscodor is connected to Induratia, whose sexual morph was described by Samuels et al. (1987). Based on a polyphasic taxonomic approach including a multi gene genealogy, as well as volatile metbolite profiles and dual culture experiments, Samarakoon et al. (2020) erected nine new species and several new combinations of Induratia mainly resolving the taxonomic confusions of previously published Muscodor species into a new family Induratiaceae. Induratia thailandica is illustrated in this entry (Fig 129).

Iodosphaeriaceae O. Hilber, The Genus Lasiosphaeria and Allied Taxa (Kelheim): 7 (2002)

Index Fungorum number: IF82138; Facesoffungi number: FoF06189; 8 species.

Saprobic on dead twigs and leaves of various hosts. Sexual morph: Ascomata superficial, solitary, black, and easily removed from the substrate, covered with dark brown, setae-like, brown hairs, comprising agglutinated mycelial strands, with a stellate arrangement, arising from cells at the perithecial surface. Ostioles pore-like opening, central, with periphyses. Peridium outer region comprising pigmented, brown cells of textura angularis, inner region comprising hyaline, flattened cells. Paraphyses numerous, hypha-like, septate, flexuose, slightly tapered towards the apex. Asci 8-spored, unitunicate, narrowly clavate, short pedicellate or apedicellate, apex rounded, with a J+, subapical ring. Ascospores biseriate, hyaline, allantoid, unicellular, smooth-walled, lacking sheaths or appendages. Asexual morph: ceratosporium-like conidia have been observed on the surface of perithecia, but may not be related.

Type genus - Iodosphaeria Samuels, E. Müll. \& Petrini

Notes - Iodosphaeriaceae was introduced to accommodate Iodosphaeria and placed in Amphisphaeriales (Hilber \& Hilber 2002). Maharachchikumbura et al. (2016b) and Samarakoon et al. (2016) placed this family within Xylariales. Iodosphaeriaceae was placed in Xylariomycetidae, families incertae sedis (Hyde et al. 2017b, Hongsanan et al. 2017, Wijayawardene et al. 2018a). We accept Iodosphaeriaceae in Amphisphaeriales based on multigene analysis of combined LSU, ITS, $r p b 2$ and $t u b 2$ sequence data (Fig. 5).

\section{Ecological and economic significance of Iodosphaeriaceae}

Most Iodosphaeria species are saprobes which occur worldwide (Samuels et al. 1987, Barr 1994, Hyde 1995d, Candoussau et al. 1996, Hsieh et al. 1997b, Taylor \& Hyde 1999, Catania \& Romero 2012, Li et al. 2015a, Marasinghe et al. 2019), but have never been reported as a pathogenic on hosts. They are probably endophytes that become saprobes at leaf senescence.

\section{Genus included in Iodosphaeriaceae}

Iodosphaeria Samuels, E. Müll. \& Petrini, Mycotaxon 28(2): 486 (1987)

Index Fungorum number: IF25402; 8 morphological species (Species Fungorum 2020), 2 species with sequence data.

Type species - Iodosphaeria phyllophila (Mouton) Samuels, E. Müll. \& Petrini

Notes - Iodosphaeria was placed in Amphisphaeriaceae by Samuels et al. (1987) and also accepted by Eriksson et al. (2001). However, Barr (1994) and Hyde (1995d) suggested this genus should be placed in Lasiosphaeriaceae. Kang et al. (1998, 1999a) and Jeewon et al. (2003b) suggested that Iodosphaeria should be excluded from Amphisphaeriaceae and the genus was 
transferred to Trichosphaeriaceae (Réblová 1999d). Hilber \& Hilber (2002) introduced Iodosphaeriaceae and treated. Iodosphaeria aquatica was excluded from Iodosphaeria based on morphology being similar to Pseudohalonectria lignicola (Hsieh et al. 1997b). Iodosphaeria tongrenensis was introduced by $\mathrm{Li}$ et al. (2015a) from China with morphology and molecular evidence. Iodosphaeria honghense was introduced from China by Marasinghe et al. (2019) and is illustrated here.

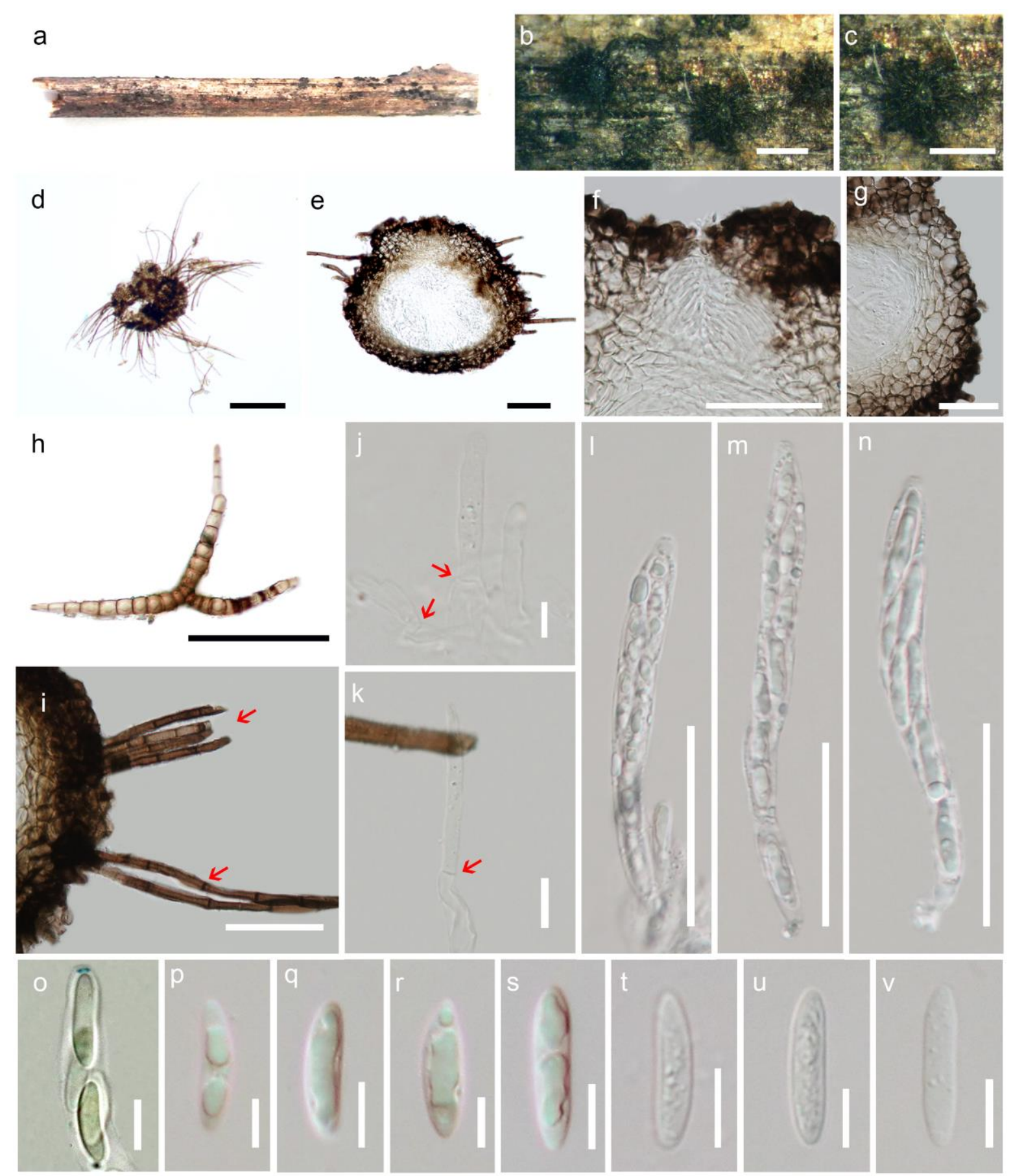

Figure 130 - Iodosphaeria honghense (Material examined - CHINA, Yunnan Province, Honghe, on dead stems, 15 June 2018, Junfu Li, MFLU 19-0719, holotype). a, b Appearance of ascomata on host substrate. c Close up of ascoma. d Fruiting body under the light microscope. e Section of ascoma. f Periphyses (septate at red arrows). g Peridium. h Associated ceratosporium-like conidia, but probably not related. i Unbranched brown hairs with septa (red arrows). j, k Paraphyses. 1-n Asci. o Ascus apical ring (stained in Melzer's reagent). p-v Ascospores. Scale bars: $b, c=500 \mu \mathrm{m}$, $\mathrm{d}=200 \mu \mathrm{m}, \mathrm{e}, \mathrm{h}=100 \mu \mathrm{m}, \mathrm{f}-\mathrm{h}, \mathrm{l}-\mathrm{n}=50 \mu \mathrm{m}, \mathrm{j}-\mathrm{k}, \mathrm{o}-\mathrm{v}=10 \mu \mathrm{m}$. 
Jobellisiaceae Réblová, Mycologia 100(6): 899 (2008)

Index Fungorum number: IF508692; Facesoffungi number: FoF03334; 8 species.

Saprobic on wood in terrestrial and freshwater habitats. Sexual morph: Ascomata perithecial, basally immersed to superficial, astromatic, globose to subglobose, lageniform to obpyriform, brown to black or yellowish, glabrous or slightly rugose, with a papilla or with upright neck. Peridium three-layered, comprising cells of textura angularis or textura prismatica or textura intricata, some with an orange, middle wall layer. Paraphyses numerous, septate. Asci 8-spored, unitunicate, cylindrical to clavate, short pedicellate, with a J-, distinct, refractive, apical ring. Ascospores uniseriate or overlapping uniseriate, oblong to ellipsoidal, fusoid to fusiform, straight or slightly curved, reddish-brown or greenish-brown to brown, darker at the median septum, 1-septate, with germ pores at one or both ends. Asexual morph: Undetermined (adapted from Réblová 2008 and Maharachchikumbura et al. 2016b).

Type genus - Jobellisia M.E. Barr

Notes - Jobellisiaceae was introduced by Réblová (2008) to accommodate a single genus Jobellisia based on LSU sequence data in the Sordariomycetes incertae sedis. In the phylogenetic analysis, Maharachchikumbura et al. (2015) introduced a new order Jobellisiales to accommodate this family, which was accepted by Maharachchikumbura et al. (2016b). With the use of molecular clock evidence, Jobellisiales fell in the ordinal time frame (146 MYA) (Hyde et al. 2017a). However, Hongsanan et al. (2017) stated that the placement of this order is unstable as sometimes it clustered with Pleurostomataceae.

\section{Ecological and economic significance of Jobellisiaceae}

Jobellisiaceae species are saprobic lignicolous taxa in terrestrial and freshwater habitats (Maharachchikumbura et al. 2016b). They play an important role in nutrient cycling as decomposers, especially on submerged woody debris or dry wood.

\section{Genus included in Jobellisiaceae}

Jobellisia M.E. Barr, Mycotaxon 46: 60 (1993)

Index Fungorum number: IF26310; 8 morphological species (Luo et al. 2019, Species Fungorum 2020), 3 species with sequence data.

Type species - Jobellisia luteola (Ellis \& Everh.) M.E. Barr

Notes - Jobellisia was introduced by Barr (1993) with two new combinations, J. luteola (type species) and J. nicaraguensis. Sequences of three species are available in GenBank (J. fraterna, J. guangdongensis and $J$. luteola), and have been used in phylogenetic analyses (Maharachchikumbura et al. 2015, 2016b, Hongsanan et al. 2017). Jobellisia guangdongensis is illustrated in this study (Fig. 131).

Juglanconidaceae Voglmayr \& Jaklitsch, Persoonia 38: 142 (2017)

Index Fungorum number: IF819587; Facesoffungi number: FoF03489; 5 species.

Saprobic on dead corticated twigs and branches of Juglandaceae attached to trees. Sexual morph: Pseudostromata comprising an inconspicuous ectostromatic disc which are erumpent from bark. Central column beneath the disc, nearly conical. Perithecia surrounding the central column, with nearly globose base, with long lateral ostioles that emerge at the margin or within an ectostromatic disc. Asci 8-spored, clavate to fusoid, with a J-, apical ring. Ascospores overlapping 1-2-seriate, hyaline, broadly fusiform, bicelled, slightly curved, guttulate, with or without gelatinous appendages. Asexual morph: Coelomycetous. Conidiomata acervular, with ectostromatic disc and conical central column. Conidiophores aseptate or septate, smooth, hyaline to brownish, occasionally branched. Conidiogenous cells annellidic. Conidia initially hyaline, becoming brown with age, various in shape, pip-shaped, narrowly ellipsoid, elongate to suballantoid, unicellular, often truncate with scar at the base, with gelatinous sheath and irregular verrucae on the inner surface of the conidial wall (adapted from Voglmayr et al. 2017).

Type genus - Juglanconis Voglmayr \& Jaklitsch 

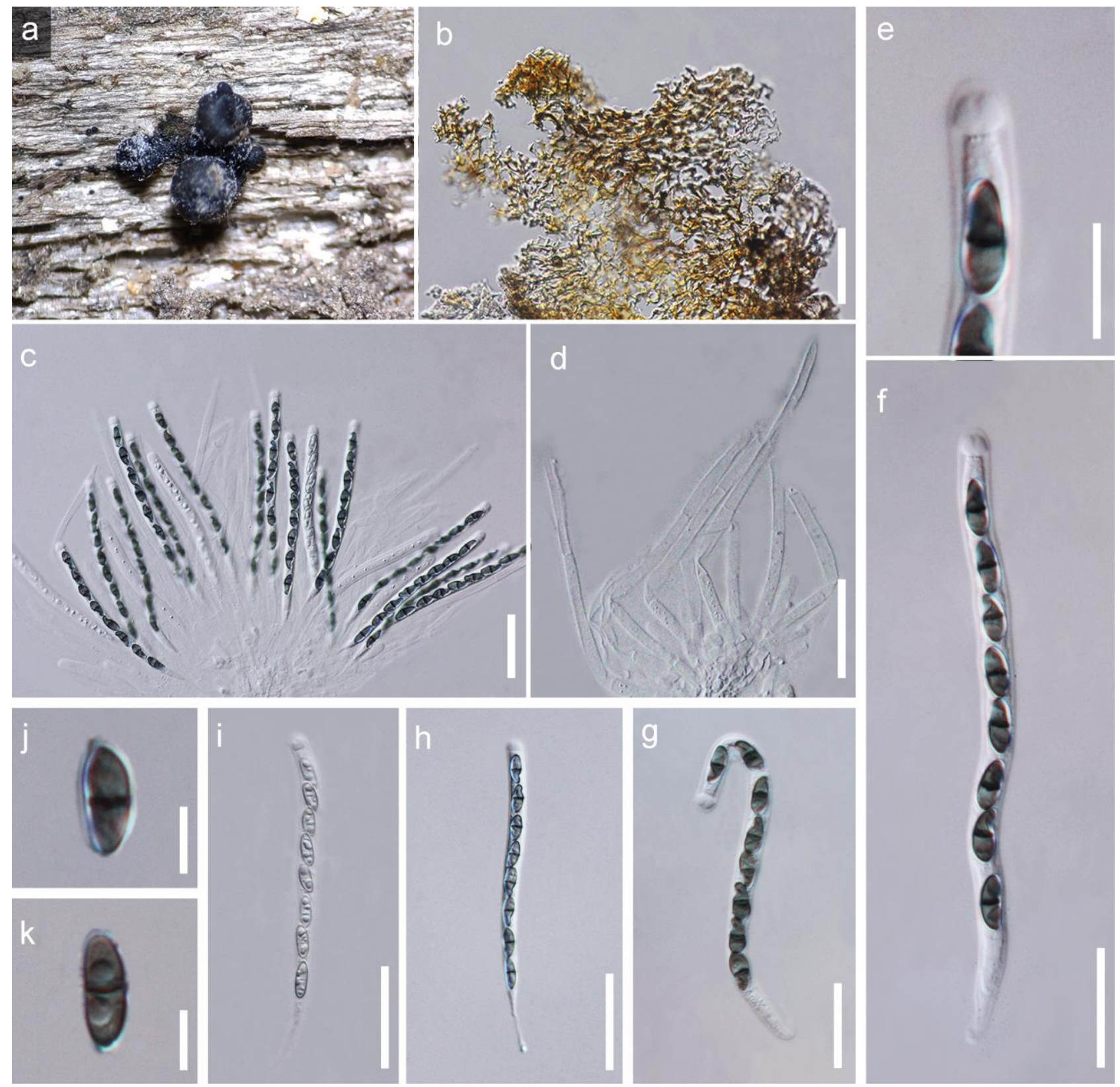

Figure 131 - Jobellisia guangdongensis (Material examined - CHINA, Yunnan Province, on submerged wood in a stream, 25 August 2019, G.N. Wang DQ09, MFLU 19-2827). a Appearance of black ascoma on host. b Structure of peridium. c, e-i Asci. d Paraphyses. j, k Ascospores. Scale bars: $\mathrm{b}=40 \mu \mathrm{m}, \mathrm{c}, \mathrm{d}, \mathrm{h}, \mathrm{i}=30 \mu \mathrm{m}, \mathrm{e}=10 \mu \mathrm{m}, \mathrm{f}, \mathrm{g}=20 \mu \mathrm{m}, \mathrm{j}, \mathrm{k}=5 \mu \mathrm{m}$.

Notes - Juglanconidaceae was erected by Voglmayr et al. (2017) to accommodate four Melanconium species on hosts of Juglandinae, viz. three species (Juglanconis appendiculata, J. juglandina, J. oblonga) on various Juglans species, and one species (J. pterocaryae) from Pterocarya spp. (Voglmayr et al. 2019b). Du et al. (2017) introduced Melanosporellaceae to accommodate Melanosporella typified by M.juglandium. It was shown that the strains Juglanconis juglandina (MC1, ME16, ME22, ME23, MC3) from Austria and Spain and strains Melansporella juglandium (CFCC 51727, CFCC 51728, CFCC 51729) from China clustered together in the multigene phylogenetic analyses and share close morphological features (Du et al. 2017, Fan et al. 2018). Thus, Senanayake et al. (2018) treated Melanosporellaceae as a synonym of Juglanconidaceae. Juglanconidaceae seems specific to Juglandaceae tree species and cause black pustular dieback (Senanayake et al. 2018). 


\section{Ecological and economic significance of Juglanconidaceae}

All species of Juglanconis have been reported on Juglandaceae (walnut family), such as Juglans ailanthifolia, J. cinerea, J. nigra, J. regia and Pterocarya rhoifolia. Juglanconis species have a wide distribution across Austria, China, the Czech Republic, France, Germany, Greece, Japan, Russia, Spain and the USA (Fan et al. 2018). Juglanconis juglandina and J. oblonga were regarded as the main causal agent of canker and dieback disease of Juglans regia in China (Fan et al. 2018).

\section{Genus included in Juglanconidaceae}

Juglanconis Voglmayr \& Jaklitsch, Persoonia 38: 142 (2017)

Index Fungorum number: IF819582; 5 species with sequence data.

Type species - Juglanconis juglandina (Kunze) Voglmayr \& Jaklitsch

Notes - Juglanconis was established by Voglmayr et al. (2017) to accommodate three combined species including J. juglandina (WU 35965, neotype), J. oblonga (MBT374386, lectotype), J. pterocaryae (TFM FPH2623, holotype) and a newly introduced species $J$. appendiculata (WU 35954, holotype). These species were previously placed in Melanconium but they are morphologically different from Melanconium sensu stricto in having irregular ornamentation on the inner surface of the conidial wall (Voglmayr et al. 2017). Fresh collections and updated morphological descriptions of Juglanconis juglandina and J. oblonga collected from Juglans regia in China were also provided by Fan et al. (2018). Subsequently, two new species Juglanconis japonica occurring on Pterocarya rhoifolia and J. pterocaryae occurring on Pterocarya fraxinifolia were introduced to this genus (Voglmayr et al. 2019b). To date, five species are accepted in Juglanconis and more fresh collections are needed (Voglmayr et al. 2019b). Currently Juglanconis species have calM, histone, ITS, LSU, ms204, rpb1, rpb2, tef1 and tub2 gene sequence data available for multilocus analyses (Voglmayr et al. 2019b).
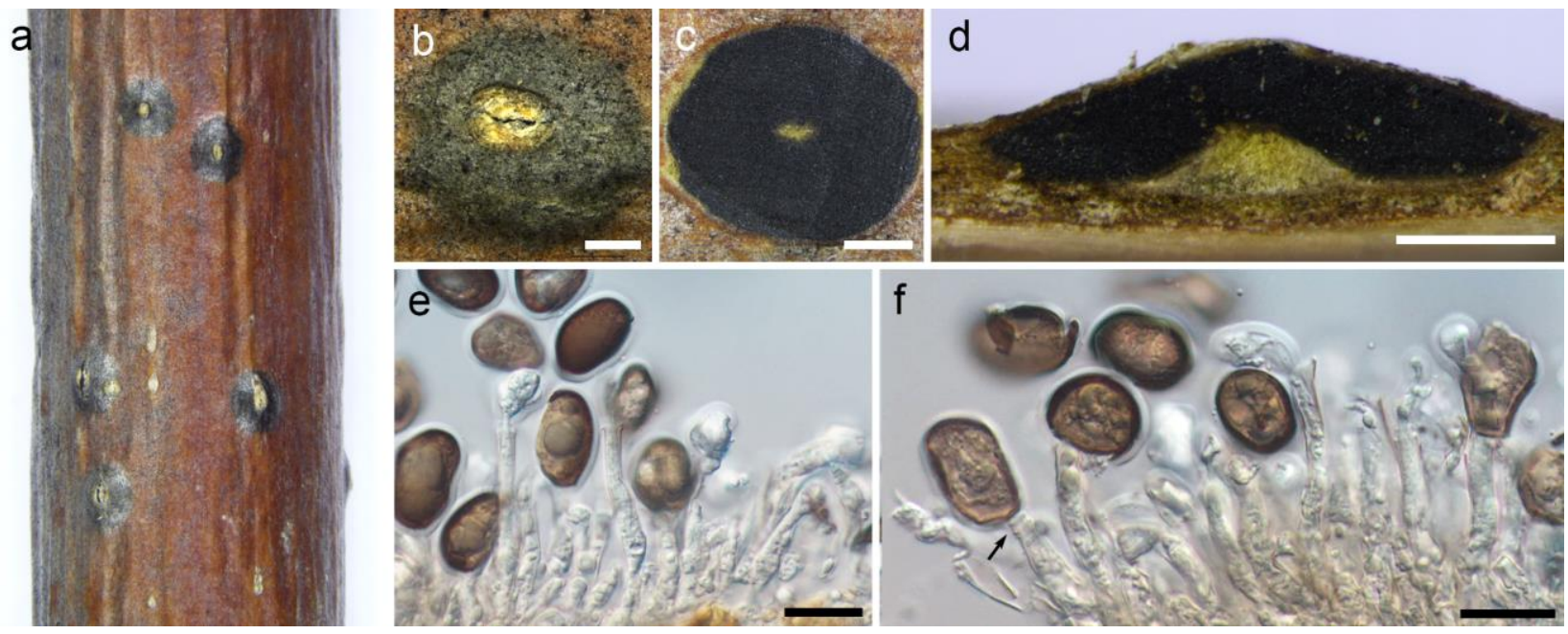

Figure 132 - Morphology of Juglanconis juglandina (Material examined - CHINA, Gansu Province, Qingyang City, Shishe village, on twigs and branches of Juglans regia, 14 July 2013, X.L. Fan, BJFC-S908), a, b Habit of acervuli on branches. c Transverse section through acervulus. $\mathrm{d}$ Longitudinal section through acervulus. e, f Conidiophores, conidiogenous cells and conidia. Annellides of conidiogenous cells are marked by black arrow in $\mathrm{f}$. Scale bars: $\mathrm{a}-\mathrm{d}=0.5 \mathrm{~mm}, \mathrm{e}, \mathrm{f}=$ $20 \mu \mathrm{m}$.

Juncigenaceae E.B.G. Jones, Abdel-Wahab \& K.L. Pang, Cryptog. Mycol. 35(2): 133 (2014)

Index Fungorum number: IF808177; Facesoffungi number: FoF01665; 8 species.

Saprobic intertidal wood, mangrove and herbaceous wood and roots, bark, leaves in marine habitats. Sexual morph: Ascomata perithecial, globose, subglobose, ovoid to pyriform, immersed, erumpent to superficial, subcoriaceous to coriaceous, olivaceous-brown, brown to dark-brown to 
black, hyaline to yellow-orange to reddish-brown, ostiolate, periphysate, papillate or hyaline to apricot coloured long neck surrounded by dense brown, septate hyphae. Peridium comprising several cell layers of ellipsoidal to subglobose cells forming textura angularis, textura epidermoidea or both, or textura prismatica or textura globulosa. Paraphyses numerous, narrow, branched or unbranched, persistent, connected to the apex and base of the peridium or catenophyses. Asci 8-spored, unitunicate, thin-walled, persistent, clavate, cymbiform, cylindrical to fusiform, short pedicellate, with or without apical ring. Ascospores 1-3 seriate, hyaline, ellipsoidal, clavate to fusiform, unicellular, or 1-4-septate, with or without equatorial and polar or subpolar appendages. Asexual morph: hyphomycetous. Hyphae septate, branched, hyaline to brown. Conidiogenous cells non-specialized, short, lateral, solitary, helicoid, septate, and light to dark brown. Conidia brown, single, helicoid, septate, constricted at the septa (adapted from AbdelWahab et al. 2010, Jones et al. 2014, Maharachchikumbura et al. 2015, Poli et al. 2019).

Type genus - Juncigena Kohlm., Volkm.-Kohlm. \& O.E. Erikss.

Notes - Juncigenaceae was typified by Juncigena by Jones et al. (2014) and included the genera Fulvocentrum, Marinokulati and Moheitospora. They formed a phylogenetically stable monophyletic clade in a SSU and LSU based phylogeny. Juncigenaceae is sister to Etheirophoraceae, Falcocladiaceae and Torpedosporaceae in the subclass Hypocreomycetidae. Jones et al. (2014) introduced Fulvocentrum to accommodate $F$. aegyptiacum and $F$. clavatisporium, which were previously introduced under Swampomyces sensu stricto. Likewise, the marine ascomycete Chaetosphaeria chaetosa did not group in Chaetosphaeria sensu stricto (Chaetosphaeriales) and was transferred to a new genus Marinokulati (Jones et al. 2014). In Jones et al. (2014), Juncigenaceae was placed in the subclass Hypocreomycetidae, order incertae sedis. This was supported by Maharachchikumbura et al. (2015). Jones et al. (2015) placed Etheirophoraceae, Juncigenaceae and Torpedosporaceae in Torpedosporales. Abdel-Wahab et al. (2018) introduced Khaleijomyces as sister to Juncigena and Poli et al. (2019) introduced Elbamycella as a separate lineage in Juncigenaceae.

\section{Ecological and economic significance of Juncigenaceae}

Members in this family have mainly been found on driftwood collected from the intertidal zone, submerged sea grasses and brown alga (Abdel-Wahab et al. 2010, Poli et al. 2019). They are likely saprobes involved in nutrient cycling.

\section{Genera included in Juncigenaceae}

Elbamycella A. Poli, E. Bovio, V. Prigione \& G.C. Varese, MycoKeys 55: 21 (2019)

Index Fungorum number: IF830648; 1 species with sequence data.

Type species - Elbamycella rosea A. Poli, E. Bovio, V. Prigione \& G.C. Varese

Notes - This genus was recorded from submerged marine environments (sea grass Posidonia oceanica and with the brown alga Padina pavonica) (Poli et al. 2019). The genus is well-supported by morphology and phylogeny. This is the first record of Juncigenaceae found in submerged environment (Poli et al. 2019). The genus is morphologically distinct from other genera with subpolar appendaged spores (Poli et al. 2019).

Fulvocentrum E.B.G. Jones \& Abdel-Wahab, Cryptog. Mycol. 35(2): 131 (2014)

Index Fungorum number: IF808181; 3 species with sequence data.

Type species - Fulvocentrum aegyptiacum (Abdel-Wahab et al.) E.B.G. Jones \& AbdelWahab

Notes - Found on decayed attached branches of Avicennia marina in the intertidal zone. The genus has immersed, dark brown, ostiolate ascomata with numerous unbranched paraphyses in a gel and short pedicellate, apically thickened asci, with 3-septate, ellipsoidal, hyaline ascospores (Jones et al. 2014). The genus is distinct in having, short pedicellate, apically thickened asci with 3 septate, ellipsoidal hyaline ascospores (Jones et al. 2014). In this entry, Fulvocentrum aegyptiacum is illustrated to demonstrate the sexual morph. Fulvocentrum aegyptiacus is commonly found in 
intertidal wood from Avicennia marina in Red sea mangroves Egyptian coast (Abdel-Wahab 2005) and Arabian Gulf mangroves of the Saudi Arabia coast (Abdel-Wahab 2005).
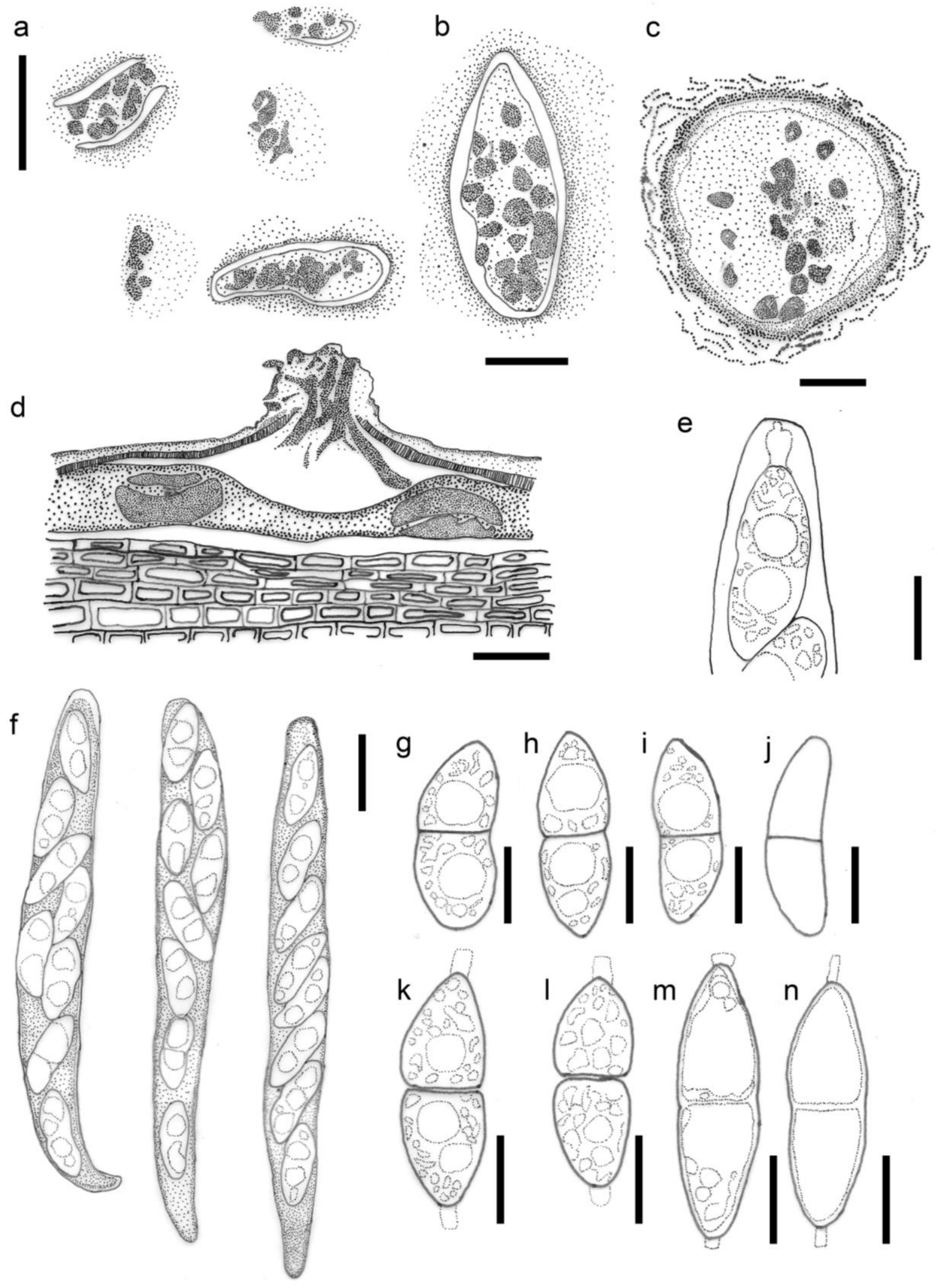

Figure 133 - Juglanconis juglandina (a-j), Juglanconis appendiculata (k-n) redrawn from Voglmayr et al. (2017). a, b Ectostromatic discs. c Transverse sections below ectostromatic disc. d Vertical section through pseudostroma, showing perithecia and entostroma. e Apical ring of asci. $\mathrm{f}$ Asci. g-n Ascospores. Scale bars: $\mathrm{a}=1 \mathrm{~mm}, \mathrm{~b}, \mathrm{c}=0.5 \mathrm{~mm}, \mathrm{f}=20 \mu \mathrm{m}, \mathrm{e}, \mathrm{g}-\mathrm{n}=10 \mu \mathrm{m}$. 
a
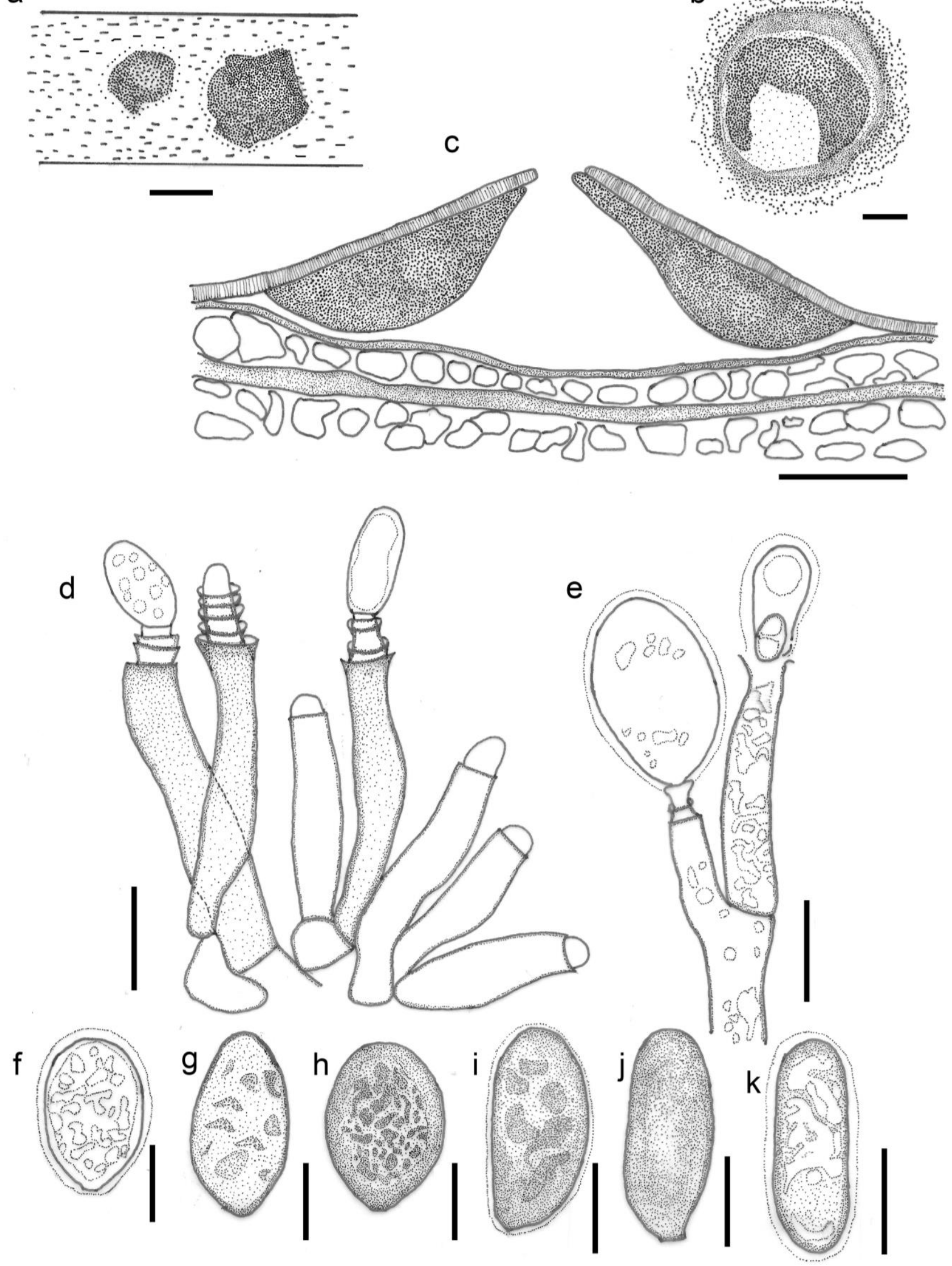

Figure 134 - Juglanconis juglandina (a-h), Juglanconis oblonga (i, j), Juglanconis pterocaryae (k) redrawn from Voglmayr et al. (2017). a Conidiomata on the host. b, c Transverse and vertical sections of conidiomata. d, e Conidiophore with conidia. f-k Conidia. Scale bars: a $=1 \mathrm{~mm}, \mathrm{~b}, \mathrm{c}=$ $0.5 \mathrm{~mm}, \mathrm{~d}-\mathrm{k}=10 \mu \mathrm{m}$. 


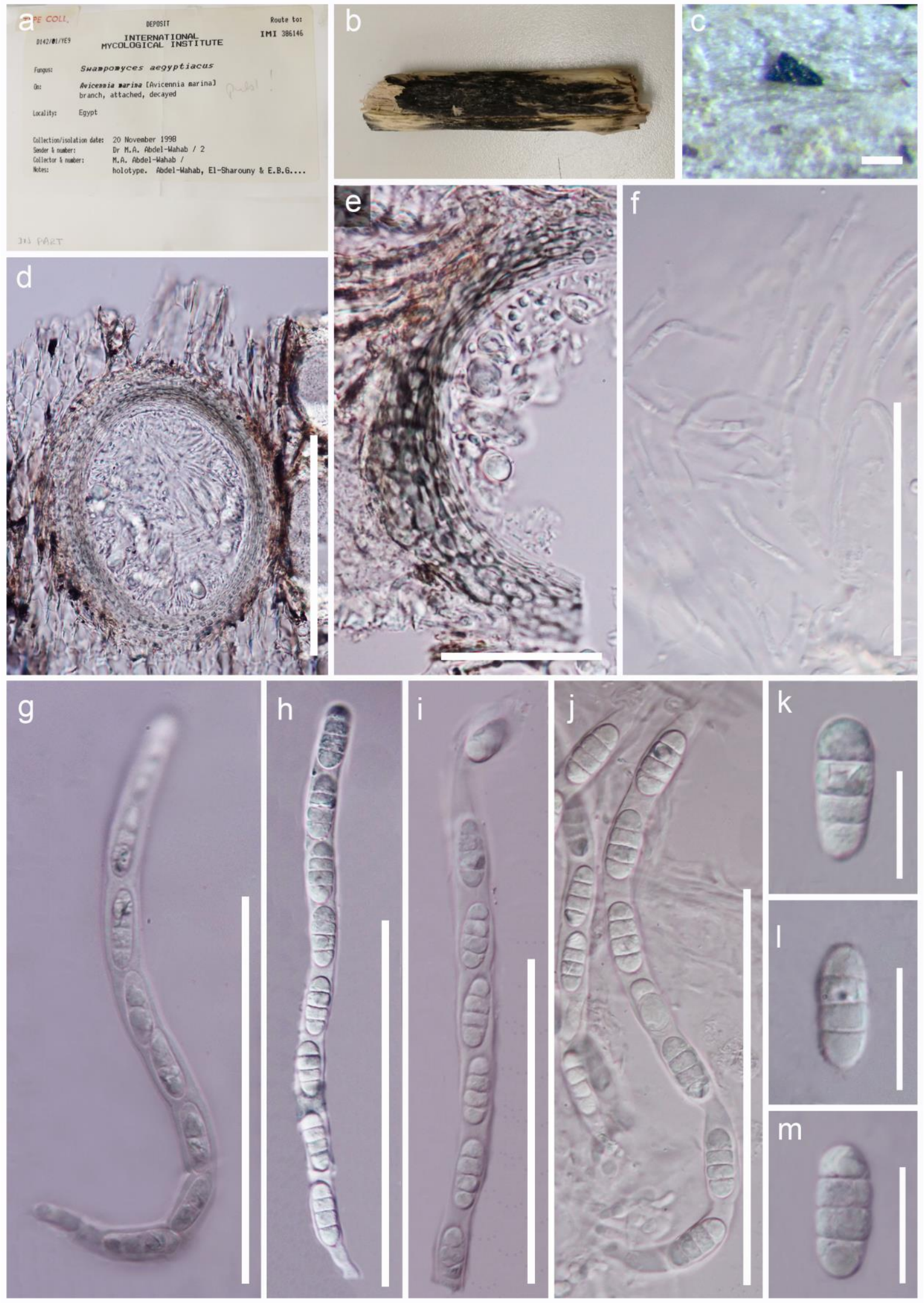

Figure 135 - Fulvocentrum aegyptiacus (Material examined - EGYPT, Red Sea Coast, Safaga mangrove, on decayed attached branches of Avicennia marina in the intertidal zone, January 1999, M.A. Abdel- Wahab, IMI 386146, holotype). a Herbarium packet. b Herbarium material. c Ascomata on host. d Section through ascoma. e Peridium. f Paraphyses. g-j Asci. k-m Ascospores. Scale bars: $\mathrm{c}, \mathrm{d}=100 \mu \mathrm{m}, \mathrm{f}-\mathrm{j}=50 \mu \mathrm{m}, \mathrm{e}, \mathrm{k}-\mathrm{m}=10 \mu \mathrm{m}$. 
Juncigena Kohlm., Volkm.-Kohlm. \& O.E. Erikss., Bot. Mar. 40(4): 291 (1997)

Index Fungorum number: IF27750; 2 morphological species (Species Fungorum 2020), 1 species with sequence data.

Type species - Juncigena adarca Kohlm., Volkm.-Kohlm. \& O. E. Erikss.

Notes - Juncigena Kohlmeyer et al. (1997). was initially included under Magnaporthaceae by Eriksson (1999). Further protein coding and rDNA based phylogeny by Schoch et al. (2006) revealed Juncigena adarca clusters with Swampomyces sp. in Coronophorales. Jones et al. (2009) included Juncigena under Hypocreales incertae sedis. With resolving the TBM (Torpedospora/Bertia/Melanospora) clade with terrestrial Falcocladium, Jones et al. (2014) referred Juncigena under Juncigenaceae. Kohlmeyer et al. (1997) revealed that Cirrenalia adarca was the asexual morph of Juncigena adarca. Abdel-Wahab et al. (2010) transferred C. adarca to Moheitospora based on phylogenetic and morphological evidence. The genus currently comprises Juncigena adarca and J. fruticosae. Juncigena is distinctive from other genera in having the cylindrical, short pedicellate asci with an apical ring (Jones et al. 2014). Réblová et al. (2016b) referred Moheitospora fruticosae to Juncigena as the two genera are congeneric, and Juncigena has priority.

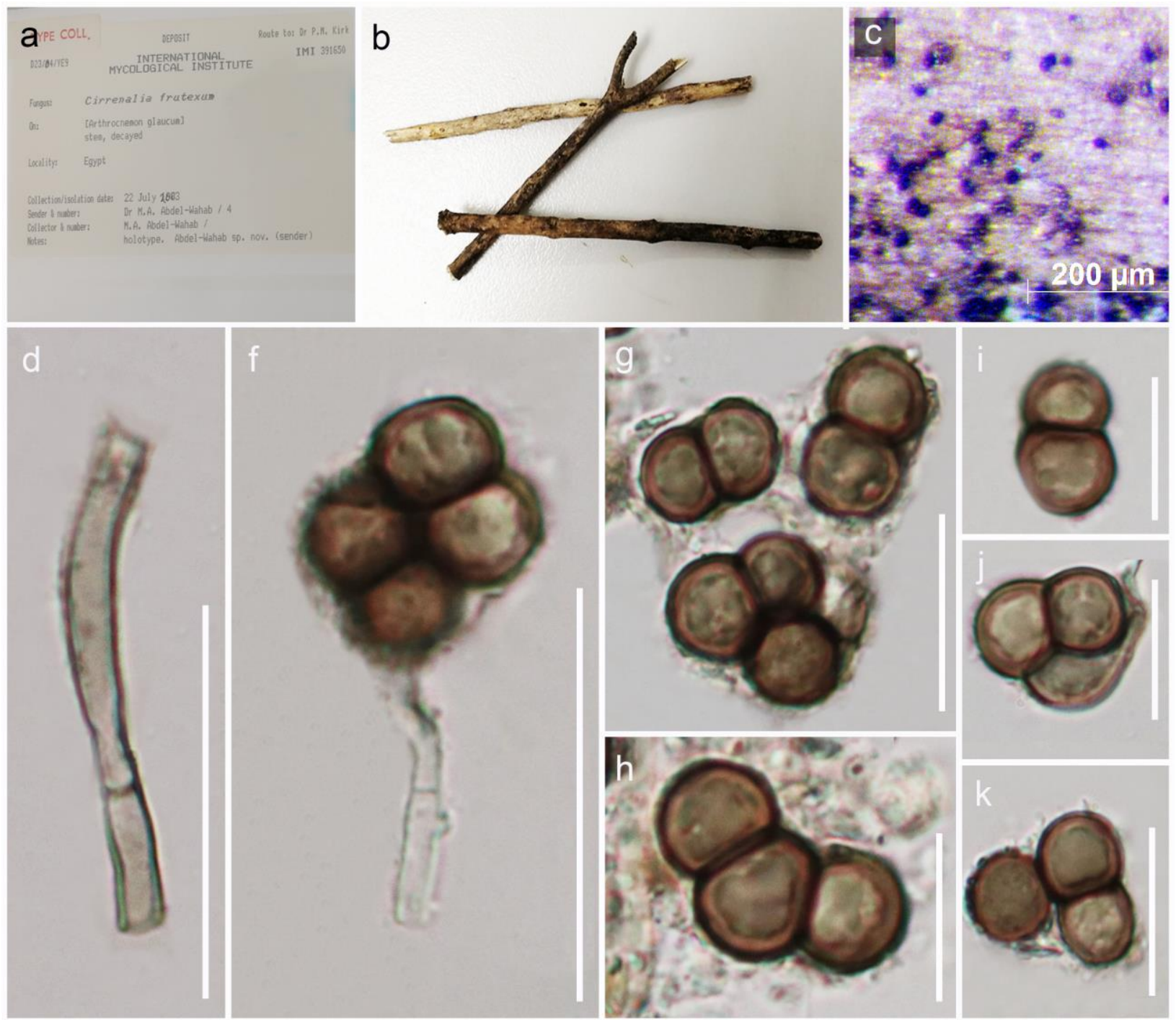

Figure 136 - Juncigena fruticosae (Material examined - EGYPT, Mediterranean coast, on decayed driftwood in the intertidal zone, June 2006, M. A. Abdel-Wahab, IMI 391650, holotype). a Herbarium packet. b Herbarium material. c Hyphae, conidiophores and conidia on host. d Conidiophores. f-k Conidiophores and variously-shaped mature conidia. Scale bars: $\mathrm{c}=200 \mu \mathrm{m}, \mathrm{d}$ $=100 \mu \mathrm{m}, \mathrm{e}, \mathrm{f}=50 \mu \mathrm{m}, \mathrm{g}-\mathrm{k}=20 \mu \mathrm{m}$. 
Khaleijomyces M.A. Abdel-Wahab, Phytotaxa 340(3): 280 (2018)

Index Fungorum number: IF823891; 1 species with sequence data.

Type species - Khaleijomyces marinus M.A. Abdel-Wahab

Notes - The genus differs from other genera in the family, in having ostiolar necks with periphyses and not having apical rings or thickenings in the asci (Abdel-Wahab et al. 2018). The ascomata differ in being yellow-orange to reddish brown. Species are found on intertidal driftwood (Abdel-Wahab et al. 2018).

Marinokulati E.B.G. Jones \& K.L. Pang, Cryptog. Mycol. 35(2): 132 (2014)

Index Fungorum number: IF808184; 1 species with sequence data.

Type species - Marinokulati chaetosa (Kohlm.) E.B.G. Jones \& K.L. Pang

Notes - While resolving the TBM (Torpedospora/Bertia/Melanospora) clade with the marine species Chaetosphaeria chaetosa and terrestrial Falcocladium, Jones et al. (2014) revealed that the former species was significantly different from Chaetosphaeria and Juncigena. Hence, Marinokulati was introduced to accommodate the previously known Chaetosphaeria chaetosa. The genus is characterised by apically thickened asci and 3-septate, hyaline, fusiform to ellipsoidal ascospores with polar and equatorial appendages.

Junewangiaceae J.W. Xia \& X.G. Zhang, Scientific Reports 7 (no. 7888): 12 (2017)

Index Fungorum number: IF818897; Facesoffungi number: FoF06602; 9 species.

Saprobic on terrestrial or freshwater habitats. Sexual morph: Ascomata scattered or solitary, immersed with neck superficial, uniloculate, globose, subglobose or ellipsoidal, glabrous, brown, coriaceous. Ostiole long, cylindrical, periphysate. Peridium comprising several layers of brown, thick-walled, compressed cells of textura porrecta. Paraphyses numerous, cylindrical, hyaline, septate, unbranched, persistent. Asci 8-spored, unitunicate, long cylindrical, with a tapering pedicel, apically rounded, with an indistinct, J-, apical ring. Ascospores fusiform, hyaline, 3-septate, with filamentous bipolar appendages. Asexual morph: Hyphomycetous. Colonies on natural substrate effuse, brown. Mycelia partly superficial, partly immersed, composed of hyaline to brown, branched, septate hyphae. Conidiophores micronematous or macronematous, when macronematous, erect, cylindrical, unbranched, straight or slightly flexuous, thick-walled, septate, brown, paler towards the apex. Conidiogenous cells blastic, integrated, terminal, cylindrical, subhyaline to brown, smooth or verrucose. Conidia acrogenous, solitary, dry, smooth, ellipsoidal, oval, clavate or obovoid, brown to dark brown (adapted from Xia et al. (2017).

Type genus - Junewangia W.A. Baker \& Morgan-Jones

Notes - Junewangiaceae was established by Xia et al. (2017) to accommodate a single genus, Junewangia, based on combined of LSU, SSU, ITS and tub2 sequence data. Although Dictyosporella and Junewangia formed a monophyletic clade with strong support, Song et al. (2018) did not transfer Dictyosporella to Junewangiaceae. Luo et al. (2019) accepted three genera, i.e. Dictyosporella, Junewangia and Sporidesmiella in Junewangiaceae in their comprehensive study of freshwater Sordariomycetes. However, in our phylogenetic analyses, Acrodictyaceae and Junewangiaceae and Sporidesmiella formed a monophyletic clade, while Acrodictyaceae and Junewangiaceae are sister groups. Therefore, we suggest Junewangiaceae contains Dictyosporella and Junewangia, while Sporidesmiella is treated as Diaporthomycetidae genus incertae sedis.

\section{Ecological and economic significance of Junewangiaceae}

Junewangiaceae species are mostly saprobic on decaying wood in both aquatic and terrestrial habitats. The main role of Junewangiaceae species in the ecosystem is participating in nutrient cycling as decomposers and recyclers. Thus, they are important for ecological balance.

\section{Genera included in Junewangiaceae}

Dictyosporella Abdel-Aziz, Fungal Divers. 75: 143 (2015)

Index Fungorum number: IF551480; 3 species with sequence data. 
Type species - Dictyosporella aquatica Abdel-Aziz

Notes - Dictyosporella was introduced by Ariyawansa et al. (2015) to accommodate an asexual morph species, D. aquatica, which is characterized by micronematous conidiophores and brown to black, muriform conidia. Based on phylogenetic analyses of LSU sequence data, Dictyosporella was assigned to Annulatascaceae (Ariyawansa et al. 2015). Zhang et al. (2017a) introduced a sexual morph species, D. thailandensis, and treated Dictyosporella as Diaporthomycetidae, genera incertae sedis. Luo et al. (2019) transferred Dictyosporella to Junewangiaceae based on multi-gene phylogenetic analyses.

Junewangia W.A. Baker \& Morgan-Jones, Mycotaxon 81: 307 (2002)

Index Fungorum number: IF28602; 6 morphological species (Species Fungorum 2020), 4 species with sequence data (Xia et al. 2017, Song et al. 2018).

Type species - Junewangia sphaerospora W.A. Baker \& Morgan-Jones

Notes - Baker et al. (2002) introduced Junewangia with J. sphaerospora as the type species. At the same time, they transferred four Acrodictys species which have subglobose, uniformly pigmented conidia with angular or oblique septa to Junewangia. Junewangia is morphologically similar with Acrodictys. However, conidia of Acrodictys is conspicuous, cuneiform or funnelshaped basal cells, while the basal cells of Junewangia are inconspicuous (Xia et al. 2017).

Kathistaceae Malloch \& M. Blackw., Can. J. Bot. 68(8): 1719 (1990)

Index Fungorum number: IF81991; Facesoffungi number: FoF06874; 6 species.

Saprobic on herbivore dung and insects. Sexual morph: Ascomata globose to subglobose, with a long necks composed of parallel hyphae, straight curved ostiolar setae, with sphaerical spore-bearing structures (sporidiomata), cylindrical unicellular extension present. Peridium thinwalled, pseudoparenchymatous, of cells of textura angularis in surface view and thick-walled in cross section. Paraphyses lacking. Asci 8-spored, unitunicate, ellipsoidal to fusoid, thin-walled, evanescent at maturity, arranged in a basal fascicle. Ascospores clavate to falcate, hyaline or pale brown, $0-1$ or transversely multi septate. Asexual morph: Conidiomata superficially similar to the ascomata, sphaerical, hyaline, without hyphal attachments, single wall layer thick at base, with or without ostiole, when present ostiole comprising with long neck. Conidiomatal wall composed of flattened cells of textura angularis. Conidiogenous cells enteroblastic, phialidic, hyaline, and smooth. Conidia sphaerical or cylindrical, produced in the centre of the conidiomata, hyaline, smooth, $0-1$ or multi septate, escaping in a continuous chain through the ostiolar neck (adapted from Maharachchikumbura et al. 2016b).

Type genus - Kathistes Malloch \& M. Blackw.

Notes - Malloch \& Blackwell (1990) established Kathistaceae to accommodate Kathistes with the type species $K$. calyculata, and two more species, K. fimbriata and $K$. analemmoides. Kathistaceae has sufficient taxonomic distance from Pyxidiophoraceae. Therefore, it was reported as a family in Ophiostomatales (Malloch \& Blackwell 1990). Maharachchikumbura et al. (2016b) provided an updated outline of Kathistaceae with the genera Kathistes, Mattirolella, and Termitariopsis.

\section{Ecological and economic significance of Kathistaceae}

Kathistaceae species are saprobic on herbivore dung and insects (Malloch \& Blackwell 1990).

\section{Genera included in Kathistaceae}

Kathistes Malloch \& M. Blackw., Can. J. Bot. 68(8): 1712 (1990)

Index Fungorum number: IF25513; 3 morphological species (Species Fungorum 2020), 2 species with sequence data.

Type species - Kathistes calyculata Malloch \& M. Blackw. 

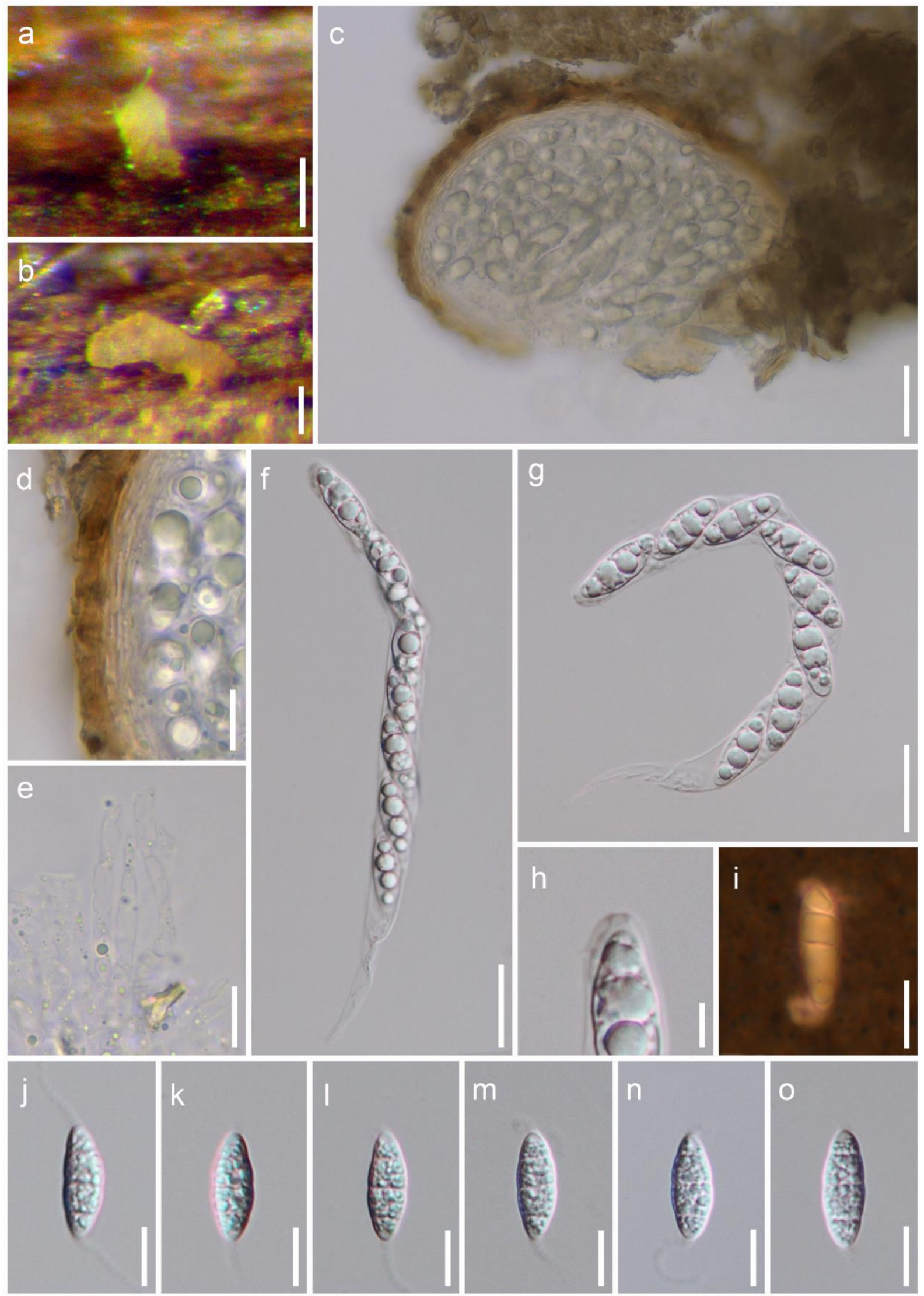

Figure 137 - Dictyosporella thailandensis (Material examined - THAILAND, Prachuap Khiri Khan, on submerged bamboo in a small river, 30 July 2015, W. Dong, MFLU 15-2706, holotype). $\mathrm{a}, \mathrm{b}$ Appearance of necks on host. c Vertical section of ascoma. d Peridium. e Paraphyses. $\mathrm{f}, \mathrm{g}$ Asci. $\mathrm{h}$ Ascus with a apical ring. i Ascospore mounted in India ink. j-o Ascospores. Scale bars: $a, b=50$ $\mu \mathrm{m}, \mathrm{c}=25 \mu \mathrm{m}, \mathrm{d}, \mathrm{e}, \mathrm{j}-\mathrm{o}=10 \mu \mathrm{m}, \mathrm{f}, \mathrm{g}=20 \mu \mathrm{m}, \mathrm{h}=5 \mu \mathrm{m}$. 


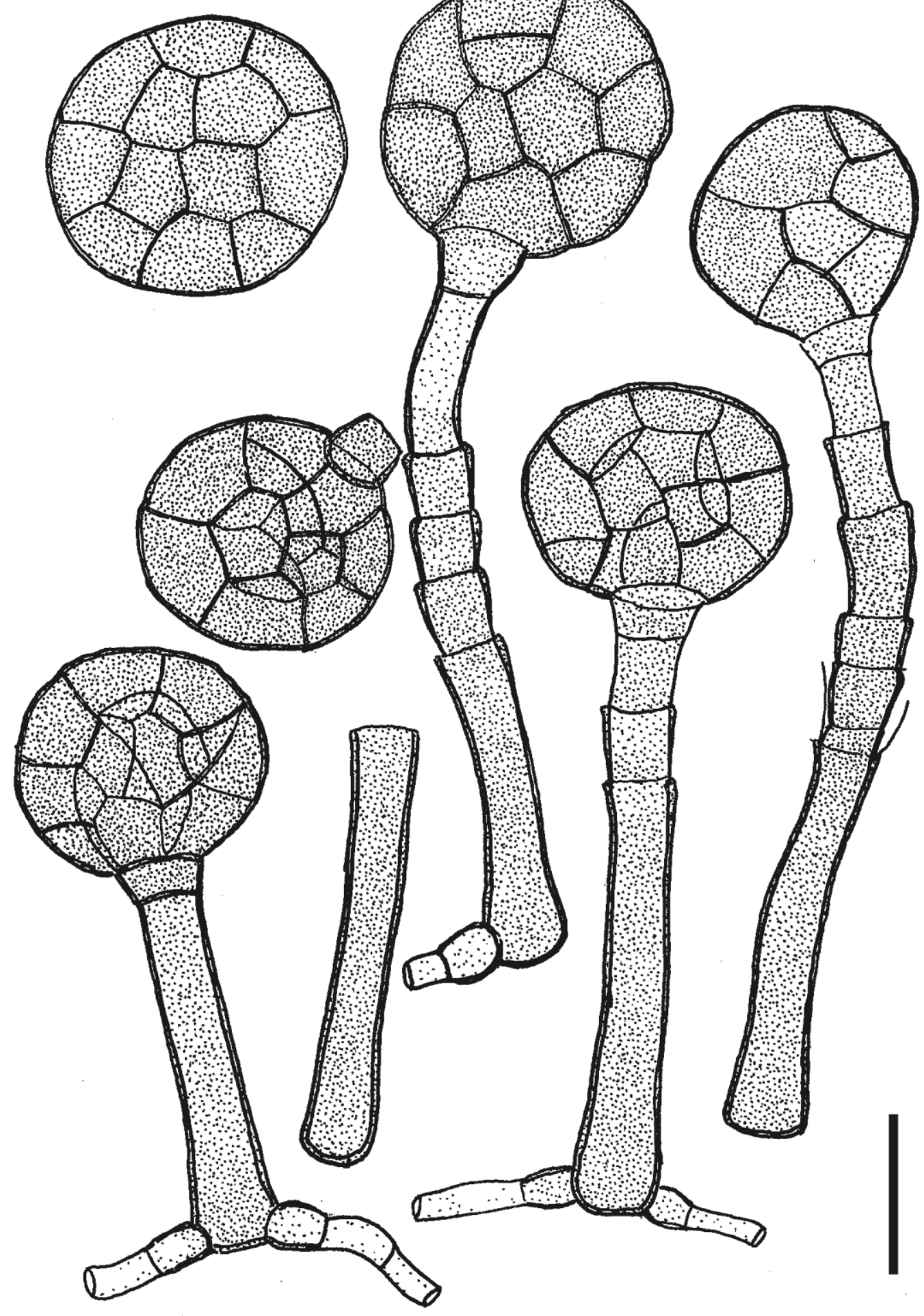

Figure 138 - Junewangia sphaerospora (redrawn from Baker et al. 2002). This drawing shows the mycelia, conidiophores, conidiogenous cells and conidia of Junewangia sphaerospora. Scale bars: $15 \mu \mathrm{m}$.

Notes - Kathistes was introduced as the type genus in Kathistaceae by Malloch \& Blackwell (1990), which was originally described with three species ( $K$. analemmoides, $K$. calyculata, $K$. fimbriata). The genus is characterized by long-necked, brown to dark ascomata, transparent at the base, and germinating ascospores produced by budding yeast-like cells (Malloch \& Blackwell 1990). 
a
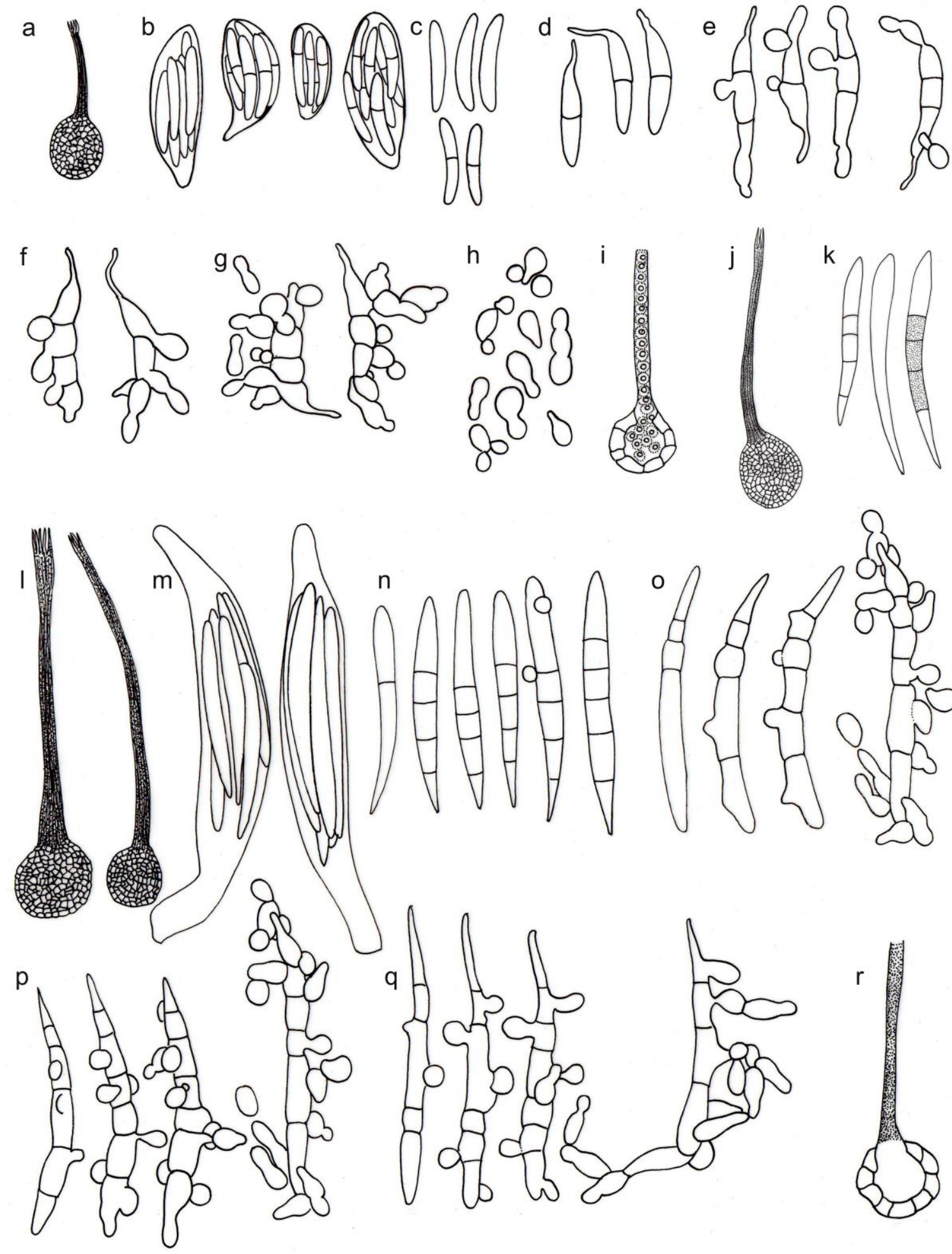

Figure 139 - Kathistes spp. (a-i: Kathistes calyculata, j, k: K. fimbriata, 1-r: K. analemmoides, redrawn from Malloch \& Blackwell 1990). a Ascoma with dark neck and hyaline base. b Asci. c Ascospores. d Ascospores after $4 \mathrm{~h}$ on agar Germ tubes have developed by this time. e-g Ascospores after 19, 27, and $42 \mathrm{~h}$ on agar, respectively. Yeast cells have begun to develop. h Yeast cells after several days. i Sporidioma showing single-celled wall at base and sporidiolae filling hollow darkened neck cell. j Ascoma with dark neck and hyaline base. $\mathrm{k}$ Three ascospores illustrating differences in septation, size, and pigmentation. 1 Ascomata. $\mathrm{m}$ Asci. $\mathrm{n}$ Ascospores from an extruded spore mass. One ascospore has begun producing yeast cells. o-q Three ascospores, each drawn at 2, 3, 4, and $18 \mathrm{~h}$ after being placed on agar $\mathrm{r}$ Sporidioma showing single wall layer of base and darkened hollow neck cell. 
Mattirolella S. Colla, Boll. Lab. Zool. Portici 22: 44 (1929)

Index Fungorum number: IF8867; 2 morphological species.

Type species - Mattirolella silvestrii S. Colla

Notes - Mattirolella was described by Colla (1929) with the type species M. silvestrii parasite on integument of the termite Rhinotermes marginales in British Guiana. Khan \& Kimbrough (1974) introduced Mattirolella crustosa, a species found on Isoptera (termites) in Panama.

Termitariopsis M. Blackw., Samson \& Kimbr., Mycotaxon 12(1): 98 (1980)

Index Fungorum number: IF10184; 1 morphological species.

Type species - Termitariopsis cavernosa M. Blackw., Samson \& Kimbr.

Notes - Termitariopsis was described by Blackwell et al. (1980) as a monotypic genus and is a species found on insects (Neivamyrmex opacithorax) in Kansas. Although Wijayawardene et al. (2017a) listed Termitariopsis as Ascomcota genera incertae sedis, we maintain Mattirolella and Termitariopsis in Kathistaceae based on similar morphology (Blackwell et al. 1980).

Koralionastetaceae Kohlm. \& Volkm.-Kohlm., Mycologia 79(5): 764 (1987)

Index Fungorum number: IF82025; Facesoffungi number: FoF01391; 13 species.

Saprobic on coralline covered rocks, sponges or on algae, found in marine habitats. Sexual morph: Ascomata black, subglobose, ovoid or ellipsoidal, superficial, ostiolate, papillate or epapillate, periphysate, subiculate, or without subiculum. Paraphyses simple, septate. Asci 8spored, unitunicate, clavate to ellipsoidal or fusiform, pedicellate, deliquescent. Ascospores overlapping, hyaline, ellipsoidal to fusiform, multi-septate near the apices, or filiform and evenly multi-septate, thick or thin walled, germinating apically, lacking appendages. Reproductive structures: Spermatia enteroblastic, subglobose.

Type genus - Koralionastes Kohlm. \& Volkm.-Kohlm.

Notes - Koralionastetaceae currently comprises 13 species (five Koralionastes species and eight Pontogeneia species) (Wijayawardene et al. 2017a). The family was introduced by Kohlmeyer \& Volkmann-Kohlmeyer (1987) to include a single genus, Koralionastes. Pontogeneia was introduced by Kohlmeyer (1975) for five perithecial ascomycetes. Koralionastetaceae is characterized by thick-walled ascospores that germinate into hyphae bearing phialidic antheridia with enteroblastic spermatia. Earlier the ordinal and higher classification of Koralionastetaceae was unresolved and Koralionastes was placed under Ascomycota genera incertae sedis (Eriksson 2006). Based on a phylogenetic study with SSU and LSU sequence data, the genera Koralionastes and Pontogeneia were assigned to Koralionastetales which is a sister group to Lulworthiales (Campbell et al. 2009). The subclass Lulworthiomycetidae was introduced to accommodate Lulworthiales and Koralionastetales based on combined sequence data by Maharachchikumbura et al. (2015).

\section{Ecological and economic significance of Koralionastetaceae}

Koralionastetaceae members are coral and algal inhabiting fungi and play a major role in heterotrophic conversion of reef biomass to nutrients (Raghukumar \& Ravindran 2012). Koralionastes have been reported to have a unique association with crustaceous sponges, developing their ascomata on or within these hosts (Kohlmeyer \& Volkmann-Kohlmeyer 1990a; Wang 2006) and is the only marine fungal group which have been identified in marine sponges (Wang et al. 2008). Pontogeneia are algae inhabiting fungi. For an example, Pontogeneia rostrata are known from red algae (Momota \& Nakaoka 2017). Furthermore, studies by Yu \& Suh (2011) showed that Pontogeneia rostrata plays an important role in the sandy shore ecosystem as a trophic link between primary producers and higher consumers.

\section{Genera included in Koralionastetaceae}

Koralionastes Kohlm. \& Volkm.-Kohlm., Mycologia 79(5): 765 (1987)

Index Fungorum number: IF25184; 5 morphological species (Wijayawardene et al. 2017a; Species Fungorum 2020), 1 species with sequence data. 


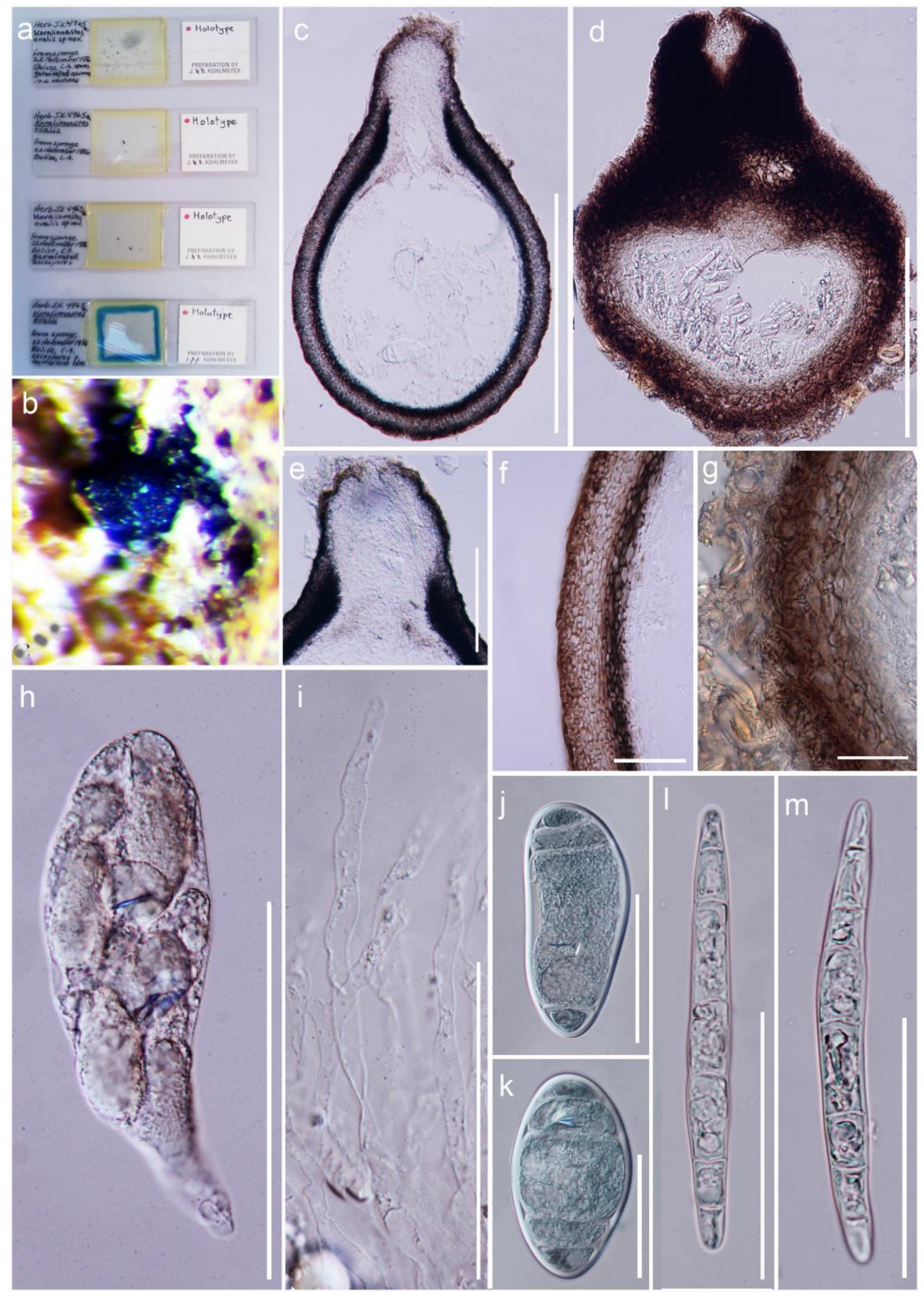

Figure 140 - Koralionastes ovalis (Material examined - BELIZE, back reef of South water Cay, sub tidal coral slab (0.2-0.5 m deep), November 1986, J. Kohlmeyer; NY 1317811, NY 1317823, NY 1317828, NY 1317838, slides from holotype), Pontogeneia padinae (Material examined Intertidal zone at the Marine Laboratory of the University of Arizona, on living plants near the base among rhizoids of the holdfast, 22 Jun 1974, J. J. Kohlmeyer, NY 985934, holotype). a Microslides of Koralionastes ovalis. b Ascomata of Pontogeneia padinae on the base of an alga. c, d Section through ascoma. e Ascoma neck region of Koralionastes ovalis. f, g Peridium. h Ascus of Koralionastes ovalis. i Paraphyses of Koralionastes ovalis. j, k Ascospores of Koralionastes ovalis. 1, m Ascospores of Pontogeneia padinae. Scale bars: c, $\mathrm{d}=200 \mu \mathrm{m}, \mathrm{h}=100 \mu \mathrm{m}, \mathrm{e}=50 \mu \mathrm{m}, \mathrm{f}, \mathrm{g}, 1$, $\mathrm{m}=20 \mu \mathrm{m}, \mathrm{f}-\mathrm{i}=10 \mu \mathrm{m}$. 
Type species - Koralionastes ovalis Kohlm. \& Volkm.-Kohlm.

Notes - Koralionastes was introduced to accommodate Koralionastes angustus, K. ellipticus and $K$. ovalis (the type species) by Kohlmeyer \& Volkmann-Kohlmeyer (1987). Kohlmeyer \& Volkmann-Kohlmeyer (1990a) introduced K. giganteus, and K. violaceus found on dead coralline covered rocks among crustose sponges and their ascospores have double walls and are ellipsoidal or fusiform (Campbell et al. 2009).

Pontogeneia Kohlm., Bot. Jb. 96(1-4): 201 (1975)

Index Fungorum number: IF4335; 8 morphological species (Wijayawardene et al. 2017a; Species Fungorum 2020), 2 species with sequence data.

Type species - Pontogeneia padinae Kohlm.

Notes - Pontogeneia was introduced by Kohlmeyer (1975) to include five perithecial ascomycetes parasitizing marine algae, belonging to the Chlorophyta, Phaeophyta or Rhodophyta (Kohlmeyer \& Kohlmeyer 1979, Kohlmeyer \& Demoulin 1981, Momota \& Nakaoka 2017).

Lamproconiaceae Norph., T.C. Wen \& K.D. Hyde, Phytotaxa 270(2): 94 (2016)

Index Fungorum number: IF552187; Facesoffungi number: FoF02248; 14 species.

Pathogenic and saprobic on dead herbaceous branches. Sexual morph: Stromata prosenchymatous around perithecia, delimited externally by greenish-blackened dense pseudoparenchymatous zone, interior whitish, composed of interwoven hyphae mixed with substrate cells, 3-5 ascomata in a stromata. Ascomata perithecial, small, aggregated, scattered, globose to subglobose, light brown to dark brown, coriaceous, ostiolate, papillate. Papilla converging and erumpent through stroma surface as single, large opening, wide at the top, narrowing towards the base, dark brown region around base of papilla. Peridium comprises light brown, compressed, cells of textura angularis. Asci 8-spored, unitunicate, cylindrical, short pedicellate, with a J-, apical ring. Ascospores uniseriate, broadly ellipsoid, 1-septate, not or lightly constricted at the septa, hyaline, smooth-walled. Asexual morph: Conidiomata pycnidial, solitary, partly immersed in host tissue, uniloculate, multilocular or convoluted, dark blue (Lamproconium), dark blackish brown (Hercospora), erumpent in the centre. Pycnidium thick-walled, thin at inner layer, hyaline (Lamproconium), dark brown (Hercospora), comprising wall cells of textura angularis (Lamproconium) or textura intricate (Hercospora). Ostiole absent, dehiscence irregular. Paraphyses interspersed within conidiophores. Conidiophores filiform or cylindrical, pale-bluish or hyaline, septate, branched, smooth-walled, formed at the base of conidiomatal wall. Conidiogenous cells holoblastic, cylindrical to subcylindrical, each forming a single conidium at the conidiophore apex, or annellidic, colourless to olivaceous, smooth-walled. Conidia fusiform, ellipsoid, thickwalled, with granular, contents granular, aseptate, bluish to glistening dark blue (Lamproconium), hyaline (Hercospora), smooth-walled, produced in mucilage but without a distinct mucilaginous envelope or appendage (adapted from Norphanphoun et al. 2016).

Type genus - Lamproconium (Grove) Grove

Notes - Lamproconiaceae was established by Norphanphoun et al. (2016) to accommodate Lamproconium and Hercospora, based on morphology and phylogenetic analyses. Lamproconiaceae forms a robust clade basal to Sydowiellaceae and Stilbosporaceae in the combined ITS and LSU phylogeny and the conidia differ from those of Sydowiellaceae and Stilbosporaceae (Norphanphoun et al. 2016, Senanayake et al. 2017b).

\section{Ecological and economic significance of Lamproconiaceae}

Species in Lamproconiaceae are pathogens and saprobes on branches and bark of various trees (Norphanphoun et al. 2016). Lamproconium desmazieresi causes canker on branches or twigs of lime trees (Tilia spp.).

\section{Genera included in Lamproconiaceae}

Hercospora Fr., Syst. orb. veg. (Lundae) 1: 119 (1825) 
Index Fungorum number: IF2301; 13 morphological species (Species Fungorum 2020), 1 species with sequence data.

Type species - Hercospora tiliae (Pers.) Tul. \& C. Tul.

Notes - Hercospora was introduced by Fries in 1825 to accommodate Sphaeria tiliae and $S$. atrovirens. Tulasne \& Tulasne (1863) accepted Hercospora tiliae $(=S$. atrovirens) as the type species of Hercospora. The characters of the genus were described in Petrak (1938) and Sutton (1980). Phylogenetic studies based on LSU sequence data, placed H. tiliae in Diaporthales, genera incertae sedis, where it grouped with Melanconis desmazierii (Castlebury et al. 2002, Rossman et al. 2007, Voglmayr et al. 2012, Voglmayr \& Jaklitsch 2014). Norphanphoun et al. (2016) placed Hercospora in a new family Lamproconiaceae based on sequence data which clustered with Melanconis desmazieri, a species synonymized under Lamproconium desmazierii.

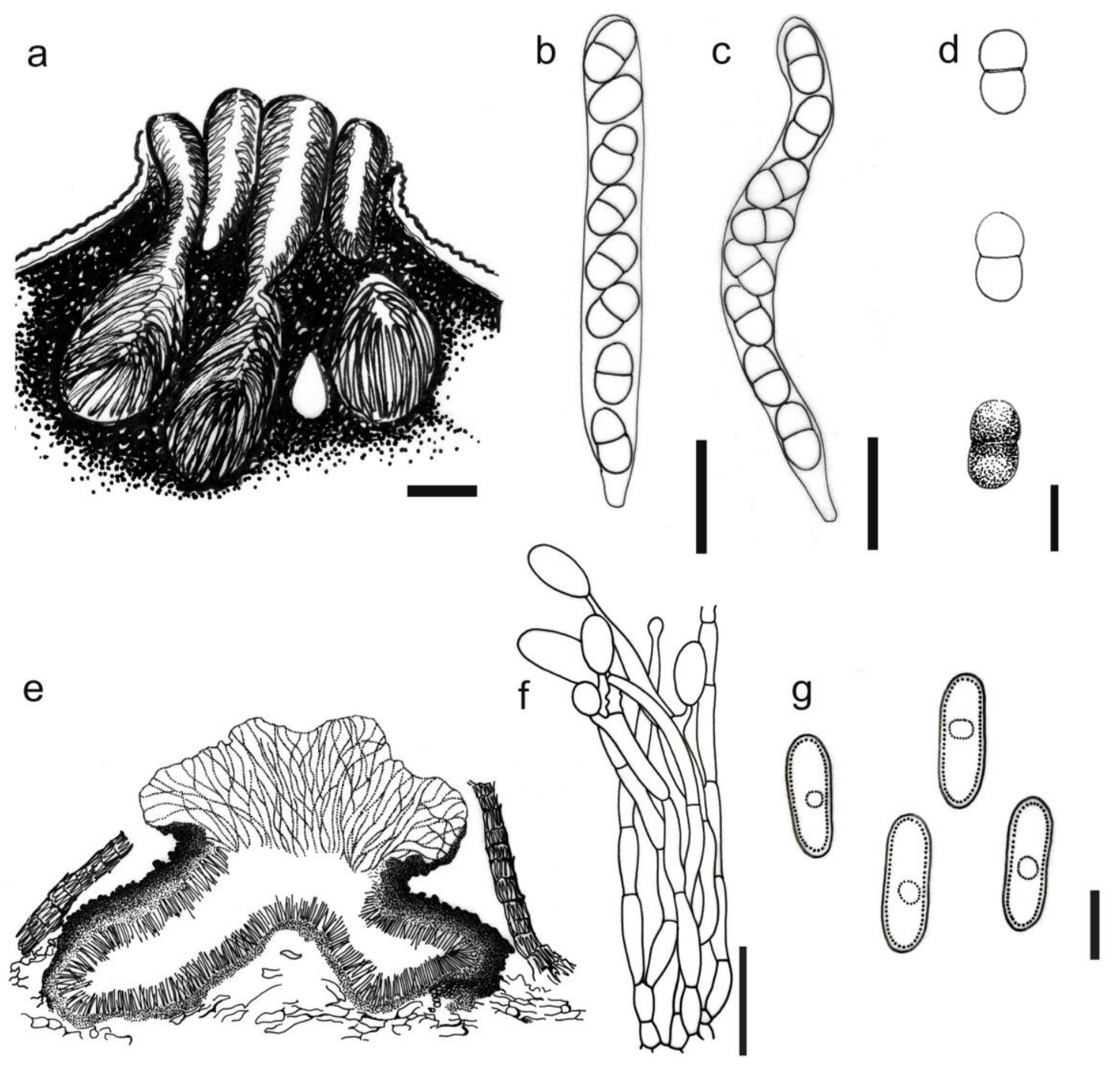

Figure 141 - Hercospora tiliae (redrawn from Sutton 1980 and Norphanphoun et al. 2016). a Ascomata. b, c Asci. d Ascospores. e Conidioma. f Conidiophores and developing conidia. g Conidia. Scale bars: $\mathrm{a}=200 \mu \mathrm{m}, \mathrm{b}, \mathrm{c}=40 \mu \mathrm{m}, \mathrm{d}, \mathrm{f}=20 \mu \mathrm{m}, \mathrm{e}=100 \mu \mathrm{m}, \mathrm{g}=10 \mu \mathrm{m}$.

Lamproconium (Grove) Grove, British Stem- and Leaf-Fungi (Coelomycetes) (Cambridge) 2: 321 (1937)

Index Fungorum number: IF8703; 1 species with sequence data.

Type species - Lamproconium desmazieri (Berk. \& Broome) Grove

Notes - Lamproconium was introduced by Grove (1918) as a section of Melanconium which was represented by $M$. desmazieri. Melanconium desmazieri was reported as the asexual morph of 
Melanconis desmazieri, from Tilia sp. (Petrak 1938). Grove (1937) re-circumscribed the species and found that $M$. desmazieri differed from the type species in having bluish to glistening dark blue, not brownish-black, 1-septate conidia. Therefore, Grove (1937) introduced Lamproconium as a new genus (Sutton 1980) and it was placed in Diaporthales genera incertae sedis by Cannon \& Minter (2014). Based on phylogenetic study and fresh collections of L. desmazieri (Norphanphoun et al. 2016) introduced Lamproconiaceae as new family for accommodate Lamproconium and Hescospora.

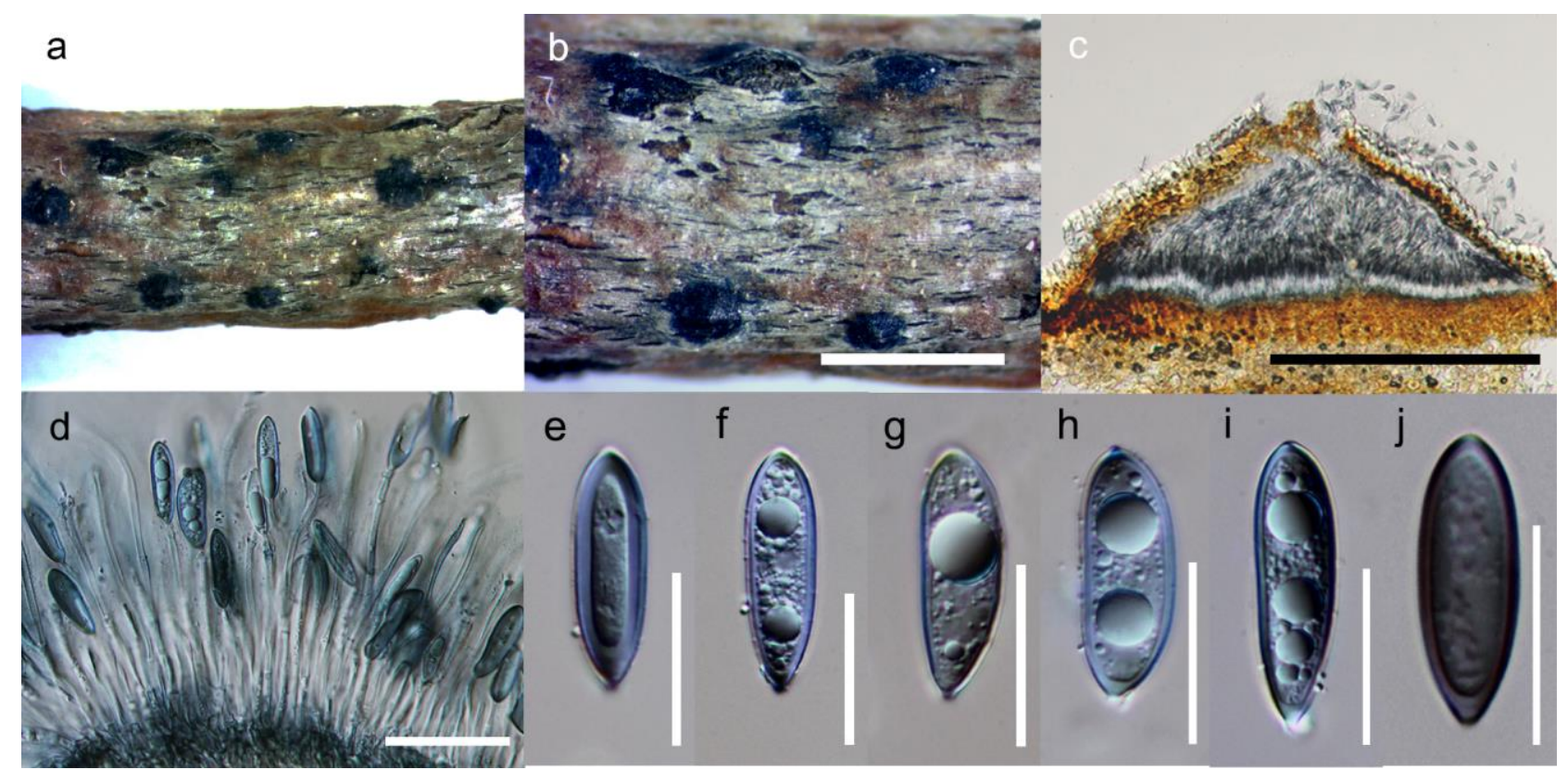

Figure 142 - Lamproconium desmazieresi (Material examined - RUSSIA, Rostov region: Krasnosulinsky district, Donskoye forestry, artificial forest, on dead branches of Tilia cordata Mill. (Tiliaceae), 21 May 2014, T. Bulgakov, MFLU 14-0780, reference specimen). a, b Conidiomata on host. c Cross section of the conidioma. d Conidiogenous cells with attached. e-i Immature conidium. j Mature conidia. Scale bars: $b=1 \mathrm{~mm}, \mathrm{c}=500 \mu \mathrm{m}, \mathrm{d}=40 \mu \mathrm{m}, \mathrm{e}-\mathrm{j}=20 \mu \mathrm{m}$.

Lasiosphaeriaceae Nannf., Nova Acta R. Soc. Scient. upsal., Ser. 4 8(no. 2): 50 (1932) Index Fungorum number: IF80930; Facesoffungi number: FoF01145; 315 species.

Saprobic on wood, rotting vegetation, soil, dung of the herbivore, in freshwater, marine or terrestrial habitats, many coprophilous. Sexual morph: Ascomata perithecial or cleistothecial, gregarious or scattered, yellow, brown to black, solitary, superficial, erumpent or immersed, globose, subglobose to ovoid, carbonaceous, coriaceous or membranaceous, ornamented, tuberculate or smooth, with setae or hair, papillate or indistinct or absent, ostiolate, when present periphysate, the apex collapsing when dry. Peridium thick, composed of two layers, outer layer comprising brown cells of textura angularis or globulosa, carbonaceous, coriaceous or membranaceous; inner layer comprising hyaline cells of textura prismatica or porrecta, thin, membranaceous. Paraphyses numerous, hyaline, septate, filiform or cylindrical. Asci 4- or 8spored, unitunicate, thin or thick-walled, cylindrical to clavate, pedicellate, with a J-, apical ring. Ascospores uni-seriate to irregular, hyaline, brown or black, allantoid, clavate, cylindrical, ellipsoid to dumbbell-like, curved or not, concolorous or versicolorous, ornamented or smooth-walled, with or without germ pore, appendage present or absent, with or without guttules. Asexual morph: Hyphomycetous. Conidiophores macronematous or mononematous, scattered or gregarious, brown, straight, septate, branched, smooth-walled. Conidiogenous cells enteroblastic or holoblastic, phialidic, hyaline to dark brown, subglobose to ampulliform, proliferating percurrently, with collarette. Conidia solitary, globose, subglobose to cylindrical, hyaline to brown, smooth, aseptate (adapted from Maharachchikumbura et al. 2016b). 
Type genus - Lasiosphaeria Ces. \& De Not.

Notes - Lasiosphaeriaceae has black ascomata and cylindrical to clavate asci with brown to hyaline ascospores, and is typified by Lasiosphaeria (Cesati \& De Notaris 1863). Wijayawardene et al. (2018a) accepted 32 genera in Lasiosphaeriaceae, but the family is in need of revision with DNA sequence data analyses. Many of the genera included in this family lack sequence data and require confirmation with fresh collections and phylogenetic analyses. Species of Lasiosphaeriaceae cluster in several clades within Sordariales (Huhndorf et al. 2004b). Wang et al. (2019a) made progress towards resolving the family and proposed Cladorrhinum, Podospora and Triangularia in Podosporaceae based on multi-gene analysis and the family is sister to Chaetomiaceae. In this study, the lasiosphaeriaceous complex is composed by Lasiosphaeriaceae sensu stricto (Lasiosphaeriaceae II) and Lasiosphaeriaceae sensu lato (Lasiosphaeriaceae I and III) (Fig. 23).

\section{Ecological and economic significance of Lasiosphaeriaceae}

Species of Lasiosphaeriaceae are found worldwide, usually as saprobes on herbs and woody plants and on dung, in freshwater, marine or terrestrial habitats (Shearer 1989, Guarro et al. 1996, Huhndorf et al. 2004b, Kruys et al. 2015, Maharachchikumbura et al. 2016b). A few species are model organisms for genetic research. Podospora anserina has been extensively studied as an experimental model, viz. mitochondrial mutants, protein products and genome sequences (Stahl et al. 1978, Cummings et al. 1979, Coustou et al. 1997, Espagne et al. 2008, Scheckhuber \& Osiewacz 2008).

\section{Genera included in Lasiosphaeriaceae}

Anopodium N. Lundq., Bot. Notiser 117: 356 (1964)

Index Fungorum number: IF211; 2 morphological species (Species Fungorum 2020), 1 species with sequence data.

Type species - Anopodium ampullaceum N. Lundq.

Notes - Anopodium was introduced based on A. ampullaceum (type species) and A. epile. The genus is characterized by subglobose ascomata, clavate asci and brown ascospores with a pedicel at one end (Lundqvist 1964a). The genus is phylogenetically related to Cercophora sulphurella with good support (Kruys et al. 2015).

Apiosordaria Arx \& W. Gams, Nova Hedwigia 13: 201 (1967)

Index Fungorum number: IF262; 24 morphological species (Species Fungorum 2020), 11 species with sequence data.

Type species - Apiosordaria verruculosa (C.N. Jensen) Arx \& W. Gams

Notes - Apiosordaria is characterized by pyriform ascomata, cylindrical asci and ascospores with verrucose or pitted walls (von Arx \& Gams 1966, Guarro et al. 1984). Echinopodospora and Lacunospora were considered as synonyms of Apiosordaria based on similar characters, such as verrucose or pitted ascospores (Krug et al. 1983, Stchigel et al. 2000).

Apodospora Cain \& J.H. Mirza, Can. J. Bot. 48(5): 891 (1970)

Index Fungorum number: IF275; 6 morphological species (Species Fungorum 2020), 3 species with sequence data.

Type species - Apodospora simulans Cain \& J.H. Mirza

Notes - Apodospora simulans has ellipsoid to subglobose ascomata, cylindrical asci and verrucose ascospores with a gelatinous sheath. The members of Apodospora nested in Lasiosphaeriaceae sensu lato based on multi-gene analysis (Wang et al. 2019a; Fig. 23).

Apodus Malloch \& Cain, Can. J. Bot. 49(6): 872 (1971)

Index Fungorum number: IF277; 2 species with sequence data.

Type species - Apodus deciduus Malloch \& Cain 
Notes - Apodus deciduus has cleistothecial ascomata, clavate asci and brown ascospores. Cai et al. (2006c) proposed to transfer this genus to Lasiosphaeriaceae from Sordariaceae based on phylogenetic analysis.

Arnium Nitschke, Bot. Ztg. 31: 450 (1873)

Index Fungorum number: IF313; 29 morphological species (Species Fungorum 2020), 9 species with sequence data.

Type species - Arnium lanuginosum Nitschke

Notes - Arnium has pyriform to ellipsoid ascomata, cylindrical asci and oblong to oval ascospores (Nitschke 1873, Kruys et al. 2015). Kruys et al. (2015) found that species of Arnium were dispersed into several groups and interspersed in Lasiosphaeriaceae sensu lato (Fig. 23).

Bellojisia Réblová, Mycologia 100(6): 897 (2008)

Index Fungorum number: IF508691; 1 species with sequence data.

Type species - Bellojisia rhynchostoma (Höhn.) Réblová

Notes - The monotypic Bellojisia is characterized by brown to black ascomata with a long neck, cylindrical asci and reniform to navicular ascospores and phylogenetic analysis of LSU sequences revealed that this genus is related to Anopodium within Lasiosphaeriaceae sensu stricto (Réblová 2008; Fig. 23).

Biconiosporella Schaumann, Veröff. Inst. Meeresf. Bremerhaven 14(1): 24 (1972)

Index Fungorum number: IF568; 1 morphological species.

Type species - Biconiosporella corniculata Schaumann

Notes - Biconiosporella corniculata is characterized by membranaceous ascomata, cylindrical asci and broadly fusiform ascospores with a tubercule at the center (Schaumann 1972).

Bombardia (Fr.) P. Karst., Bidr. Känn. Finl. Nat. Folk 23: 20 (1873)

Index Fungorum number: IF616; 15 morphological species (Species Fungorum 2020), 1 species with sequence data.

Type species - Bombardia bombarda (Batsch) J. Schröt.

Notes - Miller \& Huhndorf (2005) reported that this genus is similar to Bombardioidea based on the bombardioid peridium and these species were also related in phylogenetic analysis.

Bombardioidea C. Moreau, Symb. bot. upsal. 20(no. 1): 274 (1972)

Index Fungorum number: IF619; 4 morphological species (Species Fungorum 2020), 1 species with sequence data.

Type species - Bombardioidea bombardioides (Auersw.) C. Moreau

Notes - Bombardioidea bombardioides is characterized by coriaceous ascomata, cylindrical asci and ellipsoid to ovoid ascospores with a gelatinous sheath (Krug \& Scott 1994). Huhndorf et al. (2004b) accepted Bombardioidea as member of Lasiosphaeriaceae based on the molecular analysis.

Camptosphaeria Fuckel, Jb. nassau. Ver. Naturk. 23-24: 140 (1870)

Index Fungorum number: IF781; 4 morphological species (Species Fungorum 2020).

Type species - Camptosphaeria sulphurea Fuckel

Notes - Huhndorf et al. (2004b) accepted this genus in Lasiosphaeriaceae based on the cylindrical asci with a subapical globule similar to Lasiosphaeria.

Cercophora Fuckel, Jb. nassau. Ver. Naturk. 23-24: 244 (1870)

Index Fungorum number: IF906; 63 morphological species (Species Fungorum 2020), 30 species with sequence data.

Type species - Cercophora mirabilis Fuckel 
Notes - Cercophora has globose to subglobose ascomata, cylindrical asci with a subapical globule and oblong ascospores with appendages at each end (Fuckel 1870). Members of Cercophora nested in the lasiosphaeriaceous complex based on multi-gene analysis (Huhndorf et al. 2004b, Kruys et al. 2015; Fig. 23).

Corylomyces Stchigel, M. Calduch \& Guarro, Mycol. Res. 110(11): 1362 (2006)

Index Fungorum number: IF510040; 1 species with sequence data.

Type species - Corylomyces selenosporus Stchigel, M. Calduch \& Guarro

Notes - Corylomyces is monotypic and characterized by tomentose ascomata, cylindrical asci and lunate to reniform ascospores (Stchigel et al. 2006). It is closely related to Zopfiella tabulata within Lasiosphaeriaceae based on multi-gene analysis (Wang et al. 2019a).

Diffractella Guarro, P.F. Cannon \& Aa, Syst. Ascom. 10: 107 (1991)

Index Fungorum number: IF25499; 1 morphological species.

Type species - Diffractella curvata (Fuckel) Guarro, P.F. Cannon \& Aa

Notes - The monotypic Diffractella has cleistothecial ascomata with alveolate-reticulate ornamentation, globose asci and reniform to fusiform ascospores with a cap-like gelatinous appendage at each end (Guarro et al. 1991).

Diplogelasinospora Cain, Can. J. Bot. 39: 1669 (1961)

Index Fungorum number: IF1609; 4 species with sequence data.

Type species - Diplogelasinospora princeps Cain

Notes - Diplogelasinospora was transferred from Sordariaceae to Lasiosphaeriaceae based on multi-gene analysis and it was found to be closely related to Bombardia and Bombardioidea (Cai et al. 2006c, Crous et al. 2014a, Wang et al. 2019a).

Emblemospora Jeng \& J.C. Krug, Can. J. Bot. 54(16): 1971 (1976)

Index Fungorum number: IF1768; 2 morphological species (Species Fungorum 2020).

Type species - Emblemospora monotrema Jeng \& J.C. Krug

Notes - Jeng \& Krug (1976) introduced Emblemospora ditrema and E. monotrema (type species) characterised by pyriform ascomata, clavate asci and ellipsoid ascospores with plate-like wrinkles.

Eosphaeria Höhn., Annls mycol. 15(5): 362 (1917)

Index Fungorum number: IF1843; 1 morphological species.

Type species - Eosphaeria uliginosa (Kunze) Höhn.

Notes - The monotypic genus Eosphaeria is characterized by verrucose ascomata, clavate asci and curved ascospores. The curved ascospores are similar to those found in Lasiosphaeria (Kruys et al. 2015). In this entry we illustrate a specimen of E. uliginosa collected in the USA. We have not compared this with the type specimens of Eosphaeria, but its morphological features fit the description of E. uliginosa (Höhnel 1917).

Episternus Górz \& Boroń, Phytotaxa 376(1): 49 (2018)

Index Fungorum number: IF811848; 1 species with sequence data.

Type species - Episternus onthophagi Górz \& Boroń

Notes - The monotypic Episternus was found on the mesosternum, legs and dung of Onthophagus beetles in Poland (Górz \& Boroń 2018).

Fimetariella N. Lundq., Bot. Notiser 117: 239 (1964)

Index Fungorum number: IF1990; 9 morphological species (Species Fungorum 2020), 1 species with sequence data.

Type species - Fimetariella rabenhorstii (Niessl) N. Lundq. 
Notes - Fimetariella is characterized by ovoid to subglobose ascomata, cylindrical asci and oval ascospores with a gelatinous sheath (Lundqvist 1964b). The ascospores are similar to Bombardioidea (Kruys et al. 2015).
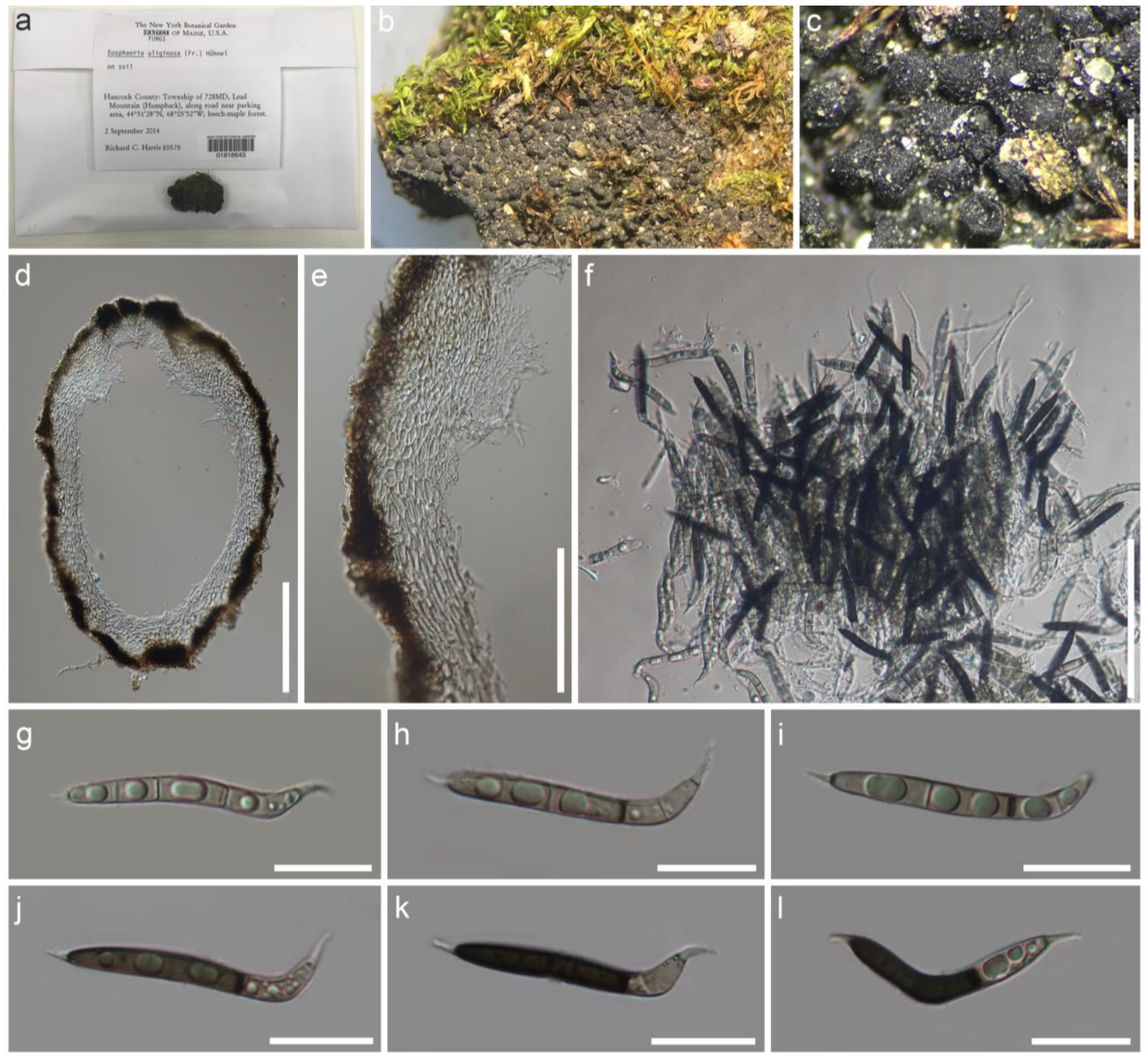

Figure 143 - Eosphaeria uliginosa (Material examined - USA, Maryland, of 728 Lead Mountain

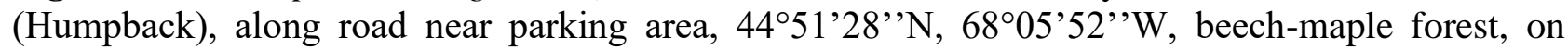
soil, 2 September 2014, RC Harris, NY 01818643). a Material label. b Material. c Ascomata on the host. $d$ Ascoma cross section. e Peridium. f Asci with paraphyses. g-1 Ascospores. Scale bars: $\mathrm{c}=1$ $\mathrm{mm}, \mathrm{d}=200 \mu \mathrm{m}, \mathrm{e}, \mathrm{f}=100 \mu \mathrm{m}, \mathrm{g}-\mathrm{l}=20 \mu \mathrm{m}$.

Immersiella A.N. Mill. \& Huhndorf, Mycol. Res. 108(1): 31 (2004)

Index Fungorum number: IF28831; 2 species with sequence data.

Type species - Immersiella immersa (P. Karst.) A.N. Mill. \& Huhndorf

Notes - Immersiella caudata and I. immersa (type species) were introduced within Sordariales, characterised by globose to subglobose ascomata, cylindrical to clavate asci and geniculate ascospores with appendages at each end (Miller \& Huhndorf 2004). The genus is closely related to Arnium hirtum, within Lasiosphaeriaceae based on phylogenetic analysis (Kruys et al. 2015).

Jugulospora N. Lundq., Symb. bot. upsal. 20(no. 1): 256 (1972) 
Index Fungorum number: IF2538; 1 species with sequence data.

Type species - Jugulospora rotula (Cooke) N. Lundq.

Notes - The monotypic Jugulospora is characterized by ovoid to subglobose ascomata, cylindrical asci and broadly ellipsoid to ovoid ascospores with plate-like wrinkles (Lundqvist 1972). It is closely related to Strattonia carbonaria within Lasiosphaeriaceae sensu lato based on multi-gene analysis (Miller \& Huhndorf 2005; Fig. 23).

Lasiosphaeria Ces. \& De Not., Comm. Soc. crittog. Ital. 1(4): 229 (1863)

Index Fungorum number: IF2656; 63 morphological species (Species Fungorum 2020), 6 species with sequence data.

Type species - Lasiosphaeria ovina (Pers.) Ces. \& De Not.

Notes - Lasiosphaeria has globose ascomata, cylindrical asci with a subapical globule and geniculate ascospores. This genus was included in Lasiosphaeriaceae based on its pale brown, geniculate ascospores (Barr 1990b). It is closely related to Anopodium based on multi-gene analysis (Maharachchikumbura et al. 2016b). Fig. 23 reveals that Lasiosphaeria groups with Anopodium and Bellojisia within Lasiosphaeriaceae sensu stricto.

Mammaria Ces., Bot. Ztg. 12: 190 (1854)

Index Fungorum number: IF8836; 2 morphological species (Species Fungorum 2020), 1 species with sequence data.

Type species - Mammaria echinobotryoides Ces.

Notes - Mammaria is an asexual genus which has brown to vinaceous brown mycelium and broadly ellipsoid conidia with a longitudinal germ slit (Rabenhorst 1854). Mammaria echinobotryoides was obtained in culture of Cercophora natalitia (Barr 1990b, del Valle Catania et al. 2011). Pseudocercophora was found in Singapore and introduced as the sexual morph of Mammaria, as they share similar conidial characters (Subramanian \& Sekar 1986). However, Mammaria is recommended as the current name, if the nomenclature principle of priority is followed (Réblová et al. 2016b).

Periamphispora J.C. Krug, Mycologia 81(3): 476 (1989)

Index Fungorum number: IF25331; 1 morphological species.

Type species - Periamphispora phacelodes J.C. Krug

Notes - The monotypic Periamphispora is characterised by tuberulate ascomata surrounded by hairs, clavate asci and ellipsoid to oval ascospores with lumpy ornamentation and a gelatinous sheath. It is similar to Emblemospora in having ornamented ascospores (Kruys et al. 2015).

Ramophialophora M. Calduch, Stchigel, Gené, Guarro, Stud. Mycol. 50(1): 84 (2004)

Index Fungorum number: IF500021; 5 morphological species (Species Fungorum 2020), 4 species with sequence data.

Type species - Ramophialophora vesiculosa M. Calduch, Stchigel, Gené \& Guarro

Notes - Ramophialophora has macronematous, mononematous conidiophores and aseptate, brown conidia in slimy masses. Wijayawardene et al. (2020) proposed to transfer this genus to Lasiosphaeriaceae from Sordariales genera incertae sedis based on phylogenetic analysis.

Rinaldiella Deanna A. Sutton, Y. Marín, Guarro \& E.H. Thomps., Persoonia 32: 301 (2014)

Index Fungorum number: IF807137; 1 species with sequence data.

Type species - Rinaldiella pentagonospora Deanna A. Sutton, Y. Marín, Guarro \& E.H. Thomps.

Notes - Rinaldiella pentagonospora resembles species of Apiosordaria, with versicolored ascospores with ornamented walls (Crous et al. 2014a). The genus is closely related to Echria in Lasiosphaeriaceae sensu lato, based on multi-gene analysis (Wang et al. 2019a; Fig. 23). 
Schizothecium Corda, Icon. fung. (Prague) 2: 29 (1838)

Index Fungorum number: IF4908; 31 morphological species (Species Fungorum 2020), 7 species with sequence data.

Type species - Schizothecium fimicola Corda

Notes - Schizothecium is characterized by pyriform ascomata, cylindrical asci and versicolor ascospores (Corda 1838). It is closely related to Jugulospora within Lasiosphaeriaceae based on multi-gene analysis (Stchigel et al. 2006, Kruys et al. 2015).

Strattonia Cif., Sydowia 8(1-6): 245 (1954)

Index Fungorum number: IF5278; 10 morphological species (Species Fungorum 2020), 4 species with sequence data.

Type species - Strattonia tetraspora (R. Stratton) Cif.

Notes - Strattonia tetraspora has pyriform to subglobose ascomata and cylindrical asci with ellipsoid ascospores (Ciferri 1954). It is closely related to Jugulospora within Lasiosphaeriaceae based on phylogenetic analysis (Wang et al. 2019a).

Thaxteria Sacc., Syll. fung. (Abellini) 9: 687 (1891)

Index Fungorum number: IF5407; 4 morphological species (Species Fungorum 2020).

Type species - Thaxteria kunkelii Giard

Notes - Thaxteria has globose ascomata, clavate asci and allantoid ascospores (Saccardo 1891).

Tripterosporella Subram. \& Lodha, Curr. Sci. 37: 246 (1968)

Index Fungorum number: IF5611; 2 morphological species (Species Fungorum 2020).

Type species - Tripterosporella coprophila Subram. \& Lodha

Notes - Tripterosorella coprophila has cleistotecial ascomata, clavate asci and triangular ascospores.

Zopfiella G. Winter, Rabenh. Krypt.-Fl., Edn 2 (Leipzig) 1.2: 56 (1884)

Index Fungorum number: IF5876; 23 morphological species (Species Fungorum 2020), 18 species with sequence data.

Type species - Zopfiella tabulata (Zopf) G. Winter

Notes - Huhndorf et al. (2004b) suggested that Zopfiella was placed in Chaetomiaceae. Cai et al. (2006c) transferred this polyphyletic genus to Lasiosphaeriaceae and we found that species of Zopfiella are widely distributed in the lasiosphaeriaceous complex (Fig. 23).

Zygopleurage Boedijn, Persoonia 2(3): 316 (1962)

Index Fungorum number: IF5889; 3 morphological species (Species Fungorum 2020), 1 species with sequence data.

Type species - Zygopleurage zygospora (Speg.) Boedijn

Notes - Zygopleurage has pyriform ascomata, cylindrical asci and ascospores consisting of 2 ellipsoid cells connected by a long cylindrical cell (Boedijn 1962, Lundqvist 1969). Sequence data of Z. zygospora (Huhndorf et al. 2004b) revealed that Zygopleurage was closely related to Arnium cirriferum based on phylogenetic analysis (Kruys et al. 2015).

Zygospermella Cain, Mycologia 27(2): 227 (1935)

Index Fungorum number: IF5894; 2 morphological species (Species Fungorum 2020), 1 species with sequence data.

Type species - Zygospermella setosa (Cain) Cain

Notes - Zygospermella is characterized by pyriform ascomata, clavate to cylindrical asci and ascospores with appendages at each end (Lundqvist 1969). It is closely related to Cercophora sordarioides based on tub2 and LSU sequence analysis (Kruys et al. 2015). 
Lautosporaceae Kohlm., Volkm.-Kohlm. \& O.E. Erikss., Bot. Mar. 38(2): 169 (1995)

Index Fungorum number: IF81975; Facesoffungi number: FoF01764; 2 species.

Saprobic on submerged mangrove wood and culms of salt marsh plants in marine habitats. Sexual morph: Ascomata fusiform to ellipsoidal, ostiolate, brown, coriaceous, solitary. Paraphyses simple, septate, persistent. Asci 4-spored, cylindrical, short pedicellate, thick-walled, unitunicate, with an ocular chamber. Ascospores uni- or biseriate, fusiform, muriform, distoseptate, hyaline, outer wall very thick. Asexual morph: Undetermined (adapted from Jones et al. 2015).

Type genus - Lautospora K.D. Hyde \& E.B.G. Jones

Notes - Lautosporaceae comprises two marine Lautospora species, collected on driftwood of Sonneratia griffithii (L. gigantea) and culms of Juncus roemerianus (L. simillima) (Hyde \& Jones 1989, Kohlmeyer et al. 1995, respectively). The family was not assigned to any order, but referred to Ascomycota incertae sedis. Jones et al. (2009) included the family in Dothideomycetidae incertae sedis, based on the thick-walled nature of the ascus. A recent collection of L. simillima on mangrove wood in Thailand by Suetrong, enabled the extraction of DNA. Based on LSU sequence data (Suetrong, unpublished data), L. simillima was referred to an unnamed clade in Sordariomycetes and in a basal clade to Diaporthales (Jones et al. 2015). Lautosporaceae was therefore excluded from the class Dothideomycetes (Hyde et al. 2013). Lautospora simillima grouped with the neotropical ascomycete Mirannulata sameulsii with weak support, and shares few morphological features with this genus (Huhndorf et al. 2003, Jones et al. 2015). The Lautospora/Mirannulata clade formed a sister group to Vertexicola caudatus and Rhamphoria delicatula (Annulatascaceae), hence Jones et al. (2015) emended the diagnosis of Lautosporaceae family.

\section{Ecological and economic significance of Lautosporaceae}

Lautosporaceae species are saprobic on submerged mangrove wood of Sonneratia griffithii, and the salt marsh sedge Juncus roemerianus (Kohlmeyer et al. 1995, Huhndorf et al. 2003, Jones et al. 2015).

\section{Genus included in Lautosporaceae}

Lautospora K.D. Hyde \& E.B.G. Jones, Bot. Mar. 32(3): 479 (1989)

Index Fungorum number: IF25368; 2 morphological species (Species Fungorum 2020).

Type species - Lautospora simillima Kohlm., Volkm.-Kohlm. \& O.E. Erikss.

Notes - Lautospora species can be distinguished by immersed ascomata, 4-spored, unitunicate asci with an ocular chamber and ring, cellular paraphyses and large ascospores which are muriform, hyaline and thick-walled (Hyde \& Jones 1989). Kohlmeyer et al. (1995) introduced Lautosporaceae to include this genus and assigned it to Ascomycotina family incertae sedis. More taxon sampling and DNA sequencing are recommended for this genus including the type $L$. gigantea to confirm the phylogenetic placement. Lautospora simillima is as an obligate marine fungus, with its ascomata occurring singly, or at the most, in pairs at the base of very soft culms, between 3 and $12 \mathrm{~cm}$ above the rhizome. However, we could not observe the ascomata on microslides of the holotype. Lautospora simillima is a second species assigned to the genus, occurring on the culms of Juncus roemerianus and no asexual morph has been reported for this species (Kohlmeyer et al. 1995, Wijayawardene et al. 2017a).

Leptosilliaceae Voglmayr \& Jaklitsch, Persoonia 42: 240 (2019)

Index Fungorum number: IF829929; Facesoffungi number: FoF06183; 9 species.

Endophytic, pathogenic or lichenized. Sexual morph: Ascomata perithecial, superficial to partly immersed, scattered or collapsed, black. Ostioles central, papillate, base of canal sulcate, sometimes with hyaline periphyses. Peridium melanized, $\mathrm{KOH}^{-}$, comprises cells of textura angularis or prismatica. Paraphyses septate, occasionally branched, embedded in a gelatinous matrix. Asci 8-spored, clavate to cylindrical, curved or sinuous, with $\mathrm{J}+$, apical ring. Ascospores bi or tri-seriate or fasciculate, hyaline, falcate, lunate, sinuous, sigmoid to hook-shaped, aseptate or 
septate, not constricted, thin and smooth-walled, with rounded to subacute apices, without appendages or gelatinous sheath. Asexual morph: Coelomycetous. Conidiomata superficial to partly immersed, scattered, aggregated or confluent, globose to pyriform, uni or irregularly pluriloculate, black. Conidiomatal wall more or less melanized, textura globulosa or angularis. Conidiophores hyaline, short with arising from the inner layer of the peridium. Conidiogenous cells cylindrical to lageniform. Conidiogenesis enteroblastic phialidic or holoblastic with sympodial proliferation to both types. Conidia falcate or filiform, aseptate, hyaline, allantoid, thin-walled (adapted from Voglmayr et al. 2019a) .

Type genus - Leptosillia Höhn.

Notes - Leptosilliaceae was introduced by Voglmayr et al. (2019a) which belongs to Xylariales and is morphologically similar to Delonicicolaceae, but differs in ascomata structure. Only one genus, Leptosillia is recognized in the family based on molecular and morphology data (Voglmayr et al. 2019a). Voglmayr et al. (2019a) clearly showed Leptosillia should be placed in the Xylariales with strong evidence from ITS and LSU analyses. However, in this study we accept this family under Delonicicolales, based on high statistical support (Figs. 1, 2, 4).

\section{Ecological and economic significance of Leptosilliaceae}

Most Leptosilliaceae species are facultative lichenised taxa. Leptosilliaceae can be endophytes in woody hosts in tropical or subtropical areas (Voglmayr et al. 2019a). Leptosillia pistaciae is a serious canker pathogen of Pistacia vera (Vitale 2018). In addition, Vitale (2018) and Voglmayr et al. (2019a) mentioned that some Leptosillia species isolated as endophytes within living plant tissues and may actually represent latent pathogens.

\section{Genus included in Leptosilliaceae}

Leptosillia Höhn., Mitt. bot. Inst. tech. Hochsch. Wien 5: 111 (1928)

Index Fungorum number: IF2797; 9 morphological species (Species Fungorum 2020), 6 species with sequence data.

Type species - Leptosillia notha Höhn.

Notes - When establishing Cresporhaphis, a synonym of Leptosillia, Aguirre-Hudson (1991) described its association with an unidentified globose chlorococcoid photobiont. Various species were included, as probably lichenized and Calatayud \& Aguirre-Hudson (2005) considered Cresporhaphis ulmi as not lichenised. Voglmayr et al. (2019a) introduced seven species as new combinations in Leptosillia. Species of Leptosillia have superficial to partly immersed, subglobose to pyriform, ostiolate ascomata, with a peridium of textura angularis or prismatica, and clavate to cylindrical asci and lunate ascospores. The asexual morph has superficial conidiomata with cells of textura globulosa to angularis in the conidiomatal wall, short hyaline conidiophores, cylindrical to lageniform conidiogenous cells and lunate or filiform conidia (Voglmayr et al. 2019a).

\section{Leptosporellaceae S. Konta \& K.D. Hyde, Mycosphere 8(10): 1956 (2017)}

Index Fungorum number: IF553956; Facesoffungi number: FoF03840; 11 species.

Saprobic or endophytic on various host plants. Sexual morph: Ascomata solitary, superficial, comprising black, subglobose, carbonaceous, dome-shaped, raised, blister-like areas, within the plant tissues, flattened at the base, ostiole central. Peridium outer cells merging with the host epidermal cells, composed of dark brown to black cells of textura angularis. Paraphyses numerous, hyaline, hypha-like, septate, longer than asci. Asci 8-spored, unitunicate, cylindrical, longpedicellate, with a J-, wedge-shaped, subapical ring. Ascospores fasciculate, hyaline or paleyellowish in mass, spiral, filiform, straight or curved, aseptate, ends rounded, with or without polar mucilaginous appendages. Asexual morph: Undetermined (adapted from Konta et al. 2017).

Type genus - Leptosporella Penz. \& Sacc.

Notes - The family was introduced by Konta et al. (2017) in Chaetosphaeriales with support from the analysis of combined LSU and ITS sequence data. In this study, a new species, Leptosporella elaeidis, is introduced (Fig. 8). 


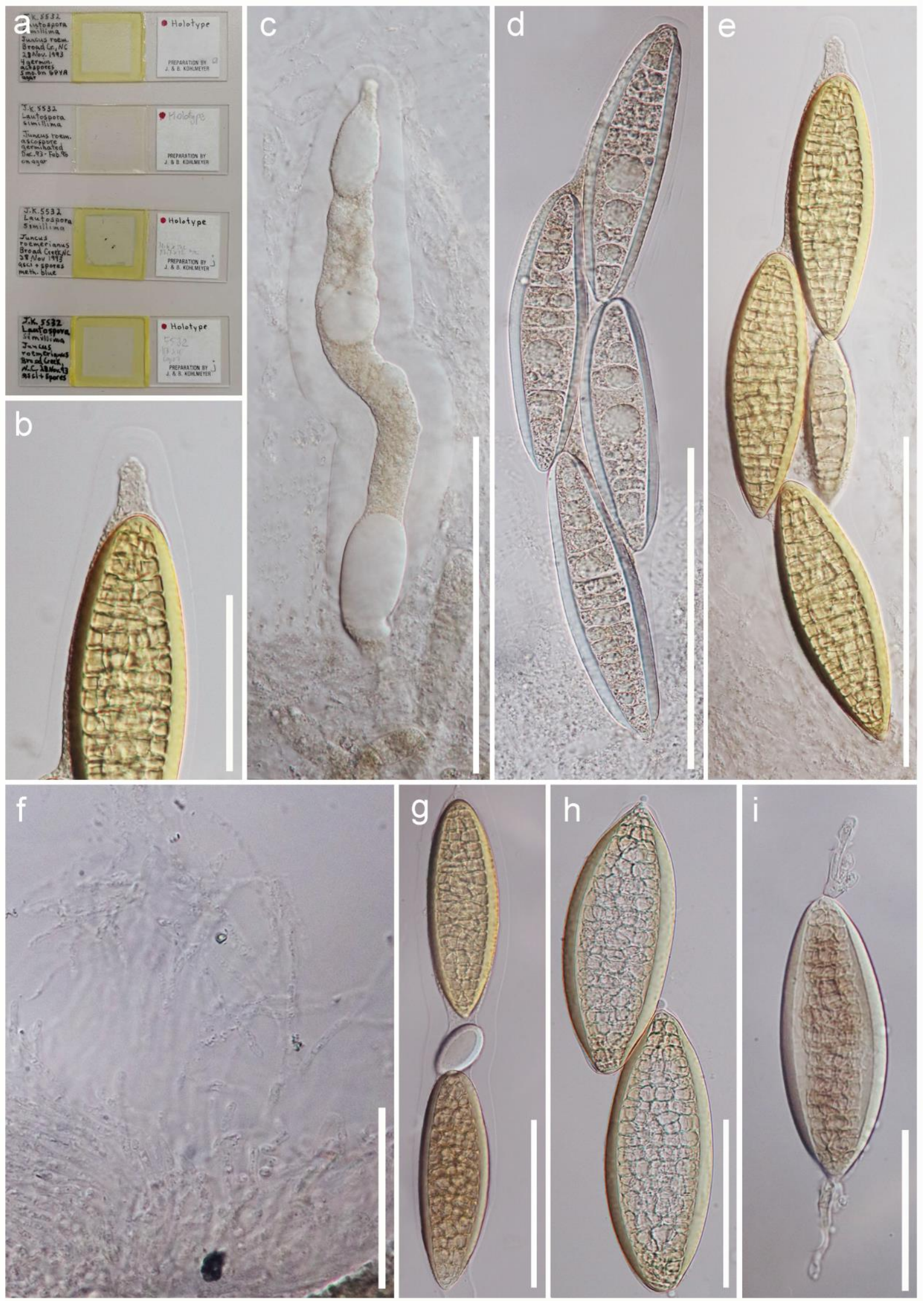

Figure 144 - Lautospora simillima (Material examined - USA, North Carolina, on senescent culms of Juncus roemerianus, J. Kohlmeyer, J.K. 5532 IMS), microslides from holotype). a Microslides of Lautospora simillima. b Apex of an asci in methylene blue. c, d Asci. e An ascus in methylene blue. f Paraphyses. g, h Ascospores. i Germinating ascospore on agar. Scale bar: $\mathrm{c}-\mathrm{e}=$ $200 \mu \mathrm{m}, \mathrm{d}-\mathrm{i}=100 \mu \mathrm{m}, \mathrm{b}=50 \mu \mathrm{m}$. 

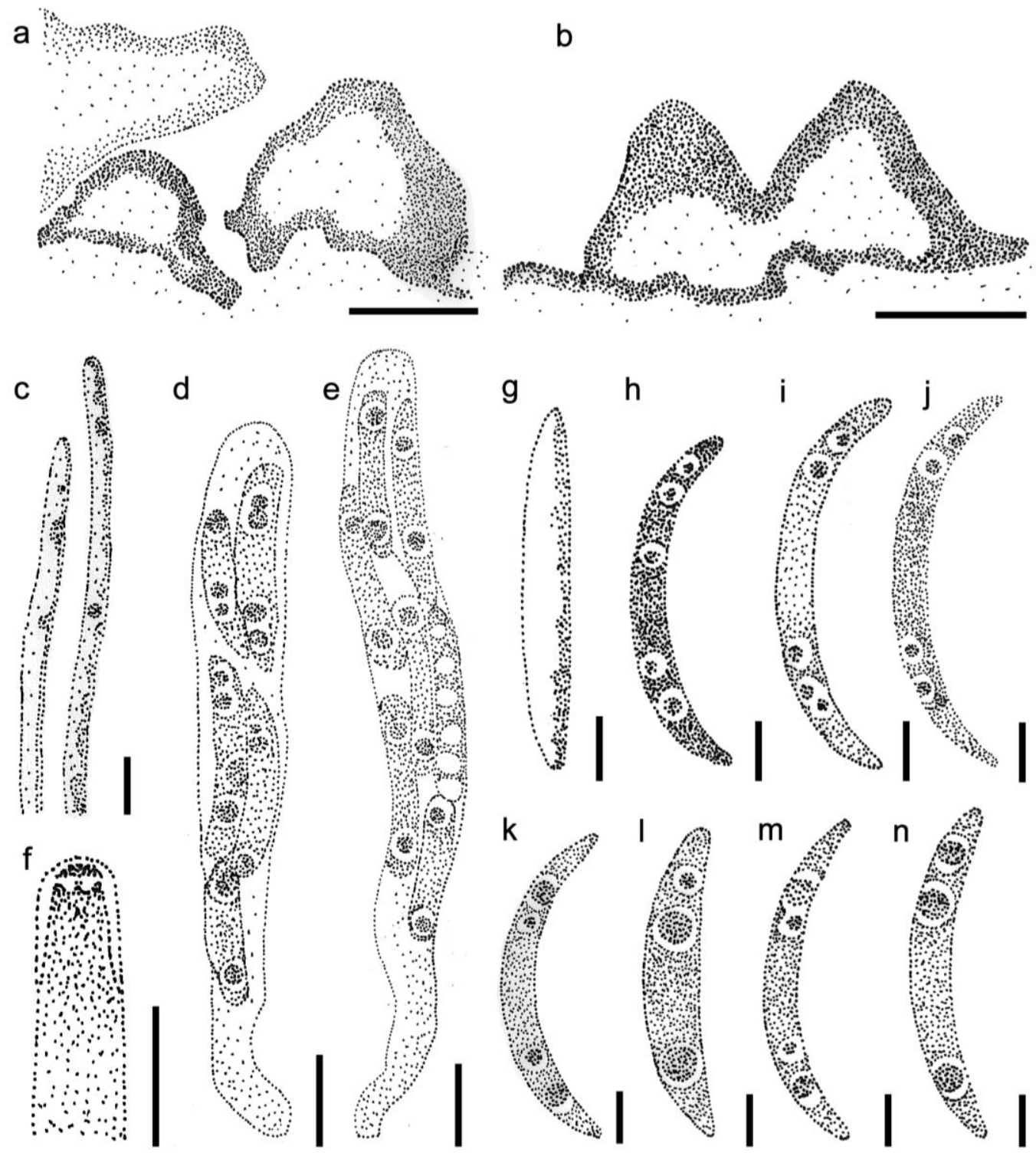

Figure 145 - Sexual morph of Leptosillia muelleri (redrawn from Voglmayr et al. 2019a). a, b Ascomata on the substrate. c Paraphyses. d, e Asci. f Ascus apex in Lugol's reagent. g Dead ascospores. h-n Vital ascospores. Scale bars: $\mathrm{a}, \mathrm{b}=100 \mu \mathrm{m}, \mathrm{c}=5 \mu \mathrm{m}, \mathrm{d}-\mathrm{f}=10 \mu \mathrm{m}, \mathrm{g}-\mathrm{n}=5 \mu \mathrm{m}$.

\section{Ecological and economic significance of Leptosporellaceae}

Species of Leptosporellaceae are saprobes and endophytes on various plants, especially monocotyledons. Appressoria have been re-observed in culture, indicating the genus may be endophytic (Konta et al. 2016).

\section{Genus included in Leptosporellaceae}

Leptosporella Penz. \& Sacc., Malpighia 11(9-10): 406 (1897)

Index Fungorum number: IF2804; 11 morphological species (Species Fungorum 2020), 4 species and 2 unnamed species with sequence data.

Type species - Leptosporella gregaria Penz. \& Sacc.

Notes - A phylogenetic tree for this genus was provided in Konta et al. (2017). The genus is characterised by solitary, superficial, carbonaceous, dome-shaped ascomata, with a central ostiole, cylindrical asci with a J-, subapical ring and spiral, filiform, hyaline (pale-yellowish in mass), aseptate ascospores, with or without polar mucilaginous appendages (Konta et al. 2017). The asexual morph and appressoria have not been reported. Leptosporella arengae is illustrated for this genus with updated the information of an appressoria-like structure that was produced at the hyphal 
tip when ascospores were germinated. Appressoria were 4-5 $\mu \mathrm{m}$ high $\times 4-5 \mu \mathrm{m}$ diameter $(\bar{x}=5$ $\mu \mathrm{m}, \mathrm{n}=5$ ), rare, globose to subglobose, irregular, and hyaline. A new species, Leptosporella elaeidis is introduced herein.
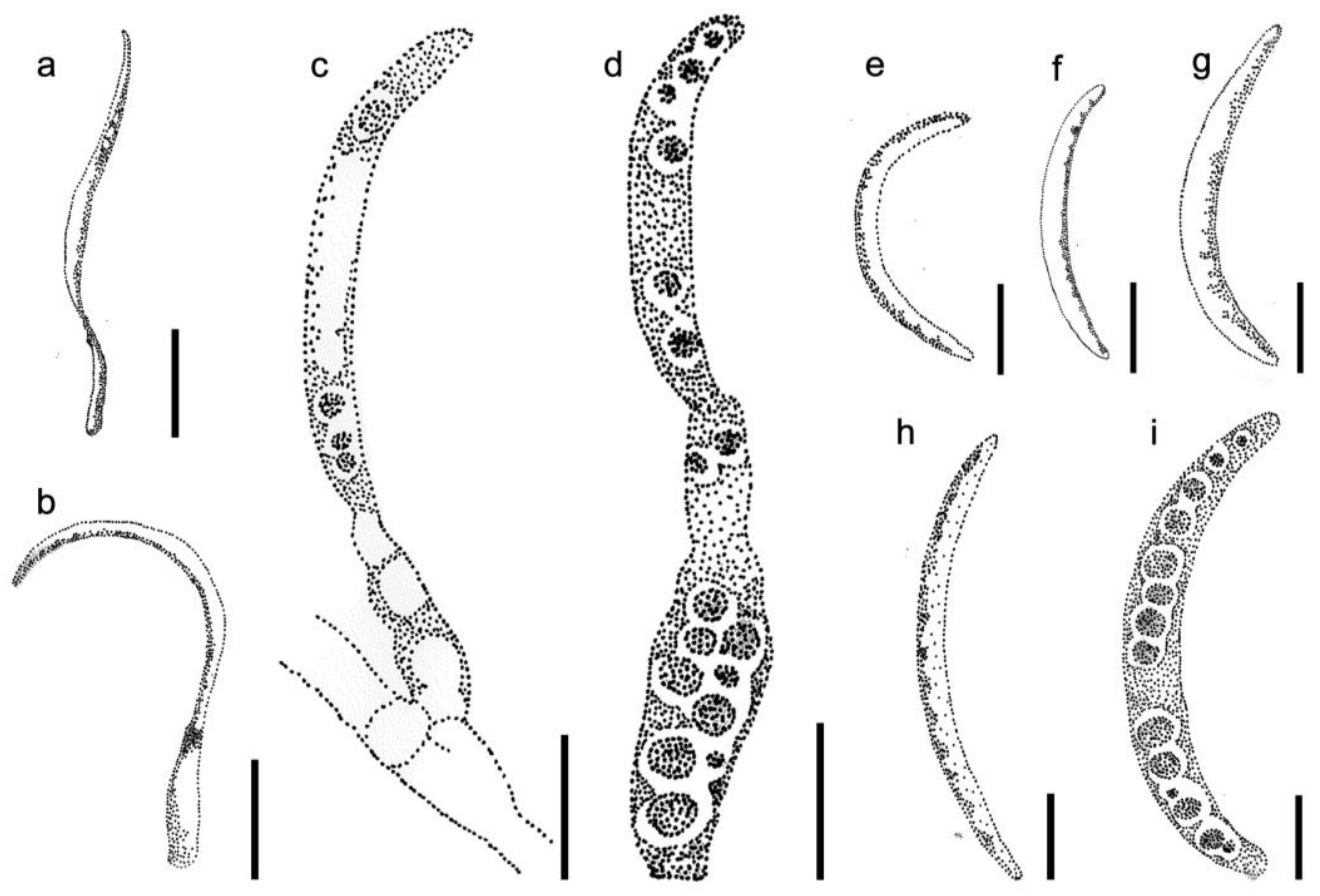

Figure 146 - Asexual morph of Leptosillia muelleri (redrawn from Voglmayr et al. 2019a). a, b Conidiophores, conidiogenous cells and conidia from pycnidia on natural substrates. c, d Conidiophores, conidiogenous cells and conidia from pycnidia in pure culture. e-i Conidia from natural substrate (e - dead, f-I - vital). Scale bars: a-d $=10 \mu \mathrm{m}, \mathrm{e}-\mathrm{i}=5 \mu \mathrm{m}$.

Leptosporella elaeidis Konta \& K.D. Hyde, sp. nov.

Fig. 148

Index Fungorum number: IF556361; Facesoffungi number: FoF06026

Etymology - Named after the host genus, Elaeis.

Holotype - MFLU 19-0669.

Saprobic on rachis and petioles of Elaeis guineensis Jacq. Sexual morph: Ascomata (included neck) $242-600 \mu \mathrm{m}$ high $\times 625-1000 \mu \mathrm{m}$ diameter $(\bar{x}=444 \times 787 \mu \mathrm{m}, \mathrm{n}=10)$, solitary, superficial, comprising black, carbonaceous, dome-shaped, raised blister-like areas, subglobose, flattened at the base, ostiolate. Ostiole central, carbonaceous, black, with periphyses. Peridium $63-113 \mu \mathrm{m}$ wide $(\bar{x}$ $=83 \mu \mathrm{m}, \mathrm{n}=10$ ), outer cells merging with the host epidermal cells, composed of dark brown to black cells of textura angularis. Paraphyses numerous, 2-7 $\mu \mathrm{m}$ diameter $(\bar{x}=4 \mu \mathrm{m}, \mathrm{n}=10)$, branched, septate, longer than asci. Asci 125-210 ×9-14 $\mu \mathrm{m}(\bar{x}=163 \times 11 \mu \mathrm{m}, \mathrm{n}=20), 8$-spored, unitunicate, cylindrical, long-pedicellate, with a J-, wedge-shaped, subapical ring. Ascospores 124$136 \times 2-4 \mu \mathrm{m}(\bar{x}=128 \times 3 \mu \mathrm{m}, \mathrm{n}=20)$, fasciculate, yellowish in mass, spiral, filiform, straight or curved, C-shaped or sigmoid, aseptate, rounded at the apex, pointed at the base, without polar mucilaginous appendages, smooth-walled. Asexual morph: Undetermined.

Material examined - THAILAND, Suratthani Province, on dead rachis and petioles of Elaeis guineensis Jacq. (Arecaceae), 21 July 2017, Sirinapa Konta SRWD14b, MFLU 19-0669, holotype.

GenBank numbers - ITS: MK659767, LSU: MK659772, SSU: MK659774, tef1: MN883560.

Notes - The ascospores of Leptosporella elaeidis failed to germinate and therefore the DNA was obtained directly from fruiting bodies. Phylogenetic analysis placed our collection with $L$. arengae, 61\% ML (Fig. 8). Leptosporella elaeidis differs from L. arengae in having larger ascomata, asci and ascospores, and lack of polar mucilaginous appendages. This is the first record of L. elaeidis on Elaeis guineensis and the fourth record of Leptosporella species from a palm tree (Arecaceae). 

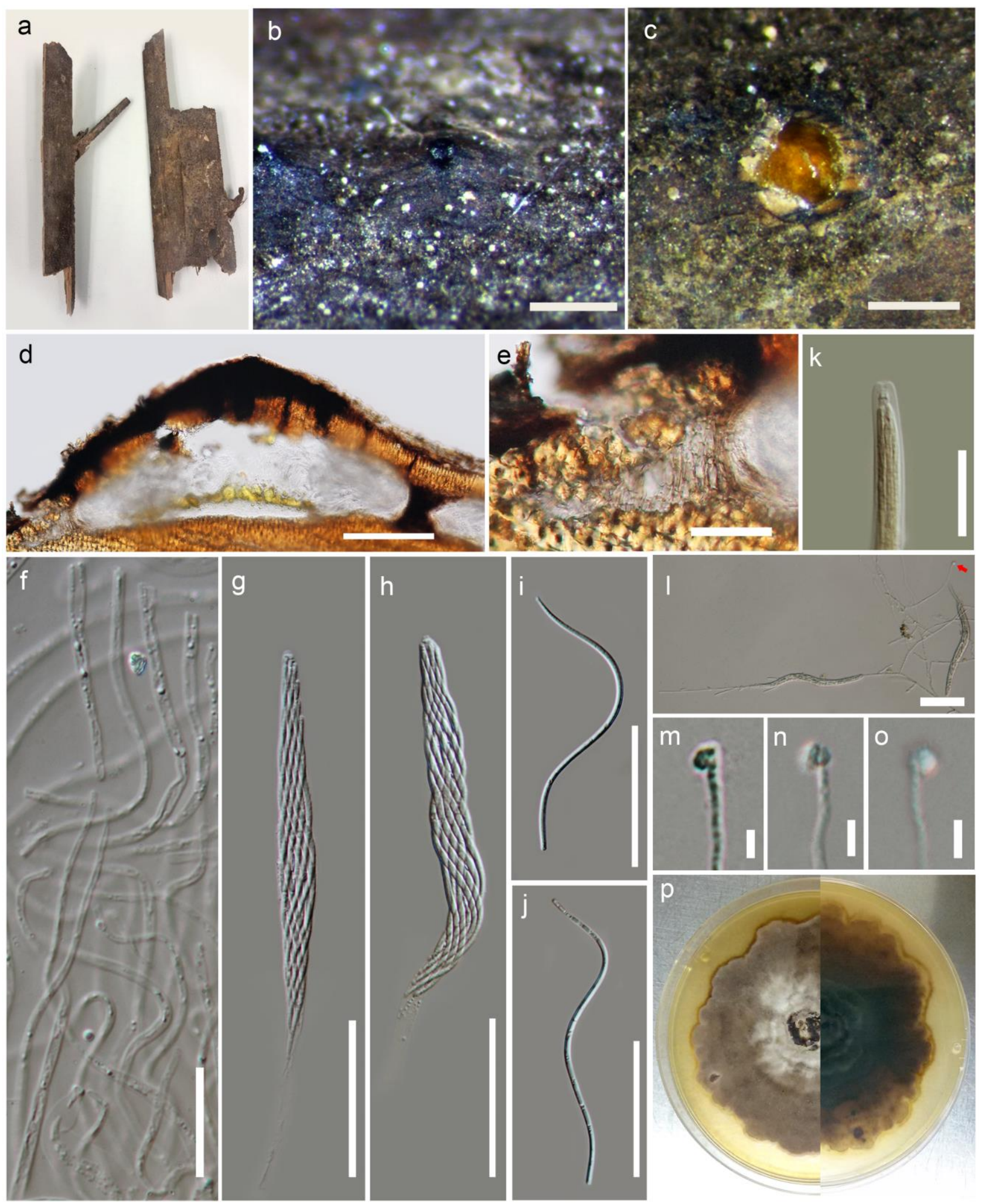

Figure 147 - Leptosporella arengae (Material examined - THAILAND, Phang-Nga Province, on dead rachis of Arenga pinnata (Wurmb) Merr. (Arecaceae), 5 December 2014, Sirinapa Konta PHR07a, MFLU 15-0305, holotype). a Appearance of ascomata on host substrate. b Close up of ascomata. c Yellowish ascospore mass. d Section of ascoma. e Peridium. f Paraphyses. g, h Asci. i, $\mathrm{j}$ Ascospores. $\mathrm{k} \mathrm{J}$-, reaction of the apical ring. 1 Germinated ascospores (appressoria-like at red arrow). m-o Appressoria. $\mathrm{p}$ Colony on MEA. Scale bars: $\mathrm{b}=1,000 \mu \mathrm{m}, \mathrm{c}=500 \mu \mathrm{m}, \mathrm{d}=200 \mu \mathrm{m}$, e, $\mathrm{g}-\mathrm{j}, \mathrm{k}=50 \mu \mathrm{m}, \mathrm{f}, \mathrm{k}=20 \mu \mathrm{m}, \mathrm{m}-\mathrm{o}=5 \mu \mathrm{m}$. 


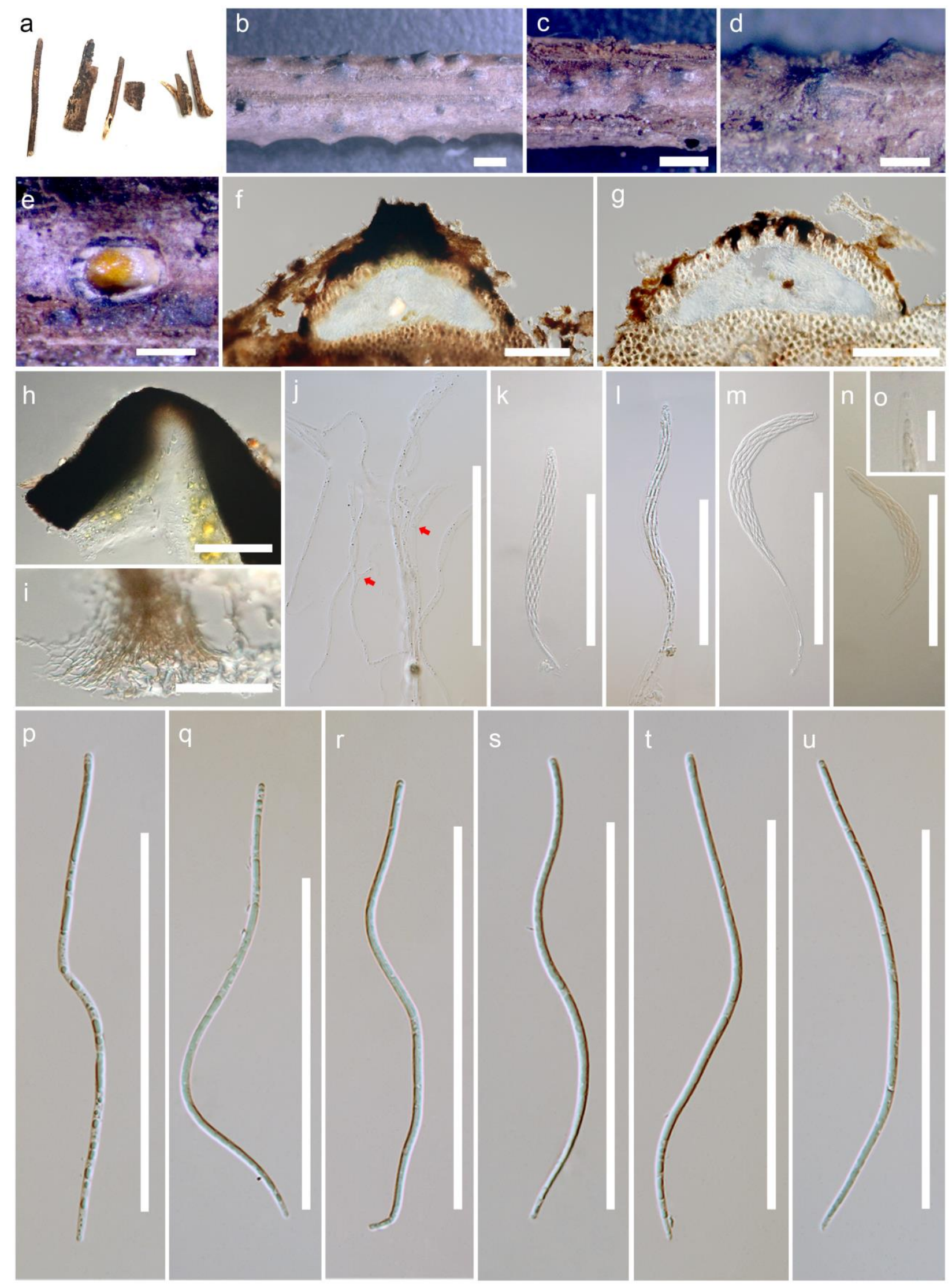

Figure 148 - Leptosporella elaeidis (MFLU 19-0669, holotype). a, b Appearance of ascomata on host substrate. c, d Close up of ascomata. e Yellowish ascospore mass. f, g Sections of ascoma. $\mathrm{h}$ Neck with periphyses. i Peridium. j Paraphyses (branch and septate at red arrow). k-m Asci. n-o J-, reaction of apical ring. p-u Ascospores. Scale bars: $b, c=1000 \mu \mathrm{m}, d, e=500 \mu \mathrm{m}, \mathrm{f}, \mathrm{g}=200 \mu \mathrm{m}, \mathrm{h}$, $\mathrm{j}-\mathrm{n}, \mathrm{p}-\mathrm{u}=100 \mu \mathrm{m}, \mathrm{i}=50 \mu \mathrm{m}, \mathrm{o}=20 \mu \mathrm{m}$. 
Linocarpaceae S. Konta \& K.D. Hyde, Mycosphere 8(10): 1962 (2017)

Index Fungorum number: IF553959; Facesoffungi number: FoF03843; 56 species.

Saprobic and endophytic fungi on monocotyledons and rarely dicotyledons. Sexual morph: Ascomata solitary, superficial comprising black, dome-shaped (Linocarpon), slightly raised or flattened circular areas, or immersed (Neolinocarpon) with a black shiny papilla. Peridium composed of dark brown to black cells of textura angularis. Paraphyses septate, longer than asci, wider at the base, tapering towards the apex. Asci 8-spored, unitunicate, cylindrical, with a J-, apical ring, developing from the base and periphery of the ascomata. Ascospores parallel or spiral in asci, hyaline or pale-yellowish in mass, filiform, straight or curved, unicellular with refringent bands, with or without polar appendages. Asexual morph: A phialophora-like spp. was found in Linocarpon appendiculatum and L. elaeidis cultures (Hyde 1992a), but has not been recovered in other species (adapted from Konta et al. 2017).

Type genus - Linocarpon Syd. \& P. Syd.

Notes - A recent treatment and updated account of Linocarpaceae by Konta et al. (2017) placed this family in Chaetosphaeriales which was confirmed by Hyde et al. (2019a). The first record of appressorium structures were from Neolinocarpon (Hyde et al. 2019a).

\section{Ecological and economic significance of Linocarpaceae}

Linocarpaceae species are saprobes and endophytes on monocotyledons and rarely dicotyledons. It is likely that they change from endophytes to saprobes as leaves scenesce and are involved in nutrient cycling.

\section{Genera included in Linocarpaceae}

Linocarpon Syd. \& P. Syd., Annls mycol. 15(3/4): 210 (1917)

Index Fungorum number: IF2882; 43 morphological species (Species Fungorum 2020); 10 species and 9 unnamed species with sequence data.

Type species - Linocarpon pandani Syd. \& P. Syd.

Notes - The most recent update of this genus is by Konta et al. (2017) who we follow here.

Linocarpon calami Konta, sp. nov.

Fig. 149

Index Fungorum number: IF556362; Facesoffungi number: FoF06024

Etymology - Named after the host genus, Calamus.

Holotype - MFLU 15-0277.

Saprobic on petioles of Calamus. Sexual morph: Ascomata 147-187 $\mu \mathrm{m}$ high $\times 565-732 \mu \mathrm{m}$ diameter $(\bar{x}=165 \times 637 \mu \mathrm{m}, \mathrm{n}=10)$, solitary or aggregated, superficial, comprising black, domeshaped, raised, blister-like areas, subglobose in section, flattened at the base, with a central ostiole. Peridium 33-70 $\mu \mathrm{m}$ diameter $(\bar{x}=47 \mu \mathrm{m}, \mathrm{n}=10)$, outer cells merging with the host epidermal cells, composed of dark brown to black cells of textura angularis. Paraphyses $3-6 \mu \mathrm{m}$ diameter $(\bar{x}$ $=4 \mu \mathrm{m}, \mathrm{n}=10)$, numerous, septate, longer than asci. Asci 120-160 $\times 13-21 \mu \mathrm{m}(\bar{x}=140 \times 16 \mu \mathrm{m}$, $\mathrm{n}=20$ ), 8-spored, unitunicate, cylindrical, long-pedicellate, with a $\mathrm{J}^{-}$, wedge-shaped, subapical ring. Ascospores 78-95 $\times 2-4 \mu \mathrm{m}(\bar{x}=91 \times 5 \mu \mathrm{m}, \mathrm{n}=20)$, parallel when immature, becoming spiral when mature, hyaline, filiform, straight or curved, aseptate, containing numerous refringent septum-like bands, ends rounded, without polar mucilaginous appendage at the apex, smoothwalled. Asexual morph: Undetermined.

Material examined - THAILAND, Phang-Nga Province, on dead petioles of Calamus (Arecaceae), 6 December 2014, Sirinapa Konta DNH02a, MFLU 15-0277, holotype.

Notes - A new species is introduced based on morphology and comparison with known Linocarpon species as well as species reported in Thailand. Linocarpon calami fits with the generic concept of Linocarpon in having superficial, dome-shaped, cylindrical asci, with J-, apical ring and filiform ascospores with refringent bands. Comparisons of Linocarpon species known in Thailand, shows that $L$. calami differs from $L$. arengae in having smaller ascomata, asci and ascospores, and ascospores without polar mucilaginous appendage, while, Linocarpon calami differs from L. cocois 
in having larger ascospores containing numerous refringent septum-like bands. Therefore, Linocarpon calami is introduced as a new species and the first geological recorded from the host genus Calanus (Arecaceae) in Thailand.

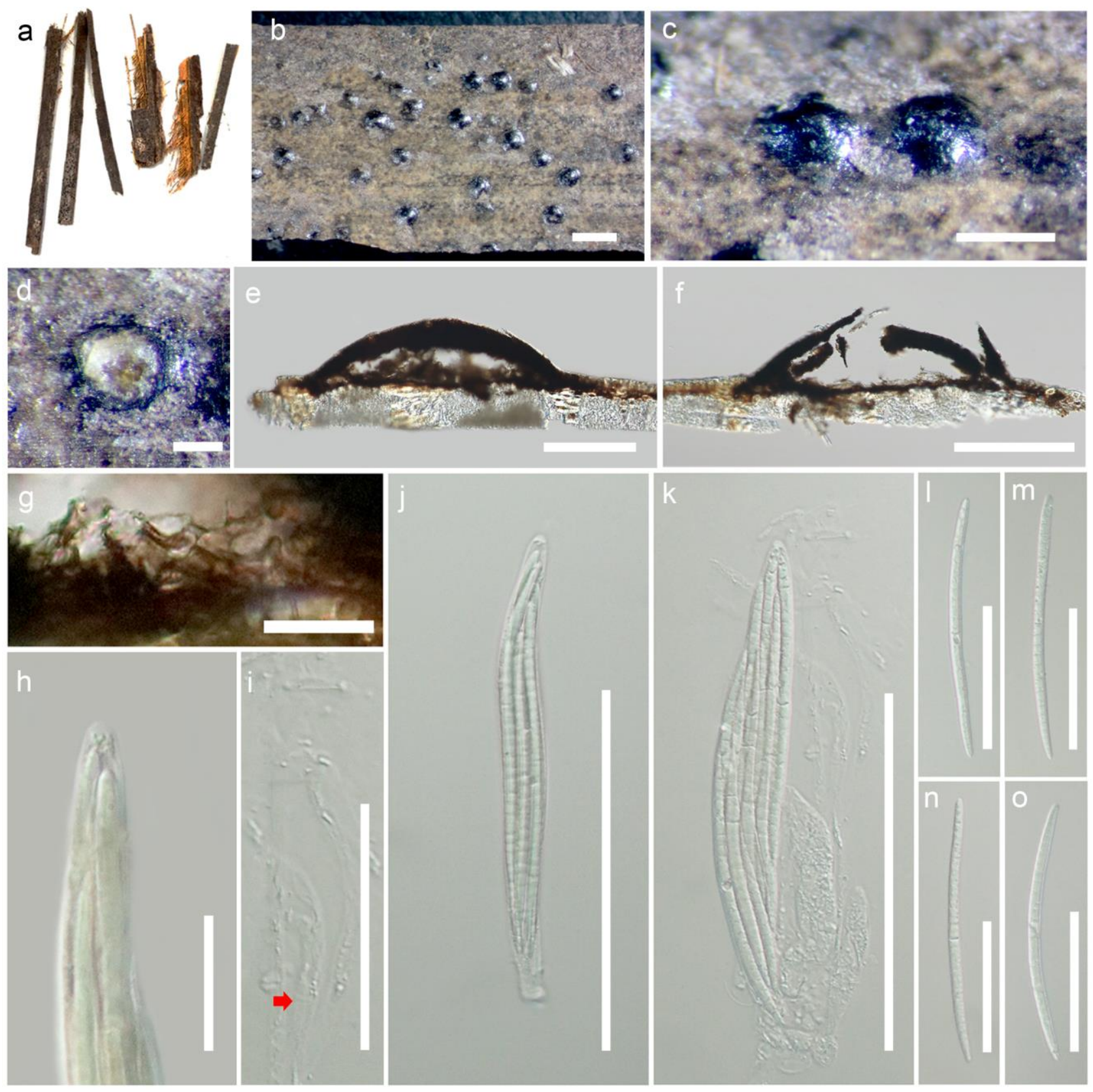

Figure 149 - Linocarpon calami (MFLU 15-0277, holotype). a, b Appearance of ascomata on host substrate. c Close up of ascoma. d Off white to yellowish ascospores mass. e, f Section of ascoma. g Peridium. h J-, reaction of apical ring. i Paraphyses (septate at the red arrow). j, k Asci (k mature asci with immature asci and paraphyses). 1-o Ascospores. Scale bars: $b=1000 \mu \mathrm{m}, c=500 \mu \mathrm{m}, \mathrm{d}-\mathrm{f}$ $=200 \mu \mathrm{m}, \mathrm{g}-\mathrm{h}=20 \mu \mathrm{m}, \mathrm{i}-\mathrm{o}=50 \mu \mathrm{m}$.

Neolinocarpon K.D. Hyde, Bot. J. Linn. Soc. 110(2): 104 (1992)

Index Fungorum number: IF26303; 13 morphological species (Species Fungorum 202 0); 7 species and 3 unnamed species with sequence data.

Type species - Neolinocarpon globosicarpum K.D. Hyde

Notes - Hyde (1992a) introduced Neolinocarpon with four new species to accommodate $N$. globosicarpum which is saprobic on Nypa fruticans in Brunei. Two new species were introduced with molecular data (Konta et al. 2017). An appressorium has been reported from $N$. rachidis 
(MFLU 15-2347) (Hyde et al. 2019a). We provide an illustration of Neolinocarpon rachidis to show the appressorium characters of Neolinocarpon (Hyde et al. 2019a).

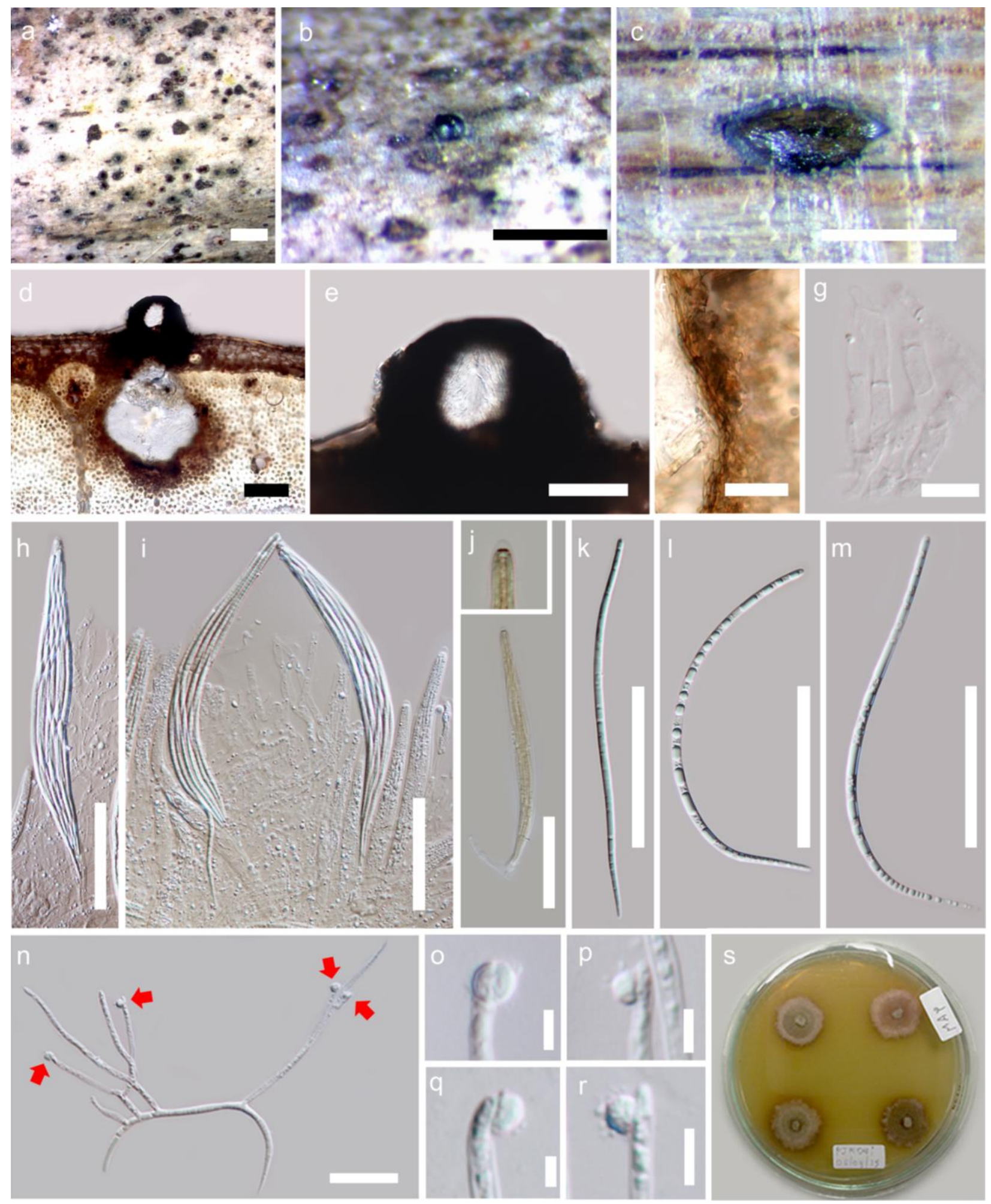

Figure 150 - Neolinocarpon rachidis (Material examined - THAILAND, Prachaupkhirikhan Province, on dead of petiole, Cocos nucifera (Arecaceae), 30 July 2015, Sirinapa Konta PJK04i, MFLU 15-2347). a Appearance of ascomata on host substrate. b Close up of ascomata. c Yellowish ascospore mass. d Section of ascoma. e Papilla. f Peridium. g Paraphyses. h-i Asci. j J-, a reaction of apical ring. $\mathrm{k}-\mathrm{m}$ Ascospores. $\mathrm{n}$ Germinated ascospore (appressoria at red arrow). o-r Appressoria. $\mathrm{s}$ Culture on MEA. Scale bars: $\mathrm{a}=1000 \mu \mathrm{m}, \mathrm{b}, \mathrm{c}=500 \mu \mathrm{m}, \mathrm{d}=100 \mu \mathrm{m}, \mathrm{e}, \mathrm{h}-\mathrm{n}=50$ $\mu \mathrm{m}, \mathrm{f}=20 \mu \mathrm{m}, \mathrm{g}=10 \mu \mathrm{m}, \mathrm{o}-\mathrm{r}=5 \mu \mathrm{m}$. 
Lopadostomataceae Daranagama \& K.D. Hyde, Fungal Divers 73: 1 (2015)

Index Fungorum number: IF91005; Facesoffungi number: FoF00071; 36 species.

Saprobic on dead wood. Sexual morph: Pseudostromata/stromata immersed to erumpent or nearly superficial, gregarious, scattered, densely compact, with abrupt margins, appearing as darkened areas, dark brown to dull black, coalescing in black linear rows, waxy, roughened, flattened at the top, with inconspicuous ascomatal mounds, embedded in carbonized encasement. Ascomata cylindrical-subglobose or flask-shaped, multi-peritheciate, single to multi-layered, clustered into valsoid groups, sometimes with long ostiolar necks (Lopadostoma), lined with whitish material. Ostioles umbilicate or at the same level as stromal surface. Peridium amorphous, outwardly comprised of dark brown to black cells, inwardly hyaline, flattened cells. Paraphyses numerous, long, rarely branched, apically free. Asci (4-)8-spored, unitunicate, cylindrical, pedicellate, apex rounded, with $\mathrm{J}+$, discoid to wedged-shaped, apical ring, J+. Ascospores uniseriate or partially biseriate, initially hyaline, turning light brown to nearly black, unicellular, oblong, narrowly ellipsoidal, smooth-walled, without any patterns, germ slit full length, straight. Asexual morph: Coelomycetous or Hyphomyceteous, libertella-like or sometimes nodulisporium or geniculosporium-like synanamorph (adapted from Senanayake et al. 2015, Daranagama et al. 2018).

Type genus - Lopadostoma (Nitschke) Traverso

Notes - Lopadostomataceae was introduced by Senanayake et al. (2015) in Xylariales to accommodate Creosphaeria and Lopadostoma. The family is typified by Lopadostoma turgidum. In earlier considerations, Creosphaeria and Lopadostoma, which have libertella-like asexual morphs were treated as a basal lineage of Xylariaceae (Tang et al. 2009b). ITS and LSU combined phylogenetic analyses revealed that the Lopadostomataceae is a monophyletic sister clade to Coniocessiaceae, hence it was treated as a separate family (Senanayake et al. 2015). At present, the family consists with four genera including Creosphaeria, Jumillera, Lopadostoma and Whalleya (Daranagama et al. 2018) and accepted as a family in Xylariales according to the evolutionary based ranking system (Hyde et al. 2017a). Antimicrobial azaphilone pigments discovered from Creosphaeria sassafras are known metabolites discovered in the family (Quang et al. 2005).

\section{Ecological and economic significance of Lopadostomataceae}

Lopadostomataceae members play a major role as saprobes on corticated and decorticated wood (Daranagama et al. 2018). Sassafrin type pigments were identified from this family, however, investigation on potential bioactive compounds in this family is needed.

\section{Genera included in Lopadostomataceae}

Creosphaeria Theiss., Beih. bot. Zbl., Abt. 2 27: 396 (1910)

Index Fungorum number: IF1288; 2 morphological species (Daranagama et al. 2018, Species Fungorum 2020), 1 species with sequence data.

Type species - Creosphaeria sassafras (Schwein.) Y.M. Ju, F. San Martín \& J.D. Rogers

Notes - Ju et al. (1993) resurrected Creosphaeria based on the morphological differences with Hypoxylon. In several phylogenetic studies, Creosphaeria is sister to Lopadostoma (Jaklitsch et al. 2014, Daranagama et al. 2018). The genus is characterised by stromata with KOH- extractable pigments, subglobose to broadly cylindrical ascomata, cylindrical, long-stipitate asci with discoid, $\mathrm{J}+$, apical rings and unicellular, ellipsoid, slightly inequilateral to oblong or cylindrical, brown ascospores, with straight germ slit and libertella-like coelomycetous asexual morphs (Daranagama et al. 2018).

Jumillera J.D. Rogers, Y.M. Ju \& F. San Martín, Mycotaxon 64: 41 (1997)

Index Fungorum number: IF27739; 8 morphological species (Species Fungorum 2020).

Type species - Jumillera mexicana J.D. Rogers, Y.M. Ju \& F. San Martín

Notes - Jumillera was introduced by Rogers et al. (1997) based on generally small ascospores as compare to Biscogniauxia and libertella-like asexual morphs with geniculosporium- 
like conidial state as synanamorphs including culture characteristics. At present the genus is placed in Lopadostomataceae. However, the taxonomic placement of the genus needs to be revised with phylogenetic studies (Daranagama et al. 2018, Wendt et al. 2018).

Lopadostoma (Nitschke) Traverso, Fl. ital. crypt. 1(2): 169 (1906)

Index Fungorum number: IF2925; 24 morphological species (Species Fungorum 2020), 11 species with sequence data.

Type species - Lopadostoma turgidum (Pers.) Traverso

Notes - Lopadostoma comprises 12 species from Europe which are saprobes producing pseudostromatic sexual morphs and libertella-like asexual morphs (Fig. 152, Jaklitsch et al. 2014). So far species delimitation of Lopadostoma is based only on ITS and LSU sequence data with low resolution, while protein coding regions, especially $r p b 2$, are essential for further species delimitation (Daranagama et al. 2016, Jaklitsch et al. 2014). The Lopadostoma gastrinum sexual morph and L. turgidum asexual morph are illustrated in this entry (Fig. 151, 152).
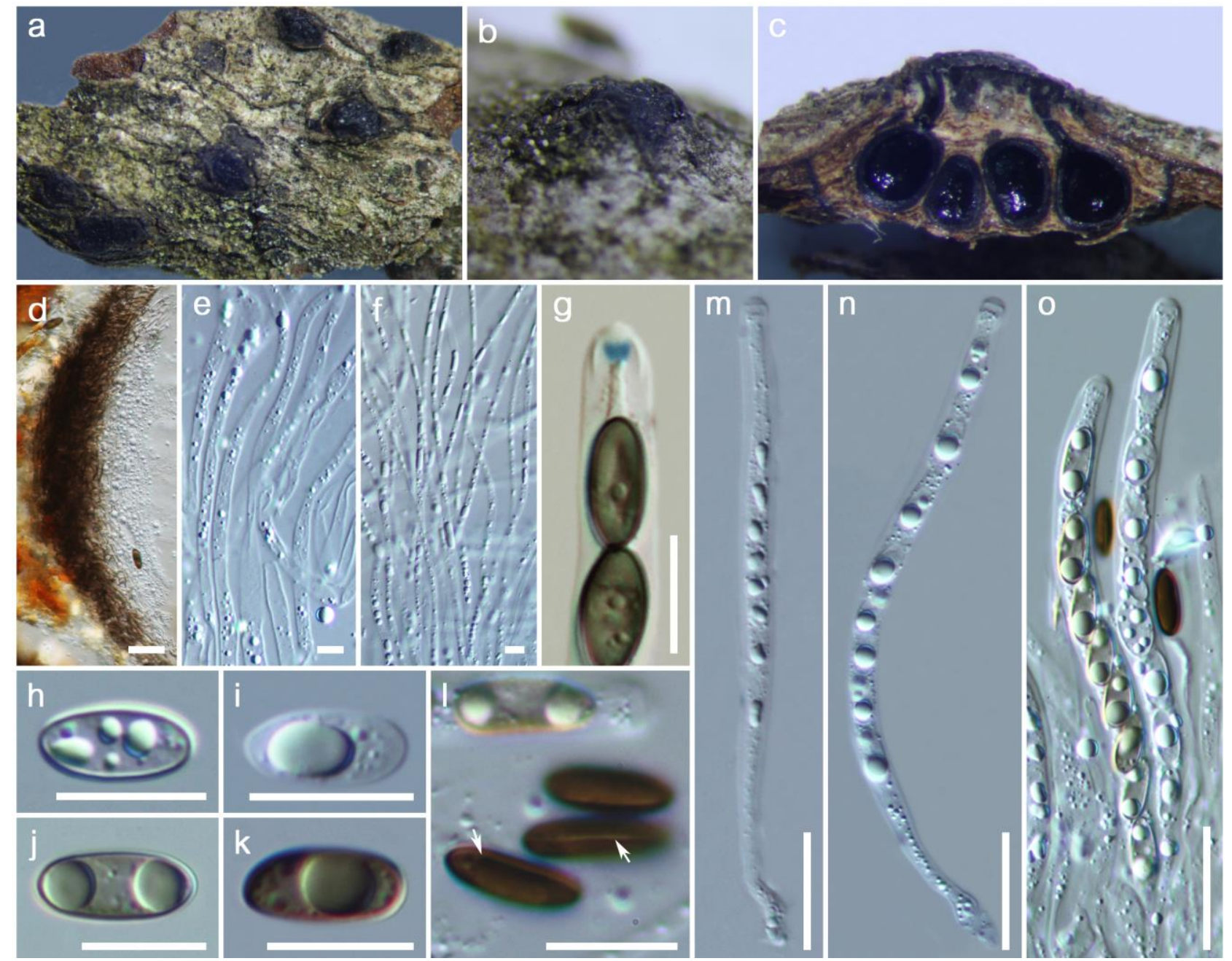

Figure 151 - Lopadostoma gastrinum (Material examined - ITALY, Province of Forlì-Cesena [FC], Monte Mirabello - Predappio, on dead fallen branch of Quercus sp. (Fagaceae), 12 April 2017, Erio Camporesi IT3269C, MFLU 17-0941; ibid. HKAS 102310). a, b Stromata on the host. c Cross section of stroma. d Peridium. e, f Paraphyses. g J+, apical ring in Melzer's reagent. h-1 Ascospores (l-white arrows show germ slit). m-o Asci. Scale bars: d, m-o $=20 \mu \mathrm{m}, \mathrm{g}-\mathrm{l}=10 \mu \mathrm{m}$, e, $\mathrm{f}=5 \mu \mathrm{m}$.

Whalleya J.D. Rogers, Y.M. Ju \& F. San Martín, Mycotaxon 64: 48 (1997) 
Index Fungorum number: IF27738; 2 morphological species (Species Fungorum 2020), 1 species with sequence data. Martín

Type species - Whalleya microplaca (Berk. \& M.A. Curtis) J.D. Rogers, Y.M. Ju \& F. San

Notes - Whalleya species have conspicuous, bipartite, stromata and asci with a $\mathrm{J}+$, apical ring, and dark, ellipsoidal ascospores and has scolecosporous conidia, similar to lopadostomaceous species (Rogers et al. 1997). Based on both xylariaceous and lopadostomaceous morphological affinities, Maharachchikumbura et al. (2016b) placed the genus in Xylariales incertae sedis. However, based on recent phylogenetic studies, the genus is accommodated in Lopadostomataceae (Daranagama et al. 2018, Wendt et al. (2018).
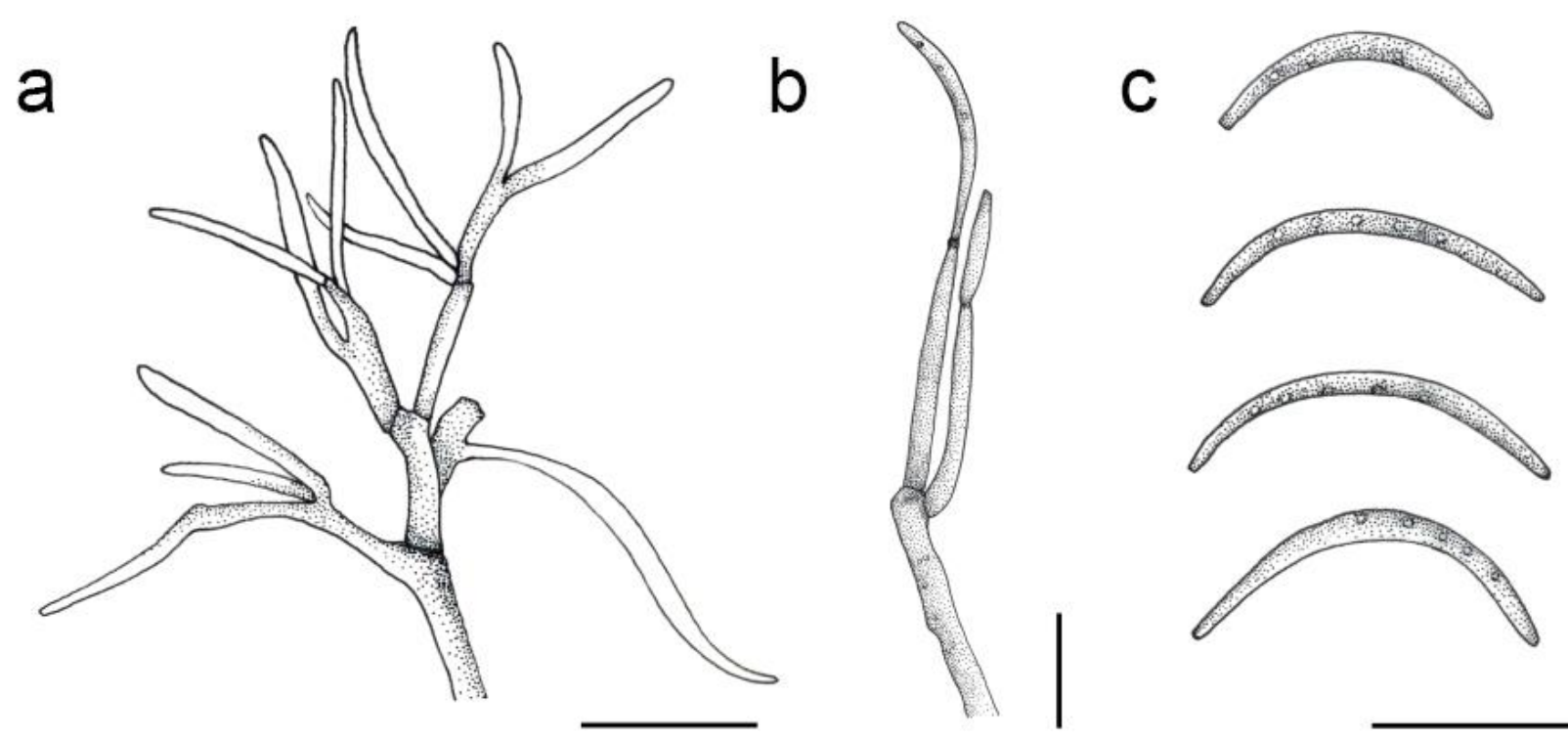

Figure 152 - Lopadostoma turgidum (ex-epitype culture CBS 133207). a, b Conidiophores (b. showing phialide bearing conidium). c Conidia. Scale bars: $10 \mu \mathrm{m}$ (redrawn from Jaklitsch et al. 2014).

Lulworthiaceae Kohlm., Spatafora \& Volkm.-Kohlm., Mycologia 92(3): 456 (2000) Index Fungorum number: IF82091; Facesoffungi number: FoF01295; 47 species.

Saprobic, on wood or growing on sea grasses, marsh plants and calcareous animal shells, endoskeletons and feathers, parasitic on algae and endophytic in sea grasses. Sexual morph: Ascomata pale to dark brown to black, occasionally purple, subglobose to cylindrical, immersed or superficial, coriaceous, ostiolate, papillate, sometimes with a long neck. Peridium mostly two layered, composed of an outer layer of cells of textura angularis and an inner layer of elongate cells. Paraphyses lacking; centrum initially filled with a hyaline pseudoparenchyma, dissolving at maturity. Asci 8-spored, unitunicate, cylindrical to fusiform, short pedicellate, deliquescent. Ascospores fasciculate, hyaline, filiform, septate or aseptate, conical or semi-globose chambers at the ends, with or without mucus. Asexual morph: hyphomycetous, hyphae pale brown, septate, branched. Conidiophores micronematous or semi-micronematous. Conidia septate or aseptate, some coiled (adapted from Maharachchikumbura et al. 2016b).

Type genus - Lulworthia G.K. Sutherl.

Notes - Lulworthia species have been recorded from various marine habitats and this is one of the largest genera among the marine fungi (Kohlmeyer et al. 2000). Sutherland (1916) introduced Lulworthia to accommodate the species L. fucicola, found on the brown seaweed, bladder wrack at Lulworth Cove on the Dorset coast, UK, but no type material was ever deposited for this taxon. Campbell et al. (2005) designated a neotype for the type species of Lulworthia ( $L$. 
fucicola) from a collection from Chile. Lulworthia has been revisited over many years (Kohlmeyer 1972, Kohlmeyer \& Kohlmeyer 1979, Koch \& Jones 1984, Schaumann et al. 1986). Johnson \& Sparrow (1961) listed 12 Lulworthia species, which were synonymized under L. medusa by Cavaliere \& Johnson (1966). Three species were described by Kohlmeyer (1972) and Koch \& Jones (1984) recognized six species. Eleven accepted species were included in Lulworthia with a number of other taxa by Kohlmeyer et al. (2000). However, their morphological differences are not sufficient to distinguish the species (Kohlmeyer et al. 2000). As a result of sequence analysis of LSU and SSU sequences a number of transfers have been recommended, such as Lulworthia crassa to Kohlmeyeriella, Lulworthia lignoarenaria to Lulwoidea and Lulworthia uniseptata to Lulwoana by Campbell et al. (2005). Jones et al. (2015) showed that only L. fucicola can be accepted in Lulworthia sensu stricto, while 11 species are referred to Lulworthia sensu lato until further taxa are collected and sequenced. Abdel-Wahab et al. (2017) introduced a novel genus Sammeyersia to accommodate L. grandispora based on molecular data. Azevedo et al. (2017) introduced a novel species Lulworthia atlantica to this genus in the Lulworthia sensu stricto clade.

The genera Lulworthia and Lindra were previously placed in Halosphaeriales (Spatafora et al. 1998). Subsequently, phylogenetic analysis of several species of Lulworthia and Lindra with filamentous ascospores led to the inclusion of their parent genera to a new family Lulworthiaceae in a new order Lulworthiales (Kohlmeyer et al. 2000). Jones et al. (2008) showed that the asexual genera Cumulospora and Orbimyces grouped in Lulworthiaceae (Lulworthiales) with statistical support. Subsequently, in a molecular analysis of SSU and LSU sequence data, Abdel-Wahab et al. (2010) demonstrated that the genera Cumulospora, and Cirrenalia were polyphyletic and introduced the new genera Halazoon, Hydea, Matsusporium and Moheirospora for species previously referred to Cirrenalia, and Moromyces to accommodate Cumulospora varia. They also introduced the genera Moleospora and Glomerulispora in Lulworthiaceae. Currently this family comprises the genera, Cumulospora, Halazoon, Haloguignardia, Hydea, Kohlmeyeriella, Lindra, Lulwoana, Lulwoidea, Lulworthia, Matsusporium, Moleospora, Moromyces, Orbimyces, Rostrupiella, and Sammeyersia (Jones et al. 2015, Maharachchikumbura et al. 2016b, AbdelWahab et al. 2017, Wijayawardene et al. 2017a, 2018).

\section{Ecological and economic significance of Lulworthiaceae}

Lulworthiaceae species are mostly saprobes occurring on wood or growing on sea grasses and marsh plants (Kohlmeyer et al. 2000, Jones et al. 2015, Azevedo et al. 2017). Calado et al. (2015) reported that Lulworthia sp. (in Castro Marim) occurrs mostly in the more frequently flooded plant portions (basal portions) associated with stems and/or leaf sheaths of salt marsh plant Spartina. Lindra thalassiae has been reported in the degradation of turtle grass which is an ecologically important marine flowering plant (Orpurt et al. 1964). Haloguignardia sp. and Lulworthia kniepii have been reported as parasites on red and brown algae (Kohlmeyer 1974, Alongi et al. 1999). Gall formation in species of the genera Cystoseira and Sargassum is generally caused by Haloguignardia spp. (Apt 1988, Alongi et al. 1999). The occurrence of Lulwoana has also been reported in extreme environments such as saline soils (Hujslova et al. 2010). It is also believed that Lulwoana sp. in Posidonia oceanica roots help the host to capture mineral nutrients, through lytic activity by living as an endophyte (Torta et al. 2015). Nambiar \& Raveendran (2015) reported Matsusporium tropicalis was commonly found on four substrates including calcareous animal shells, 'chicken bone', endoskeleton of Seibia and feathers.

\section{Genera included in Lulworthiaceae}

We do not provide notes on each genus as these can be found at marinefungi.org (Jones et al. 2019). A monograph on genera of Lulworthiaceae is also planned by Dayarathne et al. (2020).

Cumulospora I. Schmidt, Mycotaxon 24: 420 (1985)

Index Fungorum number: IF25713; 1 species with sequence data.

Type species - Cumulospora marina I. Schmidt 
Halazoon Abdel-Aziz, Abdel-Wahab \& Nagah., Mycol. Progr. 9(4): 545 (2010)

Index Fungorum number: IF543113; 2 species with sequence data.

Type species - Halazoon melhae Abdel-Aziz, Abdel-Wahab \& Nagah.

Haloguignardia Cribb \& J.W. Cribb, Pap. Dept. Bot. (formerly Biol.) Univ. Qd. 3: 97 (1956)

Index Fungorum number: IF2205; 6 morphological species (Species Fungorum 2020), 1 species with sequence data.

Type species - Haloguignardia deciduas Cribb \& J.W. Cribb

Hydea K.L. Pang \& E.B.G. Jones, Mycol. Progr. 9(4): 549 (2010)

Index Fungorum number: IF543118; 1 species with sequence data.

Type species - Hydea pygmea (Kohlm.) K.L. Pang \& E.B.G. Jones

Notes - Abdel-Wahab et al. (2010) transferred Cirrenalia pygmea to Hydea based on phylogenetic analyses of combined LSU and SSU sequence data. Hydea pygmea is commonly found on mangrove wood, especially growing on Rhizophora species (Abdel-Wahab et al. 2010). Hydea pygmea is different from all other cirrenalia-like species by the dark-brown to black hooked nature of the conidia and by the internal proliferation of the conidia (Kohlmeyer \& Kohlmeyer 1979).

Kohlmeyeriella E.B.G. Jones, R.G. Johnson \& S.T. Moss, J. Linn. Soc., Bot. 87: 208 (1983) Index Fungorum number: IF25816; 2 species with sequence data.

Type species - Kohlmeyeriella tubulata (Kohlm.) E.B.G. Jones, R.G. Johnson \& S.T. Moss

Lindra I.M. Wilson, Trans. Br. mycol. Soc. 39(4): 411 (1956)

Index Fungorum number: IF2877; 5 morphological species (Species Fungorum 2020), 3 species with sequence data.

Type species - Lindra inflata I.M. Wilson

Lulwoana Kohlm., Volkm.-Kohlm., J. Campb., Spatafora \& Gräfenhan, Mycol. Res. 109(5): 562 (2005)

Index Fungorum number: IF28935; 1 species with sequence data.

Type species - Lulwoana uniseptata (Nakagiri) Kohlm., Volkm.-Kohlm., J. Campb., Spatafora \& Gräfenhan

Lulwoidea Kohlm., Volkm.-Kohlm., J. Campb., Spatafora \& Gräfenhan, Mycol. Res. 109(5): 564 (2005)

Index Fungorum number: IF28936; 1 species with sequence data.

Type species - Lulwoidea lignoarenaria (Jørg. Koch \& E.B.G. Jones) Kohlm., Volkm.Kohlm., J. Campb., Spatafora \& Gräfenhan

Lulworthia G.K. Sutherl., Trans. Br. mycol. Soc. 5(2): 259 (1916)

Index Fungorum number: IF2953; 22 morphological species (Species Fungorum 2020), 3 species with sequence data.

Type species - Lulworthia fucicola G.K. Sutherl.

Matsusporium E.B.G. Jones \& K.L. Pang, Mycol. Progr. 9(4): 550 (2010)

Index Fungorum number: IF543120; 1 species with sequence data.

Type species - Matsusporium tropicale (Kohlm.) E.B.G. Jones \& K.L. Pang

Moleospora Abdel-Wahab, Abdel-Aziz \& Nagah., Mycol. Progr. 9(4): 547 (2010)

Index Fungorum number: IF543116; 1 species with sequence data.

Type species - Moleospora maritima Abdel-Wahab, Abdel-Aziz \& Nagah. 


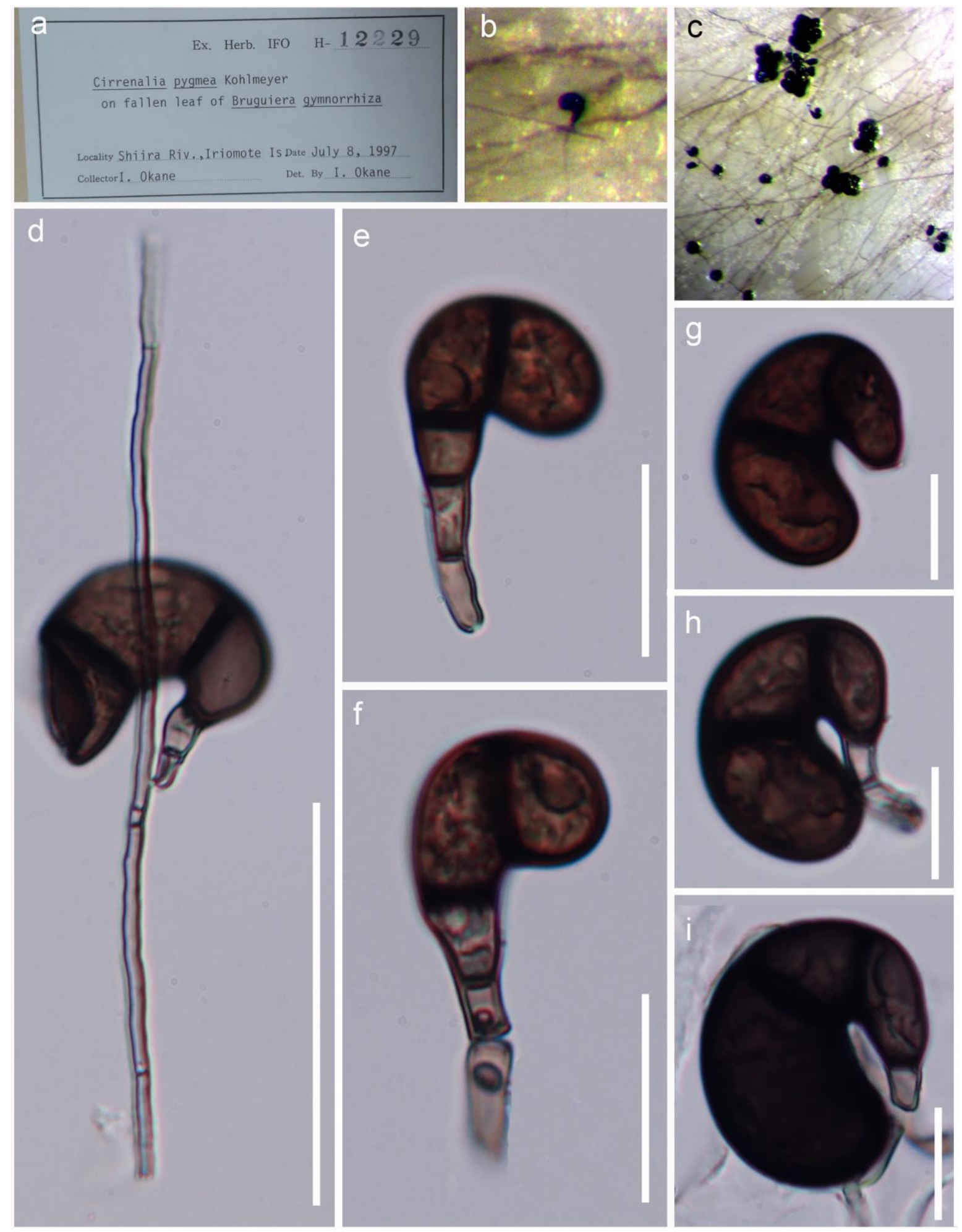

Figure 153 - Hydea pygmea (Material examined - JAPAN, Shiira Riv., Iriomote, Bruguiera gymnrrhiza., on fallen leaf, July 8 1997, I. okane, IFO-H 12229). a Herbarium label. b, c Appearance of conidia and conidiophores on CMSWA. d-f Conidia attached to the conidiophores. g-i Helicoid conidia. Scale bars: $d-f=20 \mu \mathrm{m}, \mathrm{g}-\mathrm{i}=10 \mu \mathrm{m}, \mathrm{j}-\mathrm{n}=5 \mu \mathrm{m}$.

Moromyces Abdel-Wahab, K.L. Pang, Nagah., Abdel-Aziz \& E.B.G. Jones, Mycol. Progr. 9(4): 555 (2010)

Index Fungorum number: IF543127; 1 species with sequence data.

Type species - Moromyces varius (Chatmala \& Somrith.) Abdel-Wahab, K.L. Pang, Nagah., Abdel-Aziz \& E.B.G. Jones 
Orbimyces Linder, Farlowia 1: 404 (1944)

Index Fungorum number: IF9170; 1 species with sequence data.

Type species - Orbimyces spectabilis Linder

Rostrupiella Jørg. Koch, K.L. Pang \& E.B.G. Jones, Bot. Mar. 50(5-6): 295 (2007)

Index Fungorum number: IF29175; 1 species with sequence data.

Type species - Rostrupiella danica Jørg. Koch, K.L. Pang \& E.B.G. Jones

Sammeyersia S.Y. Guo, E.B.G. Jones \& K.L. Pang, Botanica Marina 15 (2017)

Index Fungorum number: IF820458; 1 species with sequence data.

Type species - Sammeyersia grandispora (Meyers) S.Y. Guo, E.B.G. Jones \& K.L. Pang

Notes - Sammeyersia was introduced by Abdel-Wahab et al. (2017) to accommodate Sammeyersia grandispora which was earlier Lulworthia grandispora. Sammeyersia grandispora is identified by the length of the ascospores over $400 \mu \mathrm{m}$ (Abdel-Wahab et al. 2017). Our new isolate groups with the $S$. grandispora isolates deposited in GenBank (Fig. 16). Therefore, based on both morphological and phylogenetic data we identified our new isolate as S. grandispora. Sammeyersia grandispora is illustred herein (Fig. 154).

Macrohilaceae Crous, IMA Fungus 6(1): 180 (2015)

Index Fungorum number: IF812795; Facesoffungi number: FoF06269; 1 species.

Endophytic or saprobic on leaves of Myrtaceae (dicotyledons). Sexual morph: Undetermined. Asexual morph: Coelomycetous. Conidiomata pycnidial, immersed, becoming erumpent, medium brown, globose to irregular. Conidiomata wall composed of pale brown-walled cells of textura globulosa. Conidiophores reduced to conidiogenous cells. Conidiogenous cells pale brown, cylindrical, percurrently proliferating at the apex with annellations. Conidia brown to dark brown, 1-septate, slightly constricted at septum, apex rounded, base flattened with a protruding hilum (adapted from Maharachchikumbura et al. 2016b).

Type genus - Macrohilum H.J. Swart

Notes - The type species of Macrohilum, M. eucalypti formed a distinct phylogenetic lineage in Diaporthales, thus Crous et al. (2015a) introduced Macrohilaceae to accommodate it. Subsequent publications by Maharachchikumbura et al. (2015, 2016b), Wijayawardene et al. (2016b, 2018a) and Senanayake et al. (2017a, 2018) accepted Macrohilaceae as a well-established family within Diaporthales and basal to Diaporthaceae. Currently, Macrohilaceae comprises only one genus.

\section{Ecological and economic significance of Macrohilaceae}

Swart (1988a) reported Macrohilum eucalypti from dead Eucalyptus leaves, while Crous et al. (2015a) isolated M. eucalypti from living leaves. However, neither Swart (1988a) nor Crous et al. (2015a) reported whether it caused leaf spots or any other symptoms. But, both of these publications did not carry out Koch's postulates to determine the pathogenicity of $M$. eucalypti. It would be appropriate to carry out more sampling from diseased Eucalyptus leaves and perform Koch's postulates to determine whether Macrohilum species are pathogens as have been done for Colletotrichum species on Artocarpus heterophyllus (Bhunjun et al. 2019).

\section{Genus included in Macrohilaceae}

Macrohilum H.J. Swart, Trans. Br. mycol. Soc. 90(2): 288 (1988)

Index Fungorum number: IF11123; 1 species with sequence data.

Type species - Macrohilum eucalypti H.J. Swart

Notes - The monotypic genus Macrohilum was introduced by Swart (1988a) with $M$. eucalypti, the type species. Macrohilum resembles coniothyrium-like taxa but is phylogenetically distinct as it has a protruding hilum (Crous et al. 2015a, Wijayawardene et al. 2016b). Furthermore, the four base pairs differences observed in their ITS sequences suggest that the New Zealand isolates may probably represent a novel Macrohilum species. 

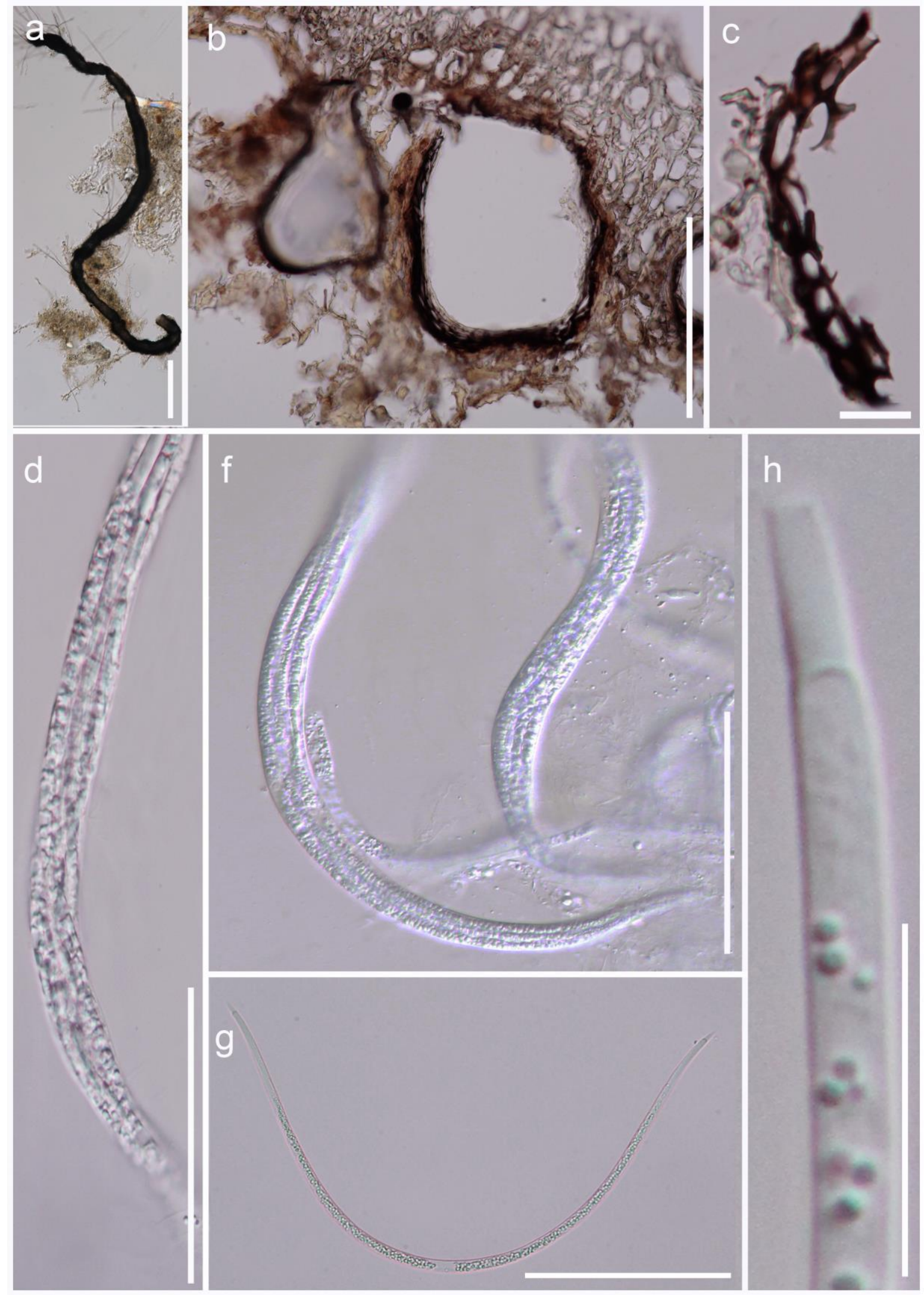

Figure 154 - Sammeyersia grandispora (Material examined - THAILAND, Phetchaburi Province, Hat Chao Samran, $47^{\circ} 72506^{\prime}$ E, $40^{\circ} 25038^{\prime}$ N, 0 m asl., on intertidal decayed wood of Rhizopora sp. at a mangrove stand, 28 August 2015, M. Dayarathne CHAM005, MFLU 16-1172). a Ascomata on wood surface. b Section through ascoma in wood. c Peridium composed of thick-walled angular cells. d, f Asci. g Filamentous ascospore. h Polar end chamber of ascospore. Scale bars: b, d, f, g = $100 \mu \mathrm{m}, \mathrm{a}=50 \mu \mathrm{m}, \mathrm{c}, \mathrm{h}=10 \mu \mathrm{m}$. 
Magnaporthaceae P.F. Cannon, Syst. Ascom. 13(1): 26 (1994)

Index Fungorum number: IF81963; Facesoffungi number: FoF01101; 135 species.

Pathogenic on monocotyledons or saprobic on plant material. Sexual morph: Ascomata perithecial, solitary or scattered, black, superficial or immersed in plant tissue, globose to subglobose, with cylindrical, black, periphysate neck. Peridium comprising a few to several layers of cells of textura epidermoidea. Paraphyses hyaline, septate, intermingled among asci. Asci 8spored, unitunicate, subcylindrical, short-pedicellate, with an apical ring. Ascospores biseriate, hyaline to olivaceous, filiform or fusoid, curved to sigmoid, with or without transverse septate ends, bluntly rounded, lacking sheaths. Asexual morph: Hyphomycetous, at times formed from sclerotia. Conidiophores unbranched or branched. Conidiogenous cells integrated, pigmented, phialidic with collarettes, or denticulate. Conidia variable in shape, hyaline to pale brown, straight or curved, with or without septa (adapted from Maharachchikumbura et al. 2016b).

Type genus - Nakataea Hara

Notes - Magnaporthaceae was introduced by Cannon (1994). The placement of taxa of Magnaporthaceae has long been problematic due to the lack of convincing morphological and inconclusive molecular data (Thongkantha et al. 2009). Based on DNA phylogenies, Magnaporthaceae was placed as a family in the Sordariomycetes (Kirk et al. 2001, Lumbsch \& Huhndorf 2007, Maharachchikumbura et al. 2016b). Thongkantha et al. (2009) established a new order, Magnaporthales to accommodate Magnaporthaceae based on characters and phylogenetic analysis. The family was originally described with six genera (Cannon 1994). Kirk et al. (2001) accepted nine genera while Kirk et al. (2008) accepted 13 genera. Luo et al. (2014) established Pseudophialophoda in the family. Maharachchikumbura et al. (2016b) provided an updated account with 22 genera and a key to species. A new genus, Bifusisporella was also introduced by Silva et al. (2009). In this study we accept 23 genera in Magnaporthaceae based on publications and taxonomy.

\section{Ecological and economic significance of Magnaporthaceae}

Most genera of Magnaporthaceae are necrotrophic and hemibiotrophic plant pathogens infecting root and shoots of Poaceae and Cyperaceae (Zhang et al. 2011, Luo \& Zhang 2013). Endophytic or apparently saprotrophic taxa on non-gramineous hosts were added by Tibpromma et al. (2018). Pyricularia oryzae (= Magnaporthe oryzae), a pathogen causing rice blast disease, was accommodated in Pyriculariaceae, while Magnaporthe salvinii which causes stem rot in rice was synonymized under Nakataea oryzae in Magnaporthaceae (Klaubauf et al. 2014). Other notable pathogens of Magnaporthaceae include Gaeumannomyces graminis, Magnaporthiopsis poae and M. rhizophila. Some members of Magnaporthaceae (e.g. Ophioceras and Ceratosphaeria) also occur in aquatic habitats, or on dead plant material, such as wood (Shearer et al. 1999, Réblová 2006, Huhndorf et al. 2008, Thongkantha et al. 2009).

\section{Genera included in Magnaporthaceae}

Bifusisporella R.M.F. Silva, R.J.V. Oliveira, J.D.P. Bezerra, Souza-Motta \& G.A. Silva, Mycol. Progr. 18: 852 (2019)

Index Fungorum number: IF828222; 1 species with sequence data.

Type species - Bifusisporella sorghi R.M.F. Silva, R.J.V. Oliveira, J.D.P. Bezerra, SouzaMotta \& G.A. Silva

Notes - Bifusisporella was introduced as an endophyte from healthy leaves of Sorghum bicolor in Brazil based on morphology and phylogenetic analysis (Silva et al. 2019). It forms phialides in culture consisting of curved, elongate and cylindrical-clavate conidiogenous cells, and both macroconidia and microconidia (Silva et al. 2019). The sexual morph of Bifusisporella has not been reported.

Budhanggurabania P. Wong, Khemmuk \& R.G. Shivas, Persoonia, Mol. Phyl. Evol. Fungi 34: $241(2015)$ 
Index Fungorum number: IF811696; 1 species with sequence data.

Type species - Budhanggurabania cynodonticola P. Wong, Khemmuk \& R.G. Shivas

Notes - Budhanggurabania cynodonticola was introduced from diseased roots and stolons of Cynodon in New South Wales, Queensland and the Northern Territory, Australia (Crous et al. 2015c, Wong et al. 2015). Sexual morphs of Budhanggurabania are characterized by ellipsoidal ascospores, 3-dark brown septa, brown in central cells, hyaline to pale brown in apical cells, with oblique striations in lateral view (Crous et al. 2015c). Hyphomycetous asexual morphs are characterized by hyaline conidiophores, phialidic conidiogenous cells, straight to slightly curved, and conidia that are hyaline, cylindrical or slightly curved, aseptate and aggregated in slimy heads (Crous et al. 2015c).
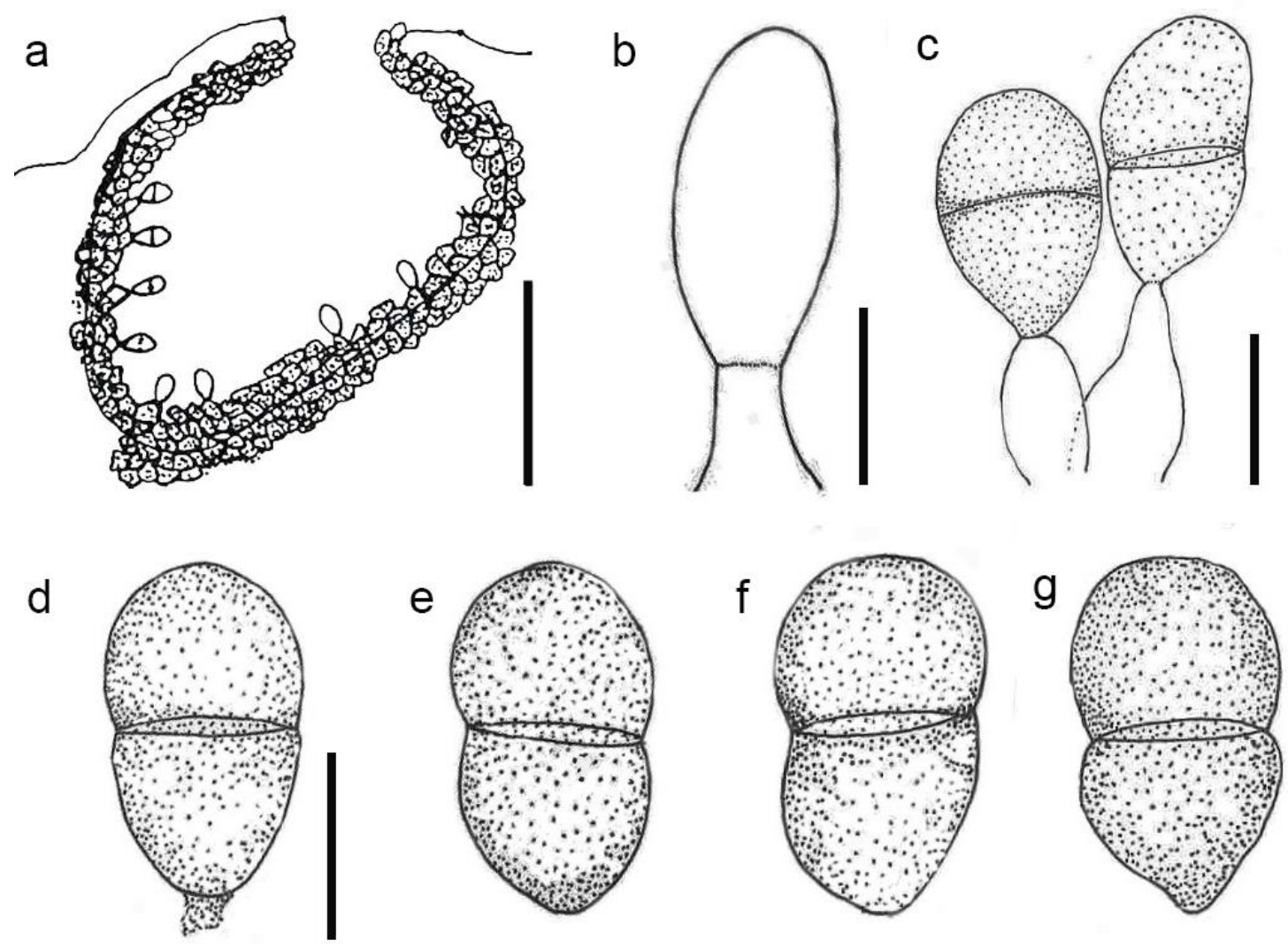

Figure 155 - Macrohilum eucalypti (a. DAR 59000, holotype; b-g. CPC 19421, epitype). a Conidioma. b Developing conidium attach to conidiogenous cell. c Developed conidia attach to conidiogenous cells. d-g Conidia. Scale bars: $a=100 \mu \mathrm{m}, b-\mathrm{f}=5 \mu \mathrm{m}$ ( $\mathrm{a}$ is extracted from Wijayawardene et al. 2016b, which was redrawn from Swart 1988a).

Buergenerula Syd., Annls mycol. 34(4/5): 392 (1936)

Index Fungorum number: IF679; 5 morphological species (Species Fungorum 2020), 1 species with sequence data.

Type species - Buergenerula biseptata (Rostr.) Syd.

Notes - Buergenerula biseptata (三 Metasphaeria biseptata) was found on Caricis vesicaria in Norway. The genus is characterized by cylindrical to subfusiform asci, and clavate, hyaline ascospores with 3-4-septa. The asexual morph has not been reported.

Bussabanomyces Klaubauf, M.-H. Lebrun \& Crous, Stud. Mycol. 79: 99 (2014)

Index Fungorum number: IF810195; 1 species with sequence data.

Type species - Bussabanomyces longisporus (Bussaban) Klaubauf, M.-H. Lebrun \& Crous

Notes - Bussabanomyces longispora (三Pyricularia longispora) was isolated as an endophyte from leaves of Amomum siamense. The genus is characterized by macronematous conidiophores, 
cylindrical and denticulate conidiogenous cells, obclavate hyaline to pale brown, 4(-5)-septate conidia. The sexual morph has not been reported (Klaubauf et al. 2014). Bussabanomyces is morphologically similar to Pyricularia, however, it is distinct in its unbranched conidiophores and terminal conidiogenous cells giving rise to 4(-5)-septate, pale brown conidia (Bussaban et al. 2003, Klaubauf et al. 2014).
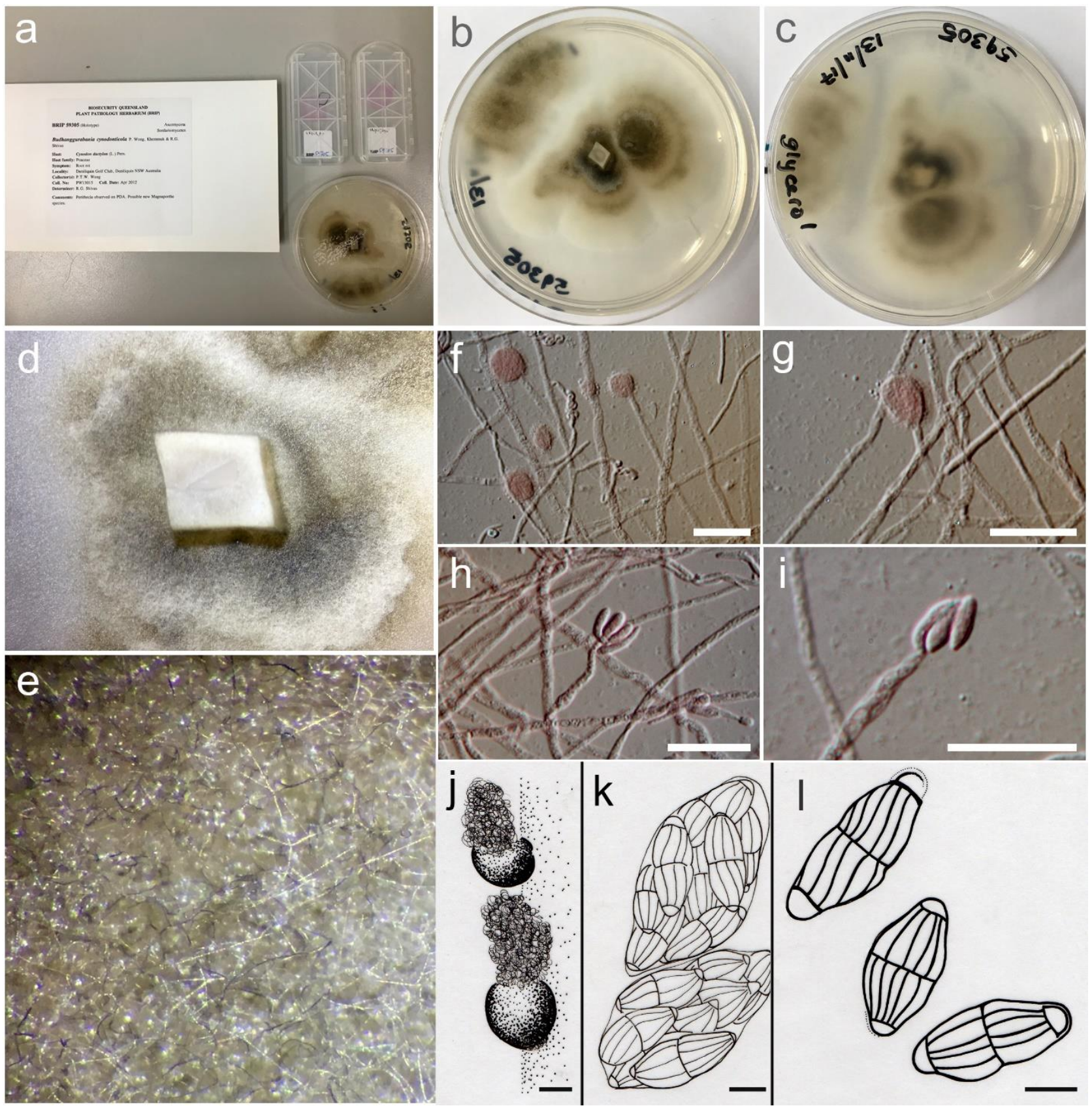

Figure 156 - Budhanggurabania cynodonticola (Material examined - AUSTRALIA, New South Wales, from rotted roots of Cynodon dactylon, April 2012, Wong P.T.W., BRIP 59305 a, holotype) a Herbarium packet. b, c Colonies on PDA (b-from above, c-from below). d, e Colonies and mycelium on PDA. f-i Conidia with slimy heads (from slides). $\mathrm{j}$ Ascomata. $\mathrm{k}$ Asci with ascospores. 1 Ascospores. Scale bars: $\mathrm{f}-\mathrm{i}=20 \mu \mathrm{m}, \mathrm{j}=100 \mu \mathrm{m}, \mathrm{k}, 1=10 \mu \mathrm{m}$.

Ceratosphaerella Huhndorf, Greif, Mugambi \& A.N. Mill., Mycologia 100(6): 941 (2008) Index Fungorum number: IF508749; 2 species with sequence data. Mill. Type species - Ceratosphaerella castillensis (C.L. Sm.) Huhndorf, Greif, Mugambi \& A.N. 


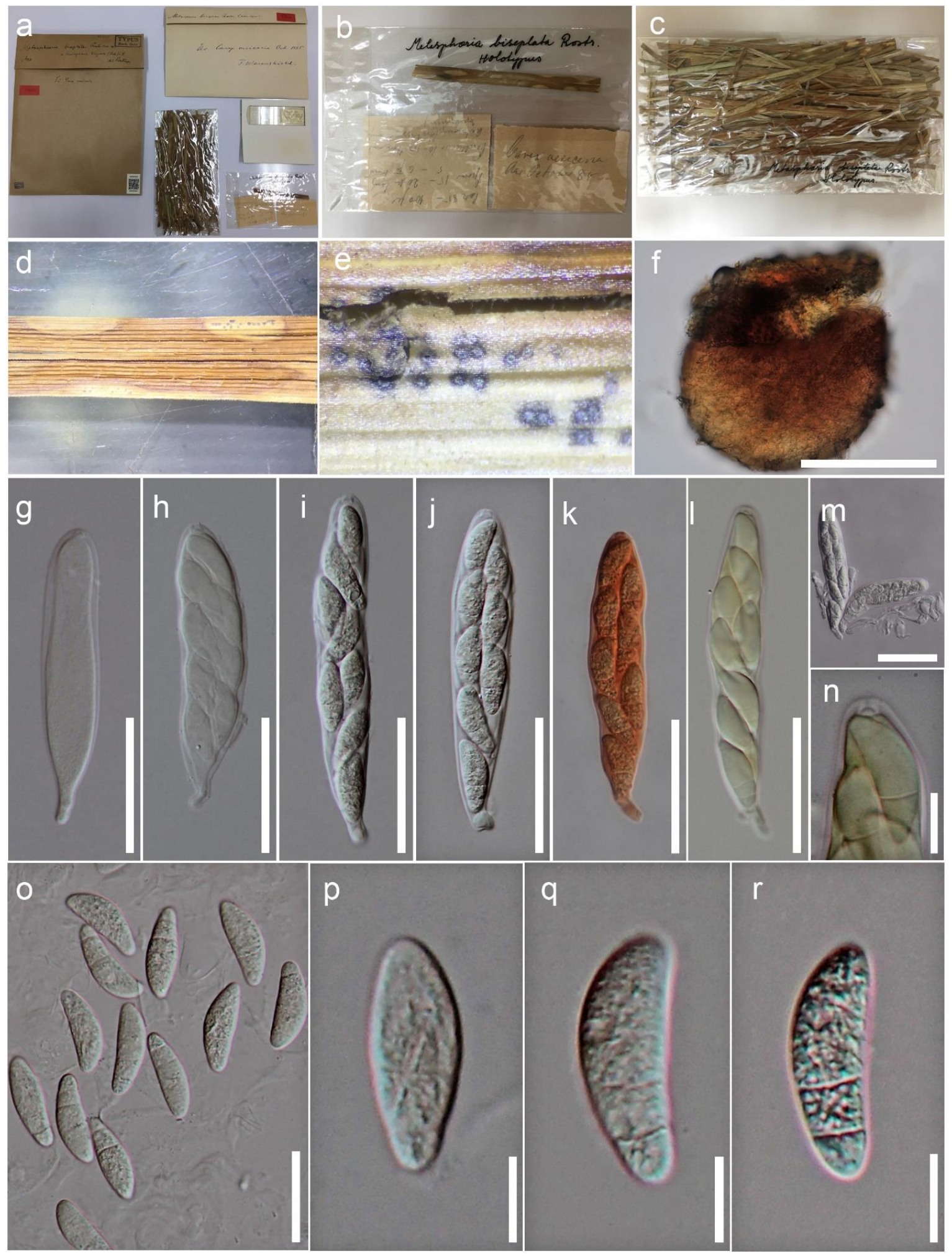

Figure 157 - Buergenerula biseptata (Material examined - NORWAY, Carex vesicaria, 1885, Werenskiold F., O-F72662 (holotype of Metasphaeria biseptata) Sydow, H. 1936. Mycotheca Germanica Fasc. LVII-LX no. 2801-3000). a-c Herbarium packet. d, e Fruiting bodies on substrate. f Ascomata. g-1 Asci. $\mathrm{m}$ Asci amoung with paraphyses. $\mathrm{n}$ Apical ring. o-r Ascospores. Scale bars: $\mathrm{f}$ $=200 \mu \mathrm{m}, \mathrm{g}-\mathrm{m}=50 \mu \mathrm{m}, \mathrm{n}=5 \mu \mathrm{m}, \mathrm{o}=30 \mu \mathrm{m}, \mathrm{p}-\mathrm{r}=10 \mu \mathrm{m}$.

Notes - Huhndorf et al. (2008) introduced Ceratosphaerella castillensis (三 Ceratosphaeria castillensis) from bark of Castillo viejo and described a new species, C. rhizomorpha from decaying wood in Kenya. The sexual morph of genus is characterized by clavate asci, fusiform and 
hyaline ascospores with 3-septa. The asexual morph has synnemata and ellipsoid to cylindrical conidia, that are pale to darker brown, and 1-3-septate.

Clasterosporium Schwein., Trans. Am. phil. Soc., New Series 4(2): 300 (1832)

Index Fungorum number: IF7685; 41 morphological species (Species Fungorum 2020), 7 species with sequence data.

Type species - Clasterosporium caricinum Schwein.

Notes -The asexual morph of Clasterosporium is characterized by dark hypha, brownish conidiophores, cylindrical or spindle-shaped, 3(+)-celled conidia. The sexual morph of Clasterosporium has reported based on a two species in Clasterosphaeria, and later Clasterosphaeria was synonymised under Clasterosporium (Zhang et al. 2016). The genus sexual characters is superficial, globose, dark brown to black, ostiolate ascomata, later collapsing, 8spored asci and hyaline to subhyaline, fusiform, 3-septate ascospores (Sivanesan 1984, Hosagoudar 2004). However, these genera have to be recollected and sequenced to confirm their placement.

Clavatisporella K.D. Hyde, Mycotaxon 55: 276 (1995)

Index Fungorum number: IF27472; 1 morphological species.

Type species - Clavatisporella musicola K.D. Hyde, Mycotaxon 55: 276 (1995)

Notes - The monophyletic genus, Clavatisporella was introduced for a saprobe on senescent leaves of Musa in Indonesia. The genus is characterized by immersed, globose to subglobose ascomata, with broad cylindrical or clavate asci, with a subapical, J-, refractive ring and hyaline ascospores that are fusiform to clavate, 1-2 septate, with a swollen base, and a mucilaginous padlike appendages at an apical (Hyde 1995e).

Falciphora J. Luo \& N. Zhang, Mycologia 107(3): 643 (2015)

Index Fungorum number: IF810801; 1 species with sequence data.

Type species - Falciphora oryzae Z.L. Yuan, Chu L. Zhang \& F.C. Lin

Notes - This monotypic genus was established based on F. oryzae (三 Harpophora oryzae) isolated from root tissues of Oryza granulata seedlings in Yunnan (Luo et al. 2015). The genus has densely branched conidiophores, phialidic and straight conidiogenous cells and sickle-shaped and strongly curved aseptate, hyaline conidia (Luo et al. 2015).

Falciphoriella Hern.-Restr. \& Crous, Stud. Mycol. 83: 9 (2016)

Index Fungorum number: IF816902; 1 species with sequence data.

Type species - Falciphoriella solaniterrestris Hern.-Restr. \& Crous

Notes - Falciphoriella solaniterrestris was isolated from soil in a potato field in the Netherlands. The genus is characterized by phialidic, subcylindrical to elongated and fusoidellipsoid conidiogenous cells and fusiform to obovoid slightly curved conidia. The sexual morph has not been reported.

Gaeumannomycella Hern.-Restr. \& Crous, Stud. Mycol. 83: 9 (2016)

Index Fungorum number: IF816904; 2 species with sequence data.

Type species - Gaeumannomycella caricis Hern.-Restr. \& Crous

Notes - Gaeumannomycella caricis was found on Carex rostrata in the UK. The genus produces phialidic conidiogenous cells that are straight or curved, ampulliform to lageniform or conical shaped, with lunate or cylindrical and hyaline conidia, and hyaline hyphopodia that become brown when mature (Hernández-Restrepo et al. 2016b). Crous et al. (2019a) introduced a second species, G. caricicola, found on a dead leaf of Carex remota in Germany.

Gaeumannomyces von Arx \& D.L. Olivier, Trans. Br. mycol. Soc. 35: 32 (1952)

Index Fungorum number: IF2026; 20 morphological species (Species Fungorum 2020), 12 species with sequence data. 
Type species - Gaeumannomyces graminis (Sacc.) von Arx \& D.L. Olivier

Notes -The sexual morph of this genus is characterized by globose or pyriform and immersed ascomata with a conical to cylindrical neck, and fusiform, hyaline, multiseptate ascospores. Asexual morphs are characterised by phialidic conidiogenous cells with refractive collarettes and lunate or phialophora-like conidia.

Herbampulla Scheuer \& Nograsek, Mycotaxon 47: 419 (1993)

Index Fungorum number: IF22427; 1 morphological species.

Type species - Herbampulla crassirostris Scheuer \& Nograsek

Notes -Herbampulla crassirostris was found on dead and rotten leaves of Carex firma in Austria. The genus produces cylindrical asci and fusiform 5-septate and yellowish brown ascospores. The asexual morph has not been reported.

Kohlmeyeriopsis Klaubauf, M.-H. Lebrun \& Crous, Stud. Mycol. 79: 101 (2014)

Index Fungorum number: IF810197; 1 species with sequence data.

Type species - Kohlmeyeriopsis medullaris (Kohlm., Volkm.-Kohlm. \& O.E. Erikss.) Klaubauf, M.-H. Lebrun \& Crous

Notes - Kohlmeyeriopsis medullaris (三 Gaeumannomyces medullaris) was reported on senescent culms of Juncus roemerianus in North Carolina. The genus has trichocladium-like asexual morphs (Klaubauf et al. 2014). The sexual morph has ellipsoid ascomata, fusoid to cylindrical asci with a large apical ring staining in Meltzer's reagent, and filamentous, hyaline ascospores, which produce appressoria when germinating (Klaubauf et al. 2014).

Magnaporthiopsis J. Luo \& N. Zhang, Mycologia 105: 1021 (2013)

Index Fungorum number: IF802972; 7 species with sequence data.

Type species - Magnaporthiopsis poae (Landsch. \& N. Jacks.) J. Luo \& N. Zhang

Notes - Magnaporthiopsis was introduced as a phialophora-like asexual genus. It was identified to Magnaporthaceae based on phylogenetic analyses of multi-genes (SSU, ITS, LSU, MCM7, rpb1, tef1) (Luo \& Zhuang 2012). The sexual morph characters are globose ascomata with a cylindrical neck and black, clavate asci with a refractive ring and fusiform to fusoid, septate, hyaline or yellow brown ascospores (Luo \& Zhuang 2012).

Muraeriata Huhndorf, Greif, Mugambi \& A.N. Mill., Mycologia 100: 948 (2008)

Index Fungorum number: IF508755; 2 species with sequence data.

Type species - Muraeriata collapsa Huhndorf, Greif, Mugambi \& A.N. Mill.

Notes - Muraeriata was introduced to accommodate two species found on wood, M. africana (from Kenya) and M. collapsa (from Costa Rica). The genus is characterised by the vacuolate middle ascomal wall layer and by phylogenetic analysis of LSU and SSU (Huhndorf et al. 2008).

Mycoleptodiscus Ostaz., Mycologia 59(6): 970 (1968)

Index Fungorum number: IF9029; 19 morphological species (Species Fungorum 2020), 5 species with sequence data.

Type species - Mycoleptodiscus terrestris (Gerd.) Ostaz.

Notes - The genus has superficial, sporodochial conidiomata, one cell thick, mostly thickwalled, dark brown conidiogenous cells with a prominent circular aperture in the upper wall, hyaline conidia with cylindrical to fusiform shaped, and 0-2-septa, sometimes bearing an apical and/or basal cellular unbranched filiform appendage (Katsuhiko 1996). Mycoleptodiscus endophyticus was described as an endophyte in leaves of Freycinetia sp. (Tibpromma et al. 2018).

Nakataea Hara, Diseases Rice Plant, Edn 2: 185 (1939)

Index Fungorum number: IF565608; 6 morphological species (Species Fungorum 2020), 1 species with sequence data. 
Type species - Nakataea oryzae (Catt.) J. Luo \& N. Zhang

Notes - Nakataea causes stem rot of rice (Ou 1985). The genus was introduced based on $N$. oryzae (= N. sigmoidea) from Oryza sativa in Italy. Krause \& Webster (1972) showed Nakataea and Magnaporthe are congeneric with their type species, $N$. oryzae and $M$. salvinii belonging to the same species. Therefore, Luo \& Zhang (2013) synonymized M. oryzae under $N$. oryzae based on the name Nakataea (1939), which is older than Magnaporthe (1972) This resulted in Nakataea becoming the correct name for the type of the family (Murata et al. 2014, Klaubauf et al. 2014, Luo et al. 2105, Maharachchikumbura et al. 2015b, 2016b). Khemmuk et al. (2016) confirmed the two genera as congeneric, based on phylogenetic analysis of multi-genes (ITS, LSU, tefl, rpb1). Only Nakataea oryzae has molecular data.

Neogaeumannomyces D.Q. Dai \& K.D. Hyde, Fungal Divers. 72: 34 (2015)

Index Fungorum number: IF550936; 1 species with sequence data.

Type species - Neogaeumannomyces bambusicola D.Q. Dai \& K.D. Hyde

Notes - The genus is monotypic with Neogaeumannomyces bambusicola found dead culm of bamboo in Thailand (Liu et al. 2015). The genus is similar to Gaeumannomyces in perithecial ascomata with long necks, cylindrical asci and filiform ascospores. However, Neogaeumannomyces lacks hyphopodia whereas Gaeumannomyces species produce hyphopodiate mycelia (Walker 1972, Liu et al. 2015).

Omnidemptus P.F. Cannon \& Alcorn, Mycotaxon 51: 483 (1994)

Index Fungorum number: IF27275; 3 morphological species (Species Fungorum 2020), 2 species with sequence data.

Type species - Omnidemptus affinis P.F. Cannon \& Alcorn

Notes - Omnidemptus affinis was found on leaves of Panicum effusum in Queensland (Cannon \& Alcorn 1994, Thongkantha et al. 2009). The sexual morph is characterized by perithecia ascomata, cylindrical to clavate, short pedicellate asci with an obtuse apex and an apical pore that stains dark blue with Melzer's reagent and fusiform, 1-3-septate, hyaline ascospores (Cannon \& Alcorn 1994). The asexual morph is sporodochium-like, with cylindrical, clavate or ellipsoid conidiogenous cells, and falcate, 2-septate conidia, the base of conidia sometimes with an abrupt change in contour to short pedicel-like extension (Hernández-Restrepo et al. 2019).

Pseudophialophora J. Luo \& N. Zhang, Mycologia 106(3): 581 (2014)

Index Fungorum number: IF807080; 9 species with sequence data.

Type species - Pseudophialophora eragrostis J. Luo \& N. Zhang

Notes -Luo et al. (2014) confirmed the placement of Pseudophialophora in Magnaporthaceae by phylogenetic analysis. The type species was isolated from roots of Eragrostis in New Jersey. The genus is phialophora-like, producing dark septate hyphae, simple and short conidiophores, typical phialides and unicellular conidia (Luo et al. 2014). (Crous et al. 2017) provided a phylogenetic update to nine species..

Pyriculariopsis M.B. Ellis, Dematiaceous Hyphomycetes (Kew): 206 (1971)

Index Fungorum number: IF9671; 9 morphological species (Soares et al. 2011, Species Fungorum 2020), 2 species with sequence data.

Type species - Pyriculariopsis parasitica (Sacc. \& Berl.) M.B. Ellis

Notes - Pyriculariopsis parasitica (= Pyricularia musae) was recognized as differing from Pyricularia by the absence of a septum to separate its denticles from the conidiophore (Ellis 1971). In a molecular study, Bussaban et al. (2005) found Pyriculariopsis was outside a clade of Magnaporthaceae. However, they concluded that Pyriculariopsis should be maintained based mainly in its straight or curved, obclavate and rostrate conidia. Soares et al. (2011) suggested an additional feature to delimit Pyriculariopsis, which was consistently observed or illustrated for most species, as pointed out by Whitton et al. (2001). Pyriculariopsis contains two distinct 
ecological groups, one is composed of saprobes occurring on foliar and stem debris and the other includes plant pathogens on monocot hosts in Zingiberales (Soares et al. 2011, Uchida \& Kadooka 1994).

Slopeiomyces Klaubauf, M.-H. Lebrun \& Crous, Stud. Mycol. 79: 102 (2014)

Index Fungorum number: IF810199; 1 species with sequence data.

Type species - Slopeiomyces cylindrosporus (D. Hornby, Slope, Gutter. \& Sivan.) Klaubauf, M.-H. Lebrun \& Crous

Notes - Klaubauf et al. (2014) described the genus based on morphology of its hyphomycetous asexual morph and phylogenetic analysis placement in Magnaporthaceae.

Malaysiascaceae Tibpromma \& K.D. Hyde, Fungal Divers. 93: 88 (2018)

Index Fungorum number: IF554753; Facesoffungi number: FoF04611; 1 species.

Saprobic on dead or decaying leaves of plants in terrestrial habitats. Sexual morph: Ascomata perithecial, immersed at the base, obpyriform, dark brown, with setae. Peridium composed of 3-5 layers of pale brown cells of textura prismatica. Paraphyses branched, septate. Asci 8-spored, unitunicate, cylindrical-clavate, short pedicellate, apex truncate with shallow ring. Ascospores biseriate, hyaline, ellipsoid to oblong, apiculate at ends with minute mucoid cap, smooth-walled, guttulate, becoming 1-septate and pale brown after discharge. Asexual morph: Conidiophores subcylindrical, macronematous, unbranched, erect, flexuous, thick-walled, rounded at apex, guttulate, multi-septate, pale brown to bark brown, smooth-walled. Conidiogenous cells enteroblastic, phialidic, subcylindrical, subhyaline, terminal, integrated. Conidia solitary, cylindrical-ellipsoid to clavate, rounded at apex, aseptate, hyaline, smooth-walled, guttulate, dry in mass (adapted from Tibpromma et al. 2018).

Type genus - Malaysiasca Crous \& M.J. Wingf.

Notes - Malaysiascaceae was introduced by Tibpromma et al. (2018) to accommodate Malaysiasca which belong in Glomerellales. The family is similar to Australiascaceae, but the latter differs in having phialidic conidiogenesis with hyaline $0(-3)$-septate conidia aggregated in slime or chains (Réblová et al. 2011).

\section{Ecological and economic significance of Malaysiascaceae}

Malaysiascaceae species are saprobic on dead or decaying leaves or wood in terrestrial habitats (Crous et al. 2016b, Tibpromma et al. 2018) involved in nutrient cycling.

\section{Genus included in Malaysiascaceae}

Malaysiasca Crous \& M.J. Wingf., Persoonia 36: 373 (2016)

Index Fungorum number: IF817044; 1 species with sequence data.

Type species - Malaysiasca phaii Crous \& M.J. Wingf.

Notes - Malaysiasca was established by Crous et al. (2016b) to accommodate Malaysiasca phaii, based on LSU gene analysis, and is related to members of Glomerellales. Tibpromma et al. (2018) found that Malaysiasca phaii belongs in Glomerellales forming a well-supported clade with other families and introduced a new family as Malaysiascaceae. This family is monotypic comprising only Malaysiasca phaii, which was found on leaves of Phaius reflexipetalus (Crous et al. 2016b) and Freycinetia javanica (Tibpromma et al. 2018).

Melanconidaceae G. Winter, Rabenh. Krypt.-Fl., Edn 2 (Leipzig) 1.2: 764 (1886)

Index Fungorum number: IF80988; Facesoffungi number: FoF01395; 36 species.

Saprobic or pathogenic on plants and wood, in terrestrial and aquatic habitats. Sexual morph: Pseudostromata well-developed, obvious, erumpent. Ectostromatic disc surrounded by bark or not, yellowish-white. Ostiolar canal opening around the disc. Ascomata arranged as circles around the ectostromatic disc, oblique or horizontal, globose to subglobose, coriaceous and black with long, periphysate and lateral ostiolar canals. Peridium with outer, thick-walled, brown cells of textura 
globosa to textura angularis and inner, thick-walled, flat, hyaline cells of textura angularis. Paraphyses wide, hypha-like, deliquescent at maturity. Asci 8-spored, unitunicate, oblong to fusiform, short pedicellate, with distinct, J-, apical ring. Ascospores overlapping uniseriate to biseriate, hyaline, ellipsoid, 1-septate. Asexual morph: Coelomycetous. melanconium-like. Conidiomata acervular, scattered, solitary, superficial, black, coriaceous. Conidiophores branched at the base, septate, Conidiogenous cells annellidic, cylindrical. Conidia hyaline to brown, ellipsoid or subglobose, smooth-walled, thick-walled (adapted from Senanayake et al. 2017a).

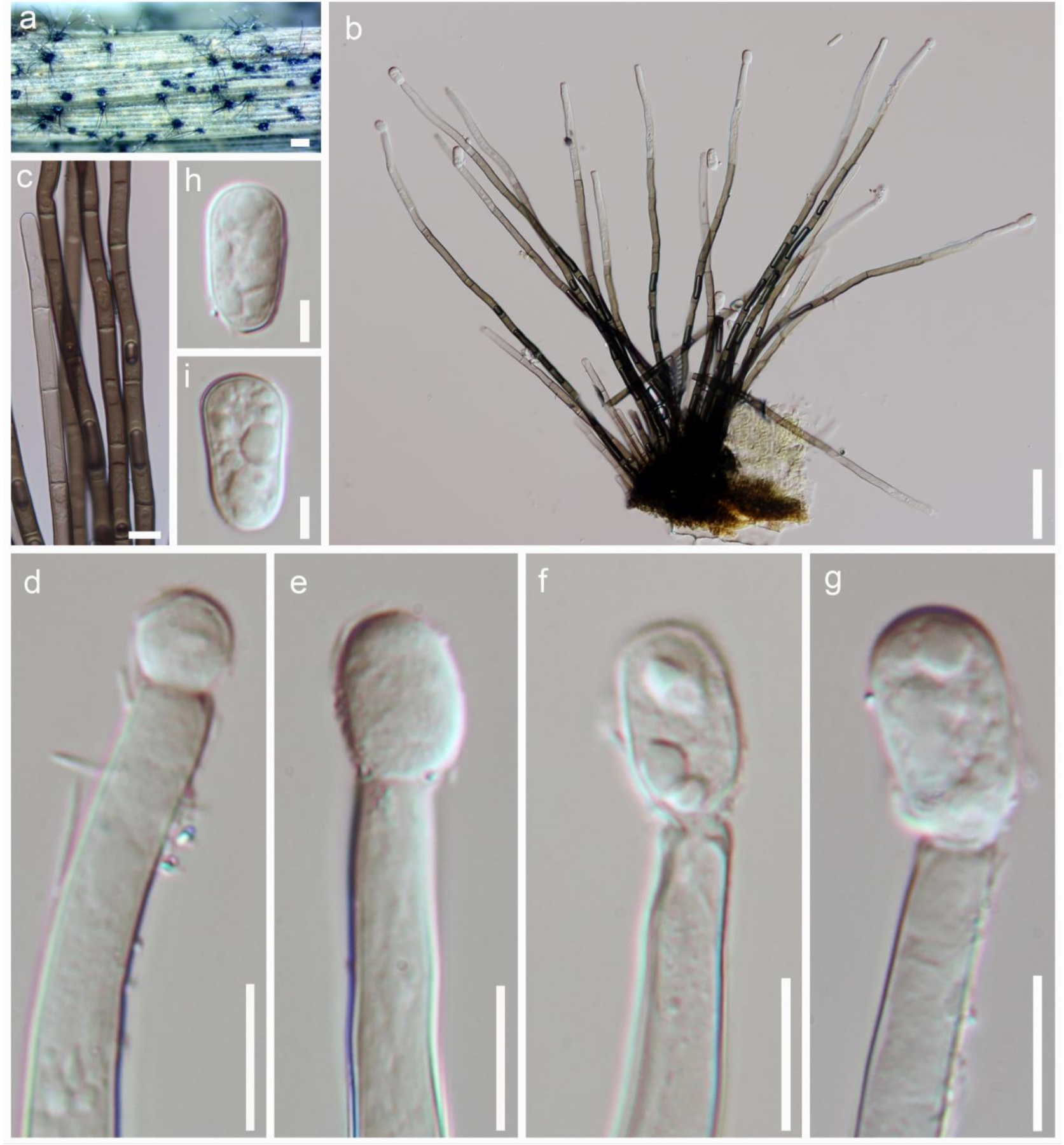

Figure 158 - Malaysiasca phaii (Material examined - THAILAND, Krabi Province, Khlong Thom District, on dead leaves of Freycinetia javanica Blume., 15 December 2015, S. Tibpromma KB032, MFLU 16-1910). a Colony on natural substrate. b Conidiogenous cells with conidiophores and conidia. c Conidiophores. d-g Conidiogenous cells with conidia. h, i Conidia. Scale bars: $a=200$ $\mu \mathrm{m}, \mathrm{b}=100 \mu \mathrm{m}, \mathrm{c}-\mathrm{g}=10 \mu \mathrm{m}, \mathrm{h}, \mathrm{i}=5 \mu \mathrm{m}$. 
Type genus - Melanconis Tul. \& C. Tul.

Notes - Melanconidaceae includes species with yellowish-white ectostromatic discs, surrounding the ascomata which are arranged in a circle. Most of the family are saprobes and pathogens which cause diseases on economically important trees. Maharachchikumbura et al. (2016b) included 24 genera in the family. Sequence data is available for Dicarpella, Melanconiella, Melanconis, Melanconium, and Prosthecium. Voglmayr \& Jaklitsch (2014) synonymized Prosthecium under Stilbospora and included the genus in Stilbosporaceae. Crous et al. (2012d) included more than half of known wuestneia-like species in Harknessia in Harknessiaceae. Morphological and molecular evidence showed that the family was monogeneric represented by Melanconis and its asexual morph Melanconium (Castlebury et al. 2002; Rossman et al. 2007). Melanconium was synonymized under Melanconis by Rossman et al. (2015). Phylogenetic analysis of Senanayake et al. (2017a) showed that Dicarpella and Melanconiella clustered away from the family. As a result, Senanayake et al. (2017a) excluded all the genera listed in Maharachchikumbura et al. (2016b) from Melanconidaceae, except Melanconis.
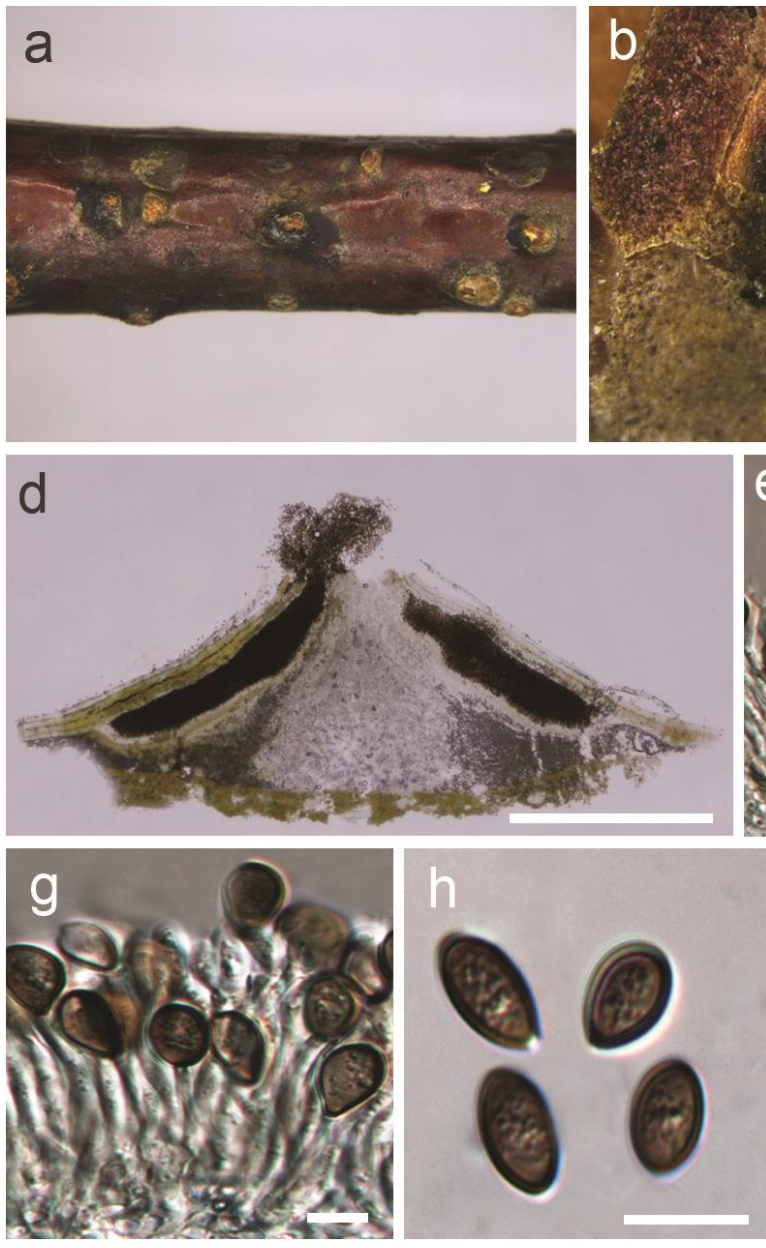
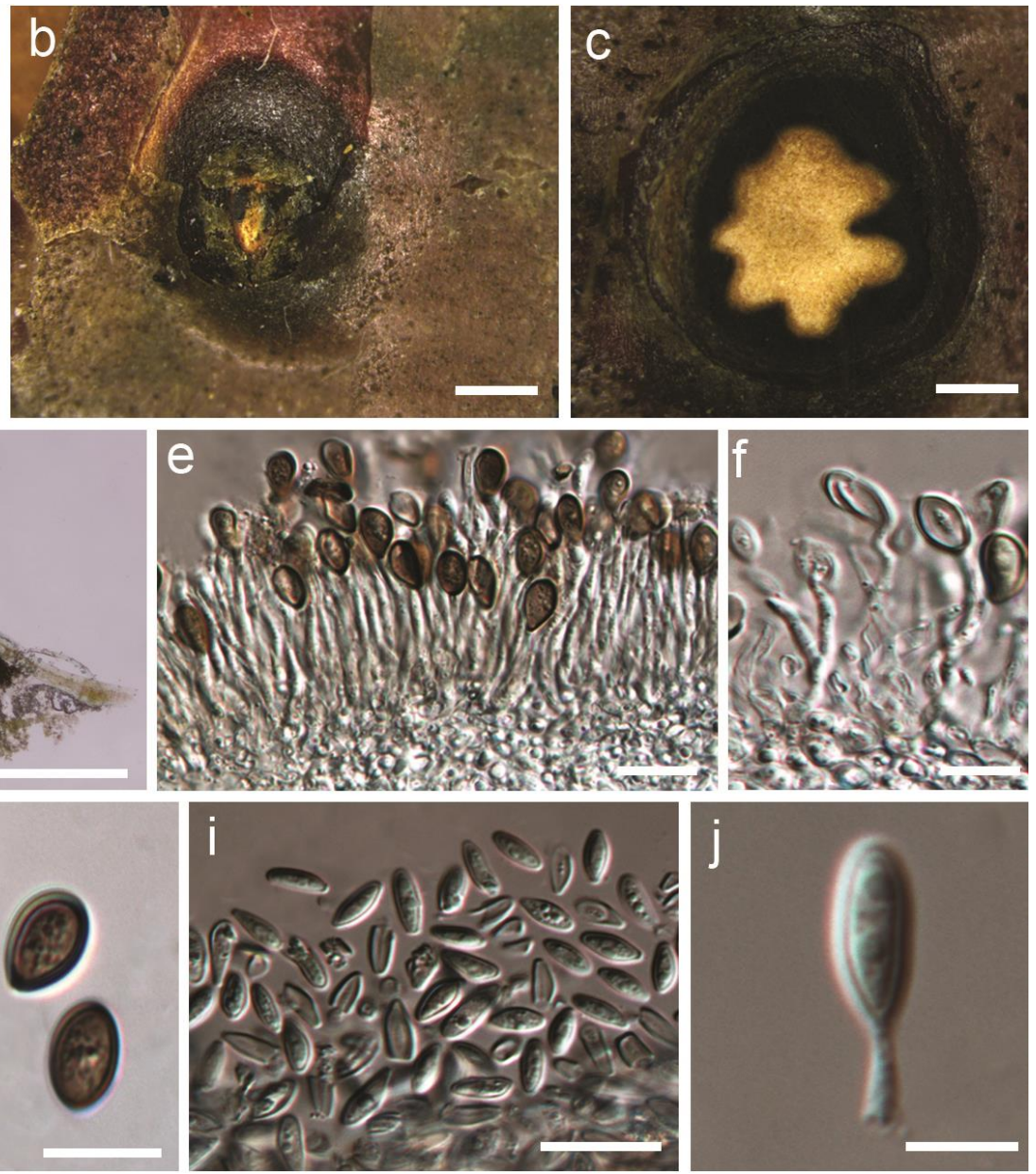

Figure 159 - Melanconis betulae (Material examined - CHINA, Gansu Province: Gannan Tibetan Autonomous Prefecture, Zhouqu County, Qiban Forestry Centre, 3356'35.36"N, 104 07'13.03"E, $3221 \mathrm{~m}$ asl, on twigs and branches of Betula albosinensis Burkill, 20 August 2014, Y.M. Liang, BJFC-S1319, holotype). a-c Appearance on host. d Sections through conidiomata. f Conidiophores and alpha conidia. g, h Alpha conidia. i, j Beta conidia. Scale bars: $b-e=500 \mu \mathrm{m}, \mathrm{f}-\mathrm{h}=10 \mu \mathrm{m}$.

\section{Ecological and economic significance of Melanconidaceae}

Most sexual and asexual morphs of Melanconis cause cankers and shoot blights (Fan et al. 2016, Senanayake et al. 2018) with various disease symptoms (Fan et al. 2016). Melanconis stilbostoma causes birch dieback (Fan et al. 2016) causing branches in the crown to die off. Some 
taxa produce antifungal compounds. Thermozymocidin (myriocin) and flavovirin were isolated from Melanconis flavovirens (Sailer et al. 1989) and have shown antifungal activity against yeasts and a few filamentous fungi.

\section{Genus included in Melanconidaceae}

Melanconis Tul. \& C. Tul., Select. fung. carpol. (Paris) 2: 115 (1863)

Index Fungorum number: IF3060; 36 morphological species (Species Fungorum 2020), 8 species with sequence data.

Type species - Melanconis stilbostoma (Fr.) Tul. \& C. Tul.

Notes - The genus comprises saprobic, pathogenic (Senanayake et al. 2018) and endophytic (Barengo et al. 2000) species associated with the hardwood of plants in Betulaceae (Fan et al. 2016). The genus is characterised by ascomata with 8-spored asci, ellipsoid, 1-septate ascospores, and acervular conidiomata with hyaline to brown, ellipsoid or subglobose conidia. Most of the species are known in North America and Europe (Senanayake et al. 2017a). In this entry we illustrate Melanconis betulae.

Melanconiellaceae Senan., Maharachch. \& K.D. Hyde, Stud. Mycol. 86: 275 (2017)

Index Fungorum number: IF821561; Facesoffungi number: FoF03495; 41 species.

Phytopathogenic or saprobic. Sexual morph: Stromata present or absent. If present; Pseudostromata inconspicuous, erumpent, pale or dark coloured ectostromatic disc or pulvillus causing a more or less pustulate bark surface. Ectostromatic disc convex, flat to concave which can be surrounded by bark or not. Central column beneath the disc is more or less conical, having hyaline or pigmented hyphae. The hyphae are mixed with a pigmented powdery amorphous substance in cream, yellow, olive, brownish or grey. Ascomata perithecial, epiphyllous without stromatic tissues and immersed in host substrate, inconspicuous or appearing as rounded bumps beneath the bark that surrounds the ectostromatic disc, oblique or horizontal, scattered or often arranged in a circle around the central column, with long lateral ostioles that converge at the margin of the central column. Ostioles emerging in various positions in the ectostromatic disc. Peridium bears dark, thick-walled cells of textura angularis. Paraphyses broad, hyaline or lacking. Asci 2-8spored, unitunicate, cylindrical-clavate, oblong or fusoid, with a distinct, J-, apical ring, tapering below to a short, narrow pedicel. Ascospores 1-2- overlapping seriate, hyaline, yellowish or brown, oblong, fusoid or ellipsoid, 0-1-septate, septa central or slightly eccentric, slightly constricted or not, smooth-walled, with or without short, blunt appendages and sometimes with a narrow gelatinous sheath. Asexual morph: Coelomycetous. Conidiomata acervular or pycnidia, punctiform, subcuticular, immersed or erumpent, sometimes with a central, well-developed, pale brown, pseudoparenchymatous layer becoming thinner or absent at the margin of the conidiomata, multiloculate, sometimes papillate, sometimes with pale coloured, ectostromatic disc and central column or with radiate scutella. Scutella convex, membranous, brown, somewhat translucent, with a central hyaline or pale disc, giving rise to radiating hyphae, thick-walled cells radiating from a central point, rounded to pointed at the tips. Conidiophores often reduced to conidiogenous cells or branched, sometimes septate only at the base, few-celled, smooth, hyaline to pale brown, sometimes short, forming under the developing scutellum. Pseudoparaphyses filiform. Conidiogenous cells annellidic or phialidic. Conidia initially hyaline becoming brown, ellipsoid, obovoid, subglobose, ovoid or oblong, thick-walled, smooth to finely verrucose, with or without distinct hyaline sheath, each with a truncate base and obtuse to bluntly pointed apex, sometimes somewhat granular, sometimes with inconspicuous to conspicuous basal hilum, with or without distinct hyaline sheath or frill (adapted from Senanayake et al. 2017a).

Type genus - Melanconiella Sacc.

Notes - Senanayake et al. (2017a) revised the family to accommodate the genera Dicarpella (previously included in Melanconidaceae), Greeneria, Melanconiella, and Sphaeronaemella fragariae (was in Microascales incertae sedis), Tubakia (previously Diaporthales incertae sedis), 
and a novel genus Microascospora. These taxa formed a distinct clade with moderate support in the phylogenetic analysis and a new family was proposed.

Dicarpella was introduced based on D. bina and the asexual morph of this genus was reported as Tubakia (Belisario 1991). Tubakia is typified by T. japonica. It was found that the type species of these two genera are not linked. However, molecular data linked Tubakia and Diplacella coupled with a few Diplacella species having Tubakia asexual morphs (Sogonov et al. 2008). Tubakia is more commonly encountered than Dicarpella and is also a more widely used name than Dicarpella. Senanayake et al. (2017a) showed a plausible relationship of Dicarpella dryina and Tubakia seoraksanensis as a holomorphic genus. Senanayake et al. (2017a) mentioned without analysing sequence data of the type species that it is hard to confirm that Dicarpella and Tubakia are congeneric. Therefore, Senanayake et al. (2017a) maintained Dicarpella and Tubakia as two separate genera until further sequence data becomes available. Senanayake et al. (2017a) introduced a new genus Microascospora to this family with $M$. rubi as the type species. Sphaeronaemella fragariae did not cluster in this analysis with other Sphaeronaemella species and clustered with Microascospora rubi. Therefore, Sphaeronaemella fragariae was excluded from Sphaeronaemella and placed in Microascospora as M. fragariae. Senanayake et al. (2017a) therefore included Dicarpella, Greeneria, Melanconiella, Microascospora and Tubakia in Melanconiellaceae. Braun et al. (2018) revised Tubakia using morphological and molecular data. They sequenced the type species of Tubakia (T. dryina) and introduced a new family Tubakiaceae to accommodate Tubakia. Braun et al. (2018) considered Tubakia suttoniana and Dicarpella dryina as synonyms..

Senanayake et al. (2018) included Massariovalsa in Melanconiellaceae based on morphology, but Massariovalsa was not included in the phylogenetic analysis due to the lack of molecular data. Senanayake et al. (2018) therefore placed Greeneria, Massariovalsa, Melanconiella and Microascospora in Melanconiellaceae. In the phylogenetic analysis of Fan et al. (2018), Melanconiella cornuta formed a distinct clade basal to Melanconiella in the family. Based on morphology and various host affinities (Cornus and Juglans vs. Betulaceae), M. cornuta was excluded from Melanconiella by Fan et al. (2018) and placed in a new genus Sheathospora. Phookamsak et al. (2019) included Septomelanconiella as a new genus in Melanconiellaceae based on Septomelanconiella thailandica. Therefore, Melanconiellaceae presently accommodates the genera Dicarpella, Greeneria, Massariovalsa, Melanconiella, Microascospora, Septomelanconiella and Sheathospora.

\section{Ecological and economic significance of Melanconiellaceae}

Some species of the family are phytopathogens. Greeneria uvicola is a common pathogen responsible for various diseases in grapes, such as grapevine dead-arm dieback, grapevine trunk disease (Navarrete et al. 2009) and bitter-rot of grapes (Farr et al. 2001). The taxon occurs on stem lesions, mummified berries, leaves, and tendrils. Greeneria uvicola infects several species of Vitis (grapes), including $V$. aestivalis, V. labrusca, V. rotundifolia, and V. vinifera. (Navarrete et al. 2009). Melanconiella species are mainly restricted to overwintered plants and are able to cause mild cankers on the hosts (Voglmayr et al. 2012).

\section{Genera included in Melanconiellaceae}

Dicarpella Syd. \& P. Syd., Annls mycol. 18(4/6): 181 (1921)

Index Fungorum number: IF1512; 5 morphological species (Species Fungorum 2020).

Type species - Dicarpella bina (Harkn.) Syd. \& P. Syd.

Notes - Dicarpella has seven species epithets in Index Fungorum (2020). Dicarpella georgiana was transferred to Mastigosporella as M. georgiana (Barr 1978). Wuestniopsis was proposed to accommodate Dicarpella georgiana and D. quercifolia (Reid \& Dowsett 1990), while Dicarpella dryina has been linked to Tubakia seoraksanensis (Senanayake et al. 2017a, Braun et al. 2018). Therefore, currently Dicarpella comprises only D. bina, D. liquidambaris-styracifluae and D. rubicola. Sequence data for the type species are unavailable. The asexual morph of Dicarpella 
was reported as Tubakia (Belisario 1991) and a few Tubakia species have diplacella-like sexual morphs (Sogonov et al. 2008, Senanayake et al. 2017a, 2018, Braun et al. 2018). Due to the unavailability of sequence data for the type species in both genera, it cannot be confirmed that Dicarpella and Tubakia are congeneric. Hence, Senanayake et al. (2017a) placed this genus in Melanconiellaceae, which we follow here until molecular data is available.

Greeneria Scribn. \& Viala, C. r. hebd. Séanc. Acad. Sci., Paris 105: 473 (1887)

Index Fungorum number: IF8399; 1 species with sequence data.

Type species - Greeneria uvicola (Berk. \& M.A. Curtis) Punith.

Notes - Greeneria was introduced based on G. fuliginea (Scribner \& Viala 1887) and synonymized under Melanconium (Cavara 1889) as M. fuligineum. van derAa (1973) placed the genus in Phyllosticta as P. ampelicida. Punithalingam (1974) renamed the taxon as Greeneria uvicola with descriptions and illustrations. LSU rDNA sequence analysis (Farr et al. 2001) showed that G. uvicola belonged in Diaporthales. Senanayake et al. (2017a) reported that G. uvicola and G. saprophytica should be accommodated in Melanconiellaceae. Greeneria saprophytica did not have a close affinity to G. uvicola and this needs further resolution. Greeneria does not have a sexual morph (Zhang \& Blackwell 2001). Based on Senanayake et al. (2018), Greeneria now has a single species, G. uvicola.

Massariovalsa Sacc., Michelia 2 (no. 8): 569 (1882)

Index Fungorum number: IF3020; 13 morphological species (Senanayake et al. 2018).

Type species - Massariovalsa sudans (Berk. \& M.A. Curtis) Sacc.

Notes - Massariovalsa is a saprobic genus found on woody bark. Massariovalsa was a subgenus of Melanconis (Wehmeyer 1941). Petrak (1952b) and Muller \& von Arx (1962) separated the genus using the pycnidial asexual morph and the mucous epispore on the ascospores. Massariovalsa sudans was considered to be the sexual morph of Melanconiopsis inquinans (type species of Melanconiopsis) (Wehmeyer 1939, Rossman et al. 2015). Massariovalsa has integrated, enteroblastic, phialidic conidiogenous cells. The stromatic disc is not present in Massariovalsa but the conidiogenesis is similar to Melanconiella. Sequence data are not available for Massariovalsa in GenBank. Therefore, Senanayake et al. (2018) accommodated Massariovalsa in Melanconiellaceae based on similar morphology.

Melanconiella Sacc., Syll. fung. (Abellini) 1: 740 (1882)

Index Fungorum number: IF3059; 19 morphological species (Species Fungorum 2020), 16 species with sequence data.

Type species - Melanconiella spodiaea (Tul.) Sacc.

Notes - Melanconiella is restricted to recently dead corticated branches. The genus is hostspecific to the plant family Betulaceae as saprobes (Senanayake et al. 2018). Voglmayr et al. (2012) revised Melanconiella using herbarium material and recently collected specimens. The dissimilarities in morphology and phylogeny of Melanconiella and Melanconis were discussed by Voglmayr et al. (2012). See Crous et al. (2016b) and Senanayake et al. (2018) for further details. Melanconiella spodiaea is illustrated in this entry.

Microascospora Senan. \& K.D. Hyde, Stud Mycol 86:217-296 (2017)

Index Fungorum number: IF821562; 1 species with sequence data.

Type species - Microascospora rubi Senan., Camporesi \& K.D. Hyde

Notes - The sexual, saprobic genus Microascospora is phylogenetically distinct from other genera in Melanconiellaceae. Species have comparatively small ascospores $(<20 \mu \mathrm{m}$ long $)$ with wavy, filiform, long appendages. Sphaeronaemella fragariae (previously placed in Microascales incertae sedis) clustered with Microascospora rubi and not with other Sphaeronaemella species (incertae sedis in Microascales, Senanayake et al. 2017a). Therefore, S. fragariae was excluded 
from Sphaeronaemella and accommodated in Microascospora as M. fragariae (Senanayake et al. 2017a).
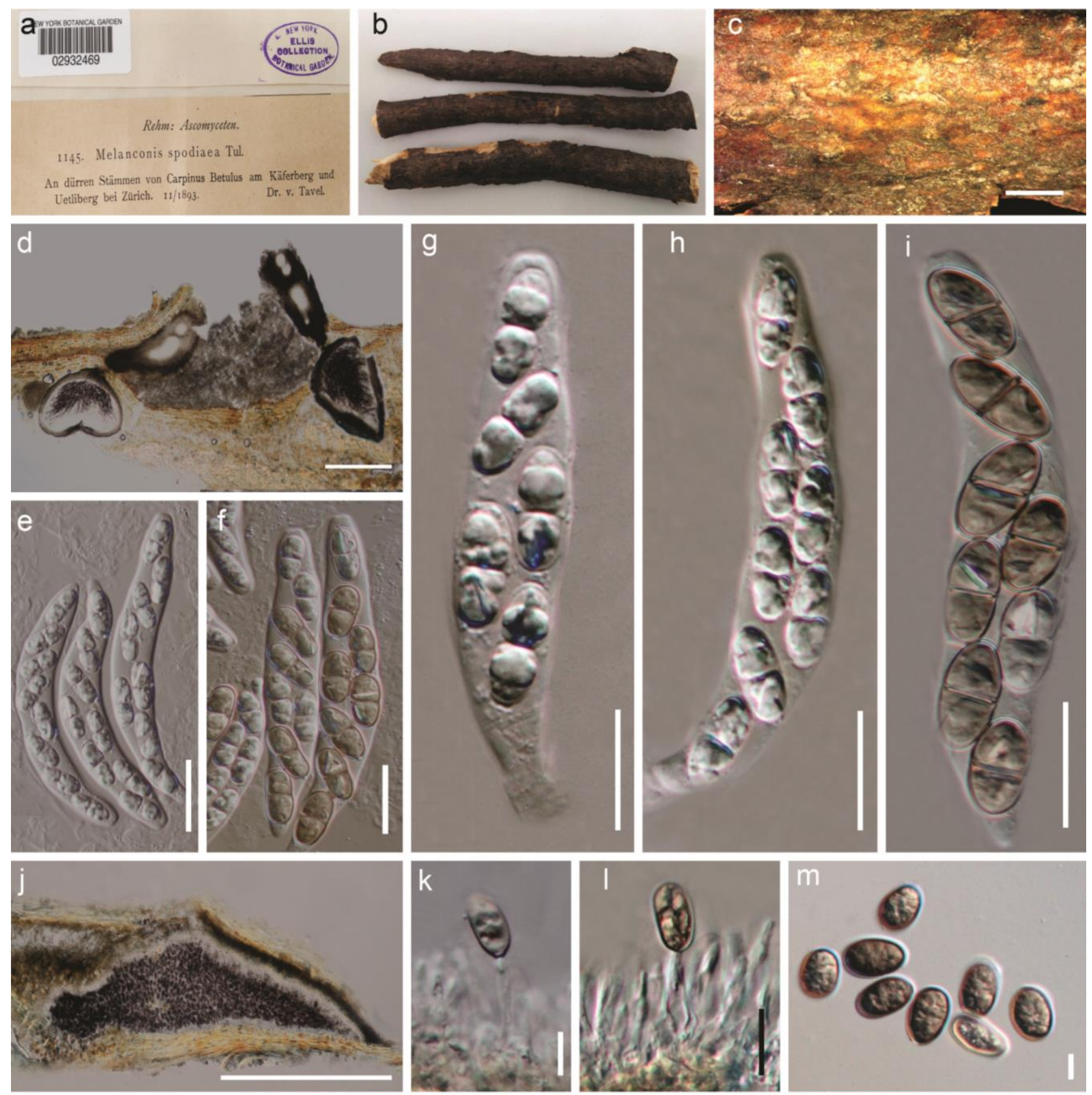

Figure 160 - Melanconiella spodiaea (Material examined - GERMANY, Berlin, Jungfernheide, on bark of Carpinus sp. (Betulaceae) P. Sydow s. n., NY 02932468; SWITZERLAND, Kaferberg und Uetliberg bei Zurich P. Sydow s. n., NY 02932469). a Herbarium packages. b, c Specimen. d Vertical cross section of ascoma. d Peridium. e-i Asci. $\mathrm{j}$ Vertical cross section of conidioma. k-1 Conidiogenous cells and conidia. $\mathrm{m}$ Conidia. Scale bars: $\mathrm{c}=1 \mathrm{~mm}, \mathrm{~d}-\mathrm{i}=20 \mu \mathrm{m}, \mathrm{J}=500 \mu \mathrm{m}, \mathrm{k}, 1=$ $10 \mu \mathrm{m}, \mathrm{m}=5 \mu \mathrm{m}$.

Septomelanconiella Samarak. \& K.D. Hyde, Fungal Divers. Notes 95: 1-273 (2019)

Index Fungorum number: IF555301; 1 species with sequence data.

Type species - Septomelanconiella thailandica Samarak. \& K.D. Hyde

Notes - Septomelanconiella is a monotypic genus distinguished from other species in Melanconiellaceae by its 1-euseptate and luminate conidia. The genus is similar to Melanconiella in its finely verrucose, brown mature conidia. Septomelanconiella thailandica forms an 
independent lineage, phylogenetically distint from other genera in Melanconiellaceae and this is in agreement with the phylogeneties of Senanayake et al. (2017).

Sheathospora X.L. Fan, MycoKeys 42: 118 (2018)

Index Fungorum number: IF828429; 1 morphological species.

Type species - Sheathospora cornuta (C.M. Tian \& Z. Du) X.L. Fan

Notes - Sheathospora was established to accommodate Melanconiella cornuta previously included in the Melanconiella clade (Voglmayr et al. 2012, Du et al. 2017). The genus can be differentiated from the other genera in Melanconiellaceae by its pycnidial conidiomata and conidia with a distinct, hyaline sheath.

Meliolaceae W. Martin, Mycol. Pap. 15: 23(1946)

Index Fungorum number: IF80993; Facesoffungi number: FoF00741; 2371 species.

Colonies epiphyllous or hypophyllous. Hyphae superficial, brown, straight to flexuous, septate, branched, reticulate, with hyphopodia and phialides. Hyphopodia alternate to unilateral or opposite, 2-celled, brown. Setae straight to hooked, dark brown, forming on hyphae or ascomata. Sexual morph: Ascomata superficial, globose to subglobose, or flattened. Peridium comprising hyaline inner stratum, and dark brown outer stratum of textura angularis. Paraphyses evanescent. Asci 2-4-spored, unitunicate, asci wall attenuated or broken when mature, without a fixed shape. Ascospores ellipsoidal to oblong, 3-4-septate, constricted at the septum, hyaline when young, becoming brown when mature. Asexual morph: Phialides ampulliform or flask-shaped on hyphae. Conidiogenous cells formed directly from vegetative hyphae. Conidia unicellular, small and hyaline (adapted from Cannon \& Kirk 2007).

Type genus - Meliola Fr.

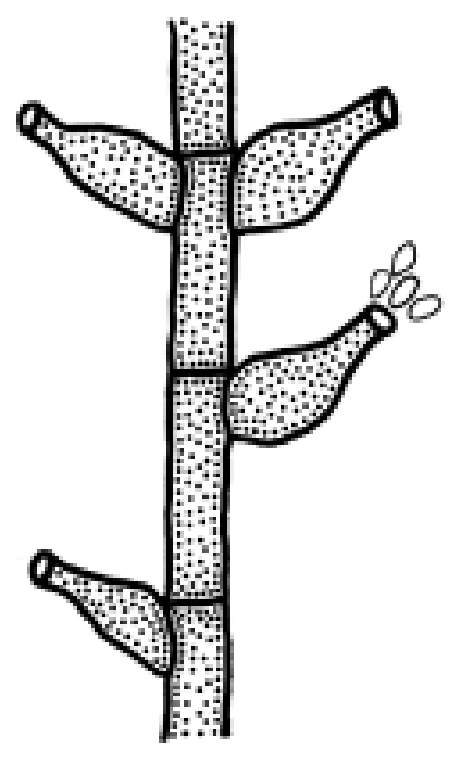

Figure 161 - Drawing of asexual morph of Meliolaceae.

Notes - Meliolaceae was established by Martin (1941) without a Latin diagnosis and later validated by Hansford (1946). Roger (1953) placed the Meliolaceae with nine other families in Hypocreales. This family has also been placed in Dothideales, Erysiphales, Meliolales, Myriangiales and Hypocreales at various times (Martin 1941, Luttrell 1951, 1989, Roger 1953, Ainsworth et al. 1971, Müller \& von Arx 1973, Yarwood 1973, Barr 1976a, Eriksson 1981, Hawksworth et al. 1983). Ainsworth et al. (1971) and Eriksson \& Hawksworth (1993) listed 50 genera in the family; later studies listed 25 genera (Hawksworth et al. 1995), 22 genera (Kirk et al. 2008), and 26 genera (Lumbsch \& Huhndorf 2010) and seven genera (Hongsanan et al. 2015). A checklist provided by Zeng et al. (2017) included the number of species in each genus of 
Meliolaceae that are accepted in Index Fungorum and excluded some erroneous records. Species with valid information were accepted, and records with only a name available was noted in that study. Previous identifications of Meliolaceae were mainly based on host association and morphology. A formula proposed by Beeli (1920) was applied and modified for rapid identification among thousands of species in Meliolaceae. It used a numerical code to summarize key diagnostic characters, such as ascospores, ascomata, setae and appressoria. Mueller et al. (1991) stated that the basal cytoplasm in phialides have a conidiogenous function and conidia-like spores was observed being extruded from terminal openings of phialides. The reason for lack of studies on phialides is that they function only in some species, certain stages, or specific environmental conditions (Mueller et al. 1991). Therefore, phialides are considered as the asexual morph of Meliolaceae. Although members of Meliolaceae are unculturable, sequence data can be obtained as described in Zeng et al. (2018). There are only 20 confirmed species of Meliolaceae with sequence data in GenBank and it has not been determined if species are host-specific. In the future, analysis of sequence data can replace the Beeli formula as a more reliable method to identify such groups, as well as establishing host-specificity and the asexual morphs of Meliolaceae.

\section{Ecological and economic significance of Meliolaceae}

Species of Meliolales can cause significant effects on crops, such as reducing yield and quality of fruits of Citrus (e.g. Meliola butleri, M. camelliae and M. citricola) (Rao 1969). They produce hyphopodia that penetrate the leaf surface to gain nutrients from host plants which results in a reduction of chlorophyll, starch, sugars, proteins and amino acids, without causing pathogenic damage (Hosagoudar et al. 1997, Old et al. 2003, Rodríguez Justavino \& Piepenbring 2007). They could reduce photosynthesis by covering the host surface and increase the temperature and respiration in those areas (Hosagoudar et al. 1997, Hosagoudar \& Raju 2013, Hongsanan et al. 2015).

\section{Genera included in Meliolaceae}

Amazonia Theiss., Annls mycol. 11(6): 499 (1913)

Index Fungorum number: IF153; 65 morphological species (Species Fungorum 2020, Zeng et al. 2017), 1 species with sequence data.

Type species - Amazonia psychotriae (Henn.) Theiss.

Notes - Amazonia shares similarities with genera in Meliolaceae based on its brown hyphae with phialides, and brown, 4-septate ascospores, but differs in its flattened ascomata. It is also similar with taxa of Microthyriaceae in the structure of ascomata, but differs in the hyphae and ascospores.

Appendiculella Höhn., Sber. Akad. Wiss. Wien, Math.-naturw. Kl., Abt. 1 128(7-8): 556 (1919)

Index Fungorum number: IF289; 74 morphological species (Species Fungorum 2020, Zeng et al. 2017), 1 species with sequence data.

Type species - Appendiculella calostroma (Desm.) Höhn.

Notes - Appendiculella is characterized by its conical appendages with transversely striate walls that develop on the surface of the ascomata. Rodríguez Justavino et al. (2014) provided the first sequence for this genus, and its phylogenetic placement is related with Asteridiella.

Asteridiella McAlpine, Proc. Linn. Soc. N.S.W. 22(1): 38 (1897)

Index Fungorum number: IF406; 365 morphological species (Species Fungorum 2020, Zeng et al. 2017), 3 species with sequence data.

Type species - Asteridiella solani McAlpine

Notes - There are no setae or appendages on either the ascomata or hyphae in species of Asteridiella. Asteridiella and Appendiculella are similar in morphology and related in phylogeny. There are few sequences available for Asteridiella and Appendiculella and thus it is necessary to verify their phylogenetic placement with more sequence data. 
Cryptomeliola S. Hughes \& Piroz., Mycol. Pap. 174: 14 (1997)

Index Fungorum number: IF27826; 3 morphological species (Species Fungorum 2020, Zeng et al. 2017).

Type species - Cryptomeliola orbicularis (Berk. \& M.A. Curtis) S. Hughes \& Piroz.

Notes - Fascicular hyphal setae with bulbous tips are the typical character to distinguish Cryptomeliola species from other genera of Meliolaceae. Colonies are comprise densely reticulate hyphae, which is similar with Asteridiella. Hosagoudar (2003) suggested not to include this genus in Meliolales, due to lack of hyphopodia. However, Hongsanan et al. (2015) described the structure of hyphopodia and placed it in Meliolales.

Endomeliola S. Hughes \& Piroz., N.Z. J1 Bot. 32(1): 53 (1994)

Index Fungorum number: IF27386; 1 species with sequence data.

Type species - Endomeliola dingleyae S. Hughes \& Piroz.

Notes - Endomeliola is the only genus lacking superficial hyphae in Meliolaceae. It contains a single species with an unverified sequence in GenBank. The brown, 4-septate ascospores places Endomeliola as a member of Meliolaceae. However, its placement needs to be confirmed with reliable sequence data.

Irenopsis F. Stevens, Annls mycol. 25(5/6): 411 (1927)

Index Fungorum number: IF2505; 152 morphological species (Species Fungorum 2020, Zeng et al. 2017), 7 species with sequence data.

Type species - Irenopsis tortuosa (G. Winter) F. Stevens

Notes - Irenopsis is typified by true setae on the ascomata and lack of hyphal setae. The phylogeny supports the separation of Irenopsis, which forms a distinct and monophyletic clade in Meliolaceae.

Meliola Fr., Syst. orb. veg. (Lundae) 1: 111(1825)

Index Fungorum number: IF3100; 1694 morphological species (Species Fungorum 2020, Zeng et al. 2017), 20 species with sequence data.

Type species - Meliola nidulans (Schwein.) Cooke

Notes - Meliola is the largest genus in Meliolaceae, which comprises more than $70 \%$ of species in the family. Members of this genus typically have hyphal setae and globose ascomata. Meliola telosmae is illustrated in this entry (Fig. 162). Meliola telosmae differs from $M$. clerodendricola in having longer appressoria and setae, and thinner, light brown ascospores. Therefore, we assign this new collection as a reference specimen of M. telosmae with sequence data provided.

Setameliola D.R. Reynolds, Gdns' Bull., Singapore 61(2): 424 (2010)

Index Fungorum number: IF540193; 17 morphological species (Species Fungorum 2020, Zeng et al. 2017).

Type species - Setameliola argentina (Speg.) D.R. Reynolds

Notes - This combination of characters could be uninformative, and needs phylogenetic confirmation.

Melogrammataceae G. Winter, Rabenh. Krypt. -Fl., Edn 2 (Leipzig) 1.2: 797 (1886)

Index Fungorum number: IF80994; Facesoffungi number: FoF00840; 17 species.

Saprobic on bark of woody plants. Sexual morph: Stromata superficial, erumpent, pulvinate or discoid, reddish-brown, subglobose, soft-textured, with pseudoparenchymatous cells, with black ostiole. Ascomata perithecial, dark brown to black, immersed, globose, ostiole periphysate. Peridium comprising rows of cells, externally brown, internally hyaline. Paraphyses hypha-like, septate. Asci 8-spored, unitunicate, clavate, or fusoid, short pedicellate, with a shallow, J-, apical ring. Ascospores 1-3-seriate, hyaline or brown, filiform, aseptate or 1-3 septate, cylindrical or 
falcate. Asexual morph: Coelomycetous. Mycelium hyphae to yellow-brown, septate, branched. Conidiophores long, cylindrical, stiffly upright, septate, verticillate and whorled or not. Conidiogenous cells holoblastic, proliferating sympodially, hyaline, thin-walled. Conidia elongate falcate or filiform (adapted from Maharachchikumbura et al. 2016b).

Type genus - Melogramma Fr.

Notes - Jaklitsch \& Voglmayr (2012) showed that Melogrammataceae clustered in Xylariales rather than Diaporthales based on analysis of ITS and LSU sequence data. Maharachchikumbura et al. $(2015,2016 b)$ confirmed the placement of Melogramma in Melogrammataceae in Xylariales based on the analyses of combined LSU, SSU, tefl and $r p b 2$ sequence data. However, Senanayake et al. (2015) showed it should be placed in Amphisphaeriales. Hongsanan et al. (2017) confirmed the status in Amphisphaeriales based on phylogenetic and MCC trees.

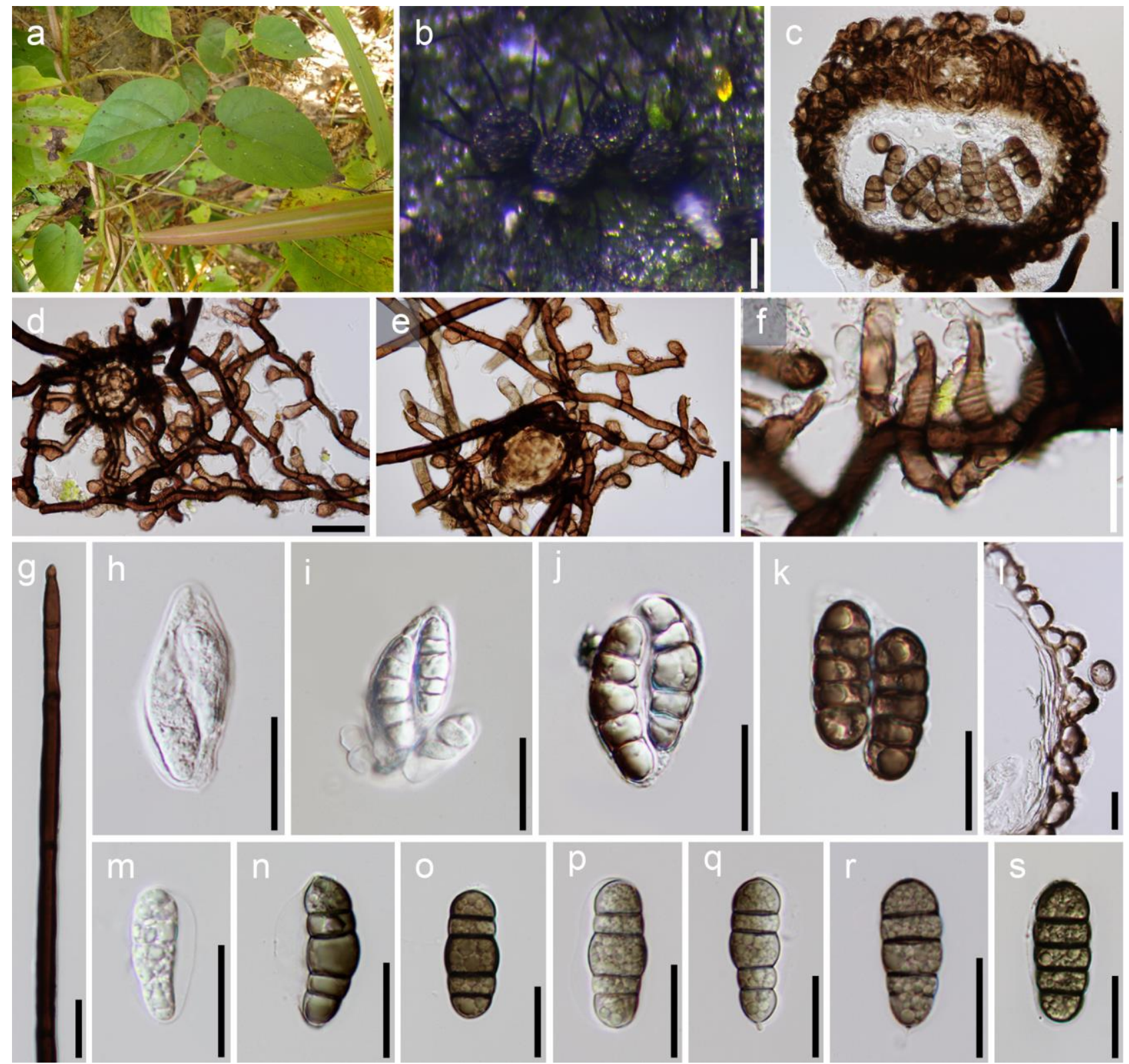

Figure 162 - Meliola telosmae (Material examined - THAILAND, Nang Lae, Chiang Rai, on the living leaves of Telosma cordata (Apocynaceae), 4 January 2014, Saranyaphat Boonmee, MFLU 14-0003, reference specimen designated here). a The host plant. b Ascomata on leaf surface. c Cross section of ascoma. d, e Hyphae with appressoria. f Phialides. g Setae. h-k Asci from young to mature state. 1 Peridium. m-s Ascospores. Scale bars: $\mathrm{b}=100 \mu \mathrm{m}, \mathrm{c}-\mathrm{e}=50 \mu \mathrm{m}, \mathrm{f}-\mathrm{s}=20 \mu \mathrm{m}$. 


\section{Ecological and economic significance of Melogrammataceae}

Species of this family are saprobes on bark of woody plants and thus involved in nutrient cycling.

\section{Genus included in Melogrammataceae}

Melogramma Fr., Summa veg. Scand., Section Post. (Stockholm): 386 (1849)

Index Fungorum number: IF3117; 17 morphological species (Species Fungorum 2020), 3 species with sequence data.

Type species - Melogramma campylosporum Fr.

Notes - Melogramma is characterized by reddish-brown stroma, dark brown to black, globose, ostiolate and perithecial ascoma, unitunicate, straight, clavate, fusoid or sigmoid, short pedicellate, 8-spored asci with a J-, apical ring and brown, 3-septate, falcate, often strongly curved ascospores with subacute ends and guttulate when mature (Maharachchikumbura et al. 2016b). In this entry we illustrate Melogramma campylosporum.

Microascaceae Luttr. ex Malloch, Mycologia 62(4): 734 (1970)

Index Fungorum number: IF81001; Facesoffungi number: FoF01798; 263 species.

Saprobic and pathogenic on various plants. Sexual morph: Ascomata black, globose cleistothecial or perithecial, superficial to immersed, ostiolate, ampulliform, aggregated to scattered, glabrous or covered with scattered hairs. Ostiole often comprises a neck with variable length and shape, with ostiolar hairs. Peridium thick-walled, dark brown to black, composed of cells of textura angularis or textura intricata. Hamathecium without interascal tissues. Asci 8spored, globose to barrel-shaped, evanescent, thin-walled, obovate, unitunicate, sessile to short pedicellate, arranged in basipetal rows. Ascospores crowded, aseptate, seriate, pale to dark reddishbrown, asymmetrical, reniform, triangular or quadrangular, dextrinoid when immature, germ pores present, or with germ slits, smooth-walled. Asexual morph: Conidiophores smooth-walled, elongate, macronematous, mononematous or sporodochial to synnematous, with or without rhizoids. Conidiogenous cells short simple or little branched, cylindrical annellides, borne singly or in groups of 2-5 on the vegetative hyphae, ampulliform or lageniform, subhyaline to dark when mature, smooth- to rough-walled. Conidia aseptate, pale yellow to dark brown, obovate or clavate, base truncate and rounded to pointed at the apex, globose to subglobose, smooth thin-walled to finely roughened thick-walled, produced singly or in basipetal dry chains. Presence of solitary conidia in some species, sessile or on short stalks from the vegetative hyphae (adapted from Sandoval-Denis et al. 2016a, Maharachchikumbura et al. 2016b).

Type genus - Microascus Zukal.

Notes - Microascaceae was circumscribed by Luttrell (1951) in Microascales and validated by Malloch (1970) (Sandoval-Denis et al. 2016a, Maharachchikumbura et al. 2016b). It comprises several closely related genera of saprobic, plant and opportunistic human pathogenic fungi (de Hoog et al. 2011, Sandoval-Denis et al. 2013, 2016b, Maharachchikumbura et al. 2016b). Sandoval-Denis et al. (2016a, b) revised and proposed several new taxa and combinations under Microascaceae. Unlike the studies by Issakainen et al. (2003), Sandoval-Denis et al. (2016a) used combined gene (LSU, ITS, tefl and tub2) phylogenetic analysis and confirmed the polyphyletic nature of the two groups, Microascus and Scopulariopsis. As a result, they reported several uncertain genera which were later resolved in Sandoval-Denis et al. (2016b). For example, Acaulium and Fairmania were circumscribed as a new lineage in Microascaceae (Sandoval-Denis et al. 2016a). In our current revision of Microascaceae, we accommodate 23 genera. Yunnania, Fairmania, Acaulium, Gamsia, and Rhinocladium are the latest additions in the family (SandovalDenis et al. 2016a, b, Wijayawardene et al. 2017a, 2018a).

\section{Ecological and economic significance of Microascaceae}

The species are mainly saprobic, coprophilous and are also clinically important. 

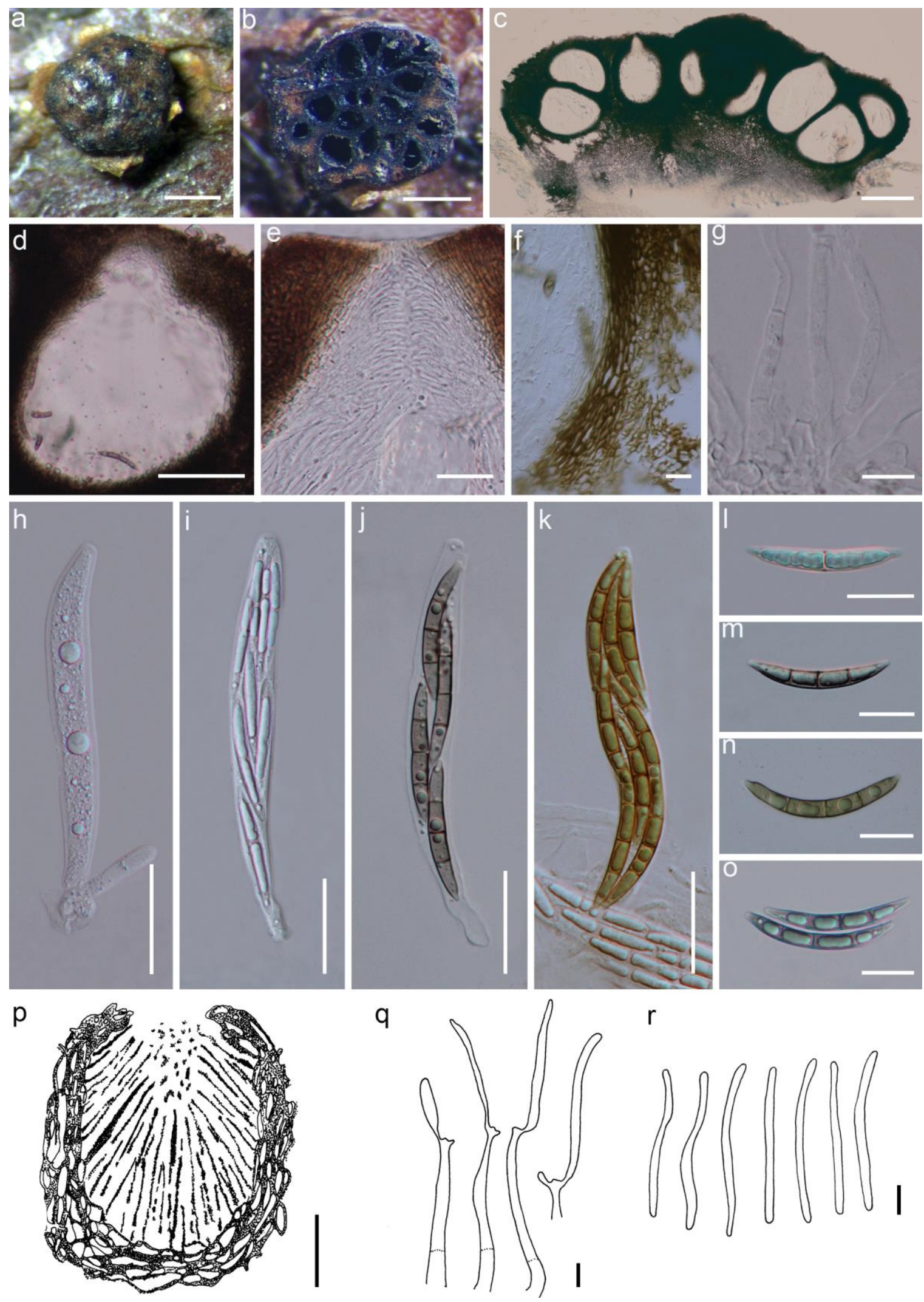

$r$

$r$

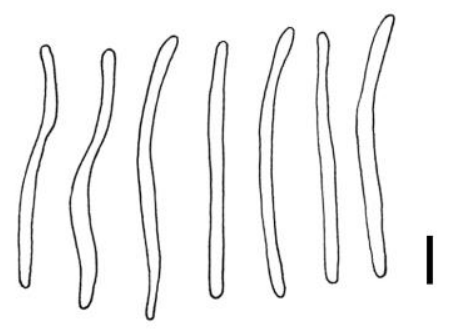

Figure 163 - Melogramma campylosporum (Material examined - AUSTRIA, Styria, Graz, distr. Mariatrost, on the north-facing hillside below the church, $47^{\circ} 06^{\prime} 29^{\prime \prime} \mathrm{N}, 15^{\circ} 29^{\prime} 32^{\prime \prime} \mathrm{E}$, MTB 8858/4, c. $440 \mathrm{~m}$ alt.; clearing, on dead shoots of Carpinus betulus L. (Betulaceae), 5 November 2006, leg. and det. C. Scheuer (\#5321), S-F123341, p-r redrawn from Laflamme 1976). a Stroma on the host. b Cross section of stroma. c Vertical section of stroma. d Ascoma. e Periphyses. f Peridium. $g$ Paraphyses. h-k Asci. 1-o Ascospores. p Pycnidia. q Conidiophores with conidia. r Conidia. Scale bars: $\mathrm{a}=500 \mu \mathrm{m}, \mathrm{b}-\mathrm{d}=200 \mu \mathrm{m}, \mathrm{e}-\mathrm{k}, \mathrm{p}=30 \mu \mathrm{m}, \mathrm{l}-\mathrm{o}=15 \mu \mathrm{m}, \mathrm{q}, \mathrm{r}=5 \mu \mathrm{m}$. 


\section{Genera included in Microascaceae}

Acaulium Sopp, Skr. VidenskSelsk. Christiania, Kl. I, Math. -Natur. (11): 42 (1912)

Index Fungorum number: IF7011; 4 morphological species (Species Fungorum 2020), 3 species with sequence data.

Type species - Acaulium albonigrescens Sopp

Notes - The asexual morph is hyphomycetous and has been treated as a synonym of Scopulariopsis by Seifert et al. (2011). Species occur in terrestrial habitats worldwide and are characterized by annellidic conidiogenesis with mycelium forming hyphal fascicles and guttulate conidia. Taxonomic revisions were carried out by Kirk et al. (2013). Sandoval-Denis et al. (2016a) accepted, Acaulium, in Microascaceae by segregating it from Microascus and Scopulariopsis based on molecular phylogenetic study. The placement of the genus was also accepted in Maharachchikumbura et al. (2015, 2016b) and Wijayawardene et al. (2017a, 2018a).

Brachyconidiellopsis Decock, R.F. Castañeda \& Adhikari, Cryptog. Mycol. 25(2): 140 (2004)

Index Fungorum number: IF28798; 1 species with sequence data.

Type species - Brachyconidiellopsis fimicola Decock

Notes - The asexual morph of Brachyconidiellopsis is hyphomycetous and species are saprobes. The genus is characterized by sporodochial to synnematal conidiomata, with a narrow, dark brown to black stipe, with a slight fasciculate fertile apex. It was described as coprophilous on dung of an unidentified Cervidae in Nepal (Decock et al. 2004). The genus was accepted in Microascaceae by Sandoval-Denis et al. (2016a), Maharachchikumbura et al. $(2015,2016 \mathrm{~b})$ and Wijayawardene et al. (2017a, 2018a).

Canariomyces Arx, Persoonia 12(2): 185 (1984)

Index Fungorum number: IF25789; 6 morphological species (Species Fungorum 2020), 5 species with sequence data.

Type species - Canariomyces notabilis von Arx

Notes - Sexual morphs are saprobes and the mature ascospores are similar to some Chaetomium species. The genus was accepted in Microascaceae by Sandoval-Denis et al. (2016a), Maharachchikumbura et al. $(2015,2016 b)$ and Wijayawardene et al. (2017a, 2018a). The asexual morph of this genus is undetermined.

Cephalotrichum Link, Mag. Gesell. naturf. Freunde, Berlin 3(1-2): 20 (1809)

Index Fungorum number: IF7527; 35 morphological species (Species Fungorum 2020), 27 species with sequence data.

Type species - Cephalotrichum stemonitis (Pers.) Nees

Notes - The genus has a similar conidiogenous apparatus to Microascus and Scopulariopsis. However, the conidiophores in Cephalotrichum arise from synnemata and produce conidia in dry basipetal chains. Asexual morphs are hyphomycetous and saprobic on soil and dung with a worldwide distribution. de Beer et al. (2013a) and Sandoval-Denis et al. (2016a) added new species. The genus was accepted in Microascaceae by Sandoval-Denis et al. (2016a), Maharachchikumbura et al. $(2015,2016 b)$ and Wijayawardene et al. (2017a, 2018a). The sexual morph of this genus is undetermined.

Doratomyces Corda, Deutschl. Fl., 3 Abt. (Pilze Deutschl.) 2: 65 (1829)

Index Fungorum number: IF8093; 3 morphological species (Species Fungorum 2020).

Type species - Doratomyces neesii Corda

Notes - Species of Doratomyces are similar to Cephalotrichum (Sandoval-Denis et al. 2016a) and are common in soil, dung and decaying plant materials. The genus was accepted in Microascaceae by Sandoval-Denis et al. (2016a), Maharachchikumbura et al. $(2015,2016 \mathrm{~b})$ and Wijayawardene et al. (2017a, 2018a). The sexual morph of this genus is undetermined. 
Echinobotryum Corda, Deutschl. Fl., 3 Abt. (Pilze Deutschl.) 3(12): 51 (1831)

Index Fungorum number: IF8120; 2 morphological species (Species Fungorum 2020).

Type species - Echinobotryum atrum Corda

Notes - Echinobotryum species are found in terrestrial habitats as saprobes with a worldwide distribution. The genus is characterized by spores clustered on the conidiophore apices and warts on the spore wall and are similar to Wardomyces (Corda 1831). However, they can be distinguished based on the germ slits on the ornamented spores in Echinobotryum. The genus was accepted in Microascaceae by Kirk et al. (2013), Maharachchikumbura et al. (2015, 2016b) and Wijayawardene et al. (2017a, 2018a). The sexual morph of this genus is undetermined.

Enterocarpus Locq.-Lin., Revue Mycol., Paris 41(4): 510 (1977)

Index Fungorum number: IF1826; 2 morphological species (Species Fungorum 2020), 1 species with sequence data.

Type species - Enterocarpus uniporus Locq. -Lin.

Notes - The genus is characterized by ascomata lacking ostioles with an apical tuft of hairs and a hyphal 'capillitium' surrounding the ascospores. Species are saprobic and coprophilous in terrestrial habitats and are distributed in Sahara Desert and Italy. The genus was accepted in Microascaceae by Kirk et al. (2013), Maharachchikumbura et al. (2015, 2016b) and Wijayawardene et al. (2017a, 2018a). The asexual morph of this genus is undetermined.

Fairmania Sacc., Annls mycol. 4(3): 276 (1906)

Index Fungorum number: IF1972; 1 morphological species.

Type species - Fairmania singularis Sacc.

Notes - Malloch \& Cain (1971) placed F. singularis in Microascus as M. singularis as they were similar and this was accepted by von Arx et al. (1988). However, due to the presence of longitudinal striations on the conidial wall and erect and thick-walled annellides of the species and phylogenetic differences, Sandoval-Denis et al. (2016), reinstated Fairmania in Microascaceae. Fairmania species are wood-decay saprobes and have been reported from Canada, Japan and the USA.

Gamsia M. Morelet, Ann. Soc. Sci. Nat. Arch. Toulon et du Var 21: 105 (1969)

Index Fungorum number: IF8306; 4 species with sequence data.

Type species - Gamsia dimera (W. Gams) M. Morelet

Notes - This genus was separated from Wardomyces on the basis of well-differentiated conidiophores, and the conidial arrangement with large apical clusters. This separation is also supported by the phylogenetic studies. The genus was accepted in Microascaceae by Kirk et al. (2013), Sandoval-Denis et al. (2016a), Maharachchikumbura et al. (2015, 2016b) and Wijayawardene et al. (2017a, 2018a). The sexual morph of the genus is undetermined.

Kernia Nieuwl., Am. Midl. Nat. 4: 379 (1916)

Index Fungorum number: IF2563; 14 morphological species (Species Fungorum 2020), 7 species with sequence data.

Type species - Kernia nitida (Sacc.) Nieuwl.

Notes - The genus is characterized by hairy ascomata and ellipsoidal reddish-brown to brown ascospores with two germ pores and graphium- or scopulariopsis-like asexual morphs. In phylogenetic studies the genus forms well-supported clades related to Scedosporium and allied genera. The genus was accepted in Microascaceae by Kirk et al. (2013), Sandoval-Denis et al. (2016a), Maharachchikumbura et al. (2015, 2016b) and Wijayawardene et al. (2017a, 2018a). The sexual morph of this genus is undetermined. 
Lomentospora Hennebert \& B.G. Desai, Mycotaxon 1(1): 45 (1974)

Index Fungorum number: IF 8790; 1 morphological species.

Type species - Lomentospora prolificans Hennebert \& B.G. Desai

Notes - Lomentospora prolificans was isolated from greenhouse soil in Belgium. However, the name was thought to be invalid and was placed under Beauveria. Malloch and Salkin (1984) synonymized the species as Scedosporium inflatum. Later the species was renamed as Scedosporium prolificans by Geuho and de Hoog (1991). However, based on its phylogenetic distance and distinguishable morphology from other Scedosporium species, the species was accepted as Lomentospora prolificans (Lackner et al. 2014). Distribution of the genus is limited to Australia, European regions and the USA. Lomentospora species have been reported to cause fungal infections in immunocompromised patients, those with malignancy, and organ and stem cell transplant recipients.

Lophotrichus R.K. Benj., Mycologia 41(3): 347 (1949)

Index Fungorum number: IF2946; 7 morphological species (Species Fungorum 2020), 6 species with sequence data.

Type species - Lophotrichus ampullus R.K. Benj.

Notes - Some species of the genus are coprophilous while others are cellulolytic, and that their appearance on dung is more or less incidental. The genus was accepted in Microascaceae by Kirk et al. (2013), Sandoval-Denis et al. (2016a), Maharachchikumbura et al. (2015, 2016b) and Wijayawardene et al. (2017a, 2018a). The sexual morph of this genus is undetermined.

Microascus Zukal, Verh. Zool-Bot. Ges. Wien 35:339 (1886)

Index Fungorum number: IF3153; 54 morphological species (Species Fungorum 2020), 39 species with sequence data.

Type species - Microascus longirostris Zukal

Notes - Phylogenetic study by Issakainen et al. (2003) indicated that subdivision of the genus was necessary. Sandoval-Denis et al. (2016b) confirmed that there were several distinct lineages which were supported by morphology, such as germ slits, synnemata or conspicuously hairy ascomata (Abbott 2000, Issakainen et al. 2003, Jagielski et al. 2016, Sandoval-Denis et al. 2016b). Sandoval-Denis et al. (2016a, b) resolved the taxonomic complexity of the genus and introduced seven new species, with new combinations in the Microascus lineage (Sandoval-Denis et al. 2016a). However, several taxa (e.g. M. longirostris and M. pseudolongirostris) have uncertain position in a phylogenetic tree, suggesting further study is needed to resolve the taxonomic placements of problematic taxa (Woudenberg et al. 2017). Microascus longirostris has a wide host range, mostly from dung of mammals, soil, wood, seeds, air, and clinical samples (Barron et al. 1961, Sandoval-Denis et al. 2016a, b, Woudenberg et al. 2017). Neither a type culture nor herbarium specimen is available (Barron et al. 1961, Sandoval-Denis et al. 2016a, Wijayawardene et al. 2017a). A neotype of $M$. longirostris was designated by Sandoval-Denis et al. (2016a), which was corresponds to the descriptions by Zukal (1885) and cultural characteristics descriptions correspond to Barron et al. (1961), Morton \& Smith (1963) and von Arx et al. (1988).

Parascedosporium Gilgado, Gené, Cano \& Guarro, Int. J. Syst. Evol. Microbiol. 57(9): 2176 (2007)

Index Fungorum number: IF506554; 2 species with sequence data.

Type species - Parascedosporium tectonae (C. Booth) Gilgado, Gené, Cano \& Guarro

Notes - The genus is characterized by denticulate conidiogenous cells with sympodial conidia. Gilgado et al. (2007) proposed a new combination for Graphium tectonae as Parascedosporium tectonae. The genus was accepted in Microascaceae by Kirk et al. (2013), Sandoval-Denis et al. (2016a), Maharachchikumbura et al. $(2015,2016 b)$ and Wijayawardene et al. (2017a, 2018a). 


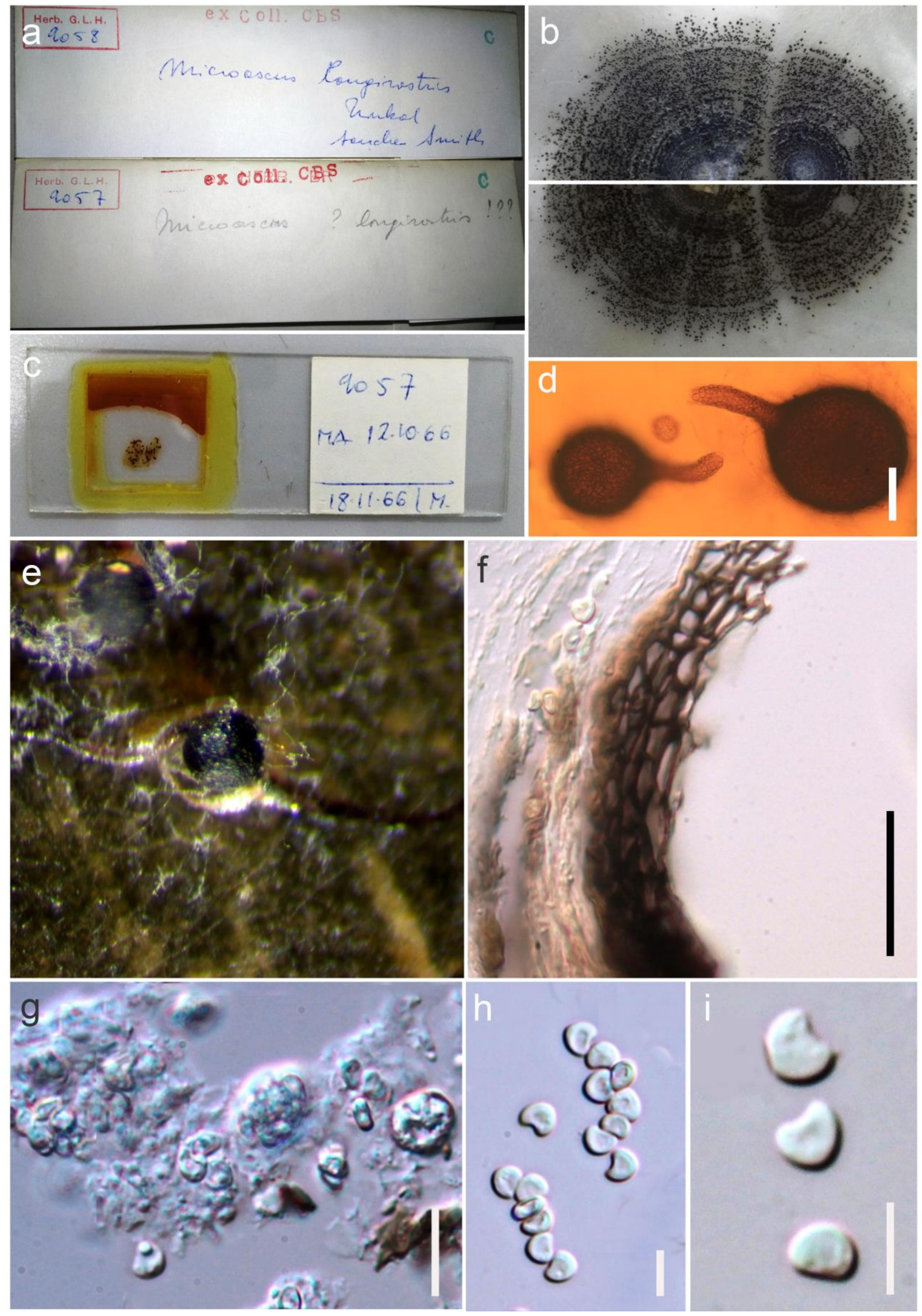

Figure 164 - Microascus longirostris (Material examined - USA, Maine, Kittery Point, from a wasp's nest, 1961, R. Thaxter, MUCL 9057, neotype). a-c Herbarium material of Microascus longirostris (dried culture and micro slide). d, e Ascomata. f Peridium. g Asci. h, i Ascospores. Scale bars: $\mathrm{d}=50 \mu \mathrm{m}, \mathrm{f}=20 \mu \mathrm{m}, \mathrm{g}=10 \mu \mathrm{m}, \mathrm{h}, \mathrm{i}=5 \mu \mathrm{m}$. 
Petriella Curzi, Boll. R. Staz. Patalog. Veget. Roma 10: 384 (1930)

Index Fungorum number: IF3852; 7 morphological species (Species Fungorum 2020), 6 species with sequence data.

Type species - Petriella asymmetrica Curzi

Notes - Petriella resembles Microascus but was segregated from Microascus by its hairy ascomata. The ascospores in Petriella are also larger than most other genera in Microascales. The genus was accepted in Microascaceae by Kirk et al. (2013), Sandoval-Denis et al. (2016a), Maharachchikumbura et al. (2015, 2016b) and Wijayawardene et al. (2017a, 2018a).

Pseudallescheria Negr. \& I. Fisch., Revista Inst. Bacteriol. Dr. Carlos G. Malbrán’ 12 (201): 5-9 (1944)

Index Fungorum number: IF4403; 8 morphological species (Species Fungorum 2020), 3 species with sequence data.

Type species - Pseudallescheria shearii Negroni \& I. Fisch.

Note - Pseudallescheria species are saprobes worldwide and have been isolated from soil, sewage, contaminated water, and the manure of farm animals. Species are also opportunistic pathogens that can cause various infections in humans. The genus was accepted in Microascaceae by Kirk et al. (2013), Sandoval-Denis et al. (2016a), Maharachchikumbura et al. (2015, 2016b) and Wijayawardene et al. (2017a, 2018a). The asexual morphs of Pseudallescheria are undetermined, however, scedosporium-like and graphium-like taxa are probably linked.

Pseudoscopulariopsis Sand.-Den., Gené \& Guarro, Persoonia, Mol. Phyl. Evol. Fungi 36: 24 (2015)

Index Fungorum number: IF809215; 2 species with sequence data.

Type species - Pseudoscopulariopsis schumacheri (E.C. Hansen) Sandoval-Denis Gené \& Guarro

Notes -Sandoval-Denis et al. (2016b) found that species of Pseudoscopulariopsis formed a distinct clade basal to the Scopulariopsis clade. Pseudoscopulariopsis species are characterised by hyaline to subhyaline conidiogenous cells, which usually comprise annellides arising from swollen conidiophores (Sandoval-Denis et al. 2016b). The sexual morphs are undetermined. The genus was accepted in Microascaceae by Kirk et al. (2013), Sandoval-Denis et al. (2016a,b), Maharachchikumbura et al. (2015, 2016b) and Wijayawardene et al. (2017a, 2018a).

Rhinocladium Sacc. \& Marchal, Bull. Soc. R. Bot. Belg. 24(1): 65 (1885)

Index Fungorum number: IF9722; 11 morphological species (Species Fungorum 2020), 1 species with sequence data.

Type species - Rhinocladium coprogenum Sacc. \& Marchal

Notes - The genus is hyphomycetous with polyblastic conidiogenous cells integrated within the conidiophores. Rhinocladium species are saprobic and occur in terrestrial habitats and have a worldwide distribution. The genus was accepted in Microascaceae by Kirk et al. (2013), SandovalDenis et al. (2016a), Maharachchikumbura et al. (2015, 2016b) and Wijayawardene et al. (2017a, 2018a).

Scedosporium Sacc. ex Castell. \& Chalm., Manual of tropical medicine (London): 1122 (1919)

Index Fungorum number: IF9794; 11 morphological species (Species Fungorum 2020), 8 species with sequence data.

Type species - Scedosporium apiospermum Sacc. ex Castell. \& Chalm.

Notes - Scedosporium is a ubiquitous filamentous genus with a wide host range and worldwide distribution (Wijayawardene et al. 2017a). The genus is characterized by hyaline, cylindrical conidiogenous cells arising from undifferentiated hyphae, with obovoidal, hyaline, sticky conidia. Graphium-like synnemata are formed with large, erect bundles of hyphae 
terminating in a dense aggregate of conidiogenous cells. The asexual morphs produce conidia from a short extension of the conidiogenous cells with annellidic development (Guého E. \& De Hoog 1991, Lackner et al. 2014, Ramirez-Garcia et al. 2018). The genus was accepted in Microascaceae by Sandoval-Denis et al. (2016a), Maharachchikumbura et al. (2015, 2016b) and Wijayawardene et al. (2017a, 2018a).

Scopulariopsis Bainier, Bull. Soc. Mycol. Fr. 23: 98 (1907)

Index Fungorum number: IF9854; 71 morphological species (Species Fungorum 2020), 21 species with sequence data.

Type species - Scopulariopsis brevicaulis (Sacc.) Bainier

Notes - The asexual morphs are hyphomycetous and saprobic. Species of Scopulariopsis have been recovered from environmental samples (soil, air, mouldy indoor environments), food (cheese and butter), as well as from human clinical samples. The sexual morph is undetermined. Scopulariopsis species are found in terrestrial habitats with worldwide distribution. The genus was accepted in Microascaceae by Kirk et al. (2013), Sandoval-Denis et al. (2016a), Maharachchikumbura et al. (2015, 2016b) and Wijayawardene et al. (2017a, 2018a).

Wardomyces F.T. Brooks \& Hansf., Trans. Br. mycol. Soc. 8(3): 137 (1923)

Index Fungorum number: IF10433; 8 morphological species (Species Fungorum 2020), 7 species with sequence data.

Type species - Wardomyces anomalus F.T. Brooks \& Hansf.

Notes - The asexual morph is hyphomycetous and saprobic. Sexual morphs can be identified by significantly larger ascomata and dark ascospores with two germ pores (Sandoval-Denis et al. 2016a). The genus was accepted in Microascaceae by Ariyawansa et al. (2015), Seifert et al. (2011), Maharachchikumbura et al. (2015, 2016b), Sandoval-Denis et al. (2016a) and Wijayawardene et al. (2012, 2017a, 2018a).

Wardomycopsis Udagawa \& Furuya, Mycotaxon 7(1): 92 (1978)

Index Fungorum number: IF10434; 8 morphological species (Species Fungorum 2020), 7 species with sequence data.

Type species - Wardomycopsis inopinata Udagawa \& Furuya

Notes - The asexual morphs are hyphomycetous saprobes. Conidiation at the early stages of Wardomycopsis resembles those of Wardomyces. However, the sexual morph of Wardomycopsis differ from those of Wardomyces, in terms of having straw-coloured, reniform to triangular ascospores with a single germ pore. Wardomycopsis species are distributed in Asia, Europe, and North America and are mainly soil-borne. The genus was accepted in Microascaceae by Ariyawansa et al. (2015), Seifert et al. (2011), Maharachchikumbura et al. (2015, 2016b), Sandoval-Denis et al. (2016a) and Wijayawardene et al. (2012, 2017a, 2018a).

Yunnania H.Z. Kong, Mycotaxon 69: 320 (1998)

Index Fungorum number: IF27939; 3 species with sequence data.

Type species - Yunnania penicillata H.Z. Kong

Notes - Jagielski et al. (2016) stated that Scopulariopsis carbonaria does not fit in Scopulariopsis and proposed a new genus, Fuscoannellis. Woudenber et al. (2017) gave priority to the already described genus Yunnania (Kong 1998) and synonymized Fuscoannellis with Yunnania. The genus was accepted in Microascaceae by Wijayawardene et al. (2017a).

Microdochiaceae Hern.-Restr., Crous \& J.Z. Groenew., Persoonia 36: 64 (2016)

Index Fungorum number: IF811871; Facesoffungi number: FoF01907; 74 species.

Saprobic, endophytic or pathogenic on leaves, seeds and soil. Sexual morph: Stromata present or absent. Ascomata perithecial. Asci 8-spored, cylindrical, oblong, clavate, with a J+, 
funnel-shaped, apical ring. Ascospores biseriate or uniseriate, hyaline to pale brown, fusoid, ellipsoid or oblong. Asexual morph: Coelomycetous. Conidiomata if present, sporodochial. Conidiophores solitary or aggregated, mono- or biverticillate. Conidiogenous cells solitary or in whorls, polyblastic, sympodial, denticulate, cylindrical often ampulliform, lageniform with elongated necks and minute annellides from percurrent proliferations, hyaline to pale brown. Conidia hyaline, lunate, oblong, fusiform or cylindrical, straight or curved, flattened at base. Chlamydospores if present, brown (adapted from Hernández-Restrepo et al. 2016b).

Type genus - Microdochium Syd. \& P. Syd.

Notes - Microdochiaceae was introduced by Hernández-Restrepo et al. (2016b) to accommodate the genera Microdochium, Idriella and Selenodriella based on LSU sequence data. In the phylogenetic analysis, the type of Microdochium (= Monographella) formed a distinct clade in Xylariales. Species belonging to Microdochiaceae are characterized by monographella-like sexual morphs and asexual morphs with polyblastic, sympodial or annellidic conidiogenous cells, and hyaline conidia without appendages (Hernández-Restrepo et al. 2016b). Combined multi-gene and divergence estimates have revealed that the family diverged around 79 MYA (Hyde et al. 2017a).

\section{Ecological and economic significance of Microdochiaceae}

Microdochiaceae includes many species which are of economic importance as phytopathogens and saprobes. They have been isolated from living, fallen, rotten and decaying leaves, stems, kernals, roots, oospores, soil and air (Kwaśna \& Bateman 2007, Hernández-Restrepo et al. 2016b, Zhang et al. 2017c, Farr \& Rossman 2018). Microdochium nivale and M. majus are both serious soil and seed borne pathogens causing microdochium patch, also known as pink snow mould/fusarium patch, seedling blight on cereals and forage grasses (Glynn et al. 2005, Glynn \& Edwards 2009, Vogelgsang et al. 2013). Control of this disease has been investigated using bacterial seed treatments and botanicals (Vogelgsang et al. 2013, Johansson et al. 2003). Some Microdochiaceae species may act as biocontrol agents, e.g. Microdochium bolleyi as a biocontrol agent of cereal root and stem base pathogens (Douglas \& Deacon 1994). Endophytic Microdochium species are also reported to have applied significance. Zhang et al. (2008) investigated effective anti-fungal, anti-bacterial and anti-algal compounds against Bacillus megaterium, Chlorella fusca Escherichia coli and Microbotryum violaceum using Microdochium bolleyi, an endophyte from Fagonia cretica.

\section{Genera included in Microdochiaceae}

Idriella P.E. Nelson \& S. Wilh., Mycologia 48: 550. (1956)

Index Fungorum number: IF8625; 30 morphological species (Hernández-Restrepo et al. 2016b), 4 species with sequence data.

Type species - Idriella lunata P.E. Nelson \& S. Wilh.

Notes - Idriella comprises soil inhabiting hyphomycetes and terrestrial species worldwide. The genus is characterised by brown, aseptate conidiophores and polyblastic conidiogenous cells with hyaline, unicellular, smooth, lunate, curved conidia in heads (Hernández-Restrepo et al. 2016b).

Microdochium Syd. \& P. Syd., Annls mycol. 22(3/6): 267 (1924)

Index Fungorum number: IF8926; 37 morphological species (Species Fungorum 2020), 20 species with sequence data.

Type species - Microdochium phragmitis Syd. \& P. Syd.

Notes - Microdochium (asexual morph, Monographella - sexual morph) is the type genus of Microdochiaceae and was established by Sydow (1924) with M. phragmitis as the type species, found on living leaves of Phragmites australis in Germany. Since Microdochium has more species and is more commonly encountered, and the name is more frequently used in literature, HernándezRestrepo et al. (2016b) suggested to use Microdochium over Monographella. Microdochium species are economically important plant pathogens on grasses and cereals worldwide (Hernández- 
Restrepo et al. 2016b, Wijayawardene et al. 2017a, Farr \& Rossman 2018). However, species identification mainly depends on multi-gene phylogenetic analyses with the prior the protein coding region tub2. Thirty-seven species have been accepted under Microdochium (Hernández-Restrepo et al. 2016b, Zhang et al. 2017c, Crous et al. 2018c, 2019b).

Microdochium phragmitis, the type species of Microdochium was isolated from leaves of Phragmites communis. Hernández-Restrepo et al. (2016b) epitypified the species and provided an ex-epitype with molecular data. However, variations among the strains and polymorphisms make it difficult to delimit species in Microdochium. This entry is illustrated with Microdochium phragmitis (Fig. 165).
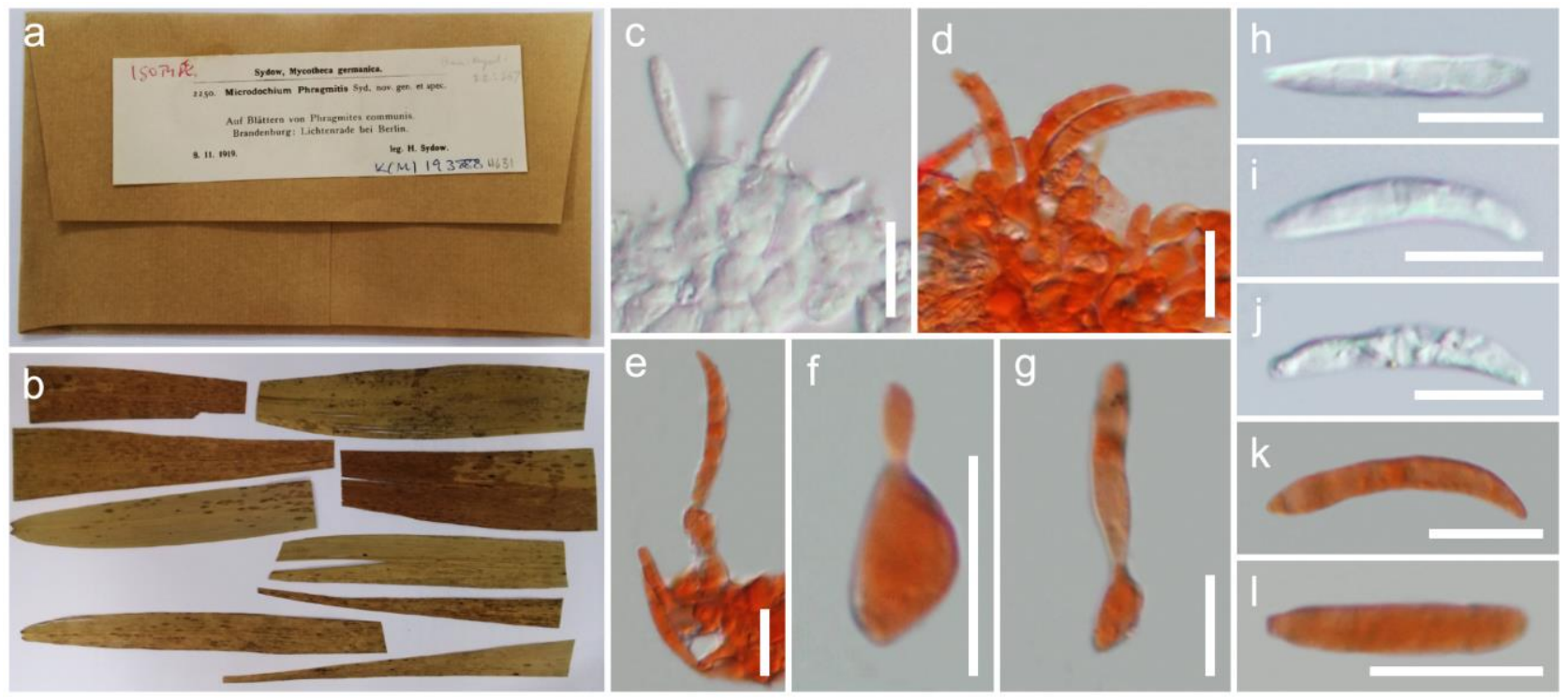

Figure 165 - Microdochium phragmitis (Material examined - GERMANY, Brandenburg, Berlin, on dead leaves of Phragmites communis (Poaceae), 8 November 1919, H. Sydow, K-IMI 193888, holotype). a Herbarium details. b Host. c, d Sporodochia. e-g Conidiogenous cells and attached conidia. h-l Conidia (d, e-g, k, 1 in Congo red). Scale bars: $10 \mu \mathrm{m}$.

Selenodriella R.F. Castañeda \& W.B. Kendr., Univ. Waterloo Biol. Ser. 33: 34 (1990) Index Fungorum number: IF11398; 7 morphological species (Hernández-Restrepo et al. 2016), 2 species with sequence data.

Type species - Selenodriella fertilis (Piroz. \& Hodges) R.F. Castañeda \& W.B. Kendr.

Notes - Selenodriella species are hyphomycetes which produce setiform conidiophores, and conidiogenous cells and branches are disposed in whorls along the main axis of setiform conidiophores. Hernández-Restrepo et al. (2016b) introduced S. cubensis and confirmed the phylogenetic placement in Microdochiaceae.

Myelospermataceae K.D. Hyde \& S.W. Wong, Mycol. Res. 44(1): 349 (1999)

Index Fungorum number: IF82090; Facesoffungi number: FoF06193; 5 species.

Pathogenic or saprobic on various plants. Sexual morph: Pseudostromata weakly raised, visible as blackened ostiolar dots, immersed, multiloculate, clustered around a common central pore. Ascomata in vertical section subglobose or ellipsoidal, brown, necks mostly eccentric leading to the common central pore. Peridium comprising mostly brown-walled, elongate cells, inwardly hyaline and becoming textura intricata and fusing with the host tissue at the outside. Paraphyses numerous, hypha-like, filamentous, septate, unbranched, tapering distally. Asci 8spored, unitunicate, cylindrical, long-pedicellate, apically rounded, with a J-, refractive, subapical, discoid ring. Ascospores overlapping uniseriate, hyaline, irregularly ellipsoidal, curved or straight, some narrower at the center, some lunate, unicellular, and surrounded by a distinct mucilaginous sheath. Asexual morph: Undetermined (adapted from Maharachchikumbura et al. 2016b). 
Type genus - Myelosperma Syd.

Notes - Myelospermataceae was introduced by Hyde \& Wong (1999) to accommodate Myelosperma. The family has been poorly studied. Four species were reported as saprobic and one species as parasitic (M. parasitica). Most of the species occur on palms (Arecaceae), except $M$. gigasporum, which was found on unidentified wood. Hyde \& Wong (1999) accommodated Myelospermataceae in Diaporthales based on lack of stroma (only pseudostroma present), the valsoid nature of the ascomata, deliquescing paraphyses, and ascus morphology. Subsequently, Kirk et al. (2001) placed the genus in Xylariales, which seemed controversial due to lack of reference taxa and molecular analysis (Eriksson 1999, Kang et al. 2002). Maharachchikumbura et al. (2016b) and Wijayawardene et al. (2017a, 2018a) followed the taxonomy of Kirk et al. (2001) and accepted the family in Xylariales. However, it is still unclear if the family belongs in Xylariales. Due to lack of molecular data, the different morphology from other xylariaceous genera with morphological affinities to Diaporthales, herein we place Myelospermataceae in Xylariomycetidae families, incertae sedis, until further studies can better resolve the placement.

\section{Ecological and economic significance of Myelospermataceae}

Species of Myelospermataceae are generally saprobes, although $M$. parasitica causes leaf spots on living leaves of Phoenix reclinata (Hyde et al. 1996). The species are likely to be endophytes which become saprobes on host senescence.

\section{Genus included in Myelospermataceae}

Myelosperma Syd. \& P. Syd., Ann. Mycol. 13: 38 (1915)

Index Fungorum number: IF3351; 5 morphological species (Species Fungorum 2020).

Type species - Myelosperma tumidum Syd. \& P. Syd.

Notes - Myelosperma was established by Sydow \& Sydow (1915) to accommodate Myelosperma tumidum which occurs on the dead rachis of Cocos nucifera. Four species were introduced from different hosts, substrates and countries (Ahmad 1971, Hyde et al. 1996, Aptroot et al. 1998, Hyde \& Wong 1999).

\section{Myrmecridiaceae Crous, Persoonia 34: 219 (2015)}

Index Fungorum number: IF812461; Facesoffungi number: FoF06703; 16 species.

Saprobic on decaying wood submerged in freshwater, leaf litter, on stem or leaves of herbaceous plants, occurring on soil and in house dust (Crous et al. 2015b, c, 2016b, 2018b, c, Peintner et al. 2016, Réblová et al. 2016a, Tibpromma et al. 2017b). Sexual morph: Ascomata immersed, solitary or aggregated, with subglobose to conical venter and ostiolate papilla as well as dark brown clypeus, glabrous. Ostiole periphysate. Peridium leathery, two-layered with hyaline to pale brown outer layer and subhyaline inner layer consisting of cells of textura angularis to textura prismatica. Paraphyses cylindrical, septate. Asci 8-spored, unitunicate, cylindrical, with a slender long pedicel, apex rounded. Ascospores uniseriate or overlapping uniseriate, hyaline, ellipsoidal, 3septate, slightly verrucose, with granular content (Réblová et al. 2016a). Asexual morph: In vitro, Mycelium submerged, hyaline, thin-walled. Conidiophores erect from creeping hyphae, unbranched, straight or flexuous, brown at base and paler towards the apex, subcylindrical, smooth, septate. Conidiogenous cells differentiating from the apical region of conidiophore, integrated, polyblastic, cylindrical, subhyaline to brown, with conidium-bearing denticles along the conidiogenous axis. Conidia hyaline to pale brown, ellipsoid to obovoid to fusoid, solitary, smooth or verrucose, aseptate or septate, some species present a wing-like sheath (adapted from Crous et al. 2015c, 2016a, 2018b, c, Peintner et al. 2016, Tibpromma et al. 2017b).

Type genus - Myrmecridium Arzanlou, W. Gams \& Crous

Notes - Myrmecridiales and Myrmecridiaceae were established by Crous et al. (2015c) to accommodate Myrmecridium species based on the analyses of LSU sequence data. Myrmecridiaceae is the type family of Myrmecridiales (Sordariomycetes). Myrmecridiales is a monotypic order in the subclass Diaporthomycetidae (Crous et al. 2015c) and has phylogenetic 
affinities with Distoseptisporaceae and Magnaporthales in a multi-gene phylogenetic tree based on LSU, SSU, tef1 and rpb2 sequence data (Hongsanan et al. 2017). Myrmecridiaceae comprises two genera Myrmecridium (Arzanlou et al. 2007) and Neomyrmecridium (Crous et al. 2018b).

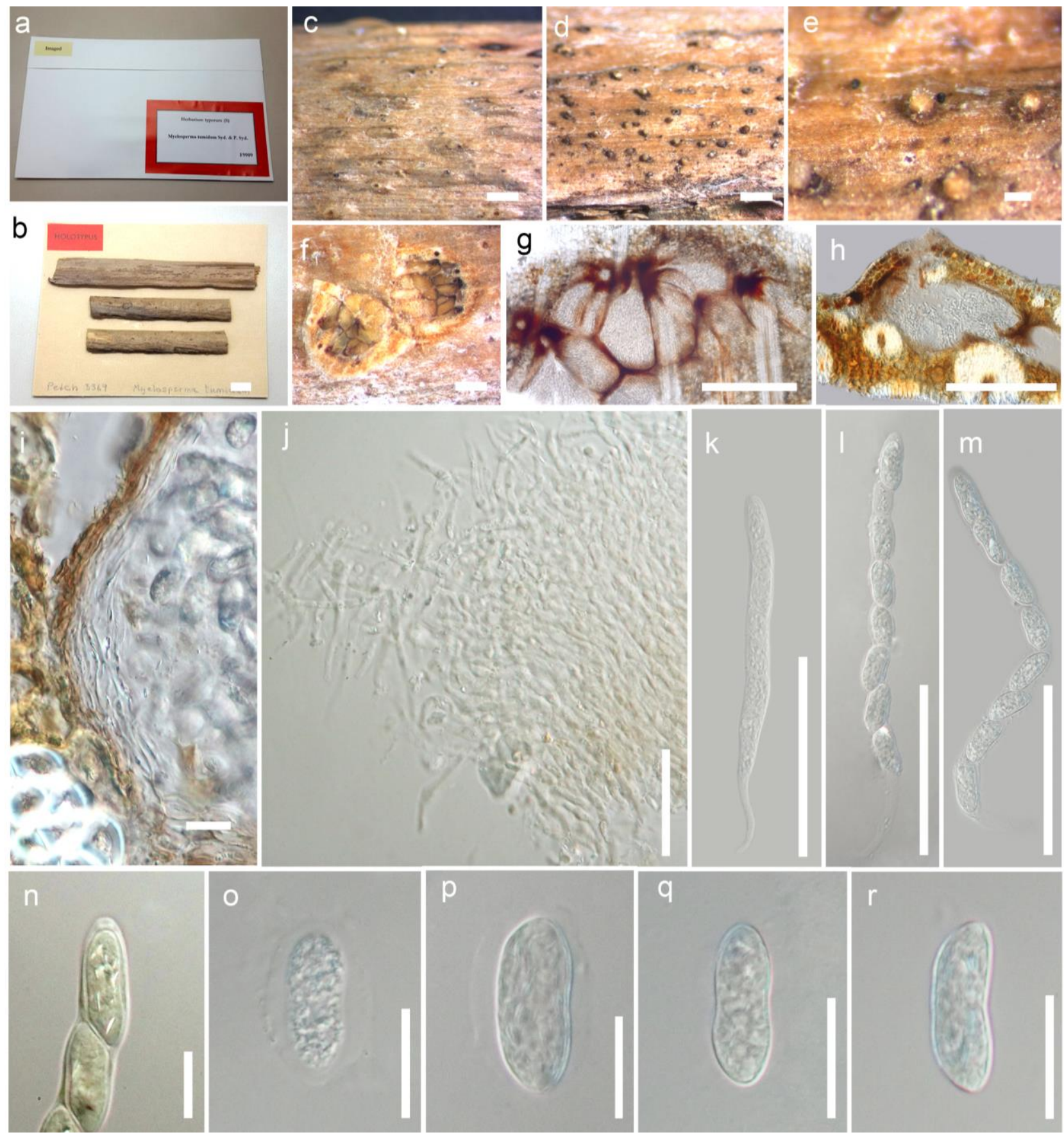

Figure 166 - Myelosperma tumidum (Material examined - SRI LANKA, Peradeniya, on the dead rachis of Cocos nucifera L. (Arecaceae), 1912, T. Petch, S (Swedish Museum of Natural History), F9909, F9911, Petch 3369, holotype). a Herbarium package. b Host. c-e Pseudostromata. f Horizontal section of ascomata. g, h Vertical section through clustered multiloculate ascomata. i Peridium. j Paraphyses. k-m Asci. $n$ Apex of ascus with the refractive subapical ring. o, $p$ Ascospores with sheath. $q, r$ Ascospores. Scale bars: $b=1 \mathrm{~cm}, \mathrm{c}, \mathrm{d}=1000 \mu \mathrm{m}, \mathrm{e}=200 \mu \mathrm{m}, \mathrm{f}=500$ $\mu \mathrm{m}, \mathrm{j}-\mathrm{m}=100 \mu \mathrm{m}, \mathrm{n}-\mathrm{r}=20 \mu \mathrm{m}$.

\section{Ecological and economic significance of Myrmecridiaceae}

As a member of soil fungal community, Myrmecridium species are positively related with the death rate of notoginseng, which is a valuable herbal medicine (Dong et al. 2016). Myrmecridium 
species also occur in the sugarcane rhizosphere, and might have a potential as biocontrol agents against pathogens (Romão-Dumaresq et al. 2016). Myrmecridium schulzeri is an excellent decomposer of wood of oak and pine. It was observed in the third stage of fungi succession during wood decomposition (Wrzesien et al. 2016). Some Myrmecridium species displayed relatively high antibacterial activity (Zhang et al. 2012a) and glyphosate-tolerance (Schlatter et al. 2017b). Myrmecridium taxa showed high abundance in live and dying glyphosate-killed wheat roots and may play an under-recognized role in green bridge dynamics of glyphosate degradation (Schlatter et al. 2017a).

\section{Genera included in Myrmecridiaceae}

Myrmecridium Arzanlou, W. Gams \& Crous, Stud. Mycol.58: 84 (2007)

Index Fungorum number: IF504559; 13 species with sequence data.

Type species - Myrmecridium schulzeri (Sacc.) Arzanlou, W. Gams \& Crous

Notes - Myrmecridium accommodates ramichloridium-like taxa with hyaline mycelium and pale brown to hyaline, conidiogenous cells with pimple-like denticles. Among the 15 epithets listed in Index Fungorum (2020), M. montsegurinum is reported as a sexual morph in Myrmecridium (Réblová et al. 2016a) and the remaining 14 taxa are based on their asexual morphs. Because Myrmecridium sorbicola has septate conidia and it phylogenetically groups with species of Neomyrmecridium, it was transferred to the latter genus (Crous et al. 2018b).

Myrmecridium montsegurinum, which is the only known sexual morph in Myrmecridium, occurs on decaying wood of various deciduous trees submerged in freshwater (Réblová et al. 2016a). Myrmecridium montsegurinum shares a close phylogenetic affinity to $M$. schulzeri and $M$. flexuosum, but statistical support for this alliance is not significant (Réblová et al. 2016a).

Neomyrmecridium Crous, Persoonia 41: 287 (2018)

Index Fungorum number: IF828190; 3 species with sequence data.

Type species - Neomyrmecridium septatum Crous

Notes - Neomyrmecridium was erected by Crous et al. (2018c) to accommodate N. asiaticum Crous, N. septatum and N. sorbicola. This genus is phylogenetically sister to Myrmecridium, however, Neomyrmecridium can be distinguished by its septate conidia.

\section{Myrotheciomycetaceae Crous, Persoonia 40: 351 (2018)}

Index Fungorum number: IF825408; Facesoffungi number: FoF06875; 45 species.

Associated with leaves. Sexual morph: Ascomata sphaerical to slightly irregular, transparent, globose, covered with sparse to abundant, but undifferentiated hyphal attachments, occasionally with conidiophores on the surface, lacking ostioles. Peridium relatively wide, composed of angular cells forming a textura angularis in surface view and rather flattened in side view. Asci crowded, 8spored, uniformly distributed in the centrum, clavate or globose. Ascospores hyaline to pale yellow or light brown, ellipsoidal, unicellular, smooth-walled, with or without pores or slits, with or without wing-like appendages and gelatinous layers. Asexual morph: Conidiomata solitary to sporodochial, with crystalline to white or orange conidial mass; with or without basal stroma. Conidiophores, hyaline, smooth to warty, unbranched or branched, subcylindrical with terminal and lateral conidiogenous cells, some progressively shortened with the formation of each conidium. Conidiogenous cells hyaline, smooth, phialidic or with retrogressive conidiogenesis. Conidia aggregated in slimy mass, with or without septa, hyaline or pale-yellow or pale-brown to brown, smooth-walled, ellipsoid or fusoid-ellipsoid or clavate (adapted from Crous et al. 2018d).

Type genus - Myrotheciomyces Crous

Notes - Myrotheciomycetaceae was introduced by Crous et al. (2018d) in Hypocreales, to accommodate a genus Myrotheciomyces based on characters and phylogenetic analyses. Presently, the family includes Emericellopsis, Leucosphaerina, Myrotheciomyces and Trichothecium (Crous et al. 2018d). 


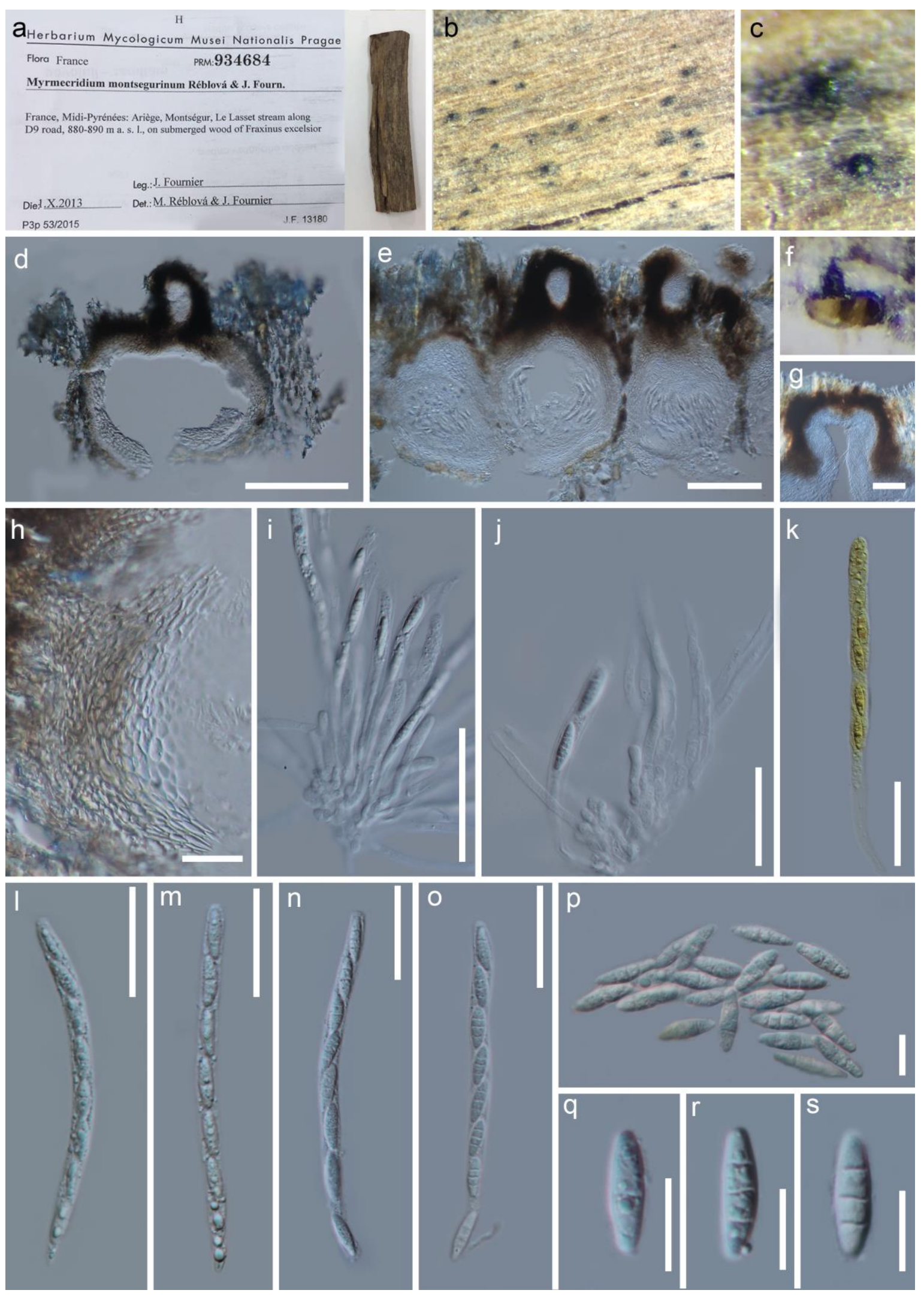

Figure 167 - Myrmecridium montsegurinum (Material examined - FRANCE, Midi-Pyrénées: Ariège, Montségur, Le Lasset stream along D9 road, 880-890 m a.s.1., on submerged wood of Fraxinus excelsior, 1 October 2013, J. Fournier J.F. 13180, PRM 934684, holotype). a Specimen label and host. b, c Appearance of stromata on substrate. d-f Vertical section of ascostroma. $g$ Ostiolar canal. h Peridium. i, j Asci and paraphyses. k-o Asci with ascospores $(\mathrm{k}=$ stained with lugo's iodine). p-s Ascospores. Scale bars: $\mathrm{d}=150 \mu \mathrm{m}, \mathrm{e}=100 \mu \mathrm{m}, \mathrm{g}, \mathrm{i}, \mathrm{k}=50 \mu \mathrm{m}, \mathrm{j}, 1-\mathrm{o}=30 \mu \mathrm{m}$, $\mathrm{h}=25 \mu \mathrm{m}, \mathrm{p}-\mathrm{s}=10 \mu \mathrm{m}$ 

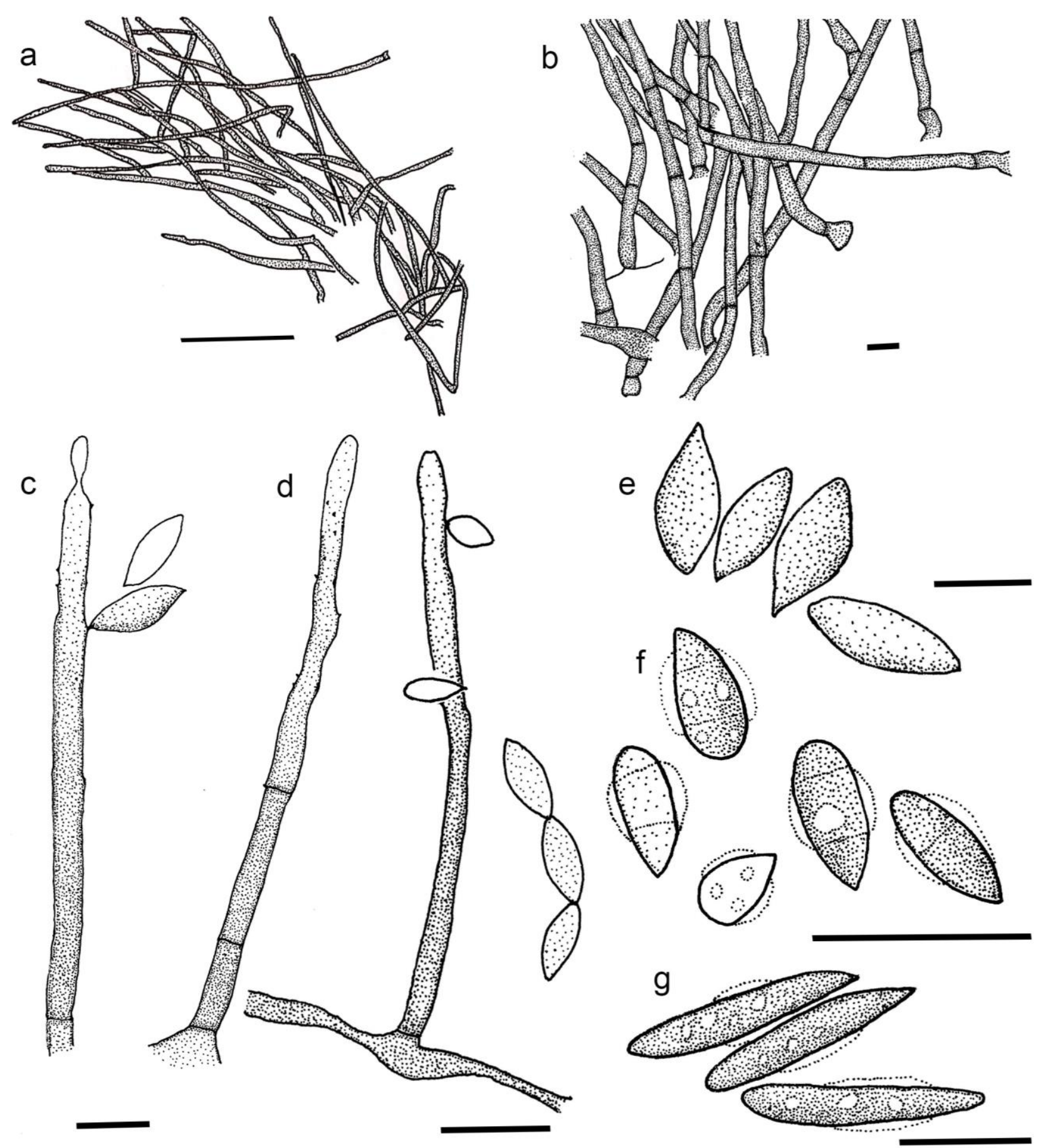

Figure 168 - Myrmecridium schulzeri (CBS 325.74) (a, b, c, e), M. flexuosum (CBS 398.76) (d), M. sorbicola (CBS 143433) (f), M. iridis Crous (CBS 139917) (g). a-d Conidiophores. e-g Conidia (Redrawn from Arzanlou et al. 2007, Crous et al. 2015c, 2018c). Scale bars: $a=100 \mu \mathrm{m}, \mathrm{b}-\mathrm{g}=10$ $\mu \mathrm{m}$.

\section{Ecological and economic significance of Myrotheciomycetaceae}

Members of Myrotheciomycetaceae are pathogens on fruits and vegetables and also saprobes on dead material, decaying vegetables, dung, agricultural and forest soils, peat, rhizomes, prairies and freshwater-, estuarine- and marine-mud sediments, (Domsch et al. 1980, Pitt \& Hocking 1999, Malloch 1989, Giraldo et al. 2012). Trichothecium roseum causes pink rot disease on various fruits and vegetables worldwide (Batt \& Tortorello 2014, Domsch et al. 1980, Pitt \& Hocking 1999). The species produces a wide variety of secondary metabolites, such as roseotoxins and trichothecenes, which can infect and spoil a variety of fruit crops (Batt \& Tortorello 2014). 


\section{Genera included in Myrotheciomycetaceae}

Emericellopsis J.F.H. Beyma, Antonie van Leeuwenhoek 6: 264 (1940)

Index Fungorum number: IF1773; 15 morphological species (Species Fungorum 2020), 14 species with sequence data.

Type species - Emericellopsis terricola J.F.H. Beyma

Notes - Emericellopsis species are primarily soil-derived fungi. Species of Emericellopsis have been isolated from various environments worldwide (viz. agricultural and forest soils, peat, rhizomes, prairies and freshwater-, estuarine- and marine-mud sediments, (Domsch et al. 1980). Globose asci contain 8 ascospores with light brown, ellipsoidal and wing-like appendages (Zuccaro et al. 2004). The asexual morphs have conidiophores arising from substratum or aerial hyphae, and hyaline, 1-2-guttulate, elongate-ellipsoidal conidia (Beyma 1940).
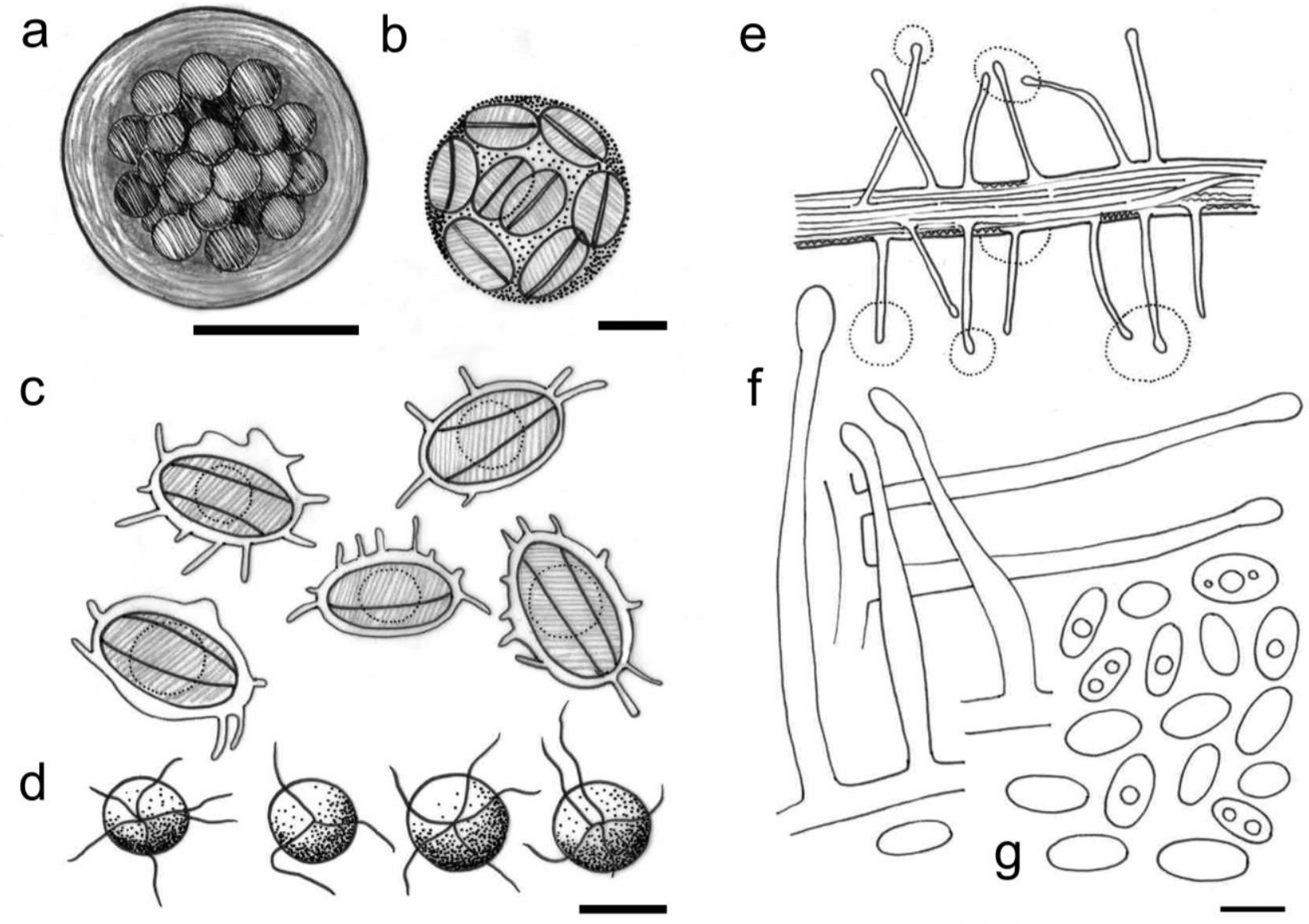

Figure 169 - Emericellopsis terricola (redrawn from Beyma 1940). a Perithecium. b Ascus. c Ascospores. d Ascospores (front view). e Hypha with conidiophores. f Conidiophores. g Conidia. Scale bars: $\mathrm{a}=50 \mu \mathrm{m}, \mathrm{b}-\mathrm{d}, \mathrm{g}=5 \mu \mathrm{m}$.

\section{Leucosphaerina Arx, Persoonia 13(3): 294 (1987)}

Index Fungorum number: IF26159; 2 morphological species (Species Fungorum 2020), 1 species with sequence data.

Type species - Leucosphaerina indica (Arx, Mukerji \& N. Singh) Arx

Notes - Leucosphaerina was introduced by von Arx (1987) based on L. indica from dung of Boselaphus tragocamelus in Delh, but lacks sequence data. Malloch (1989) introduced L. arxii fungi from dung of Equus in North Carolina. Summerbell et al. (2011) provided sequence data for L. arxii. The genus is characterized by clavate asci, ellipsoidal, hyaline ascospores with sheaths, and an acremonium-like asexual morphs with solitary or paired tapering conidiogenous cells, septate at the base, bearing small apical clusters of conidia, conidia are ellipsoidal to obovate, hyaline, 1-celled and produced in wet masses (von Arx 1987, Malloch 1989). 
a

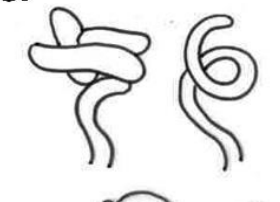

(2)

c

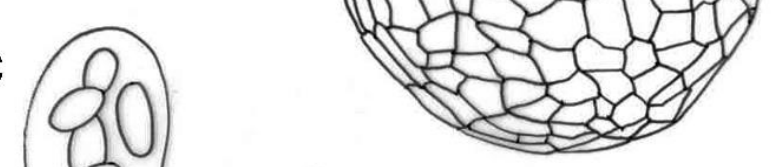

d

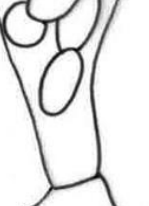

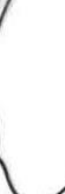

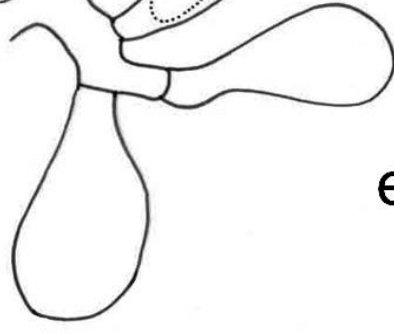

e

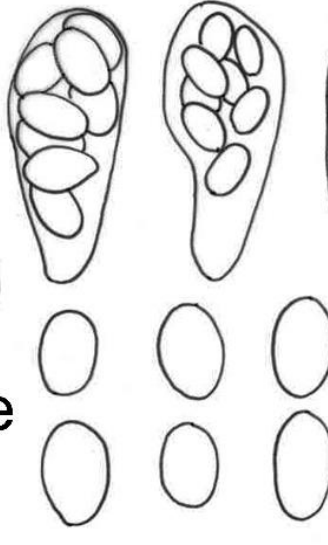

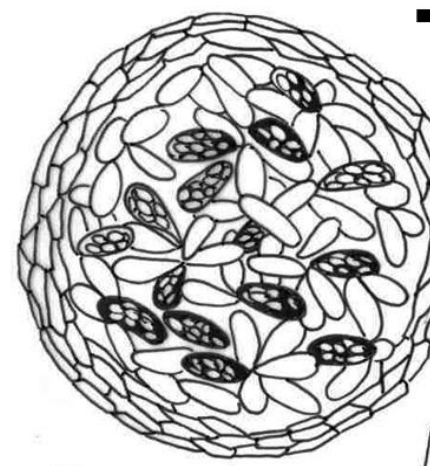

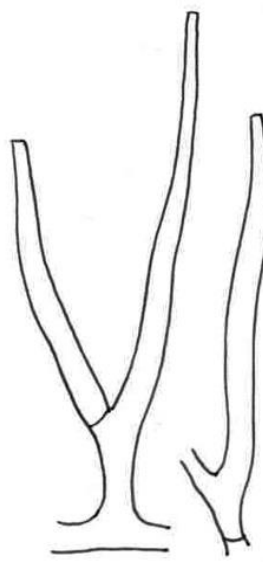

$f$
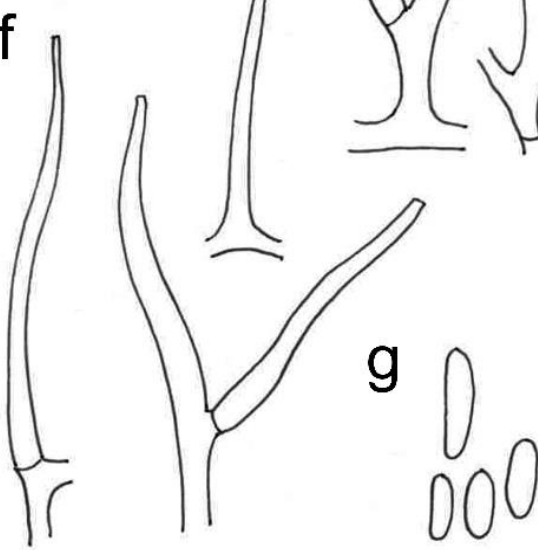

Figure 170 - Leucosphaerina arxii (redrawn from Malloch 1989). a Ascomatal initials. b Ascomata (surface view at left, cross section at right). c Developing asci. d Mature asci. e Ascospores. f Conidiogenous cells. g Conidia. Scale bars: $b=40 \mu \mathrm{m}, \mathrm{a}, \mathrm{c}-\mathrm{g}=10 \mu \mathrm{m}$.

Myrotheciomyces Crous, Persoonia 40: 351 (2018)

Index Fungorum number: IF825409; 1 species with sequence data.

Type species - Myrotheciomyces corymbiae Crous

Notes - The genus was introduced from Corymbia based on morphology and an ITS megablast search (Crous et al. 2018d).
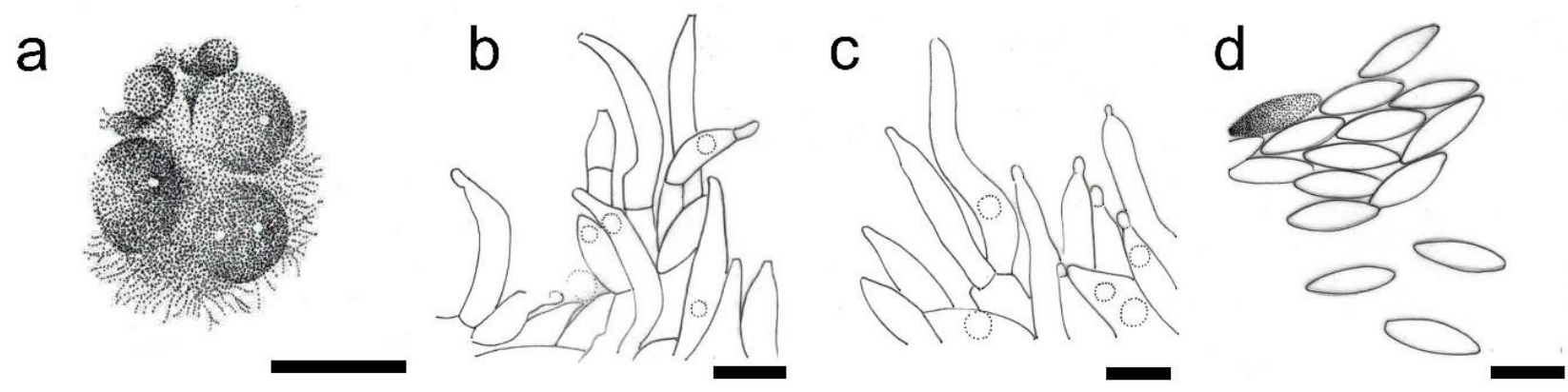

Figure 171 - Myrotheciomyces corymbiae (redrawn from Crous et al. 2018d). a Conidiomata sporulating on pine needle agar. $b$, c Conidiogenous cells. $d$ Conidia. Scale bars: $a=200 \mu \mathrm{m}, \mathrm{b}-\mathrm{d}=$ $10 \mu \mathrm{m}$.

Trichothecium Link, Mag. Gesell. naturf. Freunde, Berlin 3(1-2): 18 (1809)

Index Fungorum number: IF10303; 27 morphological species (Species Fungorum 2020), 5 species with sequence data.

Type species - Trichothecium roseum (Pers.) Link 
Notes - Species of Trichothecium grow on various fruits and vegetables, as well as cereal grains (Pitt \& Hocking 1999) and on decaying vegetation and in soil. Species are characterized by simple hyphae conidiophores and septate, 2-celled, clavate conidia, with the apical cell being larger than the curved basal cell. The sexual morph is undetermined.

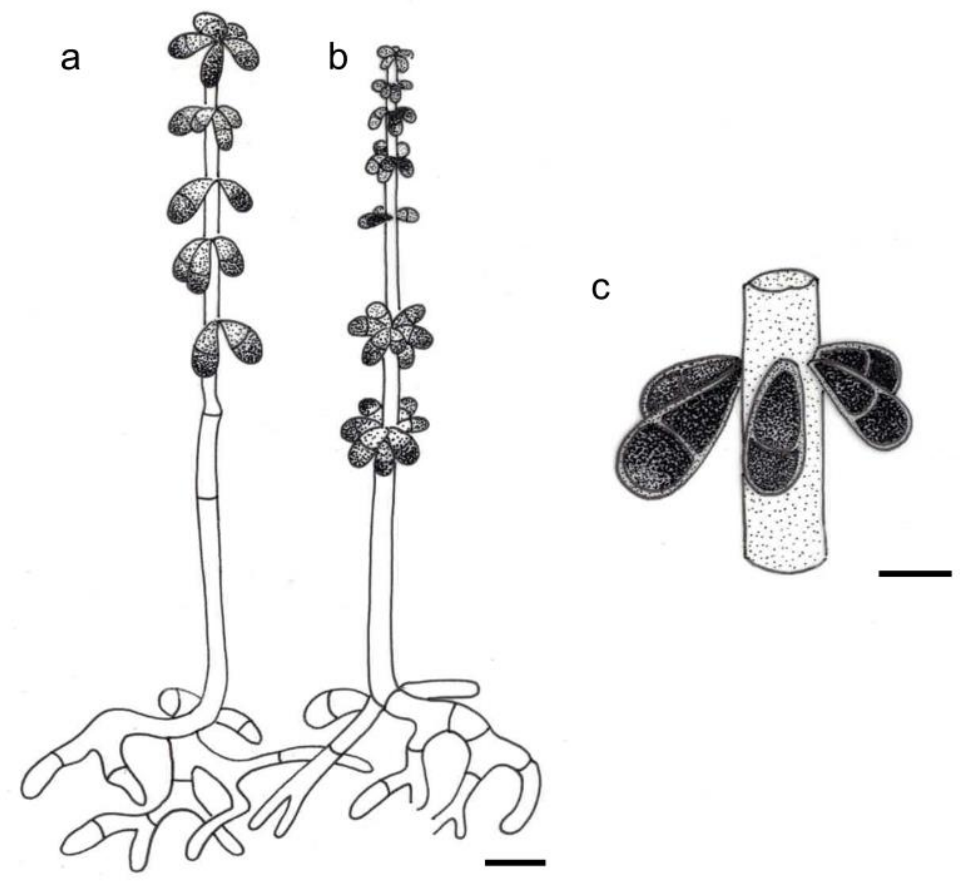

Figure 172 - Trichothecium roseum (redrawn from Halstead 1876 in Popular Science Monthly Vol 9). a-c Conidiophores with conidia. Scale bars: $a, b=20 \mu \mathrm{m}, \mathrm{c}=10 \mu \mathrm{m}$.

Nectriaceae Tul. \& C. Tul., Select. fung. carpol. (Paris) 3: 3 (1865)

Index Fungorum number: IF81059; Facesoffungi number: FoF01396; 2081 species.

Endophytic, foliicolous or saprobic on woody plant hosts, some are entomogenous, a few species are human pathogens, in terrestrial and aquatic habitats. Sexual morph: Ascomata stromatic or astromatic, white, red, dark red, reddish-brown, orange, orange-red, orange-brown, yellow, pale yellow, brown, greyish yellow-green, dark bluish, bluish purple, bluish black or black, solitary or aggregated in groups, perithecial, globose to subglobose, ovoid, elongate-ovoid, obpyriform, obovoid or pyriform, $\mathrm{KOH}+/-$, surface smooth to papillate, striate, warted, verrucose or scaly, with or without setae, ostiolar region sometimes papillate, periphysate. Paraphyses present or absent. Asci 4-8-spored, unitunicate, clavate to narrowly clavate, cylindrical or ellipsoidal, with or without apical ring, with pointed or pedicellate base. Ascospores uniseriate to biseriate or overlapping, hyaline to yellow, yellow-brown, golden-brown, pale-brown or green, fusiform, long-fusiform, ellipsoidal, oblong, biconic, pyriform, reniform or allantoid, aseptate to multi-septate or muriform, constricted at the septum or not, smooth-walled, spinulose, verruculose or striate. Asexual morph: Mainly hyphomycetous, less commonly coelomycetous. Conidiomata synnematous, sporodochial or pycnidial. Conidiophores branched or unbranched, penicillate, verticillate. Conidiogenous cells monophialidic to polyphialidic, ampulliform to lageniform, cylindrical, elongate-ampulliform or subcylindrical, hyaline, smooth-walled. Conidia globose, ovate, ellipsoidal, cylindrical to subcylindrical, fusiform, long-fusiform, filiform, allantoid or falcate, straight to slightly or strongly curved, hyaline, aseptate to multi-septate, constricted at septum or not, with or without visible abscission scars, sometimes guttulate, smooth-walled. Chlamydospores present or absent (adapted from Maharachchikumbura et al. 2016b).

Type genus - Nectria (Fr.) Fr.

Notes - Nectriaceae species occur worldwide, have higher diversity in warm temperate and tropical regions (Rossman et al. 1999, Rossman 2000, Chaverri et al. 2011, Schroers et al. 2011, 
Hyde et al. 2014, Lombard et al. 2015). They are commonly found on bark of recently dead woody substrates, especially in tropical regions. Some are plant endophytes or pathogens, other fungi or insects (Rossman et al. 1999, Lombard et al. 2015).

Seaver (1909) divided Hypocreales into two families: Nectriaceae and Hypocreaceae, based on stromatic and perithecial characters. Petch (1938) also accepted Nectriaceae as a family in Hypocreales, while Munk (1957) and Dennis (1960) placed it in Sphaeriales. However, Kreisel (1969) and Rossman et al. (1999) accepted Nectriaceae and Hypocreaceae as two separate families in Hypocreales. Lumbsch \& Huhndorf (2010) listed 26 genera in Nectriaceae. Maharachchikumbura et al. (2016b) and Lombard et al. (2015) accepted 47 genera in the family based on molecular data. The asexual morphs of Nectriaceae species are mainly hyphomycetous, except Thyronectria, which forms pycnidia (Wijayawardene et al. 2017b). Corinectria was introduced to the family by González \& Chaverri (2017). Another genus Neothyronectria was added to Nectriaceae by Yang et al. (2019). Aiello et al. (2017) introduced the new genus Pleiocarpon, based on morphology and molecular data. Xenocalonectria was placed in synonymy with Xenocylindrocladium by Rossman et al. (2016). Rossman et al. (2016) synonymised Antipodium under Ophionectria. Pleonectria was considered as an synonym of Thyronectria by Wijayawardene et al. (2017b). Stachybotryna, previously listed in Nectriaceae by Maharachchikumbura et al. (2016b), was maintained in Ascomycota genera incertae sedis by Wijayawardene et al. (2018a). Wijayawardene et al. (2018a) accepted 63 genera in Nectriaceae including Baipadisphaeria, Varicosporella, Xenocylindrocladium and Xenoleptographium. A new name was proposed for the monotypic genus Curvicladium by Crous et al. (2016a), as the generic name "Curvicladium" was already occupied for a moss species.

\section{Ecological and economic significance of Nectriaceae}

The members of the Nectriaceae are facultative, sometimes virulent plant pathogens, causing serious problems on crop plants, often encountered as asexual morphs eg. Albonectria rigidiuscula, causes green point gall of cocoa (Ploetz 2007, Pérez et al. 2012, Yang et al. 2018c), while Fusarium sambucinum causes hop canker, potato storage rot, and root rot of many crops (Ray \& Hammerschmidt 1998, Wharton et al. 2006). Fusarium oxysporum causes root rots, foot rots, and wilt diseases of numerous crop plants (Hyde et al. 2014, Chittem et al. 2015, McGovern 2015, Rossman et al. 1999). They also cause cankers, root rots, and other diseases on hardwood and coniferous trees, e.g. Abies and Acer cankers caused by Neonectria castaneicola; beech (Fagus spp.) bark disease caused by Nectria coccinea and $N$. ditissima, black foot disease of grapevines (Vitis spp.) caused by Neonectria liriodendri; 'coral spot Nectria canker' caused by N. cinnabarina; root rots caused by $N$. radicicola; and cankers caused by $N$. rugulosa, among others (Hirooka et al. 2005, 2012, Kobayashi et al. 2005, Castlebury et al. 2006, Halleen et al. 2006, Chaverri et al. 2011). Some of the species of Nectriaceae are important in agricultural industry as they can be used for production of plant hormones eg. gibberellic acid production by Fusarium moniliforme (Panchal \& Desai 2016, Puyam et al. 2017).

\section{Genera included in Nectriaceae}

In this paper we only list the genera in Nectriaceae. Notes will be provided in a monograph.

Albonectria Rossman \& Samuels, Stud. Mycol. 42: 105 (1999)

Index Fungorum number: IF27953; 1 morphological species.

Type species - Albonectria rigidiuscula (Berk. \& Broome) Rossman \& Samuels

Allantonectria Earle, Plant. Bak. 2(1): 11 (1901)

Index Fungorum number: IF128; 2 morphological species (Species Fungorum 2020), 1 species with sequence data.

Type species - Allantonectria miltina (Durieu \& Mont.) Weese 
Allonectella Petr., Sydowia 4(1-6): 345 (1950)

Index Fungorum number: IF140; 2 morphological species (Species Fungorum 2020).

Type species - Allonectella rubescens Petr.

Aphanocladium W. Gams, Cephalosporium-artige Schimmelpilze (Stuttgart): 196 (1971)

Index Fungorum number: IF7184; 3 morphological species (Species Fungorum 2020), 1 species with sequence data.

Type species - Aphanocladium album (Preuss) W. Gams

Aquanectria L. Lombard \& Crous, Stud. Mycol. 80: 207 (2015)

Index Fungorum number: IF810949; 7 species with sequence data.

Type species - Aquanectria penicillioides (Ingold) L. Lombard \& Crous

Atractium Link, Mag. Gesell. naturf. Freunde, Berlin 3(1-2): 10 (1809)

Index Fungorum number: IF7291; 5 morphological species (Species Fungorum 2020), 2 species with sequence data.

Type species - Atractium stilbaster Link, Mag. Gesell.

Baipadisphaeria Pinruan, Mycosphere 1: 58 (2011)

Index Fungorum number: IF518245; 1 species with sequence data.

Type species - Baipadisphaeria spathulospora Pinruan

Bisifusarium L. Lombard, Crous \& W. Gams, Stud. Mycol. 80: 223 (2015)

Index Fungorum number: IF810226; 7 species with sequence data.

Type species - Bisifusarium dimerum (Penz.) L. Lombard \& Crous

Calonectria De Not., Comm. Soc. crittog. Ital. 2(3): 477 (1867)

Index Fungorum number: IF746; 203 morphological species (Species Fungorum 2020), 157

species with sequence data.

Type species - Calonectria pyrochroa (Desm.) Sacc.

Calostilbe Sacc. \& P. Syd., Syll. fung. (Abellini) 16: 591(1902)

Index Fungorum number: IF758; 3 morphological species (Species Fungorum 2020), 1 species with sequence data.

Type species - Calostilbe striispora (Ellis \& Everh.) Seaver

Campylocarpon Halleen, Schroers \& Crous, Stud. Mycol. 50(2): 448 (2004)

Index Fungorum number: IF28858; 3 species with sequence data.

Type species - Campylocarpon fasciculare Schroers, Halleen \& Crous

Chaetonectrioides Matsush., Matsush. Mycol. Mem. 9: 5 (1996)

Index Fungorum number: IF27663; 1 morphological species.

Type species - Chaetonectrioides malaysiana Matsush.

Chaetopsina Rambelli, Atti Accad. Sci. Ist. Bologna, Cl. Sci. Fis. Rendiconti 3: 5 (1956)

Index Fungorum number: IF7584; 18 morphological species (Species Fungorum 2020), 7

species with sequence data

Type species - Chaetopsina fulva Rambelli

Coccinonectria L.Lombard \& Crous, Stud. Mycol. 80: 218 (2015)

Index Fungorum number: IF810176; 2 species with sequence data.

Type species - Coccinonectria pachysandricola (B.O. Dodge) L. Lombard \& Crous 
Corallomycetella Henn., Hedwigia 43: 245 (1904)

Index Fungorum number: IF1237; 3 morphological species (Species Fungorum 2020), 2 species with sequence data.

Type species - Corallomycetella heinsenii Henn.

Corallonectria C. Herrera \& P. Chaverri, Mycosystema 32(3): 539 (2013)

Index Fungorum number: IF803108; 1 species with sequence data.

Type species - Corallonectria jatrophae (Möller) C.Herrera \& P. Chaverri

Corinectria C. González \& P. Chaverri, Mycol. Progr. 16(11-12): 1021 (2017)

Index Fungorum number: IF822856; 1 species with sequence data.

Type species - Corinectria fuckeliana (C. Booth) C. González \& P. Chaverri

Cosmospora Rabenh., Hedwigia 2: 59 (1862)

Index Fungorum number: IF1273; 48 morphological species (Species Fungorum 2020), 27

species with sequence data.

Type species - Cosmospora coccinea Rabenh.

Cosmosporella S.K. Huang, R. Jeewon \& K.D. Hyde, Cryptog. Mycol. 39(2): 179 (2018)

Index Fungorum number: IF554371; 1 species with sequence data.

Type species - Cosmosporella olivacea S.K. Huang, R. Jeewon \& K.D. Hyde

Curvicladiella Decock \& Crous, Stud. Mycol. 55: 225(2006)

Index Fungorum number: IF500866; 1 species with sequence data.

Type species - Curvicladiella cignea (Decock \& Crous) Decock \& Crous

Cyanochyta Höhn., Sber. Akad. Wiss. Wien, Math.-naturw. Kl., Abt. 1 124: 92 (1915)

Index Fungorum number: IF7853; 1 morphological species.

Type species - Cyanochyta cyanogena (Speg.) Höhn.

Cyanonectria Samuels \& P. Chaverri, Mycol. Progr. 8(1): 56 (2009)

Index Fungorum number: IF537057; 1 species with sequence data.

Type species - Cyanonectria cyanostoma (Sacc. \& Flageolet) Samuels \& P. Chaverri

Cyanophomella Höhn., Hedwigia 60: 156 (1918)

Index Fungorum number: IF25077; 1 morphological species.

Type species - Cyanophomella acervalis (Sacc.) Höhn.

Cylindrocladiella Boesew., Can. J. Bot. 60(11): 2289 (1982)

Index Fungorum number: IF7869; 45 morphological species (Species Fungorum 2020), 43 species with sequence data.

Type species - Cylindrocladiella parva (P.J. Anderson) Boesew.

Cylindrodendrum Bonord., Handb. Allgem. mykol. (Stuttgart): 98 (1851)

Index Fungorum number: IF7873; 42 morphological species (Species Fungorum 2020), 40 species with sequence data.

Type species - Cylindrodendrum album Bonord.

Dacryoma Samuels, Brittonia 40(3): 328 (1988)

Index Fungorum number: IF25250; 2 morphological species (Species Fungorum 2020).

Type species - Dacryoma album Samuels 
Dactylonectria L. Lombard \& Crous, Phytopathol. Medit. 53: 348 (2014)

Index Fungorum number: IF810142; 13 morphological species (Species Fungorum 2020), 12 species with sequence data.

Type species - Dactylonectria macrodidyma (Halleen et al.) L. Lombard \& Crous

Dematiocladium Allegr., Aramb., Cazau \& Crous, Mycol. Res. 109(7): 836 (2005)

Index Fungorum number: IF28939; 2 species with sequence data.

Type species - Dematiocladium celtidis Allegr., Aramb., Cazau \& Crous

Fusarium Link, Mag. Gesell. naturf. Freunde, Berlin 3(1-2): 10 (1809)

Index Fungorum number: IF8284; 298 morphological species (Species Fungorum 2020, Xia et al. 2019), 189 species with sequence data.

Type species - Fusarium roseum Link

Fusicolla Bonord., Handb. Allgem.mykol. (Stuttgart): 150 (1851)

Index Fungorum number: IF8294; 10 morphological species (Species Fungorum 2020), 9 species with sequence data.

Type species - Fusicolla betae Bonord.

Geejayessia Schroers, Gräfenhan \& Seifert, Stud.Mycol. 68(1): 124 (2011)

Index Fungorum number: IF519479; 6 morphological species (Species Fungorum 2020), 2 species with sequence data.

Type species - Geejayessia cicatricum (Berk.) Schroers

Gliocephalotrichum J.J. Ellis \& Hesselt., Bull. Torrey bot. Club 89: 21 (1962)

Index Fungorum number: IF8340; 13 species with sequence data.

Type species - Gliocephalotrichum bulbilium J.J. Ellis \& Hesselt.

Gliocladiopsis S.B. Saksena, Mycologia 46: 662 (1954)

Index Fungorum number: IF8341; 14 species with sequence data.

Type species - Gliocladiopsis sagariensis S.B. Saksena

Notes - A new isolate MFLUCC 19-0309 grouped with the ex-type of Gliocladiopsis tenuis (IMI 68205) and other G. tenuis isolates (data not shown). Our collection is also similar to G. tenuis in conidiophore and conidial dimensions (Crous \& Wingfield 1993, Crous \& Peerally 1996). Based on morphological similarities and phylogenetic analysis we identified our fungus as Gliocladiopsis tenuis, which is illustrated here (Fig. 15).

Ilyonectria P. Chaverri \& C. Salgado, Stud. Mycol. 68(1): 69 (2011)

Index Fungorum number: IF518558; 23 species with sequence data.

Type species - Ilyonectria radicicola (Gerlach \& L. Nilsson) P. Chaverri \& C. Salgado

Macroconia (Wollenw.) Gräfenhan, Seifert \& Schroers, Stud. Mycol. 68(1): 101 (2011)

Index Fungorum number: IF519441; 4 morphological species (Species Fungorum 2020), 1 species with sequence data.

Type species - Macroconia leptosphaeriae (Niessl) Gräfenhan \& Schroers

Mariannaea G. Arnaud, Bull. trimest. Soc. mycol. Fr. 68:196 (1952)

Index Fungorum number: IF529380; 18 morphological species (Species Fungorum 2020), 16 species with sequence data.

Type species - Mariannaea elegans G. Arnaud

Microcera Desm., Annls Sci. Nat., Bot., sér. 3 10: 359 (1848) 
Index Fungorum number: IF8920; 4 species with sequence data.

Type species - Microcera coccophila Desm.
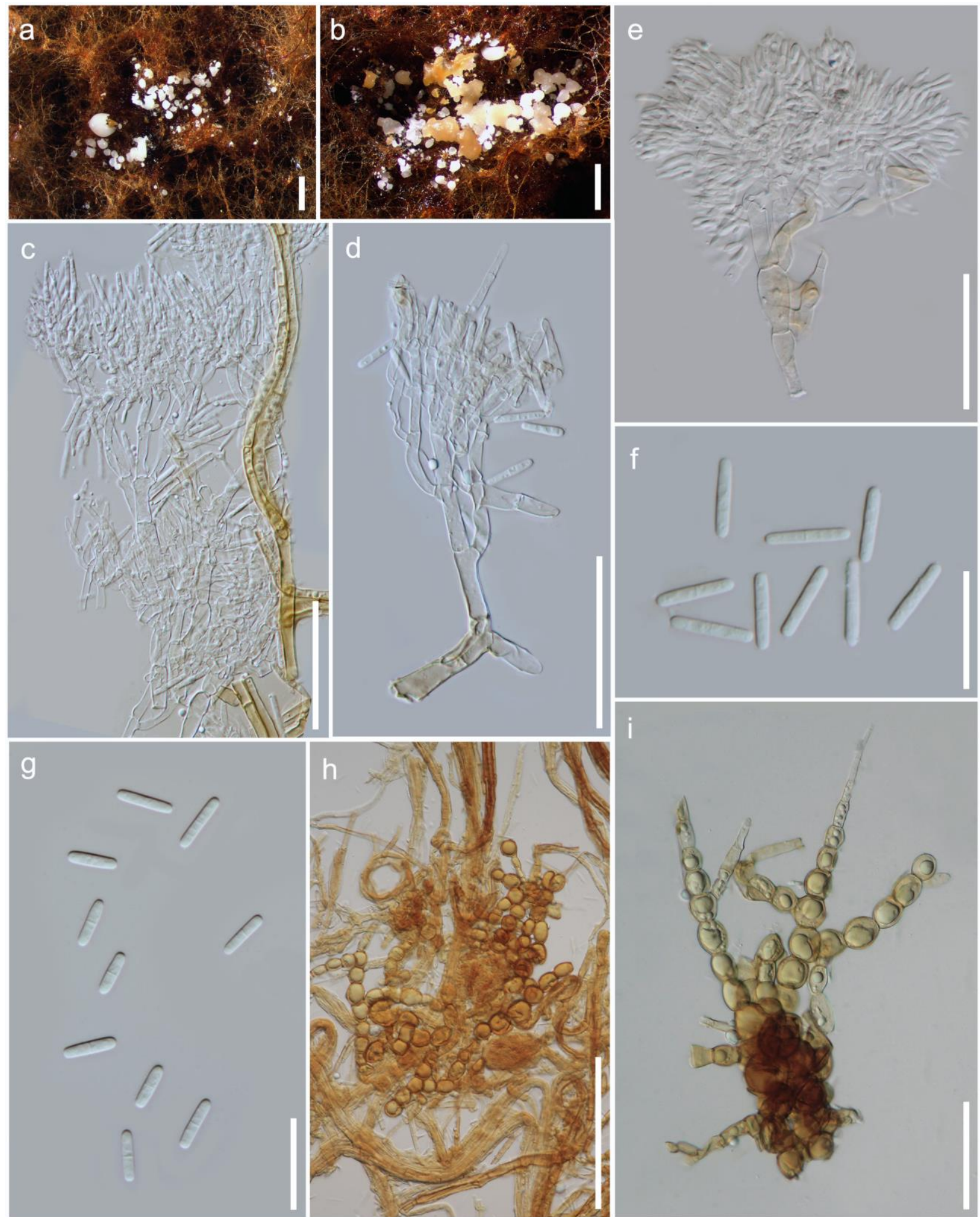

Figure 173 - Gliocladiopsis tenuis (Material examined - THAILAND, Chiang Rai Province, Mae Fah Luang University, on decaying fruit of a palm tree, 18 August 2017, R.H. Perera CR-F 12, MFLU 19-0956; living culture, MFLUCC 19-0309). a, b Conidiomata on PDA. c-e Conidiophores, conidiogenous cells with attached conidia. f, g Conidia. h Mycelium with chlamydospores. i Chlamydospores. Scale bars: $\mathrm{a}, \mathrm{b}=1 \mathrm{~mm}, \mathrm{c}-\mathrm{e}, \mathrm{g}=50 \mu \mathrm{m}, \mathrm{f}, \mathrm{g}=20 \mu \mathrm{m}, \mathrm{h}, \mathrm{i}=50 \mu \mathrm{m}$. 
Murinectria M. Niranjan \& V.V. Sarma, gen. nov.

Index Fungorum number: IF556843; Facesoffungi number: FoF06587; 4 species with sequence data.

Etymology - The generic name refers to Nectria spp. having muriform ascospores.

Sexual morph: Stromata immersed to erumpent, subiculate, solitary to aggregated, bright red. Ascomata perithecial, superficial, globose, gregarious, immersed in the stroma, $\mathrm{KOH}+\mathrm{ve}$ pigments, often associated with synnemata of the asexual state. Peridium consists of cells of textura globulosa and textura angularis, walls pigmented. Asci unitunicate, 8-spored, cylindric-clavate, with or without an inconspicuous ring at apex, early deliquescent. Ascospores overlapping biseriate, hyaline to pale brown, yellow in Lugol's solution, ellipsoidal to fusiform, muriform, often constricted at each septum, straight or slightly curved. Asexual morph: Synnematous on natural substrata, laterally oriented near perithecial ascomata, usually erumpent through epidermis, solitary to gregarious around ascomata, erect or nodding, red-brown at base, becoming dark brown to black with age, Conidiogenous cells phialidic. Conidia hyaline, obovoid, slightly flat to rounded apex, narrow towards base, acute or obtuse ends.

Type species - Murinectria murispora M. Niranjan \& V.V. Sarma.

Notes - Murinectria is characterized by muriform ascospores, which are similar to some muriform species in Nectria. In our phylogenetic analysis, M. murispora branched separately from other species of Nectria but clustered closely with Nectria species with muriform ascospores. Hence, we establish a new genus Murinectria based on muriform ascospores in the sexual morph and a synnematous asexual morph with phialospores.

Murinectria murispora M. Niranjan \& V.V. Sarma, sp. nov.

Figs 175,176

Index Fungorum number: IF556613; Facesoffungi number: FoF06267

Etymology - The specific epithet "murispora" refers to the fungus having muriform ascospores.

Holotype - AMH-10077.

Saprobic on decaying climber. Sexual morph: Stromata up to $1 \mathrm{~mm}$ high and $3.2 \mathrm{~mm}$ diam., erumpent through epidermis, subiculate, pseudoparenchymatous cells forming textura prismatica cell layers, intergrading with peridium. Ascomata 550-580 × 415-500 $\mu \mathrm{m}$, perithecial, globose, superficial, gregarious, $\mathrm{KOH}+$ dark red, $\mathrm{LA}+$ yellow, often associated with synnemata of the asexual state, depressed apical region, periphysate, apical region without stroma. Peridium up to 43 $\mu \mathrm{m}$ thick, wall consists of textura globulosa and textura angularis cells, walls pigmented. Asci 64$92 \times 14.5-18 \mu \mathrm{m}, 8$-spored, unitunicate, cylindric-clavate, with an inconspicuous ring at apex, early deliquescent. Ascospores (25-) 26-36.6 (-38) $\times 10-16.5(-18.5) \mu \mathrm{m}(\bar{x}=32.8 \times 14.9, \mathrm{n}=28)$, overlapping biseriate, hyaline, yellow in Lugol's solution, ellipsoidal to fusiform, muriform, with 5-9 transverse septa and 1-5 longitudinal septa, often constricted at each septum, straight, sometimes slightly curved, smooth-walled. Asexual morph: Synnematous on natural substrata, 892 $\mu \mathrm{m}$ length $\times 144-164 \mu \mathrm{m}$ diameter, laterally oriented near perithecial ascomata, usually erumpent through epidermis, solitary to gregarious around ascomata, erect or nodding, unbranched, narrowing towards apex, red-brown at base, becoming dark brown to black with age, ovoid heads consisting of pools of conidia, individual conidiophores septate. Conidiogenous cells phialidic. Conidia 4.7-6.3 × 2.6-3.4 $\mu \mathrm{m}(\bar{x}=5.5 \times 3, \mathrm{n}=28)$, hyaline, obovoid, slightly flat to rounded apex, narrow towards base, acute ends, smooth-walled.

Culture characteristics - White cottony colonies on malt extract agar, becoming gray-brown at maturity, filamentous, radial, background pale yellow colour, $42 \mathrm{~mm}$ diameter in one-week old culture grown at $28{ }^{\circ} \mathrm{C}$.

Material examined - INDIA, Andaman and Nicobar Islands, South Andaman, Pongibalu, Manjery (11 $\left.{ }^{\circ} 52^{\prime} 25.7^{\prime \prime} \mathrm{N} 92^{\circ} 64^{\prime} 89.9^{\prime \prime} \mathrm{E}\right)$, on decaying twig, 10 December, 2017. M. Niranjan PUFNI 17634 (AMH-10077, holotype), extype-living culture, NFCCI-4515.

GenBank numbers - ITS: MK860769, LSU: MK860767. 
Notes - Murinectria murispora has similar characters to three species of Nectria in having muriform ascospores (Table 1) (Hirooka et al. 2012). In comparison to Murinectria murispora, Nectria polythalama stromata are shorter and narrower and have smaller ascomata and ascospores. The synnemata (asexual state) on natural substrata are scattered or grow around the stromata of Murinectria murispora, while in Nectria polythalama, the synnemata are frequently found in the middle of the stromata. Nectria pseudotrichia also resembles Murinectria murispora in having similar ascomata and muriform ascospores, but is distinct in having smaller ascomata and ascospores. Nectria antarctica also has muriform ascospores. The ascostromata and ascospores of $N$. antarctica, however, are smaller and have longer asci when compared to Murinectria murispora. Murinectria murispora is quite similar to Nectria polythalama and N. pseudotrichia in terms of septal constrictions, unlike $N$. antarctica. Murinectria murispora is distinct from all three species in often having 5 longitudinal septa. Hence, based on the above mentioned differences and DNA sequence analysis, a new species, $M$. murispora is introduced.

Murinectria antarctica (Speg.) M. Niranjan \& V.V. Sarma, comb. nov.

Index Fungorum number: IF557053

Basionym - Nectria antarctica (Speg.) Rossman., Mem. New York Bot. Gard. 49: 25 (1989)

Murinectria pseudotrichia (Schwein) M. Niranjan \& V.V. Sarma, comb. nov.

Index Fungorum number: IF557054

Basionym - Nectria pseudonectria (Schewein.) Berk. \& M.A. Curtis, Journal of the Academy of Natural Sciences, Phiadelphia 2: 289 (1853)

Murinectria polythalama (Berk) M. Niranjan \& V.V. Sarma, comb. nov.

Index Fungorum number: IF557055

Basionym - Nectria polythalama Berk., The botany of the Antarctic Voyage II, Flora NovaeZealandiae 2: 203, t. 106:15 (1855)

Notes - Nectria was originally described with light to bright, soft-textured, superficial, uniloculate perithecia, unitunicate asci and phialidic asexual morphs (Hirooka et al. 2012). For a long time, the concept of Nectria was very broad with more than 1000 species described under Nectria sensu lato. Many species of Nectria sensu lato have been placed in segregate genera in Bionectriaceae and Nectriaceae (Rossman et al. 1999, Schoch et al. 2000, Luo \& Zhuang 2010, Chaverri et al. 2011). Saccardo (1883c) also separated genera based on single characters e.g. species with medium length ascospores having more than one horizontal septum were placed in Calonectria, while those with very long ascospores and multiple septa were placed in Ophionectria.

Nectria and Thyronectria have some species with muriform ascospores (Jaklitsch \& Voglmayr 2014). Thyronectria species have immersed ascomata with a bright yellow scurf, muriform ascospores that produce small ascoconidia in the asci and pycnidial asexual morphs. On the contrary, Nectria is characterized by immersed to erumpent ascomata without a bright yellow scurf and one to many horizontally septate to muriform ascospores, but lacks ascoconida and has synnematous or sporodochial asexual morphs (Hirooka et al. 2012, Jaklitsch \& Voglmayr 2014). Rossman et al. (1999) accepted only 28 species in Nectria. Only N. antarctica, N. polythalama, and N. pseudotrichia have muriform ascospores. A new taxon collected on decaying twigs in Andaman Islands, India has similarities to Nectria and has muriform ascospores. In our molecular analysis based on ITS and LSU sequence data (Fig. 174) it clustered with other muriform species of Nectria (Fig. 15). These three species and the new taxon branched separately in our phylogram and were distantly placed from other species of Nectria, such as $N$. balansiae. Hence, based on the characteristics (muriform ascospores) and the molecular sequence analysis, a new genus Murinectria is introduced with $M$. murispora as the type species. Nectria antarctica, $N$. 
pseudotrichia and N. polythalama. which produce muriform ascospores are herein transferred to Murinectria as M. antarctica, M. pseudotrichia and M. polythalama.

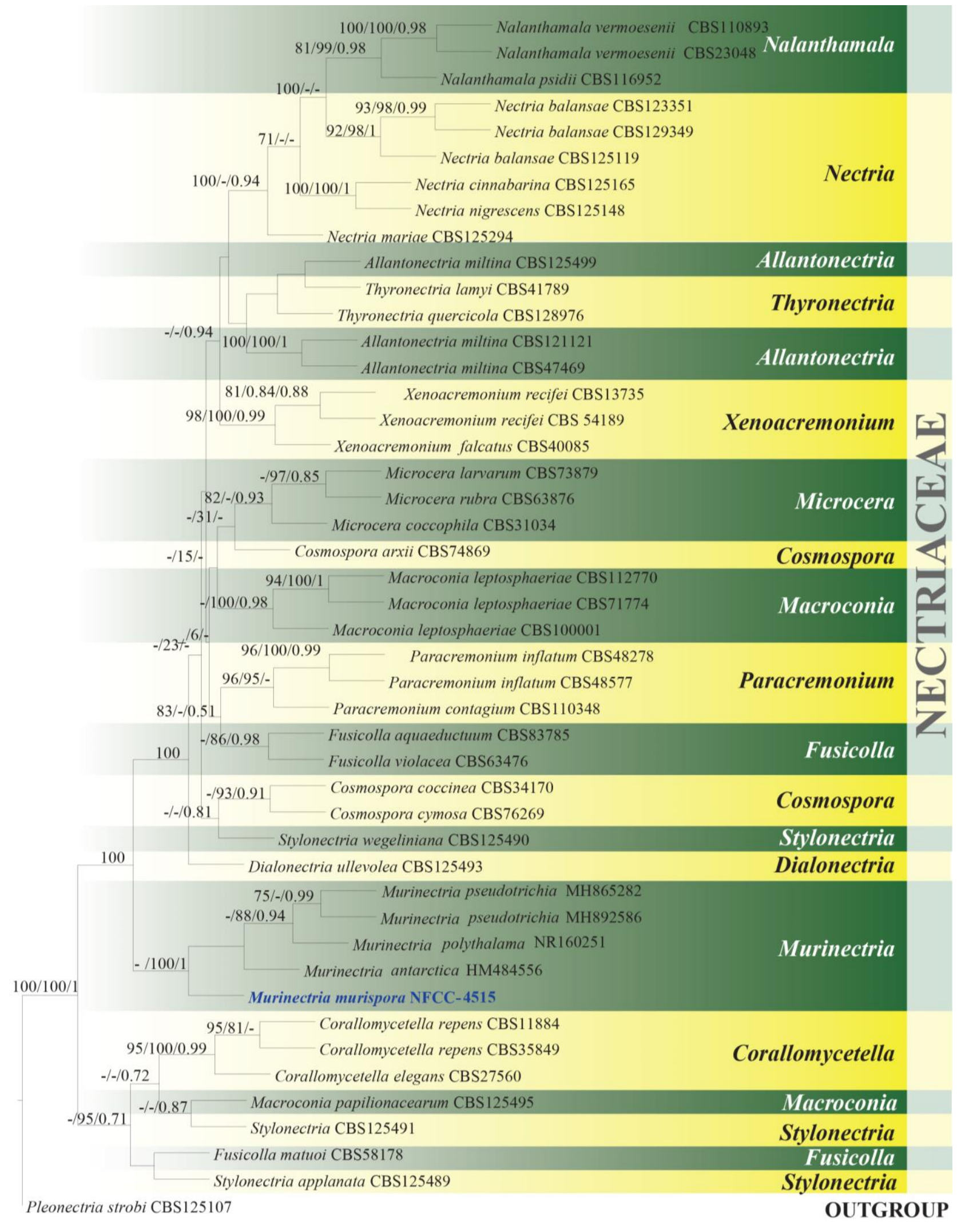

90.0

Figure 174 - Maximum parsimony phylogeny constructed using the ITS and LSU sequences from strains of Nectriaceae with the new taxon Murinectria murispora. 

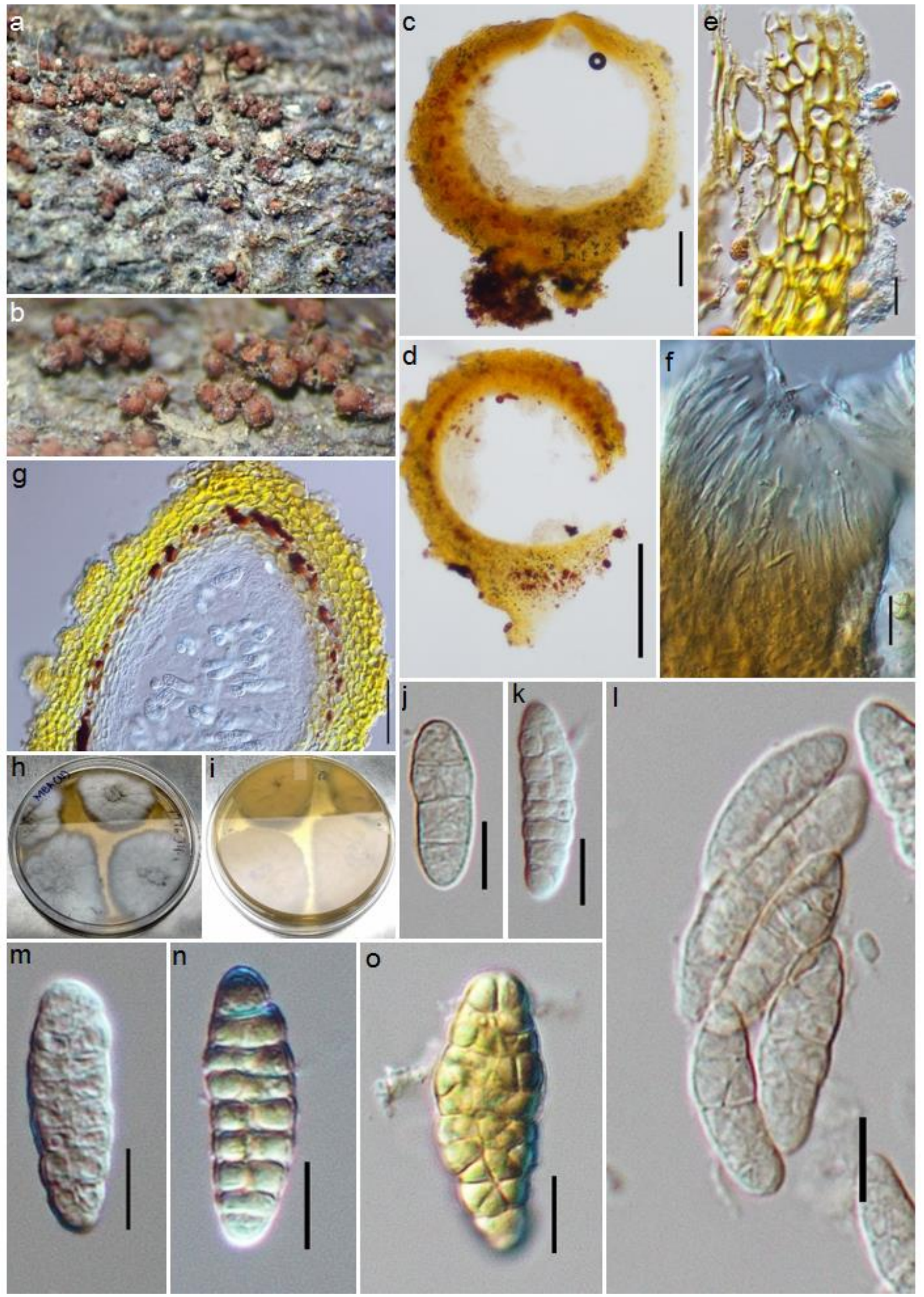

Figure 175 - Murinectria murispora (AMH-10077, holotype), a, b Ascomata on host. c, d, g Vertical section of ascomata. e Peridium. f Neck. h, i Culture on MEA plate. 1 Asci. j, k, m-o Ascospores. Scale bars: $d=100 \mu \mathrm{m}, \mathrm{d}, \mathrm{f}, \mathrm{g}=50 \mu \mathrm{m}, \mathrm{j}-\mathrm{o}=10 \mu \mathrm{m}$. 


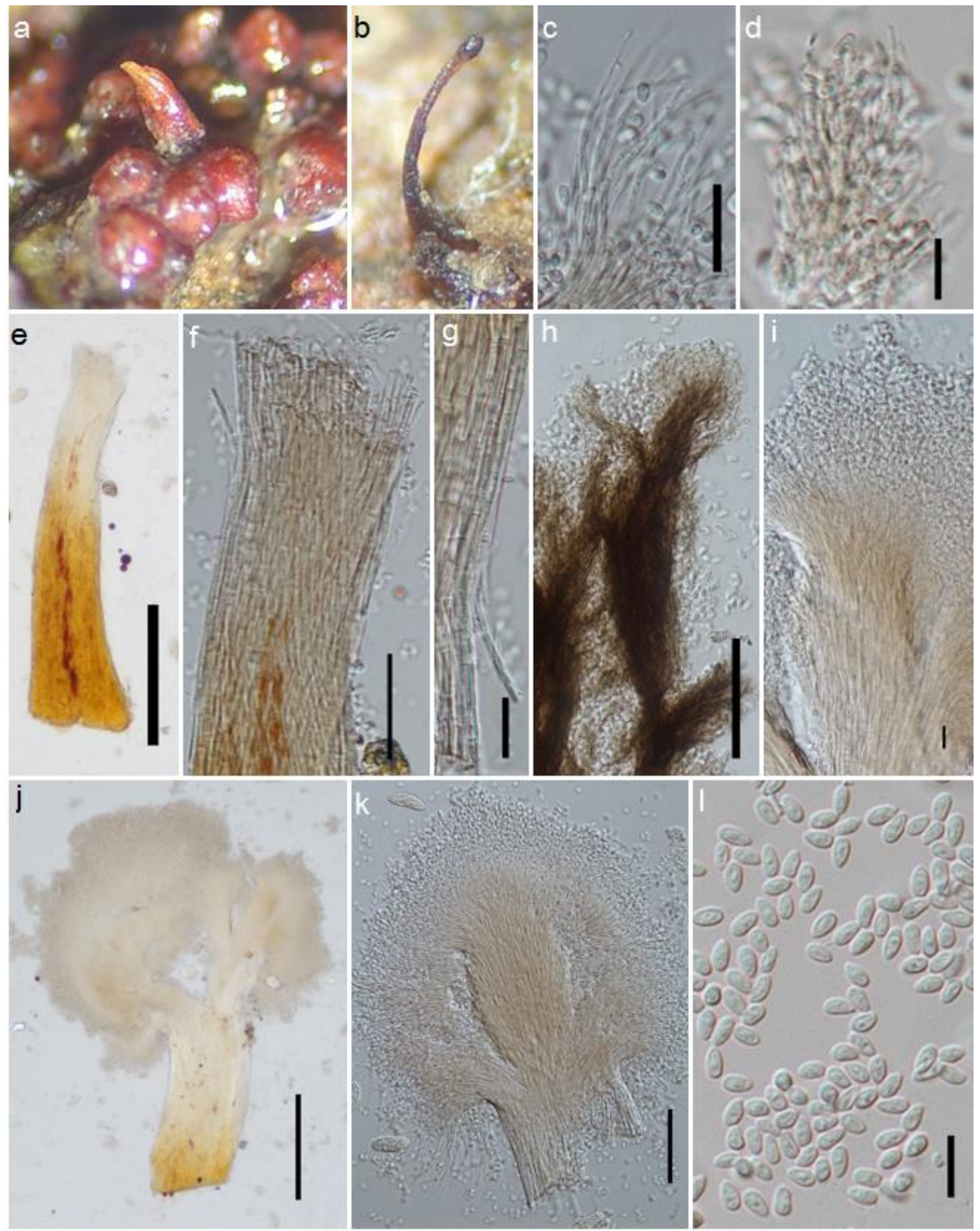

Figure 176 - Murinectria murispora (AMH 10077). a, b Synnemata on natural substrate. c-e Synnemata. f, g Synnemata head. h, i Conidiophores and conidia. j, k Conidiogenous cells. 1 Conidia. Scale bars: $\mathrm{f}=200 \mu \mathrm{m}, \mathrm{c}, \mathrm{d}, \mathrm{g}, \mathrm{h}=50 \mu \mathrm{m}, \mathrm{e}, \mathrm{j}, \mathrm{k} 20 \mu \mathrm{m}, \mathrm{i}, \mathrm{l}=10 \mu \mathrm{m}$.

Nalanthamala Subram., J. Indian bot. Soc. 35: 478 (1956)

Index Fungorum number: IF9076; 6 morphological species (Species Fungorum 2020), 5 species with sequence data.

Type species - Nalanthamala madreeya Subram. 
Table 1 List of the Murinectria species having muriform ascospores.

\begin{tabular}{|c|c|c|c|c|}
\hline Fungi & Ascomata & Asci & Ascospores & Septation \\
\hline $\begin{array}{l}\text { Murinectria } \\
\text { antarctica }\end{array}$ & $\begin{array}{l}315-548 \mu \mathrm{m} \text { high } \\
\times 270-520 \mu \mathrm{m} \\
\text { diam }\end{array}$ & $\begin{array}{l}95-125 \times 15- \\
25 \mu \mathrm{m}\end{array}$ & $\begin{array}{l}(19.4-) 23.0- \\
30.4(-35.1) \times \\
(6.8-) 8.1-10.9(- \\
13.6) \mu \mathrm{m}\end{array}$ & $\begin{array}{l}5-8 \text { transverse septa } \\
\text { and } 1-2 \\
\text { longitudinal septum, } \\
\text { not constricted at } \\
\text { each septum }\end{array}$ \\
\hline M. polythalama & $\begin{array}{l}300-435 \mu \mathrm{m} \text { high } \\
\times 290-345 \mu \mathrm{m} \\
\text { diam }\end{array}$ & $\begin{array}{l}70-96 \times 15.7- \\
17.9 \mu \mathrm{m}\end{array}$ & $\begin{array}{l}(17.9-) 21.8- \\
29.0(-35.4) \times \\
(6.1-) 7.3-10.1(- \\
12.3) \mu \mathrm{m},\end{array}$ & $\begin{array}{l}5-8 \text { transverse } \\
\text { septate and } 1-2 \\
\text { longitudinal septate, } \\
\text { often constricted at } \\
\text { each septum }\end{array}$ \\
\hline M. pseudotrichia & $\begin{array}{l}333-548 \mu \mathrm{m} \text { high } \\
\times 296-534 \mu \mathrm{m} \\
\text { diam }\end{array}$ & $\begin{array}{l}65-125 \times 13- \\
32 \mu \mathrm{m}\end{array}$ & $\begin{array}{l}(14.8-) 21.0- \\
28.8(-41.3) \times \\
(4.6-) 7.5-11.4(- \\
15.0) \mu \mathrm{m}\end{array}$ & $\begin{array}{l}5-8 \text { transverse septa } \\
\text { and } 1-2 \text { longitudinal } \\
\text { septum, often } \\
\text { constricted }\end{array}$ \\
\hline M. murispora & $\begin{array}{l}550-580 \mu \mathrm{m} \text { high } \\
\times 415-500 \mu \mathrm{m} \\
\text { diam }\end{array}$ & $\begin{array}{l}70-96 \times 14.5- \\
18 \mu \mathrm{m}\end{array}$ & $\begin{array}{l}(25.0-) 26.1- \\
36.6(-38.3) \times \\
(9.7-) 10.2-16.3 \\
(-18.6) \mu \mathrm{m},\end{array}$ & $\begin{array}{l}5-9 \text { transverse } \\
\text { septate and 1-2 (-5) } \\
\text { longitudinal septate, } \\
\text { often constricted at } \\
\text { each septum }\end{array}$ \\
\hline
\end{tabular}

Nectria (Fr.) Fr., Summa veg. Scand., Sectio Post. (Stockholm): 387 (1849)

Index Fungorum number: IF3431; 931 morphological species (Species Fungorum 2020), 49 species with sequence data.

Type species - Nectria cinnabarina (Tode) Fr.

Notes - Nectria was recognized as Hypocrea sect. Nectria and raised to generic level by Fries (1849) without designating a type species. Seaver (1909) designated $N$. peziza as the type, but it was considered as illegitimate (Rossman et al. 1999). Clements \& Shear (1931) made the first legitimate typification of the genus by designating $N$. cinnabarina as the lectotype (Rossman et al. 1999). There were around 800 epithets proposed for Nectria sensu lato with 200 estimated species (Booth 1959, Rossman 1996). Species in Nectria sensu stricto have been listed with a key to 28 species by Rossman (1989). Rossman et al. (1999) restricted Nectria sensu stricto to species considered congeneric with the type species Nectria cinnabarina and accepted 27 species in the genus. Based on morphology (Hirooka et al. 2010, Rossman et al. 1999) and LSU sequence data (Rehner \& Samuels 1995), Nectria sensu lato was separated into a number of genera.

Neocosmospora E.F. Sm., U.S.D.A. Div. Veg. Pathol. Bull.17: 45 (1899)

Index Fungorum number: IF3447; 70 morphological species (Species Fungorum 2020), 8 species with sequence data.

Type species - Neocosmospora vasinfecta E.F. Sm.

Neonectria Wollenw., Annls mycol. 15(1/2): 52 (1917)

Index Fungorum number: IF3469; 25 morphological species (Species Fungorum 2020), 18 species with sequence data.

Type species - Neonectria candida (Ehrenb.) Rossman, L. Lombard \& Crous

Neothyronectria Crous \& Thangavel, Persoonia 37: 329 (2016)

Index Fungorum number: IF819079; 2 morphological species (Species Fungorum 2020), 1 species with sequence data.

Type species - Neothyronectria sophorae Crous \& Thangavel 
Ophionectria Sacc., Michelia 1(no. 3): 323 (1878)

Index Fungorum number: IF3608; 11 morphological species (Species Fungorum 2020), 1 species with sequence data.

Type species - Ophionectria trichospora (Berk. \& Broome) Sacc.

Pandanaceomyces Tibpromma \& K.D. Hyde, Fungal Divers. 92: 107 (2018)

Index Fungorum number: IF554537; 1 species with sequence data.

Type species - Pandanaceomyces krabiensis Tibpromma \& K.D. Hyde

Paracremonium L. Lombard \& Crous, Stud. Mycol. 80: 233 (2015)

Index Fungorum number: IF810267; 5 species with sequence data.

Type species - Paracremonium inflatum L. Lombard \& Crous

Payosphaeria W.F. Leong, Bot. Mar. 33: 511 (1990)

Index Fungorum number: IF25521; 1 morphological species.

Type species - Payosphaeria minuta H.Y.M. Leung

Penicillifer Emden, Acta bot. neerl. 17: 54 (1968)

Index Fungorum number: IF9256; 7 morphological species (Species Fungorum 2020), 5 species with sequence data.

Type species - Penicillifer pulcher Emden

Persiciospora P.F. Cannon \& D. Hawksw., J. Linn. Soc.,Bot. 84: 133 (1982)

Index Fungorum number: IF3839; 4 morphological species (Species Fungorum 2020), 1 species with sequence data.

Type species - Persiciospora moreaui P.F. Cannon \& D.Hawksw.

Pleiocarpon L. Lombard \& D. Aiello, IMA Fungus 8(1): 73 (2017)

Index Fungorum number: IF820028; 3 species with sequence data.

Type species - Pleiocarpon strelitziae L. Lombard \& D. Aiello

Pleogibberella Sacc., Syll.fung., Addit. I-IV (Abellini): 217 (1886)

Index Fungorum number: IF4211; 3 morphological species (Species Fungorum 2020).

Type species - Pleogibberella calamia (Cooke) Berl. \& Voglino

Pleurocolla Petr., Annls mycol. 22(1/2): 15 (1924)

Index Fungorum number: IF9458; 1 morphological species.

Type species - Pleurocolla tiliae Petr.

Pseudoachroiostachys Tibpromma \& K.D. Hyde, Fungal Divers. 92: 107 (2018)

Index Fungorum number: IF554547; 1 species with sequence data.

Type species - Pseudoachroiostachys krabiense Tibpromma \& K.D. Hyde

Pseudocosmospora C. Herrera \& P. Chaverri, Mycologia 105: 1291 (2013)

Index Fungorum number: IF802432; 13 morphological species (Species Fungorum 2020), 6 species with sequence data.

Type species - Pseudocosmospora eutypellae C. Herrera \& P. Chaverri

Pseudonectria Seaver, Mycologia 1(2): 48 (1909)

Index Fungorum number: IF4460; 17 morphological species (Species Fungorum 2020), 2 species with sequence data.

Type species - Pseudonectria buxi DC.) Seifert, Gräfenhan \& Schroers 
Rectifusarium L. Lombard, Crous \& W. Gams, Stud. Mycol. 80: 229 (2015)

Index Fungorum number: IF810252; 2 species with sequence data.

Type species - Rectifusarium ventricosum (Appel \& Wollenw.) L. Lombard \& Crous

Rugonectria P. Chaverri \& Samuels, Stud. Mycol. 68(1): 73 (2011)

Index Fungorum number: IF518563; 5 species with sequence data.

Type species - Rugonectria rugulosa (Pat. \& Gaillard) Samuels, P. Chaverri \& Salgado

Sarcopodium Ehrenb., Synop. Pl. Crypt. 2: 101. (1824)

Index Fungorum number: IF9788; 15 morphological species (Species Fungorum 2020), 6 species with sequence data.

Type species - Sarcopodium circinatum Ehrenb.

Stylonectria Höhn., Sber. Akad. Wiss. Wien, Math.-naturw. Kl., Abt. 1 124: 52 (1915)

Index Fungorum number: IF5301; 5 species with sequence data.

Type species - Stylonectria applanata Höhn.

Thelonectria P. Chaverri \& C. Salgado, Stud. Mycol. 68(1): 76 (2011)

Index Fungorum number: IF518567; 41 morphological species (Species Fungorum 2020),

29 species with sequence data.

Type species - Thelonectria discophora (Mont.) P. Chaverri \& C. Salgado

Thyronectria Sacc., Grevillea 4(no. 29): 21 (1875)

Index Fungorum number: IF5469; 41 morphological species (Species Fungorum 2020), 33

species with sequence data.

Type species - Thyronectria rhodochlora (Mont.) Seeler

Varicosporella Lechat \& J. Fourn., Ascomycete.org 7(1): 2 (2015)

Index Fungorum number: IF810690; 1 species with sequence data.

Type species - Varicosporella aquatica Lechat \& J. Fourn.

Varicosporellopsis Lechat \& J. Fourn., Ascomycete.org 8(3): 96 (2016) Index Fungorum number: IF815311; 1 species with sequence data Type species - Varicosporellopsis aquatilis Lechat \& J. Fourn.

Volutella Tode, Fung. mecklenb. sel. (Lüneburg) 1: 28 (1790)

Index Fungorum number: IF39165; 32 morphological species (Species Fungorum 2020), 9 species with sequence data.

Type species - Volutella ciliata (Alb. \& Schwein.) Fr.

Xenoacremonium L. Lombard\& Crous, Stud. Mycol. 80: 234 (2015)

Index Fungorum number: IF810270; 2 species with sequence data.

Type species - Xenoacremonium recifei (Leão \& Lõbo) L. Lombard \& Crous

Xenocylindrocladium Decock, Hennebert \& Crous, Mycol. Res. 101(7): 788 (1997)

Index Fungorum number: IF27788; 3 species with sequence data.

Type species - Xenocylindrocladium serpens Decock, Hennebert \& Crous

Xenogliocladiopsis Crous \& W.B. Kendr., Canad. J. Bot. 72: 63 (1994)

Index Fungorum number: IF27282; 2 species with sequence data.

Type species - Xenogliocladiopsis eucalyptorum Crous \& W.B. Kendr. 
Xenoleptographium Marinc., T.A. Duong, Z.W. de Beer \& M.J. Wingf., Persoonia 35: 319 (2015) Index Fungorum number: IF812683; 1 species with sequence data.

Type species - Xenoleptographium phialoconidium Marinc.

Xenonectriella Weese, Sber. Akad. Wiss. Wien, Math.-naturw. Kl., Abt. 1 128: 749 (1919)

Index Fungorum number: IF5822; 15 morphological species (Species Fungorum 2020).

Type species - Xenonectriella lutescens (Arnold) Weese

Neomelanconiellaceae Crous, Persoonia 41: 267 (2018)

Index Fungorum number: IF828247; Facesoffungi number: FoF07079; 1 species.

Endophytic forming leaf spots. Sexual morph: Undetermined. Asexual morph: Conidiomata solitary to aggregated, pycnidial, brown with central ostiole. Conidiomatal wall comprising several layers of medium brown cells of textura angularis. Conidiophores lining the inner cavity, septate, hyaline, smooth, subcylindrical with slight apical taper, branched or not. Conidiogenous cells hyaline, smooth, ampulliform, terminal and intercalary, phialidic. Conidia solitary, aseptate, hyaline, smooth, guttulate, subcylindrical to narrowly ellipsoid, apex obtuse, tapering to truncate hilum (adapted from Crous et al. 2018b).

Type - Neomelanconiella Crous

Notes - Neomelanconiellaceae was introduced by Crous et al. (2018b) based on single collection of Neomelanconiella combreti. Phylogenetically, this family clusters between Melanconiellaceae and Harknessiaceae.

\section{Ecological and economic significance of Neomelanconiellaceae}

Neomelanconiella combreti forms spots on leaves of Combretum sp., which is a native plant to southern Africa, Madagascar, tropical Asia and tropical America. This plant is used in African or Indian herbal medicine.

\section{Genus included in Neomelanconiellaceae}

Neomelanconiella Crous, Persoonia 41: 267 (2018)

Index Fungorum number: IF828246; 1 species with sequence data.

Type species - Neomelanconiella combreti Crous

Notes - The monotypic genus Neomelanconiella was introduced by Crous et al. (2018b) based on $N$. combreti. The sexual morph is undetermined and the asexual morph is similar to Melanconiella (Crous et al. 2018b). However, most of Melanconiella species occur on recently dead twigs and branches of Betulaceae in the north temperate zone (Voglmayr et al. 2012), while Neomelanconiella combreti occurs on leaves of Combretaceae in the Southern Hemisphere. Neomelanconiella differs from Melanconiella in having pycnidial conidiomata without ectostromatic discs and central columns and ellipsoid conidia without two large and numerous small guttules. Phylogenetically Neomelanconiella combreti clustered with Cryptodiaporthe vepris forming a distinct clade between Melanconiellaceae and Harknessiaceae (Crous et al. 2018b).

Niessliaceae Kirschst., Annls mycol. 37(1/2): 89 (1939)

Index Fungorum number: IF81070; Facesoffungi number: FoF01126; 13 species.

Saprobic or parasitic on wood, leaves and stems in freshwater and terrestrial habitats, some possibly fungicolous and lichenicolous. Sexual morph: Ascomata perithecial or cleistothecial, yellow, brown, dark brown to black, solitary or gregarious, superficial, erumpent to immersed in a subiculum or crustose stroma, cupulate, globose to subglobose, membranaceous, tuberculate, with or without circinately coiled, lightly pigmented, brown, septate, apical setae, collabent, or collapsing laterally, or not collapsing, papilla present or lacking, when present with periphysate ostiole. Peridium thick, membranaceous, outer layer composed of yellow, light brown or brown cells of textura angularis; inner layer composed of hyaline cells of textura prismatica. Paraphyses- 
a

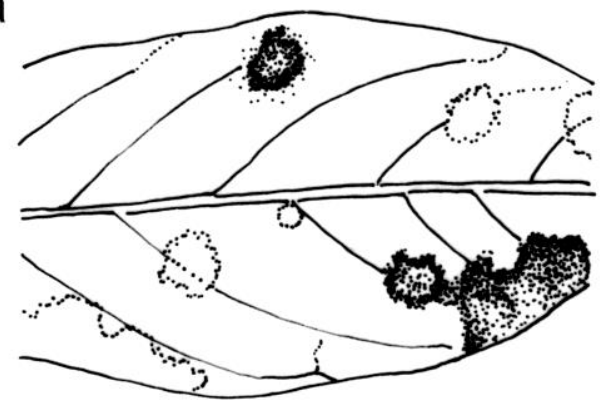

C

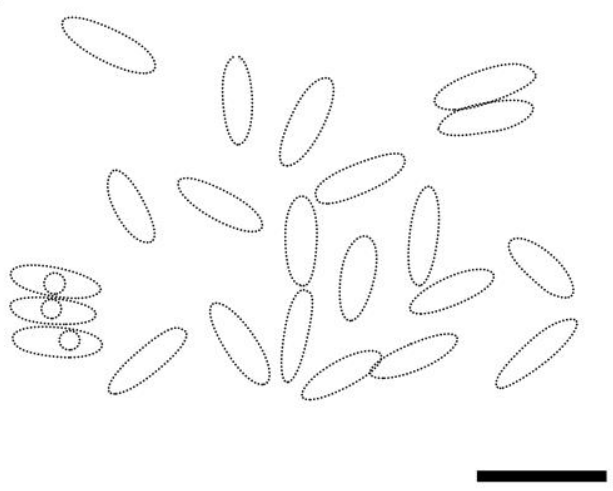

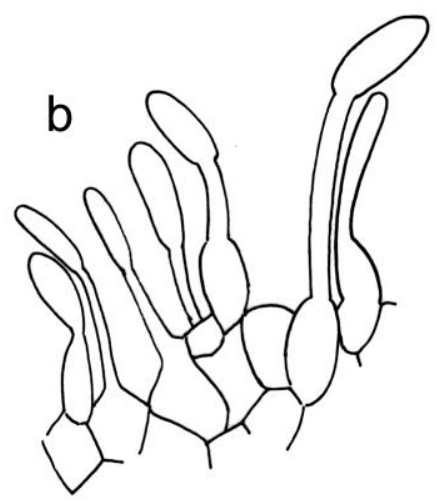

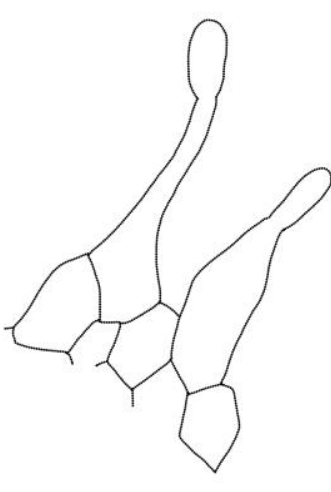

d
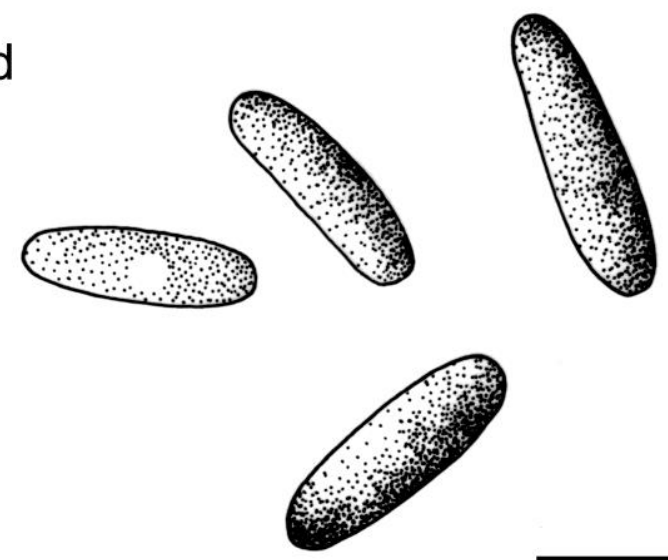

Figure 177 - Neomelanconiella combreti (redrawn from Crous et al. 2018b). a Symptomatic leaf. b Conidiogenous cell with conidia. $c-d$ Conidia. Scale bars: $b-c=10 \mu \mathrm{m}, \mathrm{d}=5 \mu \mathrm{m}$.

-filiform, hyaline, septate, or absent. Asci 8-spored, unitunicate, oblong to clavate, long or short pedicellate, with narrowly discoid, J-, apical ring or ring absent, evanescent at maturity. Ascospores 1-3-seriate, hyaline to brown, ellipsoid to fusiform, slightly curved, aseptate to 1-septate, striate or verrucose, smooth-walled. Asexual morph: Hyphomycetous. Mycelium white to light brown, superficial, effused, thick subiculum. Conidiophores thin-walled, hyaline, unbranched, aseptate, swollen, with a short and distinct collarette, terminating in a single conidium. Phialides straight, smooth. Conidia oval to ellipsoid, aseptate to 1-septate, hyaline, smooth. Coelomycetous, Conidiomata subimmersed, globose to subglobose, dark brown. Peridium thick-walled, wall composed of brown to hyaline cells of textura angularis, becoming hyaline towards inner conidiogenous region. Conidiophores hyaline, subcylindrical, branched apically, 1-2-septate. Conidiogenous cells phialidic, hyaline, fusiform to ellipsoid, straight to curved, tapering towards a subtruncate apex. Conidia oval to ellipsoid, aseptate to 2-septate, hyaline, with guttulate, smoothwalled (adapted from Maharachchikumbura et al. 2016b).

Type genus - Niesslia Auersw.

Notes - Niessliaceae was introduced by Kirschstein (1939) based on superficial, dark, setose perithecial or cleistothecial ascomata, and is typified by Niesslia. Barr (1990b) proposed that members of this family be accepted in a narrow sense and transferred genera from Sphaeriaceae (Müller \& von Arx 1962, 1973) and Trichosphaeriaceae, such as Melchioria, Pseudorhynchia and Valetoniella (Barr 1983, Hawksworth et al. 1983, Eriksson \& Hawksworth 1990). Samuels \& Barr (1997) referred the family to Hypocreales (including Atronectria, Circinoniesslia, Cryptoniesslia, Malmeomyces, Melanopsamma, Miyakeomyces, Myrmaeciella, Niesslia, Paraniesslia, Pseudorhynchia, Trichosphaerella, Taiwanascus, Valetoniella, Valetoniellopsis), based on the short ostiolar periphyses and phialidic conidiogenous cells (Starbäck 1899, Hara 1913, Eriksson \& Hawksworth 1991, 1993, Hawksworth et al. 1995, Rossman et al. 1999, Cai \& Hyde 2007b, Etayo 
\& Sancho 2008). The placement of Niessliaceae in the Hypocreales is supported by molecular data and includes Eucasphaeria, Hyaloseta, Myrtacremonium, Niesslia, Rosasphaeria, Trichosphaerella and Valetoniellopsis (Tang et al. 2007, Jaklitsch \& Voglmayr 2012, Lombard et al. 2015, Crous et al. 2016a, 2017b). Many genera included in Niessliaceae lack sequence data and several are monotypic and thus recollection and sequence data is needed.

\section{Ecological and economic significance of Niessliaceae}

Members of Niessliaceae are usually saprobic or/and parasitic on wood or lichens or other fungi, such as Niesslia echinoides on Erioderma barbellatum and Pseudorhynchia mauritiana on Cordemoya integrifolia (Müller \& von Arx 1962, 1973, Barr 1990b, Samuels \& Barr 1997, Dulymamode et al. 2001, Tang et al. 2007, Jaklitsch \& Voglmayr 2012, Etayo et al. 2013, Lombard et al. 2015, Crous et al. 2016a, 2017b).

\section{Genera included in Niessliaceae}

Atronectria Etayo, Biblthca Lichenol. 98: 52 (2008)

Index Fungorum number: IF532866; 1 morphological species.

Type species - Atronectria magellanica Etayo

Notes - Atronectria was established based on Atronectria magellanica which has clavate asci with an outer layer of textura epidermoidea and oblong, 1-septate ascospores (Etayo \& Sancho 2008). Atronectria is similar to Pseudonectriella in having hyaline, oblong ascospores and it is the only species with ascoma having an outer layer of textura epidermoidea in Niessliaceae (Etayo \& Sancho 2008).

Circinoniesslia Samuels \& M.E. Barr, Can. J. Bot. 75(12): 2166 (1998)

Index Fungorum number: IF27818; 1 morphological species.

Type species - Circinoniesslia nectriae Samuels \& M.E. Barr

Notes - The monotypic Circinoniesslia was established by $C$. nectriae and has ascomata surrounded by circinate setae, cylindrical asci and oblong to ellipsoid ascospores with striate appendages (Samuels \& Barr 1997). The ascospores are similar to Valetoniella and it was separated from other members of Niessliaceae based on the special circinate setae on the ascomata (Samuels \& Barr 1997).

\section{Cryptoniesslia Scheuer, Mycol. Res. 97(5): 543 (1993)}

Index Fungorum number: IF22420; 1 morphological species.

Type species - Cryptoniesslia setulosa Scheuer

Notes - Cryptoniesslia setulosa, the only species of Cryptoniesslia, has ascomata surrounded by short, branched, apical setae, clavate asci and elongate ascospores (Scheuer 1993). The setae and ascospores are similar to Niesslia erysipheoides and should be given generic status in Niessliaceae based on different characters of immersed ascomata and clavate asci (Samuels \& Barr 1997).

Eucasphaeria Crous, Fungal Divers. 25: 21 (2007)

Index Fungorum number: IF501093; 2 species with sequence data.

Type species - Eucasphaeria capensis Crous

Notes - Eucasphaeria capensis is characterized by brown ascomata, clavate asci with $\mathrm{J}+$, apical ring and fusoid-ellipsoidal ascospores and falcate conidia (Crous et al. 2007b). The second species, Eucasphaeria rustici, was introduced by Crous et al. (2016a) based on phialidic conidiogenous cells and falcate conidia. This genus is related to Rosasphaeria and Niesslia in Niessliaceae (Crous et al. 2016a).

Hyaloseta A.W. Ramaley, Mycotaxon 79: 269 (2001)

Index Fungorum number: IF28517; 1 species with sequence data.

Type species - Hyaloseta nolinae A.W. Ramaley 
Notes - The monotypic Hyaloseta has ascomata surrounded by hyaline setae with swollen apices, cylindrical asci and ellipsoid, 1-septate ascospores (Ramaley 2001). The genus is closely related to Trichosphaerella based on multi-gene analysis (Lombard et al. 2015; Fig. 15) and has a monocillium-like asexual morph.

Malmeomyces Starbäck, Bih. K. svenska VetenskAkad. Handl., Afd. 3 25(no. 1): 32 (1899)

Index Fungorum number: IF2989; 1 morphological species.

Type species - Malmeomyces pulchellus Starbäck

Notes - Malmeomyces pulchellus as the only member in Malmeomyces with cupulate ascomata with septate setae, clavate asci and cylindrical ascospores (Starbäck 1899, Lumbsch \& Huhndorf 2007).

Melchioria Penz. \& Sacc., Malpighia 11(9-10): 399 (1897)

Index Fungorum number: IF3099; 6 morphological species (Species Fungorum 2020).

Type species - Melchioria leucomelaena Penz. \& Sacc.

Notes - Melchioria leucomelaena has glabrous ascomata, clavate asci and cylindrical ascospores (Penzig \& Saccardo 1897a).

Miyakeomyces Hara, Bot. Mag., Tokyo 27(no. 317): (248) (1913)

Index Fungorum number: IF3226; 1 morphological species.

Type species - Miyakeomyces bambusae Hara

Notes - The monotypic Miyakeomyces has cushion-like ascomata, cylindrical asci and oblong-fusiform ascospores (Hara 1913).

Myrmaeciella Lindau, Nat. Pflanzenfam., Teil. I (Leipzig) 1(1): 478 (1897)

Index Fungorum number: IF3384; 2 morphological species (Species Fungorum 2020).

Type species - Myrmaeciella endoleuca (Sacc.) Lindau

Notes - Myrmaeciella endoleuca has black, turbinate stromata and clavate asci with ellipsoid, verruculose ascospores (Saccardo 1880b; Rossman et al. 1999, Jaklitsch \& Voglmayr 2011). Rossman et al. (1999) suggested that Myrmaeciella is allied with members of Niessliaceae.

Myrtacremonium Crous, Persoonia 38: 259 (2017)

Index Fungorum number: IF820937; 1 species with sequence data.

Type species - Myrtacremonium eucalypti Crous

Notes - The asexual genus Myrtacremonium has solitary conidiophores and subcylindrical straight conidia. The genus is closely related to Valetoniellopsis in Niessliaceae (Fig. 15).

Neoeucasphaeria Crous, Persoonia 41: 293 (2018)

Index Fungorum number: IF828249; 1 species with sequence data.

Type species - Neoeucasphaeria eucalypti Crous

Notes - Crous et al. (2018b) found Neoeucasphaeria eucalypti on Eucalyptus sp. in Australia. The genus is related to Eucasphaeria, but has aseptate conidia that are different from Eucasphaeria (Crous et al. 2018b).

Niesslia Auersw., Myc. Europ. Pyren. 5-6: 30 (1869)

Index Fungorum number: IF3506; 98 morphological species (Species Fungorum 2020), 11 species with sequence data.

Type species - Niesslia chaetomium (Ces. \& De Not.) Auersw.

Notes - Niesslia is characterized by tuberculate perithecia, surrounded by brown, septate setae, clavate asci and filiform ascospores (Gonnermann \& Rabenhorst 1869, Gams et al. 2019). The members of Niessliaceae nest in this family based on multi-gene analysis (Fig. 15). 
Paraniesslia C.K.M. Tsui, K.D. Hyde \& Hodgkiss, Mycologia 93(5): 1002 (2001)

Index Fungorum number: IF28568; 2 morphological species (Species Fungorum 2020).

Type species - Paraniesslia tuberculata C.K.M. Tsui, K.D. Hyde \& Hodgkiss

Notes - Paraniesslia tuberculata has pyriform to subglobose ascomata and clavate asci with ellipsoid, verruculose ascospores (Saccardo 1880b, Rossman et al. 1999, Tsui et al. 2001b, Jaklitsch \& Voglmayr 2011). The second species Paraniesslia aquatica, a freshwater taxon, was introduced by Cai \& Hyde (2007b).

Pseudonectriella Petr., Sydowia 13(1-6): 127 (1959)

Index Fungorum number: IF4461; 1 morphological species.

Type species - Pseudonectriella ahmadii Petr.

Notes - Pseudonectriella ahmadii has cupulate, verruculose ascomata and cylindrical asci with ellipsoid to oval ascospores (Petrak 1959).

Pseudohyaloseta Tibpromma \& K.D. Hyde, Fungal Divers. 93: 113 (2018)

Index Fungorum number: IF 554542; 1 species with sequence data.

Type species - Pseudohyaloseta pandanicola Tibpromma \& K.D. Hyde

Notes - Pseudohyaloseta is similar to Hyaloseta in having globose to subglobose ascomata and obclavate asci with cylindrical and 1-septate ascospores, but they are well-separated in phylogenetic analyses (Tibpromma et al. 2018).

Pseudorhynchia Höhn., Sber. Akad. Wiss. Wien, Math.-naturw. Kl., Abt. 1 118: 1206 (1909)

Index Fungorum number: IF4483; 2 morphological species (Species Fungorum 2020).

Type species - Pseudorhynchia polyrrhyncha (Penz. \& Sacc.) Höhn.

Notes - Pseudonectriella was established by Pseudorhynchia polyrrhyncha which found on Elettaria sp. in Java (Höhnel 1909b). The genus is characterized by subglobose ascomata with setae surrounded by ostiole and cylindrical to clavate asci with ellipsoid ascospores. Dulymamode et al. (2001) introduced the second species, Pseudorhynchia mauritiana, found on fallen leaves of Cordemoya integrifolia in Mauritius.

Rosasphaeria Jaklitsch \& Voglmayr, Fungal Divers. 52(1): 93 (2012)

Index Fungorum number: IF561139; 1 species with sequence data.

Type species - Rosasphaeria moravica (Petr.) Jaklitsch \& Voglmayr

Notes - Rosasphaeria moravica has immersed, subglobose ascomata and cylindrical asci with 1-septate, fusiform to cylindrical ascospores. The genus is closely related to Eucasphaeria in Niessliaceae (Jaklitsch \& Voglmayr 2012; Fig. 15).

Taiwanascus Sivan. \& H.S. Chang, Mycol. Res. 101(2): 176 (1997)

Index Fungorum number: IF27752; 2 morphological species (Species Fungorum 2020).

Type species - Taiwanascus tetrasporus Sivan. \& H.S. Chang

Notes - Taiwanascus tetrasporus has cleistothecial ascomata with branched setae and broadly cylindrical asci with fusiform to ellipsoid ascospores (Sivanesan \& Chang 1997). The second species Taiwanascus samuelsii was collected in India (Rajeshkumar \& Rossman 2013).

Trichosphaerella E. Bommer, M. Rousseau \& Sacc., Bull. Soc. R. Bot. Belg. 29(no. 1): 261 (1890) Index Fungorum number: IF5587; 7 morphological species (Species Fungorum 2020), 1 species with sequence data.

Type species - Trichosphaerella decipiens E. Bommer, M. Rousseau \& Sacc.

Notes - Trichosphaerella decipiens has tuberculate ascomata with setae and cylindrical to clavate asci with ellipsoid ascospores (Saccardo 1891, Döbbeler et al. 2015). Sequence data of $T$. ceratophora were provided by Lombard et al. (2015) and reveals that Trichosphaerella is closely related to Hyaloseta in Niessliaceae. 
Valetoniella Höhn., Sber. Akad. Wiss. Wien, Math.-naturw. Kl., Abt. 1 118: 1499 (1909)

Index Fungorum number: IF5700; 3 morphological species (Species Fungorum 2020).

Type species - Valetoniella crucipila Höhn.

Notes - Valetoniella was established by Valetoniella crucipila and has globose ascomata with branched setae, clavate asci with ellipsoid ascospores (Höhnel 1909a). The other two species, $V$. claviornata and V. pauciornata, were introduced by Samuels \& Barr (1997). Valetoniella crucipila is illustrated in this entry (Fig. 175).
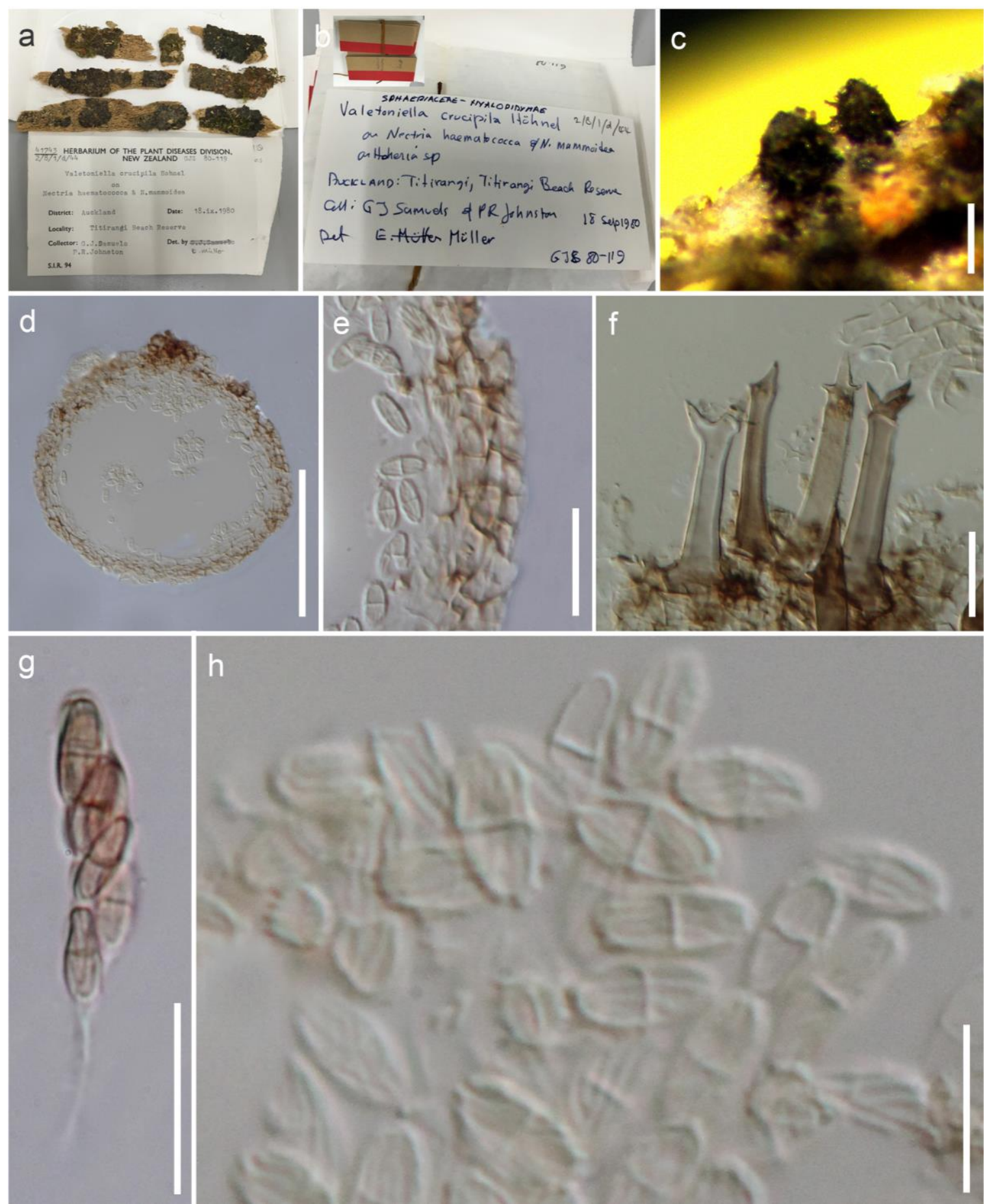

Figure 178 - Valetoniella crucipila (Material examined - NEW ZEALAND, Auckland, Titirangi beach reserve; on ascomata of Nectria haematococca and N. mammoidea, 18 September 1980, Samuels GJ \& Johnston PR, PDD no. 41743). a, b Material label. c Ascomata. d Ascoma cross section. e Peridium. f Setae. g Asci stained in Congo red reagent. h Ascospores (d-f, h. from permanent slides). Scale bars: $\mathrm{c}=200 \mu \mathrm{m}, \mathrm{d}=100 \mu \mathrm{m}, \mathrm{e}-\mathrm{g}=20 \mu \mathrm{m}, \mathrm{h}=10 \mu \mathrm{m}$. 
Valetoniellopsis Samuels \& M.E. Barr, Can. J. Bot. 75(12): 2175 (1998)

Index Fungorum number: IF27817; 1 species with sequence data.

Type species - Valetoniellopsis laxa Samuels \& M.E. Barr

Notes - The monotypic Valetoniellopsis with V. laxa has globose ascomata with setae and clavate asci with ellipsoid to cylindrical ascospores (Samuels \& Barr 1997). The genus is closely related to Myrtacremonium based on multi-gene analysis (Fig. 15).

Nitschkiaceae Nannf., Nova Acta R. Soc. Scient. upsal., Ser. 4 8(no. 2): 56 (1932)

Index Fungorum number: IF81071; Facesoffungi number: FoF01120; 110 species.

Saprobic or parasitic on wood, leaves or lichens, in freshwater, marine and terrestrial habitats. Sexual morph: Ascomata perithecial, dark brown to black, gregarious, superficial to erumpent, sitting on or in a subiculum or subiculum absent, cupuliform, globose to subglobose, carbonaceous, coriaceous to membranaceous, rough, tuberculate, smooth or with short spines, with or ostiolar opening indistinct, the apex collapsing when dry or shallowly cupulate when moist. Subiculum thin or thick-walled, numerous or scanty, brown to dark brown, septate, branched hyphae, with spiny termination. Peridium thick, composed of three layers, outer layer comprising dark tissues, thin, carbonaceous; middle layer comprising dark brown to brown cells of textura angularis, thick, membranaceous, while the inner layer has hyaline cells of textura prismatica, thin, and membranaceous, munk pores present or absent. Paraphyes when present, filamentous, septate, simple or branched. Asci 4- to multi-spored, unitunicate, clavate to cylindrical, long or short pedicellate or sessile, ends blunt. Ascospores 2-3-seriate or irregularly arranged, hyaline or brown, fusiform, allantoid or subcylindrical, slightly curved, 0-4-aseptate, concolourous, smooth-walled, sheath and appendages present or absent, with or without guttules. Asexual morph: Undetermined (adapted from Maharachchikumbura et al. 2016b).

Type genus - Nitschkia G.H. Otth

Notes - Nitschkiaceae was introduced by Nannfeldt (1932) based on erumpent, black, rough ascomata and clavate asci with hyaline allantoid ascospores. Nannfeldt (1975) concluded that Nitschkiaceae comprised three separate groups, but that the differences between them were not sufficient to place them in separate families. He accepted five genera in this family and provided additional taxonomic details with descriptions. Mugambi \& Huhndorf (2010) accepted 12 genera based on a multi-gene dataset and morphology (Lumbsch \& Huhndorf 2010). The monotypic genera Neochaetosphaerella and Tortulomyces were introduced based on morpholy (Vasilyeva et al. 2012, 2013). In this study, 14 genera are included in this family. Most taxa assigned to the family need to be re-evaluated with sequence data analysis.

\section{Ecological and economic significance of Nitschkiaceae}

Members of Nitschkiaceae are usually saprobic or/and parasitic on wood, lichens or other fungi and are distributed worldwide, such as Nitschkia parasitans on stromata of Nectria and Rhagadostoma corrugatum on Peltigera sp. (Hawksworth 1980, Gonzalez \& Martin 1996, Vasilyeva et al. 2010).

\section{Genera included in Nitschkiaceae}

Acanthonitschkea Speg., Anal. Mus. nac. B. Aires, Ser. 3 17(10): 116 (1908)

Index Fungorum number: IF12; 9 morphological species (Species Fungorum 2020), 2 species with sequence data.

Type species - Acanthonitschkea argentinensis Speg.

Notes - Acanthonitschkea argentinensis has spinate ascomata and clavate asci with reniform ascospores (Spegazzini 1908). It was considered as a member of Coronophoraceae (Müller \& von Arx 1973, von Arx 1981a, Subramanian \& Sekar 1990). Mugambi \& Huhndorf (2010) transferred the genus to Nitschkiaceae based on multi-gene analysis. The genus is closely related to Nitschkia in Fig. 15. 
Biciliosporina Subram. \& Sekar, Kavaka 18(1-2): 69 (1993)

Index Fungorum number: IF21072; 1 morphological species.

Type species - Biciliosporina karwarensis Subram. \& Sekar

Notes - Biciliosporina karwarensis was placed in Coronophoraceae and is characterized by cylindrical asci and oval to reniform ascospores with filiform appendages at each end (Subramanian \& Sekar 1990). Maharachchikumbura et al. $(2015,2016 b)$ and Wijayawardene et al. (2018b) accepted it as member of Nitschkiaceae.

Botryola Bat. \& J.L. Bezerra, Publicações Inst. Micol. Recife 431: 11 (1964)

Index Fungorum number: IF634; 1 morphological species.

Type species - Botryola tetrasperma Bat. \& J.L. Bezerra

Notes - The monotypic Botryola has clavate asci and ellipsoid, 4-spored ascospores with 1 septa (Batista et al. 1964).

Fracchiaea Sacc., Atti Soc. Veneto-Trent. Sci. Nat. 2(1): 163 (1873)

Index Fungorum number: IF2008; 22 morphological species (Species Fungorum 2020), 2 species with sequence data.

Type species - Fracchiaea heterogenea Sacc.

Notes - Fracchiaea heterogenea has clavate, polysporous asci and oblong ascospores (Saccardo 1873). The genus was placed in Coronophoraceae (Müller \& von Arx 1973, Subramanian \& Sekar 1990) and Mugambi \& Huhndorf (2010) transferred it to Nitschkiaceae based on multi-gene analysis.

Groenhiella Jørg. Koch, E.B.G. Jones \& S.T. Moss, Bot. Mar. 26(6): 265 (1983)

Index Fungorum number: IF25806; 1 morphological species.

Type species - Groenhiella bivestia Jørg. Koch, E.B.G. Jones \& S.T. Moss

Notes - Groenhiella has clavate asci and subglobose ascospores with appendages formed by fragmentation of a sheath (Koch et al. 1983). Groenhiella, a marine genus, was initially placed in Coronophoraceae (Koch et al. 1983), but assigned to Nitschkiaceae (Eriksson \& Hawksworth 1987).

Janannfeldtia Subram. \& Sekar, Kavaka 18(1-2): 69 (1993)

Index Fungorum number: IF27492; 1 morphological species.

Type species - Janannfeldtia karwarensis Subram. \& Sekar

Notes - The monotypic Janannfeldtia has clavate asci and reniform ascospores with filiform appendages at each end (Subramanian \& Sekar 1990).

Lasiosphaeriopsis D. Hawksw. \& Sivan., Trans. Br. mycol. Soc. 74(2): 371 (1980)

Index Fungorum number: IF2658; 7 morphological species (Species Fungorum 2020).

Type species - Lasiosphaeriopsis salisburyi D. Hawksw. \& Sivan.

Notes - Lasiosphaeriopsis salisburyi has 4-spored asci and broadly fusiform ascospores with 3-4 septa (Hawksworth 1980). The genus was collected on Peltigera rufescens associated with Rhagadostoma lichenicola (Hawksworth 1980).

Loranitschkia Lar.N. Vassiljeva, Mikol. Fitopatol. 24(3): 207 (1990)

Index Fungorum number: IF25456; 1 morphological species.

Type species - Loranitschkia viticola Lar.N. Vassiljeva

Notes - Loranitschkia viticola is characterised by clavate asci and clavate ascospores with a tail-like appendage and was isolated from Vitis sp. in Russia (Vasilyeva 1990, Vasilyeva et al. 2010). 
Neochaetosphaerella Lar.N. Vassiljeva, S.L. Stephenson \& Chernyshev, Fungal Divers. 52(1): 192 (2012)

Index Fungorum number: IF519185; 4 morphological species (Species Fungorum 2020).

Type species - Neochaetosphaerella thaxteriospora Lar.N. Vassiljeva, S.L. Stephenson \& Chernyshev

Notes - The monotypic Neochaetosphaerella has clavate asci and broadly allantoid ascospores with 3 septa (Vasilyeva et al. 2012).

Neotrotteria Sacc., Bulletino dell'orto Botanico della R. Universitá di Napoli 6: 45 (1921)

Index Fungorum number: IF3487; 1 morphological species.

Type species - Neotrotteria pulchella Sacc.

Notes - Neotrotteria has multi-spored asci with ellipsoid ascospores (Saccardo 1918) and was treated as synonym of Acanthonitschkea (Nannfeldt 1975, Nannfeldt \& Santesson 1975). Vasilyeva et al. (2010) accepted the genus as synonym of Fracchiaea based on similar morphs such as polysporous asci and hyaline ascospores. Maharachchikumbura et al. (2016b) considered Neotrotteria as an independent genus in Nitschkiaceae based on a Quellkörper in the peridium and its difference from Fracchiaea.

Nitschkia G.H. Otth, Bidr. Känn. Finl. Nat. Folk 23: 13 (1873)

Index Fungorum number: IF3515; 52 morphological species (Species Fungorum 2020), 5 species with sequence data.

Type species - Nitschkia fuckelii Nitschke

Notes - The taxonomy of Nitschkia introduced by Karsten (1873) is confused and currently includes 65 species (Index Fungorum 2020). The name Nitschkia fuckelii was first introduced by Nitschke (1870), but Saccardo (1873) suggested Coelosphaeria to replace Nitschkia, because the spelling of "Nitschkia" was similar to the generic name for a diatom. Fitzpatrick (1923) reviewed the nomenclature of Coelosphaeria and the name was rejected. Confusion as to the type species arises because Fuckel (1870) introduced the type species $N$. fuckelii based on Sphaeria cupularis. Neither taxon has been sequenced, and phylogenetic analysis is based on Nitschkia calyculus, $N$. grevillei, N. meniscoidea and N. tetraspora (Mugambi \& Huhndorf 2010).

Rhagadostoma Körb., Parerga lichenol. (Breslau) 5: 472 (1865)

Index Fungorum number: IF4689; 8 morphological species (Species Fungorum 2020).

Type species - Rhagadostoma corrugatum Körb.

Notes - Rhagadostoma was established by Rhagadostoma corrugatum and has clavate, 2-4spored asci and cylindrical ascospores with 1 septum (Körber 1865). The lichenicolous genus, Rhagadostoma, was considered as a member of Sordariales (Navarro-Rosinés \& Hladun 1994, Navarro-Rosinés et al. 1999) and Huhndorf et al. (2004a) proposed a possible relationship with Bertia. Maharachchikumbura et al. (2016b) accepted this genus in Nitschkiaceae.

Rhagadostomella Etayo, Biblthca Lichenol. 84: 109 (2002)

Index Fungorum number: IF28689; 1 morphological species.

Type species - Rhagadostomella gregaria Etayo

Notes - Rhagadostomella was established by Rhagadostomella gregaria and has clavate asci and cylindrical ascospores with 1 septa (Etayo 2002, Diederich 2003). Diederich (2003) proposed this genus to be included in Nitschkiaceae.

Tortulomyces Lar.N. Vassiljeva, S.L. Stephenson, Chernyshev \& K.D. Hyde, Mycoscience 54(1): 111 (2013)

Index Fungorum number: IF564276; 1 morphological species.

Type species - Tortulomyces thailandicus Lar.N. Vassiljeva, S.L. Stephenson, Chernyshev \& K.D. Hyde 
Notes - The monotypic Tortulomyces was established for $T$. thailandicus which has cylindrical asci and subglobose, 1-septate ascospores (Vasilyeva et al. 2013).

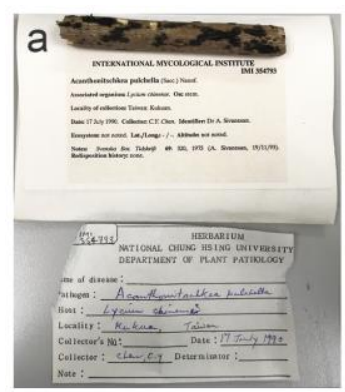

d
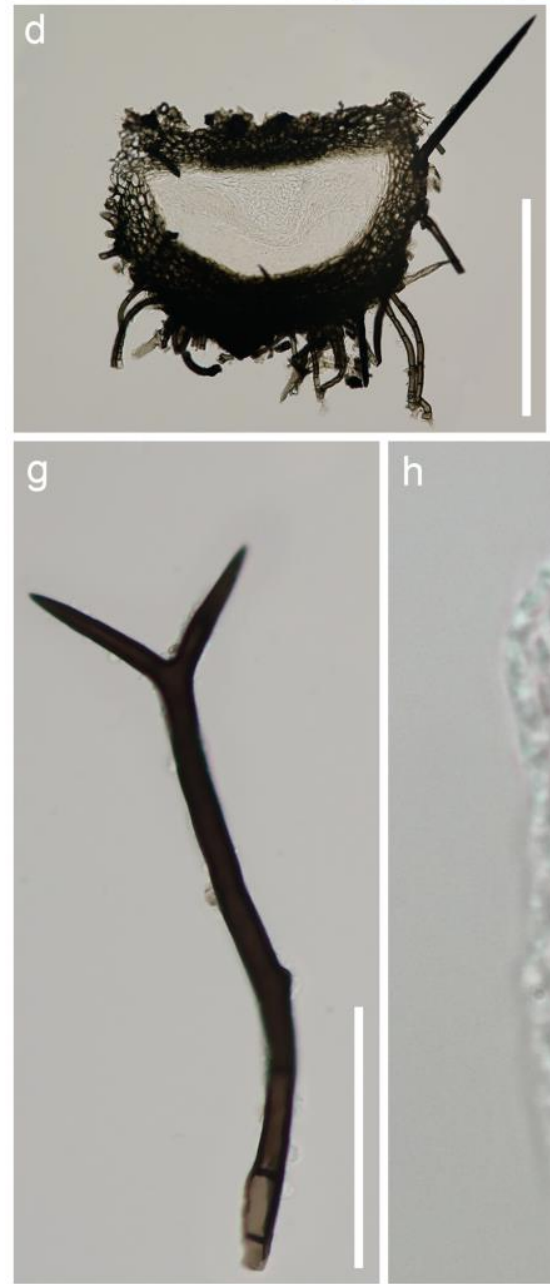
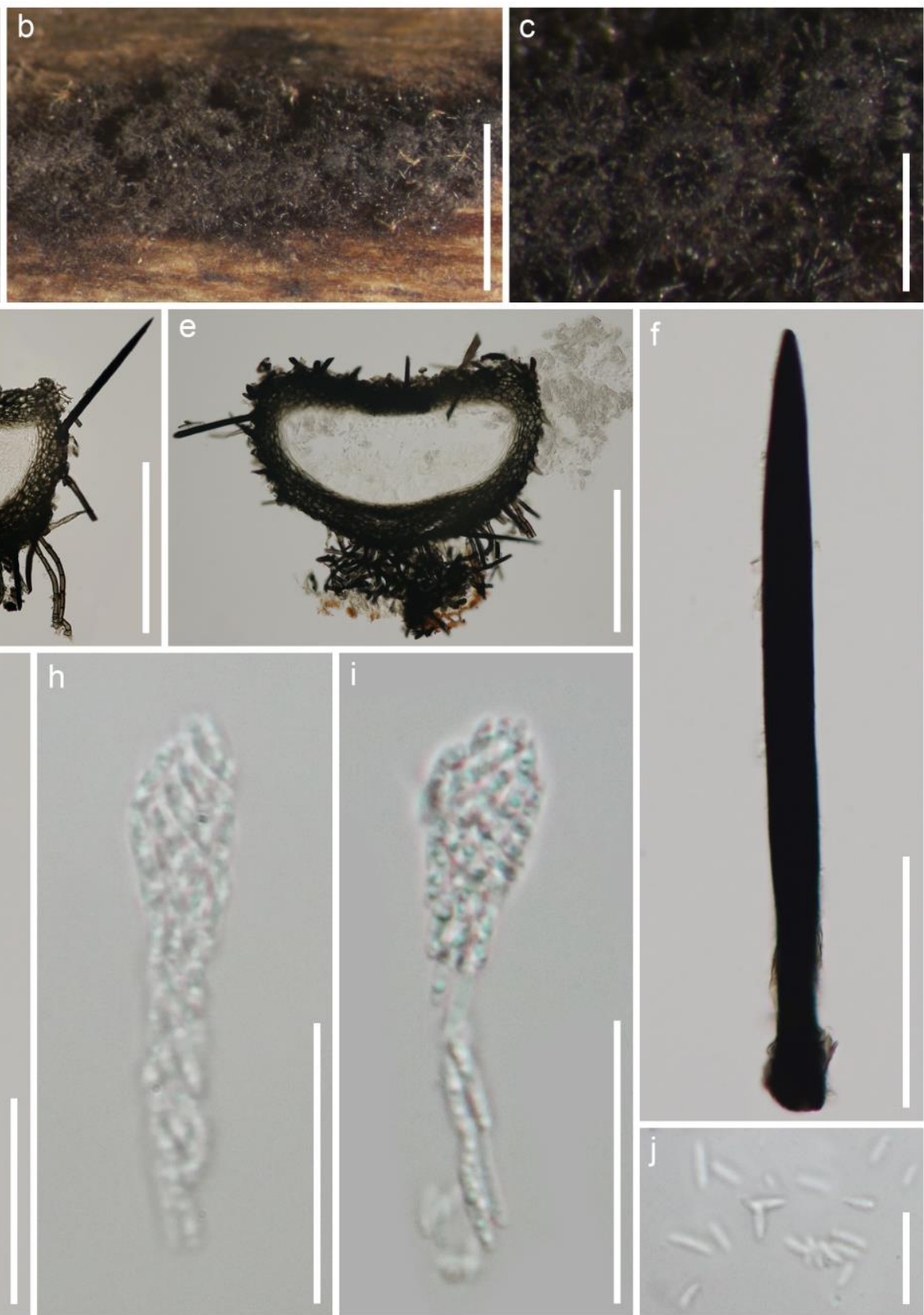

Figure 179 - Neotrotteria pulchella (Material examined - Taiwan, Kukuan; on stem of Lycium chinense, Chen CY, 17 July 1990, IMI no. 354793). a Material label. b Ascostroma on the host. c Collapsed ascoma. d Section through perithecium with quellkörper. e Ascoma cross section. $\mathrm{f}$ Setea. g Branched hyphe of subiculum. h-i Asci. j Asocspores. Scale bars: $b=2 \mathrm{~mm}, \mathrm{c}=500 \mu \mathrm{m}$, $\mathrm{d}-\mathrm{e}=200 \mu \mathrm{m}, \mathrm{f}-\mathrm{g}=50 \mu \mathrm{m}, \mathrm{h}-\mathrm{i}=20 \mu \mathrm{m}, \mathrm{j}=10 \mu \mathrm{m}$.

Obryzaceae Körb., Syst. lich. germ. (Breslau): 427 (1855)

Index Fungorum number: IF81075; Facesoffungi number: FoF05205; 3 species.

Mainly lichenicolous with green algae on rocks or bark and seldom on mosses. Sexual morph: Ascomata perithecial, pyriform, astromatic, immersed. Ostiole periphysate. Peridium hyaline with ostiolar region appearing light brown at times. Asci 4-8-spored, unitunicate, clavate, closely ellipsoid to ovoid, short-pedicellate, with barely visible apical ring, deliquescent at the base. Ascospores overlapping 1-2-seriate, hyaline, aseptate, smooth-walled, fusiform to limoniform or 
ellipsoid, lacking any mucilaginous sheath or appendages. Asexual morph: Undetermined (adapted from Cannon \& Kirk 2007, Maharachchikumbura et al. 2016b).

Type genus - Obryzum Wallr.

Notes - Obryzaceae is an insufficiently studied family which has been closely associated with plant pathogenic taxa in Gnomoniaceae, although it was mainly mentioned in lichenological studies (McNeill et al. 2006). Gnomoniaceae was subsequently recommended for conservation by Hawksworth \& Eriksson (1988) with rejection of Obryzaceae and this suggestion was acknowledged by McNeill et al. (2006). However, members in Gnomoniaceae can be distinguished as the latter have ascomata with minimally developed stroma and most often, the ascospores are small, typically less than $25 \mu \mathrm{m}$ and aseptate or one-septate either at the median or excentric position (Sogonov et al. 2008). Furthermore, the host substrates for Gnomoniaceae range from leaves, twigs and stems from herbaceous plants to bark or wood (Sogonov et al. 2008). Lumbsch \& Huhndorf (2010) listed Obryzaceae in Sordariomycetes, families incertae sedis, which was followed by Maharachchikumbura et al. (2015). Later, it was excluded from Sordariomycetes, families incertae sedis (Maharachchikumbura et al. 2016b). Furthermore, based on the ICN Article 36.1, the name Obryzaceae is invalid since Körber (1855) established this family name "ad int.". Its validation should be attributed to Eriksson (1981.

\section{Ecological and economic significance of Obryzaceae}

Species of this family are lichenicolous.

\section{Genus included in Obryzaceae}

Obryzum Wallr., Naturgesch. Flecht. 1: 253 (1825)

Index Fungorum number: IF3537; 3 morphological species (Species Fungorum 2020).

Type species - Obryzum corniculatum (Hoffm.) Wallr.

Notes - Species of this genus have been reported to be derived mainly from temperate areas and observed to be occasionally parasitic on cyanobacterial lichens of Leptogium genus. At first, Obryzum corniculatum was Collema corniculatum. However, after it had been considered improper to give the lichenicolous fungus similar name as its host, Collema corniculatum, the generic name was changed to Obryzum (Lücking et al. 2017). Given the fact that Obryzum was at first mistakenly introduced as generic name for a presumed pyrenocarpous gelatinous lichen (Wallroth 1825), neither $C$. corniculatum nor Obryzum can be lectotypified on the lichenicolous fungus (Lücking et al. 2017). In this case, a conservation proposal is essential if O. corniculatum and Obryzum are to be maintained in their currently used sense (Lücking et al. 2017). Obryzum is now maintained in the Pezizomycotina, genera incertae sedis and is still a poorly studied genus with insufficient molecular data (Lücking et al. 2017). Obryzum corniculatum is illustrated in this entry.

Ophioceraceae Klaubauf, E.G. LeBrun \& Crous, Studies in Mycology 79: 85-120 (2014)

Index Fungorum number: IF810201; Facesoffungi number: FoF01254; 23 species.

Saprobic on wood and other plant material, commonly isolated in aquatic habitats. Sexual morph: Ascomata perithecial, solitary or in small groups, immersed or semi-immersed, dark brown to black, globose to subglobose, coriaceous, ostiolate. Ostiole a long neck, lined with periphyses. Paraphyses numerous, septate, tapering, hypha-like, thin-walled, filamentous, branched, intermingled among asci. Peridium thick, 3-layered, blackened. Asci 8-spored, unitunicate, subcylindrical to narrowly fusoid, apedicellate, with thimble-shaped, J-, apical ring. Ascospores fasciculate, hyaline, yellowish in mass, filiform, septate. Asexual morph: Undetermined (adapted from Maharachchikumbura et al. 2016b).

Type genus - Ophioceras Sacc.

Notes - The monotypic family Ophioceraceae was introduced by Klaubauf et al. (2014) in Magnaporthales to accommodate Ophioceras. Ophiocera, contains species that mostly occur on wood submerged in freshwater. Previously, Ophioceras was placed in Magnaporthaceae following- 


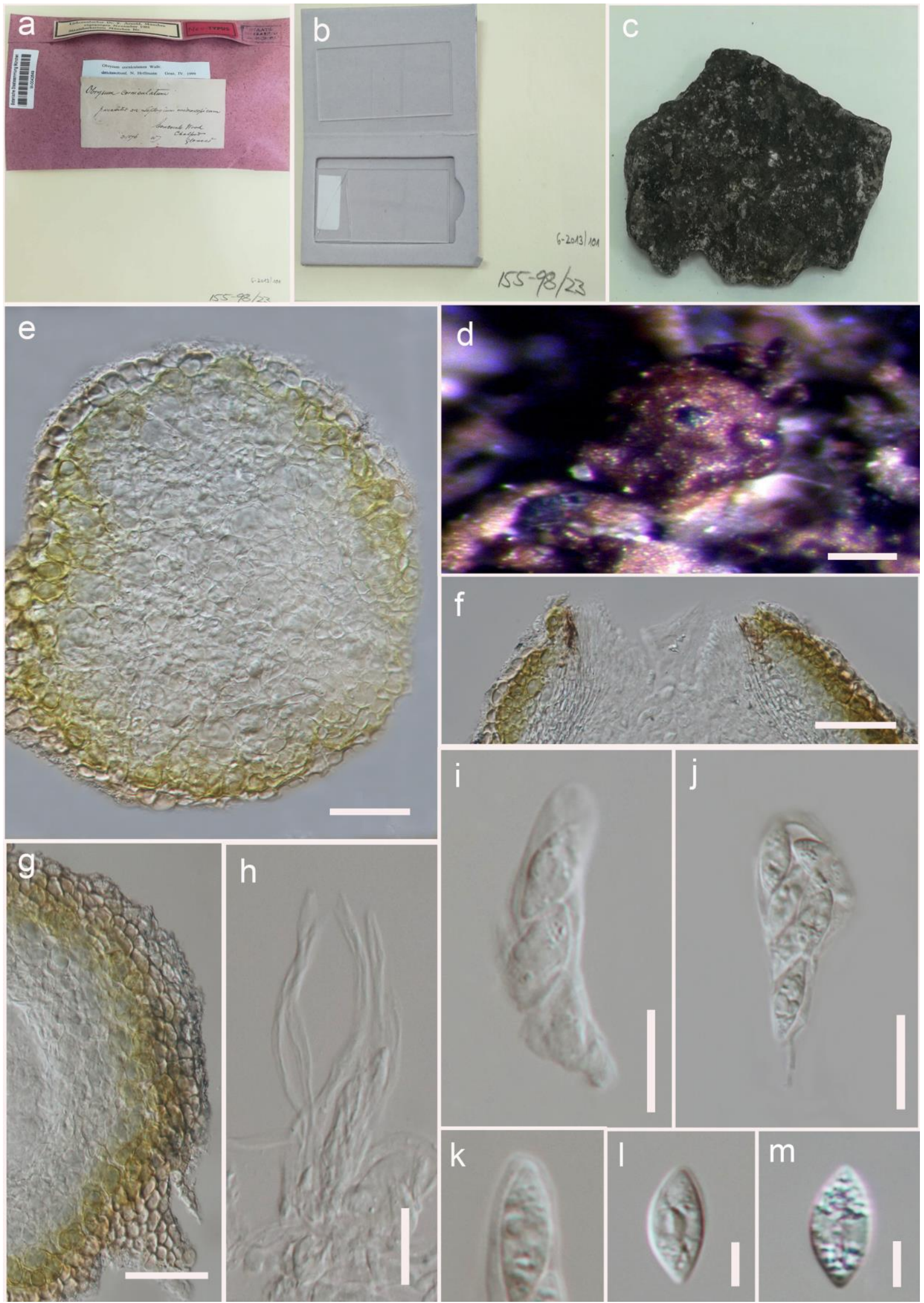

Figure 180 - Obryzum corniculatum (Material examined - UK, March 1876 W. Joshua W, M0042649, neotype). a-c Herbarium material. d Appearance of ascomata on host substrate. e Transverse section through ascoma. f Transverse section through ostiole. g Peridium. h Paraphyses $\mathrm{i}-\mathrm{j}$ Asci. $\mathrm{k}$ Lack of apical ring. 1, m Ascospores. Scale bars: $d=300 \mu \mathrm{m}, \mathrm{e}=50 \mu \mathrm{m}, \mathrm{f}-\mathrm{g}, \mathrm{j}=30 \mu \mathrm{m}$, $\mathrm{h}, \mathrm{l}=10 \mu \mathrm{m}, \mathrm{i}=20 \mu \mathrm{m}$. 
-the phylogenetic analysis of Chen et al. (1999) and Inderbitzin \& Berbee (2001). However, based on analysis of combined LSU and rpbl, Ophioceras clusters separately from Magnaporthaceae in Magnaporthales (Thongkantha et al. 2009) and hence a new monotypic family was introduced (Klaubauf et al. 2014).

\section{Ecological and economic significance of Ophioceraceae}

Saprobic taxa such as Ophioceras species have the ability to decompose lignocellulosic matter in woody litter, resulting in softening of the wood and releasing nutrients in the form of simple molecules that go back into the soil and can be reused by plants and all other organisms (Yuen et al. 1998, Bucher et al. 2004). Thus, they play an important role in nutrient and carbon cycling, biological diversity and ecosystem functioning (Palmer et al. 1997, Wong et al. 1998a). Reátegui et al. (2005) isolated four new tetrahydropyran derivatives called ophiocerins A-D and a new africane sesquiterpenoid (ophioceric acid) from cultures of the aquatic fungus venezuelense, provided structures and relative stereochemistry of these compounds. Dong et al. (2010) isolated a novel neolignan with an unprecedented dibenzo-1, 6-dioxacyclodecane carbon skeleton, ophiocerol from cultural filtrates of the freshwater fungus Ophioceras dolichostomum. Ophioceras is therefore a source of novel biologically active secondary metabolites.

\section{Genus included in Ophioceraceae}

Ophioceras Sacc., Syll. fung. (Abellini) 2: 358 (1883)

Index Fungorum number: IF3595; 23 morphological species (Species Fungorum 2020), 11 species with sequence data.

Type species - Ophioceras dolichostomum (Berk. \& M.A. Curtis) Sacc.

Notes - Saccardo (1883c) introduced Ophioceras based on O. dolichostomum. The genus is characterized by black ascomata with long necks, cylindrical asci with small, refractive, apical rings and filiform ascospores (Teng 1934, Conway \& Barr 1977, Shearer et al.1999, Tsui et al. 2001c, Thongkantha et al. 2009, Klaubauf et al. 2014). Ophioceras species are commonly encountered on decaying woody substrates in freshwater habitats all over the world (Hyde 1992c, Hyde \& Goh 1998, Shearer et al. 1999, Tsui et al. 2001c, Thongkantha et al. 2009, Hu et al. 2012). In this entry, Ophioceras commune is illustrated (Fig. 181).

Ophiocordycipitaceae G.H. Sung, J.M. Sung, Hywel-Jones \& Spatafora, Stud. Mycol. 57: 35 (2007)

Index Fungorum number: IF504190; Facesoffungi number: FoF01315; 469 species.

Parasitic on arthropods, protozoans, rotifers, nematodes, humans, animals and fungi worldwide. Sexual morph: Stromata or subiculum darkly pigmented or brightly coloured, tough, fibrous, pliant to wiry, rarely fleshy, often with aperithecial apices or lateral pads. Ascomata superficial to completely immersed, ordinal or oblique in arrangement. Asci unitunicate, cylindrical, rarely fusoid to ellipsoid, usually with thickened and almost bulbous ascus apex. Ascospores fasciculate, hyaline, usually filiform, multi-septate, disarticulating into part-spores or non-disarticulating. Asexual morph: see notes (adapted from Maharachchikumbura et al. 2016b).

Type genus - Ophiocordyceps Petch

Notes - Ophiocordycipitaceae was introduced based on phylogenetic analyses. Quandt et al. (2014) included Ophiocordyceps, Tolypocladium, Polycephalomyces, Purpureocillium, Drechmeria and Harposporium in Ophiocordycipitaceae based on morphology and phylogenetic analyses. Spatafora et al. (2015) confirmed this classification and introduced species combinations ito Drechmeria, Harposporium, Ophiocordyceps and Purpureocillium. Perennicordyceps was introduced by Matočec et al. (2014) based on morphology and phylogenetic analyses. Later,Simmons et al. (2015) provided 23 species of Hirsutella with sequence data for 23 species of Hirsutella. Most species in this family produce dark pigmented, tough to pliant stromata, that often have aperithecial apices (Sung et al. 2007). Asexual generic names associated with- 

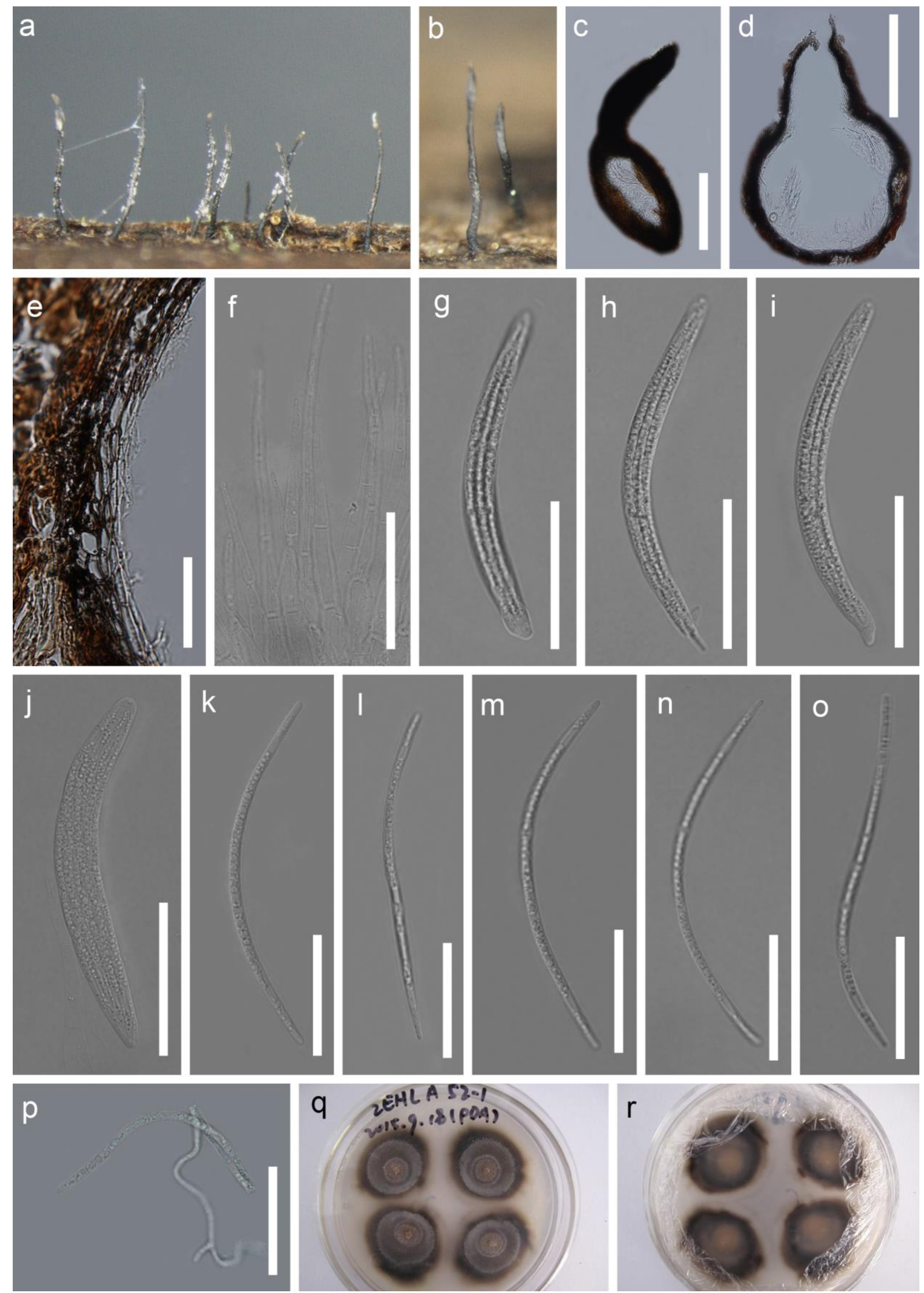

Figure 181 - Ophioceras commune (Material examined - CHINA, Yunnan Province, saprobic on decaying wood submerged in Erhai lake, March 2015, X.Y. Liu, S-578, HKAS 92587; March 2015, H.Y. Su, S-536, HKAS 92569; June 2015, S.M. Tang, S-338, HKAS 92640). a, b Neck. c, d Longitudinal section through ascomata. e Longitudinal section of peridium. f Paraphyses. g-j Asci. k-o Ascospores. Scale bars: c, $\mathrm{d}=200 \mu \mathrm{m}, \mathrm{f}-\mathrm{j}=50 \mu \mathrm{m}, \mathrm{e}, \mathrm{k}-\mathrm{o}=30 \mu \mathrm{m}$. 
-Ophiocordyceps include Sorosporella (Sorokin 1888), Hirsutella (Doassans \& Patouillard 1892, Gams \& Zare 2003), Hymenostilbe (Petch 1931a), Stilbella (Seifert 1985), Syngliocladium (Petch 1932), and Paraisaria (Samson \& Brady 1983). Based on morphology and phylogenetic analyses, Ophiocordyceps was protected and other names suppressed in accordance with the "one fungus one name" (Quandt et al. 2014). Paraisaria was also resurrected as a genus under this family (Mongkolsamrit et al. 2019).

Tolypocladium was proposed for protection over Elaphocordyceps and Chaunopycnis based on molecular analysis (Quandt et al. 2014). There is a wide ranges of asexual lineages associated with this family, some of which are restricted in their phylogenetic distribution, while others are often found in distant lineages (Quandt et al. 2014). For example, verticillium-like conidiophores, a common asexual morph of many species in several hypocrealean families, including Ophiocordycipitaceae, Cordycipitaceae and Clavicipitaceae (Zare et al. 2000, Gams \& Zare 2001, Sung et al. 2001, 2007). Thus the asexual genera links are unresolved and need further research.

\section{Ecological and economic significance of Ophiocordycipitaceae}

Many species in Ophiocordycipitaceae are economically important fungi and Ophiocordyceps sinensis is collected throughout the Himalaya's with great value to the local populations. Tolypocladium ophioglossoides is also reported as a Traditional Chinese Medicine (Quandt et al. 2015, Huang et al. 2017). Tolypocladium sp. is well-known as a producer of cyclosporine, which is an important immunosuppressant drug and also increases the competitiveness of the fungus in the environment (Bushley et al. 2013, Yang et al. 2018). The Zombie ant fungi have important roles in the ecosystem by controlling the behaviour of ants (Evans et al. 2011, Araújo et al. 2018, de Bekker et al. 2018).

\section{Genera included in Ophiocordycipitaceae}

Drechmeria W. Gams \& H.-B. Jansson, Mycotaxon 22(1): 36 (1985)

Index Fungorum number: IF105294; 12 morphological species (Species Fungorum 2020), 5 species with sequence data

Type species - Drechmeria coniospora (Drechsler) W. Gams \& H.B. Jansson

Notes - The genus was introduced to accommodate two hyphomycetes species (Gams \& Jansson 1985). Quandt et al. (2014) placed ten species (most of them pathogens of protozoans) in the genus based on phylogenetic analyses, including species of Haptocillium and Cordyceps gunnii. Species of the genus infect protozoa and have crescent-shaped, helical conidia (Gams \& Jansson 1985, Quandt et al. 2014).

Harposporium Lohde, Tagbl. Versamml. Ges. Deutsch. Naturf. 47: 206 (1874)

Index Fungorum number: IF8454; 36 morphological species (Species Fungorum 2020), 9 species with sequence data.

Type species - Harposporium guillulae Lohde

Notes - Most species in this genus were reported as pathogens of nematodes and sexual morphs of this genus are podocrella-like (Quandt et al. 2014, Spatafora et al. 2015). Species of the genus infect nematodes and rotifers and have ascospores breaking into two lanceolate multi-septate part-spores, sphaerical or hirsutella-like conidiogenous cells, and crescent-shaped or helicoid conidia (Quandt et al. 2014, Spatafora et al. 2015).

Hirsutella Pat., Revue mycol., Toulouse 14(no. 54): 67 (1892)

Index Fungorum number: IF8538; 83 morphological species (Species Fungorum 2020), 39 species with sequence data

Type species - Hirsutella entomophila Pat.

Notes - The genus was introduced for hyphomycetes pathogenic on insects, mites and nematodes (Simmons et al. 2015). The sexual morph of this genus was linked to Ophiocordyceps (Simmons et al. 2015). The genus is characterised by synnematous or mononematous 
conidiophores, fusiform, conidia, with a distinct chromophilic slime layer or covered by a finely warted epispore (Doassans \& Patouillard 1892, Quandt et al. 2014).

Hymenostilbe Petch, Naturalist (Hull), ser. 3: 101 (1931)

Index Fungorum number: IF8598; 12 morphological species (Species Fungorum 2020), 1 species with sequence data

Type species - Hymenostilbe muscaria Petch

Notes - This genus was considered as pathogenic on arthropods (Samson \& Evans 1975). The sexual morph was linked to Ophiocordyceps (White et al. 2003). The genus is characterised by polyblastic, cylindrical to clavate conidiogenous cells, bearing multiple apical or subapical denticles (Samson \& Evans 1975).

Ophiocordyceps Petch, Trans. Br. mycol. Soc. 16(1): 73 (1931)

Index Fungorum number: IF3598; 242 morphological species (Species Fungorum 2020), 125 species with sequence data.

Type species - Ophiocordyceps blattae (Petch) Petch

Notes - This genus is the type genus of Ophiocordycipitaceae (Sung et al. 2007). Quandt et al. (2014) emended this genus based on morphology and phylogenetic analyses. Based on phylogenetic analyses, the oldest name in the Ophiocordycipitaceae clade is Sorosporella, a synonym of Syngliocladium. Sorosporella was suppressed (Quandt et al. 2014), while Syngliocladium was previously treated with respect to the second oldest name Hirsutella (Evans \& Samson 1982). Ophiocordyceps should be protected over the other names. Most species of the genus are considered as entomopathogenic and have darkly pigmented, tough, fibrous, pliant to wiry, stipitate or sessile stromata, superficial to completely immersed perithecia and ascospores disarticulating into part-spores or non-disarticulating (Sung et al. 2007). The asexual morphs of this genus are members of Hirsutella, Hymenostible, Paraisaria and Syngliocladium (Sung et al. 2007).

Paraisaria Samson \& B.L. Brady, Trans. Br. mycol. Soc. 81(2): 285 (1983)

Index Fungorum number: IF25834; 11 species with sequence data.

Type species - Paraisaria gracilis (Grev.) Luangsa-ard, Mongkolsamrit \& Samson

Notes - The genus was resurrected from Ophiocordyceps to accommodate three new species and eight combinations based on morphology and phylogenetic analyses (Mongkolsamrit et al. 2019). The genus is characterised by robust solitary stroma with globose or ovoid, fertile heads, and fleshy and cream stipes (Mongkolsamrit et al. 2019). Asexual morphs are developed as white, loose synnemata, with verticillately branched conidiophores and narrowly cylindrical to fusiform conidia (Mongkolsamrit et al. 2019).

Perennicordyceps Matočec \& I. Kušan, Ascomycete.org 6(5): 129 (2014)

Index Fungorum number: IF810775; 4 species with sequence data.

Type species - Perennicordyceps prolifica (Kobayasi) Matočec \& I. Kušan

Notes - This genus was introduced to accommodate 4 species, which have superficial perithecia and hirsutella-like or acremonium-like asexual morphs.

Polycephalomyces Kobayasi, Sci. Rep. Tokyo Bunrika Daig., Sect. B 5: 245 (1941)

Index Fungorum number: IF9494; 17 morphological species (Species Fungorum 2020), 13 species with sequence data.

Type species - Polycephalomyces formosus Kobayasi

Notes - Polycephalomyces species are found in subtropical regions and are parasitic or hyperparasitic on insects (Xiao et al. 2018). This genus was considered as pathogenic on insects or mycoparasites on Ophiocordyceps species and has stipitate, bright stromata, immersed perithecia, ascospores which break into part spores, lanceolate to narrowly lageniform phialides and one or two types of conidia (Matočec et al. 2014, Xiao et al. 2018). 

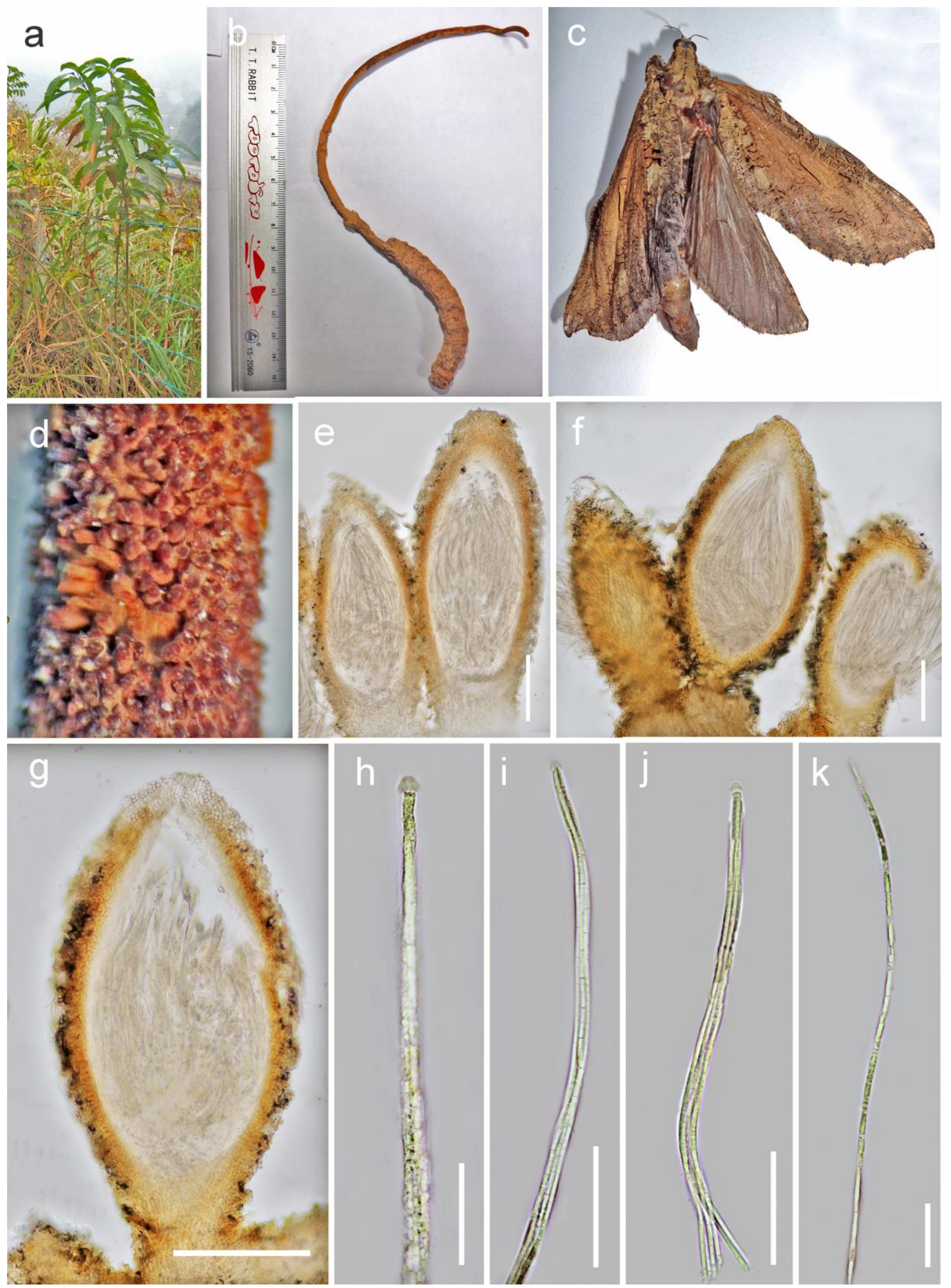

Figure 182 - Ophiocordyceps xuefengensis (Material examined - CHINA, Hunan Province, on Phassus nodus in root of living Clerodendrum cyrtophyllum, 20 October 2012, Ru-Cai Zhu, GZUH 2012HN14, holotype). a Habitat of Ophiocordyceps xuefengensis. b Overview of stromata and the host. c Adult of the host. d Brown, superficial ascomata on stroma. e-g Cross sections showing the complete stromata and perithecia. h-j Asci. k Part of ascospore. Scale bars: Scale bars: e-g = 200 $\mu \mathrm{m}, \mathrm{h}-\mathrm{k}=50 \mu \mathrm{m}$. 

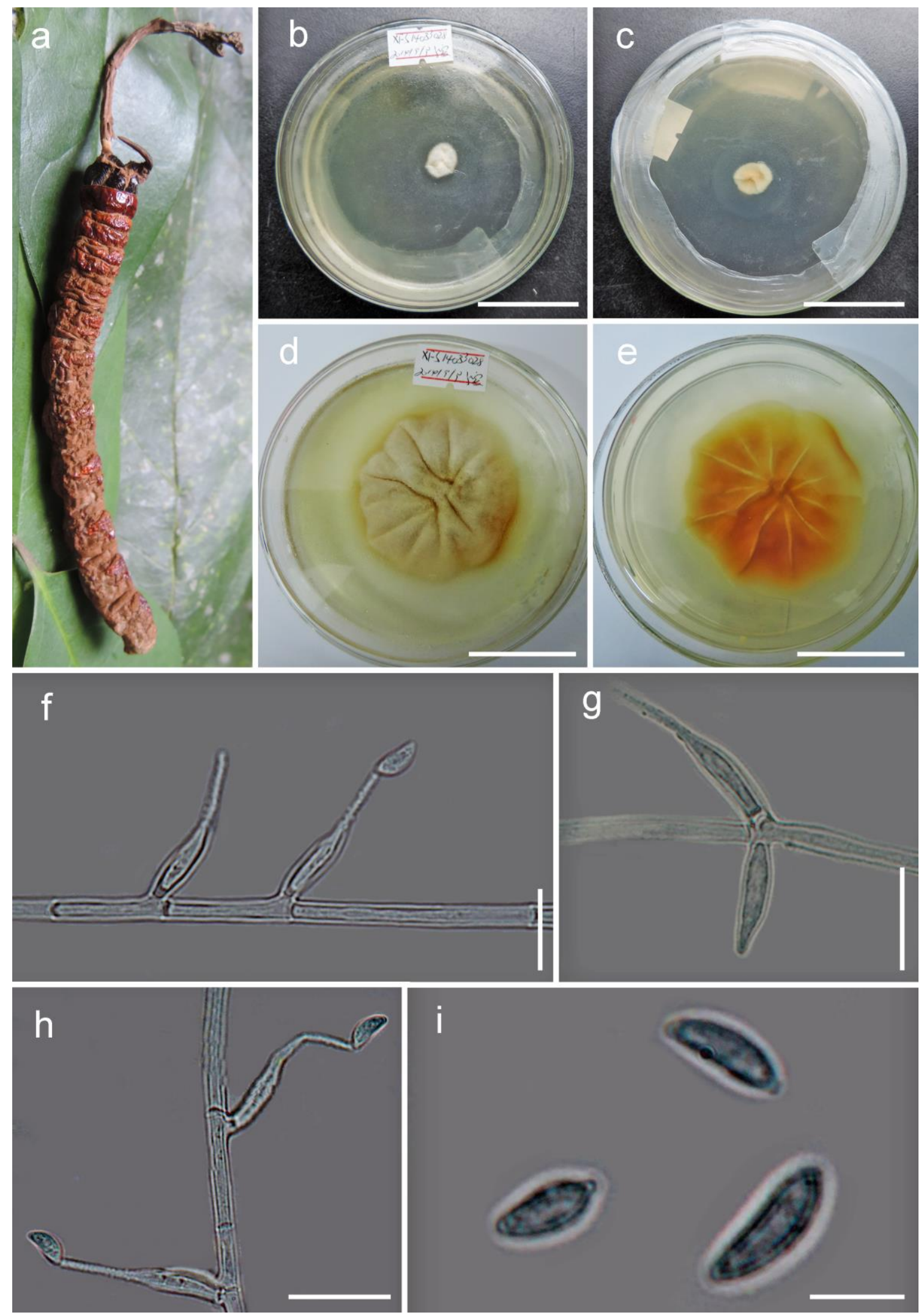

Figure 183 - Ophiocordyceps xuefengensis (Material examined - CHINA, Hunan Province, on Phassus nodus in root of living Clerodendrum cyrtophyllum, 20 October 2012, Ru-Cai Zhu, GZUCCHN131, ex-paratype living culture). a Overview of stromata and the host. b Colonies on PDA after 1 week. c Back of colonies on PDA after 1 week. d Colonies on PDA after 3 weeks. e Back of colonies on PDA after 1 week. f Solitary conidiogenous cells from vegetative hyphae. $g$ Opposite conidiogenous cells. h Conidiogenous cells in whorls. i Conidia. Scale bars: $b-e=2 \mathrm{~cm}$, $\mathrm{f}-$ $\mathrm{h}=10 \mu \mathrm{m}, \mathrm{i}=5 \mu \mathrm{m}$. 
Purpureocillium (Thom) Luangsa-ard, Houbraken, Hywel-Jones \& Samson, FEMS Microbiol. Lett. 321(2): 144 (2011)

Index Fungorum number: IF519529; 5 species with sequence data.

Type species - Purpureocillium lilacinum (Thom) Luangsa-ard, Houbraken, Hywel-Jones \& Samson

Notes - The genus was described for one emended medical species, Paecilomyces lilacinum, based on morphology and phylogenetic analyses (Luangsa-ard et al. 2011). Two new species were added by Perdomo et al. (2013a) and Hyde et al. (2016b) and 2 new combinations were introduced by Ban et al. (2015) and Spatafora et al. (2015). No sexual morph has been reported for this genus. The genus is characterised by ovate to cylindric phialides with distinct necks or erect and densely grouped phialides, which are purple in mass (Matočec et al. 2014, Xiao et al. 2018).

Tolypocladium W. Gams, Persoonia 6(2): 185 (1971)

Index Fungorum number: IF10242; 47 morphological species (Species Fungorum 2020), 24 species with sequence data.

Type species - Tolypocladiumin inflatum W. Gams

Notes - This genus was was protected over Elaphocordyceps and Chaunopycnis by Quandt et al. (2014). It contains parasites of insects, rotifers and other fungi or is a soil-inhabitant (Quandt et al. 2014). The asexual morph is characterised by solitary or branched, cylindrical to conical phialides and cylindrical to globose conidia, the sexual morph is characterised by darkly pigmented, stipitate stromata, half-immersed to immersed perithecia, a yellow to brown pigmented peridium and ascospores breaking into part-spores (Gams 1971, Bissett 1983, Gazis et al. 2014).

Ophiostomataceae Nannf., Nova Acta R. Soc. Scient. upsal., Ser. 4 8(no. 2): 30 (1932)

Index Fungorum number: IF91154; Facesoffungi number: FoF01807; 353 species.

Saprobic or parasitic on woody plants, occasionally on herbaceous plants, symbionts of or associated with beetles and mites. Sexual morph: Ascomata superficial, perithecial or cleistothecial, globose to subglobose, with external hairs, pale brown, dark brown or black, with long or short ostiolar necks, or sometimes lacking ostioles. Ostiolar neck short or long, slender, straight or flexuous, brown to dark brown at the base, pale brown to hyaline at the apex, containing parallel hyphae with pigmented cell walls around the ostiole. Ostiolar hyphae present or absent; when present, convergent or divergent, filamentous, septate, pale brown to hyaline, with some genera containing ostiolar beak (e.g. Subbaromyces). Peridium pseudoparenchymatous, with outer wall layers composed of angular cells with thickened, pigmented walls, and lined by thin-walled, hyaline cells of textura angularis. Asci 8-spored, unitunicate, evanescent, fusiform, oblong to clavate, some genera globose to subglobose (e.g. Fragosphaeria), with thin, deliquescent walls. Ascospores bi- to multi-seriate, variable in shape, frequently asymmetrical, oval, allantoid, fusiform, cylindrical, ellipsoidal, reniform, or falcate, aseptate or 1-septate, hyaline or appearing yellowish in mass, with or without a sheath. Asexual morph: Hyphomycetous. Conidiophores mononematous or synnematous, simple or branched, with some bearing a brush-like apical branching structure (e.g. Leptographium), erect, hyaline or dark brown to black. Conidiogenous cells holoblastic, polyblasic, sympodial, denticulate, phiailidic, with some proliferating at or somewhat below the apex and giving rise to another series of denticles or conidiogenous loci (e.g. Ophiostoma, Sporothrix). Conidia solitary or aggregated, fusiform, obovate to oblong, cylindrical, aseptate, hyaline, some bearing conidia in a viscoid pale reddish-brown head (e.g. pesotum-like) (adapted from Maharachchikumbura et al. 2016b).

Type genus - Ophiostoma Syd. \& P. Syd.

Notes - Ophiostomataceae was originally described with three genera (Ophiostoma, Ceratostomella, Endoconidiophora) (Nannfeldt 1932). de Beer et al. (2013a) accepted six genera (Ceratocystiopsis, Ophiostoma, Fragosphaeria, Leptographium, Raffaelea, Graphium) based on phylogenetic analyses. Maharachchikumbura et al. (2015, 2016b) provided an updated outline of Ophiostomataceae with 12 genera (Ceratocystiopsis, Fragosphaeria, Hyalobelemnospora, 
Hyalorhinocladiella, Klasterskya, Leptographium, Ophiostoma, Pesotum, Phialographium, Raffaelea, Spumatoria, Subbaromyces), which included sexual and asexual morphs, based on a phylogenetic analysis. Pesotum and Hyalorhinocladiella appear to be synonyms of Ophiostoma, but this may need further study. de Beer et al. (2016a) accepted Sporothrix in Ophiostomatales based on DNA sequence data and morphology of both morphs. Bateman et al. (2016) introduced Afroraffaelea. We accept 13 genera based on previous research (Afroraffaelea, Aureovirgo, Ceratocystiopsis, Fragosphaeria, Graphilbum, Hawksworthiomyces, Klasterskya, Leptographium, Ophiostoma, Raffaelea, Sporothrix, Spumatoria, and Subbaromyces) (Bateman et al. 2016, de Beer et al. 2013a, 2016a, Maharachchikumbura et al. 2015b, 2016b).

\section{Ecological and economic significance of Ophiostomataceae}

Members of this family are mostly saprobes on sap-wood. Species are specialized with sticky spores to facilitate insect dispersal. Many bark beetles act as vectors of ophiostomatoid fungi, e.g. Ophiostoma, Leptographium, Ceratocytiopsis species (Upadhyay 1981, Wingfield et al. 1993, Jacobs \& Wingfield 2001, Zipfel et al. 2006). Most species cause sap stain or blue stain of freshly cut logs and affect timber quality (Seifert 1993), and several species are important pathogens on species of Protea, Pinus, Larix, Tsuga and Pistacia and other tree species (Wingfield et al. 1988, Jacobs \& Wingfield 2001, Roets et al. 2013, Zhou et al. 2013).

\section{Genera included in Ophiostomataceae}

Afroraffaelea C.C. Bateman, Y.T. Huang \& D.R. Simmons, Fungal Ecology 25: 46 (2016)

Index Fungorum number: IF816236; 1 species with sequence data.

Type species - Afroraffaelea ambrosiae C.C. Bateman, Y.T. Huang \& D.R. Simmons

Notes - This monotypic genus was identified as symbionts of Premnobius cavipennis from pharyngeal mycangia, which were collected in the USA. The fungus was introduced based on culture characteristic on potato dextrose agar (PDA), sequencing data, and microtome sectioning wtih micro-CT scanning of mycangia (Bateman et al. 2016).

Aureovirgo J.A. van der Linde, Z.W. de Beer \& Jol. Roux, Antonie van Leeuwenhoek 109: 593 (2016)

Index Fungorum number: IF813870; 1 species with sequence data.

Type species - Aureovirgo volantis J.A. van der Linde, Z.W. de Beer \& Jol. Roux

Notes - Aureovirgo volantis was isolated from galleries of Cyrtogenius africus, on diseased Euphorbia ingens in Limpopo Province, South Africa (van der Linde et al. 2016). The sexual morph has globose ascomata with ostiolar hyphae and contains lunate ascospores with sheaths attenuated around each end. The asexual morph is leptographium-like with holoblastic, oblongelliptical and oval conidia (van der Linde et al. 2016).

Ceratocystiopsis H.P. Upadhyay \& W.B. Kendr., Mycologia 67(4): 799 (1975)

Index Fungorum number: IF889; 5 morphological species (Species Fungorum 2020), 4 species with sequence data.

Type species - Ceratocystiopsis minuta (Siemaszko) H.P. Upadhyay\& W.B. Kendr.

Notes - Ceratocystiopsis has globose to subglobose ascomata with long necks and hyaline ascospores with or without gelatinous sheaths; the asexual morph has sympodially proliferating conidiogenous cells, with holoblastic, hyaline, aseptate conidia.

Fragosphaeria Shear, Mycologia 15(3): 124 (1923)

Index Fungorum number: IF2011; 2 species with sequence data.

Type species - Fragosphaeria purpurea Shear

Notes - Fragosphaeria is characterised by globose ascomata lacking ostioles and globose ascospores produced in yellowish-brown masses from subglobose asci. The asexual morph has 
micronematous, unbranched or sparingly branched, sympodial and holoblastic conidia (Shear 1923).

Graphilbum H.P. Upadhyay \& W.B. Kendr., Mycologia 67(4): 800 (1975)

Index Fungorum number: IF8393; 13 morphological species (Species Fungorum 2020), 10 species with sequence data.

Type species - Graphilbum sparsum H.P. Upadhyay\& W.B. Kendr.

Notes - Graphilbum sparsum was collected from Picea glauca in Alaska. The genus is characterised by allantoid to reniform ascospores with sheaths and the asexual morph has synnematous/sporothrix-like conidiophores with solitary and holoblastic reniform to obovate conidia.

Hawksworthiomyces Z.W. de Beer, Marinc. \& M.J. Wingf., Fungal Biology 120(11): 1329 (2016)

Index Fungorum number: IF815685; 4 species with sequence data.

Type species - Hawksworthiomyces lignivorus (De Mey., Z.W. de Beer \& M.J. Wingf.) Z.W. de Beer, Marinc. \& M.J. Wingf.

Notes - The genus was introduced to accommodate the type species, Hawksworthiomyces lignivorus, based on morphology and phylogenetic analyses (de Beer et al. 2016b). The asexual morphs have micronematous, unbranched or sparingly branched conidiophores and holoblastic, ellipsoidal to cylindrical conidia (de Beer et al. 2016b). The sexual morph is undetermined. Three species were detected by using environmental nucleic acid sequences (ENAS) to assess Fungal Diversity. (de Beer et al. 2016b).

Klasterskya Petr., Annls mycol. 38(2/4): 225 (1940)

Index Fungorum number: IF2569; 3 morphological species (Species Fungorum 2020).

Type species - Klasterskya acuum (Mouton) Petr.

Notes - Klasterskya was introduced to accommodate Lentomita acuum found on dry leaves of Pinus sylvestris. The genus is characterised by subglobose to obpyriform ascomata having ostioles with fimbriate hyphae and 1-septate, elliptical to cylindrical ascospores, surrounded by a hyaline gelatinous sheath, discharged in gummy masses (Petrak 1940, Valldosera \& Guarro 1989). The asexual morph is undetermined.

Leptographium Lagerb. \& Melin, Svensk SkogsvårdsföreningTidskr. 25: 257 (1927)

Index Fungorum number: IF8749; 74 morphological species (Species Fungorum 2020), 68 species with sequence data.

Type species - Leptographium lundbergii Lagerb. \&Melin

Notes - Leptographium lundbergii was introduced from wood of Coniferae in Sweden. The strain was introduced as the asexual morph of Grosmannia (Lagerberg et al. 1927). de Beer et al. (2013b) synonymized Grosmannia under Leptographium. The genus causes sap-stain of mainly conifer timber, and less often of hardwoods (Harrington \& Cobb 1988, Wingfield et al. 1993, Jacobs \& Wingfield 2001). A few species are saprobes found in the soil or decaying plant material, and some are important tree pathogens (Harrington \& Cobb 1988). Like most ophiostomatoid taxa, Leptographium spp. are best known for their association with bark beetles (Harrington \& Cobb 1988, Kirisits 2004). They are adapted to be carried by these insects, having erect conidiophores or ascomata with long necks and conidia and ascospores produced in slimy masses at the apices of these structures (Six 2003, Kirisits 2004, Cardoza et al. 2008).

Ophiostoma Syd. \& P. Syd., Annls mycol. 17(1): 43 (1919)

Index Fungorum number: IF3614; 134 morphological species (de Beer et al. 2013), 62 species with sequence data.

Type species - Ophiostoma piliferum (Fr.) Sydow \& P. Sydow 
Notes - de Beer et al. (2013a) accepted 134 species in Ophiostoma and some species are important tree pathogens, such as $O$. ulmi and $O$. novo-ulmi, the causal agents of Dutch elm disease, transmitted by elm bark beetles (Webber \& Gibbs 1989, Brasier 1991). The sexual morph is characterized by globose to subglobose ascomata, surrounded by external hairs, with ostiolar necks and some species containing divergent, ostiolar hyphae. The asexual morph has sporothrixlike or pesotum-like conidiogenous cells with ellipsoidal to cylindrical obovate, globose and aseptate conidia. The asexual morph of Ophiostoma piliferum is illustrated in this entry (Figs. 184, 185).
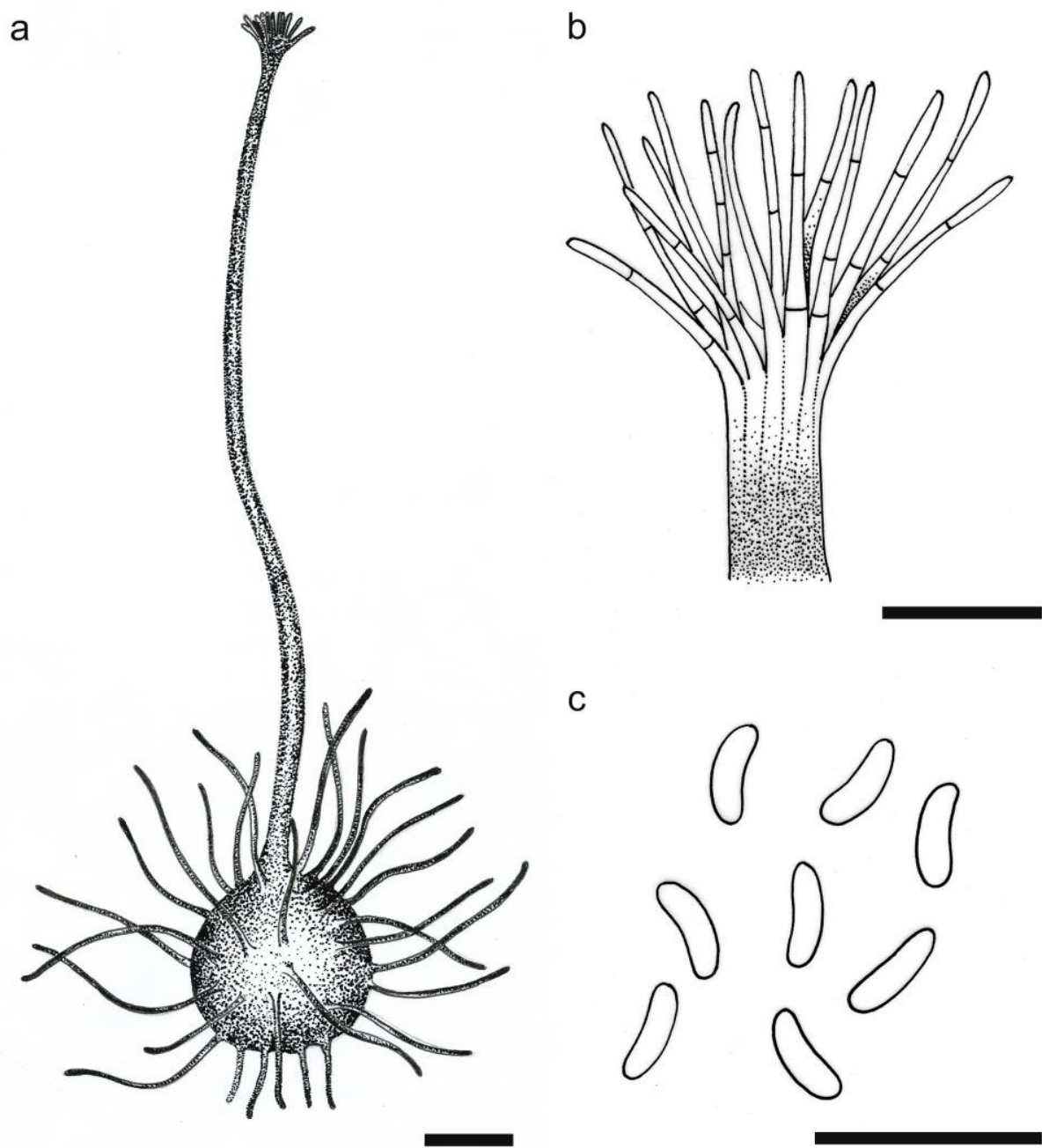

C

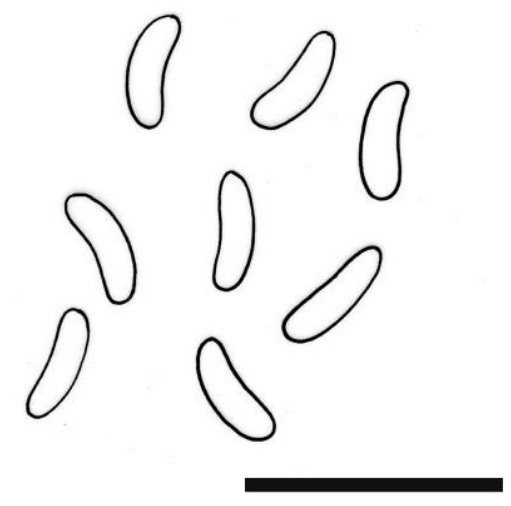

Figure 184 - Ophiostoma piliferum (redrawn from Osorio 1985). a Ascoma. b Ostiolar region with ostiolar hyphae. c Ascospores. Scale bars: $\mathrm{a}-\mathrm{c}=10 \mu \mathrm{m}, \mathrm{b}=5 \mu \mathrm{m}$.

Raffaelea Arx \& Hennebert, Mycopath. Mycol. appl. 25: 310 (1965)

Index Fungorum number: IF9685; 33 morphological species (Species Fungorum 2020), 30 species with sequence data.

Type species - Raffaelea ambrosiae Arx \& Hennebert

Notes - Raffaelea ambrosiae is associated with Platypus cylindrus on Quercus in the UK. Raffaelea is a genus associated with ambrosia beetles worldwide (Harrington et al. 2010, de Beer et al. 2013a, Musvuugwa et al. 2015, Simmons et al. 2016). These fungi commonly occur in symbioses with wood-boring ambrosia beetles, Coleoptera, Curculionidae, Scolytinae and Platypodina and cause sap stain or blue stain of freshly cut logs and affect timber quality. The genus is characterised by hyphae bearing typical phialides and conidiogenous cells with globose/ovoid to elongated conidia, often truncate at the base, with conidia budding yeast-like daughter cells. The sexual morph is undetermined. 


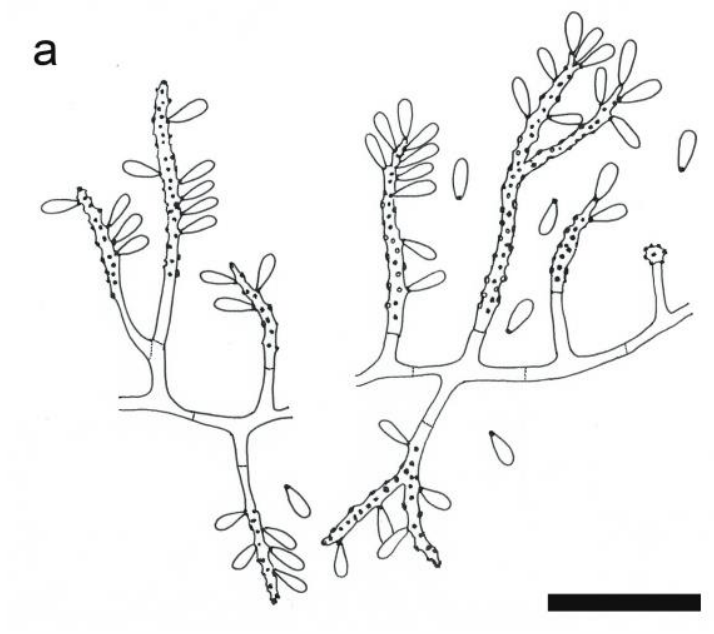

b
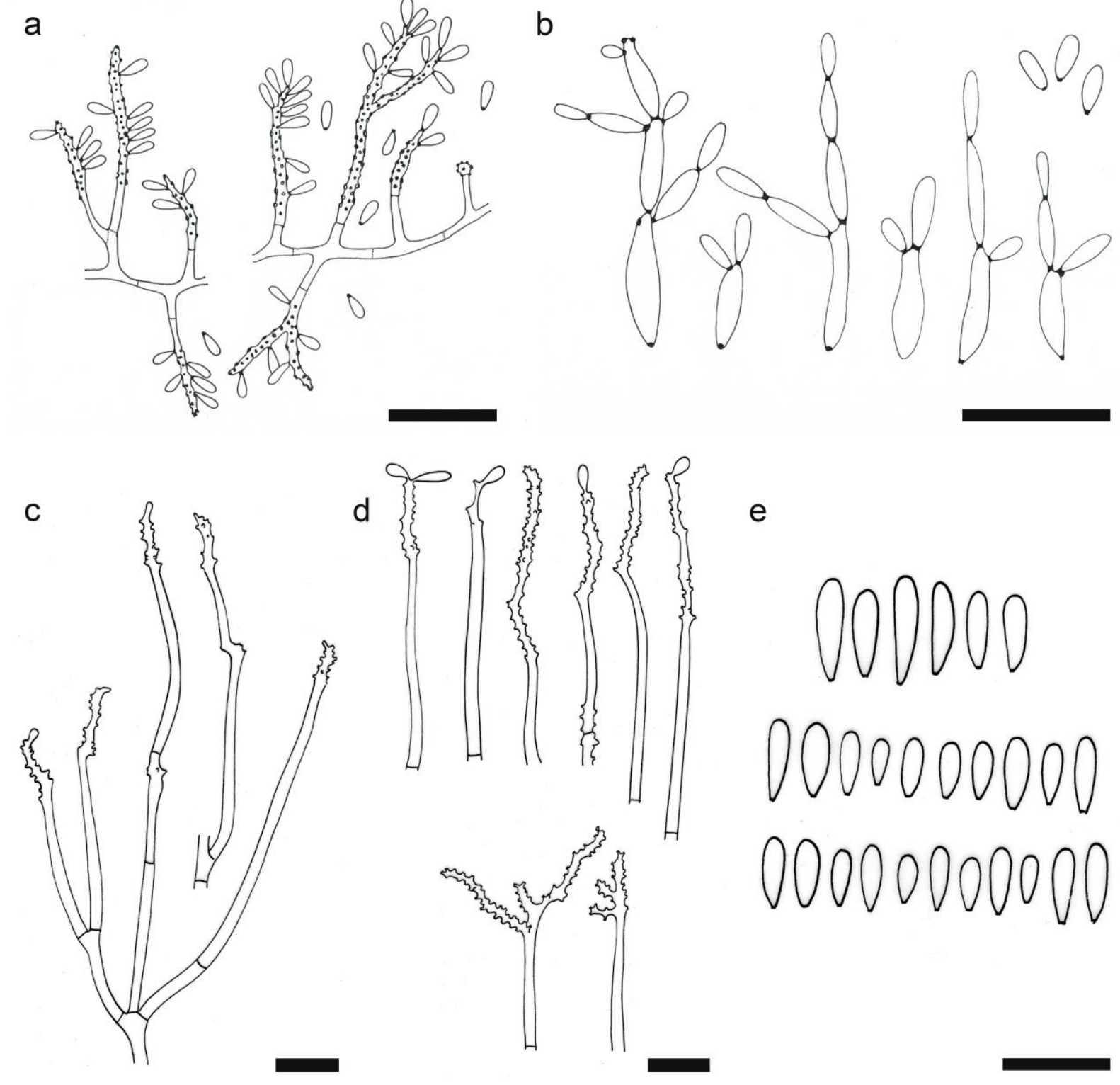

Figure 185 - Ophiostoma piliferum. a Conidiophores and conidia with sporothrix-like conidiogenous cells. b Conidiophores and conidia with raffaelea-like conidiogenous cell structure (redrawn from Osorio 1985). c Conidial apparatus. d Conidial apparatus from various living cultures with conidiogenous cells. e Conidia (redrawn from de Hoog 1974). Scale bars: a-e $=10$ $\mu \mathrm{m}$.

Sporothrix Hektoen \& C.F. Perkins, J. Exp. Med. 5: 80 (1901)

Index Fungorum number: IF10046; 80 morphological species (Species Fungorum 2020), 60 species with sequence data

Type species - Sporothrix schenckii Hektoen \& C.F. Perkins

Notes -"Sporotrichosis", a human disease caused by Sporothrix schenckii was reported by Benjamin Schenck in 1898. The disease agent was isolated from a specimen taken from cutaneous lesions of a patient (Hektoen \& Perkins 1900). Sporothrix schenckii lives in soil, plants and many mammals (Barros et al. 2011, Chakrabarti et al. 2015). The S. schenckii species complex occurs worldwide, being most commonly found in Africa, America and Asia (Sizar \& Talati 2019). de Beer et al. (2013b) reported Sporothrix schenckii/Ophiostoma stenoceras is a species complex in Ophiostomasensu lato, representing a distinct genus in Ophiostomatales. Based on phylogenetic analyses of four gene regions (LSU, ITS, tub2, calM), de Beer et al. (2016b) concluded that Sporothrix was distinct from Ophiostoma sensu stricto, and synonymised Sporotrichopsis and 
Dolichoascus under this genus. The sexual morph is characterized by globose ascomata with long necks and brown to black bases, 8-spored, evanescent globose to broadly clavate asci and hyaline, aseptate, lunate, allantoid, reniform ascospores. The asexual morph is dimorphic with a mycelial and a yeast phase (de Hoog 1974).

Spumatoria Massee \& E.S. Salmon, Ann. Bot., Lond. 15: 350 (1901)

Index Fungorum number: IF5175; 1 species with sequence data.

Type species - Spumatoria longicollis Massee \& E.S. Salmon

Notes -Spumatoria longicollis was found on dung of Equus caballus in the UK. The genus is characterised by globose perithecia, with one or seldom two necks, with ostiolar hyphae and hyaline, 2(-3)-celled, clavate, coarsely guttulate ascospores. The asexual morph is sporothrix-like, with dacrioid conidia and blastoconidia growing directly from undifferentiated hyphae (Giraldo et al. 2017a).

Subbaromyces Hesselt., Bull. Torrey bot. Club 80: 511 (1953)

Index Fungorum number: IF5303; 2 morphological species (Species Fungorum 2020), 1 species with sequence data.

Type species - Subbaromyces splendens Hesselt.

Notes - Subbaromyces splendens was repeatedly found growing on trickling filter beds in New York. Hesseltine (1953) reported both the sexual and asexual morphs. The genus is characterised by ascomata with ostiolar necks and 1-septate ascospores surrounded by a sheath. The asexual morph has micronematous conidiophores, with non-apically branching structures and solitary, holoblastic, oblong-elliptical to obovate conidia.

Oxydothidaceae S. Konta \& K.D. Hyde, Mycosphere 7(9): 1431 (2016)

Index Fungorum number: IF552561; Facesoffungi number: FoF02700; 79 species.

Saprobic, endophytic or parasitic on monocotyledons. Sexual morph: Ascomata solitary or irregularly scattered, ellipsoidal or subglobose, immersed or semi-immersed, slightly raised from host surface with light or darkened discs, with most taxa lying horizontal to the host surface. Peridium thick-walled, brown to dark brown, and/or peridium cells merging with the host tissue. Paraphyses hypha-like, filamentous, irregular, septate, persisting between asci, but often fragmenting in dried material. Asci 8-spored, unitunicate, cylindrical, pedicellate, with a J+ (rarely $\mathrm{J}-$ ), subapical ring. Ascospores fasciculate, hyaline, sometimes appearing yellow in mass, fusiform or filiform, 1-septate, tapering from the center to spine-like, pointed or rounded ends. Appressoria produced by germinating ascospores in some species, solitary, hyaline or greenish, or pale brown to brown, irregular in shape, thick-walled. Asexual morph: Hyphomycetous. Selenosporella sp. Conidiophores mononematous, (1-)2-3-septate, unbranched or 1-branced, brown olivaceous, thickwalled at below, thin-walled and colourless above, unicellular, colourless, distinct obviously differentiated apex or base (adapted from Samuels \& Rossman 1987, Konta et al. 2016).

Type genus - Oxydothis Penz. \& Sacc.

Notes - Oxydothidaceae (Konta et al. 2016) was established to accommodate the monotypic genus Oxydothis, and it is phylogenetically related to Vialaeaceae and Iodosphaeriaceae in Xylariales. Hyde et al. (2017a) provided a molecular clock estimates to evaluate the ranking of taxa of Sordariomycetes, and indicated that the status of Oxydothidaceae is supported with a divergence of 114 MYA (stem age), which is in the recommended divergence range for families (50-130 MYA).

\section{Ecological and economic significance of Oxydothidaceae}

Oxydothis is one of the most common genera encountered in monocotyledons, such as palms (Arecaceae), Pandanus (Pandanaceae) and bamboo (Gramineae) (Hyde 1993b, c, 1994a, Wang \& Hyde 1999, Wong \& Hyde 2001, Fröhlich \& Hyde 2000, Taylor \& Hyde 2003, Shenoy et al. 2005, Hidayat et al. 2006, Tibpromma et al. 2018) and are saprobes important in nutrient cycling. The 
taxa are also pathogens (Fröhlich \& Hyde 1994) and endophytes (Hyde 1994a). It is important to identify species and study their biotrophic nature, which may provide resources for biological control and protect plants during planting.

\section{Genus included in Oxydothidaceae}

Oxydothis Penz. \& Sacc., Malpighia 11(11-12): 505 (1897)

Index Fungorum number: IF3661; 79 morphological species (Species Fungorum 2020), 12 species with sequence data.

Type species - Oxydothis grisea Penz. \& Sacc.

Notes - Oxydothis was described from Cibodas, Java, Indonesia by Penzig \& Saccardo (1897b) with three species $O$. grisea, O. nigricans and $O$. maculosa, and placed in Amphisphaeriaceae (sensu Eriksson \& Hawksworth 1991). The genus is characterized by two types of ascomata, one is developed singly or in clusters, in darkened, ellipsoidal raised areas on the host surface, and have distinctive eccentric ostioles, whereas another are those developed below a raised sheet of host epidermis, and usually not darkened (Fröhlich \& Hyde 2000). Hyde reviewed the taxa of Oxydothis and emphasized that ascus and ascospore morphology in this genus is consistent and reliable for distinguishing species, and also discussed the morphology of closely related genera, Ceriospora, Frondispora, Lasiobertia and Leiosphaerella (Hyde 1993b, 1994a). However, the familial classification of this genus was uncertain and it has been placed in Hyponectriaceae (Hyde 1993b) and Clypeosphaeriaceae (Kang et al. 1999b) based on morphology. Jeewon et al. (2003b) analysed DNA sequence datas and mentioned that Oxydothis was closely related to Leiosphaerella (Xylariales, genera incertae sedis), and Konta et al. (2016) placed the genus in Oxydothidaceae (Xylariales). Konta et al. (2016) also suggested that Oxydothis species may be associated with healthy plants as endophytes and become saprobes, based on their observations of appressoria. In this study, we introduce a new species, Oxydothis phoenicis, from mangrove habitats.

Oxydothis phoenicis S.N. Zhang, K.D. Hyde \& J.K. Liu, sp. nov.

Fig. 186

Index Fungorum number: IF555516; Facesoffungi number: FoF05092

Saprobic on rachis of Phoenix paludosa. Sexual morph: Ascomata 230-600 $\mu \mathrm{m}$ diam., solitary or clustered in groups, forming under slightly raised, blackened, ellipsoidal regions on the host surface. Peridium 20-25 $\mu \mathrm{m}$ wide, composed of 2-3 layers of pale brown to hyaline cells with textura prismatica. Paraphyses seems to dissolve during maturation. Asci $142-159 \mu \mathrm{m} \times 14-21 \mu \mathrm{m}$ $(\bar{x}=148.9 \times 17 \mu \mathrm{m}, \mathrm{n}=20), 8$-spored, cylindrical, mostly straight, pedicellate, unitunicate, with a wedge-shaped, J+, subapical ring, 3.5-5 $\mu \mathrm{m}$ high, 3.5-4.5 $\mu \mathrm{m}$ diam. Ascospores $60-78 \mu \mathrm{m} \times 6-7.5$ $\mu \mathrm{m}(\bar{x}=72 \times 6.7 \mu \mathrm{m}, \mathrm{n}=30)$, fusiform, hyaline, obliquely 1-2-seriate, tapering gradually from a constricted central or seldom upper central septum to short, pointed processes. Asexual morph: Undetermined.

Material examined - THAILAND, Chang Wat Chanthaburi, Amphoe Khlung, Tambon Wan Yao, on rachis of Phoenix paludosa (Arecaceae Roxb.), intertidal, 25 April 2017, S.N. Zhang, SNT134 (MFLU 18-1074 holotype); ibid., (HKAS 97485, isotype); ex-type living culture MFLUCC 18-0269 (= MFLUCC 18-0270).

GenBank numbers - Sequence data used in this study: ITS: MK088065 (MFLUCC 18-0269), LSU: MK088061 (MFLUCC 18-0269), SSU: MK088063 (MFLUCC 18-0269), ITS: MK088066 (MFLUCC 18-0270), LSU: MK088062 (MFLUCC 18-0270), SSU: MK088064 (MFLUCC 180270). Sequence data not used in this study but submitted in GenBank: tef1: MK087667 (MFLUCC 18-0269), tef1: MK087668 (MFLUCC 18-0270).

Notes - Oxydothis phoenicis is similar to O. asiatica, O. mauritiae, $O$. uniseriata and $O$. rattanica, but differs in ascospore and apical ring size (Fröhlich \& Hyde 2000). Oxydothis phoenicis also shares similar ascospores and ascal apical rings with $O$. calami, $O$ licualae (and $O$. rubella, but is distinct in ascomata morphology (Hyde 1993c). The phylogeny based on multi-gene analysis also supports $O$. phoenicis as an independent lineage and indicates it is distinct from other species with sequence data. 

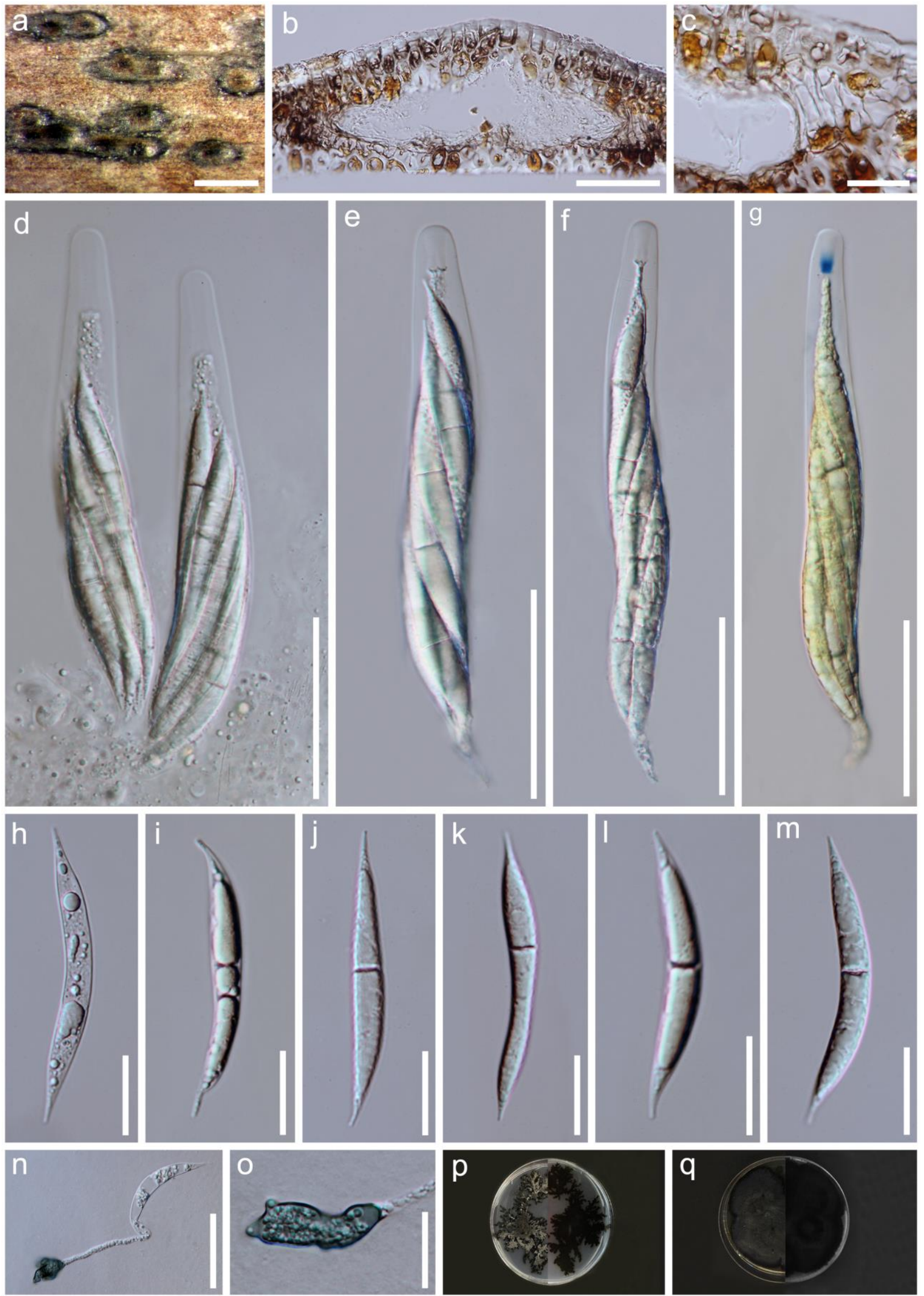

Figure 186 - Oxydothis phoenicis (MFLU 18-1074, holotype). a Appearance of fruiting bodies on host substrate. b Section of ascoma. c Peridium. d-g Asci. g Reaction of apical ring in Melzer's reagent. h-m Ascospores. $\mathrm{n}$ Germinating ascospores. o Appressoria. $\mathrm{p}$ Colonies on PDA. $\mathrm{q}$ Colonies on MEA. Scale bars: $\mathrm{a}=500 \mu \mathrm{m}, \mathrm{b}, \mathrm{d}-\mathrm{g}, \mathrm{n}=50 \mu \mathrm{m}, \mathrm{c}, \mathrm{h}-\mathrm{m}, \mathrm{o}=20 \mu \mathrm{m}$. 
Papulosaceae Winka \& O.E. Erikss., Mycoscience 41 (2):102 (2000)

Index Fungorum number: IF82096; Facesoffungi number: FoF01284; 9 species.

Saprobic on wood in freshwater or marine habitats, and pathogenic on roots in terrestrial habitats. Sexual morph: Ascomata perithecial, solitary, immersed or semi-immersed, black to dark brown, globose to ellipsoidal, coriaceous, ostiolate. Necks cylindrical, periphysate. Peridium composed of cells of textura angularis or brown-walled compressed cells. Paraphyses tapering, simple or branched, septate. Asci 8-spored, unitunicate, cylindrical, short pedicellate, with a J-, or $\mathrm{J}+$, refractive, bipartite or discoid, apical ring. Ascospores uniseriate to biseriate, hyaline or brown, ellipsoidal or fusiform, unicellular to 3-septate, smooth or verruculose, with or without cup-like, bipolar appendages. Asexual morph: Undetermined (adapted from Réblová et al. 2013).

Type genus - Papulosa Kohlm. \& Volkm.-Kohlm.

Notes - Winka \& Eriksson (2000) introduced Papulosaceae and concluded that the exact phylogenetic position of Papulosa could not be established due to the small number of SSU sequences available for unitunicate pyrenomycetes at that time. Papulosa shared similarities with Diaporthales, Ophiostomatales, Phyllachorales and Sordariales based on molecular data, thus the genus was accommodated in the subclass Sordariomycetidae. Maharachchikumbura et al. (2015) placed Papulosaceae as a sister clade to Coniochaetaceae and Cordanaceae. Abdel-Wahab et al. (2011) analyzed LSU sequence data and found that Brunneosporella and Fluminicola clustered with Papulosa amerospora and Cataractispora receptaculorum. A similar relationship was seen in phylogenetic analyses carried out by Réblová et al. (2013) using LSU, SSU, and rpb2 sequence data. Both Brunneosporella and Fluminicola appear in the same clade as that of Papulosa and Pleurophragmium parvisporum and were named as Papulosaceae (Réblová et al. 2013). LSU and SSU sequence analyses of Boonyuen et al. (2012), showed that Brunneosporella (as Ascobrunneispora aquatica) clustered with Papulosa. Maharachchikumbura et al. $(2015,2016 \mathrm{~b})$ placed Brunneosporella and Fluminicola in Papulosaceae. Platytrachelon which was introduced by Réblová et al. (2013) has a close phylogenetic relationship with the Papulosaceae. Réblová et al. (2013) included Platytrachelon in Sordariomycetes incertae sedis while Wijayawardene et al. (2018a) listed it under Papulosaceae. However, the phylogenetic placement of Platytrachelon should be verified with more taxon sampling. Khemmuk et al. (2016) introduced a novel genus, Wongia to Papulosaceae based on phylogenetic analyses of combined ITS, LSU, rpbl and tefl sequence data. Hence, the family comprises four genera at present.

\section{Ecological and economic significance of Papulosaceae}

Most members in this family are found on submerged wood in freshwater or marine habitats as saprobes (Ranghoo et al. 2001).

\section{Genera included in Papulosaceae}

Brunneosporella Ranghoo \& K.D. Hyde, Mycol. Res. 105(5): 625 (2001)

Index Fungorum number: IF28492; 1 species with sequence data.

Type species - Brunneosporella aquatica Ranghoo \& K.D. Hyde

Notes - Brunneosporella was introduced by Ranghoo et al. (2001) which comprises 1-septate and concolorous ascospores and asci with a discoid apical ring. Brunneosporella aquatica is the only species assigned to this genus.

Fluminicola S.W. Wong, K.D. Hyde \& E.B.G. Jones, Fungal Divers. Res. Ser. 2: 190 (1999)

Index Fungorum number: IF28031; 4 morphological species (Species Fungorum 2020), 3 species with sequence data.

Type species - Fluminicola bipolaris S.W. Wong, K.D. Hyde \& E.B.G. Jones

Notes - Wong et al. (1999) introduced Fluminicola for the freshwater species F. bipolaris. The genus is characterized by cylindrical asci with a relatively massive, refractive apical ring and fusiform and hyaline ascospores with irregular bifurcate or cup-like bipolar appendages (Wong et al. 1999, Zhang et al. 2017a). Five species are accommodated in the genus, i.e. F. aquatica, F. 
bipolaris, F. coronata, F. saprophytica and F. thailandensis (Zhang et al. 2017a, Index Fungorum 2020). Fluminicola saprophytica and $F$. thailandensis are illustrated below; for descriptions see Zhang et al. (2017a).

Papulosa Kohlm. \& Volkm.-Kohlm., Syst. Ascom. 11(2): 96 (1993)

Index Fungorum number: IF26426; 1 species with sequence data

Type species - Papulosa amerospora Kohlm. \& Volkm.-Kohlm.

Notes - Kohlmeyer \& Volkmann-Kohlmeyer (1993) established the monotypic genus Papulosa, but were unable to place this genus with certainty into any order or family.

Wongia Khemmuk, Geering \& R.G. Shivas, IMA fungus 7(2): 247-252 (2016)

Index Fungorum number: IF817529; 3 species with sequence data.

Type species - Wongia garrettii (P. Wong \& M.L. Dickinson) Khemmuk, Geering \& R.G. Shivas

Notes - This genus was introduced to accommodate two root infecting fungi from Australia Magnaporthe garrettii and M. griffinii, which formed a well-supported separate clade in Papulosaceae and clustered outside Magnaporthales (Khemmuket al. 2016). Wongia species have J, apical rings in the asci and 3-septate ascospores that have dark brown middle cells and pale brown to subhyaline shorter distal cells (Khemmuket al. 2016).

Pararamichloridiaceae Crous, Persoonia 39: 357 (2017)

Index Fungorum number: IF823463; Facesoffungi number: FoF05314; 3 species.

Pathogenic on plant leaves. Sexual morph: Undetermined. Asexual morph: Mycelium consisting of hyaline, smooth, septate, branched, hyphae. Conidiophores erect, solitary, straight to flexuous, septate, branched at apex or not, subcylindrical, subhyaline to medium brown, smooth. Conidiogenous cells terminal and intercalary, subcylindrical, subhyaline to medium brown, smooth, polyblastic, denticulate. Conidia solitary, hyaline, smooth, aseptate, thin-walled, clavate to ellipsoid (adapted from Crous et al. 2017a).

Type genus - Pararamichloridium Crous

Notes - Crous et al. (2017a) introduced Pararamichloridiaceae and accepted Pararamichloridium and Woswasia. However, Woswasia, along with Xylochrysis and Cyanoannulus, was placed in Diaporthomycetidae families incertae sedis by Zhang et al. (2017a) based on morphology, phylogenetic analysis and molecular dating. In the multi-loci ITS, LSU, SSU and $r p b 2$ phylogenetic tree, Pararamichloridium livistonae (CBS 143166) and P. verrucosum (CBS 128.86) grouped together and formed a separate clade with 99\% MP bootstrap support, 92\% ML bootstrap support and 100\% Bayesian posterior probabilities (data not shown). Woswasia atropurpurea (CBS 133167), Xylochrysis lucida (CBS 135996) and Cyanoannulus petersenii (R044a and R044b) formed a separate branch which is distant from Pararamichloridium clade (data not shown). In this study, we exclude Woswasia from Pararamichloridiaceae based on its close phylogenetic affinity with Xylochrysis and Cyanoannulus in Woswasiaceae.

\section{Ecological and economic significance of Pararamichloridiaceae}

Pararamichloridium livistonae was collected from the leaves of Livistona australis in Australia and it causes leaf spots of the host plant (Crous et al. 2017a).

\section{Genus included in Pararamichloridiaceae}

Pararamichloridium Crous, Persoonia 39: 357 (2017)

Index Fungorum number: IF823369; 3 species with sequence data.

Type species - Pararamichloridium livistonae Crous

Notes - Currently, three species, Pararamichloridium caricicola, $P$. livistonae and $P$. verrucosum are accepted in this genus. The genus is characterised by branched or unbranched, 
medium brown, septate conidiophores, medium brown, denticulate conidiogenous cells and solitary, hyaline, smooth, granular, aseptate, and clavate conidia (Crous et al. 2017a).
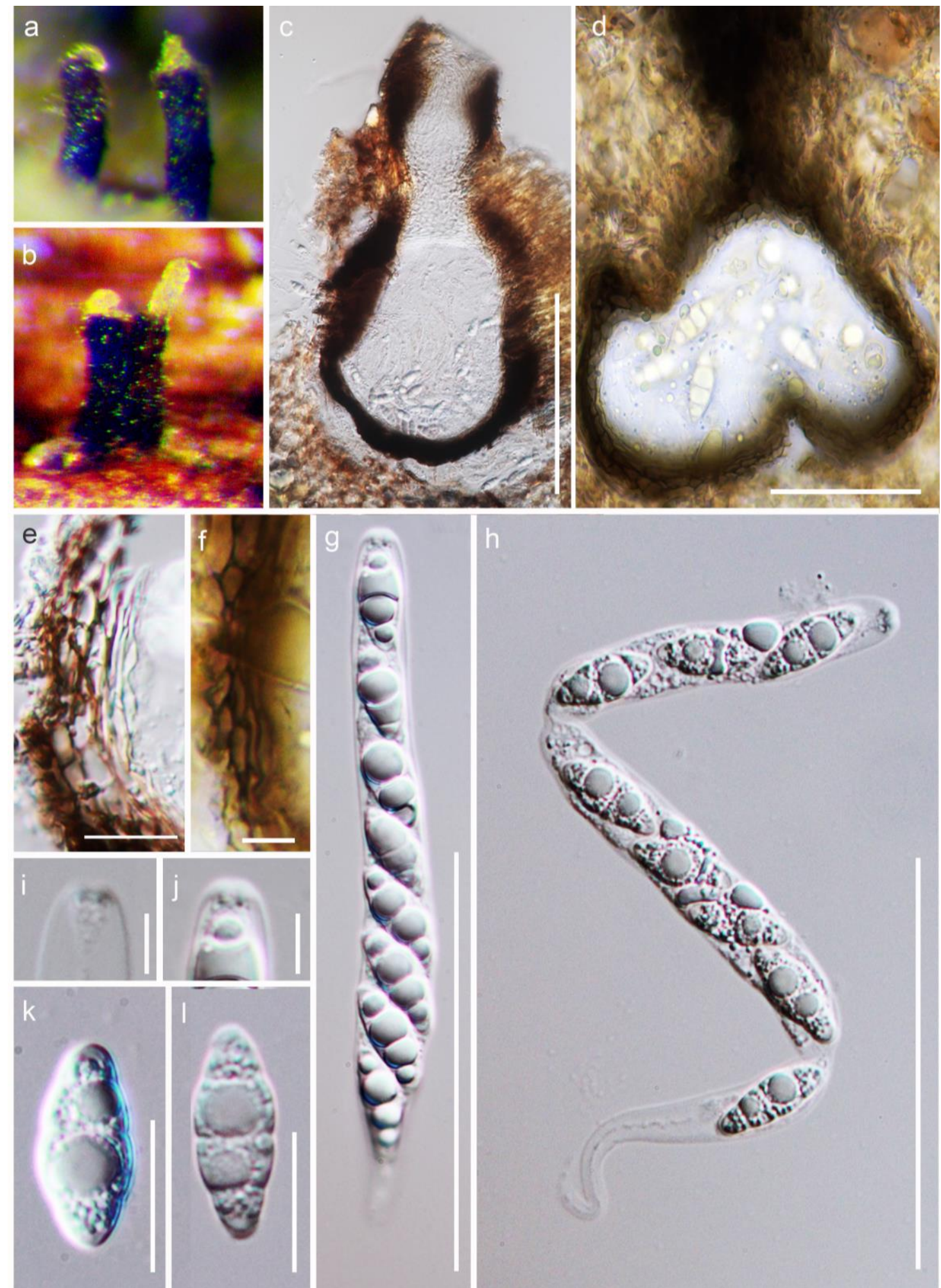

Figure 187 - Fluminicola saprophytica (Material examined - THAILAND, Prachuap Khiri Khan, on submerged bamboo in a small river, 30 July 2015, W. Dong 04A, MFLU 15-2694, holotype; extype culture MFLUCC 15-0976) and Fluminicola thailandensis (Material examined - THAILAND, Prachuap Khiri Khan, on submerged wood in a small river, 30 July 2015, W. Dong 22A (MFLU 15-2704, holotype). a, b Appearance of necks on host. c, d Vertical sections of ascomata. e, $\mathrm{f}$ Peridium. g, h Asci. i, j Apex of asci. k, 1 Ascospores. Scale bars: $\mathrm{c}, \mathrm{h}=100 \mu \mathrm{m}, \mathrm{d}=50 \mu \mathrm{m}, \mathrm{e}, \mathrm{f}=$ $10 \mu \mathrm{m}, \mathrm{g}, \mathrm{k}, \mathrm{l}=20 \mu \mathrm{m}, \mathrm{i}, \mathrm{j}=5 \mu \mathrm{m}$. 


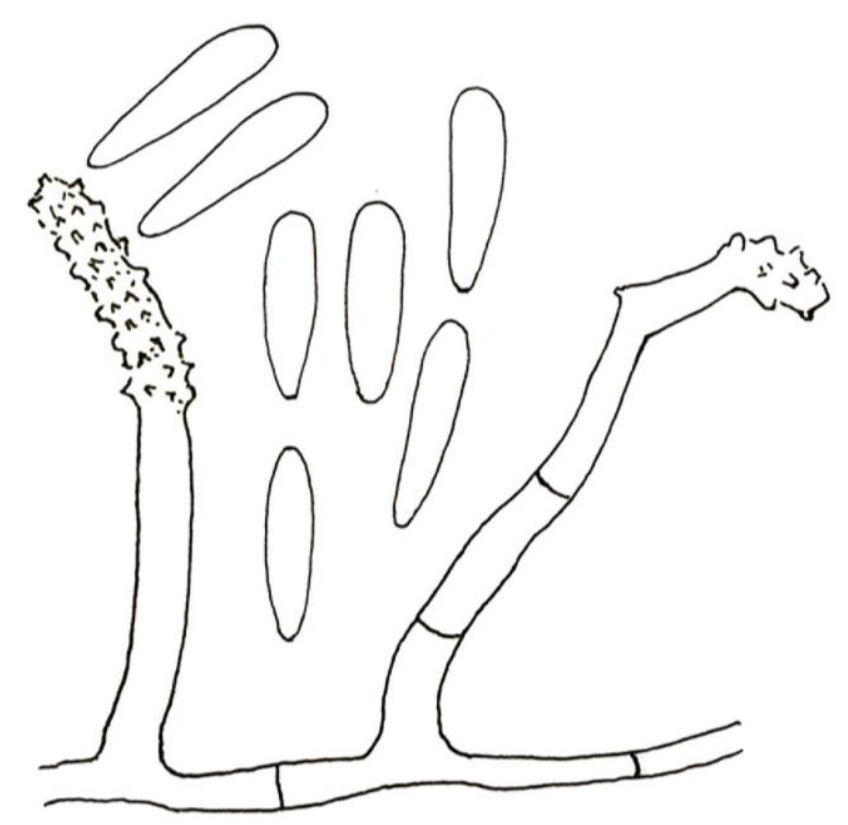

Figure 188 - Pararamichloridium livistonae (Redrawn from Crous et al. 2017a).

Parasympodiellaceae Hern.-Restr., Gené, Guarro \& Crous, Stud. Mycol. 86: 87 (2017)

Index Fungorum number: IF820298; Facesoffungi number: FoF05187; 9 species.

Saprobic on leaves and twigs. Sexual morph: Undetermined. Asexual morph: Colonies effuse, cottony, partly superficial, greyish. Conidiophores mononematous, erect, conspicuous and properly differentiated from vegetative hyphae, flexuous, smooth, regularly septate, branched, brown. Conidiogenous cells smooth, pale brown or hyaline, holoblastic, multiplying sympodially, undergoing basipetal secession to produce conidia. Conidia thallic-arthric, aseptate or septate, hyaline, produced in unbranched pseudo-chains. Synasexual morph: often stylaspergillus-like (adapted from Hernández-Restrepo et al. 2017).

Type genus - Parasympodiella Ponnappa

Notes - Parasympodiellaceae, as established by Hernández-Restrepo et al. (2017), is accommodated in Parasympodiellales and it includes the monotypic genus Parasympodiella (Hernández-Restrepo et al. 2017). Species of this family most commonly grow as saprobes on plant litter, conifers and dicotyledons (Subramanian \& Vittal 1973, Crous et al. 1995, Cheewangkoon et al. 2009, Seifert et al. 2011, Hernández-Restrepo et al. 2017). Parasympodiellales along with Parasympodiellaceae have been introduced to represent the clade which includes four of the nine Parasympodiella species, namely, P. lauri, P. elongata, P. eucalypti and P. laxa (HernándezRestrepo et al. 2017).

\section{Ecological and economic significance of Parasympodiellaceae}

Saprotrophic fungi are prominently important decomposers of plant litter through secretion of lignocellulolytic enzymes. In so doing, they regulate cycling of nutrients as well as carbon in the terrestrial ecosystem (Baldrian \& Valášková 2008, Crowther et al. 2012). Additionally, Parasympodiella species may cause commercial damage to economically important plants since they often colonize coniferous and dicotyledonous plants (Crous et al. 1995, Cheewangkoon et al. 2009, Seifert et al. 2011).

\section{Genus included in Parasympodiellaceae}

Parasympodiella Ponnappa, Trans. Br. mycol. Soc. 64(2): 344 (1975).

Index Fungorum number: IF820298; 9 morphological species (Species Fungorum 2020), 4 species with sequence data.

Type species - Parasympodiella laxa (Subram. \& Vittal) Ponnappa 


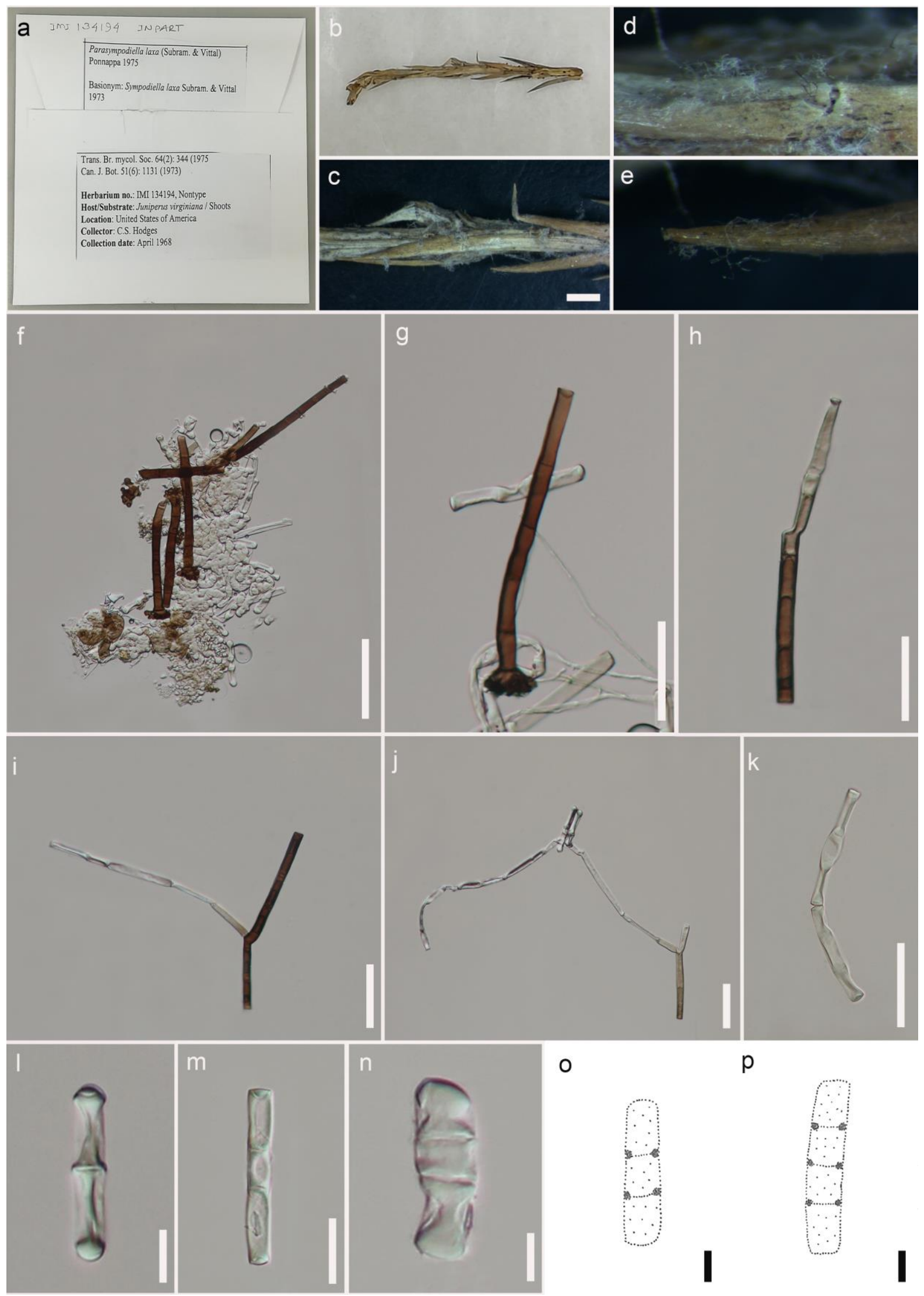

Figure 189 - Parasympodiella laxa (Material examined - USA, shoots of Juniperus virginiana, April 1968, C.S Hodges, IMI 134194; o, p redrawn from Cheewangkoon et al. 2009). a-c Herbarium material. d, e Appearance of colonies on host substrate. $f$ Mount of colonies. $g$ Conidiophore. $\mathrm{h}-\mathrm{j}$ Conidiophores, conidiogenous cells and conidia. $\mathrm{k}$ Chain of conidia. 1-p Conidia. Scale bars: $\mathrm{c}=1 \mathrm{~mm}, \mathrm{f}-\mathrm{i}, \mathrm{k}=100 \mu \mathrm{m}, \mathrm{j}=50 \mu \mathrm{m}, \mathrm{l}, \mathrm{n}=20 \mu \mathrm{m}, \mathrm{m}=30 \mu \mathrm{m}, \mathrm{o}, \mathrm{p}=10 \mu \mathrm{m}$. 
Notes - Parasympodiella was introduced by Ponnappa (1975), with P. laxa as the type species. The latter species was earlier placed in Sympodiella (Ponnappa 1975). However, whereas Sympodiella species have small conidiophores, up to $280 \mu \mathrm{m}$ along with terminal or subterminal conidiogenous cells which give rise to conidial chains reaching up to six conidia, Parasympodiella species have larger conidiophores, reaching up to $700 \mu \mathrm{m}$, together with conidiogenous cells residing along the conidiophore stipe at irregular distances and conidia being produced in ever extending loose chains (Kendrick 1958). Parasympodiella includes distinct and solitary conidiophores with conidiogenous cells which extend sympodially and produce catenate, cylindrical, thallic conidia when the fertile hyaline branches disarticulate, characters which distinguish this genus from similar genera such as Polyscytalum (Riess 1853), Sympodiella (Kendrick 1958), Bahusakala (Subramanian 1958) and Neoscytalidium (Crous et al. 2006a). Parasympodiella laxa is illustrated in this entry.

Phaeoappendicosporaceae Crous \& M.J. Wingf., Fungal Systematics and Evolution. 3: 96 (2019). Index Fungorum number: IF829458; Facesoffungi number: FoF06297; 2 species.

Saprobic on dead woody bark. Sexual morph: Pseudostroma immersed, becoming erumpent; ectostroma pale brown to grey, containing periphyses; ostioles cylindrical. Perithecia globose to lenticular, dark brown, wall of cells of textura angularis. Paraphyses septate, unbranched, hyphalike. Asci 8-spored, ellipsoid to fusoid, without a refractive canal at apex. Ascospores brown, ellipsoid-fusoid, 1-euseptate, with gelatinous appendage at each truncate end. Asexual morph: Coelomycetous. Conidiomata pycnidial, multilocular, forming a long neck. Paraphyses hyaline, cylindrical, septate, unbranched, hypha-like. Conidiophores subcylindrical, hyaline to pale brown, septate, unbranched. Conidiogenous cells cylindrical, hyaline to pale brown, proliferating percurrently at apex. Conidia ellipsoid to oblong, straight to slightly curved, thick-walled, transversely euseptate with oblique septa.

Type genus - Phaeoappendicospora Senan., Q.R. Li \& K.D. Hyde

Notes - Phaeoappendicosporaceae was introduced by Crous et al. (2019b) based on Phaeoappendicospora as the type genus and Neophaeoappendicospora as the second genus. Both genera have similar characters, but Neophaeoappendicospora is distinct from Phaeoappendicospora by its larger ascospores and presence of asexual morph.

\section{Ecological and economic significance of Phaeoappendicosporaceae}

All members in this family are saprobes. Neophaeoappendicospora leucaenae was isolated from Leucaena leucocephala, a commercially and environmental important Fabaceae used as fodder, charcoal, organic manure and in the paper industry. However, members in both genera are involved in nutrient recycling through litter decomposition.

\section{Genera included in Phaeoappendicosporaceae}

Neophaeoappendicospora Crous \& M.J. Wingf., Fungal Systematics and Evolution 3: 96 (2019)

Index Fungorum number: IF829323; 1 species with sequence data.

Type species - Neophaeoappendicospora leucaenae Crous \& M.J. Wingf.

Notes - Neophaeoappendicospora was isolated from Leucaena leucocephala from France, which is a source of quality animal feed, firewood or used in charcoal production, green manure and biomass, food for humans and pulpwood for paper industry.

Phaeoappendicospora Senan., Q.R. Li \& K.D. Hyde, Stud. Mycol. 86: 217-296 (2017)

Index Fungorum number: IF821572; 1 species with sequence data.

Type species - Phaeoappendicospora thailandensis Q.R. Li, Senan. \& K.D. Hyde

Notes - Phaeoappendicospora was introduced in Diaporthales genera incertae sedis. The genus has been introduced based on Phaeoappendicospora thailandensis, obtained from a dead branch of Quercus sp. The species resembles Hapalocystis berkeleyi (Sydowiellaceae). It did not, however, cluster with any Hapalocystis taxa nor with any family in the Diaporthales, which 
resulted to its being classified as genera incertae sedis (Senanayake et al. 2017b). Crous et al. (2019b) introduced Phaeoappendicosporaceae for this genus with Neophaeoappendicospora. The genus is characterised by brown and small ascospores. Phaeoappendicospora thailandensis is illustrated in this entry.
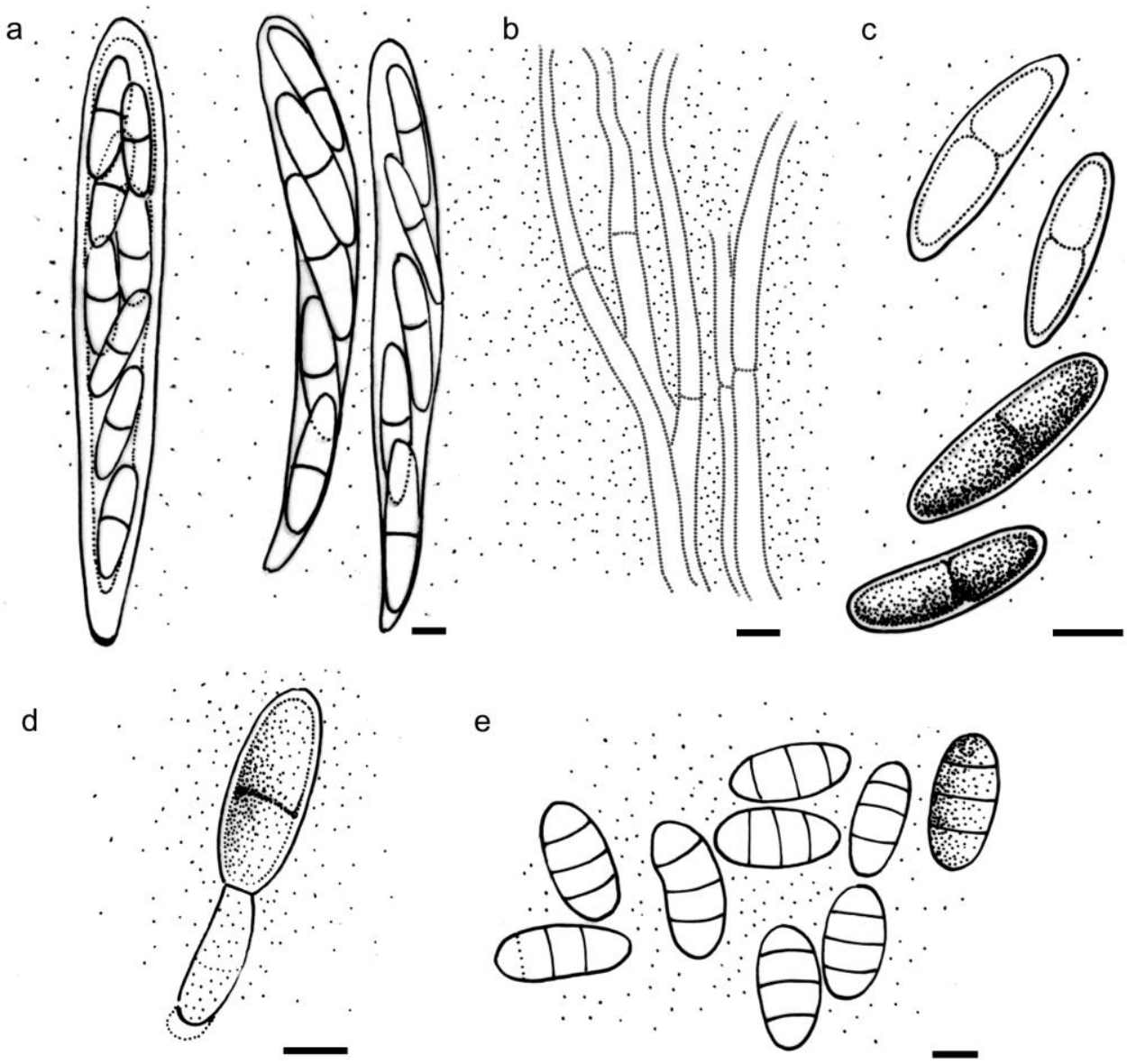

Figure 190 - Neophaeoappendicospora leucaenae (CPC 27240 redrawn from Crous et al. 2019b). a Asci. b Paraphyses. c Ascospores. d Conidiogeneous cells giving rise to conidia. e Conidia. Scale bars: $10 \mu \mathrm{m}$.

Phaeochoraceae K.D. Hyde, P.F. Cannon \& M.E. Barr. Syst. Ascom. 15(1-2):118 (1997)

Index Fungorum number: IF81916; Facesoffungi number: FoF01910; 17 species.

Saprobic or biotrophic on palms leaves. Sexual morph: Stromata as blackened regions scattered on the host, usually raising above the substrate surface, rarely inconspicuous, one or multi-loculate. Ascomata ellipsoidal to subglobose, dark brown, clustered and fusing to form multiostiolate cavity or solitary with one ostiole. Ostiole conspicuous or inconspicuous. Peridium several layered, composed of flattened, brown to dark brown-walled cells, thinner at the base. Paraphyses wide, cylindrical hypha-like, septate, thin-walled, evanescent early. Asci 6-8-spored, unitunicate, saccate or fusiform, with long or short pedicellate, very thin-walled, usually without apical structures, deliquescing early. Ascospores uniseriate to biseriate, various shades of brown, ellipsoidal, fusiform or cylindrical, aseptate, thick-walled, sometimes with one flattened face, sometimes delicately striated, with or without appendages. Asexual morph: Coelomycetous. Conidiogenous cells narrowly conical, usually percurrently proliferating, but occasionally sympodially proliferating, with periclinal thickening, without a collarette. Conidia aseptate, narrowly fusiform to bacillary, hyaline, thin-walled (adapted from Cannon 1992, Hyde et al. 1997a, Taylor \& Hyde 2003, Maharachchikumbura et al. 2016b).

Type genus - Phaeochora Höhn. 

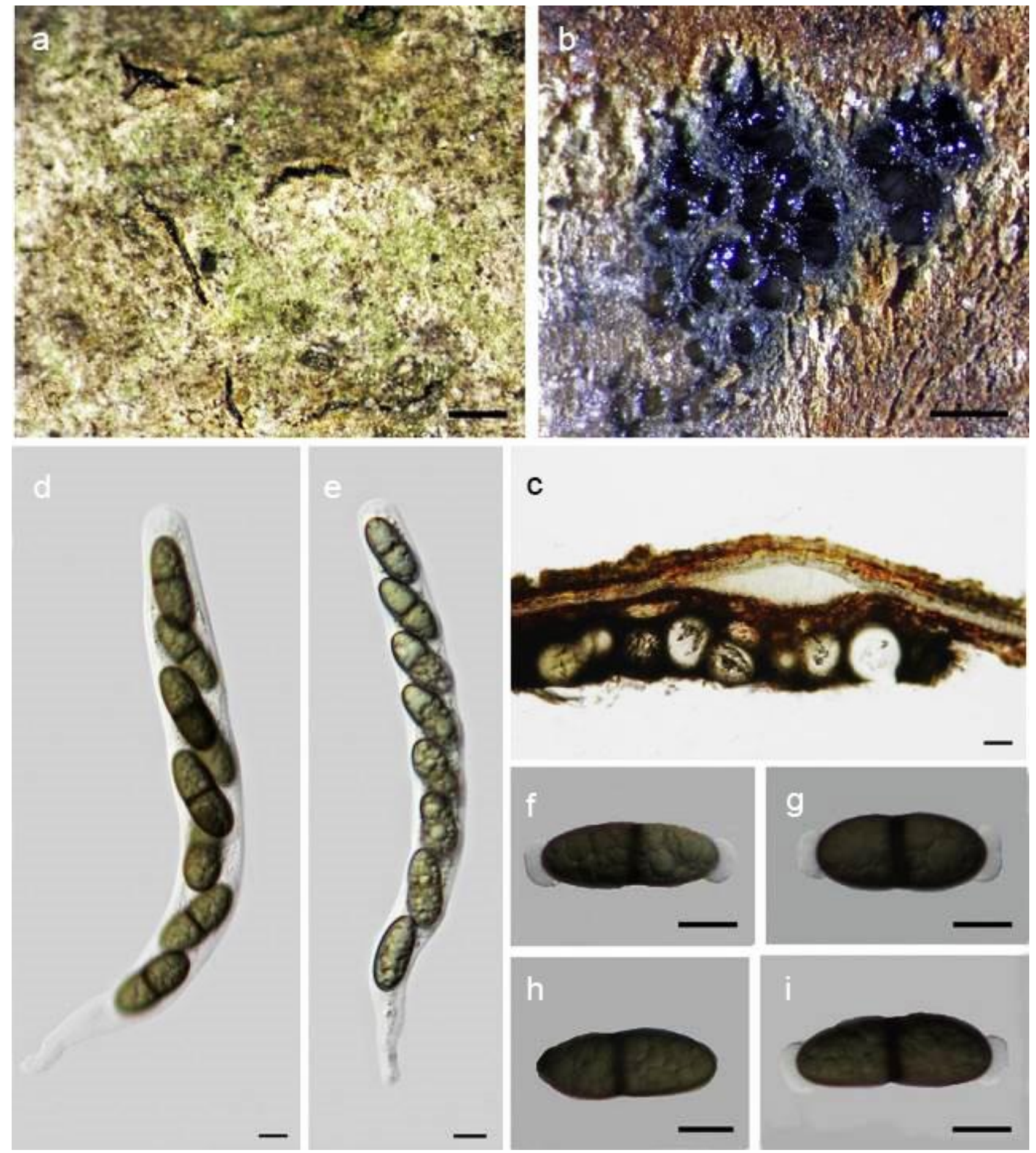

C
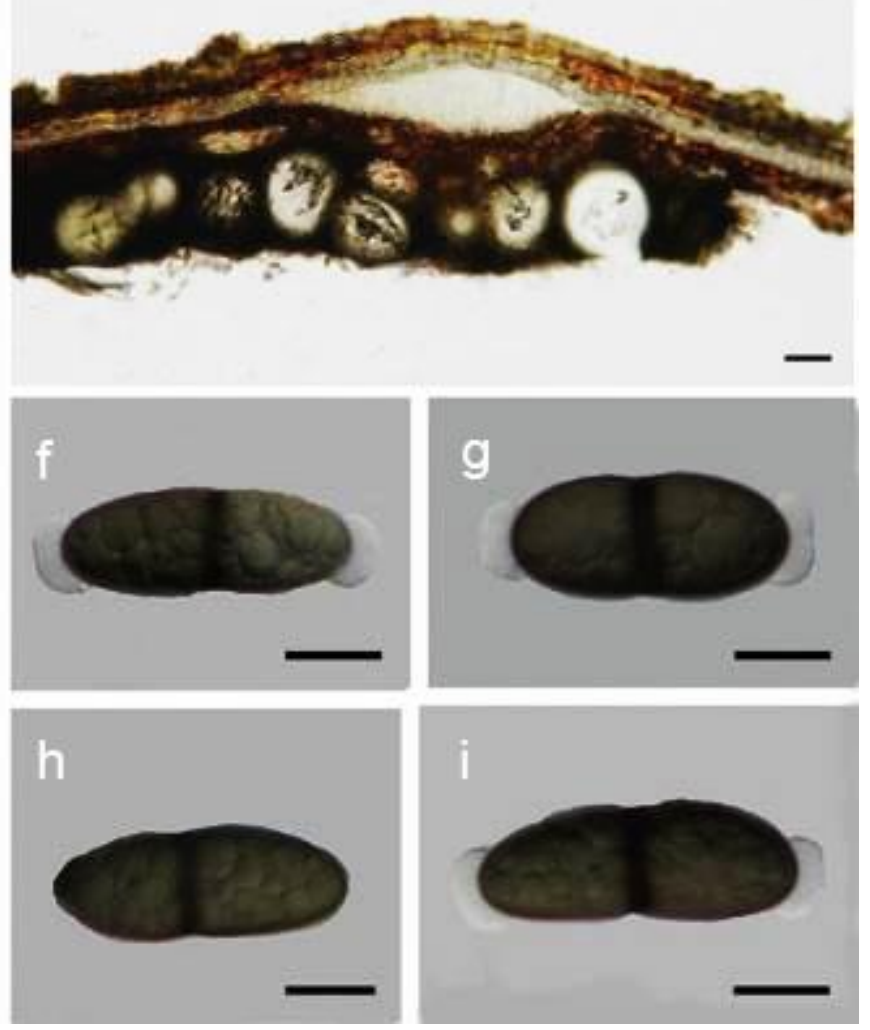

Figure 191 - Phaeoappendicospora thailandensis (Material examined - THAILAND, Chiang Rai, near Khun Korn water fall, on branch of Quercus sp. (Fagaceae), 25 December 2012, Q.R. Li, TL19, MFLU 12-2131, holotype). a Appearance of fungus on host substrate. b Horizontal cross section of stroma. c Vertical cross section of stroma. d, e Asci. f-i Ascospores. Scale bars: $a=1$ $\mathrm{mm}, \mathrm{b}=500 \mu \mathrm{m}, \mathrm{c}=100 \mu \mathrm{m}, \mathrm{d}-\mathrm{i}=10 \mu \mathrm{m}$.

Notes - Phaeochoraceae was introduced by Hyde et al. (1997a) to accommodate the genera Cocoicola, Phaeochora and Serenomyces. Phaeochoropsis was subsequently included to Phaeochoraceae. Species of Phaeochoraceae are biotrophic and saprobic on palms (Arecaceae), and characterized by a well-developed stroma and usually form tar-spots. Phaeochoraceae was previously assigned to Phyllachorales mainly because of the stromatic characteristics. Mardones et al. (2017) showed the phylogenetic placement of Phaeochoraceae in Phyllachorales. 


\section{Ecological and economic significance of Phaeochoraceae}

Phaeochoraceae accommodates species that visible as tar spot or lesions on plant leaves, which may cause diseases of host plant. Species of Cocoicola are pathogens associated with petiole blight. Serenomyces invades palms and causes rachis blight or petiole blight (Elliott \& Des Jardin 2014). The diseased palms may be significantly affected in terms of yield and quality including incidence of fruit rots.

\section{Genera included in Phaeochoraceae}

Cocoicola K.D. Hyde, Nova Hedwigia 60(3-4): 600 (1995a)

Index Fungorum number: IF27575; 5 morphological species (Species Fungorum 2020), 1 species with sequence data.

Type species - Cocoicola cylindrospora (C. Booth \& D.E. Shaw) K.D. Hyde

Notes - Cocoicola was introduced by Hyde (1995a) to accommodate C. cylindrospora (= Anthostomella cylindrospora) and C. fusispora (= A. fusispora). Currently, Cocoicola contains five species, which were found from palms. They are characterized by strongly flattened ascomata, clustered around a central ostiole, or with a series of separate ostioles and surrounded by a stroma, visible as ostiolar dots and present pale brown blister-like regions on the host surface. The ascospores are cylindrical to fusiform, yellow to olivaceous, aseptate, with longitudinal striations. Cocoicola is similar to Serenomyces by striated ascospores. However, they are distinct as the latter has exclusively uniloculate ascomata with elongated necks. Serenomyces californica was synonymized as Cocoicola californica because of its fusiform ascospores and multi-ostiolate ascomata lacking necks (Hyde 1995a).

Phaeochora Höhn., Sber. Akad. Wiss. Wien, Math.-naturw. Kl., Abt. I, 118: 1513 (1909)

Index Fungorum number: IF3898; 4 morphological species (Species Fungorum 2020).

Type species - Phaeochora chamaeropis (Cooke) Höhn.

Notes - Phaeochora was introduced by Höhnel (1909a) to accommodate Auerswaldia chamaeropis (= Dothidea chamaeropsis). Höhnel (1909a) treated A. chamaeropis as the type, and also considered A. densa belongs to Phaeochora. However, Shear (1909) transferred A. densa to Sphaerodothis found an earlier name $S$. steinheilii for the type species of Phaeochora, and synonymized it as P. steinheilii. The two genera Phaeochora and Sphaerodothis were superficially similar and were treated as synonyms by von Arx \& Müller (1954) and Joly (1961). Species in Phaeochora cause blackened regions on the host surface with stromata and ellipsoidal, fusiform or cylindrical ascospores, but are different in ascomata and ascospores structure; while Sphaerodothis has cylindrical asci (Hyde \& Cannon 1999). Phaeochora steinheilii is characterized by ascospores having one flattened face, with two, tpulvinate extrusions of the epispore near the apices of the flattened surface (Cannon 1992, Hyde et al. 1997a).

Phaeochoropsis K.D. Hyde \& P.F. Cannon, Mycol. Pap.175: 30 (1999)

Index Fungorum number: IF27928; 4 morphological species (Species Fungorum 2020).

Type species - Phaeochoropsis neowashingtoniae (Shear) K.D. Hyde \& P.F. Cannon

Notes - Phaeochoropsis was introduced by Hyde \& Cannon (1999) based on $P$. diplothemiifolii, P. mucosa, P. neowashingtoniae and P. palmicola. Species of Phaeochoropsis occur on leaves and rachides of the host plant with lesions which become yellow and contain a number of stromata.

Serenomyces Petr., Sydowia 6(1-4): 296 (1952b)

Index Fungorum number: IF5008; 4 morphological species (Species Fungorum 2020), 1 species with sequence data.

Type species - Serenomyces shearii Petr.

Notes - Serenomyces (Petrak 1952b) was described based on S. shearii from a dead palm leaf of Serenoa serrulata collected in Florida and other Serenomyces species occur only in association 
with palms (Arecaceae). The genus causes of leaf disease and rachis/petiole blight (Elliott \& Des Jardin 2014). Serenomyces was placed in Ceratostomataceae by Petrak (1952b) because of evanescent asci and elongated neck, in Melanosporaceae by von Arx \& Müller (1954), and tentatively assigned in Phyllachoraceae by Barr et al. (1989). Hyde et al. (1997a) included Serenomyces in Phaeochoraceae, because of immersed ascomata in pseudostromatic tissues and paraphyses. Barr et al. (1989) revised Serenomyces and accepted four species, and later included $S$. virginiae (Barr et al. 1997). Serenomyces californica was transferred to Cocoicola californica (Hyde \& Cannon 1999). Serenomyces is presumed as biotrophic and it is difficult to culture strains from palm tissues. Elliott \& Des Jardin (2014) obtained cultures and provided molecular data for three Serenomyces species, which were isolated from palm leaves. Serenomyces is characterized by immersed ascomata or stromata with elongated neck, evanescent asci and ovoid or fusiform, pale brown and aseptate ascospores (Hyde \& Cannon 1999).
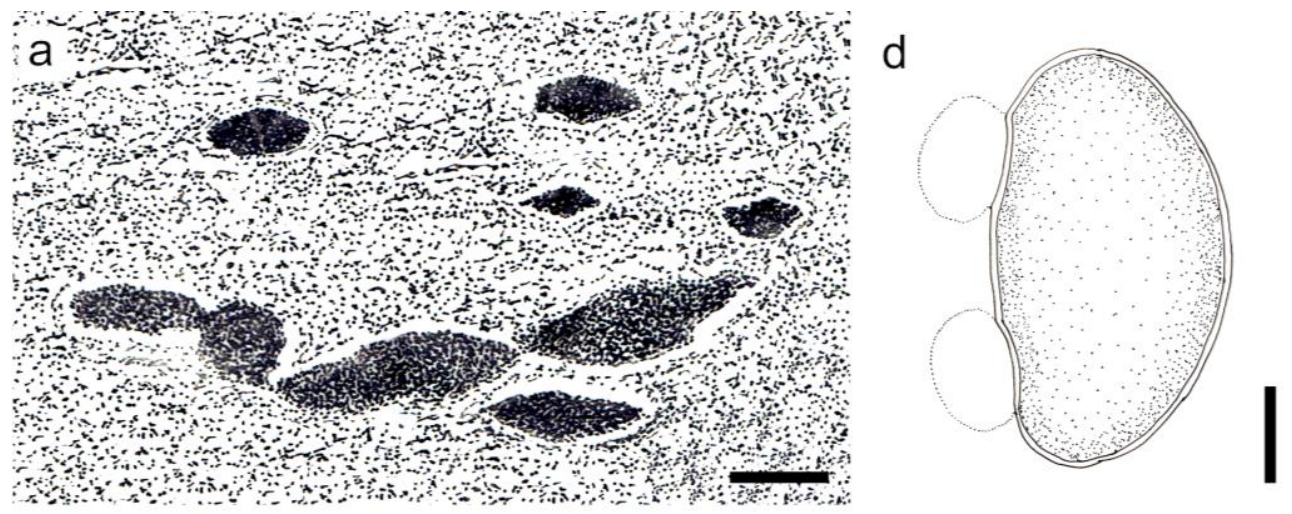

$\mathrm{b}$

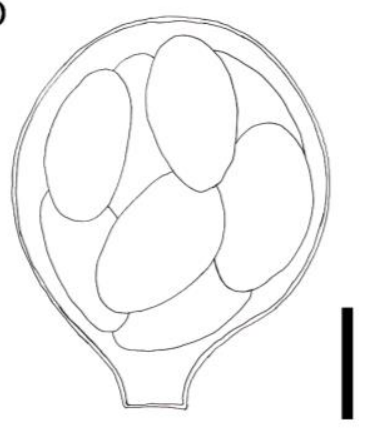

$f$

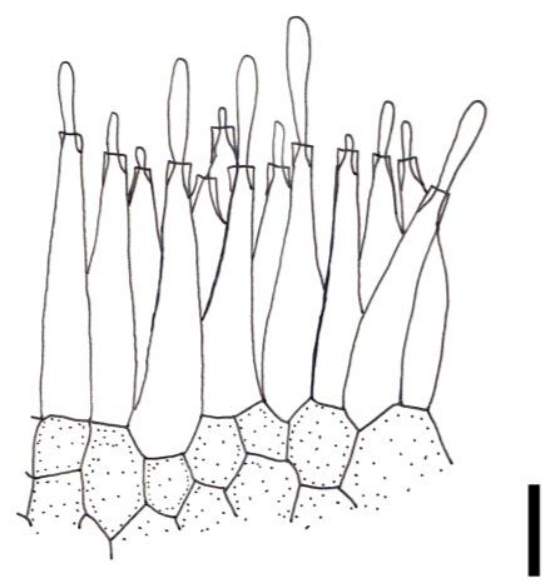

$\mathrm{C}$

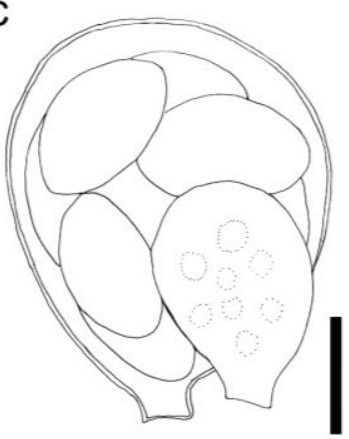

e

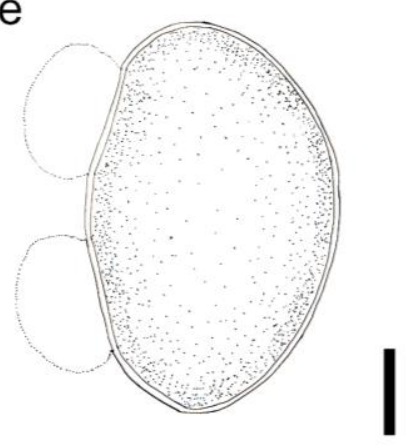

g

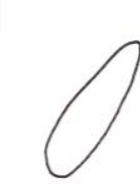

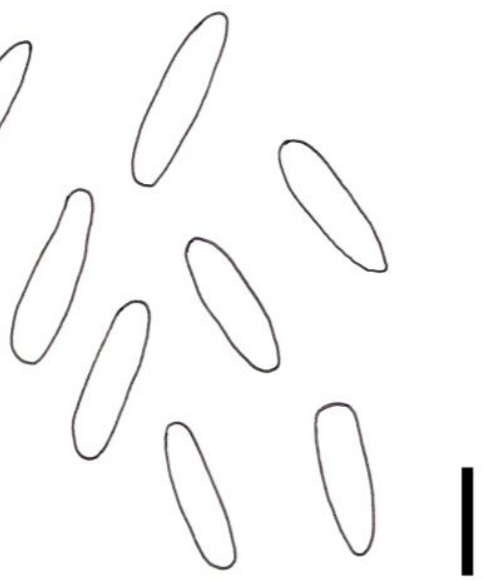

Figure 192 - Phaeochora steinheilii (redrawn from Cannon 1992, Hyde \& Cannon 1999). a Stromata visible as blackened spot on leaf surfaces. b, c Asci without apical structures, evanescent. $\mathrm{d}$, e Ascospores, golden to mid-brown, with two \pm globose hyaline appendages near the apices of the flattened surface. $\mathrm{f}$ Conidiogenous cells developing conidia. $g$ Conidia. Scale bars: $\mathrm{a}=1 \mathrm{~mm}$, $\mathrm{b}-$ $\mathrm{c}=10 \mu \mathrm{m}, \mathrm{d}-\mathrm{g}=5 \mu \mathrm{m}$. 
Phaeochorellaceae Guterres, Galvão-Elias \& Dianese, Mycologia 111: 660-675 (2019)

MycoBank number: IF825364; Facesoffungi number: FoF06856; 2 species.

Biotrophic on living leaves or saprotrophs on decaying plant materials. Sexual morph: Pseudostromata dark brown to black, subepidermal on living leaves, also present in saprobic state. Ascomata perithecial, globose to subglobose or pyriform, wall heavily pigmented, ostiolate. Ostiole comprising many thin, filiform periphyses. Paraphyses filiform. Asci 8-spored, unitunicate, thinwalled, cylindrical to subclavate or ellipsoidal. Ascospores ellipsoidal to cylindrical, aseptate to 1septate, dark brown. Asexual morph: Undetermined (adapted from Guterres et al. 2019).

Type genus - Phaeochorella (Henn.) Theiss. \& Syd.

Notes - Phaeochorellaceae has been introduced based on two genera, namely, Phaeochorella and Phaeoappendicospora (Guterres et al. 2019). The former genus was initially accommodated in Phyllachoraceae (Phyllachorales) only based on morphology since no species had molecular data. The acquisition of DNA sequence data for Phaeochorella parinarii was instrumental since a multigene phylogeny confirmed the placement of the genus in Diaporthales, forming a sister clade with Phaeoappendicospora thailandensis. Since the two genera formed a distinct clade, phylogenetically distant from other sister clades, the new family Phaeochorellaceae was established (Guterres et al. 2019). Crous et al. (2019b) later introduced family Phaeoappendicosporaceae to accommodate Phaeoappendicospora with a new genus Neophaeoappendicospora.

\section{Ecological and economic significance of Phaeochorellaceae}

Species of Phaeochorella are parasitic mostly on leaves of plants belonging to the Chrysobalanaceae and Fabaceae families (Guterres et al. 2019).

\section{Genus included in Phaeochorellaceae}

Phaeochorella (Henn.) Theiss. \& Syd., Ann Mycol 13:405. 1915.

Index Fungorum number: IF3899; 2 morphological species (Guterres et al. 2019), 1 species with sequence data.

Type species - Phaeochorella parinarii (Henn.) Theiss. \& Syd.

Notes - Phaeochorella, typified by $P$. parinarii, was initially accommodated in several families, viz. Phacidiaceae, Phyllachoraceae and Polystigmataceae (Theissen \& Sydow 1915, Müller \& von Arx 1973). It was then maintained in Phyllachoraceae, Phyllachorales (Cannon 1991) until now, where it has finally been transferred to a new family, Phaeochorellaceae (Guterres et al. 2019). The type species is a synonym of the basionym, Cocconia parinarii, reported on the leaves of Parinari curatellifolia (Hennings 1901) and its asexual morph was initially recognised as Phomachorella parinarii, reported from Pa. capensis (Petrak 1947c). However, this was reported as a misidentification since it was observed that $P$. parinarii produces both micro- and macroconidia while no macroconidia were seen in "Phomachorella parinaril" (Swart 1965). Conidia of "Phomachorella parinarii" also originated from the basal layer of stroma and were surrounded by slimy material, while conidia produced by $P$. parinarii were produced from all over the surface of the stroma cavity and formed a powdery conidial mass. It was concluded that the conidia observed by Petrak were from another fungus parasitizing the stroma of $P$. parinarii (Swart 1965).

Phaeochorella originally comprised five species, namely, $P$. parinarii, $P$. zonata, $P$. artocarpi, $P$. ciliata, and $P$. machaerii which originated from tropical regions (Theissen \& Sydow 1915, Petrak 1947c, Ramakrishnan \& Ramakrishnan 1948, Batista \& Peres 1960, Batista \& Bezerra 1961). However, at present the genus comprises only $P$. parinarii and $P$. zonata (Guterres et al. 2019). Phaeochorella machaerii is now considered as synonym of Phyllachora puncta, while $P$. ciliata and $P$. artocarpi comprise bitunicate asci and ascospores without any equatorial hyaline band (Guterres et al. 2019). Auerswaldia clypeata was also placed in Phaeochorella and synonymised to Phaeochorella clypeata, but it was subsequently excluded from the genus based on ascospore morphology (Theissen \& Sydow 1915, Petrak 1947c). Similarly, Phaeochorella sphaerospora was not accepted as a species belonging to Phaeochorella but recognised as synonym of Phyllachora conica since ascospore colour was considered insufficient to differentiate 
between the two species (Cannon 1991). The holotype of P. sphaerospora, was however, not examined since it was apparently lost, and thus, only the colour of the ascospores was deemed as insufficient character to differentiate between the two species (Cannon 1991).
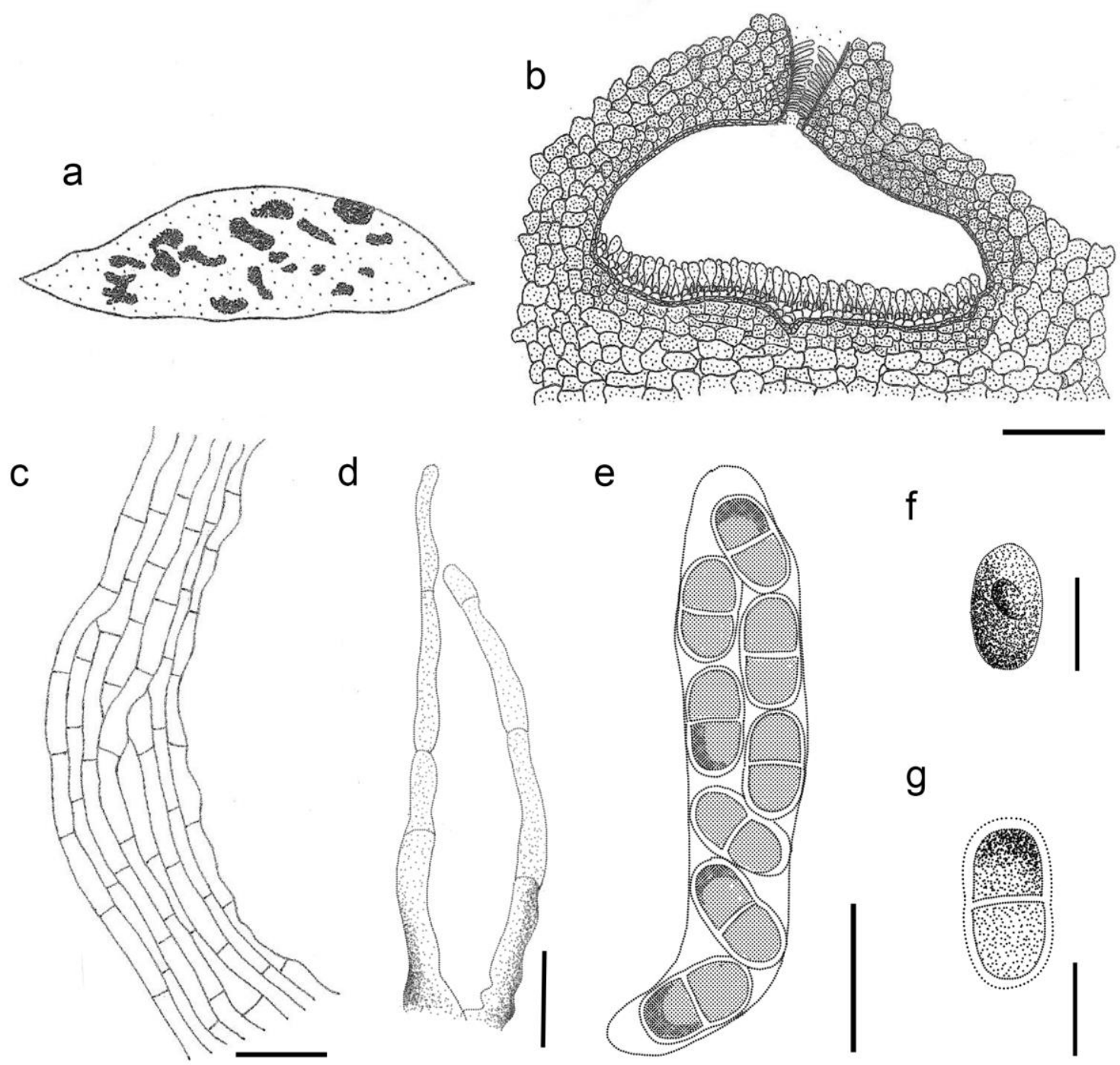

g

Figure 193 - Phaeochorella parinarii (epitype UB Mycol. Coll. 23270, redrawn from Guterres et al. 2019). a Pseudostromata on leaf of Parinari obtusifolia. b Immersed perithecial ascoma with a periphysate ostiole. c Peridium comprising cells of textura prismatica. d Septate paraphyses. e Ascus containing mature ascospores with typical subhyaline equatorial band. f, g Immature and mature ascospores. Scale bars: $\mathrm{a}=2 \mathrm{~cm}, \mathrm{~b}=100 \mu \mathrm{m}, \mathrm{c}, \mathrm{d}=20 \mu \mathrm{m}, \mathrm{e}-\mathrm{g}=10 \mu \mathrm{m}$

Phlogicylindriaceae Senan. \& K.D. Hyde, Fungal Divers. 73: 35 (2015)

Index Fungorum number: IF551190; Facesoffungi number: FoF00681; 10 species.

Saprobic on leaves, twigs and branches of dicotyledons especially on Eucalyptus (Myrtaceae). Sexual morph: Pseudostroma solitary, black, scattered, immersed. Ascomata forming under pseudostroma, solitary, brown to black, scattered, globose, coriaceous, ostiolate, papillate. Papilla short, narrow, surrounding thickened. Peridium comprising outer, brown thick-walled cells of textura angularis and inner, hyaline, thin-walled cells of textura angularis. Asci 8-spored, unitunicate, cylindrical, short pedicellate, rounded at apex, with $\mathrm{J}_{+}$, discoid, subapical ring. Ascospores overlapping uniseriate, hyaline, fusiform, rounded at ends, 1-septate, slightly constricted at septa. Asexual morph: Coelomycetous. Conidiomata appearing as slimy, erect tufts of hyaline conidial masses, eustromatic, unilocular or multilocular, sporodochial, synnematous, indeterminate, turning brown with age. Conidiophores brown, smooth, branched. Conidiogenous 
cells annellidic, smooth, hyaline becoming light brown with maturity, subcylindrical, ampulliform with elongated necks, often having percurrent proliferations. Conidia cylindrical to subcylindrical, fusoid, hyaline, straight, smooth, rounded apex, rounded or subobtuse apex, truncate base, aseptate to 1-septate, guttulate (adapted from Senanayake et al. 2015).

Type genus - Phlogicylindrium Crous, Summerb. \& Summerell

Notes - Senanayake et al. (2015) introduced Phlogicylindriaceae to accommodate the genera Phlogicylindrium and Ciferriascosea. The asexual genus produces slimy erect flame-like tufts of hyaline conidial masses, and cylindrical, unicellular to 1-septate, hyaline conidia (Summerell et al. 2006). The sexual morph of Phlogicylindrium has not been reported. Ciferriascosea is a sexual genus with no reported asexual morph, and was included in Phlogicylindriaceae due to its phylogenetic affinity to Phlogicylindrium (Senanayake et al. 2015). The sexual genus Idriellomyces was introduced in Phlogicylindriaceae by Crous et al. (2018c) based on its distinct morphology and molecular data.

\section{Ecological and economic significance of Phlogicylindriaceae}

Phlogicylindrium eucalypti and P. uniforme were reported occurring in association with a Mycosphaerella spp. causing lesions on living leaves of Eucalyptus sp. (Summerell et al. 2006, Crous et al. 2011). Therefore, they possibly play a role as secondary invaders (Crous et al. 2011). Phlogicylindrium tereticornis was found on leaves of Eucalyptus tereticornis infected with circular to angular, brown leaf spots and red-purple margins (Crous et al. 2017a). All Phlogicylindrium species have so far been reported on leaves from various Eucalyptus species in Australia. Ciferriascosea species were isolated as saprobes on Spartium junceum from Italy (Senanayake et al. 2015). All Phlogicylindrium species and Idriellomyces eucalypti have been reported on leaves from various Eucalyptus species in Australia. Chitonospora and Ciferriascosea species have been reported as saprobes from Africa and Europe.

\section{Genera included in Phlogicylindriaceae}

Ciferriascosea Senan., Bhat, Camporesi \& K.D. Hyde, Fungal Divers. 73: 35 (2015)

Index Fungorum number: IF551191; 2 species with sequence data.

Type species - Ciferriascosea rectamurum Senan., Bhat, Camporesi \& K.D. Hyde

Notes - Ciferriascosea was introduced to accommodate two sexual morph species Ciferriascosea fluctamurum and C. rectamurum occurring on Sparticum junceum collected, from Italy (Senanayake et al. 2015). They are characterized by having immersed, black pseudostromata, ostiolate and papillate ascomata that produce asci with an indistinct $\mathrm{J}_{+}$, apical ring, and hyaline, 1septate, fusiform ascospores with narrowly rounded ends (Senanayake et al. 2015). Both species of Ciferriascosea were introduced based on LSU and ITS sequence data.

Idriellomyces Crous, Persoonia 40: 369 (2018)

Index Fungorum number: IF825426; 1 species with sequence data.

Type species - Idriellomyces eucalypti Crous

Notes - Idriellomyces introduced by Crous et al. (2018d) is characterized by branched conidiophores arranged as thick, erect synnemata, subcylindrical conidiogenous cells tapering towards the apex to a rachis and fusoid, hyaline, aseptate conidia. It is similar to Idriella in Microdochiaceae but distinct in having pigmented conidiophores often in aggregated synnemata and in lacking chlamydospores (Crous et al. 2018d). The type species was found on leaves of Eucalyptus obliqua from Australia (Crous et al. 2018d).

Phlogicylindrium Crous, Summerb. \& Summerell, Fungal Divers. 23: 340 (2006)

Index Fungorum number: IF510013; 7 species with sequence data.

Type species - Phlogicylindrium eucalypti Crous, Summerb. \& Summerell

Notes - All species of Phlogicylindrium have been reported from Australian Eucalyptus (Summerell et al. 2006, Crous et al. 2011, 2016a, 2019b, Farr \& Rossman 2019). Phlogicylindrium 
dunnii differs from other Phlogicylindrium species by eustromatic, multilocular conidiomata with subcylindrical, 1-septate macroconidia and cylindrical aseptate microconidia in the same conidioma (Crous et al. 2019b). Here, we provide an illustration of P. uniforme (Fig. 194). All species of Phlogicylindrium are introduced based on LSU or ITS sequence data, while rpb2 and tefl sequence data are available for P. dunnii and P. tereticornis (Crous et al. 2017a, 2019b).
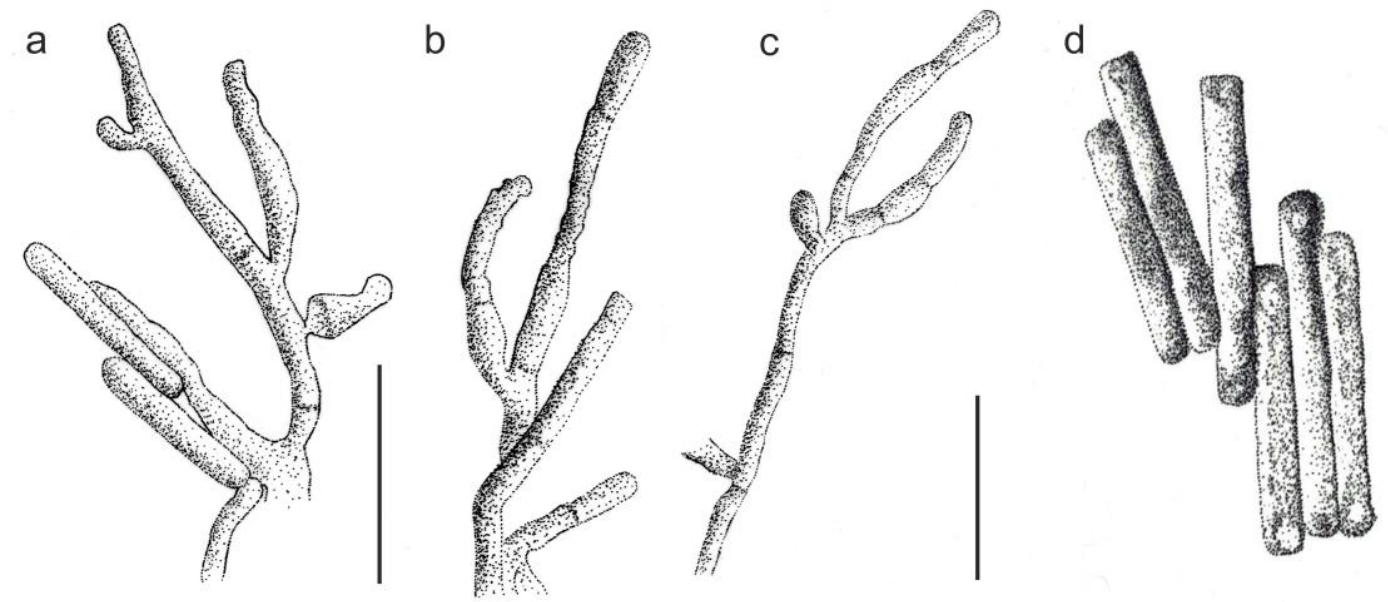

Figure 194 - Phlogicylindrium uniforme (redrawn from Crous et al. 2011). a-c Conidiophores with conidia. d Conidia. Scale bars: a-c $=10 \mu \mathrm{m}$.

Phomatosporaceae von Arx, Antonie van Leeuwenhoek 17: 271 (1951)

Index Fungorum number: IF552312; Facesoffungi number: FoF02486; 74 species.

Saprobic on submerged wood or decaying twigs in both terrestrial and aquatic habitats. Sexual morph: Ascomata perithecial, solitary, seldom gregarious, immersed or gradually becoming erumpent with age, subglobose to globose, light brown to dark brown or black, coriaceous, occasionally developing beneath a small blackened clypeus, ostiolate, with a short papilla or rarely with a rostrate or cylindrical, hyaline neck, central or eccentric. Ostiole periphysate. Peridium composed of small, brown pseudoparenchymatous cells. Paraphyses filamentous, aseptate or septate, tapering. Asci 8-spored, unitunicate, cylindrical or oblong-fusiform, thin-walled, shortpedicellate or sessile, J- ring in the ascal apex. Ascospores overlapping uniseriate to rarely biseriate, hyaline, ellipsoidal to fusiform, aseptate or septate, not constricted at the septum, at times biguttulate, with striations or appendages or a sticky mucilaginous sheath (Senanayake et al. 2016). Asexual morph: sporothrix-like (adapted from Rappaz 1992, Fournier \& Lechat 2010, Senanayake et al. 2016).

Type genus - Phomatospora Sacc.

Notes - After von Arx (1951) invalidly established Phomatosporaceae, Senanayake et al. (2016) formally introduced the family to accommodate Phomatospora, Lanspora and Tenuimurus. Three genera, based on LSU, SSU and ITS phylogeny, formed a clade distantly related to other existing orders in the Diaporthomycetidae, for which, the new order Phomatosporales, was established (Senanayake et al. 2016).

\section{Ecological and economic significance of Phomatosporaceae}

Saprobic fungi secrete enzymes to degrade celluloses and lignocelluloses, thereby, giving rise to soft-rot cavities in woody tissues, which lead to decay of dead plant materials both in the terrestrial and freshwater ecosystems (Zare-Maivan \& Shearer 1988a, b, Shearer 1993).

\section{Genera included in Phomatosporaceae}

Lanspora K.D. Hyde \& E.B.G. Jones, Can. J. Bot. 64(8): 1581 (1986)

Index Fungorum number: IF25051; 1 species with sequence data.

Type species - Lanspora coronata K.D. Hyde \& E.B.G. Jones 
Notes - The monotypic marine genus Lanspora was introduced by Hyde \& Jones (1986) based on Lanspora coronata, isolated from driftwood collected on rocky coasts. The species differs from species of other marine genera in having ascospores with crown-like appendages on getting into contact with water (Hyde \& Jones 1986). The asexual morph of the type species is undetermined.

Phomatospora Sacc., Nuovo G. bot. ital. 7: 306 (1875).

Index Fungorum number: IF4015; 72 morphological species (Species Fungorum 2020), 4 species with sequence data.

Type species - Phomatospora berkeleyi Sacc.

Notes - Phomatospora, typified by P. berkeleyi, originates from terrestrial, freshwater and marine habitats (Hyde 1993a, Raja \& Shearer 2008). Ascospores of aquatic species have adaptive features such as appendages or slimy sheaths in order to facilitate entrapment of and/or adhesion to substrates (Hyde 1993a, Raja \& Shearer 2008). Phomatospora berkeleyi and P. arenaria were initially observed to produce a Sporothrix asexual morph in culture, similar to some taxa in the Xylariales, which led to Phomatospora being placed in Xylariales (Rappaz 1992). Molecular analyses conducted by Lumbsch \& Huhndorf (2007), however, did not support this placement and subsequently, the genus was placed in Sordariomycetes genera incertae sedis. Réblová et al. (2016a) as well as Senanayake et al. (2016) revealed through phylogenetic analyses that Phomatospora groups together with Lanspora, for which Phomatosporaceae was introduced. Phomatospora biseriata is excluded from the phylogenetic analysis conducted in the present study since it does not cluster with other species of Phomatospora. Further studies should confirm the definite identity of the species introduced as 'Phomatospora biseriata'. Phomatospora berkeleyi is illustrated herein (Fig. 195).

Tenuimurus Senan., Camporesi \& K.D. Hyde, Mycosphere 7(5): 637 (2016)

Index Fungorum number: IF552315; 1 species with sequence data.

Type species - Tenuimurus clematidis Senan., Camporesi \& K.D. Hyde

Notes - Tenuimurus typified by T. clematidis, which was introduced by Senanayake et al. (2016) to accommodate species primarily having thin, delicate peridium as compared to other species in Phomatosporaceae. The species is saprobic on overwintered plants, for example, on Clematis vitalba (Ranunculaceae) (Senanayake et al. 2016).

Phyllachoraceae Theiss. \& P. Syd., Annls mycol. 13(3/4): 168 (1915)

Index Fungorum number: IF81156; Facesoffungi number: FoF01329; 1125 species.

Parasitic on living leaves or saprobic on dead wood submerged in water. Sexual morph: Leaf spots on host black, abundant, scattered, raised, mostly rounded to oblong or elongated, sometimes parallel with leaf venation, surrounded by light brown necrotic region. Ascomata flattened, globose to subglobose, with thin walls, lying in leaf tissues or in a pseudostroma or stroma and maturing in living leaves, ostiolate. Ostiolar canal conical, wide, lacking periphyses. Peridium clypeate, thickest adjacent to ostiolar canal, composed of a deeply melanized, brown-black, amorphous layer of host cuticle and epidermal cells, often merging with a lighter pigmented region of brownish, distorted parenchyma cells infiltrated with fungal hyphae, beneath the clypeus. Lower and lateral peridium composed of two layers; an outer region comprising several layers of dark brown, flattened, thin-walled fungal cells, which internally fuse with several layers of hyaline, flattened, thin-walled fungal cells. Lateral peridium fuses outwardly with an irregular, narrow region of distorted host parenchyma infiltrated by fungal cells. The basal peridium merges outwardly with either a narrow zone of infiltrated and distorted host parenchyma and occasionally lower epidermal cells, or integrates directly with a lower clypeus, similar in construction to that basal peridium. Paraphyses numerous, persistent, filiform, branched or unbranched, septate, slightly longer than asci. Asci 8-spored, persistent, cylindrical to fusiform, short pedicellate, with walls uniform in thickness, not especially thickened at apex, apical ring often present, rarely absent, J-, or J+. 
Ascospores multi-seriate, fusiform to narrowly oval, usually hyaline, aseptate or rarely septate, often with a mucilaginous sheath, with or without an attenuated base, sometimes with pad like appendages. Asexual morph: Coelomycetous, with conidia in locules in a stroma, spermatial or disseminative. Conidiomata similar to ascomata, immersed, subcuticular, strongly raising the host surface, occasionally pycnidial, occupying the region between the cuticle and epidermis, ostiolate. Conidiogenous cells arising from the basal and lateral walls, cylindrical, phialidic, aseptate, hyaline, forming conidia singly at the apex. Conidia hyaline, filiform, aseptate (adapted from Maharachchikumbura et al. 2016b).

Type genus - Phyllachora Nitschke

Notes - Theissen \& Sydow (1915) introduced Phyllachoraceae, previously placed in several orders, including Dothideales (Horst 1990), Sphaeriales (Nannfeldt 1932, Miller 1951, 1954, Muller \& von Arx 1962, Wehmeyer 1975), Xylariales (Luttrell 1951, Barr 1990a), Glomerellales (Chadefaud 1960, Locquin 1984), Phyllachorales (Barr 1976a, b, 1983), Polystigmatales (Eriksson 1982b, Hawksworth et al. 1983), and Diaporthales (Cannon 1988). Currently, it is placed in order Phyllachorales (Maharachchikumbura et al. 2015b, 2016b, Santos et al. 2016, Dayarathne et al. 2017). Phyllachoraceae is characterised by ascohymenial development with paraphyses, thinwalled asci, which may have an apical ring, that does not stain blue in iodine (J-) and ascospores that are often hyaline and 1-celled (Cannon 1991). Asexual morphs are coelomycetes, spermatial or disseminative (Hawksworth et al. 1995). Munk (1957) and Barr (1990a) had a different concept of the family, including genera with $\mathrm{J}+$, apical rings, in the ascus. However, in a study based on available molecular data and literature Maharachchikumbura et al. (2015, 2016b) listed 58 genera in Phyllachoraceae. Mardones et al. (2017) proposed a new family Telimenaceae with Telimena as the type genus, resulting in three families in Phyllachorales and removal of Telimena from Phyllachoraceae. Dayarathne et al. (2017) excluded Polystigma from the Phyllachorales based on analysis of combined LSU, SSU and ITS sequence data. Hence, at present family Phyllachoraceae comprises 54 genera. However, sequence data are available only for a few members of the genera Ascovaginospora, Coccodiella and Phyllachora because of the difficulties in obtaining cultures.

The family contains a large number of species which are probably host-specific. Most genera are monotypic and the majority lack sequence data. The family therefore needs recollecting with sequence data. Many genera are poorly known and therefore the notes below are brief.

\section{Ecological and economic significance of Phyllachoraceae}

Members of family Phyllachoraceae are mostly obligate biotrophs known to be minor pathogens, and facilitate pathways for secondary infection by other severe pathogenic organisms (Dayarathne et al. 2017). They produce distinct leaf spots on forage grasses of Poaceae especially members of Acer (Karami et al. 2014); species of Rosaceae (Cannon 1996); on Leguminosae spp. (Cannon 1991), on Duranta spp. in the tropics (Hanlin \& Tortolero 1991); small scabby leaf spots or "lixa-pequena" on coconut palms in Brazil (Subileau et al. 1993); on plants of family Asclepiadaceae (Pearce et al. 1999); Prunus species (Habibi et al. 2015); and on Myrcia spp. (Santos et al. 2016). They are limited in the area of action and when they kill leaf tissues, they increase lignin content and decreasing host protein content, acceptability and digestibility (Burton \& Wills 1981). Furthermore, leaf spots caused by phytopathogenic fungi including tar spot pathogens on leaves decrease the rate of photosynthesis and alter the physiological and biochemical aspects thereby reducing crop production (Martinez et al. 2010, Karami et al. 2014).

\section{Genera included in Phyllachoraceae}

Ascovaginospora Fallah, Shearer \& W.D. Chen, Mycologia 89(5): 813 (1997)

Index Fungorum number: IF27832; 1 species with sequence data.

Type species - Ascovaginospora stellipala Fallah, Shearer \& W.D. Chen

Notes - This monotypic genus was introduced by Fallah et al. (1997) to accommodate $A$. stellipala, which is characterized by 1-celled, hyaline, rhomboid ascospores, surrounded by a tetraradiate sheath, the arms of which elongate in water (Fallah et al. 1997). 

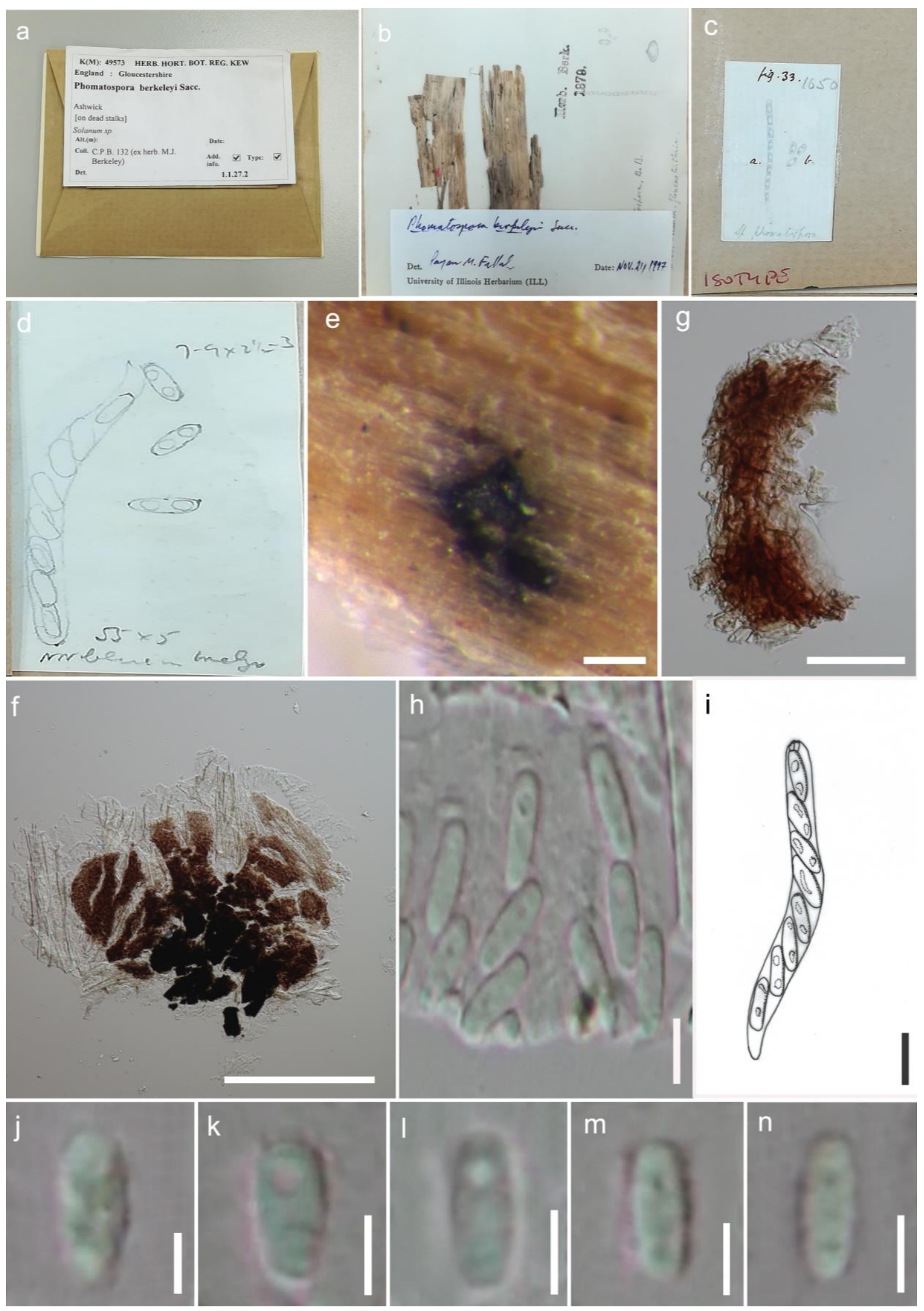

Figure 195 - Phomatospora berkeleyi (Material examined - ENGLAND, Gloucestershire, dead stalks of Solanum sp., M.J. Berkeley, K(M): 49573, isotype). a-d Herbarium material. e Appearance of ascomata on host substrate. f squash mount of ascoma. g Peridium. i Ascus (redrawn from Fallah \& Shearer 1998). h, j-n Ascospores. Scale bars: e, $f=100 \mu \mathrm{m}, \mathrm{g}=20 \mu \mathrm{m}, \mathrm{h}, \mathrm{j}-\mathrm{n}=3$ $\mu \mathrm{m}, \mathrm{i}=10 \mu \mathrm{m}$. 

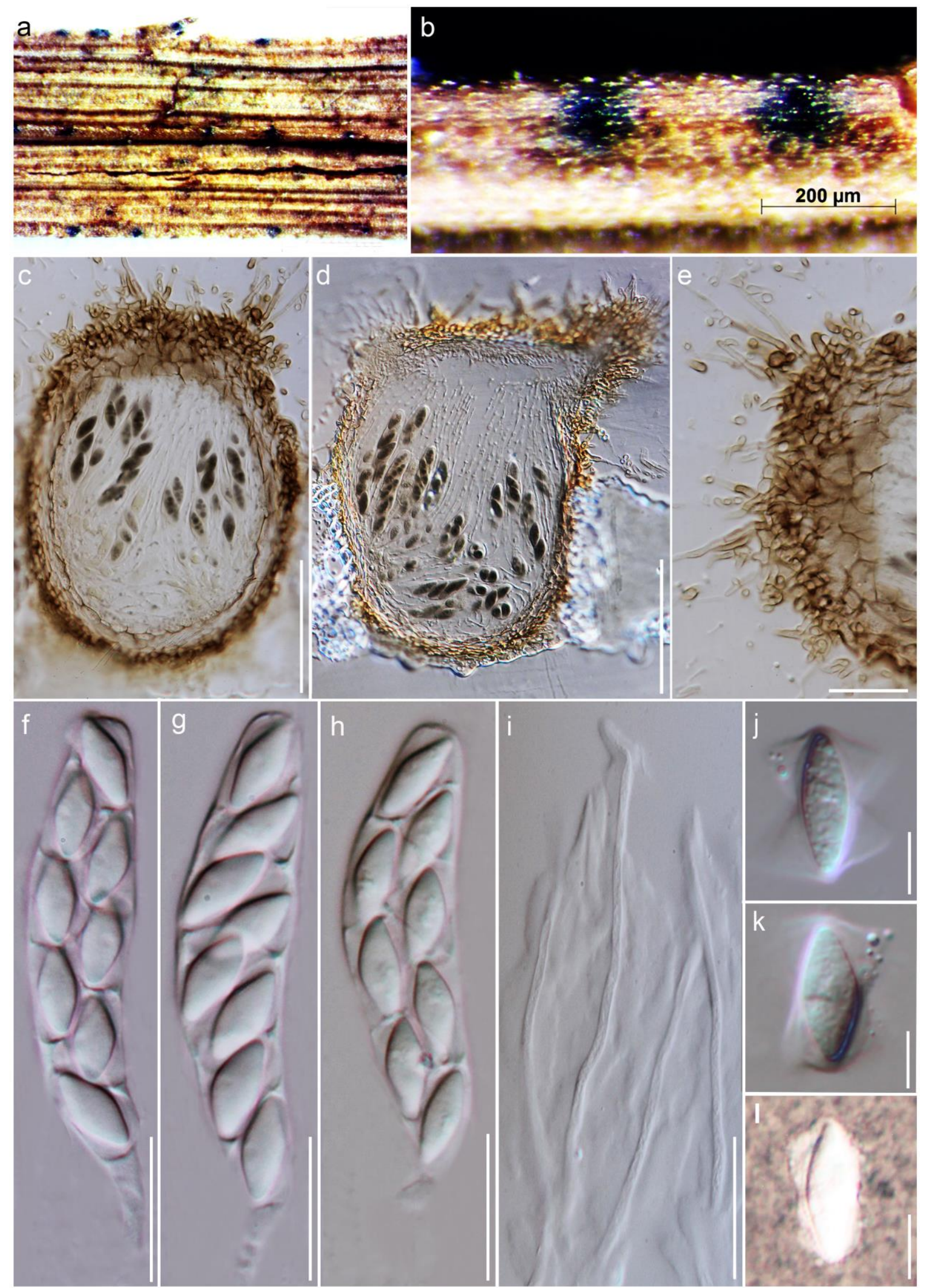

Figure 196 - Ascovaginospora stellipala (Material examined - USA. Wisconsin, on Carex limosa, 28 May 1996, Payam M. Fallah, ILLS 52319, holotype). a Herbarium material. b Ascomata on Carex limosa leaf. c, d Transverse section through ascoma. e Peridium. f-h Asci. i Paraphyses. j, k Ascospores with tetraradiate sheath. i Ascospores stained with Indian ink. Scale bars: $b=200 \mu \mathrm{m}$, $\mathrm{c}, \mathrm{d}=50, \mathrm{f}-\mathrm{i}=20 \mu \mathrm{m}, \mathrm{e}, \mathrm{j}-\mathrm{l}=5 \mu \mathrm{m}$. 
Ascovaginospora stellipala occurs on submerged dead stems and leaves of Carex limosa collected from two sphagnum bogs in northern Wisconsin (Fallah et al. 1997). Based on morphology and nuclear ribosomal DNA sequence data, this species was first placed in Lasiosphaeriaceae, Sordariales by Fallah et al. (1997), in Phyllachorales by Maharachchikumbura et al. (2015, 2016b) and this is supported by Dayarathne et al. (2017). In our observation, tetraradiate sheaths of ascospores arms did not extend in the water as described by Fallah et al. (1997), perhaps due to age.

Brobdingnagia K.D. Hyde \& P.F. Cannon, Mycol. Pap. 175: 47 (1999)

Index Fungorum number: IF27915; 2 morphological species (Species Fungorum 2020).

Type species - Brobdingnagia nigeriensis (Sivan. \& Okpala) K.D. Hyde \& P.F. Cannon

Notes - Brobdingnagia is characterised by large cylindrical to clavate ascospores inside a gelatinous, evanescent, unitunicate ascus (Hyde \& Cannon 1999, Sivanesan \& Shivas 2002). They can be saprobes or pathogens, while cultures and sequences are not available for any of the four species (Hyde \& Cannon 1999, Sivanesan \& Shivas 2002, Wijayawardene et al. 2018a).

Camarotella Theiss. \& Syd., Annls mycol. 13(3/4): 370 (1915)

Index Fungorum number: IF776; 8 morphological species (Species Fungorum 2020), 2 species with sequence data.

Type species - Camarotella astrocaryae (Rehm) Theiss. \& Syd.

Notes - Theissen \& Sydow (1915) described Camarotella as having thick-walled asci and hyaline, 4-celled ascospores. Petrak (1940) revised this genus, while Clements \& Shear (1931) and Wehmeyer (1975) treated Camarotella, but ignored the changes introduced by Petrak (1940). Hyde \& Cannon (1999), who examined parasitic fungi causing tar spots and similar diseases on palms, revaluated and accepted the genus.

Coccodiella Hara, Bot. Mag., Tokyo 25: 224 (1910)

Index Fungorum number: IF1139; 21 morphological species (Species Fungorum 2020), 5 species with sequence data.

Type species - Coccodiella arundinariae Hara

Notes - Hara (1911) introduced Coccodiella for a plant parasitic species characterized by a stroma originating in the mesophyll, which then proliferates through the lower epidermis, forming a sessile hypostroma attached to the host tissue. Members of Coccodiella are host-specific and tropical in distribution (Mardones et al. 2017).

Cyclodomus Höhn., Sber. Akad. Wiss. Wien, Math.-naturw. Kl., Abt. 1 118: 1527 [67 repr.] (1909)

Index Fungorum number: IF7859; 2 morphological species (Species Fungorum 2020).

Type species - Cyclodomus umbellulariae Höhn.

Notes - Cyclodomus is a coelomycetous genus, which currently comprises five species (Wijayawardene et al. 2018a) and they are saprobes that can be found in terrestrial environments (Hyde et al. 1996).

Deshpandiella Kamat \& Ullasa, Bull. Torrey bot. Club 100: 41 (1973)

Index Fungorum number: IF1479; 1 morphological species.

Type species - Deshpandiella jambolana (T.S. Ramakr., Sriniv. \& Sundaram) Kamat \& Ullasa

Notes - The monotypic genus Deshpandiella is typified by D. jambolana, which causes leaf spots and was collected from Coorg Forests, Mysore State, India parasitizing leaves of Eugenia cuminii (Syzygium jambolanum) (Ullasa \& Rao 1973). The genus is characterized by astromatic, perithecial ascomata with eccentric necks and bent ostioles (Ullasa \& Rao 1973). Asci are 8-spored, unitunicate, with a J-, apical ring and pedicels gelatinize at maturity. Ascospores are brown and equally 2-celled (Ullasa \& Rao 1973). 

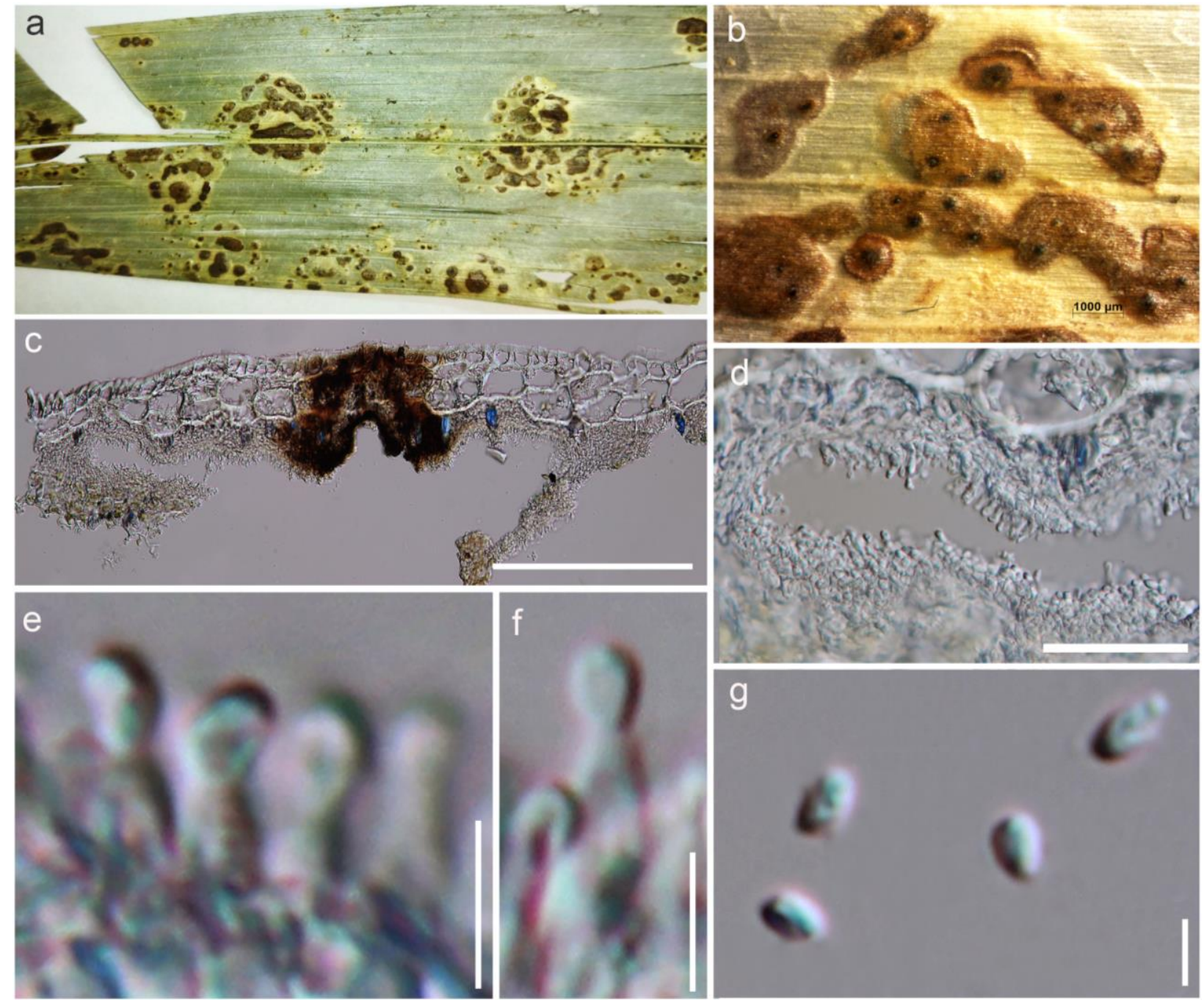

Figure 197 - Cyclodomus aequatoriensis (Material examined - ECUADOR, Oriente, Napo Province, Rio Cuyabeno, Cuyabeno rainforest, on living leaves of young palm (probably Astrocayum) in rainforest, August 1993, K.D. Hyde, BRIP 23240, holotype). a Herbarium material. b Leaf spots on palm leaf. c, d Transverse section through conidioma. e, f Conidiogenous cells attached to conidia. g Conidia. Scale bars: $\mathrm{b}=1000 \mu \mathrm{m}, \mathrm{c}=200 \mu \mathrm{m}, \mathrm{d}=100 \mu \mathrm{m}, \mathrm{e}, \mathrm{f}=10 \mu \mathrm{m}, \mathrm{f}=$ $5 \mu \mathrm{m}$.

Diachora Müll. Arg., Jb. wiss. Bot. 25: 623 (1893)

Index Fungorum number: IF1488; 4 morphological species (Species Fungorum 2020).

Type species - Diachora onobrychidis (DC.) Jul. Müll.

Notes - Diachora comprises obligately biotrophic plant parasites, forming restricted or expanded pseudostromata in leaves or stems, filling the epidermal host cells with dark walled cells, while the fungal structures of the inner host tissues are colourless (Muller 1986). The asexual morph was in Diachorella which are coelomycetous saprobes found in terrestrial habitats (Ciccarone 1963, Sutton 1967).

Diatractium Syd. \& P. Syd., Annls mycol. 18(4/6): 183 (1921)

Index Fungorum number: IF1502; 2 morphological species (Species Fungorum 2020); 1 species with sequence data.

Type species - Diatractium cordiae (F. Stevens) Syd. \& P. Syd.

Notes - Diatractium have ascospores that are isthmoid (narrowed over a significant length of the central portion of the spore, Cannon 1989). Species of Diatractium are parasitic on leaves 
(Cannon 1989). Palmateer et al. (2008) provided sequence data for D. cordianum (Ellis \& Kelsey) Syd.

Erikssonia Penz. \& Sacc., Malpighia 11(11-12): 526 (1898)

Index Fungorum number: IF1884; 5 morphological species (Species Fungorum 2020).

Type species - Erikssonia pulchella Penz. \& Sacc.

Notes - Erikssonia was named by Penzig \& Saccardo as a member of Hysteriaceae (Stevenson 1943). Erikssonia can be distinguished by erumpent to superficial stromata, with uniloculate epistromata, which sometimes are attached to the host tissue by a partly immersed hypostroma (Penzig \& Saccardo 1897a, b).

Fremitomyces P.F. Cannon \& H.C. Evans, Mycol. Res. 103(5): 585 (1999)

Index Fungorum number: IF28323; 2 morphological species (Species Fungorum 2020).

Type species - Fremitomyces punctatus P.F. Cannon \& H.C. Evans

Notes - Fremitomyces was introduced by Cannon \& Evans (1999) for two species, $F$. punctatus and F. mahe from East Africa and the Seychelles occurring on Erythroxylaceae with initially brightly coloured stromata (Cannon \& Evans 1999, Lumbsch \& Huhndorf 2007).

Geminispora Pat., Bull. Soc. mycol. Fr. 9: 151 (1893)

Index Fungorum number: IF2041; 2 morphological species (Species Fungorum 2020).

Type species - Geminispora mimosae Pat.

Notes - Geminispora includes two terrestrial saprobes, G. derridis and G. mimosae (Cannon 1991, Wijayawardene et al. 2018a).

Gibellina Pass., Revue mycol., Toulouse 8: 177 (1886)

Index Fungorum number: IF2064; 2 morphological species (Species Fungorum 2020), 1 species with sequence data.

Type species - Gibellina cerealis (Pass.) Pass.

Notes - This genus includes two species, G. cerealis and G. rehmiana that are pathogens.

Imazekia Tak. Kobay. \& Y. Kawabe, Japanese Journal of Tropical Agriculture 36(3): 201 (1992)

Index Fungorum number: IF27271; 1 morphological species.

Type species - Imazekia ryukyuensis Tak. Kobay. \& Y. Kawabe

Notes - Imazekia ryukyuensis causes black leaf spots of Stephania living leaves. There are two species in this genus, which are distinct from the other known genera of Phyllachorales by having apiospores (Kobayashi \& Kawabe 1992).

Isothea Fr., Summa veg. Scand., Section Post. (Stockholm): 421 (1849)

Index Fungorum number: IF2516; 4 morphological species (Species Fungorum 2020).

Type species - Isothea rhytismoides (Bab.) Fr.

Notes - Isothea was erected for the single species Sphaeria rhytismoides (Cannon 1996). Five taxa have been transferred to Isothea by different authors (Cannon 1996).

Lichenochora Hafellner, Nova Hedwigia 48(3-4): 358 (1989)

Index Fungorum number: IF25318; 45 morphological species (Species Fungorum 2020).

Type species - Lichenochora thallina (Cooke) Hafellner

Notes - Lichenochora (Phyllachorales) was introduced by Hafellner (1989) to include different lichenicolous taxa characterized by typical perithecia and unitunicate asci. However, some of the species with bitunicate asci have been referred to other genera such as Didymella and Stigmidium. Hafellner (1989) included six species of Lichenochora; L. constrictella, $L$. inconspicua, L. galligena, L. polycoccoides, L. thallina (currently L. obscuroides) and L. weillii, in Physciaceae. Subsequently, the number of Lichenochora taxa has increased with the description of- 

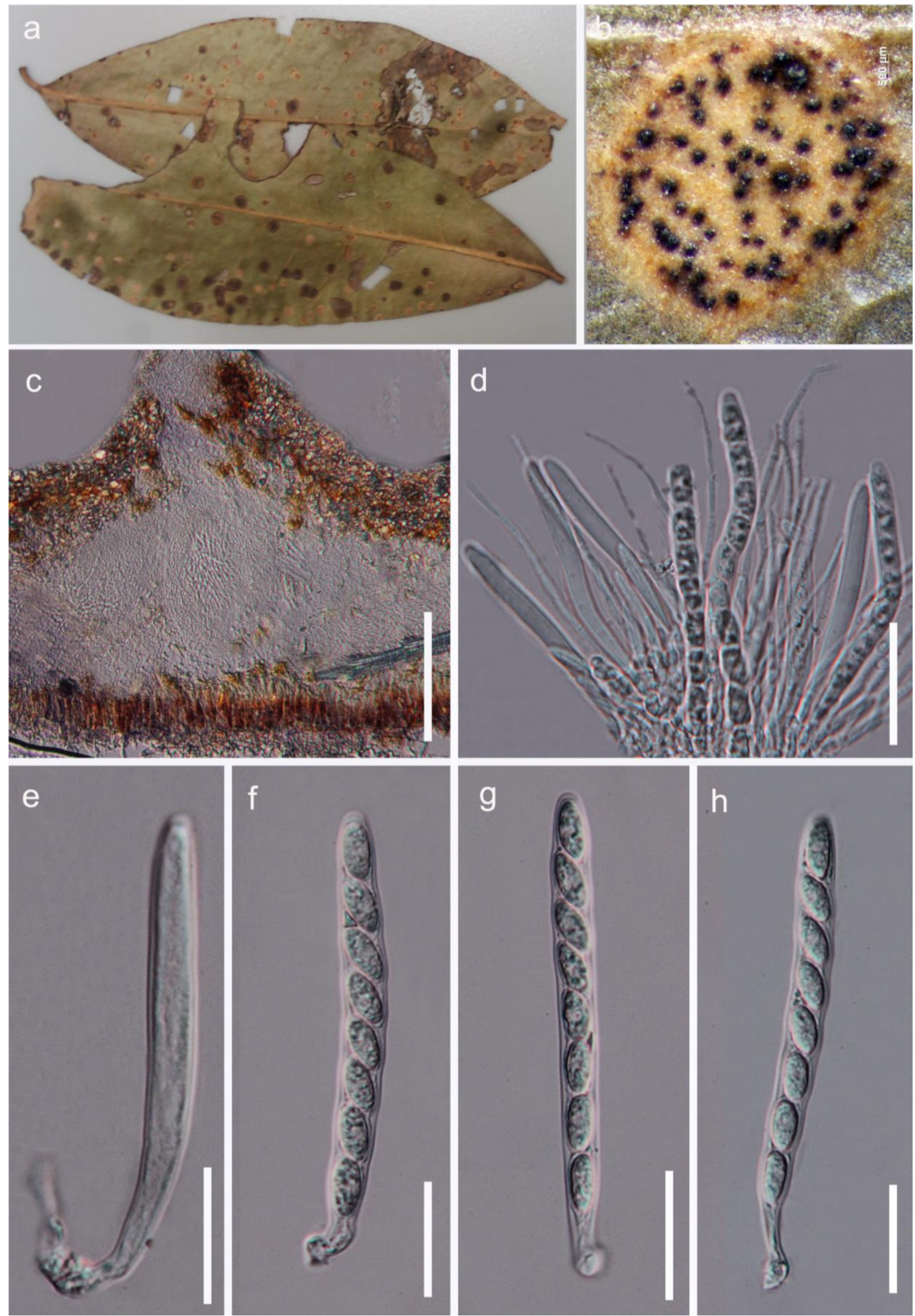

Figure 198 - Fremitomyces punctatus (Material examined - KENYA, from living leaf of Erythroxylum fischeri, IMI 355095, holotype). a, b Herbarium material of Fremitomyces paunctatus. c Fruiting bodies on Erythroxylum fischeri leaf surface. d Section through ascoma. e Immature asci. f Mature asci. g Asci with paraphyses. Scale bars: $\mathrm{e}=10 \mu \mathrm{m}, \mathrm{f}, \mathrm{g}=20 \mu \mathrm{m}, \mathrm{d}=50$ $\mu \mathrm{m}$. 
-new species or the inclusion of some new combinations in various studies (Triebel et al. 1991, Roux \& Triebel 1994, Navarro-rosinés et al. 1994, Navrotskaya et al. 1996, Aptroot et al. 1997, Hafellner et al. 2008).

Lindauella Rehm, Hedwigia 39: 82 (1900)

Index Fungorum number: IF2874; 1 morphological species.

Type species - Lindauella pyrenocarpoidea Rehm

Notes - This genus included two taxa L. amylospora and L. pyrenocarpoidea. Currently $L$. amylospora is referred to Flaminia amylospora. Hence, this genus is currently monotypic.

Linochora Höhn., Sber. Akad. Wiss. Wien, Math.-naturw. Kl., Abt. 1 119: 638 (1910)

Index Fungorum number: IF8781; 25 morphological species (Species Fungorum 2020).

Type species - Linochora leptospermi Höhn.

Notes - A spermatial state of Phyllachora has been placed in the form genus Linochora by Höhnel (1910), but currently maintained as a Phyllachora species (Species Fungorum 2020). A genus with many species (circa 40) mostly causing leaf spots of grasses.

Lohwagia Petr., Bot. Arch. 43: 205 (1942)

Index Fungorum number: IF2917; 3 morphological species (Species Fungorum 2020).

Type species - Lohwagia intermedia (Speg.) Petr.

Notes - Lohwagia was erected by Petrak (1942) to accommodate Phyllachora intermedia. Its erumpent stromata cause galls and hypertrophy to the host plant.

Maculatifrondes K.D. Hyde, Mycol. Res. 100(12): 1509 (1996)

Index Fungorum number: IF27719; 1 morphological species.

Type species - Maculatifrondes aequatoriensis K.D. Hyde

Notes - Hyde et al. (1996) introduced Maculatifrondes to accommodate M. aequatoriensis, obtained from living leaves of an unidentified palm in Cuyabeno, Ecuador. Maculatifrondes aequatoriensis has early deliquescing asci and a cyclodomus-like asexual morph (Hyde et al. 1996).

Malthomyces K.D. Hyde \& P.F. Cannon, Mycol. Pap. 175: 69 (1999)

Index Fungorum number: IF27923; 2 morphological species (Species Fungorum 2020).

Type species - Malthomyces calamigena (Berk. \& Broome) K.D. Hyde \& P.F. Cannon

Notes - Malthomyces is typified by $M$. calamigena and currently comprises two species including M. coimbatoricus (Species Fungorum 2020). Both these species cause tar spots on palms (Hyde \& Cannon 1999) and are saprobes found from India and Sri Lanka. The asexual morph of Malthomyces is undetermined (Wijayawardene et al. 2018a).

Muelleromyces Kamat \& Anahosur, Experientia 24: 849 (1968)

Index Fungorum number: IF3284; 1 morphological species.

Type species - Muelleromyces indicus Kamat \& Anahosur

Notes - Muelleromyces is characterized by astromatic perithecia with a well-developed clypeus, 8-spored, unitunicate, evanescent asci and with a thick apical canal, and brown, unequally 2-celled ascospores (Anahosur 1968). This genus comprises one species, which parasitizes leaves of Eugenia jambolana. and is characterized by ascospores with a wide equatorial pallid band above the septum on the large apical cell (Anahosur 1968; Kang et al. 1999a). A second species Muelleromyces variisporus has been referred to Kamatella (Anahosur 1969).

Neoflageoletia J. Reid \& C. Booth, Can. J. Bot.44: 450 (1966)

Index Fungorum number: IF3453; 1 morphological species.

Type species - Neoflageoletia bambusina (Syd.) J. Reid \& C. Booth 
Notes - Neoflageoletia is a monotypic genus that was introduced to accommodate Flageoletia bambusina by Reid \& Booth (1966).
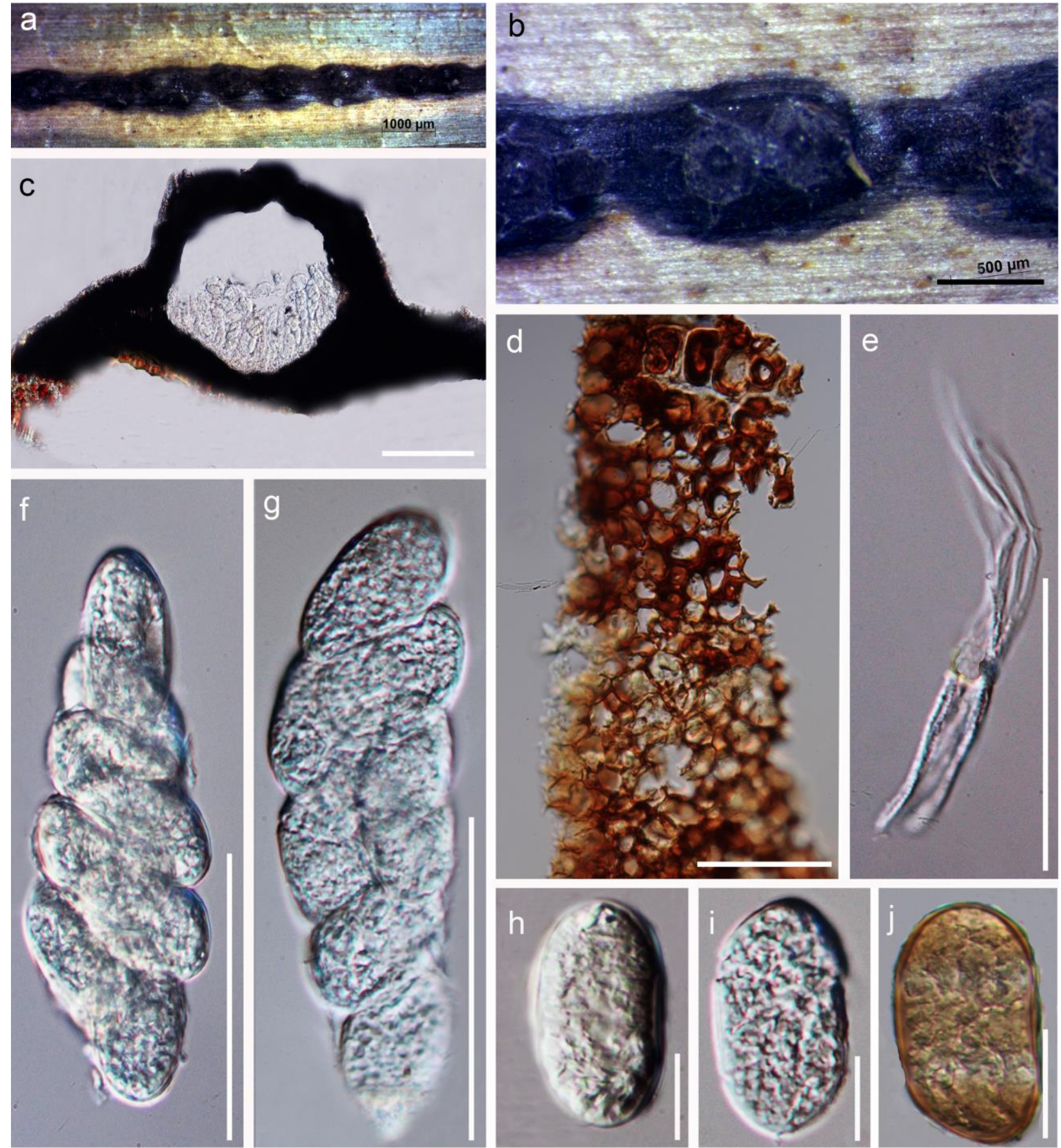

Figure 199 - Malthomyces calamigena (Material examined - SRI LANKA, Peradeniya, on leaves of Calamus rudentum Lour. (Arecaceae), January 1868, G.H.K. Thwaites (ex-herb. M.J. Berkeley), K(M) 35077, holotype). a Leaf spots on Calamus rudentum leaf. b Stromata on host substrate. c Transverse section through stroma. d Peridium. e Paraphyses-like hyphae. f, g Asci. h-j Immature and mature ascospores. Scale bars: $b=500 \mu \mathrm{m}, \mathrm{c}=100, \mathrm{e}-\mathrm{g}=50 \mu \mathrm{m}, \mathrm{d}, \mathrm{h}-\mathrm{j}=10 \mu \mathrm{m}$.

Neophyllachora Dayar. \& K.D. Hyde, Mycosphere 8(10): 1613 (2017)

Index Fungorum number: IF553633; 4 species with sequence data.

Type species - Neophyllachora myrciae (Lév.) Dayar. \& K.D. Hyde

Notes - Members of Neophyllachora have subepidermal, intra-epidermal stromata without a deep invasion of the mesophyl, and clavate asci. Three species appear to specifically infect Myrcia 
species, one on Myrciaria species, and one on different Psidium species (Dayarathne et al. 2017). Neophyllachora myrciae has characteristically lunate ascospores, and two types of conidia (ellipsoidal and falcate) formed in separate conidiomata, but both with phialidic conidiogenesis. Neophyllachora trucatisporum, on Myrciaria camapuanensis has sublunate ascospores with both ends showing characteristic wall thickenings; $N$. cerradensis on $M$. torta shows elliptical ascospores with predominantly longer dimensions when compared to $N$. subcircinans, which is found only on Psidium species; and $P$. myrciariae has ascospores similar in form to those of $P$. cerradensis, but also forms fusoid-clavate phialidic conidia (Santos et al. 2016, Dayarathne et al. 2017).

Ophiodothis Sacc., Sylloge Fungorum 2: 652 (1883)

Index Fungorum number: IF3601; 8 morphological species (Species Fungorum 2020).

Type species - Ophiodothis vorax (Berk. \& M.A. Curtis) Sacc.

Notes - There are around 33 species described in this genus (Index Fungorum 2020), however, only six species currently belong to Phyllachoraceae, while others are referred to various families, such as the Clavicipitaceae. Sequence data are not available for any of Ophiodothis species.

Ophiodothella Henn., Hedwigia 43: 258 (1904)

Index Fungorum number: IF3600; 31 morphological species (Species Fungorum 2020), 1 species with sequence data.

Type species - Ophiodothella atromaculans (Henn.) Höhn.

Notes - This genus comprises saprobic, terrestrial taxa which have perithecial ascomata that are characterized by the formation of ostiolate perithecia immersed in host leaves in which a blackened clypeus typically occurs around the ostiole and beneath the perithecium opposite the ostiole (Hanlin et al. 1992). Their unitunicate asci comprise a J+, apical ring and contain hyaline, scolecosporous ascospores (Hanlin et al. 2002). Most species of Ophiodothella are leaf parasites.

Orphnodactylis Malloch \& A. Mallik, Can. J. Bot.76(7): 1267 (1998)

Index Fungorum number: IF539031; 2 morphological species (Species Fungorum 2020).

Type species - Orphnodactylis kalmiae Malloch \& A. Mallik

Notes - Two species, Orphnodactylis kalmiae and O. wittrockii were described in this genus based on morphology (Malloch \& Mallik 1998). Orphnodactylis kalmiae causes twig blight disease of Kalmia angustifolia (Ericaceae).

Oxodeora K.D. Hyde \& P.F. Cannon, Mycol. Pap. 175: 75 (1999)

Index Fungorum number: IF27926; 1 morphological species.

Type species - Oxodeora petrakii (Cif.) K.D. Hyde \& P.F. Cannon

Notes - This is a monotypic genus containing Oxodeora petrakii which was described from palms (Hyde \& Cannon 1999). Oxodeora shows substantial ascospore ornamentation and comprises erumpent, linear stromata and light brown ascospores, covered with wide, longitudinal, irregular ridges (Hyde \& Cannon 1999).

Parberya C.A. Pearce \& K.D. Hyde, Fungal Divers. 6: 90 (2001)

Index Fungorum number: IF28524; 2 morphological species (Species Fungorum 2020).

Type species - Parberya kosciuskoa C.A. Pearce \& K.D. Hyde

Notes - Parberya was introduced to accommodate phyllachoraceous species forming tar spots on leaves, which contain golden-brown to brown, spinose ornamented ascospores (Pearce \& Hyde 2001). The distinctly ornamented ascospores of Parberya appear to be unique in Phyllachoraceae (Pearce \& Hyde 2001). This genus includes two taxa, Parberya arxii and $P$. kosciuskoa. 
Petrakiella Syd., Annls mycol. 22(1/2): 230 (1924)

Index Fungorum number: IF3849; 1 morphological species.

Type species - Petrakiella insignis Syd.

Notes - This is a monotypic genus, containing the single species Petrakiella insignis, which is characterized by the markedly developed stroma having a perithecial layer on its peripheral part and phragmosporous ascospores (Kobayashi et al. 1939). Sydow (1924) stated that the centrum structure of perithecia in $P$. insignis is quite similar to the members of Diaporthaceae.

Phycomelaina Kohlm., Phytopath. Z. 63: 350 (1968)

Index Fungorum number: IF4044; 1 morphological species.

Type species - Phycomelaina laminariae (Rostr.) Kohlm.

Notes - Phycomelaina is a monotypic genus which is typified by $P$. laminariae that was originally described by Rostrup (1894-95) in Dothidella. Phycomelaina laminariae is a parasitic on marine algal kelps; Laminaria saccacharina and other Laminaria species (Schatz 1983 and is not a common species.

Phyllachora Nitschke, Fungi rhenani exsic., suppl., fasc. 6(nos 2001-2100): no. 2056 (1867)

Index Fungorum number: IF4049; 866 morphological species (Species Fungorum 2020), 23 species with sequence data.

Type species - Phyllachora graminis (Pers.) Fuckel

Notes - Phyllachora, which is typified by $P$. graminis and is the type genus of Phyllachoraceae with around 1513 species currently recognized (Maharachchikumbura et al. 2016b, Dayarathne et al. 2017, Species Fungorum 2020). Most species are named based on their host association and this may not reflect the actual number of species (Cannon 1988). Phyllachora comprises species that grow immersed in a clypeate pseudostroma in leaf tissues, varying from a subcuticular or intra epidermal, to a generalized infection of the entire section of the mesophyll, inducing characteristic black shiny superficial symptoms, commonly known as tar spots (Santos et al. 2016). However, differences in depth of ascomata can be influenced by the consistency of the host tissue (Cannon 1991), therefore, this is not a valid character to distinguish genera.

Phylleutypa Petr., Annls mycol. 32(5/6): 429 (1934)

Index Fungorum number: IF4052; 2 morphological species (Species Fungorum 2020).

Type species - Phylleutypa dioscoreae (Wakef.) Petr.

Notes - Phylleutypa, typified by $P$. dioscoreae, is a stromatic parasite on Dioscorea species (Wakefield 1918, Petrak 1934). This genus currently comprises two additional taxa, P. kalmiae and P. wittrockii.

Phyllocrea Höhn., Annls mycol. 16(1/2): 38 (1918)

Index Fungorum number: IF4063; 3 morphological species (Species Fungorum 2020).

Type species - Phyllocrea quitensis (Pat.) Höhn.

Notes - The plant parasitic species, Phyllocrea indica, $P$. paulliniae and $P$. quitensis collectively represent Phyllocrea. These species are characterized by ascomata immersed in a bright stroma and 2-celled ascospores (Ainsworth et al. 1973).

Pseudothiella Petr., Hedwigia 68(5): 257 (1928)

Index Fungorum number: IF25396; 1 morphological species.

Type species - Pseudothiella hirtellae (Henn.) Petr.

Notes - Pseudothiella is a monotypic genus typified by $P$. hirtellae which is parasitic on Hirtella. It can be distinguished by ascomata immersed in a stroma or pseudostroma that is covered by a stromatic clypeus and ascospores with a hyaline equatorial band (Ainsworth et al. 1973).

Pseudothiopsella Petr., Hedwigia 68(5): 259 (1928) 
Index Fungorum number: IF9618; 1 morphological species.

Type species - Pseudothiopsella hirtellae Petr.

Notes - Pseudothiopsella, a coelomycete, comprises a single species $P$. hirtellae, which has branched conidiophores that give rise to discrete, hyaline, cylindrical, indeterminate, smooth conidiogenous cells with 1-3 enteroblastic-percurrent proliferations, resulting in clearly visible collarettes (Furlanetto \& Dianese1998).

Pterosporidium W.H. Ho \& K.D. Hyde, Can. J. Bot. 74(11): 1826 (1996)

Index Fungorum number: IF27720; 2 morphological species (Species Fungorum 2020).

Type species - Pterosporidium rhizophorae (Vizioli) W.H. Ho \& K.D. Hyde

Notes - Pterosporidium was introduced by Ho \& Hyde (1996) to accommodate $P$. rhizomorphae, and $P$. rhizophorae, associated with foliar diseases of mangrove leaves (Ho \& Hyde 1996). Species are characterized by thin-walled, clavate and unicellular brown ascospores that are covered by a thin paper like sheath (Ho \& Hyde 1996). The genus differs from Anthostomella as the ascospores lack a germ slit and are covered in a thin paper-like sheath.

Rehmiodothis Theiss. \& Syd., Annls mycol. 12(2): 192 (1914)

Index Fungorum number: IF4666; 8 morphological species (Species Fungorum 2020).

Type species - Rehmiodothis osbeckiae (Berk. \& Broome) Theiss. \& Syd.

Notes - Rehmiodothis species are typical tar spot pathogens which have flattened domeshaped, glossy, black stromata, with ascomatal ostioles emerging through the leaf surface as slightly protruding structures (Swart 1987). The stromata originate in or beneath the epidermis, become heavily melanised and contain a few ascomata with oblique necks. The haustoria originate from vegetative hyphae growing between palisade cells (Park et al. 2000). Rehmiodothis osbeckiae causes black, shiny and tar-spots in living leaves of Melastoma malabathricum, with oblong to eggshaped, light-coloured, unequally 2 -celled and ascospores that are constricted at septa (Narendra \& Rao 1976).

Retroa P.F. Cannon, Mycol. Pap. 163: 201 (1991)

Index Fungorum number: IF15437; 2 morphological species (Species Fungorum 2020).

Type species - Retroa dimorphandrae (F. Stevens) P.F. Cannon

Notes - This genus comprises $R$. centrolobii and $R$. dimorphandrae that parasitize the angiosperm family Leguminosae (Cannon 1991).

Rhodosticta Woron., Izv. Imp. St.-Peterburgsk. Bot. Sada 11: 13 (1911)

Index Fungorum number: IF9739; 3 morphological species (Species Fungorum 2020).

Type species - Rhodosticta caraganae Woron.

Notes - Rhodosticta comprises plant parasitic taxa on a variety of hosts (Davay et al. 1965). Rhodosticta caraganae has conidia formed on branched, short, almost doliiform conidiogenous cells, supported by short septate conidiophores (Sutton 1980)

Rikatlia P.F. Cannon, Syst. Ascom. 11(2): 83 (1993)

Index Fungorum number: IF25550; 1 morphological species.

Type species - Rikatlia lungusaensis (Henn.) P.F. Cannon

Notes - Cannon (1992) introduced Rikatlia, which is unique in having banded ascospores.

This genus is monotypic and lacks molecular data to substantiate its classification.

Schizochora Syd. \& P. Syd., Annls mycol. 11(3): 265 (1913)

Index Fungorum number: IF4894; 3 morphological species (Species Fungorum 2020).

Type species - Schizochora elmeri Syd. \& P. Syd.

Notes - Currently, S. calocarpa, S. elmeri, S. pandani and S. stenosperm, are included in Schizochora. 
Sphaerodothella C.A. Pearce \& K.D. Hyde, Fungal Divers. 6: 85 (2001)

Index Fungorum number: IF28523; 1 morphological species.

Type species - Sphaerodothella danthoniae (McAlpine) C.A. Pearce \& K.D. Hyde

Notes - Sphaerodothella was introduced by Pearce \& Hyde (2001) to accommodate $S$. danthoniae which produces black tar spots on leaves and culms of Danthonia spp. Sphaerodothella danthoniae has a peridium composed of hyaline to brown, thin-walled, flattened fungal cells which merge with host cells, rather than a distinct stroma of melanized textura globosa, and pale brown ascospores which have a distinctive, dark brown, mucilaginous perisporium (Pearce \& Hyde 2001).

Sphaerodothis (Sacc. \& P. Syd.) Shear, Mycologia 1(4): 162 (1909)

Index Fungorum number: IF5100; 18 morphological species (Species Fungorum 2020).

Type species - Sphaerodothis arengae (Racib.) Shear

Notes - Sphaerodothis was introduced by Saccardo \& Sydow (1902) for a subgenus of Auerswaldia to include the single species Sphaerodothis arengae. The prominent character used in separating this subgenus from Auerswaldia was the shape of the spores which are sphaerical or subsphaerical (Shear 1909).

Stigmatula (Sacc.) Syd. \& P. Syd., Bull. Herb. Boissier, 2 sér. 1: 77 (1901)

Index Fungorum number: IF5258; 9 morphological species (Species Fungorum 2020).

Type species - Stigmatula sutherlandiae (Kalchbr. \& Cooke) Syd. \& P. Syd.

Notes - Stigmatula is a genus confined to the two tribes Galegeae and Hedysareae of the Leguminosae (Cannon 1994). Stigmatula has brightly coloured stromata which contain starch granules (Müller 1986).

Stigmochora Theiss. \& Syd., Annls mycol. 12(3): 272 (1914)

Index Fungorum number: IF5262; 9 morphological species (Species Fungorum 2020).

Type species - Stigmochora controversa (Starbäck) Theiss. \& Syd.

Notes - Stigmochora species are characterized by hyaline, unequally septate ascospores (Barr \& Hodges 1987). All Stigmochora species recognized by Muller \& von Arx (1962) are parasitic on tropical legumes forming tar spots on the leaves.

Stromaster (Pat.) Höhn., Mitt. bot. Inst. tech. Hochsch. Wien 7(3): 93 (1930)

Index Fungorum number: IF5287; 1 morphological species.

Type species - Stromaster tuberculatus (Pat.) Höhn

Notes - Stromaster is a poorly known monotypic genus which lacks molecular data.

Tamsiniella S.W. Wong, K.D. Hyde, W.H. Ho \& S.J. Stanley, Can. J. Bot. 76(2): 334 (1998)

Index Fungorum number: IF27935; 1 morphological species.

Type species - Tamsiniella labiosa S.W. Wong, K.D. Hyde, W.H. Ho \& S.J. Stanley

Notes - Tamsiniella was introduced by Wong et al. (1998c) to accommodate the freshwater fungus, T. labiosa (Wong et al. 1998c). The genus can be distinguished by dark brown, immersed to semi-immersed, subglobose ascomata, with periphyses, papillate, thin-walled, pale brown peridium, paraphyses, 8-spored, unitunicate, cylindrical asci, with an unusual J-, lip-like, refractive apical ring, and hyaline, ellipsoidal-fusiform, aseptate ascospores, with narrow, roughed mucilaginous sheath (Wong et al. 1998c, Phookamsak et al. 2019).

Telimenella Petr., Annln K. K. naturh. Hofmus. Wien 50: 468 (1940)

Index Fungorum number: IF5365; 2 morphological species (Species Fungorum 2020).

Type species - Telimenella persica Petr.

Notes - Petrak (1940) erected Telimenella which comprises saprobes or weak parasites forming conspicuous, black stromata on grasses (Barr 1977, Makelii \& Koponen1974). 
Telimenochora Sivan., Trans. Br. mycol. Soc. 88(4): 474 (1987)

Index Fungorum number: IF25143; 1 morphological species.

Type species - Telimenochora abortiva (F. Stevens) Sivan.

Notes - The monotypic genus, Telimenochora is characterized by 2-septate ascospores, persistent periphysoids (apical downwardly growing free, colourless, filamentous hyphae), and evanescent, filamentous, colourless, branched paraphyses (Sivanesan 1987).

Trabutia Sacc. \& Roum., Revue mycol., Toulouse 3(no. 9): 27 (1881)

Index Fungorum number: IF5509; 1 morphological species.

Type species - Trabutia quercina (F. Rudolphi) Sacc. \& Roum.

Notes - Trabutia quercina forms ascomata embedded in stromata with 8-spored, clavate or saccate asci with short pedicels with apex obtuse acute and fusiform to ellipsoidal-fusiform, hyaline, aseptate, smooth-walled ascospores, often curved and flattened on one side, without a gelatinous sheath or appendage (Trapero \& Sánchez 2003).

Tribulatia Joanne E. Taylor, K.D. Hyde \& E.B.G. Jones, Fungal Divers. Res. Ser. 12: 189 (2003)

Index Fungorum number: IF28739; 1 morphological species.

Type species - Tribulatia appendicospora Joanne E. Taylor, K.D. Hyde \& E.B.G. Jones

Notes - Tribulatia is a monotypic genus, containing T. appendicospora growing on the palm Archontophoeniox alexandrae. The genus is characterized by dark, ostiolate ascomata forming under a clypeus, cylindrical asci with discoid, J-, apical ring, and hyaline, fusiform, aseptate, ascospores with a mucilaginous appendage (Taylor et al. 2003).

Uropolystigma Maubl., Bull. Soc. mycol. Fr. 36: 36 (1920)

Index Fungorum number: IF5688; 1 morphological species.

Type species - Uropolystigma atrotestaceum Maubl.

Notes - Uropolystigma is a poorly known monotypic genus and no molecular data are available to confirm its phylogenetic affinities.

Vitreostroma P.F. Cannon, Mycol. Pap. 163: 206 (1991)

Index Fungorum number: IF25153; 1 morphological species.

Type species - Vitreostroma desmodii (Henn.) P.F. Cannon

Notes - This is also a poorly known monotypic genus with $V$. desmodii as the type species.

Zimmermanniella Henn., Hedwigia 41: 142 (1902)

Index Fungorum number: IF5870; 1 morphological species.

Type species - Zimmermanniella trispora Henn.

Notes - Zimmermanniella was introduced to accommodate Z. trispora, a leaf parasite of mango in Malaysia.

Pisorisporiaceae Réblová \& J. Fourn., Persoonia 34: 43 (2015)

Index Fungorum number: IF810339; Facesoffungi number: FoF01286; 4 species.

Saprobic on decaying wood in freshwater and terrestrial habitats. Sexual morph: Ascomata astromatic, perithecial, solitary to small groups, immersed to superficial, subhyaline to pale brown or dark brown to black, upright or obliquely lying, papillate or with a long cylindrical neck, sometimes hairy, ostiolate, periphysate. Peridium soft-textured, leathery to fragile, two-layered, inner layer of hyaline, elongated cells, outer layer partly carbonaceous. Paraphyses abundant, persistent, cylindrical, septate, tapering, longer than asci. Asci 8-spored, unitunicate, cylindricalclavate, pedicellate, with a $\mathrm{J}+$, or $\mathrm{J}$-, apical ring. Ascospores uni- to biseriate, smooth-walled, fusiform, hyaline, cylindrical to cymbiform, slightly falcate, multi-septate, without appendages or mucilaginous sheath, with or without guttules. Asexual morph: Undetermined (adapted from Réblová et al. 2010, 2015a). 
Type genus - Pisorisporium Réblová \& J. Fourn.

Notes - Based on morpho-molecular data, Pisorisporiaceae was introduced by Réblová et al. (2015a) in Pisorisporiales. The family predominantly includes aquatic fungi and few terrestrial taxa in Achroceratosphaeria and Pisorisporium. In the phylogenetic analysis, the two genera cluster in a sister clade. However, the genera differ in ascomata and presence of a $\mathrm{J}_{+}$, apical ring in the asci: Achroceratosphaeria has hyaline to pale brown ascomata and a $\mathrm{J}$-, apical ascus ring, while Pisorisporium has carbonaceous ascomata with a $\mathrm{J}+$, ascal apical ring (Réblová et al. 2015a, 2016c). The apical ring colouration reactions found with Pisorisporium spp. are commonly encountered in genera with chitinoid apical rings (Réblová et al. 2015a). Distribution of the family is limited to countries in Europe and Asia (Maharachchikumbura et al. 2016b).

\section{Ecological and economic significance of Pisorisporiaceae}

Decomposes wood with its saprobic activity.

\section{Genera included in Pisorisporiaceae}

Achroceratosphaeria Réblová, J. Fourn., K.D. Hyde \& Ranghoo, Fungal Divers. 43: 79 (2010)

Index Fungorum number: IF515196; 2 morphological species (Species Fungorum 2020), 1 species with sequence data.

Type species - Achroceratosphaeria potamia Réblová, J. Fourn. \& K.D. Hyde

Notes - Currently, two species are accepted in Achroceratosphaeria (Réblová et al. 2010, Wijayawardene et al. 2017a, 2018a), although molecular data is only available for A. potamia. The asexual morph is undetermined. Achroceratosphaeria differs from Pisorisporium in having hyaline to pale brown ascomata and $\mathrm{J}$-, ascus, apical ring.

Pisorisporium Réblová \& J. Fourn., Persoonia 34: 45 (2015)

Index Fungorum number: IF810340; 2 morphological species (Species Fungorum 2020), 1 species with sequence data.

Type species - Pisorisporium cymbiforme Réblová \& J. Fourn.

Notes - The genus was introduced by Réblová et al. (2015a), to accommodate taxa isolated from decaying wood submerged in freshwater and is characterized by brown to black astromatic ascomata and a $\mathrm{J}+$, apical ring in the asci. The ascospores of Pisorisporium cymbiforme are slightly constricted at the septa, while the paraphyses and ascospores have thick walls.

Plectosphaerellaceae W. Gams, Summerb. \& Zare, Nova Hedwigia 85(3-4): 476 (2007)

Index Fungorum number: IF510694; Facesoffungi number: FoF01334; 164 species.

Saprobic on dead plant material or in soil and water, or pathogenic on plants or animal or mycoparasitic on fungi. Sexual morph: Ascomata perithecial or cleistothecial, superficial, brown to dark brown, subglobose to pyriform or globose, with elongate neck, with or without setae around the base of the neck. Peridium multi-layered, composed of dark brown cells of textura angularis. Paraphyses conspicuous in young ascomata or absent. Asci 8-spored, unitunicate, cylindrical, clavate or saccate, without an apical ring. Ascospores irregularly arranged, hyaline or pale brown, fusiform or ellipsoidal or ovoid, 1-celled or 2-celled, wall asperulate or smooth. Asexual morph: Hyphomycetous or coelomycetous. Conidiomata synnematous, sporodochial or acervular when present. Conidiophores simple or branched, hyaline or centrally pale brown or pale olivaceous. Conidiophores cells blastic or phialidic, hyaline, some become orange-brown or olivaceous-brown, partly melanized, verticillate or single, pigmented chlamydospores and microsclerotia formed by some species. Conidia aggregated in slimy heads, hyaline or pigmented, shapes variable (ranging from subglobose to oval or cylindrical, slightly curved, or fusiform with pointed ends), 1-2-celled, smooth-walled (adapted from Maharachchikumbura et al. 2016b, Giraldo \& Crous 2019)

Type genus - Plectosphaerella Kleb.

Notes - Plectosphaerellaceae was introduced by Zare et al. (2007) typified by Plectosphaerella (Zare et al. 2007, Kirk et al. 2008). The family is referred to Glomerellales by 
Maharachchikumbura et al. (2016b). Based on Maharachchikumbura et al. (2016b), there are nine genera accepted and listed in the family (Zare et al. 2007, Kirk et al. 2007, Réblová et al. 2011, Cannon et al. 2012a, Wijayawardene et al. 2012, Grum-Grzhimaylo et al. 2013, 2016, Hirooka et al. 2014, Maharachchikumbura et al. 2015b, 2016b). Brunneomyces was introduced and typified by Brunneomyces brunnescens (Giraldo et al. 2017b). Based on phylogenetic analyses of a combined LSU, SSU, ITS and tefl sequence data and the difference in morphology, Longitudinalis (Hyde et al. 2017b) and Acremoniisimulans (Tibpromma et al. 2018) were introduced in Plectosphaerellaceae. Giraldo \& Crous (2019) introduced another 12 genera in Plectosphaerellaceae based on phylogenetic analyses with a combined LSU, SSU, ITS, tefl, tryptophan synthase ( $t s)$, act and $r p b 2$ dataset and their unique morphology. Currently, 24 genera are recognized in the Plectosphaerellaceae viz. Acremoniisimulans, Acrostalagmus, Brunneomyces, Brunneochlamydosporium, Chlamydosporiella, Chordomyces, Furcasterigmium, Fuscohypha, Gibellulopsis, Lectera, Longitudinalis, Musicillium, Musidium, Nigrocephalum, Paragibellulopsis, Paramusicillium, Phialoparvum, Plectosphaerella, Sayamraella, Stachylidium, Sodiomyces, Summerbellia, Theobromium and Verticillium sensu stricto. The placement of Cephalosporium serrae, Gliocladium cibotii and several Acremonium species remains unresolved, but are presently included in Plectosphaerellaceae.

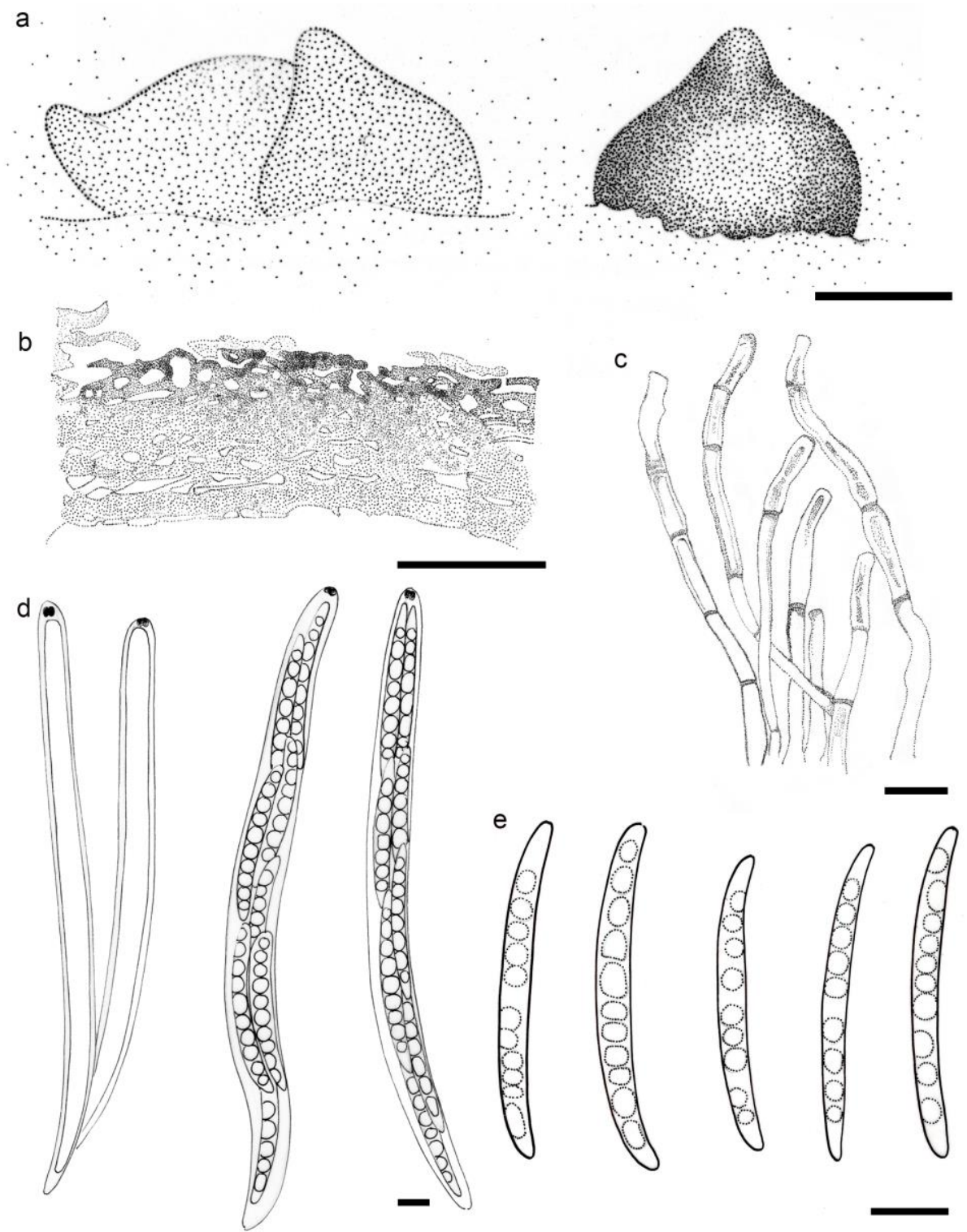

Figure 200 - Pisorisporium cymbiforme (redrawn from Réblová et al. 2015a). a Ascomata b Peridium. c Paraphyses. d Asci. e Ascospores. Scale bars: $a=200 \mu \mathrm{m}, \mathrm{b}=20 \mu \mathrm{m}, \mathrm{c}-\mathrm{e}=10 \mu \mathrm{m}$. 


\section{Ecological and economic significance of Plectosphaerellaceae}

Plectosphaerellaceae species play an important role in nature as saprobic and pathogenic taxa. Many in genera such as Acrostalagmus, Lectera, Musicillium, Plectosphaerella and Verticillium are pathogens of different plants worldwide (Cannon et al. 2012a, Carlucci et al. 2012, Garibaldi et al. 2012, Mersha et al. 2012, Masudi \& Bonjar 2012, Kanakala \& Singh 2013, Hyde et al. 2014, O’Neal \& Davis 2015, Zhang et al. 2015b, Carrieri et al. 2017, Giraldo et al. 2017b, Raimondo \& Carlucci 2018, Giraldo \& Crous 2019). Brunneomyces hominis, and some Chordomyces species have been isolated from human patients, while others occur in plant debris, or are saprobes of plants. Gibellulopsis and Plectosphaerella have been reported as opportunistic pathogens of animals (Batista \& Da Silva Maia 1959, Domsch et al. 2007, Duc et al. 2009). Verticillium nonalfalfae and some Acrostalagmus species are used as biological control agents. (Mohammadi \& Amini 2015, Kasson et al. 2019). Gibellulopsis nigrescens, Verticillium longisporum and many plectosphaerellaceous Acremonium species are reported as soil-borne saprobes (Gams 1975, Domsch et al. 2007, Zare et al. 2007, Fogelqvist et al. 2018). Moreover, some Sodiomyces members have alkaliphilic or alkalitolerant properties (Okada et al. 1993, Grum-Grzhimaylo et al. 2013, 2016, 2018, Kozlova et al. 2019).

\section{Genera included in Plectosphaerellaceae}

Acremoniisimulans Tibpromma \& K.D. Hyde, Fungal Divers. 93(1): 1-160 (2018)

Index Fungorum number: IF555329; 1 species with sequence data.

Type species - Acremoniisimulans thailandensis Tibpromma \& K.D. Hyde

Notes - Acremoniisimulans was introduced by Tibpromma et al. (2018) based on phylogenetic analysis of a combined LSU, SSU, ITS and tefl dataset and its unique morphology. Acremoniisimulans is characterized by septate, unbranched conidiophores, which are brown to pale brown to hyaline at the apex, and have solitary, pale brown to brown, oval, aseptate conidia.

Acrostalagmus Corda, Icon. fung. (Prague) 2: 15 (1838)

Index Fungorum number: IF7044; 13 morphological species (Species Fungorum 2020), 2 species with sequence data.

Type species - Acrostalagmus luteoalbus (Link) Zare, W. Gams \& Schroers

Notes - Acrostalagmus cinnabarinus turned out to be identical to Verticillium luteoalbum (三 Sporotrichum luteoalbum), introduced by Link (1809). Thus, the new combination Acrostalagmus luteoalbus was proposed as the type species of Acrostalagmus (Zare et al. 2004). Acrostalagmus has mononematous or synnematous conidiophores, enteroblastic, monophialidic conidiogenous cells, and hyaline or bright orange to reddish, oval, ellipsoidal to oblong-ellipsoidal conidia, held together by slime (Corda 1838, Giraldo \& Crous 2019). Based on morphology, substrate relationships, and phylogenetic analyses, Zare et al. (2004) demonstrated the asexual-sexual connection was erroneous for Acrostalagmus. Its sexual morph is undetermined.

Brunneochlamydosporium Giraldo López \& Crous, Stud. Mycol. 92: 260 (2018)

Index Fungorum number: IF828053; 4 species with sequence data.

Type species - Brunneochlamydosporium nepalense (W. Gams) Giraldo López \& Crous

Notes - Based on phylogenetic analyses of combined LSU, ITS, tef1 and rpb2 loci, Brunneochlamydosporium was introduced by Giraldo \& Crous (2019) to accommodate the new combinations Brunneochlamydosporium nepalense, $B$. cibotii and the new species $B$. macroclavatum, and $B$. terrestre. The genus is characterized by enteroblastic, monophialidic, sometimes polyphialidic, terminal, lateral, (sub)cylindrical to subulate, hyaline, conidiogenous cells, with conspicuous collarette and a periclinal thickening at the conidiogenous locus. Conidia are ellipsoidal, 1-celled, hyaline, thin- and smooth-walled, containing two guttules, arranged in slimy heads. Chlamydospores are lateral, terminal, intercalary, solitary, in pairs or short chains, 12-celled, pale to dark brown, smooth and thick-walled (Giraldo \& Crous 2019). 
Brunneomyces Giraldo, Gene \& Guarro, Mycol. Progr. 16(4): 357 (2017)

Index Fungorum number: IF811471; 3 species with sequence data.

Type species - Brunneomyces brunnescens (W. Gams) Giraldo, Gene \& Guarro

Notes - Brunneomyces was introduced by Giraldo et al. (2017b) with B. brunnescens as the type species. The genus is characterized by brown hyphae, sympodial conidiophores and chains of ovoidal to ellipsoidal conidia. Three species, B. brunnescens, B. europaeus and B. hominis are including in this genus.

Chlamydosporiella Giraldo López \& Crous, Stud. Mycol. 92: 270 (2019)

Index Fungorum number: IF828069; 1 species with sequence data.

Type species - Chlamydosporiella restricta (J.F.H. Beyma) Giraldo López \& Crous

Notes - Based on the research of Gams (1971), the study of original material for seven strains and additional specimens and the phylogenetic analysis of the combined alignment of the LSU, ITS, tef1 and rpb2 loci, Giraldo \& Crous (2019) introduced Chlamydosporiella to accommodate Acremonium restrictum (三Verticillium dahliae f. cerebriforme) (Beyma 1940, Gams 1971). The genus is characterized by bent, unbranched or basitonously branched conidiophores and conidiogenous cells with short collarettes and inconspicuous periclinal thickening at the conidiogenous locus. Conidia are obovoid, widely ellipsoidal, 1-celled, hyaline, thick- and smoothwalled, arranged in slimy heads. Chlamydospores are terminal or intercalary, mostly chains, dark olive green and thick-walled. The sexual morph is undetermined (Giraldo \& Crous 2019).

Chordomyces Bilanenko, Georgieva \& Grum-Grzhim., Fungal Divers. 71(1): 29 (2015)

Index Fungorum number: IF811265; 2 species with sequence data.

Type species - Chordomyces antarcticus Bilanenko, Georgieva \& Grum-Grzhim.

Notes - Grum-Grzhimaylo et al. (2016) introduced Chordomyces based on the phylogenetic analyses of a combine ITS and LSU dataset for 12 alkaliphilic isolates. Two species, Chordomyces antarcticum and C. albus were introduced in the genus (Grum-Grzhimaylo et al. 2016, Giraldo et al. 2017b). Chordomyces is characterized by erect conidiophores, solitary or forming in synnemata. Conidiogenous cells are enteroblastic, mono- or polyphialidic, tapering towards the apex and often proliferating sympodially. Conidia are subglobose, limoniform, ellipsoidal to cylindrical, rounded at the apex, sometimes with protuberant hilum and1(-2)-celled (Giraldo et al. 2017b).

Furcasterigmium Giraldo López \& Crous, Stud. Mycol. 92: 251 (2019)

Index Fungorum number: IF828041; 1 species with sequence data.

Type species - Furcasterigmium furcatum (Moreau \& V. Moreau) Giraldo López \& Crous

Notes - Based on the phylogenetic analyses of combined LSU, ITS, tef1 and rpb2 sequence data from 20 isolates of Acremonium furcatum, Giraldo \& Crous (2019) introduced Furcasterigmium for species of A. furcatum. This genus is characterized by erect conidiophores, often proliferating sympodially, with conidiogenous cells as short lateral and cylindrical asymmetrical projections. Conidiogenous cells are enteroblastic, mono- and polyphialidic, terminal, lateral, subulate, hyaline, with conspicuous collarette and periclinal thickening at the conidiogenous locus. Conidia are ellipsoidal, 1-celled, hyaline, smooth-walled and arranged in slimy heads (Giraldo \& Crous 2019).

Fuscohypha Giraldo López \& Crous, Stud. Mycol. 92: 264 (2019)

Index Fungorum number: IF828058; 1 species with sequence data.

Type species - Fuscohypha expansa Giraldo López \& Crous

Notes - Based on the analyses of combined LSU, ITS, tef1 and rpb2 sequence data and morphological differences from Verticillium, Giraldo \& Crous (2019) introduced Fuscohypha to accommodate a single species $F$. expansa. The genus is characterized by simple or verticillate, erect conidiophores. Conidiogenous cells are enteroblastic, monophialidic, terminal, lateral, cylindrical to subulate, hyaline, with cylindrical collarette and a conspicuous periclinal thickening at the 
conidiogenous locus. Conidia are subglobose or ellipsoidal, 1-celled and hyaline (Giraldo \& Crous 2019).

Gibellulopsis Bat. \& H. Maia, Anais Soc. Biol. Pernambuco 16(1): 153 (1959)

Index Fungorum number: IF8331; 7 species with sequence data.

Type species - Gibellulopsis piscis Bat. \& H. Maia

Notes - Gibellulopsis was introduced by Batista \& da Silva Maia (1959) and reused by Zare et al. (2007) with G. piscis as its type species. Currently the genus comprises seven species (Zare et al. 2007, Hirooka et al. 2014, Giraldo \& Crous 2019, Index Fungorum 2020). This genus is characterized by conidiophores arising from submerged or superficial hyphae, which are erect, mostly terminal, usually 1-2 times branched, bearing one or two verticillate branches at a node. Conidiogenous cells have inconspicuous collarettes and distinct periclinal thickenings at the conidiogenous locus. Conidia are elongate ellipsoidal to cylindrical, 1- or 2-celled, hyaline, smooth-walled and produced in slimy heads. Chlamydospores are lateral, terminal or intercalary, pale to dark brown and form singly or in chains (Zare et al. 2007, Giraldo \& Crous 2019).

Lectera P.F. Cannon, MycoKeys 3: 28 (2012)

Index Fungorum number: IF550041; 6 morphological species (Species Fungorum 2020), 4 species with sequence data.

Type species - Lectera colletotrichoides (J.E. Chilton) P.F. Cannon

Notes - Lectera established by Cannon et al. (2012a) for the plant pathogen Lectera colletotrichoides and L. longa, based on the difference in ITS and gapdh sequences and the size of conidia. Lectera capsici, L. humicola, L. nordwiniana and L. phaseoli were introduced in the genus (Crous et al. 2017b, Giraldo \& Crous 2019). This genus is characterized by sporodochial or acervular conidiomata, erumpent through host tissues and without a clear upper wall, globose to subglobose, pink or flesh coloured, with few marginal, erect setae. Setae are dark brown, septate, and taper towards the apex. Conidiophores are often reduced to the conidiogenous cell. Conidia are navicular or fusiform with pointed ends, and slightly curved (Cannon et al. 2012a).

Longitudinalis Tibpromma \& K.D. Hyde, Fungal Divers. 87: 155 (2017)

Index Fungorum number: IF553099; 1 species with sequence data.

Type species - Longitudinalis nabanheensis Tibpromma \& K.D. Hyde

Notes - Based on the phylogenetic analyses of a combined LSU, ITS and tefl dataset in Plectosphaerellaceae and the morphological difference from Synnemellisia and other Plectosphaerellaceae genera, Longitudinalis was established by Tibpromma et al. (2018) for a taxon L. nabanheensis (Giraldo \& Crous 2019, Index Fungorum 2020, NCBI 2019). The genus is characterized by synnemata with yellow-green to dark-brown stem and a dark-brown pin-like head of conidiogenous cells. Conidia are aggregated on a pin-like head, fusoid-ellipsoid, tapering towards both ends, with apex subobtuse to obtuse, at the beginning hyaline with dark brown at the towards both ends and immature conidia yellow-green with brown longitudinal striations (Tibpromma et al. 2018).

Musicillium Zare \& W. Gams, Nova Hedwigia 85(3-4): 482 (2007)

Index Fungorum number: IF510696; 4 species with sequence data.

Type species - Musicillium theobromae (Turconi) Zare \& W. Gams

Notes - Musicillium was introduced for the causal agent of cigar-end rot by Zare et al. (2007) based on the morphological difference from Verticillium species. Musicillium elettariae, M. pandanicola, M. theobromae and M. tropicale were included in this genus (Zare et al. 2007, Tibpromma et al. 2018, Giraldo \& Crous 2019, Index Fungorum 2020). The genus is characterized by conidiophores that arise from submerged hyphae, and are erect, septate, repeatedly verticillate towards the apex and distinctly brown throughout (slightly pale only near the tip). Chlamydospores 
are lacking, but moniliform hyphae are initially subhyaline, but turning brown (Zare et al. 2007, Giraldo \& Crous 2019).

Musidium Giraldo López \& Crous, Stud. Mycol. 92: 253 (2019)

Index Fungorum number: IF828045; 1 species with sequence data.

Type species - Musidium stromaticum (W. Gams \& R.H. Stover) Giraldo López \& Crous

Notes - Musidium was established by Giraldo \& Crous (2019) to accommodate the isolate previously classified as Acremonium stromaticum. The genus is closely related to Sayamraella, Summerbellia and Theobromium based on the analyses of a combine LSU, ITS, tef1 and rpb2 dataset, however, Musidium differs in its branched, dark olivaceous, incrusted or smooth and thick walled stromatic hyphae (Giraldo \& Crous 2019).

Nigrocephalum Giraldo López \& Crous, Stud. Mycol. 92: 271 (2019)

Index Fungorum number: IF828071; 1 species with sequence data.

Type species - Nigrocephalum collariferum (Weisenb. \& R. Kirschner) Giraldo López \& Crous

Notes - The monotypic genus Nigrocephalum was introduced by Giraldo \& Crous (2019) to accommodate two isolates formerly described as Acremonium collariferum, which were isolated from the skin and nail lesions of humans. Nigrocephalum species can degrade keratin in vitro at 33 ${ }^{\circ} \mathrm{C}$. The genus is characterized by erect, slightly bent, simple or basitonously branched conidiophores. Conidiogenous cells have a conspicuous funnel-shaped collarette and periclinal thickening at the conidiogenous locus. Conidia are ellipsoidal, concave in lateral view and pigmented (Giraldo \& Crous 2019).

Paragibellulopsis Giraldo López \& Crous, Stud. Mycol. 92: 265 (2019)

Index Fungorum number: IF828060; 1 species with sequence data.

Type species - Paragibellulopsis chrysanthemi (Hirooka, Kawaradani \& Toy. Sato) Giraldo López \& Crous

Notes - Paragibellulopsis is characterized by straight or slightly curved, 2-celled cylindrical conidia, with tapering ends. Chlamydospores are grey brown, intercalary and single or in short in chains (Giraldo \& Crous 2019).

Paramusicillium Giraldo López \& Crous, Stud. Mycol. 92: 269 (2019)

Index Fungorum number: IF828067; 1 species with sequence data.

Type species - Paramusicillium asperulatum Giraldo López \& Crous

Notes - Giraldo \& Crous (2019) introduced Paramusicillium to accommodate Musicillium theobromae, based on the length and rough walls of conidiophores, and the phylogenetic analyses of a combined LSU, ITS, tefl and rpb2 dataset of the type species.

Phialoparvum Giraldo López \& Crous, Stud. Mycol. 92: 265 (2019)

Index Fungorum number: IF828063; 1 species with sequence data.

Type species - Phialoparvum bifurcatum Giraldo López \& Crous

Notes - Phialoparvum was established by Giraldo \& Crous (2019) to accommodate the strain CBS 299.70B, which was formerly classified as Acremonium furcatum. The genus was introduced based on its difference in the apex of the conidiogenous cells and its conidia being longer than the type of Acremonium and phylogenetically distant from the type strain as a single lineage.

Plectosphaerella Kleb., Phytopath. Z. 1: 43 (1929)

Index Fungorum number: IF4197; 20 morphological species (Species Fungorum 2020), 14 species with sequence data.

Type species - Plectosphaerella cucumerina (Lindf.) W. Gams 
Notes - Plectosphaerella was introduced by Klebahn in 1929 (Palm et al. 1995). The type species is Plectosphaerella cucumerina, a holomorphic fungus (Zare et al. 2007, Carlucci et al. 2012). Plectosphaerella can be distinguished from other taxa by its asexual morph with the ratio of septate conidia, conidial shape and dimensions and presence or absence of chlamydospores (Carlucci et al. 2012).

Sayamraella Giraldo López \& Crous, Stud. Mycol. 92: 255 (2019)

Index Fungorum number: IF828047; 1 species with sequence data.

Type species - Sayamraella subulata Giraldo López \& Crous

Notes - Sayamraella was introduced as a monotypic genus for the isolates from soil based on analysis of a LSU, ITS, tefl and rpb2 dataset. The genus is characterized by conidiophores often proliferating sympodially and conidiogenous cells as short lateral and cylindrical asymmetrical projections. Conidiogenous cells have minute cylindrical collarettes and an inconspicuous periclinal thickening at the conidiogenous locus.

Sodiomyces A.A. Grum-Grzhim., Debets \& Bilanenko, Fungal Systematics and Evolution 3: 131 (2019)

Index Fungorum number: IF829354; 4 species with sequence data.

Type species - Sodiomyces alkalinus Grum-Grzhim., Debets \& Bilanenko

Notes - Sodiomyces was introduced by Grum-Grzhimaylo et al. (2013) to accommodate the holomorphic alkaliphilic species Heleococcum alkalinum based on the taxonomic reference and analyses of a combined ITS, LSU, SSU, rpb2 and tefl dataset. All Sodiomyces species were invalid as the basionym lacked a valid type species (Giraldo \& Crous 2019). Giraldo \& Crous (2019) and Crous et al. (2019b) redescribed, accepted and validated all Sodiomyces species. This genus is characterized by cleistothecial ascomata, saccate asci, ellipsoidal or ovoid 2-celled and pale brown ascospores and subglobose, cylindrical to oval or allantoid conidia (Grum-Grzhimaylo et al. 2013; Giraldo \& Crous 2019).

Stachylidium Link, Mag. Gesell. naturf. Freunde, Berlin 3(1-2): 15 (1809)

Index Fungorum number: IF10053; 7 morphological species (Species Fungorum 2020), 2 species with sequence data.

Type species - Stachylidium bicolor Link

Notes - Stachylidium was introduced by Link (1809) without assigning a type specimen. Stachylidium bicolor was recognized as the type specimen (Hughes 1951b, Ellis 1971, Matsushima 1971, Barnett \& Hunter 1972, von Arx 1981b, Dewi 2006). The lectotype of the S. bicolor was designated by Hughes (1951b) and Gams (2017) based on the specimen under the name and synonym of S. bicolor (Hughes 1958, Giraldo \& Crous 2019). However, the lectotype designation was controversial (Fries 1832, Giraldo \& Crous 2019). Based on specimen examination from B and L, Giraldo \& Crous (2019) proposed the specimen with code B700016303 from B to be the most suitable lectotype. The genus is characterized by septate, verticillate conidiophores which are pale brown to brown at the base, sometimes pale to hyaline towards the apex, and roughened, singly or in groups, sometimes forming lax synnemata. Conidiogenous cells are enteroblastic, monophialidic, in whorls, terminal, lateral, cylindrical, ellipsoidal, hyaline or pale brown. Conidia are ellipsoidal or cylindrical, 1-celled and pale brown to brown.

Summerbellia Giraldo López \& Crous, Stud. Mycol. 92: 252 (2019)

Index Fungorum number: IF828043; 1 species with sequence data.

Type species - Summerbellia oligotrophica Giraldo López \& Crous

Notes - Summerbellia was established by Giraldo \& Crous (2019) with Summerbellia oligotrophica as the type species. It was introduced as the monotypic genus for a group of isolates, which clustered as a monophyletic lineage in the analyses of a combined LSU, ITS, tefl and rpb2- 


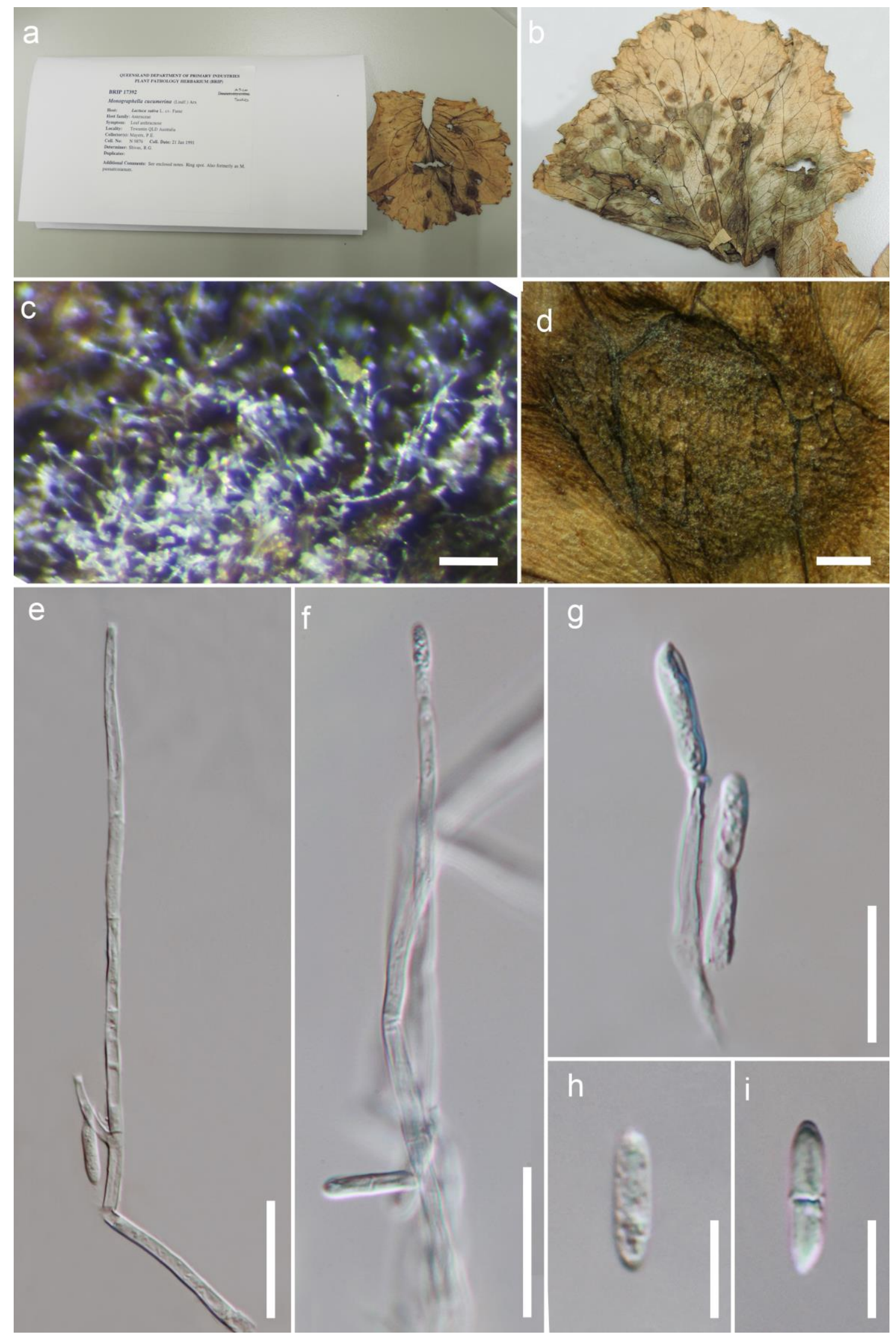

Figure 201 - Plectosphaerella cucumerina (Material examined - AUSTRALIA, Queensland, Tewantin, on the leaf of Lactuca sativa, 22 January 1991, Mayers, P.E., BRIP 17392, = Monographella cucumerina). a Herbarium material. b Host. c Colony on the host. d Appearance of colonies on leaf surface. e, f Conidiophores. g Conidiogenous cell. h, i Conidia. Scale bars: $\mathrm{c}=100$ $\mu \mathrm{m}, \mathrm{d}=1 \mathrm{~mm}, \mathrm{e}, \mathrm{f}=25 \mu \mathrm{m}, \mathrm{g}=15 \mu \mathrm{m}, \mathrm{h}-\mathrm{i}=5 \mu \mathrm{m}$. 
-dataset and previously identified as Gliocladium cibotii. This genus is characterized by erect or (sub-)erect, unbranched or poorly branched conidiophores. Chlamydospores are terminal or intercalary, mostly in chains, pale to dark brown, smooth- and thick-walled (Giraldo \& Crous 2019).

Theobromium Giraldo López \& Crous, Stud. Mycol. 92: 256 (2019)

Index Fungorum number: IF828049; 1 species with sequence data.

Type species - Theobromium fuscum Giraldo López \& Crous

Notes - Theobromium was introduced by Giraldo \& Crous (2019) to accommodate a strain isolated from Theobroma sp. This genus is characterized by conidiophores often proliferating sympodially and conidiogenous cells with short lateral and cylindrical asymmetrical projections (Giraldo \& Crous 2019).

Verticillium Nees, Syst. Pilze (Würzburg): 57 (1816)

Index Fungorum number: IF10400; 81 morphological species (Species Fungorum 2020), 20 species with sequence data.

Type species - Verticillium dahliae Kleb.

Notes - Species of this genus are plant pathogens (Domsch et al. 2007). This genus is characterized by conidiophores arising from submerged hyphae or aerial mycelium, erect, mostly verticillate, septate, hyaline to subhyaline, sometimes turning brown at the base. Conidiogenous cells are enteroblastic, monophialidic, inserted in a mesotonous to acrotonous position, terminal, lateral, flask-shaped or aculeate, hyaline, with inconspicuous collarettes. Resting structures include pigmented resting mycelium, chlamydospores in short chains, and/or microsclerotia (Giraldo \& Crous 2019).

Pleurostomataceae Réblová, L. Mostert, W. Gams \& Crous, Stud. Mycol. 50: 540 (2004)

Index Fungorum number: IF500153 Facesoffungi number: FoF01136; 5 species.

Saprobic on wood or soil in terrestrial habitats, or in sewage or pathogen of humans causing subcutaneous phaeohyphomycosis. Sexual morph: Ascomata perithecial, black, gregarious or scattered, superficial, stipitate, globose to subglobose, coriaceous, smooth, without setae, papillate; papilla positioned laterally. Peridium composed of two to four layers, outer layer comprising brown cells of textura intricata or epidermoidea, thick, coriaceous; inner layer comprising hyaline cells of textura prismatica or angularis, thin, membranaceous; sometimes middle layers comprised of two types of cells, forming thin-walled and brown cells of textura epidermoidea to in the outer part, merging with thin-walled and dark brown cells of textura angularis in the inner part, thick, coriaceous. Paraphyses numerous, hyaline, filamentous, early deliquescing. Asci polysporous, unitunicate, reniform or oval, with short pedicel or sessile, apical ring lacking. Ascospores 2-3seriate, hyaline, oblong to allantoid, curved, aseptate, smooth-walled. Asexual morph: Mycelium composed of branched, septate, hyaline or brown hyphae. Conidiophores in vitro arising from aerial or submerged hyphae, hyaline, straight or flexuous, 0-2-septate, tuberculate or smoothwalled. Conidiogenous cells mono- or polyphialidic, cylindrical, hyaline, smooth-walled. Conidia aggregated in slimy droplets, hyaline, aseptate, oblong to allantoid, curved or straight, smooth, with or without guttules (adapted from Réblová et al. 2015b, Maharachchikumbura et al. 2015, 2016b).

Type genus - Pleurostoma Tul. \& C. Tul.

Notes - Pleurostomataceae was introduced by Réblová et al. (2004). The genus was placed in Calosphaeriales based on allantoid ascospores, ascogenous hyphae and other characteristics uniting members, as well analyses of SSU and LSU sequence data (Réblová et al. 2004). Berlese (1900) introduced Neoarcangelia with $N$. ootheca based on upright papillae on the ascomata. However, Barr (1985) maintained there were insufficient features to separate the species from Pleurostoma candollei and placed Neoarcangelia as the synonym of Pleurostoma (Höhnel 1918b, Barr 1985). Shear (1937) also reexamined Sphaeria ootheca, the basionym of $P$. ootheca from Virginia, and concluded the species was similar to P. candollei. Pleurostomophora was accepted as the asexual 
morph of Pleurostoma based on morphology and phylogenetic evidence (Réblová et al. 2004, Vijaykrishna et al. 2004, Najwa et al. 2012). However, only the life history of Pleurostoma ootheca has been experimentally verified and linked with Pleurostomophora ootheca. The asexual morph of $P$. candollei is undetermined, except for an illustration in the protologue showing a sporodochial conidiomata (Tulasne \& Tulasne 1863). Réblová et al. (2015b) and Maharachchikumbura et al. (2015) reported that Pleurostoma and Pleurostomophora are congeneric as both genera constitute a strongly supported monophyletic clade in Pleurostomataceae in a multi-gene phylogenetic analysis. Réblová et al. (2015b) proposed Pleurostoma as the correct name for the genus following the principle of priority.

\section{Ecological and economic significance of Pleurostomataceae}

Several members of Pleurostomataceae are pathogenic on plants or/and humans. Pleurostoma richardsiae has been isolated from wood, sewage and soil (Schol-Schwarz 1970) and in grafted unions of nursery vines and diseased vines (Halleen et al. 2003, Halleen \& Groenewald 2005, Carlucci et al. 2015) and also infects humans (de Hoog et al. 2000). Pleurostoma repens was associated with subcutaneous infections with granulomatous nodules in humans (Hironaga et al. 1989).

\section{Genus included in Pleurostomataceae}

Pleurostoma Tul. \& C. Tul., Select. fung. carpol. (Paris) 2: 247 (1863)

Index Fungorum number: IF4247; 5 morphological species (Species Fungorum 2020), 4 species with sequence data.

Type species - Pleurostoma candollei Tul. \& C. Tul.

Notes - Pleurostoma candollei is characterized by globose, black ascomata, with reniform to oblong asci and allantoid, aseptate ascospores (Tulasne \& Tulasne 1863, Réblová et al. 2015b, Maharachchikumbura et al. 2016b).

\section{Pleurotheciaceae Réblová \& Seifert, Persoonia 37: 63 (2015)}

Index Fungorum number: IF813229; Facesoffungi number: FoF05316; 85 species.

Saprobic on plant tissues of a variety of hosts. Sexual morph: Ascomata perithecial, immersed, semi-immersed or superficial, papillate or with a central rarely eccentric neck. Ostiole periphysate. Peridium leathery to fragile, carbonaceous, comprising two layers, outer layer comprising brown to dark brown cells, inner layer comprising hyaline to pale brown cells. Paraphyses abundant, sparsely branched, partially disintegrating, cylindrical. Asci 8-spored, unitunicate, cylindrical or cylindrical-clavate, short or long pedicellate, with a pronounced J-, apical ring. Ascospores overlapping or 1-3-seriate, hyaline or versicolorous with polar cells hyaline and middle cells brown, ellipsoidal to fusiform, transversely multi-septate, lacking a mucilaginous sheath or appendages. Asexual morph: Conidiomata present or absent, when present indeterminate synnemata or loose fascicles. Conidiophores macronematous or semi-macronematous, sometimes elongating percurrently. Conidiogenous cells holoblastic, conidial secession rhexolytic on short denticles or rachis on sympodially extending polyblastic conidiogenous cells, or schizolytic on monoblastic or solitary thallic conidiogenous cells. Conidia hyaline, sometimes with protracted maturation of the middle cells, which turn brown, or brown or versicolorous, septate or aseptate. (adapted from Réblová et al. 2016c).

Type genus - Pleurothecium Höhn.

Notes - Pleurotheciaceae was introduced by Réblová et al. (2016c) in Pleurotheciales. Ten genera, i.e. Adelosphaeria, Brachysporiella, Helicoon, Melanotrigonum, Phaeoisaria, Phragmocephala, Pleurotheciella, Pleurothecium, Sterigmatobotrys and Taeniolella, were included in this family (Réblová et al. 2016c). Maharachchikumbura et al. (2016b) accepted eleven genera in Pleurotheciaceae including Plagiascoma, which was placed in Fuscosporellales (Réblová et al. 2016c, Yang et al. 2016b, Wijayawardene et al. 2017a, 2018a). In addition, Monotosporella and Helicoon were considered as members of Savoryellaceae (Savoryellales) in Maharachchikumbura 
et al. (2016b), while they were confirmed in Pleurotheciaceae by Réblová et al. (2012, 2016c). Monotosporella was treated as a synonym of Brachysporiella by Ellis (1959). Hernández-Restrepo et al. (2017) considered the genera Brachysporiella and Monotosporella distinct with support of multi-locus phylogenetic analysis, and placed the genera in Kirschsteiniotheliales and Pleurotheciales, respectively. Wijayawardene et al. (2017a) placed Brachysporiella in Pleurotheciaceae and Monotosporella in Savoryellaceae, however, Wijayawardene et al. (2018a) transferred Brachysporiella to Kirschsteiniotheliales genera incertae sedis and retained Monotosporella in Savoryellaceae. Anapleurothecium was introduced by Hernández-Restrepo et al. (2017) and placed in Pleurotheciaceae. Plagiascoma was accepted in Pleurotheciaceae by Wijayawardene et al. (2017a, 2018a).
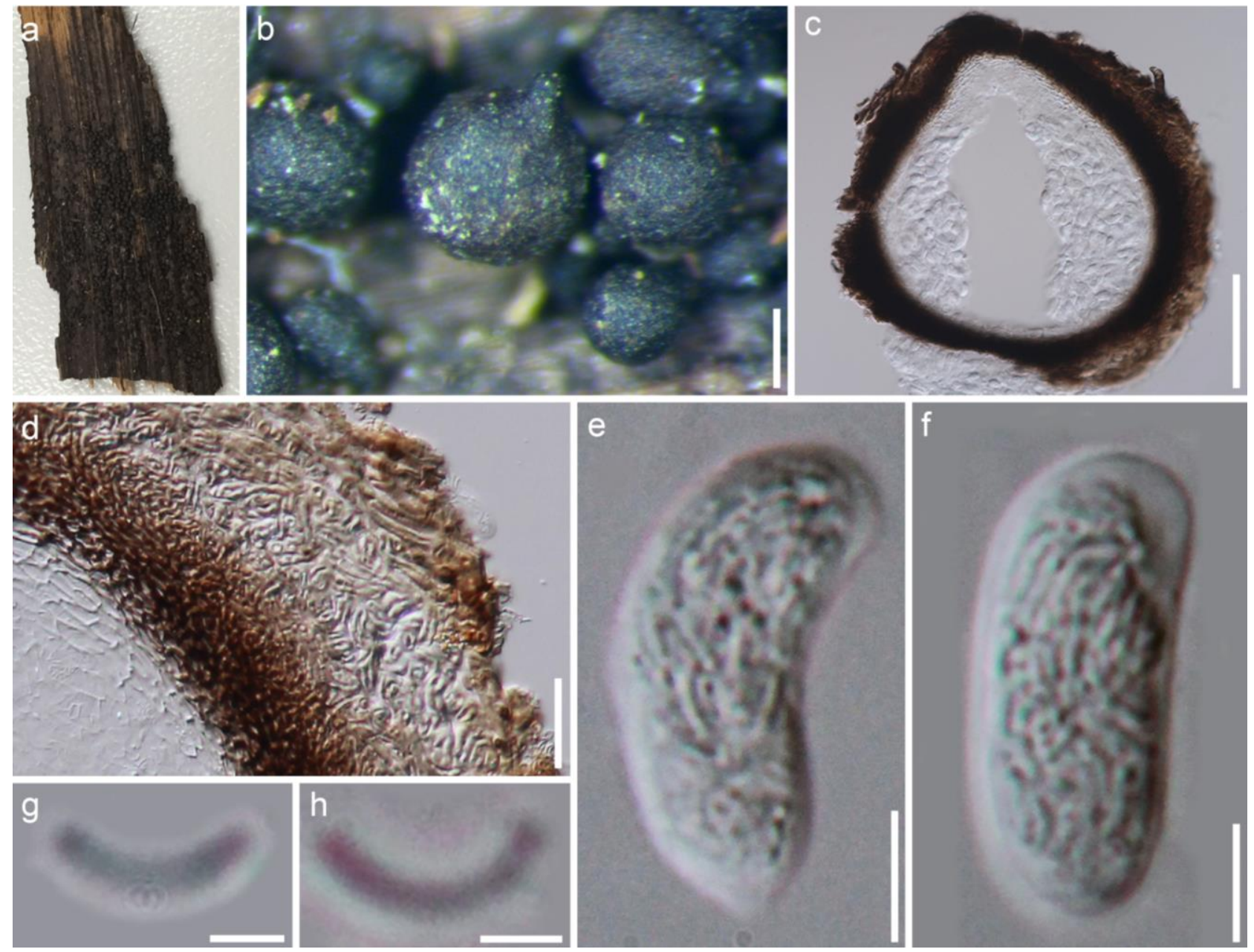

Figure 202 - Pleurostoma candollei (Material examined - FRANCE, Hauts-de-Seine, Chaville, on dead wood of Quercus sp., 8 March 1859, PC 0167640). a Material. b Ascomata on host. c Ascoma cross section. $d$ Peridium. e, f Asci. g, h Ascospores. Scale bars: $b=200 \mu \mathrm{m}, \mathrm{c}=100 \mu \mathrm{m}, \mathrm{d}=20$ $\mu \mathrm{m}, \mathrm{e}-\mathrm{f}=5 \mu \mathrm{m}, \mathrm{g}-\mathrm{h}=1 \mu \mathrm{m}$.

Taeniolella, based on T. rudis, was included in Pleurotheciaceae by Réblová et al. (2016c) as sister to Sterigmatobotrys. The fertile, penicillate sterigmatobotrys-like conidiophores developing at the apex of the Taeniolella conidium were earlier reported by Réblová \& Seifert (2011) suggesting a close relationship between the two genera. Ertz et al. (2016) transferred Taeniolella rudis to Sterigmatobotrys, based on the morphology of the penicillate synasexual morph and molecular data. The type species, Taeniolella exilis, was placed in Kirschsteiniotheliaceae in Dothideomycetes, and Taeniolella was recovered as strongly polyphyletic (Ertz et al. 2016). Wijayawardene et al. (2017a) placed in Kirschsteiniotheliaceae (Kirschsteiniotheliales, Dothideomycetes), however, Ekanayaka et al. (2017) transferred this genus to Mytilinidiaceae 
(Mytilinidiales, Dothideomycetes) and Wijayawardene et al. (2018a) accepted this treatment. In this study, we accept the treatment of Ertz et al. (2016) and excluded Taeniolella from Pleurotheciaceae.

It was shown that Helicoon is strongly polyphyletic. It was placed in three different classes, viz. Leotiomycetes, Sordariomycetes and Dothideomycetes (Tsui \& Berbee 2006). Helicoon farinosum was included in Pleurotheciaceae by Réblová et al. (2016c) and Maharachchikumbura et al. (2016b) based on the support of the multi-locus phylogenetic analyses. Wijayawardene et al. (2017a) placed this genus in Orbiliaceae (Orbiliales, Orbiliomycetes), however, Wijayawardene et al. (2018a) placed it in Savoryellaceae (Savoryellales, Sordariomycetes). Dayarathne et al. (2019a) introduced Helicoascotaiwania to accommodate Ascotaiwania hughesii (asexual morph is Helicoon farinosum) and placed this genus in Pleurotheciaceae.

Phragmocephala is polyphyletic (Su et al. 2015, Réblová et al. 2016b, Hernández-Restrepo et al. 2017). Currently, there are nine species epithets in Index Fungorum (2020), however, only three of them, $P$. garethjonesii, $P$. glanduliformis and P. stemphylioides, have molecular data available. Su et al. (2015) introduced $P$. garethjonesii based on DNA sequence data and morphology and placed this species in Melanommataceae in Dothideomycetes. Réblová et al. (2016c) placed $P$. stemphylioides in Pleurotheciaceae in Sordariomycetes based on multi-locus phylogenetic analyses. Phragmocephala glanduliformis was placed in Microthyriaceae in Dothideomycetes by HernándezRestrepo et al. (2017).

In this study, a multi-locus phylogenetic analyses based on a combined ITS, LSU, SSU and rpb2 sequence data of Pleurotheciales is presented (Fig. 10). Bayesian inference, maximum parsimony and maximum likelihood were used for phylogenetic analyses. The analyses provided similar tree topologies, which are similar with those in Réblová et al. (2016c), Yang et al. (2016b), Hernández-Restrepo et al. (2017), Hyde et al. (2017b, 2018b) and Luo et al. (2018). The problematic genera and species and the newly introduced genus after Réblová et al. (2016c), Phragmocephala stemphylioides (DAOM 673211), "Brachysporiella setosa" (HKUCC 3713) (current name: Monotosporella setosa), Anapleurothecium botulisporum (FMR 11490), "Taeniolella rudis" (DAOM 229838) (current name: Sterigmatobotrys rudis), Helicoon farinosum (current name: Helicoascotaiwania hughesii) (ILLS 53605 and DAOM 241947), are grouped in a robust clade Pleurotheciaceae (Fig. 10).

In conclusion, genera that accepted in the family in this study are: Adelosphaeria, Anapleurothecium, Helicoascotaiwania, Melanotrigonum, Monotosporella, Phaeoisaria, Phragmocephala, Pleurotheciella, Pleurothecium and Sterigmatobotrys.

\section{Ecological and economic significance of Pleurotheciaceae}

Some species of Pleurotheciaceae are human pathogens. A case of infectious keratitis caused by presumed Carpoligna pleurothecii (current name: Pleurothecium recurvatum) was reported by Chew et al. (2010). Taeniolella exilis was reported to infect humans and cause human subcutaneous phaeohyphomycosis (Réblová et al. 2016c). Other species are likely to be aquatic and terrestrial saprobes which are important in nutrient cycling.

\section{Genera included in Pleurotheciaceae}

Adelosphaeria Réblová, Persoonia 37: 63 (2016)

Index Fungorum number: IF813230; 1 species with sequence data.

Type species - Adelosphaeria catenata Réblová

Notes - This genus is similar to Pleurotheciella, however, its asexual morph is undetermined (Réblová et al. 2016c). The genus is characterised by perithecial, astromatic, subglobose, dark brown, papillate ascomata, periphysate ostioles, abundant, persistent, septate paraphyses, unitunicate, cylindrical-clavate, pedicellate, 8-spored asci with a $\mathrm{J}$-, apical ring, and ellipsoidal, slightly curved, hyaline, transversely septate ascospores (Réblová et al. 2016c).

Anapleurothecium Hern.-Restr., R.F. Castañeda \& Gené, Stud. Mycol. 86: 87 (2017) 
Index Fungorum number: IF820300; 1 species with sequence data.

Type species - Anapleurothecium botulisporum Hern.-Restr., R.F. Castañeda \& Gené

Notes - The genus is characterised by mononematous, unbranched, brown conidiophores, sympodial, denticulate, brown conidiogenous cells and solitary, acropleurogenous, septate, botuliform to cylindrical, brown conidia (Hernández-Restrepo et al. 2016a). It differs from other genera by its polyblastic, sympodial, denticulate, brown conidiogenous cells that produce septate, botuliform to cylindrical, brown conidia. Conidial secession is schizolytic.

Helicoascotaiwania Dayar., Maharachch. \& K.D. Hyde, Frontiers in Microbiology 10 (no. 840): 22 (2019)

Index Fungorum number: IF555625; 1 species with sequence data. Hyde

Type species - Helicoascotaiwania hughesii (Fallah, J.L. Crane \& Shearer) Dayar. \& K.D.

Notes - See the notes for Pleurotheciaceae. The genus is characterised by rarely branched, hyaline conidiophores, determinate, denticles conidiogenous cells and helicosporous hyaline conidia (Dayarathne et al. 2019a).

Melanotrigonum Réblová, Persoonia 37: 65 (2016)

Index Fungorum number: IF813232; 1 species with sequence data.

Type species - Melanotrigonum ovale Réblová

Notes - Melanotrigonum differs from Pleurotheciella by its triangular to ampulliform conidiogenous cells which taper towards the apex with a single or rarely two denticles (Réblová et al. 2016c).

Monotosporella S. Hughes, Can. J. Bot. 36: 786 (1958)

Index Fungorum number: IF8991; 4 morphological species (Species Fungorum 2020).

Type species - Monotosporella setosa (Berk. \& M.A. Curtis) S. Hughes

Notes - See the notes for Pleurotheciaceae. The genus is characterised by unbranched, brown conidiophores, monoblastic, percurrent, brown conidiogenous cells and septate, brown conidia (Seifert et al. 2011).

Phaeoisaria Höhn., Math.-naturw. Kl., Abt. 1 118: 330 (1909)

Index Fungorum number: IF9305; 23 morphological species (Species Fungorum 2020), 11 species with sequence data.

Type species - Phaeoisaria bambusae Höhn.

Notes - Phaeoisaria is characterized by indeterminate synnemata with septate or aseptate ellipsoidal, obovoidal, fusiform-cylindrical or falcate conidia.

Phragmocephala E.W. Mason \& S. Hughes, Naturalist (Hull), ser. 3, 1951: 97 (1951)

Index Fungorum number: IF9367; 9 morphological species (Species Fungorum 2020), 4 species with sequence data.

Type species - Phragmocephala cookei E.W. Mason \& S. Hughes

Notes - See the notes for Pleurotheciaceae. The genus is characterised by mononematous or synnematous, unbranched, brown, percurrent conidiophores, monoblastic or solitary thallic, brown conidiogenous cells and brown conidia with dark bands around septa (Seifert et al. 2011).

Pleurotheciella Réblová, Seifert \& J. Fourn., Mycologia 104(6): 1304 (2012)

Index Fungorum number: IF564282; 11 species with sequence data.

Type species - Pleurotheciella rivularia Réblová, Seifert \& J. Fourn.

Notes - Pleurotheciella was established by Réblová et al. (2012) with a dactylaria-like asexual morph. The genus is characterised by unbranched to sparingly branched, septate 
conidiophores, integrated, denticles conidiogenous cells and ellipsoidal to clavate, hyaline, 0several-septate (Réblová et al. 2012). Pleurotheciella fusiformis is illustrated in this entry.
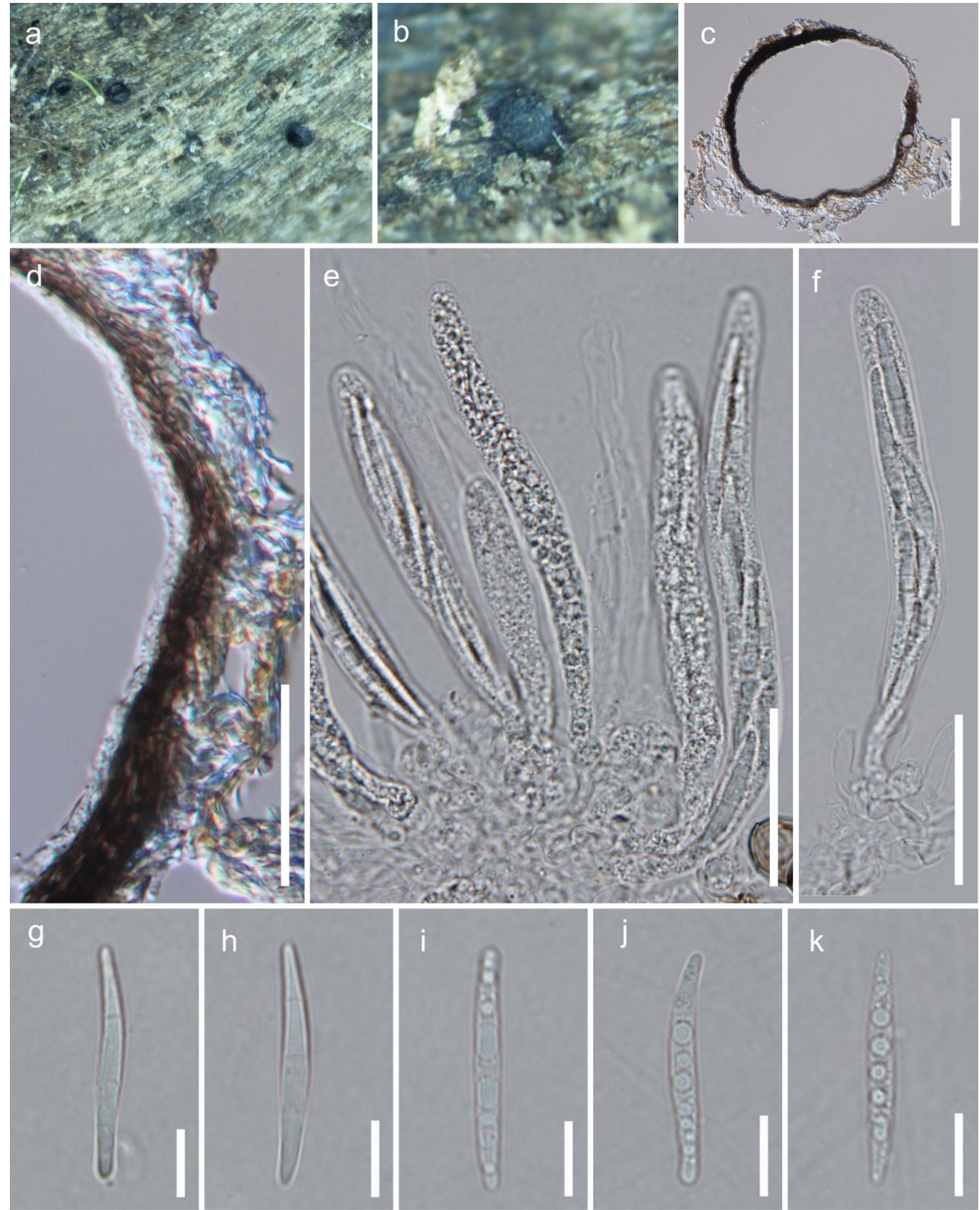

Figure 203 - Pleurotheciella fusiformis (Material examined - CHINA, Yunnan Province, saprobic on decaying wood submerged in Erhai Lake, March 2015, H.Y. Su 1EHS A 17-5, MFLU 17-0908, HKAS 92611; living culture, MFLUCC 17-0115, KUMCC 15-0196). a, b Ascomata on the natural substratum. c, d Vertical sections of the peridium. e, f Asci. g-k Ascospores. Scale bars: $\mathrm{c}=100$ $\mu \mathrm{m}, \mathrm{d}-\mathrm{f}=30 \mu \mathrm{m}, \mathrm{g}-\mathrm{k}=10 \mu \mathrm{m}$. 
Pleurothecium Höhn., Ber. dt. bot. Ges. 37: 154 (1919)

Index Fungorum number: IF9475; 11 morphological species (Species Fungorum 2020), 6 species with sequence data.

Type species - Pleurothecium recurvatum (Morgan) Höhn.

Notes - Pleurothecium was introduced by Höhnel (1919) to accommodate P. recurvatum (Morgan) Höhn (Goos 1969). Fernández et al. (1999) introduced a sexual genus Carpoligna and linked it to Pleurothecium. Réblová et al. (2016b) proposed using Pleurothecium rather than Carpoligna, because of its priority and greater number of species. Pleurothecium floriforme is illustrated in this entry.
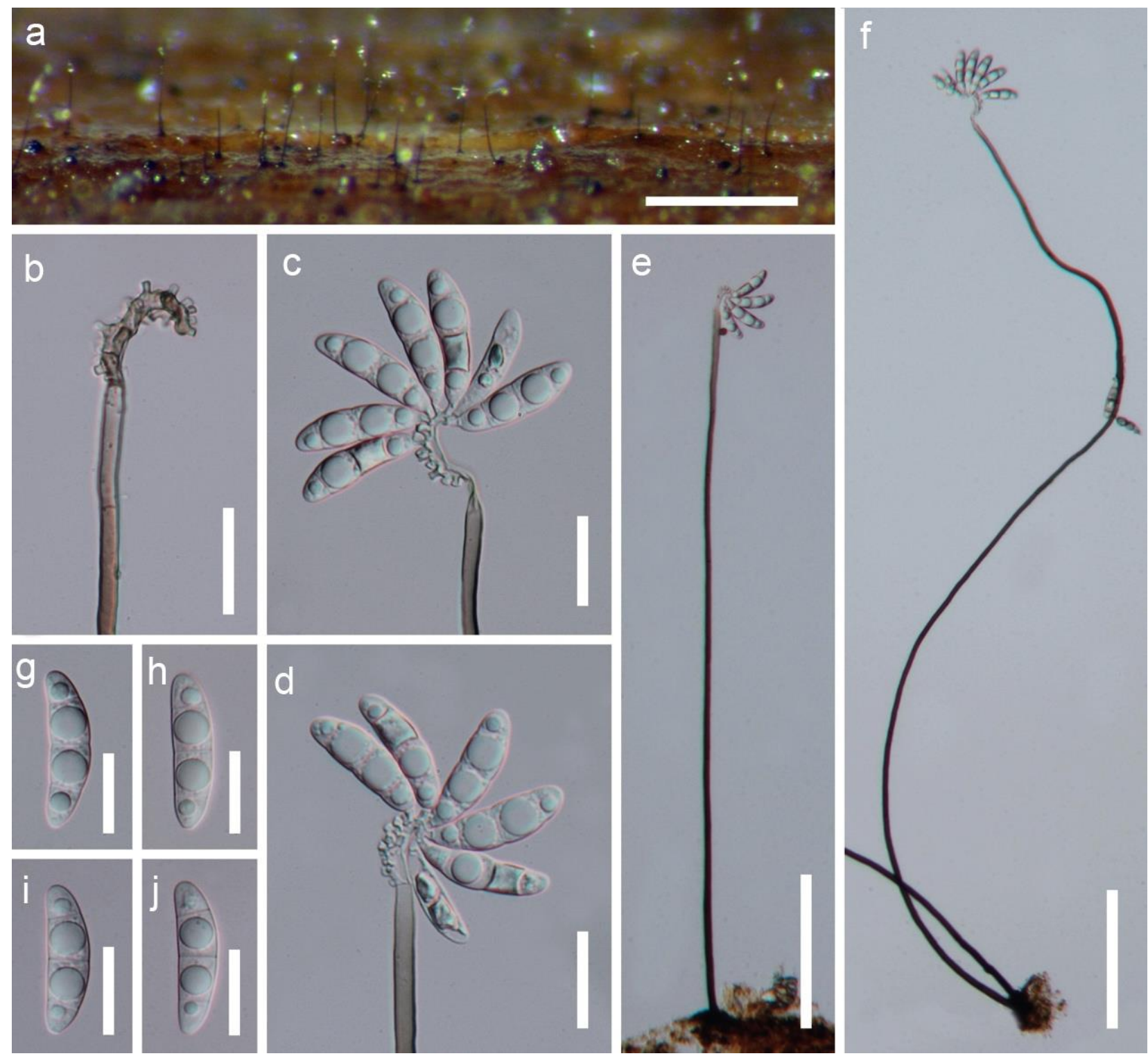

Figure 204 - Pleurothecium floriforme (Material examined - THAILAND, Prachuap Khiri Khan Province, on decaying wood submerged in a freshwater stream, 25 December 2014, Jaap van Strien, Site 5-2-1, MFLU 15-1163, holotype, GZAAS 17-0013, isotype), ex-type living cultures MFLUCC 15-0628, GZCC 15-0063). a Colonies on natural substrate. b Conidiogenous cells. c, d Conidiogenous cells with conidia. e, $\mathrm{f}$ Conidiophores with conidia. g-j Conidia. Scale bars: $a=500$ $\mu \mathrm{m}, \mathrm{b}-\mathrm{d}=20 \mu \mathrm{m}, \mathrm{e}, \mathrm{f}=100 \mu \mathrm{m}, \mathrm{g}-\mathrm{j}=15 \mu \mathrm{m}$.

Sterigmatobotrys Oudem., Ned. kruidk. Archf, 2 sér. 4: 548 (1886)

Index Fungorum number: IF10090; 4 morphological species (Species Fungorum 2020), 3 species with sequence data. 
Type species - Sterigmatobotrys elatus (Sacc.) Oudem.

Notes - The genus is characterised by penicillately branched, brown conidiophores, sympodial conidiogenous cells without scars or denticles and septate, hyaline or brown, slimy conidia (Seifert et al. 2011). It differs from other genera in the family by its penicillately branched conidiophores. Réblová \& Seifert (2011) reported that the sexual morph of S. macrocarpa is similar to species in Carpoligna and Chaetosphaeria.

Podosporaceae X. Wei Wang \& Houbraken, Stud. Mycol. (2019)

Index Fungorum number: IF829841; Facesoffungi number: FoF06877; 92 species.

Saprobic on dung. Sexual morph: Ascomata superficial to immersed in medium, solitary or loosely aggregated, ostiolate and ovoid to obpyriform, or lacking ostioles, globose to subglobose, glabrous or having hypha-like to seta-like hairs. Peridium membranaceous to coriaceous, usually opaque, in some species semi-translucent. Asci (2-)4- or 8- or multi-spored, unitunicate, cylindrical to elongated clavate or fusiform, pedicellate, with or without an apical thickened ring, evanescent or persistent until ascospores mature. Ascospores 1-2-seriate, 1-celled and pigmented, or 2-celled and composed of a larger, pigmented upper cell and a smaller, pale or hyaline cell, with or without appendage, usually smooth, in a few species ornamented. Asexual morph: Hyphomycetous. not observed or cladorrhinum-like: Conidiophores micronematous, reduced to conidiogenous cells. Conidiogenous cells intercalary or occasionally terminal, originating lateral or terminal peg-like structure with a flaring collarette, with blastic conidia. Conidia single-celled, hyaline, smooth, usually with a truncated base and a rounded apex (adapted from Wang et al. 2019a).

Type genus - Podospora Ces.

Notes - Podosporaceae was invalidly introduced by Hochberzanke (1930). The proposed Podosporaceae introduced by Wang et al. (2019a) is based on Podospora, but they are delimited based on morphology and DNA sequence data. Podosporaceae is sister to Chaetomiaceae in Sordariales and accommodates Podospora, Trangularia and Cladorrhinum, which were positioned in the polyphyletic family Lasiosphaeriaceae (Wang et al. 2019a). Based on the available sequences of Apiosordaria, we consider this genus should be placed in Podosporaceae (Fig. 23). However, Mouchacca \& Gams (1993) indicated that several Apiosordaria species have asexual morph connections with Cladorrhinum. Further work is required to determine the additional taxa in this family.

\section{Ecological and economic significance of Podosporaceae}

Members of Podosporaceae mostly grow on dung of herbivore as saprobes and some are endophytes (Cladorrhinum). Some Cladorrhinum species have activity against plant pathogenic fungi and have potential for industrial and biotechnological applications (Martin et al. 2019).

\section{Genera included in Podosporaceae}

Cladorrhinum Sacc. \& Marchal, Bull. Soc. Roy. Bot. Belgique 24: 64. (1885)

Index Fungorum number: IF7678; 11 morphological species (Species Fungorum 2020), 9 species with sequence data.

Type species - Cladorrhinum foecundissimum Sacc. \& Marchal

Notes - Cladorrhinum was introduced for asexually reproducing species in 1885 by Saccardo \& Marchal, and the sexual morphs have been linked to Apiosordaria and Cercophora (Mouchacca \& Gams 1993). The species with Cladorrhinum asexual morphs, Apiosordaria verruculosa, Cercophora samala, C. striata, and Podospora fimiseda, are phylogenetically closely related (Cai et al. 2006b). Two species from Thielavia (Th. hyalocarpa and Th. intermedia) were placed in Cladorrhinum based on their phylogenetic affinities with the type species of this genus. Therefore, this genus is re-defined to accommodate sexually producing species. Phylogenetic evidence indicated that the morphologically defined Cladorrhinum is polyphyletic (Carmarán et al. 2015). Based on the phylogenetic analysis (Wang et al. 2019a), Cladorrhinum bulbillosum and Clad. 
phialophoroides, belong to the redefined genera Podospora and Triangularia, respectively. Further work is needed to delimit the phylogenetic position of the Cladorrhinum species.

Cladorrhinum is found in soil as saprobes on dung or plant material (Lewis \& Larkin 1998, Madrid et al. 2011), or in roots as endophytes (Gasoni \& Stegman de Gurfinkel 1997). Also, $C$. foecundissimum and some species have activity against damping-off of the various crops caused by Rhizoctonia solani and Pythium ultimum (Domsch \& Gams 1968, Lewis \& Larkin 1998, Gasoni \& Gurfinkel 2009).

\section{Podospora Ces., Hedwigia 1(15): 103 (1856)}

Index Fungorum number: IF4284; 72 morphological species, 2 species with sequence data (Wang et al. 2019a).

Type species - Podospora fimiseda (Ces. \& De Not.) Niessl

Notes - Podospora is one of the most common of coprophilous ascomycetes genera worldwide, growing on herbivore dung (Doveri 2008b). Podospora is common in the temperate regions but is rare in the tropics (Lundqvist 1972). This genus has over 100 species epithets. The morphologically defined Podospora species are polyphyletic and distributed over at least 7 genericor higher-level clades based on rpb2 phylogeny in Wang et al. (2019a). Among the species in Wang et al. (2019a), based on the phylogenetic analysis, only the type species and P. bulbillosum are maintained in Podospora sensu stricto (Wang et al. 2019a). Further work is required to determine the additional taxa in the genus.

a
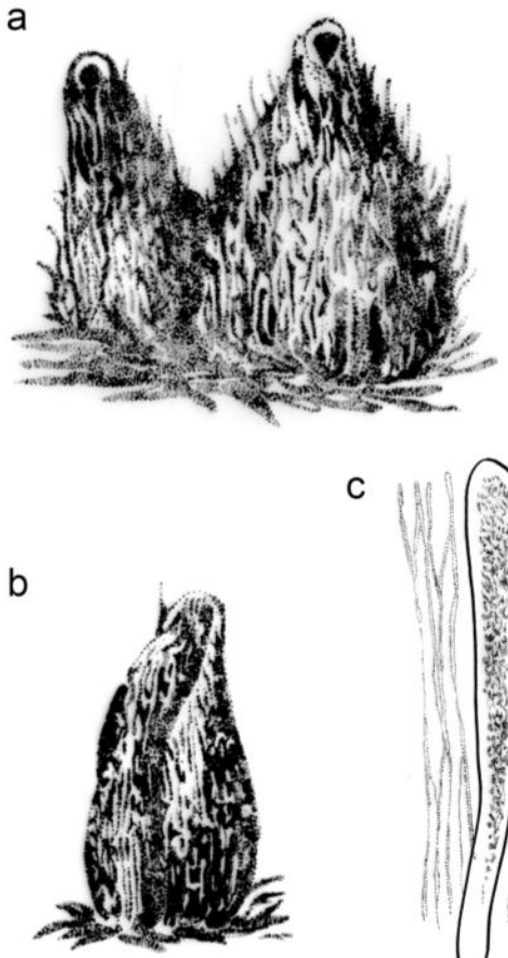

C

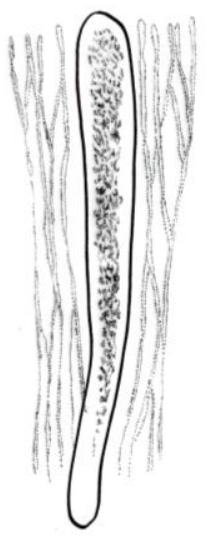

d

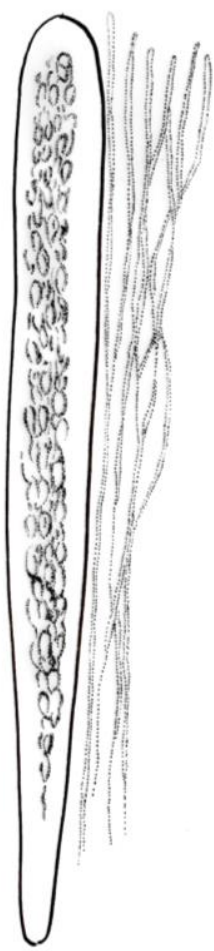

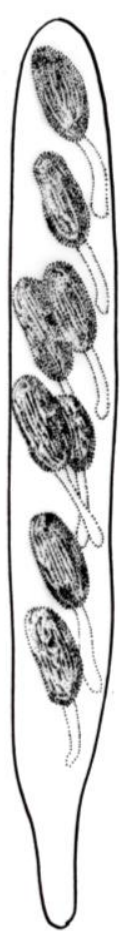

e
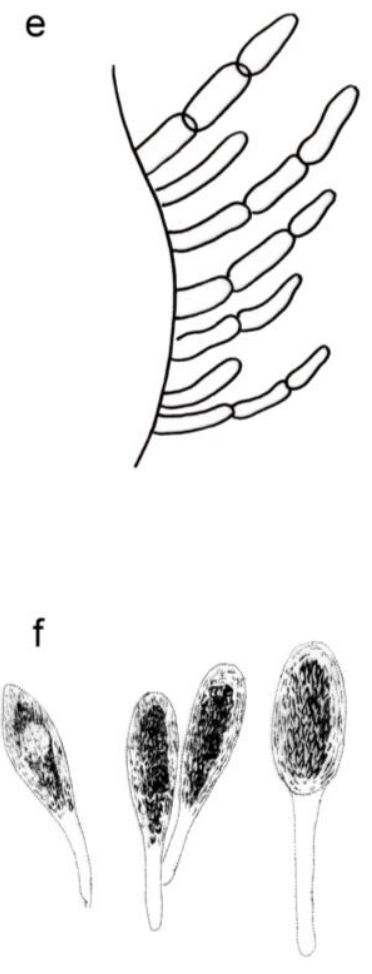

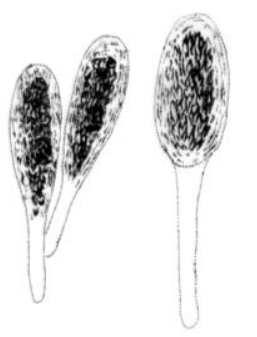

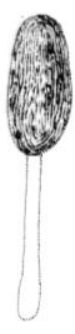

Figure 205 - Podospora fimiseda (redrawn from Cesati 1856). a, b Ascomata. c Immature ascus with paraphyses. d Asci. e Ascomal hairs. f Ascospores.

Triangularia Boedijn, Ann. Mycol. 32: 302 (1934)

Index Fungorum number: IF5534; 14 morphological species (Wang et al. 2019a), 9 species with sequence data.

Type species - Triangularia bambusae (J.F.H. Beyma) Boedijn

Notes - Triangularia was introduced by Boedijn and defined by cylindrical or clavate asci with a thickened apical ring and 2-celled smooth ascospores, with a larger, pigmented and conical 
to triangular upper cell and a smaller, paler or hyaline and triangular to hemisphaerical lower cell, without gelatinous appendages (Guarro \& Gene 1988). However, phylogenetic analysis in Wang et al. (2019a) did not support the morphologically defined genus concept of Triangularia. Therefore, this genus is re-defined which includes morphologically diverse species. Triangularia species are usually isolated from soil and plant debris and occasional from aquatic sediments, generally from warm places (Guarro \& Cano 1988).

Polystigmataceae Höhn., Nova Acta R. Soc. Scient. upsal., Ser. 4 8(no. 2): 51 (1932)

Index Fungorum number: IF81595; Facesoffungi number: FoF03518; 20 species.

Parasitic on deciduous living leaves and shoots of Rosaceae. Stromata typically developing in late spring and summer on living leaves, producing conidia in summer and autumn, and ascospores from fallen overwintered leaves the following spring, irregular, bright red or orange, surrounded apparently by healthy leaf tissue. Sexual morph: Ascostromata usually roughly circular and covering a large area of the leaf, significantly raising the adaxial surface of the leaf, reddishbrown to black, the ostioles occasionally conspicuous. Ascomata sphaerical, immersed, distinct walls, thin-walled. Paraphyses thinly dispersed, gradually tapering towards the apex, very thinwalled, strongly inflated between the septa. Asci 8-spored, unitunicate, clavate, long-pedicellate, thin-walled in every stage, the apex obtuse, with an apical ring. Ascospores biseriate, cylindrical to ellipsoidal or obovoid, occasionally slightly curved (fabiform), hyaline, aseptate, with or without gelatinous sheath. Asexual morph: Conidial stromata irregular, yellowish-brown in very young lesions, changing to orange to reddish-brown to black on maturity, occasionally causing small creases on the leaves but without apparent significant hypertrophic lesion, composed of an upper layer of epidermal cells filled with bright orange-brown material, a middle layer of hyaline fungal cells which are angular to vertically elongated, and the lower layer resembling the upper one. Conidiomata sphaerical, epigenous or hologenous, the ostiole unnoticeable and whose quantity corresponds to the number of conidiomata, papillate or apapillate. Conidiomatal wall poorly developed and not clearly distinguishable, composed of thin layer of small hyaline thick-walled textura angularis. Conidiogenous cells nearly cylindrical, narrowing towards the upper region, which appears somewhat irregular as a result of successive conidial scars, undergoing sympodial proliferation, spreading the entire conidiomatal wall inner surface, emerging as lateral or terminal branches from short and relatively undifferentiated conidiophores. Conidia hyaline, aseptate, apparently smooth-walled, widest nearly at the base which is lanceolate to fusiform and truncate, the upper part filiform, sigmoidally curved (adapted from Cannon 1996, Dayarathne et al. 2017).

Type genus - Polystigma DC.

Notes - Polystigmataceae was earlier considered a synonym of Phyllachoraceae and, consequently, all taxa belonging to Phyllachoraceae were accommodated in Polystigmataceae (Dennis 1968, Müller \& von Arx 1973). Polystigmataceae was later raised to Polystigmatales (syn. Phyllachorales) and this order accommodated Phyllachoraceae as the sole family (Hawksworth et al. 1983, Mehrotra \& Aneja 1990). This led to all Polystigma species then being placed in Phyllachoraceae (Hawksworth et al. 1983, Mehrotra \& Aneja 1990). Phylogenetic analyses involving DNA sequence data for Polystigma amygdalinumis, however, showed that Polystigma grouped in the subclass Xylariomycetidae, where it diverged from the Xylariales around 90 Million years ago in the late Cretaceous (Habibi et al. 2015, Habibi \& Banihashemi 2017). Therefore, it cannot be accommodated in Phyllachorales (Sordariomycetidae) (Habibi et al. 2015, Habibi \& Banihashemi 2017). Phylogenetic analyses by Dayarathne et al. (2017) confirm that taxa of Polystigma are phylogenetically distant from the Phyllachorales, and belong to Xylariales. They have thus re-established Polystigmataceae in the subclass Xylariomycetidae (Dayarathne et al. 2017).

\section{Ecological and economic significance of Polystigmataceae}

Several species of Polystigma are foliicolous parasites on Prunus species (Suzuki et al. 2008). Polystigma amygdalinum is often responsible for red blotch of almonds, while $P$. rubrum causes 
red leaf spot of plum (Habibi et al. 2015). Borovinova (2001) observed that, among the 16 plum cultivars in the Institute of Agriculture in Kyustendil, Bulgaria (during the period 1997-1999), the cultivars 'Green gage' and 'Cacanska najbolja' were most susceptible to infection from $P$. rubrum, while cultivars 'Lyubimtsa Hramova', 'Ashatan', 'Sofia-2', 'Gilej', 'Strinava' and 'Stanley plum' were the least affected (Borovinova 2001).

\section{Genus included in Polystigmataceae}

Polystigma DC., Fl. franç., Edn 3 (Paris) 5/6: 164 (1815)

Index Fungorum number: IF4324; 20 morphological species (Species Fungorum 2020), 3 species with sequence data.

Type species - Polystigma rubrum (Pers.) DC.

Notes - Polystigma is the type genus of Polystigmataceae, established by Lamarck \& de Candolle (1815). It is a small genus, parasitic mainly to Prunus, with almost all of the species reported with both asexual and sexual morphs (Cannon 1996). The generic name of Polystigma has been recommended for use instead of the usually associated additional names, Polystigmina and Rhodoseptoria, since it contains a greater number of species. Five taxa of Polystigmina are already synonyms of Polystigma rubrum while the type species of Rhodoseptoria is synonym of Polystigma rubrum (Réblová et al. 2016b). Suzuki et al. (2008) reported Polystigmina pallescens as the asexual state of Polystigma fulvum.

Prosopidicolaceae Senan. \& K.D. Hyde, Stud. Mycol. 86: 281 (2017) Index Fungorum number: IF821565; Facesoffungi number: FoF03502; 2 species.

Pathogenic on species of Fabaceae. Sexual morph: Undetermined. Asexual morph: Coelomycetous. Conidiomata pycnidial, rarely acervular, solitary or aggregated in a eustromatic stroma with one to several ostioles or astromatic, grey to black, erumpent to immersed. Peridium comprising grey-brown cells of textura angularis. Conidiophores reduced to conidiogenous cells or lining the whole inner layer of the wall, subcylindrical, branched, septate, straight to irregularly curved, base pale brown, becoming medium green-brown at apex. Conidiogenous cells mono- to polyphialidic, tightly aggregated, hyaline, smooth, ampulliform, subcylindrical to lageniform, prominent periclinal thickening, at times with percurrent proliferation. Conidia solitary, subhyaline to grey-brown, smooth, guttulate, straight to variously curved, ellipsoid to fusoid-ellipsoid, apex obtuse, base truncate to bluntly round (adapted from Senanayake et al. 2017a).

Type genus - Prosopidicola Crous \& C.L. Lennox

Notes - Prosopidicolaceae was introduced by Senanayake et al. (2017a) for Prosopidicola species. The sexual morph has not been reported for this family and it is distinct from other families of Diaporthales in having pycnidial, rarely acervular, eustromatic conidiomata with one to several ostioles, mono- to polyphialidic, ampulliform, subcylindrical to lageniform conidiogenous cells with periclinal thickening and subhyaline to brown, ellipsoid to fusoid-ellipsoid conidia.

\section{Ecological and economic significance of Prosopidicolaceae}

Prosopidicola mexicana is the causative agent of pod disease of Prosopis glandulosa in Mexico and the USA (Lennox et al. 2004). Prosopidicola albizziae causes stem cankers on Albizzia falcataria and has been reported from leaves of Albizzia (Crous et al. 2016b).

\section{Genus included in Prosopidicolaceae}

Prosopidicola Crous \& C.L. Lennox, Stud. Mycol. 50(1): 187 (2004)

Index Fungorum number: IF500048; 2 species with sequence data.

Type species - Prosopidicola mexicana Crous \& C.L. Lennox

Notes - Prosopidicola albizziae is the second species of this genus (Lennox et al. 2004, Crous et al. 2016b). Prosopidicola mexicana forms pod disease of Prosopis glandulosa and it has been proposed as a biocontrol agent (Lennox et al. 2004). 


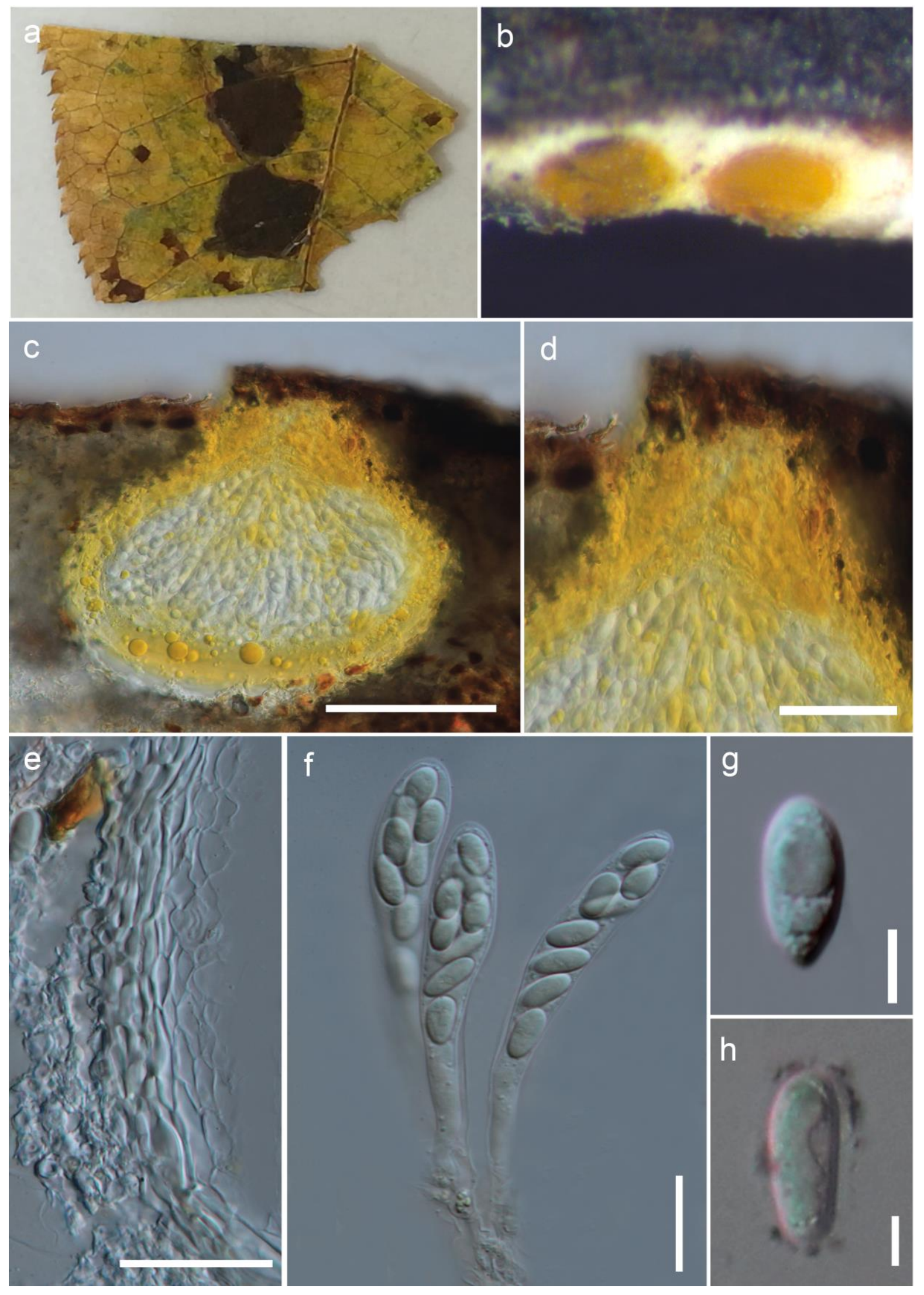

Figure 206 - Polystigma fulvum (Material examined - BELARUS, Minsk region, Maladzyechna District, Sychevichi Village, near children's health camp "Brigantina", deciduous forest on Prunus padus (Rosaceae), 15 Oct. 2017, A.K. Khramtsov T-2083, MFLU 18-0261). a Swollen leaf spots on Prunus padus L. b Close-up of ascomata. c Vertical section through ascoma. d Close-up of inconspicuous ostiole. e Peridium of ascoma. f Asci. g Ascospore. h Faint sheath around ascospore. Scale bars: $\mathrm{a}=200 \mu \mathrm{m}, \mathrm{c}=50 \mu \mathrm{m}, \mathrm{d}, \mathrm{f}=50 \mu \mathrm{m}, \mathrm{e}=20 \mu \mathrm{m}, \mathrm{g}, \mathrm{h}=5 \mu \mathrm{m}$. 


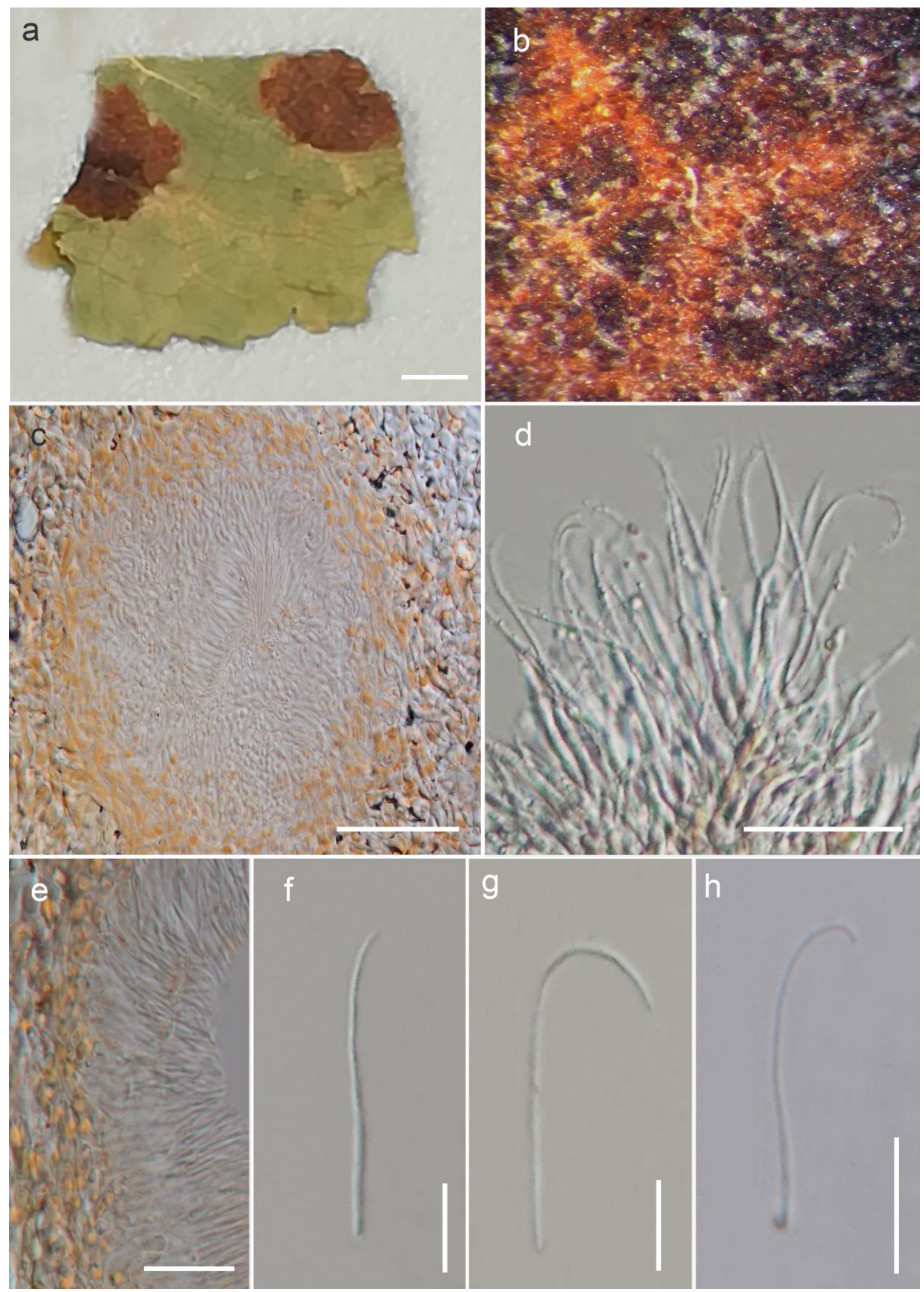

Figure 207 - Polystigma rubrum (Material examined - RUSSIA, Rostov region, Shakhty City, Cotton fabric microdistrict, torn shrubs near Grushevka river on Prunus stepposa Kotov., 9 October 2017, Timur S. Bulgakov, T-2093, MFLU 18-0271). a Swollen leaf spots on Prunus stepposa K. b Close-up of leaf spots. c Vertical section through conidioma. d Conidiogenous cells and developing conidia. e Conidiomatal wall. f-h Conidia. Scale bars: $\mathrm{a}=200 \mu \mathrm{m}, \mathrm{c}=50 \mu \mathrm{m}, \mathrm{d}-\mathrm{h}=10 \mu \mathrm{m}$. 


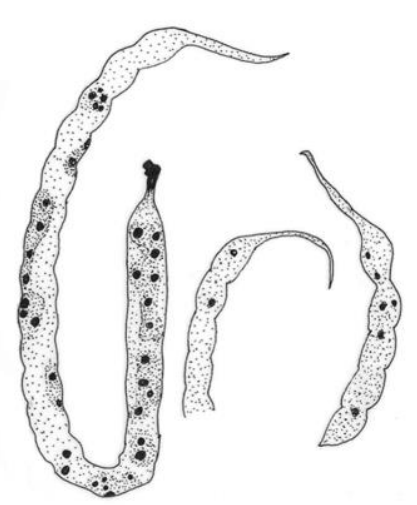

a

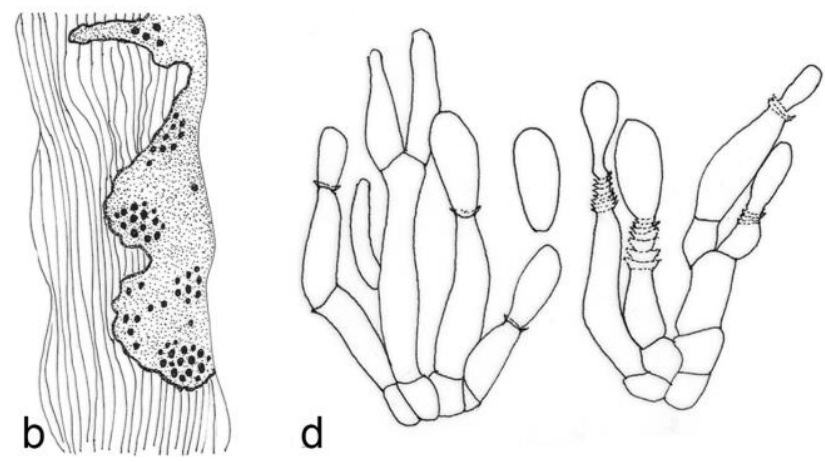

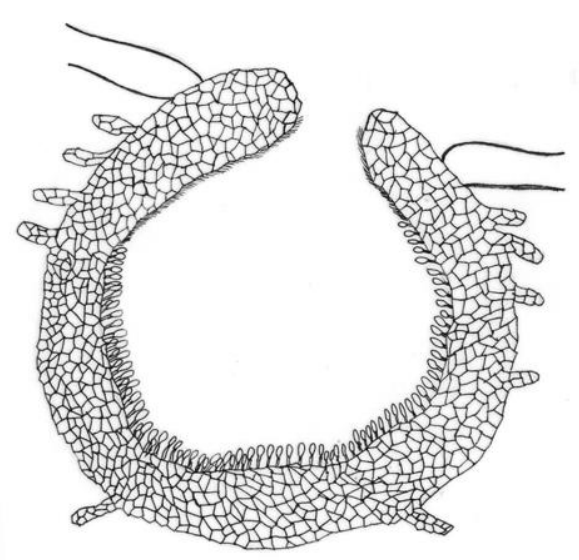

C

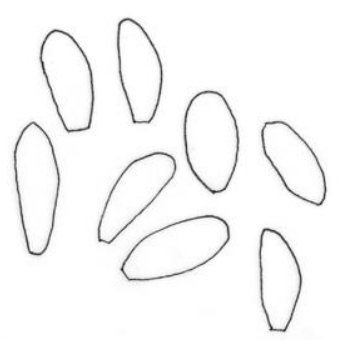

Figure 208 - Prosopidicola mexicana (redrawn from Lennox et al. 2004). a, b Disease symptoms associated with Prosopidicola mexicana on pods of Prosopis glandulosa. c Cross section of conidioma. d Conidiophores, conidiogenous cells and conidia. Scale bars: $10 \mu \mathrm{m}$.

Pseudodactylariaceae Crous, Persoonia 39: 421 (2017)

Index Fungorum number: IF823469; Facesoffungi number: FoF05318; 2 species.

Saprobic on plants. Sexual morph: Undetermined. Asexual morph: Conidiophores hyaline, subcylindrical, straight to flexuous, unbranched or branched, thick-walled, septate. Conidiogenous cells terminal, integrated, subcylindrical, denticulate. Conidia solitary, aggregating in slimy mass, fusoid-ellipsoid, hyaline, smooth-walled, guttulate, septate, surrounded by a thin mucilaginous sheath (adapted from Crous et al. 2017a).

Type genus - Pseudodactylaria Crous

Notes - A new order Pseudodactylariales and new family Pseudodactylariaceae were introduced by Crous et al. (2017a) to accommodate a single genus Pseudodactylaria. Pseudodactylariales and the new family Pseudodactylariaceae differs from other orders and families as Pseudodactylaria species have 1-septate conidia encased in a mucoid sheath (Crous et al. 2017a). Presently, one genus (Pseudodactylaria) with three species (P. brevis, P. hyalotunicata and $P$. xanthorrhoeae) are accepted in Pseudodactylariaceae (Crous et al. 2017a, Lin et al. 2018).

\section{Ecological and economic significance of Pseudodactylariaceae}

All of the three accepted species are saprobic and thus are important in nutrient recycling.

\section{Genus included in Pseudodactylariaceae}

Pseudodactylaria Crous, Persoonia 39: 421 (2017)

Index Fungorum number: IF823411; 2 species with sequence data.

Type species - Pseudodactylaria xanthorrhoeae Crous

Notes - Pseudodactylaria was introduced by Crous et al. (2017a) for two dactylaria-like species, $P$. hyalotunicata and $P$. xanthorrhoeae, in the subclass Sordariomycetidae and class 
Sordariomycetes (Fig. 22). The genus is characterised by distinct, single, hyaline, unbranched and septate conidiophores, terminal, integrated, polyblastic, denticulate conidiogenous cells and solitary, fusoid-ellipsoid, hyaline conidia (Lin et al. 2018). Pseudodactylaria brevis is illustrated below.
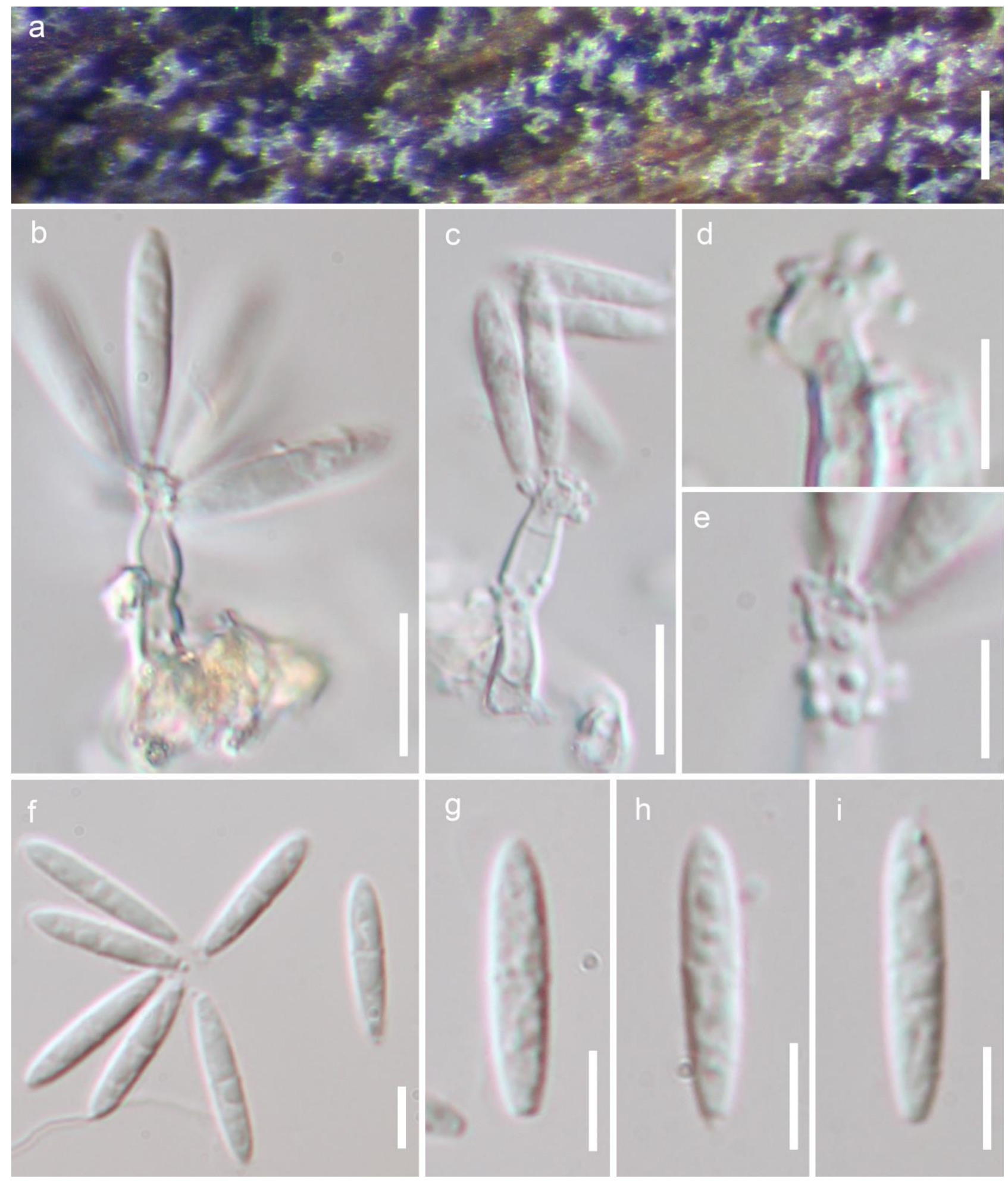

Figure 209 - Pseudodactylaria brevis (Material examined - THAILAND, Krabi, Wat Thum Sua, on decaying wood, 15 December 2015, S. Tibpromma M 1-5, MFLU 18-1038; HKAS 102202, paratype; living culture MFLUCC 16-0034). a Conidiophores on the host surface. b, c Conidiophores, conidiogenous cells with denticles and conidia. d, e Conidiogenous cells with denticles. f-i Conidia. Scale bars: $b, c=10 \mu \mathrm{m}, \mathrm{d}-\mathrm{i}=5 \mu \mathrm{m}$. 
Pseudohalonectriaceae Hongsanan \& K.D. Hyde, Fungal Divers. 84:33 (2017)

Index Fungorum number: IF553215; Facesoffungi number: FoF03355; 14 species.

Saprobic on wood and other plant material, commonly isolated in marine and terrestrial or freshwater habitats. Sexual morph: Ascomata erumpent to immerse with a protruding neck, cylindrical, periphysate necks, greenish yellow, bright yellow to brown. Neck conical, composed of parallel hyphae, outer hyphae outwardly directed, subglobose with enlarged ends, greenish yellow, periphysate. Peridium multi-layered. Paraphyses tapering towards the apex, thin-walled, attached to ascogenous hyphae. Asci 8-spored, unitunicate, cylindrical to clavate, with a J-, thimble-shaped, refractive apical ring. Ascospores overlapping uniseriate to biseriate, hyaline to slightly coloured and pale brown, pink/orange in mass in some species, cylindrical or ellipsoidal, straight to curved, usually multi-septate, constricted or not-constricted at the septa, smooth-walled. Asexual morph: Undetermined (adapted from Shearer \& Zare-Maivan 1988, Hyde et al. 1999b).

Type genus - Pseudohalonectria Minoura \& T. Muroi

Notes - Pseudohalonectriaceae was introduced in Magnaporthales by Hongsanan et al. (2017) and comprises a single genus. Pseudohalonectria was previously placed in Lasiosphaeriaceae, Sordariales supported by the preliminary phylogenetic analysis of SSU sequence data by Chen et al. (1999). Shearer et al. (1999) transferred Pseudohalonectria to Magnaporthaceae. Klaubauf et al. (2014) found that Pseudohalonectria clustered with species of Magnaporthaceae, Pyriculariaceae and Ophioceraceae in the Magnaporthales in their phylogenetic study of Pyriculariaceae. Similar results were obtained by Maharachchikumbura et al. (2015, 2016b), and they maintained Pseudohalonectria in Magnaporthales genera, incertae sedis.

\section{Ecological and economic significance of Pseudohalonectriaceae}

Most species of Pseudohalonectria have antagonistic activity against other fungi and bacteria. Asthana \& Shearer (1990) tested paired cultures on agar against representatives of Pseudohalonectria and showed that most tested species were strongly inhibited at a distance. Pseudohalonectria adversaria exhibited potent nematicidal activity against pine wood nematodes (Dong et al. 2004). Pseudohalonectria adversaria produce azaphilone compounds which are active against several pests, weeds, nematodes, bacteria and fungi (Dong et al. 2006). The azaphilone compounds can be developed as effective and alternative natural pest management products (Foremska et al. 1992, Park et al. 2005, Dong et al. 2006). Pseudohalonectria species also degrade lignocellulose and are involved in nutrient cycling.

\section{Genus included in Pseudohalonectriaceae}

Pseudohalonectria Minoura \& T. Muroi, Trans. Mycol. Soc. Japan 19(2): 132 (1978)

Index Fungorum number: IF4437; 14 morphological species (Species Fungorum 2020), 5 species with sequence data.

Type species - Pseudohalonectria lignicola Minoura \& T. Muroi

Notes - Pseudohalonectria was introduced to accommodate P. lignicola (Minoura \& Muroi 1978), without being assigned to an order or family (Minoura \& Muroi 1978). Hongsanan et al. (2017) reviewed this genus and established a new family Pseudohalonectriaceae to accommodate this genus in Magnaporthales. The genus is characterized by bright yellow to brown ascomata, with long cylindrical, periphysate necks; unitunicate, cylindrical to clavate asci, with a J-, thimbleshaped, refractive apical rings and cylindrical, hyaline to slightly pigmented, and usually septate ascospores (Shearer 1989). Members in Pseudohalonectria are found in marine and terrestrial or freshwater habitats (Perera et al. 2016a). In this study, Pseudohalonectria lutea is illustrated.

Pseudomassariaceae Senan., Maharachch. \& K.D. Hyde, Fungal Divers. 73: 132 (2015) Index Fungorum number: IF551208; Facesoffungi number: FoF00843; 42 species.

Saprobic on recently dead twigs attached to the trees, immersed below rounded, slightly elevated epidermis of the host. Sexual morph: Ascomata perithecial, scattered, solitary or- 


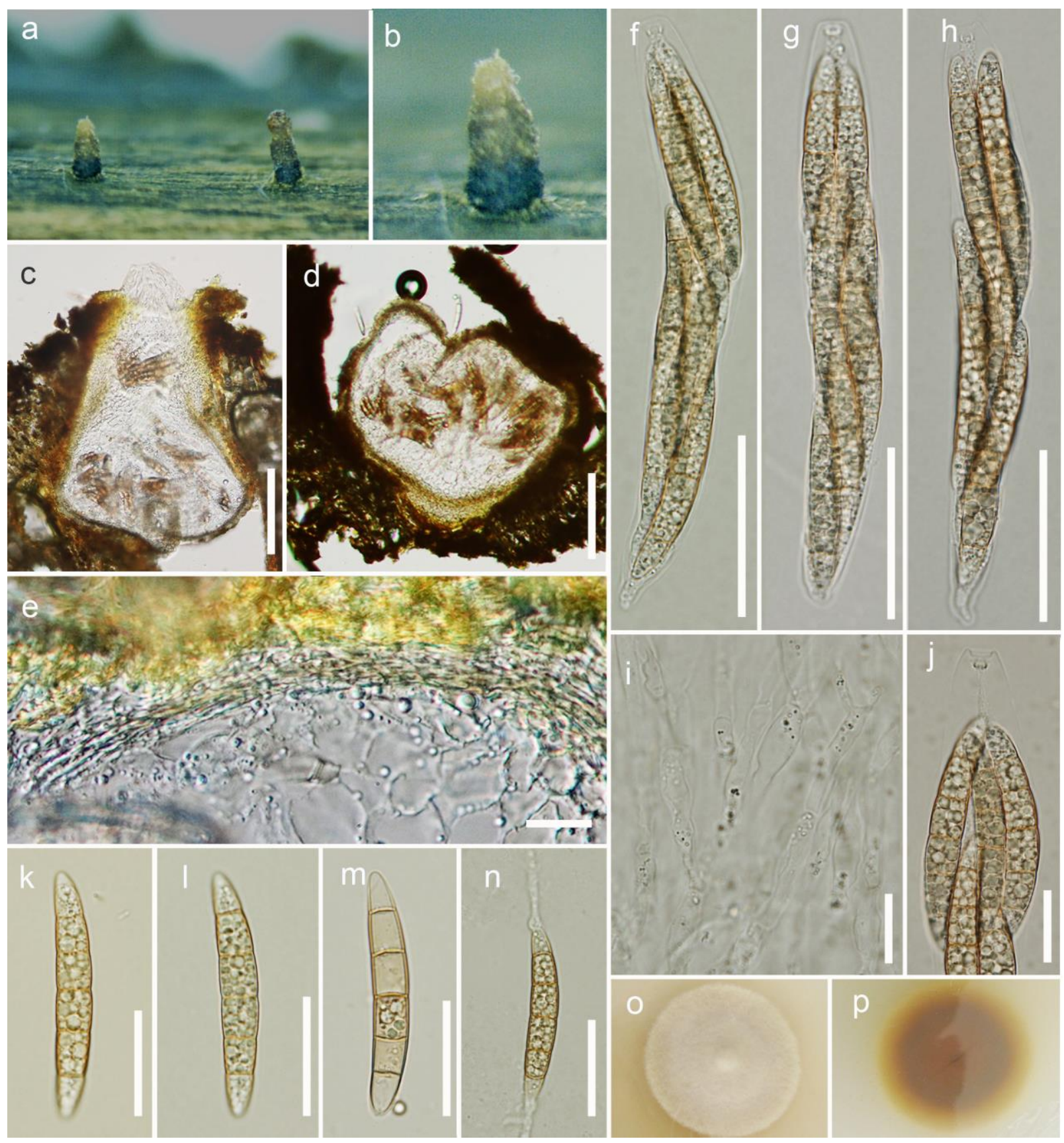

Figure 210 - Pseudohalonectria lutea (Material examined - CHINA, Tibet Autonomous Region, on submerged decaying wood, 28 April 2015, Z.L. Luo, XZ A 2-2-1, S-1048, MFLU 18-1463; living culture, MFLUCC 18-1297.). a, b Ascomata necks on decaying wood. c, d Sections of ascomata. e Peridium. f-h Asci. i Paraphyses. j Ascal apical ring in side view. k-m Ascospores. $n$ Germinating ascospore. $o, p$ Culture on PDA. Scale bars: $c, d=150 \mu \mathrm{m}, \mathrm{e}, \mathrm{i}, \mathrm{j}, \mathrm{n}=20 \mu \mathrm{m}, \mathrm{f}, \mathrm{g}=40$ $\mu \mathrm{m}, \mathrm{i}=45 \mu \mathrm{m}, \mathrm{k}-\mathrm{m}=25 \mu \mathrm{m}$.

-aggregated, immersed, depressed globose to ellipsoid, coriaceous, black, ostiolate, papillate. Ostiolar papilla short, cylindrical, wide at the apex, periphysate. Peridium comprising strongly compressed, narrow, light to medium brown, thin-walled cells of textura angularis. Paraphyses numerous, apically narrow, basally wide, hyaline. Asci 8-spored, unitunicate, easily disintegrated when fresh, clavate to fusoid, short pedicellate, apically rounded, with $\mathrm{J}_{+}$, or $\mathrm{J}_{-}$, apical ring. Ascospores biseriate or partially uniseriate, hyaline, broadly ellipsoid, oblong or narrowly clavate, mostly apiosporous, with a rounded to subconical, small, lower cell or equally uniseptate, straight or curved, thick-walled, smooth-walled. Asexual morph: Hyphomycetous. Setae erect, dark brown, straight to flexuous, arising from superficial hyphae, branched at base, subcylindrical, tapering to 
obtuse apex, 3-7-septate, basal cell slightly swollen. Conidiophores subcylindrical to setiform, with radially lobed basal cells, pale brown, smooth, arising from superficial mycelium, straight to flexuous, 1-10 septate. Conidiogenous cells terminal or lateral, polyblastic, subcylindrical to somewhat clavate, pale brown, smooth, with 1-4 denticulate loci. Conidia lageniform, distal end free, truncate, rostrate at proximal end, pale brown, with a subhyaline transverse band at equatorial zone, smooth, guttulate, aseptate (adapted from Senanayake et al. 2015, Jaklitsch et al. 2016b).

Type genus - Pseudomassaria Jacz.

Notes - Jaklitsch \& Voglmayr (2012) showed a separate taxonomic clade that included Pseudomassaria and Leiosphaerella through separate analyses of ITS and LSU sequence data. With emphasis on combined ITS-LSU analyses and morphological similarities the clade was introduced as a family Pseudomassariaceae in Senanayake et al. (2015). Maharachchikumbura et al. (2016b) accepted Pseudomassaria with apiosporous ascospores and Leiosphaerella with elongate, bi-celled ascospores. Jaklitsch et al. (2016b) treated Leiosphaerella, Pseudomassaria, Pseudapiospora and Pseudomassariella in Pseudomassariaceae. However, Pseudomassariella has been treated in this family with no phylogenetic support. Pseudomassariaceae commonly appears with Apiosporaceae, Beltraniaceae, Hyponectriaceae and Melogrammataceae clades in Amphisphaeriales in various phylogenetic placements (Senanayake et al. 2015, Konta et al. 2016, Maharachchikumbura et al. 2016b, Samarakoon et al. 2016, Hongsanan et al. 2017, Wijayawardene et al. 2018a). In this study, we accept Pseudomassariaceae in Amphisphaeriales comprising four genera as Leiosphaerella, Pseudomassaria, Pseudapiospora and Pseudomassariella. Only ITS and LSU sequences are available and revisions are required.

\section{Ecological and economic significance of Pseudomassariaceae}

Pseudomassariaceae species are common as saprobes on recently dead twigs and leaves or branches in terrestrial habitats (Barr 1964, Senanayake et al. 2015). The leaf-inhabiting species are commonly recorded in overwintered leaves and rarely as parasites on dead spots on leaves i.e. Pseudomassaria leucothoës has been reported in leaf spots of Leucothoё sp. (Barr 1964).

\section{Genera included in Pseudomassariaceae}

Leiosphaerella Höhn., Sber. Akad. Wiss. Wien, Math.-naturw. Kl., Abt. 1 128(7-8): 579 (1919)

Index Fungorum number: IF2717; 14 morphological species (Jaklitsch \& Voglmayr 2012), 3 species with sequence data.

Type species - Leiosphaerella praeclara (Rehm) Höhn.

Notes - Leiosphaerella species are characterized by immersed perithecial ascomata with apically free paraphyses, asci with $\mathrm{J}+$, apical rings, and elongate, bicelled, hyaline ascospores. Barr (1990b) treated the genus in Hyponectriaceae. Jaklitsch \& Voglmayr (2012) revisited the genus and placed it in Pseudomassariaceae.

Leiosphaerella praeclara is typified Leiosphaerella previously placed in Xylariales genera incertae sedis and are associated with Vaccinium species (Ericaceae). Jaklitsch \& Voglmayr (2012) provided an epitype with living culture and sequence data. Combined LSU-ITS phylogenetic analyses revealed that the Leiosphaerella belongs in Pseudomassariaceae (Senanayake et al. 2015, Jaklitsch et al. 2016b). Hyde (1993d) described the similar genera to Leiosphaerella with the shape of ascomata, asci, ascospores and $\mathrm{J}+\mathrm{J}-$ reactions of the apical ring. The genera Leiosphaerella, Marinospora and Oxydothis share similar characters of cylindic-clavate asci, J+, apical ring and 2celled ascospores (Hyde 1993d). However, Marinospora is only known from marine habitats and phylogenetically placed in Halosphaeriaceae (Sakayaroj et al. 2011), while Konta et al. (2016) introduced Oxydothidaceae to accommodate Oxydothis. Leiosphaerella praeclara is illustrated in this entry (Fig. 211).

Pseudapiospora Petr., Hedwigia 68: 233 (1928)

Index Fungorum number: IF4404; 3 morphological species (Jaklitsch \& Voglmayr 2012), 1 species with sequence data. 
Type species - Pseudapiospora corni (Sowerby) Petr.

Notes - Senanayake et al. (2015) treated P. corni under Pseudomassaria corni. However, Jaklitsch et al. (2016b) re-established Pseudapiospora corni, based on known host-specificity and septum characterization.
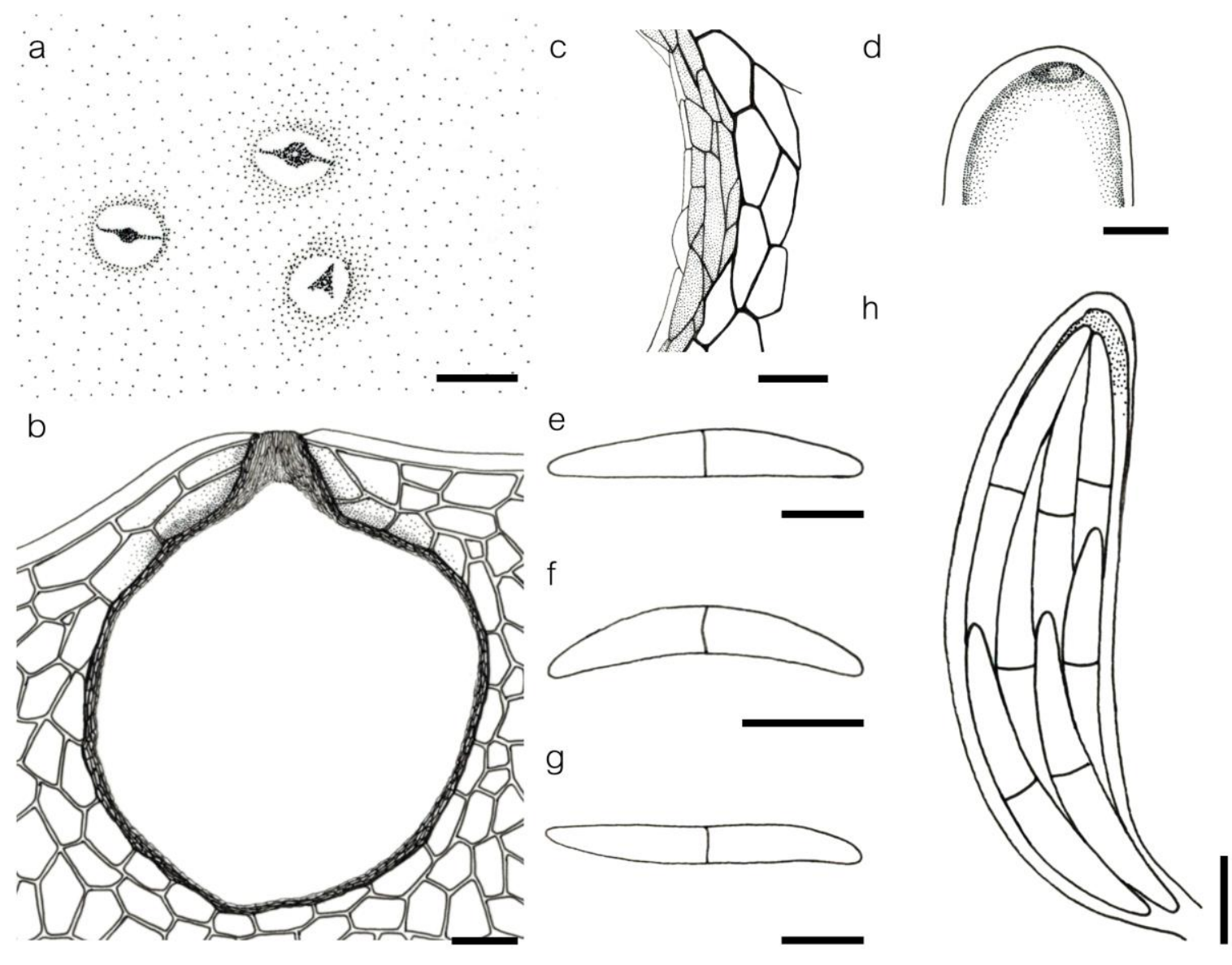

Figure 211 - Leiosphaerella praeclara (redrawn from Jaklitsch \& Voglmayr 2012). a Ostioles and perithecial dots on bark surface. $b$ Cross section of ascoma. c Peridium. d Apical ascus ring. e-g Ascospores. h Ascus. Scale bars: $\mathrm{a}=150 \mu \mathrm{m}, \mathrm{b}=300 \mu \mathrm{m}, \mathrm{c}=10 \mu \mathrm{m}, \mathrm{e}-\mathrm{h}=10 \mu \mathrm{m}$.

Pseudomassaria Jacz., Bull. Herb. Boissier 2: 663 (1894)

Index Fungorum number: IF4452; 24 morphological species (Species Fungorum 2020), 2 species with sequence data.

Type species - Pseudomassaria chondrospora (Ces.) Jacz.

Notes - Pseudomassaria was earlier accepted in Hyponectriaceae and Jaklitsch \& Voglmayr (2012) and Senanayake et al. (2015) showed the taxonomic placement of Pseudomassaria in Pseudomassariaceae.

Pseudomassariella Petr., Sydowia 9(1-6): 602 (1955)

Index Fungorum number: IF4453; 1 species with sequence data.

Type species - Pseudomassariella vexata (Sacc.) Petr.

Notes - Petrak (1955b) erected Pseudomassariella as closely related to Pseudomassaria with the type P. vexata. Müller \& von Arx (1962) transferred the species to Leiosphaerella. Jaklitsch et al. (2016b) provided taxonomic any phylogenetic revisions and provisionally accepted the genus in Pseudomassariaceae.

Pseudomelanconidaceae C.M. Tian \& X.L. Fan, Persoonia 40: 128 (2018)

Index Fungorum number: IF823991; Facesoffungi number: FoF04889; 2 species. 
Pathogenic forming cankers on trees. Sexual morph: Undetermined. Asexual morph: Coelomycetous, melanconium-like. Conidiophores acervular, hyaline to pale brown, aseptate, unbranched, cylindrical, smooth-walled. Conidiogenous cells annellidic, occasionally with distinct annellations and collarettes. Conidia hyaline to greyish sepia to olivaceous as it matures, ellipsoid to oblong, multiguttulate, aseptate, with distinct hyaline sheath, becoming inconspicuous when mature. Conidial wall smooth (adapted from Fan et al. 2018).

Type genus - Pseudomelanconis C.M. Tian \& X.L. Fan

Notes - Pseudomelanconidaceae shares similar characteristics to other families in Diaporthales having acervular conidiomata covered by a pustulate conidial mass on the bark surface, similar to Juglanconidaceae, Melanconiellaceae and Melanconidaceae (Fan et al. 2016, Voglmayr et al. 2017). However DNA sequence data confirmed them to represent a distinct phylogenetic lineage. Molecular investigations have revealed a remarkably high diversity of corticolous melanconium-like fungi in Diaporthales (Fan et al. 2016, Voglmayr et al. 2012, 2017), thus Fan et al. (2018) intrduced Pseudomelanconidaceae. In phylogenetic analysis of ITS, LSU, rpb2 and tef1 sequence data in Fan et al. (2018), Pseudomelanconis forms a distinct clade sister to Melanconiellaceae (Senanayake et al. 2018). Jiang et al. (2018) introduced a new genus Neopseudomelanconis in Pseudomelanconidaceae from dead branches of Castanea mollissima in China.

\section{Ecological and economic significance of Pseudomelanconidaceae}

Pseudomelanconis caryae causes branch canker and dieback of hickory trees, Carya cathayensis, a popular nut food tree species mainly distributed in southeastern China (Wu et al. 2014a, Fan et al. 2018).

\section{Genera included in Pseudomelanconidaceae}

Neopseudomelanconis C.M. Tian \& N. Jiang, Mycosphere 9: 1273 (2018)

Index Fungorum number: IF825183; 1 species with sequence data.

Type species - Neopseudomelanconis castaneae C.M. Tian \& N. Jiang

Notes - The genus was introduced to accommodate Neopseudomelanconis castaneae, a species on dead branches of Castanea mollissima in China (Jiang et al. 2018). The new genus was based on morphology and phylogenetic evidence of ITS and LSU genes (Jiang et al. 2018). Neopseudomelanconis was reported to have acervular conidiomata, cylindrical and hyaline conidiophores, conidiogenous cells with apical collaretes and discreet annellations, and ellipsoid to oblong, 2-celled, hyaline to brown mature conidia with a hyaline conidial sheath (Jiang et al. 2018).

Pseudomelanconis C.M. Tian \& X.L. Fan, Persoonia 40: 128 (2018)

Index Fungorum number: IF823992; 1 species with sequence data.

Type species - Pseudomelanconis caryae C.M. Tian \& X.L. Fan

Notes - The monospecific genus Pseudomelanconis has acervular conidiomata covered by pustulate conidial masses on the bark surface. This genus is significantly different from other taxa due to its distinct conidiogenous cells with apical collarettes showing discrete annellations. The conidial sheath becomes inconspicuous when mature (Fan et al. 2018).

Pseudoplagiostomataceae Cheew., M.J. Wingf. \& Crous, Fungal Divers. 44: 95 (2010) Index Fungorum number: IF542097; Facesoffungi number: FoF01403; 7 species.

Pathogen on leaves, forming spots. Sexual morph: Ascomata solitary, immersed, scattered, slanted to horizontal on host tissue, globose or ellipsoidal, black, coriaceous, papillate, ostiolate. Papilla short, internally covered with hyaline, periphyses. Peridium composed of few layers of brown, thick-walled cells of textura angularis. Paraphyses lacking. Asci 8-spored, unitunicate, apedicellate, cylindrical, with $\mathrm{J}-$, subapical ring. Ascospores overlapping uniseriate to biseriate, hyaline, fusiform to ellipsoid, 1-septate, with terminal, elongate, hyaline appendages. Asexual morph: Coelomycetous. Conidiomata brown, acervular or pycnidial. Peridium comprising small, 
brown cells of textura angularis. Conidiophores reduced to conidiogenous cells. Conidiogenous cells enteroblastic, cylindrical to ampulliform, percurrently proliferating with periclinal thickening and collarette. Conidia unicellular, ellipsoid, hyaline to brown, subglobose to broadlyallantoid, with obtuse apex and a flat protruding scar at the base (adapted from Cheewangkoon et al. 2010).

Type genus - Pseudoplagiostoma Cheew. Cheew., M.J. Wingf. \& Crous

Notes - Pseudoplagiostomataceae is distinct from other related families due to its unique morphology with ascomata slanted horizontally to the host with an aparaphysate hamathecium and ascospores with terminal, elongate, hyaline appendages. It has a distinct placement in Diaporthales based on the maximum parsimony analysis of LSU sequence data (Cheewangkoon et al. 2010). This placement was confirmed by the studies of Suwannarach et al. (2016), Du et al. (2017) and Phookamsak et al. (2019).

\section{Ecological and economic significance of Pseudoplagiostomataceae}

This monotypic family comprises foliar pathogens recorded from Eucalyptus and Mangifera and an endophyte on Dipterocarpus tuberculatus. This family produces leaf spot and shoot blight diseases which can become a problem for eucalyptus plantations, especially in the case of $P$. eucalypti (Lueangpraplut et al. 2013). Moreover, the species P. mangiferae is also associated with leaf blight of Mangifera sp. (Phookamsak et al. 2019).

\section{Genus included in Pseudoplagiostomataceae}

Pseudoplagiostoma Cheew., M.J. Wingf. \& Crous, Fungal Divers. 44: 96 (2010)

Index Fungorum number: IF516496; 7 species with sequence data.

Type species - Pseudoplagiostoma eucalypti Cheew., M.J. Wingf. \& Crous

Notes - Pseudoplagiostoma is a foliar pathogen of Eucalyptus with astromatic, slanted to horizontal, globose perithecia lacking paraphyses, with aseptate ascospores with terminal, elongate, hyaline appendages and a cryptosporiopsis-like asexual morph. Cryptosporiopsis eucalypti falls in Diaporthales in the phylogenetic analyses using combined gene analysis of ITS and tub2 gene sequence data which resolved the species in Pseudoplagiostoma (Cheewangkoon et al. 2010). A newly added species is $P$. dipterocarpi, an asexual endophyte isolated from the leaves of Dipterocarpus tuberculatus in Chiang Mai, Thailand (Suwannarach et al. 2016). The asexual morph of Pseudoplagiostoma mangiferae isolated from a living leaf of Mangifera in Yunnan, China was introduced by Phookamsak et al. (2019) based on the morphology and phylogenetic analyses of a combined ITS, LSU, tub2 and tefl dataset.

Pseudoproboscisporaceae H. Zhang, K.D. Hyde \& Maharachch., Fungal Divers. 85: 93 (2017)

Index Fungorum number: IF553760; Facesoffungi number: FoF03338; 5 species.

Saprobic on decaying wood and bamboo submerged in freshwater. Sexual morph: Ascomata scattered or solitary, immersed, with long or short neck, dark brown to black, ostiolate. Neck central or lateral, dark brown, erect or curve upwards. Peridium comprising several layers of compressed cells. Paraphyses hypha-like, septate, tapering. Asci 8-spored, unitunicate, cylindrical, pedicellate, with a relatively large, J-, apical ring. Ascospores uni- to tri-seriate, hyaline, fusiform, aseptate or septate, smooth or rugose, thin-walled, with bipolar filamentous appendages. Appendages initially coiled then unfurling to form long threads on release. Asexual morph: Undetermined (adapted from Zhang et al. 2017a).

Type genus - Pseudoproboscispora Punith.

Notes - Pseudoproboscisporaceae was introduced in a newly established order Atractosporales by Zhang et al. (2017a) based on phylogenetic and morphology and included two genera Diluviicola and Pseudoproboscispora. Cateractispora also clustered in Pseudoproboscisporaceae in the phylogenetic tree (Zhang et al. 2017a), however, it has not been validly published (Ranghoo et al. 1999). Zhang et al. (2017a) observed the photo-plate of $C$. 
recepticuli from the $\mathrm{PhD}$ thesis of Ranghoo (1998) and thought that Cateractispora was likely to be a synonym of Pseudoproboscispora.

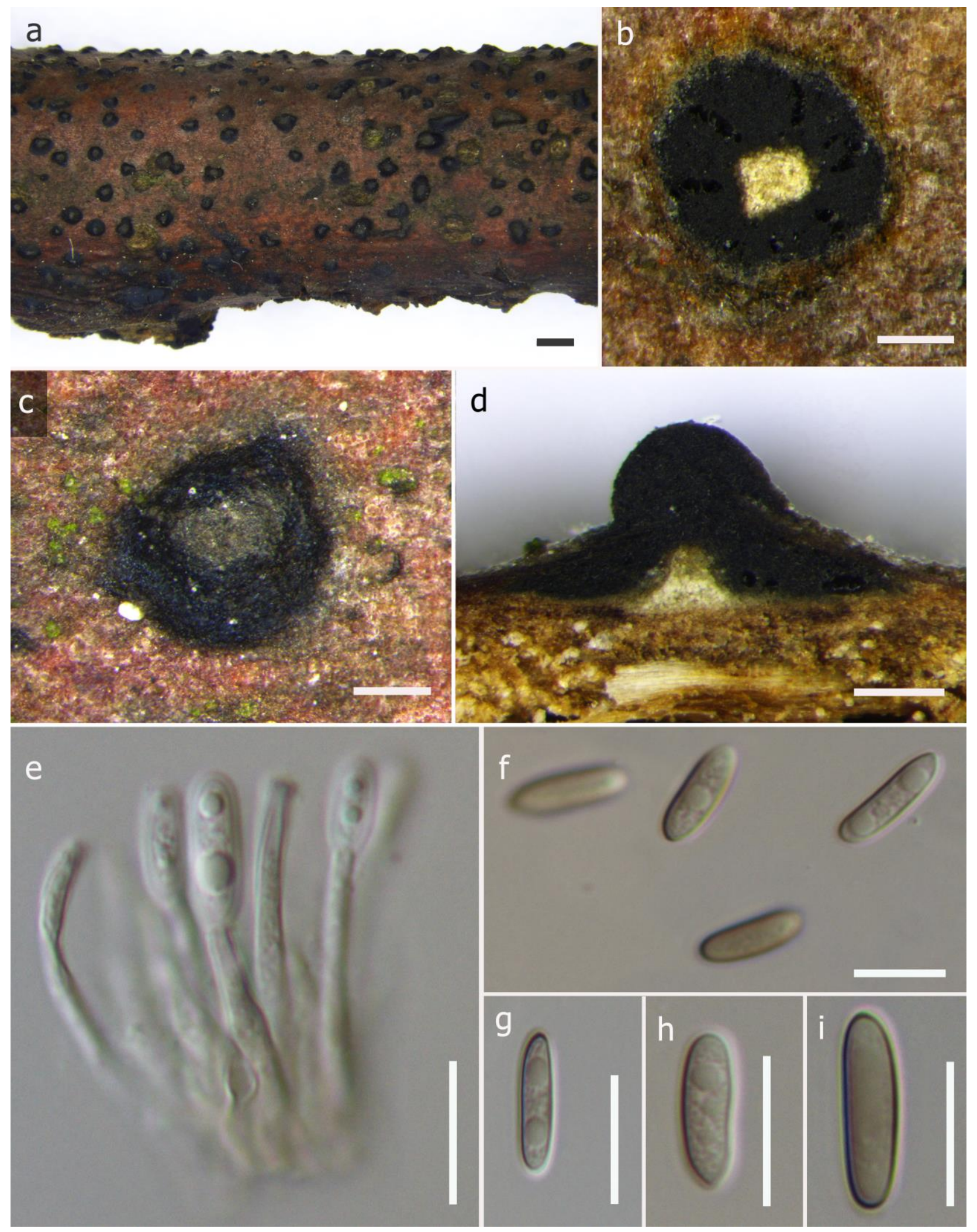

Figure 212 - Pseudomelanconis caryae (Material examined - CHINA, Zhejiang Province, Hangzhou City, Linan, Tianmu Mountain, N30 18'48.85" E119²6'36.99", $288 \mathrm{~m}$ asl, on twigs and branches of Carya cathayensis, 21 April 2017, Q. Yang \& Z. Du, CF 2017466, holotype). a Conidiomata in host. b-d Locules. e Conidiophores and conidiogenous cells. f-i Conidia. Scale bars: $\mathrm{a}=1 \mathrm{~mm}, \mathrm{~b}-\mathrm{d}=200 \mu \mathrm{m}, \mathrm{e}-\mathrm{h}=10 \mu \mathrm{m}$. 

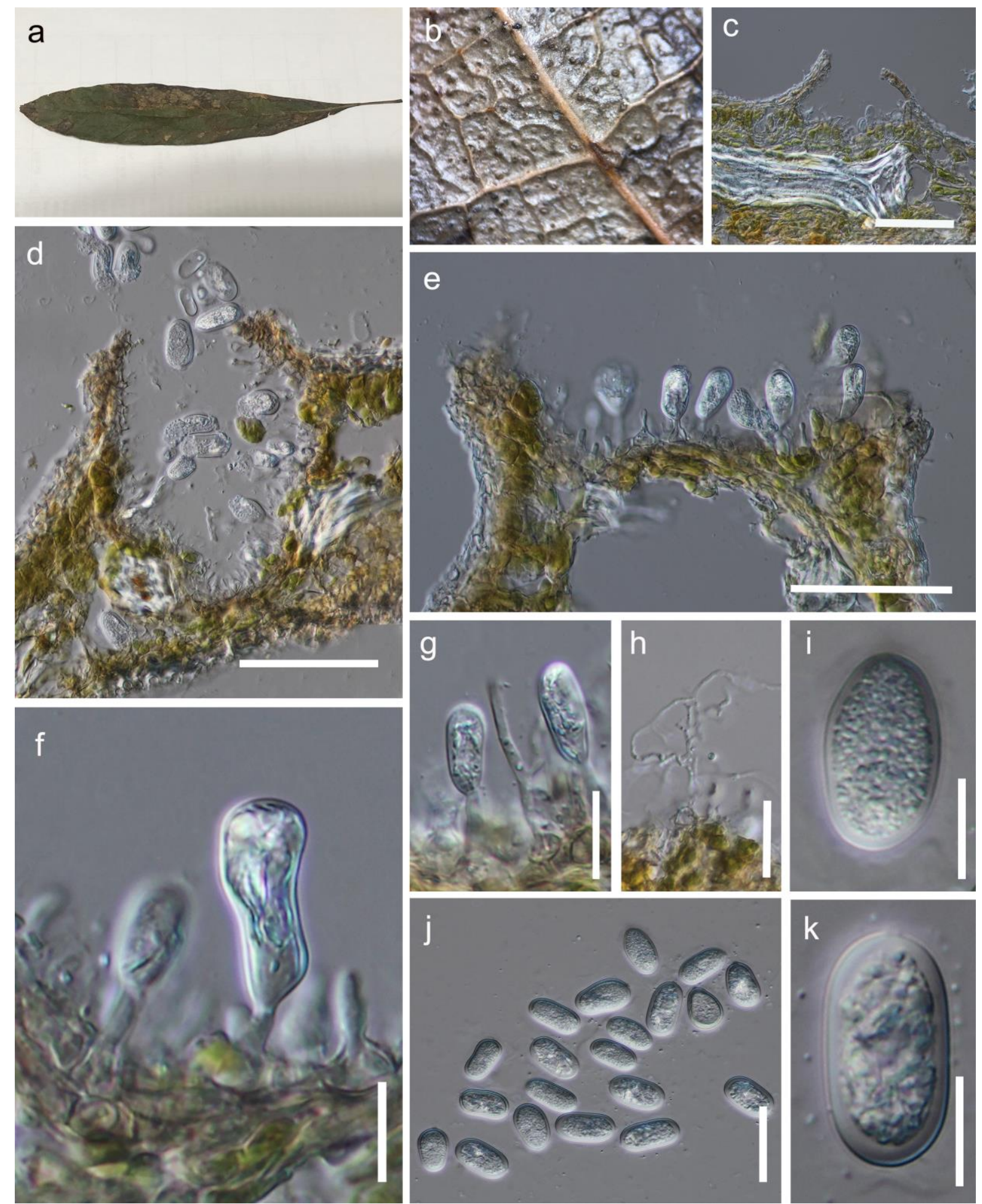

Figure 213 - Pseudoplagiostoma mangiferae (Material examined - CHINA, Yunnan Province, Xishuangbanna, Jinghong, Nabanhe, associated with leaf blight symtom on living leaf of Mangifera sp. (Anacardiaceae), 21 November 2015, R. Phookamsak, XB010, KUN-HKAS 102244, holotype). a Leaf blight symptom on living leaf of Mangifera sp. b Conidiomata on host surface. c, d Sections through conidiomata. e Conidioma wall and the base. $\mathrm{f}, \mathrm{g}$ Conidiogenous cells. h Paraphyses. i-k Conidia. Scale bars: $\mathrm{c}-\mathrm{e}=50 \mu \mathrm{m}, \mathrm{f}-\mathrm{h}=20 \mu \mathrm{m}, \mathrm{j}=25 \mu \mathrm{m}, \mathrm{i}, \mathrm{k}=10 \mu \mathrm{m}$.

\section{Ecological and economic significance of Pseudoproboscisporaceae}

Pseudoproboscisporaceae currently comprises three species, one of which is invalidly published (Ranghoo et al. 1999, Zhang et al. 2017a), isolated from decaying bamboo and are important decomposers of bamboo in freshwater and involved in nutrient recycling. 
Index Fungorum number: IF24138; 2 morphological species (Species Fungorum 2020), 1 species with sequence data.

Type species - Diluviicola capensis K.D. Hyde, S.W. Wong \& E.B.G. Jones

Notes - Diluviicola was introduced by Hyde et al. (1998b) to accommodate D. capensis from submerged wood in freshwater in Brunei. Diluviicola aquatica was introduced by Zhang et al. (2017a) from submerged bamboo in a small river in Thailand and considered to differ from the type species, D. capensis, in having subglobose or ellipsoidal ascomata with dark brown necks and mostly biseriate ascospores. Sequence data for D. capensis are not available.

\section{Pseudoproboscispora Punith., Kew Bull. 54(1): 234 (1999)}

Index Fungorum number: IF28391; 3 morphological species (Species Fungorum 2020), 2 species with sequence data.

Type species - Pseudoproboscispora aquatica (S.W. Wong \& K.D. Hyde) Punith.

Notes - Proboscispora was introduced by Wong \& Hyde (1999) to accommodate P. aquatica which was collected on submerged wood in freshwater. It was renamed Pseudoproboscispora by Punithalingam (1999). Pseudoproboscispora was placed in Annulatascaceae by Maharachchikumbura et al. (2016b) and later transferred to a new family Pseudoproboscisporaceae based on phylogenetic analysis (Zhang et al. 2017a). However, Pseudoproboscispora caudae-suis clustered in Annulatascaceae which is distant from Pseudoproboscisporaceae (Zhang et al. 2017a).

\section{Pseudosporidesmiaceae Crous, Persoonia 39: 365 (2017)}

Index Fungorum number: IF823464; Facesoffungi number: FoF05493; 2 species.

On leaves of living plants. Sexual morph: Undetermined. Asexual morph: Hyphomycetous. Mycelium consisting of branched, septate, pale brown hyphae. Conidiophores solitary or in clusters, flexuous or erect, arising from superficial hyphae, rejuvenating percurrently, with cylindrical stipe, brown, smooth, thick-walled, mostly unbranched. Conidiogenous cells terminal, cylindrical, brown, scars truncate, not thickened. Conidia solitary, obclavate, brown, subobtuse at apex, truncate at base, euseptate, smooth-walled (adapted from Crous et al. 2017a).

Type genus - Pseudosporidesmium K.D. Hyde \& McKenzie

Notes - Pseudosporidesmiaceae, introduced by Crous et al. (2017a), included two species of Pseudosporidesmium and a taxon tentatively identified as Repetophragma inflatum (GenBank number DQ408576), of which the characters could not be confirmed. Pseudosporidesmiaceae is assigned to Xylariales (Xylariomycetidae, Sordariomycetes) based on phylogenetic analysis (Su et al. 2016b, Crous et al. 2017a).

\section{Ecological and economic significance of Pseudosporidesmiaceae}

Saprobic taxa having the ability to decompose lignocellulose in woody litter, softening the wood and releasing nutrients as simple molecules that can be reused by plants and all other organisms (Yuen et al. 1998, Bucher et al. 2004). Thus, they play an important role in nutrient and carbon recycling, biological diversity and ecosystem functioning (Palmer et al. 1997, Wong et al. 1998a).

\section{Genus included in Pseudosporidesmiaceae}

Pseudosporidesmium K.D. Hyde \& McKenzie, Fungal Divers. 80: 404 (2016)

Index Fungorum number: IF551835; 2 species with sequence data.

Type species - Pseudosporidesmium knawiae (Crous) K.D. Hyde \& McKenzie

Notes - Pseudosporidesmium was established by Su et al. (2016b) to accommodate Sporidesmium knawiae, which was introduced by Crous (2008). Presently, two species are accepted in Sporidesmium and both were isolated from leaves of living plants (Crous 2008, Crous et al. 2017a). 


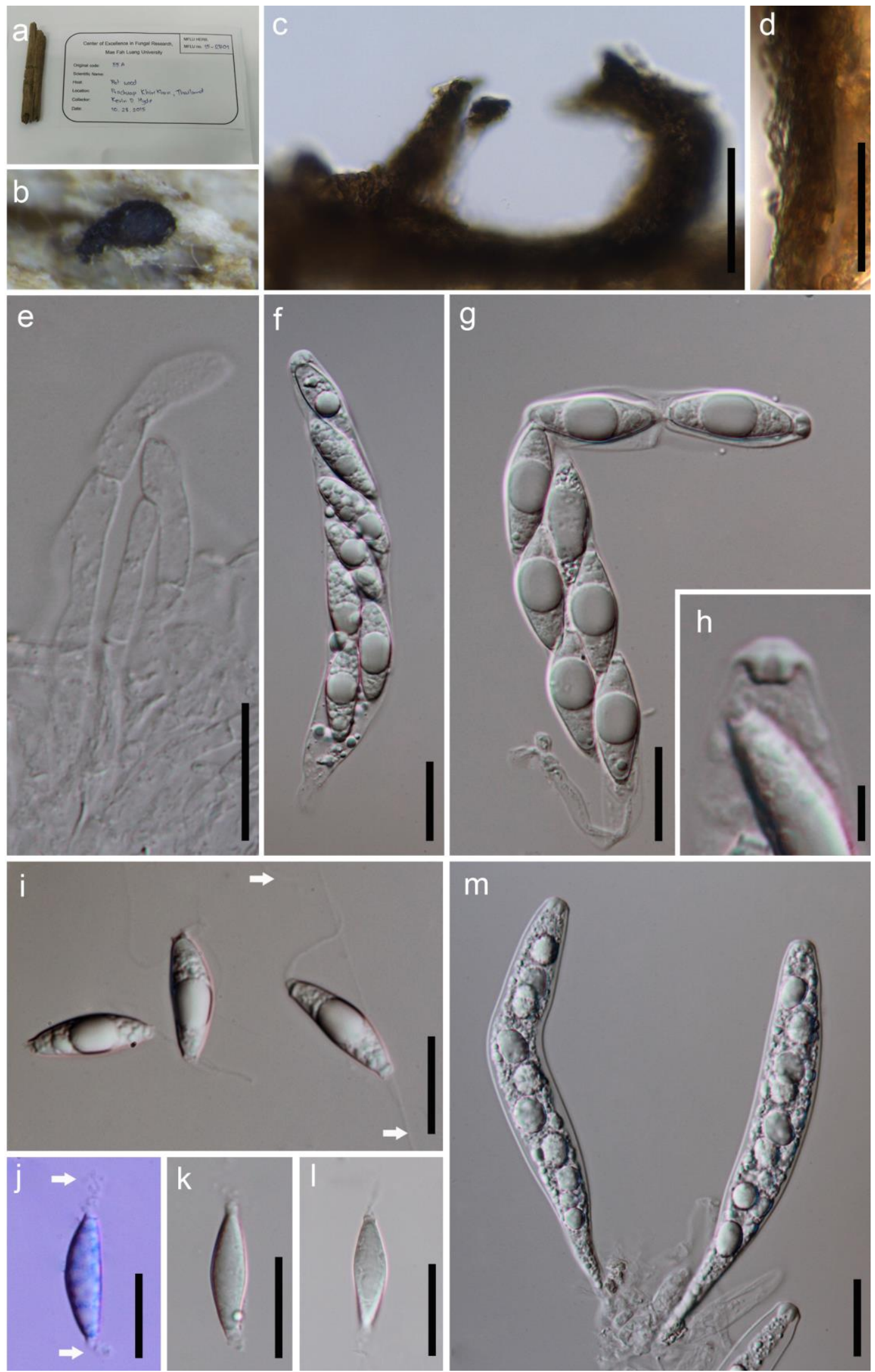

Figure 214 - Diluviicola aquatica (Material examined - THAILAND, Prachuap Khiri Khan, on submerged bamboo in a small river, 30 July 2015, W. Dong 55A, MFLU 15-2701, holotype). a Herbarium material. b Appearance of black ascomata semi-immersed or superficial on host. c Vertical section of ascoma. d Structure of peridium. e Paraphyses. f, g Asci. h Asci apicalring, j, l, $\mathrm{m}$ Ascospores mounted in water. $\mathrm{k}$ Ascospore mounted in cotton blue. $\mathrm{j}$, $\mathrm{k}$ Appendages marked by arrows. Scale bars: $\mathrm{c}=50 \mu \mathrm{m}, \mathrm{d}-\mathrm{h}, \mathrm{j}-\mathrm{m}=20 \mu \mathrm{m}, \mathrm{i}=5 \mu \mathrm{m}$. 


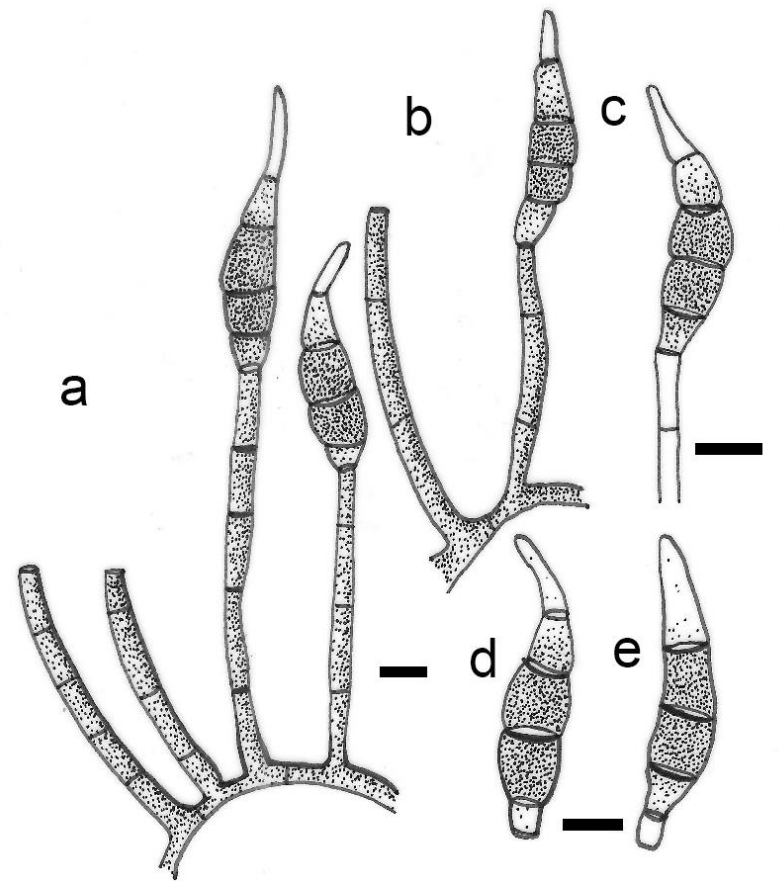

Figure 215 - Pseudosporidesmium knawiae (redrawn from Crous 2008). a, b Conidiophores with conidia. c Conidiogenous cells with conidium. d, e Conidia. Scale bars: $10 \mu \mathrm{m}$.

Pseudotruncatellaceae Crous, Persoonia 42: 309 (2019)

Index Fungorum number: IF830823; Facesoffungi number: FoF06878; 2 species.

Saprobic on dead plant stems or associated with leaves. Asexual morph: coelomycetous. Conidiomata acervular to pycnidioid, gregarious, immersed to semi-immersed, oval. Peridium of hyaline to pale brown, thick-walled cells forming textura angularis. Conidiophores arising from basal and lateral cells in cavity, cylindrical, septate, branched or rarely unbranched, sometimes reduced to conidiogenous cells, hyaline, smooth-walled. Conidiogenous cells subcylindrical, proliferating percurrently at apex, hyaline, smooth-walled. Conidia fusoid, straight, 2 or 3septate, with 2-3(-4) tubular apical appendages; two median cells guttulate, fusoid, dark brown, thick-, smooth-walled; basal cell, narrowly obconic with a truncate base, hyaline, smooth-walled. Sexual morph: Undetermined (adapted from Crous et al. 2019a).

Type genus - Pseudotruncatella R.H. Perera, Camporesi, Maharachch. \& K.D. Hyde

Notes - Pseudotruncatellaceae was introduced by Crous et al. (2019a) to accommodate a single genus Pseudotruncatella, which was previously placed in Amphisphaeriales genera incertae sedis (Perera et al. 2018).

\section{Ecological and economic significance of Pseudotruncatellaceae}

Pseudotruncatella arezzoensis is a saprobe on woody substrates (Perera et al. 2018). Saprobic taxa play an important role in nutrient and carbon cycling in ecosystems (Harley 1971). Pseudotruncatella bolusanthi is associated with plant leaves of Bolusanthus speciosus (Crous et al. 2019a). However, no study has confirmed pathogenicity of Pseudotruncatellaceae species.

\section{Genus included in Pseudotruncatellaceae}

Pseudotruncatella R.H. Perera, Camporesi, Maharachch. \& K.D. Hyde, Phytotaxa 338(2): 181 (2018)

Index Fungorum number: IF553932; 2 species with sequence data.

Type species - Pseudotruncatella arezzoensis .H. Perera, Camporesi, Maharachch. \& K.D. Hyde

Notes - Perera et al. (2018) established asexual morphic genus Pseudotruncatella to accommodate $P$. arezzoensis. Pseudotruncatella bolusanthi was added to the genus and family 
Pseudotruncatellaceae was introduced to accommodate them (Crous et al. 2019a). The genus is characterized by acervular to pycnidioid conidiomata, holoblastic, annellidic, conidiogenous cells, 2 or 3-septate, fusiform to clavate conidia with up to 2-3(-4) apical appendages and dark brown median cells (Perera et al. 2018, Crous et al. 2019a).
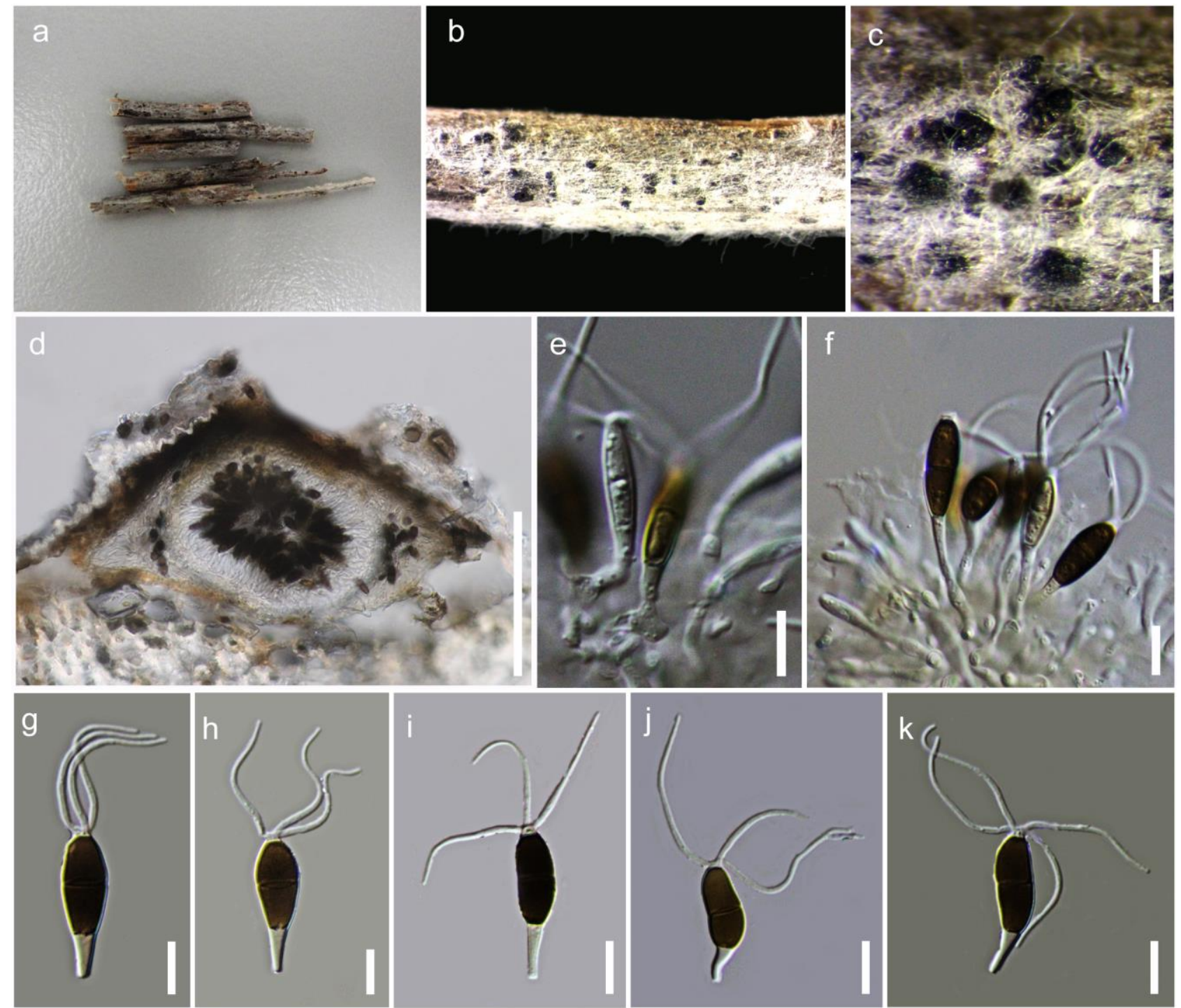

Figure 216 - Pseudotruncatella arezzoensis (Material examined - ITALY, Arezzo Province, Croce di Pratomagno, aerial stem of Helichrysum italicum (Roth) G. Don fil. (Asteraceae), 18 July 2013, Erio Camporesi, IT1322E, MFLU 17-1776, paratype). a Herbarium material. b, c Conidiomata on host. d Vertical section of conidioma. e, f Conidiogenous cells with mature and immature conidia. g-k Conidia. Scale bars: c $=500 \mu \mathrm{m}, \mathrm{d}=200 \mu \mathrm{m}, \mathrm{e}-\mathrm{k}=10 \mu \mathrm{m}$.

Pyriculariaceae Klaubauf, M.-H. Lebrun \& Crous, Stud. Mycol. 79: 104 (2014)

Index Fungorum number: IF810202; Facesoffungi number: FoF05054; 82 species.

Pathogenic or saprobic on various plant hosts, commonly on monocotyledons. Sexual morph: Ascomata perithecial, immersed, solitary, scattered or gregarious, black, coriaceous, with long cylindrical necks, covered in setae. Peridium brown to dark brown, comprising several layers of textura angularis. Paraphyses septate, intermingled among asci. Asci 8-spored, unitunicate, subcylindrical, short pedicellate, with a large, J+, apical ring. Ascospores overlapping 2-3-seriate, ellipsoid to obclavate, fusiform, with 3 septa, often with median cells pigmented, pale brown. Asexual morph: Hyphomycetous. Conidiophores solitary or in fascicles, subcylindrical, erect, olivaceous, pale brown or brown, branched or unbranched. Conidiogenous cells holoblastic, 
polyblastic, integrated, pigmented, denticulate. Conidia hyaline to brown, pyriform to elliptical, 15-transversely septate, in some genera with apical mucoid appendages (adapted from Klaubauf et al. 2014).

Type genus - Pyricularia Sacc.

Notes - Klaubauf et al. (2014) introduced Pyriculariaceae as a sister family to the Ophioceraceae, and accepted two genera Deightoniella and Pyricularia in Pyriculariaceae, and introduced seven genera (viz. Bambusicularia, Barretomyces, Macgarvieomyces, Neopyricularia, Proxipyricularia, Pseudopyricularia, Xenopyricularia) based on morphology and phylogenetic analyses. DNA replication licensing factor (MCM7) and calmodulin (calM) genes were used as a phylogenetic marker for some genera by Pordel et al. (2015, 2017). Hernández-Restrepo et al. (2015b) established Neocordana, a new genus in Pyriculariaceae. Wijayawardene et al. (2017a, 2018a) accepted ten genera in Pyriculariaceae. It is difficult to identify some of these genera in this family without molecular data. We illustrate both morphs of Pyricularia with line diagrams and describe and illustrate a new collection of Deightoniella africana.

\section{Ecological and economic significance of Pyriculariaceae}

Pyriculariaceae species cause serious crop diseases on a wide range of hosts, including major diseases on monocotyledons (Klaubauf et al. 2014). Species of Pyricularia are important pathogens in a species-rich genus, and sampling leaf spot diseases in Poaceae, which revealed many taxa (Klaubauf et al. 2014).

Rice blast disease caused by $P$. oryzae has been found in more than 85 countries (Kato 2001). Pyricularia grisea is responsible for a foliar disease of Digitaria (Klaubauf et al. 2014), and it also causes disease on about 50 species of cereals, other grasses and sedges, including Oryza sativa, Triticum aestivum, Hordeum vulgare, Zea mays, Avena sativa, Secale cereal, Eleusine corocana, Lolium perenne and weeds and ornamental grasses (Ou 1985). Both P. grisea and P. oryzae cause rice blast disease and infect all aerial parts of rice, leading to leaf-blast, neck and panicle rot, collar rot and node blast (Skamnioti \& Gurr 2009).

\section{Genera included in Pyriculariaceae}

Bambusicularia Klaubauf, Lebrun \& Crous, Stud. Mycol. 79: 104 (2014)

Index Fungorum number: IF810203; 1 species with sequence data.

Type species - Bambusicularia brunnea Klaubauf, M.-H. Lebrun \& Crous

Notes - The genus is a pathogenic hyphomycetous asexual morph (Klaubauf et al. 2014).

Barretomyces Klaubauf, Lebrun \& Crous, Stud. Mycol. 79: 104 (2014)

Index Fungorum number: IF810205; 1 species with sequence data.

Type species - Barretomyces calatheae (D.J. Soares, F.B. Rocha \& R.W. Barreto) Klaubauf, Lebrun \& Crous

Notes - The monotypic genus was introduced by Klaubauf et al. (2014) with $B$. calatheae, a hyphomycetous species. It was recorded as a pathogen on leaves of Calathea longifolia in Brazil (Maharachchikumbura et al. 2015b, Wijayawardene et al. 2017a, 2018a).

Deightoniella S. Hughes, Mycol. Pap. $48: 27$ (1952)

Index Fungorum number: IF7934; 14 morphological species (Species Fungorum 2020), 1 species with sequence data.

Type species - Deightoniella africana S. Hughes

Notes - Deightoniella was introduced by Hughes (1952), who described D. africana on living leaves of Imperata cylindrica var. africana in West Africa. The genus, which is worldwide in distribution, is pathogenic and only a hyphomycetous asexual stage is known (see Seifert et al. 2011 for morphology). The phylogeny was introduced in Klaubauf et al. (2014) and an outline of species, and nomenclature has been resolved for this genus (Maharachchikumbura et al. 2015b, 2016b, Zhang et al. 2016, Wijayawardene et al. 2017a, 2018a). 


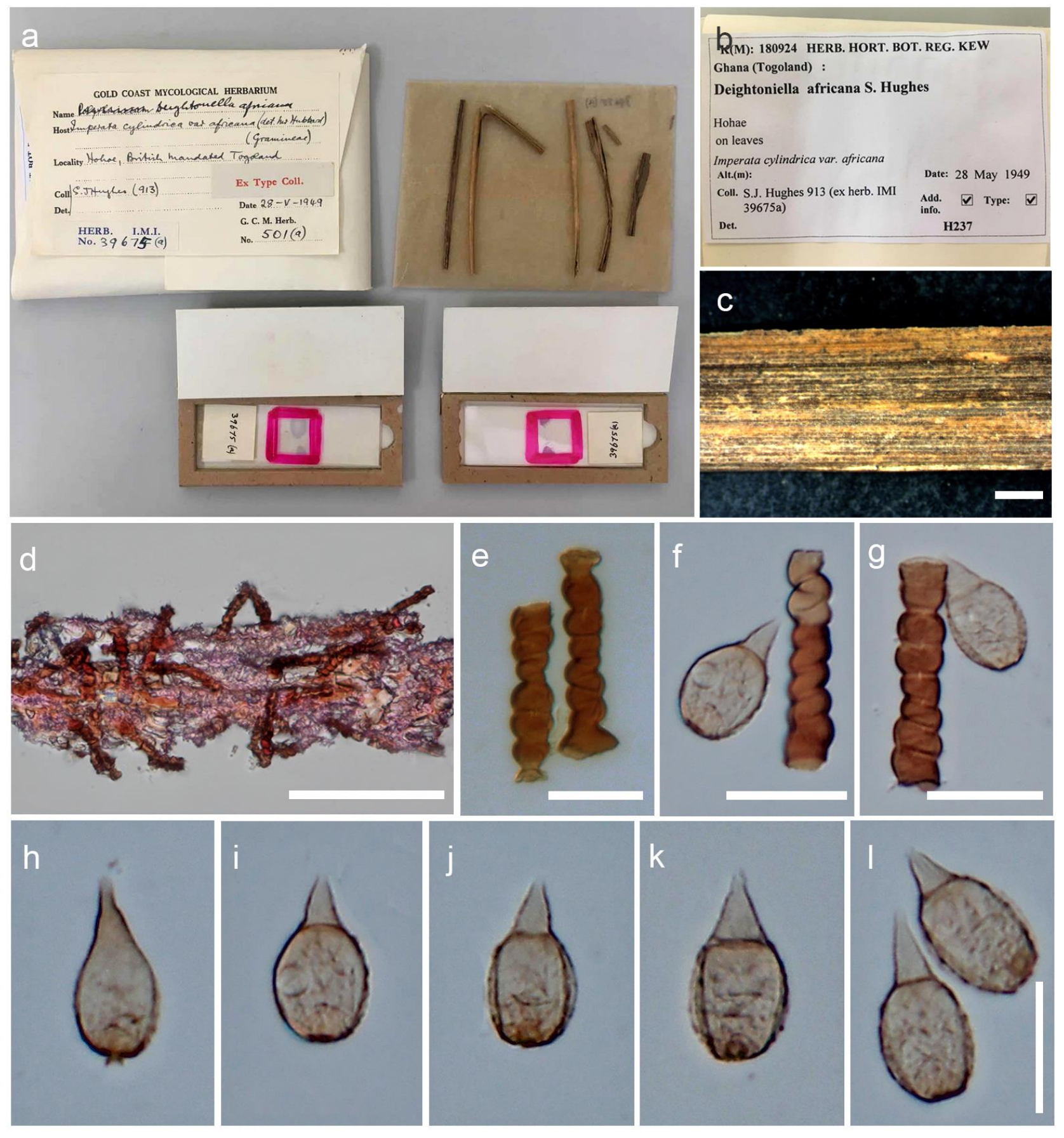

Figure 217 - Deightoniella africana (Material examined - GHANA, Togoland, on leaves of Imperata cylindrica var. africana, 28 May 1949, S.J. Hughes 913, IMI 39675(a), type). a-c Herbarium packets and specimens. d Conidiophores on substrate. e Conidiophores. f, g Conidiophores with conidia. $\mathrm{h}-\mathrm{l}$ Conidia ( $\mathrm{h}-\mathrm{k}$ were using the same scale bar as 1 ). Scale bars: $\mathrm{c}=$ $1000 \mu \mathrm{m}, \mathrm{d}=100 \mu \mathrm{m}, \mathrm{e}-\mathrm{l}=20 \mu \mathrm{m}$.

Macgarvieomyces Klaubauf, Lebrun \& Crous, Stud. Mycol. 79: 106 (2014)

Index Fungorum number: IF810207; 3 species with sequence data.

Type species - Macgarvieomyces borealis (de Hoog \& Oorschot) Klaubauf, Lebrun \& Crous

Notes - Macgarvieomyces was introduced to accommodate two species, M. borealis and $M$. juncicola occurring on leaf spots and stem bases of Juncus, respectively. The species were based on host plant and taxa cannot clearly be distinguished from other genera in the family (Klaubauf et al. 2014). However, molecular analyses distinguished a distinct clade sister to Deightoniella. Pyricularia luzulae was synonymised as Macgarvieomyces luzulae (Marin-Felix et al. 2018). 
Neocordana Hern.-Restr. \&Crous, Phytotaxa 205(4): 233 (2015)

Index Fungorum number: IF811105; 7 morphological species (Species Fungorum 2020), 5 species with sequence data.

Type species - Neocordana musae (Zimm.) M. Hern.-Rest. \& Crous

Notes - Neocordana was introduced by Hernández-Restrepo et al. (2015b) to accommodate $N$. musae (type species), N. johnstonii, $N$. versicolor and $N$. musicola, based on morphology and phylogenetic studies. The genus occurs on leaves of Musa spp. (Musaceae) and Canna denudata (Cannaceae) (Hernández-Restrepo et al. 2015b). Neocordana musarum and N. musigena were introduced with evidence from phylogenetic analysis and morphology (Crous et al. 2016a, 2017b).

Neopyricularia Klaubauf, Lebrun \& Crous, Stud. Mycol. 79: 108 (2014)

Index Fungorum number: IF810210; 1 species with sequence data. Crous

Type species - Neopyricularia commelinicola (M.J. Park \& H.D. Shin) Klaubauf, Lebrun \&

Notes - Klaubauf et al. (2014) introduced the monotypic genus Neopyricularia from leaves of Commelina communis in South Korea (Maharachchikumbura et al. 2015b, 2016b, Wijayawardene et al. 2017a, 2018a).

Proxipyricularia Klaubauf, Lebrun \& Crous, Stud. Mycol. 79: 109 (2014)

Index Fungorum number: IF810211; 1 species with sequence data.

Type species - Proxipyricularia zingiberis (Y. Nisik.) Klaubauf, Lebrun \& Crous

Notes - Klaubauf et al. (2014) introduced Proxipyricularia to accommodate the type species, $P$. zingiberis, which is a pathogen on Zingiber mioga and Z. officinale in Japan. The sexual morph is undetermined (Klaubauf et al. 2014).

Pseudopyricularia Klaubauf, Lebrun \& Crous, Stud. Mycol. 79: 109 (2014)

Index Fungorum number: IF810213; 8 species with sequence data.

Type species - Pseudopyricularia kyllingae Klaubauf, M.-H. Lebrun \& Crous

Notes - The genus was introduced by Klaubauf et al. (2014), along with four other species. The type species, Pseudopyricularia kyllingae is a pathogen on Kyllinga brevifolia (Cyperaceae) in Japan. Additional species were introduced by Crous et al. (2015d, 2018b), Marin-Felix et al. (2017) and Pordel et al. (2017).

Pyricularia Sacc., Mycelia 2(no. 6): 20 (1880)

Index Fungorum number: IF9670; 44 morphological species(Species Fungorum 2020), 18 species with sequence data.

Type species - Pyricularia grisea Sacc.

Notes - The name Pyricularia refers to the pyriform shape of the conidia, which is a specific character of this genus (Bussaban et al. 2005). Pyricularia species can infect various monocotyledons including Cenchrus, Echinochloa, Lolium, Oryza, Pennisetum or Zingiber. Pyricularia oryzae is the cause of rice blast disease, one of the most important diseases of rice. Klaubauf et al. (2014) synonymised Magnaporthe grisea under Pyricularia grisea, by clarifying the taxonomic relationships among species that are magnaporthe- or pyricularia-like using molecular phylogeny (LSU, ITS, rpbl, act and calM).

Pyriculariomyces Y. Marín, M.J. Wingf. \& Crous, Stud. Mycol. 92: 118 (2019)

Index Fungorum number: IF823760; 1 species with sequence data.

Type species - Pyriculariomyces asari (Crous \& M.J. Wingf.) Y. Marín, M.J. Wingf. \& Crous

Notes - Pyriculariomyces was introduced to accommodate $P$. asari, collected from leaves and stems of Asarum sp. in Malaysia. Pyriculariomyces is similar to Pyricularia, except the 
character of integrated terminal conidiogenous cells, and papillate necks with the ostioles of ascomata (Marín-Felix et al. 2018).
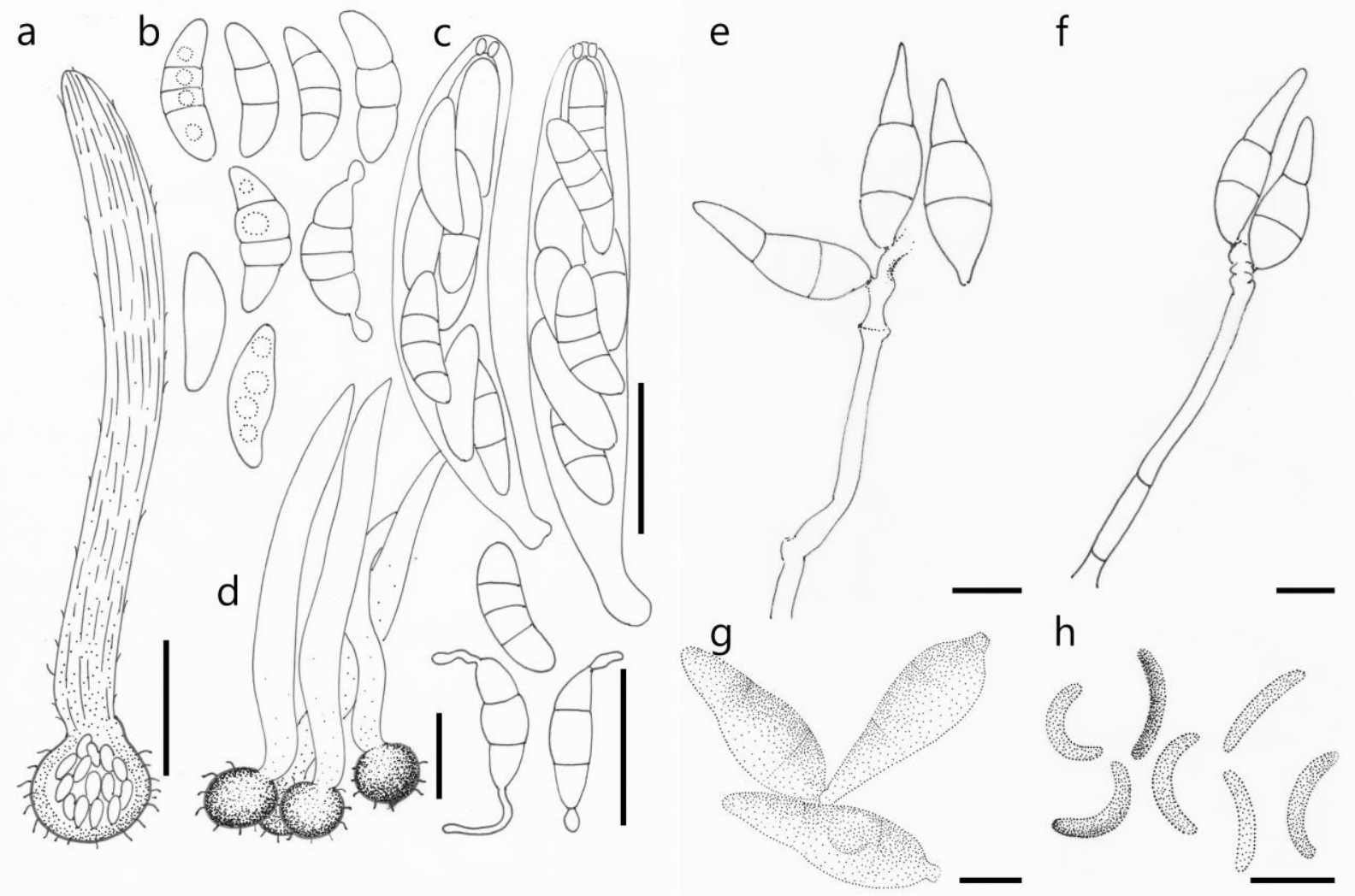

Figure 218 - Pyricularia oryzae (a-d, g-h), Pyricularia grisea (e, f). a-d Perithecia, asci and ascospores (redrawn from Yaegashi \& Udagawa 1978). e, f Conidiophores and conidia (redrawn from Klaubauf et al. 2014). g Pyriform conidia (redrawn from Zhang et al. 2014). h Microconidia produced from phialides (redrawn from Zhang et al. 2014). Scale bars: $a, d=200 \mu \mathrm{m}, \mathrm{b}, \mathrm{c}=20 \mu \mathrm{m}$, $\mathrm{e}, \mathrm{f}=10 \mu \mathrm{m}, \mathrm{g}, \mathrm{h}=5 \mu \mathrm{m}$.

Xenopyricularia Klaubauf, Lebrun \& Crous, Stud. Mycol. 79: 116 (2014)

Index Fungorum number: IF810223; 1 species with sequence data.

Type species - Xenopyricularia zizaniicola (Hashioka) Klaubauf, Lebrun \& Crous

Notes - Xenopyricularia is a monotypic genus, introduced to accommodate X. zizaniicola which is pathogenic on Zizania latifolia in Japan. Xenopyricularia is similar to Pyricularia, except the conidia are very wide and more obovoid than in Pyricularia, and some conidia appear to be irregularly pigmented (Klaubauf et al. 2014).

Requienellaceae Boise, Mycologia 78(1): 37 (1986)

Index Fungorum number: IF81336; Facesoffungi number: FoF06879; 13 species.

Saprobic on dead wood or pathogenic on plants. Sexual morph: Ascomata immersed or erumpent, globose to subglobose base with prominent apex, solitary or aggregated, perithecioid, sometimes whitish, greyish to black at the margin. Ostiole inconspicuous or strongly erumpent, flattened or papillate to conical, black. Peridium comprising thick-walled angular cells, thickened in upper regions. Paraphyses numerous, apically free, aseptate, curved, scarcely branched. Asci 8spored, unitunicate, cylindrical, subfusiform to narrowly clavate, with thick-walled apex, wide ocular chamber comprising a slightly refractive, inversely funnel-shaped dome, turning slightly reddish in Congo Red. Ascospores uni - to biseriate, olivaceous or brown, ellipsoid to oblong, with round or acute ends, with one or several transverse distosepta and large lumina. Asexual morph: Undetermined (adapted from Jaklitsch et al. 2016b). 
Type genus - Requienella Fabre.

Notes - Requienellaceae has historically been treated in Melanommatales (Barr 1990a) based on its trabeculate-like paraphyses (Liew et al. 2000). Aptroot (1991) followed this and added more lichenised taxa to the non-lichenised Requienella. Jaklitsch et al. (2016b) determined Requienellaceae as a distinct family in Xylariales based on the DNA based sequence analyses of its generic type. Phylogenetically this family is a strongly supported monophyletic lineage sister to the taxa in Cainiaceae (Jaklitsch et al. 2016b). Currently the family comprises four genera viz. Acrocordiella (Jaklitsch et al. 2016b), Lacrymospora, Parapyrenis and Requienella (Wijayawardene et al. 2018a).

\section{Ecological and economic significance of Requienellaceae}

Requienellaceae species have a widespread distribution and inhabit bark (Cannon \& Krik 2007). They frequently occur on economic plants or lichens, such as $R$. seminuda on bark of dead Olea europaea trees, R. fraxini on bark of living trunks of old Fraxinus excelsior, Acrocordiella occulta on bark of Ribes spp., Acrocordiella omanensis saprobic on stems of Juniper sp. and Parapyrenis lichenicola probably on thalli of Pertusaria erythrella (Aptroot 1997, Hawksworth \& Halici 2007, Jaklitsch et al. 2016b, Maharachchikumbura et al. 2018a). Therefore, members of this family are saprobes, parasites or mutualistic and play an important role in material recycling and energy conversion in natural ecosystems.

\section{Genera included in Requienellaceae}

Acrocordiella O.E. Erikss., Mycotaxon 15: 189 (1982)

Index Fungorum number: IF47; 2 species with sequence data.

Type species - Acrocordiella occulta (Romell) O.E. Erikss.

Notes - Acrocordiella is characterised by solitary or small groups of immersed ascomata with white or black margins, a peridium comprising brown to hyaline, thick-walled cells of textura angularis and 3-distoseptate ascospores with rhomboid lumina. This genus has been considered as a synonym of Requienella (Boise 1986). Wijayawardene et al. (2018a) listed Acrocordiella in Pyrenulaceae. However, Jaklitsch et al. (2016b) and Maharachchikumbura et al. (2016b) confirmed Acrocordiella and Requienella as distinct genera of Requienellaceae in Xylariales (Sordariomycetes) based on phylogenetic analyses.

\section{Lacrymospora Aptroot, Biblthca Lichenol. 44: 95 (1991)}

Index Fungorum number: IF25383; 1 morphological species.

Type species - Lacrymospora parasitica Aptroot

Notes - Lacrymospora is distinguished from Parapyrenis by blackening of the thallus around the ascomata (Aptroot 1991) and asymmetrical ascospores with several rows of granules, indicating septation (Calatayud et al. 2001). The generic position is still doubtful and fresh collections are needed to understand the taxonomic status and provide support as a separate genus.

Parapyrenis Aptroot, Biblthca Lichenol. 44: 96 (1991)

Index Fungorum number: IF26301; 8 morphological species (Species Fungorum 2020), 2 species with sequence data.

Type species - Parapyrenis aurora (Zahlbr.) Aptroot

Notes - Parapyrenis was described to accommodate $P$. aurora, $P$. conica, $P$. elongata and $P$. guayaci that are treated as non-lichenized, and are associated with plant bark, having cellular paraphyses and ascospores with a thickened internal wall layer (Aptroot 1991), Aptroot (1995) introduced $P$. maclurae, $P$. maritima and $P$. tecomatis and provided a key to Parapyrenis species. A lichenized fungus $P$. lichenicola was also assigned to this non-lichenized genus by Aptroot et al. (1997). Hawksworth \& Halici (2007) reviewed this genus and provided a brief description for Parapyrenis without illustrations. Vu et al. (2019) added LSU and ITS sequences to P. conica and P. maritima. 
Requienella Fabre, Annls Sci. Nat., Bot., sér. 6 15: 55 (1883)

Index Fungorum number: IF4676; 2 species with sequence data.

Type species - Requienella seminuda (Pers.) Boise.

Notes - Requienella was introduced by Fabre (1883), however, it has been shown that the three species recognised by him in Requienella belonged to other genera. Boise (1986) reinstated Requienella by typifying the genus with $R$. seminuda (= Sphaeria seminuda). Based on morphology, the genus was been classified in Dothideomycetes, however, Jaklitsch et al. (2016b) showed the genus belongs to the class Sordariomycetes, despite its apparently fissitunicate asci. Requienella fraxini and $R$. seminuda are accepted in Requienella based on morphology and sequence data and $R$. princeps has been transferred to Decaisnella (Barr 1990a).

a

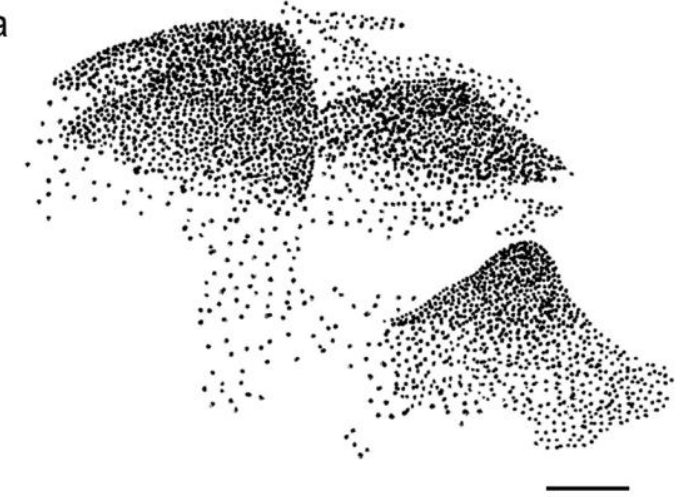

d
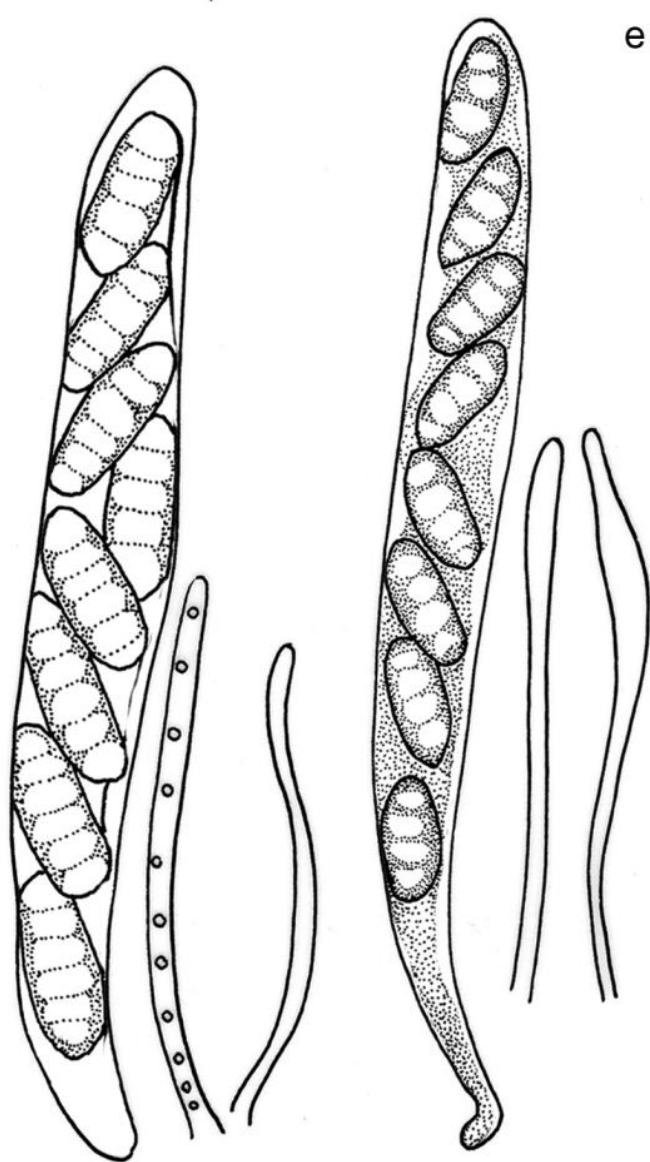

b

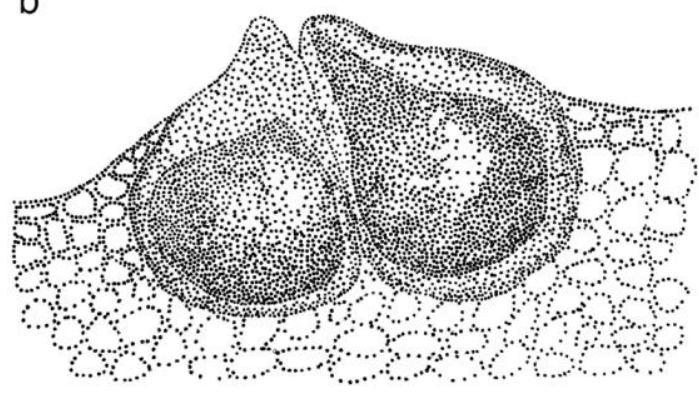

C

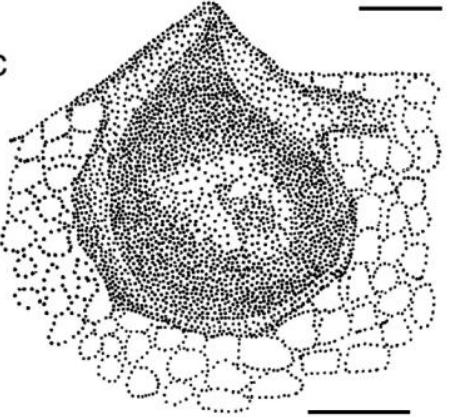

f

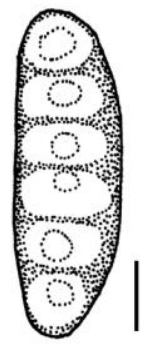

g

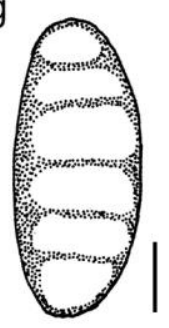

$\mathrm{h}$

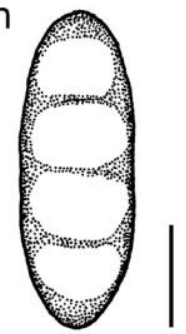

i
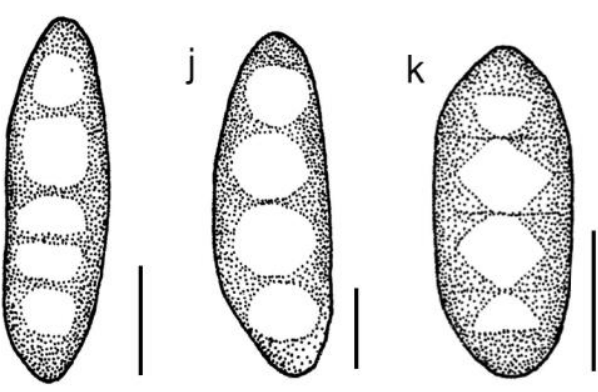

Figure 219 - Requienella seminuda (a, b, d, e, h, i, j), Requienella fraxini (c, k, 1), Acrocordiella occulta $(\mathrm{j}, \mathrm{m}, \mathrm{n})$ redrawn from Jaklitsch et al. (2016b). a Ascomata. b, c Sections of ascomata. d, e Asci and paraphyses. e Apical region of asci. f-k Ascospores. Scale bars: $a=0.2 \mathrm{~mm}, \mathrm{~b}=0.2 \mathrm{~mm}$, $\mathrm{c}=0.3 \mathrm{~mm}, \mathrm{~d}=25 \mu \mathrm{m}, \mathrm{d}, \mathrm{f}=15 \mu \mathrm{m}, \mathrm{e}, \mathrm{k}, \mathrm{l}, \mathrm{n}=10 \mu \mathrm{m}, \mathrm{i}, \mathrm{j}, \mathrm{m}=7 \mu \mathrm{m}$. 
Reticulascaceae Réblová \& W. Gams, Stud. Mycol. 68(1): 180 (2011)

Index Fungorum number: IF515435; Facesoffungi number: FoF01311; 37 species.

Saprobic on wood or bark in terrestrial and freshwater habitats. Sexual morph: Stromata if present minute. Ascomata perithecial, superficial, gregarious to solitary, brown to black, subglobose to conical, base flattened, slightly verruculose, glabrous with minute papilla, ostiole periphysate. Peridium 2-layered, fragile, the whole wall heavily sclerotized in the upper part, poorly developed towards the rim, absent at the base. Paraphyses numerous, filiform, sparsely septate, hyaline. Asci 8-spored, unitunicate, cylindrical to clavate, short-pedicellate, apex truncate to broadly rounded, with J-, apical ring. Ascospores uni to bi-seriate, hyaline or dark brown, ellipsoidal to fusiform, septate, mostly 2-celled, with a delayed formation of the 2 additional septa, smooth-walled, with or without end pores. Asexual morphs: Setae straight, cylindrical, septate, dark brown, paler towards the apex when present. Conidiophores macronematous, mononematous, solitary, erect, straight, sometimes curved, branched or unbranched, thick-walled, brown to dark brown, becoming paler towards the apex, terminating in a cylindrical to slightly flask-shaped or funnel-shaped, smooth-walled. Conidiogenous cells mono- or polyphialidic, collarette hyaline to subhyaline. Conidia hyaline to brown, pyriform to cylindrical, 1- or multi-septate, distal end bluntly rounded, basal end truncate, smooth-walled (adapted from Réblová et al. 2011).

Type genus - Cylindrotrichum Bonord.

Notes - Reticulascaceae was introduced by Réblová et al. (2011) in Glomerellales based on analysis of combined ITS, LSU, SSU and $r p b 2$ sequence data. Three genera were included, i.e. Cylindrotrichum (as Reticulascus), Kylindria and Sporoschismopsis. Presently, Blastophorum is also accepted in Reticulascaceae by Hyde et al. (2016b) based on the phylogenetic analysis and morphology. In addition, Hongsanan et al. (2017) provided further evidence for the placement of Reticulascaceae in Glomerellales by showing good support in both phylogenetic and MCC trees.

\section{Ecological and economic significance of Reticulascaceae}

Member of Reticulascaceae are saprobes involved in nutrient cycling. Marsault \& Peterson (2017) reported a new compound cyclic decadepsipeptide isolated from Cylindrotrichum tulasneorum.

\section{Genera included in Reticulascaceae}

Blastophorum Matsush., Microfungi of the Solomon Islands and Papua-New Guinea (Osaka): 8 (1971)

Index Fungorum number: IF7394; 4 morphological species (Species Fungorum 2020), 1 species with sequence data.

Type species - Blastophorum truncatum Matsush.

Notes - This genus is characterized by unbranched, percurrently proliferating, septate and dark brown conidiophores; enteroblastic to polyblastic and sympodial conidiogenous cells, which are subhyaline at the base and hyaline above and inconspicuous flattened denticles at conidiogenous loci; and septate, elongated, cuneiform and slimy conidia (Hyde et al. 2016b). This genus resembles Kylindria in its polyblastic and sympodial conidiogenous cells, but differs in having cuneiform and larger conidia (Hyde et al. 2016b). Hyde et al. (2016b) placed Blastophorum in Reticulascaceae based on the phylogenetic analysis of a combined LSU and ITS sequence data and morphology.

Cylindrotrichum Bonord., Handb. Allgem. mykol. (Stuttgart): 88 (1851)

Index Fungorum number: IF7881; 15 morphological species (Species Fungorum 2020), 6 species with sequence data

Type species - Cylindrotrichum oligospermum (Corda) Bonord.

Notes - Cylindrotrichum was introduced by Bonorden (1851) with $C$. oligospermum as the type species. Reticulascus was introduced by Réblová et al. (2011) for a holomorphic species $R$. tulasneorum (asexual morph C. oligospermum, Réblová \& Gams 1999), the generic type, and $R$. 
clavatus (asexual morph Cylindrotrichum clavatum). Réblová et al. (2016b) recommended the use of Cylindrotrichum over Reticulascus given its widespread use, priority, and greater number of names. Cylindrotrichum oligospermum is illustrated in this entry.
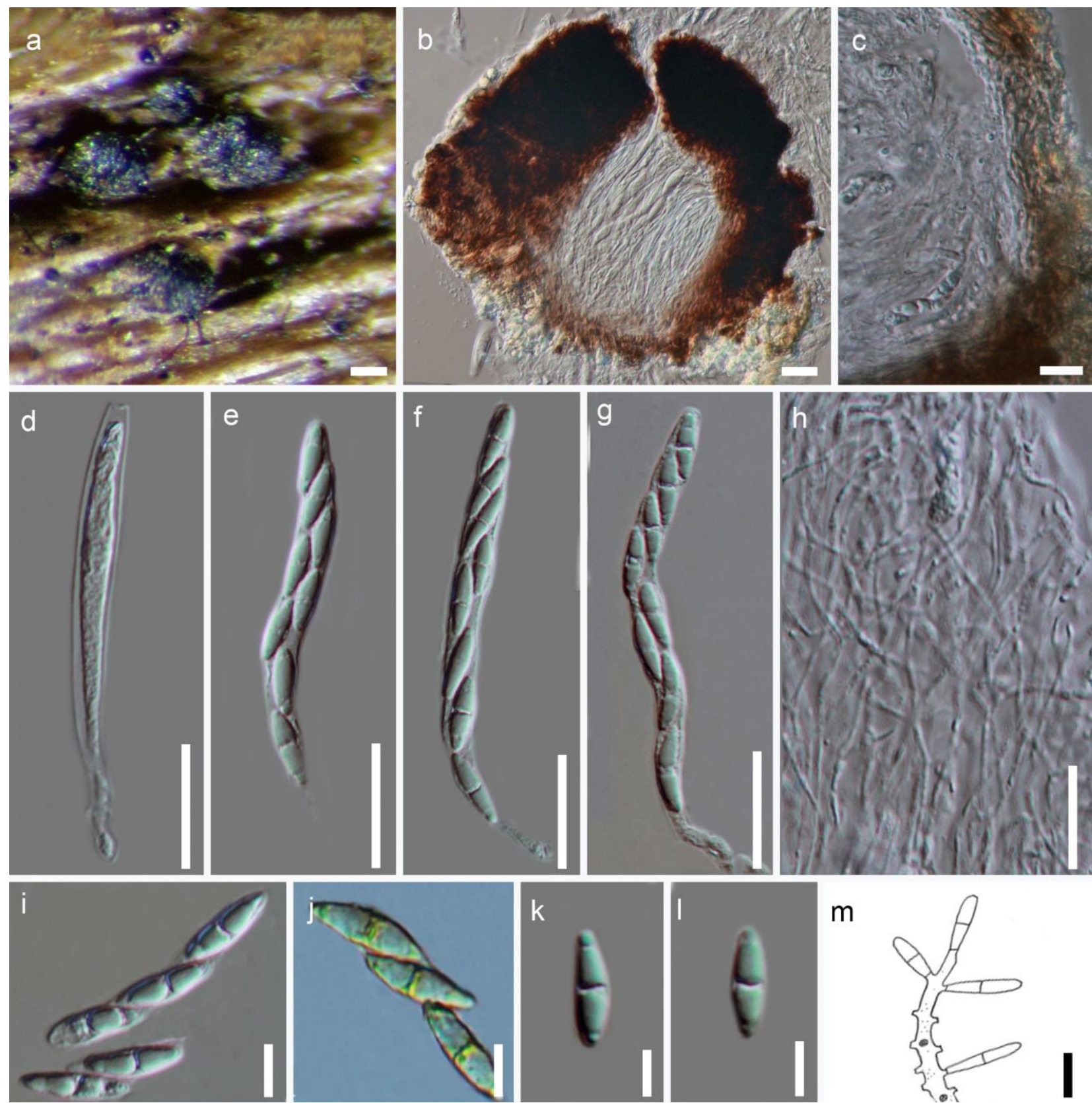

Figure 220 - Cylindrotrichum oligospermum (Material examined - CZECH REPUBLIC, Southwestern Bohemia, Javornická, Hornatina Mts, Strašín, near Sušice, on dead branch of Sambucus nigra L. (Adoxaceae), 21 October 1997, M. Svrček, PRM 842978, holotype). a Ascomata on the host. b Section through ascoma. c Peridium. d-g Asci. h Interthecial filaments. i-1 Ascospores ( $\mathrm{j}$ Ascospores stained with Meltzer reagent). $\mathrm{m}$ Conidia (redrawn from Réblová \& Gams 1999). Scale bars: $\mathrm{a}=100 \mu \mathrm{m}, \mathrm{b}, \mathrm{c}=50 \mu \mathrm{m}, \mathrm{d}-\mathrm{g}=25 \mu \mathrm{m}, \mathrm{h}-1=10 \mu \mathrm{m}, \mathrm{m}=20 \mu \mathrm{m}$.

Kylindria DiCosmo, S.M. Berch \& W.B. Kendr., Mycologia 75(6): 970 (1983)

Index Fungorum number: IF11115; 11 morphological species (Species Fungorum 2020), 2 species with sequence data.

Type species - Kylindria triseptata (Matsush.) DiCosmo, S.M. Berch \& W.B. Kendr.

Notes - Kylindria was erected by DiCosmo et al. (1983) with the type species K. triseptatum (三Cylindrotrichum triseptatum) and another four Cylindrotrichum species. Based on the 
phylogenetic analyses of a combine ITS, LSU, SSU dataset, Réblová et al. (2011) show that Kylindria should be accommodated in Reticulascaceae instead of Chaetosphaeriaceae. Maharachchikumbura et al. (2015, 2016b) confirmed Kylindria belongs to Reticulascaceae based on the phylogenetic analyses of a combine LSU, SSU, tefl and rpb2 dataset. Two species were introduced by Maharachchikumbura et al. (2018b). The genus is characterized by setiform, branched and septate conidiophores, monophialidic conidiogenous cells and septate, oblongellipsoid with hyaline conidia (Maharachchikumbura et al. 2016b, 2018b).
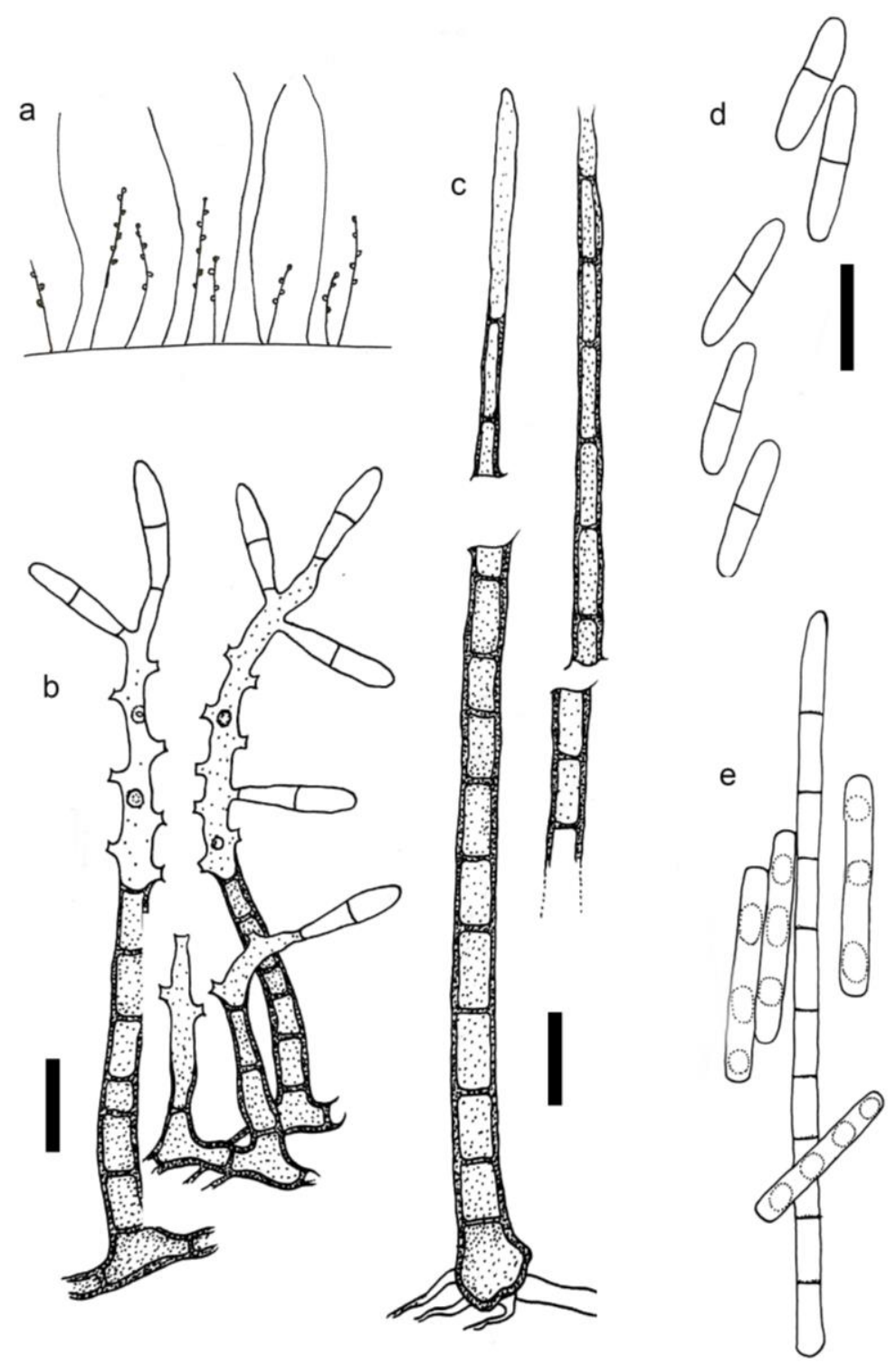

Figure 221 - Cylindrotrichum oligospermum a-d Asexual morph of Reticulascus tulasneorum, CBS 101319, PR M 842978, redrawn from Réblová \& Gams (1999) e Menispora oligosperma, redrawn from Corda (1838). a Habit sketch of conidiophores and setae. b-d Conidiophores and hyaline conidia of Reticulascus tulasneorum. e A flake of conidiophore and spores of Menispora oligosperma. Scale bars: b-d $=10 \mu \mathrm{m}$.

Sporoschismopsis Hol.-Jech. \& Hennebert, Bull. Jard. Bot. natn. Belg. 42(4): 385 (1972)

Index Fungorum number: IF10043; 7 morphological species (Species Fungorum 2020), 1 species with sequence data.

Type species - Sporoschismopsis moravica Hol.-Jech. \& Hennebert

Notes - Sporoschismopsis was described for saprobic, wood-inhabiting dematiaceous hyphomycetes by Holubová-Jechová \& Hennebert (1972). The sexual-asexual relationship between 
Porosphaerellopsis and Sporoschismopsis has been established by Réblová (2014), and the sexual morph Porosphaerellopsis has been treated as the synonym of Sporoschismopsis given its priority. The asexual morph of this genus is characterized by robust conidiophores with a funnel-shaped collarette, brown, septate, clavate, cuneiform, obovate or pyriform conidia, bluntly rounded at the distal end and truncate at the base, developing in a basipetal succession in fragile chains. The sexual morph is characterized by superficial to semi-immersed, subglobose, conical or ovate, dark brown ascomata and with ellipsoidal, fusiform, septate, brown to dark-brown ascospores (Réblová 2014). In addition, Réblová (2014) also provided key to the species accepted in Sporoschismopsis.

Rhamphoriaceae Réblová, Mycologia: 110(4):750-770 (2018)

Index Fungorum number: IF823918; Facesoffungi number: FoF06880; 17 species.

Saprobes on wood. Sexual morph: Ascomata perithecial, immersed or particularly erumpent becoming superficial, papillate or with a central cylindrical or rostrate neck. Ostiole periphysate. Peridium leathery to fragile, comprising two layers. Paraphyses consisting of septate, cylindrical paraphyses. Asci 8-spored, unitunicate, cylindrical or cylindrical-clavate, persistent, with a J-, apical ring. Ascospores overlapping uniseriate, hyaline or brown, ellipsoidal, obovoid, clavate, fusiform to fusiform-clavate, dictyoseptate or transversely septate, lacking mucilaginous sheaths or appendages, in some species ascospores may produce ascoconidia while in the asci (e.g. Rhamphoria pyriformis). Asexual morph: Hyphomycetous. Conidiophores macronematous or semi-macronematous, mononematous or loosely fasciculate. Conidiogenous cells producing conidia holoblastically, conidial secession rhexolytic on sympodially extending polyblastic conidiogenous cells, or schizolytic on monoblastic conidiogenous cells. Conidia hyaline (Rhamphoria, Rhamphoriopsis, Rhodoveronaea and Xylolentia) or brown (Linkosia multiseptum), aseptate or septate (adapted from Réblová \& Štěpánek 2018).

Type genus - Rhamphoria Niessl

Notes - Rhamphoriaceae was introduced by Réblová \& Štěpánek (2018) with Rhamphoria as the type genus and included the genera Rhamphoriopsis, Rhodoveronaea, Xylolentia and a dematiaceous hyphomycete Linkosia multiseptum. They formed a monophyletic clade with high statistical support based on a combined dataset of SSU, LSU and rpb2 sequences. Munk (1957) placed Rhamphoria in the subfamily Rhamphorioidae of the Diaporthaceae based on morphology. However, the position of Rhamphoria in the Sordariomycetes was uncertain (Lumbsch \& Huhndorf 2010). A strongly supported monophyletic clade based on LSU sequence data of Rhamphoria delicatula and Rhodoveronaea varioseptata was recovered and selected as members of the Sordariomycetidae (Réblová 2009). Despite Rhamphoria and Rhodoveronaea differing in sexual characters, their asexual morphs are similar dematiaceous hyphomycetes with same mode of conidiogenesis.

These genera (except for Linkosia) share a few features such as perithecial ascomata, absence of stromatic tissues or clypeus, similar anatomy of the two-layered peridium, unitunicate, pedicellate asci with a J-, apical ring, cylindrical paraphyses and dictyoseptate or transversely septate ascospores (Réblová \& Štépánek 2018). Linkosia multiseptum, on the other hand, lacks conidiophores, has distoseptate, thick-walled conidia and ampulliform, monoblastic conidiogenous cells. Based on the morphology, it is unexpected to place L. multiseptum in Rhamphoriaceae. Shenoy et al. (2006) suggested that Linkosia (Hernández-Gutiérrez \& Sutton 1997) is polyphyletic, based on LSU sequence data. The most similar relatives of Rhamphoriaceae are members of the Sporidesmiaceae (Su et al. 2016b).

\section{Ecological and economic significance of Rhamphoriaceae}

Members of Rhomphoriaceae are saprobes of decaying wood, reported predominantly from temperate regions of Europe. Members of Rhamphoria are uncommon except for $R$. pyriformis, which occurs on various hard wood trees (Munk 1948, 1957, Sivanesan 1976, Müller \& Samuels 1982a, Réblová \& Štěpánek 2018). Other Rhamphoria species have been collected only a few times and mostly only once (Réblová \& Štěpánek 2018). 


\section{Genera included in Rhamphoriaceae}

Rhamphoria Niessl, Verh. nat. Ver. Brünn 14: 204 (1876)

Index Fungorum number: IF4690; 13 morphological species (Species Fungorum 2020), 3 species with sequence data.

Type species - Rhamphoria delicatula Niessl

Notes - Rhamphoria is characterized by black, astromatic, perithecial ascomata with a distinct papilla or rostrate neck, unitunicate asci with a J-, apical ring and hyaline, dictyospores that may produce ascoconidia while still in the asci (e.g. Rhamphoria pyriformis). The species in Rhamphoria are mainly separated by the size of ascospores, number of transverse and longitudinal septa and to a lesser degree on spore shape (Réblová \& Štěpánek 2018).

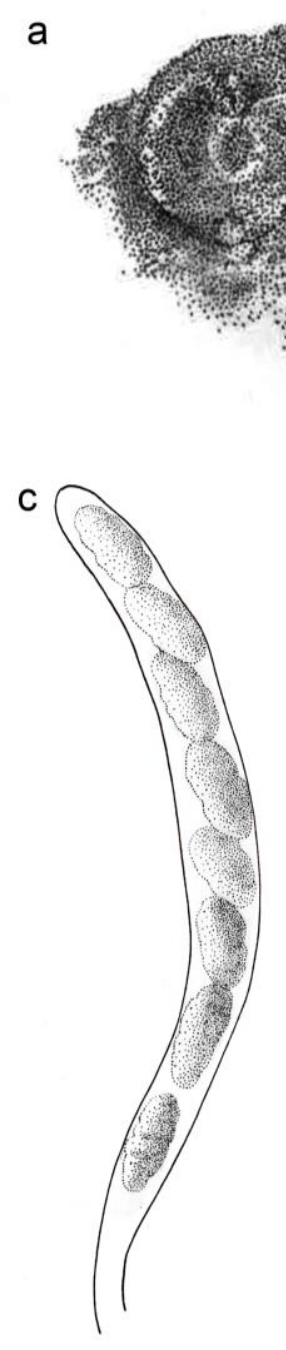

a

f

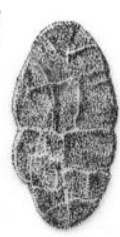

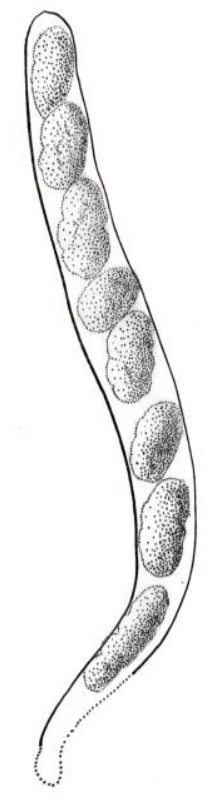
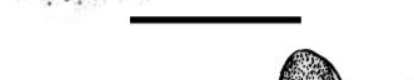

d
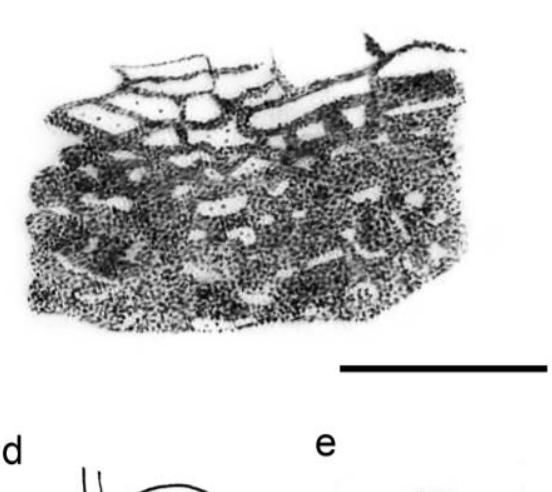

e
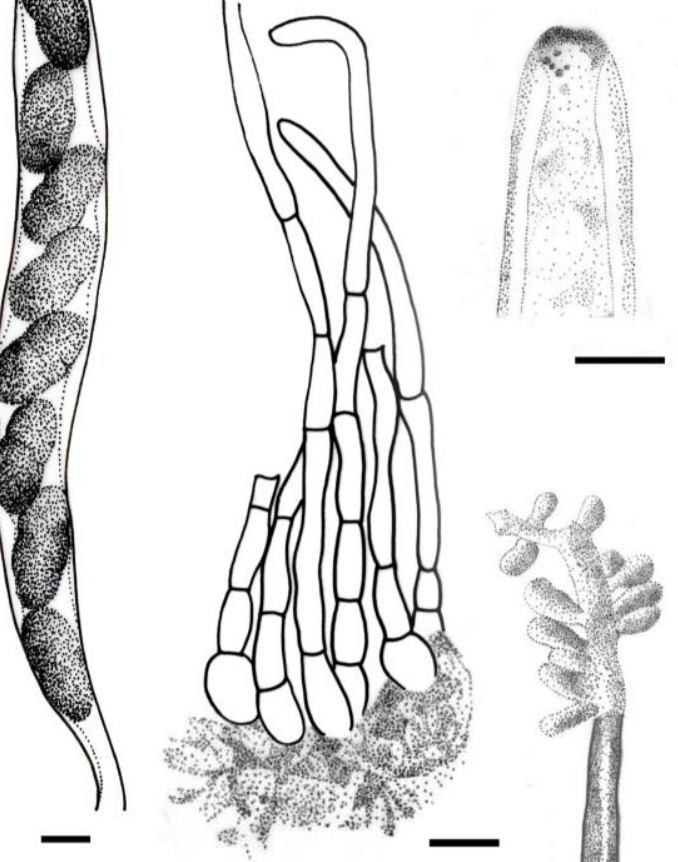

g
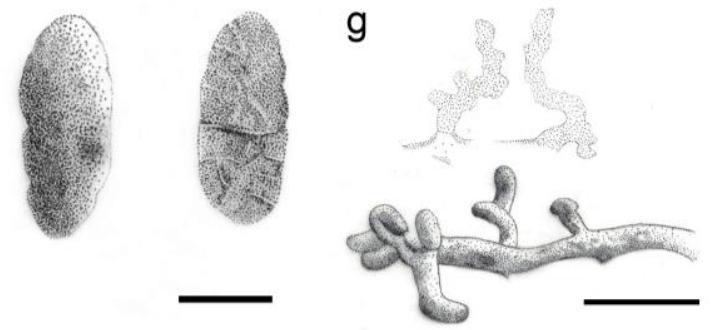

h

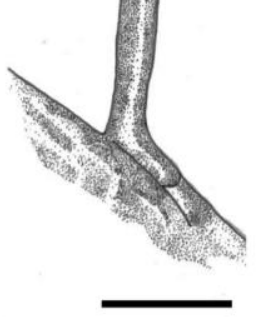

Figure 222 - Rhamphoria delicatula (redrawn from Réblová \& Štěpánek 2018). a Ascomata. b Peridium. c Asci. d Paraphyses. e Ascal apices with apical ring. f Ascospores. g Idriella-like conidiophores and conidia in PDA, 4 weeks. $h$ Phaeoisaria-like conidiophores with conidia in PDA culture, 4 weeks. Scale bars: $\mathrm{a}=200 \mu \mathrm{m}, \mathrm{b}=20 \mu \mathrm{m}, \mathrm{c}-\mathrm{h}=10 \mu \mathrm{m}$. 
Rhamphoriopsis Réblová \& Gardiennet, Mycologia: 6 (2018)

Index Fungorum number: IF823919; 1 species with sequence data.

Type species - Rhamphoriopsis muriformis Réblová \& Gardiennet

Notes - Rhamphoriopsis muriformis was introduced by Réblová \& Gardiennet (2018) from decaying wood of Buxus sempervivens. Rhamphoriopsis muriformis differs from Rhamphoria buxi Richon by longer asci and longer, hyaline ascospores and transverse and longitudinal, thin-walled septa (Réblová \& Štěpánek 2018).

Rhodoveronaea Arzanlou, W. Gams \& Crous, Stud. Mycol. 58: 89 (2007)

Index Fungorum number: IF504569; 2 species with sequence data.

Type species - Rhodoveronaea varioseptata Arzanlou, W. Gams \& Crous

Notes - Rhodoveronaea was introduced by Arzanlou et al. (2007), with the characters similar to Veronaea and isolated from Bertia moriformis. This monophyletic genus was described as an asexually reproducing taxon with no known sexual morph (Arzanlou et al. 2007). Réblová (2009) showed the connection between the sexual and asexual morphs of Rhodoveronaea varioseptata, the latter which differs from the similar ramichloridium-like taxa by a basal, marginal conidial frill, and variably septate conidia.

Xylolentia Réblová, Mycologia: 10 (2018)

Index Fungorum number: IF823921; 1 species with sequence data.

Type species - Xylolentia brunneola Réblová

Notes - Xylolentia brunneola was collected on decaying wood of Fagus sylvatica. This genus is distinct among members of the Rhamphoriaceae in having brown, septate ascospores. It is similar to Brunneosporella aquatica (Ranghoo et al. 2001), Hyalorostratum brunneisporum (Raja et al. 2010), and Jobellisia spp. (Huhndorf et al. 1999), all of which have 1-septate, brown ascospores arranged uniseriately in the ascus. However, analysis of a combined SSU, LSU and $r p b 2$ sequence dataset did not show a close relationship of Xylolentia with these genera (Réblová \& Štěpánek 2018).

Sarocladiaceae Lombard, Persoonia 41: 343 (2018)

Index Fungorum number: IF828245; Facesoffungi number: FoF06265; 25 species.

Saprobic on dried stems and branches of monocotyledons and dicotyledons, occasionally hemibiotrophic or necrotrophic, soil associated fungi, and clinical trial samples, and clinical wash fluid. Sexual morph: Undetermined. Asexual morph: Colonies effuse on the natural substrate, scattered, hairy, dark brown, septate. Vegetative hyphae hyaline, branched, partly immersed, smooth- and thin-walled, branched, composed of pale brown, septate hyphae. Conidiophores macronematous, synnematous, tree-like, dark brown, parallel and unbranched in the stipe, gregarious or scattered, erect, stripes straight or slightly flexuous, constricted at septa, tapering towards the apex, irregularly branched, cylindrical, smooth. Conidiogenous cells phialidic, integrated, terminal, cylindrical, straight to slightly curved, slightly narrowing at apex, acropetally proliferating, hyaline to pale brown, verrucose. Conidia forming slimy heads on the phialides or produced in chains, unicellular, fusiform to broad fusiform, hyaline, aseptate, thick-walled, verrucose, bud scars or disjunctions present at the site of attachment, guttulate (adapted from Crous et al. 2018b).

Type genus - Sarocladium Gams \& D. Hawksw.

Notes - Sarocladiaceae was introduced by Crous et al. (2018b) to accommodate the distinctive lineage of Parasarocladium and Sarocladium as the generic type. Sarocladium was previously placed in genera incertae sedis of Hypocreales as it is formed a phylogenetic affinity with species of Acremonium (Summerbell et al. 2011, Giraldo et al. 2015, Maharachchikumbura et al. 2015b, 2016b, Wijayawardene et al. 2017b). The phylogenetic distinction of Acremonium and Sarocladium is confirmed since the type species of Acremonium (A. alternatum) formed a well-supported lineage in Bionectriaceae (Crous et al. 2018b; Fig. 15 in this study). The 
phylogenetic placement of Sarocladium and related species was provided, with Parasarocladium, a second genus for the Acremonium radiatum complex (Summerbell et al. 2018).

A phylogenetic analysis of the LSU sequence alignment showed that Sarocladiaceae shares a close relationship with Bionectriaceae (Crous et al. 2018b). In our multilocus phylogenetic analysis of the combined LSU, ITS, $c m d A, r p b 2$, tef1 and tub2 sequence data of Hypocreales, Sarocladiaceae formed a close relationship with Flammocladiellaceae as basal lineage of Hypocreales. Sarocladiaceae comprise two genera, Parasarocladium and Sarocladium.

\section{Ecological and economic significance of Sarocladiaceae}

Sarocladiaceae species have been recorded as plant pathogens causing sheath-rot of rice and bamboo (Sawada 1922, Gams \& Hawksworth 1976, Sakthivel et al. 2002, Ayyadurai et al. 2005). They are also saprobes on monocotyledons and dicotyledons, and soils-associated fungi (Giraldo et al. 2015, Liu et al. 2017, Crous et al. 2018b, Phukhamsakda et al. 2020). The genus was also reported as human pathogens from calf tissue of legs, sputum and clinical wash fluid (Giraldo et al. 2015). Sarocladium oryzae produced antibiotic cerulenin and helvolic acid (Bills et al. 2004).

\section{Genera included in Sarocladiaceae}

Parasarocladium Summerb., J.A. Scott, Guarro \& Crous, Microorganisms 6(88): 17 (2018)

Index Fungorum number: IF826815; 4 species with sequence data.

Type species - Parasarocladium radiatum (Sukapure \& Thirum.) Summerb., J.A. Scott, Guarro \& Crous

Notes - Parasarocladium was introduced for Acremonium species that formed a sister clade with Sarocladium sensu stricto (Crous et al. 2018b, Summerbell et al. 2018). The genus is distinguished from Sarocladium by branched tufts of up to four conidiophores and the homologues characteristic of CAACTTT motif at 5' end of 5.8S rDNA (Summerbell et al. 2018).

Sarocladium Gams \& D. Hawksw., Kavaka 3: 57 (1976)

Index Fungorum number: IF9790; 21 species with sequence data.

Type species - Sarocladium oryzae (Sawada) W. Gams \& D. Hawksw.

Notes - Sarocladium oryzae was originally described as Acrocylindrium oryzae for a sheathrot associated fungus on rice (Sawada 1922, Sakthivel et al. 2002). Gams \& Hawksworth (1976) introduced Sarocladium for Acrocylindrium oryzae based on Sawada's holotype collection. Giraldo et al. (2012) re-examined cultures of Acremonium, and included seven species in the Sarocladium clade. Thereafter, the phylogenetic relationship of Acremonium and Sarocladium species has been clarified, and 18 species are included in Sarocladium (Giraldo et al. 2015). Liu et al. (2017), Crous et al. (2018b) and Phukhamsakda et al. (2020) described Sarocladium brachiariae, S. clematidicola and $S$. dejongiae, respectively.

Sarocladium can be distinguished by its elongated phialides rising solitary on vegetative hyphae or on conidiophores that are sparsely or repeatedly branched, and the production of cylindrical conidia (Fig. 223). Below we illustrate Sarocladium clematidis.

Savoryellaceae Jaklitsch \& Réblová, Index Fungorum 209: 1 (2015)

Index Fungorum number: IF551026; Facesoffungi number: FoF01283; 42 species.

Saprobic on submerged wood in freshwater, marine and brackish habitats. Sexual morph: Ascomata perithecial, brown to black, immersed or superficial, globose to pyriform, coriaceous, periphysate, ostiolate, papillate. Papilla central or eccentric when lying horizontally to the host. Peridium membranous, comprising several layers of brown, thick-walled cells of textura angularis, inner layers hyaline. Paraphyses hypha-like, numerous or sparse, septate. Asci 2-8-spored, unitunicate, clavate to cylindrical, pedicellate, persistent, with a small or relatively large, J-, apical ring. Ascospores uniseriate or overlapping biseriate, versicolorous with brown middle cells and hyaline end cells, ellipsoid, fusiform, 3 to many septate, smooth, thick-walled, with or without- 


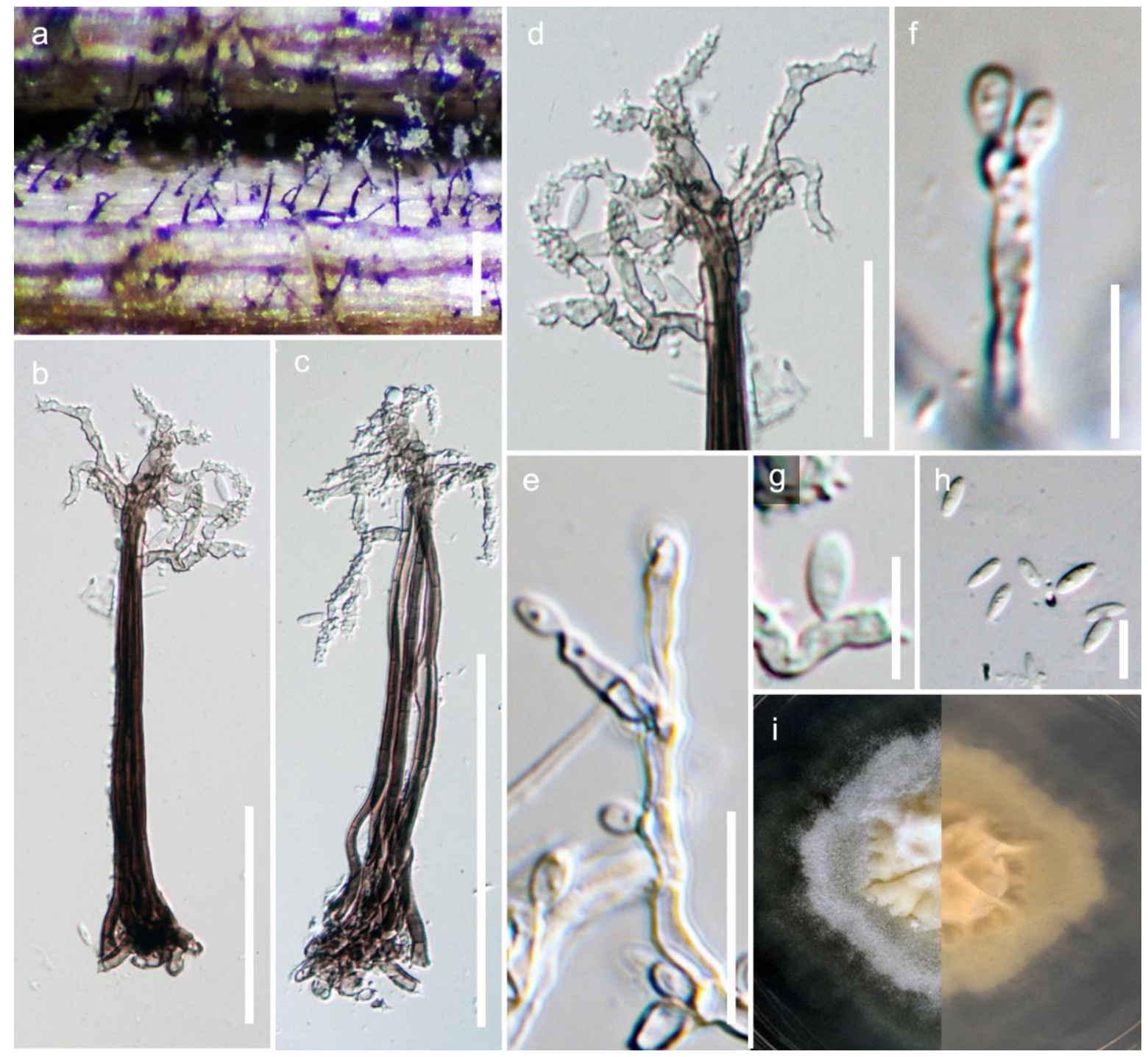

Figure 223 - Sarocladium clematidis (Material examined - BELGIUM, Flemish Brabant, Botanic Garden, Bouchout Domain, on dead stems of Clematis patens (Ranunculaceae), 13 June 2017, D. Ertz BRCP3, MFLU17 -1507, holotype). a Appearance of synnemata on Clematis viticella. b, c Synnemata. d Conidiogenous cells and conidia. e Asexual morph produced in culture. f, g Conidiogenous cells and developing conidia. h Conidia. i Culture on PDA. Scale bars: $\mathrm{a}=500 \mu \mathrm{m}$, $\mathrm{b}, \mathrm{c}=100 \mu \mathrm{m}, \mathrm{d}, \mathrm{e}=50 \mu \mathrm{m}, \mathrm{f}=10 \mu \mathrm{m}, \mathrm{g}, \mathrm{h}=5 \mu \mathrm{m}$.

-polar mucilaginous pads or appendages. Asexual morph: Hyphae septate, branched, hyaline to pale brown. Conidiophores semi-macronematous (conidiophores that are only slightly different from the vegetative hyphae). Conidiogenous cells absent or if present erect, smooth and thick-walled, holoblastic, cylindrical, flask-shaped. Conidia solitary, dry, smooth, applanate or rounded, globose to subglobose or obovate to oval, with longitudinal septa and transverse septa or only transversely septate, slightly constricted at the septa, with a pale brown small basal cell, olive green to brown or blackish brown to black, with prominent scar at the point of secession from the conidiogenous cell (adapted from Luo et al. 2019).

Type genus - Savoryella E.B.G. Jones \& R.A. Eaton

Notes - Savoryellaceae was introduced by Jaklitsch \& Réblová (2015) to accommodate Savoryella. Savoryellaceae was previously placed in Sordariales genera incertae sedis by Jones et al. (2009), in Savoryellales by Boonyuen et al. (2011). Hyde et al. (2017a) suggested that Savoryellales be raised to subclass rank based on the estimated stem age (Savoryellales; 267 MYA) and Hongsanan et al. (2017) supported this by phylogenetic and molecular clock analyses and, hence, introduced the subclass Savoryellomycetidae. Four other genera, i.e. Ascotaiwania, 
Canalisporium, Savoryella and Neoascotaiwania were included in the family along with the species Helicoön farinosum and Monotosporella species (Jones et al. 2015, Hernández-Restrepo et al. 2017, Wijayawardene et al. 2018a). Several types of asexual morphs, bactrodesmium-like, dictyosporium-like, monodictys-like, monotosporella-like, trichocladium-like are linked under Savoryellaceae (Sivichai et al. 1998, Ranghoo \& Hyde 1998, Chang 2001, Sri-indrasutdhi et al. 2010, Réblová et al. 2015, Hernández-Restrepo et al. 2017). The distant placement of Helicoon farinosum, the asexual morph of Ascotaiwania hughesii (Fallah et al. 1999), from species of Savoryellales was revealed by rDNA data (Boonyuen et al. 2011, Réblová et al. 2012) and, hence, Ascotaiwania was considered polyphyletic (Hernández-Restrepo et al. 2017). Dayarathne et al. (2019a) revised the family with combined LSU, SSU, tefl and rpb2 data along with molecular clock analyses and synonymized Neoascotaiwania under Ascotaiwania and, further, excluded the Monotosporella species, Helicoön farinosum and Ascotaiwania hughesii from the family. Dematisporium was introduced by Luo et al. (2019) and therefore, currently Savoryellaceae comprises four genera, Ascotaiwania, Canalisporium, Dermatrosporium and Savoryella.

\section{Ecological and economic significance of Savoryellaceae}

Many Savoryellaceae species cause soft rot decay of wood (Eaton \& Jones 1971, Leightly \& Eaton 1979, Mouzouras 1986, Leightly 1980). This type of decay is prevalent where wood is exposed to wet conditions, such as submerged wood in marine and freshwater habitats (Jones 1972, Bucher et al. 2004), water cooling towers (Findlay \& Savory 1950, Savory 1954a, b), archeological timbers (Jones \& Jones 1993), and terrestrial environments (Duncan 1960).

\section{Genera included in Savoryellaceae}

Ascotaiwania Sivan. \& H.S. Chang, Mycol. Res. 96(6): 481 (1992)

Index Fungorum number: IF25163; 13 morphological species (Species Fungorum 2020, Dayarathne et al. 2019a), 7 species with sequence data.

Type species - Ascotaiwania lignicola Sivan. \& H.S. Chang

Notes - Ascotaiwania was established by Sivanesan \& Chang (1992) for an ascomycete comprising dark-brown to black ascomata with a short to long, lateral neck, asci with a relatively massive, J-, apical ring and 5 or 3 or 7-septate pigmented ascospores with hyaline end cells, with $A$. lignicola as the type species. This genus currently comprises 12 species (Dayarathne et al. 2019a). Divergence estimates are a crown age of 146 (200-196) MYA. (Dayarathne et al. 2019a).

Canalisporium Nawawi \& Kuthubutheen, Mycotaxon 34(2): 477 (1989)

Index Fungorum number: IF11041; 15 morphological species (Zhao et al. 2012), 11 species with sequence data.

Type species - Canalisporium caribense (Hol.-Jech. \& Mercado) Nawawi \& Kuthub.

Notes - Canalisporium was introduced to accommodate Berkleasmium caribense, $B$. pulchrum (Holubová-Jechová \& Mercado Sierra 1984) and Canalisporium elegans (Nawawi \& Kuthubutheen 1989). At present, 15 species are recognized in this genus (Zhao et al. 2012). Sriindrasutdhi et al. (2010) described a sexual morph for $C$. grenadoideum and introduced Ascothailandia, typified by A. grenadoidea. Dayarathne et al. (2019a) showed that this genus emerged at the crown age of 56 (23-94) MYA.

Dematiosporium Z.L. Luo, K.D. Hyde \& H.Y. Su, Fungal Divers.: 99: 573 (2019)

Index Fungorum number: IF555672; 1 species with sequence data.

Type species - Dematiosporium aquaticum Z.L. Luo, K.D. Hyde \& H.Y. Su

Notes - Dematisporium which is typified by $D$. aquaticum which mostly resembles Conioscypha aquatica in having micronematous conidiophores and dry, dark brown to black, globose to subglobose conidia (Luo et al. 2019). However, Dematisporium aquaticum is distinguished from Conioscypha aquatica in having larger conidia and $C$. aquatica belongs to Conioscyphaceae. 

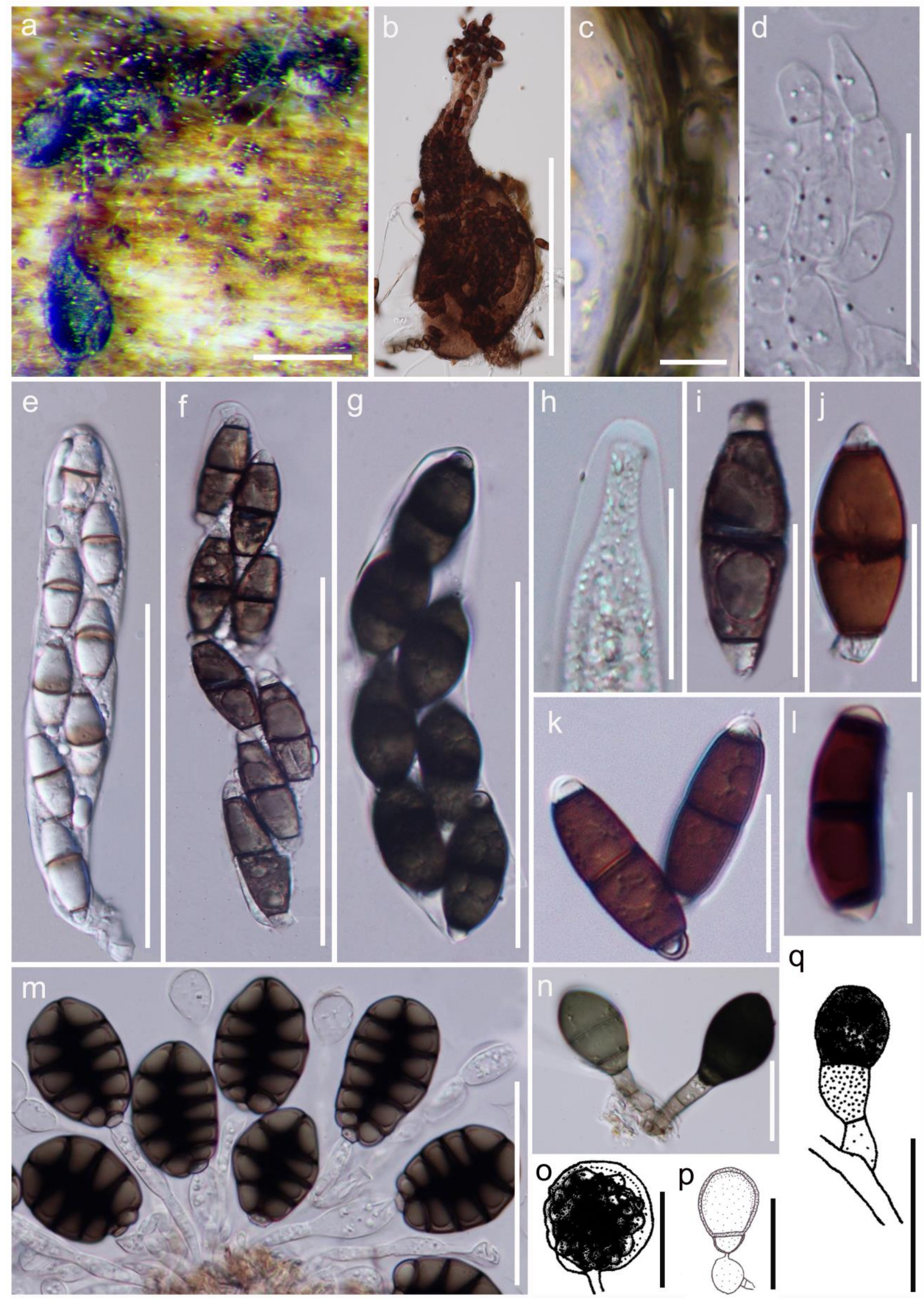

Figure 224 - Ascomatal, asci and ascospore morphology of the genera of Savoryellaceae: $S$. grandispora (Material examined - MALAYSIA, State Negara, Lipur Lentang Nature Reserve, on submerged wood, October 1991, K.D. Hyde, BRIP 20918, holotype), Savoryella lignicola 
(Material examined - UK, Flintshire, Connah's Quay, on Scots pine test-blocks placed for 168 days amongst the packing timber of a water -cooling tower at Connah's Quay, 16 June 1966 and 1 December 1966, IMI 129784, IMI 129785 holotype), S. longispora (Material examined - UK, Flintshire, Connah's Quay, on Scots pine test-blocks placed for 168 days amongst the packing timber of a water -cooling tower at Connah's Quay, 16 June1966 and 1 December 1966, IMI 129784, IMI 129785, holotype), S. yunnanensis (Material examined - CHINA, Yunnan Province, Dehong, on submerged wood in a stream, 25 November 2017, W. Dong, H40C, MFLU 18-1203, holotype), Canalisporium caribense (Material examined - THAILAND, Chiang Rai Province, stream flowing in Tham Luang Nang Non Cave, on submerged wood, 25 November 2014, J. Yang, MFLU15-3581, holotype). a, b Ascomata of S. lignicola. c, d Peridium and paraphyses of $S$. yunnanensis. e-g Asci of S. lignicola, S. grandispora, S. yunnanensis respectively. h Apical ring of S. grandispora. i-l Ascospores of S. grandispora, S. lignicola, S. longispora and S. yunnanensis respectively. $m$ Conidia attached to the conidiophores of $C$. caribense. $\mathrm{n}$ Conidia attached to the conidiophores of A. fusiformis. o-q Conidiogenous cells and conidia of A. lignicola (Chang 2001). c, d A. sawadae (Ranghoo \& Hyde 1998) A. uniseptata (Kirk 1983) respectively. Scale bars: b, c = $100 \mu \mathrm{m}, \mathrm{d}, \mathrm{e}=50 \mu \mathrm{m}, \mathrm{f}-\mathrm{i}=10 \mu \mathrm{m}$.

Savoryella E.B.G. Jones \& R.A. Eaton, Trans. Br. mycol. Soc. 52(1): 161 (1969)

Index Fungorum number: IF4870; 13 morphological species (Species Fungorum 2020), 9 species with sequence data.

Type species - Savoryella lignicola E.B.G. Jones \& R.A. Eaton

Notes - Savoryella (Jones \& Eaton 1969) currently comprises eleven species (HernandezRestrepo et al. 2017, Dayarathne et al. 2019a). Savoryella limnetica was combined under Ascotaiwania limnetica, re-described with a new asexual morph by Réblová et al. (2015c) and synonymized under Neoascotaiwania limnetica by Hernandez-Restrepo et al. (2017). However, Dayarathne et al. (2019a) synonymized Neoascotaiwania under Ascotaiwania. Savoryella has been placed in several orders; Sphaeriales family incertae sedis by Kohlmeyer \& Kohlmeyer (1979), ascomycetes incertae sedis by Kohlmeyer (1986), Amphisphaeriaceae (Eriksson \& Hawksworth 1986b) and Sordariales (Jones \& Hyde 1992). Barr (1990a) transferred this genus to Halosphaeriales (now Microascales) based on morphology (the catenophyses-like paraphyses) and ultrastructural observations. Vijaykrishna et al. (2006) and Cai et al. (2006a) referred Savoryella elongata and S. longispora to Hypocreales, subclass Hypocreomycetidae, based on a phylogenetic analysis of LSU data, although with weak statistical support. Jones et al. (2009) referred the genus to the Sordariales genera incertae sedis based on morphology. Boonyuen et al. (2011) introduced the new order Savoryellales to accommodate the genera Ascotaiwania, Ascothailandia (and its asexual morph, Canalisporium) and Savoryella based on multigene dataset. Dayarathne et al. (2019a) showed that divergence of this genus was 108 (72-146) MYA.

Schizoparmaceae Rossman, D.F. Farr \& Castl., Mycoscience 48(3): 137 (2007)

Index Fungorum number: IF82150; Facesoffungi number: FoF04613; 57 species.

Saprobic, endophytic, parasitic or pathogenic on fruits, leaves, stems, and roots of wide variety of woody and herbaceous plants, and in soil. Sexual morph: Ascomata perithecial, solitary, when collapsed collabent, scattered, subepidermal, erumpent to superficial, globose, coriaceous, brown to black, papillate, with periphysate ostiole in the center. Peridium of thick-walled, brown cells of textura angularis. Paraphyses lacking. Asci 8-spored, unitunicate, clavate to subcylindrical, sessile, with a J-, apical ring, floating free at maturity. Ascospores biseriate, hyaline, becoming pale brown at maturity, ellipsoidal, aseptate, with or without mucoid caps. Asexual morph: Coelomycetous. Conidiomata pycnidial, subepidermal, immersed to semi-immersed, erumpent, unilocular, globose, slightly depressed globose to subglobose, glabrous, brown to dark brown or black, ostiolate. Peridium of irregularly thickened, with plate-like orientation, comprising brown cells of textura angularis. Conidiophores densely aggregated, simple or branched at base, occasionally septate, smooth, hyaline, subulate, invested in mucus, developing from basal pad. 
Conidiogenous cells phialidic, often annellidic, subcylindrical, obclavate or lageniform, discrete, hyaline, smooth, proliferating percurrently, or with prominent periclinical thickening. Conidia hyaline, becoming olivaceous brown to brown at maturity, unicellular, smooth, thin- or thickwalled, ellipsoid, globose, napiform, fusiform or naviculate with a truncate base and an obtuse to apiculate apex, at times with a longitudinal germ slit, with or without a mucoid appendage (adapted from Rossman et al. 2007).

Type genus - Coniella Höhn.

Notes - Schizoparmaceae was introduced by Rossman et al. (2007) to accommodate Schizoparme and the asexual genera Coniella and Pilidiella (Rossman et al. 2007, Alvarez et al. 2016). Species of Schizoparmaceae are common in both tropical and temperate regions, worldwide (Rossman et al. 2007). Initially, the species in this family were placed in Melanconidaceae. Following Castlebury et al. (2002), who established the name 'Schizoparme complex' and their distinct lineage in Diaporthales, many comprehensive studies were conducted on the family (van Niekerk et al. 2004, Rossman et al. 2007, Alvarez et al. 2016). Even though, the family was established with three genera (Coniella, Pilidiella and Schizoparme), and after several taxonomic refinements, the family currently comprises a single genus (van Niekerk et al. 2004, Rossman et al. 2007, Alvarez et al. 2016). Based on the International Code of Nomenclature for algae, fungi and plants (McNeil et al. 2012), Alvarez et al. (2016) synonymized Pilidiella and Schizoparme under the accepted generic name Coniella. Schizoparmaceae has a stem age at 70 MYA (Hongsanan et al. 2017). However, authors have mentioned that the data set used in the study was not sufficient to represent this morphologically diverse family. Most of the previous studies of this genus used single gene phylogenies of ITS and LSU for species delimitation (Castlebury et al. 2002, van Niekerk et al. 2004, Miranda et al. 2012). This approach is accepted for the preliminary identification. Confusions and inconsistencies in this method were addressed by multigene phylogenetic approach used in Alvarez et al. (2016) and Chethana et al. (2017). Therefore, it is recommended to use ITS, LSU, tefl, rpb2 and histone (selection of 4 genes) in combined analyses (Fig. 227) to resolve Coniella species (Alvarez et al. 2016, Chethana et al. 2017).

\section{Ecological and economic significance of Schizoparmaceae}

Coniella species are economically important due to the negative role they play by causing foliar, fruit, leaf, stem and root diseases on a range of economically important plants. Coniella diplodiella and $C$. vitis cause grape white rot of grapes (Chethana et al. 2017); Coniella castaneicola causes fruit and leaf diseases on strawberry (Mass 1998). Coniella granti causes cankers, crown rots, die backs, fruit rots, leaf spots, shoot blights and twig blights on pomegranates (Chen et al. 2014, Mirabolfathy et al. 2012, KC \& Vallad 2016). Many of these hosts are fruit plants. Therefore, these diseases can lead to production losses and also reduce the marketability of the fruits.

$\mathrm{Yu}$ et al. (2018) reported seven Azaphilone derivatives known as coniellins A-G from Coniella fragariae. These Coniellins exhibited moderate cytotoxicity, significant inhibition of $\mathrm{NF \kappa B}$ activation in the triple negative breast cancer cell lines and reduced the tumour cell migration. This is the only report on natural products from this genus. Therefore, further studies might discover natural products from Coniella species.

\section{Genus included in Schizoparmaceae}

Coniella Höhn., Ber. Dt. Bot. Ges. 36(7): 316 (1918)

Index Fungorum number: IF7753; 57 morphological species (Species Fungorum 2020), 38 species with sequence data.

Type species - Coniella fragariae (Oudem.) B. Sutton

Notes - The cosmopolitan genus, Coniella was established by Höhnel (1918a) and is typified by Coniella pulchella (= Coniella fragariae). Species of this genus are plant pathogens (van Niekerk et al. 2004, Mirabolfathy et al. 2012, Chethana et al. 2017). In addition, they have saprobic, endophytic, and parasitic lifestyles, as well as being secondary invaders of plant tissues 
infected by other organisms or injured by other causes (Samuels et al. 1993, Ferreira et al. 1997, Alvarez et al. 2016). Several Coniella species are host-specific, contradictory to their wide host range (Alvarez et al. 2016, Chethana et al. 2017). This genus has been subjected to many revisions. Initially, Coniella and Pilidiella were given distinct identities due to their conidial pigmentation (von Arx 1973, 1981b). Conidial pigmentation was rejected as a distinguishing character and Pilidiella was synonymized under Coniella (Sutton 1980, Nag Raj 1993). With molecular data used in species delimitation, Coniella and Pilidiella were considered as distinct genera (Castlebury et al. 2002, van Niekerk et al. 2004, Wijayawardene et al. 2016b). In an attempt to resolve many species complexes residing in the genus, Alvarez et al. (2016) accepted Coniella as the only genus in Schizoparmaceae and synonymized Pilidiella and Schizoparme. The most recent phylogenetic status of this genus is by Chethana et al. (2017). Coniella destruens and Coniella vitis are illustrated in this study (Figs. 225, 226).
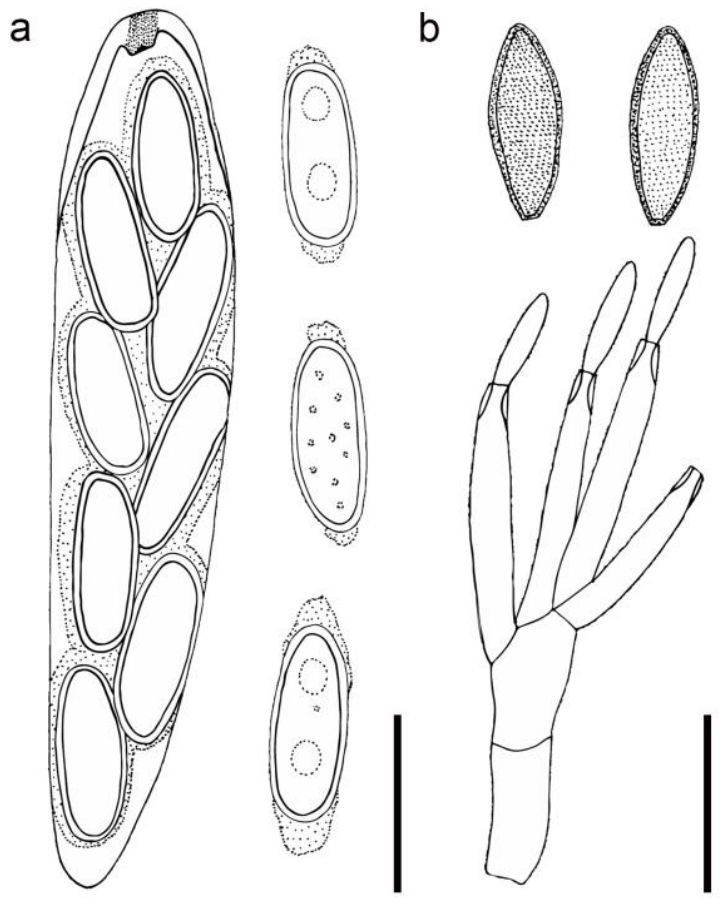

Figure 225 - Coniella destruens (redrawn from van Niekerk et al. 2014). a Ascus and ascospores of Coniella destruens. b Conidiophores and conidia of $C$. destruens. Scale bars: $\mathrm{a}, \mathrm{b}=10 \mu \mathrm{m}$.

Scortechiniaceae Huhndorf, A.N. Mill. \& F.A. Fernández, Mycol Res 108(12): 1387 (2004)

Index Fungorum number: IF82146; Facesoffungi number: FoF01123; 33 species.

Saprobic on woody substrates in terrestrial habitats. Sexual morph: Ascomata perithecial, scattered or gregarious, superficial, semi-immersed or immersed in host, sitting on or in a subiculum or subiculum absent, globose, obpyriform or ovoid, dark brown to black, coriaceous to membranous, turbinate or tuberculate or smooth, with or without brown branched setae, collabent or not collapsing. Subiculum thin or thick, brown to dark brown, septate, crisp when dry, branched or unbranched hyphae, with spines or smooth. Peridium thick, Munk pores present or absent, outer layer composed of black to brown cells of textura angularis, thick-walled; inner layer composed of hyaline cells of textura prismatica, thin-walled. Hamathecium Quellkörper present, conical, wide at the base, paraphyses absent or indistinct, filiform, hyaline. Asci 8- to multi-spored, unitunicate, cylindrical to clavate, long or short pedicellate, apical ring J-, indistinct or absent, evanescent. Ascospores 2-seriate to irregularly arranged, hyaline or light brown, allantoid, ellipsoid to oval, straight to slightly curved, aseptate, with or without appendages. Asexual morph: Conidiophores erect, solitary, straight to flexuous. Conidiogenous cells hyaline, smooth, subcylindrical. Conidia aseptate, hyaline, smooth, ellipsoid to ovoid, granular (adapted from Huhndorf et al. 2004a). 
Type genus - Scortechinia Sacc.

Notes - Scortechiniaceae was introduced by Huhndorf et al. (2004a) based on superficial, black, turbinate ascomata with a quellkörper and clavate asci with hyaline ascospores, as well as on LSU sequence analyses. The Quellkörper is believed to play a role to rupture the ascoma and probably is involved in ascospore discharge (Mugambi \& Huhndorf 2010). This structure was accepted as a main character to define this family when other morphs were not significant (Huhndorf et al. 2004a, Mugambi \& Huhndorf 2010, Carneiro de Almeida et al. 2016). Huhndorf et al. (2004a) accepted Euacanthe, Neofracchiae and Scortechinia as the members in the family based on LSU sequence data. Mugambi \& Huhndorf (2010) added Biciliospora, Coronophorella, Cryptosphaerella, Scortechiniella, Scortechiniellopsis, and Tympanopsis in Scortechiniaceae based on multi-gene phylogenetic analyses. Crous et al. (2013) introduced the monotypic genus, Pseudocatenomycopsis, which closely related to Neofracchiaea, Cryptosphaerella and Scortechiniellopsis based on LSU sequence analyses. Members of Scortechiniaceae constitute a strongly supported monophyletic group in Fig. 11. In this entry we illustrate Neofracchiaea callista. Most members of this family have molecular support for their inclusion, but several of the genera are monotypic.
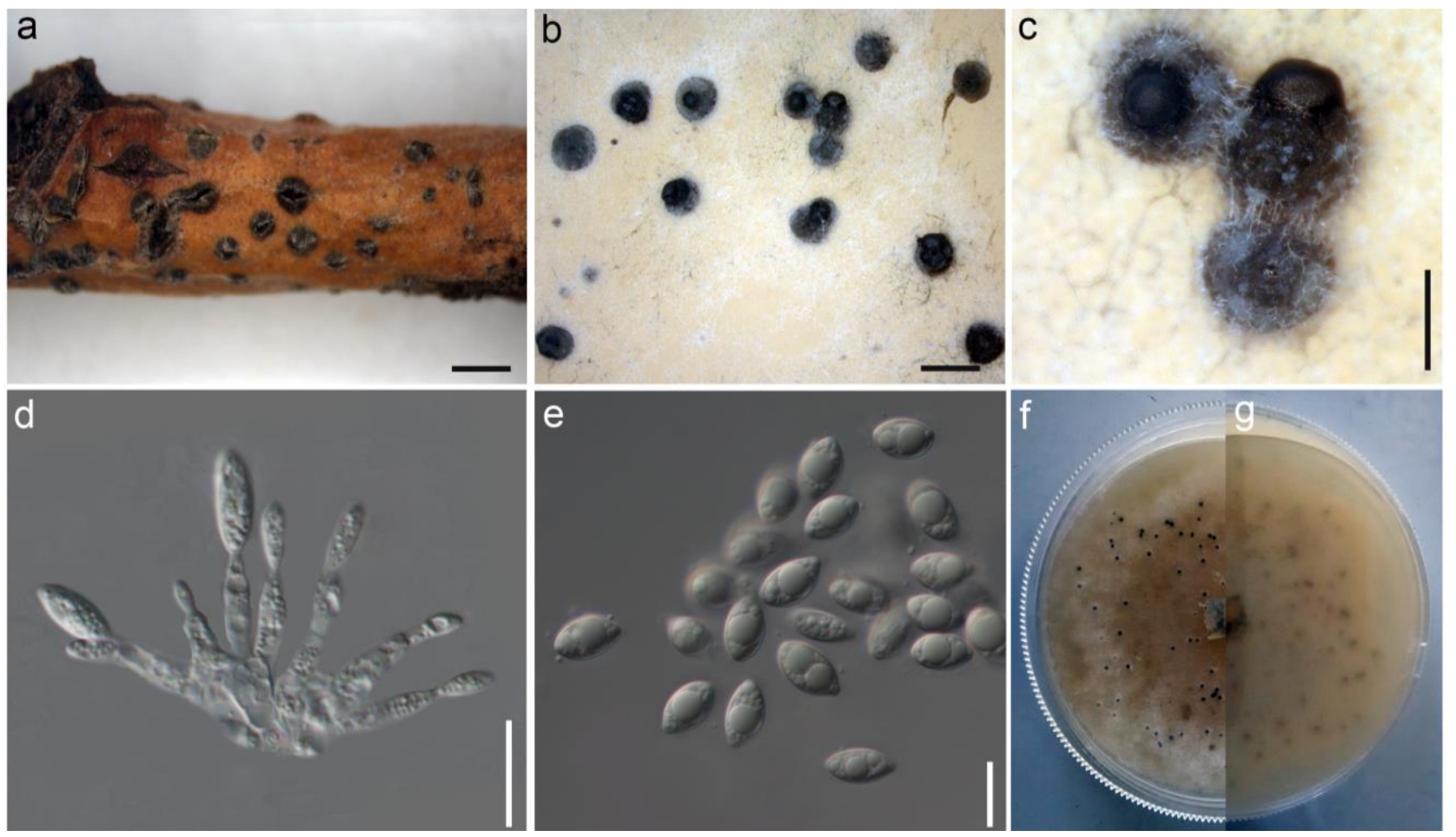

Figure 226 - Coniella vitis (Material examined - RUSSIA, Rostov Region, Shakhty City, on dead and dying branch of Salix alba L. (Salicaceae), 5 March 2016, T.S. Bulgakov, T1278 (MFLU 161572). a Host tissue. b Submerged pycnidia on PDA. c Close view of the pycnidia and the spore mass. d Conidiogenous cells. e Hyaline to brown conidia. f, g Upper view (f) and the reverse view (g) of the colony on the PDA. Scale bars: $\mathrm{a}, \mathrm{b}=1 \mathrm{~mm}, \mathrm{c}=500 \mu \mathrm{m}, \mathrm{d}=5 \mu \mathrm{m}, \mathrm{e}=10 \mu \mathrm{m}$.

\section{Ecological and economic significance of Scortechiniaceae}

Most Scortechiniaceae species are saprobic on wood and widespread worldwide (Saccardo 1882, Saccardo \& Berlese 1885, Höhnel 1909a, Petrak 1952a).

\section{Genera included in Scortechiniaceae}

Biciliospora Petr., Sydowia 6(5-6): 429 (1952)

Index Fungorum number: IF567; 1 species with sequence data.

Type species - Biciliospora velutina Petr. 
Notes - Biciliospora velutina has tuberculate ascomata and cylindrical asci with ellipsoid ascospores with filiform appendage at each ends (Petrak 1952a). Biciliospora was accepted as a member of Coronophoraceae or synonym of Nitschkia in Nitschkiaceae (Müller \& von Arx 1973, Nannfeldt 1975, Subramanian \& Sekar 1990). Mugambi \& Huhndorf (2010) however, reported it was a member of Scortechiniaceae based on multi-gene analysis.

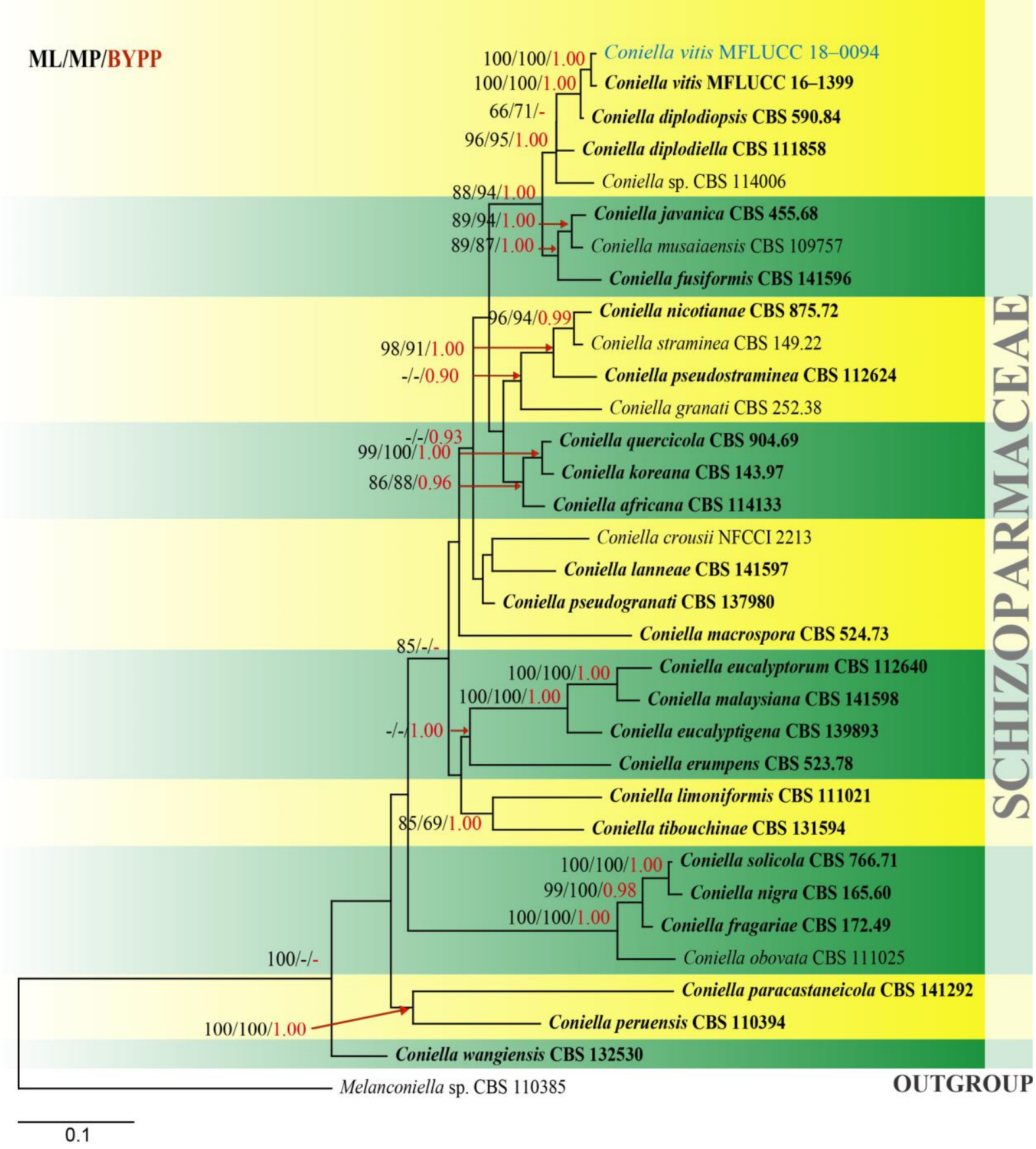

Figure 227 - Phylogenetic tree generated by maximum likelihood analysis of combined ITS, LSU, histone and tef1 sequence data of Coniella species. Related sequences were obtained from GenBank. Thirty-three strains are included in the analyses, which comprise 2876 characters including gaps. The tree was rooted with Melanconiella sp. (CBS 110385). Tree topology of the ML analysis was similar to the MP and BI. The best scoring RAxML tree with a final likelihood value of -15134.164466 is presented. The matrix had 807 distinct alignment patterns, with $23.87 \%$ of undetermined characters or gaps. Estimated base frequencies were as follows; $\mathrm{A}=0.249426, \mathrm{C}=$ $0.245786, \mathrm{G}=0.256290, \mathrm{~T}=0.248498$; substitution rates $\mathrm{AC}=0.996078, \mathrm{AG}=2.077237, \mathrm{AT}=$ $1.158367, \mathrm{CG}=0.708887, \mathrm{CT}=4.169021, \mathrm{GT}=1.000000$; gamma distribution shape parameter $\alpha$ 
$=0.145978$. The maximum parsimonious dataset consisted of constant 2083, 512 parsimonyinformative and 282 parsimony-uninformative characters. The parsimony analysis of the data matrix resulted in the maximum of five equally most parsimonious trees with a length of 2495 steps $(\mathrm{CI}=0.532, \mathrm{RI}=0.583, \mathrm{RC}=0.310, \mathrm{HI}=0.468)$ in the first tree. $\mathrm{RAxML}$ and maximum parsimony bootstrap support values $\geq 60 \%$ (black) and Bayesian posterior probabilities $\geq 0.90$ (red) are shown near the nodes. The scale bar indicates 0.1 changes. The ex-type strains are in bold.

Coronophorella Höhn., Sber. Akad. Wiss. Wien, Math.-naturw. Kl., Abt. 1 118: 1507 (1909)

Index Fungorum number: IF1255; 1 species with sequence data.

Type species - Coronophorella chaetomioides (Penz. \& Sacc.) Höhn.

Notes - Coronophorella chaetomioides is characterised by reniform ascospores and is considered as a member of Coronophoraceae (Nannfeldt 1975). It was accepted as a member of Scortechiniaceae based on multi-gene analysis by Mugambi \& Huhndorf (2010).

Cryptosphaerella Sacc., Syll. fung. (Abellini) 1: 186 (1882)

Index Fungorum number: IF1329; 18 morphological species (Species Fungorum 2020), 6 species with sequence data.

Type species - Cryptosphaerella nitschkei (Auersw.) Sacc.

Notes - Cryptosphaerella has multi-spored asci with allantoid ascospores (Saccardo 1882). This genus was considered as a synonym of Coronophora (Nannfeldt 1975) or a member of Coronophoraceae (Subramanian \& Sekar 1990). It was clarified as an independent genus of Scortechiniaceae based on multi-gene analysis (Mugambi \& Huhndorf 2010). The monophyletic Cryptosphaerella is closely related to Biciliospora, Scortechiniella and Scortechiniellopsis (Fig. $11)$.

Euacanthe Theiss., Annls mycol. 15(3/4): 272 (1917)

Index Fungorum number: IF1906; 1 species with sequence data.

Type species - Euacanthe usambarensis (Rehm) Theiss.

Notes - Euacanthe was established and considered as a synonym of Acanthonitschkea, Nitschkiaceae or a member of Coronophoraceae (Theissen 1917, Nannfeldt 1975, Subramanian \& Sekar 1990). A second species, E. foveolata (三Sphaeria foveolata) was accepted as a member of Scortechiniaceae based on multi-gene analysis (Subramanian \& Sekar 1990, Mugambi \& Huhndorf 2010).

Neofracchiaea Teng, Sinensia, Shanghai 9: 255 (1938)

Index Fungorum number: IF3454; 1 species with sequence data.

Type species - Neofracchiaea callista (Berk. \& M.A. Curtis) Teng

Notes - Neofracchiaea callista has multi-spored asci with ellipsoid ascospores (Teng 1938) and was treated as synonym of Nitschkia (Nannfeldt 1975). Mugambi \& Huhndorf (2010) accepted it as a member of Scortechiniaceae based on multi-gene analysis.

Pseudocatenomycopsis Crous \& L.A. Shuttlew., Persoonia 31: 221 (2013)

Index Fungorum number: IF805836; 1 species with sequence data.

Type species - Pseudocatenomycopsis rothmanniae Crous \& L.A. Shuttlew.

Notes - Pseudocatenomycopsis rothmanniae has hyaline, ovoid, granular conidia. Pseudocatenomycopsis, the only asexual genus of Scortechiniaceae nests in clade of Scortechiniaceae (Fig. 11).

Scortechinia Sacc., Atti Inst. Veneto Sci. lett., ed Arti, Sér. 6 3: 713 (1885)

Index Fungorum number: IF4968; 3 morphological species (Species Fungorum 2020), 2 species with sequence data.

Type species - Scortechinia acanthostroma (Mont.) Sacc. \& Berl. 
Notes - Scortechinia is characterized by tuberculate ascomata with a quellkörper, clavate asci and obovate ascospores (Huhndorf et al. 2004a). It nested in the clade of Scortechiniaceae and is related to Neofracchiaea callista (Fig. 11).

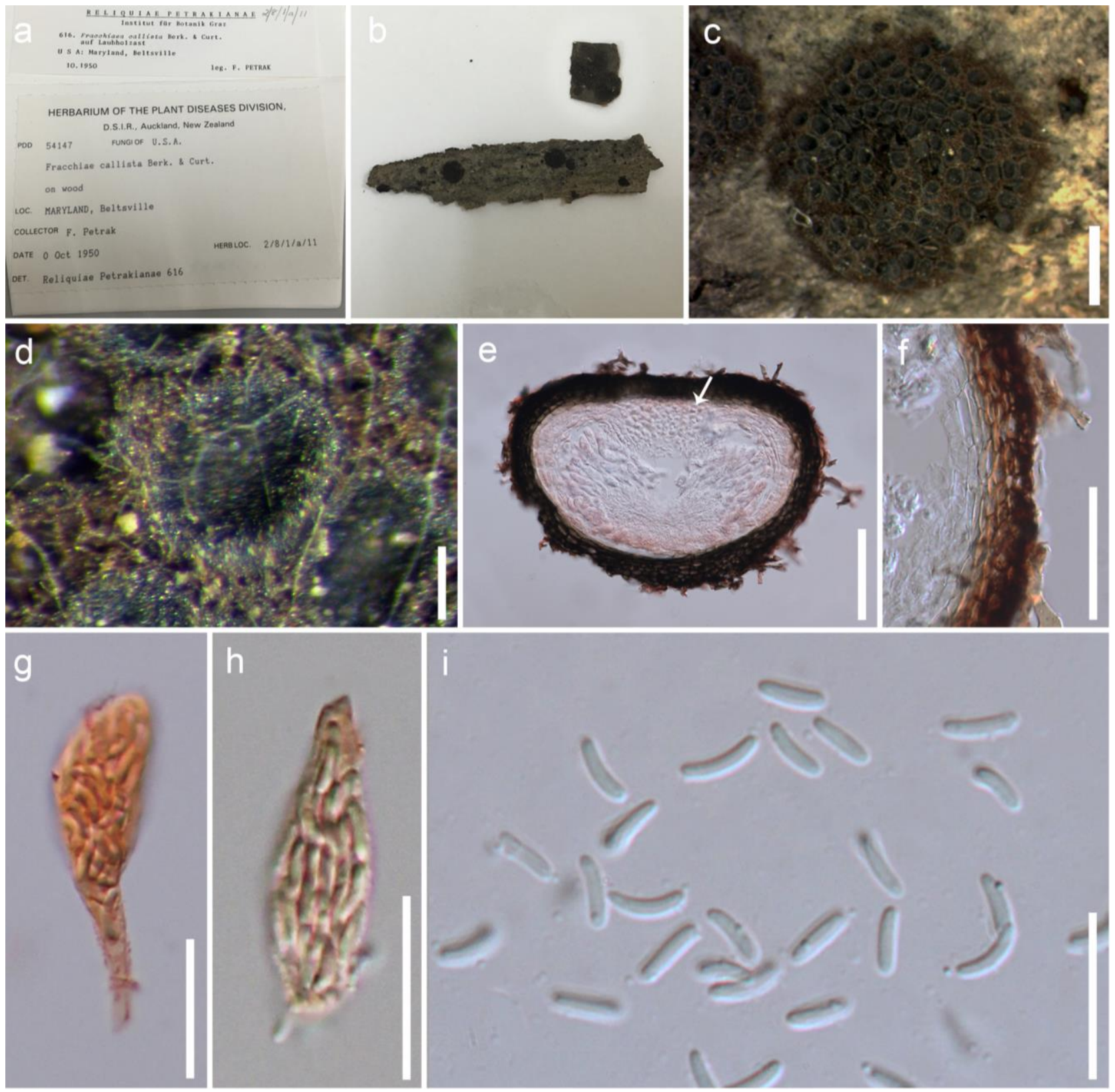

Figure 228 - Neofracchiaea callista (Material examined - USA, Maryland, Beltsville; on wood, October 1950, F. Petrak, PDD 54147). a Material label. b Specimen c Ascomata subimmersed in subiculum on substrate. d Collapsing ascoma. e Section through ascoma with quellkörper (arrowhead). f Peridium. g, h Asci. i Ascospores. Notes: figs. e, g-h are stained in Congo red reagent. Scale bars: $\mathrm{c}=1 \mathrm{~cm}, \mathrm{~d}-\mathrm{e}=100 \mu \mathrm{m}, \mathrm{f}=50 \mu \mathrm{m}, \mathrm{g}-\mathrm{i}=20 \mu \mathrm{m}$.

Scortechiniella Arx \& E. Müll., Beitr. Kryptfl. Schweiz 11(no. 1): 382 (1954)

Index Fungorum number: IF4969; 1 species with sequence data.

Type species - Scortechiniella similis (Bres.) Arx \& E. Müll.

Notes - Scortechiniella similis has multi-spored asci and obovate ascospores with filiform appendages at each end (von Arx \& Müller 1954) and was accepted as a member of Coronophoraceae (Müller \& von Arx 1973, Nannfeldt 1975). Mugambi \& Huhndorf (2010) however, accepted it as a member of Scortechiniaceae based on multi-gene analysis. 
Scortechiniellopsis Sivan., Trans. Br. mycol. Soc. 62(1): 36 (1974)

Index Fungorum number: IF4970; 1 species with sequence data.

Type species - Scortechiniellopsis leonensis Sivan.

Notes - Scortechiniellopsis leonensis has multi-spored asci and reniform ascospores (Sivanesan 1974) and was accepted as a synonym of Nitschkia (Nannfeldt 1975). Mugambi \& Huhndorf (2010) however, accepted it as a member of Scortechiniaceae based on multi-gene analysis.

Tympanopsis Starbäck, Bih. K. svenska VetenskAkad. Handl., Afd. 3 19(no. 2): 24 (1894)

Index Fungorum number: IF5651; 5 morphological species (Species Fungorum 2020), 1 species with sequence data.

Type species - Tympanopsis euomphala (Berk. \& M.A. Curtis) Starbäck

Notes - Tympanopsis euomphala is characterised by pyriform asci with ellipsoid ascospores and was considered as a member of Coronophoraceae (Starbäck 1894, Nannfeldt 1975, von Arx 1981a). It was considered as a member of Scortechiniaceae based on multi-gene analysis by Mugambi \& Huhndorf (2010).

Sordariaceae G. Winter, Rabenh. Krypt.-Fl., Edn 2 (Leipzig) 1.2: 162 (1885)

Index Fungorum number: IF81384; Facesoffungi number: FoF01148; 113 species.

Saprobic on wood, rotting vegetation and dung in terrestrial habitats, also associated with food. Sexual morph: Ascomata perithecial or cleistothecial, brown to black, gregarious or scattered, solitary, superficial, erumpent or immersed, globose, subglobose to ovoid, carbonaceous, coriaceous or membranaceous, tuberculate or smooth, with setae or hairs, papillate or papilla indistinct or absent, ostiolate, with hyaline periphyses or periphyses absent. Peridium relatively thick, carbonaceous, coriaceous or membranaceous, comprising brown to hyaline cells of textura angularis or globulosa or prismatica. Paraphyses numerous, septate, un- or branched, filiform or cylindrical or absent. Asci 8-spored, unitunicate, cylindrical to clavate, pedicellate, J-. Ascospores uniseriate or biseriate, hyaline, yellowish, brown or black, stellate, oval or ellipsoid, 0-1-septate, concolorous or versicolorous, with or without guttules, uneven in thickness with striate to reticulate patterns or with a sheath, with or without germ pores, appendages present or absent. Asexual morph: Undetermined (adapted from Maharachchikumbura et al. 2016b).

Type genus - Sordaria Ces. \& De Not.

Notes - Sordariaceae was introduced by Winter (1885b) based on brown to black ascomata and cylindrical asci with brown to black ascospores, and is typified by Sordaria. Most species in this family are coprophilous and can be heterothallic, homothallic or pseudo-homothallic (Dutta et al. 1976, Cai et al. 2006c). Species of Sordariaceae have unique ascospores and Copromyces, Effetia, Guilliermondia and Stellatospora are coprophilous taxa but without sequence data. Ascospores with glutinous sheaths or/and special ornamentations on the wall were considered to be similar characters as found in Sordariaceae and Lasiosphaeriaceae (Lundqvist 1972, Huhndorf et al. 2004b, Cai et al. 2006c). Multi-gene analysis placed Neurospora, Pseudoneurospora and Sordaria in Sordariaceae and related to Lasiosphaeriaceae (Huhndorf et al. 2004b, Cai et al. 2006b, c, Maharachchikumbura et al. 2015b, 2016b, Hyde et al. 2017a). In this entry we illustrate Guilliermondia saccoboloides Boud.

\section{Ecological and economic significance of Sordariaceae}

Most species of Sordariaceae were isolated from dung of herbivores and are saprobes important in nutrient cycling. Some of the homothallic species has a long-standing history as model organisms, viz. Neurospora crassa, Sordaria fimicola and Sordaria macrospora (Kück et al. 2009, Thatoi et al. 2013, Froyd et al. 2014, Kuo et al. 2014, Newcombe et al. 2016). 
Index Fungorum number: IF1230; 2 morphological species (Species Fungorum 2020), 1 species with sequence data.

Type species - Copromyces bisporus N. Lundq.

Notes - Copromyces has 2-spored asci and globose ascospores (Lundqvist 1967). Huhndorf et al. (2004b) and Vu et al. (2019) used LSU and ITS sequence data from Copromyces octosporus (CBS 386.78) which was provided by J.C. Krug (TRTC 51747).

Effetia Bartoli, Maggi \& Persiani, Mycotaxon 19: 517 (1984)

Index Fungorum number: IF25588; 1 morphological species.

Type species - Effetia craspedoconidica Bartoli, Maggi \& Persiani

Notes - The monotypic genus Effetia is characterized by aseptate, oval conidia with sheaths and has irregular, brown chlamydospores (Bartoli et al. 1984).

Guilliermondia Boud., Bull. Soc. mycol. Fr. 20(1): 19 (1904)

Index Fungorum number: IF2150; 1 morphological species.

Type species - Guilliermondia saccoboloides Boud.

Notes - This monotypic genus Guilliermondia has sphaerical asci and ellipsoid ascospores surrounded by a brown sheath (Boudier 1904).
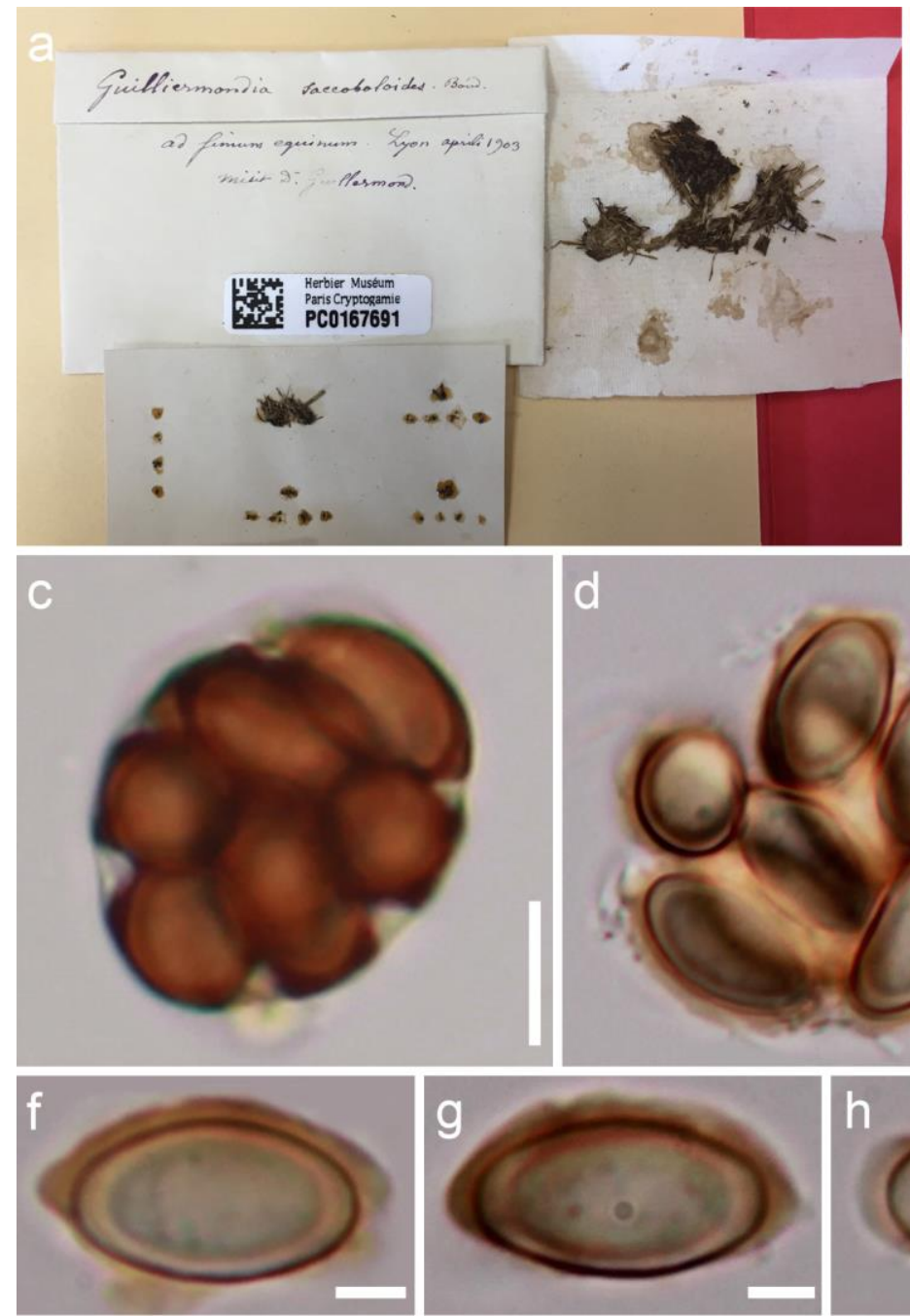
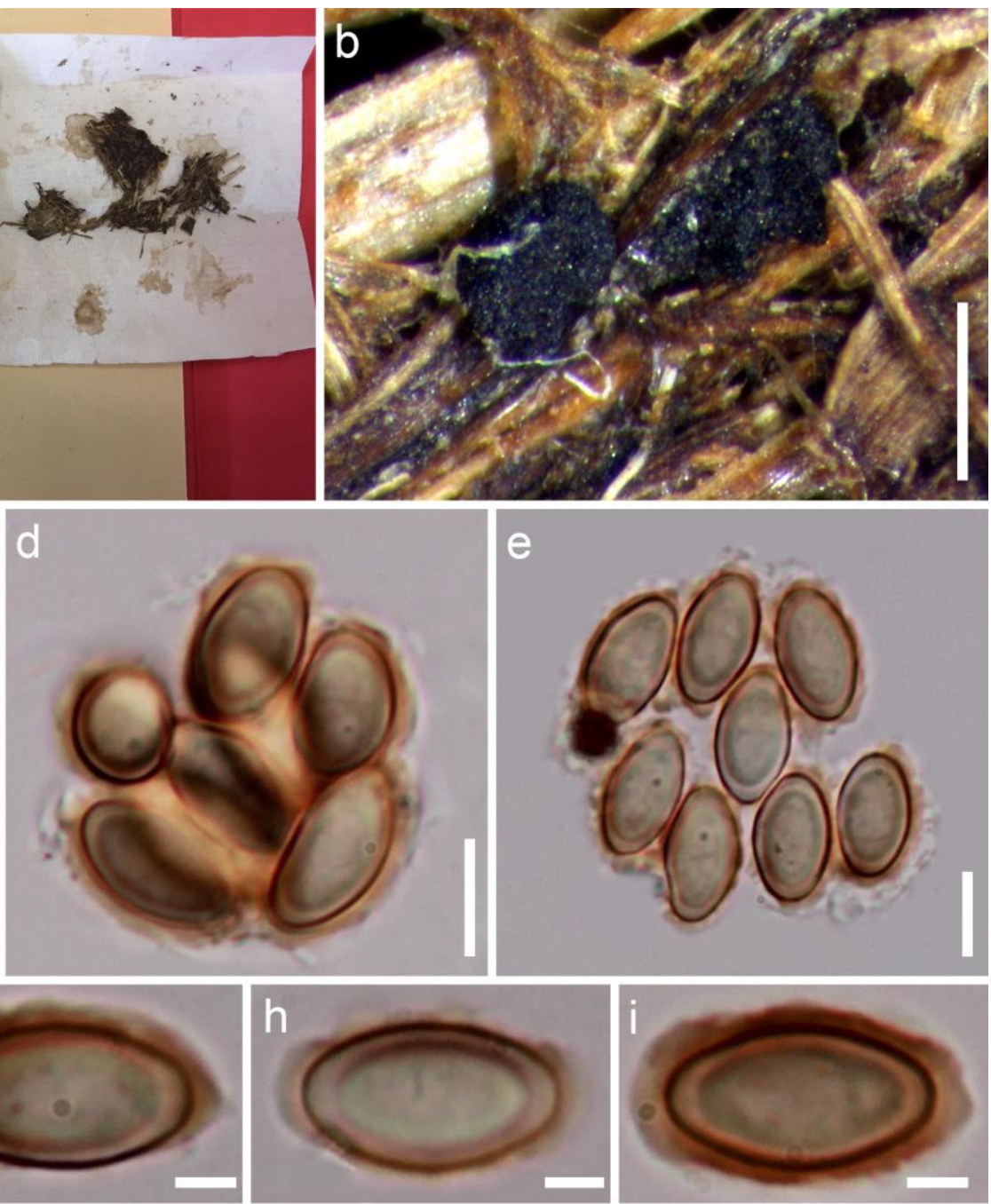

Figure 229 - Guilliermondia saccoboloides (Material examined - FRANCE, Lyon, 69 Rhôneon, on horse dung, April 1903, MAA Guilliermond, PC 0167691, holotype). a Label and material. b Ascomata. c-e Asci. f-i Ascospores. Scale bars: $b=500 \mu \mathrm{m}, \mathrm{c}-\mathrm{e}=5 \mu \mathrm{m}, \mathrm{f}-\mathrm{i}=2 \mu \mathrm{m}$. 
Neurospora Shear \& B.O. Dodge, J. Agric. Res., Washington 34: 1025 (1927)

Index Fungorum number: IF3502; 56 morphological species (Species Fungorum 2020), 35 species with sequence data.

Type species - Neurospora sitophila Shear \& B.O. Dodge

Notes - Neurospora is the largest genus in Sordariaceae. It is characterized by cylindrical asci and brown ascospores with striate to reticulate patterns on the wall. Gelasinospora was accepted as a synonym of Neurospora based on LSU analysis (García et al. 2004).

Pseudoneurospora Dania García, Stchigel \& Guarro, Mycol. Res. 108(10): 1139 (2004)

Index Fungorum number: IF28887; 2 species with sequence data. Guarro

Type species - Pseudoneurospora amorphoporcata (Udagawa) Dania García, Stchigel \&

Notes - Gelasinospora amorphoporcata was transferred to Pseudoneurospora as the type species (García et al. 2004) and a second species P. canariensis was introduced by Crous et al. (2014a). Species have brown ascomata with cylindrical asci and ellipsoid ascospores with an epispore with an irregular pattern (García et al. 2004, Crous et al. 2014a).

Sordaria Ces. \& De Not., Comm. Soc. crittog. Ital. 1(4): 225 (1863)

Index Fungorum number: IF5061; 50 morphological species (Species Fungorum 2020), 15 species with sequence data.

Type species - Sordaria fimicola (Roberge) Ces. \& De Not.

Notes - This mainly coprophilous genus has perithecial ascomata, cylindrical asci and brown ascospores, some with appendages, sheaths and/or pores and may also be saprobic on wood (Barr 1990b, Maharachchikumbura et al. 2016b). Species such as S. fimicola occur on herbaceous plants, wood and soil (Lundqvist 1972, Chambers \& De Wet 1987, Alma et al. 2000, Kavak 2012, Ivanová 2015). A new species, S. clematidis, will be introduced from the UK on Clematis by Phukhamsakda et al. (2020).

Stellatospora Tad. Ito \& Nakagiri, Mycoscience 35(4): 413 (1994)

Index Fungorum number: IF27456; 1 morphological species.

Type species - Stellatospora terricola Tad. Ito \& Nakagiri

Notes - The monotypic genus Stellatospora was isolated from soil and is characterized by obpyriform asci with stellate ascospores (Ito \& Nakagiri 1994).

Spathulosporaceae Kohlm., Mycologia 65(3): 615 (1973)

Index Fungorum number: IF81388; Facesoffungi number: FoF01798; 6 species.

Parasitic on marine algae. Sexual morph: Ascomata subglobose, ovoid, pyriform, subiculate, coriaceous or leathery, dark brown, sterile hairs enclosing ascoma, ostiolate, ostiolar canal surrounded by tube-like projection extending into the ascomatal cavity, papillate or epapillate. Paraphyses lacking. Asci 8-spored, clavate to subglobose, thin-walled, unitunicate, without apical ring, deliquescing early. Ascospores overlapping multi-seriate, hyaline, fusiform, cylindrical or ellipsoidal, aseptate to 3-septate, with apical appendages. Reproductive structures: Antheridial. Spermatia ellipsoidal to fusiform, without appendages. Trichogynes simple or branched, septate, arising from the margin of young ascoma (adaped from Maharachchikumbura et al. 2016b).

Type genus - Spathulospora A.R. Caval. \& T.W. Johnson

Notes - Spathulosporaceae is characterized by crustose, dark thalli, peg-like individual penetrating cells, intracellular crusts and stromata, antheridia with spermatia and trichogynes, ostiolate ascomata without paraphyses, deliquescing asci, and 1-celled, appendaged ascospores. The genus was introduced by Cavaliere \& Johnson (1965) and currently comprises Spathulospora and Retrostium with six species (Nakagiri \& Ito 1997, Index Fungorum 2020, Jones et al. 2019). However, sequence data are available only for S. antarctica and S. adelpha. This family was first placed in Spathulosporales then so as to read and then in Lulworthia (Kohlmeyer 1973, Inderbitzin 
et al. 2004, Campbell et al. 2005, Jones et al. 2009). However, Maharachchikumbura et al. (2015, 2016b) confirmed the placement of Spathulosporaceae in Spathulosporales by molecular analysis using available sequence data. Spathulospora was introduced by Cavaliere \& Johnson (1965) and referred to the Spathulosporomycetes, Spathulosporomycetidae (Locquin 1984), Spathulosporales (Kohlmeyer 1973), Spathulosporaceae (Kohlmeyer 1973). It is a marine genus on the seaweed Ballia spp. (Rhodophyta), and is typified by Spathulospora phycophila. However, two Spathulospora species (S. antarctica, S. adelpha), have shown a relationship to Lulworthiales, but with low support (Inderbitzin et al. 2004, Campbell et al. 2005, Jones et al. 2009, 2019). There are no sequences for the type of this genus, hence, new collections, isolations and sequencing are required to determine its phylogenetic placement.

\section{Ecological and economic significance of Spathulosporaceae}

Spathulospora species are obligate parasites on some marine algae (Ballia spp.) and may cause malformations. They proliferate in the host cells without penetrating the plasma membrane, and only afterwards form the stroma and sexual structures on the surface, presumably using nutrients acquired from the host. In some cases, the interaction of species of Spathulospora and host triggers a reaction analogous to witches' broom in vascular plants: the alga produces long hairs, which surround the stromata and ascomata of the fungus (Inderbitzin et al. 2004). Retrostium species inhabit marine Rhodophytes in coastal habitats. This fungus forms mononematous spermatiophores with penicillate phialides and trichogynes at the edge of ascomata on the surface of the host alga and consume nutrients (Nakagiri \& Ito 1997).

\section{Genera included in Spathulosporaceae}

Retrostium Nakagiri \& Tad. Ito, Mycologia 89(3): 485 (1997)

Index Fungorum number: IF27834; 1 morphological species.

Type species - Retrostium amphiroae Nakagiri \& Tad. Ito

Notes - This genus was introduced by Nakagiri \& Ito (1997) to accommodate R. amphiroae, a taxon inhabiting Amphiroa zonata (marine Rhodophyta) in coastal habitats in Japan (Nakagiri \& Ito1997). Molecular data are unavailable for the species of this genus. Ascomata of R. amphiroae are conical to hemisphaerical, superficial, carbonaceous, epapillate and ostiolate (Nakagiri \& Ito 1997). The ostiolar canal is surrounded by a tube-like projections extending into the ascomatal cavity and the two-layered peridial structure is similar to that of Spathulospora (Nakagiri \& Ito 1997). This taxon differs from Spathulospora by thalli, ascomatal structure, ascospores and host (Kohlmeyer 1973, Nakagiri \& Ito 1997). Retrostium amphiroae has true hyphae that grow between host cells, unlike Spathulospora, which have crustose thalli with "intramural hyphae" that invade the host cells (Kohlmeyer 1973). Paraphyses are absent, but pseudoparenchyma cells are present, similar to S. lanata (Kohlmeyer \& Kohlmeyer 1975). Ascospores are 1-celled, oblong and furnished with a mucilaginous appendage at each end, while some Spathulospora species have spathulate ascospores (Kohlmeyer \& Kohlmeyer 1975). Antheridium of $R$. amphiroae is a mononematous spermatiophore rather than a spermodochium as in Hispidicarpomyces and spermatia lack appendages as in Hispidicarpomyces, but can be distinguished by shape, as the latter forms a clavate spermatium with a cupulate base (Nakagiri \& Ito 1997).

Spathulospora A.R. Caval. \& T.W. Johnson, Mycologia 57(6): 927 (1965)

Index Fungorum number: IF5071; 5 morphological species (Species Fungorum 2020), 2 species with sequence data.

Type species - Spathulospora phycophila A.R. Caval. \& T.W. Johnson

Notes - Spathulospora phycophila was illustrated in Maharachchikumbura et al. (2016b) and thus is not illustrated here.

Sporidesmiaceae Fr., Summa veg. Scand., Section Post. (Stockholm): 504 (1849) Index Fungorum number: IF81405; Facesoffungi number: FoF01830; 188 species. 


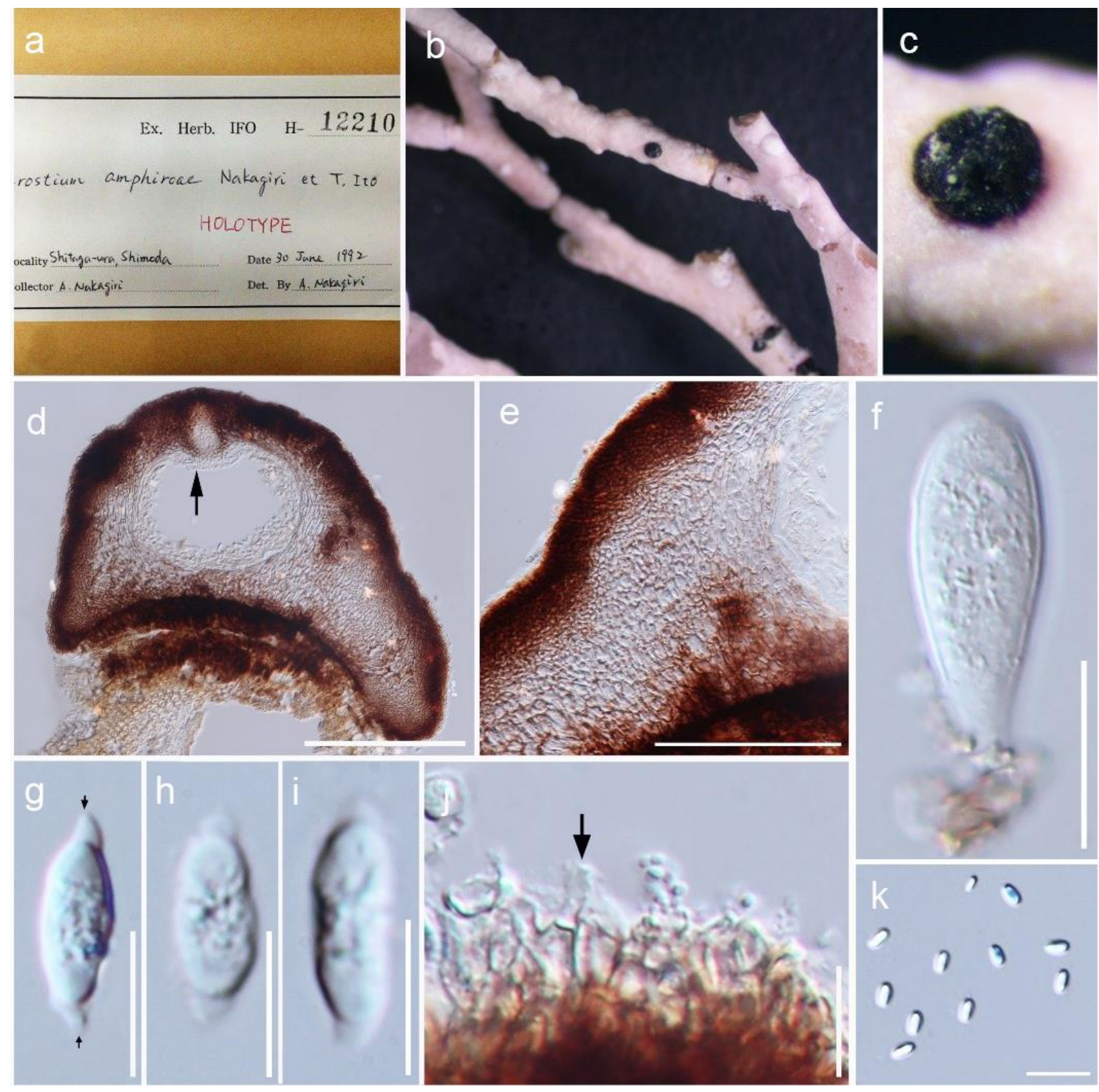

Figure 230 - Retrostium amphiroae (Material examined - JAPAN, Honshu: Shizuoka Pref., Shimoda, on living thalli of Amphiroa zonata, 30 June 1992, A. Nakagiri, IFO H-12210, holotype) a Herbarium material. b Host. c Ascomata on host surface. d Section through ascoma (arrow indicates tube-like projection extending into the ascoma cavity). e Peridium. f Ascus. g-i Ascospores. $\mathrm{j}$ Broken pieces of outgrowths attached to the ascomata outer wall. $\mathrm{k}$ Spermatiophores arising from the margin of young ascoma. Scale bars: $d=100 \mu \mathrm{m} . \mathrm{e}=50 \mu \mathrm{m}, \mathrm{f}, \mathrm{i}=20 \mu \mathrm{m}, \mathrm{g}-\mathrm{i}=10$ $\mu \mathrm{m}, \mathrm{j}=5 \mu \mathrm{m}$.

Saprobic on woody debris in terrestrial and aquatic habitats or mycoparasites. Sexual morph: Ascomata perithecial, scattered or solitary, immersed with neck erumpent through host surface, uniloculate, subglobose or ellipsoidal. Neck cylindrical, central or lateral. Ostiolum periphysate. Peridium three-layered. Paraphyses numerous, hypha-like, hyaline, septate, unbranched, persistent, embedded in a gelatinous matrix. Asci 8-spored, unitunicate, long cylindrical, apically rounded, with a distinct, relatively small, refractive, J-, wedge-shaped, apical ring. Ascospores obliquely uniseriate, hyaline, fusiform, septate, with a thin sheath. Asexual morph: Colonies black, effuse. Mycelium comprising hyaline to pale brown, branched, septate, thin-walled hyphae. Conidiophores solitary or in clusters, single, or sometimes aggregated in groups, brown, cylindrical, straight or 
curved, erect or somewhat repent, septate, smooth-walled. Conidiogenous cells monoblastic, holoblastic, terminal, cylindrical, brown, elongating once or twice percurrently at the apex. Conidia dry, solitary, medium brown, smooth, obclavate to cylindrical or fusoid, straight to flexuous, apex obtuse, base obconically truncate, smooth-walled.

Type genus - Sporidesmium Link

Notes - Sporidesmiaceae was introduced by Fries (1849) and has received very little usage. Presently, there is only one genus accepted in this family. Shenoy et al. (2006) found that Sporidesmium and morphologically similar genera are not monophyletic, as they are distributed among different families and orders in Dothideomycetes and Sordariomycetes. Su et al. (2016b) reported similar results. A monophyletic clade with species resembling the type species of Sporidesmium was designated as Sporidesmiaceae sensu stricto, and a new family Distoseptisporaceae was introduced to accommodate a new sporidesmium-like genus Distoseptispora (Su et al. 2016b).

\section{Ecological and economic significance of Sporidesmiaceae}

Saprobes have the ability to decompose lignocellulose in woody litter, resulting in the softening of the wood and release of nutrients in the form of simple molecules that are reused by plants and other organisms (Yuen et al. 1998, Bucher et al. 2004). Thus, they play an important role in nutrient and carbon cycling, biological diversity and ecosystem functioning (Palmer et al. 1997, Wong et al. 1998a).

\section{Genus included in Sporidesmiaceae}

Sporidesmium Link, Mag. Gesell. naturf. Freunde, Berlin 3(1-2): 41 (1809)

Index Fungorum number: IF10024; 188 morphological species (Species Fungorum 2020), 17 species with sequence data.

Type species - Sporidesmium atrum Link

Notes - Sporidesmium is a large and heterogeneous genus. To date, 383 epithets are referred to the genus (Index Fungorum 2020). However, many previously described species were revised and transferred to over 30 genera (Iturriaga et al. 2008). Studies based on phylogenetic analysis have been carried out to further re-examine the classification of sporidesmium-like taxa, given that the generic delimitations based on morphology data appear to be questionable. Sporidesmium and morphologically similar genera are clearly not monophyletic, as they are distributed among different families and orders in Dothideomycetes and Sordariomycetes (Shenoy et al. 2006, Su et al. 2016b, Yang et al. 2017). Sporidesmium was an asexual genus until Zhang et al. (2017a) introduced a sexual morph species Sporidesmium thailandense which is collected from freshwater habitat in Thailand. In this entry, we introduce a new species Sporidesmium dulongense based on morphology and phylogeny. It was collected from a freshwater river in northwestern Yunnan Province, China.

Sporidesmium dulongense Z.L. Luo, K.D. Hyde \& H.Y. Su, sp. nov.

Fig. 231

Index Fungorum number: IF555377; Facesoffungi number: FoF04924

Etymology - Referring to the collect location of the fungus.

Holotype - HKAS 92659.

Saprobic on submerged decaying wood. Sexual morph: Undetermined. Asexual morph: Colonies effuse on natural substrate, scattered, hairy, dark brown to black. Mycelium immersed, composed of septate, branched, brown, smooth hyphae. Conidiophores 88-124 $\mu \mathrm{m}(\bar{x}=106 \mu \mathrm{m}$, $\mathrm{SD}=18, \mathrm{n}=25), 5.5-7.5 \mu \mathrm{m}(\bar{x}=6.5 \mu \mathrm{m}, \mathrm{SD}=1, \mathrm{n}=25)$, macronematous, mononematous, unbranched, erect, straight or flexuous, dark brown, septate, smooth. Conidiogenous cells monoblastic, holoblastic, terminal, determinate, dark brown, cylindrical. Conidia $50-58 \mu \mathrm{m}(\bar{x}=$ $54 \mu \mathrm{m}, \mathrm{SD}=4, \mathrm{n}=30), 13-15 \mu \mathrm{m}(\bar{x}=14 \mu \mathrm{m}, \mathrm{SD}=1, \mathrm{n}=30)$, acrogenous, solitary, dry, lageniform, straight or slight curved, tapering and hyaline at apex, truncate at base, dark brown, septate, with sphaerical guttules in almost all cells, smooth-walled. 

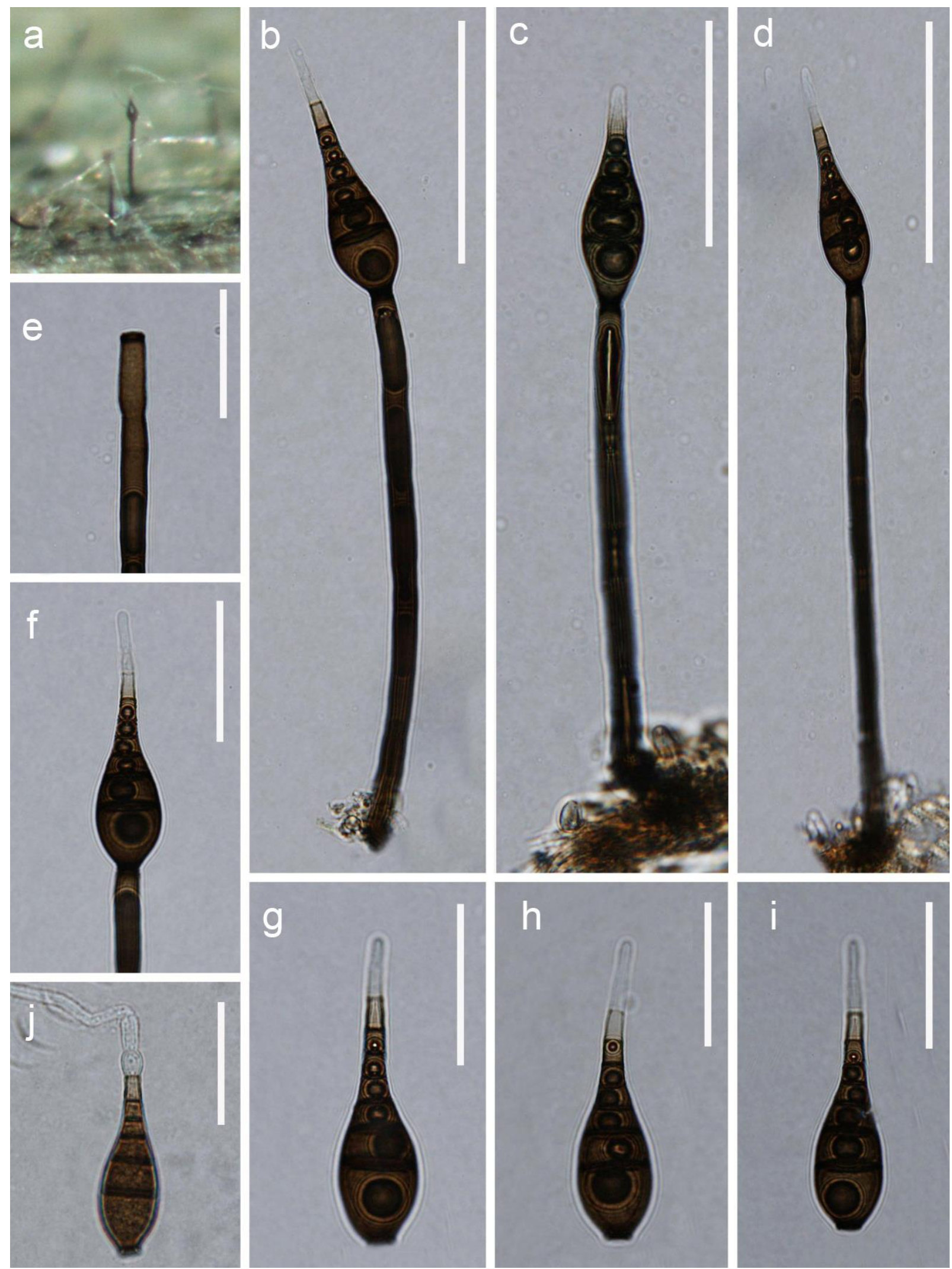

Figure 231 - Sporidesmium dulongense (HKAS 92659, holotype). a Colonies on wood. b-d Conidiophore with conidia. e, f Conidiogenous cells. g-i Conidia. j Germinating conidium. Scale bars: $b=55 \mu \mathrm{m}, \mathrm{c}, \mathrm{d}=45 \mu \mathrm{m}, \mathrm{e}, \mathrm{h}, \mathrm{j}=25 \mu \mathrm{m}, \mathrm{f}-\mathrm{g}, \mathrm{i}=30 \mu \mathrm{m}$.

Material examined - CHINA, Yunnan Province, saprobic on decaying wood submerged in Dulong River, May 2015, Z.L. Luo S-436 (HKAS 92659, holotype), ex-type living culture MFLUCC 17-0116. 
GenBank numbers - ITS: MH795812, LSU: MH795817, rpb2: MH801190, tef1: MH801191.

Notes - Sporidesmium dulongense is most similar to S. submersum in having unbranched, dark brown, septate conidiophores and acrogenous, solitary, pyriform, septate conidia with sphaerical guttules in almost all cells. However, $S$. dulongense differs from $S$. submersum by its longer conidiophores $(88-124 \mu \mathrm{m} v s .59-72 \mu \mathrm{m})$ and lageniform conidia with a long hyaline apex. Phylogenetic analysis based on multi-genes also showed that they are distinct species in Sporidesmium.

Sporocadaceae Corda, Icon. Fungorum (Prague) 5: 34 (1842)

Index Fungorum number: IF81408; Facesoffungi number: FoF06111; 750 species.

Saprobic or pathogenic on leaves, twigs, branches, fruits of flowering plants and gymnosperms, as endophytes or parasitic on humans and animals. Sexual morph: Ascomata scattered or confluent, perithecial, immersed to erumpent, black to dark brown. Ostiole circular, papillate. Peridium comprising several layers of cells of textura prismatica, brown at the base, dark brown outwardly. Paraphyses numerous, hypha-like, flexuose, filiform. Asci 8-spored, unitunicate, obclavate to cylindrical, with or without a discoid, J+ subapical ring. Ascospores overlapping uniseriate or biseriate, obovoid to ellipsoid, transversally septate, longitudinal septum in mid cells, with or without vertical septa, hyaline, pale brown to brown. Asexual morph: Coelomycetous. Conidiomata scattered to gregarious, subepidermal or subepidermal in origin, immersed to erumpent, pycnidial, acervular, stromatic or synnematous in Synnemapestaloides. Conidiomata wall composed of at least 3-4 layers of cells of textura angularis to textura prismatica, outer 1-2layers brown and inner 1-2 layers hyaline or pale brown. Conidiophores arising from the inner layer cells of basal stroma, absent or reduced to conidiogenous cells, when present, long, septate and branched, hyaline, smooth. Conidiogenous cells holoblastic, annellidic, ampulliform, cylindrical to subcylindrical, or lageniform, mostly hyaline. Conidia cylindrical to clavate, or fusiform, straight or curved, 2-4-euseptate, smooth or verruculose, median cells hyaline, pale olivaceous or pale brown to dark brown, bearing cellular, terminal cells mostly hyaline, appendages absent or if present, tubular, filiform, straight or flexuous, branched or unbranched (adapted from Maharachchikumbura et al. 2016b, Liu et al. 2019a).

Type genus - Sporocadus Corda

Notes - Sporocadaceae includes genera that are typically appendaged bearing coelomycetes and have been subjected to several taxonomic re-classifications (Nag Raj 1993, Maharachchikumbura et al. 2016b, Liu et al. 2019a). The family was re-validated by Jaklitsch et al. (2016b) and Bartaliniaceae, Discosiaceae, Pestalotiopsidaceae and Robillardaceae (Crous et al. 2015a, Senanayake et al. 2015) were treated as synonyms of Sporocadaceae. In addition to the phylogeny, morphology of the asexual morph genera having acervular conidiomata that produce hyaline, pale or dark brown, septate conidia were taken into the consideration when they were assigned to the family. Jaklitsch et al. (2016b) and Wijayawardene et al. (2018a) accepted 22 genera under Sporocadaceae.

Studies on Sporocadaceae were mostly based on ITS and LSU sequence data and these regions were not informative in resolving generic boundaries within the family (Jaklitsch et al. 2016b, Liu et al. 2019a). The most recent study by Liu et al. (2019a) provided a revision of this family complete with morphology and multi-gene phylogeny based on the LSU, ITS and $r p b 2$ sequence data and further analysis using protein coding genes (tef1 or tub2) for each genus. As a result, seven new genera were introduced and the placement of 23 known genera were confirmed. Here, we follow the treatments and updated classification as presented by Liu et al. (2019a). The accepted genera are listed below with illustrations and a description with two new host records of Sporocadaceae.

\section{Ecological and economic significance of Sporocadaceae}

Spodocadaceae taxa are ecologically important as they occur as saprobes, endophytes or pathogens, on leaves, twigs, branches and fruits on a wide range of host plants (Nag Raj 1993, 
Hyde et al. 2017b, Liu et al. 2019a). A number of species, especially related to Pestalotiopsis, Neopestalotiopsis, Pseudopestalotiopsis and Truncatella are considered to be destructive pathogens diseases in several economically important crops (Maharachchikumbura et al. 2016b). Furthermore, commonly isolated endophytes of Spodocadaceae produce a wide range of chemically novel diverse metabolites (Maharachchikumbura et al. 2014a, b, Liu et al. 2019a)

\section{Genera included in Sporocadaceae}

Allelochaeta Petr., Sydowia 9(1-6): 464 (1955)

Index Fungorum number: IF7095; 41 morphological species (Species Fungorum 2020), 37 species with sequence data.

Type species - Allelochaeta gaubae Petr.

Notes - Allelochaeta was considered as a synonym of Diploceras, one of the five groups of fungi into which the Seimatosporium complex was split by Nag Raj (1993). Based on a multi-gene phylogenetic study using the type species, Crous et al. (2018a) resurrected Allelochaeta. Members of this genus are characterized by mostly 3-septate, hyaline or pigmented, concolourous or versicolourous conidia, having branched or solitary, cellular or continuous appendages (Crous et al. 2018a). Crous et al. (2018a) discussed the conidial septation, appendage types and pigmentation loss and gain during the evolution of Allelochaeta species.

Annellolacinia B. Sutton, Mycol. Pap. 97: 31 (1964)

Index Fungorum number: IF7161; 2 morphological species (Species Fungorum 2020).

Type species - Annellolacinia dinemasporioides B. Sutton

Notes - The coelomycete genus Annellolacinia was introduced by Sutton (1964) and is characterized by conidia that are fusiform, aseptate, bearing a single, cellular, unbranched appendage at each end (Nag Raj 1993). Wijayawardene et al. (2016b) tentatively placed the genus in Discosiaceae (now Sporocadaceae) based on its morphological similarities, and we follow the same. However, there are no cultures or sequence data to confirm the placement of Annellolacinia.

Bartalinia Tassi, Bulletin Labor. Orto Bot. de R. Univ. Siena 3: 4 (1900)

Index Fungorum number: IF7327; 21 morphological species (Species Fungorum 2020), 7 species with sequence data.

Type species - Bartalinia robillardoides Tassi

Notes - Bartalinia was established by Tassi (1990) and is characterized by 3-4-septate conidia (Nag Raj 1993). They have a worldwide distribution, occurring as saprobes on various shrubs and trees and are often associated with leaf spots (Wong et al. 2003, Maharachchikumbura et al. 2016b, Wijayawardene et al. 2017a, Phookamsak et al. 2019, Farr \& Rossman 2019). They have also been recorded in freshwater (Nguyen et al. 2019). The genus was previously placed in Bartaliniaceae by Senanayake et al. (2015) which was later synonymized under Sporocadaceae by Jaklitsch et al. (2016b).

Broomella Sacc., Syll. fung. (Abellini) 2: 557 (1883)

Index Fungorum number: IF658; 14 morphological species (Species Fungorum 2020), 2 species with sequence data

Type species - Broomella vitalbae (Berk. \& Broome) Sacc.

Notes - Broomella species have been mostly reported from Asia and Europe (Farr \& Rossman 2019), as saprobes from terrestrial habitats (Li et al. 2015d, Wijayawardene et al. 2018a). The sexual morph is characterized by cylindric-elongate, unitunicate asci, with $\mathrm{J}_{-}$, discoid apical ring, bearing 2-3-septate, ellipsoid-fusiform ascospores with brown, median and hyaline, terminal cells bearing centric appendages at each end (Shoemaker \& Müller 1963, Li et al. 2015d, Wanasinghe et al. 2018, Liu et al. 2019a). The asexual morph is pestalotia-like and this is yet to be confirmed by phylogeny (Wanasinghe et al. 2018, Liu et al. 2019a). Li et al. (2015d) provided an epitype for Broomella vitalbe illustrating both its sexual and asexual morphs. 
Ciliochorella Syd., Annls mycol. 33(1/2): 62 (1935)

Index Fungorum number: IF7657; 7 morphological species (Species Fungorum 2020), 2 species with sequence data.

Type species - Ciliochorella mangiferae Syd.

Notes - Ciliochorella, introduced by Sydow \& Mitter (1935) consists of saprobic species reported from India, Japan, South America and Thailand (Tangthirasunun et al. 2015, Hyde et al. 2016b, Liu et al. 2019a, Farr \& Rossman 2019), from terrestrial habitats. Sutton (1980) mentioned Ciliochorella mangiferae as a common species found in both tropical and subtropical leaf litter.

Diploceras (Sacc.) Died., Mykol. Untersuch. Ber.: 342 (1915)

Index Fungorum number: IF8043; 2 morphological species (Species Fungorum 2020).

Type species - Diploceras hypericinum (Ces.) Died.

Notes - Diploceras was introduced as a subgenus of Hyaloceras by Saccardo (1892) and subsequently raised to generic rank by Diedicke (1915). After re-examining the type, Sutton (1975) re-classified this genus as a synonym of Seimatosporium. Nag Raj (1993) resurrected Diploceras as a genus to accommodate $D$. hypericinum. Most other species previously classified as Diploceras were later included in Allelochaeta during a study based on multi-gene phylogeny by Crous et al. (2018a). An emended description for this genus was provided by Liu et al. (2019a).

Disaeta Bonar, Mycologia 20: 299 (1928)

Index Fungorum number: IF8066; 1 species with sequence data.

Type species - Disaeta arbuti Bonar

Notes - Disaeta was introduced by Bonar (1928) without mentioning the type species. The genus is characteristic in producing 4-septate conidia, with bristle-like appendages (Bonar 1928). Liu et al. (2019a) provided a representative strain of D. arbuti isolated from Acacia pycnantha, Australia, along with an emended description and further citing the need for a taxonomic revision of this genus.

Discosia Lib. ex Durieu \& Mont., Fl. d'Algérie, Cryptog. 1: 587 (1849)

Index Fungorum number: IF8072; 50 morphological species (Species Fungorum 2020), 11 species with sequence data.

Type species - Discosia artocreas (Tode) Fr.

Notes - Species of Discosia are mostly saprobes and have been recorded worldwide from terrestrial habitats on a various range of host plants (Farr \& Rossman 2019). Based on phylogenetic evidence, Liu et al. (2019a) synonymised Adiscio under Discosia, the former which was introduced by Tanaka et al. (2011) to accommodate the sexual morph species of this genus. An epitype for the type species was designated by Liu et al. (2019a) as the type specimen was destroyed.

Distononappendiculata F. Liu, L. Cai \& Crous (2019)

Index Fungorum number: IF828323; 3 species with sequence data.

Type species - Distononappendiculata banksiae (Crous \& Summerell) F. Liu, L. Cai \& Crous.

Notes - Distononappendiculata species are characteristic in producing distoseptate conidia that lack appendages (Liu et al. 2019a). They occur on leaves of Banksia sp. in Australia (Liu et al. 2019a).

Diversimediispora F. Liu, L. Cai \& Crous (2019)

Index Fungorum number: IF828326; 1 species with sequence data.

Type species - Diversimediispora humicola F. Liu, L. Cai \& Crous.

Notes - Diversimediispora species produce conidia with versicolourous median cells where the second and third cells (from the apex) are darker, making it characteristically different from other genera in Sporocadaceae (Liu et al. 2019a). 
Doliomyces Steyaert, Darwiniana 12(2): 169 (1961)

Index Fungorum number: IF11007; 3 morphological species (Species Fungorum 2020).

Type species - Doliomyces senegalensis (Speg.) Steyaert

Notes - Doliomyces was initially placed in Amphisphaeriaceae (Kirk et al. 2008) but due to the lack of sequence data or cultures, this placement was considered uncertain. Senanayake et al. (2015) listed Doliomyces in Amphisphaeriales, genera incertae sedis. However, Wijayawardene et al. (2016b) classified this genus under Bartaliniaceae (now Sporocadaceae), based on its morphology. In this study we tentatively place Doliomyces in Sporocadaceae. Species of Doliomyces are characterized by cylindrical to navicular, fusiform, 3-5-septate, conidia with dark brown median cells, bearing a single, unbranched, basal appendage and several branched, apical appendages (Nag Raj 1993, Wijayawardene et al. 2016b).

\section{Heterotruncatella F. Liu, L. Cai \& Crous (2019)}

Index Fungorum number: IF828340; 17 species with sequence data.

Type species - Heterotruncatella lutea (H.J. Swart \& D.A. Griffiths) F. Liu, L. Cai \& Crous

Notes - Heterotruncatella was introduced by Liu et al. (2019a) to accommodate several new and previously described Truncatella species. Although morphologically similar, phylogenetically they were distinct from Truncatella. Most species have been recorded from Australia and Europe (Senanayake et al. 2015, Liu et al. 2019a, Farr \& Rossman 2019).

Hyalotiella Papendorf, Trans. Br. mycol. Soc. 50(1): 69 (1967)

Index Fungorum number: IF8588; 6 morphological species (Species Fungorum 2020), 3 species with sequence data.

Type species - Hyalotiella transvalensis Papendorf

Notes - Hyalotiella was introduced by Papendorf \& Du-Toit (1967). Hyalotiella species are characterized by vase-shaped pycnidia, producing 3-septate, cylindrical conidia bearing more than one branched apical appendage but without a basal appendage (Nag Raj 1993, Li et al. 2015d, Senanayake et al. 2016). They occur as saprobes, and have been recorded from India, Italy, South Africa and South America (Nag Raj 1993, Li et al. 2015d, Farr \& Rossman 2019).

Hymenopleella Munk, Dansk bot. Ark. 15(no. 2): 89 (1953)

Index Fungorum number: IF2416; 7 species with sequence data.

Type species - Hymenopleella hippophaëicola Jaklitsch \& Voglmayr

Notes - Hymenopleella is a sexual morph genus recorded from Africa, China and India (Jeewon et al. 2003a, Liu et al. 2019a). In the study by Liu et al. (2019a), the type species of Dyrithiopsis and Neotruncatella clustered together with Hymenopleella and therefore both genera were synonymized under the latter genus (Liu et al. 2019a).

Immersidiscosia Kaz. Tanaka, Okane \& Hosoya, Persoonia 26: 94 (2011)

Index Fungorum number: IF519746; 1 species with sequence data.

Type species - Immersidiscosia eucalypti (Pat.) Kaz. Tanaka, Okane \& Hosoya

Notes - The genus was introduced by Tanaka et al. (2011) to accommodate Immersidiscosia eucalypti which has been recorded from France, Japan and Tunisia (Tanaka et al. 2011, Wijeyawardene et al. 2017a, Farr \& Rossman 2019).

Monochaetia (Sacc.) Allesch., Rabenh. Krypt.-Fl., Edn 2 (Leipzig) 1(7): 665 (1902)

Index Fungorum number: IF8971; 42 morphological species (Species Fungorum 2020), 11 species with sequence data.

Type species - Monochaetia monochaeta (Desm.) Allesch.

Notes - Members of this genus have been reported worldwide, as saprobes, endophytes or pathogens, occurring on various hosts, especially on Quercus spp. (Maharachchikumbura et al. 2016b, De Silva et al. 2017, Wijayawardene et al. 2017a, Liu et al. 2019a, Farr \& Rossman 2019). 
Morinia Berl. \& Bres., Annuario Soc. Alpinisti Trident., 1887-88: 82 (1889)

Index Fungorum number: IF8997; 4 species with sequence data.

Type species - Morinia pestalozzioides Berl. \& Bres.

Notes - Morinia species are characterised by transversely or muriformly septate conidia (Collado et al. 2006). They are recorded from terrestrial habitats (Wijayawardene et al. 2017a). Zetiasplozna was combined under Morinia based on phylogeny and similarity (Liu et al. 2019a).

Neopestalotiopsis Maharachch., K.D. Hyde \& Crous, Stud. Mycol. 79: 135 (2014)

Index Fungorum number: IF809759; 43 species with sequence data. Crous

Type species - Neopestalotiopsis protearum (Crous \& L. Swart) Maharachch., K.D. Hyde \&

Notes - Neopestalotiopsis, established by Maharachchikumbura et al. (2014b) is widespread, occurring as saprobes or pathogens on various host plants (Maharachchikumbura et al. 2014b, Farr $\&$ Rossman 2019). The genus is distinct from Pestalotiopsis in having versicolourous median cells. Neopestalotiopsis rhizophorae is illustrated in this entry (Fig. 232).

Nonappendiculata F. Liu, L. Cai \& Crous, Stud. Mycol. 92: 358 (2018)

Index Fungorum number: IF828374; 1 species with sequence data.

Type species - Nonappendiculata quercina F. Liu, L. Cai \& Crous

Notes - Nonappendiculata, introduced by Liu et al. (2019a) produces 3-septate, fusoid conidia without appendages. It occurs on Quercus from Italy (Liu et al. 2019a).

Parabartalinia F. Liu, L. Cai \& Crous, Stud. Mycol. 92: 358 (2018)

Index Fungorum number: IF828376; 1 species with sequence data.

Type species - Parabartalinia lateralis F. Liu, L. Cai \& Crous

Notes - This genus was introduced by Liu et al. (2019a) and is similar to Bartalinia, yet phylogenetically distinct. It is recorded from South Africa on Acacia sp. (Liu et al. 2019a).

Pestalotiopsis Steyaert, Bull. Jard. bot. État Brux. 19: 300 (1949)

Index Fungorum number: IF9272; 225 morphological species (Species Fungorum 2020), 138 species with sequence data.

Type species - Pestalotiopsis maculans (Corda) Nag Raj

Notes - Pestalotiopsis was erected by Steyaert (1949). Pestalotiopsis species occur worldwide, as saprobes, endophytes or opportunistic pathogens on economically important plants as well as ornamental crops (Maharachchikumbura et al. 2014b, 2016b). The diversity and phylogenetic affinities based on ITS, tub2 and tefl gene regions for this genus has been discussed comprehensively in several studies (Jeewon et al. 2003a, Maharachchikumbura et al. 2011, 2012, 2013, 2014a, Liu et al. 2019a).

Pseudopestalotiopsis Maharachch., K.D. Hyde \& Crous, Stud. Mycol. 79: 180 (2014)

Index Fungorum number: IF809753; 15 species with sequence data.

Type species - Pseudopestalotiopsis theae (Sawada) Maharachch., K.D. Hyde \& Crous

Notes - Pseudopestalotiopsis species are widely distributed as saprobes or pathogens, occurring on leaves (Maharachchikumbura et al. 2014b, 2016a). They have conidia with concolourous, brown to dark brown or olivaceous median pigmented cells (Maharachchikumbura et al. 2014b).

Pseudosarcostroma F. Liu, L. Cai \& Crous, Stud. Mycol. 92: 374 (2018)

Index Fungorum number: IF828385; 1 morphological species.

Type species - Pseudosarcostroma osyridicola F. Liu, L. Cai \& Crous

Notes - Pseudosarcostroma, introduced by Liu et al. (2019a) is phylogenetically related to Broomella, Bartalinia, Truncatella, Parabartalinia, and Diversimediispora. It shares similar 
characters with Sarcostroma, such as having conidia bearing a single appendage at each end, with an undulate or verruculose conidial wall (Liu et al. 2019a). The genus was recorded from France on Osyris alba (Liu et al. 2019a).

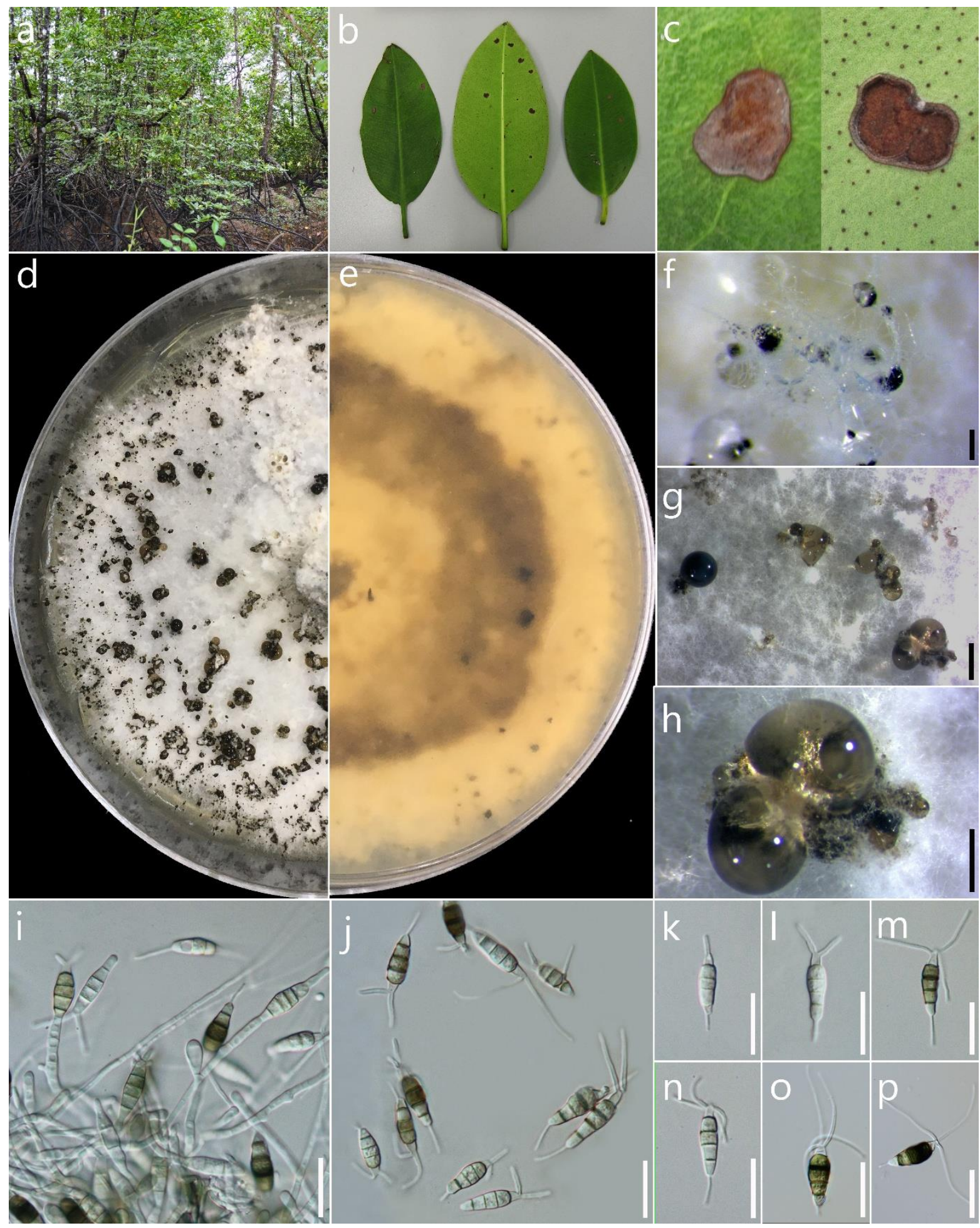

Figure 232 - Neopestalotiopsis rhizophorae (Material examined - THAILAND, Kor Chang, Trat Province, leaf spots of Rhizophora mucronata L., 27 April 2017, Norphanphoun C. KC23-1, KC23-2 (MFLU); living cultures, MFLUCC 17-1728. THAILAND, Kor Chang, Trat Province, leaf spots of Rhizophora mucronata L., 27 April 2017, Norphanphoun C. KC23-2 (MFLU); living cultures, MFLUCC 17-1729). a Collecting place. b, c Leaf spots of Rhizophora mucronata. d, e Culture on PDA (d-above, e-below). f-h Colony sporulating on PDA. i Conidiogenous cells giving rise to conidia. $\mathrm{j}$-p Conidia. Scale bars: $\mathrm{f}=200 \mu \mathrm{m}, \mathrm{g}=1000 \mu \mathrm{m}, \mathrm{h}=500 \mu \mathrm{m}, \mathrm{i}-\mathrm{p}=20 \mu \mathrm{m}$. 
Robillarda Sacc., Michelia 2(no. 6): 8 (1880)

Index Fungorum number: IF22470; 17 morphological species (Species Fungorum 2020), 6 species with sequence data.

Type species - Robillarda sessilis (Sacc.) Sacc.

Notes - The genus was introduced by Saccardo (1880a) and have flexuous, narrow tubular, aseptate appendages and holoblastic conidiogenous cells, proliferating sympodially or percurrently near the apex (Crous et al. 2015a, Wijayawardene et al. 2016a). Robillarda species have been reported worldwide, as saprobes (Wijayawardene et al. 2017a, Farr \& Rossman 2019). Most recently, Robillarda mangiferae was introduced from leaf blight on mango in Yunnan, China (Phookamsak et al. 2019).

Sarcostroma Cooke, Journal of the Quekett microsc. Club 2: 267 (1871)

Index Fungorum number: IF9789; 17 morphological species (Species Fungorum 2020), 11 species with sequence data.

Type species - Sarcostroma berkeleyi Cooke

Notes - Species of this genus are saprobes, endophytes, pathogens on leaves in both tropical and temperate regions (Maharachchikumbura et al. 2016b, Norphanphoun et al. 2015, Farr \& Rossman 2019). Sarcostroma was resurrected to accommodate several species characterised by fusoid conidia with four or more cells, having pigmented median cells and paler, thin-walled end cells, bearing an attenuated tubular apical appendage and a similar excentric basal appendage (Nag Raj 1993). The holotype of the genus has been reported lost and epitypification is needed (Liu et al. 2019a).

Seimatosporium Corda, Deutschl. Fl., 3 Abt. (Pilze Deutschl.) 3(13): 79 (1837)

Index Fungorum number: IF9865; 71 morphological species (Species Fungorum 2020), 24 species with sequence data.

Type species - Seimatosporium rosae Corda

Notes - Seimatosporium species are widely distributed, occurring as saprobes or pathogens (Norphanphoun et al. 2015, Maharachchikumbura et al. 2016b, Wijayawardene et al. 2017a, Wanasinghe et al. 2018). It was introduced by Corda (1833). Phylogenetically, they have been linked to Discostroma sexual morphs (Tanaka et al. 2011). However, there are no sequence data for the type species, this requires further study.

Seiridium Nees, Syst. Pilze (Würzburg): 22 (1816)

Index Fungorum number: IF9868; 39 morphological species (Jaklitsch et al. 2016b, Species Fungorum 2020), 20 species with sequence data.

Type species - Seiridium marginatum Nees

Notes - Seiridium are characterized by 6-celled conidia (Jeewon 2003a, Maharachchikumbura et al. 2014b) and are widely distributed as saprobes and plant pathogens (Tsopelas et al. 2007). The genus was established by Nees (1816). Blogiascospora and Lepteutypa was identified as the sexual morph (Senanayake et al. 2015). Jaklitsch et al. (2016b) epitypified Seiridium marginatum and confirmed its sexual morph as Blogiascospora marginata based on molecular data. Seiridium spyridiicola is illustrated in this entry (Fig. 233).

Sporocadus Corda, Icon. fung. (Prague) 3: 23 (1839)

Index Fungorum number: IF10026; 49 morphological species (Species Fungorum), 13 species with sequence data.

Type species - Sporocadus lichenicola Corda

Notes - Sporocadus was established by Corda (1839b) to include four species, but with no mention of the type. Hughes (1958) lectotypified Sporocadus based on S. lichenicola. The genus was once synonymised under Seimatosporium by Sutton (1975), but later classified as a distinct 
genus by Brockman (1976) and Nag Raj (1993). Liu et al. (2019a) showed that both Sporocadus and Seimatosporium are phylogenetically distinct and species in Sporocadus lack appendages.
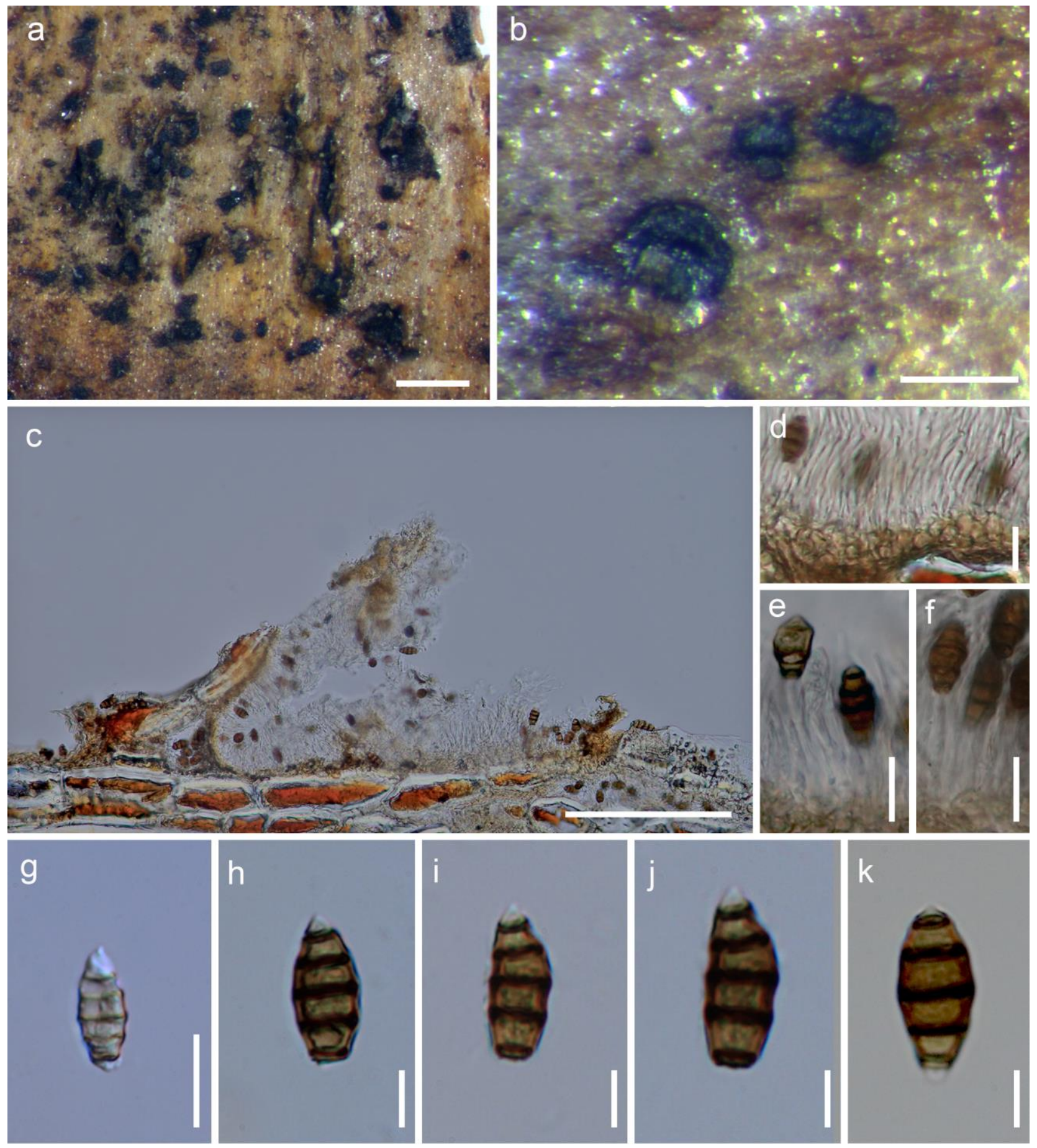

Figure 233 - Seiridium spyridiicola (Material examined - ITALY, Forli-Cesena Province, near Camposonaldo - Santa Sofia, on dead and land cone of Picea excelsa, 15 April 2015, Erio Camporesi IT2444, MFLU 15-0813; living culture KUMCC 16-0115). a Appearance on host. b Close up of several conidiomata. c Section of conidioma. $d$ Wall of conidioma. e, f Conidiogenous cells giving rise to conidia. $\mathrm{f}, \mathrm{g}$ Conidiophores with conidia. h-k Conidia (upside down). Scale bars: $\mathrm{a}=500 \mu \mathrm{m}, \mathrm{c}=1 \mathrm{~mm}, \mathrm{~d}=100 \mu \mathrm{m}, \mathrm{e}-\mathrm{l}=20 \mu \mathrm{m}$.

Strickeria Körb., Parerga lichenol. (Breslau) 5: 400 (1865)

Index Fungorum number: IF5283; 33 morphological species (Species Fungorum 2020), 1 species with sequence data. 
Type species - Strickeria kochii Körb.

Notes - Strickeria was introduced and described as a lichenised fungus by Körber (1865). It was often classified in Dothideomycetes and upon re-examination of the type material, it was placed under Sordariomycetes genera incertae sedis (Eriksson \& Hawksworth 1991, Lumbsh \& Huhndorf 2010). Subsequently this genus was classified in Xylariales by Jaklitsch et al. (2016b).

Synnemapestaloides T. Handa \& Y. Harada, Mycoscience 45:138 (2004)

Index Fungorum number: IF28803; 2 species with sequence data.

Type species - Synnemapestaloides rhododendri T. Handa \& Y.Harada.

Notes - Synnemapestaloides species are distinct in producing spores on synnemata (Watanabe et al. 2016). They occur on Juniperus and Rhododendron (Liu et al. 2019a).

Truncatella Steyaert, Bull. Jard. bot. État Brux. 19: 293 (1949)

Index Fungorum number: IF10328; 13 morphological species (Species Fungorum 2020), 7 species with sequence data.

Type species - Truncatella truncata (Lév.) Steyaert

Notes - Truncatella was established by Steyaert (1949) to accommodate distinct species having 3-septate, verruculose, pigmented conidia (Steyaert 1949, Jeewon et al. 2002, Maharachchikumbura et al. 2016b, Tibpromma et al. 2017b). They occur worldwide as saprobes on various dicotyledons and monocotyledons (Farr \& Rossman 2019).

Xenoseimatosporium F. Liu, L. Cai \& Crous, Stud. Mycol. 92: 411 (2018)

Index Fungorum number: IF828424; 1 species with sequence data.

Type species - Xenoseimatosporium quercinum (Goonas., R.K. Schumach. \& K.D. Hyde) F. Liu, L. Cai \& Crous

Notes - This genus was introduced by Liu et al. (2019a) to accommodate the previously described species Seimatosporium quercinum on Quercus from Germany (Goonasekara et al. 2016). It is phylogenetically close to the genera Allelochaeta and Sarcostroma. Xenoseimatosporium is distinct from Seimatosporium in producing allantoid and subcylindrical conidia with ragged appendages (Liu et al. 2019a).

Stachybotryaceae L. Lombard \& Crous, Persoonia 32: 283 (2014)

Index Fungorum number: IF90922; Facesoffungi number: FoF05320; 304 species.

Saprobic or pathogenic on plants and commonly isolated from soil. Sexual morph: Ascomata superficial or immersed, solitary or scattered, sometimes fused, globose to subglobose, bright to dark yellow or black, sometimes covered with intertwined hyphae. Papilla central, short, black, without periphyses. Ostiole conical, thin, black. Peridium composed of several layers of dark brown, thin-walled cells of textura angularis (Stachybotrys), or textura intricata (Scopinella), or outwardly composed of thick-walled textura angularis and inwardly with textura prismatica (Peethambara). Paraphyses moniliform or filiform, hyaline, septate or aseptate, intermingled with asci. Asci 4-8-spored, unitunicate, clavate to cylindrical, apex rounded to nearly truncate, deliquescent at maturity, lacking an apical ring. Ascospores 2-3-seriate, hyaline or brown to dark brown, ellipsoidal to fusiform or broadly reniform, 0-1-septate, with or lacking a mucilaginous sheath. Asexual morph: Hyphomycetous. Conidiophores single, sporodochial or synnematous, if conidiophore single, macronematous, mononematous, solitary or gregarious, simple or irregularly branched, hyaline or pale brown, smooth-walled; if conidiophores sporodochial or synnematous, pulvinate, gelatinous, hyaline to dark green, with or without setae, with irregularly penicillate, bior triverticillately branched conidiogenous ring. Conidiogenous cells enteroblastic, monophialidic to polyphialidic, discrete, cylindrical, ellipsoidal or clavate to broadly reniform, with conspicuous collarettes, determinate or proliferating percurrently, initially hyaline becoming pale brown at maturity. Conidia arising from the apices of the phialides, elongate, cylindrical, fusiform or ellipsoidal, 0-3-septate, smooth-walled, smooth, striate or roughened, hyaline, brown to dark 
brown, aggregated in slimy, dark green to black masses (adapted from Maharachchikumbura et al. 2016b).

Type genus - Stachybotrys Corda

Notes - Stachybotryaceae was established by Crous et al. (2014a) to accommodate Myrothecium, Peethamabra and Stachybotrys. This family is characterized by asexual morphs having mononematous, sporodochial or synnematous conidiophores and phialidic conidiogenous cells that produce conidia in chains or in slimy or dry masses (Seifert et al. 2011, Crous et al. 2014a, Wang et al. 2015b, Lombard et al. 2016). Lombard et al. (2016) monographed the family based on morphology and LSU, ITS, rpb2, cmdA, tef1 and tub2 sequence data and 33 genera were accepted. Wijayawardene et al. (2018a) accepted 36 genera, however the family seems to be split into rather numerous genera based on few distinguishing characters and poor phylogenetic resolution.

\section{Ecological and economic significance of Stachybotryaceae}

Some species in Stachybotryaceae are serious plant, animal and human pathogens. The most serious plant pathogenic species are Myrothecium roridum and $M$. verrucaria that cause dieback and leaf spots of various plant hosts (Zhao et al. 2010, Zhang et al. 2011, Hong et al. 2013, Ben et al. 2015, Fujinawa et al. 2016). Stachybotrys chartarum (often cited as $S$. atrus Corda) is one of the most feared of fungi in the world, which can produce mycotoxins and result in serious buildingrelated illness and agricultural damage (Drobotko 1945, Dankó 1975, Page \& Trout 2001, Seifert et al. 2011, Hyde et al. 2018a). It was reported that mycotoxins produced by Stachybotrys can cause a variety of symptoms in humans, including cold- and flu-like symptoms, sore throats, diarrhea, headaches, dermatitis, patches of hair loss, and fatigue, and also can cause the death of animals (Schneider 1979, Croft et al. 1986, Johanning et al. 1996, Page and Trout 2001).

\section{Genera included in Stachybotryaceae}

Achroiostachys L. Lombard \& Crous, Persoonia 36: 172 (2016)

Index Fungorum number: IF815916; 6 species with sequence data.

Type species - Achroiostachys humicola L. Lombard \& Crous

Notes - Achroiostachys was introduced by Lombard et al. (2016) to accommodate $A$. aurantispora, A. betulicola, A. humicola, A. levigata, A. phyllophila and A. saccharicola. The genus is characterised by hyaline, mostly smooth, thin-walled conidiophores, phialidic conidiogenous cells and hyaline, aseptate, smooth-walled, ellipsoidal to limoniform conidia (Lombard et al. 2016).

Albifimbria L. Lombard \& Crous, Persoonia 36: 177 (2016)

Index Fungorum number: IF815924; 6 species with sequence data.

Type species - Albifimbria verrucaria (Alb. \& Schwein.) L. Lombard \& Crous

Notes - Albifimbria was established by Lombard et al. (2016) to accommodate A. lateralis, A. terrestris, A. verrucaria and A. viridis. No sexual morph has been determined. The genus is characterised by the formation of verrucose setae surrounding the sporodochia and conidia sometimes bearing a funnel-shaped mucoid appendage (Lombard et al. 2016).

Albosynnema E.F. Morris, Mycopath. Mycol. appl. 33: 179 (1967)

Index Fungorum number: IF7086; 2 morphological species (Species Fungorum 2020), 1 species with sequence data.

Type species - Albosynnema elegans E.F. Morris

Notes - Lombard et al. (2016) accepted this genus in Stachybotryaceae with support from phylogenetic analysis. The genus is characterised by synnematous, branched, hyaline conidiophores, phialidic conidiogenous cells and dark, septate, slimy conidia (Seifert et al. 2011).

Alfaria Crous, Montaño-Mata \& García-Jim., Persoonia 32: 239 (2014)

Index Fungorum number: IF808923; 15 species with sequence data. 
Type species - Alfaria cyperi-esculenti Crous, Montaño-Mata \& García-Jim.

Notes - Alfaria was established to accommodate A. cyperi-esculenti, which is a plant pathogen. The genus is characterised by solitary or sporodochial, verticillately or penicillately branched, hyaline conidiophores, phialidic conidiogenous cells and cylindrical to ellipsoidal to ossiform, hyaline to lightly pigmented, aseptate conidia (Lombard et al. 2016). When setae are present, they are septate and unbranched (Lombard et al. 2016).

Alfariacladiella Crous \& R.K. Schumach., Beihefte zur Sydowia 68: 202 (2016)

Index Fungorum number: IF817207; 1 species with sequence data.

Type species - Alfariacladiella spartii Crous \& R.K. Schumach.

Notes - Alfariacladiella is characterised by sporodochial, cupulate conidiomata surrounded by hyaline and septate marginal hyphae (Hernández-Restrepo et al. 2016b). Conidiophores are hyaline, smooth, septate and monoverticillate or not. Conidiogenous cells are phialidic. Conidia are single, hyaline, smooth-walled, guttulate and fusiform. The genus is similar to Alfaria, but differs in lacking brown setae surrounding the conidiomata, and having fusiform conidia with apical mucoid caps (Hernández-Restrepo et al. 2016c).

Brevistachys L. Lombard \& Crous, Persoonia 36: 182 (2016)

Index Fungorum number: IF815934; 5 species with sequence data.

Type species - Brevistachys variabilis L. Lombard \& Crous

Notes - Brevistachys was introduced by Lombard et al. (2016) to accommodate stachybotryslike species having distinctly short conidiophores and conidiogenous cells borne on conidiophores or directly from vegetative hyphae.

Capitofimbria L. Lombard \& Crous, Persoonia 36: 185 (2016)

Index Fungorum number: IF815940; 1 species with sequence data.

Type species - Capitofimbria compacta (R.F. Castañeda, Gusmão, Stchigel \& M. Stadler) L. Lombard \& Crous

Notes - Lombard et al. (2016) transferred Myrothecium compactum to Capitofimbria. No sexual morph was identified. The genus is characterised by the marginal hyphae terminating in a capitate to clavate thick-walled cells surrounding the sporodochia (Lombard et al. 2016).

Cymostachys L. Lombard \& Crous, Persoonia 36: 186 (2016)

Index Fungorum number: IF815942; 4 species with sequence data.

Type species - Cymostachys coffeicola L. Lombard \& Crous

Notes - Two species, C. coffeicola and C. fabispora, were introduced by Lombard et al. (2016). The third species, C. garethjonesii, was introduced by Lin et al. (2016). The genus is characterised by irregularly cymosely branched conidiophores and olivaceous brown to dark brown, fabiform conidia.

Didymostilbe Henn., Hedwigia 41: 148 (1902)

Index Fungorum number: IF8021; 10 morphological species (Species Fungorum 2020), 2 species with sequence data.

Type species - Didymostilbe coffeae Henn.

Notes - The genus has large, thick-walled conidia, having prominent apical and/or basal mammiform protuberances. Lombard et al. (2016) placed the genus in Stachybotryaceae with the support of phylogenetic analysis.

Digitiseta Gordillo \& Decock, Mycol. Progr. 17: 179-190 (2017)

Index Fungorum number: IF820512; 4 species with sequence data.

Type species - Digitiseta setiramosa (R.F. Castañeda) Gordillo \& Decock 
Notes - The genus is characterised by sporodochial conidiomata with a green mucoid mass of conidia on the top and setoid hypha-like extensions with short apical branches, biverticillate conidiophores, phialidic conidiogenous cells and aseptate, cylindrical, hyaline to pale greenish conidia (Gordillo \& Decock 2018).

Dimorphiseta L. Lombard \& Crous, Persoonia 36: 188 (2016)

Index Fungorum number: IF815956; 3 species with sequence data.

Type species - Dimorphiseta terrestris L. Lombard \& Crous

Notes - The genus is similar to Smaragdiniseta, but differs by the setae morphology. Type I setae of Dimorphiseta are hyaline, and type II setae taper to sharp apices, however, type I setae of Smaragdiniseta are emerald green, and type II setae narrow to an obtuse apex (Lombard et al. 2016).

Globobotrys L. Lombard \& Crous, Persoonia 36: 189 (2016)

Index Fungorum number: IF815990; 1 species with sequence data.

Type species - Globobotrys sansevieriicola (Crous \& M.J. Wingf.) L. Lombard \& Crous

Notes - The stachybotrys-like genus Globobotrys was introduced by Lombard et al. (2016) to accommodate G. sansevieriicola (三 Stachybotrys sansevieriicola). Only one species is accepted in the genus, which is characterised by mononematous, mostly unbranched, hyaline conidiophores, phialidic conidiogenous cells and aseptate, hyaline to olivaceous brown, smooth-walled, thickwalled, globose to broadly ellipsoidal conidia (Lombard et al. 2016).

Grandibotrys L. Lombard \& Crous, Persoonia 36: 189 (2016)

Index Fungorum number: IF815992; 3 species with sequence data.

Type species - Grandibotrys pseudotheobromae L. Lombard \& Crous

Notes - Two species, G. pseudotheobromae and G. xylophilus, were introduced by Lombard et al. (2016) in Grandibotrys. Hyde et al. (2017b) added G. hyalinus. The genus is characterised by mononematous, unbranched or branched, hyaline conidiophores, phialidic conidiogenous cells and olivaceous green to dark brown, limoniform to ellipsoidal conidia, having a mammiform apical and/or basal protrudance (Lombard et al. 2016).

Gregatothecium L. Lombard \& Crous, Persoonia 36: 191 (2016)

Index Fungorum number: IF815995; 1 species with sequence data.

Type species - Gregatothecium humicola L. Lombard \& Crous

Notes - The genus differs from the similar genera by the slimy olivaceous green conidial masses produced on the conidiophores and sporodochia (Lombard et al. 2016). Unbranched and hyaline setae arise from the basal stroma, (Lombard et al. 2016). Conidiophores are penicillately branched, conidiogenous cells are phialidic and hyaline and conidia are aseptate and cylindrical to subcylindrical (Lombard et al. 2016).

Hyalinostachys C.G. Lin \& K.D. Hyde, gen. nov.

Index Fungorum number: IF555606; Facesoffungi number: FoF03883; 1 species with sequence data.

Etymology: Name reflects the hyaline stachybotrys-like conidiophores and conidia.

Saprobic on plant host. Sexual morph: Undetermined. Asexual morph: Hyphomycetous. Colonies effuse, hairy, pale to pale brown. Mycelium partly superficial and partly immersed. Conidiophores macronematous, mononematous, single or in small groups, simple or branched, erect, straight, septate, thick-walled, smooth, hyaline, narrower at the apex. Conidiogenous cells monophialidic, discrete, determinate, terminal, elongate ampulliform, clavate or subcylindrical, the outer ones somewhat curved and ventricose, hyaline, smooth; conidial mass slimy, pale orange. Conidia acrogenous, aseptate, smooth, hyaline, cylindrical, ellipsoidal.

Type species - Hyalinostachys cylindrospora C.G. Lin \& K.D. Hyde 
Notes - The combined LSU and rpb2 phylogenetic analyses indicate that Hyalinostachys forms a separate clade and sister taxon to Achroiostachys, Globobotrys, Melanopsamma and Sirastachys in Stachybotryaceae (Fig. 15). Hyalinostachys is distinguished from these genera by simple or branched, thick-walled, smooth and hyaline conidiophores and hyaline, cylindrical or ellipsoidal conidia.

Hyalinostachys cylindrospora C.G. Lin \& K.D. Hyde, sp. nov.

Fig. 235

Index Fungorum number: IF555605; Facesoffungi number: FoF03884

Etymology - Name reflects the cylindrical conidia.

Holotype - MFLU 17-2650.

Saprobic on plant host. Sexual morph: Undetermined. Asexual morph: Hyphomycetous. Colonies effuse, hairy, pale to pale brown. Mycelium partly superficial and partly immersed. Conidiophores macronematous, mononematous, single or in small groups, simple or sometimes branched, erect, straight, septate, thick-walled, smooth, hyaline, up to $310 \mu \mathrm{m}, 4-12 \mu \mathrm{m}$, narrower at the apex, bearing a whorl of 4-5 conidiogenous cells. Conidiogenous cells monophialidic, discrete, determinate, terminal, elongate ampulliform, clavate or subcylindrical, the outer ones somewhat curved and ventricose, hyaline, smooth, 13-19 × 3.5-6 $\mu \mathrm{m}$; conidial mass slimy, pale orange. Conidia acrogenous, aseptate, smooth, hyaline, cylindrical or ellipsoidal, 14-16.5 × 5.5-7 $\mu \mathrm{m}$.

Culture characteristics: Conidia germinating on PDA in $12 \mathrm{~h}$. Colonies on PDA, reaching 3 $\mathrm{mm}$ in 2 weeks at $25^{\circ} \mathrm{C}$, flat, dark from above and the reverse. Mycelium immersed in media, composed of branched, septate, smooth, hyaline hyphae.

Material examined - THAILAND, Chiang Mai, Mae Taeng District, Sop Poeng, on decaying wood, 25 September 2016, Chuan-Gen Lin, LCG 11-5 (MFLU 17-2650, holotype), ex-type living culture, MFLUCC 17-2583.

Genbank numbers - ITS: MG717501, LSU: MG717503, rpb2: MK133023.

Notes - This species belongs to family Stachybotryaceae, and its placement is supported by morphology and phylogenetic analysis. Hyalinostachys cylindrospora can be distinguished from other stachybotrys-like species by its hyaline conidiophores and hyaline, cylindrical or ellipsoidal conidia.

Inaequalispora L. Lombard \& Crous, Persoonia 36: 191 (2016)

Index fungorum number: IF815997; 3 species with sequence data.

Type species - Inaequalispora prestonii (M.C. Tulloch) L. Lombard \& Crous

Notes - Inaequalispora was established by Lombard et al. (2016) to accommodate I. prestonii (三 Myrothecium prestonii). Gordillo \& Decock (2018) introduced Inaequalispora cylindrospora and I. longiseta to this genus. The genus is characterised by sporodochial, stromatic conidiomata, penicillately branched, hyaline conidiophores, phialidic, hyaline conidiogenous cells and aseptate, fusiform to ellipsoidal to asymmetrically ellipsoidal, hyaline conidia, with a funnel-shaped mucoid apical appendage (Lombard et al. 2016).

Kastanostachys L. Lombard \& Crous, Persoonia 36: 192 (2016)

Index Fungorum number: IF815999; 1 species with sequence data.

Type species - Kastanostachys aterrima (Fuckel) L. Lombard \& Crous

Notes - The asexual morph of Kastanostachys is characterised by unbranched, percurrent conidiophores, hyaline, phialidic conidiogenous cells and hyaline, smooth, ellipsoidal conidia (Lombard et al. 2016). An epitype was designated for K. aterrima (三 Melanomma aterrima Fuckel) by Lombard et al. (2016).

Koorchalomella Chona, Munjal \& J.N. Kapoor, Indian Phytopath. 11: 130 (1958)

Index Fungorum number: IF8681; 2 morphological species (Species Fungorum 2020), 1 species with sequence data. 


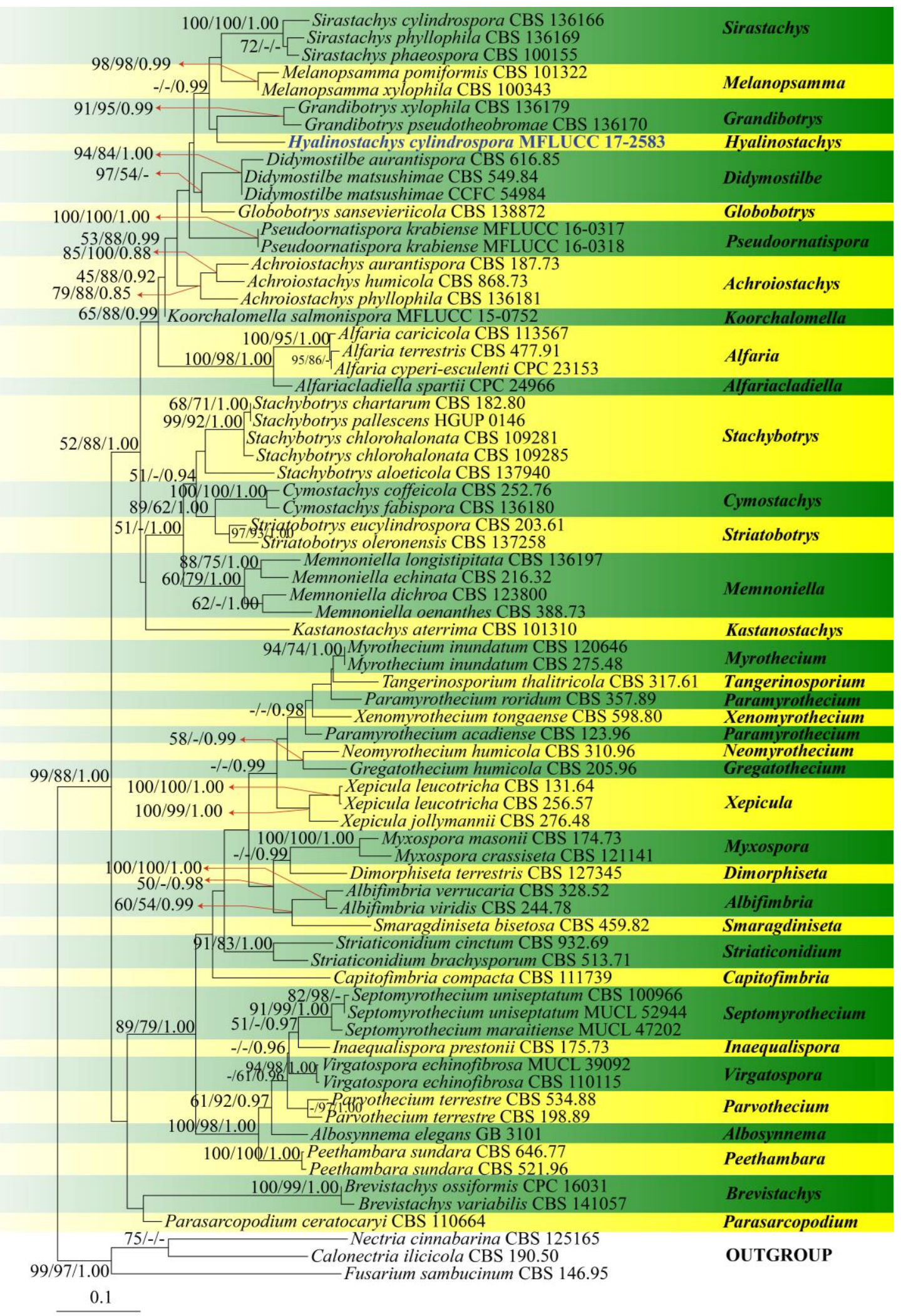

Figure 234 - Phylogenetic tree generated from maximum likelihood (ML) analysis based on combined LSU and $r p b 2$ sequence data of genera of Stachybotryaceae. Bootstrap support values for maximum likelihood (ML, first value) and maximum parsimony (MP, second value) and greater than 50\% and Bayesian posterior probabilities (BYPP, third value) greater than 0.90 are indicated above or below the nodes. Hyphen ("-") indicates a value lower than 50\% for ML and MP and a posterior probability lower than 0.90 for BYPP. New isolates are in blue bold. The tree is rooted with Calonectria ilicicola (CBS 190.50), Fusarium sambucinum (CBS 146.95), and Nectria cinnabarina (CBS 125165). 
Type species - Koorchalomella oryzae Chona, Munjal \& J.N. Kapoor

Notes - Hyde et al. (2017b) introduced the second species for this genus and provided DNA sequence data for it, which placed the genus in Stachybotryaceae. The genus is characterised by sporodochial conidiomata, unbranched, hyaline setae, branched, hyaline conidiophores, phialidic, hyaline conidiogenous cells and aseptate, hyaline, slimy conidia with funnel-shaped mucilaginous polar appendages (Seifert et al. 2011).

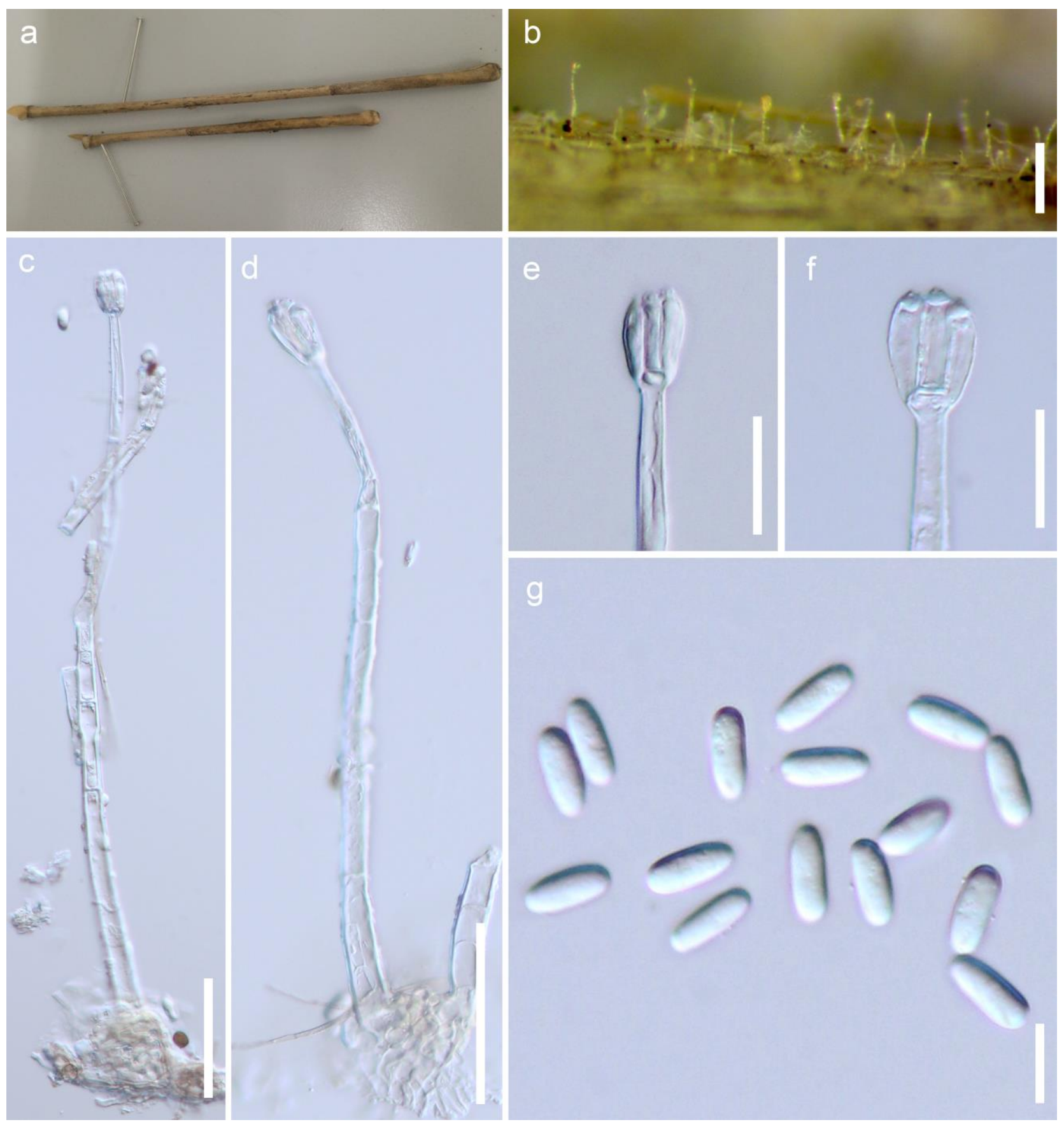

Figure 235 - Hyalinostachys cylindrospora (MFLU 17-2650, holotype). a Host material. b Conidiophores on the host surface. c, d Conidiophores and conidiogenous cells. e, f Conidiogenous cells. g Conidia. Scale bars: $\mathrm{b}=200 \mu \mathrm{m}, \mathrm{c}, \mathrm{d}=50 \mu \mathrm{m}$, e, $\mathrm{f}=20 \mu \mathrm{m}, \mathrm{g}=10 \mu \mathrm{m}$.

Melanopsamma Niessl, Verh. nat. Ver. Brünn 14: 200 (1876)

Index Fungorum number: IF3079; 42 morphological species (Species Fungorum 2020), 2 species with sequence data.

Type species - Melanopsamma pomiformis (Pers.) Sacc. 
Notes - Wang et al. (2015b) synonymised this genus under Stachybotrys, however, Lombard et al. (2016) resurrected it based on multigene phylogenetic analysis. The genus is characterised by mononematous, unbranched, hyaline conidiophores, phialidic, hyaline conidiogenous cells, and aseptate, hyaline to olivaceous brown to dark brown, smooth to verrucose, limoniform to obovoid to globose to ellipsoidal conidia (Lombard et al. 2016).

Memnoniella Höhn., Centbl. Bakt. ParasitKde, Abt. II 60: 16 (1923)

Index Fungorum number: IF8900; 9 species with sequence data.

Type species - Memnoniella aterrima Höhn.

Notes - Wang et al. (2015b) synonymised this genus under Stachybotrys, however, Lombard et al. (2016) resurrected it based on multigene phylogenetic analysis. The genus is characterised by mononematous, unbranched, septate conidiophores, phialidic conidiogenous cells and aseptate, ellipsoidal to globose to reniform conidia (Lombard et al. 2016). The conidia of this genus sometimes are in dry or slimy chains (Lombard et al. 2016).

Myrothecium Tode, Fung. mecklenb. sel. (Lüneburg) 1: 25 (1790)

Index Fungorum number: IF9049; 35 morphological species (Species Fungorum 2020), 11 species with sequence data.

Type species - Myrothecium inundatum Tode

Notes - Lombard et al. (2016) narrowed the concept of Myrothecium to include only species with conidia that are less than $5 \mu \mathrm{m}$ long, borne in olivaceous to dark green slimy masses surrounded by a setose fringe; only two species are accepted.

Myxospora L. Lombard \& Crous, Persoonia 36: 202 (2016)

Index Fungorum number: IF816011; 5 species with sequence data.

Type species - Myxospora masonii (M.C. Tulloch) L. Lombard \& Crous

Notes - This genus is characterised by the formation of mostly fusiform conidia, bearing an apical hilum without funnel-shaped mucoid appendages; some species form synnematal conidiomata (Lombard et al. 2016).

Neomyrothecium L. Lombard \& Crous, Persoonia 36: 205 (2016)

Index Fungorum number: IF816017; 1 species with sequence data.

Type species - Neomyrothecium humicola L. Lombard \& Crous

Notes - The genus is characterised by sporodochial, stromatic conidiomata, penicillately branched, hyaline conidiophores, phialidic conidiogenous cells and aseptate, hyaline, cylindrical conidia. The genus is similar to Paramyrothecium but differs by multiseptate and unbranched setae and pulvinate sporodochia that lack a white setosee fringe (Lombard et al. 2016).

Paramyrothecium L. Lombard \& Crous, Persoonia 36: 206 (2016)

Index Fungorum number: IF815988; 15 species with sequence data.

Type species - Paramyrothecium roridum (Tode) L. Lombard \& Crous

Notes - Paramyrothecium was introduced by Lombard et al. (2016) to accommodate 12 myrothecium-like species. The genus differs from Myrothecium sensu stricto and other myrothecium-like genera by having 1-3-septate, thin-walled setae surrounding the sporodochia.

Parasarcopodium Melnik, S.J. Lee \& Crous, Mycol. Progr. 3(1): 22 (2004)

Index Fungorum number: IF28802; 3 species with sequence data.

Type species - Parasarcopodium ceratocaryi Melnik, S.J. Lee \& Crous

Notes - Lombard et al. (2016) placed this genus in Stachybotryaceae with the support of phylogenetic analysis. The genus is characterised by sporodochial conidiomata, branched, setiform conidiophores, phialidic, hyaline conidiogenous cells and aseptate, hyaline conidia with polar mucilaginous caps (Seifert et al. 2011). 
Parvothecium L. Lombard \& Crous, Persoonia 36: 214 (2016)

Index Fungorum number: IF816019; 2 species with sequence data.

Type species - Parvothecium terrestre L. Lombard \& Crous

Notes - Gordillo \& Decock (2018) described the second species, P. amazonense in this genus. The genus is characterised by sporodochial, stromatic conidiomata, penicillately branched, hyaline conidiophores, phialidic conidiogenous cells and aseptate, ellipsoidal to asymmetrically ellipsoidal, hyaline to pigmented conidia (Lombard et al. 2016).

Peethambara Subram. \& Bhat, Revue Mycol., Paris 42(1): 52 (1978)

Index Fungorum number: IF3786; 1 species with sequence data.

Type species - Peethambara sundara Subram. \& Bhat

Notes - Lombard et al. (2016) placed this genus in Stachybotryaceae with the support of multigene phylogenetic analysis. The genus is characterised by white to yellow, synnematous conidiomata and ellipsoidal to limoniform, hyaline to subhyaline, 1-septate conidia with a mammiform basal and/or apical protrudance (Lombard et al. 2016).

Pseudoornatispora Tibpromma \& K.D. Hyde, Fungal Divers. 92: 115 (2018)

Index Fungorum number: IF555336; 1 species with sequence data.

Type species - Pseudoornatispora krabiense Tibpromma \& K.D. Hyde

Notes - The genus is characterised by black ascomata with seta and ostioles, 6-8-spored, unitunicate asci, hyaline, 1-septate, verrucose, fusiform ascospores, mononematous conidiophores, phialidic, hyaline conidiogenous cells, ellipsoid, hyaline to subhyaline, aseptate, guttulate conidia, without a mucilaginous sheath (Tibpromma et al. 2018). This genus is similar to Koorchaloma and the species of these two genera grouped together in the phylogenetic analysis generated from combined ITS, LSU and rpb2 sequence data ( $\mathrm{Li}$ et al. unpublished data). We maintain these two genera as distinct. Pseudoornatispora krabiense is illustrated in this entry.

Septomyrothecium Matsush., Bull. natn. Sci. Mus., Tokyo, N.S. 14: 469 (1971)

Index Fungorum number: IF9885; 2 species with sequence data.

Type species - Septomyrothecium uniseptatum Matsush.

Notes - Decock et al. (2008) introduced one new species and one new combination to this genus. The genus is characterised by sporodochial conidiomata surrounded by white to grey fringe, long, hyaline dichotomously branched hyphoid extensions extending beyond the olivaceous green to black conidial masses, and 0-1-septate, cylindrical, straight to curved conidia (Lombard et al. 2016).

Sirastachys L. Lombard \& Crous, Persoonia 36: 215 (2016)

Index Fungorum number: IF816021; 9 species with sequence data.

Type species - Sirastachys phaeospora L. Lombard \& Crous

Notes - Sirastachys was introduced by Lombard et al. (2016) to accommodate seven stachybotrys-like species which are characterised by the formation of synnemata in culture from which the conidiophores arise laterally. The genus is characterised by mononematous, unbranched or branched conidiophores arising laterally from synnemata, phialidic conidiogenous cells and aseptate, hyaline to pale olivaceous brown to dark brown, ellipsoidal to obovoid to cylindrical conidia (Lombard et al. 2016).

Smaragdiniseta L. Lombard \& Crous, Persoonia 36: 218 (2016)

Index Fungorum number: IF816029; 1 species with sequence data.

Type species - Smaragdiniseta bisetosa (V.G. Rao \& de Hoog) L. Lombard \& Crous

Notes - Smaragdiniseta was introduced by Lombard et al. (2016) to accommodate S. bisetosa ( $\equiv$ Myrothecium bisetosum). The genus is characterised by sporodochial, stromatic conidiomata surrounded by two types of setae, verticillately or penicillately branched, hyaline conidiophores, 
phialidic, hyaline conidiogenous cells and aseptate, obclavate to narrowly ellipsoidal, hyaline conidia.

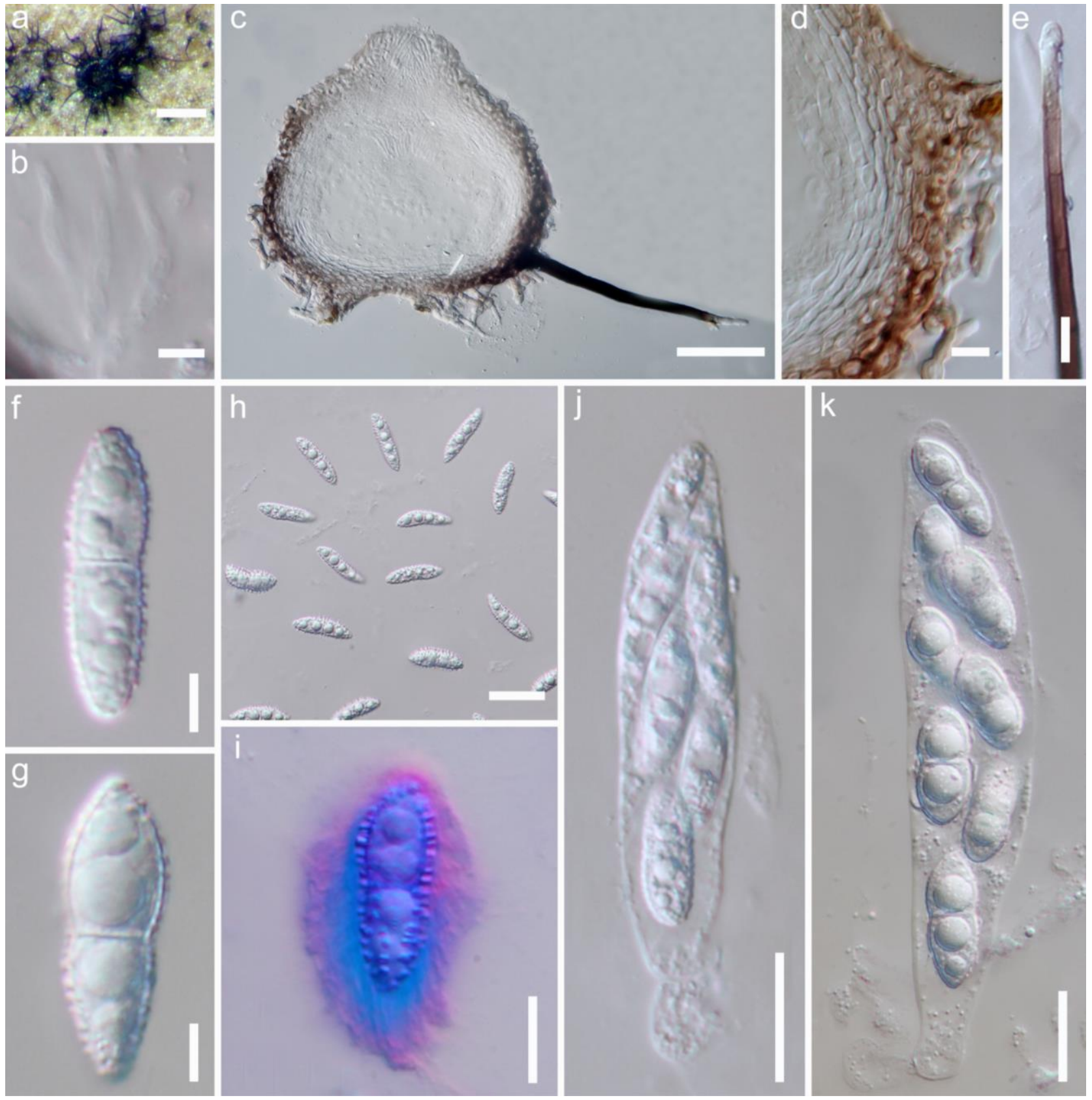

Figure 236 - Pseudoornatispora krabiense (Material examined - THAILAND, Krabi Province, Mueang Krabi District, on Pandanus sp., 15 December 2015, S. Tibpromma KB014, MFLU 161892, holotype, HKAS 96242, isotype; ex-type living culture, MFLUCC 16-0317). a Appearance of taxon on dead leaves of Pandanus sp. b Paraphyses. c Section of ascoma. d Section of peridium. e Papilla. f-h Ascospores. i Ascospore stained with India ink. j, k Asci. Scale bars: $a=200 \mu \mathrm{m}, \mathrm{b}=$ $5 \mu \mathrm{m}, \mathrm{c}=50 \mu \mathrm{m}, \mathrm{d}, \mathrm{e}, \mathrm{i}=10 \mu \mathrm{m}, \mathrm{f}, \mathrm{g}=5 \mu \mathrm{m}, \mathrm{h}=30 \mu \mathrm{m}, \mathrm{j}, \mathrm{k}=20 \mu \mathrm{m}$.

Stachybotrys Corda, Icon. fung. (Prague) 1: 21 (1837)

Index Fungorum number: IF10052; 88 morphological species (Species Fungorum 2020), 30 species with sequence data.

Type species - Stachybotrys atrus Corda

Notes - Lombard et al. (2016) revised this genus and transferred many previously accepted species to other genera, e.g. Brevistachys, Globobotrys, Sirastachys, and Striatibotrys. 
Striatibotrys L. Lombard \& Crous, Persoonia 36: 224 (2016)

Index Fungorum number: IF816035; 7 species with sequence data.

Type species - Striatibotrys eucylindrosporus (D.W. Li) L. Lombard \& Crous

Notes - Striatibotrys was introduced by Lombard et al. (2016) to accommodate six stachybotrys-like species which are characterised by mononematous conidiophores, phialidic conidiogenous cells and aseptate, pale olivaceous to dark brown, smooth-walled, longitudinally striate, ellipsoidal to subcylindrical to fusiform conidia (Lombard et al. 2016).

Striaticonidium L. Lombard \& Crous, Persoonia 36: 227 (2016)

Index Fungorum number: IF816042; 5 species with sequence data.

Type species - Striaticonidium cinctum (Corda) L. Lombard \& Crous

Notes - Striaticonidium was introduced by Lombard et al. (2016) to accommodate four myrothecium-like species which are characterised by synnematous or sporodochial or mononematous, verticillately or penicillately branched conidiophores, phialidic, hyaline conidiogenous cells and aseptate, fusiform to ellipsoidal, olivaceous green to brown, longitudinally striate conidia (Lombard et al. 2016).

Tangerinosporium L. Lombard \& Crous, Persoonia 36: 231 (2016)

Index Fungorum number: IF816048; 1 species with sequence data.

Type species - Tangerinosporium thalictricola L. Lombard \& Crous

Notes - Tangerinosporium was introduced by Lombard et al. (2016) to accommodate $T$. thalictricola which is characterised by sporodochial, stromatic conidiomata covered by an apricot to orange slimy or dry mass of conidia, hyaline, penicillately branched conidiophores, phialidic conidiogenous cells and aseptate, ellipsoidal to ossiform, hyaline conidia (Lombard et al. 2016).

Virgatospora Finley, Mycologia 59(3): 538 (1967)

Index Fungorum number: IF10411; 2 morphological species (Species Fungorum 2020), 1 species with sequence data.

Type species - Virgatospora echinofibrosa Finley

Notes - This genus was synonymised under Didymostilbe (Rossman 1983, Rossman et al. 1999). Lombard et al. (2016) resurrected the genus based on multigene phylogenetic analysis and accepted it in Stachybotryaceae. The genus is characterised by white to dark brown or black to olivaceous grey, synnematous conidiomata, branched conidiophores, 3-septate, fusiform, olivaceous grey, coarsely striate conidia with papillate and truncate ends (Finley 1967, Lombard et al. 2016).

Xenomyrothecium L. Lombard \& Crous, Persoonia 36: 232 (2016)

Index Fungorum number: IF816050; 1 species with sequence data.

Type species - Xenomyrothecium tongaense (W.B. Kendr., DiCosmo \& Michaelides) L. Lombard \& Crous

Notes - Xenomyrothecium was introduced by Lombard et al. (2016) to accommodate $X$. tongaense (三 Myrothecium tongaense). The genus is characterised by sporodochial, stromatic conidiomata, hyaline conidiophores, phialidic, pale green conidiogenous cells and aseptate, oblongellipsoidal, pale green conidia (Lombard et al. 2016). The genus differs from other genera by its oblong-ellipsoidal conidia and lack of setae formed in the sporodochia.

Xepicula Nag Raj, Coelomycetous Anamorphs with Appendage-bearing Conidia (Ontario): 979 (1993)

Index Fungorum number: IF26431; 3 species with sequence data.

Type species - Xepicula leucotricha (Peck) Nag Raj

Notes - The genus is characterised by cupulate conidiomata with septate conidiomatal setae and lack of exipular elements (Rungjindamai et al. 2012). 
Xepiculopsis Nag Raj, Coelomycetous Anamorphs with Appendage-bearing Conidia (Ontario): 9823 (1993)

Index Fungorum number: IF26432; 2 morphological species (Species Fungorum 2020).

Type species - Xepiculopsis perpulchra Nag Raj

Notes - Xepiculopsis was introduced by Nag Raj (1993) to accommodate X. graminea and X. perpulchra. The placement of this genus in Stachybotryaceae needs to be confirmed with DNA sequence data. The genus is characterised by pulvinate to cupulate, stromatic conidiomata, hyaline conidiophores, phialidic, hyaline conidiogenous cells and fusiform to ellipsoid, aseptate, pale olivaceous conidia with an obtuse apex (Nag Raj 1993).

Stilbosporaceae Link, Abh. dt. Akad. Wiss. Berlin: 180 (1826)

Index Fungorum number: IF81439; Facesoffungi number: FoF01411; 58 species.

Saprobic on bark of trees and shrubs. Sexual morph: Pseudostromata inconspicuous and immersed. Ectostromatic disc absent or present, if present inconspicuous, light brown to rarely dark brown. Entostroma prosenchymatous, pale coloured, slightly differentiated from surrounding bark. Ascomata loosely arranged as valsoid groups, in a single layer, immersed, aggregated, globose to subglobose, coriaceous, black, ostiolate, papillate. Ostiole not obvious and convergent in groups. Paraphyses filiform, aseptate, hyaline. Asci 8-spored, unitunicate, cylindrical, initially attached to the base, later floating in centrum, with a J-, refractive, apical ring. Ascospores overlapping uniseriate to biseriate, brown, ellipsoid to oblong, distoseptate. Asexual morph: Coelomycetous. Conidiomata acervular, with paraphyses. Conidiophores cylindrical, hyaline. Conidiogenous cells annellidic. Conidia brown, cylindrical, clavate to pyriform, eu- or distoseptate, oblique or longitudinal septa present or absent (adapted from Voglmayr \& Jaklitsch2014, Senanayake et al. 2017a).

Type genus - Stilbospora Pers.

Notes - Stilbosporaceae was introduced by Link (1826) with Prosthecium as the asexual morph. This family was not phylogenetically well-resolved and synonymized in several families. Voglmayr \& Jaklitsch (2014) accommodated Stilbosporaceae in Diaporthales based on LSU sequence data. Stegonsporium and Stilbospora were included in the family and Prosthecium was synonymized under Stilbospora. The type species of Stilbospora is S. macrosperma and it was connected with its asexual morph Prosthecium ellipsosporum (Voglmayr \& Jaklitsch 2008). Prosthecium ellipsosporum is the generic type of Prosthecium. Maharachchikumbura et al. (2015) accommodated Natarajania in the family using multigene phylogenetic analysis. Crinitospora was added to the family by Senanayake et al. (2017a). At present the family comprises four genera including Crinitospora, Natarajania, Stegonsporium and Stilbospora.

\section{Ecological and economic significance of Stilbosporaceae}

Voglmayr \& Jaklitsch (2014) reported most taxa in the family as discovered from Europe and North America. Asexual morphs of several species are opportunistic and moderate phytopathogens. Those species cause branch dieback or twig blight on several plants in the region (Voglmayr \& Jaklitsch 2008). Some species have been found in dead branches of overwintered plants (Voglmayr \& Jaklitsch 2014).

\section{Genera included in Stilbosporaceae}

Crinitospora B. Sutton \& Alcorn, Trans. Br. mycol. Soc. 84(3): 437 (1985)

Index Fungorum number: IF11057; 1 species with sequence data.

Type species - Crinitospora pulchra B. Sutton \& Alcorn

Notes - The asexual caulicolous Crinitospora is monotypic and the sexual morph has not yet been determined (Crous et al. 2014b). The genus was recorded from the leaves of Mangifera indica in Queensland. There are no published data on the ecology and pathology of the genus (Senanayake et al. 2018). Previously the genus was placed in Melanconidaceae (Diaporthales). Maharachchikumbura et al. (2015), Senanayake et al. (2017a, 2018) and Voglmayr et al. (2017) 
have confirmed the taxonomic placement in Stilbosporaceae. The genus is characterised by coelomycetous conidiomata and hyaline conidia, having several apical appendages which are tubular or filiform, and unbranched.

Natarajania Pratibha \& Bhat, Kavaka 33: 129 (2005)

Index Fungorum number: IF522499; 1 species with sequence data.

Type species - Natarajania indica J. Pratibha \& Bhat

Notes - This asexual hyphomycetous genus was recorded as a saprobe on leaf litter. The sexual morph of the genus has not been identified. Natarajania was accommodated in Diaporthales genera incertae sedis by Senanayake et al. (2017a). Based on molecular data, Senanayake et al. (2018) has accommodated Natarajania in Stilbosporaceae.

Stegonsporium Corda, Naturalientausch 11: 458 (1827)

Index Fungorum number: IF10071; 40 morphological species (Species Fungorum 2020), 5 species with sequence data.

Type species - Stegonsporium pyriforme (Hoffm.) Corda

Notes - Members of the genus are saprobes or mild pathogens in overwintered plants such as Acer sp. (Senanayake et al. 2018). The genus has both sexual and asexual morphs and Stegonsporium shows a high similarity with Stilbospora (Voglmayr \& Jaklitsch 2008). Stegonsporium has pyriform conidia which bear 2-7 transverse and 1-3 longitudinal distosepta. In addition the ascospores of the genus are distoseptate. These two significant characters separate Stegonsporium from Stilbospora (Voglmayr \& Jaklitsch 2008).

Stilbospora Pers., Neues Mag. Bot. 1: 93 (1794)

Index Fungorum number: IF10116; 16 morphological species (Species Fungorum 2020), 3 species with sequence data.

Type species - Stilbospora macrosperma Pers.

Notes - The type species Stilbospora macrosperma was epitypified by Voglmayr \& Jaklitsch (2014). Prosthecium (the asexual morph) includes opportunistic and moderately phytopathogenic taxa, which are responsible for the branch dieback or twig blight in several overwintered plants (Voglmayr \& Jaklitsch 2008). Some species of Prosthecium were also recorded from corticated and dead branches of the same plants (Voglmayr \& Jaklitsch 2014). In this entry, we illustrated the sexual morph of Stilbospora macrosperma.

Sydowiellaceae Lar.N. Vassiljeva, Pirenomits. Lokuloaskomits. Severa Dal'nego Vostoka (Leningrad): 210 (1987)

Index Fungorum number: IF81867; Facesoffungi number: FoF06882; 47 species.

Saprobic or parasitic on plant matter. Sexual morph: Stromata well- or poorly developed, prosenchymatous, scattered, immersed to erumpent, appearing as an aggregation of ostioles, rounded or elliptic, dark brown to black, composed of compact pseudoparenchymatous tissues, several ascoma in a stroma, some species turning umber in $5 \% \mathrm{KOH}$. Ascomata solitary or aggregated, immersed or erumpent, globose to subglobose, sometimes circinate, coriaceous, with central or asymmetrically located ostiolar canal opening through an individual or converged ostiole, internally covered by filamentous, hyaline periphyses, sometime ostiolar opening wider than canal, black to brown. Peridium comprising a few layers of brown, thick-walled cells of textura angularis. Paraphyses cellular, septate, branched, hyaline. Asci 8-spored, unitunicate, cylindrical to subglobose, short pedicellate, apex blunt, with J-, apical ring. Ascospores uni- to multi-seriate, hyaline, pale brown to dark brown, filamentous, ellipsoid or long fusoid-cylindrical, 1-11-septate, sometimes with apical and basal appendages, wall smooth or verruculose ornamentation. Asexual morph: Coelomycetous. Conidiomata sometimes stromatic, pycnidia, uniloculate, superficial, aggregated 3-5 in one group, globose, orange to brown. Conidiomatal wall comprising thickwalled, orange cells of textura angularis. Conidiophores elongate, branched, hyaline, few 
conidiogenous cells arising from one conidiophore, attached to conidiomatal wall. Conidiogenous cells cylindrical, hyaline, ampulliform, septate, ends pointed, phialidic. Conidia ovoid to ellipsoid, unicellular, hyaline, smooth-walled.

Type genus - Sydowiella Petr.

Notes - Vasilyeva (1987) introduced this family to accommodate an assortment of diversified taxa. Vasilyeva (2001) and Kruys \& Castlebury (2012) introduced several genera to this family. Senanayake et al. (2017b) revised this family and introduced several genera and species following a phylogenetic analysis. Voglmayr \& Mehrabi (2018) accommodated Caudospora in this family introducing $C$. iranica as new species. Currently this family comprises 16 genera.

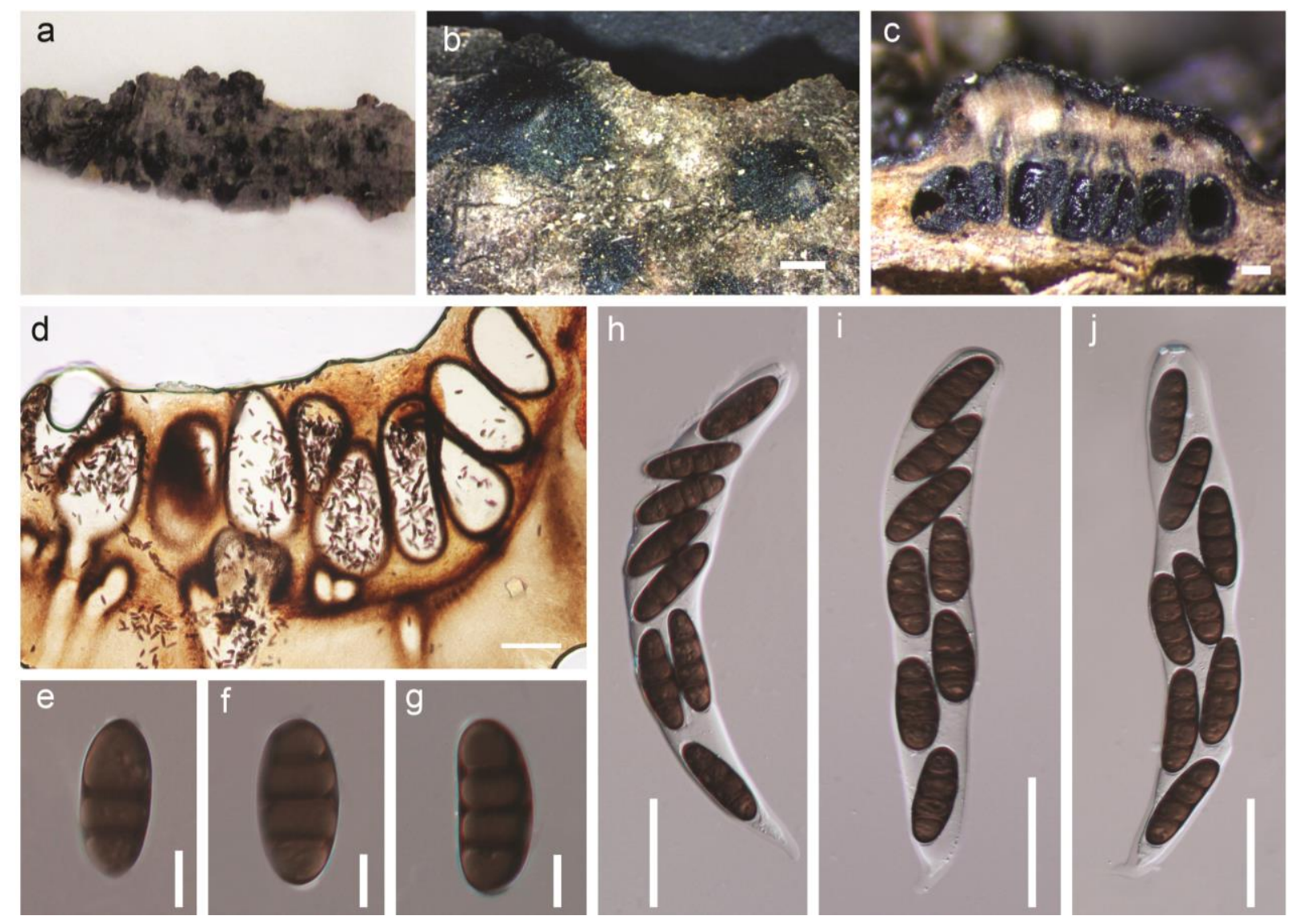

Figure 237 - Stilbospora macrosperma (Material examined - AUSTRIA, Niederösterreich, Rekawinkel, grid square 7862/1, on a trunk of Carpinus betulus L. (Betulaceae), 20 October 2001, W. Jaklitsch, W.J. 1840, D25, WU 24708, epitype). a Herbarium specimen. b Ascomata on substrate. c Cut showing ascomata in stroma. d Vertical section of stroma. e-g Ascospores. h-j Asci. Scale bars: $\mathrm{b}, \mathrm{c}=200 \mu \mathrm{m}, \mathrm{d}=20 \mu \mathrm{m}, \mathrm{e}-\mathrm{g}=5 \mu \mathrm{m}, \mathrm{h}-\mathrm{j}=20 \mu \mathrm{m}$.

\section{Ecological and economic significance of Sydowiellaceae}

Species of Sydowiellaceae are saprobes, endophytes or pathogens on herbaceous, dicotyledonous and hardwood trees. Sydowiella species was reported on leaves and stem cankers (Nordskog et al. 2003). Cainiella johansonii occurs on both living and dead leaves and petioles of Dryas species, while Cainiella borealis occurs as a saprobe on dead branches of Cassiope tetragona (Kruys \& Castlebury 2012). Paragnomonia fragariae causes a dieback disease of strawberry (Klebahn 1918). Hapalocystis berkeleyi forms stromatic fruiting bodies on dead woody plants. Most of other members in this family are saprobes and help in litter decomposition.

\section{Genera included in Sydowiellaceae}

Alborbis Senan. \& K.D. Hyde, Mycosphere 8(1): 183 (2017)

Index Fungorum number: IF552717; 1 species with sequence data. 
Type species - Alborbis galericulata (Tul. \& C. Tul.) Senan. \& K.D. Hyde

Notes - Alborbis is a monotypic genus introduced based on Valsa galericulata. This species is a mild pathogen causing canker of Fagus species and saprobic on branches of Fagus sylvatica (Mejía et al. 2011). Mejía et al. (2011) suggested that Valsa galericulata has an affiliation with Sydowiellaceae based on the molecular data and Senanayake et al. (2017b) introduced Alborbis to accommodate this taxon. This genus is characterised by inconspicuous or astromatic ascomata and ellipsoid to cylindrical, 1-septate, 4-guttulate ascospores with short appendages.

Breviappendix Senan. \& K.D. Hyde, Mycosphere 8(1): 186 (2017)

Index Fungorum number: IF552719; 3 species with sequence data.

Type species - Breviappendix rubi (Rehm) Senan., Maharachch. \& K.D. Hyde

Notes - Breviappendix comprises three species, B. rubi, B. rosae and $B$. rostellata (Senanayake et al. 2017b). Breviappendix rubi was reported as a severe stem canker and dieback forming pathogen of various cultivated and wild Rubus species in both Europe and America (Nordskog et al. 2003).

Cainiella E. Müll., Sydowia 10(1-6): 120 (1957)

Index Fungorum number: IF720; 2 species with sequence data.

Type species - Cainiella johansonii (Rehm) E. Müll.

Notes - Cainiella was introduced by Muller (1957) based on Lizonia johansonii. Cainiella comprises $C$. borealis in addition to the type species. This genus is characterized by dark, immersed ascomata, with long-necks, deliquescing paraphyses, as well as asci with a J-, refractive ring and 1septate ascospores. Cainiella species are saprobic or very mild pathogens on arctic dwarf shrubs and prostrate evergreen subshrubs.

Calosporella J. Schröt., Krypt.-Fl. Schlesien (Breslau) 3.2(4): 442 (1897)

Index Fungorum number: IF757; 1 species with sequence data.

Type species - Calosporella innesii (Curr.) J. Schröt.

Notes - Calosporella was typified with $C$. innesii using a specimen collected from Austria associated with dead corticated branches of Acer pseudoplatanus (Voglmayr \& Jaklitsch 2014). Calosporella innesii has hyaline, mostly 3-septate ascospores, with small apical appendages.

Caudospora Starbäck, Bih. K. svenskaVetensk Akad. Handl.,Afd. 3 15(no. 2): 11 (1889)

Index Fungorum number: IF854; 2 species with sequence data.

Type species - Caudospora taleola (Fr.) Starbäck

Notes - Caudospora is characterized by immersed perithecia in corticolous pseudostromata delimited by a distinct blackish zone, a whitish ectostromatic disc with few converging ostioles, cylindrical asci and hyaline, 2-celled ascospores with or without an appendage at each end and 2-3 median appendages. Caudospora taleola is a saprobe or weak pathogen which can cause canker diseases (Phillips \& Burdekin 1992).

Chapeckia M.E. Barr, Mycol. Mem. 7: 164 (1978)

Index Fungorum number: IF983; 2 morphological species (Species Fungorum 2020), 1 species with sequence data.

Type species - Chapeckia nigrospora (Peck) M.E. Barr

Notes - Chapeckia was introduced based on Diatrype nigrospora (Barr 1978). This genus comprises Chapeckia ribesia as the second species. Chapeckia was placed in Sydowiellaceae based on molecular data (De Silva et al. 2009, Kruys \& Castlebury 2012, Senanayake et al. 2017b).

Hapalocystis Auersw., Fungi rhenaniexsic., fasc. 6: no. 585 (1863)

Index Fungorum number: IF2222; 7 morphological species (Species Fungorum 2020), 3 species with sequence data. 
Type species - Hapalocystis berkeleyi Auersw.

Notes - Hapalocystis was established to accommodate Sphaeria hapalocystis and Sphaeria inquinans var. ulmi as Hapalocystis berkeleyi and H. bicaudata respectively (Fuckel 1863). Clements \& Shear (1931) designated $H$. berkeleyi as the type species. The asexual morph of Hapalocystis was reported as a phoma-like asexual morph for $H$. berkeleyi from culture (Glawe 1985, Liu et al. 2015).
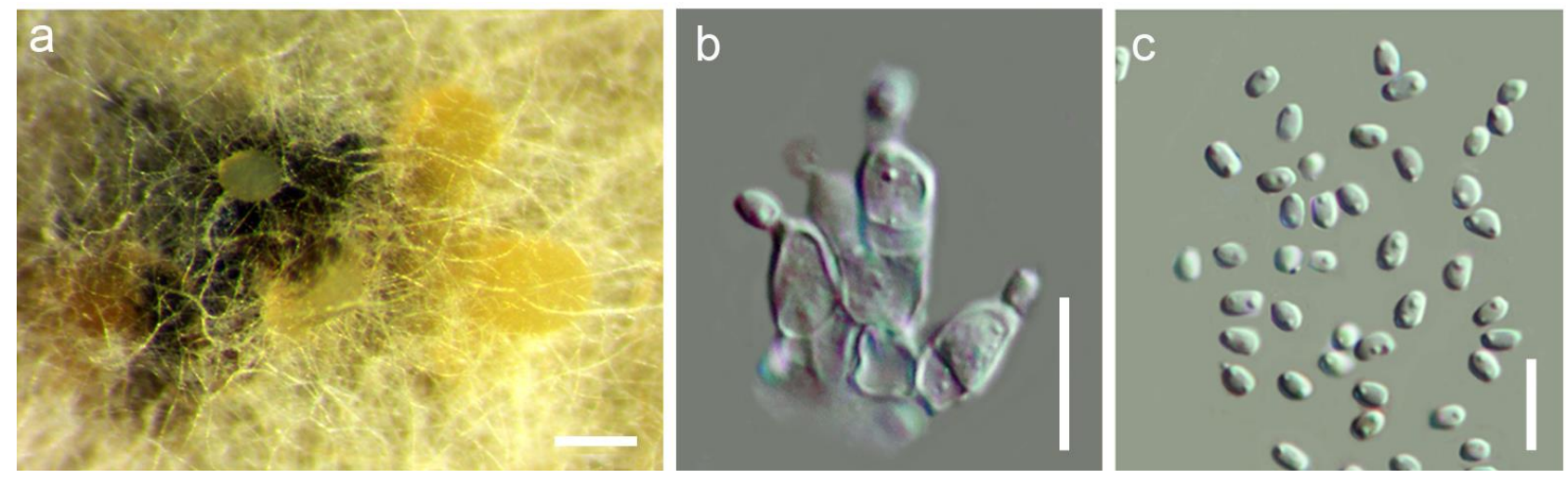

Figure 238 - Hapalocystis berkeleyi (Material examined - GERMANY, Rhineland, Hattenheim (near), Gruenau, L. Fuckel (Fungi rhenani exs. 585; ex herb. C.E. Brome), isotype, K (M) 195743; ITALY, Province of Forl1'-Cesena, Modigliana, Montebello, on branch of Platanus hybrid, 14 April 2013, E. Camporesi, MFLU 14-0798). a Conidiomata on MEA. b Conidiophores, conidiogenous cells and conidia. c Conidia. Scale bars: $\mathrm{a}=500 \mu \mathrm{m}, \mathrm{b}=10 \mu \mathrm{m}, \mathrm{c}=5 \mu \mathrm{m}$.

Italiomyces Senan., Camporesi \& K.D. Hyde, Mycosphere 8(1): 196 (2017)

Index Fungorum number: IF552721; 1 species with sequence data.

Type species - Italiomyces centaureae Senan., Camporesi \& K.D. Hyde

Notes - Italiomyces is distinct in its bi-guttulate or rarely 4-guttulate ascospores with minute, spine-like apical appendages. Phylogenetically, Italiomyces forms a distinct clade in Sydowiellaceae.

Lambro Racib., Parasit. Alg. Pilze Java's (Jakarta) 2: 13 (1900)

Index Fungorum number: IF552801; 3 morphological species (Species Fungorum 2020).

Type species - Lambro insignis Racib.

Notes - Lambro insignis produces necrotic spots in leaves of Sterculia subpeltata (Raciborski 1900). The asexual morph of Lambro is reported as a cylindrosporella-like.

Paragnomonia Senan. \& K.D. Hyde, Mycosphere 8(1): 198 (2017)

Index Fungorum number: IF552723; 1 species with sequence data.

Type species - Paragnomonia fragariae (Kleb.) Senan. \& K.D. Hyde

Notes - Paragnomonia fragariae was isolated from dead petioles and leaves of strawberry and causes strawberry decline.

Ranulospora Senan., Camporesi \& K.D. Hyde, Mycosphere 8(1): 202 (2017)

Index Fungorum number: IF552725; 1 species with sequence data.

Type species - Ranulospora alnea Senan., Camporesi \& K.D. Hyde

Notes - Ranulospora alnea is a saprobe collected from bark of grey alder. This genus comprises grouped ascomata combined by brown, hyphae.

Rossmania Lar.N. Vassiljeva, Mycoscience 42(4): 401 (2001)

Index Fungorum number: IF28578; 2 morphological species (Species Fungorum 2020), 1 species with sequence data. 
Type species - Rossmania ukurunduensis Lar.N. Vassiljeva

Notes - Rossmania was introduced to accommodate taxa having clustered ascomata with long beaks, a non-united ectostromatic disc, and septate, elongate ascospores (Vasilyeva 2001). Rossmania comprises $R$. ukurunduensis and $R$. aculeata (Vasilyeva 2001). Rossmania ukurunduensis was collected in Russia associated with Acer ukurunduense, while R. aculeata was collected from Sri Lanka associated with Theaceae (Vasilyeva 2001).

Sillia P. Karst., Bidr. Känn. Finl. Nat. Folk 23: 159, 251 (1873)

Index Fungorum number: IF5029; 8 morphological species (Species Fungorum 2020), 3 species with sequence data.

Type species - Sillia ferruginea (Pers.) P. Karst.

Notes - Ascospores of Sillia are filiform or acicular, scolecosporous and multi-septate. Rossman et al. (2007) was accommodated Sillia in Sydowiellaceae based on its morphology. De Silva et al. (2009), Kruys \& Castlebury (2012) and Senanayake et al. (2017b) placed Sillia in Sydowiellaceae based on phylogeny.

Sydowiella Petr., Annls mycol. 21(1/2): 30 (1923)

Index Fungorum number: IF5312; 9 morphological species (Species Fungorum 2020), 5 species with sequence data.

Type species - Sydowiella fenestrans (Duby) Petr.

Notes - Sydowiella are mild pathogens or saprobes characterized by solitarily, erumpent ascomata without stromatic tissues and 2-celled ascospores (Kobayashi 1970). Sydowiella species are mostly distributed in temperate regions (Farr \& Rossman 2018). Betula, Centaurea, Dryas, Epilobium, Juncus, Rubus, and Urtica are the common host genera from which Sydowiella species have been collected. In this entry we illustrate the sexual morph of Sydowiella fenestrans. The asexual morph of Sydowiella has not been reported.

Tenuiappendicula Senan., Camporesi \& K.D. Hyde, Mycosphere 8(1): 207 (2017)

Index Fungorum number: IF552728; 1 species with sequence data.

Type species - Tenuiappendicula alnicola Senan., Camporesi \& K.D. Hyde

Notes - Tenuiappendicula is characterized by 1-septate ascospores with long, thin appendages and asci without an apical ring.

Tortilispora Senan. \& K.D. Hyde, Mycosphere 8(1): 208 (2017)

Index Fungorum number: IF552802; 3 morphological species (Species Fungorum 2020), 1 species with sequence data.

Type species - Tortilispora aurantiaca (Wehm.) Senan. \& K.D. Hyde

Notes - Tortilispora was introduced to accommodate some Winterella species and currently this genus comprises $T$. aurantiaca, $T$. albofusca and $T$. cinctula. Tortilispora species are characterized by multi-septate elongated ascospores, and valsoid ascomata.

Synnemasporellaceae X.L. Fan \& J.D.P. Bezerra, Persoonia 40: 130 (2018)

Index Fungorum number: IF823994; Facesoffungi number: FoF05208; 2 species.

Saprobic, pathogenic or endophytic on several hosts. Sexual morph: Pseudostromata appearing upon the bark surface as pustules containing a small cluster of ostioles developing through the adherent periderm, covered by a whitish pulverulence. Stromatic zones absent. Ascomata perithecial, sphaerical or slightly flattened, with long necks, thickly clustered underneath the ectostromatic disks. Asci clavate. Ascospores biseriate, fusoid-ellipsoid, 2-celled, hyaline, usually with a short, hyaline, bristle-like appendage at both ends. Asexual morph: Coelomycetous or hyphomycetous. Conidiomata pycnidial or synnematal. Synnemata long and determinate, parallel, comprised of slender, cylindrical black stalks emerging from host tissue and a sphaerical, capitate, shiny black mass of conidia, conidiogenous cells zone concave, dark. Pycnidia centrally 
ostiolate, hemisphaerical, immersed, slightly erumpent. Conidiophores aggregated, straight to curved. Conidiogenous cells aggregated, hyaline, straight to curved, cylindrical. Conidia cylindrical to clavate, with a discrete hilum, smooth, pale brown (adapted from Fan et al. 2018).

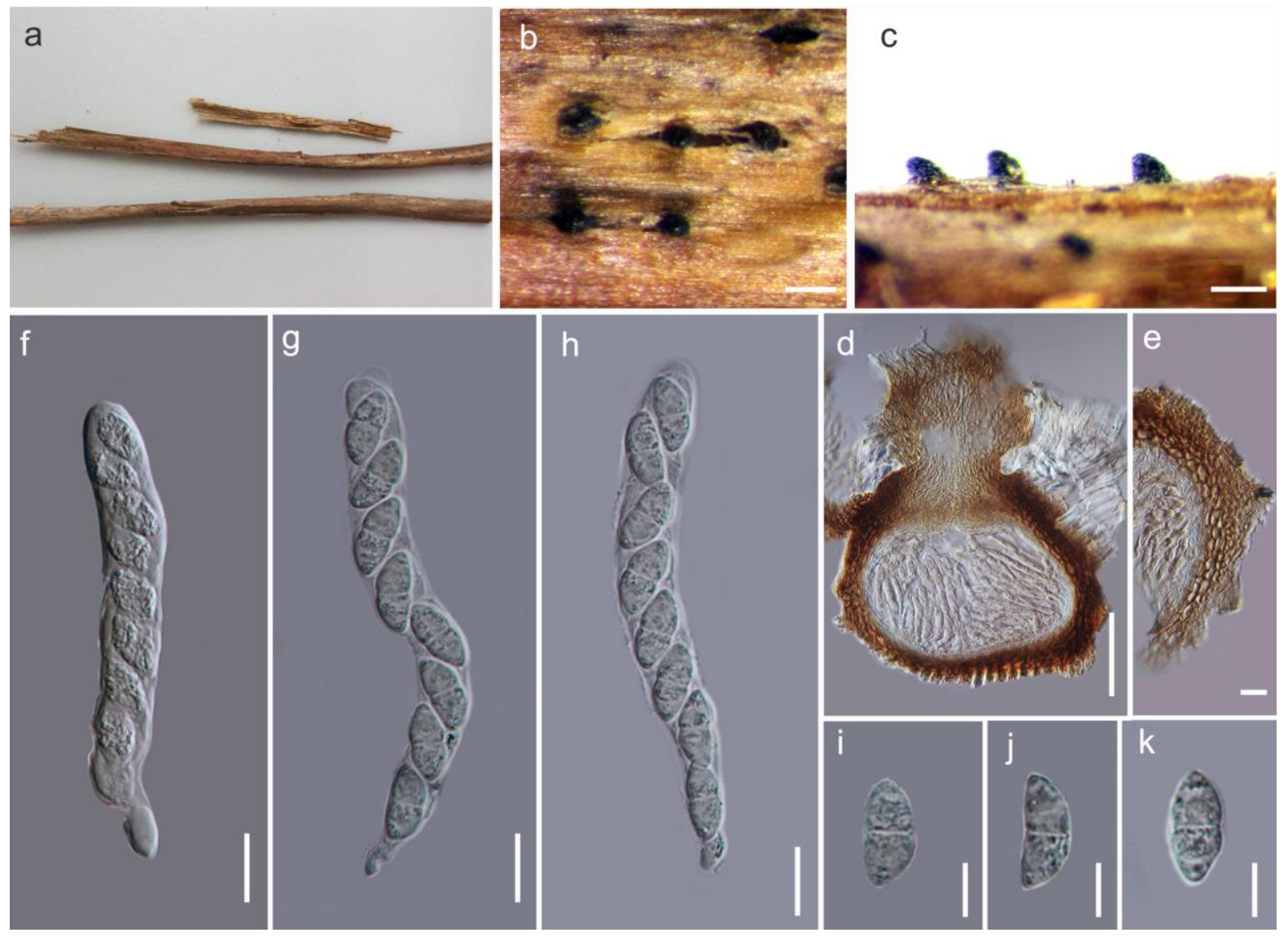

Figure 239 - Sydowiella fenestrans (Material examined - GERMANY, Hessen, Wiesenwald pr. Oestrich (Nassau), on Epilobii angustifolii, Fuckel, 1894, F109251, holotype). a Herbarium specimen. b, c Ascomata on host surface. d Cross section of ascoma. e Peridium. f-h Asci. i-k Ascospores. Scale bars: b, $c=200 \mu \mathrm{m}, \mathrm{d}=100 \mu \mathrm{m}, \mathrm{e}-\mathrm{h}=20 \mu \mathrm{m}, \mathrm{i}-\mathrm{k}=10 \mu \mathrm{m}$.

Type genus - Synnemasporella X.L. Fan \& J.D.P. Bezerra

Notes - Synnemasporellaceae was established by Fan et al. (2018) to accommodate taxa with synnematous conidiomata and which lack the usual characters of any of the hyaline, didymosporous, stromatic genera in Diaporthales. Based on phylogenetic analyses, Synnemasporellaceae forms a well-supported clade between the families Apiosporopsidaceae and Juglanconidaceae. Species in the family have distinct synnemata, ascomatal and/or conidiomatal characters, ascospore shape, conidiogenous cells and conidia as well as different fungi-host associations and disease symptoms from species in Apiosporopsidaceae and Juglanconidaceae (Senanayake et al. 2017a, Voglmayr et al. 2017). Synnemasporellaceae has also been placed in a sister clade with Melanconidaceae (Mejía et al. 2011), the latter family having different conidia colour and hilum to the species in Synnemasporellaceae (Wehmeyer 1933b).

\section{Ecological and economic significance of Synnemasporellaceae}

Species belonging to Synnemasporellaceae are saprobic, endophytic or pathogenic. Synnemasporella toxicodendri has been reported to grow solely on diseased wood of Toxicodendron sylvestre in China, while $S$. aculeans affects several species of Rhus, namely, Rhus copallina, $R$. diversiloba, $R$. glabra, $R$. javanica, $R$. typhina and $R$. vernix mainly in Japan and the USA (Wehmeyer 1933b, Kobayashi 1970, Mejía et al. 2011), and R. chinensis in China (Fan et al. 2018). 


\section{Genus included in Synnemasporellaceae}

Synnemasporella X.L. Fan \& J.D.P. Bezerra, Persoonia 40: 130 (2018)

Index Fungorum number: IF823995; 2 species with sequence data.

Type species - Synnemasporella toxicodendri X.L. Fan \& J.D.P. Bezerra

Notes - Synnemasporella accommodates two species, S. aculeans and S. toxicodendri (Fan et al. 2018). Cryptodiaporthe aculeans, which has perithecial ascomata as well as sporodochial and/or pycnidial conidiomata (Fan et al. 2018), was transferred to Synnemasporella. Cryptodiaporthe aculeans was introduced by Wehmeyer (1933b) who noted that Cryptodiaporthe contained a heterogeneous group of species which would probably be separated into several genera when their relationships were fully understood. Initially, Cryptodiaporthe was considered a synonym of Plagiostoma (Sogonov et al. 2008, Mejía et al. 2011, Voglmayr et al. 2017). However, phylogenetic analyses (Senanayake et al. 2017a) indicated that they are two separate genera. Synnemasporella toxicodendri differs from Cryptodiaporthe aculeans in having longer synnemata, a flat to slightly concave conidiogenous cell on the top of the synnemata and smaller conidia. Synnemasporella toxicodendri is illustrated for this entry.

Telimenaceae Mardones, T. Trampe \& M, Piepenbr., Persoonia 39: 83 (2017)

Index Fungorum number: IF818222; Facesoffungi number: FoF06883; 39 species.

Mostly biotrophic on monocotyledons and dicotyledons (except Poaceae). Sexual morph: Stroma of various shapes, covered by a cuticular or epidermal shiny blackened clypeus, with limited development around the ostiole or extensively above the ascomata and sometimes below the ascomata. Pseudostroma strongly developed, interfusing and conspicuously expanding into the host tissue. Ascomata perithecial, amphigenous, epiphyllous or hyphophyllous, uni- to multiloculate, sometimes confluent, frequently surrounded by a bright yellow to reddish coloured zone, subcuticular, epidermal, subepidermal or immersed in the host tissue, pyriform, globose, lenticular, or deformed by vascular bundles, with a periphysate ostiole. Peridium hyaline to pigmented, composed of cells of textura intricata. Paraphyses hyaline, thin-walled, slightly longer than the asci, septate, often dissolving during maturation. Asci 8-spored, rarely 4-spored, unitunicate, clavate or cylindrical, usually, apical ring often J-. Ascospores 1-2-seriate, usually hyaline, rarely pale brown, globose to filiform, mostly cylindrical, thin and smooth-walled, aseptate to 3-septate, sometimes surrounded mucilaginous sheath. Spermatogonia infrequently found, pycnidial, spermatiogenous cells cylindrical, tapering towards the tip, proliferating percurrently, with filiform, hyaline, aseptate scolecospores, probably spermatial in function. Asexual morph: Undetermined (adapted from Mardones et al. 2017).

Type genus - Telimena Racib.

Notes - Mardones et al. (2017) redefined Phyllachoraceae and proposed the new family Telimenaceae with Telimena erythrinae as the type species, resulting in three families in Phyllachorales. Telimena species occur on monocotyledons and eudicotyledons, except Poaceae, and generally have enlarged black pseudostroma around the perithecia (Mardones et al. 2017, 2018). Phylogenetic analyses of combined LSU, SSU, ITS, rpb2 and tefl sequence data showed that Telimena spp. formed a well-separated monophyletic clade in Phyllachorales (Mardones et al. 2017) and this was also found in Dayarathne et al. (2017).

\section{Ecological and economic significance of Telimenaceae}

Telimena species occur as parasites on several monocotyledons and eudicotyledons (Mardones et al. 2017). The hyphae of Telimena species, such as Telimena zanthoxylicola, penetrate intracellularly through the host tissue by appressoria-like structures against the host cell walls, which are then perforated by fine canals of the hyphae to form haustoria-like swellings on the other side, which can serve in nutrient absorption (Speer 1980a). Hyphae can continually grow and infect new cells, which are stimulated to divide spontaneously, and this is clearly visible in the palisade cells (Speer 1980a). On the leaves, infected areas do not spread far beyond the radius of the clypeus, however, on twigs hyphal growth is less limited, seeming to cause die-back in the 
youngest shoots (Speer 1980a). Telimena erythrinae, is a parasite of the dicotyledonous plant host Erythrina variegata (Fabaceae) forming necrotic leaf spots (Mardones et al. 2017).

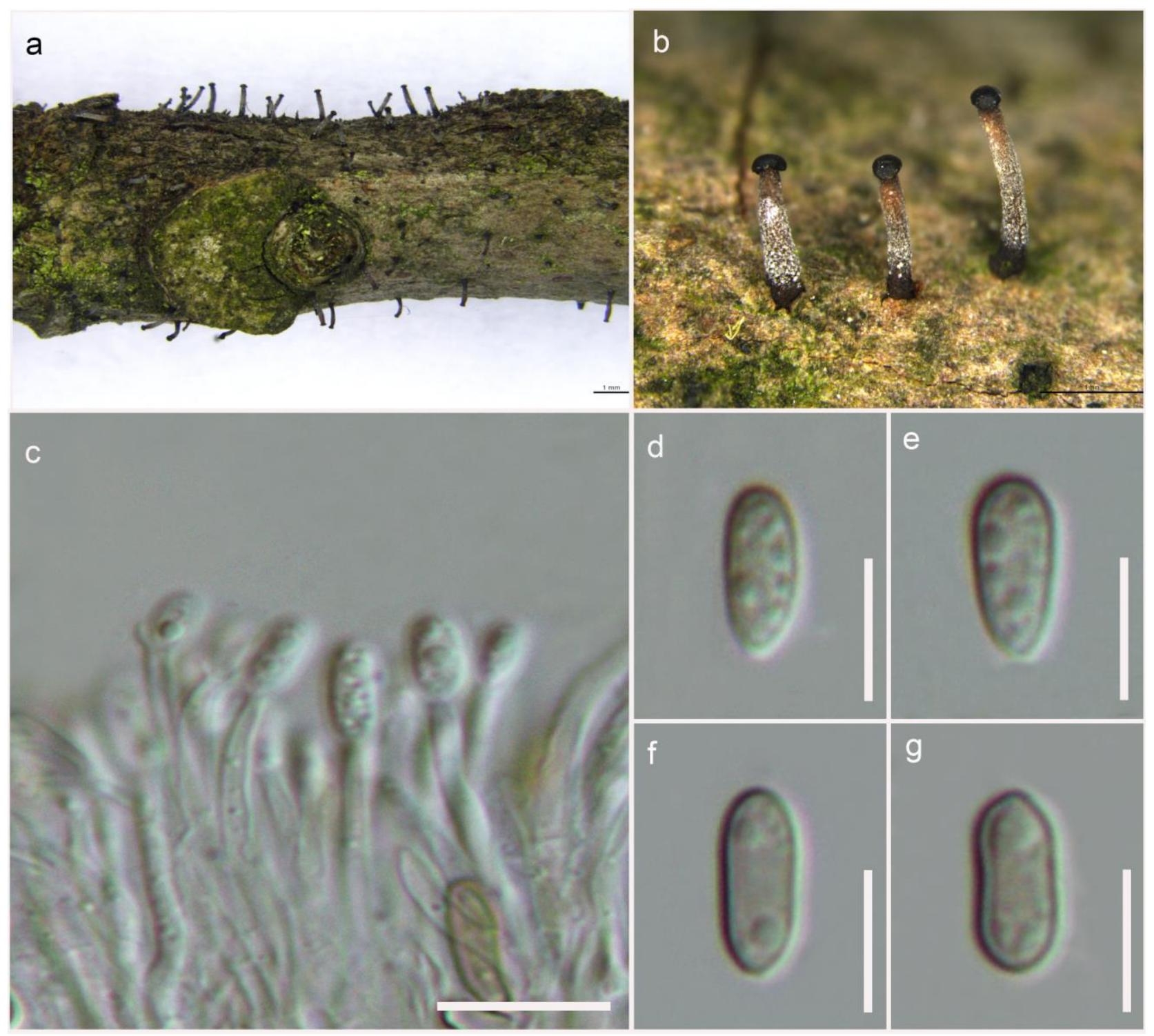

Figure 240 - Synnemasporella toxicodendri (Material examined - CHINA, Zhejiang Province, Hangzhou City, Linan, Xijing Mountain, N30¹5'32.84" E11943'31.21", 54 m asl, on twigs and branches of Toxicodendron sylvestre, 22 April 2017, Q. Yang \& Z. Du, CF 2017481, holotype). a, b Habit of synnemata on branches. c Conidiophores and conidiogenous cells and developing conidia. d-g Conidia. Scale bars: $\mathrm{a}, \mathrm{b}=1 \mathrm{~mm}, \mathrm{c}-\mathrm{g}=10 \mu \mathrm{m}$.

\section{Genus included in Telimenaceae}

Telimena Racib., Parasit. Alg. Pilze Java's (Jakarta) 1: 18. 1900.

Index Fungorum number: IF5364; 39 morphological species (Species Fungorum 2020), 18 species with sequence data.

Type species - Telimena erythrinae Racib.

Notes - Raciborski (1900) introduced Telimena for phyllachora-like species with 3-septate ascospores. Currently, there are 14 species in this genus (Mardones et al. 2017). Close relationships of Telimena with the genera Telimenopsis and Telimenella and Telimenochora have been reported (Petrak 1931, Müller 1975, Barr 1977). These genera are segregated by the shape and septation of the ascospores (Sivanesan 1987). However, there are no molecular sequence data from the type material of most Telimena species (Mardones et al. 2017). 

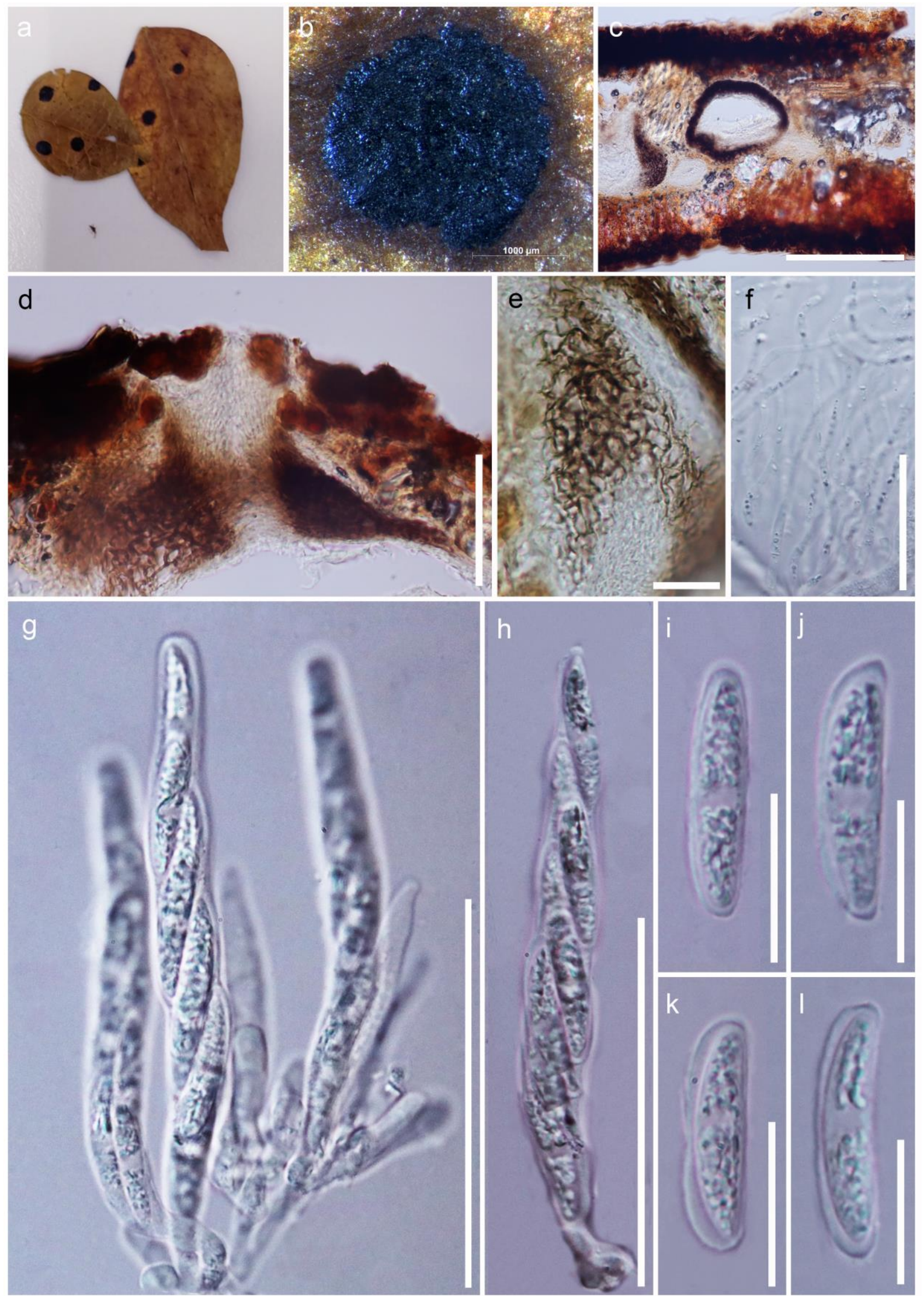

Figure 241 - Telimena picramniae (Material examined - COSTA RICA, Aserri, (as P. antidesma), on Picramnia antidesma (= P. bonplandiana), 26 June 1923, F.L. Stevens, ILL00005686, holotype, ILL00005686, ILL00005687, paratypes). a Herbarium material. b Close up of a leaf spot. c Section through pseudostroma. d Section through ostiolar region. e Peridium. f Paraphyses. g, h Asci. i-l Ascospores. Scale bars: $\mathrm{b}, \mathrm{c}=1000 \mu \mathrm{m}, \mathrm{d}=100 \mu \mathrm{m}, \mathrm{g}, \mathrm{h} 50 \mu \mathrm{m}, \mathrm{f}, \mathrm{i}-1=20 \mu \mathrm{m}$. 
Thyridiaceae J.Z. Yue \& O.E. Erikss., Syst. Ascom. 6(2): 233 (1987)

Index Fungorum number: IF82030; Facesoffungi number: FoF01913; 35 species.

Hemibiotrophic or saprobic on woody substrates. Sexual morph: Ascomata stromatic. Stromatal tissue immersed, becoming erumpent to superficial, soft-textured, reddish brown to brightly pigmented. Ascomata immersed in stromata, globose, ostiolate. Ostioles periphysate, with short or long papilla or necks, sometimes convergent necks merging into one ostiole. Peridium composed of compressed rows of cells, externally brown, internally hyaline. Paraphyses filamentous, septate. Asci 8-spored, unitunicate, oblong cylindric, apical ring J-. Ascospores uniseriate, shades of brown, ellipsoid or biconoid, symmetric, 1-septate or muriform. Asexual morph: Coelomycetous or hyphomycetous, often developing on the edge of sexual morph stroma. Conidiomata immersed in stromata, irregular, multilocular and folded inside. Conidiogenous cells emerging from the interior of the cavity, bearing one or more conidiogenous cells. Conidiogenous cells enteroblastic, phialidic, hyaline. Conidia ellipsoidal, aseptate, small, hyaline. Holoblastic sympodial conidia also produced from hyphae. Sometimes ascospores produce primary conidia (adapted from Barr 1990b, Leuchtmann \& Müller 1986, Maharachchikumbura et al. 2016b).

Type genus - Thyridium Nitschke

Notes - In a phylogenetic and molecular clock analyses, Thyridiaceae showed a close relationship to Annulatascales and Myrmecridiales (Hyde et al. 2017a, Hongsanan et al. 2017, Senanayake et al. 2017a). However, only a single strain of the type genus has sequence data (Thyridium vestitum strain AFTOL-ID 172), and the ordinal placement remains uncertain in Diaporthomycetidae (Maharachchikumbura et al. 2015b, 2016b, Hongsanan et al. 2017). Maharachchikumbura et al. (2015, 2016b) and Wijayawardene et al. (2018a) accepted three genera in Thyridiaceae (Mattirolia, Pleurocytospora, and Thyridium). No sequence data are available for Pleurocytospora species. Mattirolia has been synonymised under Thyronectria (Nectriaceae) by Jaklitsch \& Voglmayr (2014) based on an ex-epitype sequence of the generic type of Mattirolia, M. roseovirens. Here we follow the treatment of Jaklitsch \& Voglmayr (2014).

\section{Ecological and economic significance of Thyridiaceae}

Species of Thyridium are saprobic on woody substrates (Checa et al. 2013, Zhou \& Hyde 2002). Pleurocytospora species are saprobic or hemibiotrophic in woody substrates (Barr 1990b, Zhu et al. 2005) and therefore, involved in nutrient recycling. Pleurocytospora taxi was recorded from Taxus cuspidata, while P. lycii was isolated from Arabidopsis thaliana as an endophyte (Sun et al. 2003, Wang et al. 2015a, Junker et al. 2012) and there are no records of pathogenic species in Thyridiaceae.

\section{Genera included in Thyridiaceae}

Pleurocytospora Petr., Annls mycol. 21(3/4): 256 (1923)

Index Fungorum number: IF9459; 3 morphological species (Species Fungorum 2020).

Type species - Pleurocytospora vestita Petr.

Notes - Pleurocytospora was introduced to accommodate P. vestita and P. lycii (Petrak 1923). Pleurocytospora taxi was introduced from the host Taxus cuspidata (Sun et al. 2003).

Thyridium Nitschke, Pyrenomyc. Germ. 1: 110 (1867)

Index Fungorum number: IF5465; 32 morphological species (Species Fungorum 2020), 1 species with sequence data.

Type species - Thyridium vestitum (Fr.) Fuckel

Notes - Thyridium was introduced by Nitschke (1867) to accommodate species with uniseriate, muriform, dark-coloured ascospores, 8-spored asci and filiform paraphyses (Nitschke 1867). Furthermore, species of Thyridium are characterized by $\mathrm{KOH}+$ stromata, cylindrical or clavate asci, and very pale brown to dark brown muriform ascospores (Checa et al. 2013, Maharachchikumbura et al. 2016b). Asexual morphs are coelomycetous, or produce holoblastic sympodial conidia from hyphae (Leuchtmann \& Müller 1986). 


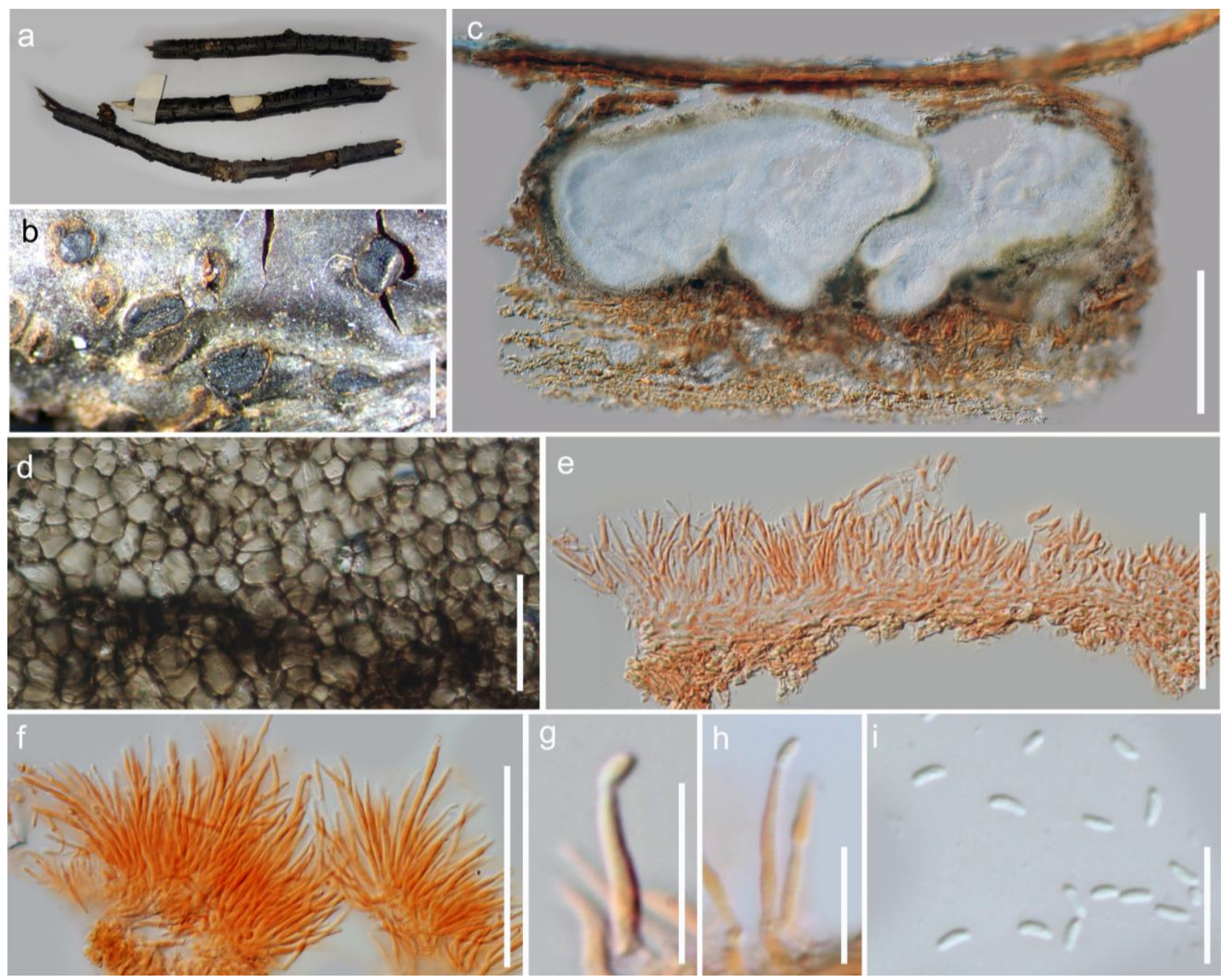

Figure 242 - Pleurocytospora vestita (Material examined - SWITZERLAND, Zurich, Zollikon, in garden, on Ribes rubrum L., 15 May 1986, E. Müller, ZT MYC 58916). a Herbarium material. b Appearance of conidiomata on the host substrate. c Transverse section of conidiomata. $d$ Surface of the stromatic tissue. e, f Conidiophores with conidiogenous cells. g, h Conidiogenous cells with conidia. i Conidia. Scale bars: $\mathrm{b}=1 \mathrm{~mm}, \mathrm{c}=200 \mu \mathrm{m}, \mathrm{d}-\mathrm{f}=50 \mu \mathrm{m}, \mathrm{g}-\mathrm{i}=10 \mu \mathrm{m}$.

Tilachlidiaceae L. Lombard \& Crous, Stud. Mycol. 80: 237 (2015)

Index Fungorum number: IF810273; Facesoffungi number: FoF01280; 20 species.

Saprobic or parasitic on other fungi, entomogenous on lepidopterous insects, associated with bryophytes, or isolated from soil. Sexual morph: Ascomata arising directly from the mycelium or formed on loosely arranged stromata, perithecial, $\mathrm{KOH}-$ - Ostiole apapillate. Asci 68-spored, clavate or cylindrical, short pedicellate. Ascospores hyaline to yellow, irregularly ovoid or ellipsoidal, muriform, 2-13 celled, with 1-5 transverse septa. Asexual morph: Hyphomycetous. Conidiophores synnematous or acremonium-like. Synnemata when present simple to branched, Conidiophores synnematous or acremonium-like. Synnemata when present simple to branched, cylindrical, narrowing towards the apex, consisting of bundles of parallel, longitudinal, closely compacted hyphae, with 1-4 phialides. Phialides scattered, cymbiform to cylindrical or allantoid, aseptate or septate, sometimes with obvious collarettes, narrowing towards the apex, sometimes integrated in septate branches, hyaline to yellow, smooth or becoming verrucose. Conidia fusiform to ellipsoid to subcylindrical or oblong, 0-7-septate, with distinct hilum at both ends, hyaline to yellow, smooth to finely ornamented, with or without mucoid sheath, formed in chains or agglutinating into large sphaerical or irregular white masses (adapted from Lombard et al. 2015).

Type genus - Tilachlidium Preuss 


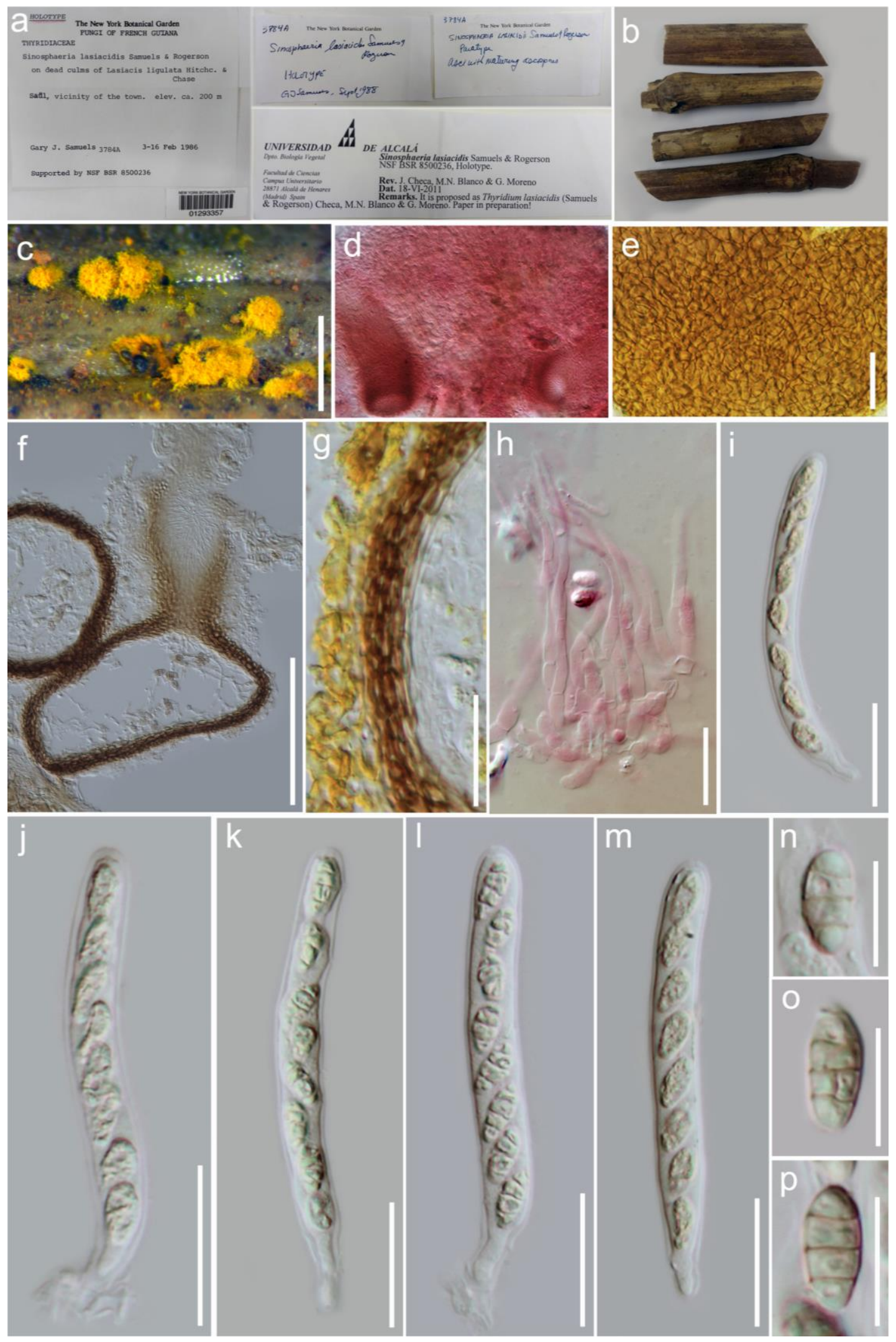

Figure 243 - Thyridium lasiacidis (Material examined - FRENCH GUIANA, Saül, vicinity of the town, elev. ca. $200 \mathrm{~m}$, on dead culms of Lasiacis ligulata, 3-16 February 1986, G.J. Samuels 3784A, NSF BSR 8500236, holotype, NY 01293357). a, b Herbarium material. c Appearance of stromata on host substrate. $d$ Stomatal tissue in $5 \% \mathrm{KOH}$. e Surface view of peridium. f Transverse section through ascomata. g. Transverse section through the peridium. h Paraphyses in $3 \% \mathrm{KOH}$ im Asci. n-p Ascospores. Scale bars: $\mathrm{c}=500 \mu \mathrm{m}, \mathrm{e}=50 \mu \mathrm{m}, \mathrm{f}=100 \mu \mathrm{m}, \mathrm{g}=50 \mu \mathrm{m}, \mathrm{h}-\mathrm{m}=20 \mu \mathrm{m}$, $\mathrm{n}-\mathrm{p}=10 \mu \mathrm{m}$. 
Notes - Tilachlidiaceae was introduced to accommodate two synnematous genera, Septofusidium and Tilachlidium, supported by phylogenetic analysis (Lombard et al. 2015). Gams (1971) had classified Tilachlidium as a member of Hypocreales family incertae sedis, whereas Septofusidium was placed in Nectriaceae based on morphology. These two genera share similar asexual morph characters and are saprobic or parasitic on other fungi (Petch 1931b, Mains 1951, Gams 1971, Samson 1974, Sun et al. 2019). They produce synnematous asexual morphs with hyaline conidia.

\section{Ecological and economic significance of Tilachlidiaceae}

Species of Tilachlidiaceae are saprobes on other fungi such as dried Basidiomycetes. For example, Tilachlidium brachiatum was recorded from Hypholoma fasciculare and Agaricus galericulatus (Mains 1951, Lombard et al. 2015, Preuss 1851). They also grow on dead lepidopterous insects, eg. Tilachlidium ramosum was isolated from a dried lepidopterous larva. Some are pathogenic on plants (Mains 1951, Kidd \& Beaumont 1924). Septofusidium sp. was reported as a pathogen of guava (Psidium guajava), causing rapid wilt of trees (Grech 1985). Evans (1974) discussed the potential use of Tilachlidium spp. for biocontrol of ants, which might have an important agricultural application in the future.

Members of this family have potential medical applications. Some species of Tilachlidium and Septofusidium produce antibiotics (Gottshall et al. 1951, Roberts 1952), as well as novel compounds with antineoplastic properties or cytotoxicity to leukemia cells (Feng et al. 2004, Vann et al. 2016). Ekiz et al. (2016) revealed the broad-spectrum antibacterial activity of a secondary metabolite from Septofusidium berolinense. Bioactive secondary metabolites from S. berolinense, with cytotoxic activities were also screened (Ekiz et al. 2016, Vann et al. 2016). Tilachlidium humicola had been used for the production of L-glutaminases, an important industrial enzyme (Shindia et al. 2007, Nandakumar et al. 2003).

\section{Genera included in Tilachlidiaceae}

Psychronectria J. Pawłowska, Istel, Wrzosek \& D. Hawksw., Mycologia 109(4): 604 (2017)

Index Fungorum number: IF821597; 1 species with sequence data.

Type species - Psychronectria hyperantarctica (D. Hawksw.) J. Pawłowska, Istel, Wrzosek \& D. Hawksw.

Notes - The monotypic genus Psychronectria was introduced to accommodate Thyronectria hyperantarctica (Pawłowska et al. 2017). Psychronectria species are associated with bryophytes (Pawłowska et al. 2017). The genus is characterised by pink, orange or pale red ascomata, arising directly from the mycelium or formed on loose stromata and, hyaline to yellow, muriform ascospores (Pawłowska et al. 2017).

Septofusidium W. Gams, Cephalosporium-artige Schimmelpilze: 147 (1971)

Index Fungorum number: IF9882; 4 morphological species (Species Fungorum 2020), 2 species with sequence data.

Type species - Septofusidium elegantulum (Pidopl.) W. Gams

Notes - Septofusidium was introduced by Gams (1971). Sequence data or cultures are not available for the generic type $S$. elegantulum, although $S$. berolinense and $S$. herbarum have molecular data. Septofusidium differs as conidia are arranged in chains, without a mucoid sheath.

Tilachlidium Preuss, Linnaea 24: 126 (1851)

Index Fungorum number: IF10236; 15 morphological species (Species Fungorum 2020), 1 species with sequence data.

Type species - Tilachlidium brachiatum (Batsch) Petch

Notes - Tilachlidium pinnatum was synonymised under $T$. brachiatum by Lombard et al. (2015). There are no records for the sexual morphs of Tilachlidium. Species of Tilachlidium are 
saprobic growing on dried fungi or entomogenous on lepidopterous insects (Mains 1951). Sequence data are available only for the type species $T$. brachiatum in GenBank.

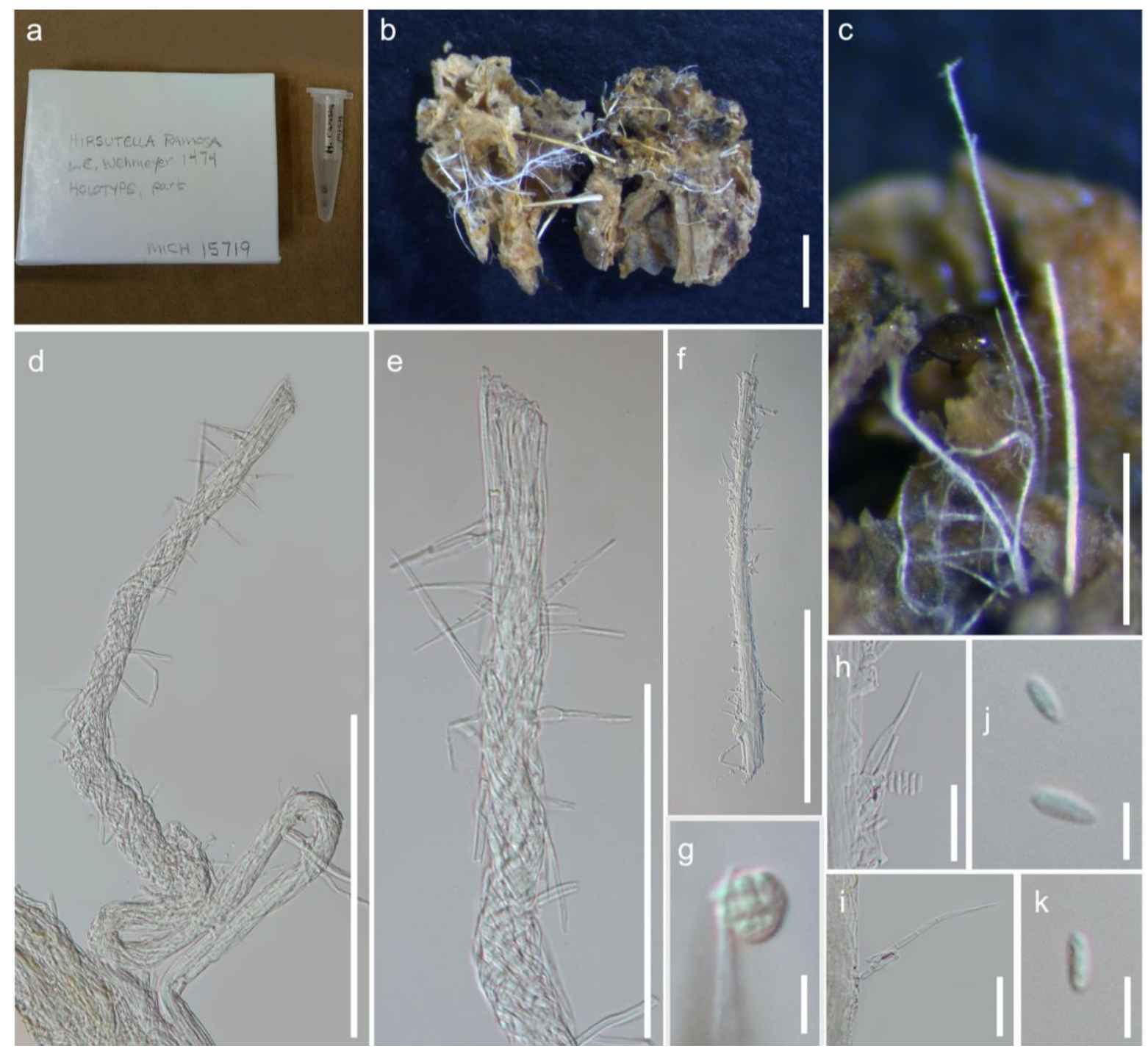

Figure 244 - Tilachlidium brachiatum (Material examined - CANADA, Nova Scotia, Salmon River, fragments of lepidopterous larva on a mossy log, 7 September 1931, L.E. Wehmeyer 1474, MICH 15719, holotype of Tilachlidium ramosum). a Herbarium material. b, c Synnemata on the host. d-f Synnemata with phialides. g Conidial mass attached to a phialide. h, i Phialides. j, k Conidia. Scale bars: $\mathrm{b}=1 \mathrm{~mm}, \mathrm{c}=500 \mu \mathrm{m}, \mathrm{d}=200 \mu \mathrm{m}, \mathrm{e}=100 \mu \mathrm{m}, \mathrm{f}=200 \mu \mathrm{m}, \mathrm{g}=5 \mu \mathrm{m}, \mathrm{h}, \mathrm{i}=$ $20 \mu \mathrm{m}, \mathrm{j}, \mathrm{k}=5 \mu \mathrm{m}$.

Tirisporellaceae Suetrong, E.B.G. Jones \& K.L. Pang, Cryptog. Mycol. 36(3): 323 (2015)

Index Fungorum number: IF812184; Facesoffungi number: FoF01413; 3 species.

Saprobic on submerged substrates in freshwater or brackish habitats. Sexual morph: Ascomata solitary or gregarious, partially immersed to superficial, globose to subglobose, black, and coriaceous to carbonaceous, papillate, ostiolate, with a neck and periphyses. Peridium thickwalled, brown to black. Paraphyses early deliquescent, irregularly wide, septate, hyaline, tapering towards the apices and embedded in a mucilaginous matrix. Asci 8 -spored, unitunicate, cylindrical to clavate, indistinctly pedicellate, apex with a J-, subapical ring. Ascospores uniseriate or bi-seriate to tri-seriate, hyaline to brown, 1-7-septate, fusoid, falcate to lunate, straight or curved, cell wall smooth or verrucose, with or without appendages. Asexual morph: Hyphomycetous. Conidiophores macronematous, mononematous, erect, pale brown to brown, paler toward the apex, straight or flexuous, smooth. Conidiogenous cells enteroblastic, monophialidic, integrated on hyphae, 
terminal, sometimes erect on hyphae, pale brown, subcylindrical, ampulliform. Conidia unicellular, hyaline, fusoid-ellipsoid, obovoid or ellipsoid, apex obtuse or broadly rounded, tapering to a truncate base, smooth-walled (adapted from Suetrong et al. 2015).

Type genus - Tirisporella E.B.G. Jones, K.D. Hyde \& Alias

Notes - Tirisporellaceae was established by Suetrong et al. (2015) to accommodate the genera, Tirisporella and Thailandiomyces, based on morphology and molecular phylogeny. Subsequently, Abdel-Wahab et al. (2017) introduced Bacusphaeria (type species: B. nypae), which formed a distinct clade in this family. Tirisporellaceae retains its uniqueness in having large, black perithecial ascomata with an ostiolate neck, a thick-walled peridium, cylindrical asci and 2-3seriate, 1-7-septate, fusoid ascospores, with or without appendages. Sequence data are available for the three genera of this family and phylogenetic analyses confirmed their placement in Tirisporellales (Jones et al. 2015). Hyde et al. (2017a) carried out divergence estimates of Sordariomycetes and estimated the stem age of Tirisporellaceae as 112 MYA.

\section{Ecological and economic significance of Tirisporellaceae}

Tirisporellaceae species are saprobes on wood or palm fronds found in freshwater to brackish water habitats (Jones et al. 1996, Pinruan et al. 2008, Abdel-Wahab et al. 2017). Tirisporella beccariana and Bacusphaeria nypae grow on the basal petioles of Nypa fruticans, which is perennially submerged in brackish water. Those species may have salt resistance to survive in this environment.

\section{Genera included in Tirisporellaceae}

Bacusphaeria Norlailatul, Alias et Suetrong, Botanica Marina 60 (4): 11 (2017)

Index Fungorum number: IF812182; 1 species with sequence data.

Type species - Bacusphaeria nypae Norlailatul, Alias \& Suetrong

Notes - The monotypic genus Bacusphaeria is similar to Tirisporella, because they have large, thick-walled ascomata, cylindrical asci and both occur on the basal petioles of Nypa fruticans in brackish water. However, Bacusphaeria is distinct from Tirisporella because it; i) lacks complex ascospore appendages; ii) has fewer septa in the ascospores (Bacusphaeria: 1-5-septate vs. Tirisporella: 5-7-septate); iii) lack of paraphyses; iv) has a prominent apical ring in contrast to faint apical ring in Tirisporella; v) having generally uniseriate ascospores in contrast to biseriate ascospores in Tirisporella. Base pair differences of Bacusphaeria nypae (MFLU 13-0617) and Tirisporella beccariana (BCC38300) are $97 \mathrm{bp}$ different out of 859 bp (11.29\%) without gaps in the LSU gene locus. Furthermore, in phylogeny, Bacusphaeria nypae is distinct from the other two genera and formed a separate lineage in Tirisporellaceae (Fig. 7).

Thailandiomyces Pinruan, Sakay., K.D. Hyde \& E.B.G. Jones, Fungal Divers. 29: 91 (2008)

Index Fungorum number: IF511583; 1 species with sequence data.

Type species - Thailandiomyces bisetulosus Pinruan, Sakay., K.D. Hyde \& E.B.G. Jones

Notes - Pinruan et al. (2008) introduced Thailandiomyces to accommodate a single species $T$. bisetulosus and described its asexual morph in Craspedodidymum. Their phylogenetic analysis based on LSU and SSU sequence data showed that the genus is well-placed in Diaporthales, but differs from Diaporthe species in morphology. Suetrong et al. (2015) conducted phylogenetic analysis of Tirisporella beccariana and revealed that Thailandiomyces formed a sister clade to Tirisporella and therefore included Thailandiomyces in Tirisporellaceae. Thailandiomyces bisetulosus is distinct from other members in Tirisporellaceae by its hyaline ascospores with bipolar appendages.

Pinruan et al. (2008) showed that Thailandiomyces bisetulosus is well-positioned in Diaporthales (Sordariomycetes, Sordariomycetidae) using SSU and LSU sequence analyses (Zhang et al. 2006, Hibbett et al. 2007), but was not referred to any family. Suetrong et al. (2015) introduced Tirisporellaceae to accommodate this taxon. Thailandiomyces bisetulosus resemble the- 

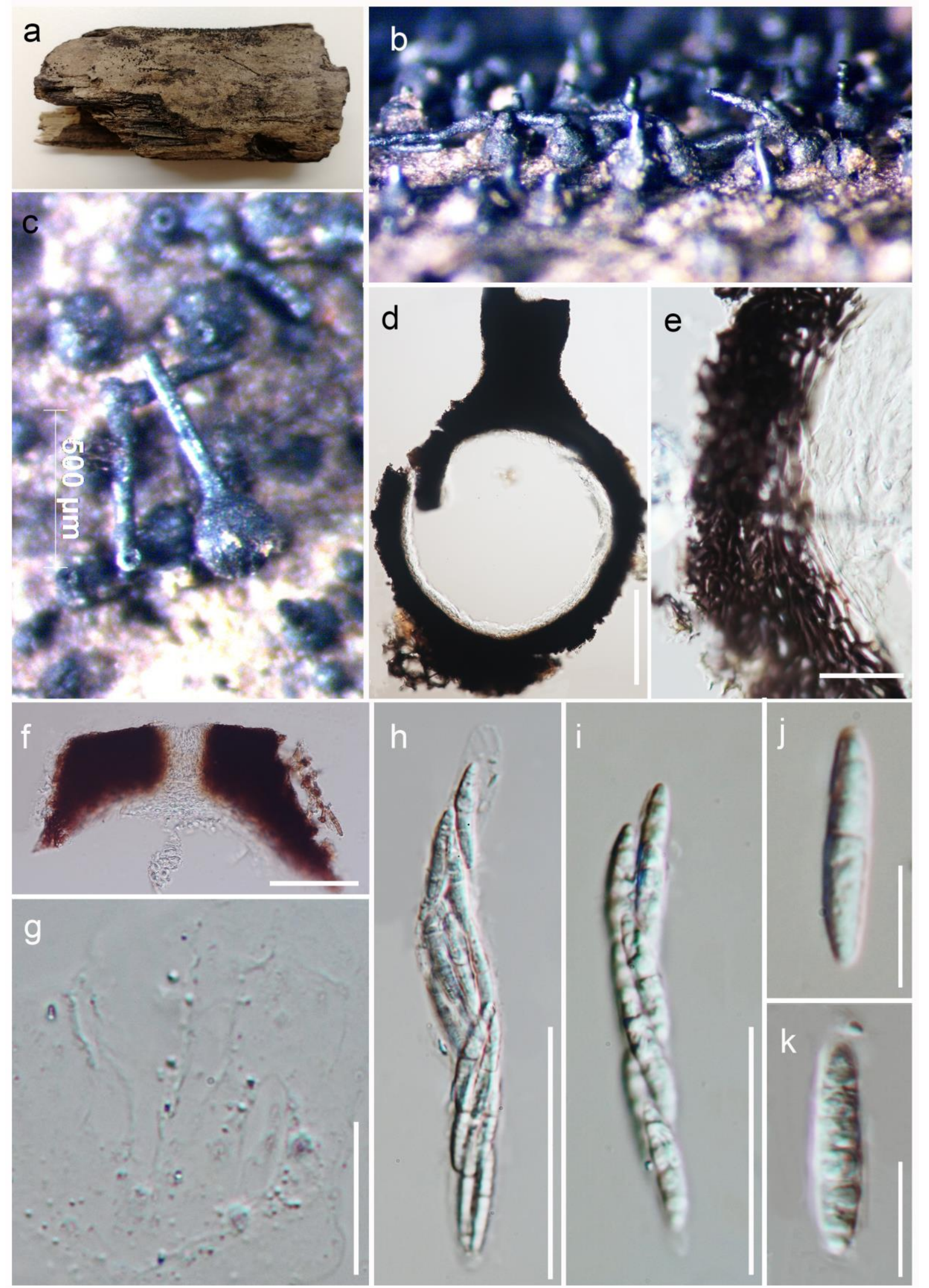

Figure 245 - Thailandiomyces bisetulosus (Material examined - THAILAND, Narathiwat, Sirindhorn Peat Swamp Forest, on submerged trunk of Licuala longicalycata, 12 May 2001, U. Pinruan, BBH Wah 110, holotype). a Herbarium material. b, c Long necked ascomata. d Vertical section through ascoma. e Peridium. f Periphysate ostiolar region. g Paraphyses. h, i Asci. j, k Ascospores. Scale bars: $\mathrm{c}=500 \mu \mathrm{m}, \mathrm{d}, \mathrm{h}, \mathrm{i}=50 \mu \mathrm{m}, \mathrm{e}-\mathrm{g}=20 \mu \mathrm{m}, \mathrm{j}, \mathrm{k}=10 \mu \mathrm{m}$. 
-morphologies of Diaporthales, including its saprobic habitat on decaying plant material, partiallyimmersed ascomata, long periphysate necks, unbranched paraphyses that deliquesce early in development, unitunicate asci that float free in the centrum and asci with a refractive, J-, apical ring (Barr 1991, Samuels \& Blackwell 2001).

Tirisporella E.B.G. Jones, K.D. Hyde \& Alias, Can. J. Bot. 74(9): 1489 (1996)

Index Fungorum number: IF27659; 1 species with sequence data.

Type species - Tirisporella beccariana (Ces.) E.B.G. Jones, K.D. Hyde \& Alias

Notes - The monotypic genus Tirisporella was introduced by Jones et al. (1996) to accommodate the type species $T$. beccariana (三Sphaeria beccariana), which was frequently encountered on intertidal petioles of Nypa fruticans (mangrove palm). This genus has historically been classified in the Loculoascomycetes incertae sedis, and Pleosporales incertae sedis because of the bitunicate-like asci (Jones et al. 2009), while the familial placement was confirmed and assigned into Sordariomycetes based on phylogenetic analysis (Suetrong et al. 2015). The most obvious characters of Tirisporella are the first basal septum delimiting a hyaline to light-coloured basal cell, the remaining cells brown and verrucose ascospores with apical appendages. During examination of intertidal fungi from Nypa fruticans, fresh collections of $T$. beccariana were made and enabled a re-description and illustration of the fungus, and herein we provide an updated phylogenetic tree with all strains of this order. Tirisporella beccariana is illustrated in this entry.

Togniniaceae Réblová, L. Mostert, W. Gams \& Crous, Stud. Mycol. 50: 540 (2004)

Index Fungorum number: IF500154; Facesoffungi number: FoF01414; 64 species.

Saprobic on dead wood or pathogenic on human and various woody plants, frequently associated with Petri and Esca disease of grapevines. Sexual morph: Ascomata perithecial, black, superficial to subimmersed, astromatic, with 1-3 necks. globose to subglobose base, with straight or flexuous, periphysate ostiole. Peridium fragile to leathery, two-layered, the outer layer comprising thin-walled, brown cells of textura prismatica to textura angularis, the inner layer comprising non-pigmented flattened cells. Paraphyses abundant, hyaline, branching, septate, attenuate towards the apex, slightly constricted at septa. Ascogenous hyphae hyaline, elongate, branched, smooth-walled, sympodial, bearing remnant of base from which a single ascus is produced. Asci 8-spored, unitunicate, clavate, with obtuse, sessile bases and thickened ascal apex without a discharge mechanism, aggregating in spicate arrangement. Ascospores 3-4-seriate, hyaline, aseptate, allantoid, oblong-ellipsoidal, slightly curved, with rounded ends. Asexual morph: Hyphomycetous. Mycelium mid-brown, dense, branched, septate, some species produce wart-like droplets. Conidiophores arising from bundled or single mycelium, branched at base or unbranched, septate, pale brown, paler towards the apex, with small warts or verruculose ornamentations at the base, percurrent rejuvenation. Conidiogenous cells usually monophialidic, integrated or discrete, hyaline to pale brown, with or without basal septum. Conidia hyaline, septate, smooth-walled, cylindrical, oblong-ellipsoidal or allantoid, straight or slightly curved, generally adhering in globose head at the tip of phialides (adapted from Réblová et al. 2004).

Type genus - Phaeoacremonium Berl.

Notes - Togninia was previously placed in the Calosphaeriales (Mostert et al. 2003). However, phylogenetic analysis based on a combined LSU and SSU dataset showed that Togninia spp. formed a distinct clade in Diaporthales, for which Togniniaceae was proposed (Réblová et al. 2004) and this was followed by later researchers (Gryzenhout et al. 2006b, Damm et al. 2008, Réblová 2008). Subsequently, Togniniaceae was relocated to a new order Togniniales based on its phylogenetic and morphological distinctiveness in the class Sordariomycetes and this family was considered to include three genera Conidiotheca, Togninia and Phaeoacremonium (Maharachchikumbura et al. 2015b). Gramaje et al. (2015) reduced Togninia under its asexual genus Phaeoacremonium and this was accepted by Dai et al. (2016) and Maharachchikumbura et al. (2016b). To date, Togniniales comprised a single family Togniniaceae, but Conidiotheca was treated as a member of Calosphaeriaceae, order Calosphaeriales (Wijayawardene et al. 2018a). 

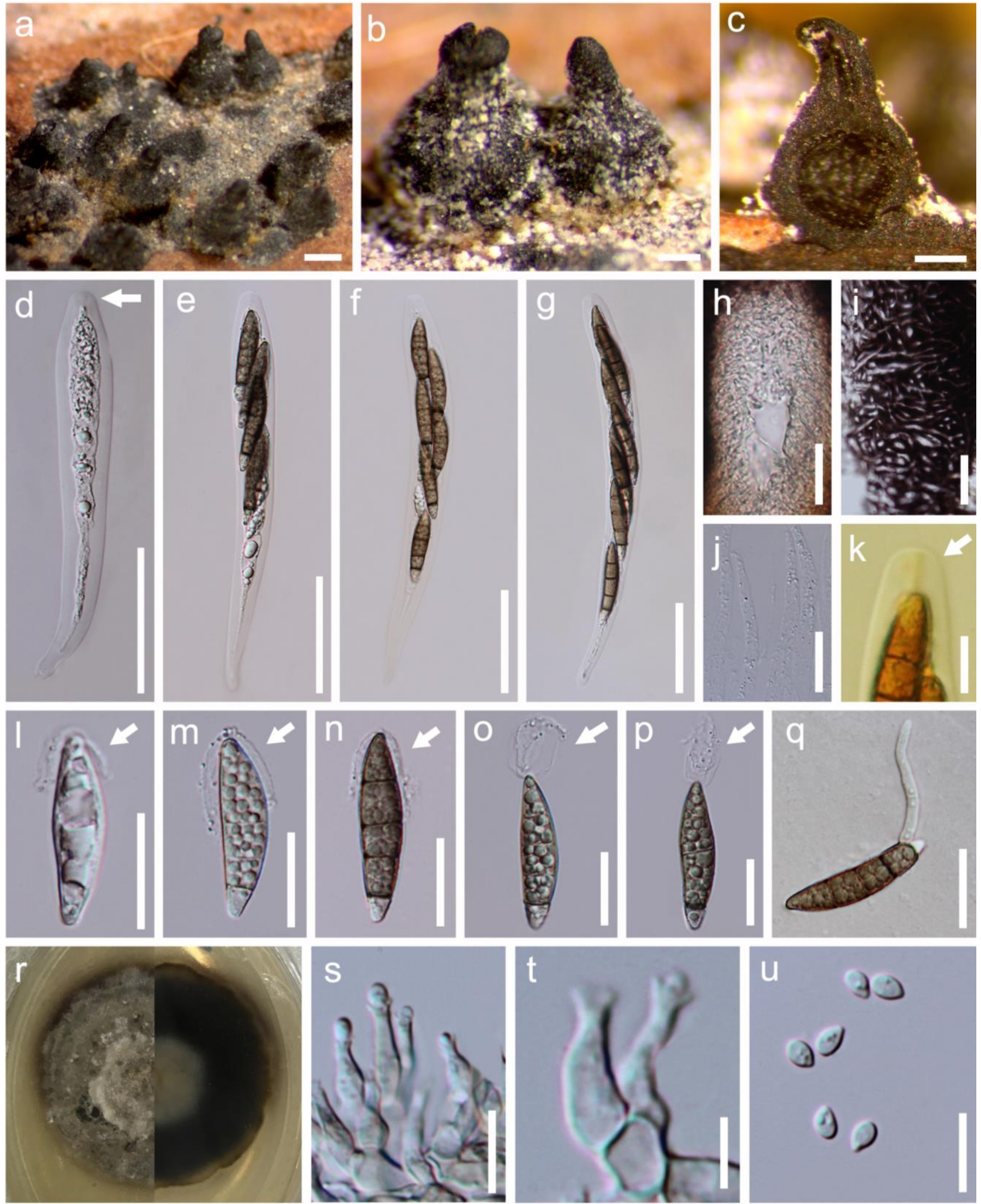

Figure 246 - Tirisporella beccariana (Material examined - THAILAND, Ranong, Ngao (Ranong) Mangrove Forest Research Center, on intertidal petiole of Nypa fruticans Wurmb., 7 December, 2016, S.N. Zhang, SNT82, living culture MFLUCC 18-1572, specimen voucher MFLU 18-1582, HKAS 97482; THAILAND, Prachuap Khiri Khan, Pak Nam Pran, on intertidal petiole of Nypa fruticans, 2 December, 2016, S.N. Zhang, SNT102, living culture MFLUCC 18-1571, specimen voucher MFLU 18-1584; THAILAND, Krabi, Pali, on intertidal petiole of Nypa fruticans, 30 August, 2017, S.N. Zhang, SNT203, specimen voucher MFLU 18-1585, HKAS 97483). a, b Appearance of ascomata on host surface with ostioles. c Vertical section through the ascoma. d-g 
Asci. h Ostiole with periphyses. i Structure of peridium. $\mathrm{j}$ Paraphyses. k Apex of ascus in Lugol's iodine, with a J-, apical ring. 1-p Ascospores. q Germinating spore. r Colony on PDA. s-u Asexual morph structure in culture. Scale bars: $\mathrm{a}=500 \mu \mathrm{m}, \mathrm{b}, \mathrm{c}=200 \mu \mathrm{m}, \mathrm{d}-\mathrm{g}=50 \mu \mathrm{m}, \mathrm{h}-\mathrm{j}, \mathrm{l}-\mathrm{q}=20 \mu \mathrm{m}, \mathrm{k}$, $\mathrm{s}, \mathrm{u}=10 \mu \mathrm{m}, \mathrm{t}=5 \mu \mathrm{m}$.

\section{Ecological and economic significance of Togniniaceae}

Phaeoacremonium species are found on wide range of hosts, including animals, plants and humans. They can be saprobic, parasitic, or hyperparasitic and play an important role in agriculture, forestry and medicine (Mostert et al. 2006, Reátegui et al. 2006). Many species of Phaeoacremonium causes trunk diseases on forest and ornamental trees (e.g. willow and poplar) resulting in severe and widespread tree decline and mortality (Hashemi \& Mohammadi 2016, Kazemzadeh et al. 2017). Phaeoacremonium minimum is a pathogenic species associated with petri disease and esca symptoms in young grapevines worldwide (Crous \& Gams 2000, Graniti et al. 2000, Fourie \& Halleen 2002, 2004, Halleen et al. 2003, Edwards \& Pascoe 2004, Feliciano et al. 2004, Essakhi et al. 2008, Gramaje et al. 2009). Phaeoacremonium minimum was also reported as a pathogen causing subcutaneous lesions on human fingers (Choi et al. 2011). In addition, novel bioactive compounds from Phaeoacremonium species have been investigated. Compounds with antifungal bioactivity against Aspergillus flavus and Fusarium verticillioides (Reátegui et al. 2006), lactone derivatives with activity against the phytopathogenic fungi (Silva et al. 2017), naphthalenone which is involved in the symptom expression of esca-effected grapevines (Evidente et al. 2000, Abou-Mansour et al. 2004) and phytotoxins p-hydoxybenzaldehyde (Tabacchi et al. 2000) have been recovered from Phaeoacremonium species.

\section{Genera included in Togniniaceae}

Conidiotheca Réblová \& L. Mostert, Mycol. Res.111(3): 305 (2007)

Index Fungorum number: IF510227; 1 morphological species.

Type species - Conidiotheca tympanoides (M.E. Barr) Réblová \& L. Mostert

Notes - Conidiotheca was introduced by Réblová \& Mostert (2007) as a monotypic genus to accommodate Conidiotheca tympanoides (三Romellia tympanoides). Lack of molecular data and absence of characteristics of its asexual morph resulted in placing this genus as incertae sedis in perithecial ascomycetes (Réblová \& Mostert 2007). The taxonomic placement of Conidiotheca is still unresolved. All studies of this genus were based on those descriptions provided by Réblová \& Mostert (2007). Lumbsch \& Huhndorf (2010) listed Conidiotheca under Calosphaeriaceae (Calosphaeriales), this treatment was followed by Wijayawardene et al. (2017a, 2018a). However, Maharachchikumbura et al. (2015, 2016b) considered Conidiotheca as a member of Togniniaceae. The exact familial position should be established with further fresh collections and based on both morpho-phylogenetic examinations.

Phaeoacremonium W. Gams, Crous \& M.J. Wingf., Mycologia 88(5): 789 (1996)

Index Fungorum number: IF27679; 63 morphological species (Species Fungorum 2020), 62 species with sequence data.

Type species - Phaeoacremonium parasiticum (Ajello, Georg \& C.J.K. Wang) W. Gams, Crous \& M.J. Wingf.

Notes - Phaeoacremonium was introduced by Crous et al. (1996) for five new species with $P$. parasiticum as the type species. They mentioned this genus is similar to Phialophora and Acremonium. Mostert et al. (2003) confirmed Phaeoacremonium as the asexual morph of Togninia based on their morphological comparison, sexual compatibility and DNA phylogeny. Togninia was introduced by Berlese (1990) with Togninia minima as the type species. Togninia has previously classified in Calosphaeriaceae, Calosphaeriales (Berlese 1900, Barr 1985, Mostert et al. 2003). Réblová et al. (2004) erected Togniniaceae in Diaporthales to accommodate Phaeoacremonium and Togninia based on phylogenetic analysis of LSU and SSU sequence data. Subsequently, Mostert et al. (2006) added several species to both Phaeoacremonium and Togninia, coupled with the generic 
descriptions. Currently, 67 epithets of Phaeoacremonium are listed in Index Fungorum (2020). Among them, Phaeoacremonium chlamydosporum was transferred to Phaeomoniella (Gams \& Crous 2000). Phaeoacremonium aleophilum, P. mortoniae and P. novae-zealandiae were synonymized under $P$. minimum, $P$. fraxinopennsylvanicum and $P$. leptorrhynchum, respectively (Réblova 2011, Gramaje et al. 2015). To date, 63 species are accepted in this genus, of which $P$. aquaticum only have ITS gene sequence available. For $P$. inconspicuum, no ex-type culture or DNA exists (Gramaje et al. 2015). The remaining 62 species have been confirmed with molecular data.

Herewith, we illustrated Phaeoacremonium inconspicuum (S F6209, holotype), an old collection without any available ex-type culture or DNA sequence data. The previous description was provided with hand-drawn illustrations (Eriksson \& Yue 1990). But the morphology of this species are poorly described. Gramaje et al. (2015) treated it as a new combined species of $P$. inconspicuum based on the original description derived from Eriksson \& Yue (1990). Here we refine it to clarify its classification with the microscopic character of ascomata, asci and ascospores and make sure that this species belonging to this genus.

Torpedosporaceae E.B.G. Jones \& K.L. Pang, Cryptog. Mycol. 35(2): 135 (2014)

Index Fungorum number: IF91154; Facesoffungi number: FoF01099; 3 species.

Saprobic on intertidal mangrove wood and roots, bark leaves, and sand in marine habitats. Sexual morph: Ascomata perithecial, hyaline, immersed or superficial, subglobose, ostiolate, papillate, subcarbonaceous to coriaceous. Paraphyses narrow, irregular, persistent or early deliquescing. Asci 8-spored, unitunicate, thin-walled, clavate to ellipsoidal, short pedicellate, lacking an apical ring, early deliquescing. Ascospores fasciculate, hyaline, cylindrical to ellipsoidal, 3-5-septate, with several radiating appendages at one or both ends. Asexual morph: Hyphomycetous. Hyphae septate, branched, hyaline. Conidiophores present or obsolete, cylindrical, clavate, septate or aseptate, acrogenous or laterally on the hyphae, hyaline to light brown. Conidia holoblastic, irregularly helicoid, muriform, cells of the conidia tightly fused, more or less similar in size and colour, acrogenous, solitary, constricted at the septa, yellow to brown. Conidial cells up to 50 in number (adapted from Maharachchikumbura et al. 2016b).

Type genus - Torpedospora Meyers

Notes - Torpedosporaceae was introduced with two Torpedospora species and Glomerulispora mangrovis (asexual morph), based on molecular analysis of partial sequences of the nuclear SSU and LSU ribosomal DNA (Jones et al. 2014). Hence, the family comprised two genera, Torpedospora and Glomerulispora (Jones et al. 2014). However, G. mangrovei, grouped with the two Torpedospora species such that these generic names are considered synonyms (AbdelWahab et al. 2010, Jones et al. 2015). Based on the widespread utility of Torpedospora and its priority, the use of Torpedospora over Glomerulispora was recommended by Réblová et al. (2016b). The family groups in the Hypocreomycetidae, order incertae sedis (Jones et al. 2014, Maharachchikumbura et al. 2015b). Subsequently, Jones et al. (2015) had referred the family to a new order Torpedosporales and this was followed by Maharachchikumbura et al. (2016b) and Wijayawardene et al. (2018a).

\section{Ecological and economic significance of Torpedosporaceae}

Torpedosporaceae species are saprobic on intertidal wood or mangrove wood and roots, bark and leaves, in marine habitats. Weber et al. (2015) reported that T. radiata has an abundance of recognizable secondary metabolite gene clusters and are under investigation (Pang et al. 2016).

\section{Genus included in Torpedosporaceae}

Torpedospora Meyers, Mycologia 49: 496 (1957)

Index Fungorum number: IF5501; 3 morphological species (Species Fungorum 2020), 2 species with sequence data.

Type species - Torpedospora radiata Meyers 


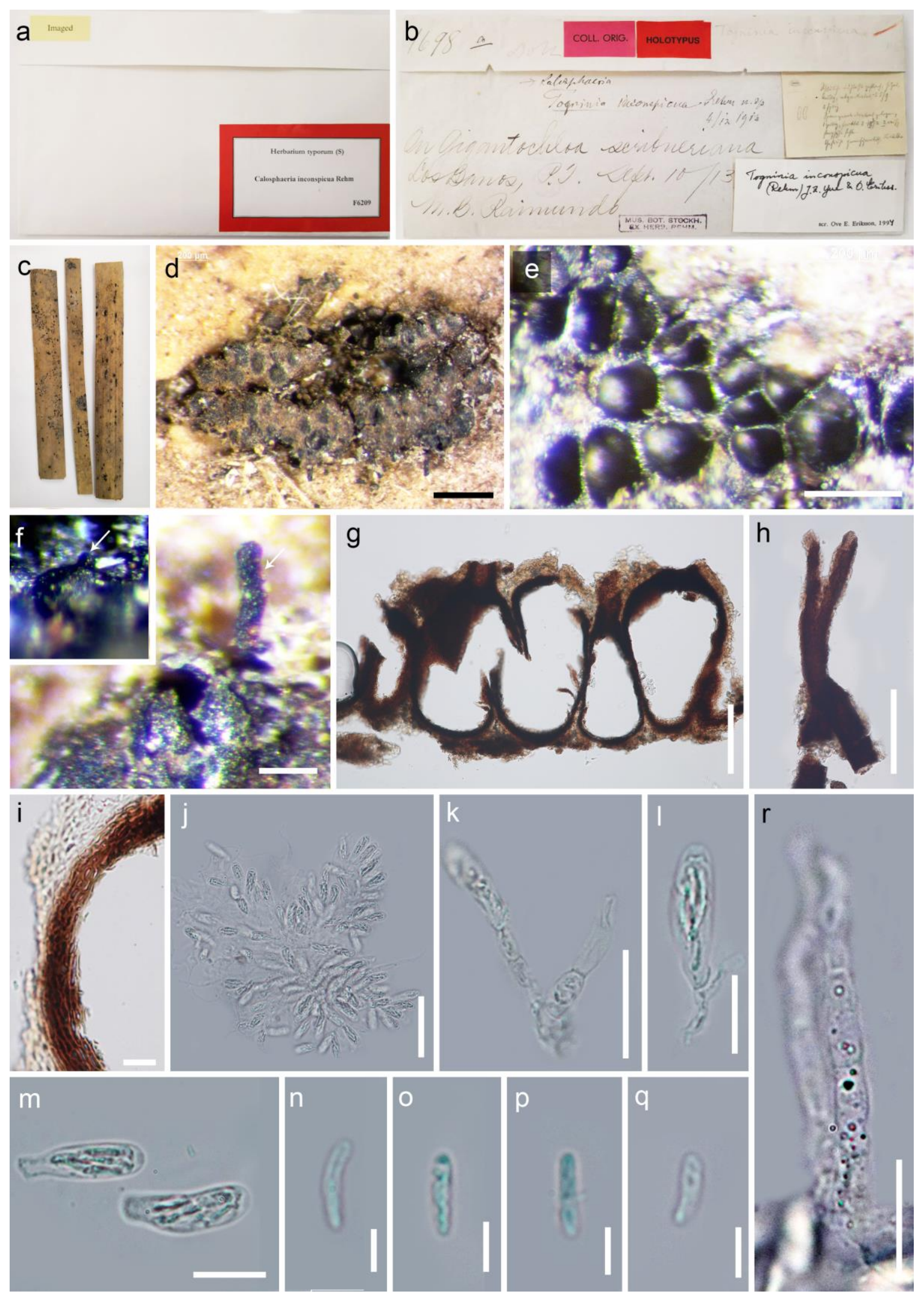

Figure 247 - Phaeoacremonium inconspicuum (Material examined - PHILIPPINES, Luzon, Laguna Province, Los Baños, on Gigantochloa schrebneriana, 10 September 1913, M.B. Raimundo, S-F6209, holotype). a, b Envelope with original information. c-e Aggregated perithecia on bamboo column. f, h Perithecial necks (arrows). g Vertical section of ascomata. i Peridium. j-1 Ascogenous hyphae with asci attached. $m$ Asci containing ascospores. $n-q$ Ascospores. $r$ Paraphyses. Scale Bars: $\mathrm{d}, \mathrm{e}=200 \mu \mathrm{m}, \mathrm{f}=1 \mathrm{~mm}, \mathrm{~g}=100 \mu \mathrm{m}, \mathrm{h}=150 \mu \mathrm{m}, \mathrm{i}, \mathrm{k}=25 \mu \mathrm{m}, \mathrm{j}=50$ $\mu \mathrm{m}, 1, \mathrm{~m}, \mathrm{r}=15 \mu \mathrm{m}, \mathrm{n}-\mathrm{q}=5 \mu \mathrm{m}$. 
Notes - Torpedospora is characterised by torpedo-like, cylindrical to elongate-ellipsoidal ascospores, together with the radiating appendages at one or both ends. This genus comprises three species, T. ambispinosa, T. mangrovei, and T. radiata (type). Molecular studies by Sakayaroj et al. (2005), Schoch et al. (2007), Abdel Wahab et al. (2010) and Jones et al. (2015) showed that they group in the same clade with high bootstrap support, which suggest that they are congeneric. A study by Abdel-Wahab et al. (2018) also supported this.

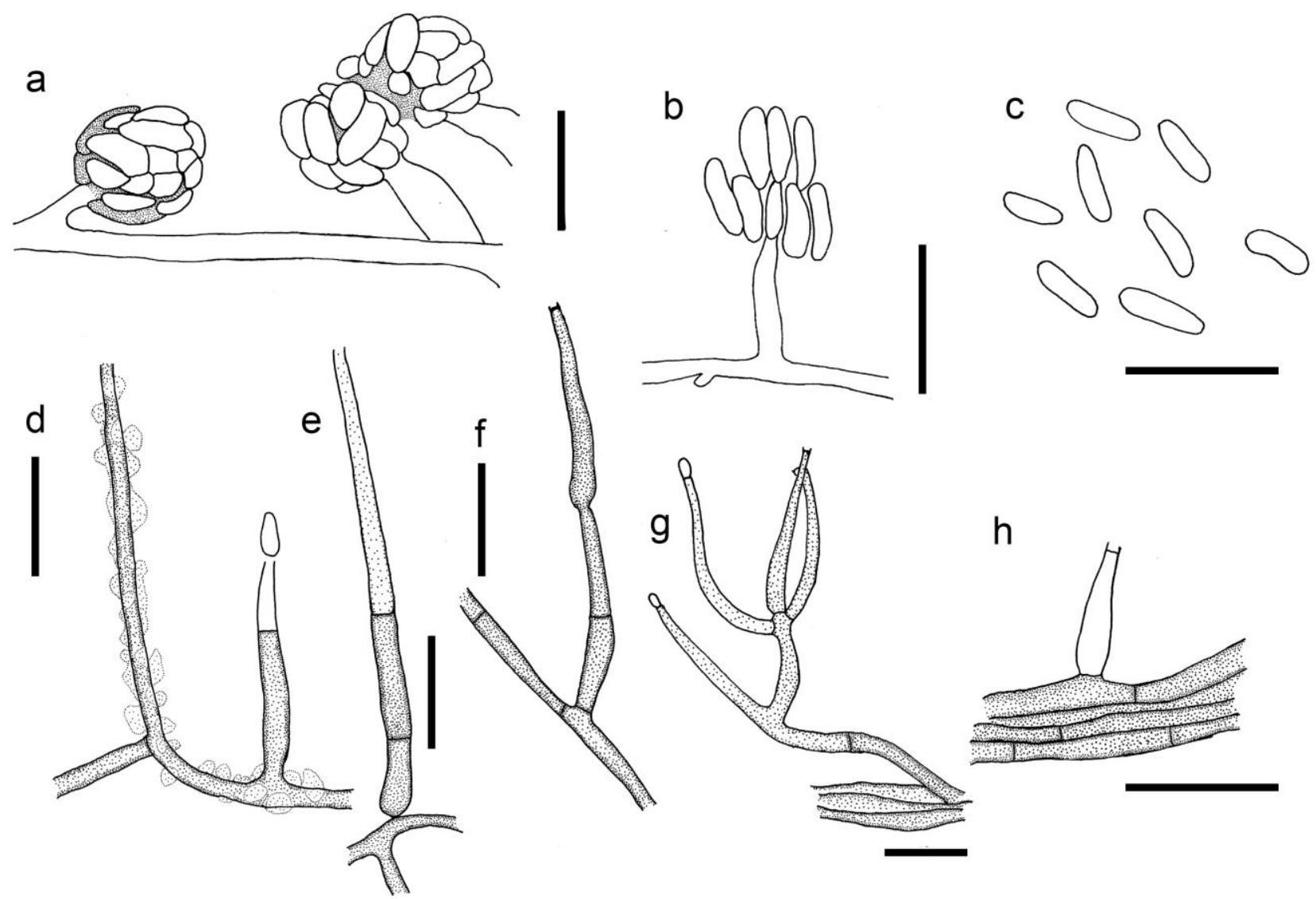

Figure 248 - Phaeoacremonium krajdenii (CBS 109479) (reproduced from Mostert et al. 2006) (a, $\mathrm{f}, \mathrm{h}$ ), P. aleophilum (CBS 246.91) (b), P. austroafricanum (CBS 112949) (c), P. parasiticum (CBS 860.73) (d, e) P. inflatipes (CBS 391.71) (g). a, b Conidiophores. c Conidia. d Mycelium with mucus and phialides. e-h Phialides. Scale bars: $\mathrm{a}-\mathrm{h}=10 \mu \mathrm{m}$.

Tracyllaceae Crous, Persoonia 40: 365 (2018)

Index Fungorum number: IF825423; Facesoffungi number: FoF06884; 3 species.

Endophytic, saprobic or pathogenic on leaves of grasses and trees. Sexual morph: Undetermined. Asexual morph: Coelomycetous. Conidiomata pycnothyrial, superficial on leaves, round, brown, with central column of cells; ostiole lacking, margin of catenate, darker brown cells. Conidiophores reduced to conidiogenous cells arising from a central columella, doliiform to ellipsoid, hyaline, smooth, with a single conidiogenous locus, phialidic. Conidia solitary, hyaline, aseptate, smooth, guttulate, falcate to naviculate or ellipsoid, apex subobtusely rounded, base truncate; with or without unbranched polar appendages, not delimited by septa (adapted from Crous et al. 2018d).

Type genus - Tracylla (Sacc.) Tassi

Notes - Tracyllaceae was introduced by Crous et al. (2018d) to accommodate the monotypic genus Tracylla. This was well-supported by the multigene analysis (ITS, LSU, SSU) of T. aristata 
and $T$. eucalypti that form a monophyletic lineage which is distinct from other groups in Sordariomycetes.

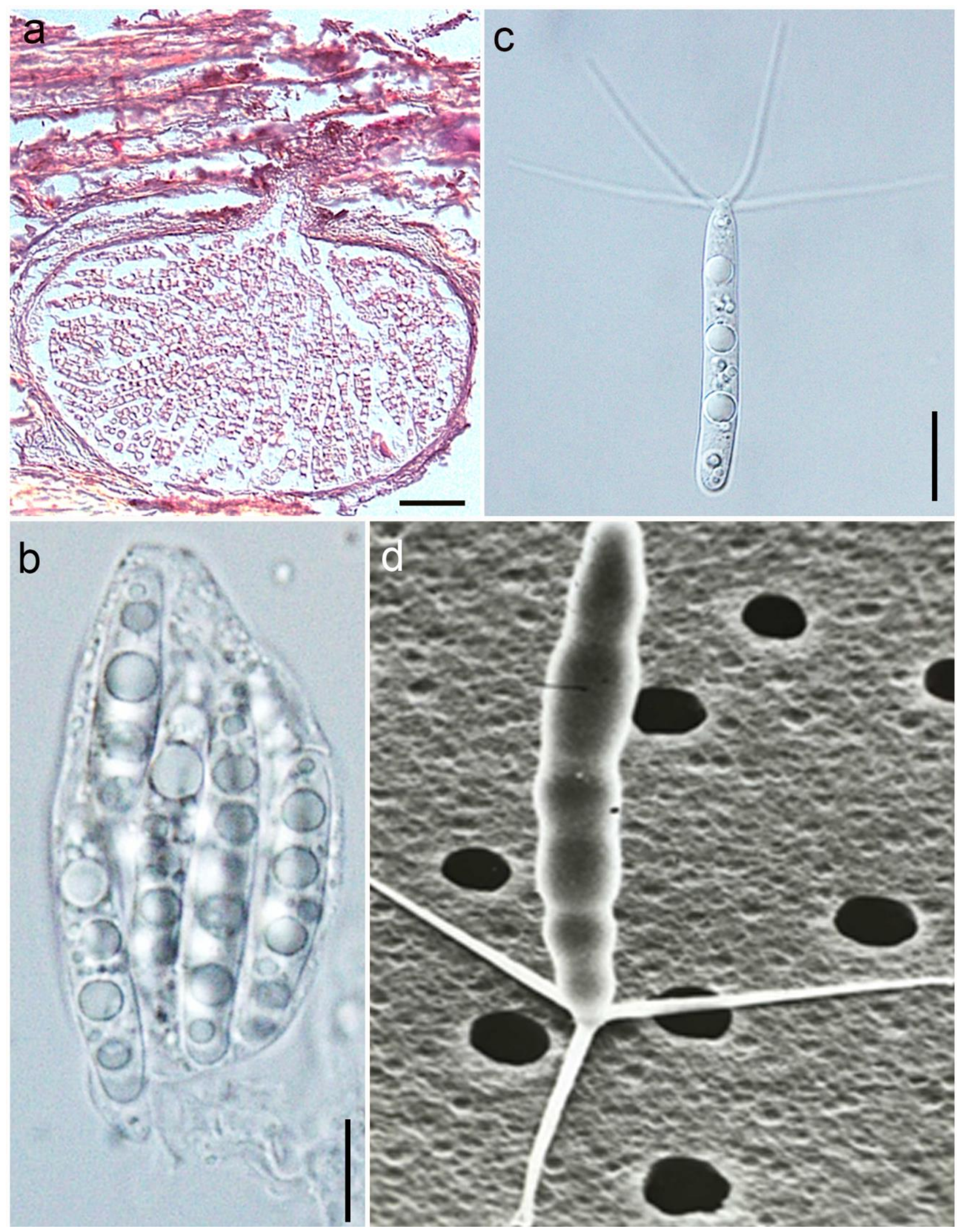

Figure 249 - Torpedospora radiata (Material examined - Taiwan, Keelung City, Chaojing Park, rocky shore, on driftwood, 3 October 2014, K.L. Pang). a Section of immersed ascoma. b Clavate ascus. c Cylindrical ascospore with unipolar appendages and three septa. d Scanning electron micrograph of the ascospore. Scale bars: $\mathrm{a}=20 \mu \mathrm{m}, \mathrm{b}, \mathrm{c}=5 \mu \mathrm{m}$. 


\section{Ecological and economic significance of Tracyllaceae}

Both Trachylla spartinae and T. aristata were reported as leaf litter saprobes, while $T$. eucalypti was observed from symptomatic leaves of Eucalyptus urophylla.

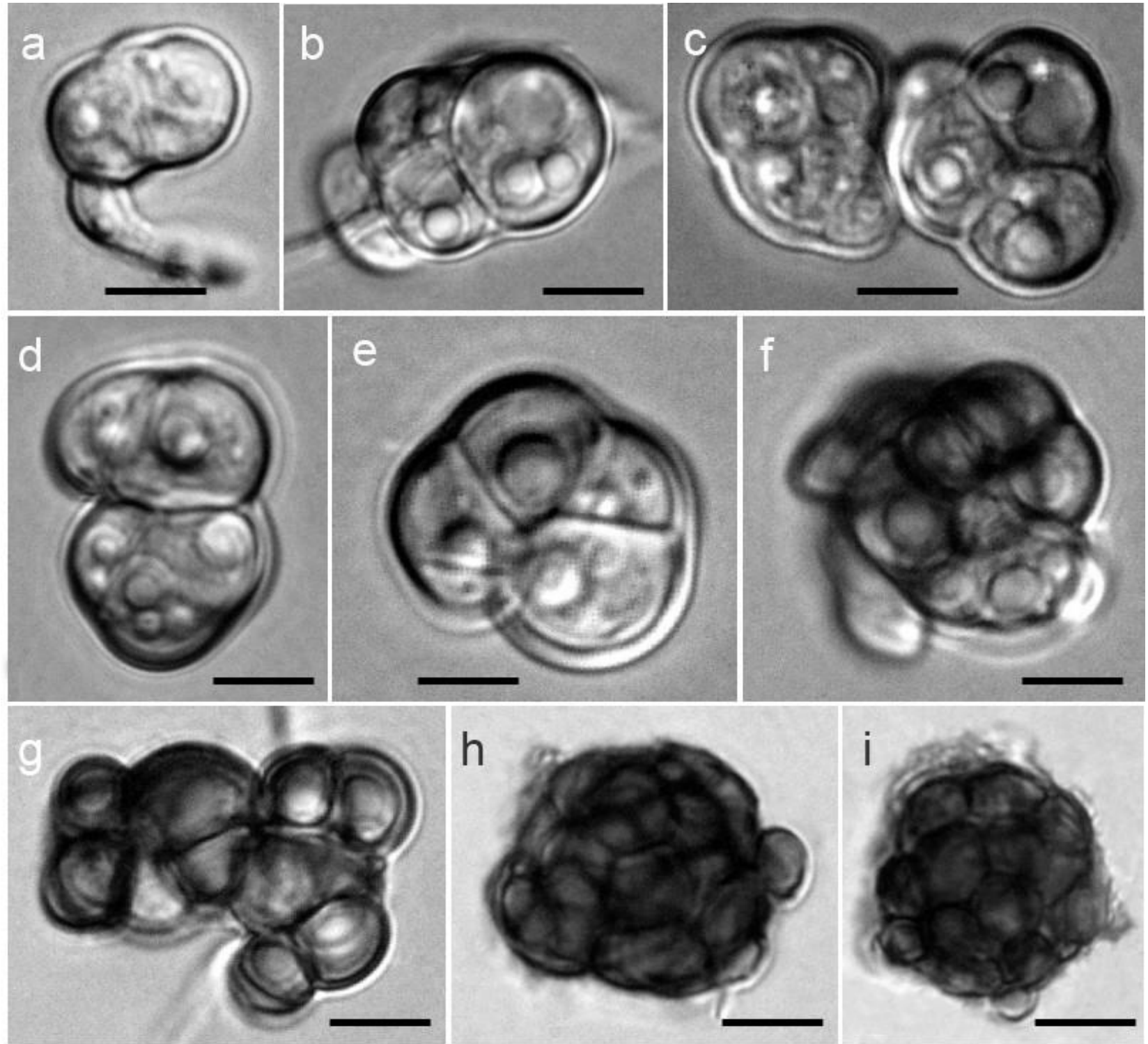

Figure 250 - Torpedospora mangrovei. (Material examined - JAPAN, Okinawa, Naha, Gesashi Bay Mangrove, $26^{\circ} 12^{\prime} \mathrm{N}, 127^{\circ} 37 \mathrm{E}$, on decayed driftwood in the intertidal zone, 17 July 2008 , M.A. Abdel-Wahab, IMI 397963, holotype; ex-type strain, MF1019, NBRC 105264). a-i Conidia at different stages of development. Scale bars: $\mathrm{a}-\mathrm{i}=5 \mu \mathrm{m}$.

\section{Genus included in Tracyllaceae}

Tracylla (Sacc.) Tassi, Bollettino del Laboratorio de Orto Botanico Reale Universita Siena 6: 62 (1904)

Index Fungorum number: IF10260; 3 morphological species (Species Fungorum 2020), 2 species with sequence data.

Type species - Tracylla spartinae (Peck) Tassi

Notes - Tracylla was introduced as a subgenus by Saccardo (1895), and raised to generic rank by Tassi (1904). The genus is typified by Tracylla spartinae observed on Spartina patens and several other grasses in Brazil, Jamaica, Philippines, Sri Lanka, Thailand and USA (Nag Raj 1993). Two other species include T. aristata and T. eucalypti. Tracylla aristata was described from 
Eucalyptus leaf litter collected in Australia (Cooke 1891), New Zealand and South Africa (Crous \& Van der Linde 1993), and on Hakea dactyloides (Nag Raj 1993). Tracylla eucalypti was observed from leaves of Eucalyptus urophylla in Colombia (Crous et al. 2018d). The three species differ in their conidial morphology with the presence (T. spartinae:14-18 $\times 6-8 \mu \mathrm{m}$, with apical and basal appendages 11-30 $\mu \mathrm{m} ; T$. aristata: 13-17 $\times 2-3 \mu \mathrm{m}$, apical appendage $6.5-14 \mu \mathrm{m})$ or absence of appendages [T. eucalypti $1-1.5 \mu \mathrm{m}$ diam, $(12-) 17-19(-20) \times(2.5-) 3 \mu \mathrm{m}]$.

Triadelphiaceae Y.Z. Lu, J.K. Liu, Z.L. Luo \& K.D. Hyde, Fungal Divers. 99: 555 (2019)

Index Fungorum number: IF555668; Facesoffungi number: FoF05449; 22 species.

Saprobic on decaying wood, or pathogenic on human, or found from the gut of red palm weevils. Sexual morph Undetermined. Asexual morph Hyphomycetous. Conidiophores lacking. Conidiogenous cells holoblastic, monoblastic, integrated, flask-shaped, fusiform, cylindrical or clavate, arising from undifferentiated hyphae, hyaline to pale brown, smooth-walled. Conidia acrogenous, solitary, develop one to five forms in distinct species (adapted from Luo et al. 2019).

Type genus - Triadelphia Shearer \& J.L. Crane

Notes - Triadelphia is placed in Microascales as genus incertae sedis (Wijayawardene et al. 2017a, 2018a, Lu et al. 2018). Luo et al. (2019) showed that the Triadelphia phylogenetically shares a sister relationship to the Graphiaceae clade with good bootstrap support (98\% ML), but Triadelphia taxa are obviously distinct from the species of Graphiaceae in conidial and conidiophore characters. They introduced a new family, Triadelphiaceae, to accommodate Triadelphia based on morphology and phylogeny.

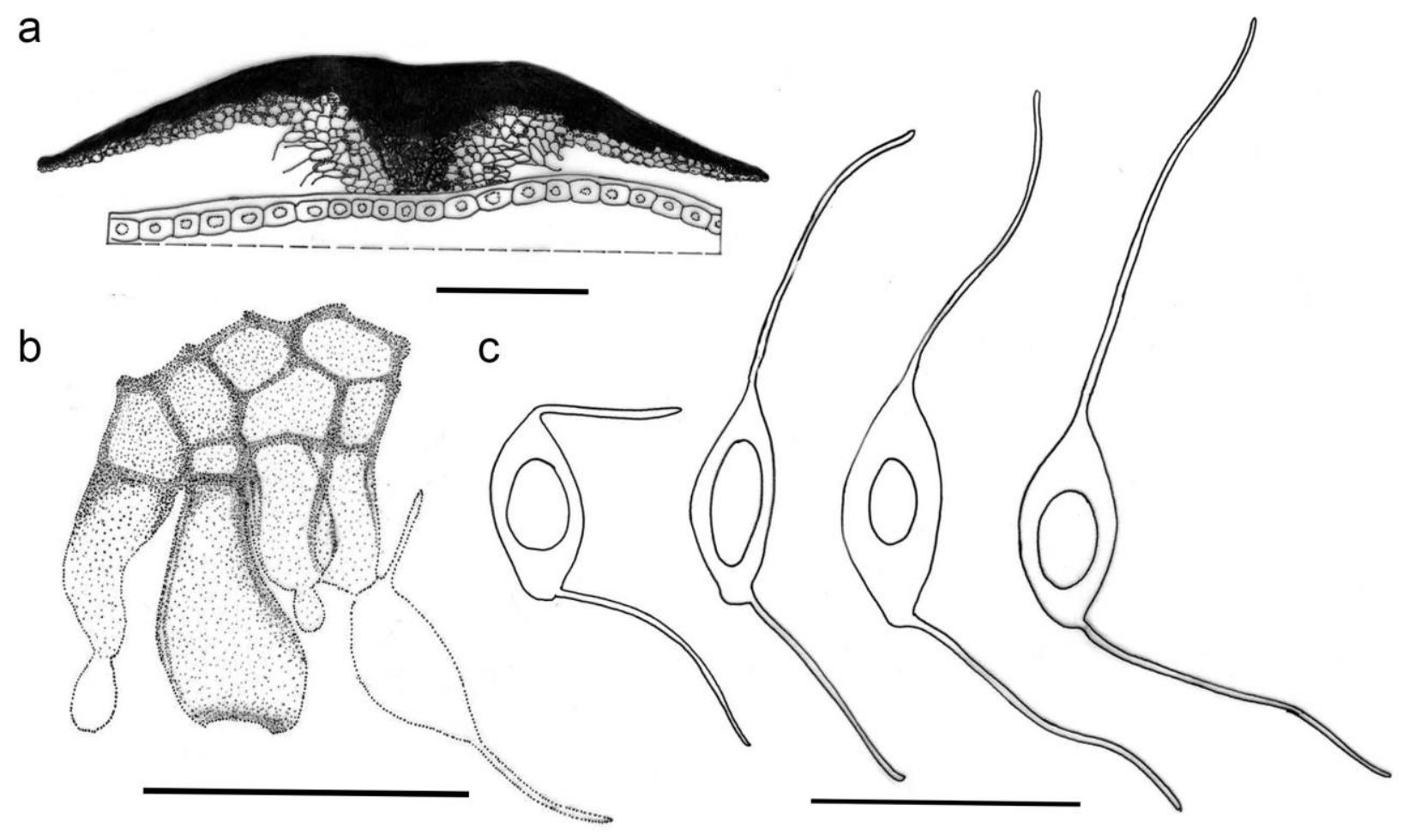

Figure 251 - Tracylla spartinae (redrawn from Nag Raj 1993). a Cross section of conidioma. b Conidiogenous cells and conidia. c Conidia. Scale bars: $\mathrm{a}=50 \mu \mathrm{m}, \mathrm{b}, \mathrm{c}=20 \mu \mathrm{m}$.

\section{Ecological and economic significance of Triadelphiaceae}

Saprobic taxa have the ability to decompose lignocellulosic matter in woody litter, resulting in softening of the wood and releasing nutrients in the form of simple molecules (Yuen et al. 1998, Bucher et al. 2004). Thus, they play an important role in nutrient and carbon cycling, biological 
diversity and ecosystem functioning (Palmer et al. 1997, Wong et al. 1998a). Most Triadelphia species are found from woody substrates, however, two Triadelphia species were found on humans. One is T. pulvinata, which has been reported from infections in humans in Saudi Arabia (AlHedaithy 2001), including a fatal disseminated infection in a woman with leukaemia (Edathodu et al. 2013). The second is $T$. disseminata, which was reported from a disseminated infection of an immunocompromised patient in Saudi Arabia (Crous et al. 2015d).

\section{Genera included in Triadelphiaceae}

Synnematotriadelphia Chuaseehar., Somrith., Nuankaew \& Boonyuen, Mycological Progress 19:137 (2020)

MycoBank number: MB833278; 2 species with sequence data.

Type species - Synnematotriadelphia stilboidea (Mercado \& R.F. Castañeda) Chuaseehar., Somrith., Nuankaew \& Boonyuen

Notes - Triadelphia was erected by Shearer \& Crane (1971) to accommodate taxa with sporodochia and characterized by Triadelphia heterospora with short, subhyaline to dark coloured conidiogenous cells with dark, septate conidia with two different pleomorphic forms. Constantinescu \& Samson (1982) re-examined herbarium specimens and emended the generic concept to agglomerated sporodochium-like structures, conidiogenous cells arising from hyphae, and blastic conidia with at least two pleomorph forms produced on synthetic media. Mercado \& Castañeda (1983) and Matsushima (1995) added two synnematous species to Triadelphia, T. stilboidea and $T$. synnematofera. However, they did not emend the generic descriptions of Triadelphia to include those with synnematous conidiophores. Therefore, Chuaseeharonnachai et al. (2020) introduced Synnematotriadelphia for species with synnematous conidiomata that produce pleomorphic spores on natural substrata or on culture media. This is supported by a phylogenetic study with the new genus forming a well-supported separate clade to Triadelphia.

Triadelphia Shearer \& J.L. Crane, Mycologia 63(2): 247 (1971)

Index Fungorum number: IF10270; 20 morphological species (Species Fungorum 2020), 10 species with sequence data.

Type species - Triadelphia heterospora Shearer \& J.L. Crane

Notes - The type species character is sporodochial hyphomycete, which was isolated from wood blocks submerged in the Patuxent River, USA and is characterized by two different forms of conidia. Li \& Ye (2017) accepted 18 species in Triadelphia and provided a key to species. Lu et al. (2018) introduced a new species of Triadelphia and accepted 21 species in this genus. Triadelphia fusiformis is illustrated in this entry.

Trichosphaeriaceae G. Winter, Rabenh. Krypt.-Fl., Edn 2 (Leipzig) 1.2: 191 (1885)

Index Fungorum number: IF81492; Facesoffungi number: FoF01809; 125 species.

Saprobic and pathogenic on plants, commonly isolated from herbivore dung. Sexual morph: Ascomata superficial, semi-immersed or immersed, ostiolate, globose to pyriform, dark brown to black, sometimes setose. Ostiole situated in a small papilla, with bristles. Setae absent or present; brown, septate, smooth when present. Peridium carbonaceous, coriaceous or membranaceous, brown to dark brown, comprising cells of textura angularis. Paraphyses simple or branched, septate, sometimes guttulate. Asci 4-8-spored, unitunicate, cylindrical to clavate, pedicellate, with rounded apex, sometimes curved, rounded above, most genera have a $\mathrm{J}-$, apical ring. Ascospores uniseriate to biseriate, hyaline or brown, ellipsoidal to fusiform, aseptate or 1-3-sepate, sometimes guttulate. Asexual morph: Coelomycetous (Koorchaloma) or hyphomycetous (Brachysporium). When coelomycetous: Conidiomata sporodochioid to acervular, superficial, scattered to gregarious, gelatinous or not, bright coloured, setose. Conidiophores hyaline, branched, septate, often reduced to conidiogenous cells. Conidiogenous cells phialidic, ampulliform to lageniform or clavate, hyaline. Conidia blastic-phialidic, fusiform to naviculate, aseptate, hyaline, bearing a mucoid, funnel-shaped appendage at only apex or both ends. When hyphomycetous: Colonies effuse, brown 
to dark brown, hairy. Mycelium mostly immersed. Conidiophores macronematous, mononematous, erect, straight or flexuous, cylindrical, unbranched, often swollen at the base, brown to dark brown. Conidiogenous cells polyblastic, terminal, proliferating sympodially, cylindrical, denticulate. Conidia usually pendulous, clavate, ellipsoidal, fusiform, limoniform, obovoid or pyriform, septate, brown, often with polar cells paler than middle cells (adapted from Maharachchikumbura et al. 2016b).
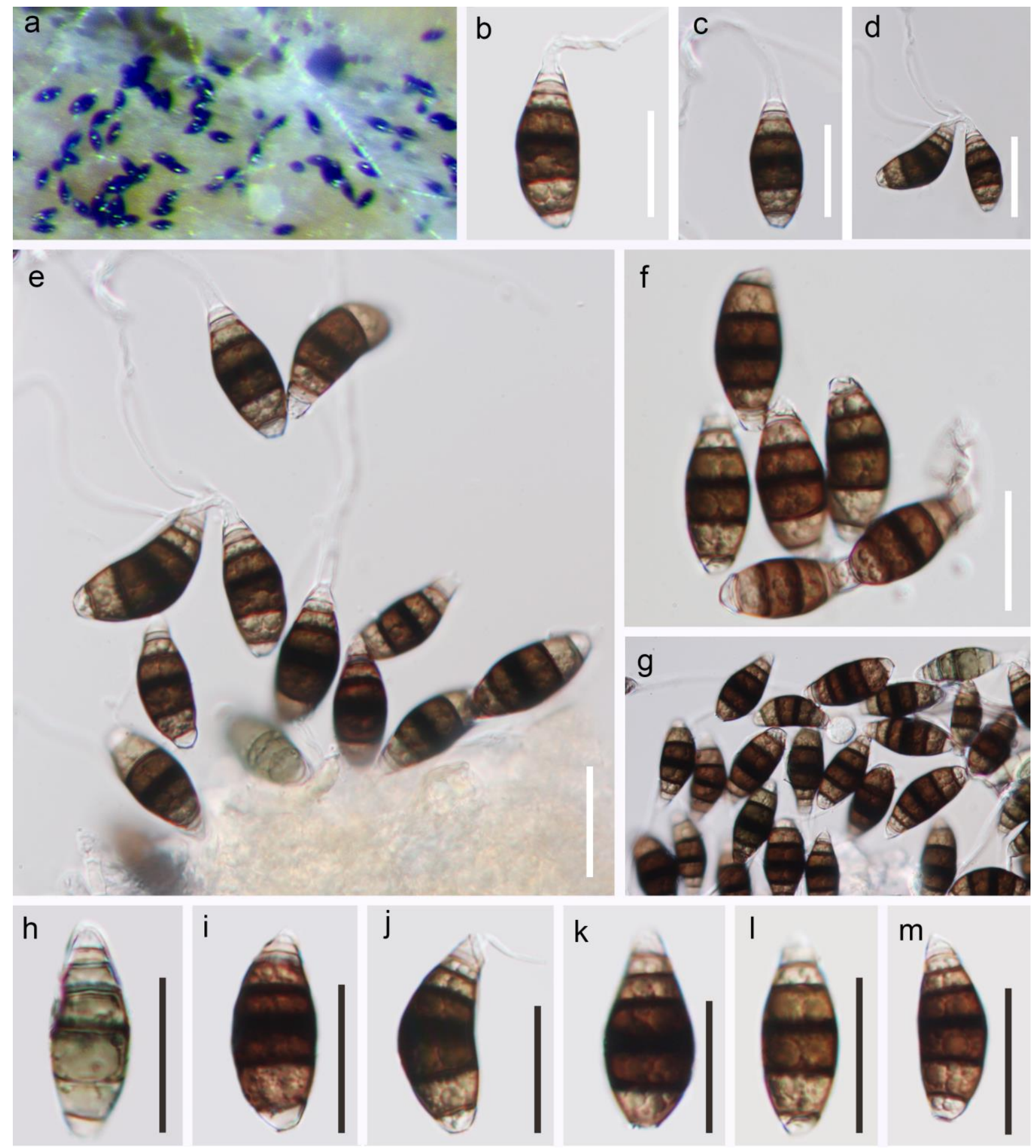

I
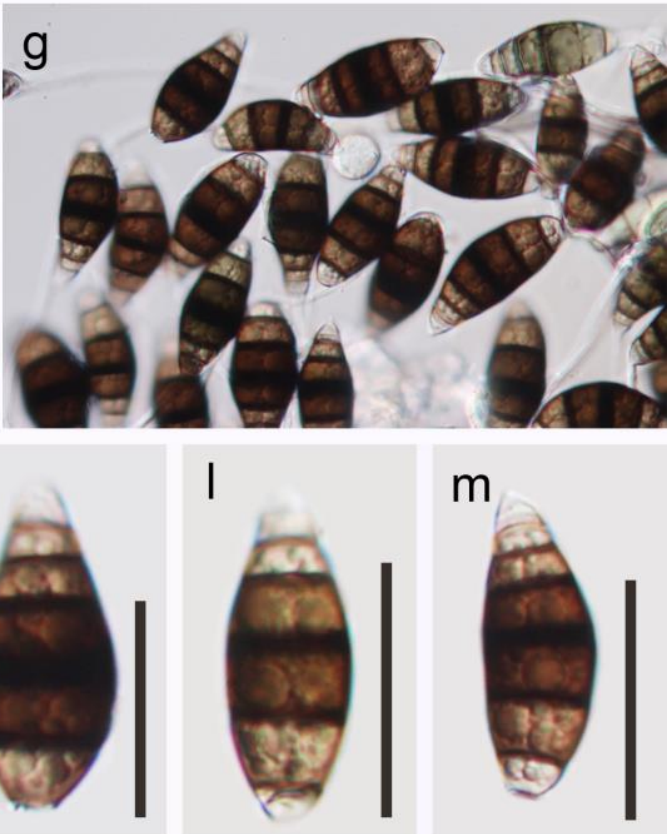

$\mathrm{m}$

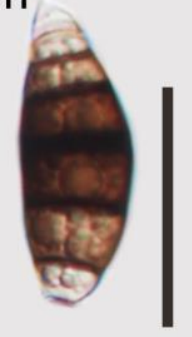

Figure 252 - Triadelphia fusiformis (Material examined - THAILAND, Krabi, Plai Praya, Khao To, Ban Bang Thao Mae, on decaying wood in a freshwater stream, 17 December 2015, Saranyaphat Boonmee BTM05-2, MFLU 18-1436, holotype; HKAS 102206). a Colony on decaying wood. b-m Conidia. Scale bars: $\mathrm{b}-\mathrm{m}=20 \mu \mathrm{m}$. 
Type genus - Trichosphaeria Fuckel

Notes - Winter (1887) introduced Trichosphaeriaceae with Trichosphaeria as the type genus and seven other astromatic genera. These seven genera were excluded from Trichosphaeriaceae by molecular evidence. In multi-gene phylogenetic analyses of LSU, SSU, tef1 and rpb2 sequence data by Maharachchikumbura et al. (2015), Trichosphaeriaceae had affinities with Papulosaceae and Thyridiaceae, but they maintained Trichosphaeriaceae as a separate family until further sequence data become available. However, due to lacking molecular recognition of $T$. pilosa, the use of Trichosphaeriales in phylogenetic studies was not recommended by Réblová \& Gams (2016). Hongsanan et al. (2017) recognized Trichosphaeriaceae as family incertae sedis in Diaporthomycetidae based on phylogenetic and molecular clock evidence, and this treatment was followed by Wijayawardene et al. (2018a). Certain species in this family are coprophilic, while other members are saprobic or pathogenic on plants, including Chrysopogon zizanioides, Arenga engleri and Ulmus minor (Hudson 1963, Yanna et al. 1998, Calatayud \& Aguirre-Hudson 2001).

Barr (1990b) accepted four genera in Trichosphaeriaceae, i.e. Acanthostigma, Eriosphaeria, Rhamphoria, and Trichosphaeria. Acanthostigma was transferred to Tubeufiaceae (Réblová \& Barr 2000, Boonmee et al. 2011, 2014), while Rhamphoria was placed in Annulatascaceae (Maharachchikumbura et al. 2016b) and more recently Rhamphoriaceae. Collematospora was introduced by Jeng \& Cain (1976) who assigned it to Trichosphaeriaceae based on the similar morphology with previously described genera, Eriosphaeria and Trichosphaeria in Trichosphaeriaceae. Réblová (1999b) introduced Coniobrevicolla and placed it in Trichosphaeriaceae based on the characters of peridium, ascal and hamathecium anatomy. Réblová \& Seifert (2004b) found some sexual morphs which produced Brachysporium asexual morphs in culture. On the basis of morphology of perithecia, asci, ascospores and conidiogenesis, Brachysporium was placed in Trichosphaeriaceae. Pinnoi et al. (2003) described Unisetosphaeria in Trichosphaeriaceae rather than Chaetosphaeriaceae based on the morphology. Réblová \& Gams (2016) studied the type material of Acanthosphaeria and relegated this genus to a synonymy of Chaetosphaeria. Voglmayr et al. (2019a) transferred all Cresporhaphis species including the type to Leptosillia (Leptosilliaceae) and Rhaphidicyrtis (Pyrenulales) except $C$. rhoina, and they did not give a clear classification for $C$. rhoina. Réblová et al. (2016b) recommended using the name Stromatographium rather than Fluviostroma because of its greater use and priority, and accepted Stromatographium in Sordariales. Trichosphaeriaceae is in need of further phylogenetic studies, including studies of types, and integration of DNA sequence data.

\section{Ecological and economic significance of Trichosphaeriaceae}

Trichosphaeriaceae species often occur as saprobes in both terrestrial and aquatic habitats (Pinnoi et al. 2003, Maharachchikumbura et al. 2016b) and are important in nutrient cycling. They can be pathogens of fungi and living plants and lichens (Aguirre-Hudson 1991, Maharachchikumbura et al. 2016b). Some species are coprophilous (Jeng \& Cain 1976).

\section{Genera included in Trichosphaeriaceae}

Brachysporium Sacc., Syll. fung. (Abellini) 4: 423 (1886)

Index Fungorum number: IF7444; 25 morphological species (Species Fungorum 2020), 3 species with sequence data.

Type species - Brachysporium obovatum (Berk.) Sacc.

Notes - Brachysporium was introduced by Saccardo (1886). Brachysporium comprise many saprobic wood-inhabiting species (Ellis 1971, Holubová-Jechová 1972, Réblová \& Seifert 2004b). Réblová \& Seifert (2004b) established the sexual morph genus Cryptadelphia and linked it with Brachysporium asexual morphs. Cryptadelphia was synonymized under Brachysporium due to nomenclatural priority. The sexual morph of this genus is characterised by superficial, globose to subglobose ascomata with ostioles, 8-spored, unitunicate, cylindrical to clavate asci with long pedicels and a distinct, refractive apical ring, and hyaline, fusiform to ellipsoidal to oblong-lemonshaped ascospores with a central septum (Réblová \& Seifert 2004b). The asexual morph has 
macronematous, mononematous, unbranched conidiophores, polyblastic, terminal, denticulate conidiogenous cells, and clavate, ellipsoidal, fusiform, limoniform, obovoid or pyriform, septate, brown conidia, which often have one or more cells paler than the others (Ellis 1971, Réblová \& Seifert 2004b, Markovskaja \& Treigienè 2007).

Collematospora Jeng \& Cain, Can. J. Bot. 54(21): 2429 (1976)

Index Fungorum number: IF1177; 1 morphological species.

Type species - Collematospora venezuelensis Jeng \& Cain

Notes - Jeng \& Cain (1976) introduced the monotypic genus Collematospora to accommodate $C$. venezuelensis from horse dung in Venezuela. The genus is characterized by subglobose to pyriform, ostiolate, hairy ascomata, 8-spored, unitunicate, cylindrical asci with a distinct, J-, apical ring, and hyaline, globose, aseptate ascospores containing one to several oil drops (Jeng \& Cain 1976). The asexual morph is undetermined.

Coniobrevicolla Réblová, Mycotaxon 70: 422 (1999)

Index Fungorum number: IF28272; 1 morphological species.

Type species - Coniobrevicolla larsenii Réblová

Notes - Coniobrevicolla is a monotypic genus introduced by Réblová (1999b) to accommodate $C$. larsenii, which is saprobic on decayed wood of an unidentified deciduous tree in Denmark. This genus is characterized by superficial, conical, ostiolate ascomata, 8 -spored asci with an indistinct apical ring, and ellipsoidal, 3-septate, ascospores with two brown central cells and hyaline end cells (Réblová 1999b). The asexual morph is undetermined.

Eriosphaeria Sacc., Atti Soc. Veneto-Trent. Sci. Nat., Padova, Sér. 4 4: 86 (1875)

Index Fungorum number: IF1892; 23 morphological species (Species Fungorum 2020).

Type species - Eriosphaeria vermicularia (Nees) Sacc.

Notes - Eriosphaeria was introduced by Saccardo (1875a). The genus is characterized by superficial, setose ascomata and 1-septate, oval ascospores (Réblová 1997). Fresh collections are required to solve the natural classification of Eriosphaeria.

Koorchaloma Subram., J. Indian bot. Soc. 32: 124 (1953)

Index Fungorum number: IF8680; 11 morphological species (Species Fungorum 2020), 1 species with sequence data.

= Kananascus Nag Raj, Mycotaxon 19: 201 (1984)

Type species - Koorchaloma madreeya Subram. (= Kananascus koorchalomagnatus Nag Raj)

Notes - Nag Raj (1984) reported two sexual morph species of Koorchaloma, including the type species, Ko. madreeya, and erected Kananascus. Based on nomenclatural priority, we synonymize Kananascus with Koorchaloma. The sexual morph of Koorchaloma is characterized by its superficial, globose to pyriform, unilocular and setose ascomata, hyaline, clavate, 8-spored asci with J-, apical rings and fusiform, 1-septate, hyaline, guttulate ascospores (Nag Raj 1984, Treigiene 2006), while the asexual morph is characterized by superficial, sporodochioid to acervular, setose conidiomata, hyaline, branched and septate conidiophores which are often reduced to phialidic conidiogenous cells, and fusiform conidia which mucoid appendages at both ends or only at the apex (Nag Raj 1984, Yanna et al. 1998, Treigiene 2006).

Rizalia Syd. \& P. Syd., Annls mycol. 12(6): 546 (1914)

Index Fungorum number: IF4761; 8 morphological species (Hyde et al. 2017b, Niranjan \& Sarma 2018).

Type species - Rizalia fasciculata Syd. \& P. Syd.

Notes - Rizalia was introduced by Sydow \& Sydow (1914). Hyde et al. (2017b) accepted five species in Rizalia, viz. R. byrsonimae, $R$. confusa, $R$. fasciculata, and $R$. glaziovii and $R$. guianensis. 
The sixth species was described by Niranjan \& Sarma (2018) from India. Rizalia is characterized by globose to pyriform, setose ascomata with long necks, clavate asci and hyaline, fusiform or falcate ascospores, sometimes with apical mucilaginous frills (Hyde et al. 2017b, Niranjan \& Sarma 2018). The asexual morph is undetermined.

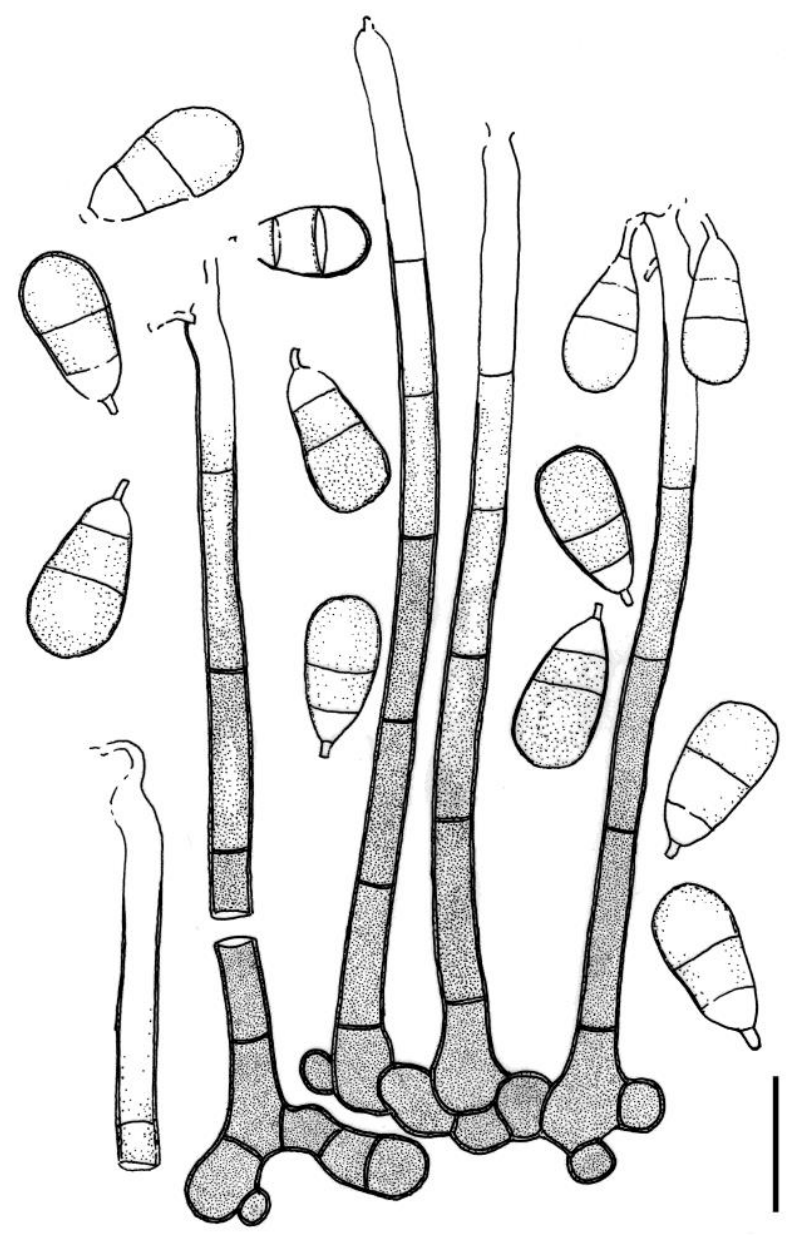

Figure 253 - Brachysporium obovatum, redrawn from Seifert et al. (2011)

Schweinitziella Speg., Anal. Soc. cient. argent. 26(1): 45 (1888)

Index Fungorum number: IF4920; 4 morphological species (Species Fungorum 2020).

Type species - Schweinitziella styracum Speg.

Notes - Schweinitziella was introduced by Spegazzini (1888). Schweinitziella is a poorly known genus since no molecular data are available. The sexual morph of Schweinitziella has clavate asci (Maharachchikumbura et al. 2016b). The asexual morph of this genus is undetermined.

Setocampanula Sivan. \& W.H. Hsieh, Mycological Research 93: 87 (1989)

Index Fungorum number: IF25337; 1 morphological species.

Type species - Setocampanula taiwanensis Sivan. \& W.H. Hsieh

Notes - Setocampanula is a monotypic genus introduced by Sivanesan \& Hsieh (1989) to accommodate S. taiwanensis. Sivanesan \& Hsieh (1989) assigned Setocampanula in Trichosphaeriaceae, because Setocampanula resembles other genera of Trichosphaeriaceae in its superficial setose ascomata and the unitunicate asci without any apical ring. Setocampanula taiwanensis is a bambusicolous fungus collected from Taiwan.

Trichosphaeria Fuckel, Jb. nassau. Ver. Naturk. 23-24: 144 (1870)

Index Fungorum number: IF5588; 50 morphological species (Species Fungorum 2020), 1 species with sequence data. 

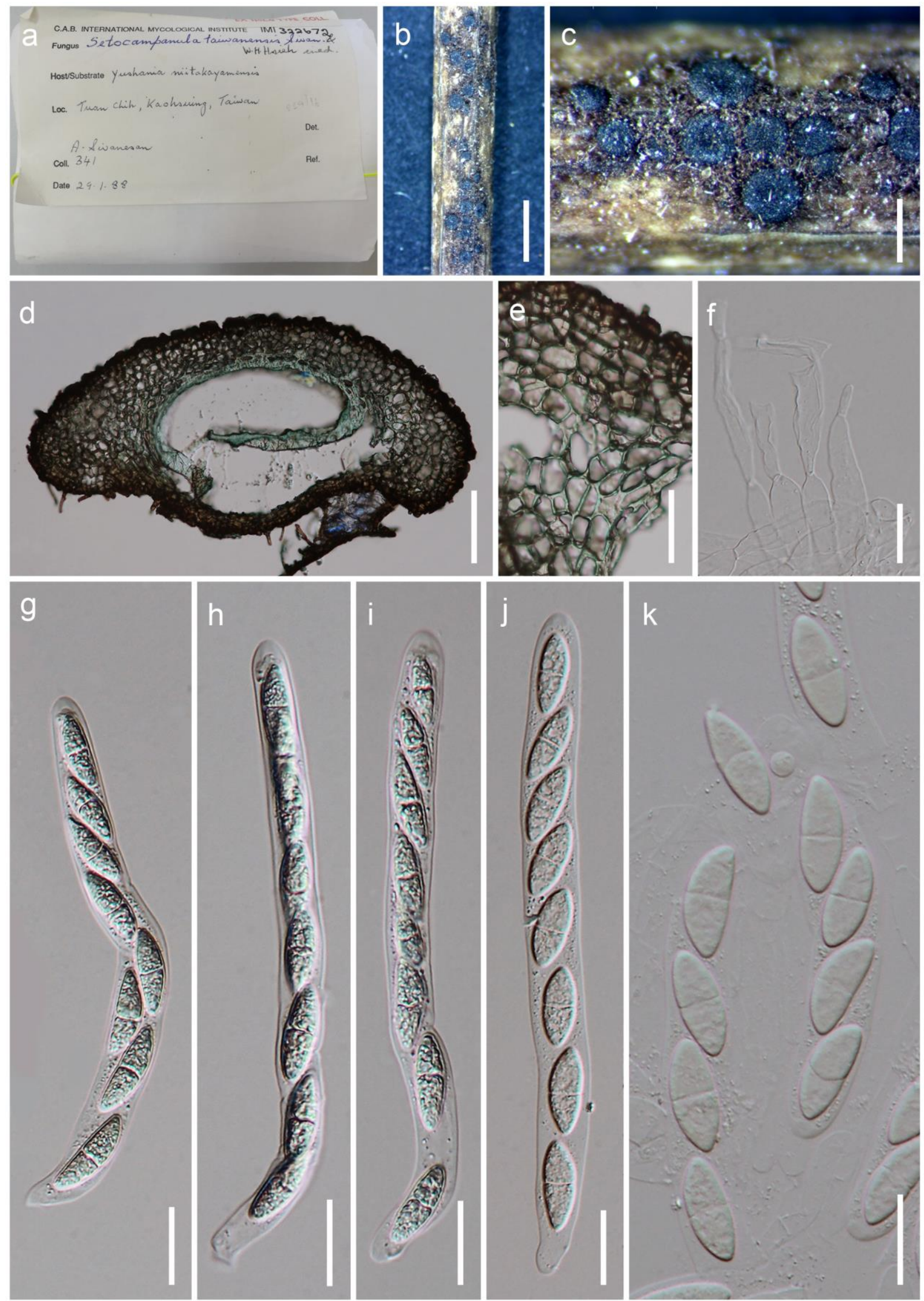

Figure 254 - Setocampanula taiwanensis (Material examined - Taiwan, Kaohsiung, on Yushania niitakayensis, 29 January 1988, A. Sivanesan, IMI 322672, holotype). a Herbarium label and specimen. b, c Ascomata on substrate. d Vertical section of ascoma. e Peridium. f Paraphyses. g-j Asci. $\mathrm{k}$ Ascospores. Scale bars: $\mathrm{b}=1000 \mu \mathrm{m}, \mathrm{c}=500 \mu \mathrm{m}, \mathrm{d}=100 \mu \mathrm{m}, \mathrm{e}=40 \mu \mathrm{m}, \mathrm{f}-\mathrm{k}=20 \mu \mathrm{m}$. 
Type species - Trichosphaeria pilosa (Pers.) Fuckel

Notes - Trichosphaeria was established by Fuckel (1870) with the type species T. pilosa collected from rotten wood from Germany. Trichosphaeria species are characterized by globose to subglobose ascomata with setae, unitunicate, 4-8-spored asci with a $\mathrm{J}$-, apical ring, and hyaline, aseptate, ellipsoidal ascospores. Since most Trichosphaeria species were introduced before 1940, molecular data are lacking in this genus. The genus needs recollection and study.

Unisetosphaeria Pinnoi, E.B.G. Jones, McKenzie \& K.D. Hyde, Mycoscience 44(5): 377 (2003)

Index Fungorum number: IF28746; 1 species without molecular data (Pinnoi et al. 2003).

Type species - Unisetosphaeria penguinoides Pinnoi, E.B.G. Jones, McKenzie \& K.D. Hyde

Notes - Pinnoi et al. (2003) introduced the monotypic genus Unisetosphaeria on submerged petiole of Eleiodoxa conferta from Sirindhorn Peat Swamp Forest in Thailand. Unisetosphaeria is characterized by pyriform, ostiolate, papillate ascomata, 8-spored, clavate, unitunicate, short pedicellate asci with a refractive, $\mathrm{J}$-, apical ring, and 2-seriate, hyaline, septate ascospores (Pinnoi et al. 2003). The asexual morph of this genus is undetermined.

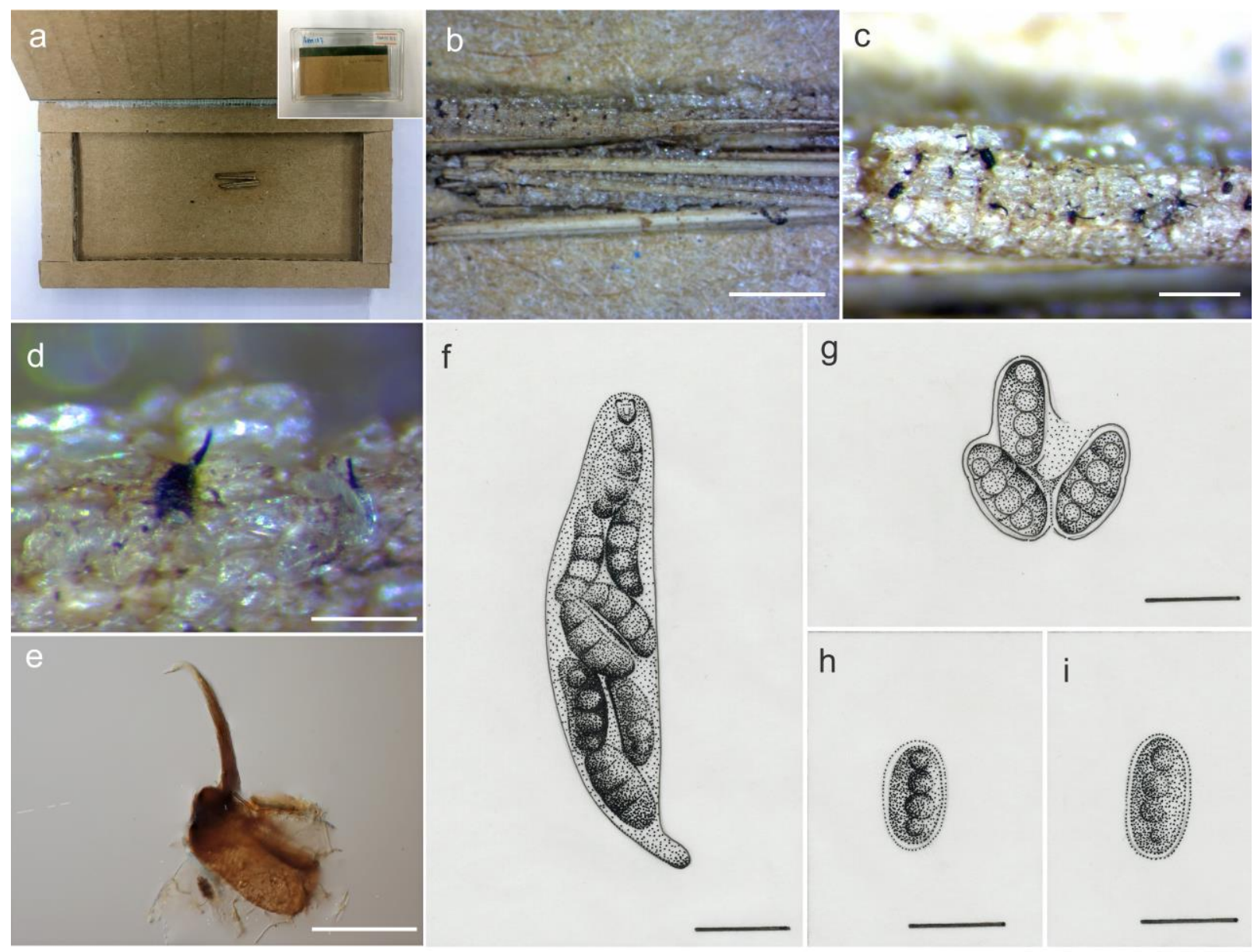

Figure 255 - Unisetosphaeria penguinoides (Material examined - THAILAND, Narathiwat, Sirindhorn Peat Swamp Forest, on submerged petiole of Eleiodoxa conferta, June 22, 2001, A. Pinnoi, BBH9843, holotype). a Herbarium packet. b-d Ascomata on substratum. e Section of ascoma. f Asci. g-i Ascospores (redrawn from Pinnoi et al. 2003). Scale bars: $b=2000 \mu \mathrm{m}, \mathrm{c}=500$ $\mu \mathrm{m}, \mathrm{d}=200 \mu \mathrm{m}, \mathrm{e}=100 \mu \mathrm{m}, \mathrm{f}-\mathrm{i}=20 \mu \mathrm{m}$.

Tubakiaceae U. Braun, J.Z. Groenew. \& Crous, Fungal Systematics and Evolution 1:62 (2018)

Index Fungorum number: IF823660; Facesoffungi number: FoF06366; 29 species.

Saprobic or endophytic and pathogenic in leaves and twigs causing leaf spots and twig dieback. Sexual morph: apiognomonia- and dicarpellum-like, diaporthaloid, dark, rostrate, ostiolate 
perithecial ascomata, with dark stromatic layers, polyascal. Asci 8-spored, unitunicate. Ascospores hyaline, aseptate or with a single septum near the apex. Asexual morph:. Coelomycetous. Conidiomata pycnothyria, Conidiogenous cells monophialidic, hyaline, having collarettes. Conidia globose to broad ellipsoid-obovoid, aseptate, hyaline to pigmented, often with basal frill or truncate peg-like hilum (adapted from Braun et al. 2018).

Type genus - Tubakia B. Sutton

Notes - Species of Tubakiaceae are characterized by conidiomata comprising a convex scutella with radiating threads of cells connected to the substratum by a central columnella, mostly surrounded by a sheath of small fertile cells which develop to 1-celled, phialidic conidiogenous cells (Braun et al. 2018). Most Tubakiaceae species have been recorded as endophytes, nevertheless some act as mild pathogens forming leaf spots or saprobes on shed or still attached leaves. Based on taxonomic investigations, Tubakiaceae comprises eight genera, viz. Tubakia, Apiognomonioides, Involutiscutellula, Oblongisporothyrium, Paratubakia, Racheliella, Saprothyrium and Sphaerosporithyrium (Braun et al. 2018, Senanayake et al. 2018).

\section{Ecological and economic significance of Tubakiaceae}

Tubakiaceae is an important family as the members are also considered as plant pathogens. The initial stages of leaf spot spread through the host plant until resulting in die back (Braun et al. 2018). Tubakia leaf spot is one of the major diseases diagnosed on oak species. Tubakia dryina is recorded from chestnuts with its typical symptom of brown necrotic leaf spots (El-Gholl et al. 1996).

\section{Genera included in Tubakiaceae}

Apiognomonioides U. Braun, J.Z. Groenew. \& Crous, Fungal Systematics and Evolution 1:63 (2018)

Index Fungorum number: IF824479; 1 species with sequence data.

Type species - Apiognomonioides supraseptata (S. Kaneko \& Tak. Kobay) U. Braun, J.Z. Groenew. \& Crous

Notes - Apiognomonioides was introduced based on the sexual morph. Kaneko \& Kobayashi (1984) showed Apiognomonia as having two celled ascospores in which the upper cell was larger than the basal cell, however, A. supraseptata is distinct in having a smaller upper cell. Subsequently, Harrington \& McNew (2018) suggested that A. supraseptata represents the only clearly demonstrated sexual morph of Tubakia. Owing to its isolated position in the LSU tree in Tubakiaceae, but distant from all other genera in this family, Apiognomonia supraseptata shows its phylogenetic distince from all other genera in the LSU tree of family Tubakiaceae (Braun et al. 2018). Apiognomonioides supraseptata and the sexual morph of Tubakia suttoniana have similar morphology (rostrate perithecia, unitunicate 8-spored asci, colourless conidia), but A. supraseptata differs in forming uniseptate ascospores with a septum near the apex (Braun et al. 2018).

Involutiscutellula U. Braun \& C. Nakash., Fungal Systematics and Evolution 1:64 (2018)

Index Fungorum number: IF824481; 1 species with sequence data.

Type species - Involutiscutellula rubra (T. Yokoy. \& Tubaki) U. Braun \& C. Nakash.

Notes - Involutiscutellula rubra can be distinguished from all other Tubakia species in having reddish brown colonies and hyphae with pycnothyria which is more or less undulate with involute margin, having, small, cylindrical to oblong bacilliform conidia (Braun et al. 2018).

Oblongisporothyrium U. Braun \& C. Nakash., Fungal Systematics and Evolution 1:66 (2018) Index Fungorum number: IF824483; 1 species with sequence data. Nakash.

Type species - Oblongisporothyrium castanopsidis (T. Yokoy. \& Tubaki) U. Braun \& C.

Notes - Oblongisporothyrium was introduced by Braun et al. (2018) to accommodate $O$. castanopsidis (三Actinopelte castanopsidis) as the type species. Oblongisporothyrium castanopsidis 
is similar to Paratubakia subglobosa in having scutellae with inwardly curved margins, hyaline to pigmented conidiogenous cells, and hyaline conidia, however it differs in having oblong conidia (vs. globose to subglobose in T. subglobosa) (Braun et al. 2018).

Paratubakia U. Braun, \& C. Nakash, Fungal Systematics and Evolution 1:67 (2018)

Index Fungorum number: IF824485; 1 species with sequence data.

Type species - Paratubakia subglobosa (T. Yokoy. \& Tubaki) U. Braun, \& C. Nakash

Notes - Paratubakia subglobosoides is phylogenetically related to $P$. subglobosa as pycnothyria formation is similar. However, they differ in the conidial shape and size and the formation of distinct leaf spots. Furthermore, the culture characteristics of the two species on MEA are quite different, and they are genetically distinct (Braun et al. 2018).

Racheliella Crous \& U. Braun, Fungal Systematics and Evolution 1:69 (2018)

Index Fungorum number: IF824487; 2 morphological species (Species Fungorum 2020), 1 species with sequence data.

Type species - Racheliella wingfieldiana Crous \& U. Braun

Notes - The conidiomata of convex scutella with radiating threads of cells connected to the substratum of type specimen are similar to other genera of Tubakiaceae. However, the genera having hyaline conidia arranged in a line are excluded from Tubakia sensu stricto. Racheliella saprophytica is characterized by crustose conidiomata and it is different from all other genera of Tubakiaceae in having branched, septate conidiophores with phialidic conidiogenous cells provided with flared, conspicuous collarettes with serrate margins (Braun et al. 2018).

Saprothyrium U. Braun, Crous \& J.Z. Groenew., Fungal Systematics and Evolution 1:72 (2018)

Index Fungorum number: IF824491; 1 species with sequence data.

Type species - Saprothyrium thailandense (Senan., Tangthir. \& K.D. Hyde) U. Braun, Crous \& J.Z. Groenew

Notes - Pycnothyria of Saprothyrium differ in having a scutellum with obtuse outer strands with globose to subglobose hyaline conidia, and is similar with Sphaerosporithyrium. However, it clusters in a phylogenetically distant clade to clades of Tubakia sensu stricto (Braun et al. 2018). Saprothyrium can be distinguished from all other species of Tubakia sensu stricto by hyaline, globose to subglobose conidia formed in pycnothyria (Braun et al. 2018). Saprothyrium thailandense is illustrated in this entry.

Sphaerosporithyrium U. Braun, Crous, O. Moreno-Rico \& Marm., Fungal Systematics and Evolution 1:73 (2018)

Index Fungorum number: IF824492; 1 species with sequence data.

Type species - Sphaerosporithyrium mexicanum O. Moreno-Rico, U. Braun \& Marm.

Notes - Sphaerosporithyrium is similar with Paratubakia (Braun et al. 2018) in conidial shape and colour. However, the formation of pycnothyria formed by species of the latter genus differs in pointed tips of hyphal scutellum strands. Sphaerosporithyrium is characterized by hyaline globose-subglobose conidia (Braun et al. 2018).

Tubakia B. Sutton, Trans. Br. Mycol. Soc. 60(1): 164 (1973)

Index Fungorum number: IF10330; 21 morphological species (Species Fungorum 2020), 15 species with sequence data.

Type species - Tubakia japonica (Sacc.) B. Sutton

Notes - Tubakia species may form different types of asexual morphs. Pycnothyria with typical scutella are a distinct character of this genus. In addition, sporodochial conidiomata are formed with clusters of conidiogenous cells e.g. on leaf veins as in T. iowensis. Crustose or pustulate pycnidioid conidiomata are formed in several Tubakia species, including T. californica, $T$. dryina, and T. iowensis. Holdenrieder \& Kowalski (1989) introduced these conidiomata as 
"pycnidial" even though they lacked ostioles with conidiomata dehiscing by irregular rupture. Harrington et al. (2012) described them as "conidioma" and wrote "pycnothyrium" in brackets. These conidiomata cannot be described as pycnidia as they lack ostioles. Rather, with stromatic wall layers and a dehiscence by irregular fissures, these should rather be classified as stromatic (Braun et al. 2018).
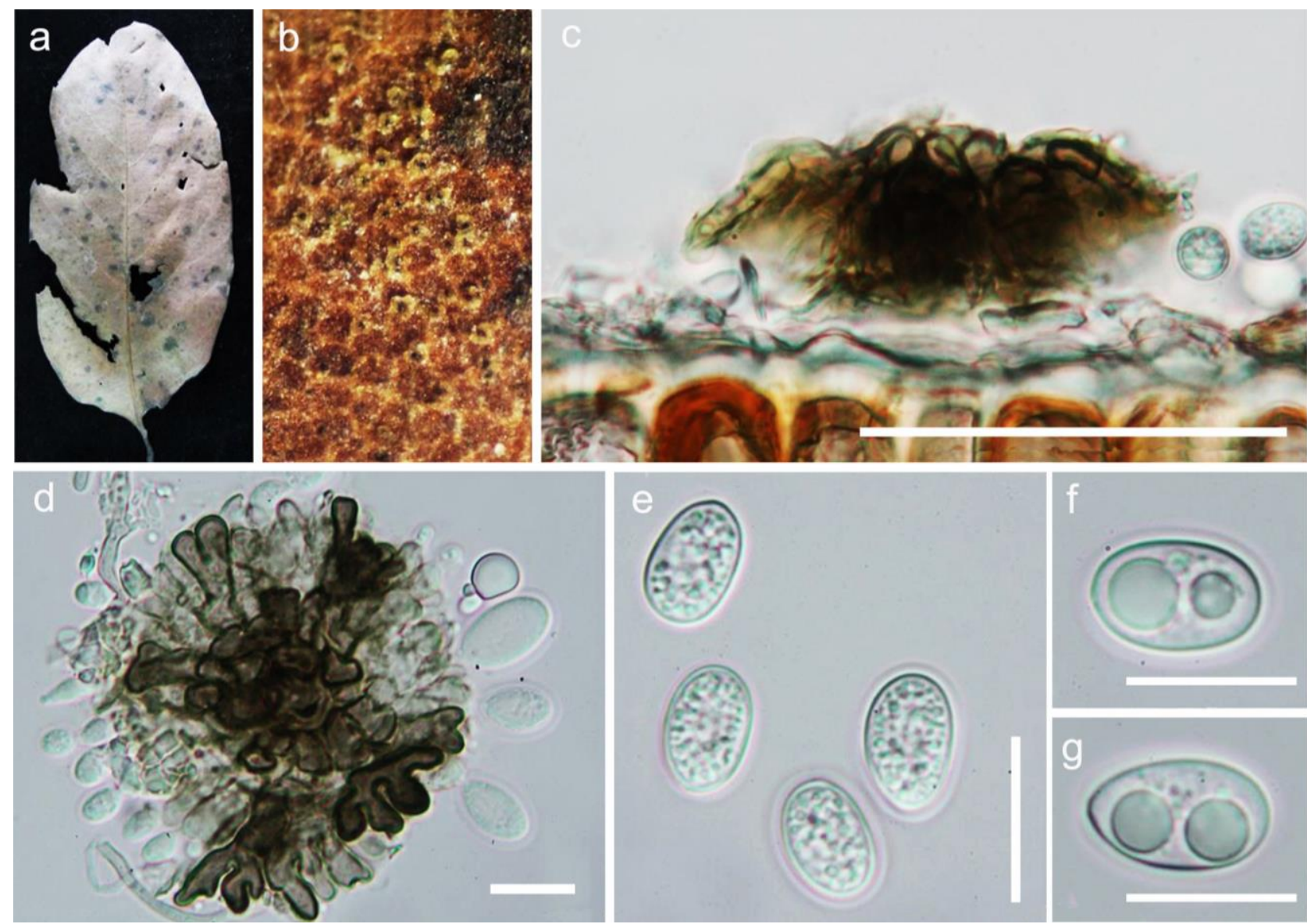

Figure 256 - Saprothyrium thailandense (Material examined - Thailand, Chiang Rai, Doi Mae Salong, on dead leaf, 2 May 2012, K. Wisitrassameewong, NTCL059, MFLU 13-0260, holotype). a Herbarium specimen. b Conidiomata on the host surface. c Vertical section of pycnothyrium. $d$ Top view of radiate scutellum and conidiogenous cells with developing conidia. e-g Conidia. Scale bars: $\mathrm{c}=50 \mu \mathrm{m}, \mathrm{d}-\mathrm{g}=10 \mu \mathrm{m}$.

Vermiculariopsiellaceae Hern.-Rest., J. Mena, Gené \& Crous, Studies in Mycology 86: 91 (2017) Index Fungorum number: IF820347; Facesoffungi number: FoF05408; 22 species.

Parasitic or saprobic on wood or leaves. Sexual morph: Undetermined. Asexual morph: Stroma present or absent. Conidiomata sporodochial, scattered, setose. Setae branched or unbranched, brown, septate, straight to flexuous. Conidiophores macronematous, subcylindrical, hyaline to pale brown, septate, densely packed in a palisade. Conidiogenous cells monophialidic, terminal, hyaline to pale brown, cylindrical to lageniform, with collarette. Conidia cylindrical to oblong, straight or slight curved, hyaline, aseptate or septate, sometimes guttulate (adapted from Hernández-Restrepo et al. 2017).

Type genus - Vermiculariopsiella Bender

Notes - Vermiculariopsiellaceae was established by Hernández-Restrepo et al. (2017) to accommodate a well-supported monophyletic clade containing Vermiculariopsiella. The sexual morph of Vermiculariopsiella was linked with Echinosphaeria based on culture studies (Puja et al. 2006, Dhargalkar \& Bhat 2009). However, phylogenetic studies, based on LSU and tub2 sequence data, showed that E. canescens, the type species of Echinosphaeria, resides in 
Helminthosphaeriaceae (Miller et al. 2014). Therefore, it is possible that the asexual morphs of Echinosphaeria were wrongly identified as Vermiculariopsiella. The linkage between Echinosphaeria and Vermiculariopsiella requires further molecular studies to confirm. We regard the sexual morph of Vermiculariopsiella as undetermined.

\section{Ecological and economic significance of Vermiculariopsiellaceae}

Vermiculariopsiella species are mostly saprobic on leaves. As decomposers and recyclers, species in this order are involved in nutrient cycling and supply members of other kingdoms with nutrients. Thus, they are important for ecological balance.

\section{Genus included in Vermiculariopsiellaceae}

Vermiculariopsiella Bender, Mycologia 24(4): 412 (1932)

Index Fungorum number: IF10383; 22 morphological species (Species Fungorum 2020), 9 species with sequence data.

Type species - Vermiculariopsiella immersa (Desm.) Bender

Notes - Torrend (1912) and Höhnel (1918a) separately introduced Vermiculariopsis. Bender (1932) synonymized Vermiculariopsis (1918) and established Vermiculariopsiella. Vermiculariopsiella endophytica and V.pteridis were linked with the Echinosphaeria sexual morph in culture (Puja et al. 2006, Dhargalkar \& Bhat 2009). Crous et al. (2014a) introduced $V$. dichapetali and placed it in Microascales incertae sedis (Hypocreomycetidae). Maharachchikumbura et al. (2015, 2016b) followed this treatment. Crous et al. (2016b) introduced another $V$. acacia and $V$. eucalypti and assigned the genus to Chaetosphaeriaceae based on LSU sequence data. Hernández-Restrepo et al. (2017) transferred Vermiculariopsiella to Vermiculariopsiellaceae based on SSU, LSU and ITS sequence data.

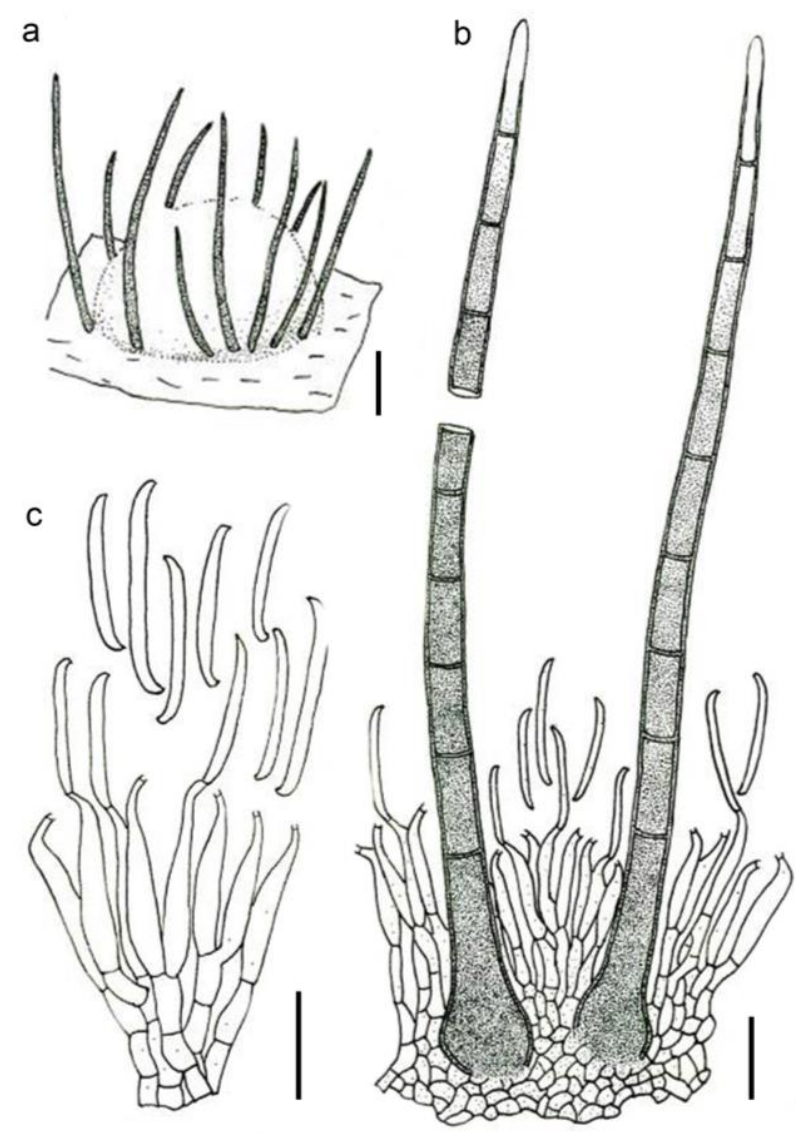

Figure 257 - Vermiculariopsiella immersa (redrawn from Seifert et al. 2011). a Colonies on leaves. b Sporodochia with setae. c Conidiophores, conidiogenous cells and conidia. Scale bars: $a=100$ $\mu \mathrm{m}, \mathrm{b}, \mathrm{c}=10 \mu \mathrm{m}$, based on Nawawi et al. (1990). 
Vialaeaceae P.F. Cannon, Mycol. Res. 99(3): 368 (1995)

Index Fungorum number: IF81967; Facesoffungi number: FoF00686; 4 species.

Parasitic or saprobic on dead plant matter. Sexual morph: Pseudostroma appears as ellipsoidal, black dots slightly raised from substrate, thick around the upper part of the ascomata. Ascomata perithecial, solitary or aggregates, immersed, globose, subglobose to ellipsoidal, coriaceous, black to brown, papillate, ostiolate with periphyses. Papilla long, sometimes distal end curving towards the substrate, periphysate. Peridium thick, composed of outer, dark-brown, thickwalled cells of textura angularis and inner, hyaline, thick-walled cells of textura angularis. Paraphyses filiform, rarely branched, septate, hyaline, sometimes apex slightly swollen. Asci 8spored, unitunicate, cylindrical, sometimes tapering towards the apex or base, short-stalked or sessile, thin-walled except apex, apex obtuse or truncate, apical ring subconical or subapical, J+. Ascospores biseriate, triseriate to fasciculate, sometimes weakly helically coiled, hyaline, strongly isthmoid, ends fusiform to rhombic, apical portion sometimes slightly larger than the basal part, 13-septate, smooth-walled. Asexual morph: Ceolomycetous. Conidiomata pycnidia, superficial, solitary, scattered, globose, with slimy, shining spore mass and basal mycelium forming thick, black strands. Conidiophores erect, branched, septate, hyaline. Conidiogenous cells phialidic, discrete or in small whorls, lageniform to cylindrical, hyaline. Conidia oblong to ellipsoidal, 1celled, hyaline smooth, with truncate abscission scar (adapted from Senanayake et al. 2014).

Type genus - Vialaea Sacc.

Notes - The phylogenetic placement of Vialaeaceae was confirmed in Xylariales (Shoemaker et al. 2013, Senanayake et al. 2014, Maharachchikumbura et al. 2015b). However, this family was accommodated in Amphisphaeriales based on phylogeny (Hyde et al. 2017a) and this is confirmed in this study.

\section{Ecological and economic significance of Vialaeaceae}

Members of Vialaeaceae are phytopathogens and endophytes. Vialaea insculpta was reported from an ornamental plant, Ilex aquifolium as a mild pathogen (Shoemaker et al. 2013). Vialaea insculpta causes dieback of tips of new twigs and older branches, as a result of cankers. However, it is not yet clear whether Vialaea insculpta are plant pathogens or colonize infected or necrotic branches (Redlin 1989). Vialaea minutella and V. mangiferae causes branch dieback or cankers on mango trees (McTaggart et al. 2013, Senanayake et al. 2014) and is likely an endophyte before it becomes a mild pathogen (McTaggart et al. 2013).

\section{Genus included in Vialaeaceae}

Vialaea Sacc., Bull. Soc. mycol. Fr. 12: 66 (1896)

Index Fungorum number: IF5736; 4 morphological species (Species Fungorum 2020), 3 species with sequence data.

Type species - Vialaea insculpta (Fr.) Sacc.

Notes - Vialaea comprises Vialaea bambusae, V. insculpta, V. minutella and V. mangiferae (Shoemaker et al. 2013, Senanayake et al. 2014, Index Fungorum 2020). Vialaea insculpta was reported from twigs and leaf veins of Ilex aquifolium grown commercially as ornamental plants. This species is reported only from in Europe and North America (Atkinson \& Trelawny 1962, Shaw 1973). In this entry we illustrate Vialaea insculpta.

Woswasiaceae H. Zhang, K.D. Hyde \& Maharachch., Fungal Divers. 85: 104 (2017)

Index Fungorum number: IF553769; Facesoffungi number: FoF03348; 3 species.

Saprobic, hypersaprotrophic on stromata of Diaporthe in freshwater or terrestrial habitats. Sexual morph: Ascomata perithecial, scattered, aggregated or in groups, stromatic or astromatic, immersed to erumpent, globose, subglobose or ellipsoid, coloured, sometimes seated in a stroma or basal stroma. Neck or papilla centrally located, cylindrical, upright or slightly horizontal to the substrate, pale brown, dark brown to black. Ostiolum periphysate. Peridium leathery to fragile, twoor three-layered. Paraphyses abundant, persistent, septate. Asci 8-spored, unitunicate, cylindrical- 

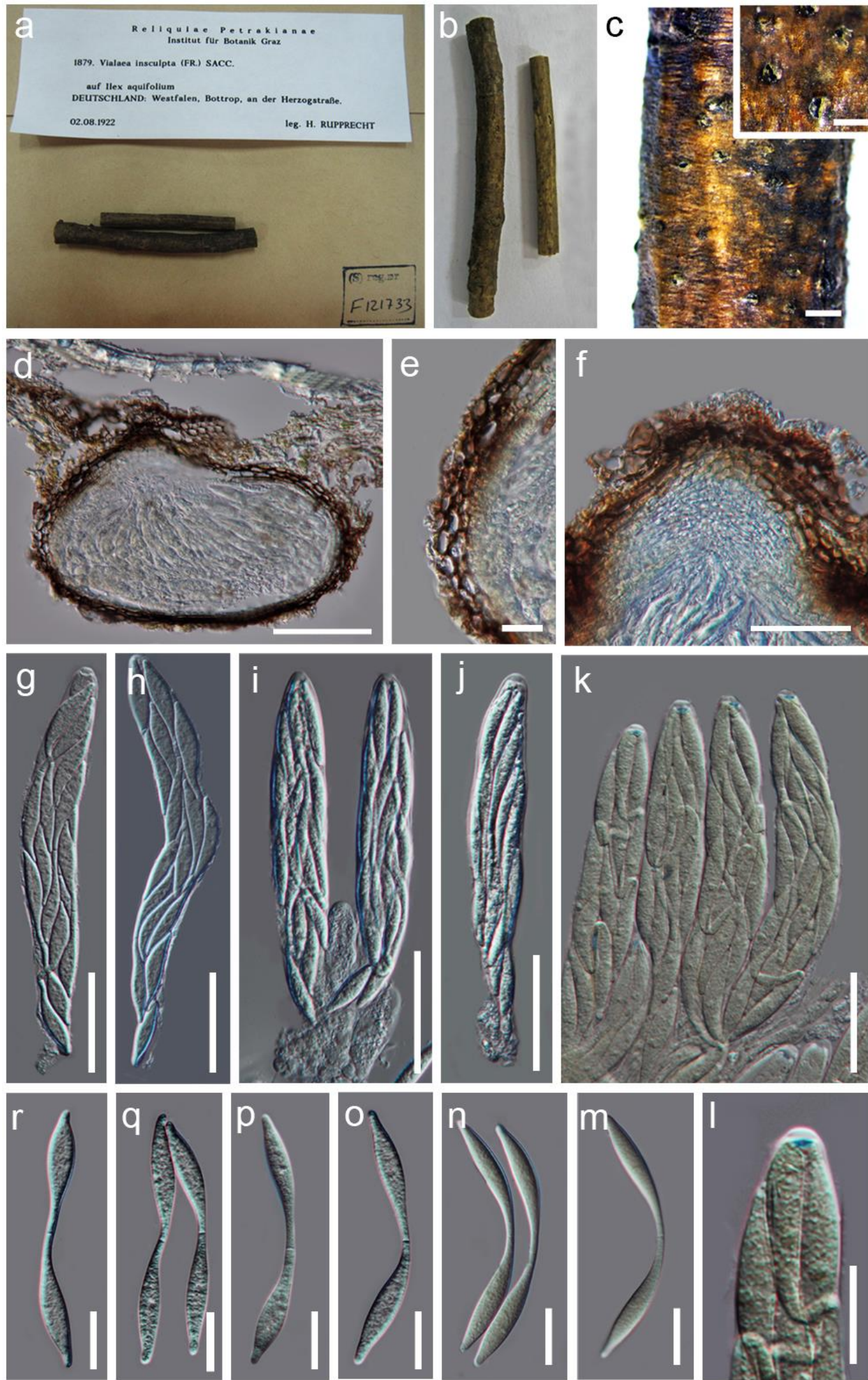

Figure 258 - Vialaea insculpta (Material examined - GERMANY, Nordrhein-Westfalen, Deutschland, Westfalen, Bottrop, an der zerzogstrasse, on twigs of Ilex aquifolium, 2 August 1922, H. Rupprecht, S-F121733). a Packet of the herbarium. b Herbarium specimens. c Ascostromata on host. d Vertical section of ascoma. e Peridium. f Periphyses in ostiolar canal. g-k Asci. 1 Apical ring bluing in Melzer's reagent. m-r Ascospores. Scale bars: $c=500 \mu \mathrm{m}, \mathrm{d}, \mathrm{f}=100 \mu \mathrm{m}, \mathrm{e}=20 \mu \mathrm{m}, \mathrm{g}-\mathrm{k}$ $=50 \mu \mathrm{m}, 1=10 \mu \mathrm{m}, \mathrm{m}-\mathrm{r}=20 \mu \mathrm{m}$. 

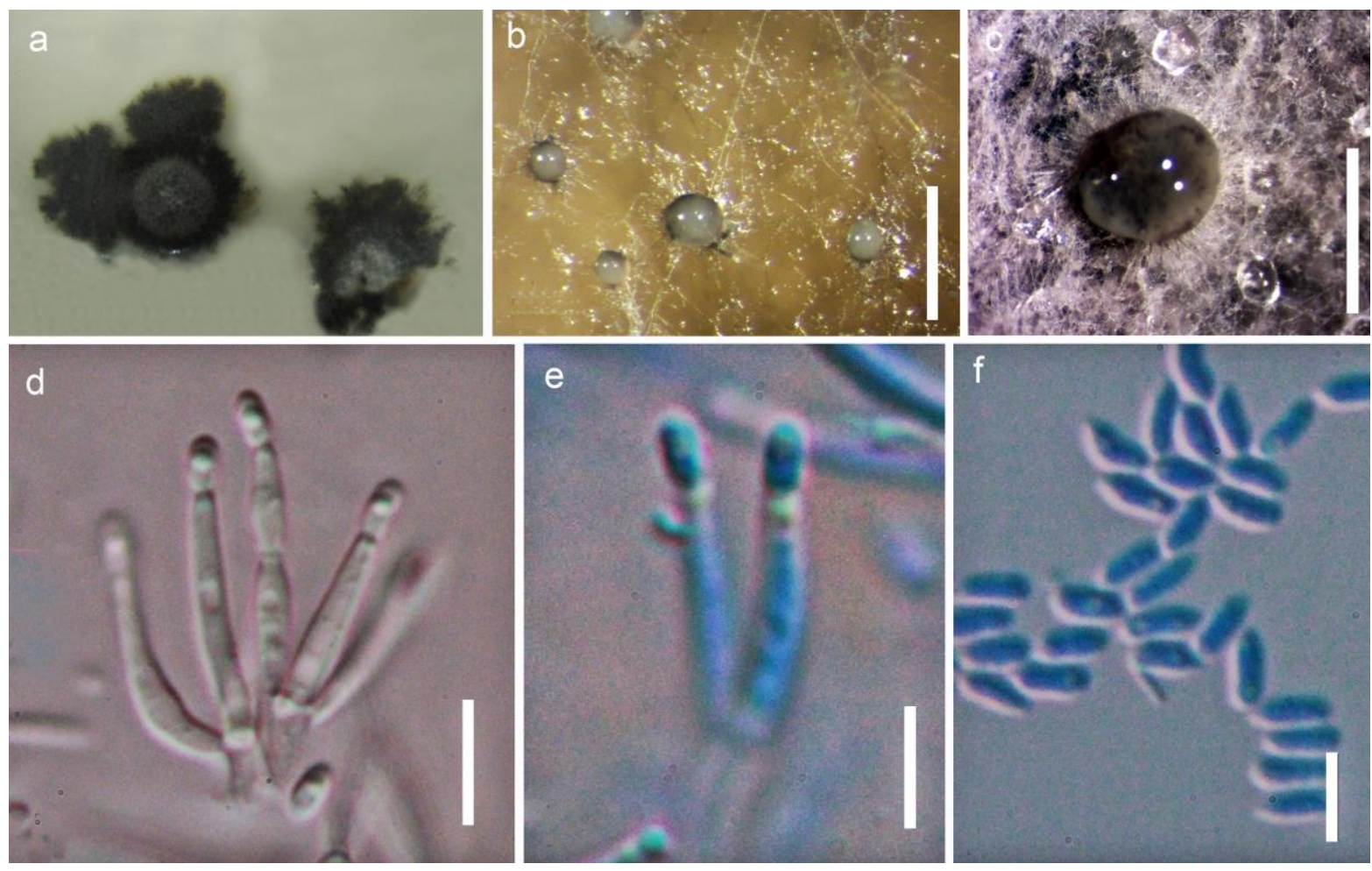

Figure 259 - Asexual morph of Vialaea mangiferae (Material examined - THAILAND, Chaing Rai Province, Muang District, near Bandu, Baan Khuakhae, at 31M. 17, (19 59' 52.05' N; $99^{\circ} 49^{\prime}$ 25.15" E), on twigs of Mangifera indica, 15 Nov. 2012, leg. K. D. Hyde, CHUNI001; MFLU130342, HKAS 81790, holotype). a Culture from above. b, c Conidiomata forming on Water Agar. d, e Conidia forming on phialides attached to conidiophores. $\mathrm{f}$ Conidia. Scale bars: $\mathrm{b}=1 \mathrm{~mm}, \mathrm{c}=500$ $\mu \mathrm{m}, \mathrm{e}, \mathrm{f}=10 \mu \mathrm{m}$.

-or fusoid, with a distinctive, J-, apical ring. Ascospores uniseriate or overlapping uni-seriate, hyaline, globose, subglobose, ellipsoidal or fusiform, unicellular or septate, thin- or thick-walled, verruculose or smooth-walled, with or without a gelatinous sheath. Asexual morph: Coelomycetous, produced in culture with or without sporodochial conidiomata. Conidiophores aggregated, hyaline to subhyaline, with a clavate or penicillate head or conidiogenous cells developing from hyphae. Conidiogenous cells monoblastic or polyblastic, sympodially proliferating, terminal, cylindrical, hyaline. Conidia ellipsoid to obovoid, hyaline, aseptate, smoothwalled (adapted from Raja et al. 2003, Jaklitsch et al. 2013, Réblová et al. 2014, Zhang et al. 2017a).

Type genus - Woswasia Jaklitsch, Réblová \& Voglmayr

Notes - Woswasiaceae was introduced by Zhang et al. (2017a) and placed in Diaporthomycetidae, families incertae sedis (Jaklitsch et al. 2013, Réblová et al. 2014, Senanayake et al. 2016, Zhang et al. 2017a). The family presently contains three genera, Cyanoannulus, Woswasia and Xylochrysis. The family status was strongly supported in the MCC tree, which has a stem age at ca 115 MYA (Hyde et al. 2017a, Zhang et al. 2017a).

\section{Ecological and economic significance of Woswasiaceae}

Woswasiaceae currently includes three taxa isolated from decaying wood (Zhang et al. 2017a). They may be important decomposers participating in nutrient cycling, especially on submerged and dry wood.

\section{Genera included in Woswasiaceae}

Cyanoannulus Raja, J. Campb. \& Shearer, Mycotaxon 88: 8 (2003)

Index Fungorum number: IF28772; 1 species with sequence data. 
Type species - Cyanoannulus petersenii Raja, J. Campb. \& Shearer

Notes - The monotypic genus Cyanoannulus was isolated from decorticated wood submerged in a stream in North Carolina. The genus is characterised by pale reddish-brown ascomata which are slightly horizontal to the substrate surface, fusoid asci and thick-walled ascospores with a narrow channel at the apices and with a mucilaginous sheath (Raja et al. 2003).

Woswasia Jaklitsch, Réblová \& Voglmayr, Mycologia 105(2): 479 (2013)

Index Fungorum number: IF800841; 1 species with sequence data.

Type species - Woswasia atropurpurea Jaklitsch, Réblová \& Voglmayr

Notes - Woswasia is monotypic genus (Jaklitsch et al. 2013). The genus, together with Cyanoannulus and Xylomelasma, was placed in Sordariomycetidae genera incertae sedis (Maharachchikumbura et al. 2016b). Later, the three genera were transferred to a new family Woswasiaceae based on phylogenetic analysis and divergence estimates (Zhang et al. 2017a). The asexual morph of this genus has not yet been reported.

Xylochrysis Réblová, Mycologia 106(3): 567 (2014)

Index Fungorum number: IF805253; 1 species with sequence data.

Type species - Xylochrysis lucida Réblová, V. Štěpánek \& R.K. Schumach.

Notes - The monotypic genus Xylochrysis was isolated from decaying bark and wood of Rhododendron in Germany. The genus is characterised by ascomata often aggregated in small groups, with astromatic or stromatic base, surrounded by a pigmented layer of cells, cylindrical asci and hyaline, ellipsoidal ascospores (Réblová et al. 2014).

Xylochrysis lucida was introduced by Réblová et al. (2014) in a newly established genus Xylochrysis with conidiomata produced in culture. Xylochrysis lucida was not assigned to any other known families when first reported. Zhang et al. (2017a) established a new family Woswasiaceae to accommodate three genera including $X$. lucida.

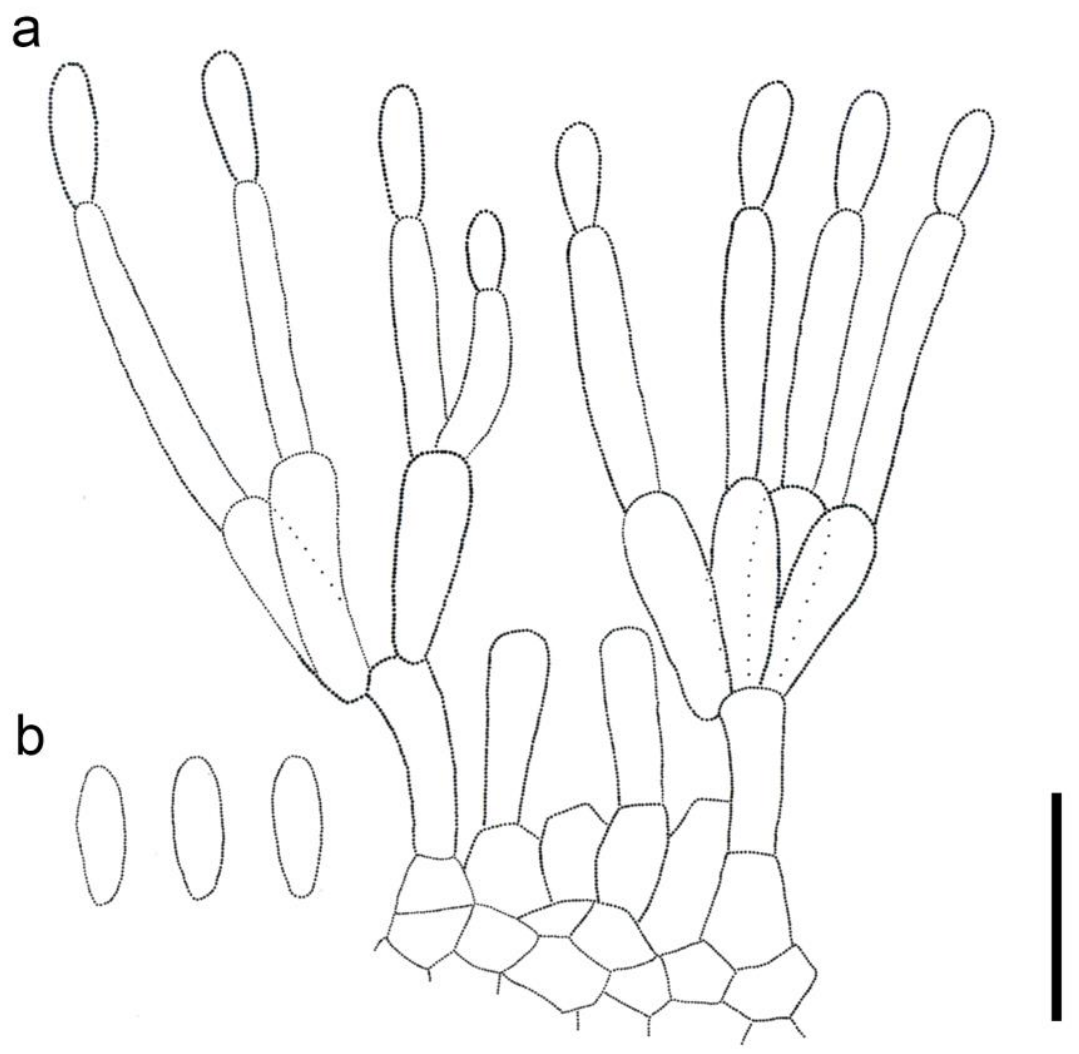

Figure 260 - Asexual morph of Xylochrysis lucida (redrawn from Réblová et al. 2014). a Conidiophores bearing conidia. $\mathrm{b}$ Conidia. Scale bars: $\mathrm{a}, \mathrm{b}=10 \mu \mathrm{m}$. 


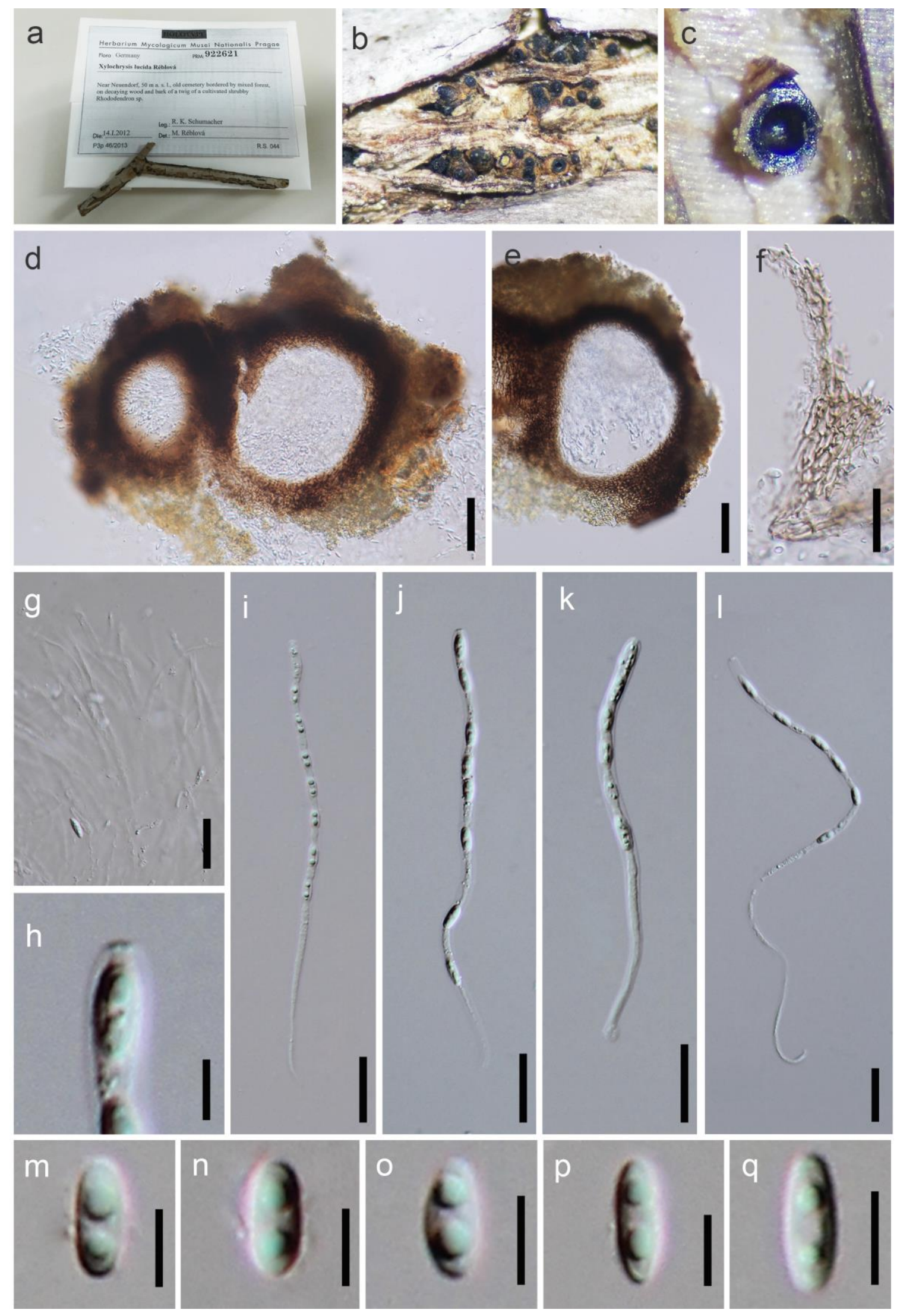

Figure 261 - Xylochrysis lucida (Material examined - GERMANY, Near Neuendorf, on decaying wood and bark of a twig of a cultivated shrubby Rhododendron sp., 14 January 2012, R.K. Schumacher R.S. 044, PRM 922621, holotype). a Herbarium material with label. b Appearance of superficial ascomata on host. c Vertical section through ascoma. d, e Vertical section through peridium. f Structure of peridium. g Paraphyses. h-1 Unitunicate asci. m-q Ascospores. Scale bars: $\mathrm{d}, \mathrm{e}=50 \mu \mathrm{m}, \mathrm{f}, \mathrm{g}, \mathrm{i}-\mathrm{l}=20 \mu \mathrm{m}, \mathrm{h}, \mathrm{m}-\mathrm{q}=5 \mu \mathrm{m}$. 
Xenodactylariaceae Crous, Persoonia 41: 289 (2018)

Index Fungorum number: IF828248; Facesoffungi number: FoF06885; 1 species.

On leaves of unidentified vine. Sexual morph: Undetermined. Asexual morph: Mycelium consisting of smooth, hyaline, branched, septate, hyphae. Conidiophores reduced to conidiogenous cells on hyphae, erect to flexuous, hyaline, smooth, with one to several denticulate apical loci. Conidia occurring in branched chains, hyaline, smooth, subcylindrical, septate (adapted from Crous et al. 2018b).

Type genus - Xenodactylaria Crous

Notes - Crous et al. (2018b) introduced Xenodactylariaceae mainly focusing on similarity with Dactylaria and Cylindrosympodium and being a phylogenetically stable independent clade.

\section{Ecological and economic significance of Xenodactylariaceae}

Xenodactylaria thailandica was found on leaves of unidentified vine in Thailand (Crous et al. 2018b).

\section{Genus included in Xenodactylariaceae}

Xenodactylaria Crous, Persoonia 41: 289 (2018)

Index Fungorum number: IF828193; 1 species with sequence data.

Type species - Xenodactylaria thailandica Crous

Notes - Dactylaria (de Hoog 1985) is heterogeneous genera (Crous et al. 2016a, 2017a) with the type species, D. purpurella, clustering in Magnaporthales (Klaubauf et al. 2014) and has similarities with Dactylaria and Cylindrosympodium. Xenodactylaria is distinct from Dactylaria and Cylindrosympodium in having hyaline hyphae, conidiophores, conidiogenous cells and hyaline conidia with occur in short chains. Xenodactylaria phylogenetically clusters on its own. In this study, $X$. thailandica is illustrated.
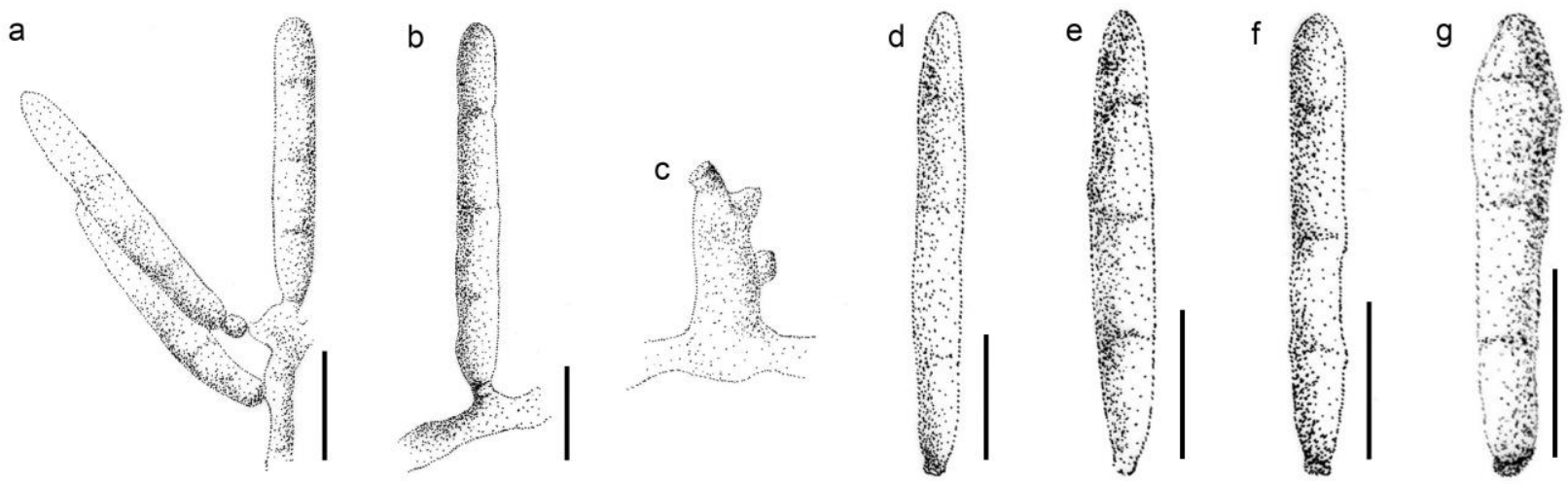

Figure 262 - Xenodactylaria thailandica (redrawn from Crous et al. 2018b), a, b Conidial attachments to the mycelia. c Conidiogenous cells. d-g conidia. Scale bars: $\mathrm{a}-\mathrm{g}=10 \mu \mathrm{m}$.

Xenospadicoidaceae Hern.-Restr., J. Mena \& Gené, Studies in Mycology 86: 91 (2017) Index Fungorum number: IF820349; Facesoffungi number: FoF05404; 74 species. = Lentomitellaceae H. Zhang, K.D. Hyde \& Maharachch, Fungal Divers. 85: 95 (2017)

Lignicolous in terrestrial and freshwater environments. Sexual morph: Ascomata perithecial, astromatic, partially superficial, scattered or grouped. Neck cylindrical or rostrate with or without sulcations, subhyaline to dark brown. Ostiole periphysate. Paraphyses septate, tapering. Peridium two layered. Asci 8-spored, unitunicate, cylindrical or cylindrical-clavate, pedicellate, with a J-, apical ring. Ascospores overlapping uniseriate, hyaline or pale brown, aseptate or septate, ellipsoidal to fusiform, ovoid, suboblong, smooth-walled or ornamented. Asexual morph: Hyphomycetous. Colonies effuse. Conidiophores macronematous, mononematous, branched or unbranched, septate, brown near base, subhyaline to hyaline towards the apex. Conidiogenous cells 
tretic or blastic, terminal or intercalary, hyaline or brown, subcylindrical, sympodially proliferating. Conidia globose, ellipsoidal, obovoid to clavate, hyaline or brown, aseptate or septate, smoothwalled. Synasexual morph: selenosporella-like asexual morphs are sometimes formed in vitro and in vivo. Conidiophores macronematous or semi-macronematous, mononematous, branched or unbranched, often reduced to conidiogenous cells. Conidiogenous cells blastic, discrete, terminal or intercalary, subcylindrical to flask-shaped, with a short terminal, rachis bearing a few denticles. Conidia globose, clavate to obovate, or narrow fusiform, hyaline, aseptate, smooth-walled (adapted from Hernández-Restrepo et al. 2017).

Type genus - Spadicoides S. Hughes

Notes - Xenospadicoidaceae was introduced by Hernández-Restrepo et al. (2017) as a monotypic family in Xenospadicoidales, which was established at the same time. Xenospadicoidaceae included two monotypic genera, the type genus Xenospadicoides and Pseudodiplococcium (Hernández-Restrepo et al. 2017). Hernández-Restrepo et al. (2017) synonymized six species under Xenospadicoides, including Spadicoides atra, the type species. Réblová et al. (2018) emended Xenospadicoidaceae based on combined act1, ITS, LSU, SSU, tub2 and rpb2 sequence data. Pseudodiplococcium and Xenospadicoides was reduced to synonymy under Spadicoides, which was assigned as the type genus (Réblová et al. 2018). Three more genera, Calyptosphaeria, Lentomitella and Torrentispora, were added to Xenospadicoidaceae. In addition, Lentomitellaceae was synonymized under Xenospadicoidaceae (Réblová et al. 2018). Subsequently, the fifth genus, Neospadicoides in Xenospadicoidaceae was introduced by Luo et al. (2019) from freshwater habitats.

\section{Ecological and economic significance of Xenospadicoidaceae}

Species of Xenospadicoidaceae are lignicolous in both terrestrial and freshwater habitats. The ecological role of freshwater fungi has increasingly been recognized (Hyde et al. 2016a). Decomposing dead plant material is the primary role. The transfer of nutrients and energy in the food web occurs through decomposition by freshwater fungi (Wong et al. 1998a).

\section{Genera included in Xenospadicoidaceae}

Calyptosphaeria Réblová \& A.N. Mill., Studies in Mycology 89: 13 (2017)

Index Fungorum number: IF821760; 4 species with sequence data.

Type species - Calyptosphaeria tenebrosa Réblová \& A.N. Mill.

Notes - Calyptosphaeria, introduced by Réblová et al. (2018), was segregated from Lentomitella to accommodate $C$. subdenudata, C. tropica, C. tenebrosa and C. collapsa based on morphology and phylogeny. Calyptosphaeria species are saprobic and have a worldwide distribution (Huhndorf et al. 2008, Réblová et al. 2018). The genus is characterized by semiimmersed, globose to conical ascomata with ostioles and necks, 8-spored, unitunicate, cylindrical, short-pedicellate asci with J-, apical rings, and ellipsoidal to fusiform, brown, septate ascospores (Réblová et al. 2018). The asexual morph is undetermined.

\section{Lentomitella Höhn., Annales Mycologici 3 (6): 552 (1906)}

Index Fungorum number: IF2736; 11 morphological species, 9 species with sequence data.

Type species - Lentomitella vestita (Sacc.) Höhn.

Notes - Lentomitella was introduced by von Höhnel (1905) who segregated this genus from Ceratostomella Sacc. based on the ornamentation of the ascospores of $C$. vestita as Lentomitella vestita. Lentomitella can be distinguished from Ceratostomella by asci, ascospores and the centrum (Réblová 2006). Lentomitella was historically assigned to Lasiosphaeriaceae (Untereiner 1993) and Clypeosphaeriaceae (Barr 1990b, Eriksson et al. 2003). Réblová (2006) reinstated Lentomitella with three accepted species, L. cirrhosa, L. crinigera and L. tomentosa, and their phylogenetic analyses showed Lentomitella resided in Sordariomycetes incertae sedis. Réblová et al. (2018) divided Ceratostomella species and other similar taxa into four genera, Calyptosphaeria, Lentomitella, Spadicoides, and Torrentispora, which represent Xenospadicoidaceae. 
Lentomitella cirrhosa is saprobic on decaying wood. Since the type specimen of L. cirrhosa is unavailable, Réblová (2006) designated a collection from New Zealand on decayed wood of Podocarpus totara (PDD 81434) as the epitype. Sphaeria cirrhosa was accepted in Ceratostoma by Fuckel (1870). However, Saccardo (1882) transferred S. cirrhosa to Ceratostomella as C. cirrhosa. Réblová (2006) again transferred C. cirrhosa to Lentomitella.
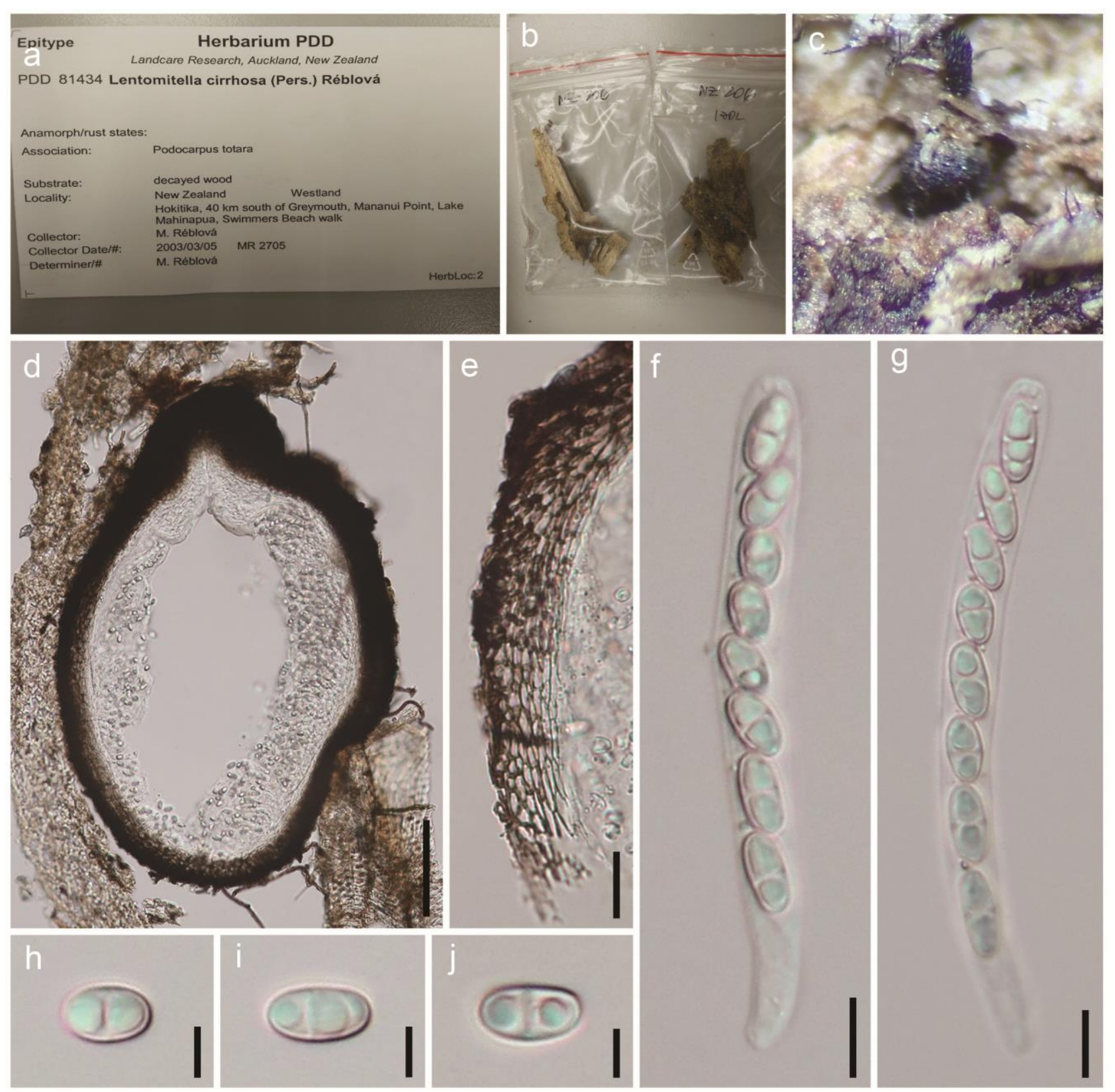

Figure 263 - Lentomitella cirrhosa (Material examined - NEW ZEALAND, Westland, Hokitika, $40 \mathrm{~km} \mathrm{~S}$ of Greymouth, Mananui Point, Lake Mahinapua, Swimmers Beach walks, on decayed wood of Podocarpus totara, 5 March 2003, M. Réblová, M.R. 2705, PDD 81434, epitype). a Herbarium packet. b Herbarium material. c Ascoma on the host. d Ascoma in cross section. e Peridium. f, g Asci. h-j Ascospores. Scale bars: $d=100 \mu \mathrm{m}, \mathrm{e}=20 \mu \mathrm{m}, \mathrm{f}, \mathrm{g}=10 \mu \mathrm{m}, \mathrm{h}-\mathrm{j}=5 \mu \mathrm{m}$.

Neospadicoides Z.L. Luo, K.D. Hyde \& H.Y. Su, Fungal Divers. 99: 513 (2019) Index Fungorum number: IF555652; 3 species with sequence data.

Type species - Neospadicoides lignicola Z.L. Luo, K.D. Hyde \& H.Y. Su

Notes - Neospadicoides was introduced by Luo et al. (2019) to accommodate $N$. aquatica, $N$. lignicola and N. yunnanensis based on morphology and phylogeny. All Neospadicoides species are 
reported from freshwater habitats in Yunnan Province, China. The genus is characterized by macronematous, mononematous, unbranched, cylindrical, brown, septate conidiophores, polytretic, terminal conidiogenous cells, and fusiform or obovoid, septate conidia (Luo et al. 2019). The sexual morph of this genus is undetermined.

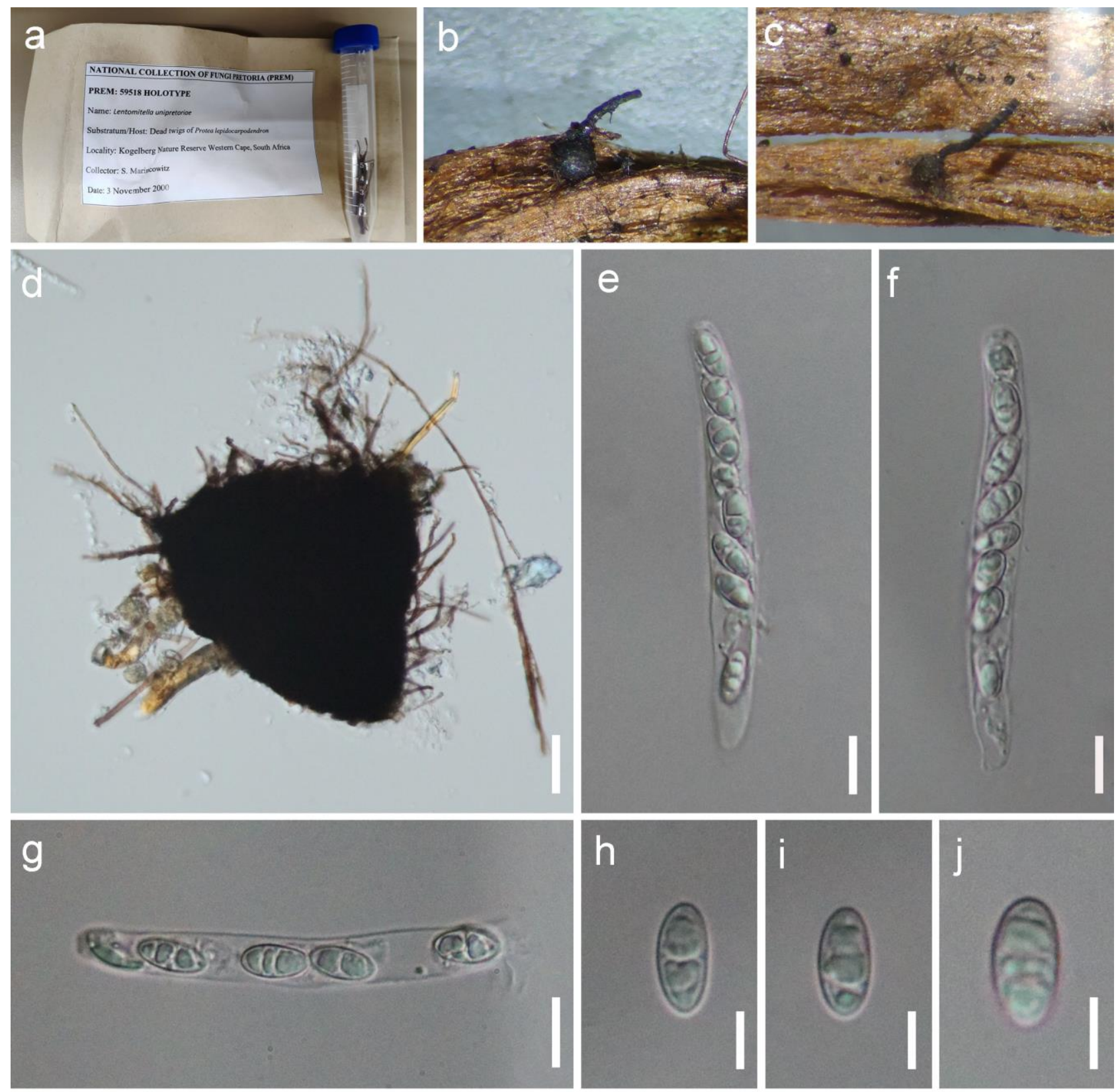

Figure 264 - Lentomitella unipretoriae (Material examined - SOUTH AFRICA, Kogelberg Nature Reserve Western Cape, on dead twigs of Protea lepidocarpodendrom, 3 November 2000, S. Marincowitz, PREM 59518, holotype). a Herbarium packet and material. b, c Ascoma on the host. d Peridium. e, f Asci. g-j Ascospores. Scale bars: $d=50 \mu \mathrm{m}$, e-g $=10 \mu \mathrm{m}, \mathrm{h}-\mathrm{j}=5 \mu \mathrm{m}$.

Spadicoides S. Hughes, Can. J. Bot.36: 805 (1958)

Index Fungorum number: IF9961; 46 morphological species, 5 species with sequence data (Ma et al. 2016a, Réblová et al. 2018, Qiao et al. 2019).

= Xenospadicoides Hern.-Restr., J. Mena \& Gené, Studies in Mycology 86: 92 (2017)

= Pseudodiplococcium Hern.-Restr., J. Mena \& Gené, Studies in Mycology 86: 92 (2017)

Type species - Spadicoides bina (Corda) S. Hughes

Notes - Spadicoides, based on S. bina, was introduced by Hughes (1958), who regarded 
unbranched conidiophores as an important character to separate Spadicoides from Diplococcium (Hughes 1958). Sinclair et al. (1985) considered conidial catenation as the main character in identification between Diplococcium and Spadicoides. Shenoy et al. (2010) indicated that Spadicoides is not monophyletic and is unrelated to Diplococcium based on LSU sequence data. Réblová et al. (2018) established the sexual-asexual connection for S. bina, S. fuscolutea and S. hyalostoma, and a selenosporella-like synasexual morph was observed for S. bina and S. fuscolutea in vitro (Réblová et al. 2018). The asexual morph of Spadicoides is characterized by mononematous, unbranched or sparingly branched conidiophores, polytretic conidiogenous cells with acropleurogenus, obovoid to ellipsoid, dark brown conidia, formed singly or in a chain and selenosporella-like synasexual morphs (Goh \& Hyde 1996, Ho et al. 2002, Cai et al. 2004, Réblová et al. 2018), while sexual morph has astromatic ascomata with long necks, 8-spored asci with a short pedicel and J-, apical ring and hyaline, aseptate or 1-septate ascospores (Réblová et al. 2018).

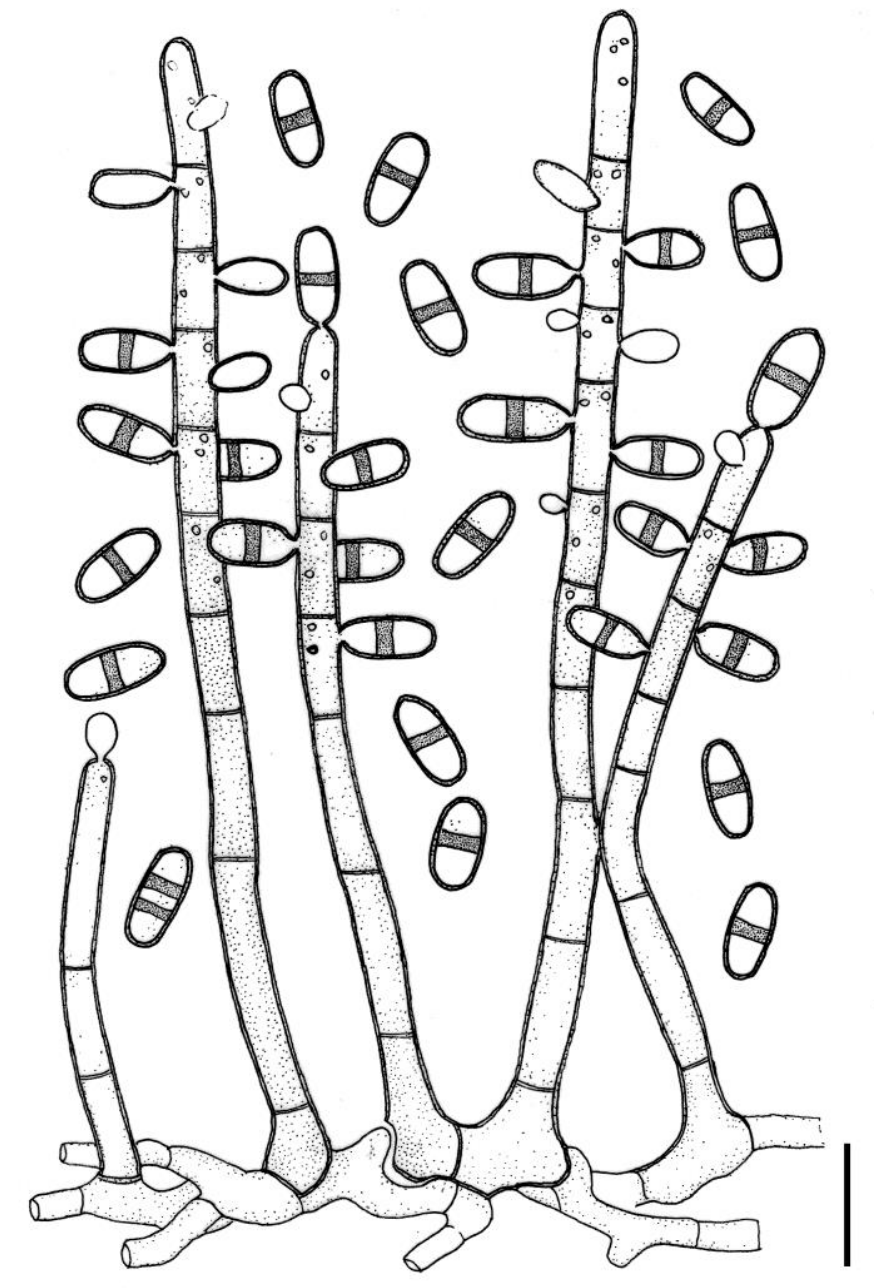

Figure 265 - Spadicoides bina, redrawn from Seifert et al. (2011). This drawing shows the conidiophores, mycelium, conidiogenous cells and conidia of S. bina. Scale bar: $10 \mu \mathrm{m}$.

Torrentispora K.D. Hyde, W.H. Ho, E.B.G. Jones, K.M. Tsui \& S.W. Wong, Mycological Research 104 (11): 1399 (2000)

Index Fungorum number: IF28453; 10 morphological species (Species Fungorum 2020), 6 species with sequence data.

= Pseudoannulatascus Z.L. Luo, Maharachch. \& K.D. Hyde, Phytotaxa 239 (2): 179 (2015)

= Fusoidispora Vijaykr., Jeewon \& K.D. Hyde, Sydowia 57 (2): 272 (2005)

Type species - Torrentispora fibrosa K.D. Hyde, Wai H. Ho, E.B.G. Jones, K.M. Tsui \& S.W. Wong 
Notes - Torrentispora was introduced by Hyde et al. (2000) to accommodate T. fibrosa on decaying wood from freshwater habitat. Subsequently, the type species was also reported on Nothofagus sp. and dried driftwood in New Zealand from terrestrial environments (Réblová et al. 2018). In the multigene phylogenetic analysis, Fusoidispora aquatica and Pseudoannulatascus biatriisporus grouped with T. fibrosa, therefore, the genera Fusoidispora and Pseudoannulatascus are synonymised with Torrentispora (Réblová et al. 2018). The sexual morph of Torrentispora is characterized by semi-immersed, globose to conical ascomata with ostioles and necks, 8-spored, unitunicate, cylindrical, short-pedicellate asci with $\mathrm{J}-$, massive, apical rings, and ellipsoidal to fusiform, hyaline, aseptate or transverse septate ascospores, sometimes with a fibrillar sheath (Réblová et al. 2018). The asexual morph is undetermined in this genus.

Xyladictyochaetaceae Crous \& Hern.-Restr., Fungal Systematics and Evolution 1: 212 (2018) Index Fungorum number: IF824802; Facesoffungi number: FoF06787; 1 species.

Saprobic on leaf litter. Sexual morph: Undetermined. Asexual morph: Mycelium medium brown, smooth, septate, branched hyphae, forming globose, intercalary, brown, smooth, chlamydospore-like structures. Conidiophores erect, brown, smooth, subcylindrical, flexuous, multiseptate. Conidiogenous cells terminal and intercalary, polyphialidic, lacking flared collarettes. Conidia solitary, aggregating in slimy mass, hyaline, smooth, fusoid-ellipsoid, slightly curved, apex subacute, base truncate, medially 1-septate; each end with flexuous, unbranched appendage (adapted from Crous et al. 2018c).

Type genus - Xyladictyochaeta Hern.-Restr., R.F. Castañeda \& Gené

Notes - Hernández-Restrepo et al. (2017) introduced Xyladictyochaeta typified by $X$. lusitanica in Xylariales based on LSU phylogeny. Xyladictyochaetaceae was introduced by Crous et al. (2018c) as a monotypic family, sister to Phlogicylindriaceae, based on LSU phylogeny. Multigene phylogeny (LSU-ITS-rpb2-tub2) in this study clearly shows that Xyladictyochaetaceae is sister to Phlogicylindriaceae in Amphisphaeriales with high statistical support (95\% ML).

\section{Ecological and economic significance of Xyladictyochaetaceae}

Xyladictyochaetaceae species are saprobes on dry leaves of Eucalyptus sp. (HernándezRestrepo et al. 2017).
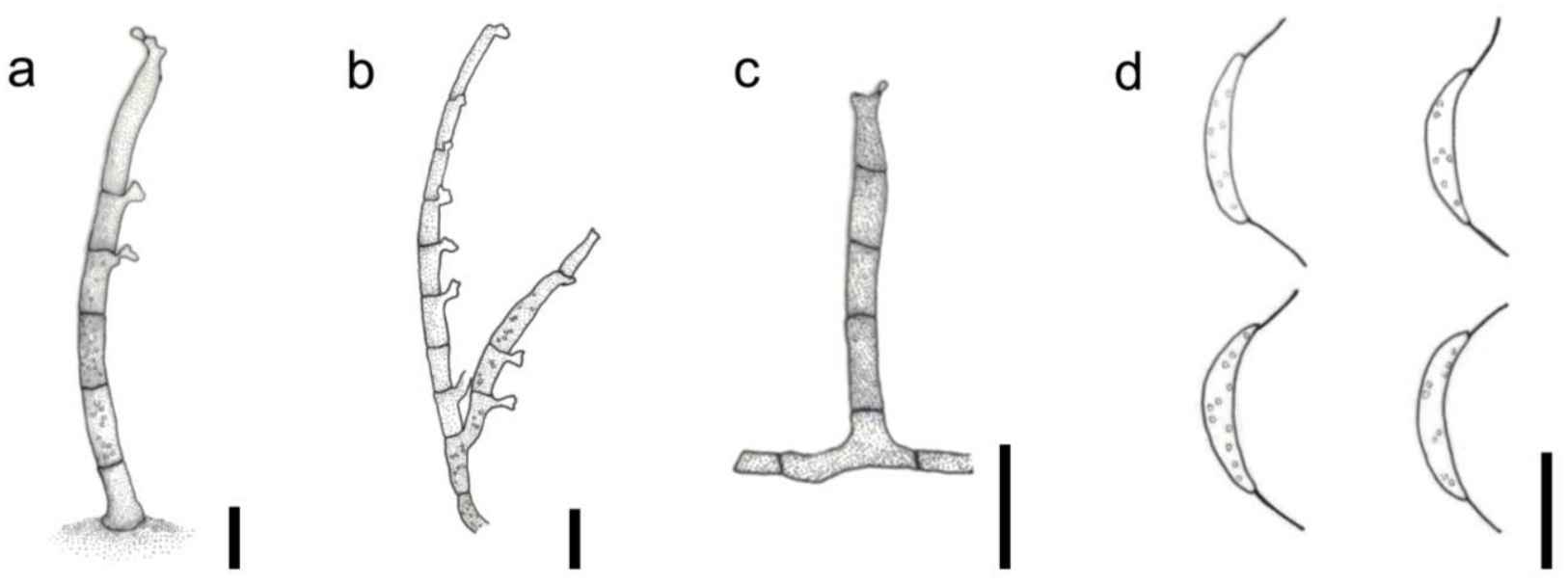

Figure 266 - Xyladictyochaeta lusitanica (FMR 12177 ex-type, redrawn from Hernández-Restrepo et al. 2017). a-c Conidiophores. d Conidia. Scale bars: $10 \mu \mathrm{m}$.

\section{Genus included in Xyladictyochaetaceae}

Xyladictyochaeta Hern.-Restr., R.F. Castañeda \& Gené, Stud. Mycol. 86: 94 (2017)

Index Fungorum number: IF820355; 1 species with sequence data.

Type species - Xyladictyochaeta lusitanica Hern.-Restr., R.F. Castañeda \& Gené 
Notes - Xyladictyochaeta is similar to Dictyochaeta in having setiform conidiophores with integrated, intercalary and terminal phialides and (0-)1-septate conidia with setulae at both ends. However, the phylogenetic analyses show that those genera in different orders i.e. Dictyochaeta (Chaetosphaeriales) and Xyladictyochaeta (Amphisphaeriales) (Crous et al. 2018c, Wei et al. 2018, this study). At present, Xyladictyochaeta is a monotypic genus with Xyladictyochaeta lusitanica isolated from dry leaves of Eucalyptus sp. in Australia and Portugal (Fig. 266) (HernándezRestrepo et al. 2017, Crous et al. 2018c).

Xylariaceae Tul. \& C. Tul., Select. fung. carpol. (Paris) 2: 3 (1863)

Index Fungorum number: IF81528; Facesoffungi number: FoF00070; 1236 species.

Saprobic, pathogenic, or endophytic in wood, leaves and fruits or associated with insect vectors. Sexual morph: Stromata extremely variable in size, shape and colour, erect or applanate or effuse-pulvinate, or sometimes rudimentary or lacking, arising singly or aggregated, with one to several ascomata, ostiolate, mostly without extractable stromal pigments, unipartite or bipartite. Ascomata variable in size, globose-pyriform, single or multi-layered. Ostioles papillate, umbilicate or at the same level as the stromal surface. Paraphyses hyaline, filamentous, septate, embedded in a gelatinous matrix. Asci 4-8-spored, unitunicate, cylindrical to clavate, pedicellate or apedicellate, apically rounded, with or without a $\mathrm{J}+$, apical ring, or with apical thickenings. Ascospores uniseriate-biseriate, brown to black, rarely hyaline, 1-2-celled, variously-shaped, mostly ellipsoidal, subglobose or reniform, mostly with a germ slit, straight, spiral or sigmoid. Perispore dehiscent or lacking, smooth or with patterns. Asexual morph: Hyphomycetous. Mostly geniculosporium-like. Conidiophores hyaline to light brown, smooth, branched. Conidia hyaline, roughened or smooth, ellipsoidal. Several hyphomycetous genera have been linked to Xylariaceae (adapted from Maharachchikumbura et al. 2016b, Daranagama et al. 2018).

Type genus - Xylaria Hill ex Schrank

Notes - Maharachchikumbura et al. (2016b) accepted 87 genera with a complete family description of Xylariaceae, which included the subfamilies Xylaroideae and Hypoxyloideae. Wendt et al. (2018) re-established Hypoxylaceae (Hypoxyloideae) based on morphology, phylogeny and secondary metabolite analyses. Based on morphology, phylogeny and molecular clock analyses, Clypeosphaeriaceae was synonymized under Xylariaceae with a stem age of 63 MYA (Jaklitsch et al. 2016b, Hongsanan et al. 2017). However, in present study, we accept Clypeosphaeriaceae as a distinct family (see notes under Clypeosphaeriaceae). Daranagama et al. (2018) provided an updated account of genera of Xylariaceae accepting 37 genera after observing type specimens. However, Wendt et al. (2018) placed Gigantospora, Nipicola, Sabalicola, Spirodecospora, Striatodecospora and Xylotumulus in Xylariales genera incertae sedis, due to lack of molecular data and undetermined asexual morphs. We accept those genera in the Xylariaceae based on study of herbarium specimens by Daranagama et al. (2018). Lee et al. (2016) and Johnston et al. (2016) introduced Abieticola and Entalbostroma in Xylariaceae. Wijayawardene et al. (2017a) validly published the genus Palmaria in Xylariaceae due to invalid nomenclature as Palmomyces (Hyde et al. 1998a). Following recent updates, we accept 32 genera in Xylariaceae.

Xylariaceae species are important producers of bioactive compounds and secondary metabolites (Stadler \& Hellwig 2005, Helaly et al. 2018). Song et al. (2014) summarized 188 secondary metabolites with bioactive properties produced by Xylaria species. Since the taxa presently included under Xylaria are not well-resolved, secondary metabolites may be possible markers for species identification (Lee et al. 2000, Song et al. 2014). Isaka et al. (2012) described novel secondary metabolites from Poronia gigantea, and suggested that poronitin A (1) and (R)-5methylmellein as useful chemotaxonomic markers for this genus. There are several other xylariaceous genera such as Coniolariella, Entoleuca, Hypocopra, Kretzschmaria, Rosellinia and Xylotumulus that have been subjected to secondary metabolites analyses (Stadler et al. 2001, Stadler \& Hellwig 2005, Helaly et al. 2018). Therefore, it is important to extend the morphology, phylogeny and chemotaxonomy approaches to discover relationships in Xylariaceae (Helaly et al. 2018). 


\section{Ecological and economic significance of Xylariaceae}

There are several important plant pathogenic species reported in this family especially belonging to the genera Entoleuca and Rosellinia. Entoleuca mammata causes canker diseases (hypoxylon canker) on Malus sp. (Rosaceae), Populus sp., Salix sp. (Salicaceae), and Sorbus sp. (Rosaceae) (Kasanen et al. 2004, Ostry \& Anderson 2009). Rosellinia necatrix and R. desmazieresii which are known from temperate regions, and $R$. bunodes known from the tropics, causes root rot of fruit trees and vines (Agrios 2005, Ten Hoopen \& Krauss 2006). Among the root-diseases causing Rosellinia species, $R$. bunodes is responsible for black root rot, $R$. necatrix for white root rot and $R$. pepo for stellate root rot (Castro et al. 2013). Most species of this family are saprobes on plant material. Cheng et al. (2015) introduced two new saprobic species of Ascotricha on the brown alga Padina tetrastromatica, in intertidal regions of China. Species of Hypocopra, Podosordaria, Poronia and Wawelia have been reported as coprophilous worldwide. Most of the species have been investigated from Poaceae hosts as saprobes worldwide. Currently, extensive studies of secondary metabolites and bioactive compouds from xylariaceous species have become a key research area (Stadler \& Hellwig 2005, Cheng et al. 2015, Hung et al. 2015, Chang et al. 2018, Helaly et al. 2018). Therefore, species in Xylariaceae are of great interest due to their economic and environmental importance as saprobes, endophytes, pathogens and secondary metabolites producers.

\section{Genera included in Xylariaceae}

Abieticola Hyang B. Lee, Mycotaxon 131(4): 755 (2016)

Index Fungorum number: IF811702; 1 species with sequence data.

Type species - Abieticola koreana Hyang B. Lee

Notes - Abieticola koreana was described as an endophyte from the inner bark of a Manchurian fir (Abies holophylla) in Korea. The genus differs from Poronia in having slightly curved conidia, and its shorter conidiogenous cells that sometimes bear 3 conidia.

Amphirosellinia Y.M. Ju, J.D. Rogers, H.M. Hsieh \& Lar.N. Vassiljeva, Mycologia 96(6): 1393 (2004)

Index Fungorum number: IF28880; 6 morphological species (Species Fungorum 2020), 3 species with sequence data.

Type species - Amphirosellinia nigrospora Y.M. Ju, J.D. Rogers \& H.M. Hsieh

Notes - Amphirosellinia has rarely erumpent to mostly immersed perithecioid, bipartite stromata, and has a close affinity to Rosellinia. The genus has synnematous, geniculosporium-like asexual morphs that produce lacrymoid conidia (Ju et al. 2004). However, Amphirosellinia differs from Rosellinia in having stromata that develop beneath the host epidermis with a thick, carbonized crust. The genus has been identified with a potential antimicrobial agent using A. nigrospora (Nguyen et al. 2018).

Anthostomella Sacc., Atti Soc. Veneto-Trent. Sci. Nat., Padova, Sér. 4 4: 84 (1875)

Index Fungorum number: IF226; 118 morphological species (Lu \& Hyde 2000, Species Fungorum 2020), 35 species with sequence data.

Type species - Anthostomella tomicoides Sacc.

Notes - Anthostomella is characterized by immersed, dark, clypeate ascomata with periphysate ostiolar canals, 8-spored, cylindrical, unitunicate asci and mostly dark, unicellular ascospores, sometimes with dwarf cells or appendages at the ends (Daranagama et al. 2015). Daranagama et al. $(2015,2016)$ described the polyphyletic nature of the genus and emphasized the need for recollection and providing molecular data. Voglmayr et al. (2018) re-evaluated the genus with suggestions to provide a new family for Anthostomella with the availability of sequence data of the type species. In this study, Anthostomella does not appear to be phylogenetically related to Xylariaceae. Daranagama et al. (2018) re-examined several herbarium specimens and tentatively synonymized Appendixia with Anthostomella based on morphological similarities. 
Anthostomelloides Tibpromma \& K.D. Hyde, Turkish Journal of Botany 41: 107-116 (2017)

Index Fungorum number: IF552117; 5 morphological species (Daranagama et al. 2018), 2 species with sequence data.

Type species - Anthostomelloides krabiensis Tibpromma \& K.D. Hyde

Notes - Anthostomelloides was introduced as a saprobe on dead leaves of Pandanus odorifer. It is characterized by immersed, globose ascomata and a peridium comprising cells of textura prismatica (Tibpromma et al. 2017a).

Ascotricha Berk., Ann. nat. Hist., Mag. Zool. Bot. Geol. 1: 257 (1838)

Index Fungorum number: IF384; 18 morphological species (Cheng et al. 2015, Li \& Zhao 2018, Species Fungorum 2020), 9 species with sequence data.

Type species - Ascotricha chartarum Berk.

Notes - Ascotricha species are characterized by ascomata having long hairs with shorter, hyaline branches, brown, ellipsoidal ascospores with an equatorial germ slit and geniculosporium type asexual morphs (Berkeley 1838, Cheng et al. 2015). Cheng et al. (2015) added two novel species and one combination of Ascotricha from algae and confirmed the taxonomic placement of the genus in Xylariaceae. Li \& Zhao (2018) added one new species and two combinations. However, BLASTn results of the available sequences and phylogenetic affinities of our multigene analyses that show Ascotricha is close to Zygosporium. Therefore, revision of Ascotricha is needed to establish its taxonomic placement.

Astrocystis Berk. \& Broome, J. Linn. Soc., Bot. 14(no. 74): 123 (1873)

Index Fungorum number: IF439; 24 morphological species (Species Fungorum 2020), 7 species with sequence data.

Type species - Astrocystis mirabilis Berk. \& Broome

Notes - Astrocystis accommodates mostly superficial, uniascomatal stromata bearing species (Berkeley \& Broome 1875). The genus formed a monophyletic clade in analyses of ITS, LSU, SSU, rpb2 and tub2 sequence data (Hsieh et al. 2010, Li et al. 2015b, c). Most Astrocystis species occur on bamboo and are widespread in tropical and subtropical regions.

Brunneiperidium Daranag., Camporesi \& K.D. Hyde, Fungal Divers. 73:221 (2015)

Index Fungorum number: IF809521; 2 species with sequence data.

Type species - Brunneiperidium gracilentum Daranag., Camporesi \& K.D. Hyde

Notes - Brunneiperidium was introduced based on its unique peridium characters, with the outermost wall of irregularly arranged brown and yellowish-brown cells. Phylogenetic analyses revealed that the genus clustered between Kretzschmaria and Xylaria (Daranagama et al. 2018).

Collodiscula I. Hino \& Katum., Bull. Faculty of Agriculture, Yamaguchi University 6: 55 (1955)

Index Fungorum number: IF1187; 5 species with sequence data.

Type species - Collodiscula japonica I. Hino \& Katum.

Notes - Collodiscula was introduced by Hino \& Katumoto (1955) to accommodate species with brown, 1-septate ascospores lacking a germ slit, superficial, stromatic ascomata and large, J+, wedge-shaped ascal apical ring. There are five species of Collodiscula are mostly associated with bamboo (Li et al. 2015b, Hyde et al. 2017b).

Coniolariella Dania García, Stchigel \& Guarro, Mycol. Res. 110(11): 1285 (2006)

Index Fungorum number: IF29050; 4 species with sequence data.

Type species - Coniolariella gamsii (Asgari \& Zare) Dania García, Stchigel \& Guarro

Notes - Coniolariella is reminiscent of Obolarina in some morphological characters as both genera have J-, short pedicellate asci without a distinct apical ring. Coniolariella is also similar to Rosellinia in asci and ascospore morphology. 
Engleromyces Henn., Bot. Jb. 28(3): 327 (1900)

Index Fungorum number: IF1819; 2 morphological species (Species Fungorum 2020).

Type species - Engleromyces goetzei Henn.

Notes - Engleromyces is characterized by massive, hard stromata similar to macroxylariaceous genera such as Sarcoxylon (Whalley et al. 2010). Engleromyces goetzei possesses medicinal values and is used in Africa and China (Kokwaro 1983). Both, Engleromyces goetzei and E. sinensis have been analysed for the secondary metabolites and contain neoengleromycin and cytochalasins (Liu et al. 2002). Daranagama et al. (2018) accepted the genus in Xylariaceae until molecular data are available.

Entalbostroma J.D. Rogers \& P.R. Johnst., Mycotaxon 131(4): 766 (2017)

Index Fungorum number: IF817225; 1 species with sequence data.

Type species - Entalbostroma erumpens J.D. Rogers \& P.R. Johnst.

Notes - Entalbostroma is a monotypic genus. Entalbostroma erumpens was described on dead leaves of Phormium tenax and P. cookianum (Johnston et al. 2016). The genus is characterized by pulvinate to applanopulvinate, orbicular to elliptical to irregular stromata, dark brown ascospores with a germ slit on flattened side, a hyaline gelatinous sheath in sexual and palisade-like layer of short, cylindric conidiophores and hyaline, smooth, ellipsoid conidia with narrowed flattened bases (Johnston et al. 2016).

Entoleuca Syd., Annls mycol. 20(3/4): 186 (1922)

Index Fungorum number: IF1833; 3 species with sequence data.

Type species - Entoleuca callimorpha Syd.

Notes - Sydow \& Petrak (1922) introduced the genus with E. callimorpha as the type species. Until 1994, Hypoxylon mammatum was considered as similar taxa to E. callimorpha. However, Læssøe \& Spooner (1994) and Læssøe (1994) treated the H. mammatum as separate, but synonym of Rosellinia. Based on these taxonomic confusions, Rogers \& Ju (1996) revised the type, authentic and other specimens and re-established the genus. Entoleuca consists of saprobic and plant pathogenic species distributed in Europe. As a pathogen, E. mammata causes canker (hypoxylon canker) on Malus sp. (Rosaceae), Populus sp., Salix sp. (Salicaceae), and Sorbus sp. (Rosaceae) (Shaw 1973, Callan 1998, Kasanen et al. 2004, Eriksson 2014) and is a saprobe on decaying tree trunks.

Euepixylon Füisting, Bot. Ztg. 25(no. 39): 309 (1867)

Index Fungorum number: IF27402; 2 morphological species (Species Fungorum 2020), 1 species with sequence data.

Type species - Euepixylon udum (Pers.) Læssøe \& Spooner

Notes - The genus is characterized by semi-immersed, multiascomatal, linear stomata with conspicuous ascomatal mounds, forming a clypeoid carbonaceous layer and cylindrical, unitunicate asci with short-pedicel. Daranagama et al. (2018) and Wendt et al. (2018) accepted the genus in Xylariaceae. However, sequence data of the type species are needed to investigate its potential synonymy with Nemania.

Halorosellinia Whalley, E.B.G. Jones, K.D. Hyde \& Læssøe, Mycol. Res. 104(3): 368 (2000)

Index Fungorum number: IF28368; 3 morphological species (Species Fungorum 2020), 2 species with sequence data. Læssøe

Type species - Halorosellinia oceanica (S. Schatz) Whalley, E.B.G. Jones, K.D. Hyde \&

Notes - Halorosellinia was established to accommodate $H$. oceanicum, which was earlier accepted as Hypoxylon oceanicum. The sexual morph of the genus is characterized by immersed ascomata in a poorly developed pseudostromata, unitunicate, 8-spored asci with a cylindrical, J+, apical ring and dark brown-opaque, ellipsoidal ascospores with a straight germ slit (Whalley et al. 
2010). Based on sexual and asexual morphology coupled with phylogenetic analyses, Daranagama et al. (2018) and Wendt et al. (2018) accepted this genus in Xylariaceae.

Helicogermslita Lodha \& D. Hawksw., Trans. Br. mycol. Soc. 81(1): 91 (1983)

Index Fungorum number: IF2254; 9 morphological species (Species Fungorum 2020).

Type species - Helicogermslita celastri (S.B. Kale \& S.V.S. Kale) Lodha \& D. Hawksw.

Notes - Hawksworth \& Lodha (1983) described the genus which is characterized by asci with a J-, apical ring and ascospores with spiral germ slits. The asexual morph has been described as geniculosporium-like. There are no sequence data for this genus.

Hypocopra (Fr.) J. Kickx f., Fl. Crypt. Flandres (Paris) 1: 362 (1867)

Index Fungorum number: IF2431; 31 morphological species (Species Fungorum 2020), 2 species with sequence data.

Type species - Hypocopra merdaria (Fr.) J. Kickx f.

Notes - Hypocopra species are characterized by sessile, clypeoid or sometimes even rudimentary stromata, mainly inhabiting dung (Krug \& Cain 1973).

Hypocreodendron Henn., Hedwigia 36(4): 223 (1897)

Index Fungorum number: IF8615; 1 species with sequence data.

Type species - Hypocreodendron sanguineum Henn.

Notes - Hypocreodendron is a monotypic genus introduced by Hennings (1897) which is characterized by more or less cylindrical, stromata with an apical discoid or shallow cup bearing conidia. The species is associated with ant nests. Based on sexual asexual morph connections, Hypocreodendron was validated over Discoxylaria (Stadler et al. 2013, Maharachchikumbura et al. 2015b, Réblová et al. 2016b).

Kretzschmaria Fr., Summa veg. Scand., Sectio Post. (Stockholm): 409 (1849)

Index Fungorum number: IF2589; 34 morphological species (Pourmoghaddam et al. 2018, Species Fungorum 2020), 11 species with sequence data.

Type species - Kretzschmaria clavus (Fr.) Sacc.

Notes - Kretzschmaria was established by Fries (1849) which is similar to Xylaria. The genus is characterized by pulvinate or effused-pulvinate stromata attached to the substrate by narrow connectives, or clavate, turbinate, obconical, peltate-discoid, often aggregated into a crustlike mass. Pourmoghaddam et al. (2018) provided an update for the genus while introducing two new species $K$. hedjaroudei and K. iranica from Iran.

Kretzschmariella Viégas, Bragantia 4(1-6): 105 (1944)

Index Fungorum number: IF2590; 1 species with sequence data.

Type species - Kretzschmariella culmorum (Cooke) Y.-M. Ju \& J. D. Rogers

Notes - Kretzschmariella is a monotypic genus which was resurrected by $\mathrm{Ju} \&$ Rogers (1994). Kretzschmariella culmorum has superficial stromata on bamboo and bamboo-like substrates and and one to multicellular, ellipsoid to oblong-obovate or cylindrical conidia. There are confusion associated among Kretzschmariella and some Hypoxylon species.

Leprieuria Læssøe, J.D. Rogers \& Whalley, Mycol. Res. 93(2): 152 (1989)

Index Fungorum number: IF25391; 1 morphological species.

Type species - Leprieuria bacillum (Mont.) Læssøe, J.D. Rogers \& Whalley

Notes - Leprieuria is characterized by cylindrical to rod-shaped stromata, umbilicate, usually 2-10 ostioles per stroma, cylindrical, short-pedicellate asci lacking an apical ring, reniform ascospores glabrous in face view and straight germ slit and a geniculosporium-like asexual morph (see Daranagama et al. 2018). Wendt et al. (2018) accepted Leprieuria in Xylariaceae based on its asexual morph. Molecular analyses are needed to resolve this genus. 
Lunatiannulus Daranag., Camporesi \& K.D. Hyde, Fungal Divers.: 73: 227 (2015)

Index Fungorum number: IF809519; 1 species with sequence data.

Type species - Lunatiannulus irregularis Daranagama, Camporesi \& K.D. Hyde

Notes - This diatrypaceous-like genus was introduced to accommodate species with ascomata with a well-developed clypeus, cylindrical asci with an apical ring, ellipsoidal ascospores with germ slits and hyaline appendages or dwarf cells and a libertella-like asexual morph. Daranagama et al. (2018) accepted this genus in Xylariaceae based on morphology and multigene phylogeny.

Nemania Gray, Nat. Arr. Brit. Pl. (London) 1: 516 (1821)

Index Fungorum number: IF3437; 53 morphological species (Species Fungorum 2020), 14 species with sequence data.

Type species - Nemania serpens (Pers.) Gray

Notes - Nemania is a species rich and well-established genus in Xylariaceae (Daranagama et al. 2018, Wendt et al. 2018) characterized by stromata not associated with bark rupturing structures, lack KOH-extractable pigments and finely papillate ostioles. Maharachchikumbura et al. (2016b) and Réblová et al. (2016b) proposed the use of Nemania over Geniculosporium following Stadler et al. (2013). Nemania bipapillata is illustrated in this paper (Fig. 267).

Podosordaria Ellis \& Holw., Bot. Gaz. 24: 37 (1897)

Index Fungorum number: IF4282; 33 morphological species (Daranagama et al. 2018), 5 species with sequence data.

Type species - Podosordaria mexicana Ellis \& Holw.

Notes - Podosordaria was described by Holway (1897) and has erumpent, obconical stromata with glomerate head and stipe, clavate-slightly pyriform, short-pedicellate asci with a J+, apical ring and equilateral ellipsoidal, dark brown ascospores with a gelatinous sheath and a geniculosporium-like asexual morph. Multigene phylogenetic studies revealed that the genus has a close affinity to Poronia in Xylariaceae (Daranagama et al. 2018, Wendt et al. 2018).

Poronia Willd., Fl. berol. prodr.: 400 (1787)

Index Fungorum number: IF4346; 9 morphological species (Species Fungorum 2020), 3 species with sequence data.

Type species - Poronia gleditschii Willd.

Notes - Poronia has a close affinity to Podosordaria and is distinguished by a lindquistia conidial state (Rogers \& Ju 1998). The sexual morph of the genus is typically stalked stromata in the form of a flattened disc (Krug \& Cain 1973). The genus is accepted in Xylariaceae based on morphology and multigene phylogeny (Daranagama et al. 2018, Wendt et al. 2018).

Rosellinia De Not., G. bot. ital. 1(1): 334 (1844)

Index Fungorum number: IF4785; 158 morphological species (Jayawardena et al. 2019), 27 species with sequence data.

Type species - Rosellinia aquila (Fr.) Ces. \& De Not.

Notes - Rosellinia was introduced to accommodate uniascomatal species (De Notaris 1844). Petrini (2013) published a monograph accepting 142 species and several species were added (Ariyawansa et al. 2015, Su et al. 2016a, Tibpromma et al. 2017b, Fournier et al. 2017, Niranjan \& Sarma 2018). We observed a herbarium specimen of Rosellinia bunodes (Fig. 268), the species occurred on dead wood and was described from Sri Lanka. It has long ascospores with thread-like ends and short germ slits. Rosellinia bunodes causes black root rot of fruit trees and vines, mainly in the tropics (Ten Hoopen \& Krauss 2006, Castro et al. 2013, dos Santos et al. 2017).

Sarcoxylon Cooke, Grevillea 12(no. 62): 50 (1883)

Index Fungorum number: IF4863; 5 morphological species (Daranagama et al. 2018), 1 species with sequence data. 

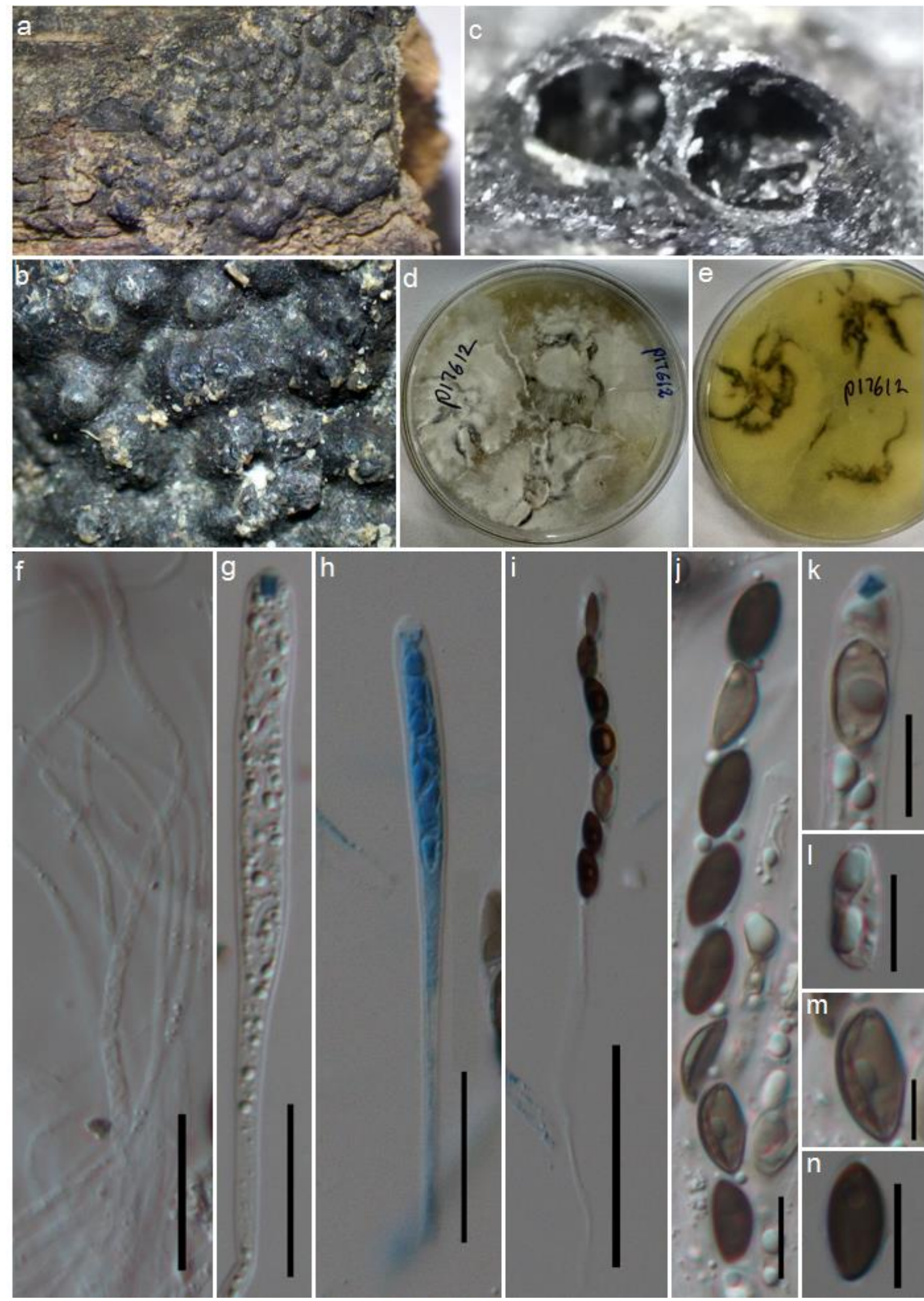

Figure 267 - Nemania bipapillata (Material examined - INDIA, Andaman and Nicobar Islands,

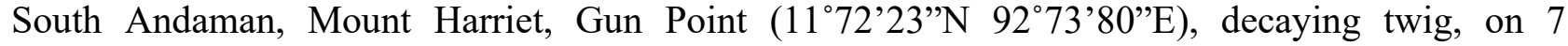
December, 2017, collected by M. Niranjan \& V.V.Sarma. Herbarium accession AMH-10074, Ajrekar Mycological Herbarium, Agarkar Research Institute (ARI), Pune, India; living culture

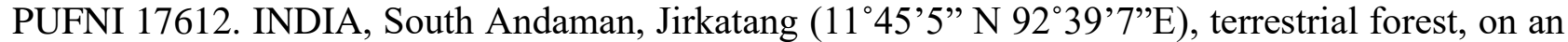
unidentified decaying twig 28 March 2017, collected by M. Niranjan \& V.V. Sarma (PUFNI T128F1) Fungal Biotechnology Lab, Department of Biotechnology, Pondicherry University inhouse herbarium code). a, b Stromata on host. c Stromata vertical section. d, e Culture on malt extract agar plates (d-from above, e-reverse). f Paraphyses. g-j Asci. k J+ apical ring. 1-n Ascospores. Scale bars: $\mathrm{i}=50 \mu \mathrm{m}, \mathrm{f}, \mathrm{h}=20 \mu \mathrm{m}, \mathrm{g}, \mathrm{j}-\mathrm{n}=10 \mu \mathrm{m}$. 

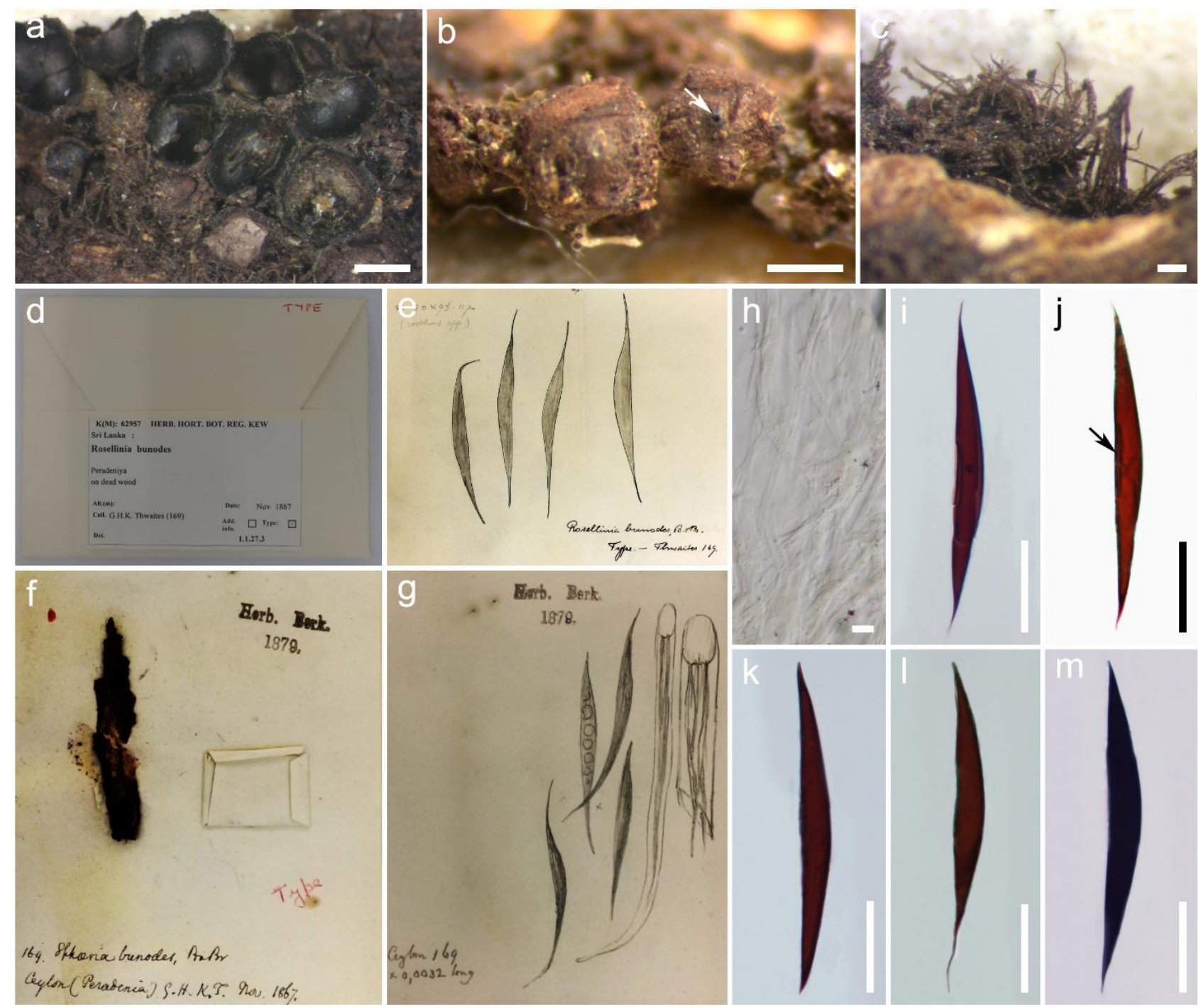

Figure 268 - Rosellinia bunodes (Material examined - SRI LANKA, Peradeniya, on dead wood, November 1867, G.H.K. Thwaites, K(M) 62957, holotype). a, b Stromata (b ostiole in white arrow). c Synnemata. d-g Herbarium details. h Paraphyses. i-m Ascospores (j germ slit in black arrow, $\mathrm{m}$ in $10 \% \mathrm{KOH})$. Scale bars: $\mathrm{a}=1000 \mu \mathrm{m}, \mathrm{b}=500 \mu \mathrm{m}, \mathrm{c}=200 \mu \mathrm{m}, \mathrm{i}-\mathrm{m}=20 \mu \mathrm{m}, \mathrm{h}=5 \mu \mathrm{m}$.

Type species - Sarcoxylon compunctum (Jungh.) Cooke

Notes - Sarcoxylon was established by Cooke (1883). Rogers (1981) maintained Sarcoxylon as a distinct genus apart from Hypoxylon, Entonaema and Xylaria. The genus is characterized by superficial, pulvinate to hemispherical to more or less upright stromata with a gelatinous zone beneath ascomatal layer, cylindrical, pedicellate asci with a $\mathrm{J}_{+}$, apical ring and unicellular, ellipsoid-inequilateral, brown ascospores. The phylogenetic studies of Senanayake et al. (2015), Daranagama et al. (2018) and Wendt et al. (2018) accepted Sarcoxylon in Xylariaceae.

Squamotubera Henn., Hedwigia 42(Beibl.): (308) (1903)

Index Fungorum number: IF5180; 1 morphological species (Daranagama et al. 2018).

Type species - Squamotubera le-ratii Henn.

Notes - Hennings (1903) erected the monotypic genus Squamotubera which is characterized by erect, cylindrical to clavate, unbranched stromata with fertile upper part and unicellular, ellipsoidal ascospores with one flattened side, sometimes bean-shaped, brown, with narrowly rounded ends and a spiral germ slit. Based on characters, Daranagama et al. (2018) and Wendt et al. (2018) accepted Squamotubera in Xylariaceae. 
Stilbohypoxylon Henn., Hedwigia 41: 16 (1902)

Index Fungorum number: IF5264; 11 morphological species (Daranagama et al. 2018), 2 species with sequence data.

Type species - Stilbohypoxylon moelleri Henn.

Notes - Hennings (1903) described the genus Stilbohypoxylon and tentatively placed it in Xylariaceae. Stilbohypoxylon has superficial, sphaerical stromata with a wrinkled surface (Rogers \& Ju 1997). Daranagama et al. (2018) and Wendt et al. (2018) accepted the genus in Xylariaceae based on morphology and phylogenetic studies.

Vamsapriya Gawas \& Bhat, Mycotaxon 94: 150 (2006)

Index Fungorum number: IF29041; 8 morphological species (Jiang et al. 2018), 6 species with sequence data.

Type species - Vamsapriya indica Gawas \& Bhat

Notes - Vamsapriya was introduced by Gawas \& Bhat (2005) based on asexual morph, and Dai et al. (2017) described the sexual morph for the genus. The sexual morph has solitary, scattered, immersed ascomata with papillate, ostiole, cylindrical, shortly pedicellate asci with a J+, apical ring, and fusiform, apiosporous, 1-septate, hyaline ascospores with pointed ends surrounded by inconspicuous sheath. The asexual morph has dark brown, erect, rigid, synnematous conidiophores, terminal or intercalary, monotretic, enteroblastic, dark brown, ellipsoidal conidiogenous cells and cylindrical, fusiform, straight to flexuous, brown to dark brown, 0-20septate, slightly verrucose conidia. Most of the species are described from bamboo (Dai et al. 2014a, 2017, Jiang et al. 2018). Based on phylogeny and morphology, Jiang et al. (2018) and Wendt et al. (2018) accepted the genus in Xylariaceae.

Virgaria Nees, Syst. Pilze (Würzburg): 54 (1816)

Index Fungorum number: IF10408; 11 morphological species (Species Fungorum 2020), 2 species with sequence data.

Type species - Virgaria nigra (Link) Nees

Notes - Virgaria is accepted over Ascovirgaria with its geniculosporium-like asexual morph (Rogers \& Ju 2002, Stadler et al. 2013, Maharachchikumbura et al. 2015b, Réblová et al. 2016b). The sexual morph is characterized by rudimentary stromata, globose ascomata, cylindrical, long pedicellate asci with a $\mathrm{J}+$, apical ring and unicellular, ellipsoid, brown ascospores. The genus is accepted in Xylariaceae (Daranagama et al. 2018, Wendt et al. 2018).

Wawelia Namysł., Bull. int. Acad. Sci. Lett. Cracovie, Cl. sci. math. nat. Sér. B, sci. nat. 2: 602 (1908)

Index Fungorum number: IF5764; 5 morphological species (Species Fungorum 2020), 1 species with sequence data.

Type species - Wawelia regia Namysł.

Notes - Wawelia was described based on W. regia, and originally placed in Hypocreaceae (Namyslowski 1908). With the introduction of more Wawelia species by Lundqvist (1992) and Webster et al. (1999) the genus was accepted in Xylariaceae. Wendt et al. (2018) confirmed the genus in Xylariaceae based on geniculosporium-like asexual morph.

Xylaria Hill ex Schrank, Baier. Fl. (München) 1: 200 (1789)

Index Fungorum number: IF5832; more than 670 morphological species (Species Fungorum 2020), 132 species with sequence data.

Type species - Xylaria hypoxylon (L.) Grev.

Notes - Mostly, species of Xylaria are characterized by large stromata, cylindrical asci with long stipes, ellipsoidal, dark ascospores in their sexual and geniculosporium-like asexual morph (Ju \& Rogers 1996, Stadler et al. 2013). Xylaria is a highly diversified genus, most likely exceeds 500 species (Peršoh et al. 2009). Most Xylaria species are saprobes growing on moist, decaying 
dicotyledonous wood and less often on monocotyledons, fruits, seeds and fallen leaves. The endophytic species are common in tropical plants. Interestingly, the subgenus Pseudoxylaria is associated with termite nests, mainly macrotermitine termites (Visser et al. 2009, Hsieh et al. 2010). Based on rDNA sequences data Arthroxylaria and Geniculisynnema were synonymised under Xylaria (Seifert et al. 2002, Okane \& Nakagiri 2007, Réblová et al. 2016b). The significant variations of the characters of Xylaria species might be the result of many convergent evolution within the genus (Lee et al. 2000).

Zygosporiaceae J.F. Li, Phookamsak \& K.D. Hyde, Mycosphere 8(10): 1860 (2017)

Index Fungorum number: IF553846; Facesoffungi number: FoF0376; 21 species.

Saprobic on various host plants, especially on monocotyledons. Sexual morph: Undetermined. Asexual morph: Hyphomycetous. Colonies effuse, white to light pink. Mycelium immersed or partly superficial, composed of smooth, thin-walled, white or light pink hyphae. Setae or setiform conidiophores with sphaerical apex. Conidiophores macronematous, mononematous, solitary or in small groups, pale brown, thin-walled, unbranched, septate, smooth, bearing swollen dark brown, thick-walled vesicles. Conidiogenous cells holoblastic, discrete, hyaline or light brown, smooth, sphaerical to ellipsoid, borne in groups of 2-4 on the vesicular cell. Conidia solitary, aseptate, hyaline or pale brown, globose or ellipsoid, thin- or thick-walled (adapted from Li et al. 2017b).

Type genus - Zygosporium Mont.

Notes - Zygosporiaceae was introduced by Li et al. (2017b) to accommodate a single genus Zygosporium. It was based on phylogenetic support as a distinct lineage and separated from other taxa in Xylariales using analysis of LSU and ITS sequence data. Species of Zygosporiaceae are saprobes on plant litter, especially on monocotyledons such as Pandanaceae and palms ( $\mathrm{Li}$ et al. 2017b).

\section{Ecological and economic significance of Zygosporiaceae}

Species are saprobes on a wide variety of plant substrates. Zygosporiaceae species are also sources of biologically active secondary metabolites (Hayakawa et al. 1968, Oh et al. 2006, Kanoh et al. 2008). For example, Zygosporium masonii is known for the production of cytochalasins (Hayakawa et al. 1968).

\section{Genus included in Zygosporiaceae}

Zygosporium Mont., Annls Sci. Nat., Bot., sér. 2 17: 120 (1842)

Index Fungorum number: IF10473; 21 morphological species (Species Fungorum 2020), 8 species with sequence data.

Type species - Zygosporium oscheoides Mont.

Notes - Zygosporium was introduced by Montagne (1842) with Z. oscheoides as the type species. Species are usually saprobes in temperate to tropical regions (Photita et al. 2001, Whitton et al. 2003, Manoharachary et al. 2006, McKenzie et al. 2007, Abbas et al. 2011, Pratibha et al. 2012, Taheriyan et al. 2014). Taxa are hyphomycetous (asexual morphs) with darkly pigmented colonies, incurved vesicular cells and globose or ellipsoid and smooth-walled or variously ornamented conidia (Mason 1941, Hughes 1951c). Sequence data are available only for $Z$. chartarum, Z. echinosporum, Z. gibbum, Z. masonii, Z. minus, Z. mycophilum, Z. oscheoides and Z. pseudogibbum. In this entry a new collection of Z. masonii from Dracaena is illustrated (Fig. 269).

\section{Placement of genera in orders incertae sedis}

Amphisphaeriales genera incertae sedis

Chitonospora E. Bommer, M. Rousseau \& Sacc., Bull. Soc. R. Bot. Belg. 29(no. 1): 270 (1890) Index Fungorum number: IF1003; 1 morphological species.

Type species - Chitonospora ammophila E. Bommer, M. Rousseau \& Sacc. 

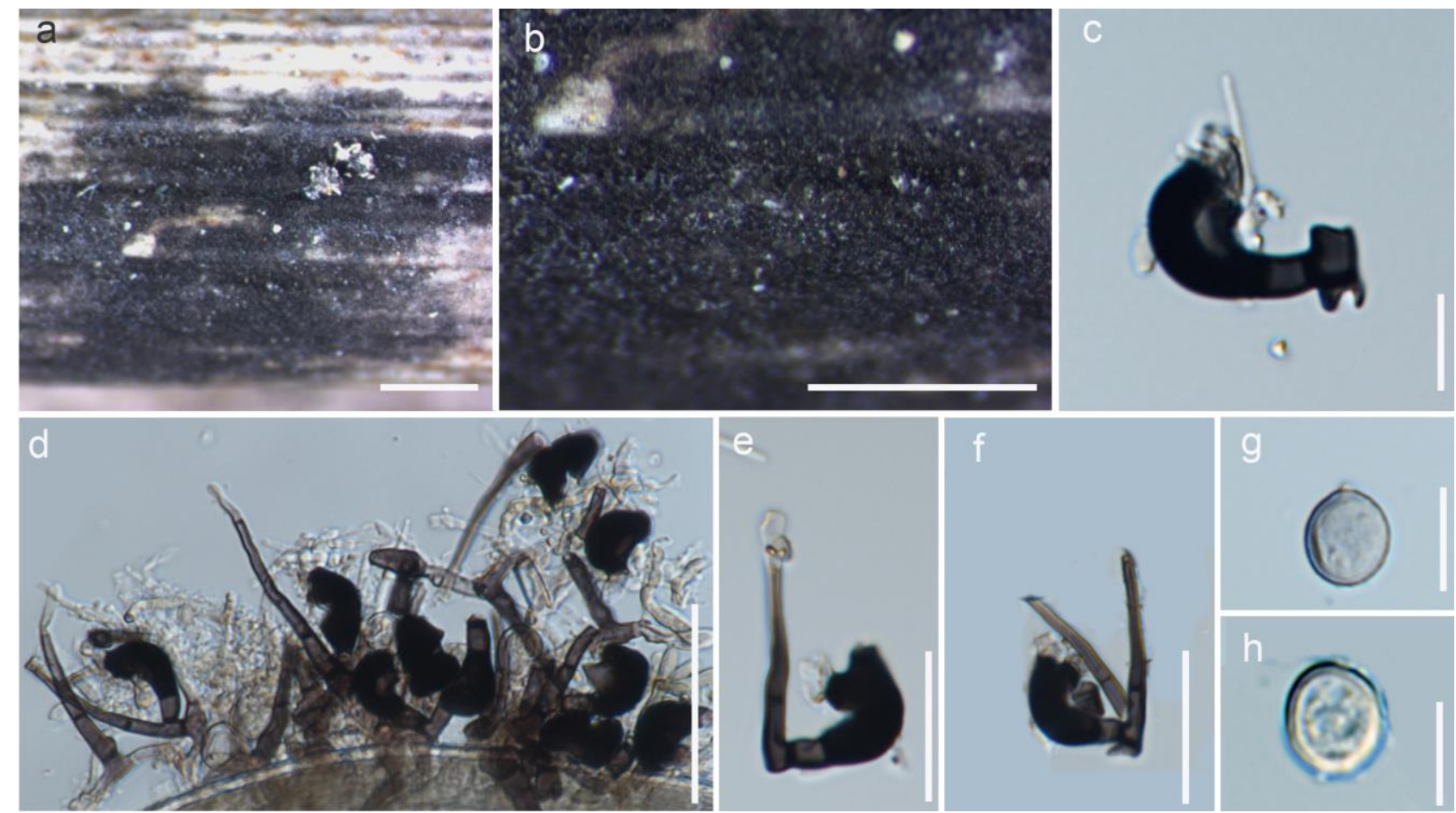

Figure 269 - Zygosporium masonii (Material examined - THAILAND, Songkhla Province, on dead leaves of Dracaena sp., 5 May 2018, Napalai Chaiwan NSW5, MFLU 18-0124). a, b Appearance on host surface. c-f Vesicle, conidiophores and conidiogenous cell. $\mathrm{g}$, $\mathrm{h}$ Conidia. Scale bars: $\mathrm{a}, \mathrm{b}=1000 \mu \mathrm{m}, \mathrm{c}, \mathrm{d}=50 \mu \mathrm{m}, \mathrm{e}, \mathrm{f}=20 \mu \mathrm{m}, \mathrm{g}, \mathrm{h}=10 \mu \mathrm{m}$.

Fasciatispora K.D. Hyde, Trans. Mycol. Soc. Japan 32(2): 265 (1991)

Index Fungorum number: IF14386; 10 morphological species (Species Fungorum 2020), 4 species with sequence data.

Type species - Fasciatispora nypae K.D. Hyde

Annulatascales genera incertae sedis

Clohiesia K.D. Hyde, Nova Hedwigia 61(1-2): 125 (1995)

Index Fungorum number: IF27574; 3 morphological species (Species Fungorum 2020), 1 species with sequence data.

Type species - Clohiesia corticola K.D. Hyde

Calosphaeriales genus incertae sedis

Calosphaeriopsis Petr., Annls mycol. 39(4/6): 272 (1941)

Index Fungorum number: IF754; 1 morphological species.

Type species - Calosphaeriopsis huberiana (Kirschst.) Petr.

Enchnoa Fr., Summa veg. Scand., Sectio Post. (Stockholm): 410 (1849)

Index Fungorum number: IF1778; 19 morphological species (Species Fungorum 2020).

Type species - Enchnoa lanata (Fr.) Fr.

Kacosphaeria Speg., Boln Acad. nac. Cienc. Córdoba 11(2): 214 (1887)

Index Fungorum number: IF2541; 1 morphological species.

Type species - Kacosphaeria antarctica Speg.

Sulcatistroma A.W. Ramaley, Mycotaxon 93: 140 (2005) 
Index Fungorum number: IF28974; 1 species with sequence data.

Type species - Sulcatistroma nolinae A.W. Ramaley

Chaetosphaeriales genera incertae sedis

Calvolachnella Marinc., T.A. Duong \& M.J. Wingf., Sydowia 68: 203 (2016)

Index Fungorum number: IF815619; 1 species with sequence data.

Type species - Calvolachnella guaviyunis (Marinc., T.A. Duong, M.J. Wingf. \& C.A. Perez) Marinc., T.A. Duong, M.J. Wingf.

Caudatispora J. Fröhl. \& K.D. Hyde, Sydowia 47(1): 38 (1995)

Index Fungorum number: IF27569; 2 morphological species (Species Fungorum 2020), 1 species with sequence data.

Type species - Caudatispora palmicola J. Fröhl. \& K.D. Hyde

Erythromada Huhndorf, A.N. Mill., F.A. Fernández \& Lodge, Fungal Divers. 20: 63 (2005)

Index Fungorum number: IF501320; 1 species with sequence data.

Type species - Erythromada lanciospora Huhndorf, A.N. Mill., F.A. Fernández \& Lodge

Lasiosphaeriella Sivan., Trans. Br. mycol. Soc. 64(3): 443 (1975)

Index Fungorum number: IF2657; 5 morphological species (Species Fungorum 2020), 3 species with sequence data.

Type species - Lasiosphaeriella dennisii Sivan.

Neoleptosporella Phukhams., Perera \& K.D. Hyde, Fungal Divers. (in prep)

Index Fungorum number: IF557060;1 species with sequence data.

Type species - Neoleptosporella clematidis Phukhams., Konta \& K.D. Hyde

Rimaconus Huhndorf, F.A. Fernández, Joanne E. Taylor \& K.D. Hyde, Mycologia 93(6): 1073 (2001)

Index Fungorum number: IF28573; 2 species with sequence data.

Type species - Rimaconus jamaicensis (Seaver) Huhndorf, F.A. Fernández, Joanne E. Taylor \& K.D. Hyde

Coniochaetales genera incertae sedis

Cannonia Joanne E. Taylor \& K.D. Hyde, Mycol. Res. 103(11): 1398 (1999)

Index Fungorum number: IF28356; 1 morphological species.

Type species - Cannonia australis (Speg.) Joanne E. Taylor \& K.D. Hyde

Pseudogliomastix W. Gams, Proc. Indian Acad. Sci., Pl. Sci. 94(2-3): 279 (1985)

Index Fungorum number: IF11172; 1 morphological species.

Type species - Pseudogliomastix protea (Sacc.) W. Gams

Coronophorales genera incertae sedis

Papulaspora Preuss, Linnaea 24: 112 (1851)

Index Fungorum number: IF9205; 33 morphological species (Species Fungorum 2020), 7 species with sequence data.

Type species - Papulaspora sepedonioides Preuss

Sphaerodes Clem., Gen. fung. (Minneapolis): 44 (1909) 
Index Fungorum number: IF 5099; 9 morphological species (Species Fungorum 2020), 4 species with sequence data.

Type species - Sphaerodes episphaerium (W. Phillips \& Plowr.) Clem.

Diaporthales genera incertae sedis

Ceratoporthe Petr., Annls mycol. 23(1/2): 14 (1925)

Index Fungorum number: IF894; 1 morphological species.

Type species - Ceratoporthe didymospora Petr.

Cryptoleptosphaeria Petr., Annls mycol. 21(3/4): 196 (1923)

Index Fungorum number: IF1319; 1 morphological species.

Type species - Cryptoleptosphaeria moravica Petr.

Cytomelanconis Naumov, Bot. Mater. Otd. Sporov. Rast. Bot. Inst. Komarova Akad. Nauk S.S.S.R. 7: 108 (1951)

Index Fungorum number: IF1396; 1 morphological species.

Type species - Cytomelanconis systema-solare Naumov

Diaporthella Petr., Annls mycol. 22(1/2): 30 (1924)

Index Fungorum number: IF1498; 1 species with sequence data.

Type species - Diaporthella aristata (Fr.) Petr.

Diatrypoidiella Manohar., Kunwar \& D.K. Agarwal, Indian Phytopath. 58(2): 205 (2005)

Index Fungorum number: IF29064; 1 morphological species.

Type species - Diatrypoidiella lignicola Manohar., Kunwar \& D.K. Agarwal

Ditopellina J. Reid \& C. Booth, Can. J. Bot. 45: 1481 (1967)

Index Fungorum number: IF1678; 1 morphological species.

Type species - Ditopellina saccardoana (Traverso \& Spessa) J. Reid \& C. Booth

Durispora K.D. Hyde, Sydowia 46(2): 315 (1994)

Index Fungorum number: IF27442; 2 morphological species (Species Fungorum 2020).

Type species - Durispora elaeidicola K.D. Hyde

Exormatostoma Gray, Nat. Arr. Brit. P1. (London) 1: 521 (1821)

Index Fungorum number: IF1965; 2 morphological species (Species Fungorum 2020).

Type species - Exormatostoma nebulosa (Pers.) Gray

Fremineavia Nieuwl., Am. Midl. Nat. 4: 501 (1916)

Index Fungorum number: IF2014; 1 morphological species.

Type species - Fremineavia berkeleyi (Berl.) Nieuwl.

Gibellia Sacc., Atti Inst. Veneto Sci. lett., ed Arti, Sér. 6 3: 714 (1885)

Index Fungorum number: IF2063; 1 morphological species.

Type species - Gibellia dothideoides Sacc. \& Berl.

Gyrostroma Naumov, Bull. Soc. mycol. Fr. 30(3): 386 (1914)

Index Fungorum number: IF8413; 3 morphological species (Species Fungorum 2020), 1 species with sequence data.

Type species - Gyrostroma sinuosum Naumov 
Hyalorostratum Raja \& Shearer, Mycosphere 1(4): 281 (2010)

Index Fungorum number: IF518893; 1 species with sequence data.

Type species - Hyalorostratum brunneisporum Raja \& Shearer

Hypophloeda K.D. Hyde \& E.B.G. Jones, Trans. Mycol. Soc. Japan 30(1): 61 (1989)

Index Fungorum number: IF25308; 1 morphological species.

Type species - Hypophloeda rhizospora K.D. Hyde \& E.B.G. Jones

Hypospilina (Sacc.) Traverso, Fl. ital. crypt., Pyrenomycetae (Florence): 495 (1913)

Index Fungorum number: IF2451; 4 morphological species (Species Fungorum 2020).

Type species - Hypospilina bifrons (DC.) Traverso

Kapooria J. Reid \& C. Booth, Can. J. Bot. 67(3): 898 (1989)

Index Fungorum number: IF25312; 1 morphological species.

Type species - Kapooria musarum (J.N. Kapoor) J. Reid \& C. Booth

Keinstirschia J. Reid \& C. Booth, Can. J. Bot. 67(3): 897 (1989)

Index Fungorum number: IF25314; 1 morphological species.

Type species - Keinstirschia megalosperma (Kirschst.) J. Reid \& C. Booth

Lollipopaia Inderb., Can. J. Bot. 79(9): 1100 (2001)

Index Fungorum number: IF28542; 1 species with sequence data.

Type species - Lollipopaia minuta Inderb.

Macrodiaporthe Petr., Annls mycol. 17(2/6): 94 (1920)

Index Fungorum number: IF2963; 1 morphological species.

Type species - Macrodiaporthe occulta (Fuckel) Petr. (三 Calospora occulta Fuckel)

Melanamphora Lafl., Sydowia 28(1-6): 243 (1976)

Index Fungorum number: IF3055; 1 morphological species.

Type species - Melanamphora spinifera (Wallr.) Lafl.

Phragmodiaporthe Wehm., Mycologia 33(1): 54 (1941)

Index Fungorum number: IF4024; 3 morphological species.

Type species - Phragmodiaporthe caryae (Peck) Wehm. (三Cryptospora caryae Peck)

Phruensis Pinruan, Mycologia 96(5): 1165 (2004)

Index Fungorum number: IF28878; 1 species with sequence data.

Type species - Phruensis brunneispora Pinruan

Plagiophiale Petr., Sydowia 9(1-6): 585 (1955)

Index Fungorum number: IF4154; 2 morphological species (Species Fungorum 2020). Type species - Plagiophiale eucarpa (P. Karst.) Petr.

Plagiostigme Syd., Annls mycol. 23(3/6): 341 (1925)

Index Fungorum number: IF4156; 7 morphological species (Species Fungorum 2020).

Type species - Plagiostigme couraliae Syd.

Prostratus Sivan., W.H. Hsieh \& Chi Y. Chen, Mycol. Res. 97(10): 1179 (1993)

Index Fungorum number: IF26496; 1 morphological species.

Type species - Prostratus cyclobalanopsidis Sivan., W.H. Hsieh \& Chi Y. Chen 
Pseudocryptosporella J. Reid \& C. Booth, Can. J. Bot. 47: 1058 (1969)

Index Fungorum number: IF4423; 1 morphological species.

Type species - Pseudocryptosporella polylepidis (E. Müll.) J. Reid \& C. Booth

Pseudothis Theiss. \& Syd., Annls mycol. 12(3): 274 (1914)

Index Fungorum number: IF4494; 11 morphological species.

Type species - Pseudothis machaerii (Rehm) Theiss. \& Syd.

Pseudovalsella Höhn., Annls mycol. 16(1/2): 123 (1918)

Index Fungorum number: IF4503; 2 morphological species (Species Fungorum 2020).

Type species - Pseudovalsella thelebola (Fr.) Höhn.

Savulescua Petr., cu Prilejul Implinirii a 70 de Ani (Bucuresti): 591 (1959)

Index Fungorum number: IF4871; 1 morphological species.

Type species - Savulescua insignis Petr.

Sphaerognomoniella Naumov \& Kusnezowa, Bot. Mater. Otd. Sporov. Rast. Bot. Inst. Komarova Akad. Nauk S.S.S.R. 8: 153 (1952)

Index Fungorum number: IF5101; 1 morphological species.

Type species - Sphaerognomoniella cornicola Naumov \& Kusnezowa

Stioclettia Dennis, Kew Bull. 30(2): 362 (1975)

Index Fungorum number: IF5267; 1 morphological species.

Type species - Stioclettia luzulina Dennis

Trematovalsa Jacobesco, C. r. hebd. Séanc. Acad. Sci., Paris 142: 290 (1906)

Index Fungorum number: IF5526; 1 morphological species.

Type species - Trematovalsa matruchotii Iacobescu

Wehmeyera J. Reid \& C. Booth, Can. J. Bot. 67(3): 895 (1989)

Index Fungorum number: IF25349; 1 morphological species.

Type species - Wehmeyera acerina (Wehm.) J. Reid \& C. Booth

Glomerellales genera incertae sedis

Ascocodinaea Samuels, Cand. \& Magni, Mycologia 89(1): 156 (1997)

Index Fungorum number: IF27833; 2 morphological species (Species Fungorum 2020), 1 species with sequence data.

Type species - Ascocodinaea stereicola Samuels, Cand. \& Magni

Hypocreales genera incertae sedis

Acremoniopsis A. Giraldo, Gené \& Guarro, Persoonia 33: 265 (2014)

Index Fungorum number: IF809883; 1 species with sequence data.

Type species - Acremoniopsis suttoniae A. Giraldo, Gené \& Guarro

Berkelella (Sacc.) Sacc., Syll. fung. (Abellini) 9: 989 (1891)

Index Fungorum number: IF549; 3 morphological species (Species Fungorum 2020).

Type species - Berkelella caledonica (Pat.) Sacc.

Bulbithecium Udagawa \& T. Muroi, Bull. natn. Sci. Mus., Tokyo, B 16(1): 13 (1990)

Index Fungorum number: IF25501; 1 species with sequence data. 
Type species - Bulbithecium hyalosporum Udagawa \& T. Muroi

Cephalosporiopsis Peyronel, Mém. R. Accad. Sci. Torino, Ser. 2 66(no. 10): 52 (1916)

Index Fungorum number: IF7524; 7 morphological species (Species Fungorum 2020).

Type species - Cephalosporiopsis alpina (Peyronel) Peyronel

Chondronectria Etayo, Flakus \& Kukwa, Opera Lilloana 50: 130 (2017)

Index Fungorum number: IF818310; 1 morphological species.

Type species - Chondronectria eriodermaticola Etayo, Flakus \& Kukwa

Cylindronectria Etayo, Opera Lilloana 50: 154 (2017)

Index Fungorum number: IF818315; 1 morphological species

Type species - Cylindronectria cyanobacteriicola Etayo

Diploospora Grove, J. Bot., Lond. 54: 220 (1916)

Index Fungorum number: IF622352; 6 morphological species (Species Fungorum 2020), 2 species with sequence data.

Type species - Diploospora rosea Grove

Gynonectria Döbbeler, Mycol. Progr. 11(2): 474 (2012)

Index Fungorum number: IF582708; 1 morphological species.

Type species - Gynonectria intraspora Döbbeler

Hapsidospora Malloch \& Cain, Can. J. Bot. 48(10): 1819 (1970)

Index Fungorum number: IF2243; 2 morphological species (Species Fungorum 2020), 1 species with sequence data.

Type species - Hapsidospora irregularis Malloch \& Cain

Haptospora G.L. Barron, Can. J. Bot. 69(3): 503 (1991)

Index Fungorum number: IF25554; 3 morphological species (Species Fungorum 2020).

Type species - Haptospora appendiculata G.L. Barron

Illosporiopsis D. Hawksw., Mycol. Res. 105(4): 457 (2001)

Index Fungorum number: IF28491; 1 morphological species.

Type species - Illosporiopsis christiansenii (B.L. Brady \& D. Hawksw.) D. Hawksw.

Illosporium Mart., Fl. crypt. erlang. (Nürnberg): 325 (1817)

Index Fungorum number: IF8626; 49 morphological species (Species Fungorum 2020), 1

species with sequence data.

Type species - Illosporium roseum Mart.

Leptobarya Etayo, Opera Lilloana 50: 214 (2017)

Index Fungorum number: IF818327; 2 morphological species (Species Fungorum 2020).

Type species - Leptobarya nigra Etayo

Lichenopenicillus Etayo, Opera Lilloana 50: 248 (2017)

Index Fungorum number: IF818339; 1 morphological species.

Type species - Lichenopenicillus versicolor Etayo

Metadothella Henn., Hedwigia 43(6): 384 (1904)

Index Fungorum number: IF3140; 1 morphological species.

Type species - Metadothella stellata Henn. 
Munkia Speg., Anal. Soc. cient. argent. 22(4): 202 (1886)

Index Fungorum number: IF9010; 4 morphological species (Species Fungorum 2020).

Type species - Munkia martyris Speg.

Neomunkia Petr., Sydowia 1(4-6): 329 (1947)

Index Fungorum number: IF9105; 1 species with sequence data.

Type species - Neomunkia sydowii Petr.

Peloronectria Möller, Bot. Mitt. Trop. 9: 297 (1901)

Index Fungorum number: IF3788; 3 morphological species (Species Fungorum 2020).

Type species - Peloronectria vinosa Möller

Pseudoacremonium Crous, Persoonia 32: 241 (2014)

Index Fungorum number: IF808925; 1 species with sequence data.

Type species - Pseudoacremonium sacchari Crous

Pseudoidriella Crous \& R.G. Shivas .

Index Fungorum number: IF560696; 1 species with sequence data.

Type species - Pseudoidriella syzygii Crous \& R.G. Shivas

Pseudomeliola Speg., Boln Acad. nac. Cienc. Córdoba 11(4): 522 (1889)

Index Fungorum number: IF4456; 10 morphological species (Species Fungorum 2020).

Type species - Pseudomeliola brasiliensis Speg.

Rodentomyces Doveri, Pecchia, Sarrocco \& Vannacci, Index Fungorum 307: 7 (2016)

Index Fungorum number: IF552580; 1 species with sequence data.

Type species - Rodentomyces reticulatus Doveri, Pecchia, Sarrocco \& Vannacci

Roselliniella Vain., Acta Soc. Fauna Flora fenn. 49(no. 2): 77 (1921)

Index Fungorum number: IF4786; 19 morphological species (Species Fungorum 2020), 2 species with sequence data.

Type species - Roselliniella nephromatis (P. Crouan \& H. Crouan) Matzer \& Hafellner

Saksenamyces A.N. Rai \& P.N. Singh, Mycotaxon 133(3): 424 (2018)

Index Fungorum number: IF821284; 1 morphological species.

Type species - Saksenamyces kamalii Surywanshi, A.N. Rai \& P.N. Singh

Sedecimiella K.L. Pang, Alias \& E.B.G. Jones, Bot. Mar. 53(6): 495 (2010)

Index Fungorum number: IF518530; 1 species with sequence data.

Type species - Sedecimiella taiwanensis K.L. Pang

Stanjemonium W. Gams, O'Donnell, Schroers \& M. Chr., Can. J. Bot. 76(9): 1579 (1999)

Index Fungorum number: IF27934; 4 morphological species (Species Fungorum 2020), 4 species with sequence data.

Type species - Stanjemonium grisellum W. Gams, Schroers \& M. Chr.

Stilbella Lindau, Nat. Pflanzenfam., Teil. I (Leipzig) 1(1**): 489 (1900)

Index Fungorum number: IF10110; 68 morphological species (Species Fungorum 2020), 3

species with sequence data.

Type species - Stilbella fimetaria (Pers.) Lindau

Ticonectria Döbbeler, Nova Hedwigia 66(3-4): 362 (1998) 
Index Fungorum number: IF27898; 3 morphological species (Species Fungorum 2020).

Type species - Ticonectria perianthii Döbbeler

Tilakidium Vaidya, C.D. Naik \& Rathod, Indian J. Mycol. Plant Path. 16(2): 115 (1986)

Index Fungorum number: IF25210; 1 morphological species.

Type species - Tilakidium indicum Vaidya, C.D. Naik \& Rathod

Microascales genera incertae sedis

Bisporostilbella Brandsb. \& E.F. Morris, Mycologia 63(5): 1078 (1971)

Index Fungorum number: IF7379; 1 species with sequence data.

Type species - Bisporostilbella fusca Brandsb. \& E.F. Morris

Cephalotrichiella Crous, Persoonia 32: 279 (2014)

Index Fungorum number: IF808954; 1 species with sequence data.

Type species - Cephalotrichiella penicillata Crous

Cornuvesica C.D. Viljoen, M.J. Wingf. \& K. Jacobs, Mycol. Res. 104(3): 366 (2000)

Index Fungorum number: IF28384; 4 species with sequence data.

Jacobs

Type species - Cornuvesica falcata (E.F. Wright \& Cain) C.D. Viljoen, M.J. Wingf. \& K.

Gabarnaudia Samson \& W. Gams, Stud. Mycol. 6: 88 (1974)

Index Fungorum number: IF8302; 2 species with sequence data.

Type species - Gabarnaudia betae (Delacr.) Samson \& W. Gams

Sporendocladia G. Arnaud ex Nag Raj \& W.B. Kendr., Monogr. Chalara Allied Genera (Waterloo): 162 (1975)

Index Fungorum number: IF10020; 6 morphological species (Species Fungorum 2020), 3 species with sequence data.

Type species - Sporendocladia castaneae G. Arnaud ex Nag Raj \& W.B. Kendr.

Phyllachorales genus incertae sedis

Marinosphaera K.D. Hyde, Can. J. Bot. 67(10): 3080 (1989)

Index Fungorum number: IF25372; 1 morphological species.

Type species - Marinosphaera mangrovei K.D. Hyde

Sordariales genera incertae sedis

Abyssomyces Kohlm., Ber. dt. bot. Ges. 83(9-10): 505 (1970)

Index Fungorum number: IF6; 1 morphological species.

Type species - Abyssomyces hydrozoicus Kohlm.

Acanthotheciella Höhn., Sber. Akad. Wiss. Wien, Math.-naturw. Kl., Abt. 1 120: 451 (1911)

Index Fungorum number: IF22; 3 morphological species (Species Fungorum 2020).

Type species - Acanthotheciella barbata (Pat.) Höhn.

Ascolacicola Ranghoo \& K.D. Hyde, Mycologia 90(6): 1055 (1998)

Index Fungorum number: IF27878; 2 morphological species (Species Fungorum 2020), 1 species with sequence data.

Type species - Ascolacicola aquatica Ranghoo \& K.D. Hyde 
Bombardiella Höhn., Sber. Akad. Wiss. Wien, Math.-naturw. Kl., Abt. 1 118: 1192 (1909) Index Fungorum number: IF618; 1 morphological species.

Type species - Bombardiella caespitosa Höhn.

Coronatomyces Dania García, Stchigel \& Guarro, Stud. Mycol. 50(1): 144 (2004)

Index Fungorum number: IF500037; 1 species with sequence data.

Type species - Coronatomyces cubensis Dania García, Stchigel \& Guarro

Cuspidatispora Shearer \& Bartolata, Mycoscience 47(4): 220 (2006)

Index Fungorum number: IF29051; 1 species with sequence data.

Type species - Cuspidatispora xiphiago Shearer \& Bartolata

Globosphaeria D. Hawksw., Lichenologist 22(3): 301 (1990)

Index Fungorum number: IF25444; 1 morphological species.

Type species - Globosphaeria jamesii D. Hawksw.

Isia D. Hawksw \& Manohar., Trans. Br. mycol. Soc. 71(2): 332 (1978)

Index Fungorum number: IF2510; 2 morphological species (Species Fungorum 2020), 1 species with sequence data.

Type species - Isia neocaledoniensis (C. Moreau) D. Hawksw. \& Manohar.

Lasiosphaeris Clem., Gen. fung. (Minneapolis): 35 (1909)

Index Fungorum number: IF2659; 3 morphological species (Species Fungorum 2020), 1 species with sequence data.

Type species - Lasiosphaeris hispida (Tode) Clem.

Lunulospora Ingold, Trans. Br. mycol. Soc. 25(4): 408 (1942)

Index Fungorum number: IF8795; 2 species with sequence data.

Type species - Lunulospora curvula Ingold

Lockerbia K.D. Hyde, Sydowia 46(1): 23 (1994)

Index Fungorum number: IF27284; 2 morphological species (Species Fungorum 2020).

Type species - Lockerbia palmicola K.D. Hyde

Nitschkiopsis Nannf. \& R. Sant., Svensk bot. Tidskr. 69: 322 (1975)

Index Fungorum number: IF3516; 1 morphological species.

Type species - Nitschkiopsis stictarum Nannf. \& R. Sant.

Onygenopsis Henn., Ann. Jard. Bot. Buitenzorg, Treub-Festschr., suppl. III 23: 64 (1910)

Index Fungorum number: IF3575; 1 morphological species.

Type species - Onygenopsis engleriana Henn.

Phaeosporis Clem., Gen. fung. (Minneapolis): 39 (1909)

Index Fungorum number: IF3954; 4 morphological species (Species Fungorum 2020).

Type species - Phaeosporis melasperma (Nyl.) Clem.

Reconditella Matzer \& Hafellner, Biblthca Lichenol. 37: 46 (1990)

Index Fungorum number: IF25462; 1 morphological species.

Type species - Reconditella physconiarum Hafellner \& Matzer

Rhexodenticula W.A. Baker \& Morgan-Jones, Mycotaxon 79: 363 (2001) 
Index Fungorum number: IF28519; 4 morphological species (Species Fungorum 2020), 2 species with sequence data.

Type species - Rhexodenticula cylindrospora (R.F. Castañeda, Saikawa \& Hennebert) W.A. Baker \& Morgan-Jones

Rhexosporium Udagawa \& Furuya, Trans. Mycol. Soc. Japan 18: 302 (1977)

Index Fungorum number: IF4698; 1 morphological species.

Type species - Rhexosporium terrestre Udagawa \& Furuya

Roselliniomyces Matzer \& Hafellner, Biblthca Lichenol. 37: 91 (1990)

Index Fungorum number: IF25464; 2 morphological species (Species Fungorum 2020).

Type species - Roselliniomyces trichotheliorum Matzer \& Hafellner

Roselliniopsis Matzer \& Hafellner, Biblthca Lichenol. 37: 97 (1990)

Index Fungorum number: IF25465; 7 morphological species (Species Fungorum 2020).

Type species - Roselliniopsis groedensis (Zopf) Matzer \& Hafellner

Stromatographium Höhn., Denkschr. Kaiserl. Akad. Wiss., Math.-Naturwiss. Kl. 83: 37 (1907)

Index Fungorum number: IF10129; 2 morphological species (Species Fungorum 2020).

Type species - Stromatographium stromaticum (Berk.) Höhn.

Utriascus Réblová, Mycologia 95(1): 128 (2003)

Index Fungorum number: IF28700; 1 morphological species.

Type species - Utriascus gabretae Réblová

Ypsilonia Lév., Annls Sci. Nat., Bot., sér. 3 5: 284 (1846)

Index Fungorum number: IF10464; 3 morphological species (Species Fungorum 2020).

Type species - Ypsilonia cuspidata Lév.

Xylariales genera incertae sedis

Adomia S. Schatz, Trans. Br. mycol. Soc. 84(3): 555 (1985)

Index Fungorum number: IF82; 1 morphological species.

Type species - Adomia avicenniae S. Schatz

Alloanthostomella Daranag., Camporesi \& K.D. Hyde, Cryptog. Mycol. 37(4): 518 (2016)

Index Fungorum number: IF552371; 1 species with sequence data.

Type species - Alloanthostomella rubicola (Speg. ex Sacc. \& Trotter) Daranag., Camporesi \& K.D. Hyde

Anungitea B. Sutton, Mycol. Pap. 132: 10 (1973)

Index Fungorum number: IF7181; 20 morphological species (Species Fungorum 2020), 6 species with sequence data.

Type species - Anungitea fragilis B. Sutton

Ascotrichella Valldos. \& Guarro, Trans. Br. mycol. Soc. 90(4): 601 (1988)

Index Fungorum number: IF25217; 1 morphological species.

Type species - Ascotrichella hawksworthii Valldos. \& Guarro

Basifimbria Subram. \& Lodha, Curr. Sci. 37: 247 (1968)

Index Fungorum number: IF7338; 1 morphological species.

Type species - Basifimbria aurea Subram. \& Lodha 
Biporispora J.D. Rogers, Y.M. Ju \& Cand., Nova Hedwigia 68(3-4): 421 (1999)

Index Fungorum number: IF28322; 1 morphological species.

Type species - Biporispora europaea J.D. Rogers, Y.M. Ju \& Cand.

Castellaniomyces Senan., Camporesi \& K.D. Hyde, Fungal Divers. 87: 183 (2017)

Index Fungorum number: IF553639; 1 species with sequence data.

Type species - Castellaniomyces rosae Senan., \& K.D. Hyde

Chaenocarpus Rebent., Prodr. fl. neomarch. (Berolini): 350 (1804)

Index Fungorum number: IF930; 3 morphological species (Species Fungorum 2020).

$3: 12 \mathrm{a}-\mathrm{b}$

Type species - Chaenocarpus setosus Rebent., Prodr. fl. neomarch. (Berolini): 350, tab.

Circinotrichum Nees, Syst. Pilze (Würzburg): 19 (1816)

Index Fungorum number: IF7667; 16 morphological species (Species Fungorum 2020), 4 species with sequence data.

Type species - Circinotrichum maculiforme Nees

Cryptostroma P.H. Greg. \& S. Waller, Trans. Br. mycol. Soc. 34(4): 593 (1952)

Index Fungorum number: IF7839; 1 species with sequence data.

Type species - Cryptostroma corticale (Ellis \& Everh.) P.H. Greg. \& S. Waller

Cyanopulvis J. Fröhl. \& K.D. Hyde, Fungal Divers. Res. Ser. 3: 308 (2000)

Index Fungorum number: IF28469; 1 morphological species.

Type species - Cyanopulvis australiensis J. Fröhl. \& K.D. Hyde

Diamantinia A.N. Mill., Læssøe \& Huhndorf, Sydowia 55(1): 94 (2003)

Index Fungorum number: IF28693; 1 species with sequence data.

Type species - Diamantinia citrina A.N. Mill., Læssøe \& Huhndorf

Gigantospora B.S. Lu \& K.D. Hyde, Nova Hedwigia 76(1-2): 202 (2003)

Index Fungorum number: IF28792; 1 morphological species.

Type species - Gigantospora gigaspora B.S. Lu \& K.D. Hyde

Guestia G.J.D. Sm. \& K.D. Hyde, Fungal Divers. 7: 107 (2001)

Index Fungorum number: IF28525; 1 morphological species.

Type species - Guestia gonetropospora G.J.D. Sm. \& K.D. Hyde

Gyrothrix (Corda) Corda, Anleit. Stud. Mykol., Prag: LXIII, 49 (1842)

Index Fungorum number: IF8414; 22 morphological species (Species Fungorum 2020), 6 species with sequence data.

Type species - Gyrothrix podosperma (Corda) Rabenh

Hadrotrichum Fuckel, Fungi rhenani exsic., suppl., fasc.: no. 1522 (1865)

Index Fungorum number: IF8419; 15 morphological species (Species Fungorum 2020), 2 species with sequence data.

Type species - Hadrotrichum phragmitis Fuckel

Idriellopsis Hern.-Restr. \& Crous, Persoonia 36: 76 (2015)

Index Fungorum number: IF811882; 1 species with sequence data.

Crous

Type species - Idriellopsis uncinospora (R.F. Castañeda \& W.B. Kendr.) Hern.-Restr. \& 
Kirstenboschia Quaedvl., Verkley \& Crous, Stud. Mycol. 75: 385 (2013)

Index Fungorum number: IF804467; 1 species with sequence data.

Type species - Kirstenboschia diospyri Quaedvl., Verkley \& Crous

Lanceispora Nakagiri, Okane, Tad. Ito \& Katum., Mycoscience 38(2): 208 (1997)

Index Fungorum number: IF27737; 2 morphological species (Species Fungorum 2020), 1 species with sequence data.

Type species - Lanceispora amphibia Nakagiri, Okane, Tad. Ito \& Katum.

Lasiobertia Sivan., Trans. Br. mycol. Soc. $70(3)$ : 383 (1978)

Index Fungorum number: IF2647; 2 morphological species (Species Fungorum 2020), 1 species with sequence data.

Type species - Lanceispora amphibia Nakagiri, Okane, Tad. Ito \& Katum.

Leptomassaria Petr., Annls mycol. 12(5): 474 (1914)

Index Fungorum number: IF2779; 4 morphological species.

Type species - Leptomassaria simplex (Nitschke ex G.H. Otth) Petr.

Neoanthostomella D.Q. Dai \& K.D. Hyde, Fungal Divers. 82(1), 1-105 (2017)

Index Fungorum number: IF552041; 2 species with sequence data.

Type species - Neoanthostomella pseudostromatica D.Q. Dai \& K.D. Hyde

Neoidriella Hern.-Restr. \& Crous, Persoonia 36: 78 (2015)

Index Fungorum number: IF811884; 1 species with sequence data.

Type species - Neoidriella desertorum (Nicot \& Mouch.) M. Hern.-Restr. \& Crous

Nipicola K.D. Hyde, Cryptog. Bot. 2(4): 330 (1992)

Index Fungorum number: IF26307; 4 morphological species (Species Fungorum 2020).

Type species - Nipicola carbospora K.D. Hyde

Occultitheca J.D. Rogers \& Y.M. Ju, Sydowia 55(2): 359 (2003)

Index Fungorum number: IF26307; 1 morphological species.

Type species - Occultitheca costaricensis J.D. Rogers \& Y.M. Ju

Ophiorosellinia J.D. Rogers, A. Hidalgo, F.A. Fernández \& Huhndorf, Mycologia 96(1): 172 (2004)

Index Fungorum number: IF28822; 1 morphological species.

Type species - Ophiorosellinia costaricensis J.D. Rogers, A. Hidalgo, F.A. Fernández \& Huhndorf

Palmicola K.D. Hyde, Sydowia 45(1): 15 (1993)

Index Fungorum number: IF22434; 4 morphological species (Species Fungorum 2020).

Type species - Palmicola archontophoenicis K.D. Hyde

Pandanicola K.D. Hyde, Sydowia 46(1): 35 (1994)

Index Fungorum number: IF22419; 2 morphological species (Species Fungorum 2020).

Type species - Pandanicola calocarpa (Syd. \& P. Syd.) K.D. Hyde

Paraidriella Hern.-Restr. \& Crous, Persoonia 37: 79 (2015)

Index Fungorum number: IF811886; 1 species with sequence data.

Type species - Paraidriella jambosae (R.F. Castañeda \& W.B. Kendr.) M. Hern.-Restr. \& Crous 
Paramphisphaeria F.A. Fernández, J.D. Rogers, Y.M. Ju, Huhndorf \& L. Umaña, Mycologia 96(1): 175 (2004)

Index Fungorum number: IF28823; 1 morphological species.

Type species - Paramphisphaeria costaricensis F.A. Fernández, J.D. Rogers, Y.M. Ju, Huhndorf \& Umaña

Paraphysalospora Crous, Persoonia 39: 373 (2017)

Index Fungorum number: IF823380; 1 species with sequence data.

Type species - Paraphysalospora eucalypti Crous

Paucithecium Lloyd, Mycol. Notes (Cincinnati) 7(4): 1200 (1923)

Index Fungorum number: IF3774; 1 morphological species.

Type species - Paucithecium rickii Lloyd

Pidoplitchkoviella Kiril., Mikrobiol. Zh. 37(5): 603 (1975)

Index Fungorum number: IF4097; 1 species with sequence data.

Type species - Pidoplitchkoviella terricola Kiril.

Polyancora Voglmayr \& Yule, Mycol. Res. 110(10): 1247 (2006)

Index Fungorum number: IF500689; 1 species with sequence data.

Type species - Polyancora globosa Voglmayr \& Yule

Polyscytalum Riess, Bot. Ztg. 11: 138 (1853)

Index Fungorum number: IF9508; 21 morphological species, 4 species with sequence data.

Type species - Polyscytalum fecundissimum Riess

Poroleprieuria M.C. González, Hanlin, Ulloa \& Elv. Aguirre, Mycologia 96(3): 676 (2004) Index Fungorum number: IF28828; 1 morphological species.

Type species - Poroleprieuria rogersii M.C. González, Hanlin, Ulloa \& Elv. Aguirre

Pseudoanthostomella Daranag., Camporesi \& K.D. Hyde, Cryptog. Mycol. 37(4): 527 (2016) Index Fungorum number: IF552377; 4 species with sequence data.

Type species - Pseudoanthostomella pini-nigrae Daranag., Camporesi \& K.D. Hyde

Pseudophloeospora Crous \& R.G. Shivas, Persoonia 25: 141 (2010)

Index Fungorum number: IF517539; 4 species with sequence data.

Type species - Pseudophloeospora eucalypti Crous \& R.G. Shivas

Pulmosphaeria Joanne E. Taylor, K.D. Hyde \& E.B.G. Jones, Sydowia 48(2): 256 (1996)

Index Fungorum number: IF27728; 1 morphological species.

Jones

Type species - Pulmosphaeria archontophoenicis Joanne E. Taylor, K.D. Hyde \& E.B.G.

Pyriformiascoma Daranag., Camporesi \& K.D. Hyde, Fungal Divers. 73: 230 (2015)

Index Fungorum number: IF809526; 1 species with sequence data.

Type species - Pyriformiascoma trilobatum Daranag., Camporesi \& K.D. Hyde

Roselymyces Fiuza, C.R. Silva, R.F. Castañeda \& Gusmão, Sydowia 70: 60 (2018)

Index Fungorum number: IF822003; 1 morphological species.

Type species - Roselymyces brasiliensis Fiuza, C.R. Silva, R.F. Castañeda \& Gusmão

Sabalicola K.D. Hyde, Nova Hedwigia 60(3-4): 596 (1995) 
Index Fungorum number: IF27636; 1 morphological species.

Type species - Sabalicola sabalensioides (Ellis \& G. Martin) K.D. Hyde

Spirodecospora B.S. Lu, K.D. Hyde \& W.H. Ho, Fungal Divers. Res. Ser. 1: 170 (1998)

Index Fungorum number: IF27893; 2 morphological species (Species Fungorum 2020).

Type species - Spirodecospora bambusicola B.S. Lu, K.D. Hyde \& W.H. Ho

Sporidesmina Subram. \& Bhat, Kavaka 15(1-2): 69 (1989)

Index Fungorum number: IF11053; 1 species with sequence data.

Type species - Sporidesmina malabarica Subram. \& Bhat

Striatodecospora D.Q. Zhou, K.D. Hyde \& B.S. Lu, Mycotaxon 76: 142 (2000)

Index Fungorum number: IF28472; 1 morphological species.

Type species - Striatodecospora bambusae D.Q. Zhou, K.D. Hyde \& B.S. Lu

Stromatoneurospora S.C. Jong \& E.E. Davis, Mycologia 65(2): 459 (1973)

Index Fungorum number: IF5289; 2 morphological species (Species Fungorum 2020), 1 species with sequence data.

Type species - Stromatoneurospora phoenix (Kunze) S.C. Jong \& E.E. Davis

Surculiseries Okane, Nakagiri \& Tad. Ito, Mycoscience 42(1): 116 (2001)

Index Fungorum number: IF28496; 1 species with sequence data.

Type species - Surculiseries rugispora Okane, Nakagiri \& Tad. Ito

Synnemadiella Crous \& M.J. Wingf., Persoonia 37: 339 (2016)

Index Fungorum number: IF819088; 1 species with sequence data.

Type species - Synnemadiella eucalypti Crous \& M.J. Wingf.

Tristratiperidium Daranag., Camporesi \& K.D. Hyde, Mycol. Progr. 15(no. 8): 4 (2015)

Index Fungorum number: IF551386; 1 species with sequence data.

Type species - Tristratiperidium microsporum Daranag., Camporesi \& K.D.Hyde

Xylocrea Möller, Bot. Mitt. Trop. 9: 307 (1901)

Index Fungorum number: IF5840; 2 morphological species.

Type species - Xylocrea piriformis Möller

Xylotumulus J.D. Rogers, Y.M. Ju \& Hemmes, Sydowia 58(2): 291 (2006)

Index Fungorum number: IF522310; 1 species with sequence data.

Type species - Xylotumulus gibbisporus J.D. Rogers, Y.M. Ju \& Hemmes

Yuea O.E. Erikss., Mycotaxon 85: 314 (2003)

Index Fungorum number: IF28721; 1 morphological species.

Type species - Yuea chusqueicola O.E. Erikss.

\section{Placement of genera in Subclasses incertae sedis}

Diaporthomycetidae genera incertae sedis

Aquapteridospora Jiao Yang, K.D. Hyde \& Maharachch., Cryptog. Mycol. 36(4): 474 (2015)

Index Fungorum number: IF551731; 2 species with sequence data.

Type species - Aquapteridospora lignicola J. Yang, K.D. Hyde \& Maharachch. 
Aquaticola W.H. Ho, C.K.M. Tsui, Hodgkiss \& K.D. Hyde, Fungal Divers. Res. Ser. 3: 88 (1999) Index Fungorum number: IF28389; 4 morphological species (Species Fungorum 2020), 1 species with sequence data.

Type species - Aquaticola hyalomura W.H. Ho, K.M. Tsui, Hodgkiss \& K.D. Hyde

Fusoidispora Vijaykr., Jeewon \& K.D. Hyde, Sydowia 57(2): 272 (2005)

Index Fungorum number: IF28975; 1 species with sequence data.

Type species - Fusoidispora aquatica Vijaykr., Jeewon \& K.D. Hyde

Platytrachelon Réblová, Mycologia 105(2): 466 (2013)

Index Fungorum number: IF800340; 1 species with sequence data.

Type species - Platytrachelon abietis (Réblová) Réblová

Proliferophorum G.N. Wang, H. Zhang \& Senan., Fungal Divers. 9: 128 (2019)

Index Fungorum number: IF555401; 1 species with sequence data.

Type species - Proliferophorum thailandicum G.N. Wang, H. Zhang \& Senan.

Pseudostanjehughesia J. Yang \& K.D. Hyde, Mycol. Progr. 17(5): 609 (2017)

Index Fungorum number: IF821274; 2 species with sequence data.

Type species - Pseudostanjehughesia aquitropica J. Yang \& K.D. Hyde

Hypocreomycetidae genera incertae sedis

Campylospora Ranzoni, Farlowia 4(3): 373 (1953)

Index Fungorum number: IF7482; 5 morphological species (Species Fungorum 2020), 5 species with sequence data.

Type species - Campylospora chaetocladia Ranzoni

Dendroclathra Voglmayr \& G. Delgado, Can. J. Bot. 79(9): 995 (2001)

Index Fungorum number: IF28541; 2 species with sequence data.

Type species - Dendroclathra caeruleofusca Voglmayr \& G. Delgado

Sordariomycetidae genera incertae sedis

Arecacicola Joanne E. Taylor, J. Fröhl. \& K.D. Hyde, Mycoscience 42(4): 370 (2001)

Index Fungorum number: IF28577; 1 morphological species.

Type species - Arecacicola calami Joanne E. Taylor, J. Fröhl. \& K.D. Hyde

Bullimyces A. Ferrer, A.N. Mill., Sarmiento \& Shearer, Mycologia 104(4): 868 (2012)

Index Fungorum number: IF561094; 3 species with sequence data.

Type species - Bullimyces communis A. Ferrer, A.N. Mill., Sarmiento \& Shearer

Cancellidium Tubaki, Trans. Mycol. Soc. Japan 16(4): 357 (1975)

Index Fungorum number: IF7483; 2 morphological species (Species Fungorum 2020), 1 species with sequence data.

Type species - Cancellidium applanatum Tubaki

Ceratolenta Réblová, Mycologia 105(2): 466 (2013)

Index Fungorum number: IF800338; 1 species with sequence data.

Type species - Ceratolenta caudata Réblová

Chaetosphaerides Matsush., Matsush. Mycol. Mem. 10: 146 (2003) 
Index Fungorum number: IF28561; 1 morphological species.

Type species - Chaetosphaerides ramichloridifera Matsush.

Cryptophyllachora L. Kiss, Kovács \& R.G. Shivas, Scientific Reports 8(no. 10806): 4 (2018)

Index Fungorum number: IF825649; 2 species with sequence data.

Type species - Cryptophyllachora eurasiatica L. Kiss, Kovács \& R.G. Shivas

Hanliniomyces Raja \& Shearer, Mycologia 100(3): 471 (2008)

Index Fungorum number: IF507448; 1 morphological species.

Type species - Hanliniomyces hyaloapicalis Raja \& Shearer

Hydromelitis A. Ferrer, A.N. Mill., Sarmiento \& Shearer, Mycologia 104(4): 876 (2012)

Index Fungorum number: IF561101; 1 species with sequence data.

Type species - Hydromelitis pulchella A. Ferrer, A.N. Mill., Sarmiento \& Shearer

Merugia Rogerson \& Samuels, Mem. N. Y. bot. Gdn 64: 166 (1990)

Index Fungorum number: IF25540; 1 morphological species.

Type species - Merugia palicoureae Rogerson \& Samuels

Mycomedusiospora G.C. Carroll \& Munk, Mycologia 56(1): 91 (1964)

Index Fungorum number: IF3325; 1 morphological species.

Type species - Mycomedusiospora flavida (Rick) G.C. Carroll \& Munk

Myxocephala G. Weber, Spaaij \& Oberw., Sydowia 41: 360 (1989)

Index Fungorum number: IF11231; 1 species with sequence data.

Type species - Myxocephala albida G. Weber, Spaaij \& Oberw.

Nigromammilla K.D. Hyde \& J. Fröhl., Cryptog. Mycol. 24(1): 17 (2003)

Index Fungorum number: IF28740; 1 morphological species.

Type species - Nigromammilla calami K.D. Hyde \& J. Fröhl.

Phaeotrichosphaeria Sivan., Trans. Br. mycol. Soc. 81(2): 313 (1983)

Index Fungorum number: IF25837; 4 morphological species (Species Fungorum 2020).

Type species - Phaeotrichosphaeria indica Sivan. \& N.D. Sharma

Phragmodiscus Hansf., Proc. Linn. Soc. London 159: 31 (1947)

Index Fungorum number: IF4026; 2 morphological species (Species Fungorum 2020).

Type species - Phragmodiscus arundinariae Hansf.

Plagiosphaera Petr., Annls mycol. 39(4/6): 289 (1941)

Index Fungorum number: IF4155; 11 morphological species.

Type species - Plagiosphaera moravica (Petr.) Petr.

Pseudobotrytis Krzemien. \& Badura, Acta Soc. Bot. Pol. 23: 761 (1954)

Index Fungorum number: IF9556; 2 morphological species (Species Fungorum 2020), 1

species with sequence data.

Type species - Pseudobotrytis fusca Krzemien. \& Badura

Xylariomycetidae genera incertae sedis

Calceomyces Udagawa \& S. Ueda, Mycotaxon 32: 448 (1988)

Index Fungorum number: IF25219; 1 species with sequence data. 
Type species - Calceomyces lacunosus Udagawa \& S. Ueda

\section{Placement of genera in Sordariomycetes genera incertae sedis}

Acerbiella Sacc. \& D. Sacc., Syll. fung. (Abellini) 17: 768 (1905)

Index Fungorum number: IF33; 4 morphological species (Species Fungorum 2020)

Type species - Acerbiella macrospora (Rick) Sacc. \& D. Sacc.

Acrospermoides J.H. Mill. \& G.E. Thomps., Mycologia 32(1): 12 (1940)

Index Fungorum number: IF53; 2 morphological species (Species Fungorum 2020)

Type species - Acrospermoides subulata J.H. Mill. \& G.E. Thomps.

Ameromassaria Hara, Journal of Plant Protection, Tokyo 5: 886 (1918)

Index Fungorum number: IF159; 1 morphological species

Type species - Ameromassaria japonica Hara

Amphisphaerellula Gucevič, Bot. Mater. Otd. Sporov. Rast. Bot. Inst. Komarova Akad. Nauk S.S.S.R. 8: 142 (1952)

Index Fungorum number: IF172; 2 morphological species (Species Fungorum 2020)

Type species - Amphisphaerellula fagi Gucevič

Amphisphaerina Höhn., Sber. Akad. Wiss. Wien, Math.-naturw. Kl., Abt. 1 128(7-8): 581 (1919) Index Fungorum number: IF174; 1 morphological species Type species - Amphisphaerina texensis (Cooke) Höhnel

Amphorulopsis Petr., Sydowia 13(1-6): 181 (1959)

Index Fungorum number: IF178; 1 morphological species

Type species - Amphorulopsis polygonacearum Petr.

Amylis Speg., Fung. parag.: 405 (1922)

Index Fungorum number: IF184; 1 morphological species

Type species - Amylis memorabilis Speg.

Anisomycopsis I. Hino \& Katum., J. Jap. Bot. 39: 325 (1964)

Index Fungorum number: IF203; 1 morphological species

Type species - Anisomycopsis rosae I. Hino \& Katum.

Anthostomaria (Sacc.) Theiss. \& Syd., Annls mycol. 16(1/2): 27 (1918)

Index Fungorum number: IF225; 1 morphological species

Type species - Anthostomaria apogyra (Nyl.) Theiss. \& Syd.

Anthostomellina L.A. Kantsch., Bolêz. Rast. 17: 82 (1928)

Index Fungorum number: IF227; 2 morphological species (Species Fungorum 2020)

Type species - Anthostomellina carpinea L.A. Kantsch.

Apodothina Petr., Sydowia 23(1-6): 276 (1970)

Index Fungorum number: IF276; 1 morphological species

Type species - Apodothina pringlei (Peck) Petr.

Apogaeumannomyces Matsush., Matsush. Mycol. Mem. 10: 152 (2003)

Index Fungorum number: IF28562; 1 morphological species

Type species - Apogaeumannomyces perplexus Matsush. 
Aquadulciospora Fallah \& Shearer, Mycologia 93(3): 570 (2001) Index Fungorum number: IF28486; 1 morphological species Type species - Aquadulciospora rhomboidia Fallah \& Shearer

Aropsiclus Kohlm. \& Volkm.-Kohlm., Syst. Ascom. 13(1): 24 (1994)

Index Fungorum number: IF6185; 1 morphological species

Type species - Aropsiclus junci (Kohlm. \& Volkm.-Kohlm.) Kohlm. \& Volkm.-Kohlm.

Ascorhiza Lecht.-Trinka, C. r. hebd. Séanc. Acad. Sci., Paris 192: 499 (1931)

Index Fungorum number: IF372; 1 morphological species

Type species - Ascorhiza leguminosarum Lecht.-Trinka

Ascoyunnania L. Cai \& K.D. Hyde, Fungal Divers. 18: 2 (2005)

Index Fungorum number: IF28946; 1 morphological species

Type species - Ascoyunnania aquatica L. Cai \& K.D. Hyde

Atrogeniculata J.S. Monteiro, Gusmão \& R.F. Castañeda, Mycotaxon 127: 40 (2014)

Index Fungorum number: IF805084; 1 morphological species

Type species - Atrogeniculata submersa J. S. Monteiro, Gusmão \& R. F. Castañeda

Aulospora Speg., Anal. Mus. nac. B. Aires, Ser. 3 12: 404 (1909)

Index Fungorum number: IF25578; 1 morphological species

Type species - Aulospora epimyces (Speg.) Speg.

Azbukinia Lar.N. Vassiljeva, Mycotaxon 35(2): 395 (1989)

Index Fungorum number: IF25350; 1 morphological species

Type species - Azbukinia ferruginea (Fuckel) Lar.N. Vassiljeva

Bactrosphaeria Penz. \& Sacc., Malpighia 11(9-10): 407 (1897)

Index Fungorum number: IF482; 1 morphological species

Type species - Bactrosphaeria asterostoma Penz. \& Sacc.

Basidiobotrys Höhn., Sber. Akad. Wiss. Wien, Math.-naturw. Kl., Abt. 1 118: 420 (1909)

Index Fungorum number: IF7336; 2 morphological species (Species Fungorum 2020)

Type species - Basidiobotrys clautriavii (Pat.) Höhn.

Biciliopsis Diederich, Biblthca Lichenol. 64: 25 (1997)

Index Fungorum number: IF27753; 2 morphological species (Species Fungorum 2020)

Type species - Biciliopsis leptogiicola Diederich

Bombardiastrum Pat., Bull. Soc. mycol. Fr. 9(3): 153 (1893)

Index Fungorum number: IF617; 1 morphological species

Type species - Bombardiastrum andinum Pat.

Botryosporium Corda, Deutschl. Fl., 3 Abt. (Pilze Deutschl.) 3(11): 9 (1831)

Index Fungorum number: IF7429; 10 morphological species (Species Fungorum 2020), 3 species with sequence data.

Type species - Botryosporium diffusum Corda

Brenesiella Syd., Annls mycol. 27(1/2): 16 (1929)

Index Fungorum number: IF649; 1 morphological species 
Type species - Brenesiella erythroxyli Syd.

Byrsomyces Cavalc., Instituto de Micologia da Universidade de Pernambuco 675: 6 (1972)

Index Fungorum number: IF696; 1 morphological species

Type species - Byrsomyces olivaceus Cavalc.

Byssotheciella Petr., Annls mycol. 21(3/4): 281 (1923)

Index Fungorum number: IF713; 2 morphological species (Species Fungorum 2020)

Type species - Byssotheciella tiliae Petr.

Caleutypa Petr., Annls mycol. 32(5/6): 434 (1934)

Index Fungorum number: IF726; 1 morphological species

Type species - Caleutypa maculans Petr.

Caproniella Berl., Icon. fung. (Abellini) 2(2-3): 62 (1896)

Index Fungorum number: IF817; 1 morphological species

Type species - Caproniella pleiospora (Mouton) Berl.

Chaetoamphisphaeria Hara, Journal of Plant Protection, Tokyo 5: 349 (1918)

Index Fungorum number: IF939; 1 morphological species

Type species - Chaetoamphisphaeria japonica Hara

Ciliofusospora Bat. \& J.L. Bezerra, Publicações Inst. Micol. Recife 385: 15 (1963)

Index Fungorum number: IF1055; 1 morphological species

Type species - Ciliofusospora oenocarpi Bat. \& J.L. Bezerra

Clypeoceriospora Sousa da Câmara, Agron. lusit. 8: 30 (1946)

Index Fungorum number: IF1113; 1 morphological species

Type species - Clypeoceriospora rubi Sousa da Câmara

Clypeosphaerulina Sousa da Câmara, Agron. lusit. 1: 195 (1939)

Index Fungorum number: IF1126; 1 morphological species

Type species - Clypeosphaerulina vincae (Sousa da Câmara) Sousa da Câmara

Cryptoascus Petri, Atti Reale Accad. Lincei, Rendic., Sér. 5 18(2): 642 (1909)

Index Fungorum number: IF1311; 2 morphological species (Species Fungorum 2020)

Type species - Cryptoascus oligosporus Petri

Cryptomycella Höhn., Mitt. bot. Inst. tech. Hochsch. Wien 2(3): 48 (1925)

Index Fungorum number: IF7831; 2 morphological species (Species Fungorum 2020) Type species - Cryptomycella pteridis (Kalchbr.) Höhn.

Cryptomycina Höhn., Annls mycol. 15(5): 322 (1917)

Index Fungorum number: IF1321; 2 morphological species (Species Fungorum 2020)

Type species - Cryptomycina pteridis (Rebent.) Höhn.

Cucurbitopsis Bat. \& Cif., Publicações Inst. Micol. Recife 95: 3 (1957)

Index Fungorum number: IF1351; 1 morphological species

Type species - Cucurbitopsis ramulorum Bat., Nascim. \& Cif.

Curvatispora V.V. Sarma \& K.D. Hyde, Nova Hedwigia 72(3-4): 480 (2001)

Index Fungorum number: IF28530; 1 morphological species 
Type species - Curvatispora singaporensis V.V. Sarma \& K.D. Hyde

Dasysphaeria Speg., Anal. Mus. nac. Hist. nat. B. Aires 23: 60 (1912)

Index Fungorum number: IF1421; 1 morphological species

Type species - Dasysphaeria andicola Speg.

Delpinoëlla Sacc., Bull. Soc. R. Bot. Belg. 38(2): 162 (1899)

Index Fungorum number: IF1446; 1 morphological species

Type species - Delpinoëlla insignis Sacc. \& Trotter

Diacrochordon Petr., Sydowia 9(1-6): 591 (1955)

Index Fungorum number: IF7973; 1 morphological species

Type species - Diacrochordon rehmii Petr.

Didymobotryum Sacc., Syll. fung. (Abellini) 4: 626 (1886)

Index Fungorum number: IF8009; 6 morphological species (Species Fungorum 2020), 1 species with sequence data.

Type species - Didymobotryum rigidum (Berk. \& Broome) Sacc.

Duradens Samuels \& Rogerson, Mem. N. Y. bot. Gdn 64: 170 (1990)

Index Fungorum number: IF25541; 1 morphological species

Type species - Duradens lignicola Samuels \& Rogerson

Esfandiariomyces Ershad, Iranian Journal of Plant Pathology 21(1-4): 8 (1985)

Index Fungorum number: IF25103; 1 morphological species

Type species - Esfandiariomyces insignis (Petr.) Ershad

Fantasmomyces D.Hyeon Lee, Marinc., Z.W. de Beer \& M.J. Wingf., Persoonia 37: 249 (2016) Index Fungorum number: IF816620; 1 species with sequence data.

Wingf.

Type species - Fantasmomyces hyalinus Dong Hyeon Lee, Marinc., Z.W. de Beer, M.J.

Fassia Dennis, Bull. Jard. bot. État Brux. 34: 240 (1964)

Index Fungorum number: IF1979; 1 morphological species

Type species - Fassia scabrosa Dennis

Flammispora Pinruan, Sakay., K.D. Hyde \& E.B.G. Jones, Stud. Mycol. 50(2): 384 (2004)

Index Fungorum number: IF500093; 2 morphological species (Species Fungorum 2020), 1 species with sequence data.

Type species - Flammispora bioteca Pinruan, Sakayaroj, K.D. Hyde \& E.B.G. Jones

Frondisphaeria K.D. Hyde, Mycoscience 37(2): 169 (1996)

Index Fungorum number: IF27664; 2 morphological species (Species Fungorum 2020)

Type species - Frondisphaeria palmicola K.D. Hyde

Hapsidascus Kohlm. \& Volkm.-Kohlm., Syst. Ascom. 10: 113 (1991)

Index Fungorum number: IF25237; 1 morphological species

Type species - Hapsidascus hadrus Kohlm. \& Volkm.-Kohlm.

Heliastrum Petr., Annls mycol. 29(3/4): 190 (1931)

Index Fungorum number: IF2256; 1 morphological species

Type species - Heliastrum concinnum Petr. 
Hyaloderma Speg., Anal. Soc. cient. argent. 17(3): 131 (1884)

Index Fungorum number: IF2385; 1 morphological species

Type species - Hyaloderma imperspicuum Speg.

Hydronectria Kirschst., Verh. bot. Ver. Prov. Brandenb. 67: 87 (1925)

Index Fungorum number: IF2405; 1 morphological species

Type species - Hydronectria kriegeriana Kirschst.

Immersisphaeria Jaklitsch, Mycotaxon 101: 18 (2007)

Index Fungorum number: IF510734; 1 morphological species

Type species - Immersisphaeria eichleriana (Bres.) Jaklitsch

Iraniella Petr., Sydowia 3(1-6): 135 (1949)

Index Fungorum number: IF2502; 1 morphological species

Type species - Iraniella rechingeri Petr.

Konenia Hara, Bot. Mag., Tokyo 27(no. 317): 250 (1913)

Index Fungorum number: IF2580; 2 morphological species (Species Fungorum 2020)

Type species - Konenia bambusae Hara

Kravtzevia Schwarzman, Trudy Inst. Bot., Alma-Ata 9: 75 (1961)

Index Fungorum number: IF2587; 1 morphological species

Type species - Kravtzevia halimodendri Schwarzman

Kurssanovia Kravtzev, Trudy Inst. Bot., Alma-Ata 2: 145 (1955)

Index Fungorum number: IF2599; 1 morphological species

Type species - Kurssanovia vassiljevskii Kravtzev

Lecythiomyces Doweld, Index Fungorum 30: 1 (2013)

Index Fungorum number: IF550264; 1 morphological species

Type species - Lecythiomyces aerugineus (Zukal) Doweld

Leptosacca Syd., Annls mycol. 26(1/2): 109 (1928)

Index Fungorum number: IF2796; 1 morphological species

Type species - Leptosacca lumae Syd.

Leptosphaerella Speg., Anal. Mus. nac. Hist. nat. B. Aires 23: 56 (1912)

Index Fungorum number: IF92186; 7 morphological species (Species Fungorum 2020)

Type species - Leptosphaerella fagaricola Speg.

Mangrovispora K.D. Hyde \& Nakagiri, Syst. Ascom., Reprint of Volumes 1-4 (1982-1985) 10(1): 19 (1991)

Index Fungorum number: IF25564; 2 morphological species (Species Fungorum 2020), 1 species with sequence data.

Type species - Mangrovispora pemphii K.D. Hyde \& Nakagiri

Marisolaris Jørg. Koch \& E.B.G. Jones, Can. J. Bot. 67(4): 1190 (1989)

Index Fungorum number: IF25320; 1 morphological species

Type species - Marisolaris ansata Jørg. Koch \& E.B.G. Jones

Melanographium Sacc., Annls mycol. 11(6): 557 (1913) 
Index Fungorum number: IF8891; 13 morphological species (Species Fungorum 2020)

Type species - Melanographium spleniosporum Sacc.

Microcyclephaeria Bat., Revta Biol., Lisb. 1(3-4): 301 (1958)

Index Fungorum number: IF3159; 1 morphological species

Type species - Microcyclephaeria palmicola (Syd.) Bat. \& H. Maia

Mirannulata Huhndorf, F.A. Fernández, A.N. Mill. \& Lodge, Sydowia 55(2): 173 (2003)

Index Fungorum number: IF28775; 2 morphological species (Species Fungorum 2020), 1 species with sequence data.

Type species - Mirannulata samuelsii Huhndorf, F.A. Fern., A.N. Mill. \& Lodge

Natantiella Réblová, Mycol. Res. 113(9): 996 (2009)

Index Fungorum number: IF512833; 1 species with sequence data.

Type species - Natantiella ligneola (Berk. \& Broome) Réblová

Naumovela Kravtzev, Trudy Inst. Bot., Alma-Ata 2: 153 (1955)

Index Fungorum number: IF3426; 2 morphological species (Species Fungorum 2020)

Type species - undetermined

Neocryptospora Petr., Sydowia 13(1-6): 51 (1959)

Index Fungorum number: IF3448; 1 morphological species

Type species - Neocryptospora rickii Petr.

Neoeriomycopsis Crous \& M.J. Wingf., Persoonia 34: 207 (2015)

Index Fungorum number: IF812453; 1 species with sequence data.

Type species - Neoeriomycopsis aristata (B. Sutton \& Hodges) Crous \& M.J. Wing

Neolamya Theiss. \& Syd., Annls mycol. 16(1/2): 29 (1918)

Index Fungorum number: IF3465; 3 morphological species (Species Fungorum 2020).

Type species - Neolamya peltigerae (Mont.) Theiss. \& Syd

Neonawawia a J. Yang, K.D. Hyde \& J.K. Liu, Mycosphere 9(6): 1132-1150 (2018)

Index Fungorum number: IF555449; 1 species with sequence data.

Type species - Neonawawia malaysiana (Crous \& S.S. Lee) J. Yang, K.D. Hyde \& J.K. Liu

Neothyridaria Petr., Annls mycol. 32(5/6): 347 (1934)

Index Fungorum number: IF3486; 1 morphological species.

Type species - Neothyridaria moravica Petr

Ophiomassaria Jacz., Bull. Herb. Boissier 2: 685 (1894)

Index Fungorum number: IF3606; 1 morphological species.

Type species - Ophiomassaria selenospora (G.H. Otth) Jacz

Ophiomeliola Starbäck, Bih. K. svenska VetenskAkad. Handl., Afd. 3 25(no. 1): 22 (1899)

Index Fungorum number: IF3607; 4 morphological species (Species Fungorum 2020).

Type species - Ophiomeliola lindmanii Starbäck

Paoayensis Cabanela, Jeewon \& K.D. Hyde, Cryptog. Mycol. 28(4): 303 (2007)

Index Fungorum number: IF510824; 2 morphological species (Species Fungorum 2020), 1

species with sequence data.

Type species - Paoayensis lignicola Cabanela, Jeewon \& K.D. Hyde 
Paradiplococcium Hern.-Restr., J. Mena \& Gené, Stud. Mycol. 86: 94 (2017)

Index Fungorum number: IF820295; 1 species with sequence data.

Type species - Paradiplococcium singulare (Hern. Restr., J. Mena, Gené \& Guarro) Hern.

Restr., J. Mena \& Gené

Paramicrodochium Hern.-Restr. \& Crous, Persoonia 36: 62 (2015)

Index Fungorum number: IF811869; 1 species with sequence data.

Type species - Paramicrodochium gracile (Mouch. \& Samson) M. Hern. Restr. \& Crous

Pareutypella Y.M. Ju \& J.D. Rogers, Mycologia 87(6): 891 (1996)

Index Fungorum number: IF27622; 2 morphological species (Species Fungorum 2020).

Type species - Pareutypella sulcata Y.M. Ju \& J.D. Rogers

Phialemoniopsis Perdomo, Dania García, Gené, Cano \& Guarro, Mycologia 105(2): 408 (2013)

Index Fungorum number: IF563874; 6 species with sequence data.

Type species - Phialemoniopsis ocularis (Gené \& Guarro) Perdomo

Phragmeriella Hansf., Mycol. Pap. 15: 89 (1946)

Index Fungorum number: IF4019; 1 morphological species.

Type species - Phragmeriella ireninae Hansf

Phyllocelis Syd., Annls mycol. 23(3/6): 353 (1925)

Index Fungorum number: IF4061; 2 morphological species (Species Fungorum 2020).

Type species - Phyllocelis oyedaeae Syd

Pleocryptospora J. Reid \& C. Booth, Can. J. Bot. 47: 1055 (1969)

Index Fungorum number: IF4209; 1 morphological species.

Type species - Pleocryptospora bambusae (Speg.) J. Reid \& C. Booth

Pleosphaeria Speg., Anal. Soc. cient. argent. 12(4): 181 (1881)

Index Fungorum number: IF4227; 21 morphological species.

Type species - Pleosphaeria lichenothricis Henssen

Pleurophragmium Costantin, Mucéd. Simpl. (Paris): 100 (1888)

Index Fungorum number: IF9470; 21 orphological species (Species Fungorum 2020), 5 species with sequence data.

Type species - Pleurophragmium bicolor Costantin

Protocucurbitaria Naumov, Bot. Mater. Otd. Sporov. Rast. Bot. Inst. Komarova Akad. Nauk S.S.S.R. 7: 110 (1951)

Index Fungorum number: IF4385; 1 morphological species.

Type species - Protocucurbitaria ribicola Naumov

Pulvinaria Bonord., Handb. Allgem. mykol. (Stuttgart): 272 (1851)

Index Fungorum number: IF4552; 4 morphological species (Species Fungorum 2020), 1

species with sequence data.

Type species - Pulvinaria typica Rodway

Pumilus Viala \& Marsais, C. r. hebd. Séanc. Agric. France 198: 1557, 1560 (1934)

Index Fungorum number: IF4555; 1 morphological species.

Type species - Pumilus medullae Viala \& Marsais 
Rehmiomycella E. Müll., Beitr. Kryptfl. Schweiz 11(no. 2): 601 (1962)

Index Fungorum number: IF4667; 1 morphological species.

Type species - Rehmiomycella phoradendri (Rehm) E. Müll

Rhamphosphaeria Kirschst., Annls mycol. 34(3): 189 (1936)

Index Fungorum number: IF338249; 1 morphological species.

Type species - Rehmiomycella phoradendri (Rehm) E. Müll

Rhizophila K.D. Hyde \& E.B.G. Jones, Mycotaxon 34(2): 527 (1989)

Index Fungorum number: IF25336; 1 morphological species.

Type species - Rhizophila marina K.D. Hyde \& E.B.G. Jones

Rhopographella (Henn.) Sacc. \& Trotter, Syll. fung. (Abellini) 22: 440 (1913)

Index Fungorum number: IF4723; 2 morphological species (Species Fungorum 2020).

Type species - Rhopographella gaduae (Henn.) Sacc. \& Trotter

Rhynchosphaeria (Sacc.) Berl., Icon. fung. (Abellini) 1(1): 40 (1890)

Index Fungorum number: IF4733; 17 morphological species (Species Fungorum 2020).

Type species - Rhynchosphaeria dusenii Henn.

Rivulicola K.D. Hyde, Nova Hedwigia 64(1-2): 186 (1997)

Index Fungorum number: IF27726; 3 morphological species (Species Fungorum 2020).

Type species - Rivulicola incrustata K.D. Hyde

Romellina Petr., Sydowia 9(1-6): 597 (1955)

Index Fungorum number: IF4781; 1 morphological species.

Type species - Romellina variabilis Petr

Saccardoëlla Speg., Michelia 1(no. 5): 461 (1879)

Index Fungorum number: IF4811; 14 morphological species (Species Fungorum 2020), 1

species with sequence data.

Type species - Saccardoella montellica Speg

Sartorya Vuill., C. r. hebd. Séanc. Acad. Sci., Paris 184: 136 (1927)

Index Fungorum number: IF1768; 8 morphological species (Species Fungorum 2020).

Type species - Sartorya fumigata Vuill

Scharifia Petr., Sydowia 9(1-6): 448 (1955)

Index Fungorum number: IF4883; 1 morphological species.

Type species - Scharifia procumbens Petr

Scoliocarpon Nyl., Mém. Soc. Acad. Maine Loire 4: 81 (1858)

Index Fungorum number: IF4960; 1 morphological species.

Type species - Scoliocarpon pupula (Tuck.) Nyl

Scotiosphaeria Sivan., Trans. Br. mycol. Soc. 69(1): 119 (1977)

Index Fungorum number: IF4971; 1 morphological species.

Type species - Scotiosphaeria endoxylinae Sivan

Selenosporella G. Arnaud ex MacGarvie, Scientific Proc. R. Dublin Soc., Ser. B 2(16): 153 (1969) 
Index Fungorum number: IF9872; 13 morphological species (Species Fungorum 2020), 1 species with sequence data.

Type species - Selenosporella curvispora G. Arnaud ex MacGarvie

Servazziella J. Reid \& C. Booth, Can. J. Bot. 65(7): 1334 (1987)

Index Fungorum number: IF25136; 1 morphological species.

Type species - Servazziella longispora (Servazzi) J. Reid \& C. Booth

Sporoctomorpha J.V. Almeida \& Sousa da Câmara, Revta agron., Lisb. 1: 90 (1903)

Index Fungorum number: IF5162; 1 morphological species.

Type species - Sporoctomorpha magnoliae J.V. Almeida \& Sousa da Câmara

Stanjehughesia Subram., Proc. Indian natn Sci. Acad., Part B. Biol. Sci. 58(4): 184 (1992)

Index Fungorum number: IF22443; 17 morphological species (Species Fungorum 2020), 2 species with sequence data.

Type species - Stanjehughesia hormiscioides (Corda) Subram

Stearophora L. Mangin \& Viala, C. r. hebd. Séanc. Acad. Sci., Paris 140: 1478 (1905)

Index Fungorum number: IF5188; 1 morphological species.

Type species - Stearophora radicicola L. Mangin \& Viala

Steganopycnis Syd. \& P. Syd., Annls mycol. 14(5): 370 (1916)

Index Fungorum number: IF5189; 1 morphological species.

Type species - Steganopycnis oncospermatis Syd. \& P. Syd

Stegophorella Petr., Sydowia 1(1-3): 15 (1947)

Index Fungorum number: IF5198; 1 morphological species.

Type species - Stegophorella lagerheimii Petr

Stellosetifera Matsush., Matsush. Mycol. Mem. 9: 26 (1996)

Index Fungorum number: IF27672; 1 morphological species.

Type species - Stellosetifera malaysiana Matsush

Stereosphaeria Kirschst., Annls mycol. 37(1/2): 96 (1939)

Index Fungorum number: IF5226; 2 morphological species (Species Fungorum 2020), 1

species with sequence data.

Type species - Stereosphaeria phloeophila Kirschst

Stomatogenella Petr., Sydowia 9(1-6): 507 (1955)

Index Fungorum number: IF5271; 1 morphological species.

Type species - Stomatogenella mirabilis Petr

Sungaiicola Fryar \& K.D. Hyde, Cryptog. Mycol. 25(3): 250 (2004)

Index Fungorum number: IF28836; 1 morphological species.

Type species - Sungaiicola bactrodesmiella Fryar \& K.D. Hyde

Synsphaeria Bonord., Handb. Allgem. mykol. (Stuttgart): 271 (1851)

Index Fungorum number: IF5340; 2 morphological species (Species Fungorum 2020).

Type species - Sphaeria versatilis Fr

Teracosphaeria Réblová \& Seifert, Mycol. Res. 111(3): 291 (2007)

Index Fungorum number: IF510202; 1 species with sequence data. 
Type species - Teracosphaeria petroica Réblová \& Seifert

Thelidiella Fink, Mycologia 25(4): 305 (1933)

Index Fungorum number: IF5423; 1 morphological species.

Type species - Thelidiella blastenicola Fink

Thyridella (Sacc.) Sacc., Syll. fung. (Abellini) 11: 351 (1895)

Index Fungorum number: IF5464; 3 morphological species (Species Fungorum 2020).

Type species - Thyridium vestitum (Fr.) Fuckel

Thyrotheca Kirschst., Hedwigia 81: 215 (1944)

Index Fungorum number: IF5473; 1 morphological species.

Type species - Thyrotheca nyssae (Berk. \& M.A. Curtis) Kirschst

Trichospermella Speg., Anal. Mus. nac. Hist. nat. B. Aires 23: 38 (1912)

Index Fungorum number: IF5585; 2 morphological species (Species Fungorum 2020).

Type species - Trichospermella pulchella Speg

Trichosphaeropsis Bat. \& Nascim., Atas Inst. Micol. Univ. Recife 1: 299 (1960)

Index Fungorum number: IF5589; 1 morphological species.

Type species - Trichosphaeropsis crescentiae Bat. \& Nascim

Tunstallia Agnihothr., Phytopath. Z. 40(3): 280 (1961)

Index Fungorum number: IF5642; 2 morphological species (Species Fungorum 2020).

Type species - Tunstallia aculeata (Petch) Agnihothr

Tulipispora Révay \& Gönczöl, Nova Hedwigia 88(1-2): 42 (2009)

Index Fungorum number: IF537065; 1 morphological species.

Type species - Tulipispora ingoldii Révay \& J. Gönczöl

Urosporella G.F. Atk., Bulletin of Cornell University, Science 3(no. 1): 9 (1897)

Index Fungorum number: IF5690; 5 morphological species (Species Fungorum 2020).

Type species - Urosporella americana G.F. Atk

Urupe Viégas, Bragantia 4(1-6): 125 (1944)

Index Fungorum number: IF5691; 1 morphological species.

Type species - Urupe guaduae Viégas

Vleugelia J. Reid \& C. Booth, Can. J. Bot. 47: 1057 (1969)

Index Fungorum number: IF5749; 1 morphological species.

Type species - Vleugelia betulina (Bubák \& Vleugel) J. Reid \& C. Booth

Xenodium Syd., Annls mycol. 33(1/2): 95 (1935)

Index Fungorum number: IF5817; 1 morphological species.

Type species - Xenodium petrakii Syd.

Zalerion R.T. Moore \& Meyers, Can. J. Microbiol. 8: 408 (1962)

Index Fungorum number: IF10467; 6 morphological species (Species Fungorum 2020), 4

species with sequence data.

Type species - Zalerion nepura R.T. Moore \& Meyers 


\section{Acknowledgments}

Kevin D. Hyde thanks the Foreign Experts Bureau of Yunnan Province, Foreign Talents Program (2018; grant no. YNZ2018002), a Visiting Professorship at Chiang Mai University, Thailand, the Thailand Research grants entitled Biodiversity, phylogeny and role of fungal endophytes on above parts of Rhizophora apiculata and Nypa fruticans (grant no: RSA5980068), the future of specialist fungi in a changing climate: baseline data for generalist and specialist fungi associated with ants, Rhododendron species and Dracaena species (grant no: DBG6080013), Impact of climate change on fungal diversity and biogeography in the Greater Mekong Subregion (grant no: RDG6130001), Mae Fah Luang University for the grant "Taxonomy diversity, phylogeny and evolution of fungi in Capnodiales" (grant no: 666713), for supporting this study. This work was partially supported by the National Natural Science Foundation of China (No. NSFC 31950410558, 31760013). E.B.G. Jones is supported under the Distinguished Scientist Fellowship Program (DSFP), King Saud University, Kingdom of Saudi Arabia. M. Stadler and K.D. Hyde thank the Thailand Research Fund (TRF) and the German Academic Exchange Service (DAAD) for a joint TRF-DAAD [PPP 2017-2018] academic exchange grant. V.V. Sarma would like to thank SERB, Department of Science and Technology, Government of India, for funding a project (SERB/SB/SO/PS/18/2014 dt.19.5.2015) and Ministry of Earth Sciences (MOES), Govt. of India for funding a project (Sanction order: MOES/36/OO1S/Extra/40/ 2014/PC-IV dt. 14.01.2015); the Department of Biotechnology, Pondicherry University for facilities; forest departments of Andaman and Nicobar Islands and Tamil Nadu, India are thanked for providing permission to collect samples. M Niranjan thanks SERB, Govt. of India for a fellowship and B. Devadatha thanks MOES, Govt. of India for a fellowship. Dong-Qin Dai would like to thank Yunnan Province Universities of the Science and Technology Innovation Team for the exploitation and utilisation of endophytes and the Thousand Talents Plan, Youth Project of Yunnan Provinces for support. D. N. Wanasinghe would like to thank the CAS President's International Fellowship Initiative (PIFI) for funding his postdoctoral research (number 2019PC0008), the National Science Foundation of China and the Chinese Academy of Sciences for financial support under the following grants: 41761144055, 41771063 and Y4ZK111B01. Rajesh Jeewon thanks the University of Mauritius for support. Saowaluck Tibpromma would like to thanks the International Postdoctoral Exchange Fellowship Program (number Y9180822S1), CAS President's International Fellowship Initiative (PIFI) (number 2020PC0009), and China Postdoctoral Science Foundation for funding her postdoctoral research and financial support. Shi-Ke Huang, Xiang-Yu Zeng and YuanPin Xiao were supported by the National Natural Science Foundation of China (No. 31760014) and the Science and Technology Foundation of Guizhou Province (No. [2017]5788). They would like to thank Ting-Chi Wen for his support and help. LS Dissanayake would like to thank JC Kang for funding her Research (NSFC Grants nos. 31670027, 31460011, 30870009). Mingkwan Doilom would like to thank the 5th batch of Postdoctoral Orientation Training Personnel in Yunnan Province (grant no.: Y934283261) and the 64th batch of China Postdoctoral Science Foundation (grant no.: Y913082271). We would like to thank Prof. Abdel-Wahab, Prof. Chang-Hsin Kuo, Dr. Rungtiwa Phookamsak, Dr. Anupama Daranagama and Dr. Lu Zonglong for their support and give advice. Jing Yang would like to thank Zuoyi Liu for his support and great help with the laboratory work. M. Réblová is appreciated for commenting on some parts of the manuscript.

\section{References}

Abbas SQ, Niaz M, Iftikhar T, Abbas A et al. 2011 - Zygosporium gibbum var. mangifera var. nov. on Mangifera indica from Shujabad Pakistan. Pakistan Journal of Botany 43, 41-46.

Abbott SP. 2000. Holomorph studies of the Microascaceae (PhD dissertation). Edmonton, Alberta, University Alberta.

Abdel-Wahab MA. 2005 - Diversity of marine fungi from Egyptian Red Sea mangroves. Botanica Marina 48, 348-355. 
Abdel-Wahab MA, El-Sharouney H, Jones EBG. 2001 - Two new intertidal lignicolous Swampomyces species from Red Sea mangroves in Egypt. Fungal Diversity 8, 35-40.

Abdel-Wahab MA, Pang KD, Nagahama T, Abdel-Aziz FA, Jones EBG. 2010 - Phylogenetic evaluation of anamorphic species of Cirrenalia and Cumulospora with the description of eight new genera and four new species. Mycological Progress 9, 537-558.

Abdel-Wahab MA, Abdel-Aziz FA, Mohamed SS, Abdel-Aziz AE. 2011 - Annulatascus nilensis sp. nov., a new freshwater ascomycete from the River Nile, Egypt. IMA Fungus 2, 1-6.

Abdel-Wahab MA, Dayarathne MC, Suetrong S, Guo SY et al. 2017 - New saprobic marine fungi and a new combination. Botanica Marina 60, 469-488.

Abdel-Wahab MA, El-Samawaty AE-R, El Gorban A, Yassin MA, Alsaadi MH. 2018 Khaleijomyces marinus gen. et sp. nov. (Juncigenaceae, Torpedosporales) a new lignicolous marine fungus from Saudi Arabia. Phytotaxa 340, 277-285.

Abou-Mansour E, Couche E, Tabacchi R. 2004 - Do fungal naphthalenones have a role in the development of esca symptoms. Phytopathol Mediterr 43, 75-82.

Acero FJ, González V, Sánchez-Ballesteros J, Rubio V et al. 2004 - Molecular phylogenetic studies on the Diatrypaceae based on rDNA-ITS Sequences. Mycologia 96, 249-259.

Adams GC, Wingfield MJ, Common R, Roux J. 2005 - Phylogenetic relationships and morphology of Cytospora species and related teleomorphs (Ascomycota, Diaporthales, Valsaceae) from Eucalyptus. Studies in Mycology 52, 1-144.

Adams GC, Roux J, Wingfield MJ. 2006 - Cytospora species (Ascomycota, Diaporthales, Valsaceae), introduced and native pathogens of trees in South Africa. Australasian Plant Pathology 35, 521-548.

Agrios GN. 2005 - Introduction to plant pathology. Elsevier Academic Press, Amsterdam.

Aguirre-Hudson B. 1991 - A taxonomic study of the species referred to the ascomycete genus Leptorhaphis. Bulletin of the British Museum (Natural History), Botany 21, 85-192.

Agustí-Brisach C, López-Moral A, Raya-Ortega MC, Franco RM et al. 2019 - Occurrence of grapevine trunk diseases affecting the native cultivar Pedro Ximénez in southern Spain. European Journal of Plant Pathology 153, 599-625.

Ahmad S. 1971 - Contributions to the fungi of West Pakistan. XI. Biologia Lahore 17, 67-85.

Ahmed SA, Khan Z, Wang XW, Moussa TAA et al. 2016 - Chaetomium-like fungi causing opportunistic infections in humans: a possible role for extremotolerance. Fungal Diversity 76, $11-26$.

Ai CC, Ma J, Zhang K, Castañeda-Ruíz RF, Zhang X-G. 2019 - Cordana meilingensis and C. lushanensis spp. nov. from Jiangxi, China. Mycotaxon 134, 329-334.

Aiello D, Polizzi G, Crous PW, Lombard L. 2017 - Pleiocarpon gen. nov. and a new species of Ilyonectria causing basal rot of Strelitzia reginae in Italy. IMA fungus 8, 65-76.

Ainsworth GC, James PW, Hawksworth DL. 1971 - Ainsworth \& bisby's dictionary of the fungi, 6th edn. CAB, Kew.

Ainsworth GC, Sparrow FK, Sussman AS. 1973 - A taxonomic review with keys: basidiomycetes and lower fungi. In: Ainsworth GC, Sparrow FK, Sussman AS (Eds.) The fungi. An advanced treatise, IV B. Academic Press, New York, London.

Alderman SC, Rao S, Martin R. 2010 - First report of Dicyma pulvinata on Epichloe typhina and its potential for control of E. typhina. Plant Health Progress 1-7.

Alfieri Jr SA, Schoulties CL, El-Gholl NE. 1980 - Nectriella (Kutilakesa) pironii, a pathogen of ornamental plants. In Proceedings of the Florida State Horticultural Society 93, 218-219.

Al-Hedaithy SSA. 2001 - First report of human infection due to the fungus Triadelphia pulvinata. Journal of Clinical Microbiology 39, 3386-3389.

Alma MH, Dığrak M, Bektaş I. 2000 - Deterioration of wood wastes-based molding materials by using several fungi. J. Mat. Sci. Let 19, 1267-1269.

Almeida DAC, Cruz ACR, Marques MFO, Gusmão LFP. 2013 - Conidial fungi from semi-arid Caatinga biome of Brazil. New and interesting Zanclospora species. Mycosphere 4, 684-692. 
Al-Naemi FA, Nishad R, Ahmed TA, Radwan O. 2014 - First Report of Thielaviopsis punctulata causing black scorch disease on date palm in Qatar. Plant disease 98, 1437-1437.

Alongi G, Catra M, Cormaci M. 1999 - First Record of Haloguignardia cystoseira (Ascomycota) Parasitic on Cystoseira elegans (Fucophyceae) from the Mediterranean Sea. Botanica Marina 42, 33-35.

Alvarez LV, Groenewald JZ, Crous PW. 2016 - Revising the Schizoparmaceae: Coniella and its synonyms Pilidiella and Schizoparme. Studies in Mycology 85, 1-34.

Amand S, Langenfeld A, Blond A, Dupont J et al. 2012 - Guaiane sesquiterpenes from Biscogniauxia nummularia featuring potent antigerminative activity. Journal of Natural Products 75, 798-801.

Ambrose KV, Koppenhöfer AM, Belanger FC. 2014 - Horizontal gene transfer of a bacterial insect toxin gene into the Epichloë fungal symbionts of grasses. Scientific Reports 4, 5562.

Anagnostakis SL. 1987 - Chestnut blight: the classical problem of an introduced pathogen. Mycologia 79, 23-37.

Anahosur KH. 1968 - Muelleromyces, a new member of the sphaeriales ascomycetes. Experientia 2, 849-850.

Anahosur KH. 1969 - Some note-worthy ascomycetes from Maharashtra, India. Sydowia 23, 6368.

Ananthanarayanan S. 1964 - Micronectria agharkarii sp. nov. from India. Mycopathologia 22, 137-140.

Ananthapadmanaban D. 1988 - Cryptascoma, a new genus of the Valsaceae. Transactions of the British Mycological Society 90, 479-482.

Ananthapadmanaban D. 1990 - Paravalsa indica gen. et sp. nov. from India. Mycological Research 94, 275-276.

Andersson K, Eriksson OE, Landvik S. 1995 - Boliniaceae transferred to Sordariales (Ascomycota). Syst Ascomycetum 14, 1-16.

Anke H, Sterner O. 1988 - Transformation of isovelleral by the parasitic fungus Calcarisporium arbuscula. Phytochemistry 27, 2765-2767.

Apt KE. 1988 - Morphology and development of hyperplasia on Cystoseira osmundacea (Phaeophyta) associated with Haloguignardia irritans (Ascomycotina). American journal of botany 75, 979-984.

Aptroot A. 1991 - A monograph of the Pyrenulaceae (excluding Anthracothecium and Pyrenula) and the Requienellaceae, with notes on the Pleomassariaceae, the Trypetheliaceae, and Mycomicrothelia (lichenized and non-lichenized ascomycetes). Bibliotheca Lichenologica $44,1-178$.

Aptroot A. 1995 - Redisposition of some species excluded from Didymosphaeria (Ascomycotina). Nova Hedwigia 60, 325-379.

Aptroot A. 1997 - Notes on the saprobic ascomycetes from Papua New Guinea, with the new genus Papilionovela. Mycol Res 101, 266-268.

Aptroot A. 1998 - A world revision of Massarina (Ascomycota). Nova Hedwigia 66, 89-162.

Aptroot A, Diederich P, Se'rusiaux E, Sipman HJM. 1997 - Lichens and lichenicolous fungi from New Guinea. Bibliotheca Lichenologica 64, 1-220.

Arambarri AM, Cabello MN. 1990 - Considerations about Dictyochaeta, Codinaeopsis and a new genus: Dictyochaetopsis. Mycotaxon 38, 11-14.

Araújo JPM, Evans HC, Kepler R, Hughes DP. 2018 - Zombie-ant fungi across continents: 15 new species and new combinations within Ophiocordyceps. I. Myrmecophilous hirsutelloid species. Studies in Mycology 90, 119-160.

Ariyawansa HA, Hyde KD, Jayasiri SC, Buyck B et al. 2015 - Fungal diversity notes 111-252taxonomic and phylogenetic contributions to fungal taxa. Fungal Diversity 75, 27-274.

Arnold GRW. 1970 - Über Sibirina und Sympodiophora zwei neue Gattungen der Moniliales. Nova Hedwigia 19, 299-304. 
Arzanlou M, Groenewald JZ, Gams W, Braun U, Crous PW. 2007 - Phylogenetic and morphotaxonomic revision of Ramichloridium and allied genera. Studies in Mycology 58, 57-93.

Asgari B, Zare R. 2011 - A contribution to the taxonomy of the genus Coniocessia (Xylariales). Mycol Prog 10, 189-206.

Asthana A, Shearer CA. 1990 - Antagonistic activity of Pseudohalonectria and Ophioceras. Mycologia 82, 554-561.

Atkinson GF. 1905 - The genera Balansia and Dothichloe in the United States with a consideration of their economic importance. The Journal of Mycology 1, 248-267.

Atkinson RG, Trelawny JG. 1962 - A spore trap to study sporulation in tree canker diseases. Canadian Plant Disease Survey 42, 151-154.

Atkinson TJ, Miller AN, Huhndorf SM, Orlovich DA. 2007 - Unusual new Chaetosphaeria species from New Zealand: Intrafamilial diversity and elucidations of the ChaetosphaeriaceaeLasiosphaeriaceae relationship (Sordariomycetes, Ascomycotina). New Zealand Journal of Botany 45, 685-706.

Atmosukarto I, Castillo U, Hess WM, Sears J, Strobel G. 2005 - Isolation and characterization of Muscodor albus I-41.3 s, a volatile antibiotic producing fungus. Plant Science 169, 854-861.

Auer S, Ludwig-Müller J. 2014 - Effects of the endophyte Acremonium alternatum on oilseed rape (Brassica napus) development and clubroot progression. Albanian Journal of Agricultural Sciences 15-20.

Augustin JO, Groenewald JZ, Nascimento RJ, Mizubuti ESG et al. 2013 - Yet more 'weeds' in the garden: fungal novelties from nests of leaf-cutting ants. PLoS ONE 8, 1-17.

Aylward J, Wingfield BD, Dreyer LL, Roets F et al. 2017 - Contrasting carbon metabolism in saprotrophic and pathogenic microascalean fungi from Protea trees. Fungal ecology 30, 88100.

Ayyadurai N, Kirubakaran S, Srisha S, Sakthivel N. 2005 - Biological and molecular variability of Sarocladium oryzae, the sheath rot pathogen of rice (Oryza sativa L.). Current Microbiology 50, 319-323.

Azevedo E, Barata M, Marques MI, Caeiro MF. 2017 - Lulworthia atlantica: a new species supported by molecular phylogeny and morphological analysis. Mycologia 109, 287-295.

Baars JJ, Hendrickx PM, Sonnenberg AS, Korsten L. 2013 - Global collection of mushroom pathogens, Plant Research International. Business Unit Plant Breeding.

Bahl J. 2006 - Molecular evolution of three morphologically similar families in the Xylariomycetidae (Apiosporaceae, Clypeosphaeriaceae, Hyponectriaceae). PhD thesis, The University of Hong Kong. Pokfulam, Hong Kong.

Bainier G. 1907 - Mycothéque de l'école de Pharmacie. XI. Paecilomyces, genre nouveau de Mucédinées. Bulletin Trimestrielle de la Societe de Mycologie Française 23, 26-27.

Baker WA, Morgan-Jones G. 2003 - Notes on Hyphomycetes. XCI. Pseudoacrodictys, a novel genus for seven taxa formerly placed in Acrodictys. Mycotaxon 85, 371-391.

Baker WA, Partridge EC, Morgan-Jones G. 2002 - Notes on hyphomycetes. LXXXV. Junewangia, a genus in which to classify four Acrodictys species and a new taxon. Mycotaxon 81, 293319.

Baldrian P, Valášková V. 2008 - Degradation of cellulose by basidiomycetous fungi. FEMS Microbiological Reviews 32, 501-521.

Ban S, Azuma Y, Sato H, Suzuki KI, Nakagiri A. 2015 - Isaria takamizusanensis is the anamorph of Cordyceps ryogamimontana, warranting a new combination, Purpureocillium takamizusanense comb. nov. International journal of systematic and evolutionary microbiology 65, 2459-2465.

Barengo N, Sieber TN, Holdenrieder O. 2000 - Diversity of endophytic mycobiota in leaves and twigs of pubescent birch (Betula pubescens). Sydowia Horn 52, 305-320.

Barghoorn ES, Linder DH. 1944 - Marine fungi: their taxonomy and biology. Farlowia 1, 395-467. 
Barna M, Mihál I. 2019 - Bark necrotic disease in a beech thicket. Plant Protection Science 55, 181-190.

Barnes I, Fourie A, Wingfield MJ, Harrington TC et al. 2018 - New Ceratocystis species associated with rapid death of Metrosideros polymorpha in Hawaii. Persoonia 40, 154-181.

Barnett HL, Hunter BB. 1972 - Genera of Imperfect fungi. Burgess Publishing Company, Minneapolis 237.

Barr ME. 1964 - The genus Pseudomassaria in North America. Mycologia 56, 841-862.

Barr ME. 1976a - Buergenerula and the Physosporellaceae. Mycologia 68, 611-621.

Barr ME. 1976b - Perspectives in the Ascomycotina. Mem N Y Bot Gard 28, 1-8.

Barr ME. 1977 - Magnaporthe, Telimenella, and Hyponectria (Physosporellaceae). Mycologia 69, 952-966.

Barr ME. 1978 - The Diaporthales in North America: with emphasis on Gnomonia and its segregates. Mycologia Memoirs 7, 1-232.

Barr ME. 1983 - The ascomycete connection. Mycologia 75, 1-13.

Barr ME. 1985 - Notes on the Calosphaeriales. Mycologia 77, 549-565.

Barr ME. 1987 - Prodromus to Class Loculoascomycetes. Newell, Amherst Mass.

Barr ME. 1990a - Melanommatales (Loculoascomycetes). North American Flora, Series 2, part 13. New York Botanical Garden, New York.

Barr ME. 1990b - Prodromus to nonlichenized, pyrenomycetous members of class Hymenoascomycetes. Mycotaxon 39, 43-184.

Barr ME. 1991 - Revisions and additions to the Diaporthales. Mycotaxon 41, 287-305.

Barr ME. 1993 - Redisposition of some taxa described by J. B. Ellis. Mycotaxon 46, 45-76.

Barr ME. 1994 - Notes on the Amphisphaeriaceae and related families. Mycotaxon 51, 191-224.

Barr ME. 1998 - Wegelina, a reinstated genus in the Calosphaeriales. Cryptogamie Mycologie 19, 169-173.

Barr ME, Boise JR. 1985 - A revision of Exarmidium (Ascomycetes). Mycotaxon 23, 233-240.

Barr ME, Hodges CS. 1987 - Hawaiian forest fungi. VIII. New species in Gnomoniella and Stigmochora. Mycologia 79, 782-786.

Barr ME, Ohr HD, Mupphy MK. 1989 - The genus Serenomyces on palms. Mycologia 81, 47-51.

Barr ME, Rogers JD, Ju YM. 1993 - Revisionary studies in the Calosphaeriaceae. Mycotaxon 48, 529-535.

Barr ME, Ohr HD, Ferrin DM, Mundo-Ocampo M. 1997 - A new species of Serenomyces from date palm in California. Mycotaxon 61, 481-484.

Barrasa JM, Martínez AT, Moreno G. 1985 - Aphysiostroma, a new nonostiolate hypocrealean fungus. Canadian Journal of Botany 63, 2439-2443.

Barrasa JM, Checa J, Martínez AT. 1993 - Crassoascus, a new nonstromatic genus in the Clypeosphaeriaceae. Mycotaxon 46, 299-305.

Barron GL. 1980 - Fungal parasites of rotifers: a new genus of Hyphomycetes endoparasitic on Adineta. Canadian Journal of Botany 58, 443-446.

Barron GL. 1991 - A new genus, Rotiferophthora, to accommodate the Diheterospora-like endoparasites of rotifers. Canadian journal of botany 69, 494-502.

Barron GL, Cain RF, Gilman JC. 1961 - The genus Microascus. Canadian Journal of Botany 39, 1609-1631.

Barros MB, de Almeida Paes R, Schubach AO. 2011 - Sporothrix schenckii and Sporotrichosis. Clinical microbiology reviews 24, 633-654.

Bartoli A, Maggi O, Persiani AM. 1984 - Effetia, a new genus of ascomycetes from tropical forest soils. Mycotaxon 19, 515-522.

Bateman C, Huang YT, Simmons DR, Kasson MT et al. 2016 - Ambrosia beetle Premnobius cavipennis (Scolytinae: Ipini) carries highly divergent ascomycotan ambrosia fungus, Afroraffaelea ambrosiae gen. nov. et sp. nov. (Ophiostomatales). Fungal Ecology 25, 41-49.

Batista AC, da Silva Maia H. 1959 - Uma nova doença fúngica de peixe ornamental. Anais da Sociedade de Biologia de Pernambuco 16, 153-159. 
Batista AC, Bezerra JL. 1960 - Beltraniopsis - novo gênero de fungos Dematiaceae. Publicações. Instituto de Micologia da Universidade do Recife 296, 1-13.

Batista AC, Peres GEP. 1960 - Ascomycetes Fitoparasitos. Publicações do Instituto de Micologia do Recife (IMUR) 277, 1-25.

Batista AC, Bezerra JL. 1961 - Discomycetidae e Pyrenomycetidae novos ou vulgares. Memórias da Sociedade Broteriana 14, 29-47.

Batista AC, Fonsêca OJM. 1965 - Pochonia humicola n. gen. e n. sp., uma curiosa entidade fúngica dos solos do Nordeste do Brasil. Publicações do Instituto de Micologia da Universidade do Recife 462, 1-11.

Batista AC, Bezerra JL, Castrillon AL, da Matta EAF. 1964 - Novos Ascomycetos foliícolas e caulinares. Publicações do Instituto de Micologia da Universidade do Recife 431, 1-22.

Batt CA, Tortorello M. 2014 - Encyclopedia of food microbiology (2 ed.). London: Elsevier Ltd. 1014.

Baumgartner K, Bergemann SE, Fujiyoshi P, Rolshausen PE, Gubler WD. 2010 - Microsatellite markers for the grapevine pathogen, Eutypa lata. Molecular Ecology Resources 9, 222-224.

Beeli M. 1920 - Note sur le genre Meliola Fr. Espèces et variétés nouvelles récoltées au Congo. Bulletin du Jardin botanique de l'Etat a Bruxelles 7, 89-160.

Belisario A. 1991- Dicarpella dryina sp. nov., teleomorph of Tubakia dryina. Mycotaxon 41, 147155.

Ben HY, Qu HY, Gao W. 2015 - First report of Myrothecium roridum causing brown spot disease on Hiemalis begonia in China. Plant Disease 99, 1866-1866.

Bender HB. 1932 - The genera of fungi imperfecti. Mycologia 24, 410-412.

Benjamin RK. 1949 - Two species representing a new genus of the Chaetomiaceae. Mycologia 41, 346-354.

Benny GL, Kimbrough JW. 1980 - A synopsis of the orders and families of Plectomycetes with keys to genera. Mycotaxon 12, 1-91.

Berbee ML, Taylor JW. 1992 - Convergence in ascospore discharge mechanism among pyrenomycete fungi based on $18 \mathrm{~S}$ ribosomal RNA gene sequence. Molecular Phylogenetics and Evolution 1, 59-71.

Berkeley MJ. 1838 - Notices of British fungi [108-137]. Ann Mag Nat Hist 1, 257-264.

Berkeley MJ, Broome CE. 1873 - Enumeration of the fungi of Ceylon. Part II. Journal of the Linnean Society. Botany 14, 29-141.

Berkeley MJ, Broome CE. 1875 - II-Notices of British fungi. J Nat Hist 15, 28-41.

Berlese AN. 1900 - Icones Fungorum ad usum Sylloges Saccardianae adcommodatae. 3. Sphaeriaceae allantosporae. Cramer, Padova 3, 1-120.

Berlese AN. 1902 - Icones Fungorum omnium Hucusque Cognitorum. (1900-1905). 3, 80-82.

Beyma FHV. 1940 - Beschreibung einiger neuer Pilzarten aus dem Centraalbureau voor Schimmelcultures, Baarn (Nederland), VI. Mitteilung. Antonie van Leeuwenhoek 6, 263290.

Bhunjun CS, Jayawardena RS, Wei DP, Huanraluek N et al. 2019 - Multigene phylogenetic characterisation of Colletotrichum artocarpicola sp. nov. Artocarpus heterophyllus in northern Thailand. Phytotaxa 418, 273-286.

Bills GF, Platas G, Gams W. 2004 - Conspecificity of the cerulenin and helvolic acid producing 'Cephalosporium caerulens', and the hypocrealean fungus Sarocladium oryzae. Mycological Research 108, 1291-1300.

Bissett J. 1983 - Notes on Tolypocladium and related genera. Canadian Journal of Botany 61, 1311-1329.

Bitzer J, Læssøe T, Fournier J, Kummer V et al. 2008 - Affinities of Phylacia and the daldinoid Xylariaceae, inferred from chemotypes of cultures and ribosomal DNA sequences. Mycological Research 112, 251-270.

Blackwell M, Samson RA, Kimbrough JW. 1980 - Termitariopsis cavernosa gen. and sp. nov., a sporodochial fungus ectoparasitic on ants. Mycotaxon 12, 97-104. 
Blanco-Ulate B, Rolshausen PE, Cantu D. 2013 - Draft Genome Sequence of the Grapevine Dieback Fungus Eutypa lata UCR-EL1. Genome Announcements 1, 1-2.

Bobeck DR, Pearce CJ. 2017 - Agricultural microbial inoculant compositions and uses thereof. United States patent application US 15/702, 417.

Boddy L, Griffith GS. 1989 - Role of endopytes and latent invasion in the development of decay communities in sapwood of angiospermous trees. Sydowia 41, 41-73.

Boedijn KB. 1962 - The Sordariaceae of Indonesia. Persoonia 2, 305-320.

Boise J. 1986 - Requienellaceae, a New Family of Loculoascomycetes. Mycologia 78, 37-41.

Bok JW, Lermer L, Chilton J, Klingeman HG, Towers GH. 1999 - Antitumor sterols from the mycelia of Cordyceps sinensis. Phytochemistry 51, 891-898.

Bolis S, Osman W, Abdelmagid M, Ahmed E et al. 2018 - Immunoinformatics Prediction of Epitope Based Peptide Vaccine Against Madurella mycetomatis Translationally Controlled Tumor Protein. BioRxiv. doi: https://doi.org/10.1101/441881.

Bolton AT. 1954 - Gnomonia fructicola on strawberry. Canadian Journal of Botany 32, 172-181.

Bonar L. 1928 - Studies on some California fungi. Mycologia 20, 292-300.

Bonorden HF. 1851 - Handbuch der allgemeinen Mykologie als Anleitung zum Studium derselben, Stuttgart 1-336.

Boonmee S, Zhang Y, Chomnunti P, Chukeatirote E et al. 2011 - Revision of lignicolous Tubeufiaceae based on morphological reexamination and phylogenetic analysis. Fungal Diversity 51, 63-102.

Boonmee S, Rossman AY, Liu JK, Li WJ. 2014 - Tubeufiales, ord. nov., integrating sexual and asexual generic names. Fungal Diversity 68, 239-298.

Boonyuen N, Chuaseeharonnachai C, Suetrng S, Sri-Indrasutdhi V et al. 2011 - Savoryellales (Hypocreomycetideae, Sordariomycetes): a novel lineage of aquatic ascomycetes inferred from multiple-gene phylogenies of the genera Ascotaiwania, Ascothailandia and Savoryella. Mycologia 103, 1351-1371.

Boonyuen N, Sri-indrasutdhi V, Suetrong S, Sivichai S, Jones EBG. 2012 - Annulatascus aquatorba sp. nov., a lignicolous freshwater ascomycete from Sirindhorn peat swamp forest, Narathiwat, Thailand. Mycologia 104, 746-757.

Boonyuen N, Chuaseeharonnachai C, Suetrong S, Sujinda S, Somrithipol S. 2016 Parafuscosporella garethii sp. nov. (Fuscosporellales) from a rivulet in a community-based northern forest, in Thailand. Mycosphere 7, 1265-1272.

Booth C. 1959 - Studies of pyrenomycetes. IV. Nectria (part 1). Mycological Papers 73, 1-15.

Booth C. 1961 - Studies of pyrenomycetes. VI. Thielavia, with notes on some allied genera. Mycological Papers 83, 1-15.

Borovinova M. 2001 - Susceptibility of plum cultivars to red leaf spot Polystigma rubrum (Persoon) De Candolle. In: VII International Symposium on Plum and Prune Genetics, Breeding and Pomology 577, 255-258.

Boudier E. 1904 - Sur un nouveau genre et une nouvelle espèce de Myriangiacées, le Guilliermondia saccoboloides. Bulletin de la Société Mycologique de France 20, 19-22.

Bovio E, Garzoli L, Gnavi G, Poli A et al. 2018 - The biotechnological potential of spongesderived fungi: an ecological perspective. 17th Congress of the International Society for Microbial Ecology.

Brader L. 1964 - Étude de la relation entre le scolyte de rameaux du caféier Xyleborus compactus Eichh. (X. morstatti Hag.) et sa plante-hôte. Mededelingen van de Landbouwhogeschool te Wageningen 64, 1-109.

Brasier CM. 1991 - Ophiostoma novo-ulmi sp. nov., causative agent of current Dutch elm disease pandemics. Mycopathologia 115, 151-161.

Braun U. 2018 - Annotated list of taxonomic novelties published in "Klotzschii Herbarium Vivum Mycologicum, Editio Nova" issued by G. L. Rabenhorst between 1855 and 1858 . Schlechtendalia 35, 8-9. 
Braun U, Nakashima C, Crous PW, Groenewald JZ et al. 2018 - Phylogeny and taxonomy of the genus Tubakia s. lat. Fungal Systematics and Evolution 1, 41-99.

Brefeld O. 1895 - Hemibasidii. Brandpilze III. Cultur der Brandpilzen in Nährlösungen. Untersuchungenausdem Gesammtgebiete der Mykologie 12, 99-236.

Bright DE, Torres JA. 2006 - Studies on West Indian Scolytidae (Coleoptera) 4: A review of the Scolytidae of Puerto Rico, USA with descriptions of one new genus, fourteen new species and notes on new synonymy (Coleoptera: Scolytidae). Koleopterologische Rundschau 76, 389-428.

Brockmann I. 1976 - Untersuchungen über die Gattung Discostroma Clements (Ascomycetes). Sydowia 28, 275-338.

Bronson AW, Klymiuk AA, Stockey RA, Tomescu AMF. 2013 - A perithecial sordariomycete (Ascomycota, Diaporthales) from the lower cretaceous of Vancouver Island, British Columbia, Canada. International Journal of Plant Sciences 174, 278-292.

Brumpt E. 1905 - Sur le mycétome à grains noirs, maladie produite par une Mucédinée du genre Madurella n. g. Comptes Rendus des Scéances de la Société de Biologie et de ses Filiales 58, 997-999.

Bucher VVC, Hyde KD, Pointing SB, Reddy CA. 2004 - Production of wood decay enzymes, mass loss and lignin solubilization in wood by marine ascomycetes and their anamorphs. Fungal Diversity 15, 1-14.

Burton GW, Wells HD. 1981 - Use of near-isogenic host populations to estimate the effect of three foliage diseases on pearl millet forage yield. Phytopathology 71, 331-333.

Bushley KE, Raja R, Jaiswal P, Cumbie JS et al. 2013 - The genome of Tolypocladium inflatum: evolution, organization, and expression of the cyclosporin biosynthetic gene cluster. PLoS Genetics, 9, e1003496.

Bussaban B, Lumyong S, Lumyong P, Hyde KD, McKenzie EHC. 2003 - Three new species of Pyricularia are isolated as zingiberaceous endophytes from Thailand. Mycologia 95, 519-24.

Bussaban B, Lumyong S, Lumyong P, Seelanan T et al. 2005 - Molecular and morphological characterization of Pyricularia and allied genera. Mycologia 97, 1002-1011.

Butler EE, McCain AH. 1968 - A new species of Stephanoma. Mycologia 60, 955-959.

Cai L, Hyde KD. 2007a - Anamorphic fungi from freshwater habitats in China: Dictyosporium tetrasporum and Exserticlava yunnanensis spp. nov., and two new records for Pseudofuscophialis lignicola and Pseudobotrys terrestri. Mycoscience 48, 290-296.

Cai L, Hyde KD. 2007b - New species of Clohiesia and Paraniesslia collected from freshwater habitats in China. Mycoscience 48, 182-186.

Cai L, Tsui CKM, Zhang KQ, Hyde KD. 2002 - Aquatic fungi from Lake Fuxian, Yunnan, China. Fungal Diversity 9, 57-70.

Cai L, McKenzie EHC, Hyde KD. 2004 - New species of Cordana and Spadicoides from decaying bamboo culms in China. Sydowia 56, 222-228.

Cai L, Hyde KD, Tsui CKM. 2006a - Genera of freshwater fungi. Fungal Diversity Research Series 18, 1-261.

Cai L, Jeewon R, Hyde KD. 2006b - Molecular systematics of Zopfiella and allied genera: evidence from multi-gene sequence analyses. Mycological research 110, 359-368.

Cai L, Jeewon R, Hyde KD. 2006c - Phylogenetic investigations of Sordariaceae based on multiple gene sequences and morphology. Mycological research 110, 137-150.

Cai L, Hu DM, Liu F, Hyde KD, Jones EBG. 2014 - The molecular phylogeny of freshwater Sordariomycetes and Discomycetes. In: Jones EBG, Hyde KD and Pang KL (eds). Freshwater fungi and fungal-like organisms. De Gruyter, Berlin 45-69.

Cain RF. 1957 - Synaptospora, a new genus of amerosporous Ascohymeniales (Ascomycetes). Beihefte zur Sydowia 1, 4-8.

Calado M, Carvalho L, Pang KL, Barata M. 2015 - Diversity and ecological characterization of sporulating higher filamentous marine fungi associated with Spartina maritima (Curtis) Fernald in two Portuguese salt marshes. Microbial Ecology 70, 612-633. 
Calatayud V, Aguirre-Hudson B. 2001 - Observations on the genus Cresporhaphis (Trichosphaeriaceae), with a key to the known species, and C. ulmi sp. nov. Mycological Research 105, 122-126.

Calatayud V, Sanz MJ, Aptroot A. 2001 - Lichenopyrenis galligena (Pleomassariaceae), a new genus of gall-forming lichenicolous fungi on Leptochidium. Mycological Research 105, 634637.

Callan BE. 1998 - Diseases of Populus in British Columbia: a diagnostic manual. Canadian Forest Service, Victoria, BC.

Campbell J, Shearer CA. 2004 - Annulusmagnus and Ascitendus, two new genera in the Annulatascaceae. Mycologia 96, 822-833.

Campbell J, Anderson JL, Shearer CA. 2003 - Systematics of Halosarpheia based on morphological and molecular data. Mycologia 95, 530-552.

Campbell J, Volkmann-Kohlmeyer B, Gräfenhan T, Spatafora JW, Kohlmeyer J. 2005 - A reevaluation of Lulworthiales: relationships based on 18S and 28S rDNA. Mycological Research 109, 556-568.

Campbell J, Inderbitzin P, Kohlmeyer J, Volkmann-Kohlmeyer B. 2009 - Koralionastetales, a new order of marine Ascomycota in the Sordariomycetes. Mycological Research 113, 373-380.

Camps C, Kappel C, Lecomte P, Leon C et al. 2010 - A transcriptomic study of grapevine (Vitis vinifera cv. Cabernet-Sauvignon) interaction with the vascular ascomycete fungus Eutypa lata. Journal of Experimental Botany 61, 1719-1737.

Camps C, Kappel C, Lecomte P, Léon C et al. 2014 - Identification of grapevine marker genes for early, non-destructive, Eutypa lata, infection diagnosis. Plant Pathology 63, 323-333.

Candoussau F, Magni JF, Petrini LE, Barr ME, Petrini O. 1996 - Bambusicolous fungi collected in Southwestern France: an annotated list. Mycologia Helvetica 8, 11-20.

Candoussau F, Boqueras M, Gómez-Bolea A, Laessoe et al. 2007 - Observations on Neobarya, including new species and new combinations. Sydowia Horn 59, 179-215.

Cannon PF. 1982 - Pustulipora, a new genus of the Melanosporaceae. Mycotaxon 15, 523-528.

Cannon PF. 1986 - A revision of Achaetomium, Achaetomiella and Subramaniula, and some similar species of Chaetomium. Transactions of the British Mycological Society 87, 45-76.

Cannon PF. 1988 - Proposal to merge the Phyllachorales with the Diaporthales, with a new family structure. System Ascom 7, 23-43.

Cannon PF. 1989 - Studies on fungi with isthmoid ascospores: the genus Diatractium. Mycological research 92, 327-334.

Cannon PF. 1991 - A revision of Phyllachora and some similar genera on the host family Leguminosae. Mycological Papers 163, 1-302.

Cannon PF. 1992 - IMI descriptions of fungi and bacteria, set 114, nos 1131-1140. Mycopathologia 120, 43-64.

Cannon PF. 1994 - Observations on coevolution of the Phyllachoraceae (Fungi: Ascomycota) with the Leguminosae. In: Sprent JJ \& McKey D (Eds.). Advances in Legume Systematics vol. 5. The Nitrogen Factor 179-188.

Cannon PF. 1996 - Systematics and diversity of the Phyllachoraceae associated with Rosaceae, with a monograph of Polystigma. Mycological Research 100, 1409-1427.

Cannon PF. 2001 - Rediscovery and redescription of the genus Uleoporthe (Melanconidaceae). Fungal Diversity 7, 17-25.

Cannon PF, Alcorn JL. 1994 - Omnidemptus affinis gen. et sp. nov., teleomorph of Mycoleptodiscus affinis sp. nov. Mycotaxon 51, 483-487.

Cannon PF, Evans HC. 1999 - Biotrophic species of Phyllachoraceae associated with the angiosperm family Erythroxylaceae. Mycological Research 103, 577-590.

Cannon PF, Hawksworth DL. 1982 - A re-evaluation of Melanospora Corda and similar pyrenomycetes, with a revision of the British species. Bot J Linn Soc 84, 115-160.

Cannon PF, Hawksworth DL. 1983 - Arxiomyces, a new name for Phaeostoma von Arx \& E. Müller. Transactions of the British Mycological Society 8, 644-645. 
Cannon PF, Kirk PM. 2007 - Fungal families of the world. CABI Bioscience, Wallingford 1-456.

Cannon PF, Minter DW. 2014 - Lamproconium desmazieresii. IMI Descriptions of Fungi \& Bacteria 1996.

Cannon PF, Buddie AG, Bridge PD, de Neergaard E et al. 2012a - Lectera, a new genus of the Plectosphaerellaceae for the legume pathogen Volutella colletotrichoides. MycoKeys 3, $23-$ 36.

Cannon PF, Damm U, Johnston PR, Weir BS. 2012b - Colletotrichum current status and future directions. Studies in Mycology 73, 181-213.

Cardoza YJ, Moser JC, Klepzig KD, Raffa KF. 2008 - Multipartite symbioses among fungi, mites, nematodes, and the spruce beetle, Dendroctonus rufipennis. Environmental Entomology 37, 956-963.

Carlucci A, Raimondo ML, Santos J, Phillips AJL. 2012 - Plectosphaerella species associated with root and collar rots of horticultural crops in southern Italy. Persoonia Molecular Phylogeny and Evolution of Fungi 28, 34.

Carlucci A, Cibelli F, Lops F, Phillips AJL et al. 2015 - Pleurostomophora richardsiae associated with trunk diseases of grapevines in southern Italy. Phytopathol Mediterr 54, 109-123.

Carmarán CC, Romero AI, Giussani LM. 2006 - An approach towards a new phylogenetic classification in Diatrypaceae. Fungal Divers 23, 67-87.

Carmarán CC, Robles CA, D’Jonsiles MF, Ceriani E et al. 2014 - Clave para la identificación de especies de la familia Peroneutypa (Xylariales, Ascomycota). Lilloa-Fundación Miguel Lillo (Tucumán-Argentina) 51, 20-32.

Carmarán CC, Berretta M, Martínez S, Barrera V et al. 2015 - Species diversity of Cladorrhinum in Argentina and description of a new species, Cladorrhinum australe. Mycol Progr 14, 94.

Carmichael JW, Kendrick WB, Conners IL, Sigler L. 1980 - Genera of Hyphomycetes. The University of Alberta Press.

Carneiro de Almeida DA, Pascholati Gusmão LF, Miller AN. 2016 - Brazilian Semi-Arid Ascomycetes II: New and interesting records of Bertiaceae, Nitschkiaceae and Scortechiniaceae (Coronophorales, Sordariomycetes). Nova Hedwigia 102, 513-522.

Carrieri R, Pizzolongo G, Carotenuto G, Tarantino P, Lahoz E. 2017 - First Report of Necrotic Leaf Spot Caused by Plectosphaerella cucumerina on Lamb's Lettuce in Southern Italy. Applied Soil Ecology 110, 43-52.

Carvalho CR, Ferreira-D'Silva A, Wedge DE, Cantrell CL, Rosa LH. 2018 - Antifungal activities of cytochalasins produced by Diaporthe miriciae, an endophytic fungus associated with tropical medicinal plants. Canadian Journal of Microbiology 64, 835-843.

Castlebury LA, Rossman AY, Jaklitsch WJ, Vasilyeva LN. 2002 - A phylogeny overview of the Diaporthales based on large subunit nuclear ribosomal DNA sequences. Mycologia 94, 10171031.

Castlebury LA, Rossman AY, Hyten AS. 2006 - Phylogenetic relationships of Neonectria/Cylindrocarpon on Fagus in North America. Botany 84, 1417-1433.

Castro BL, Carreño AJ, Galeano NF, Roux J et al. 2013 - Identification and genetic diversity of Rosellinia spp. associated with root rot of coffee in Colombia. Australas Plant Pathology 42, 515-523.

Catania MV, Romero AI. 2012 - Crassoascus monocaudatus and Iodosphaeria podocarpi, two new species on Podocarpus parlatorei from "Las Yungas", Argentina. Mycosphere 3, 37-44.

Cavaliere AR, Johnson TW. 1965 - A new marine Ascomycete from Australia. Mycologia 57, 927.

Cavaliere AR, Johnson TW. 1966 - Marine Ascomycetes: ascocarp morphology and its application to taxonomy. III. A revision of the genus Lulworthia Sutherland. Nova Hedwigia 10, 425437.

Cavara F. 1888 - Sul fungo ehe e causa del bitter rot degli americani. Atti del'Istituto Botanico edel Laboratorio Crittogamico dell'Università di Pavia series 2 1, 359.

Cesati V. 1856 - Explicatio Iconum. Hedwigia 1, 103-104. 
Cesati V, De Notaris G. 1863 - Schema di classificazione degle sferiacei italici aschigeri piu' o meno appartenenti al genere Sphaeria nell'antico significato attribuitoglide Persono. Commentario della Società Crittogamologica Italiana 1, 177-420.

Chadefaud M. 1960 - Les V eg etaux non Vasculaires (Cryptogamie). In: Chadefaud M, Emberger L (eds). Trait e de Botanique Syst ematique. Masson, Paris 1-1018.

Chakrabarti A, Bonifaz A, Gutierrez-Galhardo MC, Mochizuki T, Li S. 2015 - Global epidemiology of sporotrichosis. Med Mycol 53, 3-14.

Chakusary MK, Mohammadi H, Khodaparast SA. 2015 - Occurence of Jattaea algeriensis (Calosphaeriales, Calosphaeriaceae) on Mespilus germanica and Parrotia persica in Iran. Iranian Mycological Congress 2, 58.

Chalkley DB, Suh SO, Volkmann-Kohlmeyer B, Zhou JJ. 2010 - Diatrypasimilis australiensis, a novel xylarialean fungus from mangrove. Mycologia 102, 430-437.

Chambers KR, De Wet DC. 1987 - Isolation of Sordaria fimicola from Maize Stalks. J. Phytopathol 120, 369-371.

Chang HS. 2001 - Trichocladium anamorph of Ascotaiwania hsilio and Monodictys-like anamorphic states of Ascotaiwania lignicola. Fungal Science 16, 35-38.

Chang HS, Hsieh SY, Jones EBG, Rwad SJ, Moss ST. 1998 - New freshwater species of Ascotaiwania and Savoryella from Taiwan. Mycological Research 102, 709-718.

Chang JC, Hsiao G, Lin RK, Kuo YH et al. 2018 - Bioactive constituents from the termite nestderived medicinal fungus Xylaria nigripes. Journal of Natural Products 80, 38-44.

Chaudhary P, Campbell J, Hawksworth DL, Sastry KN. 2006 - Vittatispora, a new melanosporaceous genus from Indian soil. Mycologia 98, 460-467.

Chaverri P, Bischoff JF, Evans HC, Hodge KT. 2005 - Regiocrella, a new entomopathogenic genus with a pycnidial anamorph and its phylogenetic placement in the Clavicipitaceae. Mycologia 97, 1225-1237.

Chaverri P, Liu M, Hodge KT. 2008 - A monograph of the entomopathogenic genera Hypocrella, Moelleriella, and Samuelsia gen. nov.(Ascomycota, Hypocreales, Clavicipitaceae), and their aschersonia-like anamorphs in the Neotropics. Studies in mycology 60, 1-66.

Chaverri P, Salgado C, Hirooka Y, Rossman A et al. 2011 - Delimitation of Neonectria and Cylindrocarpon (Nectriaceae, Hypocreales, Ascomycota) and related genera with Cylindrocarpon-like anamorphs. Studies of Mycology 68, 35-78.

Checa J, Blanco MN, Moreno G. 2013 - Contributions to the family Thyridiaceae. New data on Sphaeria mutabilis. Mycotaxon 125, 149-164.

Cheewangkoon R, Groenewald JZ, Summerell BA, Hyde KD et al. 2009 - Myrtaceae, a cache of fungal biodiversity. Persoonia 55-85.

Cheewangkoon R, Groenewald JZ, Verkley GJM, Hyde KD et al. 2010 - Re-evaluation of Cryptosporiopsis eucalypti and Cryptosporiopsis-like species occurring on Eucalyptus leaves. Fungal Diversity 44, 89-105.

Chen SF, Wingfield MJ, Roux J. 2013 - Diversimorbus metrosiderotis gen. et sp. nov. and three new species of Holocryphia (Cryphonectriaceae) associated with cankers on native Metrosideros angustifolia trees in South Africa. Fungal Biology 117, 289-310.

Chen SF, Wingfield MJ, Li GQ, Liu FF. 2016 - Corticimorbus sinomyrti gen. et sp. nov. (Cryphonectriaceae) pathogenic to native Rhodomyrtus tomentosa (Myrtaceae) in South China. Plant Pathology 65, 1254-1266.

Chen W, Shearer CA, Crane JL. 1999 - Phylogeny of Ophioceras spp. based on morphological and molecular data. Mycologia 91, 84-94.

Chen Y, Shao DD, Zhang AF, Yang X et al. 2014 - First report of a fruit rot and twig blight on pomegranate (Punica granatum) caused by Pilidiella granati in Anhui province of China. Plant Disease 98, 695.

Cheng X, Li W, Cai L. 2015 - Molecular phylogeny of Ascotricha, including two new marine algae-associated species. Mycologia 107, 490-504. 
Chesters CGC. 1935 - Studies on British Pyrenomycetes: I. The life histories of three species of Cephalotheca Fuck. Trans Brit Mycol Soc 19, 261-279.

Chethana KWT, Zhou Y, Zhang W, Liu M et al. 2017 - Coniella vitis sp. nov. is the common pathogen of white rot in Chinese vineyards. Plant Disease 101, 2123-2136.

Chew HF, Jungkind DL, Mah DY, Raber IM et al. 2010 - Post-traumatic fungal keratitis caused by Carpoligna sp. Cornea 29, 449-452.

Chittem K, Mathew FM, Gregoire M, Lamppa RS et al. 2015 - Identification and characterization of Fusarium spp. associated with root rots of field pea in North Dakota. European journal of plant pathology 143, 641-649.

Choi J, Lee Y, Chung HS, Koo JS et al. 2011 - Subcutaneous phaeohyphomycosis caused by Phaeoacremonium species in a kidney transplant patient: the first case in Korea. The Korean journal of laboratory medicine 31, 201-204.

Chomnunti P, Hongsanan S, Aguirre-Hudson B, Tian Q et al. 2014 - The sooty moulds. Fungal Diversity $66,1-36$.

Chuaseeharonnachai C, Somrithipol S, Suetrong S, Klaysuban A et al. 2017 - Conioscypha nakagirii, a new species from naturally submerged wood in Thailand based on morphological and molecular data. Mycoscience 58, 424-431.

Chuaseeharonnachai C, Suetrong S, Nuankaew S, Somrithipo S et al. 2020 - Synnematotriadelphia gen. nov. (S. stilboidea comb. nov. and S. synnematofera comb. nov.) and Triadelphia hexaformispora sp. nov. in the family Triadelphiaceae. Mycological Progress, 19:127-137.

Ciccarone A. 1951 - Primo contributo alla conoscenza dei Micromiceti dell'Africa orientale. Mycopathologia 5, 208-235.

Ciccarone A. 1963 - Osservazioni sistematiche su Diachorella onobrychidis(DC) Hamel. Phytopathologia Mediterranea 2, 239-250.

Ciferri R. 1950 - Schedae Mycologicae I-XI Direttore dell Istituto Botanico e Laboratorio Crittogamico Italiano. Universitdi Pavia, Pavia.

Ciferri R. 1954 - Schedae Mycologicae XII-XXXIV. Sydowia 8, 245-270.

Clements FE, Shear CL. 1931 - The genera of Fungi 1-496.

Cole GT, Samson RA. 1979 - Patterns of Development in Conidial Fungi. Pitman: London, San Francisco, Melbourne.

Colla S. 1929 - Su alcuni funghi parassiti delle termiti. Boll Lab Zool Portici 22, 39-48.

Collado J, Platas G, Bills GF, Basilio A et al. 2006 - Studies on Morinia: Recognition of Morinia longiappendiculata sp. nov. as a new endophytic fungus, and a new circumscription of Morinia pestalozzioides. Mycologia 98, 616-627.

Constantinescu O, Samson RA. 1982 - Triadelphia, a pleomorphic genus of hyphomycetes. Mycotaxon 15, 472-486.

Conway KE, Barr ME. 1977 - Classification of Ophioceras dolichostomum. Mycotaxon 5, 376380.

Cooke MC. 1883 - The genus Anthostoma. Grevillea 12, 49-53.

Cooke MC. 1888 - New British fungi. Grevillea 17, 38-42

Cooke MC. 1891 - Australian fungi. Grevillea 20, 4-7.

Corda ACJ. 1829 - In J. Sturm (Ed.), Deutschlands Flora, III (Die Pilze Deutschlands) 2, heft 7.

Corda ACJ. 1837 - Icones fungorum hucusque cognitorum. Abbildungen der Pilze und Schwaemme I. Pragae.

Corda ACJ. 1838 - Icones fungorum hucusque cognitorum 2.

Corda ACI. 1839a - Coniomycetes Nees ab Esenb. Icones Fungorum hucusque Cognitorum 3, 155.

Corda ACJ. 1839b - Icones fungorum hucusque cognitorum 3, 1-55.

Corda ACJ. 1842 - Icones fungorum hucusque cognitorum. Calve, Prague 5, 92.

Corda F. 1833 - In Sturm's Deutschl. Flora 3, 85.

Coronado-Ruiz C, Avendaño R, Escudero-Leyva E, Conejo-Barboza G et al. 2018 - Two new cellulolytic fungal species isolated from a $19^{\text {th }}$-century art collection. Scientific Report 7492. 
Costantin J. 1888 - Les Mucédinées Simples. Paul Klincksieck, Paris: 1-209.

Costantin J. 1892 - Sur quelques maladies du blanc de Champignon. Comptes Rendues des Séances Hebdomadaires de l'Académie des Sciences Paris 114, 849-851.

Coumans JW, Harvey J, Backhouse D, Poljak A et al. 2011 - Proteomic assessment of host -associated microevolution in the fungus Thielaviopsis basicola. Environmental Microbiology 13, 576-588.

Coustou V, Deleu C, Saupe S, Begueret J. 1997 - The protein product of the het-s heterokaryon incompatibility gene of the fungus Podospora anserina behaves as a prion analog. Proceedings of the National Academy of Sciences 94, 9773-9778.

Crane JL, Miller AN. 2016 - Studies in genera similar to Torula: Bahusaganda, Bahusandhika, Pseudotorula, and Simmonsiella gen. nov. IMA Fungus 7, 29-45.

Croft WA, Jarvis BB, Yatawara C. 1986 - Airborne outbreak of trichothecene toxicosis. Atmospheric Environment (1967) 20, 549-552.

Crous PW. 2008 - Sporidesmium knawiae Crous, sp. nov. Fungal Planet 29.

Crous PW, Gams W. 2000 - Phaeomoniella chlamydospora gen. et comb. nov., a causal organism of Petri grapevine decline and esca. Phytopathologia Mediterranea 39, 112-118.

Crous PW, Groenewald JZ. 2013 - A phylogenetic re-evaluation of Arthrinium. IMA Fungus 4, 133-154.

Crous PW, Peerally A. 1996 - Gliocladiopsis irregulare sp. nov. and notes on Cylindrocladium spathiphylli. Mycotaxon 58, 119-128.

Crous PW, Van der Linde EJ. 1993 - New and interesting fungi. 11. Eucalyptus leaf fungi. South African Journal of Botany 59, 300-304.

Crous PW, Wingfield MJ. 1993 - A re-evaluation of Cylindrocladiella, and a comparison with morphologically similar genera. Mycological Research 97, 433-448.

Crous PW, Knox-Davies PS, Wingfield MJ. 1989 - Newly-recorded foliage fungi of Eucalyptus spp. in South Africa. Phytophylactica 21, 85-88.

Crous PW, Wingfield MJ, Nag Raj TR. 1993 - Harknessia species occurring in South Africa. Mycologia 85, 275-280.

Crous PW, Wingfield MJ, Alfenas AC, Silviera SF. 1994a - Cylindrocladium naviculatum sp. nov., and two new vesiculate hyphomycete genera, Falcocladium and Vesicladiella. Mycotaxon $50,441-458$.

Crous PW, Wingfield MJ, Kendrick WB. 1994b - Kionochaeta pini sp. nov. and Verrucophragmia splendens gen. nov. from leaf litter in South Africa. Mycologia 447-450.

Crous PW, Wingfield MJ, Kendrick WB. 1995 - Foliicolous dematiaceous hyphomycetes from Syzygium cordatum. Canadian Journal of Botany 73, 224-234.

Crous PW, Gams W, Wingfield MJ, Van Wyk PS. 1996 - Phaeoacremonium gen. nov. associated with wilt and decline diseases of woody hosts and human infections. Mycologia 88, 786-796.

Crous PW, Kendrick W, Alfenas A. 1997 - New species of hyphomycetes associated with Eucalyptus. South African Journal of Botany 63, 286-290.

Crous PW, Slippers B, Wingfield MJ, Rheeder J et al. 2006a - Phylogenetic lineages in the Botryosphaeriaceae. Studies in Mycology 55, 235-253.

Crous PW, Wingfield MJ, Mansilla JP, Alfenas AC, Groenewald JZ. 2006b - Phylogenetic reassessment of Mycosphaerella spp. and their anamorphs occurring on Eucalyptus. Studies in Mycology 55, 99-131.

Crous PW, Groenewald JZ, Himaman W. 2007a - Falcocladium thailandicum. Fungal Planet 18.

Crous PW, Mohammed C, Glen M, Verkley GJM et al. 2007b - Eucalyptus microfungi known from culture. 3. Eucasphaeria and Sympoventuria genera nova, and new species of Furcaspora, Harknessia, Heteroconium and Phacidiella. Fungal Diversity 25, 19-36.

Crous PW, Groenewald JZ, Lee SS. 2009 - Fungal planet 41. Nawawia malaysiana. Persoonia 23, 194-195.

Crous PW, Summerell BA, Shivas RG, Romberg M et al. 2011 - Fungal Planet description sheets: 92-106. Persoonia: Molecular Phylogeny and Evolution of Fungi 27, 130-162. 
Crous PW, Shivas RG, Wingfield MJ, Summerell BA et al. 2012a - Fungal Planet description sheets. 128-153. Persoonia 29, 146-201.

Crous PW, Summerell BA, Alfenas AC, Edwards J et al. 2012b - Genera of diaporthalean coelomycetes associated with leaf spots of tree hosts. Persoonia 28, 66-75.

Crous PW, Summerell BA, Shivas RG, Burgess TI et al. 2012c - Fungal Planet description sheets: 107-127 Persoonia 28, 138-182.

Crous PW, Summerell BA, Shivas RG, Carnegie AJ, Groenewald JZ. 2012d - A re-appraisal of Harknessia (Diaporthales), and the introduction of Harknessiaceae fam.nov. Persoonia 28, 49-65.

Crous PW, Verkley GJM, Christensen M, Castaneda-Ruiz RF, Groenewald JZ. 2012e - How important are conidial appendages? Persoonia 28, 126-137.

Crous PW, Wingfield MJ, Guarro J, Cheewangkoon R et al. 2013 - Fungal Planet description sheets: 154-213. Persoonia 31, 188-296.

Crous PW, Shivas RG, Quaedvlieg W, van der Bank M et al. 2014a - Fungal Planet Description Sheets: 214-280. Persoonia 32, 184-306.

Crous PW, Wingfield MJ, Schumacher RK, Hyde KD et al. 2014b - Fungal Planet description sheets: 281-319. Persoonia 33, 212-289.

Crous PW, Carris LM, Giraldo A, Groenewald JZ et al. 2015a - The genera of fungi-fixing the application of the type species of generic names-G 2: Allantophomopsis, Latorua, Macrodiplodiopsis, Macrohilum, Milospium, Protostegia, Pyricularia, Robillarda, Rotula, Septoriella, Torula, and Wojnowicia. IMA Fungus 6, 163-198.

Crous PW, Schumacher RK, Wingfield MJ, Lombard L et al. 2015b - Fungal Systematics and Evolution: FUSE 1. Sydowia 67, 81-118.

Crous PW, Wingfield MJ, Guarro J, Hernández-Restrepo M et al. 2015c - Fungal Planet description sheets: 320-370. Persoonia 34, 167-266.

Crous PW, Wingfield MJ, Le Roux JJ, Richardson DM et al. 2015d - Fungal Planet description sheets: 371-399. Persoonia 35, 264-327.

Crous PW, Wingfield MJ, Burgess TI, Hardy GE et al. 2016a - Fungal Planet description sheets: 469-557. Persoonia : Molecular Phylogeny and Evolution of Fungi 37, 218-403.

Crous PW, Wingfield MJ, Richardson DM, Le Roux JJ et al. 2016b - Fungal Planet description sheets: 400-468. Persoonia 36, 316-458.

Crous PW, Wingfield MJ, Burgess TI, Carnegie AJ et al. 2017a - Fungal Planet description sheets: 625-715. Persoonia: Molecular Phylogeny and Evolution of Fungi 39, 270-467.

Crous PW, Wingfield MJ, Burgess TI, Hardy GE et al. 2017b - Fungal Planet description sheets: 558-624. Persoonia 38, 240-384.

Crous PW, Liu F, Cai L, Barber PA et al. 2018a - Allelochaeta (Sporocadaceae): pigmentation lost and gained. Fungal Systematics and Evolution 2, 273-309.

Crous PW, Luangsa-Ard JJ, Wingfield M, Carnegie AJ et al. 2018b - Fungal Planet description sheets: 785-867. Persoonia: Molecular Phylogeny and Evolution of Fungi 41, 238-417.

Crous PW, Schumacher RK, Wingfield MJ, Akulov A et al. 2018c - New and Interesting Fungi. 1. Fungal Systematics and Evolution 1, 169-215.

Crous PW, Wingfield MJ, Burgess TI, Hardy GSJ et al. 2018d - Fungal Planet description sheets: 716-784. Persoonia: Molecular Phylogeny and Evolution of Fungi 40, 240-393.

Crous PW, Carnegie AJ, Wingfield MJ, Sharma R et al. 2019a - Fungal Planet description sheets: 868-950. Persoonia 42, 291-473.

Crous PW, Schumacher RK, Akulov A, Thangave R et al. 2019b - New and Interesting Fungi. 2. Fungal Systematics and Evolution 3, 57-134.

Crowther TW, Boddy L, Jones TH. 2012 - Functional and ecological consequences of saprotrophic fungus-grazer interactions. The ISME Journal 6, 1992-2001.

Cruywagen EM, de Beer ZW, Roux J, Wingfield MJ. 2010 - Three new Graphium species from baobab trees in South Africa and Madagascar. Persoonia: Molecular Phylogeny and Evolution of Fungi 25, 61. 
Cummings DJ, Belcour L, Grandchamp C. 1979 - Mitochondrial DNA from Podospora anserina. Molecular and General Genetics MGG 171, 239-250.

Cruz ACR, Leão-Ferreira SM, Barbosa FR, Gusmão LFP. 2008 - Conidial fungi from semi-arid Caatinga biome of Brazil. New and interesting Dictyochaetaspecies. Mycotaxon 106, 15-27.

Curzi M. 1931 - Rapporti fra i generi Microascus Zukal e Scopulariopsis Bainier. Bolletino della Stazione di Patologia Vegetale Roma 11, 55-60.

Dai DQ, Bahkali AH, Li QR, Bhat DJ et al. 2014a - Vamsapriya (Xylariaceae) re-described, with two new species and molecular sequence data. Cryptogamie Mycologie 35, 339-357.

Dai DQ, Wijayawardene NN, Bhat DJ, Chukeatirote E et al. 2014b - Pustulomyces gen. nov. accommodated in Diaporthaceae, Diaporthales, as Revealed by Morphology and Molecular Analyses. Cryptogamie Mycologie 35, 63-72.

Dai DQ, Jiang HB, Tang LZ, Bhat DJ. 2016 - Two new species of Arthrinium (Apiosporaceae, Xylariales) associated with bamboo from Yunnan, China. Mycosphere 7, 1332-1345.

Dai DQ, Phookamsak R, Wijayawardene NN, Li WJ et al. 2017 - Bambusicolous fungi. Fungal Diversity 82, 1-105.

Daisy BH, Strobel GA, Castillo U, Ezra D et al. 2002 - Naphthalene, an insect repellent, is produced by Muscodor vitigenus, a novel endophytic fungus. Microbiology 148, 3737-3741.

Damm U, Crous PW, Fourie PH. 2008 - A fissitunicate ascusmechanism in the Calosphaeriaceae, and novel species of Jattaea and Calosphaeria on Prunus wood. Persoonia 20, 39-52.

Damm U, Fourie PH, Crous PW. 2010 - Coniochaeta (Lecythophora), Collophora gen. nov. and Phaeomoniella species associated with wood necroses of Prunus trees. Persoonia 24, 60-80.

Dankó G. 1975 - Stachybotryotoxicosis and immunosuppression. International Journal of Environmental Studies 8, 209-211.

Danti R, Sieber TN, Sanguineti G. 2002 - Endophytic mycobiota in bark of European beech (Fagus sylvatica) in the Apennines. Mycological Research 106, 1343-1348.

Daranagama DA, Liu XZ, Chamung S, Stadler M et al. 2014 - A multigene genealogy reveals the phylogenetic position of Rhopalostroma lekae. Phytotaxa 186, 177-187.

Daranagama DA, Camporesi E, Tian Q, Liu X et al. 2015 - Anthostomella is polyphyletic comprising several genera in Xylariaceae. Fungal Diversity 73, 203-238.

Daranagama DA, Camporesi E, Liu XZ, Jeewon R et al. 2016 - Taxonomic rearrangement of Anthostomella (Xylariaceae) based on multigene phylogenies and morphology. Cryptogamie Mycologie 37, 509-538.

Daranagama DA, Tian Q, Liu XZ, Hyde KD. 2017 - Towards a natural classification of Amplistromataceae. Mycosphere 8, 1392-1402.

Daranagama DA, Hyde KD, Sir EB, Thambugala KM et al. 2018 - Towards a natural classification and backbone tree for Graphostromataceae, Hypoxylaceae, Lopadostomataceae and Xylariaceae. Fungal Diversity 88, 1-165.

Devay J, Lukezic F, English W, Moller W, Parkinson B. 1965 - Controlling: Ceratocystis canker of stone fruit trees. California Agriculture 19, 2-4.

Davolos D, Pietrangeli B, Persiani AM, Maggi O. 2019 - Victoriomyces antarcticus gen. nov., sp. nov., a distinct evolutionary lineage of the Cephalothecaceae (Ascomycota) based on sequence-based phylogeny and morphology. Int J Syst Evol Microbiol 69, 1099-1110.

Dayarathne MC, Maharachchikumbura SSN, Phookamsak R, Fryar S et al. 2016a - Morphomolecular characterization and epitypification of Annulatascus velatisporus. Mycosphere 7, 1389-1398.

Dayarathne MC, Phookamsak R, Hyde KD, Manawasinghe IS et al. 2016b - Halodiatrype, a novel diatrypaceous genus from mangroves with $H$. salinicola and $H$. avicenniae spp. nov. Mycosphere 7, 612-627.

Dayarathne MC, Maharachchikumbura SSN, Jones EBG, Goonasekara ID et al. 2017 Neophyllachora gen nov. (Phyllachorales), three new species of Phyllachora from Poaceae and resurrection of Polystigmataceae (Xylariales). Mycosphere 8, 1598-1625. 
Dayarathne MC, Maharachchikumbura SSN, Jones EBG, Dong W et al. 2019a - Phylogenetic revision of Savoryellaceae and evidence for its ranking as a subclass. Frontiers in Microbiology 10, 840.

Dayarathne MC, Wanasinghe DN, Devadatha B, Abeywickrama P et al. 2019b - Modern taxonomic approaches to identifiying diatrypaceous fungi from marine habitats, a novel genus Halocryptovalsa and expansion of Halodiatrype, Cryptogam., Mycol (in rev.).

Dayarathne MC, Maharachchikumbura SSN, Devadatha B, Jones EBG et al. 2020 - Towards an Integrative Morpho-Molecular Classification and Evolution of Halosphaeriaceae and Lulwothiaceae. Fungal Diversity (in prep.)

de Almeida DAC, Gusmão LFP, Miller AN. 2016 - Taxonomy and molecular phylogeny of Peroneutypa (Ascomycota, Xylariales) species from the Brazilian semi-arid region, including four new species. Mycological Progress 15, 1-27.

de Beer ZW, Seifert KA, Wingfield MJ. 2013a - A nomenclator for ophiostomatoid genera and species in the Ophiostomatales and Microascales. In: Seifert KA, de Beer ZW, Wingfield MJ (eds). The ophiostomatoid fungi: expanding frontiers CBS biodiversity series. CBS-KNAW Fungal Biodiversity Centre, Utrecht, The Netherlands 245-322.

de Beer ZW, Seifert KA, Wingfield MJ. 2013b - The ophiostomatoid fungi: their dual position in the Sordariomycetes. In: Seifert KA, de Beer ZW, Wingfield MJ (eds). The ophiostomatoid fungi: expanding frontiers CBS biodiversity series. CBS-KNAW Fungal Biodiversity Centre, Utrecht, The Netherlands 12, 1-9.

de Beer ZW, Duong TA, Barnes I, Wingfield BD, Wingfield MJ. 2014 - Redefining Ceratocystis and allied genera. Study in Mycology 79, 187-219.

de Beer ZW, Duong TA, Wingfield MJ. 2016a - The divorce of Sporothrix and Ophiostoma: solution to a problematic relationship. Studies in mycology 83, 165-191.

de Beer ZW, Marincowitz S, Duong TA, Kim JJ et al. 2016b - Hawksworthiomyces gen. nov. (Ophiostomatales), illustrates the urgency for a decision on how to name novel taxa known only from environmental nucleic acid sequences (ENAS). Fungal Biology 120, 1323-1340.

de Beer ZW, Marincowitz S, Duong TA, Wingfield MJ. 2017 - Bretziella, a new genus to accommodate the oak wilt fungus, Ceratocystis fagacearum (Microascales, Ascomycota). MycoKeys 27, 1-19.

de Bekker C, Will I, Das B, Adams RM. 2018 - The ants (Hymenoptera: Formicidae) and their parasites: effects of parasitic manipulations and host responses on ant behavioral ecology. Myrmecological News, 28, 1-24.

de Errasti A, Novas MV, Carmarán CC. 2014 - Plant-fungal association in trees: Insights into changes in ecological strategies of Peroneutypa scoparia (Diatrypaceae). Flora Morphology, Distribution, Functional Ecology of Plants 209, 704-710.

de Gruyter J, Aveskamp MM, Woudenberg JHC, Verkley GJM et al. 2009 - Molecular phylogeny of Phoma and allied anamorph genera: towards a reclassification of the Phoma complex. Mycological Research 113, 508-519.

de Hoog GS. 1974 - The genera Blastobotrys, Sporothrix, Calcarisporium and Calcarisporiella gen. nov. Studies in Mycology 7, 1-84.

de Hoog GS. 1978 - Notes some fungicolous Hyphomycetes and their relatives. PersooniaMolecular Phylogeny and Evolution of Fungi 10, 33-81.

de Hoog GS. 1985 - Taxonomy of the Dactylaria complex, IV. Dactylaria, Neta, Subulispora and Scolecobasidium. Studies in Mycology 26, 1-60.

de Hoog GS, Guarro J, Gené J, Figueras MJ. 2000 - Atlas of Clinical Fungi. Centraalbureau voor Schimmelcultures, Utrecht.

de Hoog GS, Guarro J, Gené J, Figueras MJ. 2011 - Atlas of clinical fungi. CD-ROM version 3.1. CBS-KNAW Fungal Biodiversity Centre, Utrecht, The Netherlands.

de Hoog GS, van Diepeningen AD, Mahgoub E, van de Sande WWJ. 2012 - New Species of Madurella, Causative Agents of Black-Grain Mycetoma. American Society for Microbiology Journals 50, 988-994. 
de Lamarck JB, de Candolle AP. 1805 - Flore française, vol 5, edn 3 (Paris) 2, 280.

De Long Q, Liu LL, Zhang X, Wen TC et al. 2019 - Contributions to species of Xylariales in China-1. Durotheca species. Mycological Progress 18, 495-510.

De Notaris G. 1844 - Cenni sulla tribù dei Pirenomiceti sferiacei e descrizione di alcuni generi spettanti alla medesima. Giornale Botanico Italiano 1, 322-355.

De Silva DD, Rapior S, Fons F, Bahkali AH, Hyde KD. 2012 - Medicinal mushrooms in supportive cancer therapies: an approach to anti-cancer effects and putative mechanisms of action. Fungal Diversity 55, 1-35.

De Silva DD, Rapior S, Sudarman E, Hyde et al. 2013 - Bioactive metabolites from macrofungi: ethnopharmacology, biological activities and chemistry. Fungal Diversity 62, 1-40.

De Silva H, Castlebury LA, Green S, Stone JK. 2009 - Characterization and phylogenetic relationships of Anisogramma virgultorum and $A$. anomala in the Diaporthales (Ascomycota). Mycological Research 113, 73-81.

De Silva NI, Phookamsak R, Maharachchikumbura SSN, Thambugala KM et al. 2017 Monochaetia ilexae sp. nov.(Pestalotiopsidaceae) from Yunnan Province in China. Phytotaxa 291, 123-132.

De Silva SC, Barrocas EN, Machado JC, Da Silva UA, Dias IE. 2014 - Effects of Stenocarpella maydis in seeds and in the initial development of corn. Journal of Seed Science 36, 79-86.

Decock C, Ruiz RC, Adhikari MK. 2004 - Taxonomy and phylogeny of Brachyconidiellopsis fimicola gen. et sp. nov., a sporodochial to synnematous coprophilous fungi related to the Microascales (Ascomycetes) from Nepal. Cryptogamie Mycologie 25, 137-147.

Decock C, Huret S, Bivort C. 2008 - Anamorphic fungi from French Guyana. Septomyrothecium maraitiense sp nov and S. setiramosum comb. nov (anamorphic Hypocreales, Ascomycota). Cryptogamie Mycologie 29, 321-331.

del Valle Catania M, Romero AI, Huhndorf SM, Miller AN. 2011 - A new species and new records of Cercophora from Argentina. Mycologia 103, 1372-1383.

Delgado G, Mercado A, Mena J, Guarro J. 2007 - Hemicorynespora clavata, a new hyphomycete (anamorphic fungi) from Cuba. Cryptogamy Mycology 28, 65-69.

Dennis RWG. 1960 - British cup fungi and their allies. An introduction to the Ascomycetes. Bernard Quaritch Ltd., London 280.

Dennis RWG. 1968 - British Ascomycetes. J Cramer, Lehre, Germany, 455 pp.

Desmazières JBHJ. 1830 - Annales des Sciences Naturelles Botanique 19, 269-279.

Dewi N. 2006 - Stachylidium pallidum Dewi sp. nov. from Java. Reinwardtia 12, 215-217.

Dhargalkar S, Bhat DJ. 2009 - Echinosphaeria pteridis sp. nov. and its Vermiculariopsiella anamorph. Mycotaxon 108, 115-122.

DiCosmo F, Berch S, Kendrick WB. 1983 - Cylindrotrichum, Chaetopsis, and two new genera of hyphomycetes, Kylindria and Xenokylindria. Mycologia 75, 949-973.

Diederich P. 2003 - Aportación al conocimiento de los hongos liquenícolas de Colombia. The Bryologist 106, 630-632.

Diedicke H. 1915 - Pilze VII. Sphaeropsideae, Melanconieae [part 5]. Kryptogamenflora der Mark Brandenburg und Angrenzender Gebiete 9, 801-962.

Diehl WW. 1950 - Balansia and the Balansiae in America. Agriculture Monograph 4, 78.

Dissanayake AJ, Phillips AJ, Hyde KD, Yan JY, Li XH. 2017 - The current status of species in Diaporthe. Mycosphere 8, 1106-1156.

Doassans JE, Patouillard NT. 1892 - Une Clavariée entomogène. Revue Mycologique Toulouse 14, $67-70$.

Döbbeler P, Davison PG, Buck WR. 2015 - Two new hypocrealean ascomycetes on bryophytes from North America. Nova Hedwigia 100, 383-390.

Doi Y. 1972 - Revision of the Hypocreales with cultural observations. IV. The genus Hypocrea and its allies in Japan (2). Enumeration of the species. Bulletin of the National Science Museum Tokyo 15, 649-751. 
Doi Y, Dargan JS, Thind KS. 1977 - Cavimalum, a new genus of the bambusicolous Clavicipitales from Asia. Bulletin of the National Science Museum Tokyo 3, 23-31.

Domsch KH, Gams W. 1968 - Die Bedeutung vorfruchtabhangiger Verschiedungen in der Bodenmikroflora. Phytopathplogische Zeitschrift 63, 165-176.

Domsch KH, Gams W, Andersen TH. 1980 - Compendium of soil fungi (2nd ed.). Academic Press, London 1, 1-860.

Domsch KH, Gams W, Anderson TH. 2007 - Compendium of soil fungi, 2nd edn. IHW Verlag, Eching 672.

Dong JY, Zhao ZX, Cai L, Liu SQ et al. 2004 - Nematicidal effect of freshwater fungal cultures against the pine-wood nematode, Bursaphelenchus xylophilus. Fungal Diversity 15, 123-133.

Dong JY, Zhou YP, Li R, Zhou W et al. 2006 - Newnematicidal azaphilones fromtheaquatic fungus Pseudohalonectria adversaria YMF1.01019. FEMS Microbiol Lett 264, 65-69.

Dong JY, Wang L, Song HC, Wang LM et al. 2010 - Ophiocerol, a novel macrocylic neolignan from the aquatic fungus Ophioceras dolichostomum YMF1.00988. Nat Prod Res 24, 10041012.

Dong L, Xu J, Feng G, Li X et al. 2016 - Soil bacterial and fungal community dynamics in relation to Panax notoginseng death rate in a continuous cropping system. Scientific Reports 6, 31802.

dos Santos AF, Thomazi H, Duarte HSS, Machado EB et al. 2017 - First report of root rot caused by Rosellinia bunodes on a Poplar species (Populus deltoides) in Brazil. Plant Disease 101, 632-633.

Douanla-Meli C, Langer E. 2012 - Diversity and molecular phylogeny of fungal endophytes associated with Diospyros crassiflora. Mycology 3, 175-187.

Douglas LI, Deacon JW. 1994 - Strain variation in tolerance of water stress by Idriella (Microdochium) bolleyi, a biocontrol agent of cereal root and stem base pathogens. Biocontrol Science and Technology 4, 239-249.

Doveri F. 2008a - "Aggiornamento sul genere Chaetomium con descrizione di alcune specie coprofile, nuove perl" Italia - "An Update on the Genus Chaetomium with Descriptions of Some Coprophilous Species, New to Italy.”. Pagine di Micologia 29, 1-60.

Doveri F. 2008b - Pagine di micologia. Associazone Micologica Bresadola Centro Studi Micologici 65-66, 110.

Doveri F. 2014 - Coprophilous pyrenomycetes s.l. from the Tuscan Archipelago and adjacent peninsular coast: description of five species new to Italy. Mycosphere 5, 188-216.

Dreyfuss M, Härri E, Hofmann HE, Kobel H et al. 1976 - Cyclosporin A and C. Applied Microbiology and Biotechnology 3, 125-133.

Drobotko VG. 1945 - Stachybotryotoxicosis. A new disease of horses and humans. American Review of Soviet Medicine 2, 238-242.

Du Z, Hyde KD, Yang Q, Liang YM et al. 2017 - Melansporellaceae: a novel family of Diaporthales (Ascomycota). Phytotaxa 305, 191-200.

Duan JX, Wu WP, Liu XZ. 2007 - Dinemasporium (coelomycetes). Fungal Diversity 26, 205-218.

Duc PM, Hatai K, Kurata O,Tensha K et al. 2009 - Fungal infection of mantis shrimp (Oratosquilla oratoria) caused by two anamorphic fungi found in Japan. Mycopathologia 167, 229-247.

Dulymamode R, Cannon PF, Sivanesan A, Peerally A. 2001 - Fungi from Mauritius: four new ascomycetes on native plants. Mycological Research 105, 247-254.

Duncan CG. 1960 - Deterioration of Wood by Terrestrial Ascomycetes and Fungi Imperfecti. In: Developments in Industrial Microbiology, Springer, Boston, MA 148-156.

Duong LM, Lumyong S, Hyde KD, Jeewon R. 2004 - Emarcea castanopsidicola gen. et sp. nov. from Thailand, a new xylariaceous taxon based on morphology and DNA sequences. Studies in Mycology 50, 253-260. 
Dutta S, Sheikh I, Choppala J, Aulakh G et al. 1976 - DNA homologies among homothallic, pseudo-homothallic and heterothallic species of Neurospora. Molecular and General Genetics MGG 147, 325-330.

Earle FS. 1901 - Collections of Alabama fungi. In: Plant life of Alabama. In: Mohr C (ed). Contributions from the United States National Herbarium 150-263.

Eaton RA, Jones EB. 1971 - The biodeterioration of timber in water cooling towers. I. Fungal ecology and the decay of wood at Connah's Quay and Ince. Material und organismen 6, 5180 .

Edathodu J, Al-Abdely HM, AlThawadi S, Wickes BL et al. 2013 - Invasive fungal infection due to Triadelphia pulvinata in a patient with acute myeloid leukemia. Journal of Clinical Microbiology 51, 3426-3429.

Edwards J, Pascoe I. 2004 - Occurrence of Phaeomoniella chlamydospora and Phaeoacremonium aleophilum associated with Petri disease and esca in Australian grapevines. Australasian Plant Pathology 33, 273-279.

Edwards RL, Jonglaekha N, Kshirsagar A, Maitland DJ et al. 2003 - The Xylariaceae as phytopathogens. Recent Research Develments in Plant Science 1, 1-19.

Ehrenberg CG. 1818 - Sylvae Mycologicae Berolinenses. Formis Theophili Bruschcke, Berlin, Germany.

Ekanayaka AH, Ariyawansa HA, Hyde KD, Jones EBG et al. 2017 - Discomycetes: the apothecial representatives of the phylum Ascomycota. Fungal Diversity 87, 237-298.

Ekiz G, Hameş EE, Nalbantsoy A, Bedir E. 2016 - Two rare quinone-type metabolites from the fungus Septofusidium berolinense and their biological activities. The Journal of antibiotics 69, 111-113.

El Feghaly RE, Sutton DA, Thompson EH, Fu J et al. 2012 - Graphium basitruncatum fungemia in an immunosuppressed child post stem-cell transplantation. Medical mycology case reports 1 , $35-38$.

El-Gholl NE, Schubert TS, Peacock ME. 1996 - Tubakia leaf spot on chestnut. Plant Pathology Circular (Gainesville) 375.

Elliott ML. 2006 - Thielaviopsis Trunk Rot of Palm. Plant Pathology Department: UF/IFAS Fort Lauderdale Research and Education Center, Davie.

Elliott ML, Des Jardin EA. 2014 - Serenomyces associated with palms in southeastern USA: isolation, culture storage and genetic variation. Mycologia 106, 698-707.

Ellis MB. 1959 - Clasterosporium and some allied Dematiaceae-Phragmosporae. II. Mycological Papers 72, 1-75.

Ellis MB. 1961 - Dematiaceous hyphomycetes. II. Mycological Papers 79, 1-23.

Ellis MB. 1971 - Dematiaceous hyphomycetes. Commonwealth Mycological Institute, Kew, Surrey, England.

Ellis MB. 1972 - Dematiaceous hyphomycetes. XI. Mycological Papers 131, 1-25.

Ellis MB. 1976 - More dematiaceous hyphomycetes. Commonwealth Mycological Institute, Kew, Surrey, England.

Eriksson B. 1974 - On ascomycetes on Diapensiales and Ericales in Fennoscandia. 2. Pyrenomycetes. Svensk Botanisk Tidskrift 68, 192-234.

Eriksson OE. 1981 - The families of bitunicate ascomycetes. Nordic Journal of Botany 1, 800-800.

Eriksson OE. 1982 - Outline of the Ascomycetes-1982. Mycotaxon 15, 203-248.

Eriksson OE. 1984 - Outline of the ascomycetes. Systema Ascomycetum 3, 1-72.

Eriksson OE. 1999 - Outline of Ascomycota. Myconet 3, 1-88.

Eriksson OE. 2001 - Outline of Ascomycota. Myconet 6, 1-27.

Eriksson OE. 2006 - Outline of Ascomycota-2006. Myconet 12, 1-82.

Eriksson OE. 2014 - Checklist of the non-lichenized ascomycetes of Sweden. Acta Universitatis Upsaliensis.

Eriksson OE, Hawksworth DL. 1985 - Outline of the Ascomycetes-1985. Systema Ascomycetum $4,1-79$. 
Eriksson OE, Hawksworth DL. 1986a - An alphabetical list of the generic names of ascomycetes. Systema Ascomycetum 5, 3-111.

Eriksson OE, Hawksworth DL. 1986b - Notes on ascomycete systematics. Nos 1-224. Systema Ascomycetum 5, 113-174.

Eriksson OE, Hawksworth DL. 1987 - Outline of the Ascomycetes. Systema Ascomycetum 6, 259-337.

Eriksson OE, Hawksworth DL. 1990 - Outline of the Ascomycetes-1989. Systema Ascomycetum 8, 119-318.

Eriksson OE, Yue JZ. 1990 - Notes on bambusicolous pyrenomycetes. Nos. 1-10. Mycotaxon 38, 201-220.

Eriksson OE, Hawksworth DL. 1991 - Outline of the Ascomycetes-1990. Systema Ascomycetum 9, 39-271.

Eriksson OE, Hawksworth DL. 1993 - Outline of the Ascomycetes-1993. Systema Ascomycetum $12,51-257$.

Eriksson OE, Winka K. 1997 - Supraordinal taxa of Ascomycota. Myconet 1, 1-16.

Eriksson OE, Baral HO, Currah RS, Hansen K et al. 2001 - Outline of Ascomycota-2001. Myconet 7, 1-88.

Eriksson OE, Baral HO, Currah RS, Hansen K et al. 2003 - Outline of the Ascomycota. Myconet 9, $1-89$.

Ertz D, Heuchert B, Braun U, Freebury CE et al. 2016 - Contribution to the phylogeny and taxonomy of the genus Taeniolella, with a focus on lichenicolous taxa. Fungal Biology 120, $1416-1447$.

Espagne E, Lespinet O, Malagnac F, Da Silva C et al. 2008 - The genome sequence of the model ascomycete fungus Podospora anserina. Genome biology 9, R77.

Essakhi S, Mugnai L, Crous P, Groenewald J et al. 2008 - Molecular and phenotypic characterisation of novel Phaeoacremonium species isolated from esca diseased grapevines. Persoonia 21, 119-134.

Etayo J. 2002 - Aportación al conocimiento de los hongos liquenícolas de Colombia. Bibliotheca Lichenologica 84, 1-154.

Etayo J, Rosato VG. 2008 - Observations on lichenicolous fungi described by Spegazzini. The Lichenologist 40, 227-232.

Etayo J, Sancho LG. 2008 - Hongos liquenícolas del sur de Sudamérica, especialmente de Isla Navarino (Chile). Bibliotheca Lichenologica 98, 1-302.

Etayo J, Sharuddin SS. 2011 - Verruculina and Lichenoverruculina nom. nov. Herzogia 24, 379380 .

Etayo J, Flakus A, Kukwa M. 2013 - Niesslia echinoides (Niessliaceae, Ascomycota), a new lichenicolous fungus on Erioderma from Bolivia. The Lichenologist 45, 21-24.

Evans HC. 1974 - Natural control of arthropods, with special reference to ants (Formicidae), by fungi in the tropical high forest of Ghana. Journal of Applied Ecology 1, 37-49.

Evans HC. 1984 - The genus Mycosphaerella and its anamorphs Cercoseptoria, Dothistroma and Lecanosticta on pines. Mycological Papers 153, 1-102.

Evans HC, Samson RA. 1982 - Cordyceps species and their anamorphs pathogenic on ants (Formicidae) in tropical forest ecosystems 1. The Cephalotes (Myrmicinae) complex. Transactions of the British Mycological Society 79, 431-453.

Evans HC, Samson RA. 1987 - Fungal pathogens of spiders. Mycologist 1, 152-159.

Evans HC, Elliot SL, Hughes DP. 2011 - Ophiocordyceps unilateralis: A keystone species for unraveling ecosystem functioning and biodiversity of fungi in tropical forests? Communicative \& integrative biology, 4, 598-602.

Evidente A, Sparapano L, Andolf A, Bruno G. 2000 - Two naphthalenone pentakides from liquid cultures of Phaeoacremonium aleophilum, a fungus associated with esca of grapevine. Phytopathol Mediterr 39, 162-168. 
Fabre JH. 1883 - Essai sur les Sphériacées du Départment de Vaucluse II. Annales des Sciences Naturelles Botanique. ser 6 15, 31-69.

Fall J. 1951 - Studies on fungus parasites of strawberry leaves in Ontario. Canadian Journal of Botany 29, 299-315.

Fallah PM, Shearer CA. 1998 - Freshwater ascomycetes: Phomatospora spp. from lakes in Wisconsin. Mycologia 90, 323-329.

Fallah PM, Shearer CA, Chen W. 1997 - Ascovaginospora stellipala gen. et sp. nov. from sphagnum bogs. Mycologia 812-818.

Fallah PM, Crane JL, Shearer CA. 1999 - Freshwater ascomycetes: two new species of Ascotaiwania from North America. Canadian Journal of Botany 77, 87-92.

Fan XL, Du Z, Liang YM, Tian CM. 2016 - Melanconis (Melanconidaceae) associated with Betula spp. in China. Mycological Progress 15, 40.

Fan XL, Bezerra JDP, Tian CM, Crous PW. 2018 - Families and genera of diaporthalean fungi associated with canker and dieback of tree hosts. Persoonia 40, 119-134.

Farr DF, Rossman AY. 2001 - Harknessia lythri, a new species on purple loosestrife. Mycologia 93, 997-1001.

Farr DF, Rossman AY. 2003 - Dwiroopa, a coelomycetous genus with two species. Mycoscience 44, 443-446.

Farr DF, Rossman AY. 2018 - Fungal Databases, U.S. National Fungus Collections, ARS, USDA. Retrieved.

Farr DF, Rossman AY. 2019 - Fungal Databases, Systematic Mycology and Microbiology Laboratory, ARS, USDA. http://nt.arsgrin.gov/f ungaldatabases.

Farr DF, Castlebury LA, Rossman AY, Erincik O. 2001 - Greeneria uvicola, cause of bitter rot of grapes, belongs in the Diaporthales. Sydowia 53, 185-199.

Feliciano AJ, Eskalen A, Gubler WD. 2004 - Differential susceptibility of three grapevine cultivars to Phaeoacremonium aleophilum and Phaeomoniella chlamydospora in California. Phytopathologia Mediterranea 43, 66-69.

Feng Y, Blunt JW, Cole ALJ, Munro MH. 2004 - Novel cytotoxic thiodiketopiperazine derivatives from a Tilachlidium sp. Journal of Natural Products 67, 2090-2092.

Fernández FA, Huhndorf SM. 2004 - Neotropical pyrenomycetes: Porosphaerella borinquensis sp. nov. and its Pseudobotrytis terrestris anamorph. Fungal Diversity 17, 11-16.

Fernández FA, Huhndorf SM. 2005 - New species of Chaetosphaeria, Melanopsammella and Tainosphaeria gen. nov. from the Americas. Fungal Diversity 18, 15-57.

Fernández FA, Lutzoni FM, Huhndorf SM. 1999 - Teleomorph-anamorph connections: the new pyrenomycetous genus Carpoligna and its Pleurothecium anamorph. Mycologia 91, 251262.

Fernández FA, Rogers JD, Ju YM, Huhndorf SM, Umaña L. 2004 - Paramphisphaeria costaricensis gen. et sp. nov. and Pachytrype rimosa sp. nov. from Costa Rica. Mycologia 96, 175-179.

Fernández FA, Miller AN, Huhndorf SM, Lutzoni FM, Zoller S. 2006 - Systematics of the genus Chaetosphaeria and its allied genera: morphological and phylogenetic diversity in north temperate and neotropical taxa. Mycologia 98, 121-130.

Fernando L, Gusmão P. 2004 - Porobeltraniella gen. nov. to accommodate two species of Beltraniella. Mycologia 96, 150-153.

Ferraris TA. 1912 - Fungi: Hyphales. Flora Italica Cryptogamica Pars I: Fungi, Italy, Rocca S. Casciano 233-234.

Ferreira FA, Demuner NL, Rezende DV. 1992 - Mancha de folha, desfolhae antracnose do Jatobá (Hymenaea spp.) causadas por Erythrogloeum hymenaeae. Fitopatologia Brasileira 17, 106109.

Ferreira FA, Alfenas AC, Coelho L. 1997 - Portas-de-entrada para Coniella fragariae em folhas de eucalipto. Revista Árvore 21, 307-311. 
Ferrer A, Miller AN, Sarmiento C, Shearer CA. 2012 - Three new genera representing novel lineages of Sordariomycetidae (Sordariomycetes, Ascomycota) from tropical freshwater habitats in Costa Rica. Mycologia 104, 865-879.

Figueras MJ, Guarro J. 1988 - A scanning electron microscopic study of ascoma development in Chaetomium malaysiense. Mycologia 80, 298-306.

Findlay GH, Vismer HF, Kiebenberg NW. 1979 - Black grain mycetoma: the ultrastructure of Madurella mycetomi. Mycopathologia 67, 51-54.

Findlay WPK, Savory JG. 1950 - Breakdown of timbers in water cooling-towers. Proc Inter Bot Congress Stockholm 7, 315-316.

Finley DE. 1967 - Virgatospora: a new genus of Stilbellaceae. Mycologia 59, 538-541.

Fitzpatrick HM. 1923 - Monograph of the Nitschkieae. Mycologia 15, 23-44.

Fogelqvist J, Tzelepis GD, Bejai S, Ilbäck J et al. 2018 - Analysis of the hybrid genomes of two field isolates of the soil-borne fungal species Verticillium longisporum. BMC Genomics.

Foremska E, Kostecki M, Chelkowski J. 1992 - Biosynthesis, preparation and properties of ascochitine. Acta Biotechnologica 12, 461-465.

Fourie A, Wingfield MJ, Wingfield BD, Barnes I. 2015 - Molecular markers delimit cryptic species in Ceratocystis sensu stricto. Mycological Progress 14, 1-18.

Fourie P, Halleen F. 2002 - Investigation on the occurrence of Phaeomoniella chlamydospora in canes of rootstock mother vines. Australasian Plant Pathology 31, 425-426.

Fourie P, Halleen F. 2004 - Occurrence of grapevine trunk disease pathogens in rootstock mother plants in South Africa. Australasian Plant Pathology 33, 313-315.

Fournier J, Lechat C. 2010 - Phomatospora luteotingens sp. nov., a new aquatic species of Phomatospora from France and Spain. Mycosphere 1, 39-43.

Fournier J, Stadler M, Hyde KD, Duong ML. 2010 - The new genus Rostrohypoxylon and two new Annulohypoxylon taxa from Northern Thailand. Fungal Diversity 40, 23-36.

Fournier J, Lechat C, Courtecuisse R, Moreau PA. 2017 - The genus Rosellinia (Xylariaceae) in Guadeloupe and Martinique (French West Indies). Ascomycete.org 9, 171-208.

Friebes G, Jaklitsch WM, García S, Voglmayr H. 2016 - Lopadostoma taeniosporum revisited and a new species of Coniochaeta. Sydowia 68, 87-97.

Fries EM. 1825 - Systema Orbis Vegetabilis 1, 1-374.

Fries EM. 1832 - Systema Mycologicum 3, 261-524.

Fries EM. 1849 - Summa vegetabilium Scandinaviae. Sectio posterior 2, 259-572.

Fröhlich J, Hyde KD. 1994 - New Oxydothis species associated with palm leaf spots in north Queensland, Australia. Mycological Research 98, 213-218.

Fröhlich J, Hyde KD. 1995 - Maculatipalma fronsicola gen. et sp. nov. causing leaf spots on palm species in north Queensland with descriptions of related genera: Apioplagiostoma and Plagiostoma. Mycological Research 99, 727-734.

Fröhlich J, Hyde KD. 2000 - Palm Microfungi. Fungal Diversity Research Series 3, 1-393.

Froyd CA, Coffey EE, van der Knaap WO, van Leeuwen JF et al. 2014 - The ecological consequences of megafaunal loss: giant tortoises and wetland biodiversity. Ecology Letters $17,144-154$.

Fu CH, Hsieh HM, Chen CY, Chang TT et al. 2013 - Ophiodiaporthe cyatheae gen et sp, nov, a diaporthalean pathogen causing a devastating wilt disease of Cyathea lepifera in Taiwan. Mycologia 105, 861-872.

Fuckel KWGL. 1863 - Fungi Rhenani exsiccati a L. Fuckel collecti. Hedwigia 2, 132-136.

Fuckel L. 1870 - Symbolae mycologicae. Beiträge zur Kenntniss der Rheinischen Pilze. Jahrbücher des Nassauischen Vereins für Naturkunde 23-24, 1-459.

Fuckel L. 1872 - Symbolae mycologicae. Beiträge zur Kenntniss der Rheinischen Pilze. Erster Nachtrag. Jahrbücher des Nassauischen Vereins für Naturkunde 25-26, 287-346.

Fujinawa MF, Pontes NC, do Vale HMM, Santos NF, Halfeld-Vieira BA. 2016 - First report of Myrothecium roridum causing myrothecium leaf spot on Begonia in Brazil. Plant Disease $100,655-655$. 
Furlanetto C, Dianese JC. 1998 - Some coelomycetes from central Brazil. Mycological Research 102, 19-29.

Gadgil PD, Dick M. 2007 - Fungi Silvicolae Novazelandiae: 7. New Zealand Journal of Forestry Science 37, 329-335.

Gams W. 1971 - Cephalosporium-artige Schimmelpilze (Hyphomycetes). Gustav Fischer Verlag. Stuttgart, Germany 1-262.

Gams W. 1975 - Cephalosporium-like Hyphomycetes: some tropical species. Transactions of the British Mycological Society 64, 389-404.

Gams W. 1983 - Two species of mycoparasitic fungi. Sydowia 36, 46-52.

Gams W. 1994 - Report of the committee for fungi: 4. Taxon 43, 265-267.

Gams W. 2017 - An annotated checklist of epithets published in Verticillium and Acrostalagmus, some similar genera, and teleomorphs associated with verticillium-like anamorphs. Nova Hedwigia 104, 381-450.

Gams W, Hawksworth DL. 1976 - The identity of Acrocylindrium oryzae Sawada and a similar fungus causing sheath-rot of rice. Kavaka 3, 57-61.

Gams W, McGinnis MR. 1983 - Phialemonium, a new anamorph genus intermediate between Phialophora and Acremonium. Mycologia 75, 977-987.

Gams W, Jansson HB. 1985 - The nematode parasite Meriaconiospora Drechsler in pure culture and its classification. Mycotaxon 22, 33-38.

Gams W, Crous PW. 2000 - Phaeomoniella chlamydospora gen. et comb. nov., a causal organism of Petri grapevine decline and esca. Phytopathologia mediterranea 39, 112-118.

Gams W, Zare R. 2001 - A revision of Verticillium sect. Prostrata. III. Generic classification. Nova Hedwigia 72, 329-337.

Gams W, Zare R. 2003 - A taxonomic review of the clavicipitaceous anamorphs parasitizing nematodes and other microinvertebrates. Mycology Series 19, 17-74.

Gams W, Stielow B, Gräfenhan T, Schroers HJ. 2019 - The ascomycete genus Niesslia and associated monocillium-likeanamorphs. Mycological Progress 18, 5-76.

Gamundí IJ, Arambarri AM, Giaiotti A. 1977 - Micoflora de la hojarasca de Nothofagus dombeyi. Darwiniana 21, 81-114.

Gangadevi V, Muthumary J. 2008 - Taxol, an anticancer drug produced by an endophytic fungus Bartalinia robillardoides Tassi, isolated from a medicinal plant, Aegle marmelos Correa ex Roxb. World Journal of Microbiology and Biotechnology 24, 717.

García D, Stchigel AM, José C, Guarro J et al. 2004 - A synopsis and re-circumscription of Neurospora (syn. Gelasinospora) based on ultrastructural and 28S rDNA sequence data. Mycological research 108, 1119-1142.

García D, Stchigel AM, Cano J, Calduch M et al. 2006 - Molecular phylogeny of Coniochaetales. Mycological Research 110, 1271-1289.

Garibaldi A, Gilardi G, Ortu G, Gullino ML. 2012 - First report of Plectosphaerella cucumerina on greenhouse cultured wild rocket (Diplotaxis tenuifolia) in Italy. Plant Disease 96, 1825-1825.

Gasoni L, Stegman de Gurfinkel B. 1997 - The endophyte Cladorrhinum foecundissimum in cotton roots. Effects on phosphorus uptake and host growth. Mycol Res 101, 867-870.

Gasoni L, Stegman de Gurfinkel B. 2009 - Biocontrol of Rhizoctonia solani by the endophytic fungus Cladorrhinum foecundissimum in cotton plants. Australas Plant Pathol 38, 389-391.

Gavin PJ, Sutton DA, Katz BZ. 2002 - Fatal endocarditis in a neonate caused by the dematiaceous fungus Phialemonium obovatum: Case report and review of the literature. Journal of Clinical Microbiology 40, 2207-2212.

Gawas P, Bhat DJ. 2005 - Vamsapriya indica gen. et sp. nov., a bambusicolous, synnematous fungus from India. Mycotaxon 94, 149-154.

Gazis R, Skaltsas D, Chaverri P. 2014 - Novel endophytic lineages of Tolypocladium provide new insights into the ecology and evolution of Cordyceps-like fungi. Mycologia 106, 1090-1105. 
Geldenhuis MM, Roux J, Cilliers AJ, Wingfield BD, Wingfield MJ. 2006 - Clonality in South African isolates and evidence for a European origin of the root pathogen Thielaviopsis basicola. Mycological Research 110, 306-311.

Ginns J. 2011 - Balansia hypoxylon (Ascomycota: Clavicipitaceae) in Canada: a mycosymbiont with Danthonia spicata (Poaceae). North American Fungi 6, 1-6.

Giraldo A, Crous PW. 2019 - Inside Plectosphaerellaceae. Studies In Mycology 92, 227-286.

Giraldo A, Gené J, Cano J, Hoog S de, Guarro J. 2012 - Two new species of Acremonium from Spanish soils. Mycologia 104, 1456-1465.

Giraldo A, Gené J, Sutton DA, Madrid H et al. 2015 - Phylogeny of Sarocladium (Hypocreales). Persoonia 34, 10-24.

Giraldo A, Crous PW, Schumacher RK, Cheewangkoon R et al. 2017a - The Genera of FungiG3: Aleurocystis, Blastacervulus, Clypeophysalospora, Licrostroma, Neohendersonia and Spumatoria. Mycol Progress 16, 325-348.

Giraldo A, Gené J, Sutton DA, Wiederhold N, Guarro J. 2017b - New acremonium-like species in the Bionectriaceae and Plectosphaerellaceae. Mycol Pro 16, 349-368.

Glawe DA. 1984 - Cryptosphaeria pullmanensis, a new species from Washington state. Mycologia 76, 166-169.

Glawe DA. 1985 - Hapalocystis berkeleyi and Macrodiplodiopsis desmazieresii in artificial culture. Mycologia 77, 880-886.

Glenn AE, Bacon CW, Price R, Hanlin RT. 1996 - Molecular phylogeny of Acremonium and its taxonomic implications. Mycologia 88, 369-383.

Glynn NC, Edwards SG. 2009 - Evaluation of PCR assays for quantifying seed-borne infection by Fusarium and Microdochium seedling blight pathogens. Journal of Applied Microbiology 108, 81-87.

Glynn NC, Hare MC, Parry DW, Edwards DW et al. 2005 - Phylogenetic analysis of EF-1 alpha gene sequences from isolates of Microdochium nivale leads to elevation of varieties majus and nivale to species status. Mycological Research 109, 872-880.

Godeas AM, Arambarri AM, Gamundí IJ, Spinedi HA. 1985 - Descomposición de la hojarasca en el bosque de Lenga (Nothofagus pumilio). Ciencia del suelo 3, 68-77.

Goh TK, Hyde KD. 1996 - Cryptophiale multiseptata, sp. nov. from submerged wood in Australia, and keys to the genus. Mycological Research 100, 999-1004.

Goh TK, Hyde KD. 1997 - The generic distinction between Chaetopsina and Kionochaeta, with descriptions of two new species. Mycological Research 101, 1517-1523.

Goh TK, Hyde KD. 1998 - A new hyphomycete genus, Conioscyphopsis, from wood submerged in a freshwater stream and a review of Conioscypha. Mycological Research 102, 305-312.

Goh TK, Hyde KD. 1999 - A synopsis of Trichocladium species, based on the literature. Fungal Diversity 2, 101-118.

Goh TK, Ho WH, Hyde KD, Umali TE. 1997 - New records and species of Sporoschisma and Sporoschismopsis from submerged wood in the tropics. Mycological Research 101, 12951307.

Goh TK, Lau WP, Teo KC. 2014 - A new species of Nawawia from Malaysia, with a synopsis of the genus. Mycotaxon 129, 109-118.

Goidànich G. 1935 - Schema di una classificazione delle Stilbaceaeche erano riunite fin'ora nel genere Graphium Corda. Annals of Botany (Torino) 21, 40-50.

Gomes RR, Glienke C, Videira SIR, Lombard L et al. 2013 - Diaporthe, a genus of endophytic, saprobic and plant pathogenic fungi. Persoonia 31, 1-41.

Gonnermann W, Rabenhorst L. 1869 - Mycologia europaea. Abbildungen sämmtlicher Schwämme Europas. Neustadt und Dresden 5-6, 1-30.

González CD, Chaverri P. 2017 - Corinectria a new genus to accommodate Neonectria fuckeliana and C. constricta sp. nov. from Pinus radiata in Chile. Mycological Progress 16, 1015-1027.

Gonzalez F, Martin S. 1996 - Contribución al conocimiento de cinco géneros de la familia Nitschkiaceae (Hymenoascomycetes: Sordariales). Acta Botánica Mexicana 36, 43-52. 
González MC, Hanlin RT, Ulloa M. 2000 - Guanomyces, a new genus of ascomycetes from Mexico. Mycologia 92, 1138-1148.

González MC, Anaya AL, Glenn AE, Macías-Rubalcava ML et al. 2009 - Muscodor yucatanensis, a new endophytic ascomycete from Mexican chakah, Bursera simaruba. Mycotaxon 110, $363-372$.

Gonzalez-Menendez V, Díaz C, GarciaB, Monteiro MC et al. 2014 - Aislamiento e identificación de hongos endófitos, epifitos y parásitos de plantas asociadas a zonas áridas de Andalucía como fuente de nuevas moléculas con actividad antifungica. Congreso Nacional De Micologia. BILBAO 18-20.

Goonasekara ID, Maharachchikumbura SSN, Wijayawardene NN, Phookamsak R et al. 2016 Seimatosporium quercina sp. nov. (Discosiaceae) on Quercus robur from Germany. Phytotaxa 255, 240-248.

Goos RD. 1969 - The Genus Pleurothecium. Mycologia 61, 1048-1053.

Gordillo A, Decock C. 2018 - Myrothecium-like (Ascomycota, Hypocreales) species from tropical areas: Digitiseta gen. nov and additions to Inaequalispora and Parvothecium. Mycological Progress 17, 179-190.

Górz A, Boroń P. 2018 - Episternus onthophagi: a new monotypic genus of epizoic fungus found on Onthophagus beetles (Scarabaeoidea). Phytotaxa 376, 43-59.

Gottshall RY, Roberts JM, Portwood LM, Jennings JC. 1951 - Synnematin, an antibiotic produced by Tilachlidium. Experimental Biology and Medicine 76, 307-311.

Gramaje D, Armengol J, Mohammadi H, Banihashemi Z et al. 2009 - Novel Phaeoacremonium species associated with Petri disease and esca of grapevine in Iran and Spain. Mycologia 101, 920-929.

Gramaje D, Mostert L, Groenewald JZ, Crous PW. 2015 - Phaeoacremonium: from esca disease to phaeohyphomycosis. Fungal Biology 119, 759-783.

Granata G, Sidoti A. 2004 - Biscogniauxia nummularia: pathogenic agent of a beech decline. Forest Pathology 34, 363-367.

Graniti A, Surico G, Mugnai L. 2000 - Esca of grapevine: a disease complex or a complex of diseases. Phytopathologia Mediterranea 39, 16-20.

Grassi E, Belen Pildain M, Levin L, Carmaran C. 2014 - Studies in Peroneutypa: the new species Eutypa microasca and investigation of ligninolytic enzyme production. Sydowia 66, 99-114.

Gray DJ, Morgan-Jones G. 1980 - Notes on Hyphomycetes. XXXIV. Some mycoparasitic species. Mycotaxon 10, 375-404.

Grech NM. 1985 - First report of guava rapid death syndrome caused by Septofusidium sp. South Africa. Plant Disease 69, 726.

Green S. 2004 - Fungi associated with shoots of silver birch (Betula pendula) in Scotland. Mycological Research 108, 1327-1336.

Green S, Castlebury LA. 2007 - Connection of Gnomonia intermedia to Discula betulina and its relationship to other taxa in Gnomoniaceae. Mycological Research 111, 62-69.

Grove WB. 1918 - The British species of Melanconium. Kew Bulletin 1918, 161-178.

Grove WB. 1937 - British stem- and leaf-fungi (Coelomycetes). Cambridge Univ Press 2, 1-406.

Grueter W, Barrie FR, Bürdet HM, Chaloner WG et al. 1994 - International Code of Botanical Nomenclature: Tokyo Code, International Association for Plant Taxonomy. Berlin.

Grum-Grzhimaylo AA, Debets AJM, van Diepeningen AD, Georgieva ML, Bilanenko EN. 2013 Sodiomyces alkalinus, a new holomorphic alkaliphilic ascomycete within the Plectosphaerellaceae. Persoonia: Molecular Phylogeny and Evolution of Fungi 31, 147-158.

Grum-Grzhimaylo AA, Georgieva ML, Bondarenko SA, Debets AJ, Bilanenko EN. 2016 - On the diversity of fungi from soda soils. Fungal Diversity 76, 27-74.

Grum-Grzhimaylo AA, Falkoski DL, van den Heuvel J, Valero-Jimenez CA et al. 2018 - The obligate alkalophilic soda-lake fungus Sodiomyces alkalinus has shifted to a protein diet. Mol Ecol 27, 4808-4819. 
Gryzenhout M, Myburg H, Wingfield BD, Montenegro F, Wingfield MJ. 2005 - Rostraureum tropicale gen. sp. nov. (Diaporthales) associated with dying Terminalia ivorensis in Ecuador. Mycological Research 109, 1029-1044.

Gryzenhout M, Myburg H, Rodas CA, Wingfield BD, Wingfield MJ. 2006a - Aurapex penicillata gen. sp. nov. from native Miconia theaezans and Tibouchina spp. in Colombia. Mycologia 98, 105-115.

Gryzenhout M, Myburg H, Wingfield BD, Wingfield MJ. 2006b - Cryphonectriaceae (Diaporthales), a new family including Cryphonectria, Chrysoporthe, Endothia and allied genera. Mycologia 98, 239-249.

Guarro J, Cano J. 1988 - The genus Triangularia. Transactions of the British Mycological Society 91, 587-591.

Guarro J, Gene J. 1988 - The genus Triangularia. Mycological Society 91, 587-591.

Guarro J, Martinez AT, von Arx JA. 1984 - A new Apiosordaria from soil. Persoonia 12, 181-184.

Guarro J, Cannon PF, van der Aa HA. 1991 - A synopsis of the genus Zopfiella (Ascomycetes, Lasiosphaeriaceae). Systema Ascomycetum 10, 79-112.

Guarro J, Abdullah SK, Al-Saadoon AH, Gene J. 1996 - A New Zopfiella (Lasiosphaeriaceae) from Iraq. Mycotaxon 59, 197-202.

Guého E, de Hoog GS. 1991 - Taxonomy of the medical species of Pseudallescheria and Scedosporium. Journal de Mycologie Medicale 1, 3-9.

Guterres DC, Galvão-Elias S, Souza BCP, Pinho DB et al. 2018 - Taxonomy, phylogeny, and divergence time estimation for Apiosphaeria guaranitica, a Neotropical parasite on bignoniaceous hosts. Mycologia 110, 526-545.

Guterres DC, Galvão-Elias S, Dos Santos MDDM, de Souza BCP et al. 2019 - Phylogenetic relationships of Phaeochorella parinarii and recognition of a new family, Phaeochorellaceae (Diaporthales). Mycologia 111, 660-675.

Habibi A, Banihashemi Z. 2017 - Dating divergence of Polystigma and other Sordariomycetes. Mycologia Iranica 4, 29-37.

Habibi A, Banihashemi Z, Mostowfizadeh-Ghalamfarsa R. 2015 - Phylogenetic analysis of Polystigma and its relationship to Phyllachorales. Phytopathologia Mediterranea 54, 45-54.

Hafellner J. 1989 - Studien über lichenicole Pilze und Flechten. VII: Über die neue Gattung Lichenochora (Ascomycetes, Phyllachorales). Nova Hedwigia 48, 357-370.

Hafellner J. 2008 - Additions and corrections to the checklist and bibliography of lichens and lichenicolous fungi of insular Laurimacaronesia. IV. Fritschiana 64, 1-28.

Halleen F, Groenewald M. 2005 - Grapevine diagnostic observations with special reference to trunk diseases. Innovations for sustainable plant health. Proc. 15th Biennial Australas. Plant Path. Soc. Conf., September, Geelong, Australia.

Halleen F, Crous PW, Petrini O. 2003 - Fungi associated with healthy grapevine cuttings in nurseries, with special reference to pathogens involved in the decline of young vines. Australas Plant Pathol 32, 47-52.

Halleen F, Schroers HJ, Groenewald JZ, Rego C et al. 2006 - Neonectria liriodendri sp. nov., the main causal agent of black foot disease of grapevines. Studies in Mycology 55, 227-234.

Halstead BD. 1876 - Our common moulds. Popular Science Monthly 9, 405.

Hamayun M, Khan SA, Khan AL, Afzal M, Lee IJ. 2012 - Endophytic Cephalotheca sulfurea AGH07 reprograms soybean to higher growth. Journal of Plant Interactions 7, 301-306.

Hanlin RT, Tortolero O. 1991 - Icones ascomycetum Venezuelae: phyllachora fuusicarpa. Mycotaxon 41, 19-26.

Hanlin RT, Goh TK, Skarshaug AJ. 1992 - A key to and descriptions of species assigned to Ophiodothella, based on the literature. Mycotaxon 44, 103-126.

Hanlin RT, González MC, Tortolero O, Renaud J. 2002 - A new species of Ophiodothella on Casearia from Venezuela. Mycoscience 43, 321-325.

Hansford CG. 1946 - The foliicolous Ascomycetes, their parasites and associated fungi. Mycological Papers 15, 1-240. 
Hara K. 1911 - New genus of fungus on Arundinaria simoni. Bot Mag Tokyo 25, 222-225.

Hara K. 1913 - Fungi on Japanese bamboo. II. Botanical Magazine Tokyo 27, 245-256.

Hara K. 1939 - The Diseases of the Rice-plant. 2nd edn. Gifu: Japanese Society for Fungi.

Harley JL. 1971 - Fungi in Ecosystems. The Journal of Ecology 59, 653-668.

Harman GE. 2000 - Myths and dogmas of biocontrol. Changes in perceptions derived from research on Trichoderma harzianum T22. Plant Disease 84, 377-393.

Harman GE. 2006 - Overview of mechanisms and uses of Trichoderma spp. Phytopathology 96, 190-194.

Harman GE, Howell CR, Viterbo A, Chet I, Lorito M. 2004 - Trichoderma species - opportunistic, avirulent plant symbionts. Nature reviews microbiology 2, 43-56.

Harrington AH, del Olmo-ruize M, U'Ren JM, Garcia K et al. 2019 - Coniochaeta endophytica sp. nov., a foliar endophyte associated with healthy photosynthetic tissue of Platycladus orientalis (Cupressaceae). Plant and Fungal Systematics 64, 65-79.

Harrington TC. 2013 - Ceratocystis diseases. Gonthier P, Nicolotti G (eds). Infectious Forest Diseases 230-255.

Harrington TC, Cobb FW. 1988 - Leptographium root diseases on conifers. APS Press, St. Paul.

Harrington TC, McNew D. 2018 - A re-evaluation of Tubakia, including three new species on Quercus and six new combinations. Antonie van Leeuwenhoek 111, 1003-1022.

Harrington TC, Aghayeva DN, Fraedrich SW. 2010 - New combinations in Raffaelea, Ambrosiella, and Hyalorhinocladiella, and four new species from the Redbay ambrosia beetle, Xyleborus glabratus. Mycotaxon 111, 337-361.

Harrington TC, McNew D, Yun HY. 2012 - Bur oak blight, a new disease on Quercus macrocarpa caused by Tubakia iowensis sp. nov. Mycologia 104, 79-92.

Harrington TC, McNew D, Mayers C, Fraedrich SW, Reed S. 2014 - Ambrosiella roeperi sp. nov. is the mycangial symbiont of the granulate ambrosia beetle, Xylosandrus crassiusculus. Mycologia 106, 835-845.

Harter LL. 1916 - Sweet-potato scurf. Journal of Agricultural Research 5, 787-791.

Harveson RM. 1999 - Evaluation of the parasitic relationship of Melanospora and other allied genera with Fusarium oxysporum. PhD thesis, University of Florida, Gainesville.

Harz CO. 1871 - Einige neue Hyphomyceten Berlins und Wiens nebst Beiträgen zur Systematik derselben. Bulletin de la Société Impériale des Naturalistes de Moscou 44, 88-147.

Hashemi H, Mohammadi H. 2016 - Identification and characterization of fungi associated with internal wood lesions and decline disease of willow and poplar trees in Iran. Forest Pathology 46, 341-352.

Hashimoto A, Sato G, Matsuda T, Hirayama K et al. 2015a - Molecular taxonomy of Dinemasporium and its allied genera. Mycoscience 56, 86-101.

Hashimoto A, Sato G, Matsuda T, Matsumura M et al. 2015b - Taxonomic revision of Pseudolachnea and Pseudolachnella and establishment of Neopseudolachnella and Pseudodinemasporium gen. nov. Mycologia 107, 383-408.

Hawksworth DL. 1977 - Rhopalostroma, a new genus in the Xylariaceae s.l. The Kew Bulletin 31, 421-431.

Hawksworth DL. 1978 - A new species of Coniochaeta with an interesting conidial state. Norwegian Journal of Agricultural Sciences 25, 15-18.

Hawksworth DL. 1980 - Notes on some fungi occurring on Peltigera, with a key to accepted species. Transactions of the British Mycological Society 74, 363-386.

Hawksworth DL. 2011 - A new dawn for the naming of fungi: impacts of decisions made in Melbourne in July 2011 on the future publication and regulation of fungal names. IMA Fungus 2, 155-162.

Hawksworth DL, Wells H. 1973 - Ornamentation on the terminal hairs in Chaetomium kunze ex fr. and some allied genera. Mycol Pap 134, 1-24.

Hawksworth DL, Lodha BC. 1983 - Helicogermslita, a new stromatic xylariaceous genus with a spiral germ slit from India. Transactions of the British Mycological Society 81, 91-96. 
Hawksworth DL, Eriksson OE. 1986 - The names of accepted orders of ascomycetes. Systema Ascomycetum 5, 175-184.

Hawksworth DL, Eriksson OE. 1988 - (895)-(906) Proposals to conserve 11 family names in the Ascomycotina (fungi). Taxon 37, 190-193.

Hawksworth DL, David JC. 1989 - Family names. Index of Fungi Supplement. C.A.B. International. Wallingford, U.K.

Hawksworth DL, Halici MG. 2007 - Gemmaspora, a new verrucarialean genus with remarkable ascospores for Adelococcus lecanorae growing on Aspicilia species in Syria and Turkey. The Lichenologist 39, 121-128.

Hawksworth DL, Sutton BC, Ainsworth GC. 1983 - Ainsworth and Bisby's dictionary of the fungi. 7th ed. Commonwealth Mycological Institute, Kew. U.K.

Hawksworth DL, Kirk PM, Sutton BC, Pegler DN. 1995 - Ainsworth \& Bisby's Dictionary of the fungi, 8th ed. CAB International, Wallingford, U.K.

Hawksworth DL, Crous PW, Redhead SA, Reynolds DR et al. 2011 - The Amsterdam declaration on fungal nomenclature. IMA Fungus 2, 105-112.

Hayakawa S, Matsushima T, Kimura T, Minato H, Katagiri K. 1968 - Zygosporin A, a new antibiotic from Zygosporium masonii. Journal of Antibiotics 21, 523-524.

Haythorn JM, Jones EBG, Harrison JL. 1980 - Observations on marine algicolous fungi, including the hyphomycete Sigmoidea marina sp. nov. Transactions of the British Mycological Society 74, 615-623.

He MQ, Zhao RL, Hyde KD, Begerow D et al. 2019 - Notes, outline and divergence times of Basidiomycota. Fungal Diversity 99, 105-367.

Hedgcock GG. 1906 - Studies upon some chromogenic fungi which discolor wood. Missouri Botanical Garden Annual Report 17, 59-124.

Heiniger U, Rigling D. 1994 - Biological control of chestnut blight in Europe. Ann Rev Phytopathol 32, 581-599.

Hektoen L, Perkins CF. 1900 - Refractory subcutaneous abscesses caused by Sporothrix schenckii. A new pathogenic fungus. Journal of Experimental Medicine 5, 77-89.

Helaly SE, Thongbai B, Stadler M. 2018 - Diversity of biologically active secondary metabolites from endophytic and saprotrophic fungi of the ascomycete order Xylariales. Natural Product Reports 35, 992-1014.

Hennebert GL, Desai BG. 1974 - Lomentospora prolificans, a new hyphomycete from greenhouse soil. Mycotaxon 1, 45-50.

Hennings P. 1901 - Fungi. In: Engler A (ed). Beiträge zur Flora von Afrika XXII. Botanische Jahrbücher für Systematik Pflanzengeschichte und Pflanzengeographie 30, 254-257.

Hennings P. 1903 - Squamotubera P. Henn. n. gen. Xylariaceaeum. Hedwigia 42, 308-309.

Hennings PC. 1897 - Fungi camerunenses. II. Botanische Jahrbücher Engler 23, 537-558.

Heredia G, Arias RM, Reyes M, Castaneda-Ruiz C. 2002 - New anamorph fungi with rhombic conidia from Mexican tropical forest litter. Fungal Diversity 11, 99-107.

Heredia G, Li DW, Wendt L, Réblová M et al. 2020 - Natonodosa speciosa gen. et sp. nov. and rediscovery of Poroisariopsis inornata: neotropical anamorphic fungi in Xylariales. Mycological Progress 19, 15-30.

Hernández-Gutiérrez A, Sutton BC. 1997 - Imimyces and Linkosia, two new genera segregated from Sporidesmium sensu lato, and redescription of Polydesmus. Mycological Research 101, 201-209.

Hernández-Restrepo M, Mena-Portales J, Gené J, Cano J, Guarro J. 2013 - New Bactrodesmiastrum and Bactrodesmium from decaying wood in Spain. Mycologia 105, 172180.

Hernández-Restrepo M, Gené J, Mena-Portales J, Cano J et al. 2014 - New species of Cordana and epitypification of the genus. Mycologia 106, 723-734.

Hernández-Restrepo M, Gené J, Castañeda-Ruiz RF, Mena-Portales J, Guarro J. 2015a Emendation of the genus Bactrodesmiastrum (Sordariomycetes) and description of 
Bactrodesmiastrum monilioides sp. nov. from plant debris in Spain. Mycological Progress 14, 48.

Hernández-Restrepo M, Groenewald JZ, Crous PW. 2015b - Neocordana gen. nov., the causal organism of Cordana leaf spot on banana. Phytotaxa 205, 229-238.

Hernández-Restrepo M, Gené J, Castañeda-Ruiz RF, Mena-Portales J et al. 2016a - Phylogeny of saprobic microfungi from Southern Europe. Studies in Mycology 86, 53-97.

Hernández-Restrepo M, Groenewald JZ, Crous PW. 2016b - Taxonomic and phylogenetic reevaluation of Microdochium, Monographella and Idriella. Persoonia: Molecular Phylogeny and Evolution of Fungi 36, 57-82.

Hernández-Restrepo M, Schumacher RK, Wingfield MJ, Ahmad I et al. 2016c - Fungal Systematics and Evolution: FUSE 2. Sydowia 68, 193-230.

Hernández-Restrepo M, Gené J, Castañeda-Ruiz RF, Mena-Portales J. 2017 - Phylogeny of saprobic microfungi from Southern Europe. Studies in Mycology 86, 53-97.

Hernández-Restrepo M, Bezerra JDP, Tan YP, Wiederhold N et al. 2019 - Re-evaluation of Mycoleptodiscus species and morphologically similar fungi. Molecular Phylogeny and Evolution of Fungi 42, 205-227.

Hesseltine CW. 1953 - Study of trickling filter fungi. Bulletin of the Torrey Botanical Club 80, 507-514.

Hibbett DS, Binder M, Bischoff JF, Blackwell M et al. 2007 - A higher-level phylogenetic classification of the Fungi. Mycological research 111, 509-547.

Hidayat I, Jeewon R, To-anon C, Hyde KD. 2006 - The genus Oxydothis: new palmicolous taxa and phylogenetic relationships within the Xylariales. Fungal Diversity 23, 159-179.

Hilber R, Hilber O. 2002 - The Genus Lasiosphaeria and allied taxa. Kelheim 1-9.

Hino I, Katumoto K. 1955 - Illustrationes fungorum bambusicolorum III. Bulletin of the Faculty of Agriculture Yamaguchi University 6, 29-68.

Hironaga M, Nakano K, Yokoyama I, Kitajima J. 1989 - Phialophora repens, an emerging agent of subcutaneous phaeohyphomycosis in humans. Journal of Clinical Microbiology 27, 394-399.

Hirooka Y, Kobayashi T, Natsuaki KT. 2005 - Neonectria castaneicola and Neo. rugulosa in Japan. Mycologia 97, 1058-1066.

Hirooka Y, Kobayashi T, Ono T, Rossman AY et al. 2010 - Verrucostoma, a new genus in the Bionectriaceae from the Bonin Islands, Japan. Mycologia 102, 418-429.

Hirooka Y, Rossman AY, Samuels GJ, Lechat C et al. 2012 - A monograph of Allantonectria, Nectria, and Pleonectria (Nectriaceae, Hypocreales, Ascomycota) and their pycnidial, sporodochial, and synnematous anamorphs. Studies in Mycology 71, 1-210.

Hirooka Y, Kawaradani M, Sato T. 2014 - Description of Gibellulopsis chrysanthemi sp. nov. from leaves of garland chrysanthemum. Mycological progress 13, 13-19.

Ho WH, Hyde KD. 1996 - Pterosporidium gen. nov. to accommodate two species of Anthostomella from mangrove leaves. Canadian journal of botany 74, 1826-1829.

Ho WH, Tsui CKM, Hodgkiss IJ, Hyde KD. 1999 - Aquaticola, a new genus of Annulatascaceae from freshwater habitats. Fungal Diversity 3, 87-97.

Ho WH, Hyde KD, Hodgkiss IJ. 2001 - Fungal communities on submerged wood from streams in Brunei, Hong Kong, and Malaysia. Mycological Research 105, 1492-1501.

Ho WH, Yanna, Hyde KD, Hodgkiss IJ. 2002 - Seasonality and sequential occurrence of fungi on wood submerged in Tai Po Kau Forest Stream, Hong Kong. Fungal Diversity 10, 21-43.

Ho WH, Hyde KD, Hodgkiss IJ. 2004 - Cataractispora receptaculorum a new freshwater ascomycete from Hong Kong. Mycologia 96, 411-417.

Hochberzanke. 1930 - Spraw. Posied. Tow. Nauk. Warsz. Wydzial 22, 95.

Hodge KT. 2003 - Clavicipitaceous anamorphs. Clavicipitalean Fungi. CRC Press.

Hoffmann K, Voigt K. 2011 - Molecular detection of human fungal pathogens. CRC Press.

Hoffmann N, Hafellner J. 2000 - Eine Revision der lichenicolen Arten der Sammelgattungen Guignardia und Physalospora. Bibliotheca Lichenologica 77, 1-190.

Höhnel F von. 1904 - Mycologische Fragmente. Annales Mycologici 2, 38-60. 
Höhnel F von. 1905 - Mykologische Fragmente CVI-CXVII. Annales Mycologici 3, 548-560.

Höhnel F von. 1907a - Ergebnisse der Botanischen Expedition der Kaiserlichen Akademie der Wissenschaften nach Süd-Brasilien 1901. Eumycetes et Myxomycetes. Denkschriften der Akademie der Wissenschaften (Wien) Mathematisch-naturwissenschaftliche Klasse 83, 1-45.

Höhnel F von. 1907b - Uberdie Familie der Coronophoreen. Sitzungsberichte der Akademieder Wissenschaften in Wien 116, 624-630.

Höhnel F von. 1909a - Fragmente zur Mykologie (IX. Mitteilung, Nr. 407 bis 467). Sitzungsberichte der Kaiserlichen Akademie der Wissenschaften Math.-naturw. Klasse, Abt. I 118, 1461-1552.

Höhnel F von. 1909b - Fragmente zur Mykologie (VIII. Mitteilung, Nr. 354 bis 406). Sitzungsberichte der Kaiserlichen Akademie der Wissenschaften Math.-naturw Klasse Abt. I $118,1157-1246$.

Höhnel F von. 1910 - Fragmente zur Mykologie (XI. Mitteilung, Nr. 527 bis 573). Sitzungsberichte der Kaiserlichen Akademie der Wissenschaften Math.-naturw Klasse Abt. I $119,617-679$.

Höhnel F von. 1917a - Cephalothecaceae. Ann Mycol 15, 360-363.

Höhnel F von. 1917b - Fragmente zur Mykologie (XX Mitteilung, Nr. 1031 bis 1057). Sitzungsberichte der Kaiserlichen Akademie der Wissenschaften Math.-naturw. Klasse Abt. I 126, 353-399.

Höhnel F von. 1917c - Mykologische Fragmente. Nrn. 120-190. Annales Mycologici 15, 293-383.

Höhnel F von. 1917d - System der Phacidiales. Berichte Deutsche Botanische Gesellschaft 35, 416-422.

Höhnel F von. 1918a - Dritte vorlaufige Mitteilung mycologischer Ergebnisse (Nr. 201-304). Berichte der Deutschen Botanischen Gesellschaft 36, 309-317.

Höhnel F von. 1918b - Mycologische Fragmente CCLXII. Ann Mycol 16, 127-132.

Höhnel F von. 1919 - Fragmente zur Mykologie. (XXIII Mitteilung, Nr. 1154 bis 1188). Sitzungsberichte der Kaiserlichen Akademie der Wissenschaften Math.-naturw. Klasse Abt. I $128,535-625$.

Holdenrieder O, Kowalski T. 1989 - Pycnidial formation and pathogenicity in Tubakia dryina. Mycological Research 92, 166-169.

Holland LA, Lawrence DP, Nouri MT, Travadon R et al. 2019 - Taxonomic Revision and Multilocus Phylogeny of the North American Clade Of Ceratocystis. Fungal Systematics and Evolution 3, 135-156.

Holm L, Holm K. 1993 - Two new northern pyrenomycetes. Blyttia 51, 121-123.

Holm L, Holm K, Barr ME. 1999 - Once again on Discosphaerina. Karstenia 39, 59-63.

Holubová-Jechová V. 1972 - Craspedodidymum, a new genus of phialosporous Hyphomycetes. Ceská Mykologie 26, 70-73.

Holubová-Jechová V. 1973a - Lignicolous Hyphomycetes from Czechoslovakia 3. Sporoschisma, Sporoschismopsis and Catenulari.Folia Geobotanica et Phytotaxonomica 8, 209-218.

Holubová-Jechová V. 1973b - Lignicolous Hyphomycetes from Czechoslovakia 4. Menispora.Folia Geobotanica et Phytotaxonomica 8, 317-336.

Holubová-Jechová V. 1982 - New or interesting phialidic hyphomycetes from Cuba. Mycotaxon 15, 277-292.

Holubová-Jechová V, Hennebert G. 1972 - Sporoschismopsis, a new genus of Lignicolous Hyphomycetes. Bulletin Du Jardin Botanique National De Belgique Bulletin Van De National Plantentuin Van België 42, 385-391.

Holubová-Jechová V, Mercado Sierra A. 1984 - Studies on Hyphomycetes from Cuba II. Hyphomycetes from the Isla de la Juventud. eskáMykol 38, 96-120

Holway EWD. 1897 - Mexican Fungi. Botanical Gazette Crawfordville 24, 23-38.

Hong CF, Tsai SF, Yeh HC, Fan MC. 2013 - First Report of Myrothecium roridum causing Myrothecium Leaf Spot on Dieffenbachia picta 'Camilla' in Taiwan. Plant Disease 97, 12531253. 
Hongsanan S, Maharachchikumbura SSN, Hyde KD, Samarakoon MC et al. 2017 - An updated phylogeny of Sordariomycetes based on phylogenetic and molecular clock evidence. Fungal Diversity 84, 25-41.

Hongsanan S, Tian Q, Peršoh D, Zeng XY et al. 2015 - Meliolales. Fungal Diversity 74, 91-144.

Horne AS, Williamson HS. 1923 - The morphology and physiology of the genus Eidamia. Annals of Botany 37, 393-432.

Horst RK. 1990 - Westcott's plant disease handbook, 5th ed. AVI Book, USA.

Horst RK. 2013 - Field Manual of Diseases on Trees and Shrubs. 2013th Edition. Springer, Netherlands, 207.

Hosagoudar VB. 2003 - Armatellaceae, a new family segregated from the Meliolaceae. Sydowia $55,162-167$.

Hosagoudar VB. 2004 - Studies on foliicolous fungi-XVI: Clasterosporium flagellatum and its teleomorph. Zoos' Print J 19, 1437-1438.

Hosagoudar VB, Raju MC. 2013 - Foliicolous fungi of Silent Valley National Park, Kerala, India. Journal of Threatened Taxa 5, 3701-3788.

Hosagoudar VB, Abraham TK, Krishnan PN, Vijayakumar K. 1997 - Biochemical changes in the leaves of ebony tree affected with black mildew. Indian Phytopathology 50, 439-440.

Howard CM, Albregts EE. 1973 - A strawberry fruit rot caused by Dendrophoma obscuran.Phytopathology 63, 419-421.

Hsieh HM, Ju YM, Rogers JD. 2005 - Molecular phylogeny of Hypoxylon and closely related genera. Mycologia 97, 844-865.

Hsieh HM, Lin CR, Fang MJ, Rogers JD et al. 2010 - Phylogenetic status of Xylaria subgenus Pseudoxylaria among taxa of the subfamily Xylarioideae (Xylariaceae) and phylogeny of the taxa involved in the subfamily. Molecular Phylogenetics and Evolution 54, 957-969.

Hsieh LS, Tzean SS, Wu WJ. 1997a - The genus Akanthomyces on spiders from Taiwan. Mycologia 89, 319-324.

Hsieh WH, Chen CY, Sivanesan A. 1997b - Iodosphaeria polygoni sp. nov., a new pyrenomycete from Taiwan. Mycological Research 101, 841-842.

Hu DM, Cai L, Bahkali AH, Hyde KD. 2012 - Two new freshwater species of Annulatascaceae from China. Mycotaxon 120, 81-88.

Huang FLH, Li Y, Chen X. 2017 - The complete mitochondrial genome of a medicinal fungus, Tolypocladium ophioglossoides. Mitochondrial DNA Part B 2, 95-96.

Huang SK, Jeewon R, Hyde KD, Bhat DJ et al. 2018 - Beta-tubulin and Actin gene phylogeny supports Phaeoacremonium ovale as a new species from freshwater habitats in China. MycoKeys 41, 1-15.

Huang SK, Hyde KD, Jeewon R, Jayarama BD et al. 2019 - Sordariomycetidae and Diaporthomycetidae. Fungal diversity.

Hudson HJ. 1963 - The perfect state of Nigrospora oryzae. Transactions of the British Mycological Society 46, 355-360.

Hughes SJ. 1951a - Calcarisporium, Verticicladium and Hansfordia (Gen. Nov.). Mycological papers $43,15$.

Hughes SJ. 1951b - Stachylidium, Gonytrichum, Mesobotrys, Chaetopsis and Chaetopsella. Transactions of the British Mycological Society 34, 551-576.

Hughes SJ. 1951c - Studies on micro-fungi X. Zygosporium. Mycological Papers 44, 1-18.

Hughes SJ. 1952 - Fungi from the Gold Coast. I. Mycological Papers 48, 1-91.

Hughes SJ. 1955 - Microfungi. I. Cordana, Brachysporium, Phragmocephala. Canadian Journal of Botany 33, 259-268.

Hughes SJ. 1958 - Revisiones hyphomycetum aliquot cum appendice de nominibus rejiciendis. Canadian Journal of Botany 36, 726-836.

Hughes SJ. 1966 - Sporoschisma Berk. and Br. New Zealand Journal of Botany 4, 77-85.

Hughes SJ. 1978 - New Zealand Fungi. 25. Miscellaneous species. New Zealand Journal of Botany $16,311-370$. 
Hughes SJ. 1979 - Relocation of species of Endophragmia auct. with notes on relevant generic names. New Zealand Journal of Botany 17, 139-188.

Hughes SJ, Kendrick WB. 1965 - New Zealand Fungi: 4. Zanclospora gen. nov. New Zealand Journal of Botany 3, 151-158.

Hughes SJ, Kendrick WB. 1968 - New Zealand Fungi: 12. Menispora, Codinaea, Menisporopsi. New Zealand Journal of Botany 6, 323-375.

Huhndorf SM, Fernandez FA, Lodge DJ. 1999 - Neotropical ascomycetes 9. Jobellisia species from Puerto Rico and elsewhere. Sydowia 51, 183-196.

Huhndorf SM, Fernando AF, Miller AN, Lodge J. 2003 - Neotropical Ascomycetes 12. Mirannulata samuelsii gen. et sp. nov. and M. costaricensis sp. nov., new taxa from the Caribbean and elsewhere. Sydowia 55, 172-180.

Huhndorf SM, Miller AN, Fernandez FA. 2004a - Molecular systematics of the Coronophorales and new species of Bertia, Lasiobertia and Nitschkia. Mycological Research 108, 1384-1398.

Huhndorf SM, Miller AN, Fernandez FA. 2004b - Molecular systematics of the Sordariales: the order and the family Lasiosphaeriaceae redefined. Mycologia 96, 368-387.

Huhndorf SM, Miller AN, Fernández FA, Lodge DJ. 2005 - Neotropical Ascomycetes 13. Cornipulvina and Erythromada, two new genera from the Caribbean and elsewhere. Fungal Diversity 20, 59-69.

Huhndorf SM, Greif M, Mugambi GK, Miller AN. 2008 - Two new genera in the Magnaporthaceae, a new addition to Ceratosphaeria and two new species of Lentomitella. Mycologia 100, 940-955.

Huhndorf SM, Miller AN, Greif M, Samuels GJ. 2009 - Amplistroma gen. nov. and its relation to Wallrothiella, two genera with globose ascospores and acrodontium-like anamorphs. Mycologia 101, 904-919.

Hujslová M, Kubátová A, Chudíčková M, Kolařík M. 2010 - Diversity of fungal communities in saline and acidic soils in the Soos National Natural Reserve, Czech Republic. Mycological Progress 9, 1-15.

Hujslová M, Kubátová A, Kostovčík M, Blanchette RA et al. 2014 - Three new genera of fungi from extremely acidic soils. Mycological Progress 13, 819-831.

Hujslová M, Bystrianský L, Benada O, Gryndler M. 2019 - Fungi, a neglected component of acidophilic biofilms: do they have a potential for biotechnology? Extremophiles 23, 267-275.

Hulvová H, Galuszka P, Frébortová J, Frébort I. 2013 - Parasitic fungus Claviceps as a source for biotechnological production of ergot alkaloids. Biotechnology Advances 31, 79-89.

Humber RA, Rombach MC. 1987 - Torrubiella ratticaudata sp. nov.(Pyrenomycetes: Clavicipitales) and other fungi from spiders on the Solomon Islands. Mycologia 79, 375-382.

Hung R, Lee S, Bennett JW. 2015 - Fungal volatile organic compounds and their role in ecosystems. Applied Microbiology and Biotechnology 99, 3395-3405.

Hussain H, Kliche-Spory C, Al-Harrasi A, Al-Rawahi A et al. 2014 - Antimicrobial constituents from three endophytic fungi. Asian Pacific journal of tropical medicine 7, 224-227.

Hutchings ML, Hiller DA, Berro J, Strobel SA. 2017 - Mycofumigation through production of the volatile DNA methylating agent $\mathrm{N}$-methyl-N-nitrosoisobutyramide by fungi in the genus Muscodor. Journal of Biological Chemistry 292, 7358-7371.

Hyde KD. 1992a - Fungi from decaying inter-tidal fronds of Nypa fruticans, including three new genera and four new species. Botanical Journal of the Linnean Society 110, 95-110.

Hyde KD. 1992b - Tropical Australian freshwater fungi. II. Annulatascus velatispora gen. et sp. nov., A. bipolaris sp. nov. and Nais aquatica sp. nov. (Ascomycetes). Australian Systematic Botany 5, 117-124.

Hyde KD. 1992c - Tropical Australian freshwater fungi. IV. Halosarpheia aquatica sp. nov., Garethjonesia lacunosispora gen. \& sp. nov. and Ophioceras dolichostomum (Ascomycetes). Australian Systematic Botany 5, 407-414.

Hyde KD. 1993a - Fungi from palms. V. Phomatospora nypae sp. nov. and notes on marine fungi from Nypa fruticans in Malaysia. Sydowia 45, 199-203. 
Hyde KD. 1993b - Fungi from palms. VI. Reflections on Oxydothis and related genera. Sydowia 45, 204-225.

Hyde KD. 1993c - Fungi from palms. VII. The genus Oxydothis from rachides of palms in north Queensland, including five new species. Sydowia 45, 226-240.

Hyde KD. 1993d - Fungi from palms. VIII. The genus Myelosperma (Ascomycotina). Sydowia 45, 241-245.

Hyde KD. 1994a - Fungi from palms. XIII. The genus Oxydothis, a revision. Sydowia 46, $265-$ 314.

Hyde KD. 1994b - Fungi from rachides of Livistona in the Western Province of Papua New Guinea. J. Linn Soc Bot 116, 315-324.

Hyde KD. 1995a - Fungi from palms. XVI. Cocoicola gen. nov. Nova Hedwigia 60, 559-604.

Hyde KD. 1995b - Fungi from palms. XVIII. Appendicospora coryphae, a new name for Apiosporella coryphae. Sydowia 47, 31-37.

Hyde KD. 1995c - Fungi from palms. XXI. The genus Seynesia. Sydowia 47, 199-212.

Hyde KD. 1995d - Tropical Australian freshwater fungi. VII: New genera and species of Ascomycetes. Nova Hedwigia 61, 119-140.

Hyde KD. 1995e - Two new interesting ascomycetes from Irian Jaya and Papua New Guinea. Mycotaxon 55, 275-282.

Hyde KD. 1996a - Fungi from palms. XXXII. Arecomyces gen.nov., with seven new species. Sydowia 48, 224-240.

Hyde KD. 1996b - Tropical Australian freshwater fungi. X. Submersisphaeria aquatica gen. et sp. nov. Nova Hedwigia 62, 171-175.

Hyde KD, Jones EBG. 1986 - Marine fungi from Seychelles. II. Lanspora coronata gen. et sp. nov. from driftwood. Canadian journal of botany 64, 1581-1585.

Hyde KD, Jones EBG. 1988 - Marine mangrove fungi. P.S.Z.N.I. Marine Ecology 9, 15-33.

Hyde KD, Jones EBG. 1989 - Intertidal Mangrove Fungi from Brunei. Lautospora gigantea gen. et sp. nov., a New Loculoascomycete from Prop Roots of Rhizophora spp. Botanica Marina 32, 479-482.

Hyde KD, Jones EBG. 1992 - Intertidal mangrove fungi: Pedumispora gen. nov. (Diaporthales). Mycological Research 96, 78-80.

Hyde KD, Nakagiri A. 1992 - Intertidal fungi from Australia. The genus Swampomyces including S. triseptatus sp. nov. Sydowia 44, 122-130.

Hyde KD, Pearce CA. 1993 - Phyllachora barringtoniicola nom. nov. and Phyllachora naqsii sp. nov. causing leaf spots on Barringtonia spp. Mycological Research 97, 1324-1327.

Hyde KD, Fröhlich J. 1995 - Fungi from palms. XXIII. Rachidicola gen. et sp. nov. Sydowia 47, 217-222.

Hyde KD, Goh TK. 1998 - Fungi on submerged wood in the Riviere St Marie-Louis, The Seychelles. South Africa Journal of Botany 64, 330-336.

Hyde KD, Cannon PF. 1999 - Fungi causing tar spots on palms. Mycological Papers 175, 1-114.

Hyde KD, Wong SW. 1999 - Ultrastructural studies on the Myelospermaceae fam. nov., with a new species of Myelosperma. Mycological Research 103, 347-352.

Hyde KD, Fröhlich J. 2003 - Nigramammilla calami gen. et sp. nov. and Arecomyces calami, A. licualae and Pseudohalonectria palmae spp. nov. from palms. Cryptogamie Mycologie 24, 13-20.

Hyde KD, Stanley SJ, Steinke TD. 1996 - Fungi associated with leaf spots of palms. Maculatifvondis aequatoriensis gene et sp. nov., with a Cyclodomus anamorph, and Myelosperma parasitica sp. nov. Mycological research 100, 1509-1514.

Hyde KD, Cannon PF, Barr ME. 1997a - Phaeochoraceae, a new ascomycete family from palms. Systema Ascomycetum 15, 117-120.

Hyde KD, Read SJ, Jones EBG, Moss ST. 1997b - Tropical Australian freshwater fungi. XII Rivulicola incrustata gen. et sp. nov. and notes on Ceratosphaeria lampadophora. Nova Hedwigia 64, 185-196. 
Hyde KD, Fröhlich J, Taylor JE. 1998a - Fungi from palms. XXXVI. Reflections on unitunicate ascomycetes with apiospores. Sydowia 50, 21-80.

Hyde KD, Wong SW, Jones EBG. 1998b - Diluviocola capensis gen. and sp. nov., a freshwater ascomycete with unique polar caps on the ascospores. Fungal Diversity 1, 133-146.

Hyde KD, Wong SW, Jones EBG. 1999a - Cataractispora gen. nov. with three new freshwater lignicolous species. Mycological Research 103, 1019-1031.

Hyde KD, Taylor JE, Fröhlich J. 1999b - Two new species of Pseudohalonectria from palms. Mycologia 91, 520-524.

Hyde KD, Taylor JE, Fröhlich J. 2000 - Genera of ascomycetes from palms. Fungal Diversity Press, Hong Kong, China.

Hyde KD, Jones EBG, Liu JK, Ariyawansa H et al. 2013 - Families of Dothideomycetes. Fungal Diversity 63, 1-313.

Hyde KD, Nilsson RH, Alias SA, Ariyawansa HA et al. 2014 - One stop shop: backbones trees for important phytopathogenic genera: I. Fungal Diversity 64, 21-125.

Hyde KD, Fryar S, Tian Q, Bahkali AH, Xu JC. 2016a - Lignicolous freshwater fungi along a north-south latitudinal gradient in the Asian/Australian region; can we predict the impact of global warming on biodiversity and function? Fungal Ecology 19, 190-200.

Hyde KD, Hongsanan S, Jeewon R, Bhat DJ et al. 2016b - Fungal diversity notes 367-490: taxonomic and phylogenetic contributions to fungal taxa. Fungal Diversity 80, 1-270.

Hyde KD, Maharachchikumbura SSN, Hongsanan S, Samarakoon MC et al. 2017a - The ranking of fungi: a tribute to David L. Hawksworth on his 70th birthday. Fungal Diversity 84, 1-23.

Hyde KD, Norphanphoun C, Abreu VP, Bazzicalupo A et al. 2017b - Fungal diversity notes 603708: taxonomic and phylogenetic notes on genera and species. Fungal Diversity 87, 1-235.

Hyde KD, Al-Hatmi AMS, Andersen B, Boekhout T et al. 2018a - The world's ten most feared fungi. Fungal Diversity 93, 161-194.

Hyde KD, Chaiwan N, Norphanphoun C, Boonmee S et al. 2018b - Mycosphere notes 169-224. Mycosphere 9, 271-430.

Hyde KD, Tennakoon DS, Jeewon R, Bhat DJ et al. 2019a - Fungal diversity notes 1036-1150: taxonomic and phylogenetic contributions on genera and species of fungal taxa. Fungal Diversity 96, 1-242.

Hyde KD, Xu J, Rapior S, Jeewon R et al. 2019b - The amazing potential of fungi: 50 ways we can exploit fungi industrially. Fungal Diversity 97, 1-136.

Illman WI, White GP. 1985 - A new Morrisographium-like species with appendaged conidia assigned to the genus Conicomyces. Canadian Journal of Botany 63, 419-422.

Inácio ML, Henriques J, Guerra-Guimarăes L, Gil-Azinheira H et al. 2011 - Platypus cylindrus Fab. (Coleoptera: Platypodidae) transports Biscogniauxia mediterranea, agent of cork oak charcoal canker. Boletín de Sanidad Vegetal Plagas 37, 181-186.

Inderbitzin P, Berbee ML. 2001 - Lollipopaia minuta from Thailand, a new genus and species of the Diaporthales (Ascomycetes, Fungi) based on morphological and molecular data. Canadian Journal of Botany 79, 1099-1106.

Inderbitzin P, Lim SR, Volkmann-kohlmeyer B, Kohlmeyer J, Berbee ML. 2004 - The phylogenetic position of Spathulospora based on DNA sequences from dried herbarium material. Mycological Research 108, 737-774.

Index Fungorum. 2018 - http://www.indexfungorum.org/Names/Names.asp.

Index Fungorum. 2019 - http://www.indexfungorum.org/Names/Names.asp.

Isaka M, Palasarn S, Chinthanom P, Thongtan J et al. 2012 - Poronitins A and B, 4-pyrone and 4pyridone derivatives from the elephant dung fungus Poronia gigantea. Tetrahedron Letters $53,4848-4851$.

Issakainen J, Jalava J, Hyvönen J, Sahlberg N. et al. 2003 - Relationships of Scopulariopsis based on LSU rDNA sequences. Medical Mycology 41, 31-42.

Ito T, Nakagiri A. 1994 - Stellatospora, a new genus of the Sordariaceae. Mycoscience 35, 413415. 
Iturriaga T, Hawksworth DL, Crane JL. 2008 - Sporidesmium lichenicola sp. nov., a new lichenicolous fungus on Leptogium from Venezuela. Mycologia 100, 392-396.

Ivanová H. 2015 - Sordaria fimicola (Ascomycota, Sordariales) on Acer palmatum. Folia oecologica 42, 67-71.

Jacobs K, Wingfield MJ. 2001 - Leptographium species: tree pathogens, insect associates, and agents of blue-stain. APS press, St Paul.

Jacobs K, Kirisits T, Wingfield MJ. 2003 - Taxonomic re-evaluation of three related species of Graphium, based on morphology, ecology and phylogeny. Mycologia 95, 714-727.

Jagielski T, Sandoval-Denis M, Yu J, Yao L. et al. 2016 - Molecular taxonomy of scopulariopsislike fungi with description of new clinical and environmental species. Fungal Biology 120, 586-602.

Jaklitsch W, Baral HO, Lücking R. 2016a - Syllabus of plant families - A. Engler's Syllabus der Pflanzenfamilien Part 1/2: Ascomycota, 13th edn. Borntraeger, Stuttgart.

Jaklitsch WM. 2009 - European species of Hypocrea Part I: The green-spored species. Stud Mycol $63,1-91$.

Jaklitsch WM. 2011 - European species of Hypocrea part II: species with hyaline ascospores. Fungal Divers 48, 1-250.

Jaklitsch WM, Voglmayr H. 2011 - Stromatonectria gen. nov. and notes on Myrmaeciella. Mycologia 103, 431-440.

Jaklitsch WM, Voglmayr H. 2012 - Phylogenetic relationships of five genera of Xylariales and Rosasphaeria gen. nov. (Hypocreales). Fungal Diversity 52, 75-98.

Jaklitsch WM, Voglmayr H. 2014 - Persistent hamathecial threads in the Nectriaceae, Hypocreales: Thyronectria revisited and re-instated. Persoonia 33, 182-211.

Jaklitsch WM, Réblová M. 2015 - Savoryellaceae Jaklitsch \& Réblová. Index Fungorum 209, 1.

Jaklitsch WM, Voglmayr H. 2015 - Biodiversity of Trichoderma (Hypocreaceae) in Southern Europe and Macaronesia. Studies in Mycology 80, 1-87.

Jaklitsch WM, Põldmaa K, Samuels GJ. 2008 - Reconsideration of Protocrea (Hypocreales, Hypocreaceae). Mycologia 100, 962-984.

Jaklitsch WM, Réblová M, Voglmayr H. 2013 - Molecular systematics of Woswasia atropurpurea gen. et sp nov. (Sordariomycetidae), a fungicolous ascomycete with globose ascospores and holoblastic conidiogenesis. Mycologia 105, 476-485.

Jaklitsch WM, Fournier J, Rogers JD, Voglmayr H. 2014 - Phylogenetic and taxonomic revision of Lopadostoma. Persoonia Molecular Phylogeny and Evolution of Fungi 32, 52-82.

Jaklitsch WM, Gardiennet A, Voglmayr H. 2016b - Resolution of morphology-based taxonomic delusions: Acrocordiella, Basiseptospora, Blogiascospora, Clypeosphaeria, Hymenopleella, Lepteutypa, Pseudapiospora, Requienella, Seiridium and Strickeria. Persoonia 37, 82-105.

James F, White Jr F. 1994 - Taxonomic relationships among the members of the Balansieae (Clavicipitales). Biotechnology of endophytic fungi of grasses 3-20.

James TY, Kauff F, Schoch CL, Matheny PB et al. 2006 - Reconstructing the early evolution of fungi using a six-gene phylogeny. Nature 443, 818-822.

Jayasiri SC, Hyde KD, Ariyawansa HA, Bhat J et al. 2015 - The Faces of Fungi database: fungal names linked with morphology, phylogeny and human impacts. Fungal Diversity 74, 3-18.

Jayasiri SC, Hyde KD, Jones EBG, McKenzie EHC et al. 2019 - Diversity, morphology and molecular phylogeny of Dothideomycetes in decaying wild seed pods and fruits. Fungal Diversity 10, 1-186.

Jayawardena RS, Hyde KD, Damm U, Cai L et al. 2016 - Notes on currently accepted species of Colletotrichum. Mycosphere 7, 1192-1260.

Jayawardena RS, Hyde KD, McKenzie EHC, Jeewon R et al. 2019 - One stop shop III: taxonomic update with molecular phylogeny for important phytopathogenic genera: 51-75. Fungal Diversity 98, 77-160. 
Jeewon R. 2001 - Pestalotiopsis taxonomy: molecular phylogenetics, species nomenclature and teleomorph relationships. Doctoral dissertation. The University of Hong Kong. Pokfulam, Hong Kong.

Jeewon R, Hyde KD. 2016 - Establishing species boundaries and new taxa among fungi: recommendations to resolve taxonomic ambiguities. Mycosphere 7, 1669-1677.

Jeewon R, Liew EC, Hyde KD. 2002 - Phylogenetic relationships of Pestalotiopsis and allied genera inferred from ribosomal DNA sequences and morphological characters. Molecular phylogenetics and evolution 25, 378-392.

Jeewon R, Cai L, Liew ECY, Zhang KQ et al. 2003a - Dyrithiopsis lakefuxianensis gen. et sp. nov. from Fuxian Lake, Yunnan, China, and notes on the taxonomic confusion surrounding Dyrithium. Mycologia 95, 911-920.

Jeewon R, Liew ECY, Hyde KD. 2003b - Molecular systematics of the Amphisphaeriaceae based on cladistic analyses of partial LSU rDNA gene sequences. Mycological Research 107, 1392-1402.

Jeewon R, Yeung SYQ, Hyde KD. 2009 - A novel phylogenetic group within Thozetella (Chaetosphaeriaceae): a new taxon based on morphology and DNA sequence analyses. Canadian Journal of Microbiology 55, 680-687.

Jeffries P, Young TWK. 1994 - Interfungal Parasitic Relationships. CAB International. Wallingford.

Jeng RS, Cain RF. 1976 - Collematospora, a new genus of the Trichosphaeriaceae. Canadian Journal of Botany 54, 2429-2433.

Jeng RS, Krug JC. 1976 - Emblemospora, a new genus of the Sordariaceae. Canadian Journal of Botany 54, 1971-1976.

Jeng RS, Cain RF. 1977 - Rhytidospora, a new cleistocarpous genus of the Melanosporaceae. Mycotaxon 5, 278-282.

Jeragh A, Ahmad S, Khan Z, Tarazi RY et al. 2018 - Subcutaneous phaeohyphomycosis caused by Amesia atrobrunnea in Kuwait. Journal de Mycologie Médicale 29, 193-197.

Jiang HB, Phookamsak R, Bhat DJ, Khan S et al. 2018 - Vamsapriya yunnana, a new species of Vamsapriya (Xylariaceae, Xylariales) associated with bamboo from Yunnan, China. Phytotaxa 356, 61-70.

Jiang YL, Wu YM, Zhang ZG, Kong JH et al. 2017 - Drechslera, Fusariella, Coniochaeta \& Pyricularia spp. Nov. from soil in China. Mycotaxon 132, 627-633.

Johanning E, Biagini R, Hull D, Morey P et al. 1996 - Health and immunologv study following exposure to toxigenic fungi (Stachybotrys chartarum) in a water-damaged office environment. International Archives of Occupational and Environmental Health 68, 207-218.

Johansson PM, Johnsson L, Gerhardson B. 2003 - Suppression of wheat-seedling diseases caused by Fusarium culmorum and Microdochium nivale using bacterial seed treatment. Plant Pathology 52, 219-227.

Johnson D, Sung GH, Hywel-Jones NL, Luangsa-Ard JJ et al. 2009 - Systematics and evolution of the genus Torrubiella (Hypocreales, Ascomycota). Mycological research 113, 279-289.

Johnson TW, Sparrow FK. 1961 - Fungi in oceans and estuaries. Cramer, Weinheim.

Johnston PR, May TW, Park D, Horak E. 2007 - Hypocreopsis amplectens sp. nov., a rare fungus from New Zealand and Australia. New Zealand Journal of Botany 45, 715-719.

Johnston PR, Rogers JD, Park D, Martin NA. 2016 - Entalbostroma erumpens gen. et sp. nov. (Xylariaceae) from Phormium in New Zealand. Mycotaxon 131, 765-771.

Joly P. 1961 - Le genre Sphaerodothis Shear. Bulletin of the Research Council of Israel Sect. D Botany 10, 187-193.

Jones AM, Jones EBG. 1993 - Observations on the marine gasteromycete Nia vibrissa. Mycological Research 97, 1-6.

Jones EBG. 1995 - Ultras tructure and taxonomy of the aquatic ascomycetous order Halosphaeriales. Canadian Journal of Botany 73, 790-801.

Jones EBG. 2011 - Are there more marine fungi to be described? Botanica Marina 54, 343-354. 
Jones EBG, Eaton RA. 1969 - Savoryella lignicola gen. et sp. nov. from water cooling towers. Transactions of British Mycological Society 52, 161-174.

Jones EBG, Hyde KD. 1988 - Methods for the study of mangrove marine fungi. 9-27, in Agate, Subramanian and Vannucci (eds.) Mangrove microbiology. role of microorganisms in nutrient cycling of mangrove soils and water. UNDP/UNESCO, New Delhi.

Jones EBG, Hyde KD. 1992 - Taxonomic studies on Savoryella Jones et Eaton (Ascomycotina). Botanica Marina 35, 83-91.

Jones EBG, Pang KL. 2012 - Marine fungi and fungal-like organisms. Walter de Gruyter GmbH and Co. KG, Berlin/Boston.

Jones EBG. Kuhne H, Trussell PC, Turner RD. 1972 - Results of an international cooperative research programme on the biodeterioration of timber submerged in the sea. Material und Organismen 7, 93-118.

Jones EBG, Johnson RG, Moss ST. 1983 - Taxonomic studies of the Halosphaeriaceae: Corollospora Werdermann. Botanical Journal of the Linnean Society 87, 193-212.

Jones EBG, Johnson RG, Moss ST. 1984 - Taxonomic studies of the Halosphaeriaceae: Halosphaeria Linder. Botanica Marina 27, 129-143.

Jones EBG, Hyde KD, Read SJ, Moss ST, Alias SA. 1996 - Tirisporella gen. nov., an ascomycete from the mangrove palm Nypa fruticans. Canadian Journal of Botany 74, 1487-1495.

Jones EBG, Klaysuban A, Pang KL. 2008 - Ribosomal DNA phylogeny of marine anamorphic fungi: Cumulospora varia, Dendryphiella species and Orbimyces spectabis. Raffles Bulletin of Zoology 19, 11-18.

Jones EBG, Sakayaroj J, Suetrong S, Somrithipol S, Pang KL. 2009 - Classification of marine Ascomycota, anamorphic taxa and Basidiomycota. Fungal Diversity 35, 1-187.

Jones EBG, Alias SA, Pang KL. 2013 - Distribution of marine fungi and fungus-like organisms in the south china sea and their potential use in industry and pharmaceutical application. Malaysian Journal of Science (Special Issue) 119-130.

Jones EBG, Suetrong S, Cheng WH, Rungjindamai N et al. 2014 - An additional fungal lineage in the Hypocreomycetidae (Falcocladium species) and the taxonomic revaluation of Chaetosphaeria chaetosa and Swampomyces species, based on morphology, ecology and phylogeny. Cryptogamie Mycologie 35, 119-138.

Jones EBG, Suetrong S, Sakayaroj J, Bahkali AH et al. 2015 - Classification of marine Ascomycota, Basidiomycota, Blastocladiomycota and Chytridiomycota. Fungal Diversity 73, $1-72$.

Jones EBG, Ju WT, Lu CL, Guo SY, Pang KL. 2017 - The Halosphaeriaceae revisited. Botanica Marina 60, 453-468.

Jones EBG, Pang KL, Abdel-Wahab MA, Scholz B et al. 2019 - An online resource for marine fungi. Fungal Diversity 96, 347-433.

Jones KG, Blackwell M. 1998 - Phylogenetic analysis of ambrosial species in the genus Raffaelea based on 18S rDNA sequences. Mycological Research 102, 661-665.

Ju YM, Rogers JD. 1994 - Kretzschmariella culmorum (Cooke) comb. nov. and notes on some other monocot-inhabiting xylariaceous fungi. Mycotaxon 51, 241-255.

Ju YM, Rogers JD. 1996 - A revision of the genus Hypoxylon. Mycologia Memoir No. 20. APS Press, St. Paul.

Ju YM, Rogers JD. 2001 - New and interesting Biscogniauxia taxa, with a key to the world species. Mycological Research 105, 1123-1133.

Ju YM, San Martín F, Rogers JD. 1993 - Three xylariaceous fungi with scolecosporous conidia. Mycotaxon 47, 219-228.

Ju YM, Rogers JD, Hsieh HM, Vasilyeva L. 2004 - Amphirosellinia gen. nov. and a new species of Entoleuca. Mycologia 96, 1393-1402.

Ju YM, Hsieh HM, Ho MC, Szu DH, Fang MJ. 2007 - Theissenia rogersii sp. nov. and phylogenetic position of Theissenia. Mycologia 99, 612-662. 
Junker C, Draeger S, Schulz B. 2012 - A fine line-endophytes or pathogens in Arabidopsis thaliana. Fungal Ecology 5, 657-662.

Kaewchai S, Soytong K, Hyde KD. 2009 - Mycofungicides and fungal biofertilizers. Fungal Diversity $38,25-50$.

Kanakala S, Singh BP. 2013 - Plectosphaerella cucumeria-occurrences as a new root rot pathogen and p-solubiliser in north-eastern India. Archives of Phytopathology and Plant Protection 46, 2016-2018.

Kaneko S, Kobayashi T. 1984 - Fungi inhabiting fagaceous trees V. Three species of Diaporthaceae on evergreen oak leaves. Transactions of the Mycological Society of Japan 25, $11-19$.

Kang GQ, Duan WG, Lin GS, Yu YP et al. 2019 - Synthesis of Bioactive Compounds from 3Carene (II): Synthesis, Antifungal Activity and 3D-QSAR Study of (Z)-and (E)-3-Caren-5One Oxime Sulfonates. Molecules 24, 477.

Kang JC, Kong RYC, Hyde KD. 1998 - Studies on the Amphisphaeriales 1.Amphisphaeriaceae (sensu stricto) and its phylogenetic relationships inferredfrom 5.8S rDNA and ITS2 sequences. Fungal Diversity 1, 147-157.

Kang JC, Hyde KD, Kong RYC. 1999a - Studies on Amphisphaeriales: the Amphisphaeriaceae (sensu stricto). Mycological Research 103, 53-64.

Kang JC, Hyde KD, Kong RYC. 1999b - Studies on Amphisphaeriales. The genera excluded from the Amphisphaeriaceae, Cainiaceae and Clypeosphaeriaceae. Fungal Diversity 2, 135-151.

Kang JC, Hyde KD, Kong RYC. 1999c - Studies on the Amphisphaeriales I. The Clypeosphaeriaceae. Mycoscience 151-164.

Kang JC, Kong RYC, Hyde KD. 2002 - Phylogeny of Amhisphaeriaceae (sensu stricto) and related taxa revisited based on nrDNA sequences. Mycotaxon 81, 321-330.

Kanoh K, Adachi K, Matsuda, S, Shizuri Y. et al. 2008 - New sulfoalkylresorcinol from marinederived fungus, Zygosporium sp. KNC52. The Journal of antibiotics, 61(3), 192.

Kantschaveli LA. 1928 - New species of fungi from Georgia. Bolezni Rastenij 17, 81-94.

Karami SM, Kavosi MR, Hajizadeh G, Jalilvand H. 2014 - Biotechnical control of tar spot (Rhytisma acerinum) disease on velvet maple (Acer velutinum Boiss) in vitro. Journal of Forest Science 60, 330-335.

Karsten PA. 1873 - Mycologia fennica. Pars secunda. Pyrenomycetes. Bidrag till Kännedom av Finlands Natur och Folk 23, 1-252.

Kasanen R, Hantula J, Ostry M, Pinon J, Kurkela T. 2004 - North American populations of Entoleuca mammata are genetically more variable than populations in Europe. Mycological Research 108, 766-774.

Kasson MT, Kasson LR, Wickert KL, Davis DD, Stajich JE. 2019 - Genome sequence of a lethal vascular wilt fungus, Verticillium nonalfalfae, a biological control used against the invasive Ailanthus altissima. Microbiol Resour Announc 8, e01619-18.

Kato H. 2001 - Rice Blast Disease. Pesticide outlook 21, 23-25.

Katsuhiko A. 1996 - A new species of Mycoleptodiscus from Australia. Czech Mycol 49, 1-5.

Kavak H. 2012 - Some biological parmaters in Sordaria fimicola. Plant protection department 44, $1079-1082$.

Kawamura S. 1929 - On some new Japanese fungi. 1. A new fungus parasitic on Bamboo. Journal of Japanese Botany 4, 291-296.

Kazemzadeh Chakusary M, Mohammadi H, Khodaparast S. 2017 - Decline-associated Phaeoacremonium species occurring on forest trees in the north of Iran. Forest pathology 47, e12368.

KC AN, Vallad GE. 2016 - First report of Pilidiella granati causing fruit rot and leaf spots on pomegranate in Florida. Plant Disease 100, 1238.

Kendrick WB. 1958 - Sympodiella, a new hyphomycete genus. Transaction of the British Mycological Society 41, 519-521.

Kendrick B (1974) - The generic iceberg. Taxon 23, 747-753. 
Kepler RM, Sung GH, Harada Y, Tanaka et al. 2012 - Host jumping onto close relatives and across kingdoms by Tyrannicordyceps (Clavicipitaceae) gen. nov. and Ustilaginoidea (Clavicipitaceae). American Journal of Botany 99, 552-561.

Kepler RM, Humber RA, Bischoff JF, Rehner SA. 2014 - Clarification of generic and species boundaries for Metarhizium and related fungi through multigene phylogenetics. Mycologia $106,811-829$.

Kepler RM, Luangsa-ard JJ, Hywel-Jones NL, Quandt CA et al. 2017 - A phylogenetically-based nomenclature for Cordycipitaceae (Hypocreales). IMA Fungus 8, 335-353.

Khan SR, Kimbrough JW. 1974 - Taxonomic position of Termitaria and Mattirolella (entomogenous Deuteromycetes). Amer J Bot 61, 395-399.

Khemmuk W, Geering AD, Shivas RG. 2016 - Wongia gen. nov.(Papulosaceae, Sordariomycetes), a new generic name for two root-infecting fungi from Australia. IMA fungus 7, 247-252.

Khumkomkhet P, Kanokmedhakul S, Kanokmedhakul K, Hahnvajanawong C, Soytong K. 2009 Antimalarial and cytotoxic depsidones from the fungus Chaetomium brasiliense. Journal of Natural Products 72, 1487-1491.

Kidd MN, Beaumont A. 1924 - Apple rot fungi in storage. Transactions of the British Mycological Society 10, 98-118.

Kiffer E, Delon RP. 1983 - Chalara elegans (= Thielaviopsis basicola) and allied species. II validation of two taxa. Mycotaxon 18, 165-174.

Kiho T, Hui J, Yamane A, Ukai S. 1993 - Polysaccharides in fungi. XXXII. Hypoglycemic activity and chemical properties of a polysaccharide from the cultural mycelium of Cordyceps sinensis. Biological and Pharmaceutical Bulletin 16, 1291-1293.

Kirisits T. 2004 - Fungal associates of European bark beetles with special emphasis on the Ophiostomatoid fungi. In: Lieutier F, Day KR, Battisti A, Grégoire JC, Evans H (eds). Bark and wood boring insects in living trees in Europe, a synthesis 181-235.

Kirk PM. 1982 - New or interesting microfungi IV. Dematiaceous hyphomycetes from Devon. Transactions of the British Mycological Society 78, 55-74.

Kirk PM. 1985 - New or interesting microfungi. XIV. Dematiaceous hyphomycetes from Mt. Kenya. Mycotaxon 23, 305-352.

Kirk PM. 1986 - New or interesting microfungi. XV. Miscellaneous hyphomycetes from the British Isles. Transactions of the British Mycological Society 86, 409-428.

Kirk PM, Sutton BC. 1985 - A reassessment of the anamorph genus Chaetopsina (Hyphomycetes). Transactions of the British Mycological Society 85, 709-717.

Kirk PM, Cannon PF, David JC, Stalpers JA. 2001 - Ainsworth and Bisby's Dictionary of the Fungi, 8th edn. CABI Publishing, London.

Kirk PM, Cannon PF, Minter DW, Stalpers JA. 2008 - Dictionary of the Fungi 10th edn. CABI, Wallingford.

Kirk PM, Stalpers JA, Braun U, Crous PW et al. 2013 - A without-prejudice list of generic names of fungi for protection under the International Code of Nomenclature for algae, fungi, and plants. IMA Fungus 4, 381-443.

Kirk PW. 1983 - Direct enumeration of marine arenicolous fungi. Mycologia 75, 670-682.

Kirschner R, Chen CJ. 2002 - Dictyochaeta multifimbriata, a new species from Taiwan. Mycological Progress 1, 287-289.

Kirschstein W. 1936 - Beiträge zur Kenntnis der Ascomyceten und ihrer Nebenformen besonders aus der Mark Brandenburg und dem Bayerischen Walde. Annales Mycologici 34, 180-210.

Kirschstein W. 1939 - Über neue, seltene und kritische Ascomyceten und Fungi imperfecti. II. Annales Mycologici 37, 88-140.

Klaubauf S, Tharreau D, Fournier E, Groenewald JZ et al. 2014 - Resolving the polyphyletic nature of Pyricularia (Pyriculariaceae). Studies in Mycology 79, 85-120.

Klaysuban A, Sakayaroj J, Jones EBG. 2014 - An additional marine fungal lineage in the Diatrypaceae, Xylariales: Pedumispora rhizophorae. Botanica Marina 57, 413-320. 
Klebahn H. 1918 - Hauptund Nebenfruchtformen der Askomuyzeten. Verlag von Gebruder Borntraeger, Leipzig.

Klebahn H. 1929 - Vergilbende junge Treibgurken, ein darauf gefundenes Cephalosporium und dessen Schlauchfrüchte. Phytopathologische Zeitschrift 1, 31-44.

Kobayashi T. 1970 - Taxonomic studies of Japanese Diaporthaceae with special reference to their life-histories. Bull Gov For Exp Station Meguro 226, 1-242.

Kobayashi T, Kawabe Y. 1992 - Tree diseases and their causal fungi in Miyako Island. Japanese Journal of Tropical Agriculture 36, 195-206.

Kobayashi T, Hirooka Y, Natsuaki KT, Kawashima Y et al. 2005 - New canker diseases of Abies veitchii and Acer crataegifolium caused by Neonectria castaneicola. Journal of General Plant Pathology 71, 124-126.

Kobayashi Y, Imazaki R, Asuyama H. 1939 - Fungi, in Asahina's Kryptogamenflora of Japan, Tokyo. 199-606.

Kobayasi Y. 1981 - Revision of the genus Cordyceps and its allies 1. Bulletin of the National Science Museum Tokyo 7, 1-13.

Koch J. 1986 - Some lignicolous marine fungi from Thailand, including two new species. Nordic Journal of Botany 6, 497-499.

Koch J, Jones EBG. 1984 - Lulworthia lignoarenaria, a new marine pyrenomycete from coastal sands. Mycotaxon 20, 389-395.

Koch J, Jones EBG, Moss ST. 1983 - Groenhiella bivestia, gen. et sp. nov., a lignicolous marine fungus from Denmark. Botanica Marina 26, 265-270.

Koch J, Pang KL, Jones EBG. 2007 - Rostrupiella danica gen. et sp. nov., a lulworthia-like marine lignicolous species from Denmark and the USA. Bot Mar 50, 1-8.

Kohlmeyer J. 1972 - A revision of Halosphaeriaceae. Canadian Journal of Botany 50, 1951-1963.

Kohlmeyer J. 1973 - Spathulosporales, a new order and possible missing link between Laboulbenniales and Pyrenomycetes. Mycologia 65, 614-647.

Kohlmeyer J. 1974 - Higher fungi as parasites and symbionts of algae. Veröffentlichungen des Instituts für Meeresforschung in Bremerhaven Supplemen 5, 339-356.

Kohlmeyer J. 1975 - Revision of algicolous Zignoëlla spp. and description of Pontogeneia gen. nov. (Ascomycetes). Bot Jahrb Syst Pflanzengesch Pflanzengeogr 96, 200-211.

Kohlmeyer J. 1986 - Taxonomic studies of the marine Ascomycotina. In: Moss ST (ed). The biology of marine fungi. Cambridge, UK: Cambridge Univ Press 234-257.

Kohlmeyer J, Kohlmeyer E. 1975 - Biology and geographical distribution of Spathulospora species. Mycologia 67, 629-637.

Kohlmeyer J, Kohlmeyer E. 1979 - Marine mycology: the higher fungi. Academic Press, New York 690.

Kohlmeyer J, Demoulin V. 1981 - Parasitic and symbiotic fungi on marine algae. Botanica Marina 24, 9-18.

Kohlmeyer J, Volkmann-Kohlmeyer B. 1987 - Koralionastetaceae fam. nov. (Ascomycetes) from coral rock. Mycologia 79, 764-778.

Kohlmeyer J, Kohlmeyer B. 1989 - Hawaiian marine fungi, including two new genera of Ascomycotina. Mycological Research 92, 410-421.

Kohlmeyer J, Volkmann-Kohlmeyer B. 1989 - Hawaiian marine fungi, including two new genera of Ascomycotina. Mycological Research 92, 410-421.

Kohlmeyer J, Volkmann-Kohlmeyer B. 1990a - A new species of Koralionastes (Ascomycotina) from the Caribbean and Australia. Canadian Journal of Botany 68, 1554-1559.

Kohlmeyer J, Volkmann-Kohlmeyer B. 1990b - Revision of marine species of Didymosphaeria (Ascomycotina). Mycological Research 94, 685-690.

Kohlmeyer J, Volkmann-Kohlmeyer B. 1993 - Observations on Hydronectria and Kallichroma gen. nov. Mycological Research 97, 753-761.

Kohlmeyer J, Volkmann-Kohlmeyer B, Eriksson OE. 1995 - Fungi on Juncus roemerianus. 3. New Ascomycetes. Botanica Marina 38, 175-186. 
Kohlmeyer J, Volkmann-Kohlmeyer B, Eriksson OE. 1997 - Fungi on Juncus roemerianus. New obligate and facultative marin ascomycotina. Botanica Marina 40, 291-300.

Kohlmeyer J, Spatafora JW, Volkmann-Kohlmeyer B. 2000 - Lulworthiales, a new order of marine Ascomycota. Mycologia 92, 453-458.

Kokwaro JO. 1983 - An African knowledge of ethnosystematics and its application to traditional medicine, with particular reference to the medicinal use of the fungus Engleromyces goetzei. Bothalia 14, 237-243.

Kolařík M, Hulcr J. 2009 - Mycobiota associated with the ambrosia beetle Scolytodes unipunctatus (Coleoptera: Curculionidae, Scolytinae). Mycological Research 113, 44-60.

Kong HZ. 1998 - Yunnania gen. nov. of hyphomycetes. Mycotaxon 69, 319-325.

Konta S, Hongsanan S, Tibpromma S, Thongbai B et al. 2016 - An advance in the endophyte story: Oxydothidaceae fam. nov. with six new species of Oxydothis. Mycosphere 7, 1425-1446.

Konta S, Hongsanan S, Eungwanichayapant PD, Liu JK et al. 2017 - Leptosporella (Leptosporellaceae fam. nov.) and Linocarpon and Neolinocarpon (Linocarpaceae fam. nov.) are accommodated in Chaetosphaeriales. Mycosphere 8, 1943-1974.

Körber GW. 1855 - Systema Lichenum Germaniae (I-XXXIV). Die Flechten Deutschlands mikroscopisch gepr"uft, kritisch gesichtet, charakteristisch beschrieben und systematisch geordnet. Trewendt \& Granier, Breslau.

Körber GW. 1865 - Parerga lichenologica. Ergänzungen zum Systema lichenum Germaniae 385501.

Kowalski DT. 1965 - The development and cytology of Melanospora tiffanii. Mycologia 57, 279290.

Kozlova MV, Bilanenko EN, Grum-Grzhimaylo AA, Kamzolkina OV. 2019 - An unusual sexual stage in the alkalophilic ascomycete Sodiomyces alkalinus. Fungal Biology 123, 140-150.

Krause RA, Webster RK. 1972 - Thermorphology, taxonomy, and sexuality of the rice stem fungus, Magnaporthe salvinii (Leptosphaeria salvinii). Mycologia 64, 103-114.

Krauss GJ, Solé M, Krauss G, Schlosser D et al. 2011 - Fungi in freshwaters: ecology, physiology and biochemical potential. FEMS microbiology reviews 35, 620-651.

Kredics L, Hatvani L, Manczinger L, Vágvölgyi C, Antal Z. 2011 - Molecular detection of human fungal pathogens. CRC Press 1-958.

Kreisel H. 1969 - Grunzüge eines natürlichen Systems der Pilze. J. Cramer. Lehre 1-245.

Kren V, Cvak L. 2003 - Ergot: the genus Claviceps. CRC Press.

Krohn K, Sohrab MdH, van Ree T, Draeger S et al. 2008 - Dinemasones A, B and C - new bioactive metabolites from the endophytic fungus Dinemasporium strigosum. European Journal of Organic Chemistry 33, 5638-5646.

Krug JC. 1978 - The genus Cainia and a new family, Cainiaceae. Sydowia 30, 122-133.

Krug JC, Cain RF. 1973 - A preliminary treatment of the genus Podosordaria. Canadian Journal of Botany 52, 589-605.

Krug JC, Jeng RS. 1979 - Rhytidospora and Pteridiosperma, gen. nov. (Melanosporaceae). Mycotaxon 10, 41-45.

Krug JC, Scott JA. 1994 - The genus Bombardioidea. Canadian Journal of Botany 72, 1302-1310.

Krug JC, Udagawa S, Jeng RS. 1983 - The genus Apiosordaria. Mycotaxon 17, 533-549.

Kruys $\AA$, Wedin M. 2009 - Phylogenetic relationships and an assessment of traditionally used taxonomic characters in the Sporormiaceae (Pleosporales, Dothideomycetes, Ascomycota), utilising multi-gene phylogenies. Systematics and Biodiversity 7, 465-478.

Kruys $\AA$, Castlebury LA. 2012 - Molecular phylogeny of Sydowiellaceae-resolving the position of Cainiella. Mycologia 104, 419-426.

Kruys $\AA$, Huhndorf SM, Miller AN. 2015 - Coprophilous contributions to the phylogeny of Lasiosphaeriaceae and allied taxa within Sordariales (Ascomycota, Fungi). Fungal Diversity 70, 101-113.

Kück U, Pöggeler S, Nowrousian M, Nolting N et al. 2009 - Sordaria macrospora, a model system for fungal development. Physiology and Genetics 15, 17-39. 
Kudalkar P, Strobel G, Riyaz-Ul-Hassan S, Geary B, Sears J. 2012 - Muscodor sutura, a novel endophytic fungus with volatile antibiotic activities. Mycoscience 53, 319-325.

Kuephadungphan W, Phongpaichit S, Luangsa-ard JJ, Rukachaisirikul V. 2014 - Antimicrobial activity of invertebrate-pathogenic fungi in the genera Akanthomyces and Gibellula. Mycoscience 55, 127-133.

Kuhnert E, Fournier J, Peršoh D, Luangsa-ard JJ, Stadler M. 2014 - New Hypoxylon species from Martinique and new evidence on the molecular phylogeny of Hypoxylon based on ITS rDNA and b-tubulin data. Fungal Diversity 64, 181-203.

Kuhnert E, Sir EB, Lambert C, Hyde KD et al. 2017 - Phylogenetic and chemotaxonomic resolution of the genus Annulohypoxylon (Xylariaceae) including four new species. Fungal Diversity 85, 1-43.

Kumar D, Sigler L, Gibas CF, Mohan S et al. 2007 - Graphium basitruncatum fungemia in a patient with acute leukemia. Journal of clinical microbiology 45, 1644-1647.

Kuo HC, Hui S, Choi J, Asiegbu FO et al. 2014 - Secret lifestyles of Neurospora crassa. Scientific reports 4, 5135.

Kuo YC, Lin CY, Tsai WJ, Wu CL et al. 1994 - Growth inhibitors against tumor cells in Cordyceps sinensis other than cordycepin and polysaccharides. Cancer Investigation 12, 611615.

Kuo YC, Tsai WJ, Wang JY, Chang SC et al. 2001 - Regulation of bronchoalveolar lavage fluids cell function by the immunomodulatory agents from Cordyceps sinensis. Life Sciences 68, $67-82$.

Kuthubutheen AJ, Nawawi A. 1987 - Cryptophialoidea gen. nov. on decaying leaves from Malaysia. Transactions of the British Mycological Society 89, 581-583.

Kuthubutheen AJ, Nawawi A. 1988 - Two new species of Kionochaeta (Hyphomycetes) and K. ramifera from Malaysia. Transactions of the British Mycological Society 90, 437-444.

Kuthubutheen AJ, Nawawi A. 1991 - Three new species of Dictyochaeta with non-setose conidiophores and non-septate setulate conidia from Malaysia. Mycological Research 95, 104-107.

Kwaśna H, Bateman GL. 2007 - Microdochium triticicola sp. nov. from roots of Triticum aestivum in the United Kingdom. Mycologia 99, 765-776.

Lackner M, de Hoog GS, Yang L, Moreno LF et al. 2014 - Proposed nomenclature for Pseudallescheria, Scedosporium and related genera. Fungal Diversity 67, 1-10.

Læssøe T. 1994 - Index Ascomycetum 1. Xylariaceae. Systema Ascomycetum 13, 43-112.

Læssøe T, Spooner BM. 1994 - Rosellinia and Astrocystis (Xylariaceae): new species and genetic concepts. Kew Bulletin 49, 1-70.

Læssøe T, Rogers JD, Whalley AJS. 1989 -Camillea, Jongiella and light-spored species of Hypoxylon. Mycological Research 93, 121-155.

Læssøe T, Srikitikulchai P, Fournier J, Köpcke B, Stadler M. 2010 - Lepraric acid derivatives as chemotaxonomic markers in Hypoxylon aeruginosum, Chlorostroma subcubisporum and $C$. cyaninum, sp. nov. Fungal Biology 114, 481-489.

Læssøe T, Štěpánek V, Réblová M. 2013 - Molecular phylogeny of Boliniales (Sordariomycetes) with an assessment of the systematics of Apiorhynchostoma, Endoxyla and Pseudovalsaria. Mycologia 105, 564-588.

Lagerberg T, Lundberg G, Melin E. 1927 - Biological and practical researches into Blueing in Pine and Spruce. Svenska Skogsvårdsföreningens Tidskrift 2, 145-272.

Lamarck JB, de Candolle AP. 1815 - Flore Française. Desray: Paris 1-662.

Lambert C, Wendt L, Hladki AI, Stadler M, Sir EB. 2019 - Hypomontagnella (Hypoxylaceae): a new genus segregated from Hypoxylon by a polyphasic taxonomic approach. Mycological Progress 18, 187-201.

Lamprecht SC, Crous PW, Groenewald JZ, Tewoldemedhin YT, Marasas WF. 2011 Diaporthaceae associated with root and crown rot of maize. IMA Fungus 2, 13-24. 
Latterell FM, Rossi AE. 1983 - Stenocarpella macrospora (= Diplodia) and S. maydis (= D. maydis) compared as pathogens of corn. Plant Disease 67, 725-729.

Lawrey JD, Etayo J, Dal-Forno M, Driscoll KE et al. 2015 - Molecular data support establishment of a new genus for the lichenicolous species Neobarya usneae (Hypocreales). The Bryologist $118,83-92$.

Lebert H. 1858 - Ueber einige neue oder unvollkommen gekannte Krankheiten der Insekten, welche durch Entwicklung niederer Pflanzen im lebenden Körper enstehen. Zeitschrift für wissenschaftliche Zoologie 9, 439-453.

Lechat C, Fournier J. 2015 - Varicosporella, a new aquatic genus in the Nectriaceae from France. Ascomycete.org 7, 1-8.

Lechat C, Fournier J. 2018a - Clonostachys spinulosispora (Hypocreales, Bionectriaceae), a new species on palm from French Guiana. Ascomycete.org 10, 127-130.

Lechat C, Fournier J. 2018b - Flammocladiella decora a new combination to accommodate the hypocrealean fungus Nectria decora. Ascomycete.org 10, 48-54.

Lee HB, Mun HY, Nguyen TTT, Kim JC, Stone JK. 2016 - Abieticola koreana gen. et sp. nov., a griseofulvin-producing endophytic xylariaceous ascomycete from Korea. Mycotaxon 131, 749-764.

Lee JS, Ko KS, Jung HS. 2000 - Phylogenetic analysis of Xylaria based on nuclear ribosomal ITS1-5.8S-ITS2 sequences. FEMS Microbiology Letters 187, 89-93.

Lee LW, Wang GJ, Lin MH, Ju YM et al. 2013 - Isolation and characterization of sesquiterpenes from Arecophila saccharicola YMJ96022401 with NO production inhibitory activity. Phytochemistry 85, 129-136.

Lee S, Hanlin RT. 1999 - Phylogenetic Relationships of Chaetomium and Similar Genera Based on Ribosomal DNA Sequences. Mycologia 91, 434-442.

Lee S, Groenewald JZ, Crous PW. 2004 - Phylogenetic reassessment of the coelomycete genus Harknessia and its teleomorph Wuestneia (Diaporthales), and the introduction of Apoharknessia gen. nov. Studies in Mycology 50, 235-252.

Leightley LE. 1980 - Wood decay activities of marine fungi. Botanica Marina 28, 387-395.

Lennox CL, Serdani M, Groenewald JZ, Crous PW. 2004 - Prosopidicola mexicana gen. et. sp. nov. causing a new pod disease of Prosopis species. Studies in Mycology 50, 187-194.

Leuchtmann A, Müller E. 1986 - Über Thyridium vestitum und sein Anamorph (Ascomycetes). Botanica Helvetica 96, 283-287.

Leuchtmann A, Bacon CW, Schardl CL, White Jr JF, Tadych M. 2014 - Nomenclatural realignment of Neotyphodium species with genus Epichloë. Mycologia 106, 202-215.

Léveillé JH. 1846 - Descriptions des champignons de l'herbier du Muséum de Paris. Annales des Sciences Naturelles Botanique 5, 249-305.

Lewis JA, Larkin RP. 1998 - Formulation of the biocontrol fungus Cladorrhinum foecundissiumum to reduce damping-off disease caused by Rhizoctonia solani and Pythium ultimum. Biol Control 12, 182-190.

Li DW, Ye JR. 2017 - Triadelphia acericola and T. centroseptata spp. nov., and a synopsis of the genus. Mycotaxon 132, 723-744.

Li DW, Zhao G. 2018 - Ascotricha microspora sp. nov. from Cayman Islands. Mycotaxon 133, 219-228.

Li DW, Cowles R, Vossbrinck C. 2008 - Metarhiziopsis microspora gen. et sp. nov. associated with the elongate hemlock scale. Mycologia 100, 460-466.

Li DW, Kendrick B, Chen J. 2012 - Two new hyphomycetes: Codinaea sinensis sp. nov. and Parapleurotheciopsis quercicola sp. nov., and two new records from Quercus phillyraeoides leaf litter. Mycological progress 11, 899-905.

Li H, Xiao J, Gao YQ, Tang JJ et al. 2014 - Chaetoglobosins from Chaetomium globosum, an endophytic fungus in Ginkgo biloba, and their phytotoxic and cytotoxic activities. J. Agric. Food Chem 62, 3734-3741. 
Li HH, Zhang K, Xia JW, Wang JY et al. 2017a -Catenularia variegata sp. nov. from southern China, and a first Chinese record of Xylocladium clautriavii. Mycotaxon 132, 621-625.

Li J, Yang JY, Xu KC, Sun YX, Huang Q. 2016 - First report of Ceratocystis fimbriata causing leaf blight on Alocasia macrorrhiza in China. Plant Disease 100, 2172.

Li JF, Phookamsak R, Jeewon R, Tibpromma S et al. 2017b - Establishment of Zygosporiaceae fam. nov. (Xylariales, Sordariomycetes) based on rDNA sequence data to accommodate Zygosporium. Mycosphere 8, 1855-1868.

Li QR, Kang JC, Hyde KD. 2015a - A multiple gene genealogy reveals the phylogenetic placement of Iodosphaeria tongrenensis sp. nov. in Iodosphaeriaceae (Xylariales). Phytotaxa 234, $121-$ 132.

Li QR, Kang JC, Hyde KD. 2015b - Two new species of the genus Collodiscula (Xylariaceae) from China. Mycological Progress 14, 52.

Li QR, Wen TC, Kang JC, Hyde KD. 2015c - A new species of Collodiscula (Xylariaceae) from China. Phytotaxa 205, 187-196.

Li SP, Li P, Dong TTX, Tsim KWK. 2001 - Anti-oxidation activity of different types of natural Cordyceps sinensis and cultured Cordyceps mycelia. Phytomedicine 8, 207-212.

Li SP, Zhang GH, Zeng Q, Huang et al. 2006 - Hypoglycemic activity of polysaccharide, with antioxidation, isolated from cultured Cordyceps mycelia. Phytomedicine 13, 428-433.

Li WJ, Maharachchikumbura SSN, Li QR, Bhat DJ et al. 2015d - Epitypification of Broomella vitalbae and introduction of a novel species of Hyalotiella. Cryptogamie, Mycologie 36, 93108.

Li XF, Lu T, Lu BS, Hyde KD. 2009 - Emarcea rostrispora nom. nov. (Xylariaceae, Ascomycota) on wood from Taiwan. Mycosystema 28, 151-153.

Liberra K, Jansen R. Lindequist U. 1998 - Corollosporine, a new phthalide derivative from the marine fungus Corollospora maritima Werderm. 11069. Phamazie 53, 578-582.

Liew ECY, Aptroot A, Hyde KD. 2000 - Phylogenetic significance of the pseudoparaphyses in Loculoascomycete taxonomy. Molecular Phylogeny \& Evolution 16: 392-402.

Limber DB. 1940 - A new form genus of the Moniliaceae. Mycologia 32, 23-30.

Lin CG, McKenzie EHC, Bhat DJ, Ran SF et al. 2016 - Stachybotrys-like taxa from karst areas and a checklist of stachybotrys-like species from Thailand. Mycosphere 7, 1273-1291.

Lin CG, Dai DQ, Bhat DJ, Hyde KD et al. 2017a - Subsessila turbinata gen. et. sp. nov. (Beltraniaceae), a Beltrania-like fungus from Thailand. Mycol Prog 16, 393-401.

Lin CG, Hyde KD, Lumyong S, McKenzie EHC. 2017b - Beltrania-like taxa from Thailand. Cryptogamie, Mycologie 38, 301-319.

Lin CG, McKenzie EHC, Bhat DJ, Liu JK et al. 2018 - Pseudodactylaria brevis sp. nov. from Thailand confirms the status of Pseudodactylariaceae. Phytotaxa 369, 241-250.

Lin CG, Bhat DJ, Liu JK, Hyde KD, Wang Y. 2019a - The genus Castanediella. MycoKeys 51, 114.

Lin CG, McKenzie EHC, Liu JK, Jones EBG, Hyde KD. 2019b - Hyaline-spored chaetosphaeriaceous hyphomycetes from Thailand and China, with a review of the family Chaetosphaeriaceae. Mycosphere 10, 655-700.

Lindau G. 1897 - Hypocreales. In: Engler HA, Prantl KAE (Eds). Natürl. Pflanzenfam 1, 343-372.

Link HF. 1809 - Observationes in ordines plantarum naturales. Dissertatio I. Magazin der Gesellschaft Naturforschenden Freunde Berlin 3, 3-42.

Link HF. 1826 - Entwurf eines phytologischen Pflanzensystems nebst einer Anordnung der Kryptogamen. Abhandlungen der königlichen Akademie der Wissenschaften zu Berlin aus dem Jahre 1824, 145-194.

Link HF. 1833 - Handbuch zur Erkennung der nutzbarsten und am häufigsten vorkommenden Gewächse 1-536.

Liu F, Hu DM, Cai L. 2012 - Conlarium duplumascospora gen. et. sp. nov. and Jobellisia guangdongensis sp. nov. from freshwater habitats in China. Mycologia 104, 1178-1186. 
Liu F, Li G, Roux J, Barnes I et al. 2018 - Nine novel species of Huntiella from southern China with three distinct mating strategies and variable levels of pathogenicity. Mycologia 110, 1145-1171.

Liu F, Bonthond G, Groenewald JZ, Cai L, Crous PW. 2019a - Sporocadaceae, a family of coelomycetous fungi with appendage-bearing conidia. Studies in mycology 92, 287-415.

Liu J, Tan J, Dong Z, Ding Z et al. 2002 - Neoengleromycin, a novel compound from Engleromyces goetzii. Helvetica Chimica Acta 85, 1439-1442.

Liu JK, Hyde KD, Jones EBG, Ariyawansa HA et al. 2015 - Fungal Divers notes 1-110: taxonomic and phylogenetic contributions to fungal species. Fungal Diversity 72, 1-197.

Liu JK, Yang J, Maharachchikumbura SSN, McKenzie EH et al. 2016 - Novel chaetosphaeriaceous hyphomycetes from aquatic habitats. Mycological Progress 15, 11571167.

Liu L, Li Y, Liu S, Zheng Z et al. 2009 - Chloropestolide A, an antitumor metabolite with an unprecedented spiroketal skeleton from Pestalotiopsis fici. Organic Letters 11, 2836-2839.

Liu NG, Bhat DJ, Hyde KD, Liu JK. 2019b - Conioscypha tenebrosa sp. nov. (Conioscyphaceae) from China and notes on Conioscypha species. Phytotaxa 413, 159-171.

Liu XB, Guo ZK, Huang GX. 2017 - Sarocladium brachiariae sp. nov., an endophytic fungus isolated from Brachiaria brizantha. Mycosphere 8, 827-834.

Locquin M. 1984 - Mycologie générale et structurale 1-551.

Locquin MV. 1972 - Synopsis generalis fungorum, excerpta ex libro'De Taxia Fungorum'. Revue de Mycologie.

Locquin-Linard M. 1973 - Recherches sur la famille des Chadefaudiellacées et considérations sur ses affinités systématiques (Doctoral dissertation).

Locquin-Linard M. 1975 - Faurelina, nouveau genre d'Ascomycètes (Chadefaudiellaceae). Rev Mycol 39, 125-129.

Lombard L, Leeuwen GCM van, Guarnaccia V, Polizzi G et al. 2014 - Diaporthe species associated with Vaccinium, with specific reference to Europe. Phytopathologia Mediterranea 53, 287-299.

Lombard L, Van der Merwe NA, Groenewald JZ, Crous PW. 2015 - Generic concepts in Nectriaceae. Studies in Mycology 80, 189-245.

Lombard L, Houbraken J, Decock C, Samson RA et al. 2016 - Generic hyper-diversity in Stachybotriaceae. Persoonia 36, 156-246.

López MJ, Nichols NN, Dien BS, Moreno J, Bothast RJ. 2004 - Isolation of microorganisms for biological detoxifi cation of lignocellulosic hydrolysates. Applied Microbiology and Biotechnology 64, 125-131.

Lu BS, Hyde KD. 2000 - A world monograph of Anthostomella. Fungal Diversity Research Series 4, 1-376.

Lu YZ, Liu JK, Hyde KD, Bhat DJ et al. 2016 - Brunneodinemasporium jonesii and Tainosphaeria jonesii spp. nov. (Chaetosphaeriaceae, Chaetosphaeriales) from southern China. Mycosphere 7, 1323-1332.

Lu YZ, Fan C, Kang JC, Liu JK et al. 2018 - Triadelphia fusiformis sp. nov. from freshwater habitat in Thailand. Phytotaxa 374, 231-240.

Luangsa-ard J, Houbraken J, van Doorn T, Hong SB et al. 2011 - Purpureocillium, a new genus for the medically important Paecilomyces lilacinus. FEMS Microbiology Letters 321, 141-149.

Luangsa-ard J, Mongkolsamrit S, Noisripoom W, Thanakitpipattana D et al. 2017a - Helicocollum, a new clavicipitalean genus pathogenic to scale insects (Hemiptera) in Thailand. Mycological progress 16, 419-431.

Luangsa-ard J, Mongkolsamrit S, Thanakitpipattana D, Khonsanit A et al. 2017b Clavicipitaceous entomopathogens: New species in Metarhizium and a new genus Nigelia. Mycological progress 16, 369-391. 
Lücking R, Hodkinson BP, Leavitt SD. 2017 - Corrections and amendments to the 2016 classification of lichenized fungi in the Ascomycota and Basidiomycota. The Bryologist 120, $58-69$.

Lueangpraplut S, Unartngam A, Unartngam J. 2013 - Molecular identification of Pseudoplagiostoma eucalypti causing leaf spot and shoot blight diseases on eucalyptus in Thailand based on ITS rDNA sequence. Journal of Agricultural Technology 9, 165-175.

Lumbsch HT, Huhndorf SM. 2007 - Outline of Ascomycota. Myconet 13, 1-58.

Lumbsch HT, Huhndorf SM. 2010 - Myconet volume 14 Part One. Outline of Ascomycota-2009. Part two. Notes on Ascomycete systematics. Nos. 4751-5113. Fieldiana Life Earth Sciences $1,1-64$.

Lundqvist N. 1964a - Anopodium, a new genus of coprophilous pyrenomycetes with apically pedicellate spores. Botaniska Notiser 117, 355-365.

Lundqvist N. 1964b - Fimetariella, a new genus of coprophilous pyrenomycetes. Botaniska Notiser 117, 238-248.

Lundqvist N. 1967 - On spore germination in the Sorediaceae, exemplified by the new cleistocarpous genus Copromyces. Arkiv før Botanik 6, 327-337.

Lundqvist N. 1969 - Zygopleurage and Zygospermella. Botaniska Notiser 122, 353-374.

Lundqvist N. 1972 - Nordic Sordariaceae s. lat. Symbolae Botanicae Upsalliensis 20, 1-374.

Lundqvist N. 1992 - Wawelia effusa Lundqvist, spec. nov. (Xylariaceae). Persoonia 14, 417-423.

Luo J, Zhuang WY. 2010 - Chaetopsinectria (Nectriaceae, Hypocreales), a new genus with Chaetopsina anamorph. Mycologia 102, 976-984.

Luo J, Zhuang WY. 2012 - Volutellonectria (Ascomycota, Fungi), a new genus with Volutella anamorphs. Phytotaxa 44, 1-10.

Luo J, Zhang N. 2013 - Magnaporthiopsis, a new genus in Magnaporthaceae (Ascomycota). Mycologia 105, 1019-1029.

Luo J, Yin JF, Cai L, Zhang KQ, Hyde KD. 2004 - Freshwater fungi in Lake Dianchi, a heavily polluted lake in Yunnan, China. Fungal Diversity 16, 93-112.

Luo J, Walsh E, Zhang N. 2014 - Four new species in Magnaporthaceae from grass roots in New Jersey Pine Barrens. Mycologia 106, 580-588.

Luo ZL, Maharachchikumbura SSN, Liu XY, Chen LJ et al. 2015 - Annulatascus saprophyticus sp. nov. and Pseudoannulatascus gen. nov. to accommodate Annulatascus biatriisporus (Annulatascales, Sordariomycetes) from Thailand. Phytotaxa 239, 174-182.

Luo ZL, Bao DF, Bhat JD, Yang J et al. 2016 - Sporoschisma from submerged wood in Yunnan, China. Mycological progress 15, 1145-1155.

Luo ZL, Hyde KD, Bhat DJ, Jeewon R et al. 2018 - Morphological and molecular taxonomy of novel species Pleurotheciaceae from freshwater habitats in Yunnan, China. Mycological Progress 17, 511-530.

Luo ZL, Hyde KD, Liu JK, Maharachchikumbura SSN et al. 2019 - Freshwater Sordariomycetes. Fungal Diversity 99, 451-660.

Luttrell ES. 1951 - Taxonomy of the Pyrenomycetes. University of Missouri Studies 24, 1-120.

Luttrell ES. 1989 - Morphology of Meliola floridensis. Mycologia 81, 192-204.

Ma J, Ma LG, Zhang YD, Castañeda-Ruíz RF et al. 2012 - New species and record of Corynesporopsis and Hemicorynespora from southern China. Nova Hedwigia 95, 233-241.

Ma J, Zhang K, Zhang XG, Castañeda-Ruíz RF. 2016a - Three new species of Spadicoides from Lushan Mountain, China. Mycol Progress 15, 43.

Ma LG, Ma J, Zhang YD, Zhang XG. 2011 - Craspedodidymum and Corynespora spp. nov. and a new anamorph recorded from southern China. Mycotaxon 117, 351-358.

Ma YR, Xia JW, Gao JM, Li Z et al. 2016b - Anacacumisporium, a New Genus Based on Morphology and Molecular Analyses from Hainan, China. Cryptogamie Mycologie 37, 4559.

Maas JL. 1998 - Compendium of Strawberry Diseases. $2^{\text {nd }}$ ed. The American Phytopathological Society 1-98. 
Macías M, Ulloa M, Gamboa A, Mata R. 2000 - Phytotoxic compounds from the new coprophilous fungus Guanomyces polythrix. Journal of Natural Products 63, 757-761.

Macías M, Ulloa M, Gamboa A, Toscano RA, Mata R. 2001 - Phytotoxic naphtopyra-none derivates from the coprophilous fungus Guanomyces polythrix. Phytochemistry58, 751-758.

Madrid H, Cano J, Gené J, Guarro J. 2011 - Two new species of Cladorrhinum. Mycologia 103, 795-805.

Magyar D, Shoemaker RA, Bobvos J, Crous PW et al. 2011 - Pyrigemmula, a novel hyphomycete genus on grapevine and tree bark. Mycological Progress 10, 307-314.

Maharachchikumbura SSN, Guo LD, Chukeatirote E, Bahkali AH et al. 2011 - Pestalotiopsismorphology, phylogeny, biochemistry and diversity. Fungal Diversity 50, 167-187.

Maharachchikumbura SSN, Guo LD, Cai L, Chukeatirote E et al. 2012 - A multi-locus backbone tree for Pestalotiopsis, with a polyphasic characterization of 14 new species. Fungal Diversity $56,95-129$.

Maharachchikumbura SSN, Guo LD, Chukeatirote E, McKenzie EHC et al. 2013 - A destructive new disease of Syzygium samarangense in Thailand caused by the new species Pestalotiopsis samarangensis. Tropical Plant Pathology 38, 227-235.

Maharachchikumbura SSN, Guo LD, Chukeatirote E, Hyde KD. 2014a - Improving the backbone tree for the genus Pestalotiopsis; addition of P. steyaertii and P. magna sp. nov. Mycological Progress 13, 617-624.

Maharachchikumbura SSN, Hyde KD, Groenewald JZ, Xu J et al. 2014b - Pestalotiopsis revisited. Studies in Mycology 79, 121-186.

Maharachchikumbura SSN, Hyde KD, Jones EBG, McKenzie EHC et al. 2015 - Towards a natural classification and backbone tree for Sordariomycetes. Fungal Diversity 72, 199-301.

Maharachchikumbura SSN, Guo LD, Liu ZY, Hyde KD. 2016a - Pseudopestalotiopsis ignota and Ps. camelliae spp. nov. associated with grey blight disease of tea in China. Mycological Progress 15, 22.

Maharachchikumbura SSN, Hyde KD, Jones EBG, McKenzie EHC et al. 2016b - Families of Sordariomycetes. Fungal Diversity 79, 1-317.

Maharachchikumbura SSN, Hyde KD, Perera RH, Al-Sadi AM. 2018a - Acrocordiella omanensis sp. nov. (Requienellaceae, Xylariales) from the Sultanate of Oman. Phytotaxa 338, 294-300.

Maharachchikumbura SSN, Luo ZL, Su HY, Al-Sadi A, Cheewangkoon R. 2018b Reticulascaceae hyphomycetes from submerged wood in Yunnan, China. Phytotaxa 348, 187-198.

Mains EB. 1951 - Entomogenous species of Hirsutella, Tilachlidium and Synnematium. Mycologia 43, 691-718.

Maire R. 1937 - Fungi Catalaunici: Series altera. Contributions a l'étude de la flore mycologique de la Catalogne. Publicacions del Instituto Botánico Barcelona 3, 1-128.

Makelii K, Koponen H. 1974 - Telimenella gangraena and Septogloeum oxysporum on grasses in Finland. Karstenia 15, 56-63.

Malloch D. 1970 - New concepts in the Microascaceae illustrated by two new species. Mycologia 62, 727-740.

Malloch D. 1989 - An undescribed species of Leucosphaerina. Studies in Mycology 31, 107-111.

Malloch D, Cain RF. 1970 - Five new genera in the new family Pseudeurotiaceae. Canadian Journal of Botany 48, 1815-1825.

Malloch D, Cain RF. 1971 - New cleistothecial Sordariaceae and a new family, Coniochaetaceae. Canadian Journal of Botany 49, 869-880.

Malloch D, Cain RF. 1973 - The genus Thielavia. Mycologia 65, 1055-1077.

Malloch D, Blackwell M. 1990 - Kathistes, a new genus of pleomorphic ascomycetes. Canadian Journal of Botany 68, 1712-1721.

Malloch D, Mallik A. 1998 - Taxonomy of Orphnodactylis kalmiae gen. et sp. nov. influenced by the hyperparasite Didymosphaeria kalmiae. Canadian Journal of Botany 76, 1265-1275. 
Malloch D, Salkin IF. 1984 - A new species of Scedosporium associated with osteomyelitis in humans. Mycotaxon 21, 247-255.

Malosso E, Costa PMO, Barbosa MA, Silva GVRD, Castañeda-Ruiz RF. 2017 - Paliphora bicolorata sp. nov. from the Brazilian Atlantic Forest. Mycotaxon 132, 903-907.

Manoharachary C, Agarwal DK, Sureshkumar G, Kunwar IK, Babu KS. 2006 - Memnoniella mohanramii sp. nov. and Zygosporium anupamvarmae sp. nov. from India. Indian Phytopathology 59, 489-491.

Marais GJ, Wingfield MJ, Viljoen CD, Wingfield BD. 1998 - A new Ophiostomatoid genus from Protea infructescences. Mycologia 90, 136-141.

Marasinghe DS, Samarakoon MC, Hongsanan H, Boonmee S, McKenzie EHC. 2019 Iodosphaeria honghense sp. nov. (Iodosphaeriaceae, Xylariomycetidae) from Yunnan Province, China. Phytotaxa 420, 273-282.

Mardones M, Trampe-Jaschik T, Oster S, Elliott M et al. 2017 - Phylogeny of the order Phyllachorales (Ascomycota, Sordariomycetes): among and within order relationships based on five molecular loci. Persoonia 39, 74-90.

Mardones M, Trampe-Jaschik T, Hofmann TA, Mangelsdorff RD, Piepenbring M. 2018 - New neotropical species of Phyllachorales based on molecular, morphological, and ecological data. Mycologia 1-25.

Mariani G. 1911 - Pyrenomycetae, Sphaeriaceae, Guignardia Atti della Societa Italiana di Scienze Naturali e del Museo Civico di Storia Naturale di Milano 50, 1-165.

Marincowitz S, Crous PW, Groenewald JZ, Wingfield MJ. 2008 - Microfungi occurring on the Proteaceae in the fynbos. CBS Biodiversity series 1-166.

Marine fungi. 2019 - www. marinefungi.org/

Marin-Felix Y, Stchigel AM, Miller AN, Guarro J, Cano-Lira JF. 2015 - A re-evaluation of the genus Myceliophthora (Sordariales, Ascomycota): its segregation into four genera and description of Corynascus fumimontanus sp. nov. Mycologia 107, 619-632.

Marin-Felix Y, Groenewald JZ, Cai L, Chen Q et al. 2017 - Genera of phytopathogenic fungi: GOPHY 1. Study in Mycology 86, 99-216.

Marin-Felix Y, Guarro J, Cano-Lira JF, García D et al. 2018 -Melanospora (Sordariomycetes, Ascomycota) and its relatives. MycoKeys 44, 81-122.

Marin-Felix Y, Restrepo HM, Wingfield MJ, Akulov A et al. 2019 - Genera of phytopathogenic fungi: GOPHY 2. Studies in Mycology 92, 47-133.

Markovskaja S. 2003 - A new species of Cordana from Lithuania. Mycotaxon 87, 179-185.

Markovskaja S, Treigien A. 2007 - A new and a rare species of Cryptadelphia and their Brachysporium anamorphs. Nova Hedwigia 84, 495-501.

Marsault E, Peterson ML. 2017 - Practical Medicinal Chemistry with Macrocycles: Design, Synthesis, and Case studies. Wiley: Hoboken, NJ.

Martin GW. 1941 - Outline of the fungi. Studies in Natural History University Iowa 18, 192-204.

Martin M, Saparrat M, Barrera V, Gasoni L. 2019 - Mini-review: Cladorrhinum species, their diversity and application in biotechnology. Nova Hedwigia 108, 489-503.

Martínez-Ballesta MC, Alcaraz-López C, Muries B, Mota-Cadenas C, Carvajal M. 2010 Physiological aspects of rootstock-scion interactions. Scientia Horticulturae 127, 112-118.

Mason EW. 1941 - Annotated account of fungi received at the Imperial Mycological Institute. Mycological Papers 5, 103-144.

Massee GE, Salmon ES. 1901 - Researches on coprophilous fungi. Annals of Botany 15, 313-357.

Masudi S, Bonjar GHS. 2012 - Fulfillment of Koch's postulates for in vitro pathogenicity of Musicillium theobromae (turconi) Zare \& W. Gams as the cause of banana cigar end rot disease. J Plant Prot Res 52, 410-414.

Mata R, Gamboa A, Macias M, Santillán S et al. 2003 - Effect of selected phytotoxins from Guanomyces polythrix on the calmodulin-dependent activity of the enzymes cAMP phosphodiesterase and NAD-kinase. Journal of Agricultural \& Food Chemistry 51, 45594562 . 
Matočec N, Kušan I, Ozimec R. 2014 - The genus Polycephalomyces (Hypocreales) in the frame of monitoring Veternica cave (Croatia) with a new segregate genus Perennicordyceps. Ascomycete 6, 125-133.

Matsushima T. 1971 - Microfungi of the Solomon Islands and Papua-New Guinea. Kobe, Japan 178.

Matsushima T. 1975 - Icones Microfungorum a Matsushima lectorum 1-209.

Matsushima T. 1993 - Matsushima Mycological Memoirs 7. Matsushima. Kobe, Japan.

Matsushima T. 1995 - Matsushima Mycological Memoirs 8. Matsushima. Mycological Memoirs 8, $1-44$.

Matsushima T. 1996 - Matsushima Mycological Memoirs 9. Matsushima. Kobe, Japan.

Mavragani DC, Abdellatif L, Mcconkey McConkey B et al. 2007 - First report of damping-off of durum wheat caused by Arthrinium sacchari in the semi-arid saskatchewan fields. Plant Disease 91, 469.

Mayers CG, McNew DL, Harrington TC, Roeper RA et al. 2015 - Three genera in the Ceratocystidaceae are the respective symbionts of three independent lineages of ambrosia beetles with large, complex mycangia. Fungal Biology 119, 1075-1092.

Mayers CG, Harrington TC, Ranger CM. 2017 - First report of a sexual state in an ambrosia fungus: Ambrosiella cleistominuta sp. nov. associated with the ambrosia beetle Anisandrus maiche. Botany 95, 503-512.

Mayers CG, Bateman CC, Harrington TC. 2018 - New Meredithiella species from mycangia of Corthylus ambrosia beetles suggest genus-level coadaptation but not species-level coevolution. Mycologia 110, 63-78.

Mayers CG, Harrington TC, Masuya H, Jordal BH et al. 2019 - Patterns of coevolution between ambrosia beetle mycangia and the Ceratocystidaceae, with five new fungal genera and seven new species. Persoonia 44, 41-66.

Mbenoun M, Wingfield MJ, Boyogueno AB, Amougou FN et al. 2016 - Diversity and pathogenicity of the Ceratocystidaceae associated with cacao agroforests in Cameroon. Plant pathology $65,64-78$.

McGovern RJ. 2015 - Management of tomato diseases caused by Fusarium oxysporum. Crop Protection 73, 78-92.

McKenzie EHC, Thongkantha S, Lumyong S. 2007 - Zygosporium bioblitzi sp. nov. on dead leaves of Cortaderia and Dracaena. New Zealand Journal of Botany 45, 433-435.

McNeill J, Barrie FR, Burdet HM, Demoulin V et al. 2006 - International code of botanical nomenclature (Vienna code) A.R.G. Gantner Verlag, Ruggell.

McNeill J, Barrie FR, Buck WR, Turland N. 2012 - International Code of Nomenclature for algae, fungi, and plants (Melbourne Code) adopted by the Eighteenth International Botanical Congress Melbourne, Australia, July 2011. Ruggell: A.R.G. Gantner Verlag.

McTaggart AR, Grice KR, Shivas RG. 2013 - First report of Vialaea minutella in Australia, its association with mango branch dieback and systematic placement of Vialaea in the Xylariales. Australasian Plant Disease Notes 8, 63-66.

Medel R, Rogers JD, Guzmán G. 2006 - Phylacia mexicana sp. nov. and consideration of other species with emphasis on Mexico. Mycotaxon 97, 279-290.

Meekes ET, Fransen JJ, van Lenteren JC. 2002 - Pathogenicity of Aschersonia spp. against whiteflies Bemisia argentifolii and Trialeurodes vaporariorum. Journal of Invertebrate Pathology 81, 1-11.

Mehrotra RS, Aneja KR. 1990 - An introduction to mycology. New Age International, India.

Mejía LC, Castlebury LA, Rossman AY, Sogonov MV, White JF. 2011 - A systematic account of the genus Plagiostoma (Gnomoniaceae, Diaporthales) based on morphology, host associations, and a four-gene phylogeny. Studies in Mycology 68, 211-235.

Mejía LC, Rossman AY, Castlebury LA, Yang ZL et al. 2012 - Occultocarpon, a new monotypic genus of Gnomoniaceae on Alnus nepalensis from China. Fungal Diversity 52, 99-105. 
Mekoguem C, Triboulet C, Alexandre G. 2019 - Madurella mycetomatis infection of the buttock in an Eritrean refugee in Switzerland: a case report. Journal of Medical Case Reports 13, 32.

Melo RF, Miller AN, Maia LC. 2016 - First records of Faurelina in the Neotropics. Mycotaxon $131,67$.

Mercado SA, Castañeda RF. 1983 - Nueva especies de Triadelphia (Hyphomycetes, Deuteromycotina) de Cuba. Revista del Jardin Botanico Nacional, Universidad de la Habana 4, 65-79.

Mercado SA, Mena PJ. 1985 - Nuevo género de hifomicete fialídico de Cuba, Revista del Jardín Botánico Nacional, Universidad de La Habana 6, 57-60.

Mercado SA, Heredia AG, Mena PJ. 1997 - Tropical hyphomycetes of Mexico I. New species of Hemicorynespora, Piricauda and Rhinocladium. Mycotaxon 63, 155-167.

Mercier J, Manker DC. 2005 - Biocontrol of soil-borne diseases and plant growth enhancement in greenhouse soilless mix by the volatile-producing fungus Muscodor albus. Crop Protection $24,355-362$.

Mersha Z, Zhang S, Fu Y. 2012 - First Report of Black Leg Caused by Plectosphaerella cucumerina on Greenhouse Grown Basil in Florida. Plant Disease 96, 1382-1382.

Milagres CA, Azevedo DMQ, Pereira OL, Furtado GQ. 2018 - Epitypification, characterization and phylogenetic positioning of Pseudobeltrania cedrelae, the causal agent of pseudobeltrania spot on Cedrela fissilis. For Pathol 48, e12434.

Miller AN, Huhndorf SM. 2004 - A natural classification of Lasiosphaeria based on nuclear LSU rDNA sequences. Mycological Research 108, 26-34.

Miller AN, Huhndorf SM. 2005 - Multigene phylogenies indicate ascomal wall morphology is a better predictor of phylogenetic relationships than ascospore morphology in the Sordariales (Ascomycota, Fungi). Molecular Phylogenetics and Evolution 35, 60-75.

Miller AN, Huhndorf SM. 2009 - Gaillardiella pezizoides. Pyrenomycetes of the World. http://www-s.life.illinois.edu/pyrenos/records/show_by_page?page=53.

Miller AN, Vasilyeva LN, Rogers JD. 2007 - Chlorostroma subcubisporum gen. et sp. nov. and notes on the systematic position of Thuemenella cubispora. Sydowia 59, 138-147.

Miller AN, Huhndorf SM, Fournier J. 2014 - Phylogenetic relationships of five uncommon species of Lasiosphaeria and three new species in the Helminthosphaeriaceae (Sordariomycetes). Mycologia 106, 505-524.

Miller JH. 1951 - Studies in the Phyllachoraceae I. Phyllachora ambrosiae (Berk. and Curt.) Sacc. American Journal of Botany 38, 830-834.

Miller JH. 1954 - Studies in the Phyllachoraceae II. Phyllachora lespedezae. American Journal of Botany 41, 825-828.

Miller JH. 1961 - A monograph of the world species of Hypoxylon. University of Georgia Press, Athens.

Minoshima A, Walker DM, Takemoto S, Hosoya T et al. 2018 - Pathogenicity and taxonomy of Tenuignomonia styracis gen. et sp. nov., a new monotypic genus of Gnomoniaceae on Styrax obassia in Japan. Mycoscience 60, 31-39.

Minoura K, Muroi T. 1978 - Some freshwater ascomycetes from Japan. Transactions of the Mycological Society of Japan 19, 129-134.

Minter DW, Sutton BC, Brady BL. 1983 - What are phialides anyway? Transactions of the British Mycological Society 81, 109-120.

Mirabolfathy M, Groenewald JZ, Crous PW. 2012 - First report of Pilidiella granati causing dieback and fruit rot of pomegranate (Punica granatum) in Iran. Plant Disease 96, 461.

Mirabolfathy M, Ju YM, Hsieh HM, Rogers JD. 2013 - Obolarina persica sp. nov., associated with dying Quercus in Iran. Mycoscience 54, 315-320.

Miranda BEC, Barreto RW, Crous PW, Groenewald JZ. 2012 - Pilidiella tibouchinase sp. nov. associated with foliage blight of Tibouchina granulose (quaresmeira) in Brazil. Ima fungus 3 , 1-7. 
Mirtalebi M, Banihashemi Z, Sabahi F, Mafakheri H. 2017 - Dieback of rose caused by Acremonium sclerotigenum as a new causal agent of rose dieback in Iran. Spanish Journal of Agricultural Research 14, 10-103.

Mitchell JK, Taber RA. 1986 - Factors affecting the biological control of Cercosporidium leaf spot of peanuts by Dicyma pulvinata. Phytopathology 76, 990-994.

Mohammadi A, Amini Y. 2015 - Molecular Characterization and Identification of Acrostalagmus luteoalbus from Saffron in Iran. Agriculture Science Developments 4, 16-18.

Molitoris HP. 1994 - Mushrooms in medicine. Folia microbiologica 39, 91.

Möller A. 1901 - Phycomyceten und Ascomyceten. Untersuchungen aus Brasilien. Botanische Mittheilungen aus den Tropen 9, 1-319.

Momota K, Nakaoka M. 2017 - Influence of different types of sessile epibionts on the community structure of mobile invertebrates in an eelgrass bed. Peer J 5, 29-52.

Mongkolsamrit S, Luangsa-Ard JJ, Spatafora JW, Sung GH, Hywel-Jones NL. 2009 - A combined ITS rDNA and $\beta$-tubulin phylogeny of Thai species of Hypocrella with non-fragmenting ascospores. Mycological research 113, 684-699.

Mongkolsamrit S, Luangsa-Ard JJ, Hywel-Jones NL. 2011 - Samuelsia mundiveteris sp. nov. from Thailand. Mycologia 103, 921-927.

Mongkolsamrit S, Thanakitpipattana D, Khonsanit A, Promharn R, Luangsa-ard JJ. 2016 Conoideocrella krungchingensis sp. nov., an entomopathogenic fungus from Thailand. Mycoscience 57, 264-270.

Mongkolsamrit S, Noisripoom W, Thanakitpipattana D, Wutikhun T et al. 2018 - Disentangling cryptic species with isaria-like morphs in Cordycipitaceae. Mycologia 110, 230-257.

Mongkolsamrit S, Noisripoom W, Arnamnart N, Lamlertthon et al. 2019 - Resurrection of Paraisaria in the Ophiocordycipitaceae with three new species from Thailand. Mycological Progress 18, 1213-1230.

Monod M. 1983 - Monographie taxonomique des Gnomoniaceae (Ascomycètes de l'ordre des Diaporthales). I. Beihefte zur Sydowia 9, $1-314$.

Montagne JPFC. 1842 - Troisième Centurie de plantes cellulaires exotiques nouvelles, Décades I, II, III et IV. Fungi cubenses. Annales des Sciences Naturelles Botanique 17, 119-128.

Montagne JPFC. 1848 - Sixième Centurie de plantes exotiques nouvelles. Décades I et II. Annales des Sciences Naturelles Botanique 10, 106-136.

Montoya QV, Martiarena MJS, Polezel DA, Kakazu S, Rodrigues A. 2019 - More pieces to a huge puzzle: Two new Escovopsis species from fungus gardens of attine ants. Mycokeys 46, 97118.

Moravec Z. 1956 - Arachnocrea, un genre nouveau de la famille des Nectriaceae. Bulletin de la Société Mycologique de France 72, 160-166.

Moreau C, Moreau M. 1951 - Pyrenomycetes of coffee shrubs in the Ivory Coast. Revue de Mycologie (France) 16, 12-80.

Moricca S, Ragazzi A. 2008 - Fungal endophytes in Mediterranean oak forests: a lesson from Discula quercina. Phytopathology 98, 380-386.

Moricca S, Linaldeddu BT, Ginetti B, Scanu B et al. 2016 - Endemic and emerging pathogens threatening cork oak trees: Management options for conserving a unique forest ecosystem. Plant Disease 100, 2184-2193.

Morton FJ, Smith G. 1963 - The genera Scopulariopsls Bainier, Microascus Zukal, and Doratomyces Corda. Mycological papers 86.

Mostert L, Crous PW, Ewald Groenewald JZ, Gams W et al. 2003 - Togninia (Calosphaeriales) is confirmed as teleomorph of Phaeoacremonium by means of morphology, sexual compatibility and DNA phylogeny. Mycologia 95, 646-659.

Mostert L, Halleen F, Creaser ML, Crous PW. 2004 - Cryptovalsa ampelina, a forgotten shoot and cane pathogen of grapevines. Australasian Plant Pathology 33, 295-299. 
Mostert L, Groenewald JZ, Summerbell RC, Gams W et al. 2006 - Taxonomy and pathology of Togninia (Diaporthales) and its Phaeoacremonium anamorphs. Studies in Mycology 54, 1113.

Moubasher AH, Abdel-Sater MA, Zeinab Soliman. 2017 - Knoxdaviesia with K. serotectus (Van der Linde \& Jol. Roux) Z.W. de Beer \& M.J. Wingf. a new world record from the gut of red palm weevils. StudiesinFungi 2, 64-70.

Mouchacca J. 1973 - Les Thielavia des sols arides: Espèces nouvelles et analyse générique. Bulletin Trimestriel de la Société Mycologique de France 89, 295-311.

Mouchacca J, Gams W. 1993 - The hyphomycete genus Cladorrhinum and its teleomorph connections. Mycotaxon 48, 415-440.

Moustafa AF, Abdul-Wahid OA. 1990 - Chaetomiopsis, a new perithecial ascomycete genus from Egyptian soils. Mycologia 82, 129-131.

Mouzouras R. 1986 - Patterns of timber decay caused by marine fungi. In: Moss (ed). The biology of marine fungi. Cambridge University Press, Cambridge 341-353.

Moyo P, Mostert L, Spies CFJ, Damm U, Halleen F. 2017 - Diversity of Diatrypaceae Species Associated with Dieback of Grapevines in South Africa, with the Description of Eutypa cremea sp. nov. Plant Disease 102, 220-230.

Muchovej JJ, Della Lucia TMC. 1990 - Escovopsis, a new genus from leaf cutting ant nests to replace Phialocladus nomen invalidum. Mycotaxon 37, 191-195.

Mueller W, Goos R, Quainoo J, Morgham A. 1991 - The structure of the phialides (mucronate hyphopodia) of the Meliolaceae. Canadian Journal of Botany 69, 803-807.

Mugambi GK, Huhndorf SM. 2010 - Multigene phylogeny of the Coronophorales: morphology and new species in the order. Mycologia 102, 185-210.

Mukerji KG. 1978 - Taxonomy of the Chaetomiales in relation to its morphology and cytology. In: Subramanian CV(ed). Taxonomy of Fungi 1, 258-262.

Mukerji KG, Manoharachary C. 2010 - Taxonomy and ecology of Indian fungi. I.K. International Pvt Ltd. New Delhi. India 293.

Müller E. 1957 - Haupt- und Nebenfruchtformen bei Guignardia Viala et Ravas. Beihefte zur Sydowia 1, 210-224.

Müller E. 1975 - Über die Gattung Telimena Raciborski (Ascomycetes). Sydowia 27, 74-77.

Muller E. 1986 - On the genus Diachora J. Mu\$ller (Ascomycetes). Transactions of the Botanical Society of Edinburgh 1836-1986 150th Anniversary Supplement 69-75.

Müller E, von Arx JA. 1962 - Die Gattungen der didymosporen Pyrenomyceten. Beitrage zur Kryptogamenflora der Schweiz 11, 1-922.

Müller E, Booth C. 1972 - Generic position of Sphaeria phaeostroma. Trans Br mycol Soc 58, 7377.

Müller E, von Arx JA. 1973 - Pyrenomycetes: Meliolales, Coronophorales, Sphaeriales. The fungi. Vol. 4A. Erliterl by GC Ainsworth, F.K. Sparrow, and A.S. Sussman. Academic Press, New York 87-132.

Müller E, Samuels GJ. 1982a - Anamorphs of pyrenomycetous Ascomycetes I. Rhamphoria Niessl and Trichosphaerella Bommer, Rousseau \& Saccardo. Sydowia 35, 143-149.

Müller E, Samuels GJ. 1982b - Anamorphs of pyrenomycetous Ascomycetes II. Porosphaerella gen. nov. and its Cordana anamorph. Sydowia 35, 150-154.

Munk A. 1948 - Pyrenomycetes collected in the peninsula Mols, Jutland. Dansk botanisk Arkiv 12, $1-19$.

Munk A. 1957 - Danish Pyrenomycetes, A preliminary flora. Dansk Botanisk Arkiv 17, 1-491

Murata N, Aoki T, Kusaba M, Tosa Y, Chuma I. 2014 - Various species of Pyricularia constitute a robust clade distinct from Magnaporthe salvinii and its relatives in Magnaporthaceae. Journal of General Plant Pathology 80, 66-72.

Musvuugwa T, de Beer ZW, Duong TA, Dreyer LL et al. 2015 - New species of Ophiostomatales from Scolytinae and Platypodinae beetles in the Cape Floristic Region, including the discovery of the sexual state of Raffaelea. Antonie Van Leeuwenhoek 108, 933-950. 
MycoBank. 2019 - http://www.mycobank.org.

$\mathrm{Na}$ F, Carrillo JD, Mayorquin JS, Ndinga-Muniania C et al. 2018 - Two novel fungal symbionts Fusarium kuroshium sp. nov. and Graphium kuroshium sp. nov. of Kuroshio shot hole borer (Euwallacea sp. nr. fornicatus) cause Fusarium dieback on woody host species in California. Plant disease 102, 154-164.

Na M, Min BS, Bae K. 2009 - Antioxidant compounds from Cercis chinensis bunge. Bulletin of the Korean Chemical Society 11, 2765-2768.

Nag Raj TR. 1974 - Icones generum coelomycetum VI. University of Waterloo Biology Series 13, $1-41$.

Nag Raj TR. 1978 - Genera coelomycetum. XIV. Allelochaeta, Basilocula, Ceuthosira, Microgloeum, Neobarclaya, Polynema, Pycnidiochaeta, and Xenodomus. Canadian Journal of Botany 56, 686-707.

Nag Raj TR. 1984 - Koorchaloma, Koorchalomella, and Kananascus gen. nov. Mycotaxon 19, 167-212.

Nag Raj TR. 1993 - Coelomycetous anamorphs with appendage bearing conidia. Mycologue publications, Waterloo 1-1101.

Nag Raj TR, DiCosmo F. 1981 - A monograph of Harknessia and Mastigosporella with notes on associated teleomorphs. Bibl Mycol 80, 1-62.

Najwa AM, Sarah AA, Ahmed HFG, Sybren DH et al. 2012 - Pleurostomophora ochracea, a novel agent of human eumycetoma with yellow grains. J Clin Microbiol 50, 2987-2994.

Nakagiri A. 1993 - A New Marine ascomycete in Spathulosporales, Hispidicarpomyces galaxauricola gen. et sp. nov. (Hispidicarpomycetaceae fam. nov.), inhabiting a red alga, Galaxaura falcata. Mycologia 85, 649.

Nakagiri A, Tubaki K. 1986 - Ascocarp peridial wall structure in Corollospora and allied genera of Halosphaeriaceae. In: Moss ST (ed). The biology of marine fungi. Cambridge University Press, Cambridge 245-252.

Nakagiri A, Ito T. 1997 - Retrostium amphiroae gen. et sp. nov. inhabiting a marine red alga, Amphiroa zonata. Mycologia 484-493.

Nambiar GR, Raveendran K. 2015 - Frequency of Marine Fungi on Animal Substrates along West Coast of India. Current Research in Environmental \& Applied Mycology 5, 394-397.

Namyslowski B. 1908 - Sur la structure et le développement de Wawelia regia nova subfam. gen. sp. Bulletin International de l'Academie des Sciences de Cracovie. Classe des Sciences Mathematiques et Naturelles series B 7, 597-603.

Nandakumar R, Yoshimune K, Wakayama M, Moriguchi M. 2003 - Microbial glutaminase: biochemistry, molecular approaches and applications in the food industry. Journal of Molecular Catalysis B: Enzymatic 23, 87-100.

Nannfeldt JA. 1932 - Studien über die Morphologie und Systematik der nichtlichenisierten inoperculaten Discomyceten. Nova Acta Regiae Societatis Scientiarum Upsaliensis 8, 1-368.

Nannfeldt JA. 1934 - Repert. mic. uomo. 498.

Nannfeldt JA. 1972 - Camarops Karst. (Sphaeriales, Boliniaceae) with special regard to its European species. Svensk Botanisk Tidskrift 66, 335-376.

Nannfeldt JA. 1975 - Stray studies in the Coronophorales (Pyrenomycetes) 1-3. Svensk Botanisk Tidskrift 69, 49-66.

Nannfeldt JA, Santesson R. 1975 - Stray studies in the Coronophorales (Pyrenomycetes) 4-8. Svensk Botanisk Tidskrift 69, 289-335.

Narendra DV, Rao VG. 1976 - Some interesting Ascomycetes from India. Sydowia 353-358.

Nasr S, Bien S, Soudi MR, Alimadadi N et al. 2018 - Novel Collophorina and Coniochaeta species from Euphorbia polycaulis, an endemic plant in Iran. Mycological Progress 17, 755-771.

Natvig DO, Taylor JW, Tsang A, Hutchinson MI, Powell AJ. 2015 - Mycothermus thermophilus gen. et comb. nov. A new home for the itinerant thermophile Scytalidium thermophilum (Torula thermophila). Mycologia 107, 319-327. 
Navarrete F, Abreo E, Bettucci L, Martı'nez S, Lupo S. 2009 - First report of Greeneria uvicola as cause of grapevine dead-arm dieback in Uruguay. Australas Plant Disease Notes 4, 117-119.

Navarro-Rosinés P, Hladun N. 1994 - Datos sobre el género Rhagadostoma (ascomicetes liquenícolas, Sordariales). Bull Soc linn Provence 45, 431-442.

Navarro-Rosinés P, Etayo J, Calatayud V. 1999 - Rhagadostoma collematum sp. nov.(ascomicetes liquenícolas, Sordariales) y nuevos datos para otras especies del género. Bull Soc linn Provence 50, 233-241.

Navrotskaya IL, Kondratyuk SY, Wasser SP, Nevo E, Zelenko SD. 1996 - Lichens and lichenicolous fungi new for Israel and other countries. Israel Journal of Plant Sciences 44, 181-193.

Nawawi A, Kuthubutheen AJ. 1989 - Canalisporium, a new genus of lignicolous Hyphomycetes from Malaysia. Mycotaxon 34, 475-487.

NCBI. 2019 - https://www.ncbi.nlm.nih.gov.

Nees CGD. 1816 - Das system der Pilze und Schwämme. Würzburg, Germany.

Nel WJ, Duong TA, Wingfield BD, Wingfield MJ, de Beer ZW. 2018 - A new genus and species for the globally important, multihost root pathogen Thielaviopsis basicola. Plant pathology 67, 871-882.

Newcombe G, Campbell J, Griffith D, Baynes M et al. 2016 - Revisiting the life cycle of dung fungi, including Sordaria fimicola. PloS one 11, e0147425.

Nguyen HT, Kim S, Yu NH, Park AR et al. 2018 - Antimicrobial activities of an oxygenated cyclohexanone derivative isolated from Amphirosellinia nigrospora JS-1675 against various plant pathogenic bacteria and fungi. Journal of Applied Microbiology 126.

Nguyen TT, Hee LS, Jeong JS, Burm LH. 2019 - First Records of Rare Ascomycete Fungi, Acrostalagmus luteoalbus, Bartalinia robillardoides, and Collariella carteri from Freshwater Samples in Korea. Mycobiology 47, 1-11.

Nicot J, Meyer J. 1956 - Un hyphomycète nouveau des sols tropicaux: Staphylotrichum coccosporum nov. gen., nov. sp. Bulletin de la Société Mycologique de France 72, 318-323.

Niessl G von. 1876 - Notizen über neue und kritische Pyrenomyceten. Verhandlungen des Naturforschenden Vereines in Brünn 14, 165-218.

Nieuwland JA. 1916 - Critical notes on new and old genera of plants VIII. The American Midland Naturalist 4, 379-386.

Niranjan M, Sarma VV. 2018 - Twelve new species of Ascomycetous fungi from Andaman Islands, India. Kavaka 50, 84-97.

Niranjan M, Tiwari S, Baghela A, Sarma VV. 2018 - New records of Ascomycetous fungi from Andaman Islands, India and their molecular sequence data. CREAM 8, 331-350.

Nitschke T. 1867 - Pyrenomycetes Germanici. Breslau 1, 1-160.

Nitschke T. 1869 - Verh. Naturhist. Vereines Preuss. Rheinl 26, 73.

Nitschke T. 1870 - Pyrenomycetes Germanici 2. Breslau 161-320.

Nitschke T. 1873 - Botanische Zeitung 31, 450.

Nonaka K, Miyazaki H, Iwatsuki M, Shiomi K et al. 2012 - Staphylotrichum bininense, a new species isolated from soil in the Bonin Islands, Japan. Mycoscience 53, 315-315.

Nordén BJ, Læssøe TH, Jordal JB. 2014 - Chlorostroma vestlandicum sp. nov., a hostspecific mycoparasite on Hypoxylon vogesiacum from western Norway. Karstenia 54, 9-14.

Nordskog B, Stensvand A, Heiberg N. 2003 - Fungi Occurring on Aerial Constituents of Cultivated Blackberry (Rubus fruticosus L.) in Norway. Acta Agriculturae Scandinavica, Section B, Soil \& Plant Science 53, 21-28.

Norina L, Aida M, Zaidin A, Syed Abdullah SAK et al. 2018 - First report of Madurella mycetomi isolate that induced systemic pulmonary and myocardium mycosis with verminious enteritis in Dugong dugon, of Mersing, Johore. Malaysian Journal of Veterinary Research 9, 30-39.

Norphanphoun C, Maharachchikumbura SSN, Daranagama A, Bulgakov TS et al. 2015 - Towards a backbone tree for Seimatosporium, with $S$. physocarpi sp. nov. Mycosphere 6, 385-400. 
Norphanphoun C, Hongsanan S, Doilom M, Bhat DJ. 2016 - Lamproconiaceae fam. nov. to accommodate Lamproconium desmazieri. Phytotaxa 270, 89-102.

Norphanphoun C, Doilom M, Daranagama DA, Phookamsak R et al. 2017 - Revisiting the genus Cytospora and allied species. Mycosphere 8, 51-97.

Norphanphoun C, Raspé O, Jeewon R, Wen TC, Hyde KD. 2018 - Morphological and phylogenetic characterisation of novel Cytospora species associated with mangroves. MycoKeys 38, 93-120.

Norphanphoun C, Jayawardena RS, Chen Y, Wen TC et al. 2019-Morphological and phylogenetic characterization of novel pestalotioid species associated with mangroves in Thailand. Mycosphere 10, 531-578.

Nungent LK, Sihanonth P, Thienhirun S, Whalley AJS. 2005 - Biscogniauxia: a genus of latent invaders. Mycologist 19, 40-43.

O’Neal ES, Davis DD. 2015 - Biocontrol of Ailanthus altissima: inoculation protocol and risk assessment for Verticillium nonalfalfae (Plectosphaerellaceae: Phyllachorales). Biocontrol Science and Technology 25, 950-969.

Ocasio-Morales RG, Tsopelas P, Harrington TC. 2007 - Origin of Ceratocystis platani on native Platanus orientalis in Greece and its impact on natural forests. Plant Disease 91, 901-904.

Oguchi T. 2001 - Aciculosporium sasicola sp. nov. on witches' broom of Sasa senanensis. Mycoscience 42, 217-221.

Oh DC, Jensen PR, Fenical W. 2006 - Zygosporamide, a cytotoxic cyclic depsipeptide from the marine-derived fungus Zygosporium masonii. Tetrahedron letters 47, 8625-8628.

Okada G, Tubaki K. 1984 - A new species and a new variety of Endocalyx (Deuteromycotina) from Japan. Mycologia 76, 300-313.

Okada G, Nimura Y, Sakata T, Uchimura T et al. 1993 - Acremonium alcalophilum, a new alkalophilic cellulolytic hyphomycete. Transactions of the Mycological Society of Japan 34, 171-185.

Okada G, Takematsu A, Takamura Y. 1997 - Phylogenetic relationships of the hyphomycete genera Chaetopsina and Kionochaeta based on 18S rDNA sequences. Mycoscience 38, 409420.

Okada G, Seifert KA, Takematsu A, Yamaoka Y et al. 1998 - A molecular phylogenetic reappraisal of the Graphium complex based on $18 \mathrm{~S}$ rDNA sequences. Canadian Journal of Botany 76, 1495-1506.

Okada G, Jacobs K, Kirisits T, Louis-Seize GW et al. 2000 - Epitypification of Graphium penicillioides Corda, with comments on the phylogeny and taxonomy of Graphium-like synnematous fungi. Studies in Mycology 45, 169-188.

Okane I, Nakagiri A. 2007 - Taxonomy of an anamorphic xylariaceous fungus from a termite nest found together with Xylaria angulosa. Mycoscience 48, 240-249.

Olatinwo RO, Hanson EJ, Schilder AMC. 2003 - A first assessment of the cranberry fruit rot complex in Michigan. Plant disease 87, 550-556.

Old KM, Wingfield MJ, Yuan ZQ. 2003 - A manual of diseases of Eucalyptus in South-East Asia. Centre for International Forestry Research, Jakarta, Indonesia.

Ono Y, Kobayashi T. 2003 - Notes on new and noteworthy plant-inhabiting fungi from Japan (2): Griphosphaerioma zelkovicola sp. nov. with Sarcostroma anamorph isolated from bark of Zelkova serrate. Mycoscience 44, 109-114.

Onofri S. 1983 - A new Beltraniella species from tropical forest litter. Mycotaxon 17, 242-246.

Orpurt PA, Boral LL. 1964 - The flowers, fruits, and seeds of Thalassia testudinum Koenig. Bulletin of Marine Science 14, 296-302.

Osorio JA, Wingfield MJ, Roux J. 2016 - A review of factors associated with decline and death of mangroves, with particular reference to fungal pathogens. South African Journal of Botany $103,295-301$.

Osorio M. 1985 - Ceratocystis pilifera, hongo causante de mancha azul en madera de Pinus radiata. Bosque (Valdivia) 6, 116-119. 
Ostazeski SA. 1968 - An undescribed fungus associated with a root and crown rot of birdsfoot trefoil (Lotus corniculatus). Mycologia 59, 970-975.

Ostry ME, Anderson NA. 2009 - Genetics and ecology of the Entoleuca mammata-Populus pathosystem: Implications for aspen improvement and management. Forest Ecology and Management 257, 390-400.

Ou SH. 1985 - Rice diseases. CAB International, Wallingford, UK.

Pádua APSL, Freire KTLS, Oliveira TGL, Silva LF et al. 2019 - Fungal endophyte diversity in the leaves of the medicinal plant Myracrodruon urundeuva in a Brazilian dry tropical forest and their capacity to produce L-asparaginase. Acta Bot Bras 33, 39-49.

Page EH, Trout DB. 2001 - The role of Stachybotrys mycotoxins in building-related illness. AIHAJ-American Industrial Hygiene Association 62, 644-648.

Palm ME, Gams W, Nirenberg HI. 1995 - Plectosporium, a new genus for Fusarium tabacinum, the anamorph of Plectosphaerella cucumerina. Mycologia 397-406.

Palmateer AJ, Perez JM, Cating RA, Ploetz RC. 2008 - First report of tar spot on orange geiger (Cordia sebestena) caused by Diatractium cordianum in the US. Plant Disease 92, 1250.

Palmer ME, Covich AP, Finlay BJ, Gilbert J et al. 1997 - Biodiversity and ecosystem processes in freshwater sediments. Ambio 26, 571-577.

Pan Z. 2018 - Research Advancement of Insect Origin Fungus Cordyceps. In: Trends in Insect Molecular Biology and Biotechnology, Springer Cham 253-282.

Panchal RR, Desai PV. 2016 - Study of Gibberellic Acid Production by Solid State Fermentation Using Fusarium moniliforme Sheldon. International Journal of Applied Sciences and Biotechnology 4, 402-407.

Pang KL. 2002 - Systematics of the Halosphaeriales: which morphological characters are important? In: Hyde KD (eds). Fungi in marine environments. Fungal Diversity Press, Hong Kong 35-57.

Pang KL, Jheng JS. 2012 - A checklist of marine fungi of Taiwan with a description of Kitesporella keelungensis gen. etp. nov. Botanica Marina 55, 459-466.

Pang KL, Vrijmoed LLP, Kong RYC, Jones EBG. 2003 - Lignincola and Nais, polyphyletic genera of the Halosphaeriales (Ascomycota). Mycological Progress 2, 29-39.

Pang KL, Overy DP, Jones EBG, Calado MdL. 2016 - 'Marine fungi' and 'marine-derived fungi' in natural product chemistry research: Toward a new consensual definition. Fungal Biology Reviews 30, 163-175.

Paolinelli-Alfonso M, Serrano-Gomez C, Hernandez-Martinez R. 2015 - Occurrence of Eutypella microtheca in grapevine cankers in Mexico. Phytopathologia Mediterranea 54, 86-93.

Papendorf MC, Du Toit JW. 1967 - Melanophoma: a new genus of the Sphaeropsidales. Transactions of the British Mycological Society 50, 503-507.

Parguey-Leduc A. 1960 - Étude des asques et du développement de 1' Helminthosphaeria clavariarum (Desm.) Fuck. ap. Munk. Bulletin de la Société Mycologique de France 76, 1533.

Parguey-Leduc A, Locquin-Linard M. 1976 - L'ontogénie et la structures des périthèces de Faurelina fimigenes Locquin-Linard. Rev Mycol 40, 161-175.

Park JH, Choi GJ, Jang KS, Lim HK et al. 2005 - Antifungal activity against plant pathogenic fungi of chaetoviridins isolated from Chaetomium globosum. FEMS Microbiology Letter 252, 309-313.

Park JP, Kim SW, Hwang HJ, Yun JW. 2001 - Optimization of submerged culture conditions for the mycelial growth and exo-biopolymer production by Cordyceps militaris. Letters in Applied Microbiology 33, 76-81.

Park RF, Keane PJ, Wingfield MJ, Crous PW. 2000 - Fungal diseases of eucalypt foliage. In: Keane PJ, Kile GA, Podger FD, Brown BN (eds). Diseases and pathogens of eucalypts. CSIRO Publishing. Melbourne 153-239

Patil V, Borse B. 2015 - Checklist of freshwater mitosporic fungi of India. International Journal of Bioassays 4, 4090-4099. 
Patouillard NT. 1890 - Dussiella nouveau genre d'Hypocreacées. Bulletin de la Société Mycologique de France 6, 107-109.

Patouillard NT, de Lagerheim G. 1895 - Champignons de l'Équateur (Pugillus V). Bulletin de la Société Mycologique de France 11, 205-234.

Patterson FW, Charles VK, Veihmeyer FJ. 1910 - Some fungous diseases of economic importance. I. Miscellaneous Diseases. II. Pineapple rot causes by Thielaviopsis paradoxa. Bulletin of the U.S. Department of Agriculture 171, 1-41.

Paulin-Mahady AE, Harrington TC, McNew D. 2002 - Phylogenetic and taxonomic evaluation of Chalara, Chalaropsis, and Thielaviopsis anamorphs associated with Ceratocystis. Mycologia 94, 62-72.

Paulus BC, Gadek P, Hyde KD. 2004 - Phylogenetic and morphological assessment of five new species of Thozetella from an Australian rainforest. Mycologia 96, 1074-1087.

Pawłowska J, Istel Ł, Gorczak M, Galera H et al. 2017 - Psychronectria hyperantarctica, gen. nov., comb. nov., epitypification and phylogenetic position of an Antarctic bryophilous ascomycete. Mycologia 109, 601-607.

Pažoutová S, Parbery DP. 1999 - The taxonomy and phylogeny of Claviceps. In: V. I (2en and Cvak L (eds) Ergot. The genus Claviceps. Harwood Academic Publishers, Amsterdam 57-77.

Pažoutová S, Šrůtka P, Holuša J, Chudíčková M, Kolař́k M. 2010 - Diversity of xylariaceous symbionts in Xiphydria woodwasps: role of vector and a host tree. Fungal Ecology 3, 392401.

Pažoutová S, Follert S, Bitzer J, Keck M et al. 2013 - A new endophytic insect-associated Daldinia species, recognised from a comparison of secondary metabolite profiles and molecular phylogeny. Fungal Diversity 60, 107-123.

Pearce CA, Hyde KD. 2001 - Two new genera in the Phyllachoraceae: Sphaerodothella to accommodate Sphaerodothis danthoniae, and Parberya gen nov. Fungal Diversity 6, 83-97.

Pearce CA, Reddell P, Hyde KD. 1999 - A revision of Phyllachora (Ascomycotina) on hosts in the angiosperm family Asclepiadaceae, including P. gloriana sp. nov., on Tylophora benthamii from Australia. Fungal Diversity 3, 123-138.

Peck CH. 1875 - Report of the Botanist (1873). Annual Report on the New York State Museum of Natural History 27, 73-116.

Peintner U, Knapp M, Fleischer V, Walch G et al. 2016 - Myrmecridium hiemale sp. nov. from snow-covered alpine soil is the first eurypsychrophile in this genus of anamorphic fungi. International Journal of Systematic and Evolutionary Microbiology 66, 2592-2598.

Peng J, Chang D, Huang Y, Yu ZF. 2016 - Nawawia oviformis sp. nov. from China. Mycotaxon $131,735-738$.

Pennycook SR. 2007 - Discula betulae comb. nov., correct name for the anamorph of Gnomonia intermedia. Mycotaxon 101, 361-364.

Penzig AJO, Saccardo PA. 1897a - Diagnoses fungorum novorum in insula Java collectorum. Ser. I. Malpighia 11, 387-409.

Penzig AJO, Saccardo PA. 1897b - Diagnoses fungorum novorum in insula Java collectorum. Ser. II. Malpighia 11, 491-530.

Perdomo H, Sutton DA, García D, Fothergill AW et al. 2011 - Molecular and phenotypic characterization of Phialemonium and Lecythophora isolates from clinical samples Journal of clinical microbiology 49, 1209-1216.

Perdomo H, Cano J, Gené J, García D et al. 2013a - Polyphasic analysis of Purpureocillium lilacinum isolates from different origins and proposal of the new species Purpureocillium lavendulum. Mycologia 105, 151-161.

Perdomo H, García D, Gené J, Cano J.et al. 2013b - Phialemoniopsis a new genus of Sordariomycetes and new species of Phialemonium and Lecythophora. Mycologia 105, 398421. 
Perera RH, Maharachchikumbura SSN, Ariyawansa H, Bahkali AH et al. 2016a - Two new Pseudohalonectria species on beech cupules (Fagus sylvatica) and a new genus to accommodate $P$. suthepensis. Phytotaxa 278, 115-131.

Perera RH, Maharachchikumbura SSN, Bhat JD, Al-Sadi AM et al. 2016b - New species of Thozetella and Chaetosphaeria and new records of Chaetosphaeria and Tainosphaeria from Thailand. Mycosphere 7, 1301-1321.

Perera RH, Maharachchikumbura SSN, Jones EBG, Bahkali AH et al. 2017 - Delonicicola siamense gen. \& sp. nov.(Delonicicolaceae fam. nov., Delonicicolales ord. nov.), a saprobic species from Delonix regia seed pods. Cryptogamie Mycologie 38, 321-341.

Perera RH, Maharachchikumbura SSN, Hyde KD, Bhat DJ et al. 2018 - An appendage-bearing coelomycete Pseudotruncatella arezzoensis gen. and sp. nov. (Amphisphaeriales genera incertae sedis) from Italy. with notes on Monochaetinula. Phytotaxa 338, 177-188.

Pérez L, Martinez E, Cantillo T. 2012 - First report in Cuba of green poi nt gall of caca cushion caused by Albonectria rigidiuscula (Fusarium decemcellulare). Fitosanidad 19, 19-25.

Peršoh D, Melcher M, Graf K, Fournier J et al. 2009 - Molecular and morphological evidence for the delimitation of Xylaria hypoxylon. Mycologia 101, 256-268.

Persoon CH. 1794 - Neuer Versuch einer systematischen Eintheilung der Schwämme. Neues Magazin für die Botanik 1, 63-80.

Persoon CH. 1822 - Mycologia Europaea 1. Palm, Erlangen.

Petch T. 1908 - The genus Endocalyx, Berkeley and Broome. Ann Bot (London) 22, 389-400.

Petch T. 1920 - Quoted from SACCARDO. P. A. SyI1. Fung 24, 691-692.

Petch T. 1931a - New species of Cordyceps, collected during the Whitby foray. The Naturalist Hull 1931, 101-103.

Petch T. $1931 \mathrm{~b}$ - Notes on entomogenous fungi. Transactions of the British Mycological Society $16,55-75$.

Petch T. 1932 - A list of the entomogenous fungi of Great Britain. Transactions of the British Mycological Society 17, 170-178.

Petch T. 1937 - Notes on British Hypocreales. III. Journal of Botany, British and Foreign 75, $217-$ 231.

Petch T. 1938 - British Hypocreales. Transactions of the British Mycological Society 21, 243-301.

Petrak F. 1921 - Mykologische Notizen II. Annales of Mycology 19, 17-128.

Petrak F. 1923 - Mykologische Notizen. VI. Annales Mycologici 21, 182-335.

Petrak F. 1924 - Mykologische Notizen. VII. Annales Mycologici 22, 1-182.

Petrak F. 1927 - Mykologische Notizen. IX. Annales Mycologici 25, 193-343.

Petrak F. 1931 - Mykologische Notizen. IX. Annales Mycologici 29, 339-397.

Petrak F. 1934 - Mykologische Notizen. XII. 764. Über die Gattung Catabotrys Theiss. \& Syd. Annales Mycologici 32, 337-339.

Petrak F. 1938 - Beiträge zur Kenntnis der Gattung Hercospora mit besonderer Berücksichtigung ihrer Typusart Hercospora tiliae (Pers.) Fr. Annales Mycologici 36, 44-60.

Petrak F. 1940 - Mykologische Notizen. XIII. Annales Mycologici 38, 181-267.

Petrak F. 1941 - Mycologische Notizen. XIV. Annales Mycologici 39, 251-349.

Petrak F. 1942 - Lohwagia gen. nov., eine neue, durch typische Gallenbildung ausgezeichnete Gattung der Pyrenomyceten. Botanisches Archiv 43, 201-206.

Petrak F. 1947a - Apiothyrium n.gen., eine neue Gattung der Sphaeriales. Sydowia 1, 1-4.

Petrak F. 1947b - Über die Gattungen Phaeoapiospora Sacc. et Syd. und Anisomyces Theiss. et Syd. Sydowia 1, 35-40.

Petrak F. 1947c - Über die Gattungen Phaeochorella Theiss. et Syd. und Phomachorella n. gen. Sydowia 1, 120-126.

Petrak F. 1950 - Epicrea n.gen, eine neue Gattung der Hypocreaceen. Sydowia 4, 325-328.

Petrak F. 1952a - Biciliospora n.gen. eine neue Gattung der Sphaeriales. Sydowia 6, 429-432.

Petrak F. 1952b - Serenomyces n. gen., eine neue Gattung der Ceratostomaceen. Sydowia 6, 296298. 
Petrak F. 1954 - Ergebnisse einer Revision der Grundtypen verschiedener Gattungen der Askomyzeten und Fungi Imperfecti. V. Sydowia 8, 287-302.

Petrak F. 1955a - Dictyoporthe ngen, eine neue Gattung der Diaportheen. Sydowia 9, 556-558.

Petrak F. 1955b - Uber Didymella Sacc. und die neue Gattung Pseudomassariella n. gen. Sydowia 9, 603.

Petrak F. 1955c - Xenotypa n.gen., eine neue Diaportheen-Gattung. Sydowia 9, 497-500.

Petrak F. 1959 - Pseudonectriella n.gen., eine neue Gattung der Nectriaceen aus Pakistan. Sydowia $13,127-130$.

Petrini LE. 2013 - Rosellinia - a world monograph. Borntraeger Verlagsbuchhandlung, Stuttgart, Germany, Gebr.

Peyronel B. 1916 - Una nuova malattia del lupino prodotta da Chalaropsis thielavioides Peyr. Le Stazioni Sperimentali Agrarie Italiane 49, 583-593.

Phillips DH, Burdekin DA. 1992 - Diseases of oak (Quercus spp.) In: Phillips DH, Burdekin DA (Eds.) Diseases of forest and ornamental trees. Palgrave Macmillan, London 241-258.

Phookamsak R, Lu YZ, Hyde KD, Jeewon R et al. 2018 - Phylogenetic characterization of two novel Kamalomyces species in Tubeufiaceae (Tubeufiales). Mycol Prog 17, 647-660.

Phookamsak R, Hyde KD, Jeewon R, Bhat DJ et al. 2019 - Fungal diversity notes 929-1035: taxonomic and phylogenetic contributions on genera and species of fungi. Fungal Diversity 95, 1-273.

Phukhamsakda C, Hyde KD, McKenzie EH, Bhat DJ et al. 2020 - Study of fungi associated with Clematis L. (Ranunculaceae) and integrated approach to delimiting species boundaries. Fungal diversity (in press).

Photita W, Lumyong S, Lumyong P, Ho WH et al. 2001 - Fungi on Musa acuminata in Hong Kong. Fungal Diversity 6.

Píchová K, Pažoutová S, Kostovčík M, Chudíčková M et al. 2018 - Evolutionary history of ergot with a new infrageneric classification (Hypocreales: Clavicipitaceae: Claviceps). Molecular phylogenetics and evolution 123, 73-87.

Pinnoi A, Jones EBG, McKenzie EHC, Hyde KD. 2003 - Aquatic fungi from peat swamp palms: Unisetosphaeria penguinoides gen. et sp. nov., and three new Dactylaria species. Mycoscience 44, 377-382.

Pinruan U, Lumyong S, McKenzie EH, Jones EBG et al. 2004 - Three new species of Craspedodidymum from palm in Thailand. Mycoscience 45, 177-180.

Pinruan U, Sakayaroj J, Hyde KD, Jones EBG. 2008 - Thailandiomyces bisetulosus gen. et sp. nov. (Diaporthales, Sordariomycetidae, Sordariomycetes) and its anamorph Craspedodidymum, is described based on nuclear SSU and LSU rDNA sequences. Fungal Diversity 29, 89-98.

Pintos A, Alvarado P, Planas J, Jarling R. 2019 - Six new species of Arthrinium from Europe and notes about $A$. caricicola and other species found in Carex spp. hosts. Mycokeys 49, 15-48.

Pirone PP. 1978 - Diseases and Pests of Ornamental Plants. Wiley-interscience Publication.

Pirozynski KA. 1963 - Beltrania and related genera. Mycological Papers 90, 1-37.

Pirozynski KA. 1968 - Cryptophiale, a new genus of Hyphomycetes. Canadian Journal of Botany 46, $1123-1127$.

Pirozynski KA. 1974 - Xenotypa Petrak and Graphostroma gen. nov., segregates from Diatrypaceae. Canadian Journal of Botany 52, 2129-2135.

Pitt JI, Hocking AD. 1999 - Fungi and food spoilage (2nd ed.). Gaithersburg, Md.: Aspen Publications.

Plaingam N, Somrithipol S, Jones EB. 2003 - Infundibulomyces: a new genus of coelomycetes from Thailand. Canadian Journal of Botany 81, 732-737.

Ploetz RC. 2007 - Cacao diseases: important threats to chocolate production worldwide. Phytopathology 97, 1634-1649.

Plumlee Q, Meason-Smith C, Dieterly A, Gomez G et al. 2017 - Chaetomiaceae Fungi, Novel Pathogens of Equine Neurotropic Phaeohyphomycosis. Veterinary Pathology 54, 813-819. 
Põldmaa K. 1999 - The genus Hypomyces and allied fungicolous fungi in Estonia. I. Species growing on aphyllophoralean basidiomycetes. Folia Cryptogamica Estonica 34, 15-31.

Põldmaa K. 2003 - Three species of Hypomyces growing on basidiomata of Stereaceae. Mycologia 95, 921-933.

Põldmaa K. 2011 - Tropical species of Cladobotryum and Hypomyces producing red pigments. Studies in Mycology 68, 1-34.

Põldmaa K, Samuels GJ. 2004 - Fungicolous hypocreaceae (Ascomycota : Hypocreales) from Khao Yai National Park, Thailand. Sydowia 56, 79-130.

Põldmaa K, Larsson E, Kõljalg U. 2000 - Phylogenetic relationships in Hypomyces and allied genera, with emphasis on species growing on wood-decaying homobasidiomycetes. Canadian Journal of Botany 77, 1756-1768.

Põldmaa K, Bills G, Lewis DP, Tamm H. 2019 - Taxonomy of the Sphaerostilbella broomeanagroup (Hypocreales, Ascomycota). Mycological Progress 18, 77-89.

Poli A, Bovio E, Verkley G, Prigione V, Verse GC. 2019 - Elbamycella rosea gen. et sp. nov. (Juncigenaceae, Torpedosporales) isolated from the Mediterranean Sea. Mycokeys 55, 15-28.

Pollack FG, Uecker FA. 1974 - Monosporascus cannonballus an unusual ascomycete in cantaloupe roots. Mycologia 66, 346-349.

Ponnappa KM. 1975 - Parasympodiella gen.nov. Transaction of the British Mycological Society 64, 344-345.

Popov ES, Kovalenko AE, Gapienko OS, Kolmakov PYu et al. 2013 - Mycobiota of the BelarusValday Lakeland. KMK Scientific Press Ltd, 1-399.

Pordel A, Javan-Nikkhah M, Khodaparast S. 2015 - A reappraisal of the Pyriculariaceae in Iran. Mycologia Iranica 2, 111-118.

Pordel A, Khodaparast S, Mckenzie E, Javan-Nikkhah M. 2017 - Two new species of Pseudopyricularia from Iran. Mycol Prog 16, 729-736.

Pote ST, Khan U, Lahiri KK, Patole MS et al. 2018 - Onychomycosis due to Achaetomium strumarium. Journal de Mycologie Médicale 28, 510-513.

Pourmoghaddam MJ, Khodaparast SA, Krisai-Greilhuber I, Voglmayr H et al. 2018 - Two new species and one new record of Kretzschmaria (Ascomycota, Xylariales) from Iran. Mycosphere 9, 1197-1208.

Prabhugaonkar A, Bhat DJ. 2009 - Rattania setulifera, an undescribed endophytic hyphomycete on rattans from Western Ghats, India. Mycotaxon 108, 217-222.

Prathumpai W, Rachathewee P, Khajeeram S, Tanjak P, Methacanon P. 2012 - Exobiopolymer application of three enthomopathogenic fungal strains as prebiotic used. Asia-Pacific Journal of Science and Technology 17, 743-753.

Pratibha J, Raghukumar S, Bhat DJ. 2012 - Diversity of litter degrading microfungi from the forests of Western Ghats, India. In: Biju Kumar A, Nayar MP, Varma RV, Peethambaran CK (Eds.) Biodiversity and Taxonomy. Narendra Publishing House, India 195-210.

Pratibha J, Prabhugaonkar A, Hyde KD, Bhat DJ. 2014 - Phylogenetic placement of Bahusandhika, Cancellidium and Pseudoepicoccum (asexual Ascomycota). Phytotaxa 176, 68-80.

Preuss CGT. 1851 - Übersicht untersuchter Pilze, besonders aus der Umgegend von Hoyerswerda. Linnaea 24, 99-153.

Proia LA, Hayden MK, Kammeyer PL, Ortiz J et al. 2004 - Phialemonium: an emerging mold pathogen that caused 4 cases of hemodialysis-associated endovascular infection. Clinical Infectious Diseases 39, 373-379.

Promputtha I, Lumyong S, Dhanasekaran V, McKenzie EHC et al. 2007 - A phylogenetic evaluation of whether endophytes become saprotrophs at host senescence. Microbial ecology $53,579-590$.

Puja GS, Shenoy BD, Hyde KD, Bhat DJ. 2006 - Echinosphaeria macrospora sp. nov., teleomorph of Vermiculariopsiella endophytica sp. nov. Cryptogamie Mycologie 27, 11-20.

Punithalingam E. 1974 -Studies on Sphaeropsidales in culture II. Mycological Papers 136, 1-63. 
Punithalingam E. 1999 - Proboscispora Punith. (1984) and Proboscispora S.W. Wong \& K. D. Hyde (1999). Kew Bulletin 54, 234-234.

Puyam A, Pannu PP, Kaur J, Sethi S. 2017 - Variability in production of gibberellic acid and fusaric acid by Fusarium moniliforme and their relationship. Journal of Plant Pathology 99, 103-108.

Qiao M, Li DW, Yu ZF, Zhang K, Castañeda-Ruiz RF. 2019 - Spadicoides matsushimae sp. nov., and Anisospadicoides gen. nov. for two atypical Spadicoides species. Mycotaxon 134, 161167.

Qin WT, Zhuang WY. 2016 - Four new species of Trichoderma with hyaline ascospores from central China. Mycological Progress 15, 811-825.

Quandt CA, Kepler RM, Gams W, Araújo et al. 2014 - Phylogenetic-based nomenclatural proposals for Ophiocordycipitaceae (Hypocreales) with new combinations in Tolypocladium. IMA Fungus 5, 121-134.

Quandt CA, Bushley KE, Spatafora JW. 2015 - The genome of the truffle-parasite Tolypocladium ophioglossoides and the evolution of antifungal peptaibiotics. BMC Genomics 16, 553.

Quang DN, Hashimoto T, Fournier J, Stadler M et al. 2005 - Sassafrins A-D, new antimicrobial azaphilones from the fungus Creosphaeria sassafras. Tetrahedron 61, 1743-1748.

Rabenhorst L. 1854 - Botanische Zeitung 12.

Raciborski M. 1900 - Parasitische. Algen und Pilze Java's. I. Theil. Staatsdruckerei. Batavia 2, 146.

Raghukumar C. 2008 - Marine fungal biotechnology: an ecological perspective. Fungal Diversity 31, 19-35.

Raghukumar C, Ravindran J. 2012 - Fungi and Their Role in Corals and Coral Reef Ecosystems. In: Raghukumar C. (Ed). Biology of Marine Fungi. Progress in Molecular and Subcellular Biology 53, 89-113. Springer, Berlin, Heidelberg.

Rai JN, Tewari JP, Mukerji KG. 1964 - Achaetomium, a new genus of ascomycetes. Canadian Journal of Botany 42, 693-697.

Rai MK. 1989 - Mycosis in man due to Arthrinium phaeospermum var. indicum. First case report: mykosedurch Arthrinium phaeospermum var. indicum beim Menschen. Erstbericht. Mycoses $32,472-475$.

Raimondo ML, Lops F, Carlucci A. 2016 - Charcoal canker of pear, plum, and quince trees caused by Biscogniauxia rosacearum sp. nov. in Southern Italy. Plant Disease 100, 1813-1822.

Raimondo ML, Carlucci A. 2018 - Characterisation and pathogenicity assessment of Plectosphaerella species associated with stunting disease on tomato and pepper crops in Italy. Plant Pathology 67, 626-641.

Raja HA, Shearer CA. 2008 - Freshwater ascomycetes: new and noteworthy species from aquatic habitats in Florida. Mycologia 100, 467-489.

Raja HA, Campbell J, Shearer CA. 2003 - Freshwater ascomycetes: Cyanoannulus petersenii, a new genus and species from submerged wood. Mycotaxon 88, 1-17.

Raja HA, Ferrer A, Shearer CA. 2009 - Freshwater ascomycetes: a new genus, Ocala scalariformis gen. et sp. nov, and two new species, Ayria nubispora sp. nov. and Rivulicola cygnea sp. nov. Fungal Diversity 34, 79-86.

Raja HA, Miller AN, Shearer CA. 2010 - Freshwater Ascomycetes: Hyalorostratum brunneisporum, a new genus and species in the Diaporthales (Sordariomycetidae, Sordariomycetes) from North America. Mycosphere 1, 275-288.

Rajeshkumar KC, Crous PW, Groenewald JZ, Seifert KA. 2016a - Resolving the phylogenetic placement of Porobeltraniella and allied genera in the Beltraniaceae. Mycological Progress $15,1119-1136$.

Rajeshkumar KC, Marathe SD, Madhusudhanan K, Castaneda-Ruiz RF. 2016b - Taxonomic reevaluation and phylogenetic position of Hemibeltrania cinnamomi within Xylariales. Mycotaxon 131, 87-94. 
Rajeshkumar KK, Rossman AY. 2013 - Taiwanascus samuelsii sp. nov., an addition to the Niessliaceae from the Western Ghats of Kerala, India. IMA Fungus 4, 1-4.

Rakvidhyasastra V, Butler EE. 1973 - Mycoparasitism by Stephanoma phaeospora. Mycologia 65, 580-593.

Ramakrishnan TS, Ramakrishnan K. 1948 - Additions to fungi of Madras IV. Proceedings of the Indian Academy of Sciences Section B 27, 33-46.

Ramaley AW. 1997 - Barrina, a new genus with polysporous asci. Mycologia 89, 962-966.

Ramaley AW. 2001 - Hyaloseta nolinae, its anamorph Monocillium nolinae, and Niesslia agavacearum, new members of the Niessliaceae, Hypocreales, from leaves of Agavaceae. Mycotaxon 79, 267-274.

Ramirez-Garcia A, Pellon A, Rementeria A, Buldain I et al. 2018 - Scedosporium and Lomentospora: an updated overview of underrated opportunists. Medical Mycology 56, S102-25.

Ranghoo VM. 1998 - Phylogeny of freshwater ascomycetes. Dissertation, University of Hong Kong.

Ranghoo VM, Hyde KD. 1998 - Ascolacicola aquatica gen. et sp. nov. and a new species of Ascotaiwania from wood submerged in a reservoir in Hong Kong. Mycologia 90, 1055-1062.

Ranghoo VM, Hyde KD, Liew ECY, Spatafora JW. 1999 - Family placement of Ascotaiwania and Ascolacicola based on DNA sequences from the large subunit rRNA gene. Fungal Diversity 2, 159-168.

Ranghoo VM, Hyde KD, Wong SW, Ckm T, Ebg J. 2000 - Vertexicola caudatus gen. et sp. nov., and a new species of Rivulicola from submerged wood in freshwater habitats. Mycologia 92, $1019-1026$.

Ranghoo VM, Tsui CKM, Hyde KD. 2001 - Brunneosporella aquatica gen. et sp. nov., Aqualignicola hyalina gen. et sp. nov., Jobellisia viridifusca sp. nov. and Porosphaerellopsis bipolaris sp. nov. (ascomycetes) from submerged wood in freshwater habitats. Mycological Research 105, 625-633.

Ranojević N. 1910 - Zweiter Beitrag zur Pilzflora Serbiens. Annales Mycologici 8, 347-402.

Rao VG. 1969 - Fungi on citrus from India. Sydowia 23, 215-224.

Rappaz F. 1987 - Taxonomie et nomenclatijre des Diatrypaceae à asques octospores. Mycologia Helvetica 2, 285-648.

Rappaz F. 1989 - Proposal to conserve Cryptosphaeria Ces. \& de Not. (1863) against Cryptosphaeria Grev. (1822) (Ascomycotina). Taxon 38, 664.

Rappaz F. 1992 - Phomatospora berkeleyi, P. arenaria and their Sporothrix anamorphs. Mycotaxon 45, 323-330.

Rappaz F. 1993 - Germination conidienne des Diatrypacées: rôle du substrat et de l'inoculum mis en évidence chez Anthostoma decipiens. Sydowia 44, 294-306.

Rappaz F. 1995 - Anthostomella and related xylariaceous fungi on hard wood from Europe and North America. Mycologia Helvetica 7, 99-168.

Ray H, Hammerschmidt R. 1998 - Responses of potato tuber to infection by Fusarium sambucinum. Physiological and Molecular Plant Pathology 53, 81-92.

Rayner RW. 1970 - A mycological colour chart. Commonwealth Mycological Institute, Kew, UK.

Raza M, Zhang ZF, Hyde KD, Diao YZ, Cai L. 2019 - Culturable plant pathogenic fungi associated with sugarcane in southern China. Fungal Diversity 99, 1-104.

Reagan DP, Waide RB. 1996 - The food web of a tropical rain forest. University of Chicago, Chicago.

Reátegui RF, Gloer JB, Campbell J, Shearer CA. 2005 - Ophiocerins A-D and Ophioceric Acid: Tetrahydropyran Derivatives and an Africane Sesquiterpenoid from the Freshwater Aquatic Fungus Ophioceras venezuelense. J Nat Prod 68, 701-705.

Reátegui RF, Wicklow DT, Gloer JB. 2006 - Phaeofurans and sorbicillin analogues from a fungicolous Phaeoacremonium species (NRRL 32148). Journal of Natural Products 69, 113117. 
Réblová M. 1997 - Revision and reclassification of some Chaetosphaeria species. Czech Mycology 50, 73-83.

Réblová M. 1999a - Studies in Chaetosphaeria sensu lato I. The genera Chaetosphaerella and Tengiomyces gen. nov. of the Helminthosphaeriaceae. Mycotaxon 70, 387-420.

Réblová M. 1999b - Studies in Chaetosphaeria sensu lato II. Coniobrevicolla gen. \& sp. nov. Mycotaxon 70, 421-429.

Réblová M. 1999c - Studies in Chaetosphaeria sensu lato III. Umbrinosphaeria gen. nov. and Miyoshiella with Sporidesmium anamorphs. Mycotaxon 71, 13-43.

Réblová M. 1999d - Studies in Chaetosphaeria sensu lato IV. Crassochaeta gen. nov., a new lignicolous genus of the Trichosphaeriaceae. Mycotaxon 71, 45-67.

Réblová M. 1999e - Teleomorph-anamorph connections in Ascomycetes 2: Ascochalara gabretae gen. et sp. nov. and its Chalara-like anamorph. Sydowia 51, 210-222.

Réblová M. 2000 - The genus Chaetosphaeria and its anamorphs. Studies in Mycology 45, 149168.

Réblová M. 2004 - Four new species of Chaetosphaeria from New Zealand and redescription of Dictyochaeta fuegiana. Studies in Mycology 50, 171-186.

Réblová M. 2006 - Molecular systematics of Ceratostomella sensu lato and morphologically similar fungi. Mycologia 98, 68-93.

Réblová M. 2007 - Barbatosphaeria gen. et comb. nov., a new genus for Calosphaeria barbirostris. Mycologia 99, 723-732.

Réblová M. 2008 - Bellojisia, a new sordariaceous genus for Jobellisia rhynchostoma and a description of Jobellisiaceae fam. nov. Mycologia 100, 893-901.

Réblová M. 2009 - Teleomorph of Rhodoveronaea (Sordariomycetidae) discovered and reevaluation of Pleurophragmium. Fungal Diversity 36, 129-139.

Réblová M. 2011 - New insights into the systematics and phylogeny of the genus Jattaea and similar fungi of the Calosphaeriales. Fungal Diversity 49, 167-198.

Réblová M. 2014 - Sporoschismopsis angustata sp. nov. a new holomorph species in the Reticulascaceae (glomerellales), and a reappraisal of Sporoschismopsis. Mycological Progress 13, 671-681.

Réblová M, Barr ME. 2000 - The genus Acanthostigma (Tubeufiaceae, Pleosporales). Sydowia 52, $258-285$.

Réblová M, Gams W. 1999 - Teleomorph-anamorph connections in Ascomycetes. 1. Cylindrotrichum and Cacumisporium anamorphs of Chaetosphaeria. Czech Mycology 51, 141.

Réblová M, Mostert L. 2007 - Romellia is congeneric with Togninia, and description of Conidiotheca gen. nov. for one species of this genus with polysporous asci. Mycological Research 111, 299-307.

Réblová M, Winka K. 2000 - Phylogeny of Chaetosphaeria and its anamorphs based on morphological and molecular data. Mycologia 92, 939-954.

Réblová M, Winka K. 2001 - Generic concepts and correlations in ascomycetes based on molecular and morphological data: Lecythothecium duriligni gen. et sp. nov. with a Sporidesmium anamorph, and Ascolacicola austriaca sp. nov. Mycologia 93, 478-493.

Réblová M, Seifert KA. 2004a-Conioscyphascus, a new ascomycetous genus for holomorphs with Conioscypha anamorphs. Studies in Mycology 50, 95-108.

Réblová M, Seifert KA. 2004b - Cryptadelphia (Trichosphaeriales), a new genus for holomorphs with Brachysporium anamorphs, and clarification of the taxonomic status of Wallrothiella. Mycologia 96, 343-367.

Réblová M, Seifert KA. 2007 - A new fungal genus, Teracosphaeria, with a phialophora-like anamorph (Sordariomycetes, Ascomycota). Mycological Research 111, 287-298.

Réblová M, Seifert KA. 2008 - A new species of Chaetosphaeria with Menispora ciliata and phialophora-like anamorphs. Fungal Diversity 29, 99-105. 
Réblová M, Seifert KA. 2011 - Discovery of the teleomorph of the hyphomycete, Sterigmatobotrys macrocarpa, and epitypification of the genus to holomorphic status. Studies in Mycology 68, 193-202.

Réblová M, Gams W. 2016 - A revision of Sphaeria pilosa Pers. and re-evaluation of the Trichosphaeriales. Mycological Progress 15, 52.

Réblová M, Štěpánek V. 2018 - Introducing the Rhamphoriaceae fam. nov. (Sordariomycetes), two new genera and new life histories for taxa with Phaeoisaria- and Idriella-like anamorphs. Mycologia 110, 750-770.

Réblová M, Barr ME, Samuels GJ. 1999 - Chaetosphaeriaceae, a new family for Chaetosphaeria and its relatives. Sydowia 51, 49-70.

Réblová M, Mostert L, Gams W, Crous PW. 2004 - New genera in the Calosphaeriales: Togniniella and its anamorph Phaeocrella, and Calosphaeriophora as anamorph of Calosphaeria. Studies in Mycology 50, 533-550.

Réblová M, Fournier J, Hyde KD. 2010 - Achroceratosphaeria, a new genus for freshwater and terrestrial fungi (Ascomycetes). Fungal Diversity 43, 75-84.

Réblová M, Gams W, Seifert KA. 2011 - Monilochaetes and allied genera of the Glomerellales, and a reconsideration of families in the Microascales. Studies in Mycology 68, 163-191.

Réblová M, Seifert KA, Fournier J, Štěpánek V. 2012 - Phylogenetic classification of Pleurothecium and Pleurotheciella gen. nov. and its dactylaria-like anamorph (Sordariomycetes) based on nuclear ribosomal and protein-coding genes. Mycologia 104, 1299-1314.

Réblová M, Untereiner WA, Réblová K. 2013 - Novel evolutionary lineages revealed in the Chaetothyriales (Fungi) based on multigene phylogenetic analyses and comparison of ITS secondary structure. PLoS One 8, e63547.

Réblová M, Stěpánek V, Schumacher RK. 2014 - Xylochrysis lucida gen. et sp. nov., a new lignicolous ascomycete (Sordariomycetidae) with holoblastic conidiogenesis. Mycologia 106, $564-572$.

Réblová M, Fournier J, Štěpánek V. 2015a - Pisorisporiales, a new order of aquatic and terrestrial fungi for Achroceratosphaeria and Pisorisporium gen. nov. in the Sordariomycetes. Persoonia 34, 40-49.

Réblová M, Jaklitsch WM, Réblová K, Štěpánek V. 2015b - Phylogenetic reconstruction of the Calosphaeriales and Togniniales using five genes and predicted RNA secondary structures of ITS, and Flabellascus tenuirostris gen. et sp. nov. PloS one 10, e0144616.

Réblová M, Réblová K, Stepanek V. 2015c - Molecular systematics of Barbatosphaeria (Sordariomycetes): multigene phylogeny and secondary ITS structure. Persoonia 35, 21-38.

Réblová M, Fournier J, Štěpánek V. 2016a - Two new lineages of aquatic ascomycetes: Atractospora gen. nov. and Rubellisphaeria gen. et sp. nov., and a sexual morph of Myrmecridium montsegurinum sp. nov. Mycological Progress 15, 1-39.

Réblová M, Miller AN, Rossman AY, Seifert KA et al. 2016b - Recommendations for competing sexual-asexually typified generic names in Sordariomycetes (except Diaporthales, Hypocreales, and Magnaporthales). IMA fungus 7, 131-153.

Réblová M, Seifert KA, Fournier J, Štěpánek V. 2016c - Newly recognised lineages of perithecial ascomycetes: the new orders Conioscyphales and Pleurotheciales. Persoonia 37, 57-81.

Réblová M, Miller A, Réblová K, Štěpánek V. 2018 - Phylogenetic classification and generic delineation of Calyptosphaeria gen. nov., Lentomitella, Spadicoides and Torrentispora (Sordariomycetes). Studies in Mycology 89, 1-62.

Redlin SC. 1989 - Observations of Vialaea insculpla (Amphisphaeriaceae). Sydowia 41, 296-307.

Rehner SA, Samuels GJ. 1995 - Molecular systematics of the Hypocreales: a teleomorph gene phylogeny and the status of their anamorphs. Canadian Journal of Botany 73, 816-823.

Rehner SA, Minnis AM, Sung GH, Luangsa-ard JJ et al. 2011 - Phylogeny and systematics of the anamorphic, entomopathogenic genus Beauveria. Mycologia 103, 1055-1073. 
Řehulka J, Kubátová A, Hubka V. 2016 - Cephalotheca sulfurea (ascomycota, sordariomycetes), a new fungal pathogen of the farmed rainbow trout Oncorhynchus mykiss. Journal of Fish Diseases 39, 1413-1419.

Reid J, Booth C. 1966 - The genus Flageoletia (SACC.) HÖHN. Canadian Journal of Botany 44, 445-451.

Reid J, Booth C. 1967 - Ditopellopsis gen. nov., Ditopellina gen. nov., Phragmoporthe and Ditopella. Can J Bot 45, 1479-1487.

Reid J, Booth C. 1989 - On Cryptosporella and Wuestneia. Canadian Journal of Botany 67, 879908.

Reid J, Dowsett JA. 1990 - On Dicarpella, Sphaerognomonia, and Apiosporopsis. Canadian Journal of Botany 68, 2398-2407.

Ren SC, Ma J, Zhang XG. 2011 - Two new species of Exserticlava and Spiropes on decaying wood from Guangdong, China. Mycotaxon 118, 349-353.

Reynolds HT, Currie CR. 2004 - Pathogenicity of Escovopsis weberi: the parasite of the attine antmicrobe symbiosis directly consumes the ant-cultivated fungus. Mycologia 96, 955-959.

Rick JE. 1906 - Pilze aus Rio Grande do Sul (Brazilien). Brotéria Série Botânica 5, 4-53.

Rick JE. 1931 - Monographia Boliniarum Riograndensium. Brotéria Série Botânica 25, 65-71.

Riess H. 1853 - Beiträge zur Pilzkunde. Botanische Zeitung 11, 129-140.

Roane MK, Griffin GJ, Elkins JR. 1986 - Chestnut blight, other Endothia diseases, and the genus Endothia. The American Phytopathological Society, USA 1-53.

Roberts JM. 1952 - Antibiotic substances produced by species of Cephalosporium, with a description of a new species. Mycologia 44, 292-306.

Rocchi F, Quaroni S, Sardi P, Saracchi M. 2010 - Studies on Anthostoma decipiens involved in Carpinus betulus decline. Journal of Plant Pathology 92, 637-644.

Rodrigues KF, Samuels GJ. 1989 - Studies in the genus Phylacia (Xylariaceae). Memories of the New York Botanical Garden 49, 290-297.

Rodríguez Justavino D, Piepenbring M. 2007 - Two new species of Appendiculella (Meliolaceae) from Panama. Mycologia 99, 544-552.

Rodríguez Justavino D, Kirschner R, Piepenbring M. 2014 - New species and new records of Meliolaceae from Panama. Fungal Diversity 70, 73-84.

Rodríguez K, Stchigel AM, Cano JF, Guarro J. 2004 - A new species of Achaetomium from Indian soil. Studies in Mycology 50, 77-82.

Roets F, Wingfield MJ, Crous PW, Dreyer LL. 2013 - Taxonomy and ecology of ophiostomatoid fungi associated with Protea infructescences. In: Seifert KA,de Beer ZW, Wingfield MJ (Eds). Ophiostomatoid fungi: expanding frontiers 177-187.

Roger L. 1953 - Phytopathologie des pays Chauda. Encyclopedia mycologique 1638-1653.

Rogers DP. 1954 - The genus Cordyceps and Fries's observationes. Mycologia 46, 248-253.

Rogers JD. 1979 - The Xylariaceae: systematic, biological and evolutionary aspects. Mycologia 71, $1-42$.

Rogers JD. 1981 - Sarcoxylon and Entonaema (Xylariaceae). Mycologia 73, 28-61.

Rogers JD, Ju YM. 1996 - Entoleuca mammata comb. nov. for Hypoxylon mammatum and the genus Entoleuca. Mycotaxon 59, 441-448.

Rogers JD, Ju YM. 1997 - The genus Stilbohypoxylon. Mycological Research 101, 135-138.

Rogers JD, Ju YM. 1998 - The genus Kretzschmaria. Mycotaxon 68, 345-393.

Rogers JD, Ju YM. 2002 - Ascovirgaria occulta gen. et sp. nov., Jumillera hawaiiensis sp. nov., and Lopadostoma hawaiianum sp. nov. from Hawaii. Canadian Journal of Botany 80, 478481.

Rogers JD, Ju YM. 2003 - Occultitheca costaricensis gen. et sp. nov. and Apiocamarops pulvinata sp. nov. from Costa Rica. Sydowia 55, 359-364.

Rogers JD, Samuels GJ. 1988 - Apiocamarops cryptocellula, a new species from Guyana. Mycologia 80, 738-741. 
Rogers JD, Ju YM, San Martín F. 1997 - Jumillera and Whalleya, new genera segregated from Biscogniauxia. Mycotaxon 64, 39-50.

Rogers JD, Yu YM, Læssøe T. 1994 - Neohypodiscus nom. nov. for Hypodiscus (Xylariales). Mycologia 86, 684-690.

Rogerson CT. 1970 - The hypocrealean fungi (ascomycetes, Hypocreales). Mycologia 62, 865910.

Rogerson CT, Samuels GJ. 1993 - Polyporicolous species of Hypomyces. Mycologia 85, 213-272.

Rogerson CT, Samuels GJ. 1994 - Agaricicolous species of Hypomyces. Mycologia 86, 839-866.

Romão-Dumaresq AS, Dourado MN, de Lima Favaro LC, Mendes R et al. 2016 - Diversity of cultivated fungi associated with conventional and transgenic sugarcane and the interaction between endophytic Trichoderma virens and the host plant. PloS one 11, e0158974.

Rombach MC, Humber RA, Evans HC. 1987 - Metarhizium album, a fungal pathogen of leaf- and plant-hoppers of rice. Transactions of the British Mycological Society 88, 451-459.

Romell L. 1892 - Nagra ord om Sphaeria astroidea, eutypa, leioplaca, lata, polycocca, aspera och Bertia collapsa. Botaniska Notiser 1892, 170-178.

Romero AI, Samuels GJ. 1991 - Studies on xylophilous fungi from Argentina VI. Ascomycotina on Eucalyptus viminalis (Myrtaceae). Sydowia 43, 228-248.

Rong IH, Gams W. 2000 - The hyphomycete genera Exochalara and Monilochaetes. Mycotaxon 76, 451-462.

Rooney-Latham S, Eskalen A, Gubler W. 2005 - Occurrence of Togninia minima perithecia in esca-affected vineyards in California. Plant Disease 89, 867-871.

Rossman AY. 1983 - The phragmosporous species of Nectria and related genera. Mycological Papers 150, 1-164.

Rossman AY. 1989 - A synopsis of the Nectria cinnabarina-group. Memoirs of the New York Botanical Garden 49, 253-255.

Rossman AY. 1996 - Morphological and molecular perspectives on systematics of the Hypocreales. Mycologia 1, 1-9.

Rossman AY. 2000 - Towards monophyletic genera in the holomorphic Hypocreales. Studies in Mycology 45, 27-34.

Rossman AY, Seifert K. 2011 - Phylogenetic revision of taxonomic concepts in the Hypocreales and other Ascomycota: A tribute to Gary J. Samuels. Studies in Mycology 68, 1-256.

Rossman AY, Samuels GJ, Rogerson CT, Lowen R. 1999 - Genera of Bionectriaceae, Hypocreaceae and Nectriaceae (Hypocreales, Ascomycetes). Studies in Mycology 42, 1-248.

Rossman AY, McKemy JM, Pardo-Schultheiss RA, Schroers HJ. 2001 - Molecular studies of the Bionectriaceae using large subunit rDNA sequences. Mycologia 93, 100-110.

Rossman AY, Farr DF, Castlebury LA. 2007 - A review of the phylogeny and biology of the Diaporthales. Mycoscience 48, 135-144.

Rossman AY, Melgar J, Walker D, Gonzales A et al. 2012 - First report of Dolabra nepheliae associated with corky bark disease of rambutan and pulasan in Honduras. Plant disease 96, $765-765$.

Rossman AY, Seifert KA, Samuels GJ, Minnis AM et al. 2013 - Genera in Bionectriaceae, Hypocreaceae, and Nectriaceae (Hypocreales) proposed for acceptance or rejection. IMA Fungus 4, 41-51.

Rossman AY, Adams GC, Cannon PF, Castlebury LA et al. 2015 - Recommendations of generic names in Diaporthales competing for protection or use. IMA Fungus 6, 145-154.

RossmanAY, Allen WC, Braun U, Castlebury LA et al. 2016 - Overlooked competing asexual and sexually typified generic names of Ascomycota with recommendations for their use or protection. IMAFungus 7, 285-304.

Roux C, Triebel D. 1994 - Révision des espèces de Stigmidium et de Sphaerellothecium (champignons lichénicoles non lichénisés, Ascomycetes) correspondant à Pharcidia epicymatia sensu Keissler ou à Stigmidium schaereri auct. Bull. Soc. Linn. Provence 45, 451-542. 
Roux J, Wingfield MJ. 2013 - Ceratocystis species on the African continent, with particular reference to $C$. albifundus, an African species in the $C$. fimbriata sensu lato species complex. The Ophiostomatoid Fungi: Expanding Frontiers. Biodiversity Series 12, 131-138.

Roux J, Wingfield MJ, Bouillet JP, Wingfield BD et al. 2000 - A serious new wilt disease of Eucalyptus caused by Ceratocystis fimbriata in Central Africa. Forest Pathology 30, 175184.

Roux J, Van Wyk M, Hatting H, Wingfield MJ. 2004 - Ceratocystis species infecting stem wounds on Eucalyptus grandis in South Africa. Plant Pathology 53, 414-421.

Ruiz RC, Iturriaga T, Saikawa M, Cano J, Guarro J. 2001 - The genus Menisporopsis in Venezuela with the addition of $M$. anisospora anam. sp. nov. from a palm tree. Cryptogamie Mycologie 22, 259-263.

Rukachaisirikul V, Pramjit S, Pakawatchai C, Isaka M et al. 2004 - 10-Membered Macrolides from the Insect Pathogenic Fungus Cordyceps militaris BCC 2816. Journal of Natural Products 67, 1953-1955.

Rungjindamai N, Sakayaroj J, Somrithipol S, Plaingam N et al. 2012 - Phylogeny of the appendaged coelomycete genera: Pseudorobillarda, Robillarda, and Xepiculopsis based on nuclear ribosomal DNA sequences. Cryptogamie Mycologie 33, 319-332.

Ryley MJ. 2003 - Nigrocornus scleroticus, a common old world balansioid fungus. In: White JFJ, Bacon CW, Hywel-Jones NL, Spatafora JW (Eds.) Clavicipitalean fungi: Evolutionary biology, chemistry, biocontrol and cultural impacts 247-272.

Saccardo PA. 1873 - Fungi Veneti novi vel critici. Series I. Nuovo Giornale Botanico Italiano 5, 269-298.

Saccardo PA. 1875a - Conspectus generum pyrenomycetum italicorum additis speciebus fungorum Venetorum novis vel criticis, systemate carpologico dispositorum. Atti della Società Veneziana-Trentina-Istriana di Scienze Naturali. 4, 77-100.

Saccardo PA. 1875 b - Fungi veneti novi vel critici. Ser. II. Nuovo giornale botanico italiano 7 , 299-329.

Saccardo PA. 1877 - Fungi Italici autographice delineati a Prof. P.A. Saccardo. Michelia 1, 73100.

Saccardo PA. 1878 - Fungi Veneti novi vel critici vel mycologiae Venetae addendi. Series VIII. Michelia 1, 239-275.

Saccardo PA. 1880a - Fungi Gallici lecti a cl. viris P. Brunaud, Abb. Letendre, A. Malbranche, J. Therry vel editi in Mycotheca Gallica C. Roumeguéri.

Series II. Michelia 2 6, 39-135.

Saccardo PA. 1880b - Fungorum extra-Europaeorum pugillus. Michelia 2, 138.

Saccardo PA. 1882 - Sylloge Pyrenomycetum, Vol. I. Sylloge Fungorum 1, 1-768.

Saccardo PA. 1883a - Pyrenomyceteae. Sylloge Fungorum omnium hucusque cognitorum 2, 1813.

Saccardo PA. 1883b - Sphaeriaceae, Pleophragmiae, Trematosphaeria. Sylloge Fungorum II, 118.

Saccardo PA. 1883c - Sylloge Pyrenomycetum, Vol. II. Sylloge Fungorum 2. Padova 2, 1-815.

Saccardo PA. 1886 - Sylloge Hyphomycetum. Sylloge Fungorum 4, 1-807.

Saccardo PA. 1891 - Supplementum Universale, Pars I. Agaricaceae-Laboulbeniaceae. Sylloge Fungorum 9, 1-1141.

Saccardo PA. 1892 - Sylloge fungorum 10, 1-964.

Saccardo PA. 1895 - Supplementum Universale, Pars. III. Sylloge Fungorum 11, 1-753.

Saccardo PA. 1902 - Sylloge Fungorum XVI Supplementum universale. Pars. 5, Padova 1291.

Saccardo PA. 1918 - 1. Fungi Singaporenses Bakeriani. 2. Fungi Abellinenses novi. Bolletino dell'Orto Botanico Regia dell'Universita de Napoli 6, 39-73.

Saccardo PA, Berlese AN. 1885 - Miscellania mycologica. Series II. Atti dell'Istituto Veneto Scienze 3, 711-742.

Saccardo PA, Sydow P. 1902 - Supplementum Universale, Pars V. Sylloge Fungorum 16, 1-1291 
Sahr T, Ammer H, Besl H, Fischer M. 1999 - Infrageneric classification of the boleticolous genus Sepedonium: Species delimitation and phylogenetic relationships. Mycologia 91, 935-943.

Saikia UN, Sarbhoy AK. 1985 - Morrisiella, a new genus of synnematous hyphomycete. Mycologia 77, 318-320.

Sailer M, Šašek V, Sejbal J, Buděšínky M et al. 1989 - Flavovirin-a new antifungal antibiotic produced by the pyrenomycete Melanconis flavovirens. Journal of Basic Microbiology 29, $375-381$.

Sakayaroj J, Pang KL, Jones EBG, Vrijmoed LLP, Abedl-Wahab MA. 2005 - A systematic reassessment of marine ascomycetes Swampomyces and Torpedospora. Botanica Marina 48, 395-406.

Sakayaroj J, Pang KL, Jones EBG. 2011 - Multi-gene phylogeny of the Halosphaeriaceae: its ordinal status, relationships between genera and morphological character evolution. Fungal Diversity 46, 87-109.

Sakthivel N, Amudha R, Muthukrishnan S. 2002 - Production of phytotoxic metabolites by Sarocladium oryzae. Mycological Research 106, 609-614.

Samarakoon MC, Hyde KD, Promputtha I, Hongsanan S et al. 2016 - Evolution of Xylariomycetidae (Ascomycota: Sordariomycetes). Mycosphere 7, 1746-1761.

Samarakoon MC, Gafforov Y, Liu N, Maharachchikumbura SSN et al. 2018 - Combined multigene backbone tree for the genus Coniochaeta with two new species from Uzbekistan. Phytotaxa 336, 43-58.

Samarakoon MC, Liu JK, Hyde KD, Promputtha I. 2019a - Two new species of Amphisphaeria (Amphisphaeriaceae) from northern Thailand. Phytotaxa 391, 207-217.

Samarakoon MC, Thongbai B, Hyde KD, Brönstrup M et al. 2019b - Elucidation of the life cycle of the endophytic genus Muscodor and its transfer to Induratia in Induratiaceae fam. nov., based on a polyphasic taxonomic approach. Fungal Diversity (submitted).

Samson RA. 1974 - Paecilomyces and some allied Hyphomycetes. Studies in Mycology 6, 1-119.

Samson RA, Mahmood T. 1970 - The genus Acrophialophora (Fungi, Moniliales). Acta Botanica Neerlandica 19, 804-808.

Samson RA, Evans HC. 1973 - Notes on entomogenous fungi from Ghana. I. The genera Gibellula and Pseudogibellula. Acta Botanica Neerlandica 22, 522-528.

Samson RA, Evans HC. 1975 - Notes on entomogenous fungi from Ghana III. The genus Hymenostilbe. InProc K Ned Akad Wet Ser C 78, 73-79.

Samson RA, Brady BL. 1983 - Paraisaria, a new genus for Isaria dubia, the anamorph of Cordyceps gracilis. Transactions of the British Mycological Society 81, 285-290.

Samuels GJ. 1993 - The case for distinguishing Ceratocystis and Ophiostoma. In: Wingfield MJ, Seifert KA, Webber JE (eds). Ceratocystis and Ophiostoma: taxonomy, ecology, and pathogenicity. American Phytopathological Society Press, St Paul (MN) 15-20.

Samuels GJ, Müller E. 1978 - Life-history studies of Brazilian Ascomycetes. 1. Two new genera of Sphaeriaceae having, respectively, Sporoschisma-like and Codinea anamorphs. Sydowia 31, 126-136.

Samuels GJ, Rogers JD. 1987 - Camarops flava sp. nov., Apiocamarops alba gen. et sp. nov., and notes on Camarops scleroderma and C. ustulinoides. Mycotaxon 28, 45-59.

Samuels GJ, Rossman AY. 1987 - Studies in the Amphisphaeriaceae (sensu lato) 2. Leiosphaerella cocoës and two new species of Oxydothis on palms. Mycotaxon 28, 461-471.

Samuels GJ, Rodrigues KF. 1989 - Batistia annulipes and its anamorph, Acrostroma annellosynnema. Mycologia 81, 52-56.

Samuels GJ, Candoussau F. 1996 - Heterogeneity in the Calosphaeriales: A new Calosphaeria with ramichloridium- and Sporothrix-like synanamorphs. Nova Hedwigia 62, 47-60.

Samuels GJ, Lodge DJ. 1996 - Rogersonia, a new genus of the Hypocreales. Sydowia 48, 250254.

Samuels GJ, Barr ME. 1997 - Notes on and additions to the Niessliaceae (Hypocreales). Canadian Journal of Botany 75, 2165-2176. 
Samuels GJ, Blackwell M. 2001 - Pyrenomycetes - Fungi with Perithecia. In: McLaughlin DJ, McLaughlin EG, Lemke PA (eds). The Mycota VII Part A. Springer, Berlin 221-255.

Samuels GJ, McKenzie EHC, Buchanan DE. 1981 - Ascomycetes of New Zealand 3. Two new species of Apiospora and their Arthrinium anamorphs on bamboo. New Zealand Journal of Botany 19, 137-149.

Samuels GJ, Müller E, Petrini O. 1987 - Studies on the Amphisphaeriaceae (sensu lato) 3. New species of Monographella and Pestalosphaeria and two new genera. Mycotaxon 28, 473499.

Samuels GJ, Barr ME, Lowen R. 1993 - Revision of Schizoparme (Diaporthales, Melanconidaceae). Mycotaxon 46, 459-483.

Samuels GJ, Candoussau F, Magni JF. 1997 - Fungicolous pyrenomycetes 1. Helminthosphaeria and the new family Helminthosphaeriaceae. Mycologia 89, 141-155.

Sandoval-Denis M, Sutton DA, Fothergill AW, Cano-Lira J et al. 2013 - Scopulariopsis, a poorly known opportunistic fungus: spectrum of species in clinical samples and in vitro responses to antifungal drugs. Journal of Clinical Microbiology 51, 3937-3943.

Sandoval-Denis M, Gené J, Sutton DA, Cano-Lira JF et al. 2016a - Redefining Microascus, Scopulariopsis and allied genera. Persoonia 36, 1-36.

Sandoval-Denis M, Gené J, Sutton DA, Wiederhold NP et al. 2016b - New species of Cladosporium associated with human and animal infections. Persoonia 36, 281.

Sankaran KV, Sutton BC, Minter D. 1995 - A checklist of fungi recorded on Eucalyptus. Mycological Papers 170-376.

Santos MD, Fonseca-Boiteux ME, Boiteux LS, Câmara PE et al. 2016 - ITS-phylogeny and taxonomy of Phyllachora species on native Myrtacae from the Brazilian Cerrado. Mycologia $108,1141-1164$.

Sarma VV, Hyde KD. 2001 - Vismaya chaturbeeja gen. et sp. nov. from a dicotyledonous twig in Hong Kong. Nova Hedwigia 73, 247-252.

Sato G, Tanaka K, Hosoya T. 2008 - Bambusicolous fungi in Japan (8): a new species of Pseudolachnella from Yakushima Island, southern Japan. Mycoscience 49, 392-394.

Savory JG. 1954a - Breakdown of timber by ascomycetes and fungi imperfecti. Annals of Applied Biology 41, 336-347.

Savory JG. 1954b - Damage to wood caused by micro-organisms. Journal of Applied Bacteriology $17,213-218$.

Sawada K. 1922 - Descriptive catalogue of Formosan fungi. II. Report of the Government Research Institute, Department of Agriculture, Formosa.

Schaechter M. 2011 - Eukaryotic microbes. Academic Press, Amsterdam.

Schatz S. 1983 - The developmental morphology and life history of Phycomelaina laminariae. Mycologia 762-772.

Schaumann K. 1972 - Veröffentlichungen des Instituts für Meeresforschung in Bremerhaven vol 14. Kommissionsverlag F. Leuwer, Bremen.

Schaumann K, Mulach W, Molitoris HP. 1986 - Comparative studies on growth and exoenzyme production of different Lulworthia isolates. The biology of marine fungi (ST Moss, ed) Cambridge Univ Pr 49-60.

Scheckhuber CQ, Osiewacz HD. 2008 - Podospora anserina: a model organism to study mechanisms of healthy ageing. Molecular Genetics and Genomics 280, 365.

Scheuer C. 1993 - Cryptoniesslia setulosa gen. et sp. nov. Mycological Research 97, 543-546.

Scheuer C, Nograsek A. 1993 - Trematosphaeria pachycarpa and gen. et spec. nov. (Ascomycetes). Mycotax on 47, 415-424.

Schlatter DC, Burke I, Paulitz TC. 2017a - Succession of fungal and Oomycete communities in gyphosate-Killed wheat roots. Phytopathology 108, 582-594.

Schlatter DC, Yin C, Burke I, Hulbert S et al. 2017b - Location, root proximity, and glyphosate-use history modulate the effects of glyphosate on fungal community networks of wheat. Microbial Ecology 76, 240-257. 
Schneider G. 1979 - A field outbreak of suspected stachybotryotoxicosis in sheep. Journal of the South African Veterinary Association 50, 73-81.

Schoch CL, Crous PW, Wingfeld MJ, Wingfeld BD. 2000 - Phylogeny of Calonectria and selected hypocrealean genera with cylindrical macroconidia. Studies in Mycology 45, 45-62.

Schoch CL, Shoemaker RA, Seifert KA, Hambleton S et al. 2006 - A multigene phylogeny of the Dothideomycetes using four nuclear loci. Mycologia 98, 1041-1052.

Schoch CL, Sung GH, Volkmann-Kohlmeyer B, Kohlmeyer J, Spatafora JW. 2007 - Marine fungal lineages in the Hypocreomycetidae. Mycological Research 110, 257-263.

Schoch CL, Sung GH, López-Giráldez F, Townsend JP et al. 2009 - The Ascomycota tree of life: a phylum-wide phylogeny clarifies the origin and evolution of fundamental reproductive and ecological traits. Systematic biology 58, 224-39.

Schol-Schwarz MB. 1970 - Revision of the genus Phialophora. Persoonia 6, 59-94.

Schroers HJ. 2001 - A monograph of Bionectria (Ascomycota, Hypocreales, Bionectriaceae) and its Clonostachys anamorphs. Studies in Mycology 46, 1-214.

Schroers HJ, Samuels GJ. 1997 - Bionectria: a genus for species of the Nectria ochroleuca group. Zeitschrift für Mykologie 63, 149-154.

Schroers HJ, Gräfenhan T, Nirenberg HI, Seifert KA. 2011 - A revision of Cyanonectria and Geejayessia gen. nov., and related species with Fusarium-like anamorphs. Studies in Mycology 68, 115-138.

Schroeter J. 1897 - Die Pilze Schlesiens. Kryptogamen-Flora von Schlesiens 3, 385-500.

Schuster A, Schmoll M. 2010 - Biology and biotechnology of Trichoderma.Applied Microbiology and Biotechnology 87, 787-799.

Schweinitz LD de. 1832 - Synopsis Fungorum in America Boreali media degentium. Transactions of the American Philosophical Society of Philadelfia New Series 4, 131-141.

Scott B. 2001 - Epichloë endophytes: fungal symbionts of grasses. Current Opinion in Microbiology 4, 393-398.

Scribner FL, Viala P. 1887- Le Greeneria fuliginea, nouvelle forme de rot des fruits de lab vigne observee en Am€arique. Com ptes rendus Hebdomadaires des Séances de l'Académie des Sciences 105, 473.

Seaver FJ. 1909 - The Hypocreales of North America. I. Mycologia 1, 41-76.

Seaver FJ. 1920 - Notes on North American Hypocreales: IV. Aschersonia and Hypocrella. Mycologia 12, 93-98.

Seaver FJ, Waterston JM. 1946 - Contributions to the mycoflora of Bermuda - IV. Mycologia 38, 180-201.

Segeth MP, Bonnefoy A, Brönstrup M, Knauf M et al. 2003 - Coniosetin, a novel tetramic acid antibiotic from Coniochaeta ellipsoidea DSM 13856. Journal of Antibiotics 56,114-122.

Seifert KA. 1985 - A monograph of Stilbella and some allied hyphomycetes. Studies in Mycology 27, 1-234.

Seifert KA. 1993 - Sapstain of commercial lumber by species of Ophiostoma and Ceratocystis. In: Wingfield MJ, Seifert KA, Webber JF (Eds). Ceratocystis and Ophiostoma: Taxonomy, Ecology and Pathogenicity. The American Phytopathological Society Press, St. Paul, Minnesota 141-151.

Seifert KA, Okada G. 1993 - Graphium anamorphs of Ophiostoma species and similar anamorphs of other ascomycetes. In: Wingfield MJ, Seifert KA, Webber JF (Eds). Ceratocystis and Ophiostoma taxonomy, ecology, and pathogenicity. The American Phytopathological Society Press, St. Paul, Minnesota 27-41.

Seifert KA, Gams W. 2011 -The genera of Hyphomycetes - 2011 update. Persoonia 27, 119-129.

Seifert KA, Wingfield MJ, Kendrick WB. 1993 - A nomenclator for described species of Ceratocystis, Ophiostoma, Ceratocystiopsis, Ceratostomella and Sphaeronaemella. In: Wingfield MJ, Seifert KA, Webber JF (Eds). Ceratocystis and Ophiostoma: Taxonomy, Ecology and Pathogenicity. The American Phytopathological Society Press, St. Paul, Minnesota 269-287. 
Seifert KA, Samson RA, Boekhout T, Louis-Seize G. 1997 - Remersonia, a new genus for Stilbella thermophila, a thermophilic mould from compost. Canadian Journal of Botany 75, 11581165 .

Seifert KA, Gams W, Louis-Seize GW. 2002 - Arthroxylaria elegans, a new coprophilous anamorphic fungus allied with the Xylariaceae, with notes on the genus Bisporostilbella. Czech Mycology 53, 297-307.

Seifert KA, Morgan-Jones G, Gams W, Kendrick B. 2011 - The Genera of hyphomycetes. CBSKNAW Fungal Biodiversity Centre, Utrecht, The Netherlands.

Senanayake IC, Maharachchikumbura SSN, Mortimer PE, Xu J et al. 2014 - Vialaeaceae; introducing a novel species Vialaea mangiferae. Sydowia 66, 203-216.

Senanayake IC, Maharachchikumbura SSN, Hyde KD, Bhat JD et al. 2015 - Towards unraveling relationships in Xylariomycetidae (Sordariomycetes). Fungal Diversity 73, 73-144.

Senanayake IC, Al-Sadi AM, Bhat JD, Camporesi E et al. 2016 - Phomatosporales ord. nov and Phomatosporaceae fam. nov., to accommodate Lanspora, Phomatospora and Tenuimurus, gen. nov. Mycosphere 7, 628-641.

Senanayake IC, Crous P, Groenewald J, Maharachchikumbura SSN et al. 2017a - Families of Diaporthales based on morphological and phylogenetic evidence. Studies in Mycology 86, 217-296.

Senanayake IC, Maharachchikumbura SSN, Jeewon R, Promputtha I et al. 2017b Morphophylogenetic study of Sydowiellaceae reveals several new genera. Mycosphere 8, $172-217$.

Senanayake IC, Jeewon R, Chomnunti P, Wanasinghe DN et al. 2018 - Taxonomic circumscription of Diaporthales based on multigene phylogeny and morphology. Fungal Diversity 93, 241443.

Senanayake IC, Lian TT, Mai XM, Camporesi E et al. 2019 - Taxonomy and phylogeny of Amphisphaeria acericola sp. nov from Italy. Phytotaxa 403.

Senwanna C, Phookamsak R, Doilom M, Hyde KD, Cheewangkoon R. 2017 - Novel taxa of Diatrypaceae from Para rubber (Hevea brasiliensis) in northern Thailand; introducing a novel genus Allocryptovalsa. Mycosphere 8, 1835-1855.

Senwanna C, Hyde KD, Phookamsak R, Jones EBG, Cheewangkoon R. 2018 - Coryneum heveanum sp. nov. (Coryneaceae, Diaporthales) on twigs of Para rubber in Thailand. Mycokeys 43, 75-90.

Serrato-Diaz LM, Rivera-Vargas LI, Goenaga R, Verkley GJM, French-Monar RD. 2011 - First report of a Lasmenia sp. causing rachis necrosis, flower abortion, fruit rot, and leaf spots on rambutan in Puerto Rico. Plant Disease 95, 1311-1313.

Shang QJ, Hyde KD, Phookamsak R, Doilom M et al. 2017 - Diatrypella tectonae, and Peroneutypa mackenziei, spp. nov. (Diatrypaceae) from northern Thailand. Mycological Progress 16, 463-476.

Shang QJ, Hyde KD, Jeewon R, Khan S et al. 2018 - Morpho-molecular characterization of Peroneutypa (Diatrypaceae, Xylariales) with two novel species from Thailand. Phytotaxa $356,1-18$.

Shaw CG. 1973 - Host fungus index for the Pacific Northwest - I. Hosts. Bulletin, Washington Agricultural Experiment Station 765, 1-121.

Shear CL. 1909 - Sphaerodothis, a new genus of dothidiaceous fungi. Mycologia 1, 161-163.

Shear CL. 1923 - Life histories and undescribed genera and species of fungi. Mycologia 15, 120 131.

Shear CL. 1937 - Mycological notes. I. Mycologia 29, 355-363.

Shear CL. 1938 - Mycological notes. II. Mycologia 30, 580-593.

Shearer A, Zare-Maivan H. 1988 - In vitro hyphal interactions among wood- and leaf-inhabiting Ascomycetes and Fungi Imperfecti from freshwater habitats. Mycologia 80, 31-37.

Shearer CA. 1973 - Fungi of the Chesapeake Bay and its tributaries II. The genus Conioscypha. Mycologia 65, 128-136. 
Shearer CA. 1989 - Pseudohalonectria (Lasiosphaeriaceae), an antagonistic genus from wood in freshwater. Canadian Journal of Botany 67, 1944-1955.

Shearer CA. 1993 - The freshwater ascomycetes. Nova Hedwigia 56, 1-33.

Shearer CA, Crane JL. 1971 - Fungi of the Chesapeake Bay and its tributaries. I. Patuxent River. Mycologia 63, 237-260.

Shearer CA, Motta JJ. 1973 - Ultrastructure and conidiogenesis in Conioscypha (Hyphomycetes). Canadian Journal of Botany 51, 1747-1751.

Shearer CA, Crane JL, Chen W. 1999 - Freshwater Ascomycetes: Ophioceras species. Mycologia 91, 145-156.

Shenoy BD, Jeewon R, Hyde KD. 2005 - Oxydothis bambusicola, a new ascomycete with a huge subapical ascal ring found on bamboo in Hong Kong. Nova Hedwigia 80, 511-518.

Shenoy BD, Jeewon R, Wu WP, Bhat DJ, Hyde KD. 2006 - Ribosomal and RPB2 DNA sequence analyses suggest that Sporidesmium and morphologically similar genera are polyphyletic. Mycological Research 110, 916-928.

Shenoy BD, Jeewon R, Wang HK, Amandeep K et al. 2010 - Sequence data reveals phylogenetic affinities of fungal anamorphs Bahusutrabeeja, Diplococcium, Natarajania, Paliphora, Polyschema, Rattania and Spadicoides. Fungal Diversity 44, 161-169.

Shi ZR, Xiang MM, Zhang YX, Huang JH. 2012 - First report of leaf spot on Tibouchina semidecandra caused by Beltrania rhombica in China. Plant Disease 96, 1380-1380.

Shih L, Tsai KL, Hsieh C. 2007 - Effects of culture conditions on the mycelial growth and bioactive metabolite production in submerged culture of Cordyceps militaris. Biochemical Engineering Journal 33, 193-201.

Shindia AA, Kkalaf SA, El-Sayed ASA. 2007 - L-glutaminase production by some filamentous fungi. Bulletin of Faculty of Science Zagazig University 29, 99-111.

Shirouzu T, Hirose D, Tokumasu S, To-Anun C, Maekawa N. 2010 - Host affinity and phylogenetic position of a new anamorphic fungus Beltraniella botryospora from living and fallen leaves of evergreen oaks. Fungal Diversity 43, 85-92.

Shivas RG, Mitchell AA, Jubb TF. 1997 - Corallocytostroma ornicopreoides sp. nov., an unusual toxic fungus on Astrebla and Dichanthium in north-western Australia. Mycological Research $101,849-852$.

Shoemaker RA, Müller E. 1963 - Generic correlations and concepts: Broomella and Pestalotia. Canadian Journal of Botany 41, 1235-1243.

Shoemaker RA, Hambleton S, Liu M. 2013 - Vialaea insculpta revisited. North American Fungi 8, $1-13$.

Sibounnavong P, Sibounnavong PS, Kanokmedhakul S, Soytong K. 2012 - Antifungal activities of Chaetomium brasilense CB01 and Chaetomium cupreum CC03 against Fusarium oxysporum f.sp. lycopersici race 2. Journal of Agricultural Technology 8, 1029-1038.

Sieber TN. 2007 - Endophytic fungi in forest trees: are they mutualists? Fungal Biology Reviews 21, 75-89.

Sierra ÁM, Portales JM. 1985 - Nuevo género de hifomicete fialídico de Cuba. Revista del Jardín Botánico Nacional 57-60.

Sigler L, Gibas CFC, Kokotovic B, Bertelsen MF. 2010 - Disseminated mycosis in veiled chameleons (Chamaeleo calyptratus) caused by Chamaeleomyces granulomatis, a new fungus related to Paecilomyces viridis. Journal of Clinical Microbiology 48, 3182-3192.

Silva GH, Zeraik ML, de Oliveira CM, Teles HL et al. 2017 - Lactone derivatives produced by a Phaeoacremonium sp., an endophytic fungus from Senna spectabilis. Journal of Natural Products 80, 1674-1678.

Silva PD, Grandi RA. 2013 -Taxonomic studies of Thozetella Kuntze (anamorphic Chaetosphaeriaceae, Ascomycota). Nova Hedwigia 97, 361-399.

Silva RMF, Oliveira RJV, Bezerra JDP, Bezerra JL et al. 2019 - Bifusisporella sorghi gen. et sp. nov. (Magnaporthaceae) to accommodate an endophytic fungus from Brazil. Mycological Progress 18, 847-854. 
Simmons DR, Kepler RM, Rehner SA, Groden E. 2015 - Phylogeny of Hirsutella species (Ophiocordycipitaceae) from the USA: remedying the paucity of Hirsutella sequence data. IMA fungus 6, 345-356.

Simmons DR, de Beer ZW, Huang YT, Bateman C et al. 2016 - New Raffaelea species (Ophiostomatales) from the USA and Taiwan associated with ambrosia beetles and plant hosts. IMA fungus 7, 265-273.

Sinclair RC, Eicker A, Morgan-Jones G. 1983 - Conicomyces, a unique synnematous hyphomycete genus from South Africa. Mycologia 75, 1100-1103.

Sinclair RC, Eicker A, Bhat DJ. 1985 - Branching in Spadicoides. Transactions of the British Mycological Society 85, 736-738.

Sivanesan A. 1974 - Two new genera of Coronophorales with descriptions and key. Transactions of the British Mycological Society 62, 35-43.

Sivanesan A. 1976 - New British species of Rhamphoria, Trematosphaeria and Chaetosphaerella. Transactions of the British Mycological Society 67, 469-475.

Sivanesan A. 1984 - Teleomorphs of Clasterosporium anomalum and C. cyperi. Transactions of the British Mycological Society 83, 710-718.

Sivanesan A. 1987 - Graminicolous species of Bipolaris, Curvularia, Drechslera, Exserohilum and their teleomorphs. Mycol Pap 158, 1-261.

Sivanesan A, Sutton BC. 1985 - Microfungi on Xanthorrhoea. Trans Br Mycol Soc 85, 239-255.

Sivanesan A, Hsieh WH. 1989 - Kentingia and Setocampanula, two new ascomycete genera. Mycological Research 93, 83-90.

Sivanesan A, Chang HS. 1992 - Ascotaiwania, a new amphisphaeriaceous ascomycete genus on wood from Taiwan. Mycological Research 96, 481-484.

Sivanesan A, Chang HS. 1997 - A lignicolous ascomycete, Taiwanascus tetrasporus gen nov. et sp. nov., and a new family Taiwanascaceae. Mycological Research 101, 176-178.

Sivanesan A, Shivas RG. 2002 - New species from each of the pyrenomycete genera Hyponectria, Physalospora and Trichosphaeria from Queensland, Australia. Fungal Diversity 9, 169-174.

Sivichai S, Hywel-Jones NL, Jones EBG. 1998 - Lignicolous freshwater Ascomycota from Thailand 1. Ascotaiwania sawada and its anamorph state Monotosporella. Mycoscience 39, 307-311.

Sivichai S, Jones EBG, Hywel-Jones N. 2002 - Fungal colonisation of wood in a freshwater stream at Tad Ta Phu, Khao Yai National Park, Thailand. Fungal Diversity 10, 113-129.

Six DL. 2003 - Bark beetle-fungus symbiosis. In: Bourtzis K, Miller TA (Eds). Insect symbiosis 97-114.

Six DL, Stone WD, de Beer ZW, Woolfolk SW. 2009 - Ambrosiella beaveri, sp. nov., associated with an exotic ambrosia beetle, Xylosandrus mutilatus (Coleoptera: Curculionidae, Scolytinae), in Mississippi, USA. Antonie van Leeuwenhoek 96, 17-29.

Sizar O, Talati R. 2019 - Sporotrichosis (Sporothrix Schenckii). StatPearls. Treasure Island (FL): StatPearls Publishing.

Skamnioti P, Gurr SJ. 2009 - Against the grain: safeguarding rice from rice blast disease. Trends in Biotechnology 27, 141-150.

Smith GJD, Hyde KD. 2001 - Fungi from palms. XLIX. Astrocystis, Biscogniauxia, Cyanopulvis, Hypoxylon, Nemania, Guestia, Rosellinia and Stilbohypoxylon. Fungal Diversity 7, 89-127.

Smith GJD, Liew ECY, Hyde KD. 2003 - The Xylariales: a monophyletic order containing 7 families. Fungal Diversity 13, 185-218.

Smyk LV. 1981 - Griby poriadku Coronophorales u Mikoflory Ukraniy. Ukr Bot Zh 38, 46-49.

Snow GA, Beland JW, Czabator FJ. 1975 - Endothia gyrosa. CMI descriptions of pathogenic fungi and bacteria. Commonwealth Mycological Institute, Great Britain.

Soares DJ, Rocha FB, Duarte LL, Barreto RW. 2011 - Pyriculariopsis calatheae sp. nov., a novel anamorphic hyphomycete from the Atlantic forest of Brazil causing leaf spots on Calathea longifolia. Mycological Progress 10, 315-321. 
Sogonov MV, Castlebury LA, Rossman AY, White JF. 2007 - The type species of Apiognomonia, A. veneta, with its Discula anamorph is distinct from A. errabunda. Mycological Research 111, 693-709.

Sogonov MV, Castlebury LA, Rossman AY, Mejía LC, White Jr JF. 2008 - Leaf-inhabiting genera of the Gnomoniaceae, Diaporthales. Studies in Mycology 62, 1-79.

Somrithipol S, Jones EBG. 2006 - Calcarisporium phaeopodium sp. nov., a new hyphomycete from Thailand. Sydowia 58, 133-140.

Somrithipol S, Sudhom N, Tippawan S, Jones EBG. 2007 - A new species of Falcocladium (Hyphomycetes) with turbinate vesicles from Thailand. Sydowia 59, 148.

Somrithipol S, Sakayaroj J, Rungjindamai N, Plaingam N, Jones EBG. 2008 - Phylogenetic relationship of the coelomycete genus Infundibulomyces based on nuclear rDNA data. Mycologia 100, 735-741.

Song F, Wu SH, Zhai YZ, Xuan QC, Wang T. 2014 - Secondary metabolites from the genus Xylaria and their bioactivities. Chemistry \& Biodiversity 11, 673-694.

Song HY, Zhong PA, Liao JL, Wang ZH et al. 2018 - Junewangia aquatica (Junewangiaceae), a new species from freshwater habitats in China. Phytotaxa 336, 272-278.

Sopp OJ. 1912 - Monographie der Pilzgruppe Penicillium mit besonderer Berucksichtigung der in Norwegen gefundenen Arten. Skrift Vidensk-Selsk Christiana 11, 1-208.

Sorokin G. 1888 - Zentralblatt für Bakteriologie 4, 644.

Soytong K, Kanokmedhakul S, Kukongviriyapa V, Isobe M. 2001 - Application of Chaetomium species (Ketomium) as a new broad spectrum biological fungicide for plant disease control: A review article. Fungal Diversity 7, 1-15.

Spatafora JW, Blackwell M. 1993 - Molecular systematics of unitunicate perithecial ascomycetes: the Clavicipitales-Hypocreales connection. Mycologia 85, 912-922.

Spatafora JW, Volkmann-Kohlmeyer B, Kohlmeyer J. 1998 - Independent terrestrial origins of the Halosphaeriales (marine Ascomycota). American Journal of Botany 85, 1569-1580.

Spatafora JW, Sung GH, Johnson D, Hesse C et al. 2006 - A five-gene phylogeny of Pezizomycotina. Mycologia 98, 1018-1028.

Spatafora JW, Quandt CA, Kepler RM, Sung GH et al. 2015 - New 1F1N species combinations in Ophiocordycipitaceae (Hypocreales). Phytopathology 6, 357-362.

Species Fungorum. 2019 - http://www.speciesfungorum.org/Names/Names.asp.

Speer EO. 1980a - Telimenopsis fagarae sp. nov., a new parasitic fungus from the Galapagos Islands. Transactions of the British Mycological Society 75, 504-506.

Speer EO. 1980b - Recherches sur la position systématique du genre Phylacia (Phylaciaceae, fam. nov.), et description de deux espèces nouvelles. Bulletin trimestriel de la Société Mycologique de France 96, 135-143.

Spegazzini C. 1880 - Fungi argentini. Pugillus tertius (Continuacion). Anales de la Sociedad Científica Argentina 10, 145-168.

Spegazzini C. 1885 - Fungi guaranitici. Pugillus I. Anales de la Sociedad Científica Argentina 19, 34-48.

Spegazzini C. 1889 - Fungi Puiggariani. Pugillus 1. Boletín de la Academia Nacional de Ciencias en Córdoba 11, 381-622.

Spegazzini C. 1908 - Hongos de la yerba mate. Anales del Museo Nacional de Historia Natural Buenos Aires 17, 111-141.

Spegazzini C. 1923 - Algunos hongos de Tierra del Fuego. Physis Revista de la Sociedad Argentina de Ciencias Naturales 7, 9-23.

Spooner BM. 1981 - New records and species of British microfungi. Transactions of the British Mycological Society 76, 265-301.

Spooner BM. 1986 - New or rare British microfungi from Esher Common, Surrey. Transactions of the British Mycological Society 86, 401-408.

Springer JP, Clardy J. 1980 - Paspaline and paspalicine, two indole-mevalonate metabolites from Claviceps paspali. Tetrahedron Letters 21, 231-234. 
Sri-indrasutdhi V, Boonyuen N, Suetrong S, Chuaseeharonnachai C et al. 2010 - Wood inhabiting freshwater fungi from Thailand: Ascothailandia gen. et sp. nov., Canalisporium sp. nov. with a key to Canalisporium species (Sordariomycetes Ascomycota). Mycoscience 51, 411-420.

Stadler M. 2011 - Importance of secondary metabolites in the Xylariaceae as parameters for assessment of their taxonomy, phylogeny, and functional biodiversity. Current Research in Environmental \& Applied Mycology (Journal of Fungal Biology) 1, 75-133.

Stadler M, Hellwig V. 2005 - Chemotaxonomy of the Xylariaceae and remarkable bioactive compounds from Xylariales and their associated asexual stages. Recent Research Developments in Phytochemistry 9, 41-93.

Stadler M, Wollweber H, Mühlbauer A, Asakawa Y et al. 2001 - Molecular chemotaxonomy of Daldinia and other Xylariaceae. Mycological Research 105, 1191-1205.

Stadler M, Ju YM, Rogers JD. 2004 - Chemotaxonomy of Entonaema, Rhopalostroma and other Xylariaceae. Mycological Research 108, 239-256.

Stadler M, Læssøe T, Vasilyeva L. 2005 - The genus Pyrenomyxa and its affinities to other cleistocarpous Hypoxyloideae as inferred from morphological and chemical traits. Mycologia 97, 1129-1139.

Stadler M, Fournier J, Beltrán-Tejera E, Granmo A. 2008 - The "red Hypoxylons"” of the Northern Hemisphere. North American Fungi 3, 73-125.

Stadler M, Fournier J, Læssøe T, Decock C et al. 2010 - Ruwenzoria, a new genus of the Xylariaceae from Central Africa. Mycological Progress 9, 169-179.

Stadler M, Kuhnert E, Persŏh D, Fournier J. 2013 - The Xylariaceae as model example for a unified nomenclature following the "One fungus-one name" (1F1N) concept. Mycology: An International Journal on Fungal Biology 4, 5-21.

Stadler M, Læssøe T, Fournier J, Decock C et al. 2014 - A polyphasic taxonomy of Daldinia (Xylariaceae). Studies in Mycology 77, 1-143.

Stahl U, Lemke PA, Tudzynski P, Kück U, Esser K. 1978 - Evidence for plasmid like DNA in a filamentous fungus, the ascomycete Podospora anserina. Molecular and General Genetics MGG 162, 341-343.

Starbäck K. 1894 - Studier i Elias Fries' svampherbarium. I "Sphaeriaceae imperfecte cognitae". Bihang till Kungliga svenska Vetenskaps-Akademiens Handlingar 19, 1-114.

Starbäck K. 1899 - Ascomyceten der ersten Regnell'schen Expedition. I. Bihang till Kungliga svenska Vetenskaps-Akademiens Handlingar 25, 1-68.

Stasinska M. 2004 - Hypocreopsis lichenoides P. Karst. [Fungi, Ascomycetes], new to Poland. Acta Societatis Botanicorum Poloniae 73, 135-137.

Stchigel AM, Cano J, Guarro J, Gugnani HC. 2000 - A new Apiosordaria from Nigeria, with a key to the soil-borne species. Mycologia 92, 1206-1209.

Stchigel AM, Figuera L, Cano J, Guarro J. 2002 - New species of Thielavia, with a molecular study of representative species of the genus. Mycological Research 106, 975-983.

Stchigel AM, Cano J, Miller AN, Calduch M, Guarro J. 2006 - Corylomyces: a new genus of Sordariales from plant debris in France. Mycological Research 110, 1361-1368.

Steiner U, Leibner S, Schardl CL, Leuchtmann A, Leistner E. 2011 - Periglandula, a new fungal genus within the Clavicipitaceae and its association with Convolvulaceae. Mycologia 103, 1133-1145.

Stevenson JA. 1943 - Fungi novi denominati-I. Mycologia 35, 629-637.

Steyaert RL. 1949 - Contribution a l'etude monographique de Pestalotia de Not. et Monochaetia Sacc. (Truncatella gen. nov. et Pestalotiopsis gen. nov.). Bulletin du Jardin botanique de l' etat, Bruxelles 19, 285-354.

Stocco MC, Mónaco CI, Abramoff C, Lampugnani G et al. 2016 - Selection and characterization of Argentine isolates of Trichoderma harzianum for effective biocontrol of Septoria leaf blotch of wheat. World Journal of Microbiology and Biotechnology 32, 1-10.

Strobel G. 2006 - Muscodor albus and its biological promise. Journal of Industrial Microbiology and Biotechnology 33, 514-522. 
Strobel GA, Dirske E, Sears J, Markworth C. 2001 - Volatile antimicrobials from Muscodor albus, a novel endophytic fungus. Microbiology 147, 2943-2950.

Strouts RG. 1972 - Canker of cypresses caused by Coryneum cardinale Wag. in Britain. European Journal of Forest Pathology 3, 13-24.

Su H, Li QR, Kang JC, Wen TC, Hyde KD. 2016a - Rosellinia convexa sp. nov. (Xylariales, Pezizomycotina) from China. Mycoscience 3, 164-170.

Su HY, Udayanga D, Luo ZL, Manamgoda DS et al. 2015 - Hyphomycetes from aquatic habitats in Southern China: Species of Curvularia (Pleosporaceae) and Phragmocephala (Melannomataceae). Phytotaxa 226, 201-216.

Su HY, Hyde KD, Maharachchikumbura SSN, Ariyawansa HA et al. 2016b - The families Distoseptisporaceae fam. nov., Kirschsteiniotheliaceae, Sporormiaceae and Torulaceae, with new species from freshwater in Yunnan Province, China. Fungal Diversity 80, 375-409.

Subileau C. 1993 - Systematic and biology of the Phyllachora torrendiella (Bat.) nov. comb. and Botryosphaeria cocogena nov. sp. parasite complex, fungi of the foliar drying of the coconut palm, in Brazil. Thesis dissertation.

Subramanian CV. 1958 - Hyphomycetes-V. Journal of the Indian Botanical Society 37, 47-64.

Subramanian CV. 1992 - A reassessment of Sporidesmium (hyphomycetes) and some related taxa. Proceedings of the Indian Academy of Science 58, 179-190.

Subramanian CV, Vittal BPR. 1973 - Three new Hyphomycetes from litter. Canadian Journal of Botany 51, 1127-1132.

Subramanian CV, Chandrashekara KV. 1977 - Beejasamuha and Sutravarana, two new genera of coprophilous hyphomycetes. Canadian Journal of Botany 55, 245-253.

Subramanian CV, Muthumary J. 1986 - Dwiroopa, a new genus of the coelomycetes. Proceedings of the Indian Academy of Science (Plant Science) 96, 191-197.

Subramanian CV, Sekar G. 1986 - Pseudocercophora ingoldii gen. et sp. nov. and its Mammaria anamorph. Journal of the Singapore National Academy of Science 15, 58-60.

Subramanian CV, Bhat DJ. 1987 - Hyphomycetes from South India I. Some new taxa. Kavaka 15, 41-74.

Subramanian CV, Sekar G. 1990 - Coronophorales from India-a monograph. Kavaka 18, 19-90.

Suetrong S, Schoch CL, Spatafora JW, KohlmeyerJ et al. 2009 - Molecular systematics of the marine Dothideomycetes. Studies in Mycology 64, 155-173.

Suetrong S, Klaysuban A, Sakayaroj J, Preedanon S et al. 2015 - Tirisporellaceae, a new family in the order Diaporthales (Sordariomycetes, Ascomycota). Cryptogamie Mycologie 36, 319330.

Suh MK, Lim JW, Lee YH, Ha GY et al. 2006 - Subcutaneous hyalohyphomycosis due to Cephalotheca foveolata in an immunocompetent host. British Journal of Dermatology 154, 1184-1189.

Suh SO. 2016 - Nomenclatural novelties. Index Fungorum No. 305, 1.

Suh SO, Blackwell M. 1999 - Molecular phylogeny of the cleistothecial fungi placed in Cephalothecaceae and Pseudeurotiaceae. Mycologia 91, 836.

Sullivan RF, Bills GF, Hywel-Jones NL, White Jr JF. 2000 - Hyperdermium: a new clavicipitalean genus for some tropical epibionts of dicotyledonous plants. Mycologia 92, 908-918.

Summerbell RC, Gueidan C, Schroers HJ, de Hoog GS et al. 2011 - Acremonium phylogenetic overview and revision of Gliomastix, Trichothecium and Sarocladium. Studies in Mycology $68,139-162$.

Summerbell RC, Gueidan C, Guarro J, Eskalen A et al. 2018 - The Protean Acremonium. A. sclerotigenum/egyptiacum: revision, food contaminant, and human disease. Microorganisms $88,1-21$.

Summerell BA, Groenewald JZ, Carnegie A, Summerbell RC, Crous PW. 2006 - Eucalyptus microfungi known from culture. 2. Alysidiella, Fusculina and Phlogicylindrium genera nova, with notes on some other poorly known taxa. Fungal Diversity 23, 323-350. 
Sun JQ, Zhou DP, Ping WX. 2003 - A new species of the genus Pleurocytospora. Mycosystema $22,12-13$.

Sun JZ, Dong CH, Liu XZ, Liu JK, Hyde KD. 2016 - Calcarisporium cordycipiticola sp. nov., an important fungal pathogen of Cordyceps militaris. Phytotaxa 268, 135-144.

Sun JZ, Liu XZ, Hyde KD, Zhao Q et al. 2017 - Calcarisporium xylariicola sp. nov. and introduction of Calcarisporiaceae fam. nov. in Hypocreales. Mycological Progress 16, 433445.

Sun JZ, Liu XZ, McKenzie EHC, Jeewon R et al. 2019 - Fungicolous fungi: terminology, diversity, distribution, evolution, and species checklist. Fungal Diversity 95, 337-430.

Sung GH, Spatafora JW, Zare R, Hodge KT, Gams W. 2001 - A revision of Verticillium sect. Prostrata. II. Phylogenetic analyses of SSU and LSU nuclear rDNA sequences from anamorphs and teleomorphs of the Clavicipitaceae. Nova Hedwigia 72, 311-328.

Sung GH, Hywel-Jones NL, Sung JM, Luangsa-ard JJ et al. 2007 - Phylogenetic classification of Cordyceps and the clavicipitaceous fungi. Studies in Mycology 57, 5-59.

Sung GH, Shrestha B, Park KB, Sung JM. 2010 - Cultural characteristics of Shimizuomyces paradoxus collected from Korea. Mycobiology 38, 189-194.

Surup F, Kuhnert E, Lehmann E, Heitkämper S et al. 2014 - Sporothriolide derivatives as chemotaxonomic markers for Hypoxylon monticulosum. Mycology: An International Journal Fungal Biology 5, 110-119.

Sutherland GK. 1916 - Additional notes on marine Pyrenomycetes. Transactions of the British Mycological Society 5, 257-263.

Sutton BC. 1964 - Coelomycetes III. Annellolacinia gen. nov., Aristastoma, Phaeocytostroma, Seimatosporium etc. Mycological Papers 97, 1-42.

Sutton BC. 1965 - Typification of Dendrophoma and a reassessment of D. obscuran. Transactions of the British Mycological Society 48, 611-616.

Sutton BC. 1967 - Two new genera of the Sphaeropsidales and their relationships with Diachorella, Strasseria, and Plagiorhabdus. Canadian Journal of Botany 45, 1249-1263.

Sutton BC. 1968 - Polynema, an earlier name for Neobarclaya. Mycologia 60, 201-213.

Sutton BC. 1971 - Coelomycetes IV. The genus Harknessia, and similar fungi on Eucalyptus. Mycological Papers 123, 1-46.

Sutton BC. 1973 - Hyphomycetes from Manitoba and Saskatchewan, Canada. Mycological Papers $132,1-143$.

Sutton BC. 1975 - Diploceras, another genetic synonym of Seimatosporium. Transactions of the British Mycological Society 64, 483-487.

Sutton BC. 1980 - The Coelomycetes. Fungi imperfecti with pycnidia, acervuli and stromata. Commonwealth Mycological Institute, Kew 1-696.

Sutton BC, Cole GT. 1983 - Thozetella (Hyphomycetes): an exercise in diversity. Transactions of the British Mycological Society 81, 97-107.

Sutton BC, Rao VG, Mhaskar DN. 1976 - Kendrickomyces gen.nov. and Waydora nom.nov., two unusual stromatic coelomycetes. Transactions of the British Mycological Society 67, 248.

Sutton J, Mason TG. 2017 - Isolated strain of clonostachys rosea for use as a biological control agent. United States Patent Application US 15/667, 861.

Suwannarach N, Kumla J, Lumyong S. 2016 - Pseudoplagiostoma dipterocarpi sp. nov., a new endophytic fungus from Thailand. Mycoscience 57, 2.

Suzuki Y, Hatakeyama S, Harada Y, Tanaka K. 2008 - Polystigma fulvum, a red leaf blotch pathogen on leaves of Prunus spp., has the Polystigmina pallescens anamorph/andromorph. Mycoscience 49, 395-398.

Swart HJ. 1965 - The conidial state of Phaeochorella parinarii. Transactions of the British Mycological Society 48, 463-468.

Swart HJ. 1981 - Australian leaf-inhabiting fungi. XI. Phyllachora eucalypti. Transactions of the British Mycological Society 76, 89-95. 
Swart HJ. 1987 - Australian leaf-inhabiting fungi. XXV. Dothidella inaequalis and Montagnella eucalypti. Transactions of the British Mycological Society 89, 483-488.

Swart HJ. 1988a - Australian leaf-inhabiting fungi. XXVI. Some noteworthy Coelomycetes on Eucalyptus. Transactions of the British Mycological Society 90, 279-291.

Swart HJ. 1988b - Australian leaf-inhabiting fungi. XXVII. Two ascomycetes on Athrotaxis in Tasmania. Transactions of the British Mycological Society 90, 445-449.

Sydow H. 1924 - Sydow, Mycotheca germanica. Fasc. XLII -XLV (No. 2051-2250). Annales Mycologici 22, 257-268.

Sydow H. 1936 - Mycotheca Germanica Fasc. LVII-LX (no. 2801-3000). Annales Mycologici 34, $387-401$.

Sydow H, Sydow P. 1914 - Diagnosen neuer philippinischer Pilze. Annales Mycologici 12, 545576.

Sydow H, Sydow P. 1915 - Novae fungorum species. Annales Mycologici 13, 35-43.

Sydow H, Petrak F. 1922 - Ein Beitragzur Kenntnisder Pilzflora Nordamerikas, insbesondere der nordwestlichen Staaten. Annales Mycologici 20, 178-218.

Sydow H, Mitter JH. 1935 - Fungi indici, II. Annales Mycologici 33, 46-71.

Sydow H, Sydow P, Butler EJ. 1916 - Fungi Indiae orientalis pars V. Annales Mycologici 14, 177220.

Tabacchi R, Fkyerat A, Poliart C, Dubin GM. 2000 - Phytotoxins from fungi of esca of grapevine. Phytopathologia Mediterranea 39, 156-161.

Taheriyan V, Khodaparast SA, Hashemi SA. 2014 - New records for anamorphic fungi of Guilan province, Iran. Mycologia Iranica 1, 7-11.

Tanaka E, Tanaka C, Tsuda M, Gafur A. 2002 - Heteroepichlö̈, gen. nov.(Clavicipitaceae; Ascomycotina) on bamboo plants in East Asia. Mycoscience 43, 87-93.

Tanaka E, Tanaka C, Ishihara A, Kuwahara Y, Tsuda M. 2003 - Indole-3-acetic acid biosynthesis in Aciculosporium take, a causal agent of witches' broom of bamboo. Journal of General Plant Pathology 69, 1-6.

Tanaka E, Ashizawa T, Sonoda R, Tanaka C. 2008 - Villosiclava virens gen. nov., comb. nov., the teleomorph of Ustilaginoidea virens, the causal agent of rice false smut. Mycotaxon 106, 491-501.

Tanaka K, Endo M, Hirayama K, Okane I et al. 2011 - Phylogeny of Discosia and Seimatosporium, and introduction of Adisciso and Immersidiscosia genera nova. Persoonia 26, 85-98.

Tanaka K, Hirayama K, Yonezawa H, Sato G et al. 2015 - Revision of the Massarineae (Pleosporales, Dothideomycetes). Studies in Mycology 82, 75-136.

Tang A, Jeewon R, Hyde K. 2009a - A re-evaluation of the evolutionary relationships within the Xylariaceae based on ribosomal and protein-coding gene sequences. Fungal Diversity 34, 127-155.

Tang AMC, Jeewon R, Hyde KD. 2007 - Phylogenetic utility of protein (RPB2, $\beta$-tubulin) and ribosomal (LSU, SSU) gene sequences in the systematics of Sordariomycetes (Ascomycota, Fungi). Antonie Van Leeuwenhoek 91, 327-349.

Tang AMC, Jeewon R, Hyde KD. 2009b - A re-evaluation of the evolutionary relationships within the Xylariaceae based on ribosomal and protein-coding gene sequences. Fungal Diversity 34, $127-155$.

Tangthirasunun N, Philippe SP, Bhat DJ, Maharachchikumbura SSN et al. 2015 - Morphology and phylogeny of two appendaged genera of coelomycetes: Ciliochorella and Discosia. Sydowia 67, 217-226.

Tanovic B, Potocnik I, Stanisavljevic B, Djordjevic M, Rekanovic E. 2006 - Response of Verticillium fungicola var. fungicola, Mycogone perniciosa and Cladobotryum sp. Mushroom pathogens to some essential oils. Pesticides and Phytomedicine (Belgrade) 21, 231-237.

Tassi F. 1900 - Bartalinia Fl. Tassi. Nuovo genere di Sphaeropsidaceae. Boll Lab Orto Bot Reale U Siena 3, 3-5. 
Tassi F. 1904 - Origine e sviluppo delle Leptostromacee e loro rapporti con le famiglie affine. Bollettino del Laboratorio de Orto Botanico Reale Universita Siena 6, 3-124.

Taylor JE, Hyde KD. 1999 - Fungi from palms. XL. Iodosphaeria. Sydowia 51, 127-132.

Taylor JE, Hyde KD. 2003 - Microfungi of tropical and temperate palms. Fungal Diversity Press, Hong Kong 1-459.

Ten Hoopen GM, Krauss U. 2006 - Biology and control of Rosellinia bunodes, Rosellinia necatrix and Rosellinia pepo: a review. Crop Protection 25, 89-107.

Teng SC. 1934 - Fungi of China. In: Korf RP (Ed). Mycotaxon Ltd, Ithaca, New York 151-153.

Teng SC. 1938 - Additional fungi from China VIII. Sinensia 9, 219-258.

Thambugala KM, Wanasinghe DN, Phillips AJL, Camporesi E et al. 2017 - Mycosphere notes 150: Grass (Poaceae) inhabiting Dothideomycetes. Mycospheare 8, 697-796.

Thatoi H, Behera BC, Mishra RR. 2013 - Ecological role and biotechnological potential of mangrove fungi: a review. Mycology 4, 54-71.

Theissen F. 1917 - Über Tympanopsis und einige andere Gattungstypen. Annales Mycologici 15, 269-277.

Theissen F, Sydow H. 1915 - Die Dothideales. Kritisch-systematische Original untersuchungen. Annales Mycologici 13, 147-746.

Thiruvudainambi S, Chandrasekar G, Baradhan G. 2010 - Potential antagonism of Trichoderma sp. against Sclerotium rolfsii Sacc. Plant Archives 10, 617-620.

Thongkantha S, Jeewon R, Vijaykrishna D, Lumyong S et al. 2009 - Molecular phylogeny of Magnaporthaceae (Sordariomycetes) with a new species Ophioceras chiangdaoense from Dracaena loureiroi in Thailand. Fungal Diversity 34, 157-173.

Tian Q, Li WJ, Hyde KD, Camporesi E et al. 2018 - Molecular taxonomy of five species of microfungi on Alnus spp. from Italy. Mycological Progress 17, 255-274.

Tibpromma S, Daranagama DA, Boonmee S, Promputtha I et al. 2017a - Anthostomelloides krabiensis gen. et sp. nov. (Xylariaceae) from Pandanus odorifer (Pandanaceae). Turkish Journal of Botany 41, 107-116.

Tibpromma S, Hyde KD, Jeewon R, Maharachchikumbura SSN et al. 2017b - Fungal diversity notes 491-602: taxonomic and phylogenetic contributions to fungal taxa. Fungal Diversity $83,1-261$.

Tibpromma S, Hyde KD, McKenzie EHC, Bhat DJ et al. 2018 - Fungal diversity notes 840-928: micro-fungi associated with Pandanaceae. Fungal Diversity 93, 1-160.

Torrend C. 1912 - Deuxième contribution pour l'étude des Champignons de l'ile de Madère. Brotéria Série Botânica 10, 29-49.

Torta L, Lo Piccolo S, Piazza G, Burruano S et al. 2015 - Lulwoana sp., a dark septate endophyte in roots of Posidonia oceanica (L.) Delile seagrass. Plant Biology 17, 505-511.

Traaen AE. 1914 - Untersuchungen über Bodenpilze aus Norwegen. Nytt Magazin for Naturvidenskapene 52, 1-121.

Trapero A, Sánchez ME. 2003 - Quercus canariensis, a New Host of Trabutia quercina. Plant disease 87, 201-201.

Traverso JB. 1906 - Flora Italica Cryptogama Pars 1: Fungi. Pyrenomycetae. Sphaeriaceae: Allantosporae, Hyalosporae, Phaeosporae: 1. Societa Botanica Italiana, Rocca San Casciano 353-492.

Treigiene A. 2006 - New species of Kananascus and its anamorph from Lithuania. Mycotaxon 96, 173-180.

Triebel D, Rambold G, Nash TH. 1991 - On lichenicolous fungi from continental North America. Mycotaxon XLII, 263-296.

Trouillas FP, Gubler WD. 2004 - Identification and characterization of Eutypa leptoplaca, a new pathogen of grapevine in Northern California. Mycological Research 108, 1195-1204.

Trouillas FP, Gubler WD. 2010 - Host range, biological variation, and phylogenetic diversity of Eutypa lata in California. Phytopathology 100, 1048. 
Trouillas FP, Lorber JD, Peduto F, Grant J et al. 2010a - First report of Calosphaeria pulchella associated with branch dieback of sweet cherry trees in California. Plant disease 94, 11671167.

Trouillas FP, Sosnowski MR, Gubler WD. 2010b - Two new species of Diatrypaceae from coastal wattle in Coorong National Park, South Australia. Mycosphere 1, 183-188.

Trouillas FP, Pitt WM, Sosnowski MR, Huang R et al. 2011 - Taxonomy and DNA phylogeny of Diatrypaceae associated with Vitis vinifera and other woody plants in Australia. Fungal Divers 49, 203-223.

Trouillas FP, Peduto F, Lorber JD, Sosnowski MR et al. 2012 - Calosphaeria canker of sweet cherry caused by Calosphaeria pulchella in California and South Australia. Plant Disease 96, 648-658.

Trouillas FP, Hand FP, Inderbitzin P, Gubler WD. 2015 - The genus Cryptosphaeria in the western United States: taxonomy, multilocus phylogeny and a new species, $C$. multicontinentalis. Mycologia 107, 10.

Tsang CC, Chan JF, Pong WM, Chen JHK et al. 2016 - Cutaneous hyalohyphomycosis due to Parengyodontium album gen. et comb. nov. Medical Mycology 54, 699-713.

Tsopelas P, Barnes I, Wingfield MJ, Xenopoulos S. 2007 - Seiridium cardinale on Juniperus species in Greece. Forest Pathology 37, 338-347.

Tsui CKM, Hyde KD. 2004 - Biodiversity of fungi on submerged wood in a stream and its estuary in the Tai Ho Bay, Hong Kong. Fungal Diversity 15, 205-220.

Tsui CKM, Berbee ML. 2006 - Phylogenetic relationships and convergence of helicosporous fungi inferred from ribosomal DNA sequences. Molecular Phylogenetics and Evolution 39, 587597.

Tsui CKM, Goh TK, Hyde KD, Hodgkiss IJ. 1999 - Reflections on Menisporopsis, with the addition of M. multisetulata sp. nov. from submerged wood in Hong Kong. Mycological Research 103, 148-152.

Tsui CKM, Hyde KD, Hodgkiss IJ. 2000 - Biodiversity of fungi on submerged wood in Hong Kong streams. Aquatic Microbial Ecology 21, 289-298.

Tsui CKM, Goh TK, Hyde KD. 2001a - A revision of the genus Exserticlava, with a new species. Fungal Diversity 7, 135-143.

Tsui CKM, Hyde KD, Hodgkiss IJ. 2001b - Paraniesslia tuberculata gen. et sp. nov., and news records of Clypeosphaeria, Leptosphaeria and Astrosphaeriella in Hong Kong freshwater habitats. Mycologia 93, 1002-1009.

Tsui CKM, Leung YM, Hyde KD, Hodgkiss IJ. 2001c - Three new Ophioceras species (Ascomycetes) from tropics. Mycoscience 42, 321-326.

Tubajika KM. 2006 - Efficacy of alkyl dimethyl benzyl ammonium chloride on suppression of Physalospora vaccinii in laboratory assays. Journal of Food Protection 69, 2460-2464.

Tubaki K. 1975 - Notes on the Japanese Hyphomycetes. VII. Cancellidium, a new hyphomycetes genus. Transactions of the Mycological Society of Japan 16, 357-360.

Tulasne LR. 1853 - Mémoire sur l'ergot des Glumacées. Annales des Sciences Naturelles Botanique 20, 5-56.

Tulasne LR, Tulasne C. 1863 - Selecta Fungorum Carpologia, Tomus Secundus. Xylariei Valsei Sphaeriei 2, 1-319.

Uchida JY, Kadooka CY. 1994 - A new disease of Heliconia caused by Pyriculariopsis. Phytopathology 84, 1119.

Udayanga D, Liu XZ, Crous PW, McKenzie EHC et al. 2012 - A multi-locus phylogenetic evaluation of Diaporthe (Phomopsis). Fungal Diversity 56, 157-171.

Udayanga D, Castlebury LA, Rossman AY, Chukeatirote E, Hyde KD. 2014 - Insights into the genus Diaporthe: phylogenetic species delimitation in the D. eres species complex. Fungal Diversity 67, 203-229.

Uecker FA. 1994 - On the ontogeny of the ascoma of Glomerella cingulata. Mycologia 86, 82-88. 
Uhlig S, Botha CJ, Vrålstad T, Rolen E, Miles CO. 2009 - Indole- diterpenes and ergot alkaloids in Cynodon dactylon (Bermuda Grass) Infected with Claviceps cynodontis from an outbreak of tremors in Cattle. Journal of Agricultural and Food Chemistry 57, 11112-11119.

Ullasa BA, Rao VG. 1973 - Deshpandiella, a new genus of the Diaporthaceae (Ascomycetes). Bulletin of the Torrey Botanical Club 41-43.

Ullasa BA, Rao VG, Patil AS. 1974 - Chadefaudiomyces, a new member of Diaporthaceae (Ascomycetes). Revue Mycologique 38, 19-22.

Untereiner WA. 1993 - A taxonomic revision of the genus Endoxyla. Mycologia 85, 294-310.

Untereiner WA, Bogale M, Carter A, Platt HW et al. 2013 - Molecular phylogeny of Boliniales (Sordariomycetes) with an assessment of the systematics of Apiorhynchostoma, Endoxyla and Pseudovalsaria. Mycologia 105, 564-588.

Upadhyay HP. 1981 - A monograph of Ceratocystis and Ceratocystiopsis. The University of Georgia Press, Athens, Georgia.

Uppala SS. 2019 - 2019 Update Mtg: New Pathology Directions in MA.

Urbez-Torres JR, Peduto F, Striegler RK, Urrea-Romero KE et al. 2012 - Characterization of fungal pathogens associated with grapevine trunk diseases in Arkansas and Missouri. Fungal Diversity 52, 169-189.

Valldosera M, Guarro J. 1989 - Coprophilous fungi from Spain: Klasterskya coronata sp. nov. Mycological Research 92, 113-116.

Van Adriechem MCY, Bosher JE. 1958 - Leaf blotch and petiole blight of strawberry caused by Gnomonia fructicola. Plant Dis Rep 42, 772-775.

Van Arsdel EP. 1972 - Some cankers on oaks in Texas. Plant Dis Rep 56, 300-304.

van den Brink J, Samson RA, Hagen F, Boekhout T, de Vries RP. 2012 - Phylogeny of the industrial relevant, thermophilic genera Myceliophthora and Corynascus. Fungal Diversity 52, 197-207.

Van der Aa HA. 1973- Studies in Phyllosticta I. Studies in Mycology 5, 1-110.

Van der Linde JA, Six DL, Wingfield MJ, Roux J. 2012 - New species of Gondwanamyces from dying Euphorbia tree in South Africa. Mycologia 104, 574-584.

Van der Linde JA, Six DL, de Beer WZ, Wingfield MJ, Roux J. 2016 -Novel ophiostomatalean fungi from galleries of Cyrtogenius africus (Scolytinae) infesting dying Euphorbia ingens. Antonie van Leeuwenhoek 109, 593.

Van Niekerk JM, Groenewald JZE, Verkley GJM, Fourie PH et al. 2004 - Systematic reappraisal of Coniella and Pilidiella, with specific reference to species occurring on Eucalyptus and Vitis in South Africa. Mycological Research 108, 283-303.

van Wyk M, Wingfield BD, Marin M, Wingfield MJ. 2010 - New Ceratocystis species infecting coffee, cacao, citrus and native trees in Colombia. Fungal Diversity 40, 103-117.

van Zinderen-Bakker EM. 1934 - Stephanoma tetracoccum spec. nov. Annales Mycologici 32, 101-103.

Vann KR, Ekiz G, Zencir S, Bedir E et al. 2016 - Effects of secondary metabolites from the fungus Septofusidium berolinense on DNA cleavage mediated by human topoisomerase II $\alpha$. Chemical research in toxicology 29, 415-420.

Varghese KIM, Rao VG. 1979a - Two new additions to the Indian Ascomycetes. Biovigyanam 5, $1-4$.

Varghese KIM, Rao VG. 1979b - Forest microfungi-I. Subramaniomyces, a new genus of hyphomycetes. Kavaka 7, 83-85.

Vasilyeva LN. 1987 - Pirenomitsety i Lokuloaskomitsety severa Dalbnego. Vostoka 1-255.

Vasilyeva LN. 1990 - New pyrenomycetous species from Kunashir. Mikologiya i Fitopatologiya 24, 207-210.

Vasilyeva LN. 1997 - Camarops pugillus (Schw.: Fr.) Shear from the Russian far East. Mikologiya i Fitopatologiya 31, 5-7.

Vasilyeva LN. 2001 - Pyrenomycetes of the Russian Far East-Additions and corrections. 1. Rossmania ukurunduensis gen. et sp. nov. Mycoscience 42, 399-401. 
Vasilyeva LN. 2007 - Pyrenomycetes of the Russian Far East 2. Mollicamarops stellata gen. et sp. nov. Mycotaxon 99, 159-162.

Vasilyeva LN, Stephenson SL. 2005 - Pyrenomycetes of the Great Smoky Mountains National Park. II. Cryptovalsa Ces. et De Not. and Diatrypella (Ces. et De Not.) Nitschke (Diatrypaceae). Fungal Diversity 19, 189-200.

Vasilyeva LN, Stephenson SL. 2006 - Pyrenomycetes of the Great Smoky Mountains National Park. III. Cryptosphaeria, Eutypa and Eutypella (Diatrypaceae). Fungal Diversity 22, 243254.

Vasilyeva LN, Rossman AY, Farr DF. 2007 - New species of the Diaporthales from eastern Asia and eastern North America. Mycologia 99, 916-923.

Vasilyeva LN, Larissa N, Stephenson SL. 2009 - The genus Diatrype (Ascomycota, Diatrypaceae) in Arkansas and Texas (USA). Mycotaxon 107, 307-313.

Vasilyeva LN, Chernyshev A, Stephenson SL. 2010 - Pyrenomycetes of the Russian Far East 4: family Nitschkiaceae (Coronophorales, Ascomycota). Mycologia 102, 233-247.

Vasilyeva LN, Chernyshev AV, Stephenson SL. 2012 - Neochaetosphaerella thaxteriospora gen. et sp. nov. and Tympanopsis texensis sp. nov. (Coronophorales, Ascomycota) from Texas, USA. Fungal Diversity 52, 191-196.

Vasilyeva LN, Chernyshev AV, Stevenson SL, Hyde KD. 2013 - Tortulomyces thailandicus gen. et sp. nov. and Nitschkia siamensis sp. nov.(Coronophorales, Ascomycota) from northern Thailand. mycoscience 54, 110-115.

Vasilyeva LN, Ma HX, Chernyshev AV, Stephenson SL. 2015 - Bertia hainanensis sp. nov. (Coronophorales) from southern China. Mycotaxon 130, 197-205.

Veihmeyer FJ. 1914 - The Mycogone disease of mushrooms and its control (No. 127). US Department of Agriculture.

Verkley GJM, Dukik K, Renfurm R, Go"ker M, Stielow JB. 2014 - Novel genera and species of coniothyrium-like fungi in Montagnulaceae (Ascomycota). Persoonia 32, 25-51.

Vermeulen M, Gryzenhout M, Wingfield MJ, Roux J. 2011 - New records of the Cryphonectriaceae from southern Africa including Latruncellus aurorae gen. sp. nov. Mycologia 103, 554-569.

Viégas AP. 1947 - Alguns fungos encontrados em S. Paulo, Minas e Espírito Santo. Bragantia 7, 107-124.

Vijaykrishna D, Mostert L, Jeewon R, Gams W et al. 2004 - Pleurostomophora, an anamorph of Pleurostoma (Calosphaeriales), a new anamorph genus morphologically similar to Phialophora. Stud Mycol 50, 387-395.

Vijaykrishna D, Jeewon R, Hyde KD. 2006 - Molecular taxonomy, origins and evolution of freshwater ascomycetes. Fungal Diversity 23, 351-390.

Viljoen CD, Wingfield BD, Wingfield MJ. 1999 - Relatedness of Custingophora olivaceae to Gondwanamyces spp. from Protea spp. Mycological Research 103, 497-500.

Visser AA, Ros VID, de Beer ZW, Debets AJM et al. 2009 - Levels of specificity of Xylaria species associated with fungus-growing termites: a phylogenetic approach. Molecular Ecology 18, 553-567.

Vitale S, Aiello D, Guarnaccia V, Luongo L et al. 2018 - Liberomyces pistaciae sp. nov., the causal agent of pistachio cankers and decline in Italy. MycoKeys 40, 29-51.

Vitoria NS, Cavalcanti MAQ, Hyde KD, Bezerra JL. 2011 - Arecomyces new to Brazil, including A. attaleae sp. nov. Cryptogamie Mycologie 32, 103-108.

Vitoria NS, Cavalcanti MAQ, Hyde KD, Bezerra JL. 2012 - Brunneiapiospora brasiliensis sp. nov. (Clypeosphaeriaceae) on palms from Brazil. Nova Hedwigia 94, 245-250.

Vogelgsang S, Bänziger I, Krebs H, Legro R et al. 2013 - Control of Microdochium majus in winter wheat with botanicals - from laboratory to the field. Plant Pathology 62, 961-1194.

Voglmayr H, Jaklitsch WM. 2008 - Prosthecium species with Stegonsporium anamorphs on Acer. Mycological Research 112, 885-905. 
Voglmayr H, Jaklitsch WM. 2014 - Stilbosporaceae resurrected: generic reclassification and speciation. Persoonia 33, 61-82.

Voglmayr H, Mehrabi M. 2018 - Molecular phylogeny and a new Iranian species of Caudospora (Sydowiellaceae, Diaporthales). Sydowia 70, 67-80.

Voglmayr H, Jaklitsch WM. 2019 - Stilbocrea walteri sp. nov., an unusual species of Bionectriaceae. Mycological Progress 18, 91-105.

Voglmayr H, Rossman AY, Castlebury LA, Jaklitsch WM. 2012- Multigene phylogeny and taxonomy of the genus Melanconiella (Diaporthales). Fungal Diversity 57, 1-44.

Voglmayr H, Castlebury LA, Jaklitsch WM. 2017 - Juglanconis gen. nov. on Juglandaceae, and the new family Juglanconidaceae (Diaporthales). Persoonia 38, 136-155.

Voglmayr H, Friebes G, Gardiennet A, Jaklitsch WM. 2018 - Barrmaelia and Entosordaria in Barrmaeliaceae (fam. nov., Xylariales) and critical notes on Anthostomella-like genera based on multigene phylogenies. Mycological progress 17, 155-177.

Voglmayr H, Aguirre-Hudson MB, Wagner HG, Tello S et al. 2019a - Lichens or endophytes? The enigmatic genus Leptosillia in the Leptosilliaceae fam. nov. (Xylariales), and Furfurella gen. nov. (Delonicicolaceae). Persoonia 42, 228-260.

Voglmayr H, Jaklitsch WM, Mohammadi H, Chakusary MK. 2019b - The genus Juglanconis (Diaporthales) on Pterocarya. Mycol. Progr 18, 425-437.

Von Arx DP, Simpson MT, Batman P. 1988 - Synovial chondromatosis of the temporomandibular joint. British Journal of Oral and Maxillofacial Surgery 26, 297-305.

von Arx JA. 1951 - Über die Gattung Laestadia und die Gnomoniaceae. Antonie van Leeuwenhoek 17, 259-272.

von Arx JA. 1973 - Centraalbureau voor Schimmelcultures Baarn and Delft. Progress Reports 1972. Verhandelingen der Koninklijke Nederlandsche Akademie van Wetenschappen, Afdeling Natuurkunde 61, 59-81.

von Arx JA. 1975 - On Thielavia and some similar genera of Ascomycetes. Studies in Mycology 8, $1-31$.

von Arx JA. 1978 - Notes on Microascaceae with the description of two new species. Persoonia 10, 23-31.

von Arx JA. 1981a - On the Monilia sitophila and some families of Ascomycetes. Sydowia 34, 1329.

von Arx JA. 1981b - The Genera of Fungi Sporulating in Pure Culture, 3rd edn. J Cramer, Vaduz $1-424$.

von Arx JA. 1985 - On Achaetomium and a new genus Subramaniula (Ascomycota). Proceedings of the Indian Academy of Sciences Section B 94, 341-345.

von Arx JA. 1987 - A re-evaluation of the Eurotiales. Persoonia 13, 273-300.

von Arx JA, Olivier DL. 1952 - The taxonomy of Ophiobolus graminis Sacc. Trans Br Mycol Soc 35, 29-33.

von Arx JA, Müller E. 1954 - Die Gattungen der amerosporen Pyrenomyceten. Beiträge zur Kryptogamenflora der Schweiz 11, 1-434.

von Arx JA, Hennebert GL. 1965 - Deux champignons ambrosia. Mycopathologia et Mycologia Applicata 25, 309-315.

von Arx JA, Gams W. 1966 - Über Pleurage verruculosa und die zugehörige Cladorrhinum Konidienform. Nova Hedwigia 13, 199-208.

von Arx JA, Mukerji KG, Singh N. 1978 - A new coprophilous ascomycete from India. Persoonia 10, 144-146.

von Arx JA, Figueras MJ, Guarro J. 1988 - Sordariaceous ascomycetes without ascospore ejaculation. Nova Hedwigia Beihefte 94, 1-104.

Vrijmoed LLP, Hyde KD, Jones EBG. 1994 - Observations on mangrove fungi from Macau and Hong Kong, with the description of two new ascomycetes: Diaporthe salsuginosa and Aniptodera haispora. Mycological Research 98, 699-704. 
Vu D, Groenewald M, De Vries M, Gehrmann T et al. 2019 - Large-scale generation and analysis of filamentous fungal DNA barcodes boosts coverage for kingdom fungi and reveals thresholds for fungal species and higher taxon delimitation. Studies in Mycology 92, 135154.

Vuillemin P. 1912 - Beauveria, nouveau genre de Verticilliacées. Bulletin de la Société Botanique de France 59, 34-40.

Wakefield EM. 1918 - New and rare British fungi. Bulletin of Miscellaneous Information (Royal Botanic Gardens, Kew) 1918, 229-233.

Walker DM, Castlebury LA, Rossman AY, Mejía LC et al. 2012 - Phylogeny and taxonomy of Ophiognomonia (Gnomoniaceae, Diaporthales), including twenty-five new species in this highly diverse genus. Fungal Divers 57, 85-147.

Walker J. 1972 - Type studies on Gaeumannomyces graminis and related fungi. Trans Br Mycol Soc 58, 427-457.

Wallroth CFW. 1833 - Flora Cryptogamica Germaniae 2, Pars posterior. Continens Algas et Fungos. sumtibus JL Schragii 1-923.

Wallroth FW. 1825 - Naturgeschichte der Flechten 1, I-XX, 1-722. Frankfurt a. M., Frederich Wilman.

Wanasinghe DN, Phukhamsakda C, Hyde KD, Jeewon R et al. 2018 - Fungal diversity notes 709839: taxonomic and phylogenetic contributions to fungal taxa with an emphasis on fungi on Rosaceae. Fungal Diversity 89, 1-236.

Wang G. 2006 - Diversity and biotechnological potential of the sponge-associated microbial consortia. Journal of Industrial Microbiology and Biotechnology 33, 545-551.

Wang G, Li Q, Zhu P. 2008 - Phylogenetic diversity of culturable fungi associated with the Hawaiian sponges Suberites zeteki and Gelliodes fibrosa. Antonie Van Leeuwenhoek 93, $163-174$.

Wang M, Zhang LM, Liu XZ. 2005 - Verticimonosporium verticale sp. nov. from Jiangxi Province, China. Mycotaxon 92, 197-200.

Wang M, Liu F, Crous PW, Cai L. 2017 - Phylogenetic reassessment of Nigrospora: ubiquitous endophytes, plant and human pathogens. Persoonia 39, 118-142.

Wang M, Tian XM, Liu F, Cai L. 2018 - Eight new Arthrinium species from China. Mycokeys 34, $1-24$.

Wang X, Wang C, Sun YT, Sun CZ et al. 2015a - Taxol produced from endophytic fungi induces apoptosis in human breast, cervical and ovarian cancer cells. Asian Pacific Journal of Cancer Prevention 16, 125-131.

Wang XW, Wang XL, Liu FJ, Zhao XM et al. 2014 - Phylogenetic assessment of Chaetomium indicum and allied species, with the introduction of three new species and epitypification of C. funicola and C. indicum. Mycological Progress 13, 719-732.

Wang XW, Houbraken J, Groenewald JZ, Meijer M et al. 2016a - Diversity and taxonomy of Chaetomium and chaetomium-like fungi from indoor environments. Studies in Mycology 84, $145-224$.

Wang XW, Lombard L, Groenewald JZ, Li J et al. 2016b - Phylogenetic reassessment of the Chaetomium globosum species complex. Persoonia-Molecular Phylogeny and Evolution of Fungi 36, 83-133.

Wang XW, Bai FY, Bensch K, Meijer M et al. 2019a - Phylogenetic re-evaluation of Thielavia with the introduction of a new family Podosporaceae. Studies in Mycology 93, 155-252.

Wang XW, Yang FY, Meijer M, Kraak B et al. 2019b - Redefining Humicola sensu stricto and related genera in the Chaetomiaceae. Studies in Mycology 93, 65-153.

Wang Y, Xu L, Ren W, Zhao D et al. 2012 - Bioactive metabolites from Chaetomium globosum L18, an endophytic fungus in the medicinal plant Curcuma wenyujin. Phytomedicine International Journal of Phytotherapy \& Phytopharmacology 19, 364-368.

Wang Y, Hyde KD, McKenzie EHC, Jiang YL et al. 2015b - Overview of Stachybotrys (Memnoniella) and current species status. Fungal Diversity 71, 17-83. 
Wang YZ, Hyde KD. 1999 - Hyponectria buxi with notes on the Hyponectriaceae. Fungal Diversity 3, 159-172.

Wang YZ, Aptroot A, Hyde KD. 2004 - Revision of the genus Amphisphaeria. Hong Kong SAR, China. Fungal Diversity Research Sereies 13, 1-168.

Watanabe K, Sekiguchi M, Sato T, Hsiang T et al. 2016 - Phylogenetic analysis of the synnemaproducing genus Synnemapestaloides. Journal of Fungi 2, 28.

Watson P. 1955 - Calcarisporium arbuscula living as an endophyte in apparently healthy sporophores of Russula and Lactarius. Transactions of the British Mycological Society 38, 409-414.

Weber T, Blin K, Duddela S, Krug D et al. 2015 - A comprehensive resource for the genome mining of biosynthetic gene clusters. Nucl. Acid Res 43.

Webber JF, Gibbs JN. 1989 - Insect dissemination of fungal pathogens of trees. Insect-fungus interactions. 14th Symposium of the Royal Entomological Society of London in collaboration with the British Mycological Society London, UK Academic Press 161-193.

Webster J, Whalley AJS, Thienhirun S, Richardson MJ. 1999 - Wawelia argentea and W. microspora, two new species of xerophilous fungi on rabbit and hare dung in Britain. Mycological Research 103, 1604-1608.

Weese J. 1919. - Beiträge zur Kenntnis der Hypocreaceen (2. Mitteilung). Sitzungsberichte der Kaiserlichen Akademie der Wissenschaften Math.-naturw. Klasse Abt. I. 128, 693-754.

Wehmeyer LM. 1976 - Cataloging the School Media Center as a Specialized Collection. Library Resources and Technical Services 20, 315-325.

Wehmeyer LE. 1933a - The British species of the genus Diaporthe Nits. and its segregates. Trans Br Mycol Soc 17, 237-295.

Wehmeyer LE. 1933b - The genus Diaporthe Nitschke and its segregates (Vol. 9). Ann Arbor: University of Michigan Press, USA.

Wehmeyer LE. 1939 - The genus Massariovalsa. Am J Bot 26, 831-834.

Wehmeyer LE. 1941 -A revision of Melanconis, Pseudovalsa, Prosthecium and Titania. University of Michigan studies. Scientific series 14, 1-161.

Wehmeyer LE. 1975 - The Pyrenomycetous Fungi. Mycologia Memoirs 6, 1-250.

Wei IC, Kirschner R. 2017 - Two fungicolous anamorphic species of Hypomyces s. lat. from Taiwan. Fungal Science 32, 15-25.

Wei MJ, Zhang H, Dong W, Boonmee S, Zhang D. 2018 - Introducing Dictyochaeta aquatica sp. nov. and two new species of Chloridium (Chaetosphaeriaceae, Sordariomycetes) from aquatic habitats. Phytotaxa 362, 187-199.

Wei X, Song X, Dong D, Keyhani NO et al. 2016 - Efficient production of Aschersonia placenta protoplasts for transformation using optimization algorithms. Canadian journal of microbiology 62, 579-587.

Wen TC, Li GR, Kang JC, Kang C, Hyde KD. 2014 - Optimization of solid-state fermentation for fruiting body growth and cordycepin production by Cordyceps militaris. Chiang Mai J Sci 41, $858-872$.

Wendt L, Sir EB, Kuhnert E, Heitkämper S et al. 2018 - Resurrection and emendation of the Hypoxylaceae, recognised from a multigene phylogeny of the Xylariales. Mycological Progress 17, 115-154.

Went FAFC. 1893 - De ananasziekte van het suikerriet. Mededeelingen Proefstation West-Java 5, $1-8$.

Whalley MA, Khalil AMA, Wei TZ, Yao YJ, Whalley AJS. 2010 - A new species of Engleromyces from China, a second species in the genus. Mycotaxon 112, 317-323.

Wharton PS, Tumbalam P, Kirk WW. 2006 - First report of potato tuber sprout rot caused by Fusarium sambucinum in Michigan. Plant disease 90, 1460.

White Jr JF. 1994 - Endophyte-host associations in grasses. XX. Structural and reproductive studies of Epichloë amarillans sp. nov. and comparisons to E. typhina. Mycologia 86, 571580 . 
White Jr JF, Glenn AE. 1994 - A study of two fungal epibionts of grasses: structural features, host relationships, and classification in the genus Myriogenospora (Clavicipitales). American journal of botany 81, 216-223.

White Jr JF, Reddy PV. 1998 - Examination of structure and molecular phylogenetic relationships of some graminicolous symbionts in genera Epichlö̈ and Parepichlö̈. Mycologia 90, 226234.

White Jr JF, Sullivan MM, Patel R, Duncan R. 2000 - An overview of problems in the classification of plant-parasitic Clavicipitaceae. Studies in Mycology 45, 95-105.

White Jr JF, Bacon CW, Hywel-Jones NL, Spatafora JW. 2003 - Clavicipitalean fungi: evolutionary biology, chemistry, biocontrol and cultural impacts (Vol. 19). CRC Press.

Whitton SR, McKenzie EHC, Hyde KD. 2000 - Dictyochaeta and Dictyochaetopsis species from the Pandanaceae. Fungal Diversity 4, 133-158.

Whitton SR, McKenzie EHC, Hyde KD. 2001 - Microfungi on the Pandanaceae: Nakatopsis gen. nov., a new hyphomyecete genus from Malaysia. Fungal Divers 8, 163-171.

Whitton SR, McKenzie EHC, Hyde KD. 2003 - Microfungi on the Pandanaceae: Zygosporium, a review of the genus and two new species. Fungal Diversity 12, 207-222.

Whitton SR, McKenzie EHC, Hyde KD. 2012 - Teleomorphic Microfungi Associated with Pandanaceae. Fungi Associated with Pandanaceae. Fungal Diversity Research Series 21, 23 124.

Wijayawardene NN, McKenzie EHC, Hyde KD. 2012 - Towards incorporating anamorphic fungi in a natural classification-checklist and notes for 2011. Mycosphere 3, 157-228.

Wijayawardene NN, Goonasekara ID, Camporesi E, Wang Y et al. 2016a - Two new Seimatosporium species from Italy. Mycosphere 7, 204-213.

Wijayawardene NN, Hyde KD, Wanasinghe DN, Papizadeh M et al. 2016b - Taxonomy and phylogeny of dematiaceous coelomycetes. Fungal Diversity 77, 1-316.

Wijayawardene NN, Hyde KD, Rajeshkumar KC, Hawksworth DL et al. 2017a - Notes for genera: Ascomycota. Fungal Diversity 86, 1-594.

Wijayawardene NN, Hyde KD, Tibpromma S, Wanasinghe DN et al. 2017b - Towards incorporating asexual fungi in a natural classification: checklist and notes 2012-2016. Mycosphere 8, 1457-1555.

Wijayawardene NN, Hyde KD, Lumbsch HT, Liu JK et al. 2018a - Outline of Ascomycota: 2017. Fungal Diversity 88, 167-263.

Wijayawardene NN, Pawłowska J, Letcher PM, Kirk PM et al. 2018b - Notes for genera: basal clades of Fungi (including Aphelidiomycota, Basidiobolomycota, Blastocladiomycota, Calcarisporiellomycota, Caulochytriomycota, Chytridiomycota, Entomophthoromycota, Glomeromycota, Kickxellomycota, Monoblepharomycota, Mortierellomycota, Mucoromycota, Neocallimastigomycota, Olpidiomycota, Rozellomycota and Zoopagomycota). Fungal Diversity 92, 43-129.

Wikee S, Hatton J, Turbé-Doan A, Mathieu Y et al. 2019 - Characterization and Dye Decolorization Potential of Two Laccases from the Marine-Derived Fungus Pestalotiopsis sp. International journal of molecular sciences 20, 1864.

Wingfield BD, van Wyk M, Roos H, Wingfield MJ. 2013 - Ceratocystis: emerging evidence for discrete generic boundaries. In: Seifert KA, De Beer ZW, Wingfield MJ (Eds). Ophiostomatoid fungi: expanding frontiers. CBS Biodiversity Series 12, 57-64.

Wingfield MJ, van Wyk PS. 1993 - A new species of Ophiostoma from Protea infructescences in South Africa. Mycological Research 97, 709-716.

Wingfield MJ, van Wyk PS, Marasas WFO. 1988 - Ceratocystiopsis proteae sp. nov., with a new anamorph genus. Mycologia 80, 23-30.

Wingfield MJ, Seifert KA, Webber JF. 1993 - Ceratocystis and Ophiostoma: Taxonomy, ecology and pathogenicity. APS Press, St Paul. 
Winka K, Eriksson OE. 2000 - Papulosa amerospora accommodated in a new family (Papulosaceae, Sordariomycetes, Ascomycota) inferred from morphological and molecular data. Mycoscience 41, 96-104.

Winter G. 1885a - Pilze: Ascomyceten. Rabenhorst's Kryptogamen Flora von Deutschland. Oesterreich und der Schweiz 1, 1-928.

Winter G. 1885b - Rabenhorst's Kryptogamen-Flora. Pilze-Ascomyceten, Edn 2 1, 193-528.

Winter G. 1886 - Fungi Australienses. Revue Mycologique Toulouse 8, 207-213.

Winter G. 1887 - Pilze, Ascomyceten. In: Rabenhorst's Kryptogamen-Flora von Deutschland, Oesterreich und der Schweiz 1, 1-928.

Won SY, Park EH. 2005 - Anti-inflammatory and related pharmacological activities of cultured mycelia and fruiting bodies of Cordyceps militaris. Journal of ethnopharmacology 96, 555561.

Wong MKM, Hyde KD. 2001 - Fungi on grasses: new species of Ascotaiwania, Diaporthe and Oxydothis (Ascomycetes). Cryptogamie Mycologie 22, 19-28.

Wong MKM, Goh TK, Hodgkiss IJ, Hyde KD et al. 1998a - Role of fungi in freshwater ecosystems. Biodiversity and Conservation 7, 1187-1206.

Wong MKM, Poon MOK, Hyde KD. 1998b - Phragmitensis marina gen et sp. nov., an intertidal saprotroph from Phragmites australis in Hong Kong. Botanica Marina 41, 379-382.

Wong MKM, Jones EB, Abdel-Wahab MA, Au DW, Vrijmoed LL. 2003 - Ultrastructure of conidiogenesis and appendage ontogeny in the coelomycete Bartalinia robillardoides. Canadian journal of botany 81, 1083-1090.

Wong PTW, Khemmuk W, Shivas RG. 2015 - Magnaporthiopsis agrostidis P. Wong, Khemmuk \& R.G. Shivas, sp. nov. Persoonia. Molecular Phylogeny and Evolution of Fungi 35, 322323.

Wong SW, Hyde KD. 1999 - Proboscispora aquatica gen. et sp. nov., from wood submerged in freshwater. Mycological Research 103, 81-87.

Wong SW, Hyde KD, Ho WH, Stanley SJ. 1998c - Tamsiniella labiosa gen. et sp.nov., a new freshwater ascomycete from submerged wood. Can J Bot 76, 332-337.

Wong SW, Hyde KD, Jones EBG. 1998d - Annulatascaceae, a new ascomycete family from the tropics. Systema Ascomycetum 16, 17-25.

Wong SW, Hyde KD, Jones EBG. 1999 - Ultrastructural studies on freshwater ascomycetes, Fluminicola bipolaris gen. et sp. nov. Fungal Diversity 2, 187-189

Worapong J, Strobel G, Ford EJ, Li JY et al. 2001 - Muscodor albus anam. gen. et sp nov., an endophyte from Cinnamomum zeylanicum. Mycotaxon 79, 67-79.

Woudenberg JHC, Sandoval-Denis M, Houbraken J, Seifert KA et al. 2017 - Cephalotrichum and related synnematous fungi with notes on species from the built environment. Stud Mycology $88,137-159$.

Wraight SP, Carruthers RI, Bradley CA, Jaronski ST et al. 1998 - Pathogenicity of the Entomopathogenic Fungi Paecilomyces spp. and Beauveria bassiana against the Silverleaf Whitefly, Bemisia argentifolii. Journal of Invertebrate Pathology 71, 217-226.

Wrzesień H, Mazur A, Łabędzki A, Kuźmiński R et al. 2016 - Communities of fungi in decomposed wood of oak and pine. Forest Research Papers 77, 261-275.

Wu J, Huang J, Liu D, Li J et al. 2014a - Effect of 26 Years of Intensively Managed Carya cathayensis Stands on Soil Organic Carbon and Fertility. The Scientific World Journal 2014, $1-6$.

Wu YM, Zhang TY. 2013 - A new species and new record of Chloridium from the Qinghai-Tibet Plateau Area, China. Mycotaxon 123, 277-280.

Wu Z, Yan S, Zhou S, Chen S. 2014b - Diversity of endophytic mycobiota in Fortunearia sinensis. Acta Ecologica Sinica 34, 160-164.

Xavier KV, KC AN, Crous PW, Groenewald JZ, Vallad GE. 2019 - Dwiroopa punicae sp. nov. (Dwiroopaceae fam. nov., Diaporthales), associated with leaf spot and fruit rot of pomegranate (Punica granatum). Fungal Systematics and Evolution 4, 33-41. 
Xia JW, Ma YR, Li Z, Zhang XG. 2017 - Acrodictys-like wood decay fungi from southern China, with two new families Acrodictyaceae and Junewangiaceae. Scientific Reports 7, 7888.

Xia JW, Sandoval-Denis M, Crous PW, Zhang XG, Lombard L. 2019 - Numbers to names restyling the Fusarium incarnatum-equiseti species complex. Persoonia 43, 186-221.

Xiao YP, Wen TC, Hongsanan S, Hyde KD et al. 2018 - Multigene phylogenetics of Polycephalomyces (Ophiocordycipitaceae, Hypocreales), with two new species from Thailand. Scientific reports 8, 18087.

Xie L, Chen YL, Long YY, Zhang Y et al. 2019 - Three new species of Conlarium from sugarcane rhizosphere in southern China. MycoKeys 56, 1-11.

Yaegashi H, Udagawa S. 1978 - The taxonomical identity of the perfect state of Pyricularia grisea and its allies. Canadian Journal of Botany 56, 180-183.

Yamaguchi Y, Masuma R, Tomoda H, Omura S. 2005 - A new species of Dinemasporium from sugar cane on Irabujima island, Japan. Mycoscience 46, 367-369.

Yang J, Maharachchikumbura SSN, Hyde KD, Bhat DJ et al. 2015 - Aquapteridospora lignicola gen. et sp. nov., a new hyphomycetous taxon (Sordariomycetes) from wood submerged in a freshwater stream. Cryptogamie, Mycologie 36, 469-478.

Yang J, Liu JK, Hyde KD, Bhat DJ et al. 2016a - New species of Sporoschisma (Chaetosphaeriaceae) from aquatic habitats in Thailand. Phytotaxa 289, 147-157.

Yang J, Maharachchikumbura SSN, Bhat DJ, Hyde KD et al. 2016b - Fuscosporellales, a new order of aquatic and terrestrial Hypocreomycetidae (Sordariomycetes). Cryptogamie Mycologie 37, 449-475.

Yang J, Liu JK, Hyde KD, Jones EBG et al. 2017 - Two new species in Fuscosporellaceae from freshwater habitats in Thailand. Mycosphere 8, 1893-1903.

Yang J, Liu NG, Liu JK, Hyde KD et al. 2018a - Phylogenetic placement of Cryptophiale, Cryptophialoidea, Nawawia, Neonawawia gen. nov. and Phialosporostilbe. Mycosphere 9, 1132-1150.

Yang J, Maharachchikumbura SSN, Liu JK, Hyde KD et al. 2018b - Pseudostanjehughesia aquitropica gen. et sp. nov. and Sporidesmium sensu lato species from freshwater habitats. Mycological Progress 17, 591-616.

Yang Q, Du Z, Liang YM, Tian CM. 2018c - Molecular phylogeny of Nectria species associated with dieback and canker diseases in China, with a new species described. Phytotaxa 356, 199-214.

Yang Q, Fan XL, Du Z, Tian CM. 2018d - Diaporthosporellaceae, a novel family of Diaporthales (Sordariomycetes, Ascomycota). Mycoscience 59, 229-235.

Yang Q, Chen WY, Jiang N, Tian CM. 2019 - Nectria-related fungi causing dieback and canker diseases in China. with Neothyronectria citri sp. nov. described. MycoKeys 56, 49-66.

Yang X, Feng P, Yin Y, Bushley K et al. 2018 - Cyclosporine biosynthesis in Tolypocladium inflatum benefits fungal adaptation to the environment. American society for microbiology, 9 , e01211-18.

Yanna, Hyde KD. 2002 - New saprobic fungi on fronds of palms from northern Queensland, Australia. Australian Systematic Botany 15, 755-764.

Yanna, Hyde KD, Fröhlich J. 1997 - A new species of Appendicospora from Hong Kong. Mycoscience 38, 395-397.

Yanna, Hyde KD, Goh TK. 1998 - Koorchaloma novojournalis sp. nov., a new sporodochial fungus from Hong Kong. Fungal Diversity 1, 193-197.

Yanna, Ho WH, Goh TK, Hyde KD. 2000 - Craspedodidymum nigroseptatum sp. nov., a new hyphomycete on palms from Brunei Darussalam. Mycological Research 104, 1146-1151.

Yarwood CE. 1973 - Pyrenomycetes: erysiphales. In: Ainsworth GC, Sparrow FK, Sussman AS (eds) The fungi: an advanced treatise. Vol. IVA. Academic, New York 71-86.

Yokoyama E, Arakawa M, Yamagishi K, Hara A. 2006 - Phylogenetic and structural analyses of the mating-type loci in Clavicipitaceae. FEMS microbiology letters 264, 182-191. 
Yu H, Sperlich J, Mándi A, Kurtán T et al. 2018 - Azaphilone derivatives from the fungus Coniella fragariae inhibit NF- $\mathrm{BB}$ activation and reduce tumor cell migration. Journal of Natural Products 81, 2493-2500.

Yu OH, Suh HL. 2011 - Secondary production of the eusirid amphipod Pontogeneia rostrata Gurjanova, 1938 (Crustacea: Peracarida) on a sandy shore in Korea. Ocean Science Journal 46, 211.

Yu R, Song L, Zhao Y, Bin et al. 2004 - Isolation and biological properties of polysaccharide CPS1 from cultured Cordyceps militaris. Fitoterapia 75, 465-472.

Yu SJ, Zhang Y, Fan MZ. 2012 - Analysis of Volatile Compounds of Mycelia of Hirsutella sinensis, the Anamorph of Ophiocordyceps sinensis. Applied Mechanics and Materials 140, 253-257.

Yu YN, Zhang ZY. 1980 - Corallocytostroma Yu et Zhang, gen. nov., astromatic Coelomycete. Acta Microbiologica Sinica 20, 230-235.

Yuan ZQ, Mohammed C. 1997 - Wuestneia epispora sp. nov. on stems of eucalypts from Australia. Mycological Research 101, 195-200.

Yuen TK, Hyde KD, Hodgkiss IJ. 1998 - Physiological growth parameters and enzyme production in tropical freshwater fungi. Material und Organismen 32, 2-16.

Yuen TK, Hyde KD, Hodgkiss IJ. 2000 - Soft rot decay in tropical freshwater fungi. Mater Organism 33, 155-161.

Yuyama KT, Pereira J, Maki CS, Ishikawa NK. 2013 -Daldinia eschcholtzii (Ascomycota, Xylariaceae) isolated from the Brazilian Amazon: taxonomic features and mycelial growth conditions. Acta Amazonica 43, 1-8.

Zare R, Gams W. 2001 - A revision of Verticillium sect. Prostrata, IV. The genera Lecanicillium and Simplicillium gen. nov. Nova Hedwigia 73, 1-50.

Zare R, Gams W. 2007 - Pochonia globispora sp. nov. Nova Hedwigia 84, 421-428.

Zare R, Gams W. 2016 - More white verticillium-like anamorphs with erect conidiophores. Mycological progress 15, 993-1030.

Zare R, Gams W, Culham A. 2000 - A revision of Verticillium section Prostrata. I. Phylogenetic studies using ITS sequences. Nova Hedwigia 71, 465-480.

Zare R, Gams W, Schroers HJ. 2004 - The type species of Verticillium is not congeneric with the plant-pathogenic species placed in Verticillium and it is not the anamorph of 'Nectria' inventa. Mycological Research. 108, 576-582.

Zare R, Gams W, Starink-Willemse M, Summerbell RC. 2007 - Gibellulopsis, a suitable genus for Verticillium nigrescens, and Musicillium, a new genus for V. theobromae. Nova Hedwigia 85, 463-489.

Zare-Maivan H, Shearer CA. 1988a - Extracellular enzyme production and cell wall degradation by freshwater lignicolous fungi. Mycologia 80, 365-375.

Zare-Maivan H, Shearer CA. 1988b - Wood decay activity and cellulase production by freshwater lignicolous fungi. International Biodeterioration 24, 459-474.

Zelski SE, Raja HA, Miller AN, Barbosa FR et al. 2011a - Longicollum biappendiculatum gen. et sp. nov., a new freshwater ascomycete from the Neotropics. Archives of Physical Medicine and Rehabilitation 2, 539-545.

Zelski SE, Raja HA, Miller AN, Shearer CA. 2011b - Chaetorostrum quincemilensis, gen. et sp. nov., a new freshwater ascomycete and its Taeniolella-like anamorph from Peru. Mycosphere 2, 593-600.

Zelski SE, Balto JA, Do C, Raja HA et al. 2014 - Phylogeny and morphology of dematiaceous freshwater microfungi from Perú. IMA Fungus 5, 425-438.

Zelski SE, Raja HA, Miller AN, Shearer CA. 2015 - Conioscypha peruensis sp. nov., its phylogenetic placement based on 28S rRNA gene, and a report of Conioscypha gracilis comb. nov. from Peru. Mycoscience 56, 319-325.

Zeng XY, Zhao JJ, Hongsanan S, Chomnunti P et al. 2017 - A checklist for identifying Meliolales species. Mycosphere 8, 218-359. 
Zeng XY, Jeewon R, Wen TC, Hongsanan S et al. 2018 - Simplified and efficient DNA extraction protocol for Meliolaceae specimens. Mycological Progress 17, 403-415.

Zeng XY, Wu HX, Hongsanan S, Jeewon R et al. 2019 - Taxonomy and the evolutionary history of Micropeltidaceae. Fungal Diversity 97, 393-436.

Zeng ZQ, Zhuang WY. 2016 - Three new species and two new Chinese records of Hypomyces (Hypocreales). Mycosystema 35, 1048-1055.

Zeng ZQ, Zhuang WY. 2017 - Phylogenetic position of Pseudohypocrea (Hypocreales). Mycoscience 58, 274-281.

Zhang H, Wu Z, Wang C, Li Y, Xu JR. 2014 - Germination and infectivity of microconidia in the rice blast fungus Magnaporthe oryzae. Nature Communications 5, 4518.

Zhang H, Dong W, Hyde KD, Maharachchikumbura SSN et al. 2017a - Towards a natural classification of Annulatascaceae-like taxa: introducing Atractosporales ord. nov. and six new families. Fungal Diversity 85, 75-110.

Zhang N, Blackwell M. 2001 - Molecular phylogeny of dogwood anthracnose fungus (Discula destructiva) and the Diaporthales. Mycologia 93, 355-365.

Zhang N, Blackwell M. 2002 - Molecular phylogeny of Melanospora and similar pyrenomycetous fungi. Mycol Res 106, 148-155.

Zhang N, Wang Z. 2015 - 3 Pezizomycotina: Sordariomycetes and Leotiomycetes. Systematics and Evolution 57-88.

Zhang N, Castelbury LA, Miller AN, Huhndorf SM et al. 2006 - An overview of the systematics of the Sordariomycetes based on a four-gene phylogeny. Mycologia 98, 1076-1087.

Zhang N, Luo J, Rossman A, Aoki T et al. 2016 - Generic names in Magnaporthales. IMA Fungus 7, 155-159.

Zhang SN, Abdel-Wahab MA, Jones EG, Hyde KD, Liu JKJ. 2019 - Additions to the genus Savoryella (Savoryellaceae), with the asexual morphs Savoryella nypae comb. nov. and $S$. sarushimana sp. nov. Phytotaxa 408, 195-207.

Zhang W, Krohn K, Draeger S, Schulz B. 2008 - Bioactive isocoumarins isolated from the endophytic fungus Microdochium bolleyi. Journal of Natural Products 71, 1078-1081.

Zhang XY, Bao J, Wang GH, He F et al. 2012a - Diversity and antimicrobial activity of culturable fungi isolated from six species of the south China sea Gorgonians. Microbial Ecology 64, 617-627.

Zhang Y, Li E, Wang C, Li Y, Liu X. 2012b - Ophiocordyceps sinensis, the flagship fungus of China: terminology, life strategy and ecology. Mycology 3, 2-10.

Zhang Y, Liu F, Wu W, Cai L. 2015a - A phylogenetic assessment and taxonomic revision of the thermotolerant hyphomycete genera Acrophialophora and Taifanglania. Mycologia 107, $768-779$.

Zhang Y, Wu W, Cai L. 2017b - Polyphasic characterisation of Chaetomium species from soil and compost revealed high number of undescribed species, Fungal Biology 121, 21-43.

Zhang YX, Huang JH, Xiang MM. 2011 - First report of Myrothecium leaf spot of Hemionitis arifolia caused by Myrothecium roridum in China. Plant Disease 95, 1030-1030.

Zhang YY, Li M, Liang Y, Zhou HY, Zhao J. 2015b - First Report of Sunflower Wilt Caused by Plectosphaerella cucumerina in China. Plant Disease 99, 1646.

Zhang ZF, Liu F, Zhou X, Liu et al. 2017c - Culturable mycobiota from Karst caves in China, with descriptions of 20 new species. Persoonia: Molecular Phylogeny and Evolution of Fungi 39, $1-31$.

Zhao G, Yu P, Liu X. 2012 - Cancellidium and Canalisporium (Hyphomycetes) from China. Nova Hedwigia 96, 221-223.

Zhao GZ, Tian YH, Liu XZ. 2009 - Ramoacrodictys, a new hyphomycete genus for one species previously accommodated in Acrodictys. Sydowia 61, 353-359.

Zhao R, Yang Y, Zhao G. 2004 - Pseudolachnella vermospora sp. nov. from Yushania vigens in China. Fungal Diversity 15, 255-260. 
Zhao YJ, Li BJ, Shi YX, Xie XW. 2010 - First report of Myrothecium leaf spot of common bean in China caused by Myrothecium roridum. Plant Disease 94, 127.

Zhou D, Hyde KD. 2002 - Fungal succession on bamboo in Hong Kong. Fungal Diversity 10, $213-$ 227.

Zhou L, Li J, Chen F, Chen J, Ye J. 2019 - First report of shoot blight on Cryptomeria japonica caused by Pestalotiopsis neglecta in China. Plant disease 103, 8.

Zhou SX, Qiao LJ, Kang JC, Hyde KD, Ma XY. 2017 - A new species of Monilochaetes from Nothapodytes pittosporoides. Phytotaxa 326, 129.

Zhou XD, de Beer ZW, Wingfield MJ. 2013 - Ophiostomatoid fungi associated with coniferinfecting bark beetles in China. In: Seifert KA, De Beer ZW, Wingfield MJ (Eds). Ophiostomatoid fungi: Expanding frontiers 91-98.

Zhu G, Gui Y, Huang Y, Liu Z. 2005 - The Endophytic fungus resources of spermatophyte in China and their coevolution. Journal of fungal research 3, 6-13.

Zhu ZX, Zhuang WY. 2014 - Discovery of the second species of Pseudohypocrea (Hypocreaceae). Mycoscience 55, 124-126.

Zhuang WY, Zeng ZQ. 2017 - Cocoonihabitus sinensis gen. et sp. nov. on remaining leaf veins of cocoons in a new family (Cocoonihabitaceae fam. nov.) of Hypocreales. Mycosystema 36, 1591-1598.

Zimmermann A. 1902 - Über einige an tropischen Kulturpflanzen beobachtete Pilze. II. Centralblatt für Bakteriologie und Parasitenkunde 8, 148.

Zipfel RD, de Beer ZW, Jacobs K, Wingfield BD, Wingfield MJ. 2006 - Multi-gene phylogenies define Ceratocystiopsis and Grosmannia distinct from Ophiostoma. Studies in Mycology 55, 75-97.

Zopf W. 1876 - Thielavia basicola Zopf. Genus novum Perisporiacearum. Verhandlungen des Botanischen Vereins der Provinz Brandenburg 18, 101-105.

Zuccaro A, Summerbell RC, Gams W, Schroers HJ, Mitchell JI. 2004 - A new Acremonium species associated with Fucus spp., and its affinity with a phylogenetically distinct marine Emericellopsis clade. Studies in Mycology 50, 283-297.

Zukal H. 1886 - Mycologische Untersuchungen. Denkschriften der Kaiserlichen Akademie der Wissenschaften 35, 337. 